\title{
SERVICEBAILTY AND FLEXURAL STRENGTH OF LIGHTWEIGHT FLOOR MADE OF COLD FORMED STEEL JOISTS
}

\author{
By \\ Quzzafi Rehman \\ M.Sc., Ryerson University Canada, June 2008 \\ B.Sc., N.W.F.P University of Engineering \& Technology Pakistan, January 2001
}

\author{
A Dissertation \\ Presented to Ryerson University \\ in partial fulfilment of the \\ requirement for the degree of \\ Doctorate of Philosophy \\ in the Program of \\ Civil Engineering.
}

Toronto, Ontario, Canada, 2014

(c) Quzzafi Rehman, 2014 


\section{AUTHOR'S DECLARATION}

I hereby declare that I am the sole author of this dissertation. This is a true copy of the dissertation, including any required final revisions, as accepted by my examiners.

I authorize Ryerson University to lend this dissertation to other institutions or individuals for the purpose of scholarly research.

I further authorize Ryerson University to reproduce this dissertation by photocopying or by other means, in total or in part, at the request of other institutions or individuals for the purpose of scholarly research.

I understand that my dissertation may be made electronically available to the public. 


\title{
SERVICEBAILTY AND FLEXURAL STRENGTH OF LIGHTWEIGHT FLOOR MADE OF COLD FORMED STEEL JOISTS
}

Quzzafi Rehman, Doctor of Philosophy, 2014

Department of Civil Engineering, Ryerson University

\begin{abstract}
The use of cold-formed steel (CFS) is becoming popular in residential and commercial building as a cost-effective alternative to traditional wood materials. CFS provides high strength-toweight ratio, resulting in permitting lighter structure and longer spans. If proper design considerations are not made, this longer span and lighter structure can result in vibration serviceability issues that may affect building occupant comfort. The available design methods to calculate the dynamic properties of floor systems (i.e. Canadian Wood Council Method, CWC; Applied Design Council Design Method, ATC; and Eurocode, EC5) are used for the design of light-frame timber-based systems, CFS C-shape joists, and structural steel and concrete floor systems. The applicability of such methods to I-shape CFS joists is as yet unavailable. In addition, the North American Code for Cold-formed Steel structural Members (CSA-S136-07) provides specifications of ultimate and serviceability limit state design of C-shape joists rather than I-shape joists. As such, this research was divided into three parts. Part 1 presented the results of laboratory and field study on the vibration of a recently developed CFS I-shape joist called "iSPAN." The main objective of the first part was to understand the dynamic characteristics of iSPAN floor system, recommend an adequate model for predicting the dynamic response and modal properties of floor systems, and correlate its results with engineered wood Ijoists in order to aid the design process. Part 2 presented comparison between the experimental findings and available code provisions for the design of CFS joists at ultimate and serviceability limit states. The effect of web utility holes was also considered on the dynamic properties, and ultimate strength of iSPAN joists. Part 3 presented a finite-element modeling and its verification with the experimental findings of the tested samples. Also, part 3 extended the finite element modelling to analyse I- and C-shape CFS joists to determine their ultimate strength and serviceability, with and without the presence of utility holes in the webs. Since CSA-S137-07 does not provide design provisions for the edge-stiffened (i.e. lipped) holes, a practical-design-
\end{abstract}


oriented parametric study, using the finite-element modelling, was conducted on CFS I- and Cshape members with circular, slotted and tri-slotted, edge-stiffened, holes under flexural loading. The optimized profile of the edge-stiffened holes was obtained using the elastic-buckling analysis. The post-buckling finite-element analysis was then utilized to determine member flexural strength as affected by utility hole geometry and web depth. Results showed that the edge-stiffened holes can significantly improve the flexural strength of CFS joists. The data generated from the parametric study was used to develop new design provisions to predict the flexural strength of such joists with the presence of edge-stiffened holes. 


\section{ACKNOWLEDEMENTS}

My sincere thanks and gratitude are due to His Almighty ALLAH, who helped me and blessed my work during the days of my study and research.

I would like to express my sincere appreciation and gratitude to my supervisor, Dr. Khaled Sennah, for his continuous advice, guidance and encouragement throughout this research.

Also, I would like to thank Mr. Mike Strickland and Mr. Douglas Fox of iSPAN Industries Inc. for their valuable guidance, encouragement and support. Moreover, I am grateful to the iSPAN for providing test specimens and funding for this research.

Finally, I wish to express my sincere thanks to my parents, wife, kids, brothers and sister for their love, support and encouragement given to me during the course of this study. 


\section{TABLE OF CONTENTS}

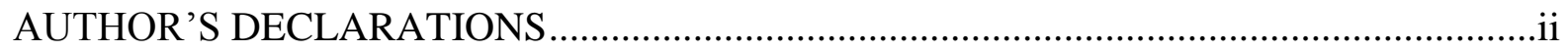

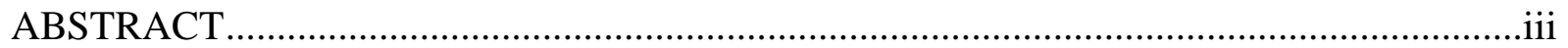

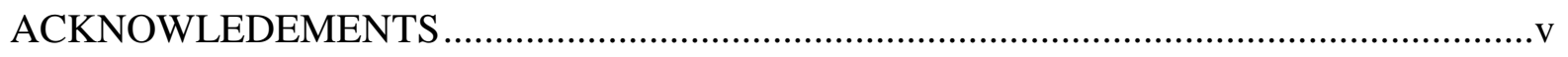

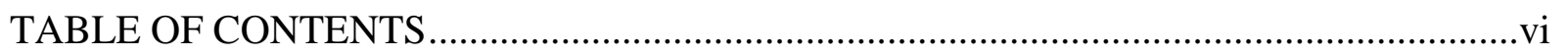

LIST OF TABLES ……………………………......................................................

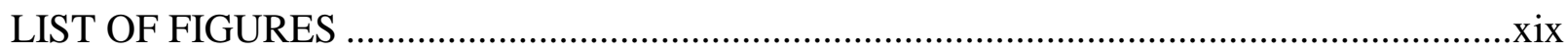

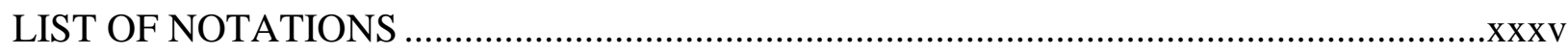

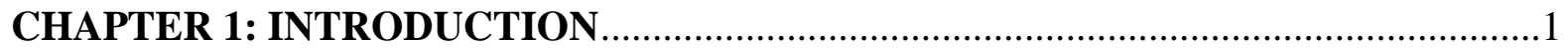

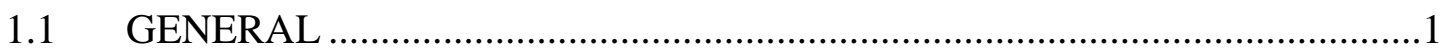

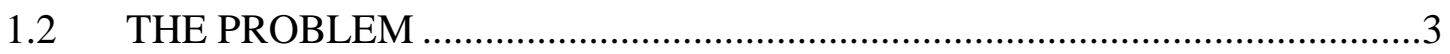

1.3 OBJECTIVES AND SCOPE OF RESEARCH …………………………......

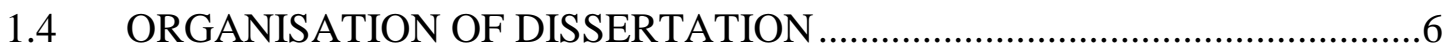

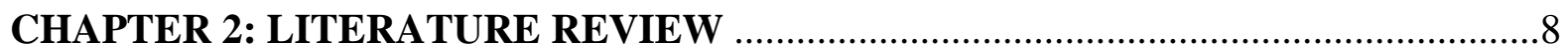

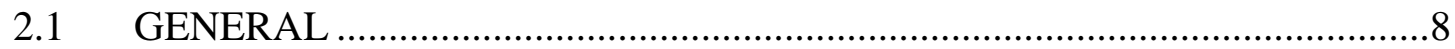

2.2 LIMITING CRITERIA FOR FLOOR VIBRATION ……………………......

$2.3 \quad$ Floor Vibration Research .............................................................................12

$2.4 \quad$ STIFFENED PLATE CONCEPT ……………….....................................15

2.4.1 ELASTIC LOCAL BUCKLING STRESS OF PLATES .................................16

2.4.2 POST BUCKLING STRENGTH AND EFFECTIVE DESIGN WIDTH.........21

2.4.3 LATERAL TORSIONAL BUCKLING …………....................................25

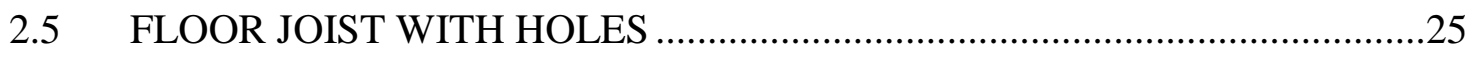

2.6 PREVOIUS EXPERIMENTAL AND THEORETICAL WORK ON CFS ......26

2.7 CURRENT DESIGN METHODS FOR WOOD AND COLD FORMED STEEL

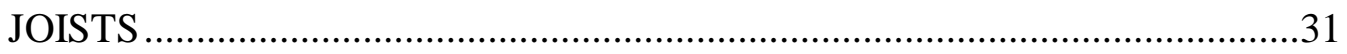

2.7.1 EXISTING DESIGN CRITERIA FOR FLOOR VIBRATION …………..........31

2.7.2 EXISTING DESIGN CRITERIA FOR ULTIMATE DESIGN ……..................31

2.8 CANADIAN WOOD COUNCIL DESIGN CRITERIA (CWC) ........................32

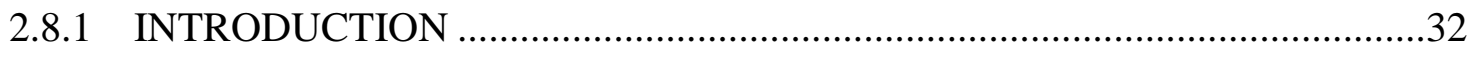




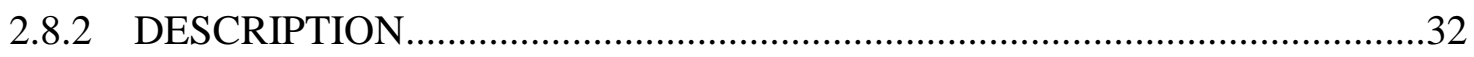

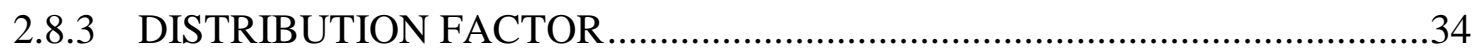

2.9 APPLIED TECHNOLOGY COUNCIL DESIGN CRITERIA …………….......36

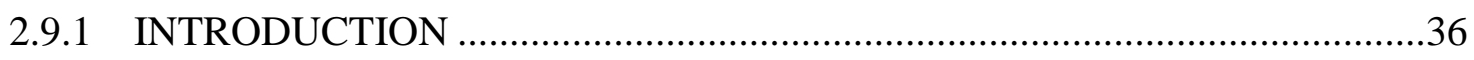

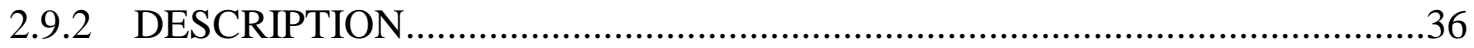

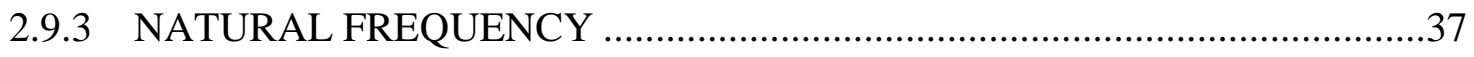

2.9.4 CALCULATION OF STIFFNESS IN ATC DESIGN GUIDE ..........................38

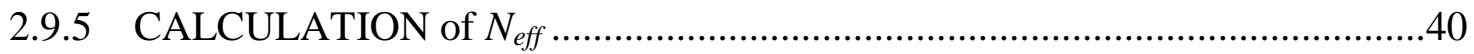

2.9.6 CALCULATION FOR "RMS” ACCELERATION ………………………........

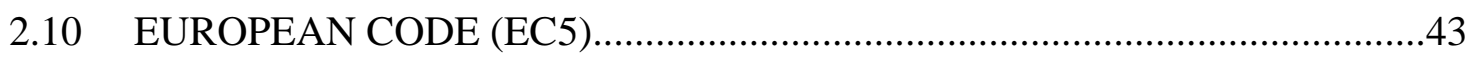

2.11 ULTIMATE LIMIT STATE DESIGN …………...........................................

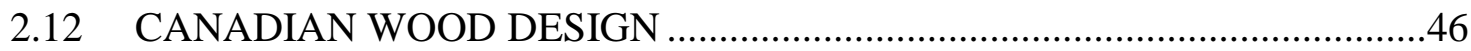

2.13 NORTH AMERICAN SPECIFICATIONS FOR THE DESIGN OF COLDFORMED STEEL STRUCTURAL MEMBERS (CSA-S136-07).....................48

2.13.1 UNIFORMLY COMPRESSED STIFFENED ELEMENT WITH CIRCULAR

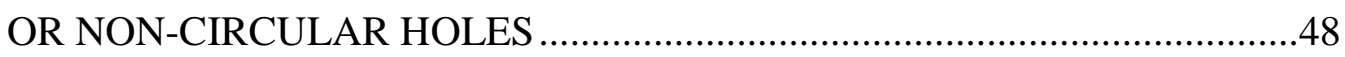

2.13.2 C-SECTION WEBS WITH HOLES UNDER STRESS GRADIENT ...............51

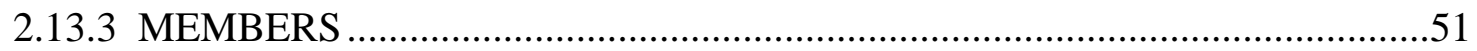

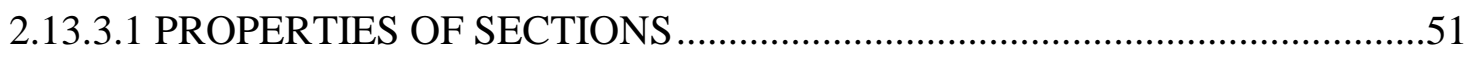

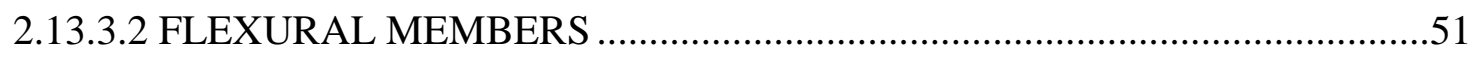

2.13.3.3 LATERAL TORSIONAL BUCKLING STRENGTH …………………........52

2.13.3.4 DETERMINATION OF LIMITING UNBRACED LENGTH $(\mathrm{Lu})$................55

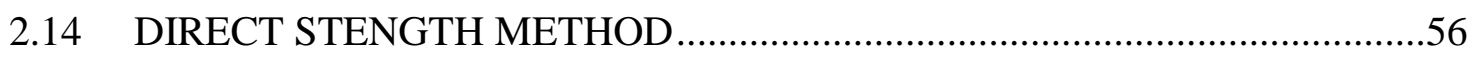

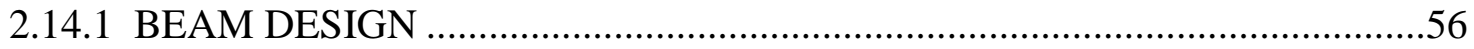

2.15 EXPLANATION OF THE DIRECT STRENGTH METHOD .........................58

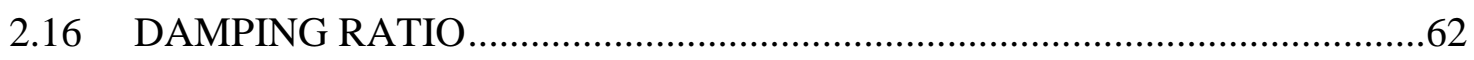

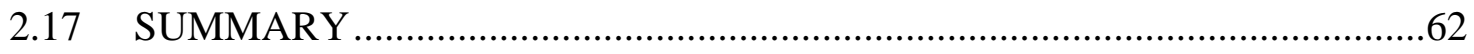

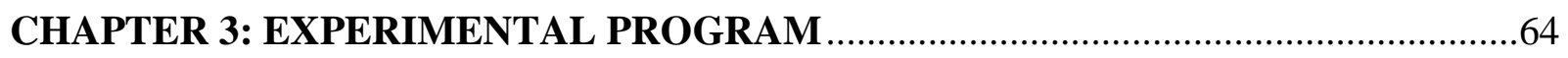

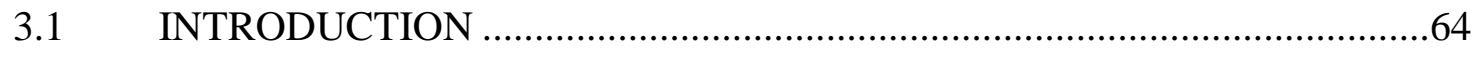

3.2 OBJECTIVES AND SCOPE OF THE LABORATORY TESTS ...................64 
3.3 EXPERIMENTAL WORK FOR ENGINEERED WOOD I-FLOOR JOISTS

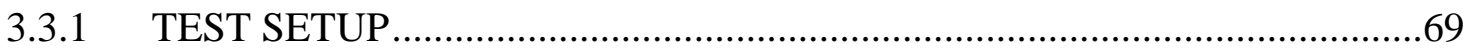

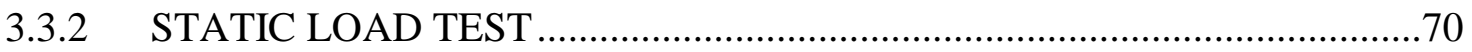

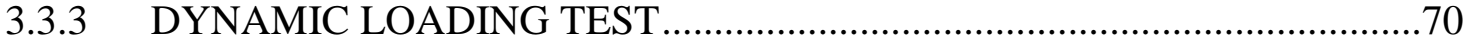

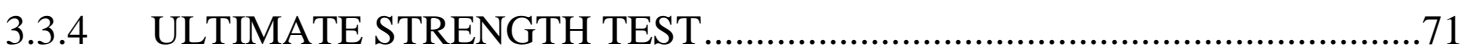

3.4 EXPERIMENTAL WORK FOR iSPAN CFS JOIST ASSEMBLY ..............79

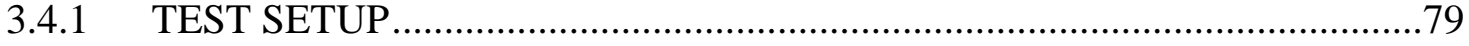

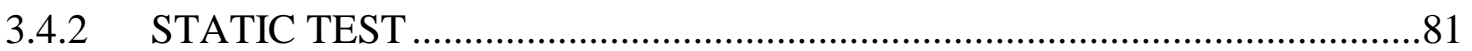

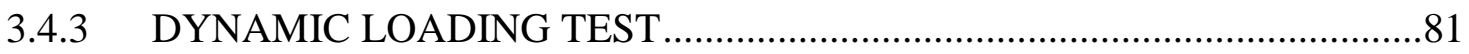

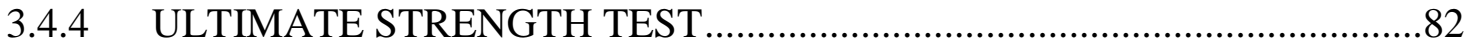

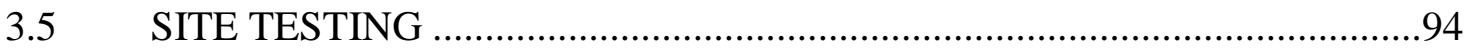

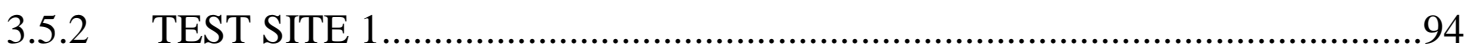

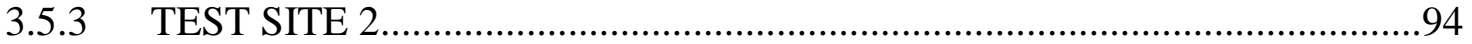

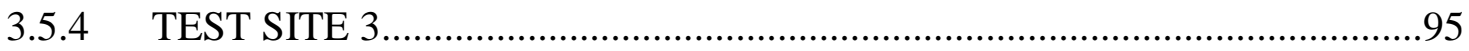

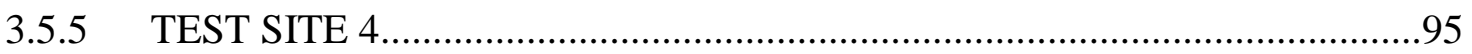

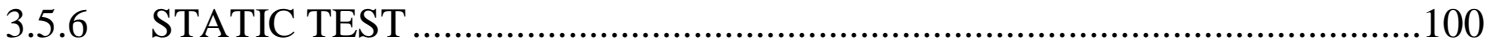

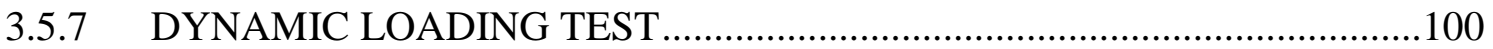

3.6 MECHANICAL PROPERTIES OF COLD FORMED STEEL MATERIAL

CHAPTER 4: EXPERIMENTAL RESULTS AND COMPARISON WITH CODE EQUATIONS ......................................................................................112

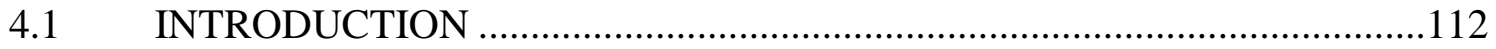

4.2 IMPACT OF CONSTRUCTION DETAILS ON A FLOOR'S NATURAL FREQUENCIES, MAXIMUM DEFLECTION, DAMPING RATIO AND ULTIMATE FLEXURAL CAPACITY

4.2.1 EXPERIMENTAL FINDINGS FOR THE ENGINEERED WOODEN I-JOIST ASSEMBLIES

4.2.2 EXPERIMENTAL FINDINGS FOR ISPAN JOIST ASSEMBLIES 122

4.2.3 EFFECT OF WEB HOLES 137 
4.2.4 TEST SITE EXPERIMENTAL RESULTS.................................................144

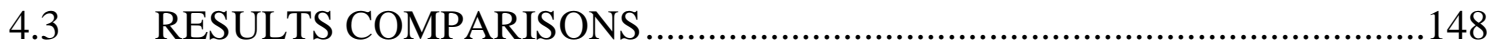

4.3.1 COMPARISON BETWEEN WOODEN TWIN JOIST AND ISPAN TWIN JOIST .148

4.3.2 COMPARISON BETWEEN BALLOON FRAMING AND SIMPLYSUPPORTED FRAMING RESULTS .....................................................150

4.3.3 COMPARISON BETWEEN EXPERIMENTAL RESULTS WITH CANADIAN WOOD COUNCIL DESIGN METHOD (CWC) ………….......152

4.3.4. COMPARISON BETWEEN EXPERIMENTAL RESULTS WITH ATC

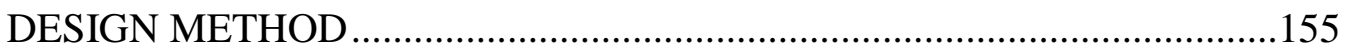

4.3.5 COMPARISON BETWEEN EXPERIMENTAL RESULTS WITH EUROPEAN DESIGN METHOD (EC5)...................................................159

4.4 RESONANCE MODEL ACCEPTABILITY CRITERIA................................162

4.5 ULTIMATE STRENGTH DESIGN..........................................................164

4.6 PROPOSED MODIFICATION TO CURRENT METHODS SPECIFICALLY FOR FLOOR SUPPORTED BY COLD-FORMED STEEL JOISTS..............168

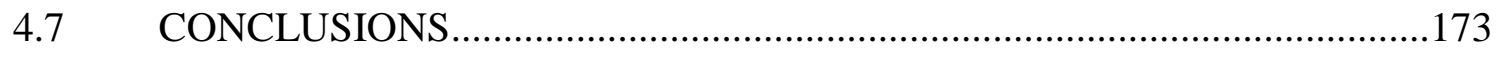

CHAPTER 5: FINITE ELEMENT MODELING AND RESULTS .....................................175

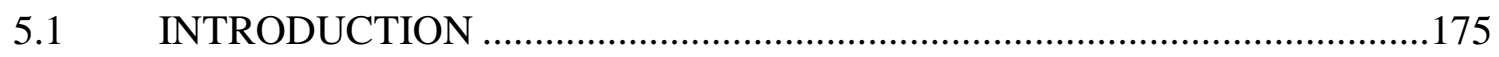

5.2 OBJECTIVES OF FINITE ELEMENT ANALYSIS .......................................175

5.3 GENERAL STEPS OF THE FINITE-ELEMENT METHOD .........................176

5.4 ELEMENTS USED IN FINITE ELEMENT MODELING ………………....176

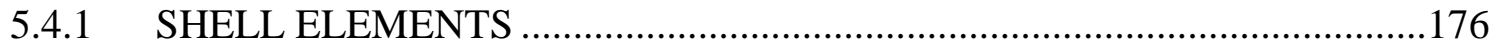

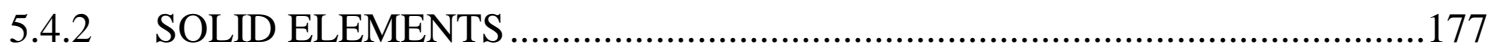

5.4.3 MULTI-POINT CONSTRAINTS (MPC) …………...................................177

5.5 MODELING DETAILS AND LOADING / BOUNDARY CONDITIONS ..

5.6 MESHING OF FINITE-ELEMENT MODEL ………………..................181

5.7 MATERIAL AND GEOMETRIC NONLINEARITY …………………........181

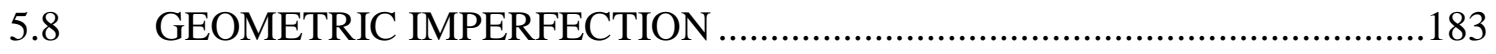




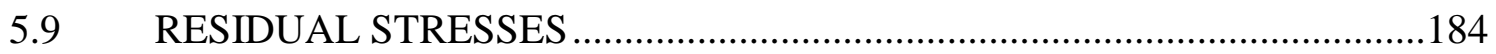

5.10 MODIFIED RIKS METHOD5.10 MODIFIED RIKS METHOD ...................184

5.11 VALIDATION OF FINITE-ELEMENT MODEL........................................186

5.12 FINITE-ELEMENT ANALYSIS RESULTS ...............................................187

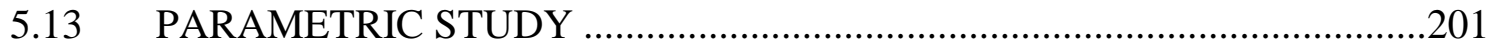

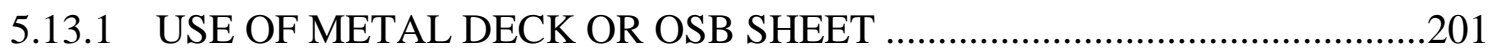

5.13.2 COMPARISON BETWEEN TWIN-JOIST RESULTS AND FULL-SCALE

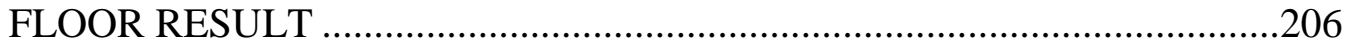

5.13.3 EFFECT OF WEB HOLES ON FLOOR VIBRATION ………………….....213

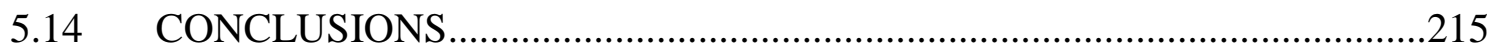

CHAPTER 6: DESIGN OF COLD-FORMED STEEL EDGE-STIFFENED HOLES ....216

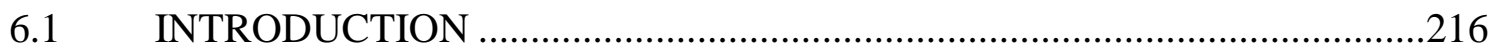

6.2 ELASTIC BUCKLING OF COLD-FORMED STEEL THIN PLATES WITH

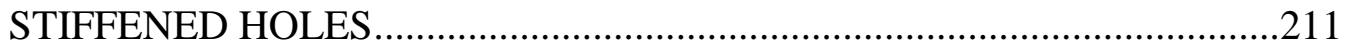

6.2.1 THIN PLATES SUBJECT TO UNIFORM COMPRESSION .......................221

6.2.2 THIN PLATES SUBJECT TO TRANSVERSE STRESS GRADIENT ..........226

6.3 ELASTIC BUCKLING OF COLD-FORMED STEEL FLEXURAL MEMBERS

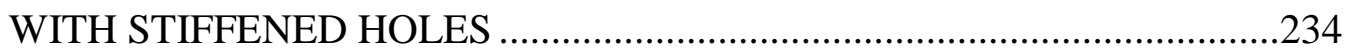

6.4 FLEXURAL STRENGTH OF COLD-FORMED STEEL JOISTS WITH

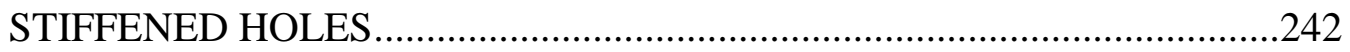

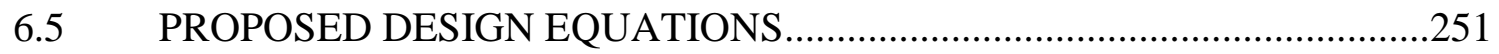

6.6 LIMITATIONS OF PROPOSED DESIGN EQUATIONS.............................252

6.7 CALIBRATION OF THE NEW SAFETY CO-EFFICIENTS ........................255

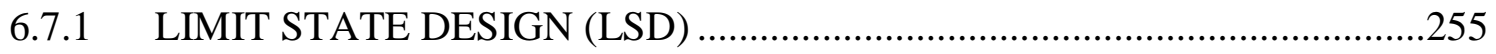

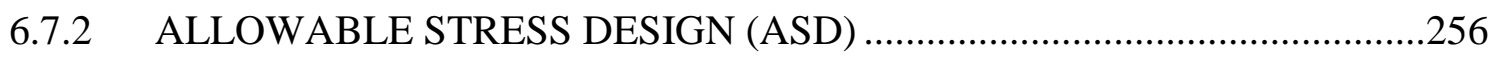

6.8 CALIBRATION OF NEW VALUES FOR RESISTANCE FACTORS ........256

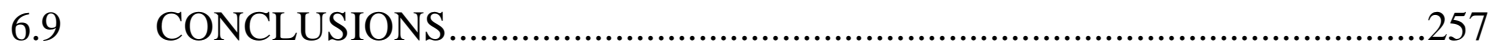

CHAPTER 7: CONCLUSIONS ................................................................................................259

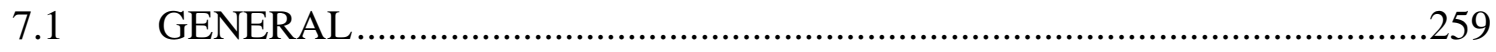




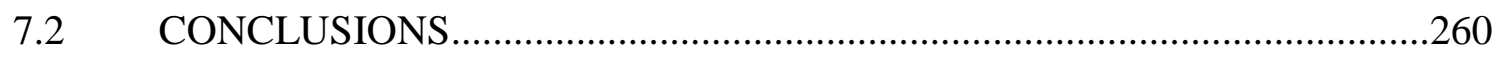

7.3 RECOMMANDATION FOR FUTURE RESEARCH …..............................262

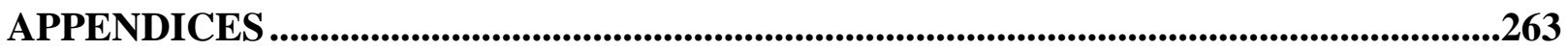

Appendix A1 Acceleration spectrum for wooden joists .............................................263

Appendix A2 Natural frequency spectrum for wooden joists ....................................267

Appendix A3 Load deflection curves for wooden joists ...........................................271

Appendix B1 Acceleration spectrum of iSPAN joists with no holes .........................275

Appendix B2 Natural frequency spectrum of iSPAN joists with no holes..................282

Appendix B3 Load deflection curves of iSPAN joists with no holes..........................289

Appendix B4 Flexural strain distribution of iSPAN joists with no holes....................292

Appendix C1 Acceleration spectrum of iSPAN joists with holes ................................310

Appendix C2 Natural frequency spectrum of iSPAN joists with holes........................315

Appendix C3 Load deflection curve of iSPAN joists with holes ................................320

Appendix C4 Normal strain value for iSPAN joists with holes ...................................323

Appendix D1 Acceleration spectrum of iSPAN joists for the onsite full scale test ...332

Appendix D2 Natural frequency spectrum of iSPAN joists for the onsite full scale test

Appendix E Failure modes of tested floor joist assemblies .........................................340

Appendix F Views of elastic buckling modes considered in FEA modelling of CFS

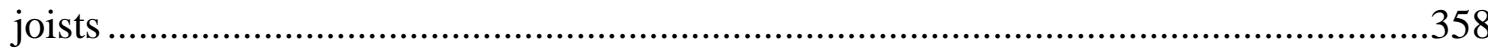

Appendix G Views of failure modes using FEA models for the joists........................358

Appendix $\mathrm{H}$ Calculations of flexural resistance, static point deflection under 1-kN load, and frequency of CFS iSPAN joists and wooden joists...................................................376

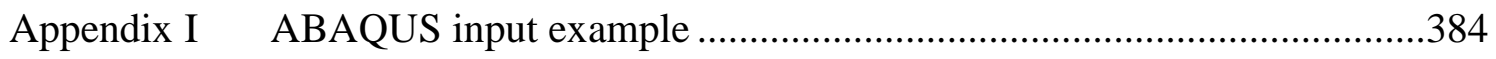

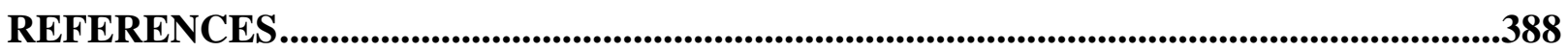




\section{LIST OF TABLES}

Table 2.1 Value of $k$ determining critical buckling stress..........................................20

Table 2.2 Slip constant for sub-floor and gypsum ceiling ...........................................34

Table 2.3 Stiffness properties of OSB sub flooring ...............................................41

Table 2.4 Pre-qualified Beam sections for DSM ..................................................61

Table $3.1 \quad$ Section properties of engineered wood I-joists...........................................66

Table 3.2 Section properties of iSPAN joists without web holes .................................66

Table 3.3 Section properties of iSPAN joists with web holes ....................................66

Table 3.4 Section properties of iSPAN joists in test sites........................................67

Table 3.5 Mechanical Properties of CFS coupons ....................................................111

Table 4.1 Experimental results of the flexural frequency of the unbraced wooden joists

Table 4.2 Experimental results of the flexural frequency of the braced wooden joists.....116

Table 4.3 Experimental results of the $1-\mathrm{kN}$ static load deflection of braced wooden joists

Table 4.4 Experimental results of damping ratio of unbraced wooden joist

Table 4.5 Experimental results of damping ratio of braced wooden joist

Table 4.6 Ultimate jacking load and corresponding deflection of wooden joists subjected to flexural loading

Table 4.7 Experimental results of flexural frequencies of iSPAN joist with balloon framing support and no web holes. 125

Table 4.8 Experimental results of 1-kN-load deflection of iSPAN joist with balloon framing support and no web holes 126

Table 4.9 Experimental results of damping ratio, $\beta_{\mathrm{d}}$, of iSPAN joist with balloon framing support and no web holes

Table 4.10 Experimental results of flexural frequencies of iSPAN joist with simply-supported framing ends and no web holes.

Table 4.11 Experimental results of 1-kN-load deflection of iSPAN joist with simplysupported framing ends and no web holes 
Table 4.12 Experimental results of damping ratio, $\beta_{\mathrm{d}}$, of iSPAN joist with simply-supported framing ends and no web holes

Table 4.13 Ultimate jacking load and corresponding deflection of iSPAN joists with no web holes subjected to flexural loading 131

Table 4.14 Experimental results of flexural frequency of iSPAN joist with balloon framing and web holes 138

Table 4.15 Experimental results of 1-kN-load deflection of iSPAN joist with balloon framing and web holes

Table 4.16 Experimental results of damping ratio, $\beta_{\mathrm{d}}$, of iSPAN joist with balloon framing and web holes 140

Table 4.17 Experimental results of flexural frequency of iSPAN joist with simply-supported framing and web holes 141

Table 4.18 Experimental results of i-kN-load deflection of iSPAN joist with simplysupported framing and web holes

Table 4.19 Experimental results of damping ratio, $\beta_{\mathrm{d}}$, of iSPAN joist with simply-supported framing and web holes 143

Table 4.20 Experimental ultimate jacking load and corresponding deflection for iSPAN joists with holes due to flexural loading.

Table 4.21 Experimental results for flexural frequencies of iSPAN joists in test sites .......145

Table 4.22 Experimental results of 1-kN-load deflection of iSPAN joists in test sites .......146

Table 4.23 Experimental results of damping ratio of iSPAN joists in test sites .................147

Table 4.24 Experimental frequency comparison between wooden and iSPAN twin-joist assembly. 148

Table 4.25 Experimental 1-kN-load deflection comparison between wooden and iSPAN twin-joist assembly

Table 4.26 Experimental damping ratio comparison between wooden and iSPAN twin-joist assembly

Table 4.27 Experimental frequency comparison between iSPAN joists with balloon framing and those with simply-supported framing. 150

Table 4.28 Experimental 1-kN-load deflection comparison between iSPAN joists with balloon framing and those with simply-supported framing 151 
Table 4.29 Experimental damping ratio comparison between iSPAN joists with balloon framing and those with simply-supported framing .....................................151

Table 4.30 Comparison between experimental results of engineered wood twin-joist assembly and CWC design method

Table 4.31 Comparison between experimental results of iSPAN twin-joist assembly with no web holes and CWC design method

Table 4.32 Comparison between experimental results of iSPAN twin-joist assembly with web holes and CWC design method 153

Table 4.33 Comparison between experimental results of iSPAN joists in test sites and CWC design method 154

Table 4.34 Comparison between experimental results of engineered wood twin-joist assembly and ATC design method

Table 4.35 Comparison between experimental results of iSPAN twin-joist assembly with no web holes and ATC design method

Table 4.36 Comparison between experimental results of iSPAN twin-joist assembly with web holes and ATC design method. 158

Table 4.37 Comparison between experimental results of iSPAN joists in test sites and ATC design method 158

Table 4.38 Comparison between experimental results of engineered wood twin-joist assembly and EC5 deign method.....

Table 4.39 Comparison between experimental results of iSPAN twin-joist assembly with no web holes and EC5 design method 160

Table 4.40 Comparison between experimental results of iSPAN twin-joist assembly with web holes and EC5 design method

Table 4.41 Comparison between experimental results of iSPAN joists in test sites and EC5 design method 161

Table 4.42 Comparison between experimental flexural results of engineered wood twin-joist assembly and CWC Design flexural strength 165

Table 4.43 Comparison between experimental flexural results of iSPAN twin-joist assembly with no web holes and S136-07 for CFS design. 166 
Table 4.44 Comparison between experimental flexural results of iSPAN twin-joist assembly with web holes and S136-07 for CFS design

Table 4.45 Recommended Values of the shear deflection coefficient, $\gamma$, obtained from Allen et al. (1999) as well as the proposed $\gamma$ values for iSPAN CFS joists .171

Table 4.46 Results of 1-kN-load deflection and frequency of iSPAN joists based on the proposed modification to the ATC design method using the proposed parameter $\gamma$ .172

Table 5.1 Comparison between ultimate jacking loads obtained experimentally and from the FE modelling of iSPAN joist assembly without web holes

Table 5.2 Comparison between ultimate jacking loads obtained experimentally and from the FE modelling of iSPAN joist assembly with web holes 195

Table 5.3 Comparison between 1-kN-load deflection and flexural frequencies obtained experimentally and using the FE modeling of iSPAN joist without web holes.

Table 5.4 Comparison between the experimental 1-kN-load deflection and flexural frequencies and those obtained using the FE modeling of iSPAN joist with web holes 196

Table 5.5 Comparison between experimental 1-kN-load deflection and flexural frequencies and those obtained using the FE modeling of iSPAN joists in test sites 196

Table 5.6 FEM results for various floor plan sizes made of 254x3000 mm iSPAN joists

Table 5.7 FEM results for various floor plan sizes made of 406x9000 mm iSPAN joists 213

Table 5.8 Results of FE modelling for the effect of web holes on the vibration performance of the 406x $9000 \mathrm{~mm}$ floor joist assembly.....

Table 6.1 Ratio of FE vs. theoretical results of elastic buckling load for 254x254x2.54 mm plate under compression for circular hole. .224

Table 6.2 Ratio of FE vs. theoretical results of elastic buckling load for 254x254x0.508 mm plate under compression for circular hole. .225

Table 6.3 Ratio of FE vs. theoretical results of elastic buckling load for $254 \times 254 \times 2.54 \mathrm{~mm}$ plate under compression for slot hole. .225 
Table 6.4 Ratio of FE vs. theoretical results of elastic buckling load for $254 \times 254 \times 0.508 \mathrm{~mm}$ plate under compression for slot hole. .225

Table 6.5 Ratio of FE vs. theoretical results of elastic buckling load for $254 \times 254 \times 2.54 \mathrm{~mm}$ plate under compression for Tri-slot hole. .226

Table 6.6 Ratio of FE vs. theoretical results of elastic buckling load for 254x254x0.508 mm plate under compression for Tri-slot hole. .226

Table 6.7 Ratio of FE vs. theoretical results of elastic buckling load for $254 \times 254 \times 2.54 \mathrm{~mm}$ plate under stress gradient for circular hole. .228

Table 6.8 Ratio of FE vs. theoretical results of elastic buckling load for 254x254x0.508 mm plate under stress gradient for circular hole .229

Table 6.9 Ratio of FE vs. theoretical results of elastic buckling load for $2.54 \mathrm{~mm}$ thick plate under stress gradient for slot hole .230

Table 6.10 Ratio of FE vs. theoretical results of elastic buckling load for $0.508 \mathrm{~mm}$ thick plate under stress gradient for slot hole .231

Table 6.11 Ratio of FE vs. theoretical results of elastic buckling load for $2.54 \mathrm{~mm}$ thick plate under stress gradient for Tri-slot hole .232

Table 6.12 Ratio of FE vs. theoretical results of elastic buckling load for $0.508 \mathrm{~mm}$ thick plate under stress gradient for Tri-slot hole .233

Table 6.13 Ratio of elastic buckling moment of iSPAN 254-i-2 joist with circular holes vs. no holes .239

Table 6.14 Ratio of elastic buckling moment of iSPAN 254-i-3 joist with circular holes vs. no holes.

Table 6.15 Ratio of elastic buckling moment of iSPAN 254-i-2 joist with slot holes vs. no holes 240

Table 6.16 Ratio of elastic buckling moment of iSPAN 254-i-3 joist with slot holes vs. no holes .240

Table 6.17 Ratio of elastic buckling moment of iSPAN 254-i-2 joist with Tri-slot holes vs. no holes .241

Table 6.18 Ratio of elastic buckling moment of iSPAN 254-i-3 joist with Tri-slot holes vs. no holes .241

Table 6.19 Geometric and yield stress of the "C" section .245 
Table 6.20 Geometric and yield stress of the "iSPAN joist" section. .245

Table 6.21 Cee section with circular hole ..................................................................247

Table 6.22 Cee section with Slot hole....................................................................248

Table 6.23 Cee section with Tri-Slot hole .................................................................248

Table 6.24 iSPAN section with Circular hole ..............................................................249

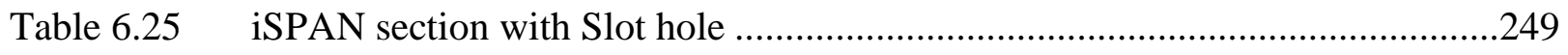

Table 6.26 iSPAN section with Tri-Slot hole .......................................................250

Table 6.27 New Proposed Safety Factor..................................................................257

Table H.1 Flexural strength of CFS iSPAN joists without hole by direct strength method

Table H.2 Flexural strength of CFS iSPAN joists with holes by direct strength method ..

Table H.3 Flexural strength of CFS iSPAN joists without hole by effective width method .378

Table H.4 Flexural strength of CFS iSPAN joists with hole by effective width method ...378

Table H.5 Flexural strength of CFS iSPAN joists without hole by effective width method (LTB) 378

Table H.6 Flexural strength of CFS iSPAN joists with hole by effective width method (LTB)

Table H.7 Flexural strength of wooden joists. 379

Table H.8 Static point load deflection calculations under $1 \mathrm{kN}$ load for iSPAN twin joists without holes 380

Table H.9 Static point load deflection calculations under $1 \mathrm{kN}$ load for iSPAN twin joists with holes .380

Table H.10 Static point load deflection calculations under $1 \mathrm{kN}$ load for iSPAN joists in test sites .381

Table H.11 Static point load deflection calculations under $1 \mathrm{kN}$ load for wooden twin joists .381

Table H.12 Flexural frequency calculation for iSPAN twin joists without holes ...............382

Table H.13 Flexural frequency calculation for iSPAN twin joists with holes.....................382

Table H.14 Flexural frequency calculation for iSPAN joists in test sites .383 
Table H.15 Flexural frequency calculation for wooden twin joists ..................................383 


\section{LIST OF FIGURES}

Figure 1.1 Typical cold formed steel floor joists ..............................................................

Figure 1.2 Outline of the Research Program ..................................................................

Figure 2.1 Reiher Meister Scales ............................................................................

Figure 2.2 Modified Reiher Meister Scale ……………................................................10

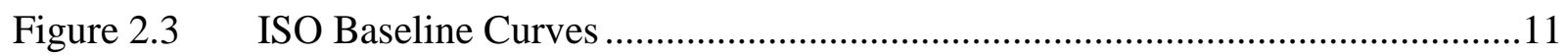

Figure 2.4 Local Buckling of stiffened compression flange of hat-shaped section .............15

Figure 2.5 Square plate subjected to compression stress ...................................................16

Figure 2.6 Rectangular plate subjected to compression stress ............................................16

Figure 2.7 Buckling Coefficient for flat rectangular plate .................................................19

Figure 2.8 Square plate model for post buckling action................................................22

Figure 2.9 Consecutive Stages of stress distribution in stiffened compression elements ...22

Figure 2.10 Effective width of stiffened compression element...........................................23

Figure 2.11 Positions of I-beam after lateral buckling .......................................................26

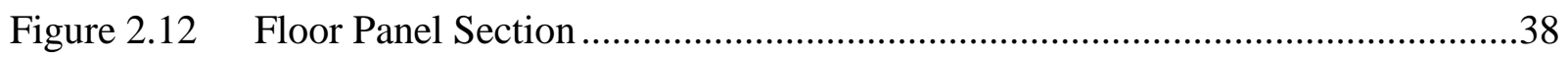

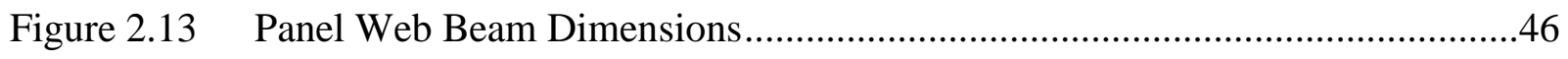

Figure 2.14 Uniformly compressed stiffened elements with non-circular holes ..................50

Figure 2.15 View of buckling mode of cold formed steel Z-section in bending ..................59

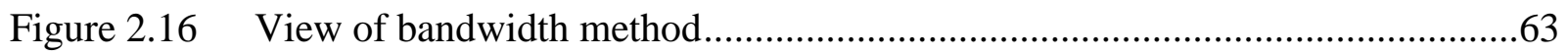

Figure 3.1 Cross-section configurations of the wooden and iSPAN joists .........................65

Figure 3.2 Outline of the experimental program.............................................................68

Figure 3.3 Plan view of engineered wood I-floor joist assembly.......................................72

Figure 3.4 Elevation view of the engineered wood I-floor joist assembly...........................72

Figure 3.5 Section A1-A1 of the engineered wood I-floor joist assembly...........................72

Figure 3.6 Section B1-B1 of the engineered wood I-floor joist assembly ..........................73

Figure 3.7 Plane view of sheathing nail pattern of the engineered wood I-floor joist assembly

Figure $3.8 \quad$ View of engineered I wood floor assembly .....................................................74

Figure 3.9 View of the LVDT attached to the wooden joist ................................................74 
Figure 3.10 View of the wooden joist assembly with 1-kN load placed at the mid-span to measure static deflection .75

Figure 3.11 View of the clamping system at support of wooden I-joist assembly to avoid bouncy effect. .75

Figure 3.12 View of the accelerometer attached to the bottom flange of the wooden joist..76

Figure 3.13 View of the transverse strap to brace the wooden joist at quarter point .76

Figure 3.14 View of the bowling ball dropped over the wooden joist assembly from a height of $0.3 \mathrm{~m}$ .77

Figure 3.15 View of the uniformly distributed loading applied to the wooden floor joist assembly .77

Figure 3.16 Schematic diagram of the test setup....................................................78

Figure 3.17 Plan view of the iSPAN floor joist assembly with balloon framing................83

Figure 3.18 Elevation of iSPAN floor joist assembly with balloon framing .....................83

Figure 3.19 Section A3-A3 of the iSPAN floor joist assembly with balloon framing.........83

Figure 3.20 Section B3-B3 of the balloon framing of the iSPAN floor joist assembly.......84

Figure 3.21 Plan view of sheathing nail pattern of the iSPAN floor joist assembly with balloon framing. .84

Figure 3.22 Plan view of the iSPAN floor joist assembly with simply-supported framing ..85

Figure 3.23 Elevation of iSPAN floor joist assembly with simply-supported framing ........85

Figure 3.24 Section A2-A2 of the iSPAN floor joist assembly with simply-supported framing .85

Figure 3.25 Section B2-B2 of the iSPAN floor joist assembly with simply-supported framing .86

Figure 3.26 View of the bracing attached to the iSPAN joists at the quarter points of the iSPAN joists (note that the joists are upside down in this photo)

Figure 3.27 View of the clip angle attached to the joist and floor track of the simply-supported framing. .87

Figure 3.28 View of the iSPAN floor joist with balloon framing ...................................8

Figure 3.29 View of the LVDT attached to the iSPAN floor joist. .88

Figure 3.30 View of the iSPAN joist assembly with $1-\mathrm{kN}$ load placed at the mid-span to measure deflection in case of balloon framing 
Figure 3.31 View of the accelerometer attached to the bottom flange of the iSPAN joist ...89

Figure 3.32 View of the bowling ball dropped from a height of $0.3 \mathrm{~m}$ over the iSPAN joist assembly with balloon framing

Figure 3.33 View of the iSPAN joist with $1-\mathrm{kN}$ load placed at mid-span to measure static deflection of the assembly with simply-supported framing.... .90

Figure 3.34 View of the clamping system at support to avoid bouncy effect on iSPAN joist assembly with simply-supported framing.... .91

Figure 3.35 View of the bowling ball dropped from a height of $0.3 \mathrm{~m}$ over the iSPAN joist assembly with simply-supported framing .91

Figure 3.36 View of the uniformly distributed loading applied to the iSPAN floor joist assembly .92

Figure 3.37 View of the iSPAN joist with web holes on which a 1-kN load was placed at midspan to measure static deflection considering balloon framing .92

Figure 3.38 View of the iSPAN joist with web holes on which a 1-kN load was placed at midspan to measure static deflection considering simply-supported framing .........93

Fig. 3.39 View of the uniformly distributed loading applied to the iSPAN floor joist assembly with web holes

Figure 3.40 Plan view of test site 1 with iSPAN joists supported over wooden stud wall at building interior .96

Figure 3.41 Plan view of test site 2 with iSPAN joists supported over wooden stud wall at building interior .97

Figure 3.42 Plan view of test site 3 with iSPAN joists supported over steel beams at building interior and concrete exterior wall .98

Figure 3.43 Plan view of test site 4 with iSPAN joists supported over steel stud walls at building interior

Figure 3.44 View of the LVDTs and accelerometers attached to the bottom flange of iSPAN joist floor in test site 1

Figure 3.45 Close-up view of the LVDTs and accelerometers attached to the bottom flange of iSPAN joist in test site 1 101

Figure 3.46 View of the bowling ball dropped from a height of $0.3 \mathrm{~m}$ over the floor in test site 1. 
Figure 3.47 View of the 1-kN load placed at mid-span of the joist to measure the static deflection in test site 1

Figure 3.48 View of the bracing attached to the bottom flange of the joist in test site 1......103

Figure 3.49 View of the LVDTs and accelerometers attached to the bottom flange of iSPAN joist in test site 2 .

Figure 3.50 Close-up view of the LVDTs and accelerometers attached to the bottom flange of iSPAN joists in test site 2 . 104

Figure 3.51 View of the bowling ball dropped from a height of $0.3 \mathrm{~m}$ over the floor in test site 2. 105

Figure 3.52 View of the 1-kN load placed at mid-span of the joist to measure the static deflection in test site 2 105

Figure 3.53 View of the LVDTs and accelerometers attached to the bottom flange of iSPAN joist in test site 3 106

Figure 3.54 View of the 1-kN load placed at mid-span of the joist to measure static deflection in tests site 3 106

Figure 3.55 View of the floor is test site 4 107

Figure 3.56 View of the LVDTs and accelerometers attached to the bottom flange of iSPAN joist in test site 4 107

Figure 3.57 View of the 1-kN load placed at mid-span of the joist to measure static deflection in test site 4 108

Figure 3.58 Schematic diagram of a CFS coupon sample per ASTM A370 109

Figure 3.59 View of a typical setup for tensile coupon testing 109

Figure 3.60 View of the coupon sample after failure in the tensile testing machine 109

Figure 3.61 View of the failure shape in one of the tested coupons 110

Figure 3.62 View of typical stress-strain relationship of a tested coupon sample 110

Figure 4.1 Typical acceleration trace for the $241 \times 3500 \mathrm{~mm}$ wooden floor joist assembly 114

Figure 4.2 Typical frequency spectrum for the $241 \times 3500 \mathrm{~mm}$ wooden floor Joist 114

Figure 4.3 Typical jacking load-deflection relationship for the 241x3500 mm wooden floor joist assembly.....

Figure 4.4 View of a wooden twin-joist assembly after pure flexural failure...... 121 
Figure 4.5 Close-up view of a wooden twin-joist assembly showing joist flexural failure and OSB-joist top flange separation

Figure 4.6 Typical acceleration-time trace for the 241x3500 mm iSPAN floor joist assembly

Figure 4.7 Typical frequency spectrum for the 241x3500 mm iSPAN floor joist assembly

Figure 4.8 Typical jacking load-deflection relationship for the $241 \times 3500 \mathrm{~mm}$ iSPAN floor joist assembly

Figure 4.9 Typical strain gauge locations for the 241x3500 mm iSPAN floor joist.

Figure 4.10 View of jacking load-strain relationship for the 241x3500 mm iSPAN floor joist under flexural loading to-collapse

Figure 4.11 Flexural strain distribution along the depth of the $241 \times 3500 \mathrm{~mm}$ iSPAN joist cross-section at the mid-span location

Figure 4.12 View of an iSPAN twin-joist assembly without web holes after failure due to global lateral torsional buckling.

Figure 4.13 View of an iSPAN twin-joist assembly with web hole after failure due to lateral torsional buckling failure 135

Figure 4.14 View of an iSPAN twin-joist assembly with web hole after failure due to lateral

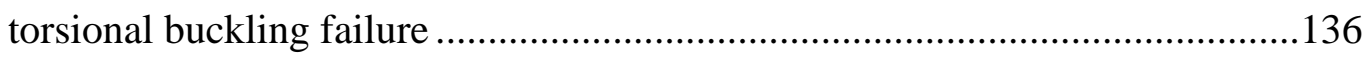

Figure 4.15 View of an iSPAN joist failed due to web crippling at support location...........136

Figure 4.16 Correlation between experimental results and CWC design criteria ................155

Figure 4.17 Correlation between experimental results and ATC design criteria ................156

Figure 4.18 Correlation between experimental results and EC5 design criteria ..................162

Figure 4.19 Correlation between experimental results and ISO acceleration design criteria

Figure 4.20 Experimental ultimate load-to-nominal ultimate load ration, $\mathrm{P}_{\mathrm{t}} / \mathrm{P}_{\mathrm{n}} \ldots \ldots \ldots \ldots \ldots . . . .165$

Figure 5.1(a) View of shell elements available in ABAQUS software ...............................178

Figure 5.1(b) View of solid elements available in ABAQUS software ................................179

Figure 5.2 View of the LINK element in ABAQUS ................................................180

Figure 5.3 Typical one-layer and two-layer fastener configuration ................................180 
Figure 5.4 Effect of FE mesh sensitivity on the load-deflection history of the $302 \times 5000 \mathrm{~mm}$ iSPAN joist assembly .....

Figure 5.5 True and engineering stress-strain curves for CFS members ........................182

Figure 5.6 Typical unstable static response.

Figure 5.7 Schematic diagram of the tested iSPAN joist assembly considered in the FE modelling 188

Figure 5.8 View of the FE model of the 254x3500 mm ISPAN two-joist Assembly with web hole. 189

Figure 5.9 View of the FE deformed shape of the 254x3500 mm ISPAN two-joist Assembly with web hole 189

Figure 5.10 View of the experimental deformed shape of the $254 \times 3500 \mathrm{~mm}$ iSPAN joist assembly showing web and track crippling at failure 190

Figure 5.11 View of the FE deformed shape of the 254x3500 mm iSPAN joist assembly showing web and track crippling in the form of in-plane stress reaching and exceeding the yield stress 190

Figure 5.12 View of the experimental deformed shape at failure of the 406x7950 mm iSPAN joist assembly.....

Figure 5.13 View of the FE deformed shape of the 406x7950 mm iSPAN joist assembly ..191

Figure 5.14 View of the experimental local buckling shape in the top flange lip of the 406x7950 iSPAN joist assembly 192

Figure 5.15 View of the FE local buckling shape in the top flange lip of the 406x7950 mm iSPAN joist assembly

Figure 5.16 View of the experimental lateral torsional buckling shape of the 300x5000 mm iSPAN joist assembly

Figure 5.17 View of the FE lateral torsional buckling shape of the 300x5000 mm iSPAN joist assembly.

Figure 5.18 Load-deflection relationship of the 254x3500 mm iSPAN joist assembly.....

Figure 5.19

Load-deflection relationship of the 254x4500 mm iSPAN joist assembly 198

Figure 5.20 Load-deflection relationship of the 300x5000 mm iSPAN joist assembly. 198

Figure 5.21 Load-deflection relationship of the 300x5250 mm iSPAN joist assembly..... 199

Figure 5.22 Load-deflection relationship of the 241x3500 mm iSPAN joist assembly. 199 
Figure 5.23 Load-deflection relationship of the $241 \times 4500 \mathrm{~mm}$ iSPAN joist assembly.......200

Figure 5.24 Load-deflection relationship of the 356x6100 mm iSPAN joist assembly.......200

Figure 5.25 Load-deflection relationship of the 406x7950 mm iSPAN joist assembly.......201

Figure 5.26 View of the FE model of the 241x $4500 \mathrm{~mm}$ joist with metal cladding attached to the joist .203

Figure 5.27 Load-deflection relationship of the $241 \times 4500 \mathrm{~mm}$ iSPAN joist assembly with the presence of OSB Sheet and metal cladding .203

Figure 5.28 Effect of OSB sheet coverage on the $241 \times 4500 \mathrm{~mm}$ iSPAN joist assembly....204

Figure 5.29 View of the FE modelling and stress contour lines of the 241x4500 mm iSPAN joist assembly with $66 \%$ coverage of OSB sheet. 204

Figure 5.30 View of the FE modelling and stress contour lines of the $241 \times 4500 \mathrm{~mm}$ iSPAN joist assembly with $75 \%$ coverage of OSB sheet. .205

Figure 5.31 View of the FE modelling and stress contour lines of the $241 \times 4500 \mathrm{~mm}$ iSPAN joist assembly with $80 \%$ coverage of OSB sheet. .205

Figure 5.32 View of the FE modeling and stress contour lines of the $241 \times 4500 \mathrm{~mm}$ iSPAN joist assembly with $90 \%$ coverage of OSB sheet. .206

Figure 5.33 View of the FE modelling and stress contour lines resulting from the nonlinear analysis of the $254 \times 3000 \mathrm{~mm}$ iSPAN joist assembly (OSB sheet is not shown for clarity) 207

Figure 5.34 View of the FE modelling and stress contour lines resulting from the nonlinear analysis of a $3 \times 3 \mathrm{~m}$ iSPAN joist floor system (OSB sheet is not shown for clarity) .208

Figure 5.35 View of the FE modelling and stress contour lines resulting from the nonlinear analysis of a 6x3 m iSPAN joist floor system (OSB sheet is not shown for clarity) .208

Figure 5.36 View of the FE modelling and stress contour lines resulting from the nonlinear analysis of a 9x3 m iSPAN joist floor system (OSB sheet is not shown for clarity) .209

Figure 5.37 View of the FE modelling and stress contour lines resulting from the nonlinear analysis of twin joist 400x9000 mm iSPAN joist assembly (OSB sheet is not shown for clarity) .209 
Figure 5.38 View of the FE modelling and stress contour lines resulting from the nonlinear analysis of a 3x9 m iSPAN joist floor system (OSB sheet is not shown for clarity)

Figure 5.39 View of the FE modelling and stress contour lines resulting from the nonlinear analysis of a 6x9 m iSPAN joist floor system (OSB sheet is not shown for clarity)

Figure 5.40 View of the FE modelling and stress contour lines resulting from the nonlinear analysis of a 9x9 m iSPAN joist floor system (OSB sheet is not shown for clarity)

Figure 5.41 Comparison of load-deflection relationship of 254x3000 mm floor joist used in different floor plan sizes

Figure 5.42 Comparison of load-deflection relationship of 406x9000 mm floor joist used in different floor plan sizes

Figure 5.43 Views of web holes locations .214

Figure 6.1 View of a typical floor built with iSPAN joists with edge-stiffened web holes

Figure 6.2 View of hole patterns

Figure 6.3 View of cold formed steel joist sections .218

Figure 6.4

View of slot holes used in the research. .218

Figure 6.5

View of Tri-slot holes used in the research .219

Figure 6.6 View of FE mesh and boundary conditions for plates under uniform compression .223

Figure 6.7 View of buckling shape for circular hole under compression .223

Figure 6.8 View of buckling shape for slotted hole under compression. .224

Figure 6.9 View of buckling shape for Tri-slotted hole under compression. .224

Figure 6.10 View of FE mesh and boundary conditions for plates under stress gradient.....227

Figure 6.11

View of buckling shape for circular hole under stress gradient. .227

Figure 6.12 View of buckling shape for slotted hole under stress gradient ....... .228

Figure 6.13

View of buckling shape for Tri-slotted hole under stress gradient .228

Figure 6.14 FE model for elastic buckling analysis on joist with circular holes .235

Figure 6.15 FE model for elastic buckling analysis on joist with slot holes. .236 
Figure 6.16 FE model for elastic buckling analysis on joist with Tri-slot holes.................236

Figure 6.17 View of elastic bulking shapes for 254-i-2 joists without holes .....................237

Figure 6.18 View of elastic bulking shapes for 254-i-2 joists with holes .........................238

Figure 6.19 FE model for post buckling analysis on joist with stiffened hole...................243

Figure 6.20 FE model for post buckling analysis on joist with stiffened hole....................244

Figure 6.21 FE model for post buckling analysis on joist with stiffened hole....................244

Figure 6.22 Failure mode of 254-i-2 joist without hole and with holes .............................246

Figure 6.23 Design curve for C-sectionl ..............................................................253

Figure 6.24 Design curve for iSPAN joists ..............................................................254

Figure A1.1 Typical acceleration trace for $241 \times 4500 \mathrm{~mm}$ wooden floor joist ...................264

Figure A1.2 Typical acceleration trace for 302x5000 mm wooden floor joist...................264

Figure A1.3 Typical acceleration trace for 302x5250 mm wooden floor joist ...................265

Figure A1.4 Typical acceleration trace for 356x6100 mm wooden floor joist ...................265

Figure A1.5 Typical acceleration trace for 406x7950 mm wooden floor joist ...................266

Figure A2.1 Typical frequency spectrum for $241 \times 4500 \mathrm{~mm}$ wooden floor Joist .................268

Figure A2.2 Typical frequency spectrum for 302x5000 mm wooden floor Joist .................270

Figure A2.3 Typical frequency spectrum for 302x5250 mm wooden floor Joist ................269

Figure A2.4 Typical frequency spectrum for 356x6100 mm wooden floor Joist................269

Figure A2.5 Typical frequency spectrum for 406 x $7950 \mathrm{~mm}$ wooden floor Joist ...............270

Figure A3.1 Typical load deflection curve for $241 \times 4500 \mathrm{~mm}$ wooden floor joist ...............272

Figure A3.2 Typical load deflection curve for 302x5000 mm wooden floor joist ..............272

Figure A3.3 Typical load deflection curve for 302x5250 mm wooden floor joist ..............273

Figure A3.4 Typical load deflection curve for 356x6100 mm wooden floor joist ...............273

Figure A3.5 Typical load deflection curve for 406 x $7950 \mathrm{~mm}$ wooden floor joist .............274

Figure B1.1 Typical acceleration trace for 241x3500 mm iSPAN floor joist (B.F)............276

Figure B1.2 Typical acceleration trace for $241 \times 3500 \mathrm{~mm}$ iSPAN floor joist (S.S) ............276

Figure B1.3 Typical acceleration trace for $241 \times 4500 \mathrm{~mm}$ iSPAN floor joist (B.F) ............277

Figure B1.4 Typical acceleration trace for 241 x4500 mm iSPAN floor joist (S.S) ............277

Figure B1.5 Typical acceleration trace for 302x5000 mm iSPAN floor joist (B.F)............278

Figure B1.6 Typical acceleration trace for 302x5000 mm iSPAN floor joist (S.S) ............278

Figure B1.7 Typical acceleration trace for 302x5250 mm iSPAN floor joist (B.F)............279 
Figure B1.8 Typical acceleration trace for 302x5250 mm iSPAN floor joist (S.S) ............279

Figure B1.9 Typical acceleration trace for 356x6100 mm iSPAN floor joist (B.F)............280

Figure B1.10 Typical acceleration trace for 356x6100 mm iSPAN floor joist (S.S) ............280

Figure B1.11 Typical acceleration trace for 406x7950 mm iSPAN floor joist (B.F)............281

Figure B1.12 Typical acceleration trace for 406x7950 mm iSPAN floor joist (S.S) ............281

Figure B2.1 Typical frequency spectrum for 241x3500 mm iSPAN floor joist (B.F) .........283

Figure B2.2 Typical frequency spectrum for 241x3500 mm iSPAN floor joist (S.S).........283

Figure B2.3 Typical frequency spectrum for $241 \times 4500 \mathrm{~mm}$ iSPAN floor joist (B.F) .........284

Figure B2.4 Typical frequency spectrum for 241x4500 mm iSPAN floor joist (S.S).........284

Figure B2.5 Typical frequency spectrum for 302x5000 mm iSPAN floor joist (B.F) .........285

Figure B2.6 Typical frequency spectrum for 302x5000 mm iSPAN floor joist (S.S).........285

Figure B2.7 Typical frequency spectrum for 302x5250 mm iSPAN floor joist (B.F) .........286

Figure B2.8 Typical frequency spectrum for 302x5250 mm iSPAN floor joist (S.S).........286

Figure B2.9 Typical frequency spectrum for 356x6100 mm iSPAN floor joist (B.F) .........287

Figure B2.10 Typical frequency spectrum for 356x6100 mm iSPAN floor joist (S.S)..........287

Figure B2.11 Typical frequency spectrum for 406x7950 mm iSPAN floor joist (B.F) .........298

Figure B2.12 Typical frequency spectrum for 406x7950 mm iSPAN floor joist (S.S)..........298

Figure B3.1 Typical load deflection curve for 241x3500 mm iSPAN floor joist................290

Figure B3.2 Typical load deflection curve for $241 \times 4500 \mathrm{~mm}$ iSPAN floor joist.................290

Figure B3.3 Typical load deflection curve for 302x5000 mm iSPAN floor joist................291

Figure B3.4 Typical load deflection curve for 302x5250 mm iSPAN floor joist................291

Figure B3.5 Typical load deflection curve for 356 x 6100 mm iSPAN floor joist...............292

Figure B3.6 Typical load deflection curve for 406 x 7950 mm iSPAN floor joist...............292

Figure B4.1 Flexural strain distribution at the middle of the $241 \times 3500 \mathrm{~mm}$ joist 1 ............294

Figure B4.2 Flexural strain distribution at the middle of the $241 \times 3500 \mathrm{~mm}$ joist 2...........295

Figure B4.3 Load-strain distribution at the middle of the $241 \times 3500 \mathrm{~mm}$ joist 1 ...............295

Figure B4.4 Load-strain distribution at the middle of the $241 \times 3500 \mathrm{~mm}$ joist 2 ..............296

Figure B4.5 Flexural-strain distribution at the middle of the $241 \times 4500 \mathrm{~mm}$ joist 1 ...........296

Figure B4.6 Flexural-strain distribution at the middle of the $241 \times 4500 \mathrm{~mm}$ joist 2 ..........297

Figure B4.7 Load-strain distribution at the middle of $241 \times 4500 \mathrm{~mm}$ joist 1 ...................298

Figure B4.8 Load-strain distribution at the middle of $241 \times 4500 \mathrm{~mm}$ joist 2 ...................298 
Figure B4.9 Flexural-strain distribution at the middle of the $302 \times 5000 \mathrm{~mm}$ joist 1 ...........299

Figure B4.10 Flexural-strain distribution at the middle of the $302 \times 5000 \mathrm{~mm}$ joist 2 ............300

Figure B4.11 Load-strain distribution at the middle of 300x5000 mm joist 1 ...................300

Figure B4.12 Load-strain distribution at the middle of 300x5000 mm joist 2 .....................301

Figure B4.13 Flexural-strain distribution at the middle of the 300x5250 mm joist 1 ............302

Figure B4.14 Flexural-strain distribution at the middle of the $300 \times 5250 \mathrm{~mm}$ joist 2 ...........302

Figure B4.15 Load-strain distribution at the middle of 300x5250 mm joist 1 ...................303

Figure B4.16 Load-strain distribution at the middle of 300x5250 mm joist 2 ....................303

Figure B4.17 Flexural-strain distribution at the middle of the 356x6100 mm joist 1 ............304

Figure B4.18 Flexural-strain distribution at the middle of the $356 \times 6100 \mathrm{~mm}$ joist 2 ...........305

Figure B4.19 Load-strain distribution at the middle of 356x6100 mm joist 1 ....................305

Figure B4.20 Load-strain distribution at the middle of 356x6100 mm joist 2 ...................306

Figure B4.21 Flexural-strain distribution at the middle of the 400x7950 mm joist 1 ............307

Figure B4.22 Flexural-strain distribution at the middle of the $400 \times 7950 \mathrm{~mm}$ joist 2 ...........308

Figure B4.23 Load-strain distribution at the middle of 400x7950 mm joist 1 ....................309

Figure B4.24 Load-strain distribution at the middle of 400x7950 mm joist 2 ...................309

Figure C1.1 Typical acceleration trace for 254x3500 mm iSPAN floor joist (B.F).............311

Figure C1.2 Typical acceleration trace for 254x3500 mm iSPAN floor joist (S.S) .............311

Figure C1.3 Typical acceleration trace for $254 \times 4500 \mathrm{~mm}$ iSPAN floor joist (B.F).............312

Figure C1.4 Typical acceleration trace for 254x4500 mm iSPAN floor joist (S.S) ..............312

Figure C1.5 Typical acceleration trace for 302x5000 mm iSPAN floor joist (B.F).............313

Figure C1.6 Typical acceleration trace for 302x5000 mm iSPAN floor joist (S.S) ............313

Figure C1.7 Typical acceleration trace for 302x5250 mm iSPAN floor joist (B.F).............314

Figure C1.8 Typical acceleration trace for 302x5250 mm iSPAN floor joist (S.S) .............314

Figure C2.1 Typical frequency spectrum for 254x3500 mm iSPAN floor joist (B.F) .........316

Figure C2.2 Typical frequency spectrum for 254x3500 mm iSPAN floor joist (S.S)..........316

Figure C2.3 Typical frequency spectrum for $254 \times 4500 \mathrm{~mm}$ iSPAN floor joist (B.F) ..........317

Figure C2.4 Typical frequency spectrum for 254x4500 mm iSPAN floor joist (S.S)..........317

Figure C2.5 Typical frequency spectrum for 302x5000 mm iSPAN floor joist (B.F) .........318

Figure C2.6 Typical frequency spectrum for 302x5000 mm iSPAN floor joist (S.S)..........318

Figure C2.7 Typical frequency spectrum for 302x5250 mm iSPAN floor joist (B.F) ..........319 
Figure C2.8 Typical frequency spectrum for 302x5250 mm iSPAN floor joist (S.S)..........319

Figure C3.1 Typical load deflection curve for 254x3500 mm iSPAN floor joist.................321

Figure C3.2 Typical load deflection curve for 254x4500 mm iSPAN floor joist.................326

Figure C3.3 Typical load deflection curve for 302x5000 mm iSPAN floor joist.................322

Figure C3.4 Typical load deflection curve for 302x5250 mm iSPAN floor joist.................322

Figure C4.1 Load-strain distribution at the middle of $254 \times 3500 \mathrm{~mm}$ joist 1 ....................324

Figure C4.2 Load-strain distribution at the middle of $254 \times 3500 \mathrm{~mm}$ joist 2 ...................325

Figure C4.3 Load-strain distribution at the middle of $254 \times 4500 \mathrm{~mm}$ joist 1 ....................326

Figure C4.4 Load-strain distribution at the middle of $254 \times 4500 \mathrm{~mm}$ joist 2 ....................327

Figure C4.5 Load-strain distribution at the middle of 300x5000 mm joist 1 ...................328

Figure C4.6 Load-strain distribution at the middle of 300x5000 mm joist 2 ...................329

Figure C4.7 Load-strain distribution at the middle of 300x5250 mm joist 1 ...................330

Figure C4.8 Load-strain distribution at the middle of $300 \times 5250 \mathrm{~mm}$ joist 2 ....................331

Figure D1.1 Typical acceleration trace unbraced floor joists in site 1 ..............................333

Figure D1.2 Typical acceleration trace braced floor joists in site 1 .................................333

Figure D1.3 Typical acceleration trace braced floor joists in site 2 ...............................334

Figure D1.4 Typical acceleration trace braced floor joists in site 3.................................334

Figure D1.5 Typical acceleration trace braced floor joists in site 4................................335

Figure D2.1 Typical frequency spectrum unbraced floor joists for site 1 ...........................336

Figure D2.2 Typical frequency spectrum braced floor joists for site 1 ...............................336

Figure D2.3 Typical frequency spectrum braced floor joists for site 2 2............................338

Figure D2.4 Typical frequency spectrum braced floor joists for site 3............................338

Figure D2.5 Typical frequency spectrum braced floor joists for site 4............................395

Figure E.1 View of deformed shape at failure of the 241 x3500 mm wooden joist assembly

Figure E.2 Close-up view of the bending fracture of the OSB web and top flange-OSB web separation at failure of the $241 \times 3500 \mathrm{~mm}$ wooden joist assembly .341

Figure E.3 View of deformed shape at failure of the 241x4500 mm wooden joist assembly 342

Figure E.4 Close-up view of bending fracture of the joist and top flange-OSB web separation of $241 \mathrm{x} 4500 \mathrm{~mm}$ wooden joist assembly. .342 
Figure E.5 View of the deformed shape at failure of the $302 \times 5000 \mathrm{~mm}$ wooden joist assembly.

Figure E.6 Close-up view of the bending fracture of bottom flange and web of the 302x5000 mm wooden joist assembly at failure. .343

Figure E.7 View of the deformed shape at failure of the $302 \times 5250 \mathrm{~mm}$ wooden joist assembly 344

Figure E.8 Close-up view of the bending fracture of the bottom flange of web of the $302 \times 5250 \mathrm{~mm}$ wooden joist assembly 344

Figure E.9 View of the deformed shape at failure of the $356 \times 6100 \mathrm{~mm}$ wooden joist assembly

Figure E.10 Close-up view of the bottom flange and web fracture and top flange-web separation at failure of the $356 \times 6100 \mathrm{~mm}$ wooden joist assembly 345

Figure E.11 View of the deformed shape at failure of the $406 \times 7950 \mathrm{~mm}$ wooden joist assembly .346

Figure E.12 Close-up view of the bending fracture of the bottom flange and web of the 406x7950 mm wooden joist assembly 346

Figure E.13 View of the deformed shape at failure of the $241 \times 3500 \mathrm{~mm}$ iSPAN joist assembly 347

Figure E.14 Close-up view of the lateral torsional buckling failure of the $241 \times 3500 \mathrm{~mm}$ iSPAN joist assembly 347

Figure E.15 View of lateral torsional buckling failure of the $241 \times 4500 \mathrm{~mm}$ iSPAN joist assembly 348

Figure E.16 Close-up View of lateral torsional buckling failure of the $241 \times 4500 \mathrm{~mm}$ iSPAN joist assembly along with rim board separation from the joist at the support ...348

Figure E.17 View of lateral torsional buckling failure of the $302 \times 5000 \mathrm{~mm}$ iSPAN joist assembly .349

Figure E.18 Close-up view of lateral torsional buckling failure of 302x5000 mm iSPAN joist assembly along with crippling of the rim board over the support

Figure E.19 View of lateral torsional buckling failure of the $302 \times 5250 \mathrm{~mm}$ iSPAN joist assembly .350 
Figure E.20 View of splitting of the OSB sheets and separation of OSB sheet and the top flange at the support region of the $302 \times 5250 \mathrm{~mm}$ iSPAN joist assembly ..........350

Figure E.21 View of lateral torsional buckling failure of the 356x6100 mm iSPAN joist assembly

Figure E.22 View of lateral torsional buckling failure at the other side of the $356 \times 6100 \mathrm{~mm}$ iSPAN joist assembly .351

Figure E.23 View of the deformed shape of the 406x7950 mm iSPAN joist assembly........352

Figure E.24 Close-up view of the local buckling of the top flange along with web local buckling at the mid-span region of the 406x7950 mm iSPAN joist assembly ..352

Figure E.25 Close-up view of the local buckling of the free lip at the top flange of the 406x7950 mm iSPAN joist assembly .353

Figure E.26 View of the deformed shape at failure of the 254x3500 mm iSPAN joist assembly at support. .354

Figure E.27 View of web and rim board crippling at failure at support of the $254 \times 3500 \mathrm{~mm}$ iSPAN joist assembly with web holes .354

Figure E.28 View of lateral torsional buckling failure of the $254 \times 4500 \mathrm{~mm}$ iSPAN joist assembly with web holes .355

Figure E.29 Close-up view of lateral torsional buckling failure of the 254x4500 mm iSPAN joist assembly with web holes. .355

Figure E.30 View of the lateral torsional buckling failure of the $302 \times 5000 \mathrm{~mm}$ iSPAN joist assembly with web holes .356

Figure E.31 Close-up view of lateral torsional buckling failure along with OSB separation normal to the joist of $302 \times 5000 \mathrm{~mm}$ iSPAN joist assembly..... .356

Figure E.32 View of lateral torsional buckling failure of the $302 \times 5250 \mathrm{~mm}$ iSPAN joist assembly with web holes

Figure E.33 Close-up view of the lateral torsional buckling failure of the joist and lateral separation of OSB sheets at mid-span region of the $302 \times 5250 \mathrm{~mm}$ iSPAN joist assembly with holes 357

Figure F.1 View of buckling curve obtained from CUFSM for 600S162-33 section .........359

Figure F.2 View of buckling curve obtained from CUFSM for 600S250-97 section .........359

Figure F.3 View of buckling curve obtained from CUFSM for 800S162-33 section .........360 
Figure F.4 View of buckling curve obtained from CUFSM for 800S250-97 section .........360

Figure F.5 View of buckling curve obtained from CUFSM for 1000S162-43 section .......361

Figure F.6 View of buckling curve obtained from CUFSM for 1000S250-97 section .......361

Figure F.7 View of buckling curve obtained from CUFSM for 1200S162-54 section .......362

Figure F.8 View of buckling curve obtained from CUFSM for 1200S250-97 section .......362

Figure F.9 View of buckling curve obtained from CUFSM for 254-i-2 section................363

Figure F.10 View of buckling curve obtained from CUFSM for 254-i-3 section................363

Figure F.11 View of buckling curve obtained from CUFSM for 305-i-2 section................364

Figure F.12 View of buckling curve obtained from CUFSM for 305-i-3 section................364

Figure F.13 View of buckling curve obtained from CUFSM for 355-i-3 section................365

Figure F.14 View of buckling curve obtained from CUFSM for 355-i-4 section................365

Figure F.15 View of buckling curve obtained from CUFSM for 406-i-3 section................366

Figure F.16 View of buckling curve obtained from CUFSM for 406-i-4 section................366

Figure G.1 View of a joist failed in local buckling of web and top lower flange of iSPAN

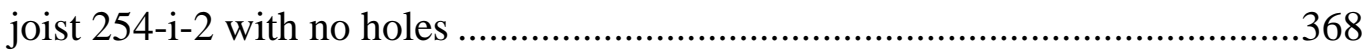

Figure G.2 View of a joist with stiffened hole failed in local buckling of top lower flange of iSPAN joist 254-i-2 with circular holes. .368

Figure G.3 View of a joist with stiffened hole failed in local buckling of top lower flange of iSPAN joist 254-i-2 with slotted holes

Figure G.4 View of a joist with stiffened hole failed in local buckling of top lower flange of iSPAN joist 254-i-2 with tri-slot holes .369

Figure G.5 View of a joist failed in local buckling of web of iSPAN joist 305-i-2 with no holes .370

Figure G.6 View of a joist failed in distortion buckling of iSPAN joist 305-i-2 with circular holes 370

Figure G.7 View of a joist failed in distortion buckling of iSPAN joist 305-i-2 with slotted holes .371

Figure G.8 View of a joist failed in distortion buckling of iSPAN joist 305-i-2 with tri-slot holes 372

Figure G.9 View of a joist failed in distortion buckling of iSPAN joist 355-i-3 with no holes .372 
Figure G.10 View of a joist failed in distortion buckling of iSPAN joist 355-i-3 with circular holes . .372

Figure G.11 View of a joist failed in distortion buckling of iSPAN joist 355-i-3 with slotted holes 373

Figure G.12 View of a joist failed in distortion buckling of iSPAN joist 355-i-3 with tri-slot holes 373

Figure G.13 View of a joist failed in distortion buckling of iSPAN joist 406-i-3 with no holes .374

Figure G.14 View of a joist failed in distortion buckling of iSPAN joist 406-i-3 with circular holes 374

Figure G.15 View of a joist failed in distortion buckling of iSPAN joist 406-i-3 with slotted holes 375

Figure G.16 View of a joist failed in distortion buckling of iSPAN joist 406-i-3 with tri-slotted holes .375 


\section{NOTATIONS}

$\begin{array}{ll}\mathrm{C}_{\phi} & \text { Calibration coefficient } \\ \alpha_{i} & \text { Dynamic coefficient of the } \mathrm{i}^{\text {th }} \text { harmonic force component } \\ \Delta & \text { Midspan floor deflection } \\ a & \text { Distance of element to the closest end of joist } \\ \bar{A} & \text { Transformed section area } \\ \mathrm{A} & \text { Cross sectional area } \\ \mathrm{a}_{\mathrm{p}} & \text { Estimated peak acceleration. } \\ A_{s} & \text { Unit axial stiffness of sub-floor parallel to the panel axis } \\ \mathrm{b}_{\mathrm{e}} & \text { Effective width } \\ \mathrm{b}_{\mathrm{f}} & \text { Flange width } \\ \mathrm{C}_{\mathrm{c}} & \text { Distance from neutral axis to compression face } \\ \mathrm{C}_{\mathrm{P}} & \text { Correction factor } \\ \mathrm{C}_{\mathrm{w}} & \text { Torsional warping constant of cross section } \\ \mathrm{D} & \text { Flexural rigidity of plate } \\ \mathrm{DF}_{\mathrm{m}} & \text { Distribution factor } \\ D F_{b} & \text { Distribution factor for bending elements } \\ D F_{v} & \text { Distribution factor for shear elements } \\ \mathrm{d}_{\mathrm{h}} & \text { Hole depth } \\ e & \text { Natural logarithmic base (2.718) } \\ \mathrm{E} & \text { Modulus of elasticity } \\ E A_{c} & \text { Unit axial stiffness of concrete topping } \\ E I_{b i} & \text { Unit flexural stiffness of individual bending member } \\ E I_{c} & \text { Unit flexural stiffness of concrete topping } \\ E I_{e f f} & \text { Effective flexural stiffness } \\ E I_{s} & \text { Unit flexural stiffness of sub floor parallel to the panel axis } \\ E I_{x} & \text { Effective flexural stiffness of strong back and straps } \\ f_{0} & \text { natural frequency corresponding to the peak value } f_{m a x} \\ \mathrm{~F}_{\mathrm{cr}} & \text { Critical stress } \\ \mathrm{F}_{\mathrm{m}} & \text { Mean value of fabrication factor } \\ f_{\mathrm{max}} & \text { Maximum natural frequency } \\ & \end{array}$




\begin{tabular}{ll}
$f_{\mathrm{n}}$ & Natural frequency \\
$f_{x}$ & Compression stress in $x$ direction \\
$\mathrm{F}_{\mathrm{y}}$ & Design yield stress \\
$\mathrm{G}$ & Shear Modulus \\
$\mathrm{g}$ & Acceleration due to gravity \\
$\mathrm{h}$ & Joist height \\
$h_{c w}$ & Distance from center of sub floor to center of concrete topping \\
$\mathrm{I}$ & Moment of inertia \\
$\mathrm{J}$ & Saint Venant torsion constant of cross section \\
$k$ & Stiffness of the floor system \\
$\mathrm{k}$ & Plate buckling coefficient \\
$\mathrm{K}_{\mathrm{D}}$ & Load duration factor \\
$\mathrm{K}_{\mathrm{H}}$ & System factor \\
$\mathrm{K}_{\mathrm{sc}}$ & Service condition factors \\
$\mathrm{K}_{\mathrm{SE}}$ & Service condition factor for modulus of elasticity of flange \\
$\mathrm{K}_{\mathrm{t}}$ & Effective length factor for twisting \\
$\mathrm{K}_{\mathrm{T}}$ & Treatment factor \\
$\mathrm{k}_{\mathrm{v}}$ & Shear buckling coefficient \\
$\mathrm{K}_{\mathrm{y}}$ & Effective length factor for bending about y-axis \\
$\mathrm{K}_{\mathrm{Zc}}$ & Size factor for compression \\
$\mathrm{L}$ & Floor span \\
$\mathrm{L}_{\mathrm{h}}$ & Hole length \\
$\mathrm{L}_{\mathrm{t}}$ & Unbraced length of member for twisting \\
$\mathrm{L}_{\mathrm{y}}$ & Unbraced length of member for bending about y-axis \\
$\mathrm{m}$ & Degrees of freedom \\
$m$ & mass of the floor system \\
$\mathrm{M}_{\mathrm{A}}$ & Absolute value of moment at quarter point of unbraced segment \\
$\mathrm{M}_{\mathrm{B}}$ & Absolute value of moment at centerline of unbraced segment \\
$\mathrm{M}_{\mathrm{C}}$ & Absolute value of moment at three quarter point of unbraced segment \\
$\mathrm{M}_{\mathrm{crd}}$ & Critical elastic distortional buckling moment \\
$\mathrm{M}_{\mathrm{rrl}}$ & Critical elastic local buckling moment \\
\hline
\end{tabular}




\begin{tabular}{|c|c|}
\hline $\mathrm{M}_{\mathrm{DSM}}$ & Flexural strength Direct Strength Method \\
\hline $\mathrm{M}_{\mathrm{feH}}$ & Flexural strength of joists with stiffened holes \\
\hline $\mathrm{M}_{\mathrm{feN}}$ & Flexural strength of normal joists \\
\hline $\mathrm{M}_{\mathrm{m}}$ & Mean value of material factor \\
\hline $\mathbf{M}_{\max }$ & Absolute value of maximum moment in unbraced segment \\
\hline $\mathrm{M}_{\mathrm{ne}}$ & Nominal flexural strength \\
\hline $\mathrm{M}_{\text {new }}$ & Flexural strength by the proposed design method for joists with stiffened holes \\
\hline $\mathrm{M}_{\mathrm{nl}}$ & Nominal flexural strength resistance for local buckling \\
\hline $\mathrm{M}_{\mathrm{r}}$ & Resisting moment \\
\hline $\mathrm{M}_{\mathrm{y}}$ & Yield moment \\
\hline $\mathrm{n}$ & Number of tests \\
\hline $\mathrm{P}$ & Applied load \\
\hline $\mathrm{P}_{\mathrm{m}}$ & Mean value of professional factor, $\mathrm{P}$ \\
\hline $\mathrm{P}_{\mathrm{n}}$ & Nominal load calculated through code equation. \\
\hline$P_{t}$ & Experimental applied load \\
\hline q & Edge stiffener \\
\hline $\mathrm{R}$ & Reduction factor \\
\hline$r_{x}, r_{y}$ & Radii of gyration of cross section about centroidal principal axes \\
\hline $\mathrm{s}$ & Joist spacing \\
\hline$S_{\mathrm{e}}$ & Elastic section modulus of effective section \\
\hline$S_{\mathrm{f}}$ & Gross-section modulus \\
\hline $\mathrm{t}$ & Plate thickness \\
\hline $\mathrm{t}_{\mathrm{w}}$ & Web thickness \\
\hline $\mathrm{V}_{\mathrm{F}}$ & Coefficient of variation of fabrication factor \\
\hline$V_{M}$ & Coefficient of variation of material factor \\
\hline $\mathrm{V}_{\mathrm{n}}$ & Nominal shear strength (resistance) \\
\hline$V_{P}$ & Coefficient of variation of test results \\
\hline $\mathrm{V}_{\mathrm{Q}}$ & Coefficient of variation of load effect \\
\hline $\mathrm{w}$ & Weight per unit length \\
\hline$W$ & Effective weight of the floor \\
\hline $\bar{y}$ & Location of neutral axis from the centroid of the joist \\
\hline
\end{tabular}


Model damping ratio

$\beta_{0} \quad$ Target reliability index,

$\gamma$

Ratio of shear deflection to flexural deflection

$\lambda$

Length of the half sine wave

$\mu$

Poisson's ratio ( 0.3 for steel in the elastic range)

$\Omega$

Factor of safety (ASD method)

$\phi$

Safety factor

$\phi_{\mathrm{b}}$

Resistance factor

$\omega$

Deflection of plate perpendicular to surface 


\section{CHAPTER 1 INTRODUCTION}

\subsection{GENERAL}

Structural steel is mainly divided into two types, namely: hot-rolled steel sections and coldformed steel (CFS) sections. The use of cold-formed steel members in building construction began in about 1850s in both the United States and Great Britain. However, in North America such steel members were not widely used in buildings until the publication of the first edition of the American Iron and Steel Institute (AISI) Specification in 1946. The first research was carried out by Professor George Winter at Cornell University in 1939. The design standard was primarily based on his research work. His research work has been published in numerous journals. In Canada, the first cold-formed steel design standard was issued in 1963. Continuous research in this field have led to a number of edition over the years, resulting in the development of the 2007 edition of the Design Standard for Cold-Formed Steel Members, CSA-S136-07 (Canadian, 2007). The use of cold formed steel members in buildings has been growing since early 1950's.

Whalen (2013) stated that the life cycle of steel is almost endless compared to the average life span of wood of 100 years or less. Both demolished wood buildings that are usually sent to the landfills and burned-down wood buildings contribute to $\mathrm{CO}_{2}$ and greenhouse gas emissions. Whalen claimed that it takes 10 tonnes of wood to make one tonne of lumber and these silent nine tonnes of wood include leaves, branches and tree trucks that are left to rot on a clear-cut landscape. On the other hand, cold-form steel are recently considered as the best material for low-rise building construction as well as for roof and floor systems based on performance, cost, safety and ultimately sustainability considerations. The use of cold-formed steel, as a framework for floor systems in multi-story buildings and single occupancy residences is becoming an increasingly popular alternative to traditional materials and techniques. Builders and designers have recognized that the high strength to-weight ratio provided by the cross-section of coldformed steel members allows lighter structures and longer spans. Cold-formed steel joists do not require specialty trades for installation. Floor systems built on the cold-formed steel joist framework can be built quickly and precisely, are impervious to rot and insect damage and can 
have long fire-separation ratings when designed appropriately. The floor systems are ideal for open-concept residential and commercial floor plans, with allowable clear span lengths of $10 \mathrm{~m}$ or greater. If joists with large lip-reinforced openings are used, mechanical components can be installed within the depth of the joists, and the overall inter-storey depth is reduced. For these reasons, cold-formed steel floor systems can be advantageous when used in place of light-frame floor systems, built with wood members, and heavy floor systems, built with reinforced concrete and hot-rolled steel joists (Parnell, 2008). However, the design process of cold-formed steel floors has not been addressed enough in the literature as well as in design code as it will appear later in this research.

Most recently, an I-shape CFS joist was developed by one of the CFS manufactures in Ontario, referred to iSPAN joist in this research. The performance of residential floors supported by iSPAN floor joist was investigated against the performance of engineered wood I-joists. The iSPAN floor joist, shown in Figure 1.1(a), is a visual I-type cold-formed steel section. The section has large lip-reinforced web openings along the joist length to accommodate the usual service elements. It should be noted that the traditional cold-formed steel C- or Z-shape sections, shown in Figure 1.1(b), are specified in S136-07 with un-stiffened circular or slotted holes in their webs for piping, electrical wiring, installing lateral bracing or for plumbing. These holes are flat punched without edge lips (i.e. with un-stiffened hole edge).

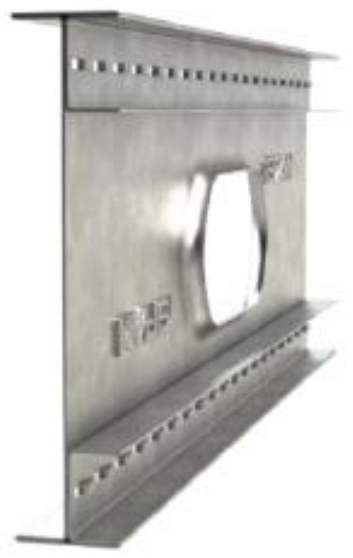

(a) iSPAN floor joist

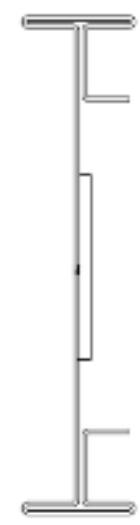

"C" Section

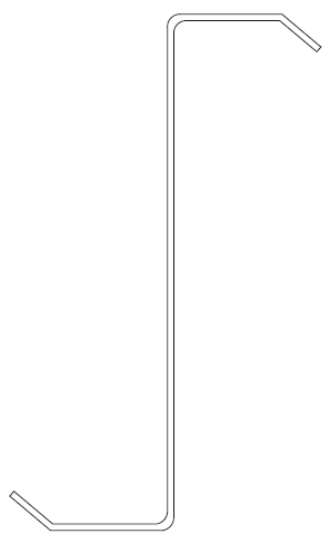

"Z" Section

Figure 1.1: Typical cold-formed steel floor joists 


\subsection{THE PROBLEM}

Floor vibrations are usually caused by human activities such as walking or rhythmic activity, machinery or other external forces, such as vehicular traffic. Problem associated with floor vibration are primarily due to resonance, which is a phenomenon that occurs when the forcing frequency or frequency of the human activity is at or close to the natural frequency of the structure. When human activity such as aerobic occurs, the cyclical force due to this activity produces acceleration in the floor. This vibration is mitigated by the presence of damping elements such as partitions or ceiling elements (Aghayere and Vigil, 2007). Traditionally, the main serviceability criteria used to control vibration was to limit deflection under uniform design load as a percentage of the floor span (i.e. for example, $\mathrm{L} / 360$ where $\mathrm{L}$ is the joist span). For shorter spans, the L/360 limit is typically found to be adequate to control floor vibrations. With the development of pre-engineered joists, combined with longer spans, more wide open areas and no partitions to provide damping, some floors have been found to have bad performance with respect to floor vibrations (Onysko, 1985). The acceptability of floor vibration is a function of the occupant's sensitivity to floor vibrations, which can be quite subjective and variable. In general, occupants are more sensitive to floor vibrations when they are engaged in low amounts of activity.

The structural and cost benefits associated with cold-formed steel floor systems can result in vibration serviceability issues if proper design considerations are not made. Providing sufficient damping within the structure is the most effective way to ensure that occupants are comfortable under typical residential and office service loads (Lenzen, 1966). The modern, open-concept interior that is made possible by cold-formed steel joists results in inherently low structural damping because it does not have the damping contributions from partition walls and heavy furnishings (Hanagan, 2005). Cold-formed steel floor systems are stiffer than similar light-frame wood floors, which also reduces the structural damping of the system. Cold-formed steel floor systems are lighter than equivalent floor systems with hot-rolled or open-web steel joists and concrete slabs, which is advantageous for structural design and overall building cost. However, less mass will increase the amplitude of the response to dynamic excitation (Parnell, 2008). The present trend in residential buildings toward the application of floor system supported by cold formed steel C- section joist has resulted in structures that are often more sensitive to dynamic 
disturbance produced by time-dependent external forces (Liu, 2001). The vibration problems that may be present in cold-formed steel floor systems, like any other floor system, can be addressed if proper consideration is given by designers. Once the dynamic properties of a floor have been determined, one of several different criteria can be used to predict the acceptability of a floor system according to those criteria. These criteria can help the designer to avoid a vibration problem when the building is occupied (Liu, 2001). In order to design a floor system to properly address occupant comfort, consideration must be given for the type of dynamic loading, resonance, dynamic response, and stiffness of the floor system. With an understanding of the dynamic characteristics of cold-formed steel floor systems and an adequate model to predict the dynamic response and modal properties, these floor systems can be designed to meet occupant requirements.

The available design methods to calculate the dynamic properties of floor systems [i.e. Canadian Wood Council Method, CWC (Canadian, 2009); Applied Design Council Design Method, ATC (Allen et al., 1999); and Eurocode EC5 (EN, 1995)] are used for the design of light-frame timber-based systems, CFS C-shape joists, and structural steel and concrete floor systems. The applicability of such methods to I-shape CFS joists is as yet unavailable. In addition, the North American Code for Cold-formed Steel structural Members (CSA-S136-07) provides specifications of ultimate and serviceability limit state design of C-shape joists rather than Ishape joists. As such, experimental study on CFS I-shape joists is needed to obtain experimental data to evaluate the available ultimate strength equations and serviceability design procedure when applied to such joist type with or without utility holes. Since CSA-S137-07 does not provide design provisions for the edge-stiffened (i.e. lipped) holes, a practical-design-oriented parametric study is required to evaluate CFS I- and C-shape members with circular, slotted and tri-slotted, edge-stiffened, holes under flexural loading.

\subsection{OBJECTIVES AND SCOPE OF RESEARCH}

The main objectives of this research can be summarized as follows:

1- Investigate, experimentally and using the finite-element modelling, the dynamic characteristics of cold-formed steel iSPAN floor systems, and recommend an adequate 
model for predicting the dynamic response and modal properties of the floor system in order to aid the design process.

2- Evaluate the accuracy and applicability of commonly used design methods for predicting fundamental frequency, static deflection, and acceleration response to walking excitation.

3- Investigate, experimentally and using the finite-element modelling, the ultimate flexural strength of the iSPAN joists with or without web holes.

4- Conduct a practical-design-oriented parametric study, using the finite-element modelling, on CFS I- and C-shape members with circular, slotted and tri-slotted, edge-stiffened, holes under flexural loading, leading to new design provisions to predict the flexural strength of such joists with the presence of edge-stiffened holes.

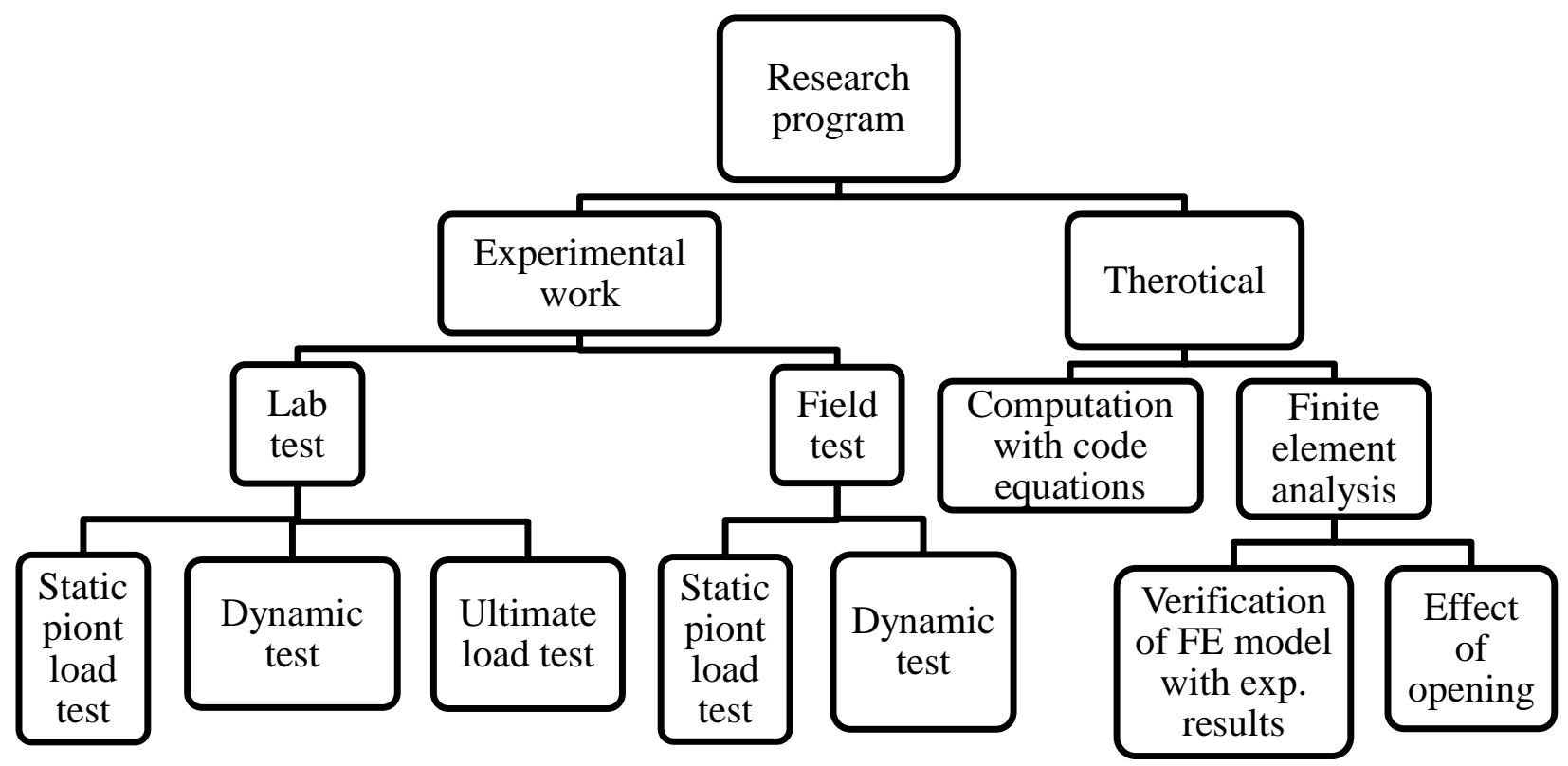

Figure 1.2: Outline of the Research Program

Figure 1.2 summarizes the outline of the research program. The research program was divided into two groups, namely: experimental work and theoretical analysis. The experimental work was further divided into two groups, namely: laboratory testing and field test on custom-made houses build with iSPAN CFS floors. In the laboratory testing, three types of tests on twin-joist specimens were conducted. These tests were static tests, free-vibration tests, and ultimate load tests to-complete-collapse. To provide confidence on the laboratory results on twin joist systems, 
field tests were carried out on actual floors built by the manufacturers in custom-made homes in Ontario. Only the static and dynamic tests were performed in the field. In the second part of research program the experimental results were compared with design equations available in the design codes. Finally, the finite-element analysis was carried out and the results from the modelling were validated by correlating them with the experimental findings. Finally, a parametric study, using the verified finite-element models, was conducted to furnish research data that could be used further to develop design procedure for CFS I- and C-shape members with circular, slotted and tri-slotted, edge-stiffened, holes under flexural loading.

\subsection{ORGANISATION OF DISSERTATION}

This dissertation was intended to examine the performance of residential floor system supported by iSPAN cold-formed steel joists. Chapter 1 includes introduction and history of cold-formed steel. Chapter 2 presents literature review and theoretical background and past research done in the field of interest. It also includes information about the behaviour of cold-formed steel, the elastic plate buckling theory, post buckling analysis of plate and lateral torsional buckling of cold formed steel. Moreover, Chapter 2 discusses the available design methods for ultimate limit sate (ULS) and serviceability limit state (SLS) of wooden I-Joists and cold-formed steel joists. Review of previous experimental work and finite element analysis carried out in the field of cold-formed steel is also presented. Chapter 3 discusses the experimental program conducted both in the laboratory and in the field. In this Chapter, the test setup and testing procedure are described in detail. The procedure for the static tests, dynamic tests and ultimate tests to-collapse are explained in details. In Chapter 4, the results from laboratory testing conducted at Ryerson University and the field testing are presented and compared with the available design methods that are used to evaluate the floor systems with respect to their natural frequencies and static deflections under gravity loading as well as ultimate flexural strength. The results from the above-mentioned methods are compared with experimental findings. In Chapter 5, the finiteelement modeling is presented to predict the fundamental natural frequency and static deflection under 1-kN load for laboratory and site tests. The finite-element modelling is also used to predict the ultimate strength of twin joist samples. Chapter 6 presents the parametric study on the flexural strength of the studies joists with edge-stiffened utility opening. Based on the theoretical 
findings, a new design procedure is proposed in this Chapter. Chapter 7 summarises the conclusions drawn from this research work as well as recommendations for future research. 


\section{CHAPTER 2 \\ LITERATURE REVIEW}

\subsection{GENERAL}

This chapter presents a literature review of recent research performed in the area of light-weight floor vibration analysis and performance. A limited number of recommended design criteria for light-weight residential floor are available. Most of these design criteria are pertained to timber and cold-formed steel "C-shape" joists for roof and floor applications. The past research performed in the area of floor vibration as well as acceptability criteria prescribed by the Applied Technology Council, ATC (Allen et al., 1999), the National Building Code of Canada, NBCC (NBCC, 2010), American Institute of Steel Construction, AISC (Allen et al., 1997), and Euro code, EC 5 (EN, 1995), are presented.

\subsection{LIMITING CRITERIA FOR FLOOR VIBRATION}

Changes in floor construction practice have resulted in widespread occupant dissatisfaction with the vibration performance of residential floors designed in accordance with the traditional live load deflection limit of joist span divided by 360 (Allen et al., 1999). Field and laboratory studies of wood floor systems were therefore conducted in Canada in the 1970's. Subjective opinions of occupants in residential occupancies were used to evaluate empirical design criteria based on the point deflection model, the impulse vibration model and the traditional model of deflection under a uniformly distributed load (Onysko, 1988). A criterion based on the point deflection model was adopted because it correlated well with subjective opinions and was suitable for design calculations. After calibrating to existing experience, the criterion was adopted into the National Building Code of Canada, NBCC, in 1990 (NBCC, 1995) for the determination of span tables of swan lumber joist floors for housing and small buildings. Recently, with the introduction of new wood joist products, an adjustment to the criterion was made for spans over $5.54 \mathrm{~m}$. This adjustment was based on further testing and industry feedback (CCMC, 1997).

For floor serviceability, stiffness and resonance are dominant considerations in the design of the floor structures and footbridges (Allen et al., 1997). The first known stiffness criterion addressing floor serviceability concerns dates back to the nineteenth century. The girders over 
long span should be made deep to avoid the inconvenience of not being able to move on the floor without shaking everything in the room. Vibration occurs when a floor has inadequate stiffness, low damping and low mass. It is possible to design and build the floor within certain tolerances of the above mentioned three factors. However, it is not as simple to determine and quantify a person's response to floor vibrations. Reiher and Meister (1931) studied human perception on floor vibration. In their study, steady state vibrations were applied to floor system for a certain period of time and perceptibility of these vibrations was evaluated by group of people on the floor system and recorded the reaction to create a table of the measured deflections plotted against the imposed frequency. The results his experiments is displayed in Figure 2.1.

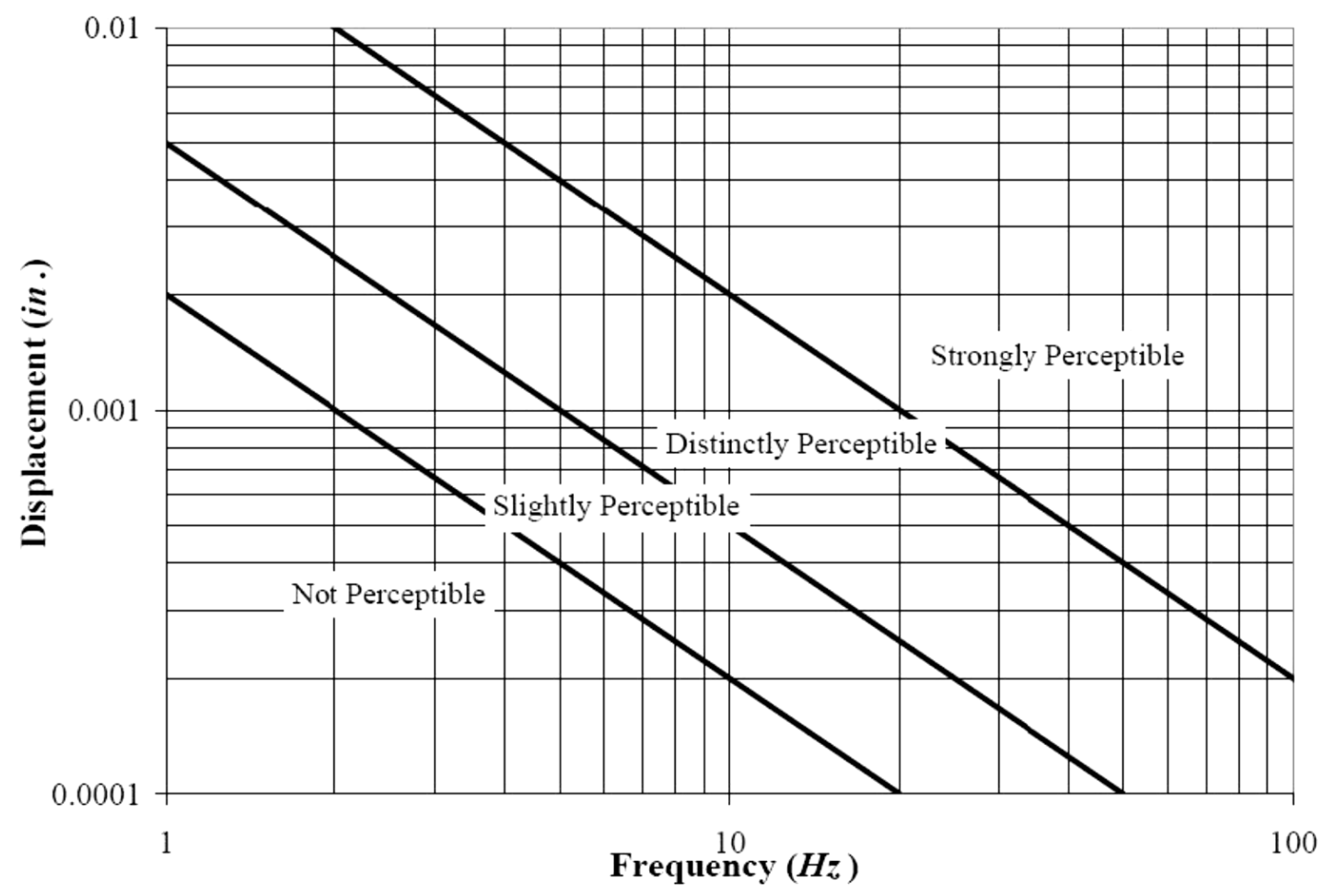

Figure 2.1: Reiher-Meister Scales (adopted from Reiher and Meister, 1931)

Lenzen (1966) judged perceptibility of vibration by conducting experimental tests on 46 steel joists supporting concrete slab floors. As a result, Lenzen modified the Reiher-Meister scale by multiplying the deflections by a factor of 10. Lenzen used transient vibration instead of steady state vibration. The results of Lenzen's tests, named herein as modified Reither-Meister scale, 
are presented in Figure 2.2. Lenzen suggested the heel drop test was a worst case scenario for transient vibrations.

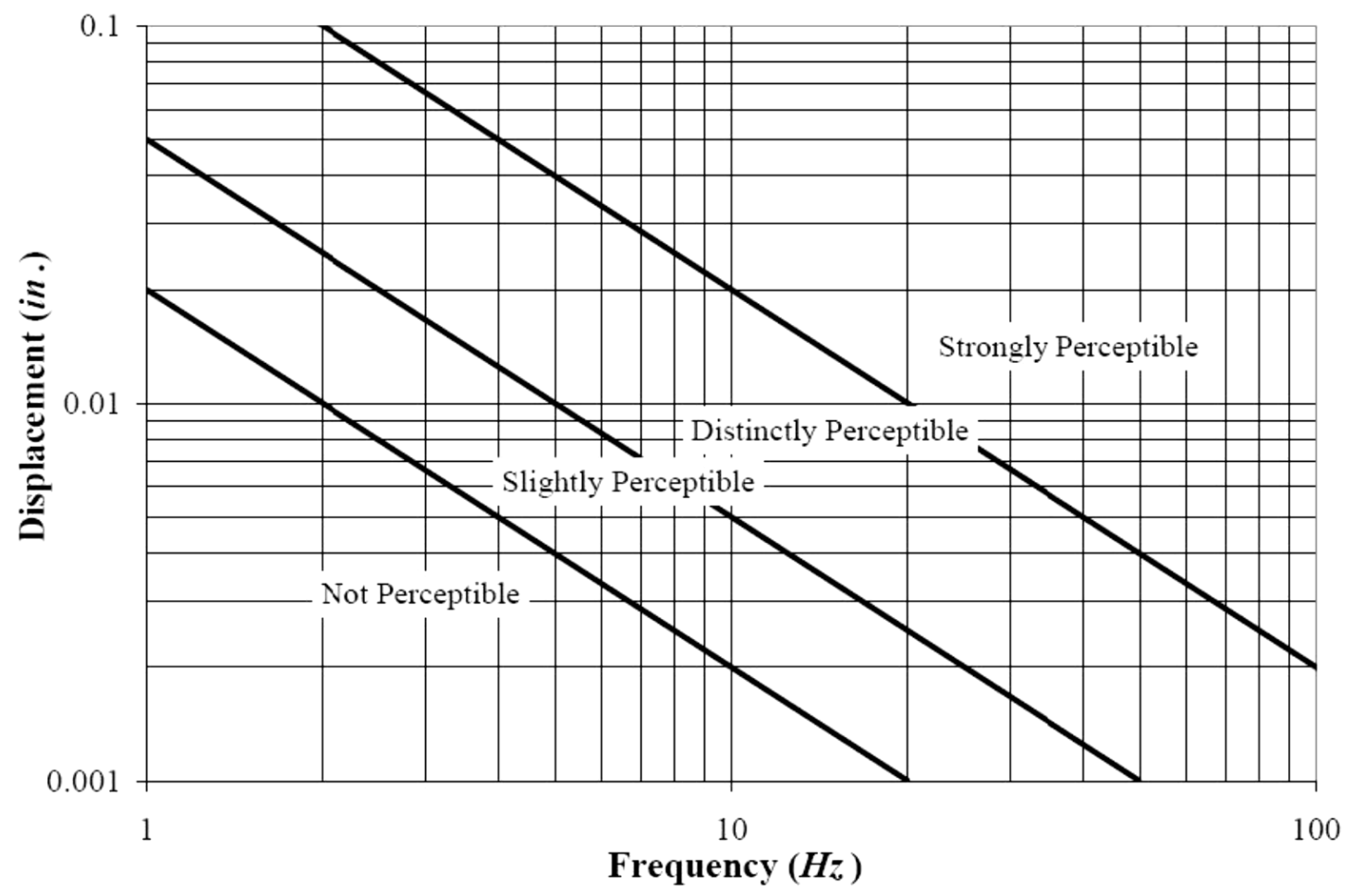

Figure 2.2: Modified Reiher Meister Scale (adopted from Lenzen, 1966)

The international standards organization (ISO, 1989) developed a limiting criterion for floor vibration that covers a number of occupancies. Acceleration limits as recommended by the International Standard Organization are adjusted for intended occupancy. The ISO standard suggests limits in terms of RMS acceleration as a multiple of the baseline curve shown in Figure 2.3. The multipliers for the proposed criterion, which is expressed in term of peak acceleration, are 10 for offices, 30 for shopping malls and indoor foot bridges, and 100 for outdoor footbridges. The shape of the base line curve indicates the lowest acceptable acceleration levels are from 4 to $8 \mathrm{~Hz}$.

The Commission of the European Community decided in an action programme in the field of construction that "The Eurocode are to establish a set of common technical rules for the design of buildings and civil engineering works which will ultimately replace the differing rules in the various Member States". Vibration criteria in Eurocode, EC5, (EN, 1995) are limited to the vibration behavior of residential floors having a fundamental frequency greater than $8 \mathrm{~Hz}$. Floors 
with a fundamental frequency less than $8 \mathrm{~Hz}$ require special investigation and are not covered in the code. The design loading conditions producing the design value at the SLS are as follows:

(a) The floor mass to be used to determine the lowest natural frequency of the floor structure.

(b) The application of a $1-\mathrm{kN}$ vertical force at the point on the floor that will result in the maximum vertical deflection to be used to determine the maximum instantaneous vertical deflection due to foot-force effect.

(c) The application of a 1 N.s impulse at the point of maximum instantaneous vertical deflection referred to in item (b) above to be used to determine the maximum initial value of the vertical floor vibration velocity due to heel impact effect.

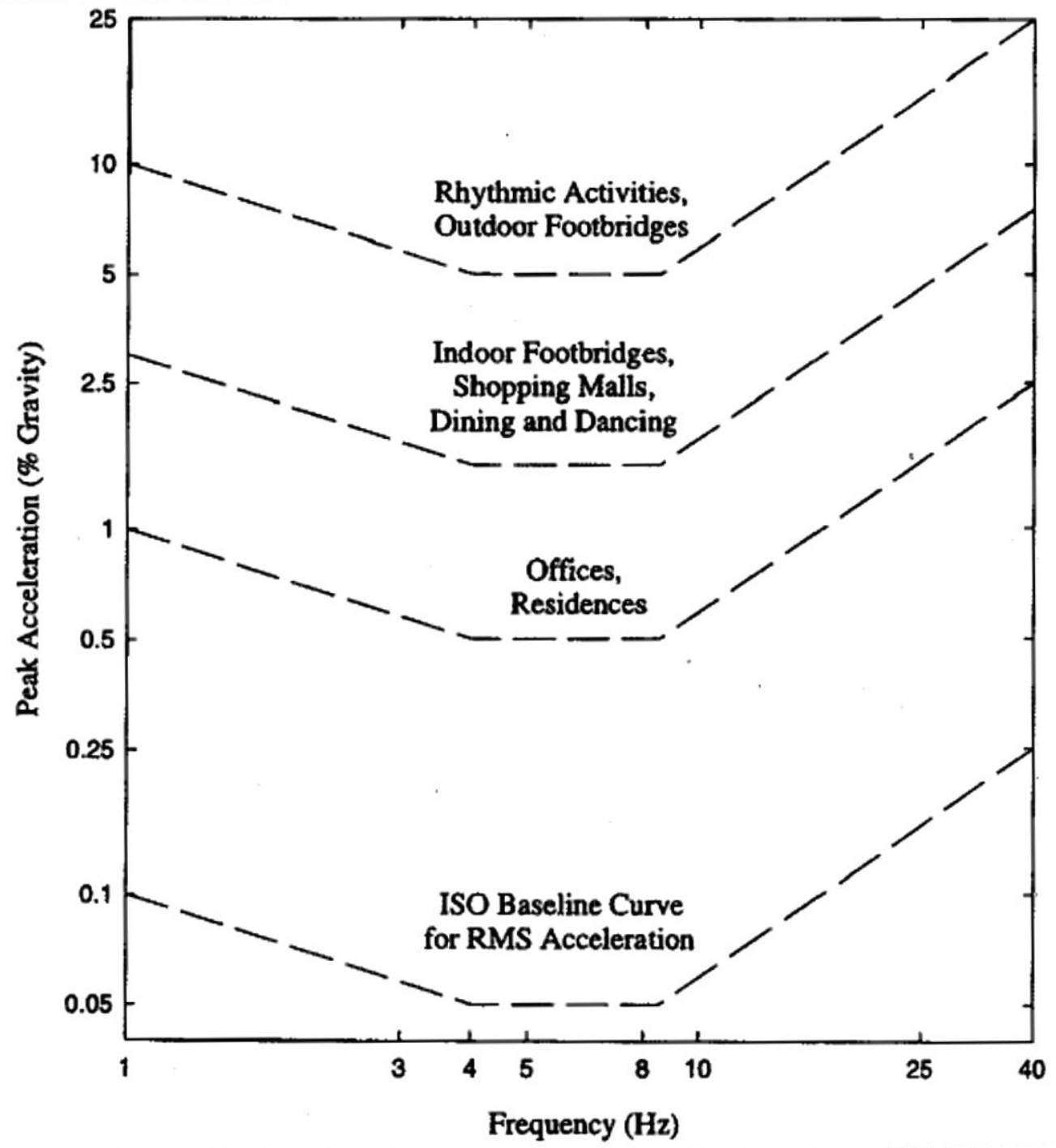

Figure 2.3: ISO Baseline Curves (adopted from ISO, 1989) 


\subsection{Floor Vibration Research}

Few authors dealt with floor vibrations research. Onysko (1970) performed a comprehensive literature review on the performance of wood joist floor system. To avoid annoying floor vibration, his study was to identify the strength and stiffness requirements of a floor system. Onysko (1985) studied 646 residential in-situ light frame floor systems in order to assess the performance of the traditional L/360 deflection criterion on occupant comfort, where $\mathrm{L}$ is the joist span. Results from subjective owner surveys were compared with static deflection and heel drop response measurements in order to develop satisfactory design criteria. Onysko (1995) further improved his acceptability design criteria for wood floor joist system, by providing a deflection limit based on a static load of $1 \mathrm{kN}$ applied to the center of the floor system. $\mathrm{He}$ claimed that wood floor systems with a span length less than $3 \mathrm{~m}$ need to have a center deflection less than $2 \mathrm{~mm}$. His criterion was adopted by the National Building Code of Canada (NBCC) and the Canadian Wood Council (CWC) in the preparation of load span table for wood joists.

Ohlsson (1988a, 1988b) developed a design approach for a light-weight floor that is independent of the construction material used. His design method is related to the floor having a fundamental frequency greater than $8 \mathrm{~Hz}$, in order to avoid the resonance with the human body. Ohlsson developed three factors to ensure acceptable vibration performance of floor system. First, the floor central deflection should be less than $1.5 \mathrm{~mm}$ under $1-\mathrm{kN}$ load; second, the floor fundamental frequency should be greater than $8 \mathrm{~Hz}$; and the third factor was imposed on the velocity of the floor system when subjected to an impulse excitation. Ohlsson's design method was adopted by the Swedish Council for Building Research. The Australian Standard for Domestic Metal Framing (AS3623, 1993) used much of the criterion proposed by Ohlsson, with only minor variations. Murray (1979) started his research in the area of floor vibration and vibration performance of floor system with the development of design and its acceptability criteria. Murray investigated the vibration performance of 91 hot-rolled steel joists, concrete slabs, and floor systems when subjected to a heel drop excitation. Based on his research, he developed a design guideline. Johnson (1994) proposed a design criterion for unfinished timber floor based on laboratory testing and in-situ wood floor. He proposed that the vibration performance of a floor system, supporting its self-weight, would be adequate if the fundamental frequency was found to be greater than $15 \mathrm{~Hz}$. This criterion is intended for use at the design 
stage. Chui (1988) proposed floor vibration acceptability criteria based on laboratory tests and in-situ wood floor system. Smith and Chui (Smith and Chui, 1988) continued this research using the Chui's original design criteria. They proposed that to avoid the discomfort experience by human in the range of $4-8 \mathrm{~Hz}$, the fundamental frequency of the floor system should be greater than $8 \mathrm{~Hz}$. When the floor is subjected to heel drop,(i-e a person stand in the middle of the floor, rises onto their toes and then drops down so that their heels strike the floor) the weighted RMS acceleration should be less than $0.45 \mathrm{~m} / \mathrm{sec}^{2}$.

Kraus and Murray (1997) conducted series of tests on annoying floor vibration due to normal human occupancy in the residential floor systems made of CFS "C-shape" joists. Dynamic impact and static load tests were performed on 12 full-scale laboratory floors and 5 two-joist line laboratory floors to determine the influencing characteristics of annoying vibration in CFS floors. Similar tests were conducted on eleven floors located in existing houses. Subjective evaluation, in terms of annoying vibration levels, of all floors was recorded. Four existing floor vibration criteria were investigated, namely: i) Australian Standard: Domestic Metal Framing Code, ii) Swedish Building Technology Design Guide developed by Ohlsson, iii) United States Timber Floor Vibration Criterion developed by Johnson, and iv) Canadian Timber Floor Criterion developed by Onysko. The results of applying these methods to the laboratory floors were compared to the actual measured values. The results showed that the Canadian Timber Floor Criterion developed by Onysko be used as a possible criterion for cold-formed steel joist residential floor because of its simplicity and satisfactory agreement with test results. The results also mentioned that a method of predicting floor deflection at mid-span was necessary to implement the recommended criterion. American Institute for Steel Construction, AISC, and Canadian Institute for Steel Construction, CISC (Allen et al., 1997) published a steel design guide series, entitled: Floor Vibrations due to Human Activity, based on the design procedure proposed by Allen et al. The guide provided basic principles and simple analytical tools to evaluate steel-framed floor systems and footbridges for vibration serviceability due to human activities. Both human comfort and the need to control movement for sensitive equipment were considered when selecting the vibration limits. 
The Applied Technology Council published an ATC Design Guide, entitled: Minimizing Floor Vibration (Allen et al., 1999). The ATC design guide provides guidance on design and retrofit of floor structures to limit transient vibration to acceptable levels, recognizing that "acceptable level" is a somewhat subjective measure. The guide also included guidance for estimating floor vibration properties and variety of floor types and design conditions. The criteria provided in ATC design guide for acceptable levels of floor vibration are based on human sensitivity to floor vibration, whether it is caused by human behavior or machinery in the structure. Xu (2000) and Rizwan (2000) conducted a comparative study of the following four design methods for the control of vibration in cold-formed steel residential floor construction: i) Applied Technology Council (ATC) design method; ii) Canadian Wood Council (CWC) design method; iii) Ohlsson design method; and iv) Smith and Chui design method. The results of experimental tests conducted at the Virginia Polytechnic Institute and State University (Kraus and Murray, 1997) and at the University of Waterloo were used to evaluate the performance of these design methods. The frequency and deflection of the floors, tested at the two universities, were computed by these design methods and compared with the actual test results.

$\mathrm{Xu}$ (2000) and $\mathrm{Xu}$ et al. (2002) investigated the construction details that influence the vibration performance of cold-formed steel floor. In his study, they considered the effect of span length, number of supported edges, joist end restraint, blocking type, screw pattern for sub floor, existence of a ceiling, gluing of sub floor and different excitation techniques. They conclude that decreasing the span length and supporting the floor system on all edges improved the vibration performance on the floor system. Liu (2001) conducted research on the vibration of floors supported by cold-formed steel joists for residential building by experimental testing, finiteelement analysis, and the equivalent plate method. Several full-scale floor systems with different key parameters, such as span length, end restraint beam, blocking pattern, screw pattern, and ceiling, were studied in the experimental testing. Two finite-element models were developed to determine the natural frequencies and the deflections of the floor system. Two acceptability criteria, namely: the CWC design method and the ATC design guide were investigated. Tangorra (2005) investigated the dynamic performance of floors supported by cold-formed steel joists by testing several full-scale floors in the laboratory and on-site. Each floor was subjected to dynamic and static load tests. The design methods currently in practice were used to evaluate and 
predict the laboratory and onsite results. Davis (2008) studied the influence of construction details on vibration characteristics of cold-formed steel floor systems. The main objectives of his research were to determine the construction details that improve the vibration performance of cold-formed steel floor systems and compare the results from the tested floor systems against current acceptability criteria. The construction details analyzed were span length, joist types, subfloor materials, ceilings type, strong backs, live loads, and framing conditions. Laboratory floor systems, with varying construction details, were constructed and tested in the laboratory at the University of Waterloo. Field floor systems were also tested to verify the laboratory results and to ensure that the laboratory floor systems represented a conservative model. Dynamic and static tests were performed on each floor system. The responses of the floor systems tested in this study were evaluated using the AISC resonance model for walking vibration and the ATC/NBC point-deflection model. Parnell (2008) studied the vibration serviceability and dynamic modeling of cold-formed steel floor systems based on extensive laboratory and field studies. He discussed the influence of different details on the transverse stiffness of the floor systems. It was found that effectively restrained strong backs and cold-formed steel deck subfloor assemblies provided significant increase in floor transverse stiffness based on the analysis of the field testing data.

\subsection{STIFFENED PLATE CONCEPT}

The purpose of this section is to provide background knowledge on the theoretical development of the design equations for cold-formed steel flexural members. The strength of a stiffened compression element such as the compression flange of a hat section is governed by yielding if its width to thickness ratio (w/t) is relatively small. It may be governed by local buckling as shown in Figure 2.4 at a stress level less than the yield point if its w/t ratio is relatively large $(\mathrm{Yu}$, 2010).

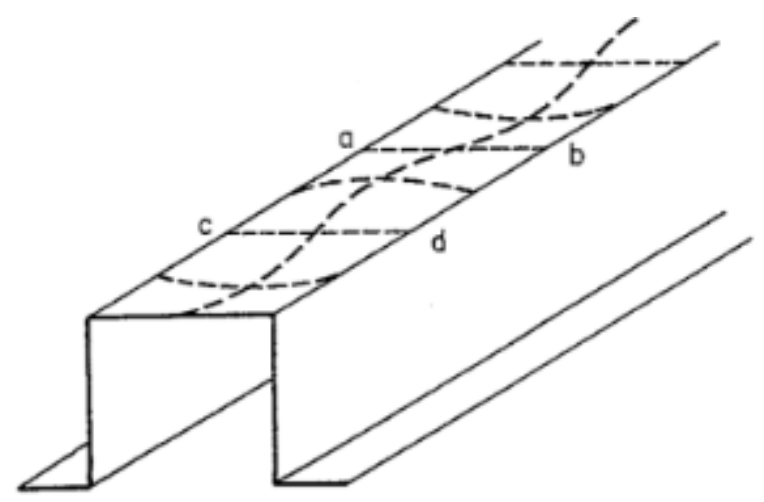


Figure 2.4: Local buckling of stiffened compression flange of hat-shaped section (adopted from $\mathrm{Yu}, 2010)$

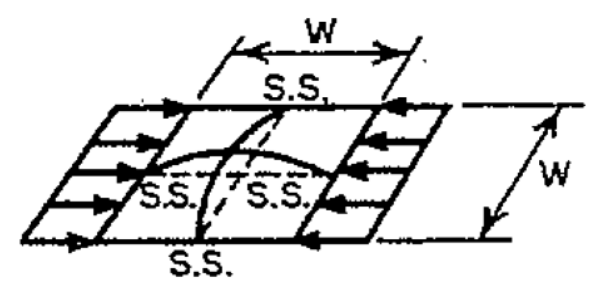

Figure 2.5: Square plate subjected to compression stress (adopted from Yu, 2010)

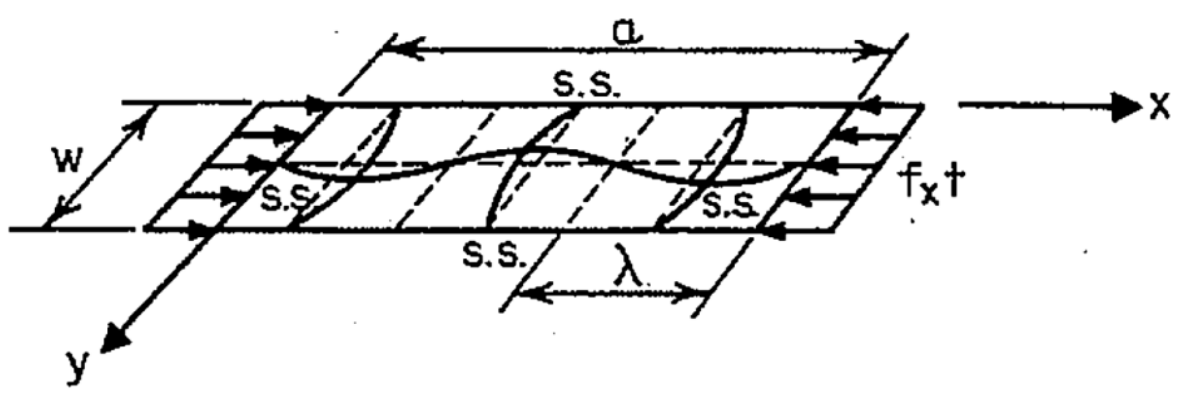

Figure 2.6: Rectangular plate subjected to compression stress. (adopted from Yu, 2010)

\subsubsection{ELASTIC LOCAL BUCKLING STRESS OF PLATES}

Considering a simply-supported square plate subjected to a uniform compression stress in one direction, it will buckle in a single curvature in both directions as shown in Figure $2.5(\mathrm{Yu}$, 2010). However for individual element of a section, the length of the element is usually much larger than the width as shown in Figure 2.4. The critical buckling stress of a plate shown in Figure 2.6 can be determined by solving Bryan's differential equation (2.1) based on small deflection theory (i.e. the significant deflection at buckling is of the order of the thickness of the plate or less) as follows:

$\frac{\partial^{4} w}{\partial x^{4}}+2 \frac{\partial^{4} w}{\partial x^{2} \partial y^{2}}+\frac{\partial^{4} w}{\partial y^{4}}+\frac{f_{x} t}{D} \frac{\partial^{2} \omega}{\partial^{2} x}=0$

Where,

$\mathrm{E} \quad=$ modulus of elasticity of steel

$\mathrm{t}=$ thickness of plate

$\mu \quad=$ Poisson's ratio, 0.3 for steel in the elastic range

$\omega=$ deflection of plate perpendicular to surface 
$f_{x} \quad=$ compression stress in $x$ direction

$\mathrm{D}=$ Flexural rigidity of plate

and

$D=\frac{E t^{3}}{12\left(1-\mu^{2}\right)}$

If " $\mathrm{m}$ " and " $\mathrm{n}$ " are the number of half sine waves in the " $x$ " and " $y$ " directions, respectively, the deflected shape of the rectangular plate as shown in Figure 2.6 may be represented by a double series. (Eq. 2.3).

$w=\sum_{m=1}^{\infty} \sum_{n=1}^{\infty} A_{m n} \sin \frac{m \pi x}{a} \sin \frac{n \pi y}{b}$

The above equation is satisfied with boundary conditions because for $x=0, a$ and $y=0, w$ (a and $\mathrm{w}$ being the length and width of the plate, respectively) and the computed deflection equal zero. Since $\partial^{2} \omega / \partial x^{2}=0$ and $\partial^{2} \omega / \partial y^{2}=0$ at four edges, Eq. (2.3) also satisfies the condition that the edge moments equal zero because

$$
\begin{aligned}
& M_{x}=-D\left(\frac{\partial^{2} \omega}{\partial x^{2}}+\mu \frac{\partial^{2} \omega}{\partial y^{2}}\right) \\
& M_{y}=-D\left(\frac{\partial^{2} \omega}{\partial y^{2}}+\mu \frac{\partial^{2} \omega}{\partial x^{2}}\right)
\end{aligned}
$$

Solving eq. (2.1) by using Eq. (2.3), we can obtain the following equation:

$$
\sum_{m=1}^{\infty} \sum_{n=1}^{\infty} A_{m n}\left[\pi^{4}\left(\frac{m^{2}}{a^{2}}+\frac{n^{2}}{w^{2}}\right)^{2}-\frac{f_{x} t}{D} \frac{m^{2} \pi^{2}}{a^{2}}\right] \sin \frac{m \pi x}{a} \sin \frac{n \pi y}{w}=0
$$

It is obvious that the solution can be obtained if either $A_{m n}=0$ or the quantity in square brackets equals zero. The former condition means that no buckling will occur, which is not applicable to this particular case. By solving

$\pi^{4}\left(\frac{m^{2}}{a^{2}}+\frac{n^{2}}{w^{2}}\right)^{2}-\frac{f_{x} t}{D} \frac{m^{2} \pi^{2}}{a^{2}}=0$

An equation for critical local buckling stress as follows:

$f_{c r}=f_{x}=\frac{D \pi^{2}}{t w^{2}}\left[m\left(\frac{w}{a}\right)+\frac{n^{2}}{m}\left(\frac{a}{w}\right)\right]^{2}$

In eq. (2.8), the minimum value in square brackets is $n=1$, that is, only one half sine waves occur in the $y$ direction. Therefore,

$f_{c r}=\frac{k D \pi^{2}}{t w^{2}}$ 
Where

$k=\left[m\left(\frac{w}{a}\right)+\frac{1}{m}\left(\frac{a}{w}\right)\right]^{2}$

Substituting the value of D in equation (2.9), Eq. (2.11) represents a general equation for critical local buckling stress for a rectangular plate subjected to compression stress in one direction:

$F_{c r}=\frac{k \pi^{2} E}{12\left(1-\mu^{2}\right)\left(\frac{w}{t}\right)^{2}}$

The value of $k$ used in Eq. (2.11) is shown in Figure 2.7 for different $a / w$ ratios. It should be noted that when the $a / w$ ratio is an integer, the value of $k$ equals 4 . This value of $k$ is also applicable for relatively large $a / w$ ratios. From Figure 2.7 and eq. (2.10), it can be seen that the transition from $m$ to $m+1$ half sine waves occurs at the condition when the two corresponding curves have equal ordinates, that is

$m\left(\frac{w}{a}\right)+\frac{1}{m}\left(\frac{a}{w}\right)=(m+1)\left(\frac{w}{a}\right)+\frac{1}{m+1}\left(\frac{a}{w}\right)$

or

$\frac{a}{w}=\sqrt{m(m+1)}$

For a long plate

$\frac{a}{w} \approx m$

Or

$\lambda=\frac{a}{b} \approx m$

Where $\lambda$ is the length of the half sine wave.

Equation (2.13) indicates that the number of half sine waves increases with the increase of $a / w$ ratios. For a long plate, the length of the half sine waves equals approximately the width of the plate, and therefore, square waves are formed, as shown in Figure 2.6. whenever the aspect ratio $a / w$ exceeds 4 , a value of $k=4$ can be used for determining the critical buckling stress for a plate simply supported along four edges and subjected to compression stress in one direction. The equation (2.11) is also applicable to square plate. For different loading and boundary conditions, the value of $k$ will vary. The value of $k$ for different loading and boundary conditions are listed in Table 2.1. 


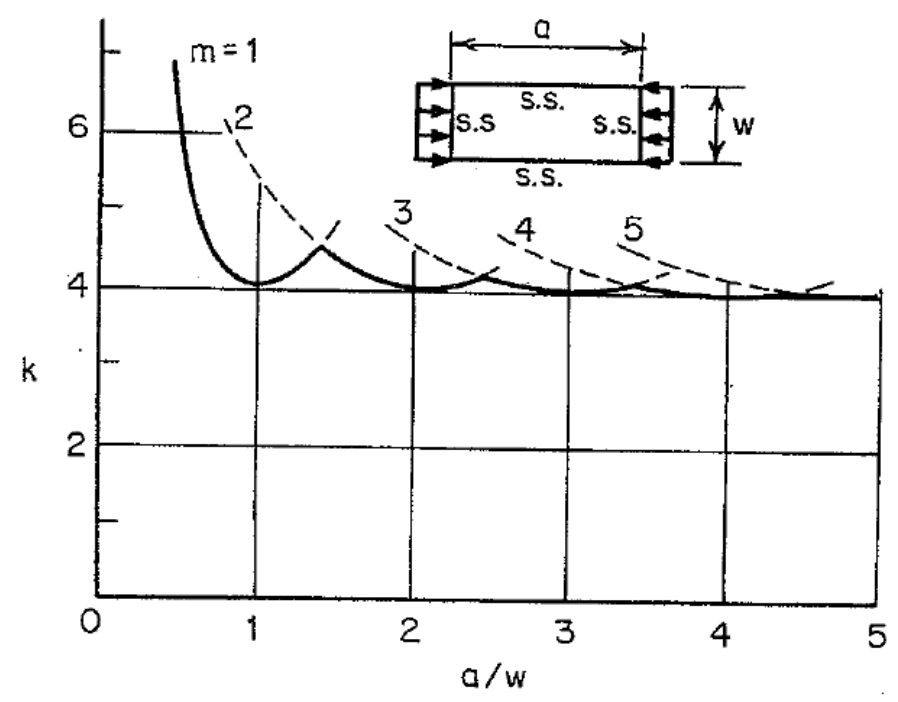

Figure 2.7: Buckling Coefficient for flat rectangular plate (adopted from Yu, 2010) 
Table 2.1: Value of " $k$ " determining critical buckling stress

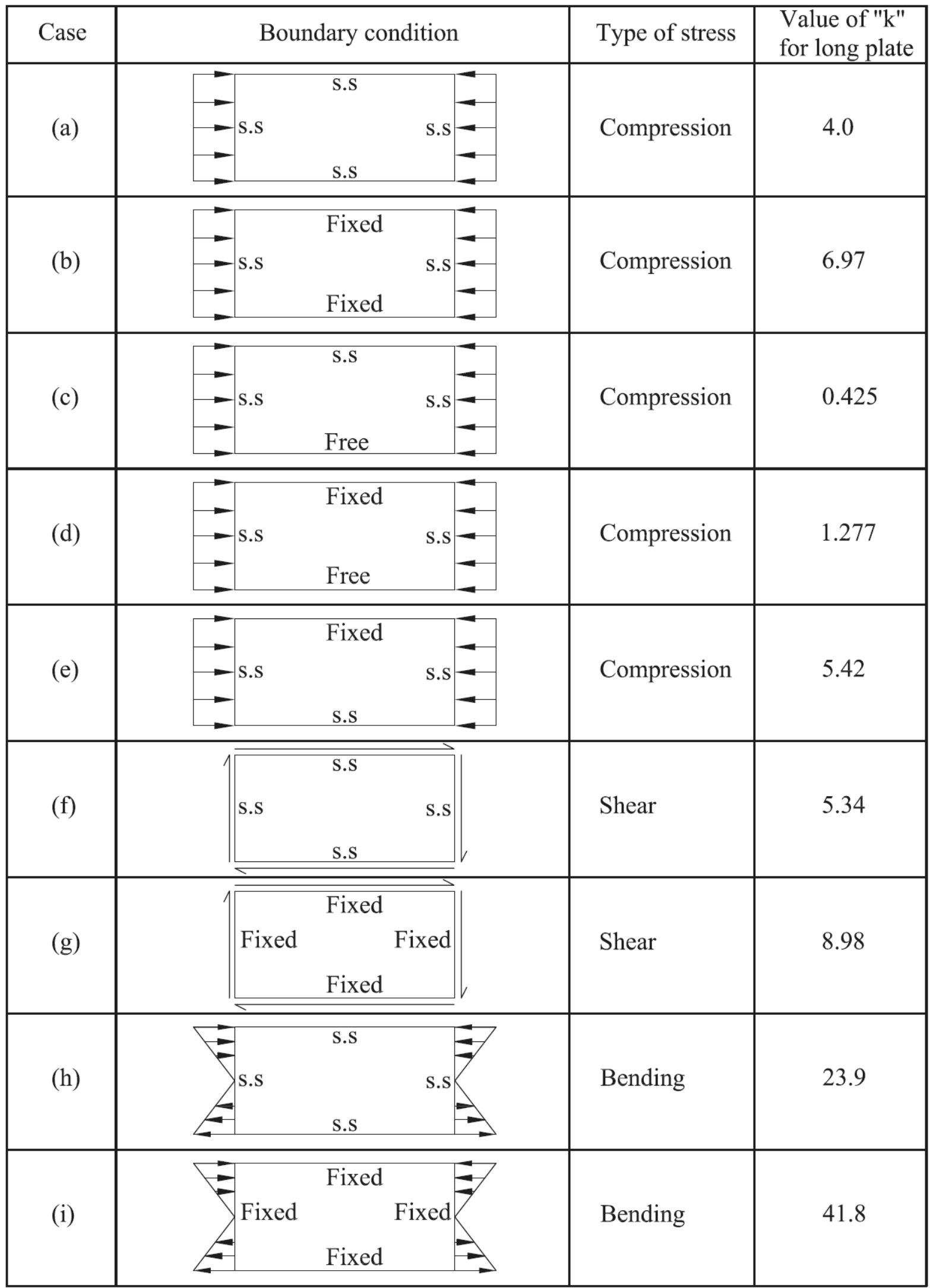




\subsubsection{POST BUCKLING STRENGTH AND EFFECTIVE DESIGN WIDTH}

Unlike one dimensional structural member such as column, stiffened compression element will not collapse when the buckling stress is reached. An additional load can be carried by the element after buckling by means of a redistribution of stress. This phenomenon is known as postbuckling strength and is most pronounced for elements with large $w / t$ ratios. (Yu, 2010). The additional load carrying capacity developed in the plate beyond $f_{c r}$ is called post-buckling capacity and is most pronounced for stiffened compression elements with large width-tothickness ratios $(w / t)$. Post-buckling strength increases with increase of the $w / t$ ratio. The mechanism of the post-buckling behavior of a compression element was discussed by Winter (1968) using a square plate model. The post-buckling action can easily be understood by from a square plate model as shown in Figure 2.8. When the compression load is applied, and as soon when the plate starts to buckle, the horizontal bar in the grid of the steel plate will act as a tie rod to counteract the increasing deflection of the longitudinal struts, at this stage the stress distribution is uniform, as shown in figure 2.9(a), before buckling of the plate occurs. After buckling, a portion of the post-buckling load of the center strip transfers to the edge portion of the plat, as a result a non-uniform stress distribution is formed, as shown in Figure 2.9(b). The redistribution of stress continues until the stress at the edge reaches the yield stress of the steel and then the plate begins to fail per stress distribution in Figure 2.9(c). (Yu, 2010).

The Post-buckling behavior of plates can be analyzed by using large deflection theory. In 1910, von Karman first proposed the following differential equation (2.14):

$\frac{\partial^{4} w}{\partial x^{4}}+2 \frac{\partial^{4} w}{\partial x^{2} \partial y^{2}}+\frac{\partial^{4} w}{\partial y^{4}}=\frac{t}{D}\left(\frac{\partial^{2} F}{\partial y^{2}} \frac{\partial^{2} w}{\partial x^{2}}-2 \frac{\partial^{2} F}{\partial x \partial y} \frac{\partial^{2} w}{\partial x \partial y}+\frac{\partial^{2} F}{\partial x^{2}} \frac{\partial^{2} w}{\partial y^{2}}\right)$

This equation depends on the external stress function $F$ and the deformation $w$. As the solution of Eq. (2.14) is complicated, it has limited application in practical design. For this reason, in 1932, Karman et al. proposed the "Effective width" concept. In this approach, instead of considering the non-uniform distribution of stress over the entire width of $w$, it is assumed that the total load is carried by a fictitious effective width $b$, subject to a uniformly distributed stress equal to the edge stress $f_{\max }$, as shown in the Figure 2.10. The width $b$ is selected so that the area under the curve of the actual non-uniform stress distribution is equal to the sum of the two parts of the 
equivalent rectangular shaded area with a total width $b$ and an intensity of stress equal to the edge stress $f_{\text {max }}$, i.e.,

$\int_{0}^{w} f d x=b f_{\max }$

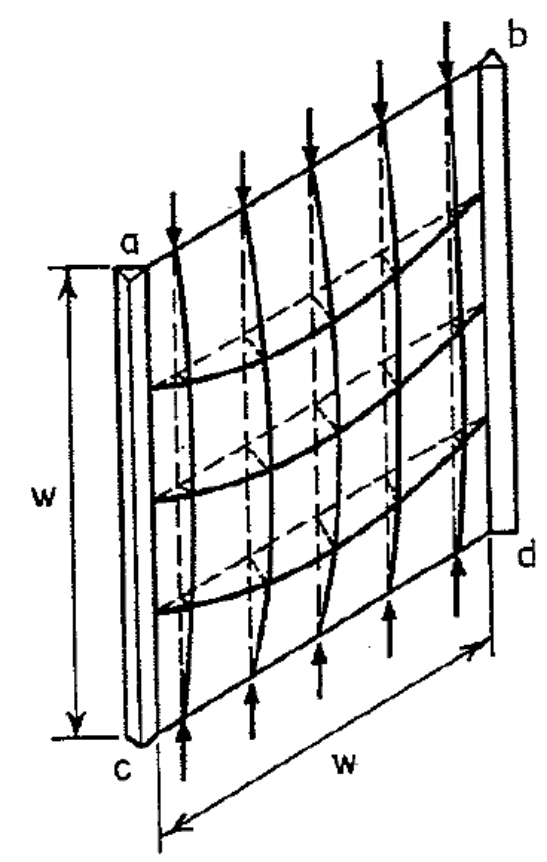

Figure 2.8: Square plate model for post buckling action (adopted from Yu, 2010)

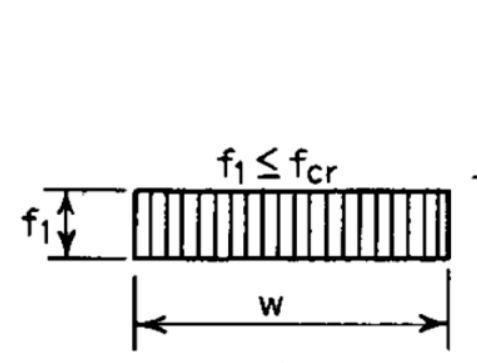

(a)

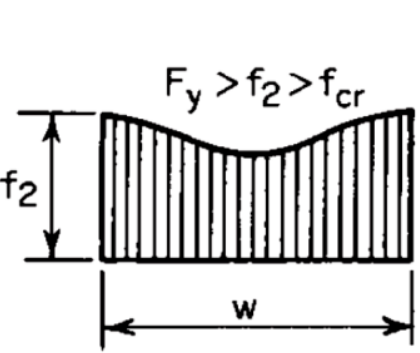

(b)

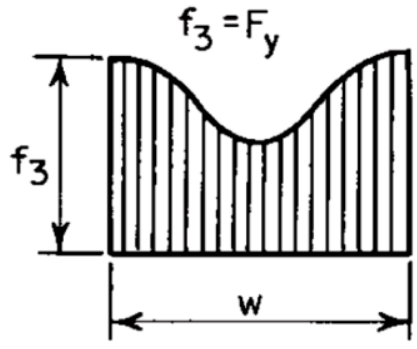

(c)

Figure 2.9: Consecutive Stages of stress distribution in stiffened compression elements (adopted from $\mathrm{Yu}, 2010)$

The effective width "b" represents a width of the plate which just buckles when the compressive stress reaches the yield stress of steel. For long plate, the theoretical value of "b" maybe determined as follows: 


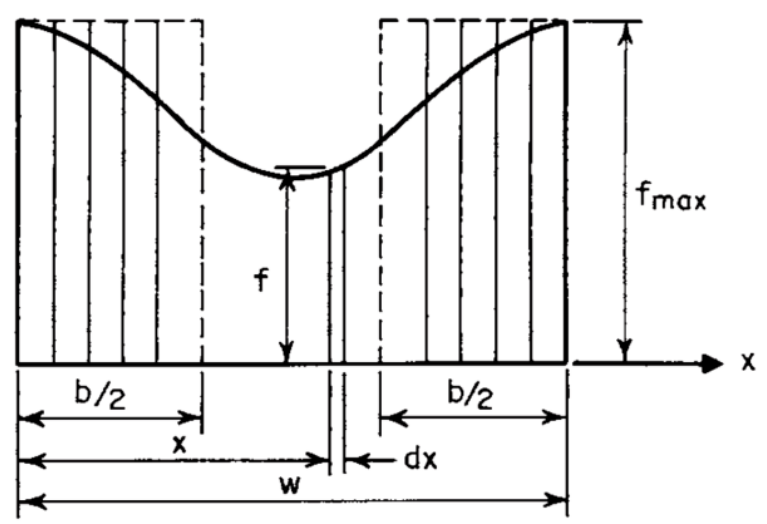

Figure 2.10: effective width of stiffened compression element (adopted from Yu, 2010)

$f_{c r}=F_{y}=\frac{\pi^{2} E}{3\left(1-\mu^{2}\right)(b / t)^{2}}$

Or

$b=C t \sqrt{\frac{E}{F_{y}}}=1.9 t \sqrt{\frac{E}{F_{Y}}}$

Where

$C=\frac{\pi}{\sqrt{3\left(1-\mu^{2}\right)}}=1.9$

$\mu=0.3$

Equation (2.17) is the von Karman's formula for the design of stiffened element derived in 1932. When $\mathrm{w}>\mathrm{b}$,

$f_{c r}=\frac{\pi^{2} E}{3\left(1-\mu^{2}\right)(b / t)^{2}}$

Or

$w=C t \sqrt{\frac{E}{f_{c r}}}$

From Eqs. 2.17 and 2.20, the following relationship of " $b$ " and "w" can be obtained:

$\frac{b}{w}=\sqrt{\frac{f_{c r}}{F_{y}}}$

Based on his extensive investigation on the cold-formed steel sections, Winter indicated that Equation 2.17 is equally applicable to the element in which the stress is below the yield stress.

$b=C t \sqrt{\frac{E}{f_{\max }}}$ 
The following equation for the term " $\mathrm{C}$ " has been developed by Winter on the basis of his experimental findings.

$C=1.9\left[1-0.475\left(\frac{t}{w}\right) \sqrt{\frac{E}{f_{\max }}}\right]$

By putting the value of "C" in the above equation the equations becomes

$$
b=1.9 t \sqrt{\frac{E}{f_{\max }}}\left[1-0.475\left(\frac{t}{w}\right) \sqrt{\frac{E}{f_{\max }}}\right]
$$

It should be noted that the effective width depends not only on the edge stress $f_{\text {max }}$ but also on the $w / t$ ratio. Equation (2.24) may be written in terms of the ratio of $f_{c r} / f_{\max }$ as:

$\frac{b}{w}=\sqrt{\frac{f_{c r}}{f_{\max }}}\left(1-0.25 \sqrt{\frac{f_{c r}}{f_{\max }}}\right)$

During the period from 1946 to 1968, the AISI design provision for the determination of the effective design width was based on equation (2.24). A longtime accumulated experience has indicated that a more realistic equation, as shown in equation (2.26) may be used in the determination of the effective width. (Yu, 2010)

$b=1.9 t \sqrt{\frac{E}{f_{\max }}}\left[1-0.415\left(\frac{t}{w}\right) \sqrt{\frac{E}{f_{\max }}}\right]$

The equation (2.26) may be rewritten in terms of the $f_{c r} / f_{\max }$ ratio as follows:

$\frac{b}{w}=\sqrt{\frac{f_{c r}}{f_{\max }}}\left[1-0.22 \sqrt{\frac{f_{c r}}{f_{\max }}}\right]$

Therefore, the effective width " $b$ " can be determined as

$b=\rho w$

Where the reduction factor " $\rho$ " is given as

$\rho=\frac{1-0.22 / \lambda}{\lambda} \leq 1$

Where

$\lambda=\sqrt{\frac{f_{\max }}{F_{c r}}}$

From the relationship between $\lambda$ and $\rho$, it is clear that when $\lambda \leq 0.673, \rho=1$

So the equation for effective width becomes

$b_{e}=w$, when $\lambda \leq 0.673$

$b_{e}=\rho w$, when $\lambda>0.673$ 


\subsubsection{LATERAL TORSIONAL BUCKLING}

The lateral-torsional buckling (also called tripping) of support members or stiffeners is a phenomenon in which the failure of a stiffened panel occurs subsequent to the stiffener twisting sideways about the edge of the stiffener web attached to the plating. When the torsional rigidity of the stiffener is small or the stiffener flange is weak, this phenomenon is more likely to take place. Tripping can be a relatively sudden phenomenon resulting in subsequent unloading of the stiffened panel. Once tripping occurs, the buckled or collapsed plating is left with essentially much reduced stiffening and thus overall collapse may follow (Paik and Thayamballi, 2006). Cold-formed steel flexural members, when loaded in the plane of the web, may twist and deflect laterally as well as vertically if braces are not adequately provided. In the design of flexural members, the moment capacity is not only governed by the flexural strength of the cross-section but it is also limited by the lateral buckling strength of the member (Yu, 2010). In a continuous steel stiffened panel, tripping may generally involve a coupling of sideways and vertical deflection and rotation of the stiffener web together with local buckling of the attached plating, as shown in Figure 2.10. Unlike an ordinary beam-column in steel-framed structures, the attached plating of a plate-stiffener combination in steel plated structures is restricted from deflecting sideways, while the beam (stiffener) flange is relatively free to deflect sideways and vertically. For unsymmetrical section profiles (e.g., angle section), vertical bending, sideways bending, and torsion are typically coupled, while for symmetric section profiles (e.g., T-section), only sideways bending and torsion are normally coupled. This implies that the overall flexural Euler buckling and lateral-torsional buckling can sometimes be closely coupled for platestiffener combinations.

\subsection{FLOOR JOIST WITH HOLES}

Web opening can be used to pass utilities through beams, and, thus help minimize storey height. A decrease in story height reduces both the exterior surface and the interior volume of a building, which lowers operational, and maintenance cost, as well as construction costs. On the negative side, web opening can significantly reduce the shear and bending capacity of steel beam. Presence of a large web opening causes localized redistribution of stresses at the opening region, resulting in changes of buckling characteristics for the entire member and loss of cross-sectional strength. Providing appropriate reinforcements for such openings may diminish the detrimental 
effects of such large web openings. Web opening have been used for many years in structural steel beams, predating the development of straightforward design procedures. Openings were often reinforced, and composite beams were often treated as non-composite member at web openings. Reinforcement schemes included the use of both, horizontal and vertical bars, or bars completely around the periphery of the opening (David, 1990). Cold-formed steel shaped member are used extensively in light steel construction for wall, roof and floor framing member. Slotted or circular holes are commonly found on the web of cold-formed steel flexural members for piping, electric-wiring, plumbing, or installing lateral bracing, etc.

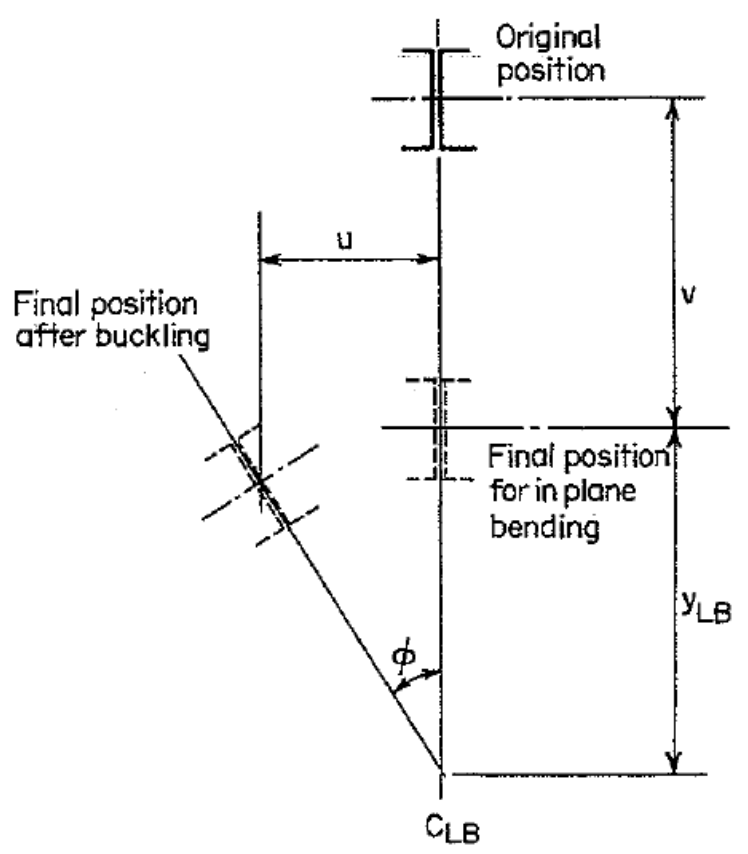

Figure 2.10: Positions of I-beam after lateral buckling (adopted from Yu, 2010)

\subsection{PREVOIUS EXPERIMENTAL AND THEORETICAL WORK ON CFS}

The finite-element method (FEM) originated from the needs for solving complex, structural analysis problems in civil, mechanical and aeronautical engineering. Research continues towards developing robust finite elements for the linear, buckling, geometric nonlinear and material nonlinear analysis of plate and shell structures. As cold-formed steel sections are subjected to local buckling, web crippling, distortional buckling, and flexural and lateral torsional buckling, depending on different shapes and dimensions, special care has to be taken during modelling to 
simulate their exact behaviour. An extensive literature review was conducted to find applications of the finite-element method to thin-walled structures. Few authors dealt with the finite element modelling of cold-formed steel sections. Some of these papers provide very important information about modelling, element selection, mesh density and highly nonlinear simulation techniques.

Shanmugam (2001) researched the ultimate load capacity of perforated cold-formed steel channel stub columns. A design equation was developed to determine the ultimate load capacity of perforated channel short columns containing either single or multiple openings of square, circular and manufacturer's opening shape. The equation was based on extensive parametric studies carried out using the finite-element modelling on plain and lipped channel sections containing openings. A wide range of parameters such as plate slenderness, opening shapes and sizes, were considered in this study. Web plate slenderness and opening area ratio were observed to be the two main variables used to derive the design equations. The accuracy of the proposed design equation was established by comparison with a number of experimental and finiteelement results reported by other researchers. Sivakumaran (2005) conducted an experimental investigation on 203-mm deep, 1.89-mm base thickness, galvanized, lipped channel sections with circular, square, and rectangular openings and two associated reinforcement schemes (screw fastening of $31.8 \times 1.1 \mathrm{~mm}$ thick bridging channel). The focus of his investigation was on the flexural strength of such joists. The test specimens were simply-supported and were subjected to two-equal-point loads at equal distance from the supports. Two lipped channel sections were set face-to-face to form the test specimen assembly. Based on 11 sets of three identical flexural tests, it was determined that $(i)$ the tension zones of the web with a large opening need not be reinforced, (ii) closely spaced screw fastening of reinforcements (bridging channel) is essential, and (iii) the reinforcements need to be fastened as close as possible to the compression edges of the opening to minimize local buckling of these edges. Sivakumaran's work demonstrated that it is possible to establish cost-effective reinforcement schemes for CFS sections with large web openings.

Yu (2005) investigated local and distortion buckling of cold steel "C" and "Z" sections. He prepared two test setups, one for local buckling to occurs in the test sample and other one for 
distortional and restrict lateral torsional buckling to occur. In the distortional buckling test, he removed the corrugated panel attached to compression flange in the constant moment region so that distortional buckling could occur. The finite-element modeling incorporating ABAQUS software was developed and verified by the two series of flexural tests. The experimental data was used to examine current specification and new direct strength method. Sultana (2007) performed finite-element analysis using ANSYS software to investigate the flexural behaviour of a built-up box girder assembled from cold-formed stud and track sections when subjected to eccentric loading. Detailed parametric studies were carried out to identify the factors affecting the flexural capacity of built-up cold-formed steel sections. The results were used to develop a design equation for calculating the flexural capacity of built-up cold formed steel section. Acharya and Sivakumaran (2008) conducted an experimental investigation on flexural strength of cold formed steel "C" channel with holes. They investigated two types of plate width-tothickness ratios (i.e. w/t $=118$ and 180) of galvanized lipped channel sections having circular and square web openings, and three associated reinforcement schemes. Web openings were first reinforced using two reinforcement schemes (plate and stud reinforcements) which are prescribed by the current AISI specification. It was observed that the current reinforcement schemes prescribed by AISI specification are ineffective for the joists having lower w/t ratio. A bridging channel reinforcement scheme was then developed and the corresponding response was experimentally established. The new reinforcement scheme was found to be effective for the joists having both lower and higher w/t ratio. Overall, it was evident from the test results that the bridging channel arrangement was an effective reinforcement scheme for CFS sections having large web openings.

Meon and Schafer (2008) conducted compression tests on 24 short and intermediate length coldformed steel columns with and without slotted web holes. For each specimen, a shell finiteelement Eigen buckling analysis was also conducted such that the influence of the boundary conditions and the hole on local, distortional, and global elastic buckling response could also be captured. Experimentally, slotted web holes are shown to have a minimal influence on the tested ultimate strength in the specimens considered, although post-peak ductility was decreased in some cases. Tangible connections were observed between elastic buckling and loaddisplacement response during the tests, including mode switching between local and distortional 
buckling. Xu et al. (2009) at University of Waterloo performed finite-element analysis to investigate the flexural strength of built-up box sections which have been extensively used in residential and commercial construction in North America. In this study, the proposed finiteelement model of the built-up box sections was validated with the experimental tests carried out by Beshara and Lawson (Beshara and Lawson, 2002). The flexural strengths obtained from the finite-element analysis were then compared with the nominal strength evaluated based on the current design method in order to assess its suitability. Parametric studies were carried out for more than 30 specimens to identify factors affecting the flexural strength of cold-formed steel built-up box sections. A recommendation was made for current design practice of evaluating the flexural strength of the box section when subjected to eccentric loading.

Dung et al. (2009) investigated the compressive strength of slender C-shaped cold-formed steel members with web openings. They tested a total of 21 channel specimens including C-shaped cross-sections with and without web openings. Comparisons were made between the test results and the predictions based on both the AISI Standard and the ANSYS finite-element analysis. The results indicated that all the observed failure modes were of the flexural-torsional buckling classification. It was found that the reduction in the compression strength of the specimens with web openings seemed to be negligible. In addition, the predictions based on the AISI Standard were conservative as compared with the test results of the specimens with web openings. Moreover, it appeared that the ANSYS finite-element analysis was able to predict the ultimate loads and failure modes of the specimens. Dinis and Dinar (2010) did numerical investigation concerning the post-buckling behaviour of cold-formed steel lipped channel beams, subjected to uniform major axis bending, affected by local/distortional mode interaction. The results presented and discussed were obtained through shell finite-element analyses performed using ABAQUS software. This study made it possible to acquire an in-depth understanding about the mechanics of the elastic and elastic-plastic post-buckling behaviour and strength in lipped channel beams affected by local/distortional mode interaction effects.

$\mathrm{Yu}$ (2011) conducted finite-element analyses to study the stability of cold-formed steel thin plates and typical C-section members when edge-stiffened circular holes are placed on those plates or members. Based on the elastic buckling analyses, the optimized profiles of the holes 
were obtained and then applied to standard C-section flexural members. The post-buckling finite-element analysis was then utilized to determine the flexural strength of those members. The results indicated that the stiffened holes can significantly improve the flexural strength of CFS C-sections. New design provisions were proposed to accurately predict the flexural strength of the new generation $\mathrm{C}$-section flexural members with the optimized hole profiles. Haidarali and David, (2011) developed finite-element models for buckling behaviour of laterally-restrained cold-formed steel Z-section beams considering material and geometrical nonlinearities. The study allowed for the possibility of combined local/distortional buckling as well as for local buckling only. A simplified configuration of the test setup was modelled in ABAQUS software. In the local buckling FE models, distortional buckling was restricted in the member using translational springs applied to the lip/flange corner of the beam. Predictions of load carrying capacity and deformed shapes exhibited excellent agreement with both the results from the more extensive models and laboratory tests.

Moen et al. (2012) conducted experimental work on cold-formed steel C-section joists with rectangular unstiffened web holes. It was observed that the presence of holes decreased joist capacity and amplified distortional buckling deformation. Distortional buckling was accompanied by unstiffened strip buckling of the compressed web. When hole depth approached the web depth, sudden buckling of the compressed flange and web above the hole was observed. Critical elastic buckling moments for local, distortional, and global buckling were calculated for each specimen including the influence of holes with recently introduced engineering expressions. Uzzaman et al. (2012a and b) did 82 web crippling tests, with 20 tests conducted on channel sections without web openings and 62 tests conducted on channel sections with web openings. The tests consider both end-two-flange and interior-two-flange loading conditions. In the case of the tests with web openings, the hole was located directly under the concentrated load. The concentrated load was applied through bearing plates; the effects of different bearing lengths were investigated. In addition, the cases of both flanges fastened and unfastened to the support were considered. It was demonstrated that the main factors influencing the web crippling strength are the ratio of the hole depth to the flat depth of the web, and the ratio of the length of bearing plates to the flat depth of the web. 


\subsection{CURRENT DESIGN METHODS FOR WOOD AND COLD FORMED STEEL JOISTS}

In this section, the available current design methods are discussed.

\subsubsection{EXISTING DESIGN CRITERIA FOR FLOOR VIBRATION}

The following three design criteria are considered in this research for floor vibration:

1) Canadian Wood Council Design criterion (CWC),

2) Applied Technology Council Design Criterion (ATC), and

3) European Code (Eurocode EC5)

The American Iron Institute of Steel Construction (AISC) and Canadian Institute of Steel Construction (CISC) have published the "Steel Design Guide Series 11: "Floor vibration Due to Human Activity" (Allen et al., 1997). The design method specified in this guide is intendant to be used for steel-framed floor systems and footbridges for vibration serviceability due to human activities, while the ATC design method is used for design and retrofit of various floor structures to limit vibration to acceptable levels for humans. The ATC design method has the design criteria for both light-weight floor systems and also for heavy floor systems. For the design of heavy floor system, the ATC design method refers to a portion of the AISC design method. Therefore the AISC design criteria are not considered in this research.

\subsubsection{EXISTING DESIGN CRITERIA FOR ULTIMATE DESIGN}

The following three design criteria are considered in this research for ultimate limit state design of the studied joists:

1) Canadian Wood Council Design (CSA-S086-10),

2) North America Specification for the Design of Cold-formed Steel Structural Members (CSA S136-07), and

3) Direct Strength Method (AISI 2006). 


\subsection{CANADIAN WOOD COUNCIL DESIGN CRITERIA (CWC)}

\subsubsection{INTRODUCTION}

The design method adopted by the National Building Code of Canada and the Canadian Wood Council is based on extensive work done by the Canadian Wood Council (CWC, 1995, 1996, 1997) and Onysko (1985, 1988).

\subsubsection{DESCRIPTION}

The criteria adopted by the CWC and NBCC (NBCC, 2010) are based on limiting a floor's deflection under a static load as expressed in Equation 2.33. Onysko (1985) found out that the best correlation of perceived floor vibration acceptability with test results was provided by the floor's dynamic response due to an impact load and the floor's deflection due to a static load. Since the use of dynamic response for any type of design procedure is conditional to the determination of the floor's damping coefficient, which is usually unknown prior to its construction, floor deflection is viewed as the only option as a limiting criteria to annoying floor vibrations in residential dwellings.

Depending on the span, L, of the floor, equation 2.33 limits the maximum floor deflection $(\Delta)$ under a $1-\mathrm{kN}$ static load to either a fixed value or a function of the span.

$$
\begin{array}{lll}
\text { i) } & \Delta \leq 2.0 \mathrm{~mm} & \text { for spans under } 3.0 \mathrm{~m} \\
\text { ii) } & \Delta \leq \frac{8.0}{\mathrm{~L}^{1.3} \mathrm{~mm}} & \text { for spans between } 3.0 \mathrm{~m} \text { to } 5.5 \mathrm{~m}, \\
\text { iii) } & \Delta \leq \frac{2.55}{\mathrm{~L}^{0.63} \mathrm{~mm}} & \text { for spans between } 5.5 \mathrm{~m} \text { to } 9.9 \mathrm{~m}, \\
\text { iv) } & \Delta \leq 0.6 \mathrm{~mm} & \text { for spans greater than } 9.9 \mathrm{~m}
\end{array}
$$

Note: The length " $\mathrm{L}$ " in the above equation should be in meters, but the resultant deflection $\Delta$ is in $\mathrm{mm}$.

The maximum floor deflection, $\Delta$, in the above equations can be calculated by the equation

$\Delta=\mathrm{DF} \frac{P L^{3}}{48 E I_{e f f}}$ 
Where:

$\Delta \quad=\quad$ Mid-span floor deflection $(\mathrm{mm})$

$\mathrm{DF}=$ Distribution factor

$E I_{\text {eff }}=$ Effective composite bending stiffness $\left(\mathrm{N} . \mathrm{mm}^{2}\right)$

$\mathrm{L}=$ floor $\operatorname{span}(\mathrm{mm})$

$\mathrm{P} \quad=\quad 1000 \mathrm{~N}$

The effective flexural stiffness, $E I_{\text {eff, }}$, can be calculated using equation 2.35 .

$E I_{e f f}=K_{\text {span }}\left[E I_{u}+\overline{E A_{1}} h_{1}^{2}+\overline{E A_{2}} h_{2}^{2}-\overline{A y^{2}}\right]$

Where:

$E I_{u}=E I_{\text {joist }}+s E I_{1}+s E I_{2}$

$E I_{1}=E I_{s p}+E I_{c}$

${\overline{E A_{l}}}_{l}=\frac{s E A_{1}}{1+10 \frac{s E A_{1}}{S_{1} L_{1}^{2}}}$

$E A_{l}=E A_{s p}+E A_{c}$

${\overline{E A_{2}}}_{2}=\frac{s E A_{2}}{1+10 \frac{s E A_{2}}{S_{2} L_{2}^{2}}}$

$\bar{A}=E A_{\text {joist }}+E A_{1}+E A_{2}$

$\bar{y}=\frac{h_{1}{\overline{E A_{1}}}-h_{2} \overline{E A}_{2}}{A}$

$h_{1}=\frac{d}{2}+\frac{E A_{s p} \frac{t_{s}}{2}+E A_{c}\left(t_{s+\frac{t_{C}}{2}}\right)}{E A_{s p}+E A_{c}}$

$h_{2}=\frac{d}{2}+\frac{t_{c e}}{2}+t_{s t}$

Where:

$K_{\text {span }}=1.0$ for simply-supported floor

$=1.4$ for joists continuous over two spans

$E I_{u}=$ Bending stiffness of unconnected member $\left(\mathrm{N} . \mathrm{mm}^{2}\right)$

$E I_{\text {joist }}=$ Bending stiffness of the joists $\left(\mathrm{N} \cdot \mathrm{mm}^{2}\right)$

$E I_{1}=$ Unit bending stiffness of gypsum ceiling perpendicular to the panel axis $\left(\mathrm{N} . \mathrm{mm}^{2} / \mathrm{mm}\right)$ 
$\mathrm{s}=$ joist spacing $(\mathrm{mm})$

$E I_{s p}=$ Unit bending stiffness of sub-floor perpendicular to the panel axis (N.mm $\left.{ }^{2}\right)$

$E I_{c}=$ Unit bending stiffness of concrete topping $\left(\mathrm{N} . \mathrm{mm}^{2} / \mathrm{mm}\right)$

$\overline{E A_{l}}=$ Effective axial flange stiffness (top flange) $(\mathrm{N})$

$\overline{E A_{2}}=$ Effective axial flange stiffness (bottom flange) $(\mathrm{N})$

$\mathrm{EA}_{\mathrm{sp}}=$ Unit axial stiffness of sub-floor perpendicular to the panel axis $(\mathrm{N} / \mathrm{mm})$

$E A_{c}=$ Unit axial stiffness of concrete topping $(\mathrm{N} / \mathrm{mm})$

$E A_{2}=$ Unit axial stiffness of gypsum ceiling perpendicular to the panel axis $(\mathrm{N} / \mathrm{mm})$

$S_{1}, S_{2}=$ Slip constant for sub-floor and gypsum ceiling connection to the joist (N/ $\mathrm{mm} / \mathrm{mm}$ ) as given in Table 2.2

$L_{l}=$ Panel joist spacing along the joist for sub-floor

$L_{l}=1220 \mathrm{~mm}$ for floors without concrete topping

$L_{l}=$ Joist span (L) for floors with concrete topping

$L_{2}=$ Panel joist spacing along the joist for gypsum ceiling

$L_{2}=$ Joist span (L) for gypsum ceiling

$\bar{A}=$ Transformed section area

$\bar{y}=$ Location of neutral axis from the centroid of the joist $(\mathrm{mm})$

$h_{1}=$ Distance from the center of the joist to the centroid of sub floor / concrete topping (if exists) $(\mathrm{mm})$

$h_{2}=$ Distance from the center of the joist to the centroid of ceiling (if exists) (mm)

Table 2.2: Slip constant for sub-floor and gypsum ceiling (Allen et al., 1999)

\begin{tabular}{|c|c|c|}
\hline $\begin{array}{c}S_{1}, S_{2} \\
(\mathrm{~N} / \mathrm{mm} / \mathrm{mm})\end{array}$ & Nailed & $\begin{array}{c}\text { Nailed and } \\
\text { Glued }\end{array}$ \\
\hline OSB & 4.14 & 340 \\
\hline Ceiling & 1.79 & 1.79 \\
\hline
\end{tabular}

\subsubsection{DISTRIBUTION FACTOR}

Distribution factor is a ratio of the longitudinal stiffness of the floor joist panel, including composite action, to the total floor stiffness in both directions and it account for shear and bending contribution. It is the portion of the concentrated load that a floor central joist will receive when the load is placed over the joists. Distribution factor accounts for the transfer of 
load to the adjacent joists due to the distribution action of sub-floor, concrete topping, bridging member and other transverse stiffening elements. The distribution factor, DF, can be calculated according to equation 2.36 .

$D F=D F_{b}-D F_{v}$

Where

$D F_{b}=0.0294+0.536 K_{1}^{1 / 4}+0.516 K_{1}^{1 / 2}-0.31 K_{1}^{3 / 4}$

$D F_{v}=-0.00253-0.0854 K_{1}^{1 / 4}+0.0797 K_{2}^{1 / 2}-0.00327 K_{2}$

Flexural Stiffness $\quad K_{l}=\frac{K_{j}}{K_{j}+\sum K_{b i}}$

Shear Stiffness $\quad K_{2}=\frac{\sum k_{v i}}{\sum K_{b i}}$

Longitudinal Stiffness $K_{j}=\frac{E I_{e f f}}{L^{3}}$

Transverse flexural components stiffness

For panel or deck components $\quad K_{b i}=0.585 E I_{b l} \frac{L}{S^{3}}$

For strong backs and straps $\quad K_{b i}=\left(\frac{2 a}{L}\right)^{1.71} \frac{E I_{x}}{s^{3}}$

Transverse shear components stiffness

For cross bridging and solid blocking $\quad K_{v i}=\left(\frac{2 a}{L}\right)^{1.71} \frac{G A}{S}$

Flexural stiffness of floor panel or deck per unit width $\left(E I_{\text {wprep }}\right)$.

For concrete on wood decks

$E I_{\text {bi }}=E I_{\text {wprep }}+E I_{c}+\frac{E A_{\text {wperp }} E A_{c} h_{c w}^{3}}{E A_{\text {wperp }}+E A_{c}}$

Where

$a=$ Distance of element to the closest end of joist (mm). (Note: $\mathrm{a} \leq 0.5 \mathrm{~L}$ )

$L=$ Joist $\operatorname{span}(\mathrm{mm})$

$s=$ Joist spacing $(\mathrm{mm})$ 
$h_{c w}=$ Distance from center of sub floor to center of concrete topping (mm)

$G=$ Effective shear modulus of blocking $\left(\mathrm{N} / \mathrm{mm}^{2}\right)$

$A=$ Effective shear area of blocking $\left(\mathrm{mm}^{2}\right)$

$E I_{x}=$ Effective flexural stiffness of strong backs or straps

$D F_{v}=$ Distribution factor for shear elements (solid blocking, cross bridging)

$D F_{b}=$ Distribution factor for bending elements (sub-floor with or without concrete topping, strapping, gypsum ceiling)

$E A_{c}=$ Unit axial stiffness of concrete topping $\left(\mathrm{N} \mathrm{mm}^{2} / \mathrm{mm}\right)$

$E A_{s}=$ Unit axial stiffness of sub-floor parallel to the panel axis $\left(\mathrm{N} \mathrm{mm}^{2} / \mathrm{mm}\right)$

$E I_{b i}=$ Unit flexural stiffness of individual bending member $\left(\mathrm{N} \mathrm{mm}^{2} / \mathrm{mm}\right)$

$E I_{c}=$ Unit flexural stiffness of concrete topping $\left(\mathrm{N} \mathrm{mm}^{2}\right)$

$E I_{\text {eff }}=$ Effective flexural stiffness $\left(\mathrm{N} \mathrm{mm}^{2}\right)$

$E I_{s}=$ Unit flexural stiffness of sub floor parallel to the panel axis $\left(\mathrm{N} \mathrm{mm}^{2} / \mathrm{mm}\right)$

$E I_{x}=$ Effective flexural stiffness of strong back and straps $\left(\mathrm{N} \mathrm{mm}^{2}\right)$

\subsection{APPLIED TECHNOLOGY COUNCIL DESIGN CRITERIA}

\subsubsection{INTRODUCTION}

The Applied Technology Council (ATC) Design Guide provides guidance on design and retrofit of floor structures to limit transient vibration to acceptable levels. The criteria provided in ATC Design Guide for acceptable level of floor vibration are based on human sensitivity to floor vibration, whether it is caused by human behavior or machinery in the structure. The point deflection model is used in ATC Design Guide for vibration due to walking in light-frame construction. A light-frame usually has a natural frequency greater than $10 \mathrm{~Hz}$ because of it short span and light weight. The stiffer the floor is when subjected to a concentrated force, the smaller are the jolts due to walking. The primary property controlling vibration acceptability, therefore, is the stiffness of the floor under concentrated load.

\subsubsection{DESCRIPTION}

The ATC design criterion is equivalent to the National Building Code of Canada (NBCC) design criterion, adjusted in accordance with CCMC (1997) results. ATC Design Guide specifies 
equation 2.40 for deflection limit for vibration due to walking in light-frame construction of natural frequency greater than $8 \mathrm{~Hz}$.

$\Delta_{\mathrm{p}} \leq 0.61+2.54 e^{-0.59(L-1.95)} \leq 2.0 \mathrm{~mm}$ (SI units)

$\Delta_{\mathrm{p}} \leq 0.024+0.1 e^{-0.18(L-6.4)} \leq 0.08 \mathrm{~mm}$ (Imperial units)

Where

$\Delta_{\mathrm{p}}=$ Maximum floor deflection under a concentrated static load of $1000 \mathrm{~N}(225 \mathrm{lb})$

$L=$ Joist span (m or ft.)

The basic formula in ATC Design Guide for calculating deflection under a concentrated load is given by equation (2.42)

$$
\Delta \mathrm{p}=\frac{C_{p d}}{N_{e f f}} \frac{P L^{3}}{48 E I_{e f f}}
$$

Where

$C_{p d}=$ Continuity factor for point load (1.0 for simply-supported joist, 0.7 for continuous)

$E I_{\text {eff }}=$ Effective flexural stiffness (includes shear deformation) of a joist panel (N.mm²)

$N_{\text {eff }}=$ Number of effective joists, which depends on the stiffness of the floor system perpendicular to the joists (transverse floor stiffness)

$L=$ Joist span (m or ft.)

$P=$ Concentrated static load of $1000 \mathrm{~N}(225 \mathrm{lb})$

It is important to note that length $\mathrm{L}$ in equations 2.40 and 2.41 must be in meters or in feet, even though the deflection $\Delta$ is in millimeters or in inches. But for equation 2.42 , the span length $\mathrm{L}$ should in millimeters or in inches so that all the units are same and the resultant deflection $\Delta$ is in millimeters or in inches.

\subsubsection{NATURAL FREQUENCY}

Equation 2.43 is considered as the basic equation for the determination of the first natural frequency of simply-supported, prismatic, and uniformly loaded beam in floor vibration.

$f_{n}=\frac{\pi}{2} \sqrt{\frac{g E I}{w L^{4}}}$

Where

$\mathrm{g}=$ Acceleration due to gravity

$\mathrm{E}=$ Modulus of elasticity

$\mathrm{I}=$ Moment of inertia 
$\mathrm{w}=$ Weight per unit length

$\mathrm{L}=$ Span length of joist

Equation 2.43 can also be rewritten as equation 2.44 .

$f_{n}=0.18 \sqrt{\frac{g}{\Delta_{j}}}$

$\Delta_{j}=C_{f l r} \frac{5 w L^{4}}{384 E I_{e f f}}$

Where

$\mathrm{g}=9806 \mathrm{~mm} / \mathrm{sec}\left(386 \mathrm{in} / \mathrm{sec}^{2}\right)$

$\Delta_{j}=$ Deflection of a simply supported beam

$C_{f l r}=$ Continuity factor ( 1.0 for simply supported joist, 0.7 for continuous)

$w=$ Weight per unit area of the floor $(\mathrm{N} / \mathrm{mm})$

$\mathrm{L}=$ Span of the joist $(\mathrm{mm})$

$\mathrm{EI}_{\text {eff }}=$ Effective bending composite bending stiffness.

\subsubsection{CALCULATION OF STIFFNESS IN ATC DESIGN GUIDE}

Equation 2.46 is used to calculate the effective stiffness in ATC Design Guide. It should be noted that this equation includes the effect of shear deformation.

$E I_{e f f}=\frac{E I}{1+\frac{\gamma E I}{C_{p d} I_{m}}}$

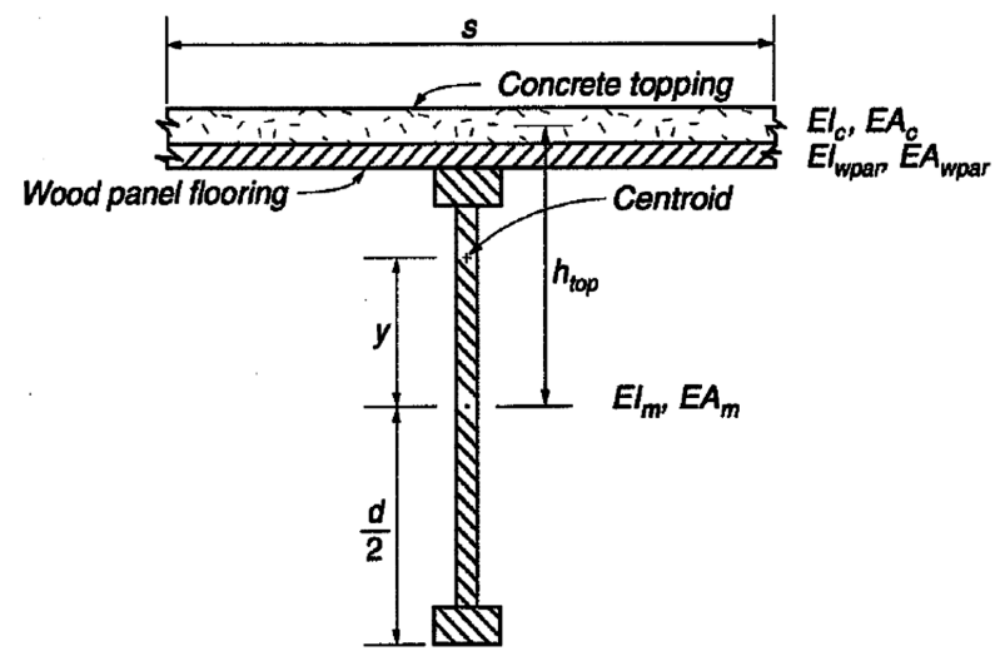

Figure 2.11: Floor Panel Section (adopted from Allen et al., 1999) 
Where

$\gamma=$ Ratio of shear deflection to flexural deflection

$C_{p d}=$ Continuity factor for point load (1.0 for simply supported joist, 0.7 for continuous)

$E I_{\text {eff }}=$ Effective flexural stiffness (includes shear deformation) of a joist panel (N.mm $\left.{ }^{2}\right)$

$E I=$ Flexural stiffness of the floor panel including composite action $\left(\mathrm{N} \mathrm{mm}^{2}\right)$

$E I_{m}=$ Flexural stiffness of the structural member $\left(\mathrm{N} \mathrm{mm}^{2}\right)$

The effective floor stiffness EI is calculated as equation 2.47

$E I=E I_{m}+E I_{\text {top }}+E A_{m} y^{2}+E A_{\text {top }}\left(h_{\text {top }}-y\right)^{2}$

Where

$E I_{\text {top }}=E I_{\text {wprep }}+E I_{c}+\frac{E A_{w p e r p} E A_{c} h_{c w}^{3}}{E A_{w p e r p}+E A_{c}}$

Note: The value of $\mathrm{EI}_{\text {top }}$ should be multiplied by the width "s" which is joist spacing for obtaining consistent units

$E A_{\text {top }}=\frac{E A_{f l r}}{1+\frac{10 E A_{f l r}}{S_{f l r} L_{f l r}^{2}}}$

$y=\frac{E A_{t o p} h_{t o p}}{E A_{m}+E A_{t o p}}$

$E I_{\text {top }}=$ Flexural stiffness of floor deck parallel to the member

$E A_{m}=$ Axial stiffness of the structural member

$E A_{\text {top }}=$ Effective axial stiffness of the floor deck parallel to the member

$E A_{f l r}=$ Axial stiffness of the floor deck (concrete and or wood) of width "s"

$S_{f l r}=$ Slip modulus for floor deck to member connection

$L_{f l r}=$ Width of floor panels (distance between joints) along the span of the structural member

$=1220$ (48 in) for floors without concrete topping

$=$ Joist span $(\mathrm{L})$ for floors with concrete topping

$h_{\text {top }}=$ Distance to centroid of floor deck from centroid of member

$s=$ Spacing of member (or effective width of deck)

$y=$ Distance to centroid of system from centroid of member 


\subsubsection{Calculation of $N_{\text {eff }}$}

The effective number of joists, $N_{\text {eff, }}$ is governed by the ratio of the longitudinal stiffness of the floor joist panel, including composite action, to the total stiffness in both directions, including the transverse stiffness of the floor perpendicular to the joists. It can be expressed as shown in equation 2.51 .

$1 / N_{\text {eff }}=D F_{b}-D F_{v}$

Where

$D F_{b}=0.0294+0.536 K_{1}^{1 / 4}+0.516 K_{1}^{1 / 2}-0.31 K_{1}^{3 / 4}$

$D F_{v}=-0.00253-0.0854 K_{1}^{1 / 4}+0.0797 K_{2}^{1 / 2}-0.00327 K_{2}$

Flexural stiffness $\quad K_{l}=\frac{K_{j}}{K_{j}+\sum K_{b i}}$

Shear stiffness $\quad K_{2}=\frac{\sum k_{v i}}{\sum K_{b i}}$

Longitudinal stiffness $\quad K_{j}=\frac{E I_{\text {eff }}}{L^{3}}$

Transverse flexural components stiffness

For panel or deck components

$$
K_{b i}=0.585 E I_{b i} \frac{L}{S^{3}}
$$

For strong backs and straps

$$
K_{b i}=\left(\frac{2 a}{L}\right)^{1.71} \frac{E I_{x}}{s^{3}}
$$

Transverse shear components stiffness

For cross bridging and solid blocking $\quad K_{v i}=\left(\frac{2 a}{L}\right)^{1.71} \frac{G A}{s}$

Flexural stiffness of floor panel or deck per unit width $\left(E I_{\text {wprep }}\right)$. For concrete on wood decks

$E I_{b i}=E I_{\text {wprep }}+E I_{c}+\frac{E A_{\text {wperp }} E A_{c} h_{c w}^{3}}{E A_{\text {wperp }}+E A_{c}}$

$a=$ Distance of element to the closest end of joist $(\mathrm{mm})$. (Note: $\mathrm{a} \leq 0.5 \mathrm{~L})$

$L=$ Joist span (mm)

$s=$ Joist spacing $(\mathrm{mm})$

$h_{c w}=$ Distance from center of sub floor to center of concrete topping (mm)

$G=$ Effective shear modulus of blocking $\left(\mathrm{N} / \mathrm{mm}^{2}\right)$ 
$A=\quad$ Effective shear area of blocking $\left(\mathrm{mm}^{2}\right)$

$E I_{x}=$ Effective flexural stiffness of strong backs or straps

$D F_{v}=$ Distribution factor for shear elements (solid blocking, cross bridging)

$D F_{b}=$ Distribution factor for bending elements (sub-floor with or without concrete topping, strapping, gypsum ceiling)

$E A_{c}=$ Unit axial stiffness of concrete topping $\left(\mathrm{N} \mathrm{mm}^{2} / \mathrm{mm}\right)$

$E A_{s}=$ Unit axial stiffness of sub-floor parallel to the panel axis (Table 2.3) $\left(\mathrm{N} \mathrm{mm}^{2} / \mathrm{mm}\right)$

$E I_{b i}=$ Unit flexural stiffness of individual bending member $\left(\mathrm{N} \mathrm{mm}^{2} / \mathrm{mm}\right)$

$E I_{c}=$ Unit flexural stiffness of concrete topping $\left(\mathrm{N} \mathrm{mm}^{2}\right)$

$E I_{\text {eff }}=$ Effective flexural stiffness $\left(\mathrm{N} \mathrm{mm}^{2}\right)$

$E I_{s}=$ Unit flexural stiffness of sub floor parallel to the panel axis $\left(\mathrm{N} \mathrm{mm}^{2} / \mathrm{mm}\right)$

$E I_{x}=$ Effective flexural stiffness of strong back and straps $\left(\mathrm{N} \mathrm{m}^{2}\right)$

Table 2.3: Stiffness properties of OSB sub flooring (Adopted from Allen et al. 1999)

\begin{tabular}{|c|c|c|c|c|}
\hline $\begin{array}{c}\text { Thickness } \\
(\mathrm{mm})\end{array}$ & $\begin{array}{c}\mathrm{EI}_{\text {par }} \\
(\mathrm{N} \mathrm{mm} / \mathrm{mm})\end{array}$ & $\begin{array}{c}\mathrm{EI}_{\text {perp }} \\
\left(\mathrm{N} \mathrm{mm}^{2} / \mathrm{mm}\right)\end{array}$ & $\begin{array}{c}\mathrm{EA}_{\text {par }} \\
(\mathrm{N} / \mathrm{mm})\end{array}$ & $\begin{array}{c}\mathrm{EA}_{\text {parp }} \\
(\mathrm{N} / \mathrm{mm})\end{array}$ \\
\hline 15.9 & 740000 & 2600000 & 31000 & 75000 \\
\hline 19 & 1300000 & 4400000 & 37000 & 89000 \\
\hline
\end{tabular}

Note: the subscripts "par" and "perp" refer to the orientation of the long direction of one panel of OSB with respect to the floor joist span.

\subsubsection{CALCULATION FOR "RMS" ACCELERATION}

The ATC and AISC methods have identical procedure for calculating the resonant RMS acceleration response due to walking excitation. Vibration of light-weight floors caused by walking can be a problem for the residence when the spans are greater than $6 \mathrm{~m}$ and natural frequency is less than $10 \mathrm{~Hz}$. Problem can be easily noticeable when a harmonic forcing frequency falling between 2 and $8 \mathrm{~Hz}$ due to walking matches the natural frequency of the floor or is close to it, causing a resonant response. Acceleration limits as recommended by the International Standards Organization (ISO 2631-2, 1989) are adjusted for intended occupancy. The ISO Standard suggests limits in terms of RMS acceleration as a multiple of the baseline curve shown in Figure 2.3. This value is taken as 10 for offices or residence, 30 for shopping malls and indoor foot bridges, and 100 for outdoor footbridges. For design purposes, the limit 
can be assumed to range between 0.8 and 1.5 times the recommended values depending on the duration of vibration and the frequency of vibration events. (Allen, 1997).

The peak acceleration due to walking occurs at resonance when $f_{n}=f_{\text {step }}$ is expressed in equation 2.55 .

$\frac{a_{p}}{g}=\frac{R \alpha_{i} P}{\beta W}$

Where:

$$
\begin{array}{ll}
\frac{a_{p}}{g} & =\text { Estimated peak acceleration (in units of } \mathrm{g} \text { ) } \\
\mathrm{R} & =\text { Reduction factor } \\
\alpha_{i} & =\text { Dynamic coefficient of the } \mathrm{i}^{\text {th }} \text { harmonic force component } \\
\mathrm{P} & =\text { Person's weight taken as } 0.7 \mathrm{kN}(157 \mathrm{Ib}) \\
\beta & =\text { Model damping ratio } \\
W & =\text { Effective weight of the floor }
\end{array}
$$

The reduction factor $\mathrm{R}$ takes into account the fact that full steady-state resonant motion is not achieved for walking and that the walking person and the person annoyed are not simultaneously at the location of maximum modal displacement. It is recommended that $\mathrm{R}$ be taken as 0.5 for floor structures with two-way mode shape configurations.

The above equation can be simplified by approximating the step relationship between the dynamic coefficient, $\alpha_{i}$ and the step frequency is set to the fundamental frequency, the RMS acceleration response is expressed as:

$\frac{a_{p}}{g}=\frac{P_{o} \exp \left(-0.35 f_{n}\right)}{\beta W} \leq \frac{a_{o}}{g}$

Where:

$\mathrm{P}_{\mathrm{o}} \quad=$ Constant force equal to $0.29 \mathrm{kN}(65 \mathrm{lb})$ for floor system

$\frac{a_{o}}{g} \quad=$ Acceleration limit from Figure 2.3.

According to the criterion, the floor system is satisfactory if the peak acceleration $a_{p}$, due to walking does not exceed the acceleration limit, $a_{0}$. For floor system such as one-way beam or joist systems supported on walls, the effective weight " $W$ " can be approximated by equation 2.57

$W=w B L$ 
Where:

$w \quad=$ Effective weight of the floor per unit area

$L \quad=$ Span of joist

$B \quad=$ Effective width of floor

$B \quad=C\left(D_{\text {perp }} / D_{\text {par }}\right)^{1 / 4} L \quad$ but not less than $2 / 3$ of the total width of the floor,

$C \quad=2.0$ for typical floor system

$D_{\text {perp }}=$ Effective stiffness $E I_{\text {eff }}$ per unit width of floor of the floor system perpendicular to the span.

$D_{\text {par }} \quad=$ Effective stiffness $E I_{\text {eff }}$ per unit width of floor of the floor system parallel to the span.

\subsection{EUROPEAN CODE (EC5)}

The design requirements in EC5 (EN, 1995) relate solely to residential floor having a fundamental frequency greater than $8 \mathrm{~Hz}$. Floors with a fundamental frequency less than $8 \mathrm{~Hz}$ requires special investigation and are not covered in the code. EC5 requirements are applicable to a rectangular floor with overall dimension $l \times b$, simply-supported along four sides and with beams spanning in the $l$ direction. In this case, the approximate value of the fundamental frequency, $f 1$, can be calculated from the equation 2.58 .

$f 1=\frac{\pi}{2 l^{2}} \sqrt{\frac{(E I)_{l}}{m}}$

Where:

$l \quad=$ Design span of the floor beams (in meters)

$(E I)_{l}=$ Equivalent flexural rigidity of the floor supporting structures about an axis perpendicular to the direction of the beam span, in $\mathrm{N} \mathrm{m}^{2} / \mathrm{m}$. Unless the floor decking is designed to act with the floor beams as a composite structures in the direction of the bean span (e.g. in the case of thin flanged composite beams), $(E L)_{l}$ should only be based on the flexural rigidity of the floor beams. Composite action between the floor decking and the joist can only be assumed to occur where the floor decking is glued to the joists.

$m=$ Mass per unit area of the floor, in $\mathrm{Kg} / \mathrm{m}^{2}$, and is based on permanent actions only without including partition loads. 
The UK National Annex states that floors with a span up to $6 \mathrm{~m}$ will normally behave satisfactorily provided the deflection " $a$ " under a point load is smaller than:

$a \leq \begin{cases}1.80 \mathrm{~mm} & \text { for } l \leq 4000 \mathrm{~mm} \\ \frac{16500}{l^{1.1}} \mathrm{~mm} & \text { for } l>4000 \mathrm{~mm}\end{cases}$

The deflection " $a$ " of the floor under a point load at the mid-span on a floor having a design span "l” mm can be evaluated using the following equation:

$a=\frac{1000 k_{d i s t} l_{e q}^{3} k_{a m p}}{48 E I_{(j o i s t)}} \mathrm{mm}$

Where:

$k_{\text {dist }} \quad=$ Proportion of point load acting on a single joist

$=$ Maximum of $\left\{\begin{array}{c}k_{\text {strut }}\left(0.38-0.08 \ln \left[\frac{14(E I)_{b}}{s^{4}}\right]\right. \\ \text { or } 0.30\end{array}\right.$

$k_{\text {strut }} \quad=1$ or

$=0.97$ where single or multiple lines of strutting are used in the floor structure

$l_{e q} \quad$ is the equivalent floor span in $\mathrm{mm}$.

$=1.0 l$ for simply supported single span joists

$=0.9 l$ for the end spans of continuous joists

$=0.85 l$ for internal spans of continuous joists

$k_{a m p} \quad$ is amplification factor to account for shear deformation

$=1.05$ for simply supported solid timber joists

$=1.10$ for continuous solid timber joists

$=1.15$ for simply supported glued thin webbed joists

$=1.30$ for continuous glued thin webbed joists

$=1.30$ for simply supported mechanically jointed floor trusses

$=1.45$ for continuous mechanically jointed floor trusses

$(E I)_{j o i s t} \quad$ is bending stiffness of a joist in $\mathrm{N} \mathrm{mm}^{2}$,

$\left.(E I)_{b} \quad 1\right)$ is the flexural stiffness and is calculated as $(E I)_{b}$ using the mean value of the modulus of elasticity of the floor decking and discontinuities at the ends of floor boards or at the edge of floor panels may be ignored. 
2) where plasterboard ceiling are fixed directly to the soffit of the floor joists, the flexural rigidity of the plasterboard can be added. It is to be assumed that $E_{\text {plasterboard }}=2000 \mathrm{~N} / \mathrm{mm}^{2}$.

3) Where the floor comprises open web joist fitted with a continuous transverse member secured to all joists within $0.1 l$ from mid span, $(E I)_{b}$ may be increased by adding the bending stiffness of the transverse member (in $\mathrm{N} \mathrm{mm}^{2}$ ) divided by the span $l$ (in meters)

$S \quad=$ joist spacing. 


\subsection{ULTIMATE LIMIT STATE DESIGN}

\subsection{CANADIAN WOOD DESIGN}

I-shape joists are structurally engineered timber joist comprising flanges made from solid timber and a web made from OSB, plywood or particleboard. The flanges and web are bonded together to form an I-section member, the panel is glued to the lumber over its whole length. The flanges are designed to carry the moment capacity of the beam while the web is designed to carry the shear force. The flanges are commonly made of laminated veneer lumber, MSR or visuallygraded lumber. While webs are normally $9.5 \mathrm{~mm}\left(3 / 8^{\prime \prime}\right)$ or $11 \mathrm{~mm}$ (7/16") OSB boards. They should be designed according to CSA-086-09 Standard (CSA, 2010).

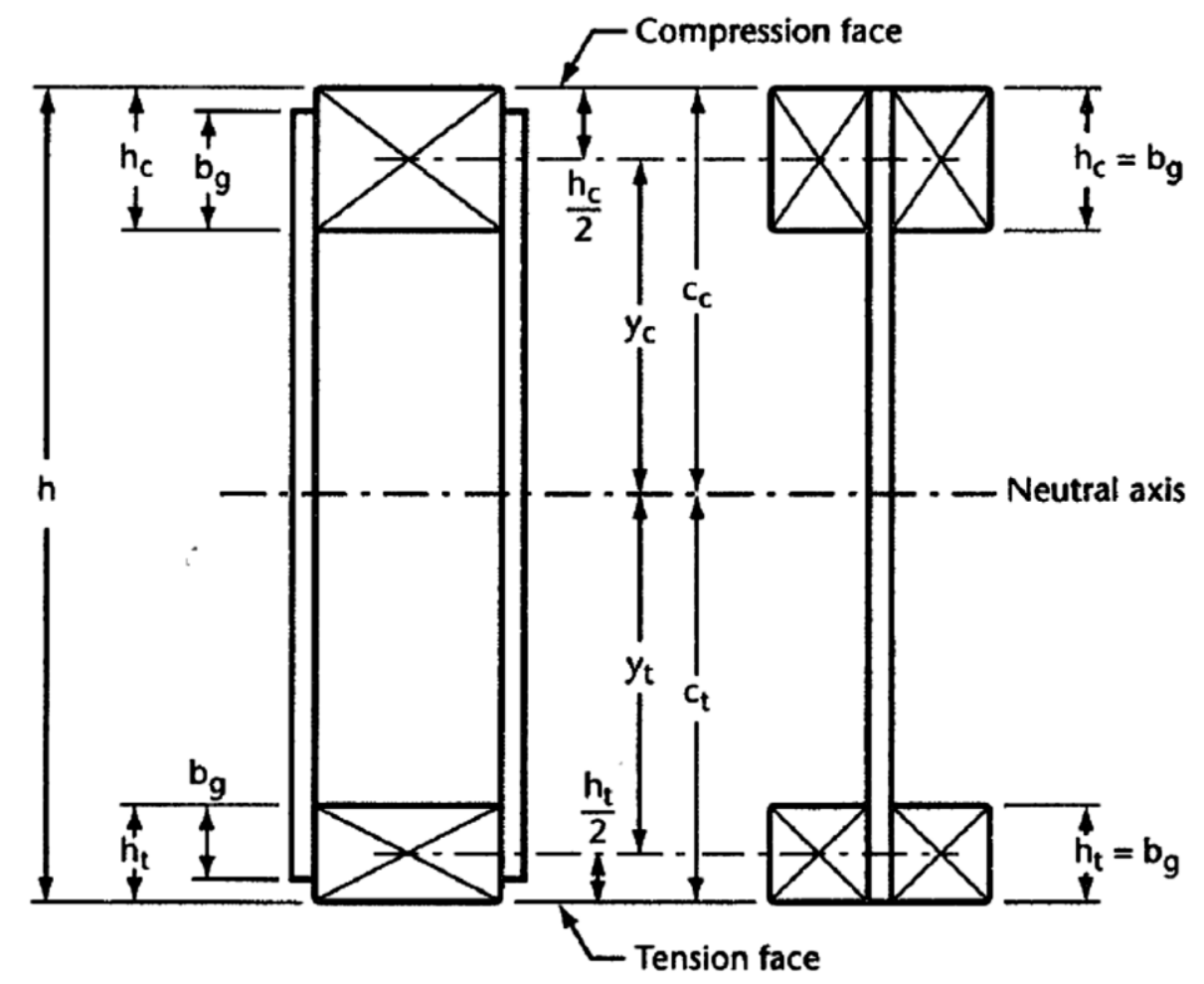

Figure 2.12: Panel web beam dimensions (adopted from CSA/086-09)

\section{Effective Stiffness:}

The effective stiffness, $(\mathrm{EI})_{\text {eff }}$ of a panel web beam shall be taken as

$(E I)_{e f f}=\left(\sum B_{a}\right) K_{s} \frac{\left(C_{t}^{3}+C_{c}^{3}\right)}{3}+(E I)_{f} K_{S E}$

Where

$\left(\sum B_{a}\right) \quad=$ sum of axial stiffness of panel webs, $\mathrm{N} / \mathrm{mm}^{2}$

$\mathrm{K}_{\mathrm{s}} \quad=$ service condition factor for web material 
$(\mathrm{EI})_{\mathrm{f}}=$ stiffness of flanges with respect to neutral axis of composite section, N/mm

$\mathrm{K}_{\mathrm{SE}} \quad=$ service condition factor for modulus of elasticity of flange

\section{Bending Resistance:}

The factored bending moment resistance of a panel web beam shall be the lesser of the factored resistance of the tension or compression flanges determined as follows:

\section{(a) Compression Flange}

$M_{r}=\phi F_{c} K_{z c} \frac{(E I)_{e}}{E K_{S E} C_{c}}$

Where:

$\phi \quad=0.8$ for sawn lumber, 0.9 for glulam

$\mathrm{F}_{\mathrm{c}} \quad=\mathrm{f}_{\mathrm{c}}\left(\mathrm{K}_{\mathrm{D}} \mathrm{K}_{\mathrm{sc}} \mathrm{K}_{\mathrm{T}} \mathrm{K}_{\mathrm{H}}\right)$

$\mathrm{f}_{\mathrm{c}} \quad=$ specified strength of flange in compression, $\mathrm{MPa}$

$\mathrm{K}_{\mathrm{D}} \quad=$ Load duration factor

$\mathrm{K}_{\mathrm{H}} \quad=$ system factor

$\mathrm{K}_{\mathrm{sc}} \quad=$ service condition factors

$\mathrm{K}_{\mathrm{T}} \quad=$ treatment factor

$\mathrm{E}=$ modulus of elasticity of flange, $\mathrm{Mpa}$

$\mathrm{K}_{\mathrm{SE}}=$ service condition factor for modulus of elasticity of flange

$\mathrm{C}_{\mathrm{c}} \quad=$ distance from neutral axis to compression face (Figure 2.12)

$\mathrm{K}_{\mathrm{Zc}} \quad=$ size factor for compression

$=6.3(\mathrm{dL})^{-0.13} \leq 1.3$

$\mathrm{d}=$ dimension in direction of buckling (depth or width), $\mathrm{mm}$

$\mathrm{L} \quad=$ length associated with member dimension, $\mathrm{mm}$

(b) Tension Flange

$M_{r}=\phi F_{t} K_{z t} \frac{(E I)_{e}}{E K_{S E} C_{t}}$

$\phi \quad=0.9$

$\mathrm{F}_{\mathrm{t}} \quad=\mathrm{f}_{\mathrm{t}}\left(\mathrm{K}_{\mathrm{D}} \mathrm{K}_{\mathrm{st}} \mathrm{K}_{\mathrm{T}} \mathrm{K}_{\mathrm{H}}\right)$

$\mathrm{f}_{\mathrm{t}} \quad=$ specified strength of flange in tension, $\mathrm{MPa}$

$\mathrm{K}_{\mathrm{H}} \quad=$ system factor

$\mathrm{E}=$ modulus of elasticity of flange, $\mathrm{MPa}$ 
$\mathrm{K}_{\mathrm{SE}} \quad=$ service condition factor for modulus of elasticity of flange

$\mathrm{C}_{\mathrm{t}} \quad=$ distance from neutral axis to tension face (Figure 2.12)

$\mathrm{K}_{\mathrm{Zt}} \quad=$ size factor for tension for swan lumber

\subsection{NORTH AMERICAN SPECIFICATIONS FOR THE DESIGN OF COLD-FORMED STEEL STRUCTURAL MEMBERS (CSA-S136-07)}

CSA S136-07 was developed jointly by CSA's Technical Committee on Cold-Formed Steel Structural Members and the American Iron and steel Institute's Committee on Specifications. Below are some limitations for web holes under subjected to uniform compression as well as normal stress gradient as specified in CSA-S136-07.

\subsubsection{UNIFORMLY COMPRESSED STIFFENED ELEMENT WITH CIRCULAR OR NON-CIRCULAR HOLES}

\section{A) STRENGTH DETERMINATION}

To determine the compressive resistance of the CFS section at the location of the hole, an effective width, $b$, can be calculated as in the following paragraphs for circular holes and noncircular holes.

\section{For Circular holes:}

The effective width, b, shown in Figure 2.13 shall be calculated by either equation 2.65 or equation 2.66 as follows:

For $0.50 \geq \frac{d_{h}}{w} \geq 0$, and $\frac{w}{t} \leq 70$, and the distance between centers of holes $\geq 0.5 \mathrm{w}$ and $\geq 3 \mathrm{~d}_{\mathrm{h}}$, when $\lambda \leq 0.673$

$\mathrm{b}=\mathrm{w}-\mathrm{d}_{\mathrm{h}}$

when $\lambda>0.673$

$\mathrm{b}=\frac{w\left[1-\frac{(0.22)}{\lambda}-\frac{\left(0.8 d_{h}\right)}{w}+\frac{\left(0.085 d_{h}\right)}{w \lambda}\right]}{\lambda}$

In all cases, $\mathrm{b} \leq \mathrm{w}-\mathrm{d}_{\mathrm{h}}$ 
Where

$\mathrm{W} \quad=$ flat width

$\mathrm{t} \quad=$ thickness of element

$\mathrm{d}_{\mathrm{h}} \quad=$ Diameter of holes

$\lambda=$ Slenderness factor

$=\sqrt{\frac{f}{F_{c r}}}$

$f \quad=$ stress in compression element for flexural members when the initial yielding is in compression in the element considered, $\mathrm{f}=\mathrm{F}_{\mathrm{y}}$. When the initial yielding is in tension, the compressive stress, $\mathrm{f}$, in the element considered is determined on the basis of the effective section at $\mathrm{M}_{\mathrm{y}}$ where $\mathrm{M}_{\mathrm{y}}$ is the yield moment.

$\mathrm{F}_{\mathrm{cr}} \quad=k \frac{E \pi^{2}}{12\left(1-\mu^{2}\right)}\left(\frac{t}{w}\right)^{2}$

Where

$\mathrm{k}=$ plate buckling coefficient and is equal to 4 for stiffened element supported by web on each longitudinal edge. Values for different types of elements are given in Table 2.1.

$\mathrm{E} \quad=$ modulus of elasticity of steel.

$\mathrm{t}=$ thickness of uniformly compressed stiffened element

$\mu \quad=$ Poisson's ratio of steel

\section{For non-circular holes:}

A uniformly compressed stiffened element with non-circular holes shall be assumed to consist of two unstiffened strip of flat width, c, adjacent to the holes as shown in Figure 2.13. The effective width, $b$, of each unstiffened strip adjacent to the holes shall be calculated by equation 2.69 or 2.70, except that plate buckling coefficient, $\mathrm{k}$, shall be taken as 0.43 and "w" as "c". These provisions shall be applicable within the following limits:

1. Centre-to-center hole spacing, $\mathrm{s} \geq 610 \mathrm{~mm}$ (24 in.),

2. Clear distance from the holes at ends, $s_{\text {end }} \geq 254 \mathrm{~mm}$ (10 in.),

3. Depth of hole, $\mathrm{d}_{\mathrm{h}} \leq 63.5 \mathrm{~mm}(2.5 \mathrm{in}$.),

4. Length of hole, $\mathrm{L}_{\mathrm{h}} \leq 114 \mathrm{~mm}$ (4.5 in.), and

5. Ratio of the depth of hole, $d_{h}$, to the out-to-out width, $w_{o}, d_{h} / w_{o} \leq 0.5$ 
When $\lambda \leq 0.673$

$\mathrm{b}=\mathrm{w}$

When $\lambda>0.673$

$\mathrm{b}=\rho \mathrm{w}$

Where:

$\mathrm{w} \quad=$ flat width

$\rho=$ local reduction factor

$=(1-0.22 / \lambda) / \lambda$

$\lambda=$ Slenderness factor

$$
=\sqrt{\frac{f}{F_{c r}}}
$$

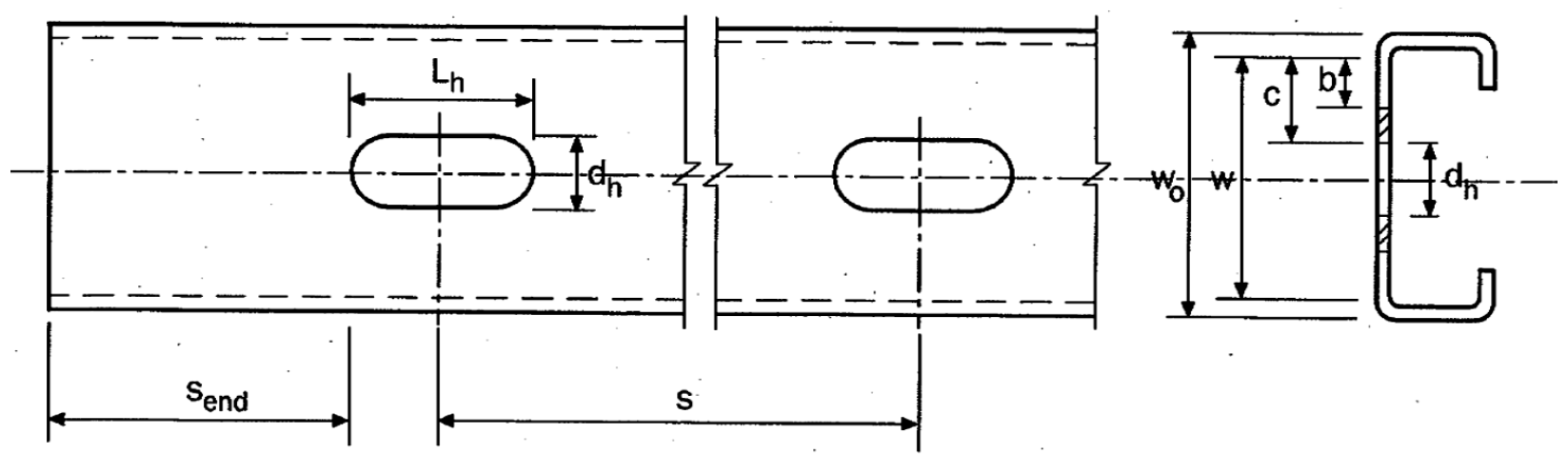

Figure 2.13: Uniformly compressed stiffened elements with non-circular holes (adopted from CSA/S136-07)

\section{B) SERVICEABILITY DETERMINATION}

The effective width, $b_{d}$, used in determining serviceability shall be equal to " $b$ " calculated in equations 2.73 and 2.74 .

When $\lambda \leq 0.673$

$\mathrm{b}_{\mathrm{d}}=\mathrm{w}$

When $\lambda>0.673$

$b_{d}=\rho w$ 
Where:

$\mathrm{w} \quad=$ flat width

$\rho \quad=$ local reduction factor as determined above.

\subsubsection{C-SECTION WEBS WITH HOLES UNDER STRESS GRADIENT}

The provision of this section shall apply within the following limits

1) $\mathrm{d}_{\mathrm{h}} / \mathrm{h} \leq 0.7$

2) $\mathrm{h} / \mathrm{t} \leq 200$

3) Holes centered at mid-depth of web

4) Clear distance between holes $\geq 457 \mathrm{~mm}$ (18 in)

5) Non circular holes, corner radii $\geq 2 \mathrm{t}$

6) Non circular holes, $\mathrm{d}_{\mathrm{h}} \leq 64 \mathrm{~mm}(2.5 \mathrm{in})$ and $\mathrm{L}_{\mathrm{h}} \leq 114 \mathrm{~mm}$ (4.5 in)

7) Circular holes, diameter $\leq 152 \mathrm{~mm}$ (6 in), and

8) $\mathrm{d}_{\mathrm{h}}>14 \mathrm{~mm}(9 / 16 \mathrm{in})$

Where

$\mathrm{d}_{\mathrm{h}} \quad=$ depth of web hole

$\mathrm{h}=$ depth of flat portion of web

$\mathrm{t} \quad=$ thickness of web

$\mathrm{L}_{\mathrm{h}} \quad=$ length of web hole

\subsubsection{MEMBERS}

\subsubsection{PROPERTIES OF SECTIONS}

Properties of sections (i.e. cross-sectional area, moment of inertia, section modulus, radius of gyration, etc.) shall be determined in accordance with conventional methods of structural design. Properties shall be based on the full cross-section of the member or net sections where the use of net section is applicable.

\subsubsection{FLEXURAL MEMBERS}

The nominal flexural strength (i.e. moment resistance), $M_{n}$, shall be calculated by equation 2.75.

$\mathrm{M}_{\mathrm{n}}=\phi_{\mathrm{b}} \mathrm{S}_{\mathrm{e}} \mathrm{F}_{\mathrm{y}}$

Where

$\phi_{\mathrm{b}} \quad=$ resistance factor and is equal to 0.9 
$\mathrm{S}_{\mathrm{e}} \quad=$ elastic section modulus of effective section calculated relative to extreme compression or tension fiber at $\mathrm{F}_{\mathrm{y}}$.

$\mathrm{F}_{\mathrm{y}} \quad=$ design yield stress.

\subsubsection{LATERAL TORSIONAL BUCKLING STRENGTH}

For laterally unbraced segments of singly, doubly, and point symmetric sections subjects to lateral torsional buckling, the nominal flexural strength, $\mathrm{M}_{\mathrm{n}, \text {, shall be calculated in accordance }}$ with equation 2.76 .

$\mathrm{M}_{\mathrm{n}}=\phi_{\mathrm{b}} \mathrm{S}_{\mathrm{c}} \mathrm{F}_{\mathrm{c}}$

Where

$\phi_{\mathrm{b}} \quad=$ resistance factor and is equal to 0.9

$\mathrm{S}_{\mathrm{c}} \quad=$ elastic section modulus of effective section calculated relative to extreme compression fiber at $F_{c}$.

$\mathrm{F}_{\mathrm{c}}$ shall be determined as follows:

For $F_{e} \geq 2.78 F_{y}$

The member segment is not subject to lateral torsional buckling at bending moments less than or equal to $\mathrm{M}_{\mathrm{y}}$. The available flexural strength shall be determined in accordance with equation 2.77 .

For $2.78 F_{y}>F_{e}>0.56 F_{y}$

$\mathrm{F}_{\mathrm{c}}=\frac{10}{9} F_{y}\left(1-\frac{10 F_{y}}{36 F_{e}}\right)$

For $F_{e} \leq 0.56 F_{y}$

$F_{c}=F_{e}$

Where

$\mathrm{F}_{\mathrm{y}} \quad=$ design yield stress

$\mathrm{F}_{\mathrm{e}} \quad=$ elastic critical lateral torsional buckling stress calculated in accordance with (a) or (b).

\section{a) For singly, doubly, and point symmetric sections:}

i) For bending about the symmetric axis:

$\mathrm{F}_{\mathrm{e}} \quad=\frac{A C_{b} r_{0}}{S_{f}} \sqrt{\sigma_{e y} \sigma_{t}} \quad$ for singly and doubly symmetric sections

$\mathrm{F}_{\mathrm{e}} \quad=\frac{A C_{b} r_{0}}{2 s_{f}} \sqrt{\sigma_{e y} \sigma_{t}} \quad$ for point symmetric sections 
Where

$\mathrm{C}_{\mathrm{b}}=\frac{12.5 M_{\max }}{2.5 M_{\max }+3 M_{A}+4 M_{B}+3 M_{C}}$

Where

$\mathrm{M}_{\max }=$ absolute value of maximum moment in unbraced segment

$\mathrm{M}_{\mathrm{A}} \quad=$ absolute value of moment at quarter point of unbraced segment

$\mathrm{M}_{\mathrm{B}} \quad=$ absolute value of moment at centerline of unbraced segment

$\mathrm{M}_{\mathrm{C}} \quad=$ absolute value of moment at three quarter point of unbraced segment

$\mathrm{C}_{\mathrm{b}}$ shall be permitted to be conservatively taken as unity for all cases.

For cantilever or overhangs where the free end is Unbraced, $\mathrm{C}_{\mathrm{b}}$ shall be taken as unity.

$\mathrm{r}_{\mathrm{o}} \quad=$ polar radius of gyration of cross section about shear center

$$
=\sqrt{r_{x}^{2}+r_{y}^{2}+x_{o}^{2}}
$$

Where

$r_{x}, r_{y}=$ radii of gyration of cross section about centroidal principal axes

$\mathrm{x}_{\mathrm{O}}=$ distance from shear center to centroid along principal $\mathrm{x}$-axis, taken as negative

A $\quad=$ Ffull unreduced cross sectional area

$\mathrm{S}_{\mathrm{f}} \quad=$ elastic section modulus of full unreduced section relative to extreme compression fiber

$\sigma_{\text {ey }} \quad=\frac{E \pi^{2}}{\left(\frac{K_{y} L y}{r y}\right)^{2}}$

Where

$\mathrm{E} \quad=$ modulus of elasticity of steel

$\mathrm{K}_{\mathrm{y}} \quad=$ effective length factor for bending about $\mathrm{y}$-axis

$\mathrm{L}_{\mathrm{y}} \quad=$ unbraced length of member for bending about $\mathrm{y}$-axis

$\sigma_{\mathrm{t}} \quad=\frac{1}{A r_{o}^{2}}\left[G J+\frac{\pi^{2} E C_{w}}{\left(K_{t} L_{t}\right)^{2}}\right]$

Where

$\mathrm{G}=$ shear Modulus

$\mathrm{J}=$ Saint-Venant torsion constant of cross section

$\mathrm{C}_{\mathrm{w}}=$ torsional warping constant of cross section

$\mathrm{K}_{\mathrm{t}} \quad=$ effective length factor for twisting

$\mathrm{L}_{\mathrm{t}} \quad=$ unbraced length of member for twisting 
For singly-symmetric section, $\mathrm{x}$-axis shall be the axis of symmetry oriented such that the shear has a negative $\mathrm{x}$-coordinate.

For point symmetric sections, such as Z-section, $\mathrm{x}$-axis shall be the centroidal axis perpendicular to the web.

Alternatively, $\mathrm{F}_{\mathrm{e}}$ shall be permitted to be calculated using the equation given in (b) for doubly symmetric I-section, singly symmetric C-sections, or point symmetric Z-sections.

ii) For singly symmetric section bending about the centroidal axis perpendicular to the axis of symmetry:

$$
\mathrm{F}_{\mathrm{e}} \quad=\frac{C_{s} A \sigma_{e x}}{C_{T F} S_{f}}\left[j+C_{s} \sqrt{j^{2}+r_{o}^{2}\left(\frac{\sigma_{t}}{\sigma_{e x}}\right)}\right]
$$

Where

$\mathrm{C}_{\mathrm{s}} \quad=+1$ for moment causing compression on shear center side of centroid $=-1$ for moment causing tension on shear center side of centroid

$\sigma_{\mathrm{ex}}=\frac{E \pi^{2}}{\left(\frac{K_{x} L_{x}}{r_{x}}\right)^{2}}$

$\mathrm{K}_{\mathrm{x}} \quad$ = effective length factor for bending about $\mathrm{x}$-axis

$\mathrm{L}_{\mathrm{x}} \quad=$ unbraced length of member for bending about $\mathrm{x}$-axis

$\mathrm{C}_{\mathrm{TF}}=0.6-0.4\left(\mathrm{M}_{1} / \mathrm{M}_{2}\right)$

Where

$\mathrm{M}_{1}$ and $\mathrm{M}_{2} \quad$ = the smaller and the larger bending moment, respectively, at the end of the unbraced length in the plan of bending; $\mathrm{M}_{1} / \mathrm{M}_{2}$, the ratio of end moments, is positive when $M_{1}$ and $M_{2}$ have the same sign (reverse curvature bending) and negative when they are of opposite sign (single curvature bending). When the bending moment at any point within an unbraced length is larger than that at both ends of this length, $\mathrm{C}_{\mathrm{TF}}$ shall be taken as unity.

$\mathrm{j}=\frac{1}{2 I_{y}}\left[\int_{A} x^{3} d A+\int_{A} x y^{2} d A\right]-x_{0}$ 
b) For I-sections, singly-symmetric C-sections, or Z-sections bent about the centroidal axis perpendicular to the web (x-axis):

The following equation shall be permitted to be used in lieu of (a) to calculate $F_{c}$ :

i) For doubly symmetric I- section and singly-symmetric C-section:

$\mathrm{F}_{\mathrm{e}}=\frac{C_{b} \pi^{2} E d I_{y c}}{S_{f}\left(K_{y} L_{y}\right)^{2}}$

ii) For point symmetric Z-section:

$\mathrm{F}_{\mathrm{e}}=\frac{C_{b} \pi^{2} E d I_{y c}}{2 S_{f}\left(K_{y} L_{y}\right)^{2}}$

Where

$\mathrm{d} \quad=$ depth of section

$\mathrm{I}_{\mathrm{yc}} \quad=$ moment of inertia of compression portion of section about centroidal axis of entire section parallel to web, using full unreduced section.

\subsubsection{DETERMINATION OF LIMITING UNBRACED LENGTH (Lu)}

For any unbraced length "L" less than the limiting unbraced length, $\mathrm{L}_{\mathrm{u}}$, lateral torsional buckling does not need to be considered, where the unbraced length " $\mathrm{L}_{\mathrm{u}}$ " is calculated using the equation 2.90 (Commentary on NAS, 2001).

a) For singly, doubly and point symmetric sections:

$\mathrm{L}_{\mathrm{u}}=\left\{\frac{G J}{2 C_{1}}+\left[\frac{C_{2}}{C_{1}}+\left(\frac{G J}{2 C_{1}}\right)^{2}\right]^{0.5}\right\}^{0.5}$

Where

i) For singly and doubly symmetric sections:

$\mathrm{C}_{1}=\frac{7.72}{A E}\left[\frac{K_{y} F_{y} S_{f}}{C_{b} \pi r_{y}}\right]^{2}$

ii) For point symmetric sections:

$\mathrm{C}_{1}=\frac{30.9}{A E}\left[\frac{K_{y} F_{y} S_{f}}{C_{b} \pi r_{y}}\right]^{2}$

$\mathrm{C}_{2}=\frac{\pi^{2} E C_{w}}{\left(K_{t}\right)^{2}}$ 


\section{(b) for I, C, or Z-section bent about the centroidal axis perpendicular to the web:}

The following equations may be used in lieu of part (a):

i) For doubly symmetric I-section and singly symmetric C-section:

$\mathrm{L}_{\mathrm{u}} \quad=\left[\frac{0.36 C_{b} \pi^{2} E d I_{y c}}{F_{y} S_{f}}\right]^{0.5}$

ii) For point symmetric “ $Z$ ” sections:

$\mathrm{L}_{\mathrm{u}} \quad=\left[\frac{0.18 C_{b} \pi^{2} E d I_{y c}}{F_{y} S_{f}}\right]^{0.5}$

\subsection{DIRECT STENGTH METHOD}

In traditional method, the effective width approach is used to determine the strength of the section. When the section is complex, the effective width method becomes complicated and time consuming. In the effective width method, each element of the whole section is treated independently. The interaction between elements is generally ignored, for example the interaction between web and the flange. To overcome this problem, the newly developed method called "Direct Strength Method" (DSM) is developed by Schafer and Pekoz (1998). The DSM was developed in early 2000s under the supervision of the AISI subcommittee on element behavior. A new Appendix 1, Design of Cold-Formed Steel Structure Members Using the Direct Strength Method, was added to the 2001 Edition of the "North American Specification in the AISI Supplement 2004. The Direct Strength Method (DSM) Design Guide was prepared by Dr. Schafer in 2006 (DSM design guide, 2006). The DSM provides expressions to determine the strength as a function of elastic buckling for a local plate mode similar to the effective width but also for distortional and global modes. The DSM is currently limited only to determining the nominal axial strength $\left(P_{n}\right)$ for the columns and flexural strengths $\left(M_{n}\right)$ for beams. Currently, the Direct Strength method provides no provision for members in tension, shear, combined bending and shear, web crippling, or combined bending and web crippling. Further, no provisions are given for structural assemblies or connections and joints (Schafer, 2006).

The following sub-sections provide the details of the Direct Strength Method Design. As mentioned above, the DSM does not depend on effective width, nor requires iteration for the determination of member design strength. Instead, the elastic buckling load is calculated based 
on gross properties to determine the member strength in local, distortional, and global buckling. The load that causes the first yield is then employed in a series of simple equations to get the strength of the member. The main problem with this method is to determine the elastic local, distortional, and global buckling loads; once these values are determined the rest of the procedure is straight forward. The freely available computer program "Cornell University Finite Strip Method" CUFSM, can provide the elastic buckling loads that the Direct Strength Method requires. This software can be downloaded from the website, www.ce.jhu.edu/bschafer/cufsm. (Schafer and Li, 2010).

\subsubsection{BEAM DESIGN}

The nominal flexural strength resistance $M_{n}$, shall be the minimum of $M_{n e}, M_{n l}$, and $M_{n d}$ as given below.

\section{(A) LATERAL TORSIONAL BUCKLING}

The nominal flexural strength, $\mathrm{M}_{\mathrm{ne}}$, for lateral torsional buckling shall be calculated in accordance with the following.

(a) For $\mathrm{M}_{\text {cre }}<0.56 \mathrm{M}_{\mathrm{y}}$

$\mathrm{M}_{\mathrm{ne}}=\mathrm{M}_{\mathrm{cre}}$

(b) For $2.78 \mathrm{M}_{\mathrm{y}} \geq \mathrm{M}_{\text {cre }} \geq 0.56 \mathrm{M}_{\mathrm{y}}$

$\mathrm{M}_{\mathrm{ne}}=\frac{10}{9} M_{y}\left(1-\frac{10 M_{y}}{36 M_{\text {cre }}}\right)$

(c) For $\mathrm{M}_{\text {cre }}>2.78 \mathrm{M}_{\mathrm{y}}$

$$
\mathrm{M}_{\mathrm{ne}}=\mathrm{M}_{\mathrm{y}}
$$

Where

$\mathrm{M}_{\text {cre }}=$ critical elastic lateral torsional buckling moment obtained using a buckling analysis software

$\mathrm{M}_{\mathrm{y}}=\mathrm{S}_{\mathrm{f}} \mathrm{F}_{\mathrm{y}}$

$\mathrm{S}_{\mathrm{f}}=$ gross-section modulus

\section{(B) LOCAL BUCKLING}

The nominal flexural strength, $\mathrm{M}_{\mathrm{nl}}$, for local buckling shall be calculated in accordance with the following.

(a) For $\lambda_{l} \leq 0.776$ 
$\mathrm{M}_{\mathrm{nl}}=\mathrm{M}_{\mathrm{ne}}$

(b) For $\lambda_{l}>0.776$

$M_{n l}=\left(1-0.15\left(\frac{M_{c r l}}{M_{n e}}\right)^{0.4}\right)\left(\frac{M_{c r l}}{M_{n e}}\right)^{0.4} M_{n e}$

Where

$\lambda_{l}=\sqrt{M_{n e} / M_{c r l}}$

$\mathrm{M}_{n e}=\mathrm{a}$ value as defined above

$\mathbf{M}_{c r l}=$ Critical elastic local buckling moment obtained using a buckling analysis software

\section{(C) DISTORTIONAL BUCKLING}

The nominal flexural strength, $\mathbf{M}_{\mathrm{nd}}$, for distortional buckling shall be calculated in accordance with the following.

(a) For $\lambda_{d} \leq 0.673$

$\mathrm{M}_{\mathrm{nd}}=\mathrm{M}_{\mathrm{y}}$

(b) For $\lambda_{d}>0.673$

$M_{n d}=\left(1-0.22\left(\frac{M_{c r d}}{M_{y}}\right)^{0.5}\right)\left(\frac{M_{c r d}}{M_{y}}\right)^{05} M_{y}$

Where

$\lambda_{\mathrm{d}}=\sqrt{\mathrm{M}_{\mathrm{y}} / \mathrm{M}_{\mathrm{crd}}}$

$\mathrm{M}_{y}=\mathrm{a}$ value as defined above

$\mathbf{M}_{c r d}=$ Critical elastic distortional buckling moment obtained using a buckling analysis software

\subsection{EXPLANATION OF THE DIRECT STRENGTH METHOD}

Below is the example for the Z-section to explain the DSM. The predictions of local buckling mode for a Z-shape member in bending using the finite-strip program CUFSM are shown in Figure 2.14. The determination of the buckling mode requires consideration of the half wavelength and the mode shape. The results are shown in a plot of buckling half wavelength vs. critical buckling moment to yield moment ratio. For the local buckling case, the minima occur at half wavelengths that are the largest dimension of the section under compressive stresses. For example, the Z-section in Figure 2.14 has a web height of $216 \mathrm{~mm}$; therefore the cut-off for local buckling is at $216 \mathrm{~mm}$. the minimum point in the buckling curve that falls at half wavelength less 
than the section depth may generally consider as local buckling modes. The buckling modes occurring at longer length are either distortional or global failure. In the local buckling, the distortion of the section occurs, this distortion only involves the rotation of individual plate element, for example web, compression flange and lip stiffener, with no translation at the fold lines of the member. The distortional buckling occurs at a half wavelength in between the local and global buckling modes (i.e. second minimum point of the half wavelength curve). The half wavelength in distortional buckling is several times larger than the largest dimension of the member. In distortional buckling mode, both translation and rotation occur at the fold line of a member. In Figure 2.14, the web of the section distorts (buckles) while the compression flange and lip rotate about the web flange fold line (DSM design guide, 2002).

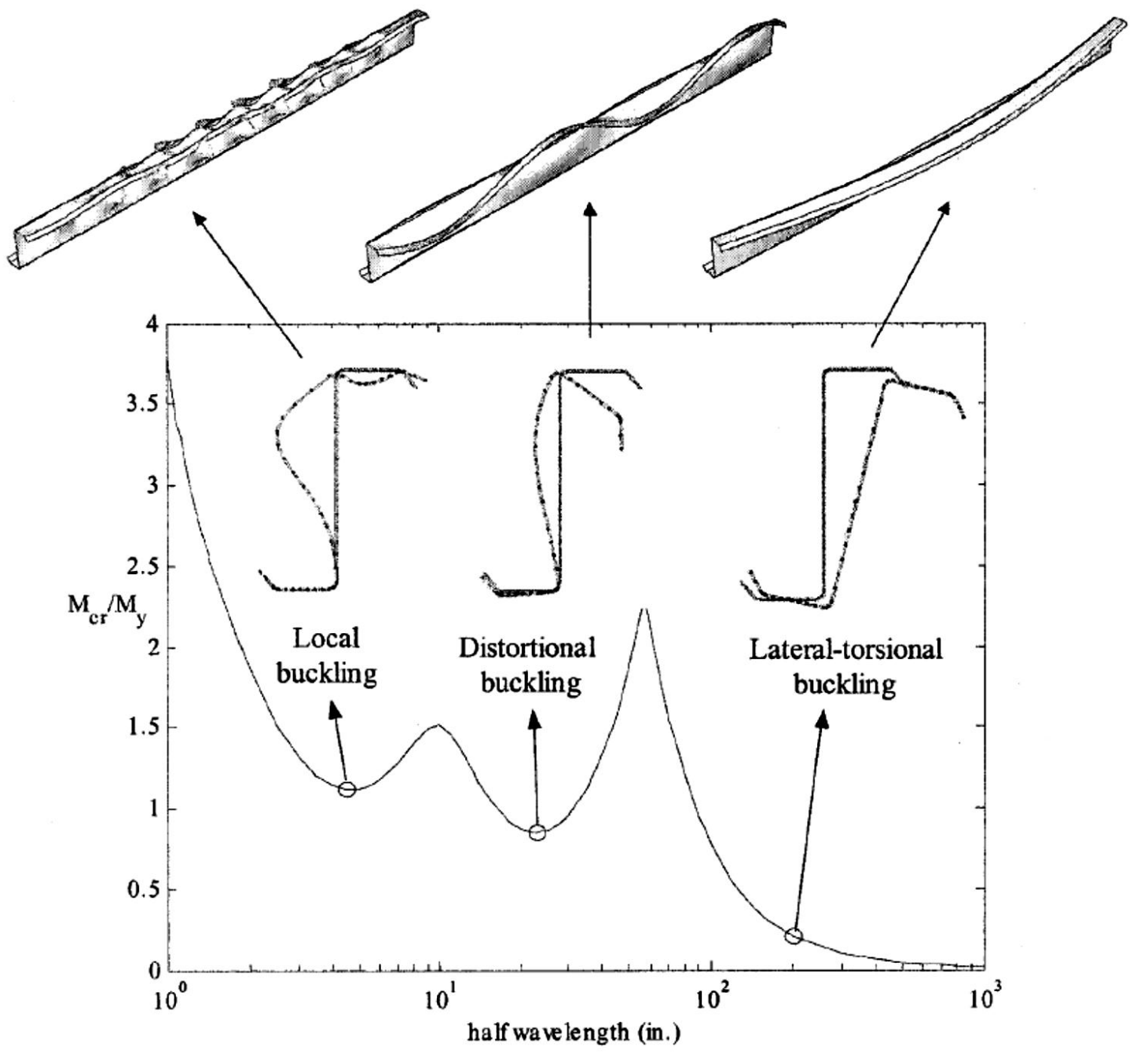

Figure 2.14: View of buckling mode of cold formed steel Z-section in bending [adopted from $\mathrm{Yu}, 2005]$ 
The third mode is the lateral-torsional buckling mode that occurs as the minimum mode at relatively long wavelengths. This mode, which is also called global buckling mode, the entire section translates and rotates as a rigid body and no distortion occurs in any of the element in the section in the long half wavelength buckling modes. In the above example, one can observe that if the member length is longer than $2540 \mathrm{~mm}$, the lateral torsional buckling mode is the first lowest elastic buckling mode, while the local buckling mode will be the lowest mode when the member length is less than $254 \mathrm{~mm}$. It should be noted that the distortional mode is in between these two lengths (DSM Guide, 2002). Table 2.4 shows the pre-qualified unperforated beams that fall within the geometric limitations of the use of the Direct Design Method. For the beam shape limitations shown in Table 2.4, the safety factor for design can be used as follow (DSM Guide, 2002): $\phi_{\mathrm{b}}=0.85$ for LSD, $\phi_{\mathrm{b}}=0.9$ for LRFD, and $\Omega_{\mathrm{b}}=1.67$ for ASD, where LSD is Limit State Design , LRFD is Load and Resistance Factor Design and ASD is Allowable Stress Design. 
Table 2.4: Pre-qualified beam sections for direct strength method, DSM (adopted from DSM Guide, 2002)

\begin{tabular}{|c|c|}
\hline Channels & $\begin{array}{l}\mathrm{h} / \mathrm{t}<321 \\
\mathrm{~b} / \mathrm{t}<75 \\
0<\mathrm{d} / \mathrm{t}<34 \\
1.5<\mathrm{h} / \mathrm{b}<17.0 \\
0.0<\mathrm{d} / \mathrm{b}<0.70 \\
44^{\circ}<\theta<90^{\circ} \\
\mathrm{E} / \mathrm{Fy}>421 \\
\mathrm{Fy}<483 \mathrm{MPa}) \text { or }\left(\mathrm{Fy}_{\mathrm{y}}<70 \mathrm{ksi}\right)\end{array}$ \\
\hline $\begin{array}{l}\text { Channels with web } \\
\text { stiffener }\end{array}$ & $\begin{array}{l}\mathrm{h} / \mathrm{t}<358 \\
\mathrm{~b} / \mathrm{t}<58 \\
14<\mathrm{d} / \mathrm{t}<17 \\
5.5<\mathrm{h} / \mathrm{b}<11.7 \\
0.27<\mathrm{d} / \mathrm{b}<0.56 \\
\theta=90^{\circ} \\
\mathrm{E} / \mathrm{Fy}>578 \\
(\mathrm{Fy}<352 \mathrm{MPa}) \text { or }\left(\mathrm{Fy}_{\mathrm{y}}<51 \mathrm{ksi}\right)\end{array}$ \\
\hline 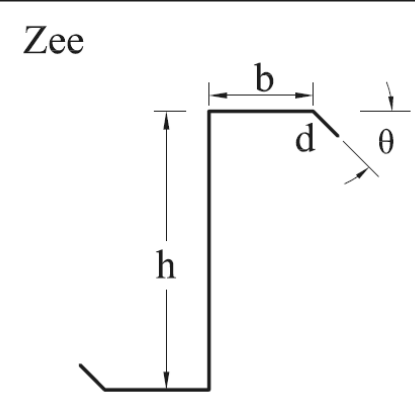 & $\begin{array}{l}\mathrm{h} / \mathrm{t}<183 \\
\mathrm{~b} / \mathrm{t}<71 \\
10<\mathrm{d} / \mathrm{t}<16 \\
2.5<\mathrm{h} / \mathrm{b}<4.1 \\
0.15<\mathrm{d} / \mathrm{b}<0.34 \\
36^{\circ}<\theta<90^{\circ} \\
\mathrm{E} / \mathrm{Fy}_{y}>440 \\
(\mathrm{Fy}<462 \mathrm{MPa}) \text { or }\left(\mathrm{Fy}_{\mathrm{y}}<67 \mathrm{ksi}\right)\end{array}$ \\
\hline Hats (Decks) & 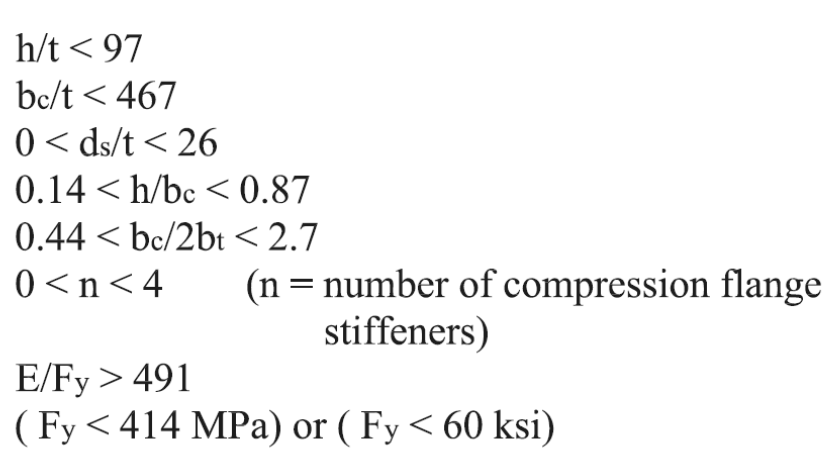 \\
\hline
\end{tabular}




\subsection{DAMPING RATIO}

Damping refers to the loss of mechanical energy in a vibrating system. A quicker rate of decay will also reduce the acceleration response. Damping is an inherent property of the material, construction methods, and dimensions of a floor system, as well as the type of occupancy. At the design stage, it is very difficult to predict the damping ratio of the floor, even if only a few variables are considered. At the design stage, the designer can assume a suitable damping ratio. Damping is usually expressed as the percent of critical damping or as the ratio of actual damping to critical damping. Critical damping is the smallest amount of viscous damping for which freevibrating system that is displaced from equilibrium and released comes to rest without oscillation. "Viscous" damping is associated with a retarding force that is proportional to velocity. The damping of tested specimens in the current research was calculated by Bandwidth method. The Bandwidth method is a widely used method for calculating the damping of the structural system. Equation 2.98 is used to compute the damping ratio for a single degree of freedom of the structural system. Graphical representation is also shown in Figure 2.15.

$\beta=\frac{\Delta f}{2 f 0}$

Where

$\Delta \mathrm{f}=$ bandwidth of the frequency corresponding to the spectral value of $\frac{f \max }{\sqrt{2}}$

$f_{0}=$ natural frequency corresponding to the peak value $f_{\max }$.

The above equation was used to find the damping ratio in the current research.

\subsection{SUMMARY}

In this Chapter, the literature review and available design methods are discussed for the serviceability and ultimate limit design for wood and cold-formed steel joists. The following design methods are explained in this chapter.

For serviceability limit state design (floor vibration), the following three design criteria were consider in this research:

1. Canadian Wood Council Design Criterion (CWC),

2. Applied Technology Council Design Criterion (ATC), and

3. European Code (Eurocode EC5)

For the ultimate state design, the following design criteria were used: 
1. Wood Design Manual, CSA 086-10,

2. North America Specification for the Design of Cold-formed Steel Structural Members (CSA S136-07), and

3. Direct Strength Method (DSM).

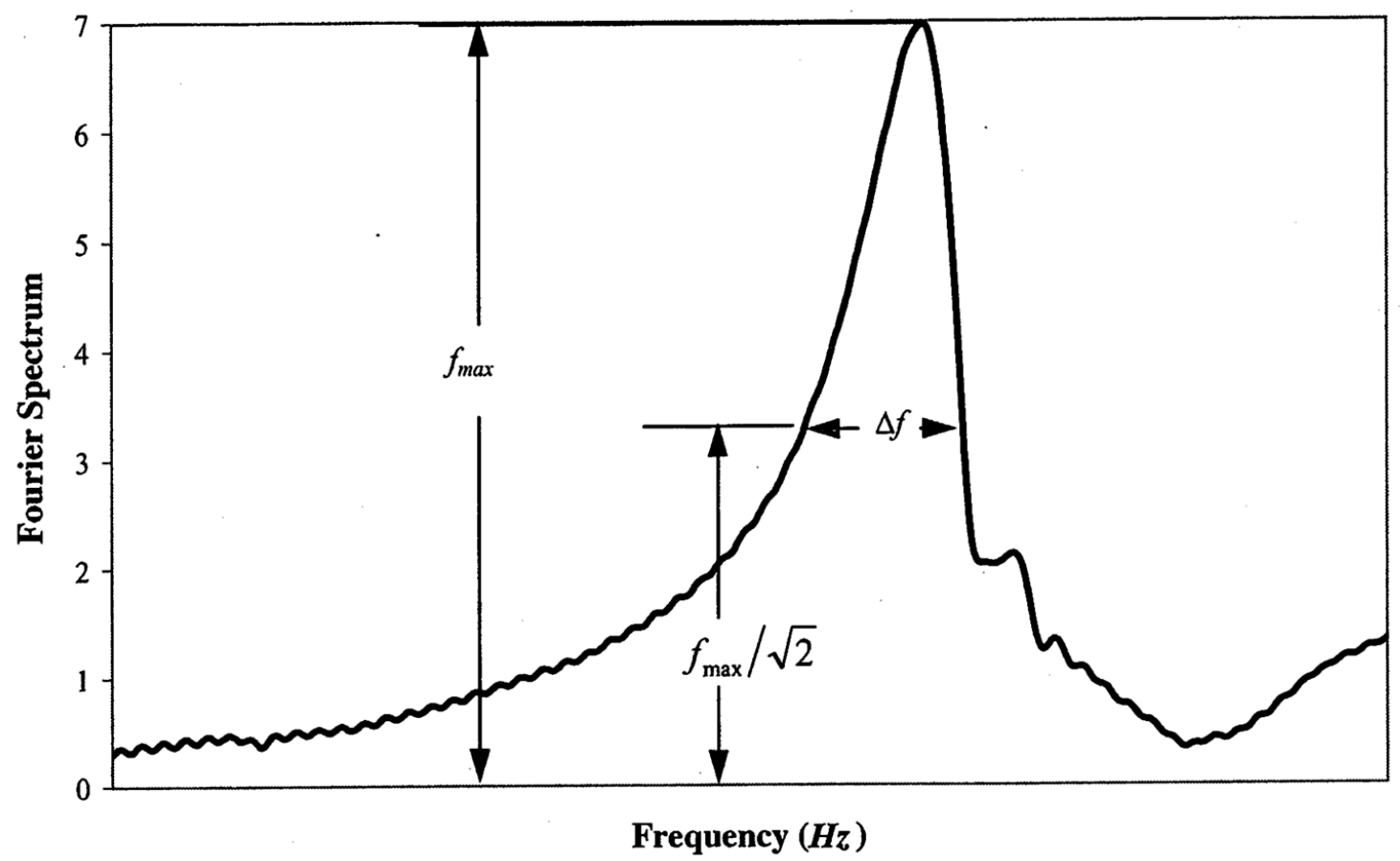

Figure 2.15: Graphical representation of the bandwidth method (adopted from Tangorra, 2005) 


\section{CHAPTER 3 \\ EXPERIMENTAL PROGRAM}

\subsection{INTRODUCTION}

The experimental research program was intended to provide experimental data that can be used further to investigate the applicability of available design methods for CFS members to the iSPAN joists. Also, the experimental data would assist in verifying and substantiating the finiteelement computer model developed in this study. The experimental work presented in the research included (i) a laboratory investigation conducted at the Structural Laboratory of Ryerson University and (ii) a field investigation conducted at four locations in Brantford, Ontario, Canada. The laboratory research involved a total of 16 twin-joist assemblies with different span lengths. These assemblies was comprised of 6 engineered wooden I-joist assemblies, 6 iSPAN joist assemblies without web holes and 4 iSPAN joist assemblies with web holes. Table 3.1 summarizes the properties of the engineered wooden I-joists, while Tables 3.2 and 3.3 show the properties of iSPAN joists without web holes and with web holes, respectively. Table 3.4 shows the properties of iSPAN joists in the test sites. Figure 3.1 show the cross sectional view of wooden and iSPAN joist respectively.

\subsection{OBJECTIVES AND SCOPE OF THE LABORATORY TESTS}

The main objectives of this experimental testing were to (i) investigate the dynamic characteristics of cold-formed steel iSPAN floor systems, and recommend an adequate model for predicting the dynamic response and modal properties of the floor system in order to aid the design process; (ii) evaluate the accuracy and applicability of commonly used design methods for predicting fundamental frequency, static deflection, and acceleration response to walking excitation; and (iii) determine the ultimate load carrying capacities of the developed joists and correlate them with those obtained from the available design codes. Figure 3.2 shows a flow chart or outline of the experimental program conducted in this study. 
Three tests were performed on each joist assembly as follows:
a) Static test with a 1-kN load applied at the mid-span of the twin-joist assembly;
b) Dynamic test through dropping a bowling ball to produce free-vibration excitation in floor assembly; and
c) Ultimate strength test to determine the joist ultimate load carrying capacities.

The experimental work was divided into three phases as follows:

i) Experimental work for engineered wood I-joist assembly;

ii) Experimental work for iSPAN cold-formed steel joist assembly without web holes; and

iii) Experimental work for iSPAN cold-formed steel joist assembly with web holes.

iv) Site testing on selected custom-made buildings built with the developed iSPAN joists.

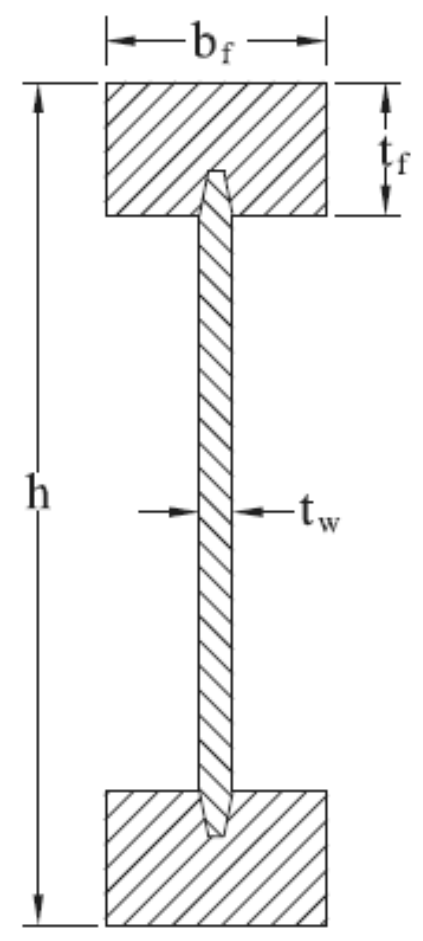

(a) Wooden I-Joist

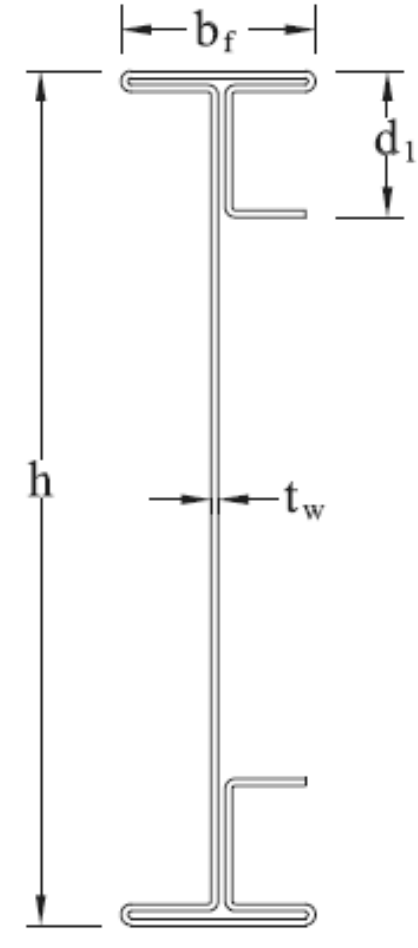

(b) iSPAN Joist

Figure 3.1: Cross-section configurations of the wooden and iSPAN joists (See Table 3.1 through 3.4 for detailed dimensioning) 
Table 3.1: Section properties of engineered wood I-joists

\begin{tabular}{|c|c|c|c|c|c|c|c|c|}
\hline Group & Description & $\begin{array}{c}\text { Joist } \\
\text { height, } \\
\mathrm{h}(\mathrm{mm})\end{array}$ & $\begin{array}{c}\text { Joist } \\
\text { length } \\
(\mathrm{m})\end{array}$ & $\begin{array}{c}\mathrm{b}_{\mathrm{f}} \\
(\mathrm{mm})\end{array}$ & $\begin{array}{c}\mathrm{t}_{\mathrm{f}} \\
(\mathrm{mm})\end{array}$ & $\begin{array}{c}\mathrm{t}_{\mathrm{w}} \\
(\mathrm{mm})\end{array}$ & $\begin{array}{c}\text { Weight } \\
(\mathrm{kg} / \mathrm{m})\end{array}$ & $\begin{array}{c}\text { Stiffness, } \\
\text { EI }\left(\mathrm{N}-\mathrm{mm}^{2}\right. \\
\left.\mathrm{x} 10^{9}\right)\end{array}$ \\
\hline \multirow{2}{*}{$\mathrm{A}$} & 241 TJI S31 & 241 & 3.50 & 63.5 & 38 & 9.5 & 3.80 & 588 \\
\cline { 2 - 10 } & 241 TJI S33 & 241 & 4.50 & 63.5 & 38 & 9.5 & 3.80 & 694 \\
\hline \multirow{2}{*}{ B } & 302 TJI S31 & 302 & 5.00 & 63.5 & 38 & 9.5 & 4.20 & 999 \\
\cline { 2 - 9 } & 302 TJI S33 & 302 & 5.25 & 63.5 & 38 & 9.5 & 4.20 & 1179 \\
\hline C & 356 TJI S33 & 356 & 6.10 & 63.5 & 38 & 9.5 & 4.50 & 1728 \\
\hline D & 406 TJI S47 & 406 & 7.95 & 89 & 38 & 11 & 5.80 & 3272 \\
\hline
\end{tabular}

Note: see Figure 3.1 for symbols

Table 3.2: Section properties of iSPAN joists without web holes

\begin{tabular}{|c|c|c|c|c|c|c|c|c|}
\hline Group & Description & $\begin{array}{c}\text { Joist } \\
\text { height, } \\
\mathrm{h}(\mathrm{mm})\end{array}$ & $\begin{array}{c}\text { Joist } \\
\text { length } \\
(\mathrm{m})\end{array}$ & $\begin{array}{c}\mathrm{b}_{\mathrm{f}} \\
(\mathrm{mm})\end{array}$ & $\begin{array}{c}\mathrm{d}_{1} \\
(\mathrm{~mm})\end{array}$ & $\begin{array}{c}\mathrm{t}_{\mathrm{w}} \\
(\mathrm{mm})\end{array}$ & $\begin{array}{c}\text { Weight } \\
(\mathrm{kg} / \mathrm{m})\end{array}$ & $\begin{array}{c}\text { Stiffness, EI } \\
\left(\mathrm{N}-\mathrm{mm}^{2} \mathrm{x}\right. \\
\left.10^{9}\right)\end{array}$ \\
\hline \multirow{2}{*}{$\mathrm{A}$} & $241-\mathrm{i}-2$ & 241 & 3.50 & 50 & 40 & 1.22 & 5.75 & 1153.10 \\
\cline { 2 - 10 } & $241-\mathrm{i}-2$ & 241 & 4.50 & 50 & 40 & 1.22 & 5.75 & 1153.10 \\
\hline \multirow{2}{*}{$\mathrm{B}$} & $302-\mathrm{i}-2$ & 302 & 5.00 & 50 & 40 & 1.22 & 6.40 & 1921.83 \\
\cline { 2 - 10 } & $302-\mathrm{i}-2$ & 302 & 5.25 & 50 & 40 & 1.22 & 6.40 & 1921.83 \\
\hline C & $356-\mathrm{i}-3$ & 356 & 6.10 & 50 & 40 & 1.36 & 8.61 & 3492.00 \\
\hline D & $406-\mathrm{i}-3$ & 406 & 7.95 & 50 & 40 & 1.36 & 9.30 & 4735.10 \\
\hline
\end{tabular}

Note: see Figure 3.1 for symbols

Table 3.3: Section properties of iSPAN joists with web holes

\begin{tabular}{|c|c|c|c|c|c|c|c|c|}
\hline Group & Description & $\begin{array}{c}\text { Joist } \\
\text { height, } \\
\mathrm{h}(\mathrm{mm})\end{array}$ & $\begin{array}{c}\text { Joist } \\
\text { length } \\
(\mathrm{m})\end{array}$ & $\begin{array}{c}\mathrm{b}_{\mathrm{f}} \\
(\mathrm{mm})\end{array}$ & $\begin{array}{c}\mathrm{d}_{1} \\
(\mathrm{~mm})\end{array}$ & $\begin{array}{c}\mathrm{t}_{\mathrm{w}} \\
(\mathrm{mm})\end{array}$ & $\begin{array}{c}\text { Weight } \\
(\mathrm{kg} / \mathrm{m})\end{array}$ & $\begin{array}{c}\text { Stiffness, EI } \\
\left(\mathrm{N}-\mathrm{mm}^{2} \mathrm{x}\right. \\
\left.10^{9}\right)\end{array}$ \\
\hline \multirow{2}{*}{$\mathrm{A}$} & $254-\mathrm{i}-2$ & 254 & 3.50 & 50 & 40 & 1.22 & 5.75 & 1276.00 \\
\cline { 2 - 9 } & $254-\mathrm{i}-2$ & 254 & 4.50 & 50 & 40 & 1.22 & 5.75 & 1276.00 \\
\hline \multirow{2}{*}{$\mathrm{B}$} & $302-\mathrm{i}-2$ & 302 & 5.00 & 50 & 40 & 1.22 & 6.40 & 1921.83 \\
\cline { 2 - 9 } & $302-\mathrm{i}-2$ & 302 & 5.25 & 50 & 40 & 1.22 & 6.40 & 1921.83 \\
\hline
\end{tabular}

Note: see Figure 3.1 for symbols 
Table 3.4: Section properties of iSPAN joists in test sites

\begin{tabular}{|l|c|c|c|c|c|c|c|c|}
\hline Group & Description & $\begin{array}{c}\text { Joist } \\
\text { height, } \\
\mathrm{h}(\mathrm{mm})\end{array}$ & $\begin{array}{c}\text { Joist } \\
\text { length } \\
(\mathrm{m})\end{array}$ & $\begin{array}{c}\mathrm{b}_{\mathrm{f}} \\
(\mathrm{mm})\end{array}$ & $\begin{array}{c}\mathrm{d}_{1} \\
(\mathrm{~mm})\end{array}$ & $\begin{array}{c}\mathrm{t}_{\mathrm{w}} \\
(\mathrm{mm})\end{array}$ & $\begin{array}{c}\text { Weight } \\
(\mathrm{kg} / \mathrm{m})\end{array}$ & $\begin{array}{c}\text { Stiffness, EI } \\
) \mathrm{N}^{2} \mathrm{~mm}^{2} \mathrm{x} \\
\left.10^{9}\right)\end{array}$ \\
\hline Site 1 & $241-\mathrm{i}-2$ & 241 & 5.20 & 50 & 40 & 1.22 & 5.75 & 1153.10 \\
\hline Site 2 & $302-\mathrm{i}-2$ & 302 & 7.26 & 50 & 40 & 1.22 & 6.40 & 1921.83 \\
\hline Site 3 & $241-\mathrm{i}-2$ & 241 & 5.33 & 50 & 40 & 1.22 & 5.75 & 1153.10 \\
\hline Site 4 & $241-\mathrm{i}-2$ & 241 & 6.50 & 50 & 40 & 1.22 & 5.75 & 1153.10 \\
\hline
\end{tabular}

Note: see Figure 3.1 for symbols 


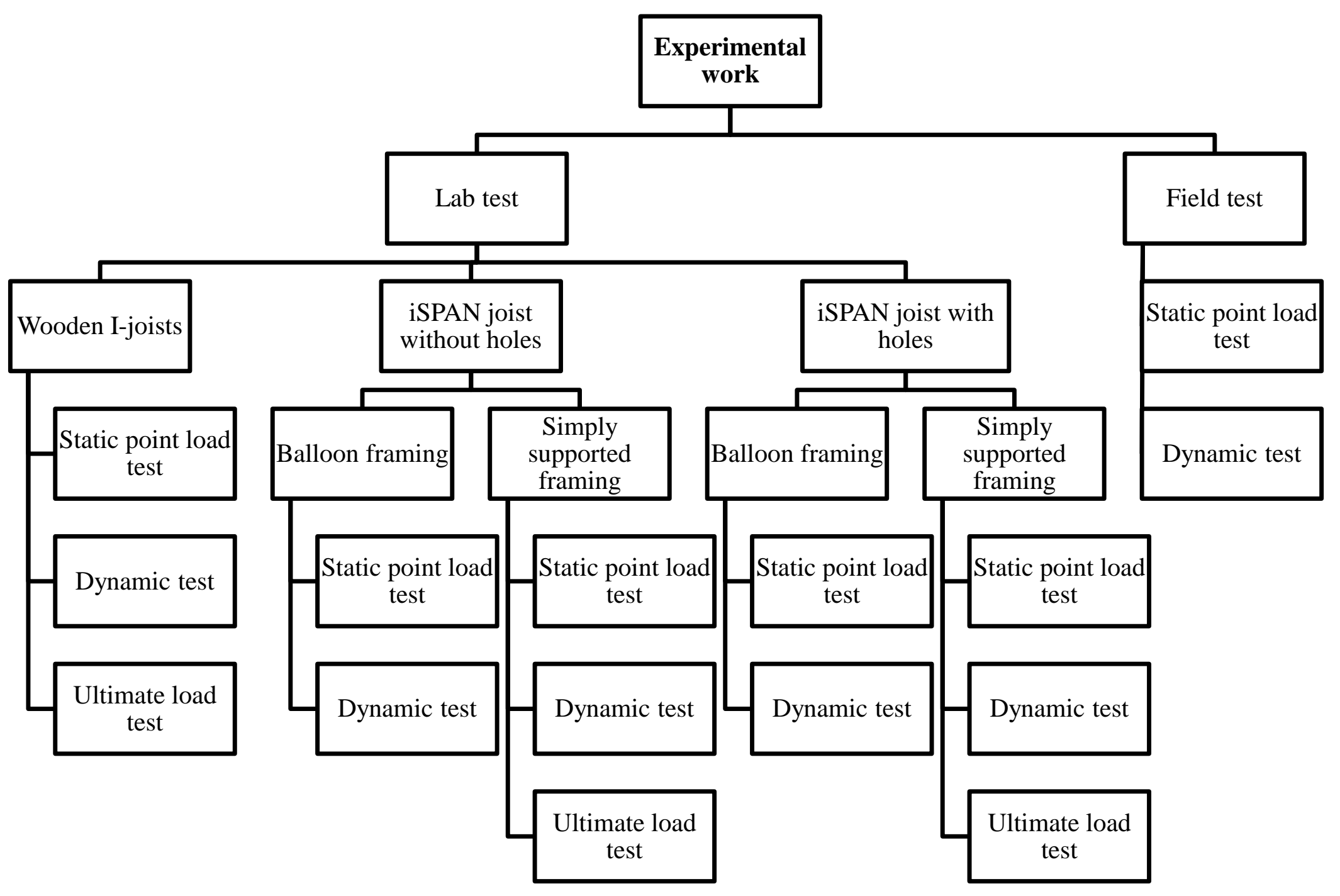

Figure 3.2: Outline of the experimental work 


\subsection{EXPERIMENTAL WORK FOR ENGINEERED WOOD I-FLOOR JOISTS}

The following sub-sections describe the test setup, static load tests, dynamic load tests and ultimate load tests conducted in this study.

\subsubsection{TEST SETUP}

Six engineered wood I- joists were selected in order to cover a large range of floor spans. These span lengths were taken as 3.50, 4.50, 5.00, 5.25, 6.10, and $7.95 \mathrm{~m}$, with joist depths of $241 \mathrm{~mm}$ (9.5 in), $302 \mathrm{~mm}$ (11.875 in), $356 \mathrm{~mm}$ (14 in) and $406 \mathrm{~mm}$ (16 in), respectively. The joist web was made of OSB sheet thicknesses of $9.5 \mathrm{~mm}(0.375 \mathrm{in})$ for the first 5 joist sizes and $11 \mathrm{~mm}$ (0.4375 in) for the last joist size. Table 3.1 summarizes joist geometry along with flexural stiffness, EI. The sizes of the studied joists were determined for bedrooms and living rooms in a residential construction based on deflection criterion of L/480 under specified live load of 1.44 $\mathrm{kPa}\left(30 \mathrm{lb} / \mathrm{ft}^{2}\right)$ and $1.92 \mathrm{kPa}\left(40 \mathrm{lb} / \mathrm{ft}^{2}\right)$, respectively. Figures 3.3 and 3.4 show schematic plan and elevation of the wood-joist assembly, respectively. While Figure 3.5 shows a schematic diagram of the assembly cross-section. The floor system was constructed with two wooden I joists spaced at $600 \mathrm{~mm}$ (24 in) on center, with $19 \mathrm{~mm}$ (3/4 in.) tongue-in-groove oriented strand board (OSB) sheathing as the sub-flooring. The OSB was nailed to the wooden I floor joist using $10 \mathrm{~d} x$ 3" nails. The nails were placed at $150 \mathrm{~mm}$ (6 in.) on center at the ends of the joists and at $300 \mathrm{~mm}$ (12 in.) on center along the length of the sample as shown in Figure 3.3, with a close-up plan view shown in Figure 3.7. The samples were tested with and without bracing. The bracing were attached to the bottom flange of the joists and placed at a maximum distance of $2134 \mathrm{~mm}$ (7 ft.) to provide lateral stability to the joists. The joists ends were connected to a $29-\mathrm{mm}(1-1 / 8$ in.) rim board as shown in Figure 3.6. The entire assembly was simply-supported at its ends by bearing on a $152 \mathrm{~mm}$ (6 in.) roller supports placed on a four 458-mm (18 in.) high steel pedestals as shown in Figure. 3.8.

Three types of tests were performed on each sample, namely: (i) static point load test with a 1$\mathrm{kN}$ force applied at the center of the twin joists; (ii) dynamic Test by dropping a bowling ball to produce the desired excitation in the assembly; and (iii) ultimate strength test. The following sub-sections provide an explanation for each test. 


\subsubsection{STATIC POINT LOAD TEST}

Static load tests were conducted to determine the maximum deflection under $1-\mathrm{kN}$ (255 $\mathrm{lb}$ ) concentrated load. The formula given in the ATC Design Guide for the calculation of deflection under $1-\mathrm{kN}$ load includes the effective flexural stiffness $\left(E I_{\text {eff }}\right)$ of the system. If there is no composite action between a structural member and other components of the floor system (such as floor or ceiling deck components), the effective flexural stiffness is equal to that of the structural member (Allen et al., 1999). In the case of twin-joist wood assembly, it is common practice to ignore the contribution of OSB in calculating $E I_{\text {eff }}$ claiming that it is insignificant to achieve composite action with the joists. Thus, the stiffness used in the calculation of deflection and frequency is simply the joist stiffness. ATC deflection formula also considers the effective number of joists $\left(N_{\text {eff }}\right)$ in deflection calculation since the applied concentrated load would be distributed over a number of adjacent joists in a floor system. In the case of two joist system considered in this study, only two joists were involved, so the effective number of joist $\left(N_{\text {eff }}\right)$ is equal to two. Figure 3.8 shows view of the engineering wood I-joist assembly, while Figure 3.9 shows view of the linear variable differential transducer (LVDT) used to measure joist deflection. The static test was performed by placing a concentrated load of $1-\mathrm{kN}$ at the middle of two joists and at center of joists along the length of the joists. The load was in the form of steel round plates as shown in Figure 3.10. The resulting deflections were measured by four LVDTs, with two LVDTs placed under each joist. The average of four readings was compared to the deflection value obtained from the available code equations. It should be noted that each test was repeated three times for greater accuracy. To provide stability and to avoid bouncy effect, the ends of the joists were clamped to the supported steel pedestals as depicted in Figure 3.11.

\subsubsection{DYNAMIC LOADING TEST}

Dynamic tests were performed to determine vibration characteristics of engineered wood I-joist floor assemblies. The floor was excited by dropping a $5.5 \mathrm{~kg}$ (12.32 lb) bowling ball over the joist assembly at the mid-span location. To find the effect of dropping height on calculating the frequency of the assembly, the ball was first dropped from a height of $0.610 \mathrm{~m}(2 \mathrm{ft})$ and then dropped from a height of $0.305 \mathrm{~m}(1 \mathrm{ft})$ over the center of the assembly. Results analyzed after testing showed that dropping height has no effect on frequency. Thus the dynamic tests on the rest of the assemblies were conducted by dropping the ball from $0.305-\mathrm{m}(1 \mathrm{ft}$.) height over the 
floor surface. The acceleration of the tested joists was measured through two accelerometers which were attached to the bottom flange of each joist at the mid-span of each joist. Figure 3.12 shows view of the accelerometer attached to the bottom flange of the wood I-joist, while Figure 3.13 shows view of the wood straps (i.e. transverse bracing) located at the quarter points of the tested assemblies. It should be noted that each assembly was tested with and without bracing. Each test was repeated three times for better accuracy. The ends of each joist were clamped at support in order to restrain the bouncy of the floor during testing. Figure 3.14 shows view of the bowling ball dropped from a height of $0.3 \mathrm{~m}$ over the wooden assembly. The acceleration-time history recorded by the accelerometers was then used to extract the flexural frequencies and damping ratios of each floor assembly. The Seismosignal (seismosoft.com) software was used to convert the acceleration-time history to frequency domain to obtain the frequency values and corresponding mode shapes. The frequencies in this study refer to the natural frequencies of the assembly.

\subsubsection{ULTIMATE STRENGTH TEST}

The static failure test was conducted on floor assemblies to determine their flexural behavior and ultimate load carrying capacities. A schematic diagram of the test setup is shown in Figure 3.16. A uniformly-distributed load was applied to the top surface of the floor assembly through a loading tree shown in Figure 3.15. To prevent premature buckling of web or flange of the joists, wide timber planks were used to distribute the loads over the joist length. A $222-\mathrm{kN}(50,000 \mathrm{lb})$ capacity hydraulic jack was used to apply the load over the loading tree that distributed the load uniformly over the joists. It should be noted that the weights of the loading system to transfer the jacking load to simulated uniform loading over the twin-joists were 6.68, 6.68, 6.68, 6.68, 6.68, and $12.71 \mathrm{kN}$ for joist spans of 3.5, 4.5, 5, 5.25, 6.10 and $7.95 \mathrm{~m}$, respectively. The jacking load was applied in increments so that the deformation of the assembly can be visually observed. However, joist deflections and applied load were recorded with rate of 1 reading per second till failure. 


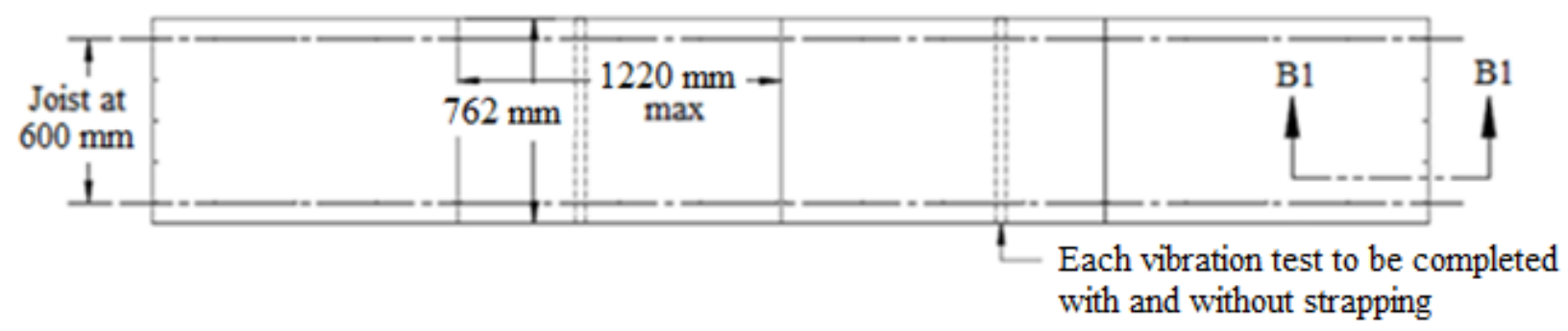

Figure 3.3: Plan view of engineered wood I-floor joist assembly

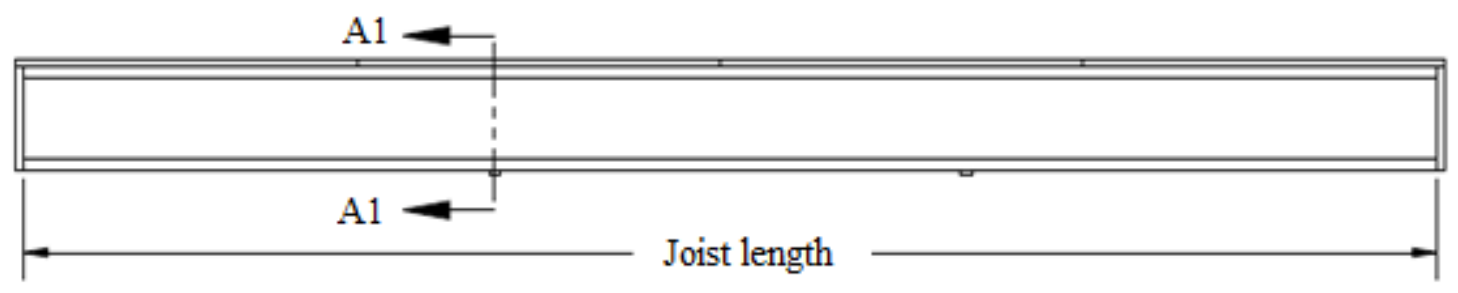

Figure 3.4: Elevation view of the engineered wood I-floor joist assembly

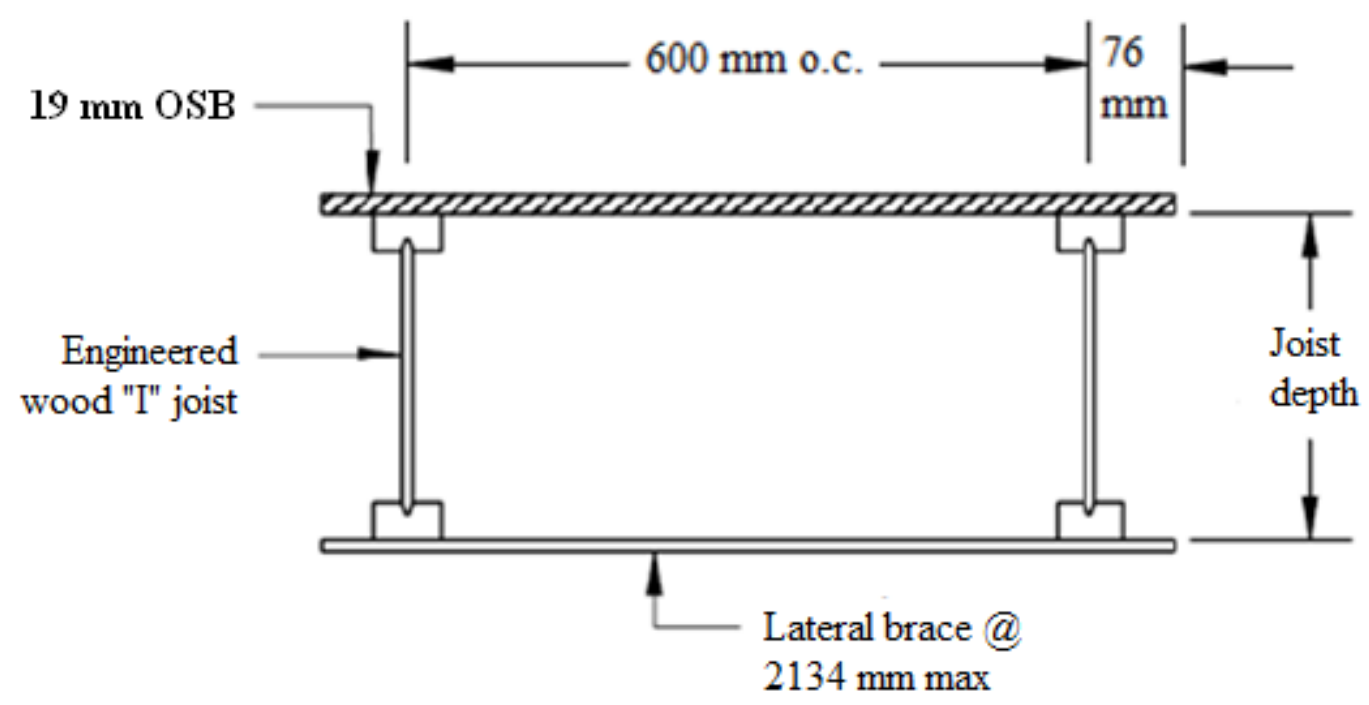

Figure 3.5: Section A1-A1 of the engineered wood I-floor joist assembly 


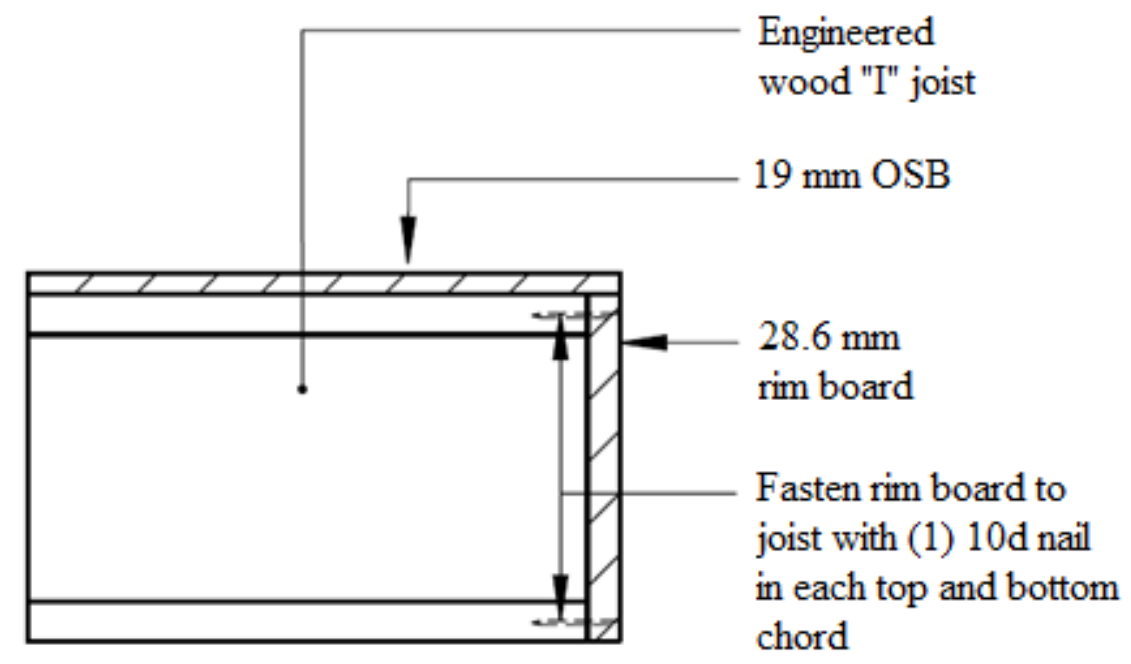

Figure 3.6: Section B1-B1 of the engineered wood I-floor joist assembly

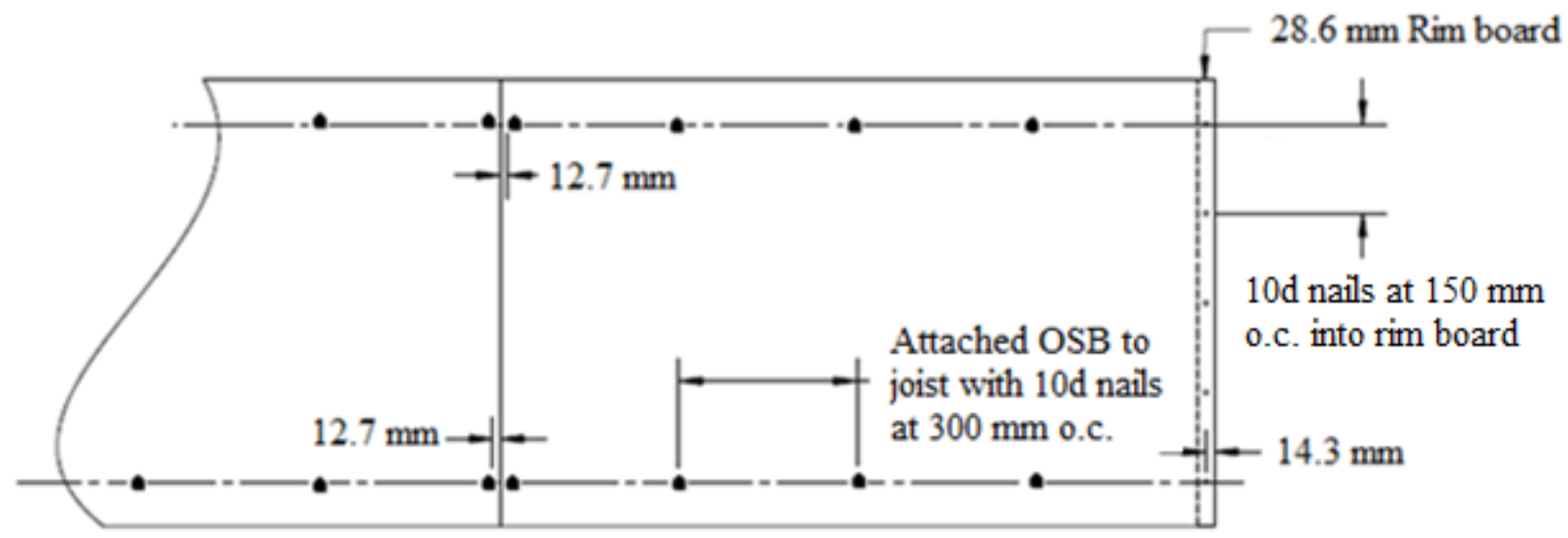

Figure 3.7: Plane view of sheathing nail pattern of the engineered wood I-floor joist assembly 


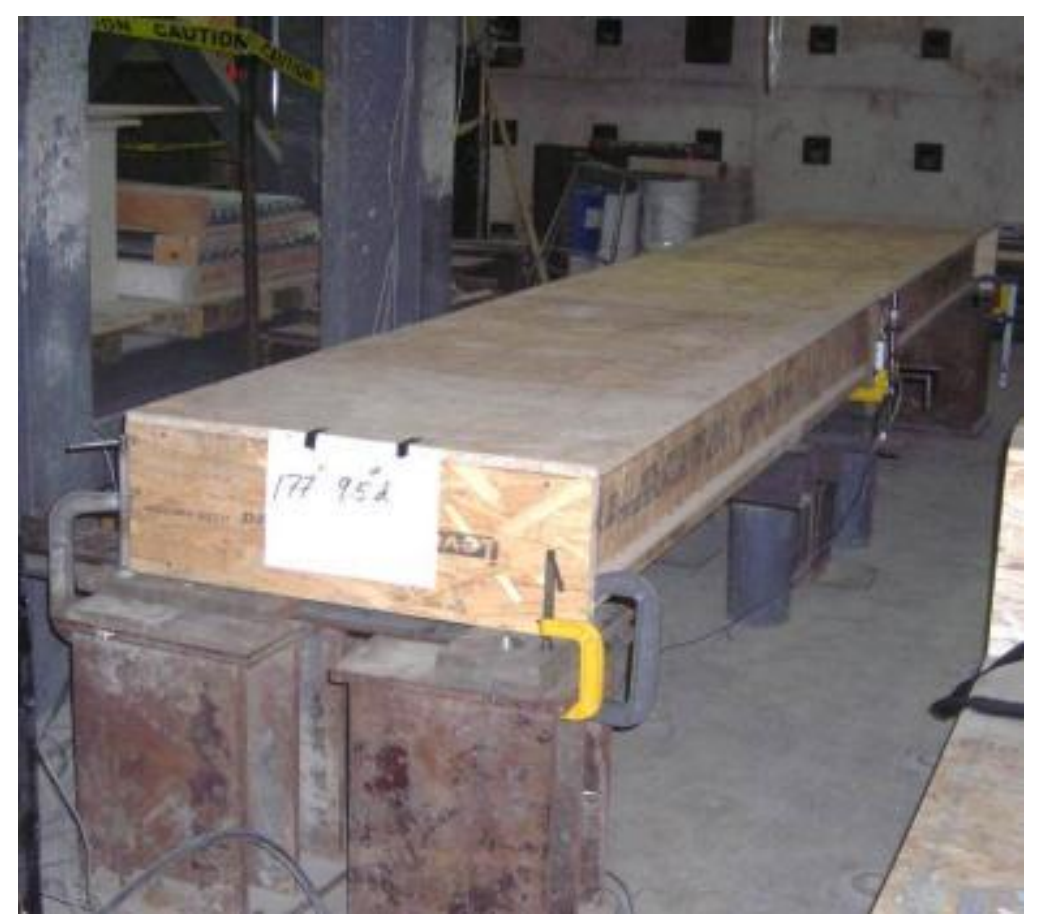

Figure 3.8: View of engineered I wood floor assembly

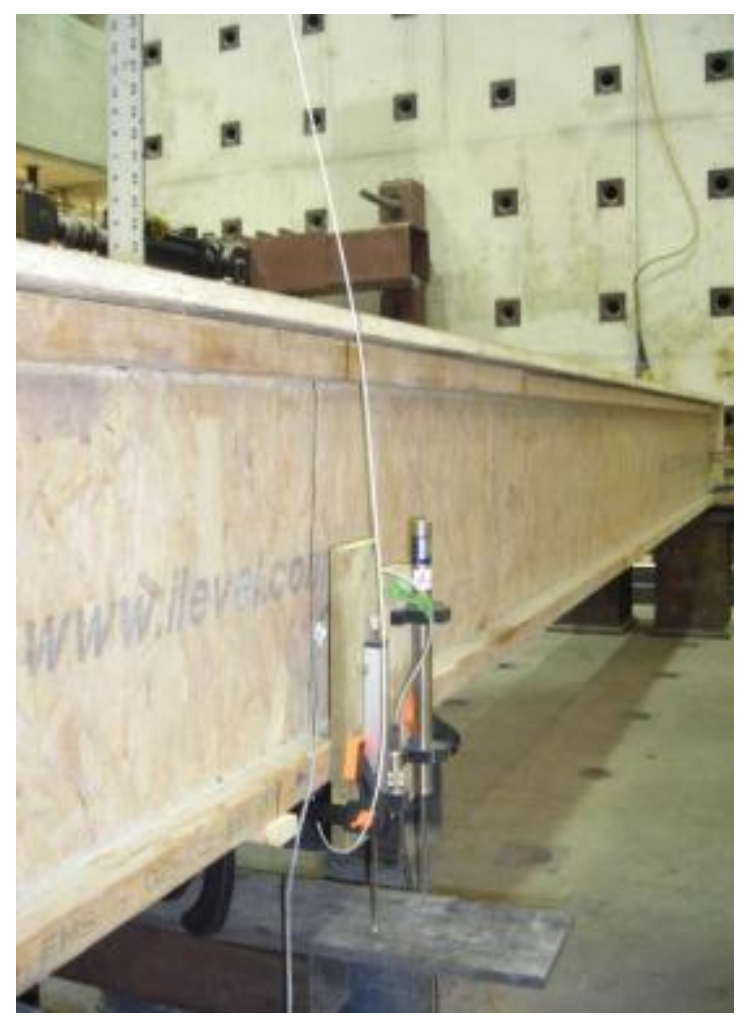

Figure 3.9: View of the LVDT attached to the wooden joist 


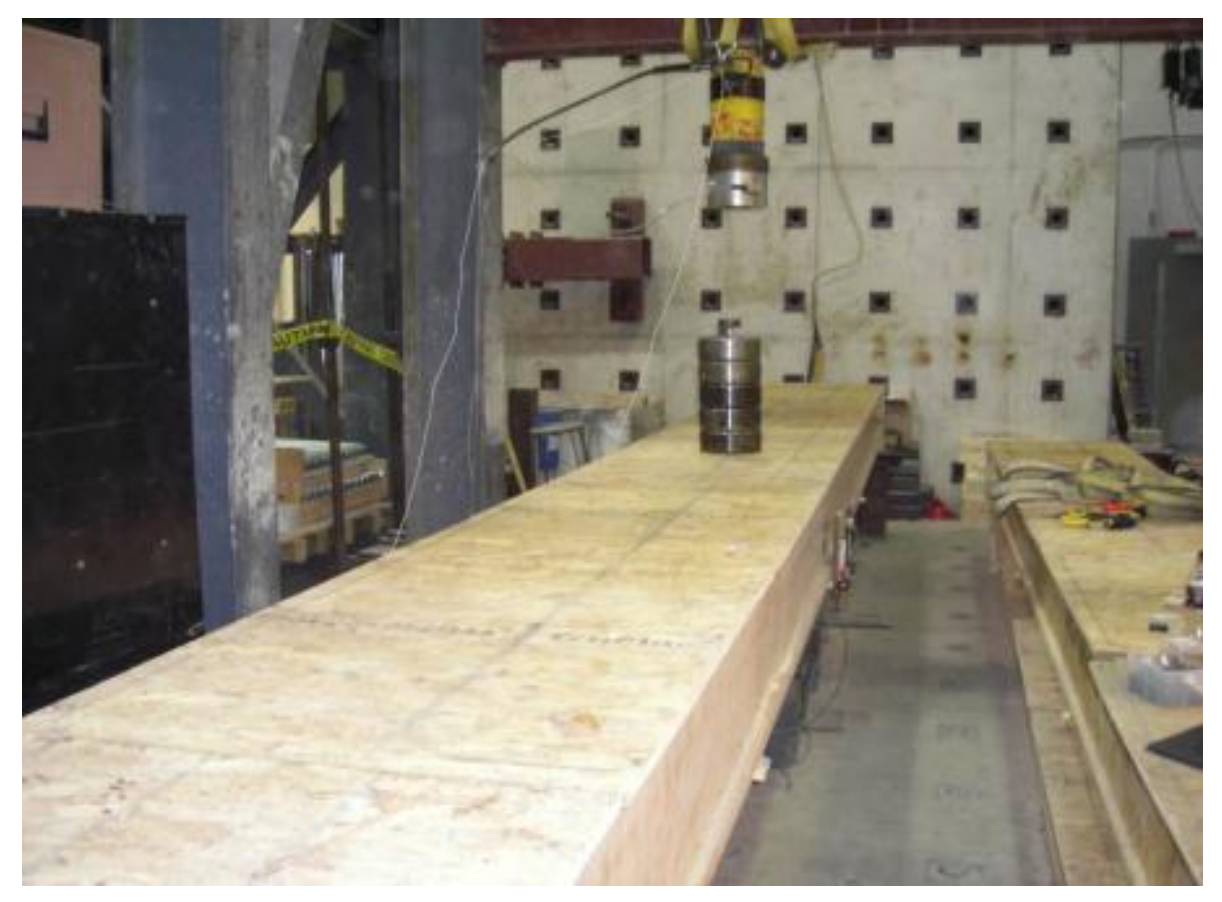

Figure 3.10: View of the wooden joist assembly with 1-kN load placed at the mid-span to measure static deflection

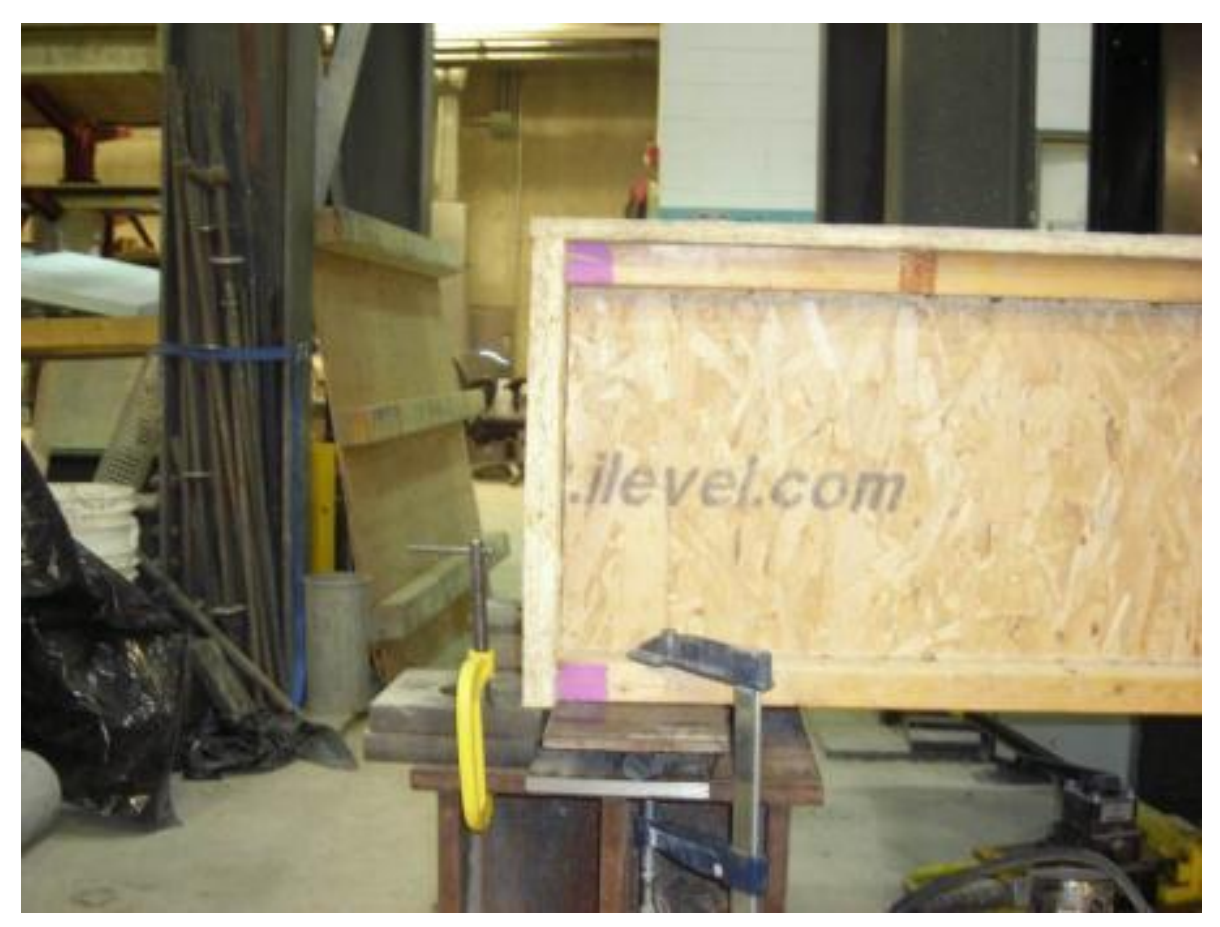

Figure 3.11: View of the clamping system at support of wooden I-joist assembly to avoid bouncy effect 


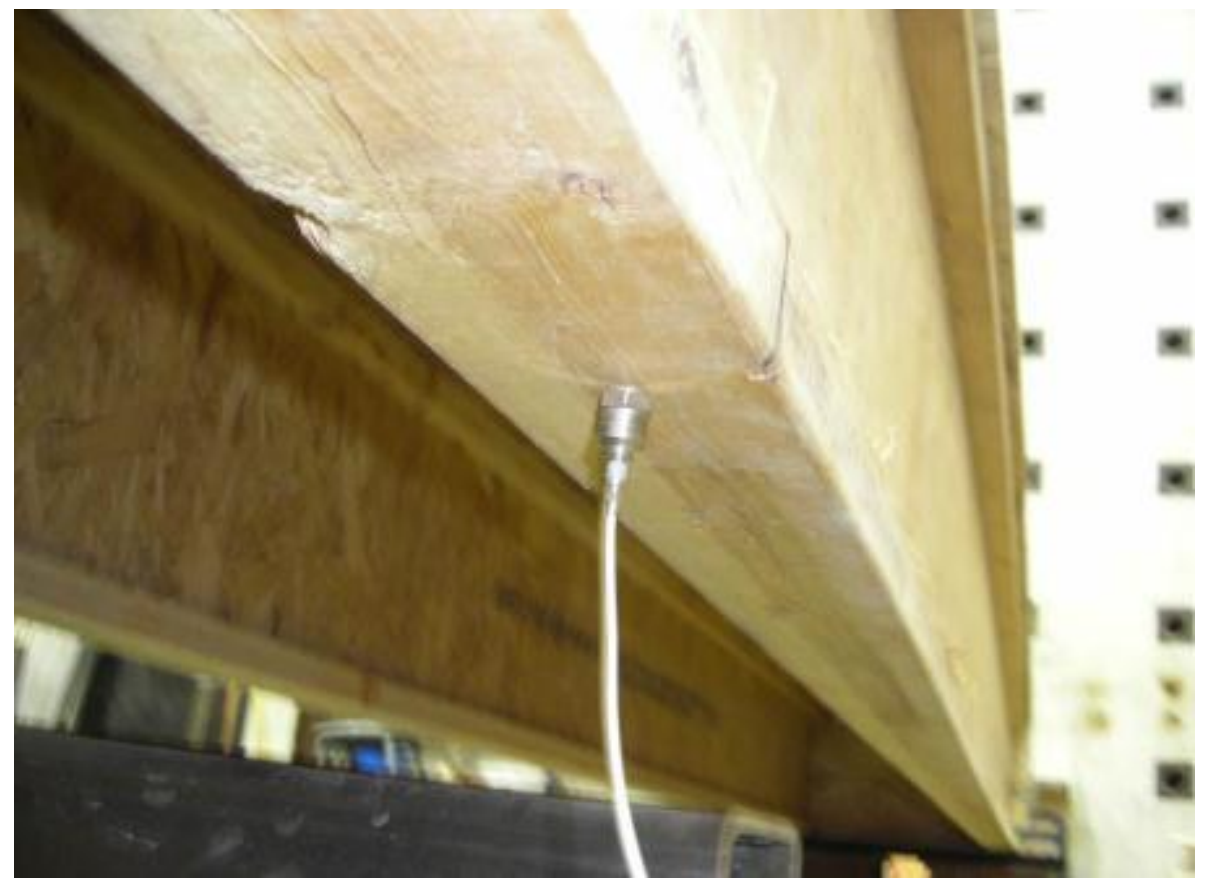

Figure 3.12: View of the accelerometer attached to the bottom flange of the wooden joist

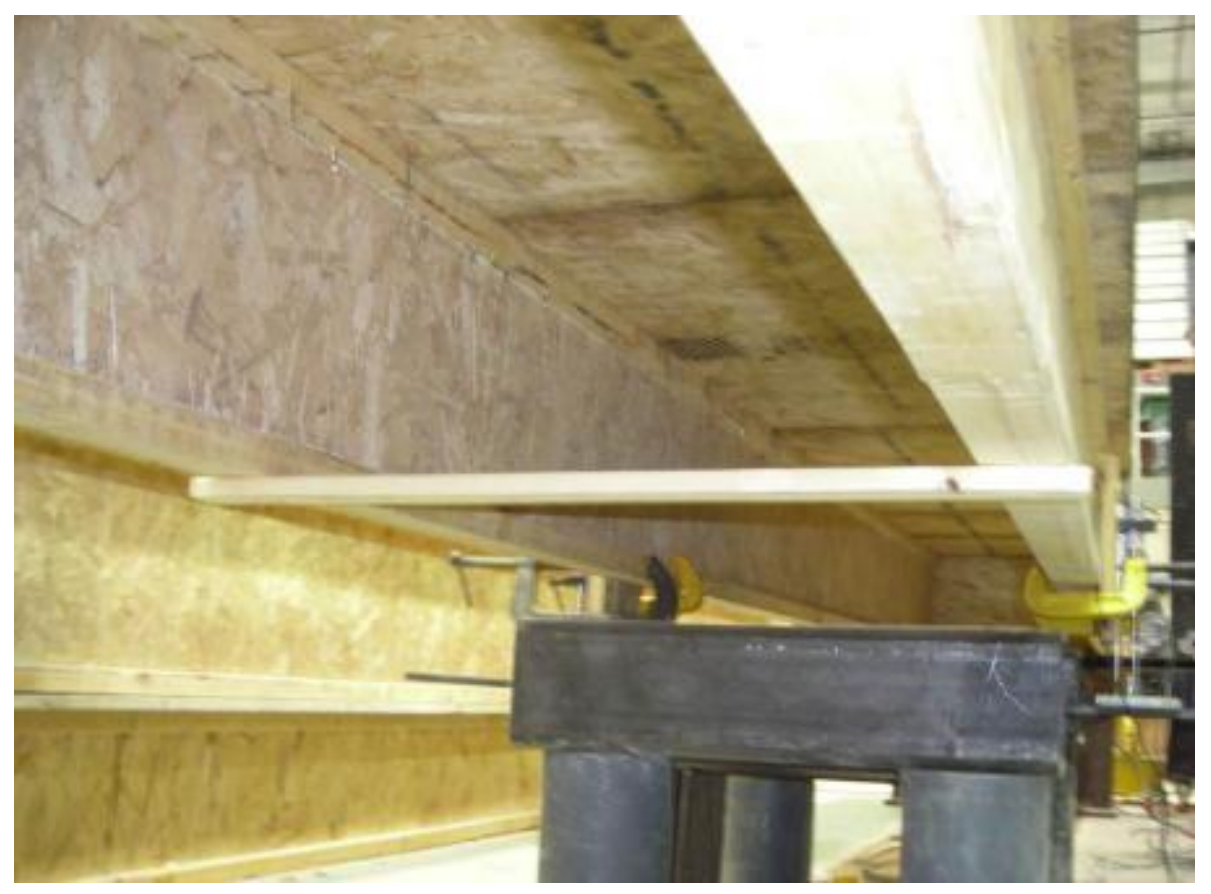

Figure 3.13: View of the transverse strap to brace the wooden joist at quarter point 


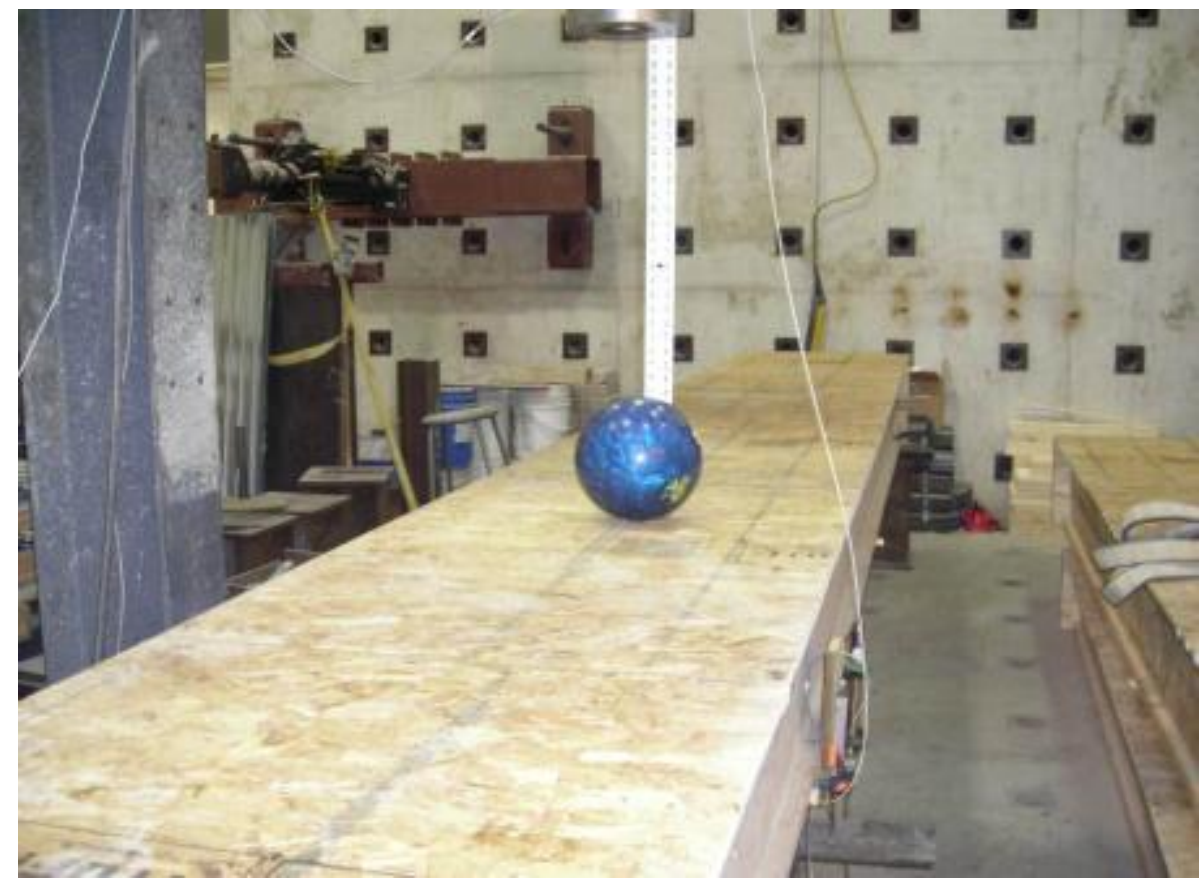

Figure 3.14: View of the bowling ball dropped over the wooden joist assembly from a height of $0.3 \mathrm{~m}$

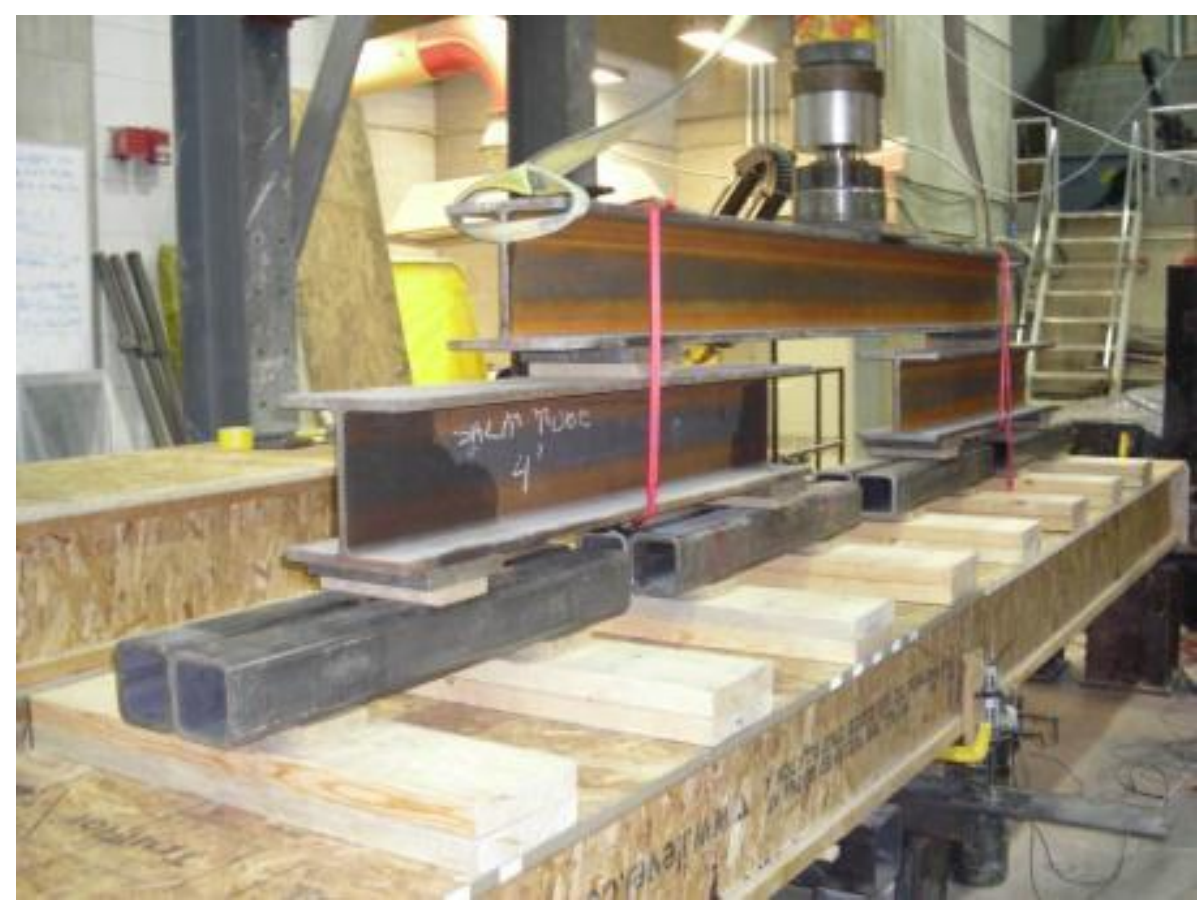

Figure 3.15: View of the uniformly distributed loading applied to the wooden floor joist assembly 


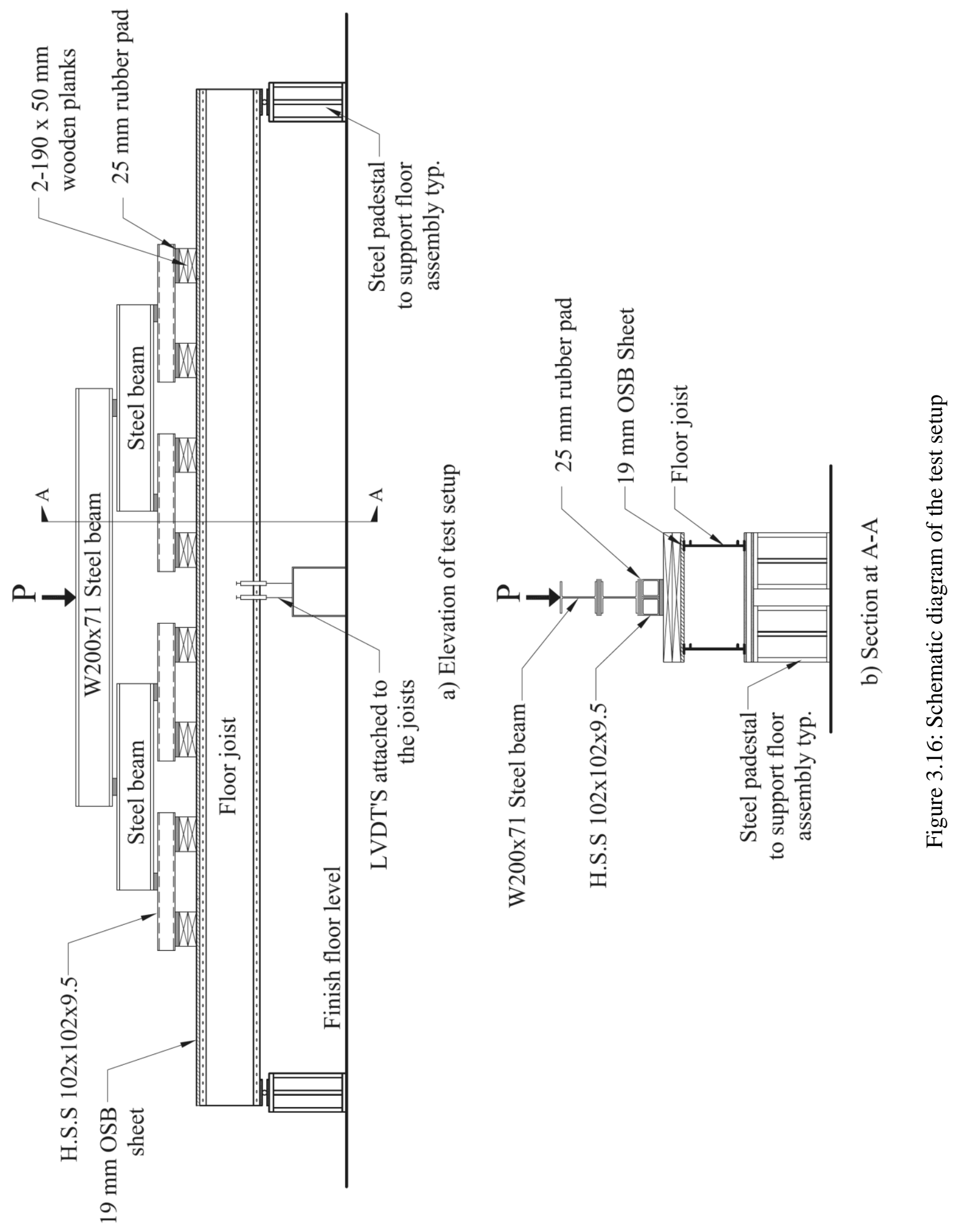




\subsection{EXPERIMENTAL WORK FOR ISPAN CFS JOIST ASSEMBLY}

The following sub-sections describe the test setup, static load tests, dynamic load tests and ultimate load tests conducted in this study on CFS joists.

\subsubsection{TEST SETUP}

Six iSPAN joists were selected in order to cover a large range of floor spans. These span lengths were taken as 3.50, 4.50, 5.00, 5.25, 6.10, and $7.95 \mathrm{~m}$, with joist depths of $241 \mathrm{~mm}$ (9.5 in), 302 $\mathrm{mm}$ (11.875 in), $356 \mathrm{~mm}$ (14 in) and $406 \mathrm{~mm}$ (16 in), respectively. The joist was cold-formed to form the shape shown in Figure 3.1(b) using sheet thicknesses of $1.22 \mathrm{~mm}$ (0.048 in) for the first 4 joists and $1.36 \mathrm{~mm}$ (0.054 in) for the last two joists designated as group C and D in Table 3.2. Table 3.2 summarizes joist geometry along with flexural stiffness, EI. The sizes of the studied joists were determined for bedrooms and living rooms in a residential construction based on deflection criterion of L/480 under specified live load of $1.44 \mathrm{kPa}\left(30 \mathrm{lb} / \mathrm{ft}^{2}\right)$ and $1.92 \mathrm{kPa}(40$ $\mathrm{lb} / \mathrm{ft}^{2}$ ), respectively. Figures 3.17 and 3.18 show schematic plan and elevation of the iSPAN joist assembly, respectively. While Figure 3.19 shows a schematic diagram of the assembly crosssection with bridging (i.e. transverse straps connection to the top flanges as well as the bottom flanges of the joists for stability reasons). The assembly was tested with bracing. The bracing was placed maximum at a distance of $2134 \mathrm{~mm}(7 \mathrm{ft})$ as depicted in Figure 3.26.

The floor assembly was constructed with two iSPAN cold-formed steel joists spaced at $600 \mathrm{~mm}$ (24 in.) on center, with $19 \mathrm{~mm}$ (3/4 in.) tongue-in-groove oriented strand board (OSB) sheathing as the sub-flooring. The OSB was fastened to the iSPAN floor joist using 10-24 x 1-1/2" Wafer self-drilling fasteners. Fasteners were placed at $150 \mathrm{~mm}$ (6 in.) on center at the ends of the joists and at $300 \mathrm{~mm}$ (12 in.) on center along the length of the joist. Figure 3.21 shows close-up view of the sheathing nail pattern described above. The joists ends were connected to a cold-formed steel track. Figures 3.25 and 3.27 show how the joist web was connected to the steel track at its ends.

Two types of support conditions were studied herein, namely: (i) balloon framing; and (ii) simply-supported framing. In the case of balloon framing shown in Figure 3.20, the floor ends were attached to the stud wall at each joist from the side. The floor joists spanned between the 
stud walls and were connected to the side of the wall studs through a clip or shear connector. Figure 3.28 shows view of the joist ends with balloon framing assembly. In this research, joist ends were attached to short wall studs of height $508 \mathrm{~mm}$ (20 in.) with 1/4"-14x1" self-drilling fasteners as shown in Figure 3.28. The shape of the balloon framing at the ends of the tested joists is also shown the joist view in Figure 3.18. The simply-supported floor framing was made by resting the joist ends on steel roller supports with joists ends shown in Figure 3.23. The detail of the simply-supported framing at the ends of the joist is depicted in Figure 3.25. In this case, the entire assembly was resting over a $152-\mathrm{mm}$ (6 in.) steel roller support placed on a four 458$\mathrm{mm}$ (18 in.) high steel pedestals as shown in Figure 3.33.

Two sets of iSPAN joist assemblies were considered in this study, namely: (i) joists without web holes; and (ii) joists with web holes. Tables 3.2 and 3.3 summarize joist configurations without and with web holes, respectively. Two web holes were located in each joist except 254x3500 $\mathrm{mm}$ joist which has only hole of 230-mm width, 100-mm height, with round corners to prevent stress concentration. The hole was located at $430 \mathrm{~mm}$ from the center line of the joist. In the $254 \times 4500 \mathrm{~mm}$ joist, the size of the hole was 230-mm width and 100-mm height, with round corners to prevent stress concentration. One hole was located at $75 \mathrm{~mm}$ from the center line of the joist while the other hole was located at the distance of $915 \mathrm{~mm}$ from the center line of the joist. In the other two joist assemblies, designated as $302 \times 5000 \mathrm{~mm}$, and $302 \times 5250 \mathrm{~mm}$ floor joists, the hole size was 317-mm width and 151-mm height, with round corners to prevent stress concentration. The hole was located at a distance of $451 \mathrm{~mm}$ on both side of the center line of the joist. Views of these opening can be seen in Figures 3.18, 3.23, 3.38 and 3.39.

Three types of tests were performed on each sample, namely: (i) static test with a 1-kN force applied at the center of the twin joists; (ii) dynamic Test by dropping a bowling ball to produce the desired excitation in the assembly; and (iii) ultimate strength test. The following sub-sections provide an explanation for each test. 


\subsubsection{STATIC POINT LOAD TEST}

Static load tests were conducted to determine the maximum deflection under 1-kN (255 lb) concentrated load to correlate the results with those obtained from the formula given in the ATC Design Guide for the calculation of deflection under 1-kN load includes the effective flexural stiffness $\left(E I_{\text {eff }}\right)$ of the system. Figure 3.29 shows view of the LVDT used to measure joist deflection. The static test was performed by placing a concentrated load of $1-\mathrm{kN}$ at the middle of two joists and at center of joists along the length of the joists. The load was in the form of steel plates as shown in Figure 3.30 for joists with balloon framing and Figure 3.33 for joists with simply-supported framing. The resulting deflections were measured by four LVDTs, with two LVDTs placed under each joist. The average of four readings was compared to the deflection value obtained from the available code equations. It should be noted that each test was repeated three times for greater accuracy. Figure 3.37 and 3.38 show view of the ISPAN joist with web holes when subjected to $1-\mathrm{kN}$ concentrated load at the mid-span location to measure the corresponding static deflection of the floor assembly with balloon framing and simply-supported framing, respectively.

\subsubsection{DYNAMIC LOADING TEST}

Dynamic tests were performed to determine vibration characteristics of iSPAN I-joist floor assemblies. The floor was excited by dropping a $5.5 \mathrm{~kg}(12.32 \mathrm{lb})$ bowling ball from $0.305-\mathrm{m}$ (1 $\mathrm{ft}$.) height over the joist assembly at the mid-span location. The acceleration of the tested joists was measured through two accelerometers which were attached to the bottom flange of each joist at the mid-span of each joist. Figure 3.31 shows view of the accelerometer attached to the bottom flange of the wood I-joist, while Figures 3.32 and 3.35 show views of the bowling ball dropped from a height of $0.3 \mathrm{~m}$ over the joist assembly with balloon framing and simply-supported framing, respectively. Each test was repeated three times for better accuracy. The accelerationtime history recorded by the accelerometers was then used to extract the flexural frequencies and damping ratios of each floor assembly. The Seismosignal (seismosoft.com) software was used to convert the acceleration-time history to frequency domain to obtain the frequency values and corresponding mode shapes. 


\subsubsection{ULTIMATE STRENGTH TEST}

The static failure test was conducted on floor assemblies to determine their flexural behavior and ultimate load carrying capacities. A uniformly-distributed load was applied to the top surface of the floor through a loading tree shown in Figures 3.36 and 3.39 for joist assembly without and with web holes, respectively. To prevent premature buckling of web or flange of the joists, wide timber planks were used to distribute the loads over the joist length. A 222-kN (50,000 lb) capacity hydraulic jack was used to apply the load over the loading tree that distributed the load uniformly over the joists. It should be noted that the weights of the loading system to transfer the jacking load to simulated uniform loading over the twin-joists were $6.68,6.68,6.68,6.68,6.68$, and $12.71 \mathrm{kN}$ for joist spans of 3.5, 4.5, 5, 5.25, 6.10 and $7.95 \mathrm{~m}$, respectively. The jacking load was applied in increments so that the deformation of the assembly can be visually observed. However, joist deflections and applied load were recorded with rate of 1 reading per second till failure. 


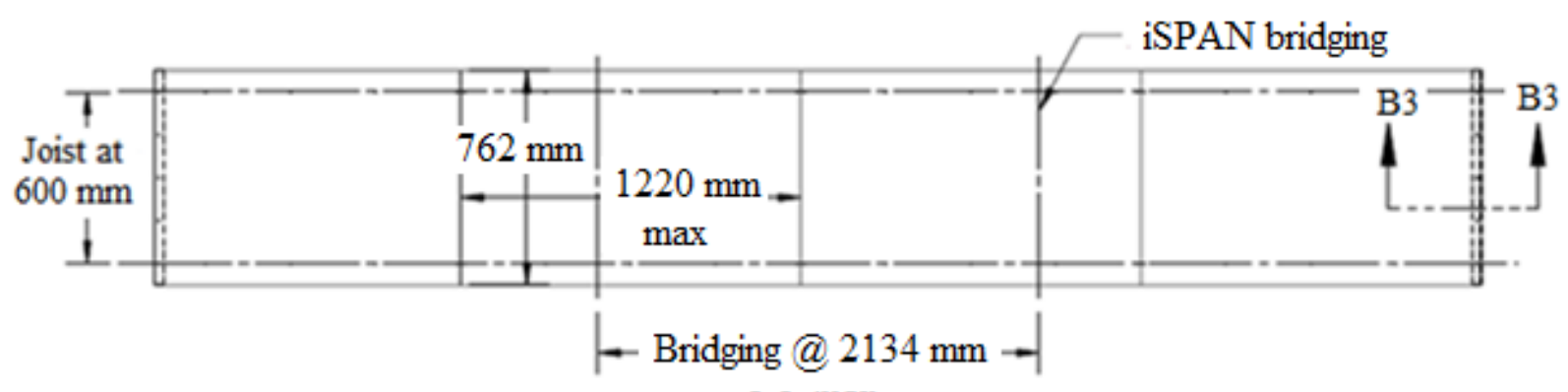
o.c. max.

Figure 3.17: Plan view of the iSPAN floor joist assembly with balloon framing

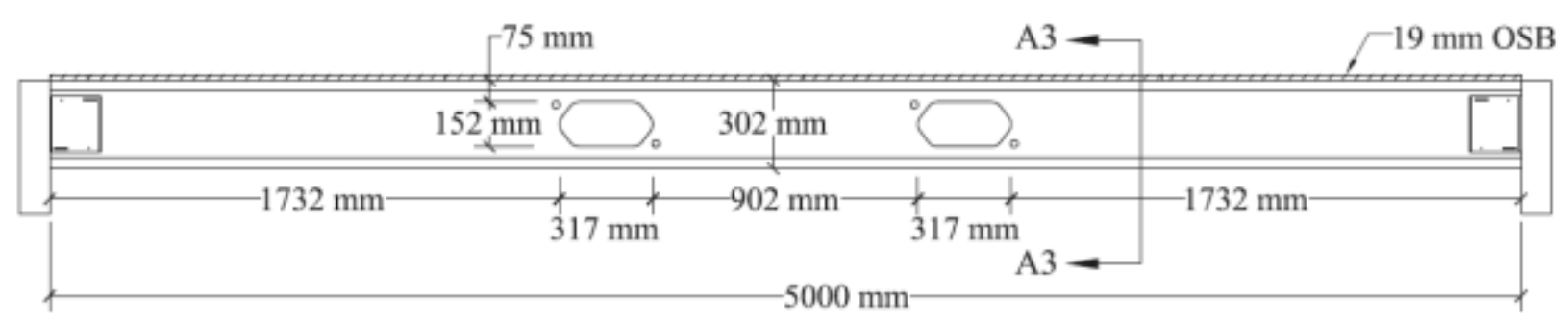

Figure 3.18: Elevation of iSPAN floor joist assembly with balloon framing

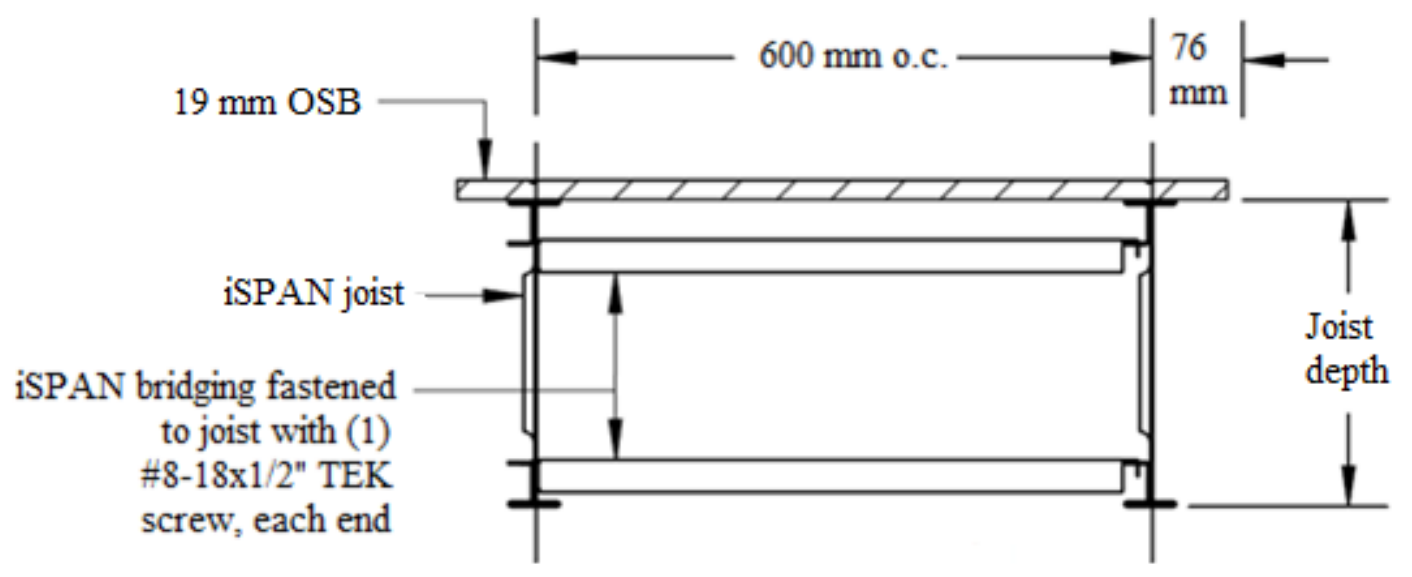

Figure 3.19: Section A3-A3 of the iSPAN floor joist assembly with balloon framing 


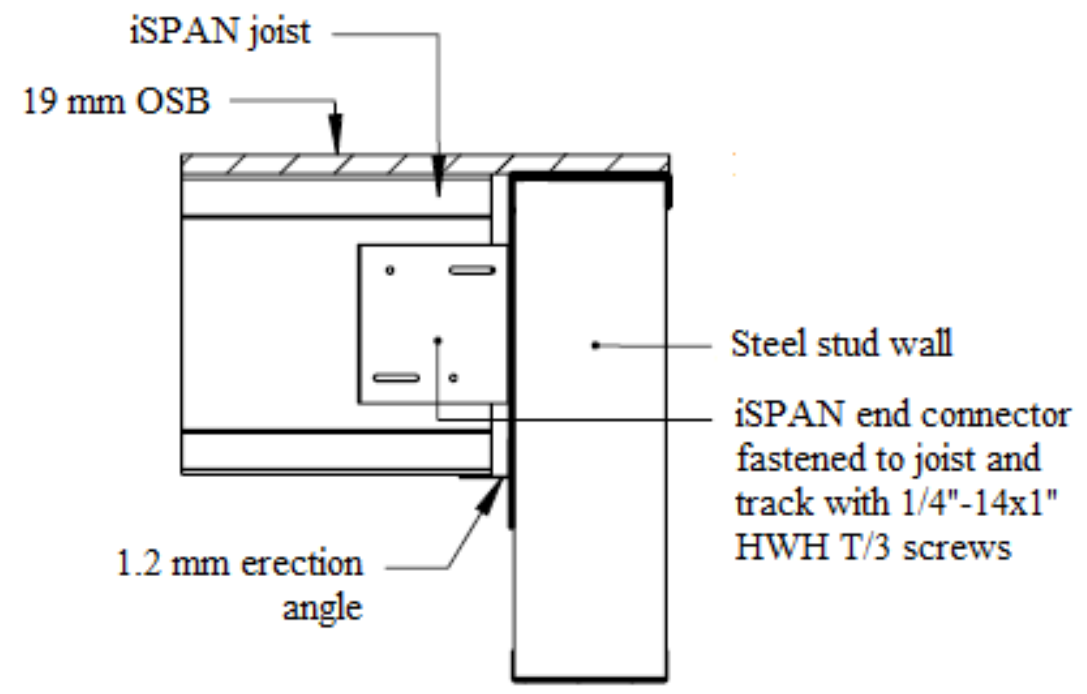

Figure 3.20: Section B3-B3 of the balloon framing of the iSPAN floor joist assembly

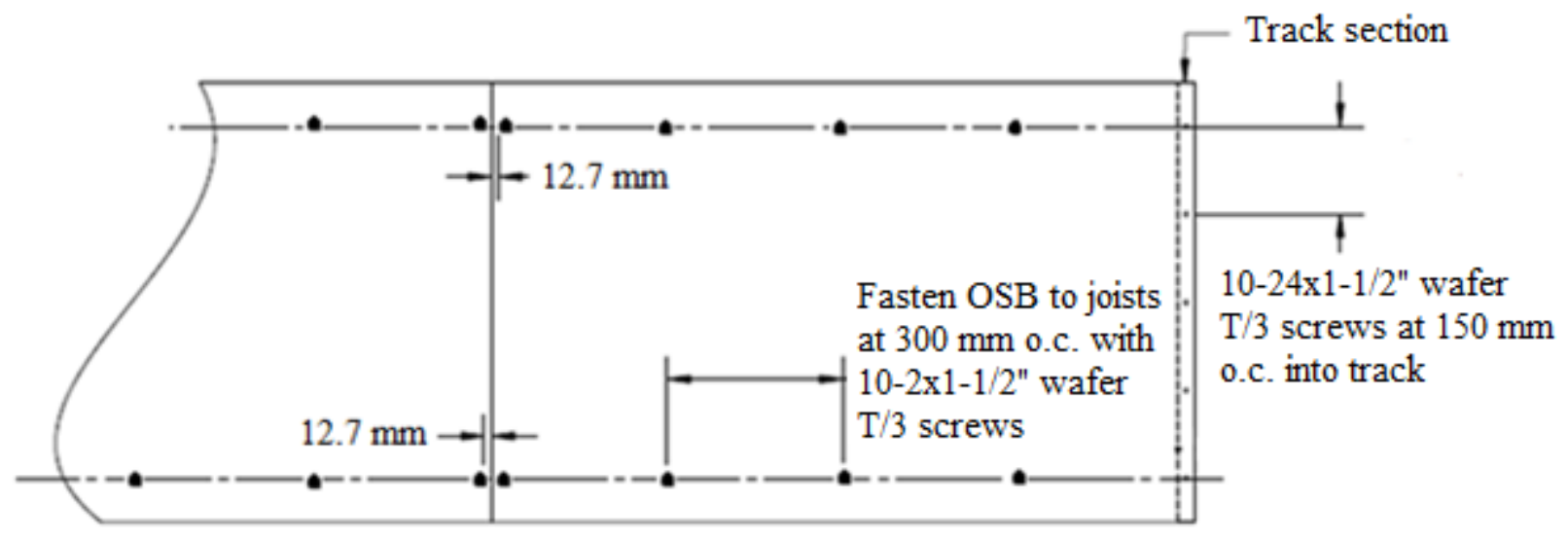

Figure 3.21: Plan view of sheathing nail pattern of the iSPAN floor joist assembly with balloon framing 


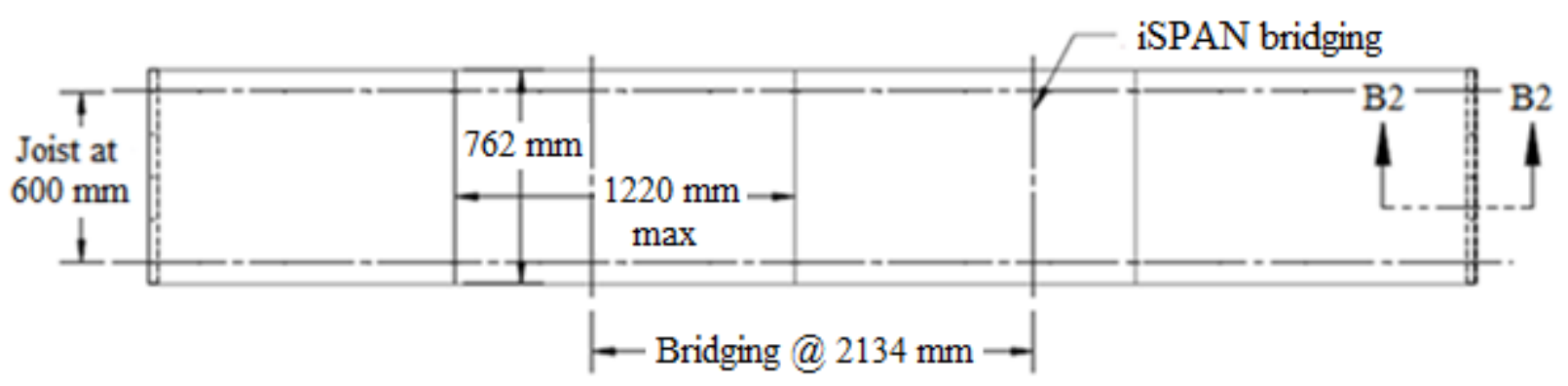

o.c. $\max$

Figure 3.22: Plan view of the iSPAN floor joist assembly with simply-supported framing

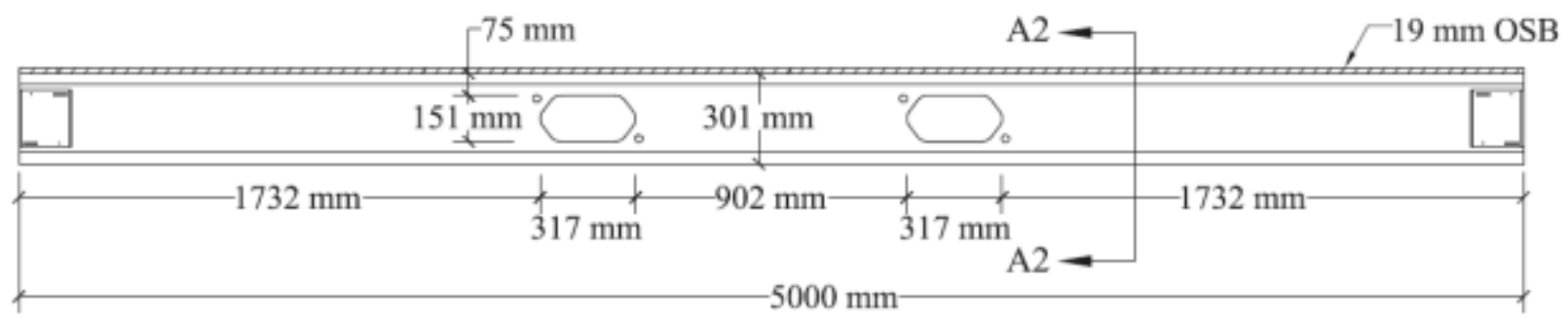

Figure 3.23: Elevation of iSPAN floor joist assembly with simply-supported framing

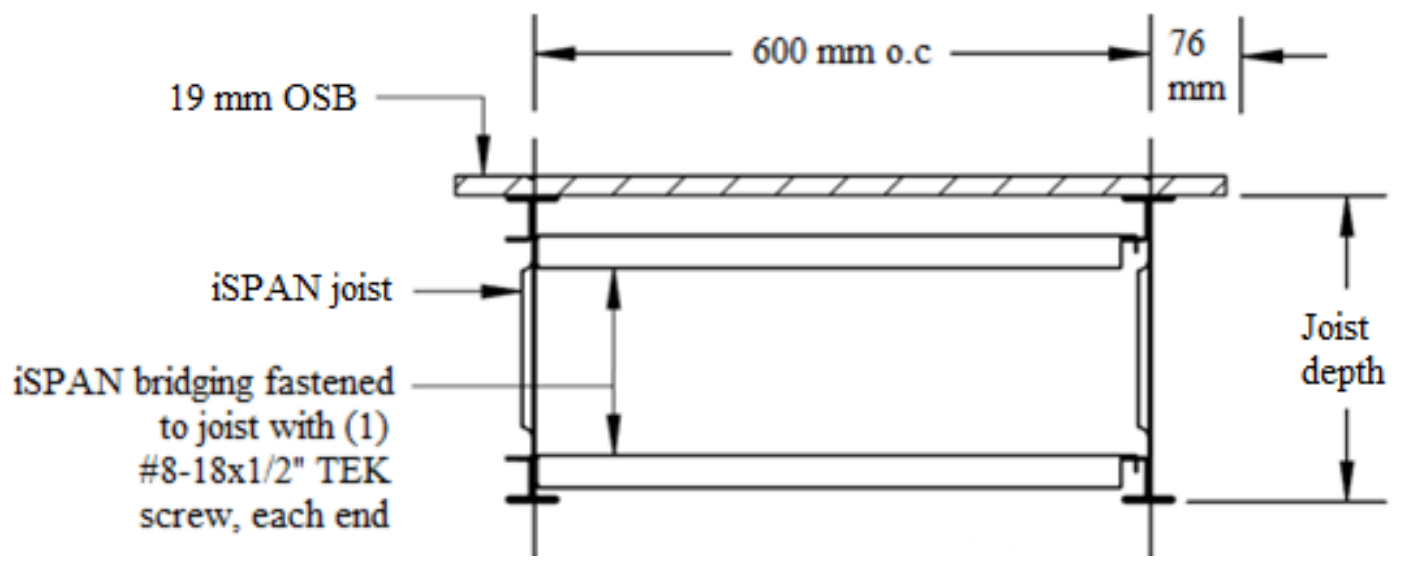

Figure 3.24: Section A2-A2 of the iSPAN floor joist assembly with simply-supported framing 


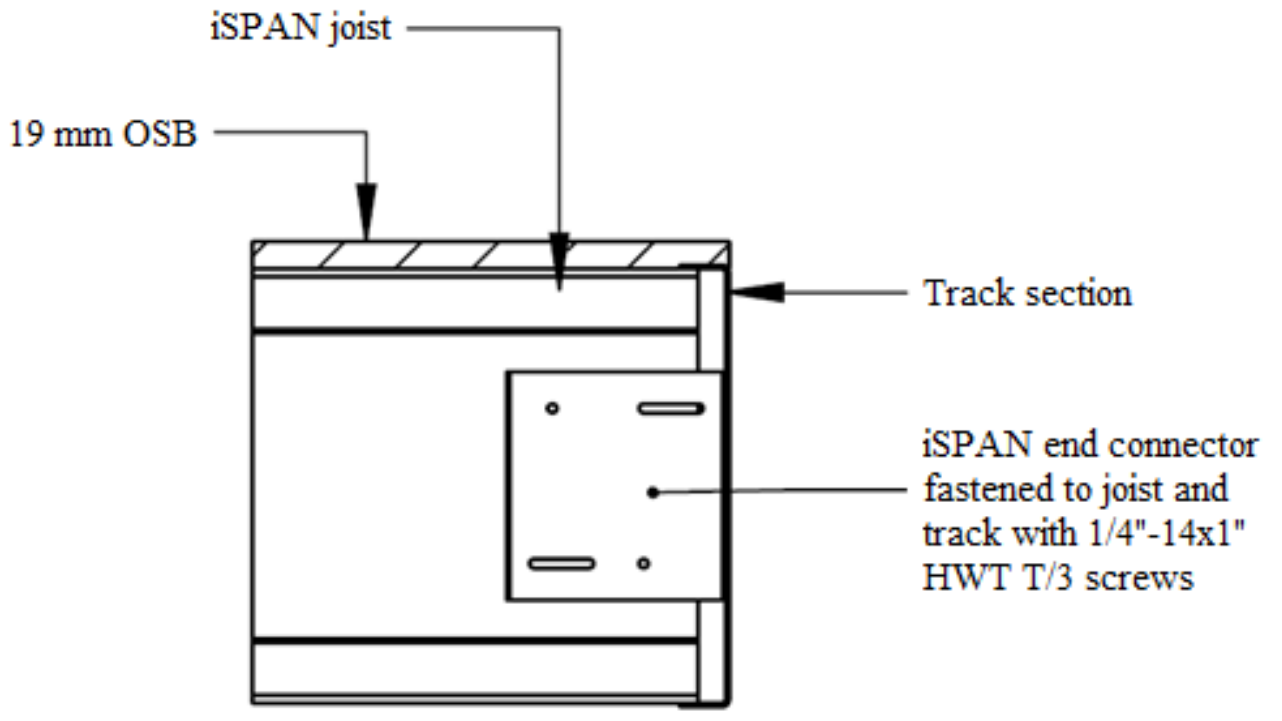

Figure 3.25: Section B2-B2 of the iSPAN floor joist assembly with simply-supported framing 


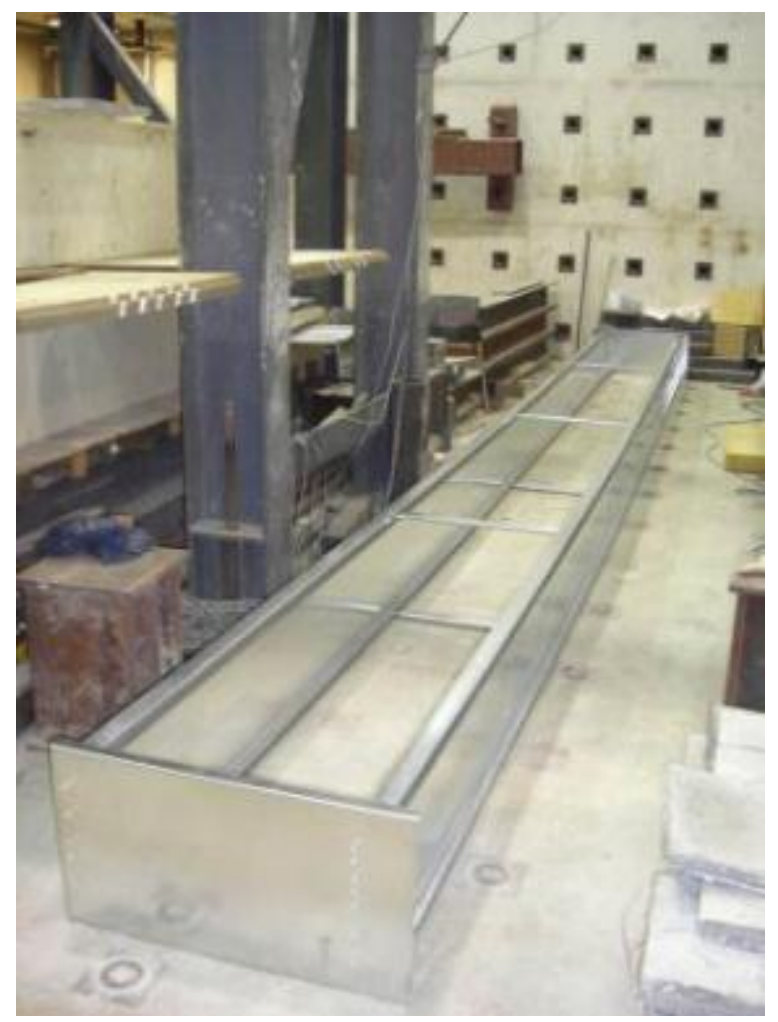

Figure 3.26: View of the bracing attached to the iSPAN joists at the quarter points of the iSPAN joists (note that the joists are upside down in this photo)

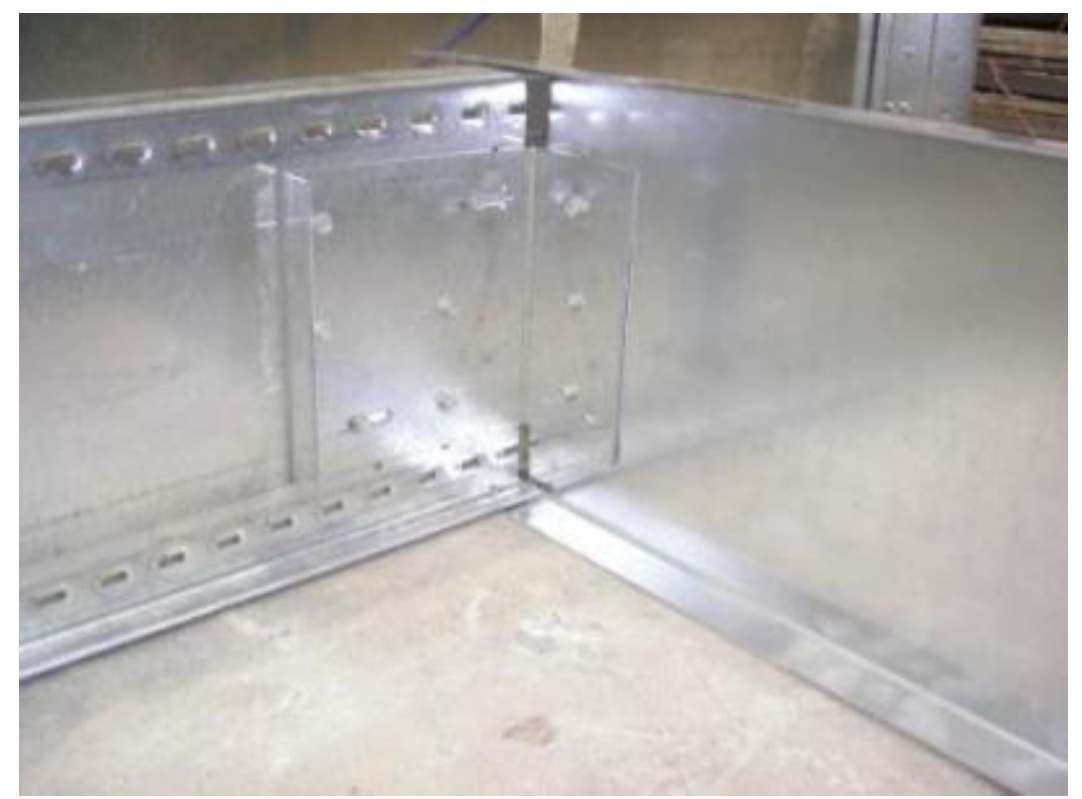

Figure 3.27: View of the clip angle attached to the joist and floor track of the simply-supported framing 


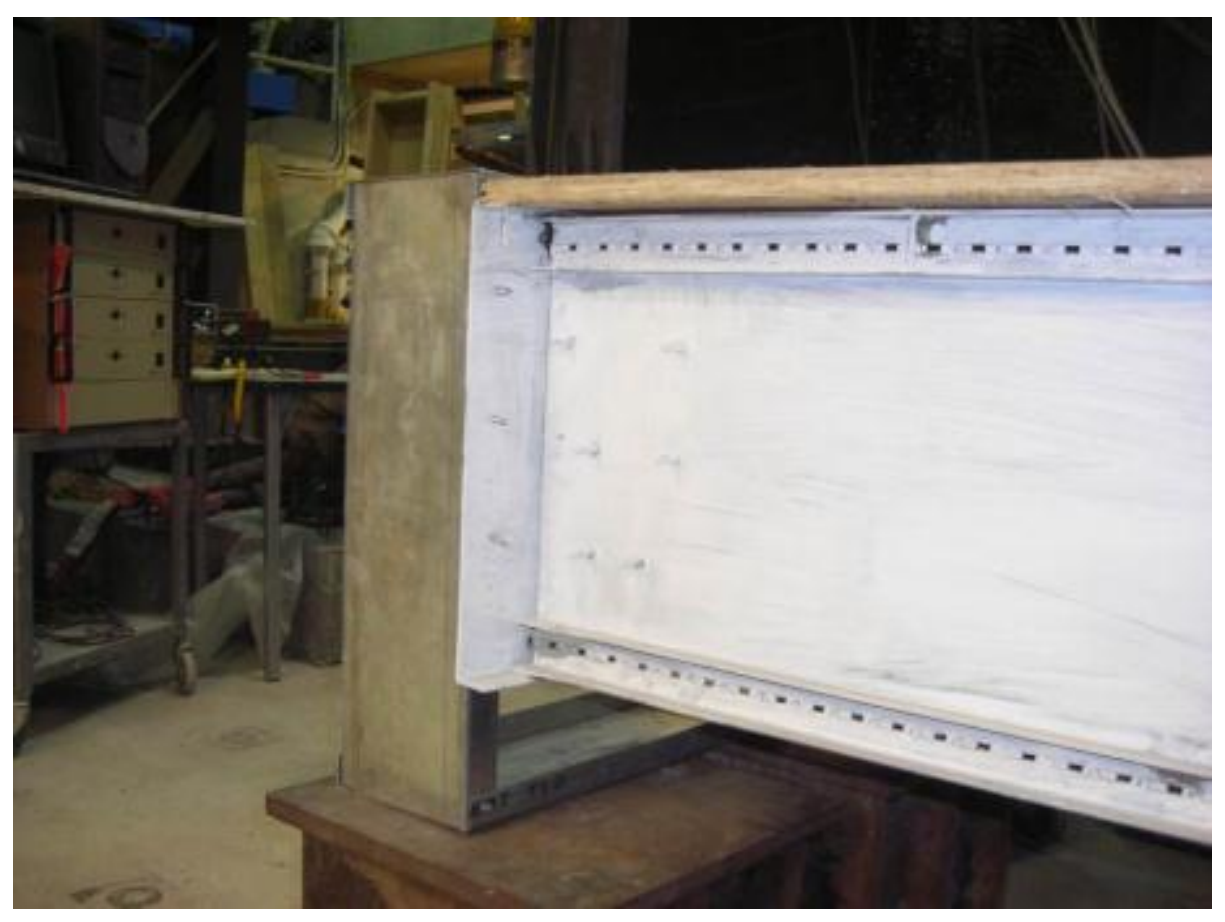

Figure 3.28: View of the iSPAN floor joist with balloon framing

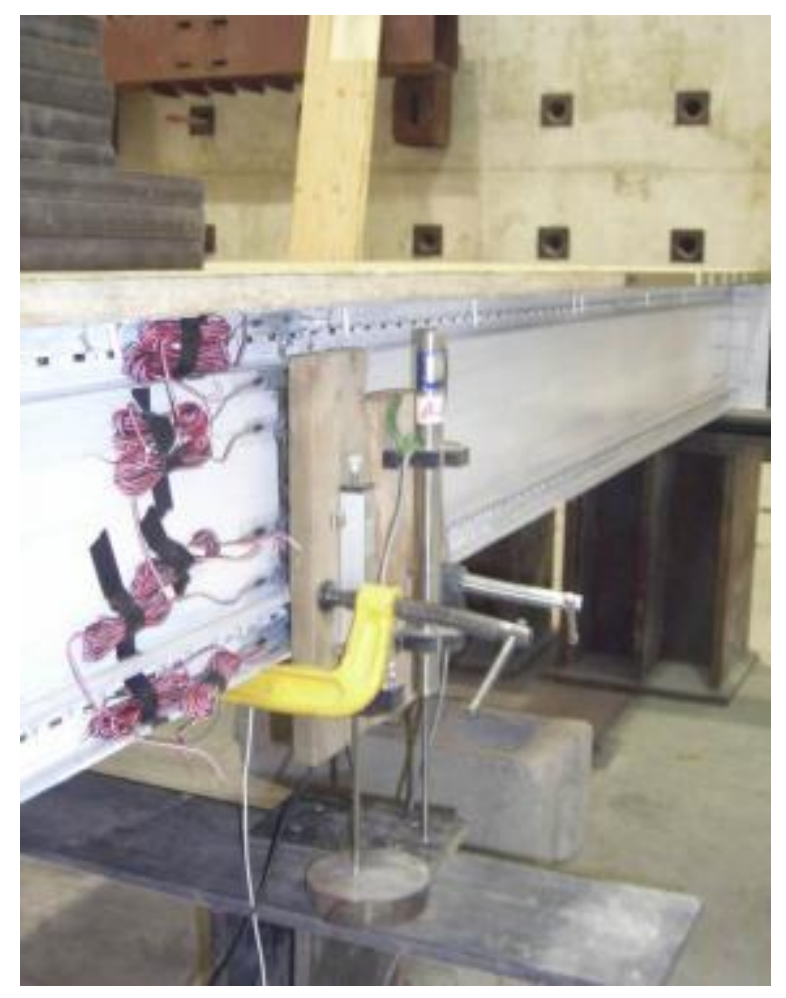

Figure 3.29: View of the LVDT attached to the iSPAN floor joist 


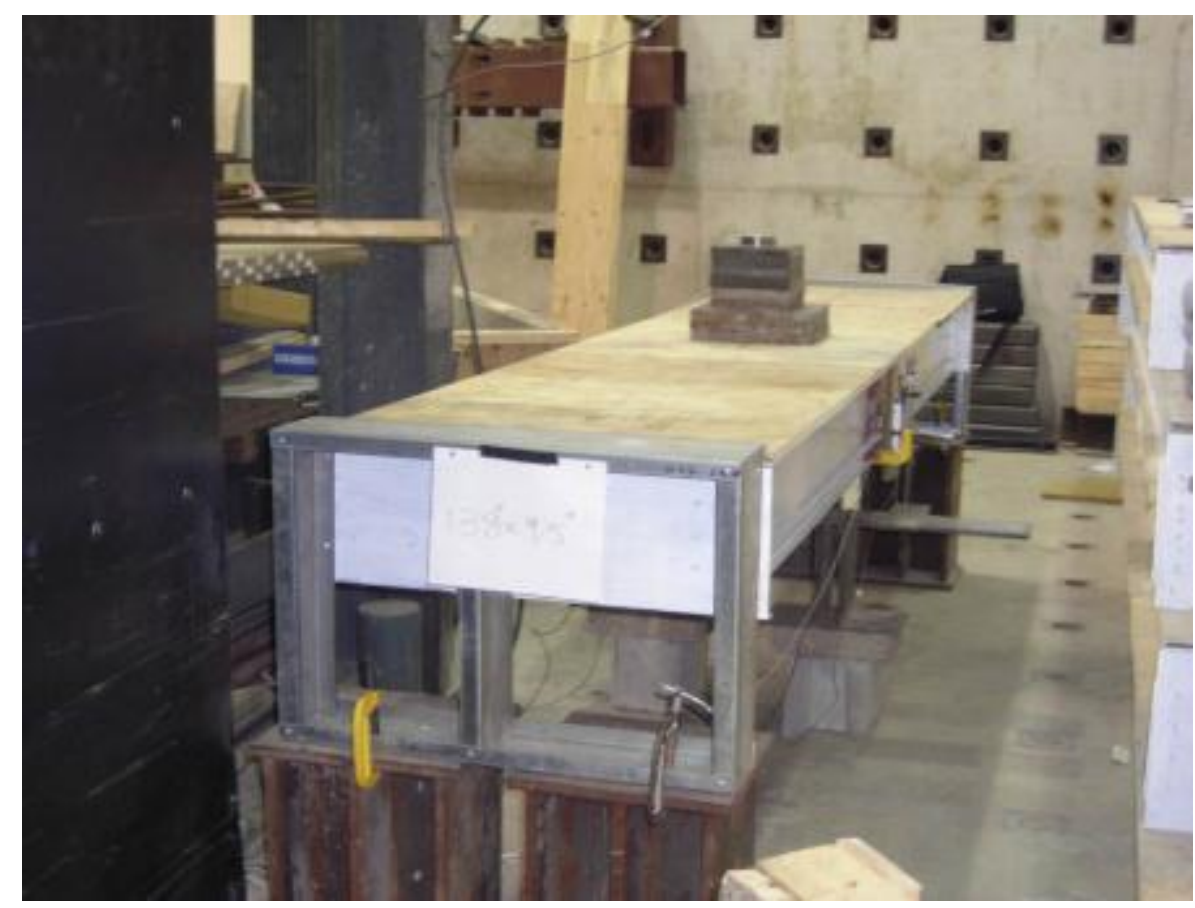

Figure 3.30: View of the iSPAN joist assembly with 1-kN load placed at the mid-span to measure deflection in case of balloon framing

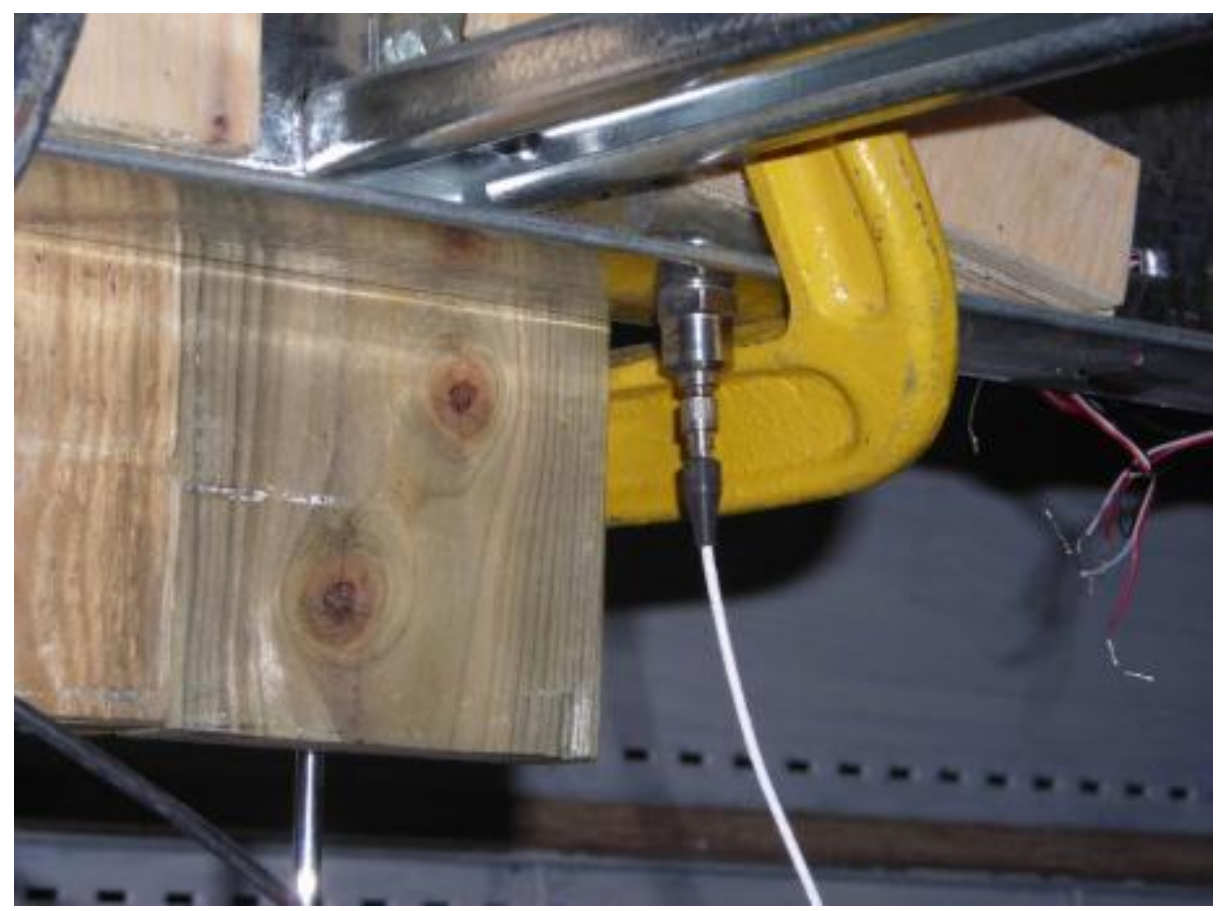

Figure 3.31: View of the accelerometer attached to the bottom flange of the iSPAN joist 


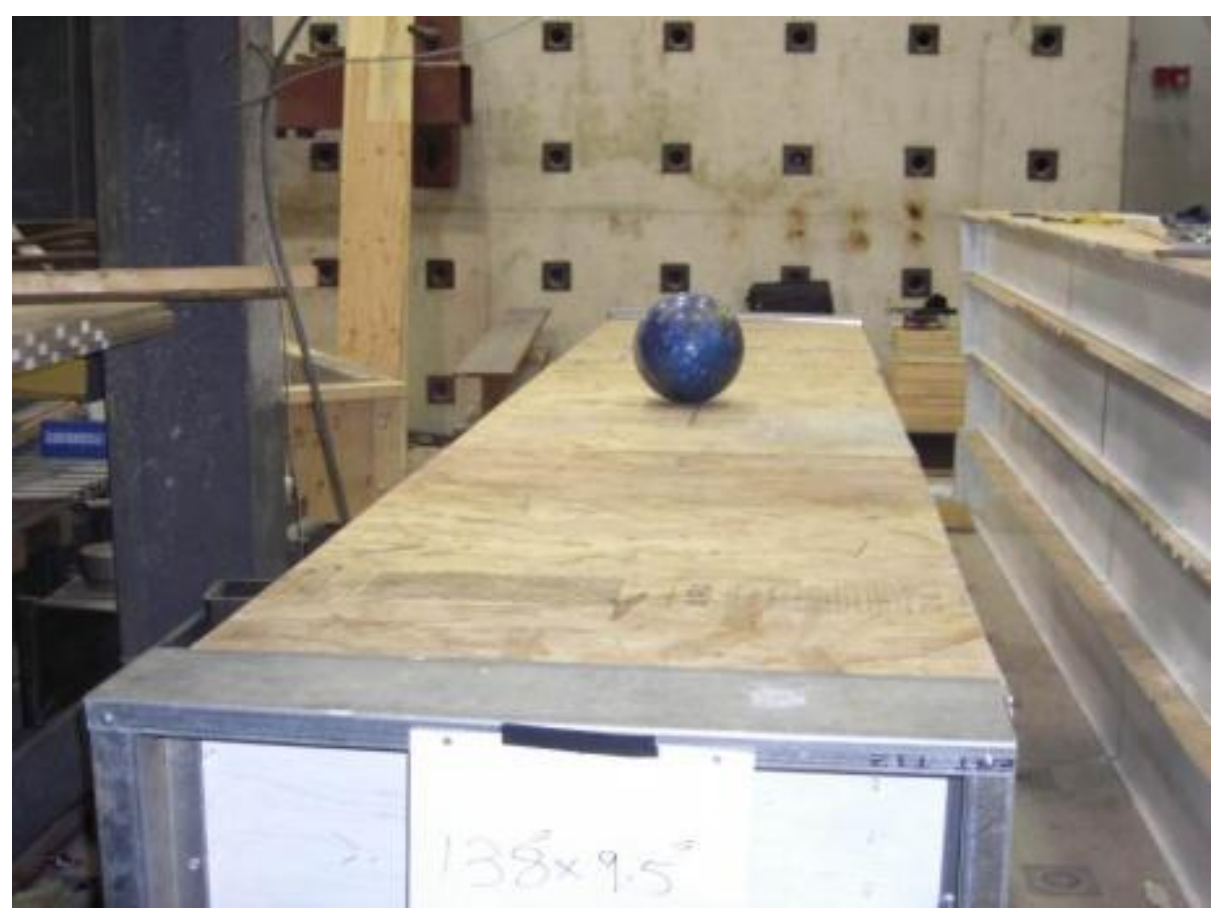

Figure 3.32: View of the bowling ball dropped from a height of $0.3 \mathrm{~m}$ over the iSPAN joist assembly with balloon framing

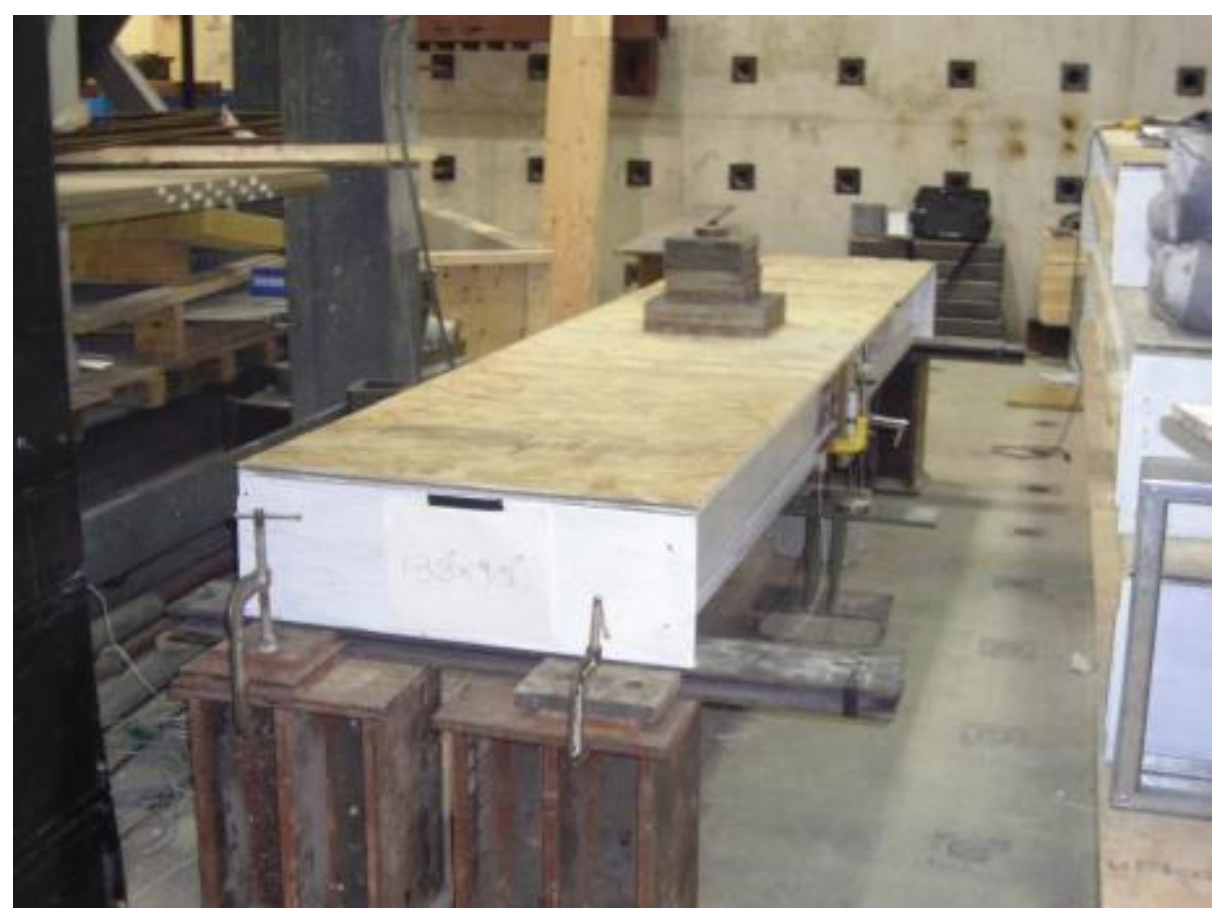

Figure 3.33: View of the iSPAN joist with 1-kN load placed at mid-span to measure static deflection of the assembly with simply-supported framing 


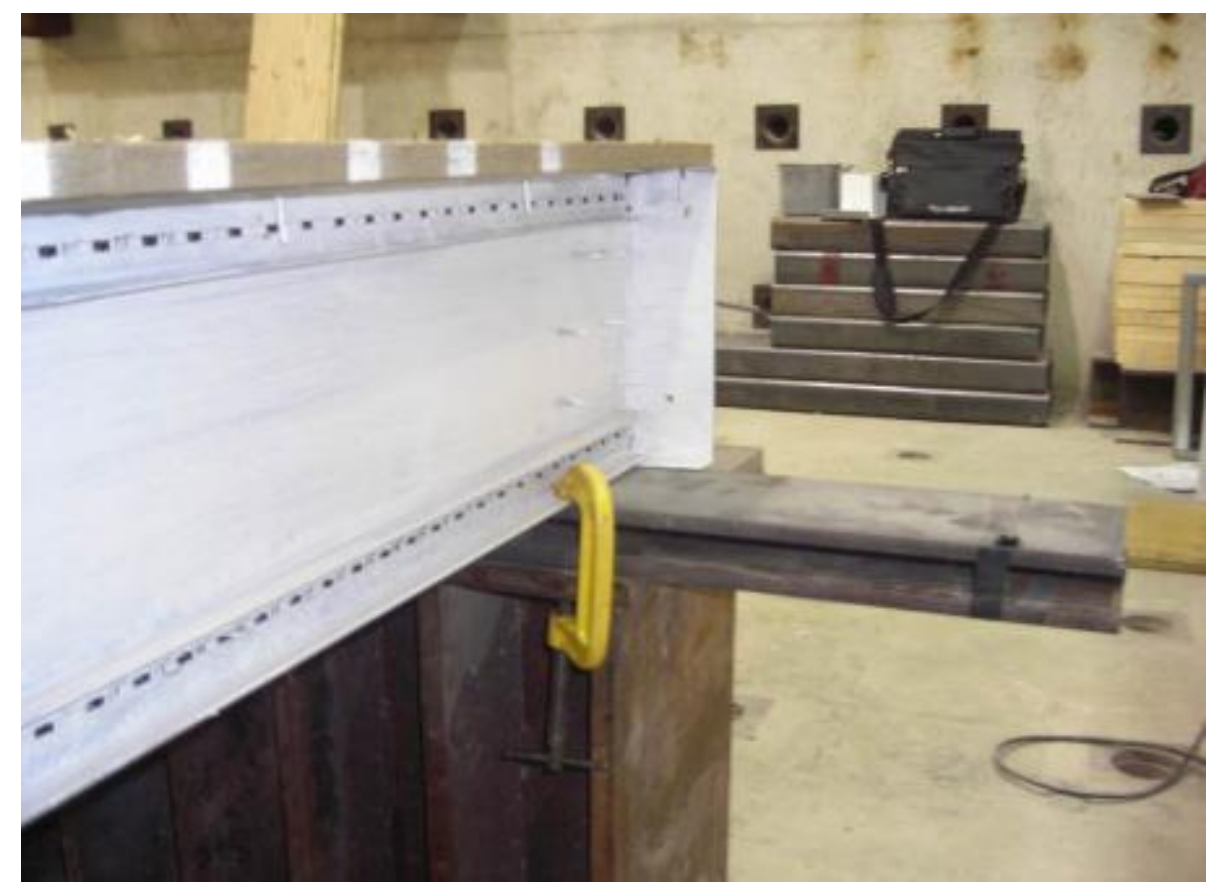

Figure 3.34: View of the clamping system at support to avoid bouncy effect on iSPAN joist assembly with simply-supported framing

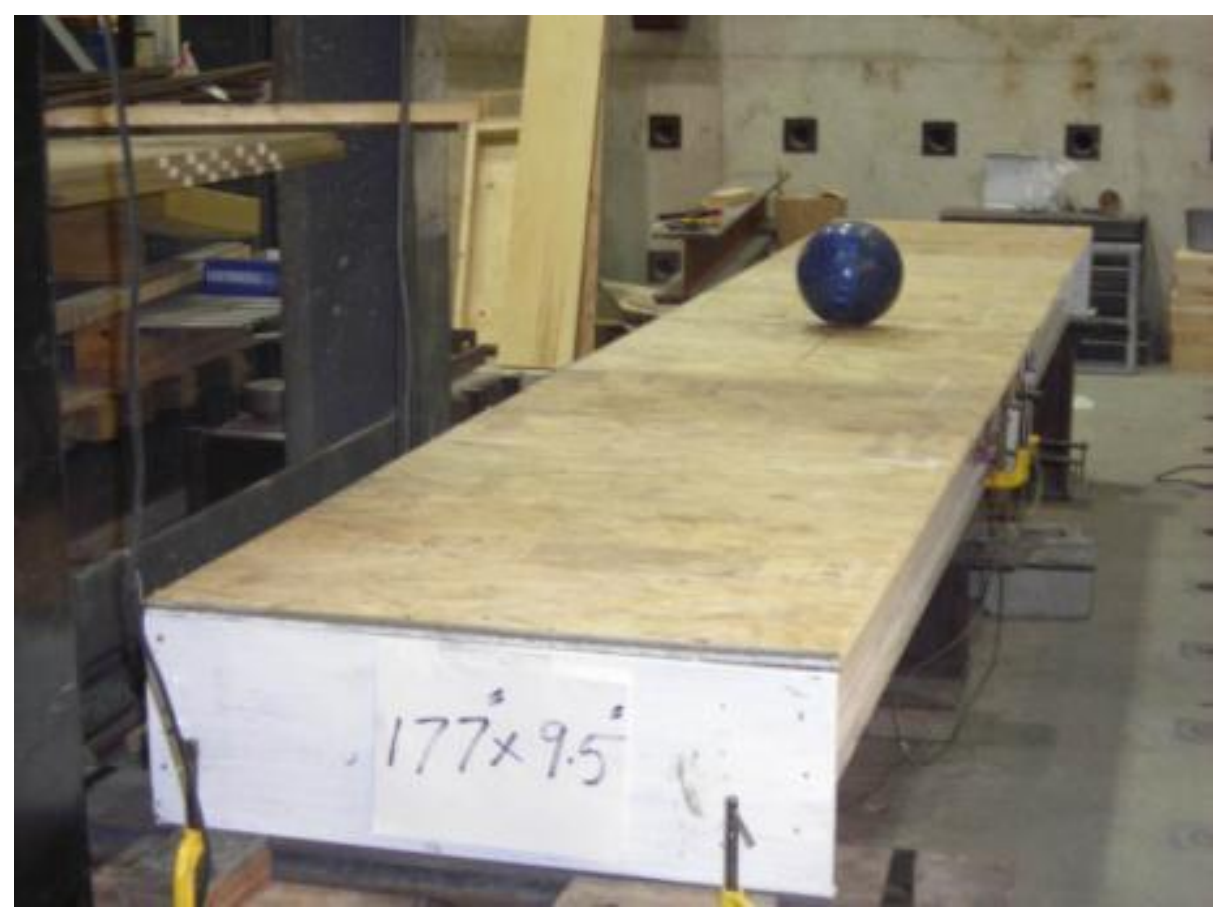

Figure 3.35: View of the bowling ball dropped from a height of $0.3 \mathrm{~m}$ over the iSPAN joist assembly with simply-supported framing 


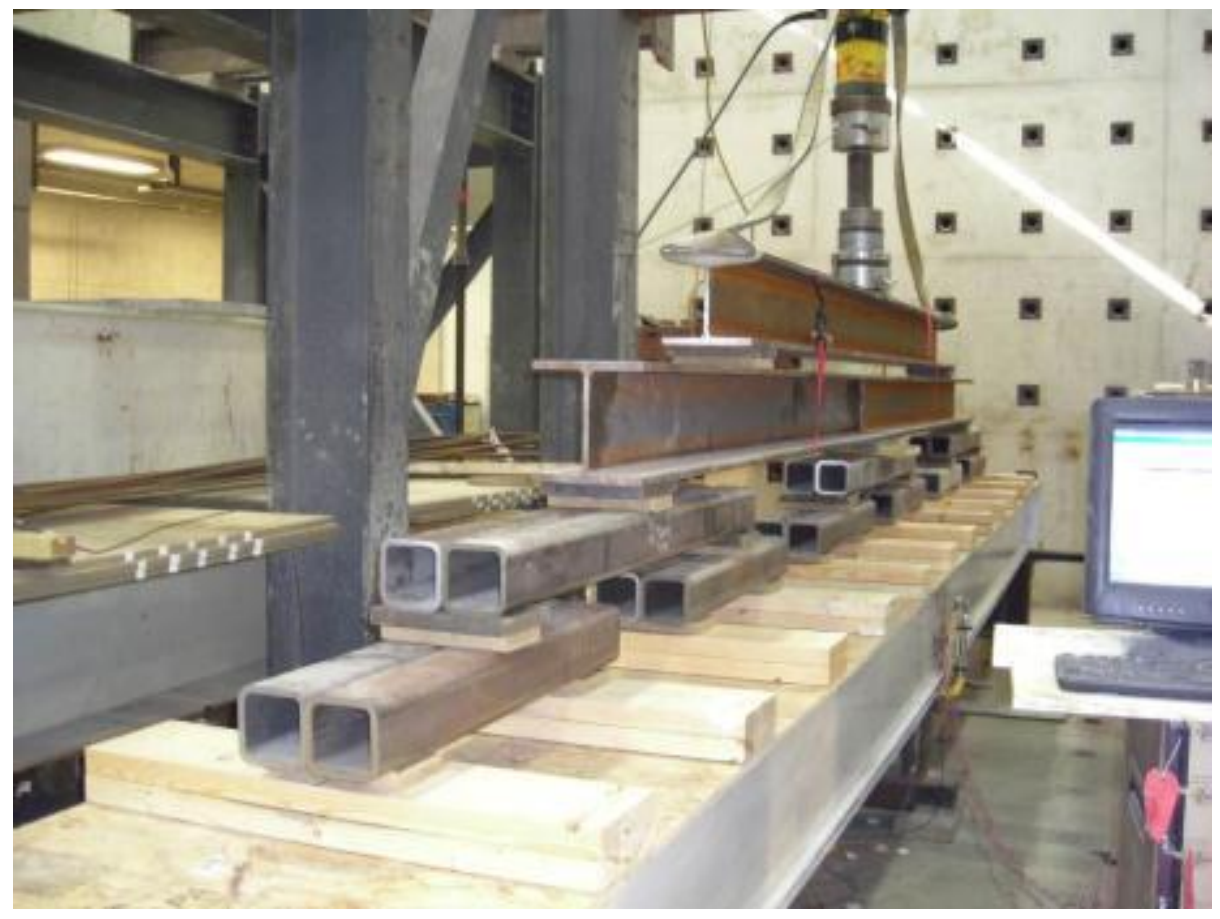

Fig. 3.36: View of the uniformly distributed loading applied to the iSPAN floor joist assembly

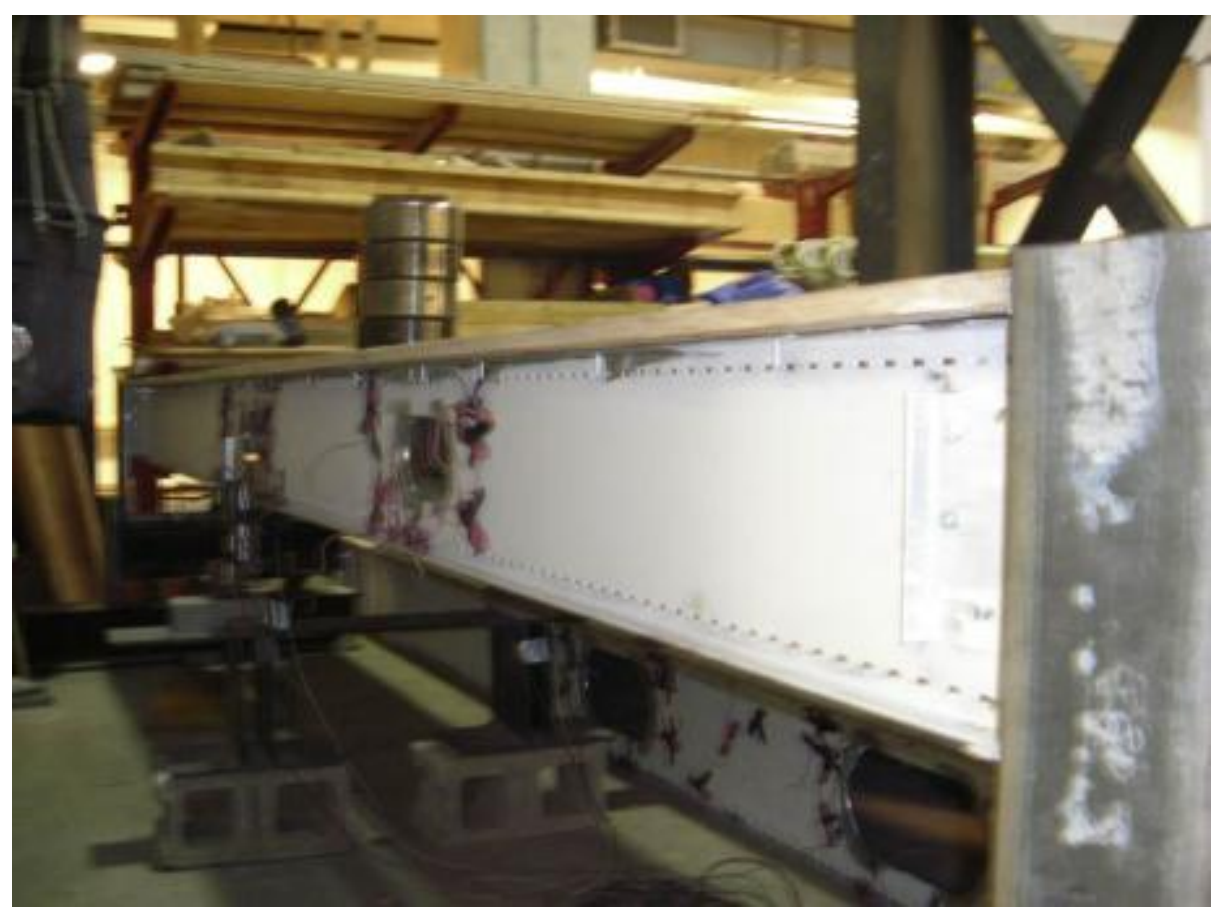

Figure 3.37: View of the iSPAN joist with web holes on which a $1-\mathrm{kN}$ load was placed at midspan to measure static deflection considering balloon framing 


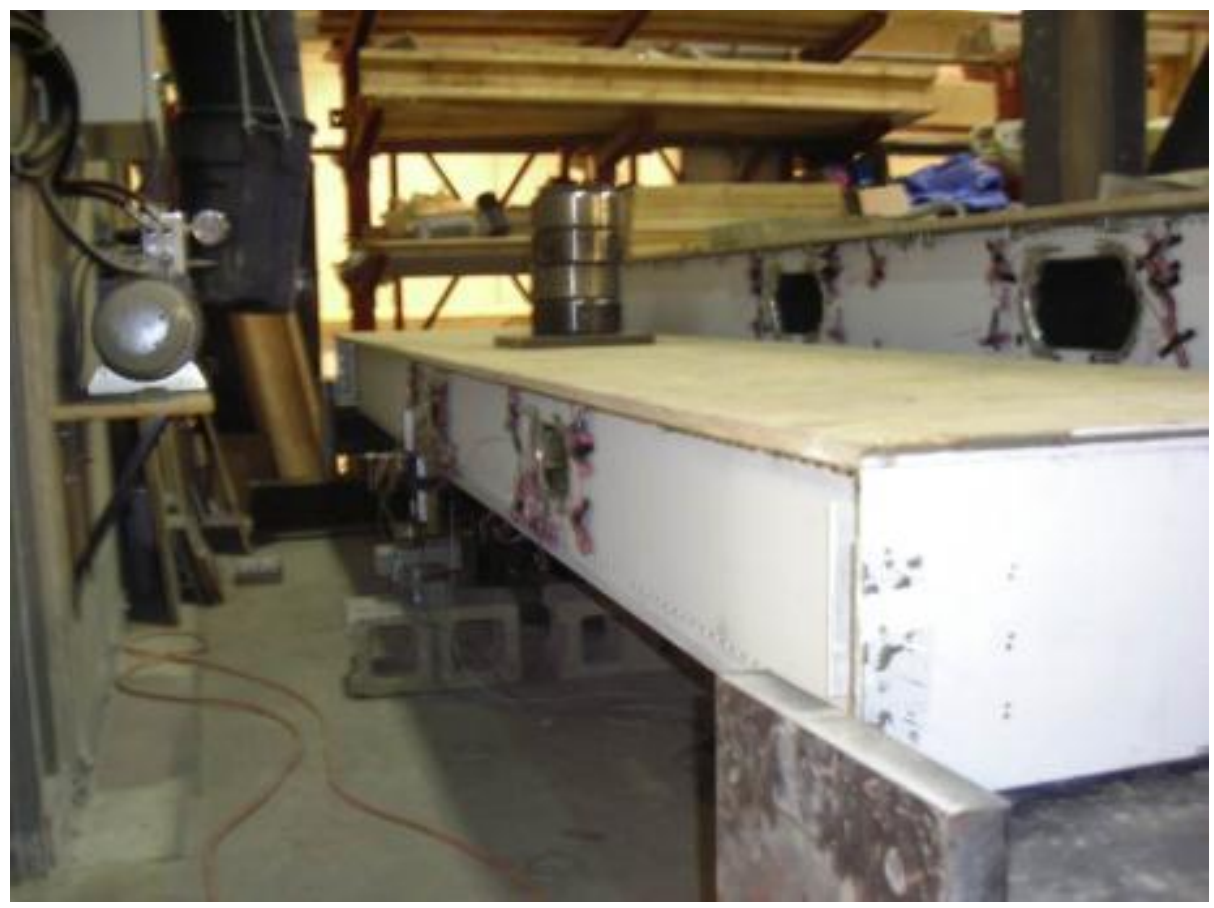

Figure 3.38: View of the iSPAN joist with web holes on which a 1-kN load was placed at midspan to measure static deflection considering simply-supported framing

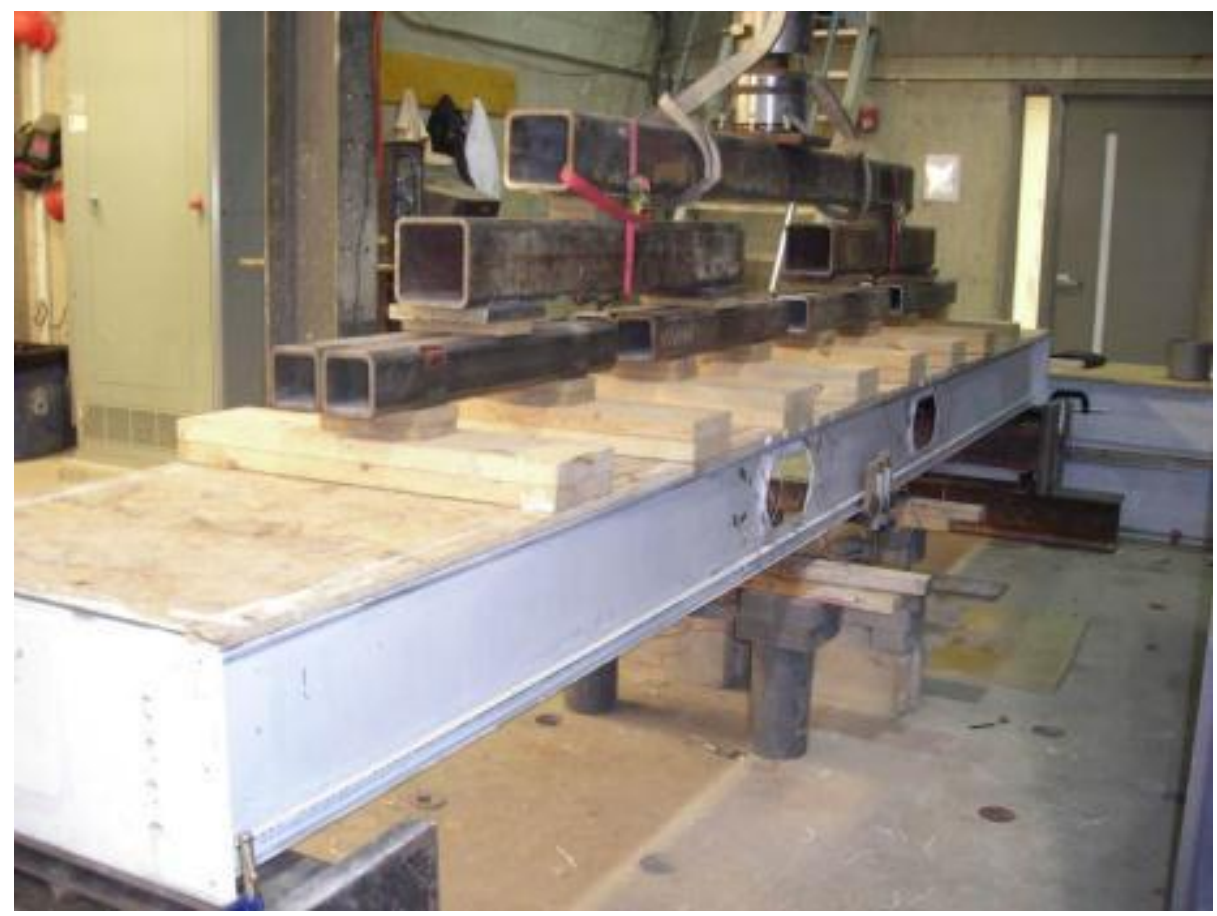

Fig. 3.39: View of the uniformly distributed loading applied to the iSPAN floor joist assembly with web holes 


\subsection{SITE TESTING}

Site tests were performed to measure the vibration response of iSPAN floor joists, given the presence of the whole framing plan of the joist in comparison with the twin-joist assembly considered in the laboratory testing. Four houses located in Brantford, Ontario, were considered for testing to determine their dynamic characteristics. Figures 3.40, 3.41, 3.42, and 3.43 show schematic diagrams of the framing plan of the tested floors in the houses located in sites 1, 2, 3 and 4, respectively. The floors were built with iSPAN cold-formed steel joists with geometries and floor flexural stiffness summarized in Table 3.4. All the joists had web holes as depicted in Figures 3.48, 3.49, 3.53, and 3.56 for test sites, 1, 2, 3 and 4, respectively. The description of the houses is summarized in the following subsections. The site tests included a static load test and a dynamic test (i.e. ball-drop test) as described in the following subsections.

\subsubsection{TEST SITE 1}

The house was under construction. The floor was unfinished and only the $19 \mathrm{~mm}$ (3/4 in.) OSB floor was glued and fastened to the iSPAN joists with utility holes oriented in the web at 1220 $\mathrm{mm}(4 \mathrm{ft})$ on center. The floor had a single span having span length of $5.20 \mathrm{~m} \mathrm{(17} \mathrm{ft)} \mathrm{and} \mathrm{was}$ supported by $241-\mathrm{mm}$ (9.5 in.) deep iSPAN section and web thickness of $1.22 \mathrm{~mm}$ (0.048 in.). Joists were spaced at $488 \mathrm{~mm}$ (19.2 in.) on center. One end of joist was resting on concrete wall while the other end was resting on stud wall. The floor was tested twice, one time without bracing and second time when bracing was attached to joists. One row of strapping was installed at the mid-span of the floor system before testing the floor with braced joists. The strapping was made of cold-rolled channels, $50-\mathrm{mm}$ ( 2 in) wide and 1.52-mm (0.059 in) thick, with a 6.4-mm (0.25 in) lip length. The layout and dimensions for the floor are show in Figure 3.40.

\subsubsection{TEST SITE 2}

The second house was under construction. The floor was unfinished and only the $19 \mathrm{~mm}(3 / 4 \mathrm{in}$.) OSB floor was fastened to the iSPAN joists with utility holes located at $1220 \mathrm{~mm}(4 \mathrm{ft})$ on center. The floor has single span of $7.26 \mathrm{~m}$ (23 ft. $10 \mathrm{in}$.) and was supported by 302-mm (11.875 in.) deep section and web thickness of $1.22 \mathrm{~mm}$ (0.048 in.). Joists were spaced at $406.4 \mathrm{~mm}$ (16

in.) on center. Both ends of joists were resting on stud wall. At the time of testing, the bracing was not attached to the joists. The layout and dimensions for floor are shown in Figure 3.41. 


\subsubsection{TEST SITE 3}

The third house was also under construction. The floor was unfinished and only the $19 \mathrm{~mm}(3 / 4$ in.) OSB floor was fastened to the iSPAN joists with utility holes located at $1220 \mathrm{~mm}(4 \mathrm{ft})$ on center. The floor has single span and having a span length of $5.33 \mathrm{~m} \mathrm{(17} \mathrm{ft.} 6$ in.) and was supported by $241-\mathrm{mm}$ (9.5 in.) deep section and web thickness of $1.22 \mathrm{~mm}$ (0.048 in.). Joists were spaced at $487.68 \mathrm{~mm}$ (19.2 in.) on center. One end of joists was resting on concrete wall while the other end was resting on steel beam. At the time of testing, the bracing was attached to the joists. The layout and dimensions for floor are shown in Figure.3.42.

\subsubsection{TEST SITE 4}

The fourth site was also under construction. The floor was unfinished and only the $19 \mathrm{~mm}(3 / 4$ in.) OSB floor was fastened to the iSPAN joists with utility holes located at $1220 \mathrm{~mm}(4 \mathrm{ft}) \mathrm{on}$ center. The floor has single span of $6.50 \mathrm{~m}$ (21 ft. 4 in.) and was supported by $241-\mathrm{mm}(9.5 \mathrm{in}$.) deep section and web thickness of $1.22 \mathrm{~mm}$ (0.048 in.). Joists were spaced at $406.4 \mathrm{~mm}$ (16 in.) on center. One end of joists was resting on concrete wall while the other end was resting on steel beam. At the time of testing, the bracing were attached to the joists. The layout and dimensions for floor are shown in Figure.3.43 


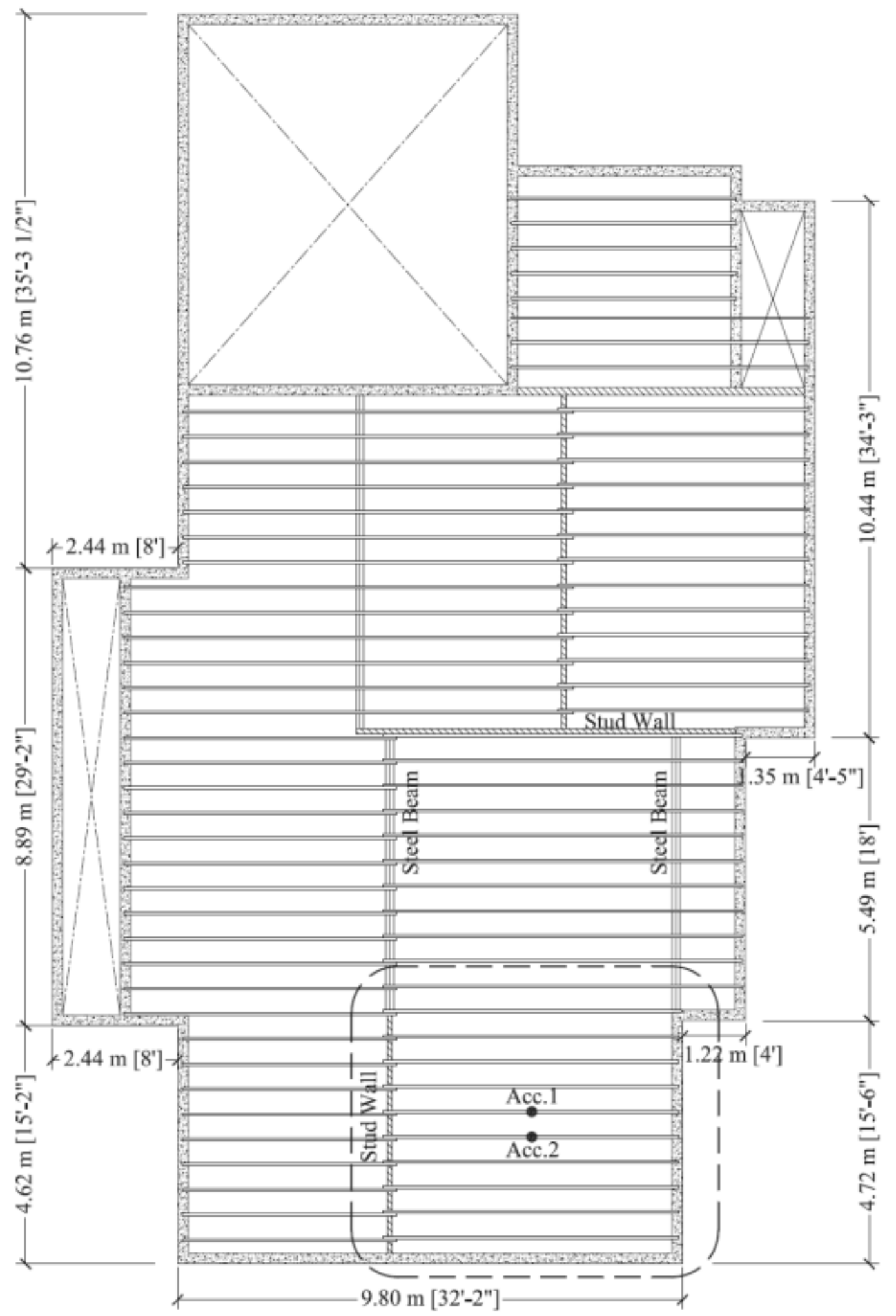

Figure 3.40: Plan view of test site 1 with iSPAN joists supported over wooden stud wall at building interior 


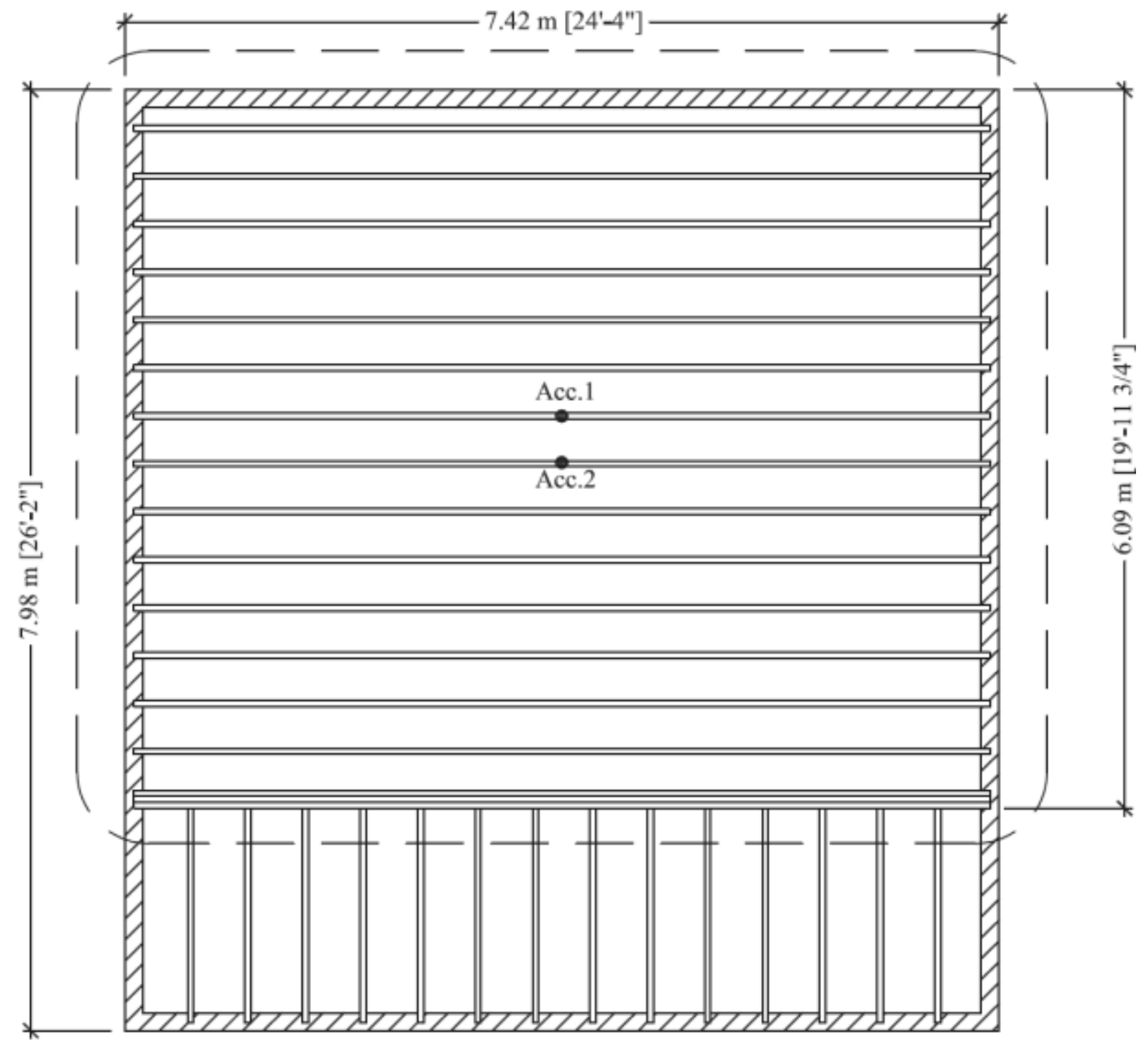

Figure 3.41: Plan view of test site 2 with iSPAN joists supported over wooden stud wall at building interior 


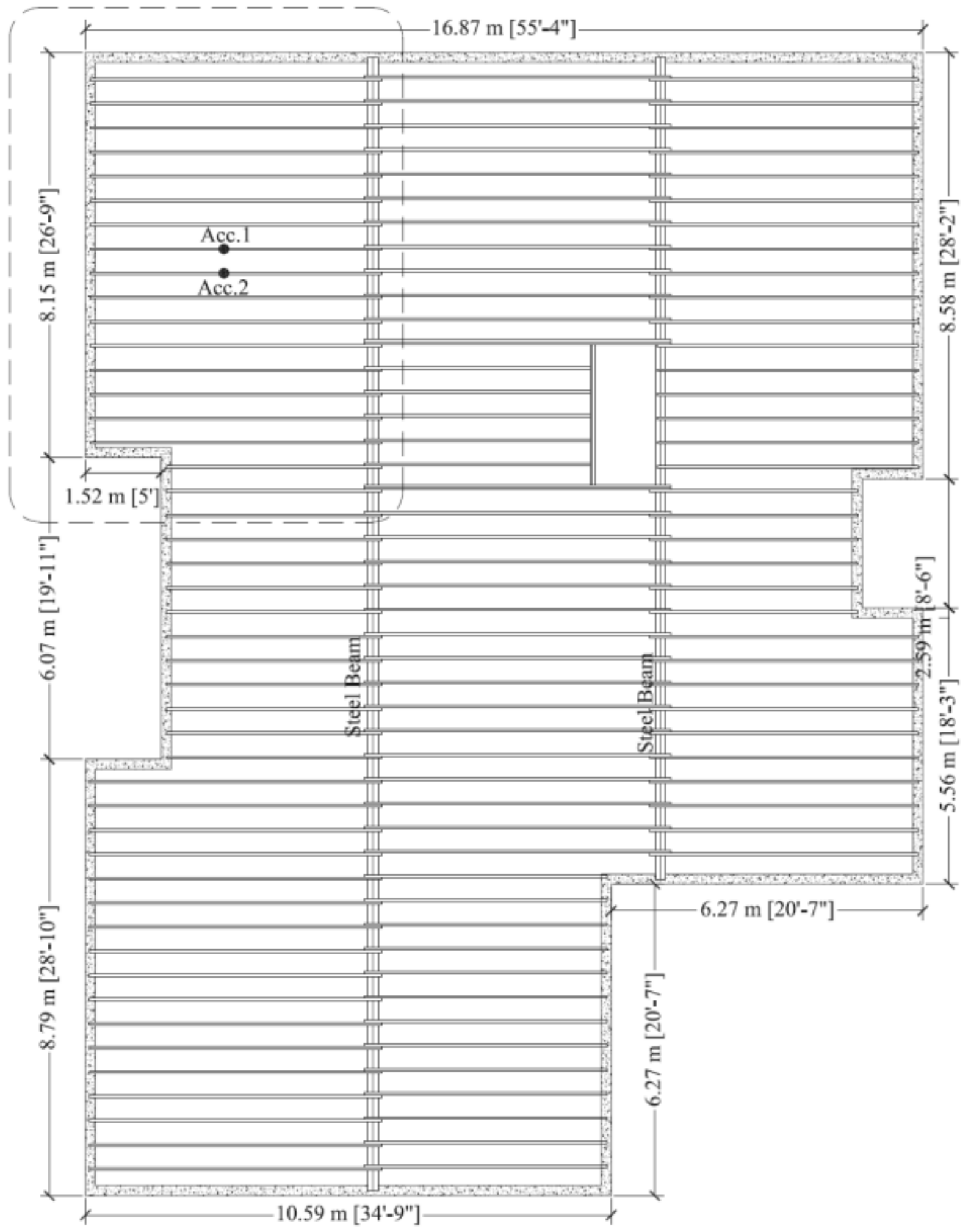

Figure 3.42: Plan view of test site 3 with iSPAN joists supported over steel beams at building interior and concrete exterior wall 


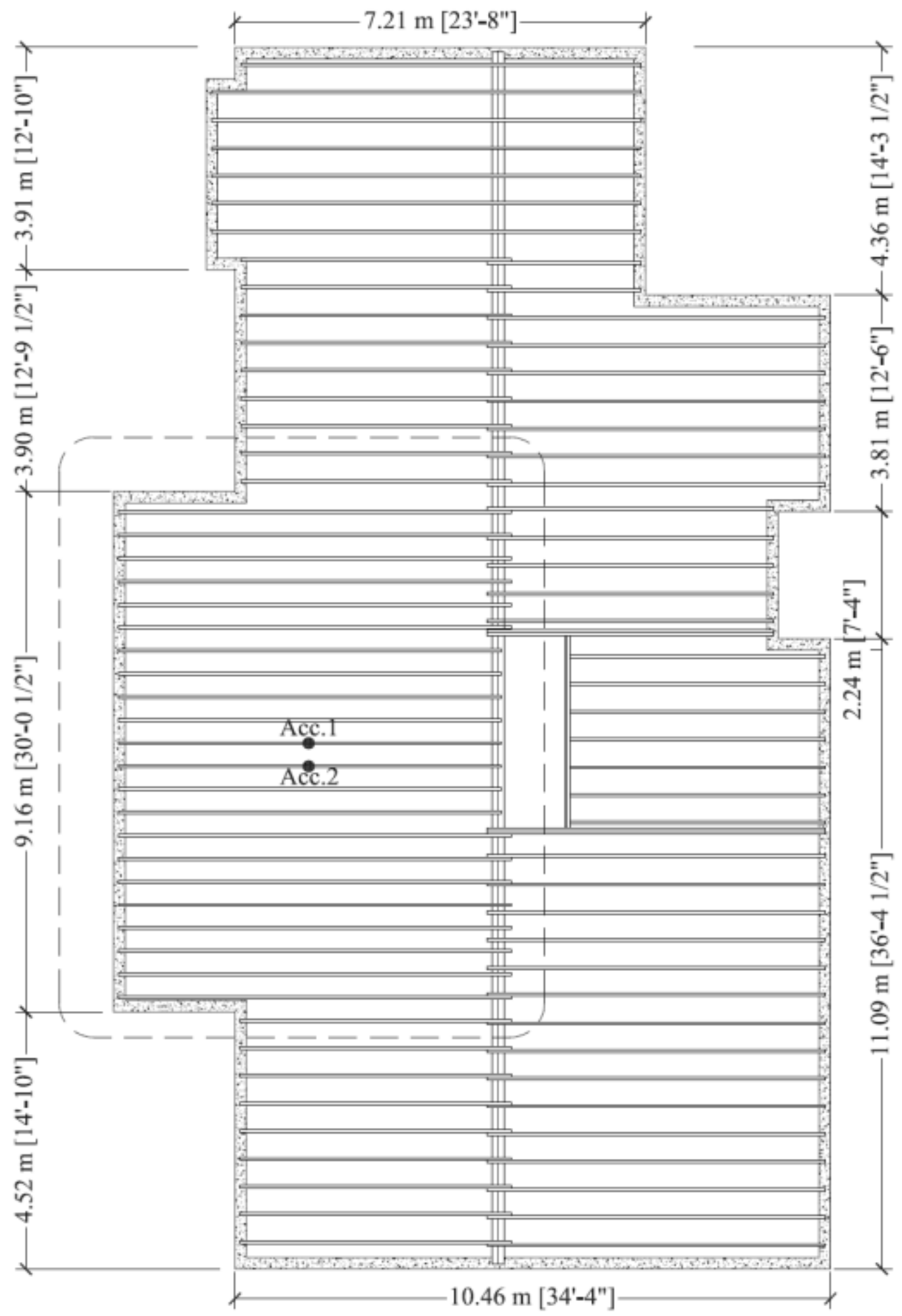

Figure 3.43: Plan view of test site 4 with iSPAN joists supported over steel stud walls at building interior 


\subsubsection{STATIC POINT LOAD TEST}

The static load test was conducted to measure the maximum deflection under $1-\mathrm{kN}$ (255 lb.) concentrated load. LVDTs were used to measure joist deflection as shown in Figures 3.45, 3.50, 3.54, and 3.56 for sites $1,2,3$ and 4, respectively. The $1-\mathrm{kN}$ weight is placed at the center of each floor system as shown in Figures 3.47, 3.52, 3.54 and 3.57 for sites 1, 2, 3 and 4, respectively. It should be noted that the joist mid-span deflections of an adjacent joist were also measured. Also, the mid-span deflection of the joist was measured at the loading and unloading conditions. Each test was repeated three times.

\subsubsection{DYNAMIC LOADING TEST}

To extract vibration characteristics of iSPAN cold-formed steel joists, the dynamic test was performed at the center of the tested floors. The floor was excited by dropping a $5.5 \mathrm{~kg}(12.32 \mathrm{lb})$ bowling ball from a height of $0.305 \mathrm{~m}(1 \mathrm{ft})$ over the middle of the floor. The acceleration of the tested floor was measured through two accelerometers which were attached to the bottom flange of joist at its mid-span. Figure.3.46, 3.51 show views of the bowling ball dropped over the floor during dynamic tests in sites 1 and 2, respectively. 


\section{Investigation Site 1}

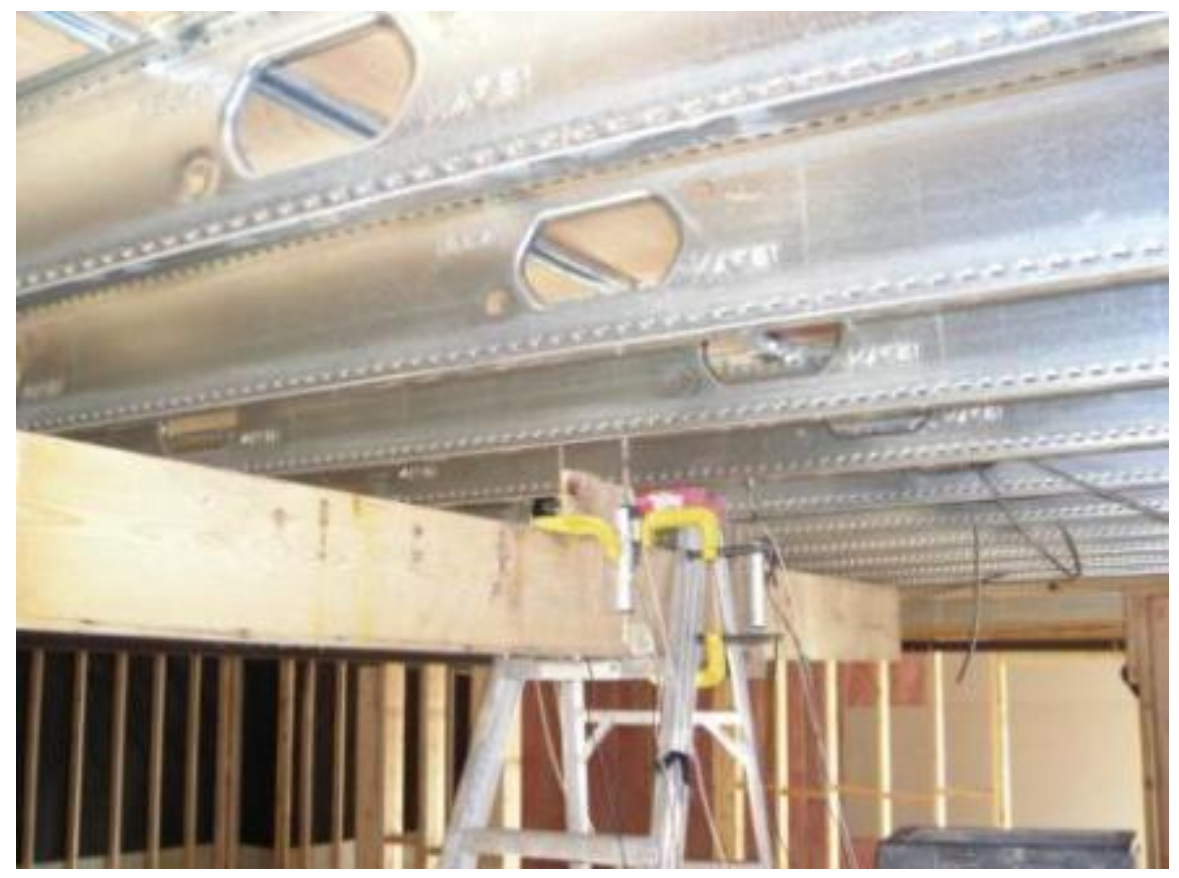

Figure 3.44: View of the LVDTs and accelerometers attached to the bottom flange of iSPAN joist floor in test site 1

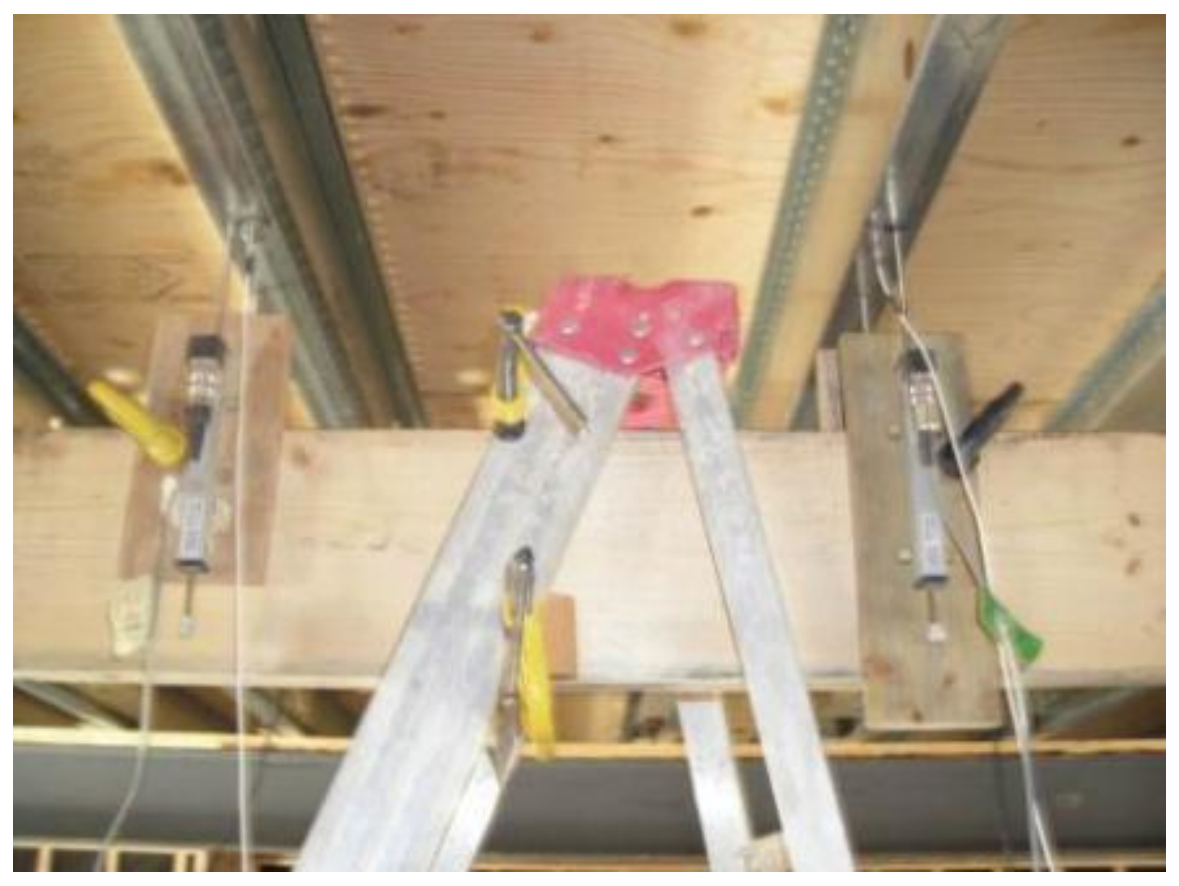

Figure 3.45: Close-up view of the LVDTs and accelerometers attached to the bottom flange of iSPAN joist in test site 1 


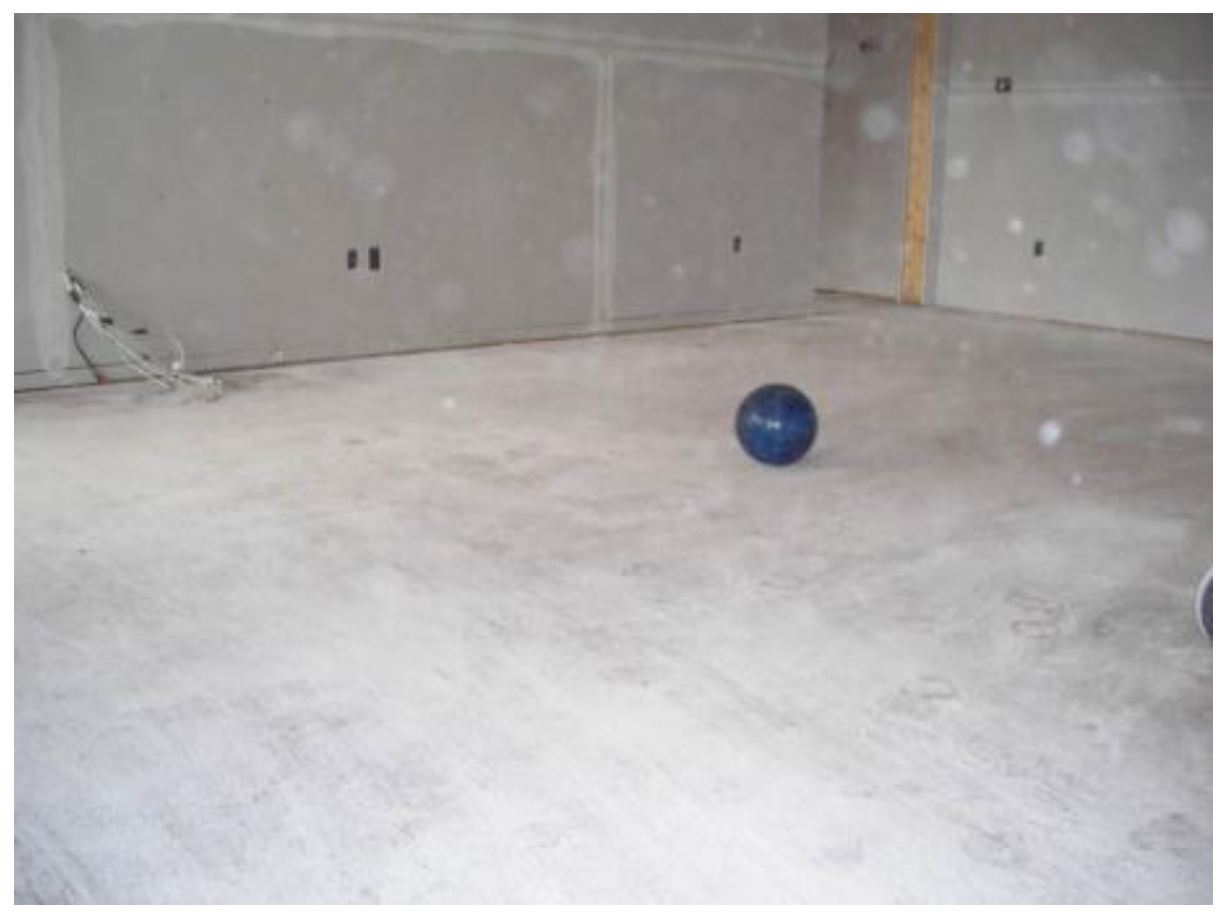

Figure 3.46: View of the bowling ball dropped from a height of $0.3 \mathrm{~m}$ over the floor in test site 1

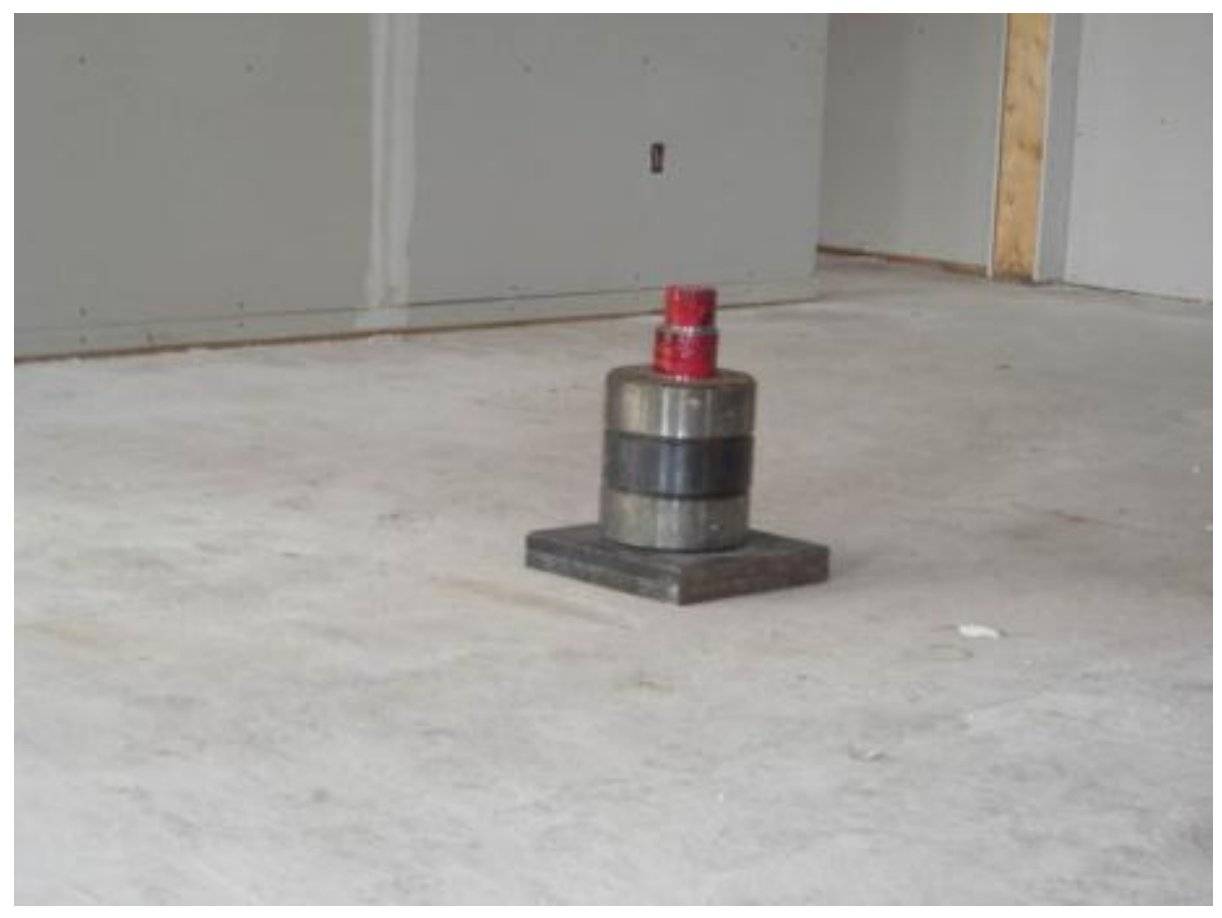

Figure 3.47: View of the 1-kN load placed at mid-span of the joist to measure the static deflection in test site 1 


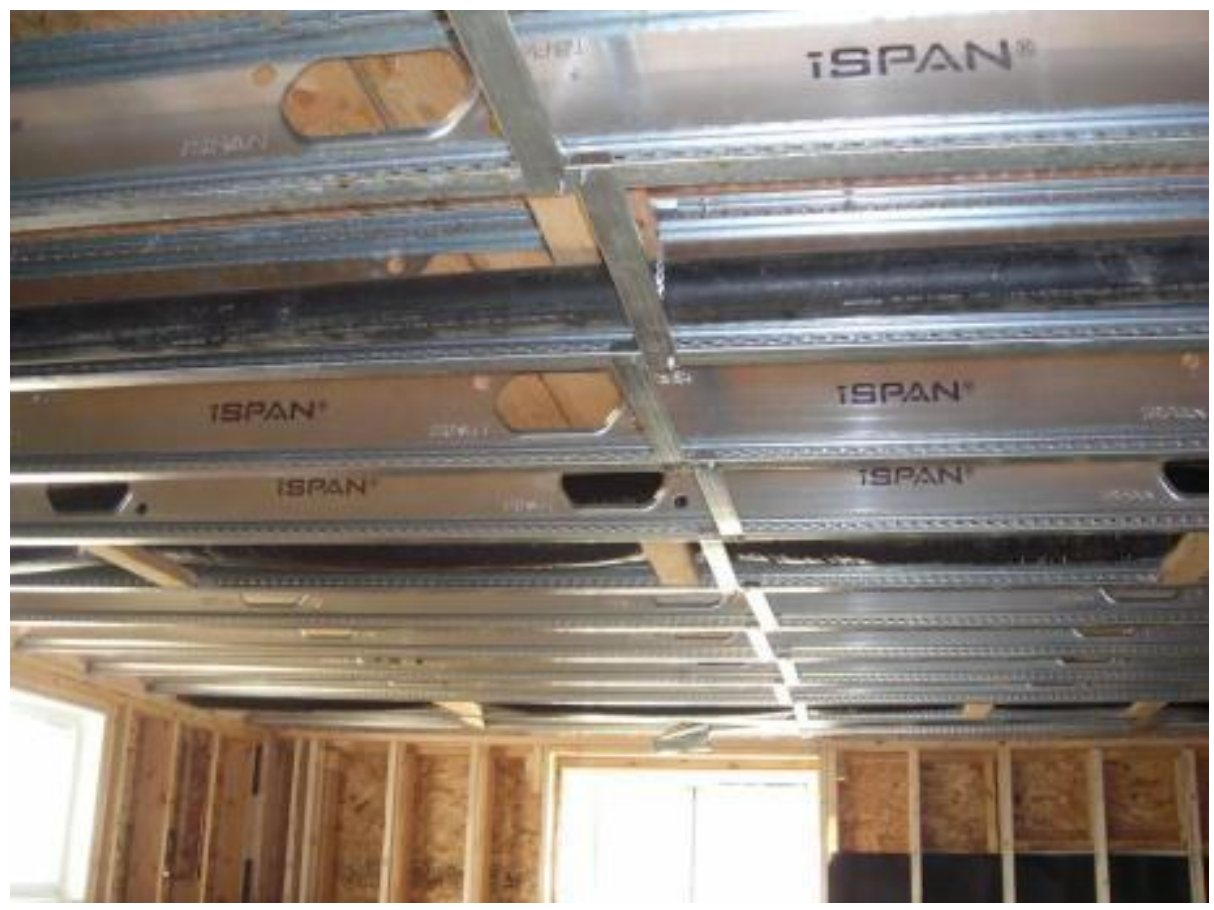

Figure 3.48: View of the bracing attached to the bottom flange of the joist in test site 1 


\section{Investigation Site 2}

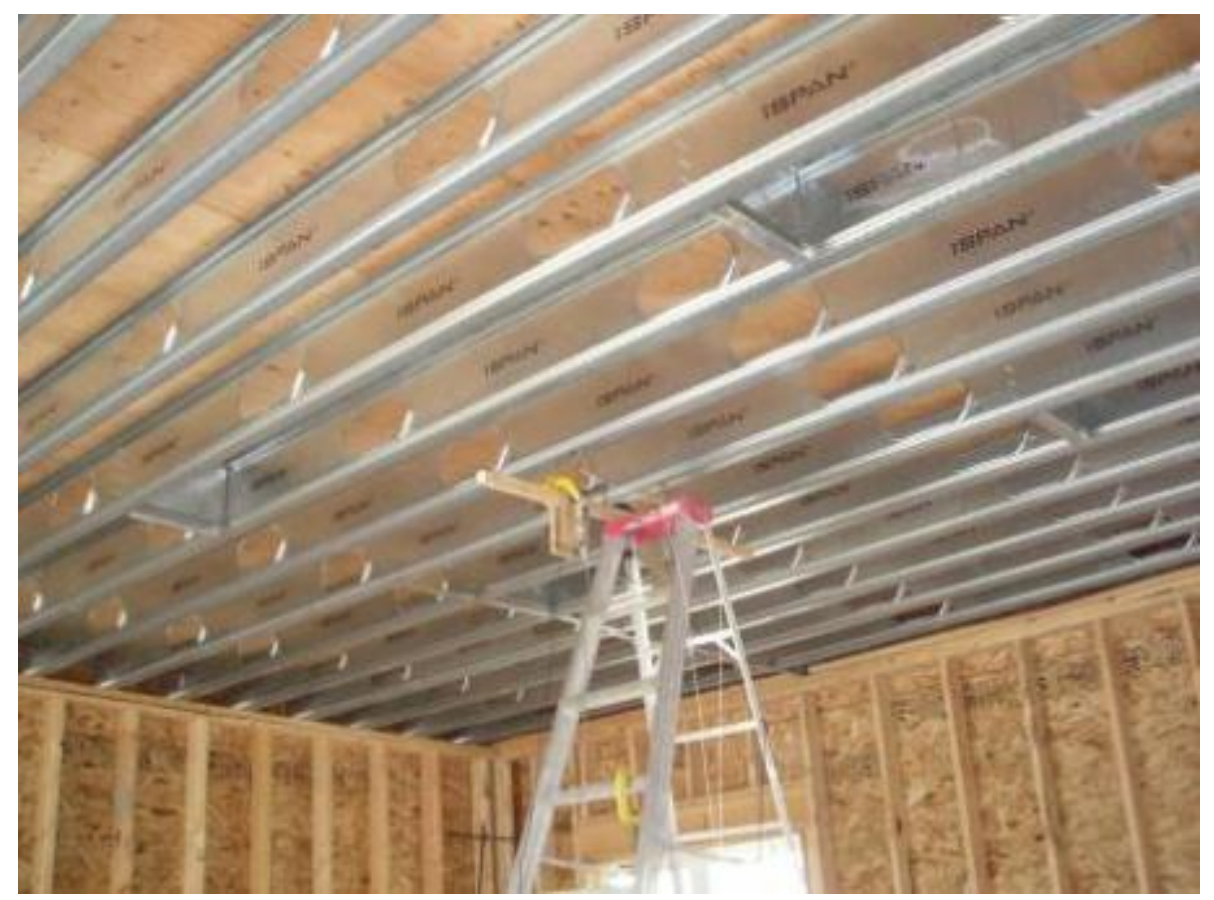

Figure 3.49: View of the LVDTs and accelerometers attached to the bottom flange of iSPAN joist in test site 2

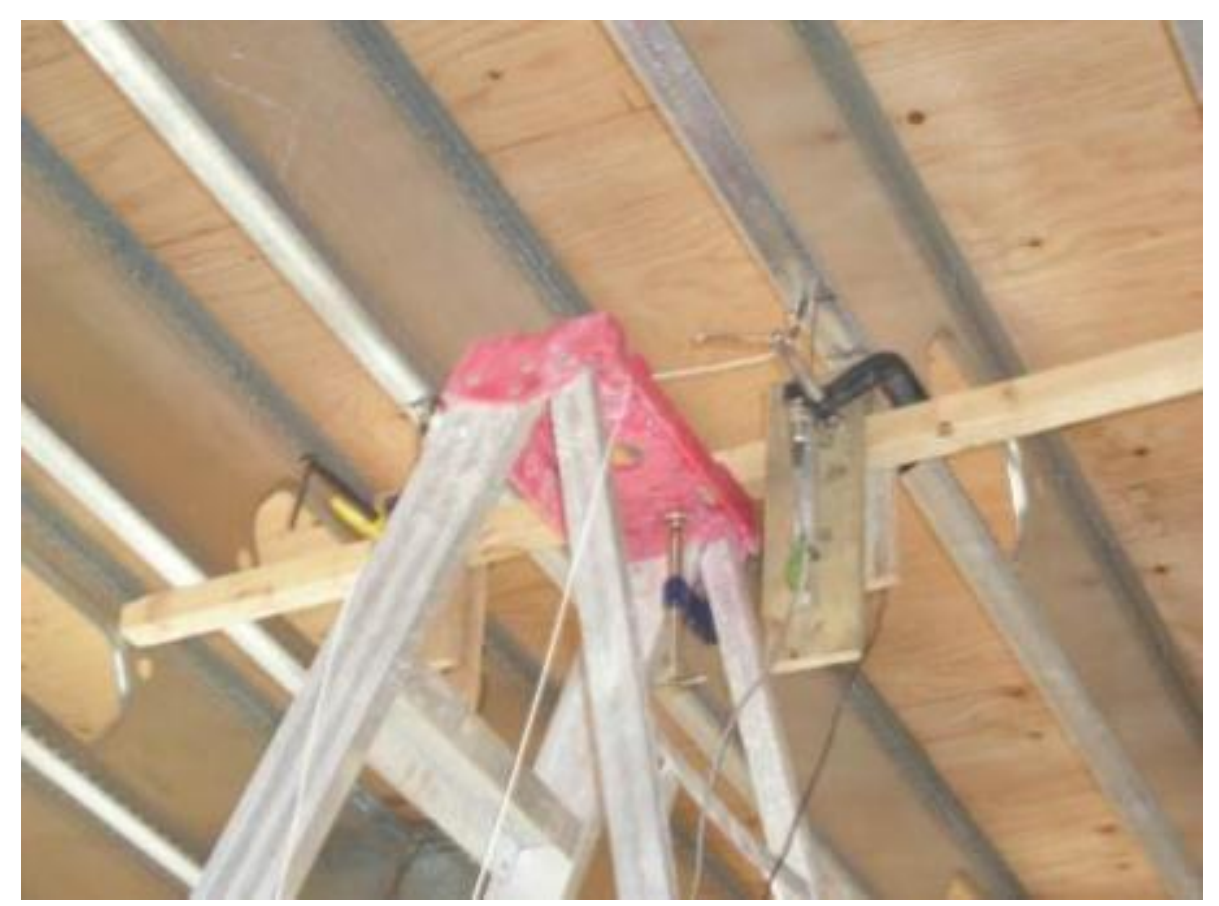

Figure 3.50: Close-up view of the LVDTs and accelerometers attached to the bottom flange of iSPAN joists in test site 2 


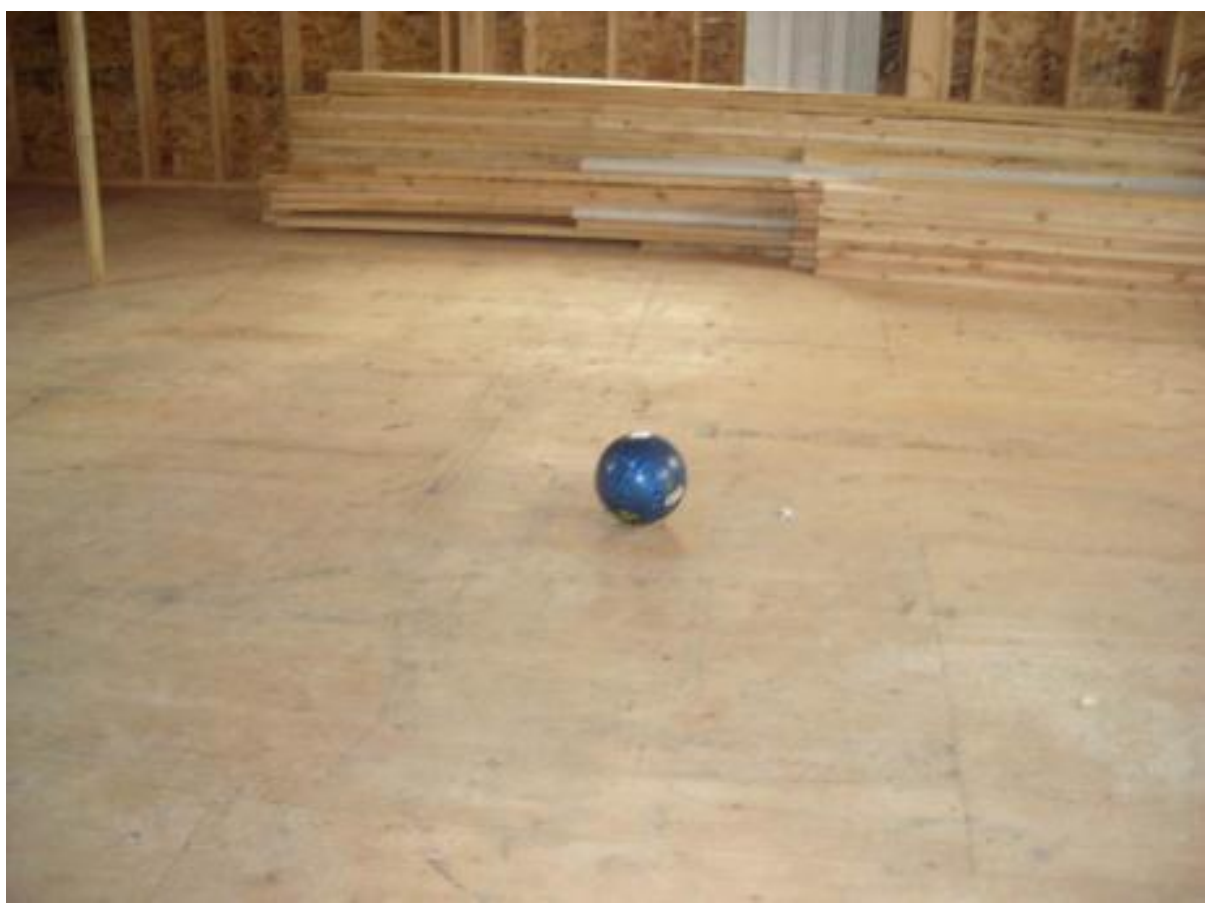

Figure 3.51: View of the bowling ball dropped from a height of $0.3 \mathrm{~m}$ over the floor in test site 2

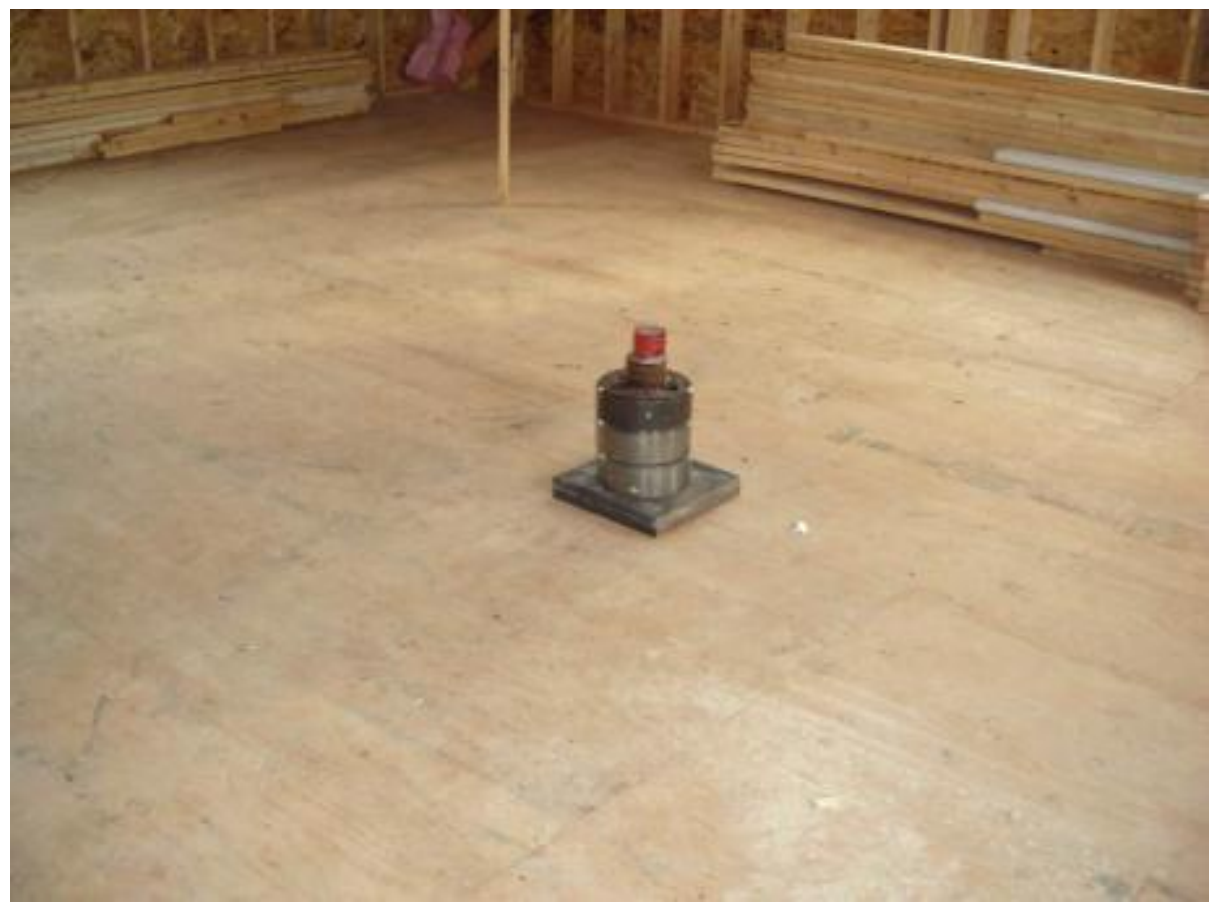

Figure 3.52: View of the 1-kN load placed at mid-span of the joist to measure the static deflection in test site 2 


\section{Investigation Site 3}

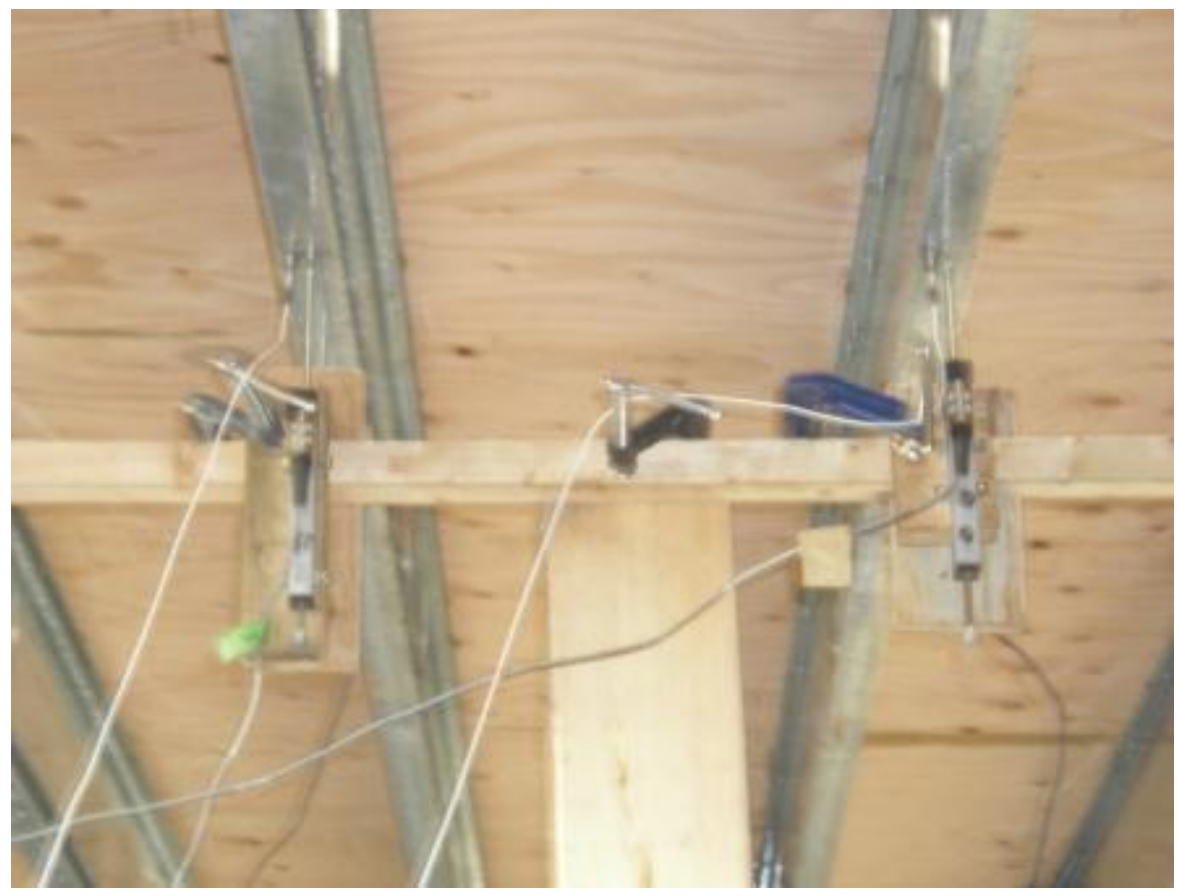

Figure 3.53: View of the LVDTs and accelerometers attached to the bottom flange of iSPAN joist in test site 3

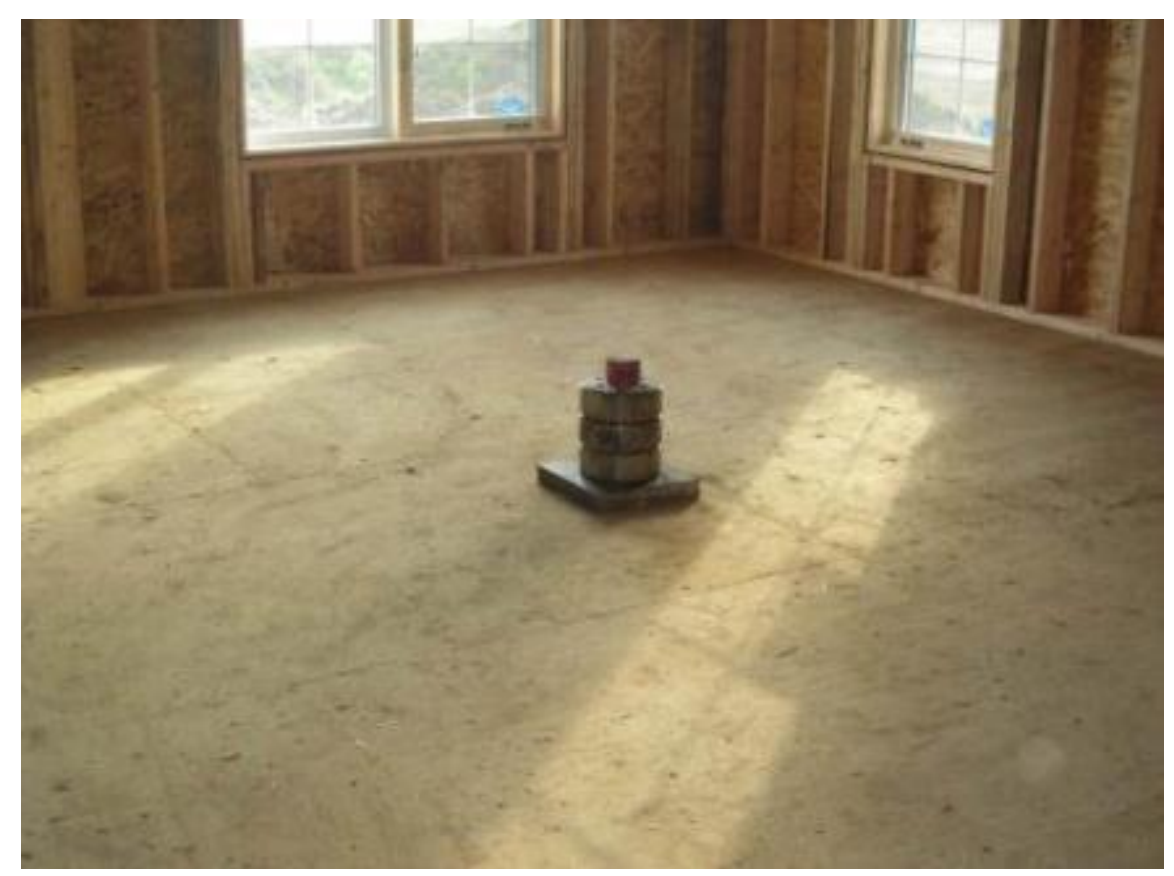

Figure 3.54: View of the 1-kN load placed at mid-span of the joist to measure static deflection in tests site 3 


\section{Investigation Site 4}

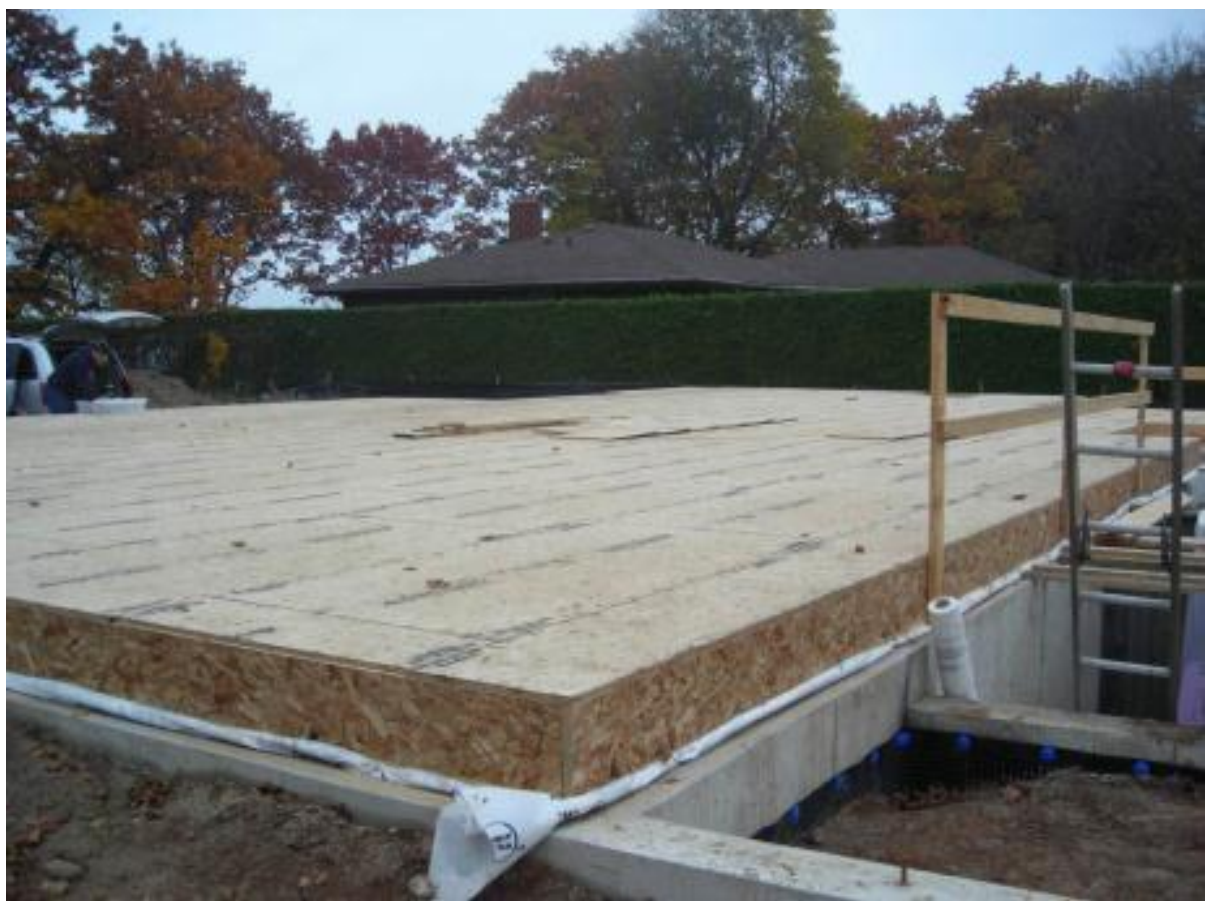

Figure 3.55: View of the floor is test site 4

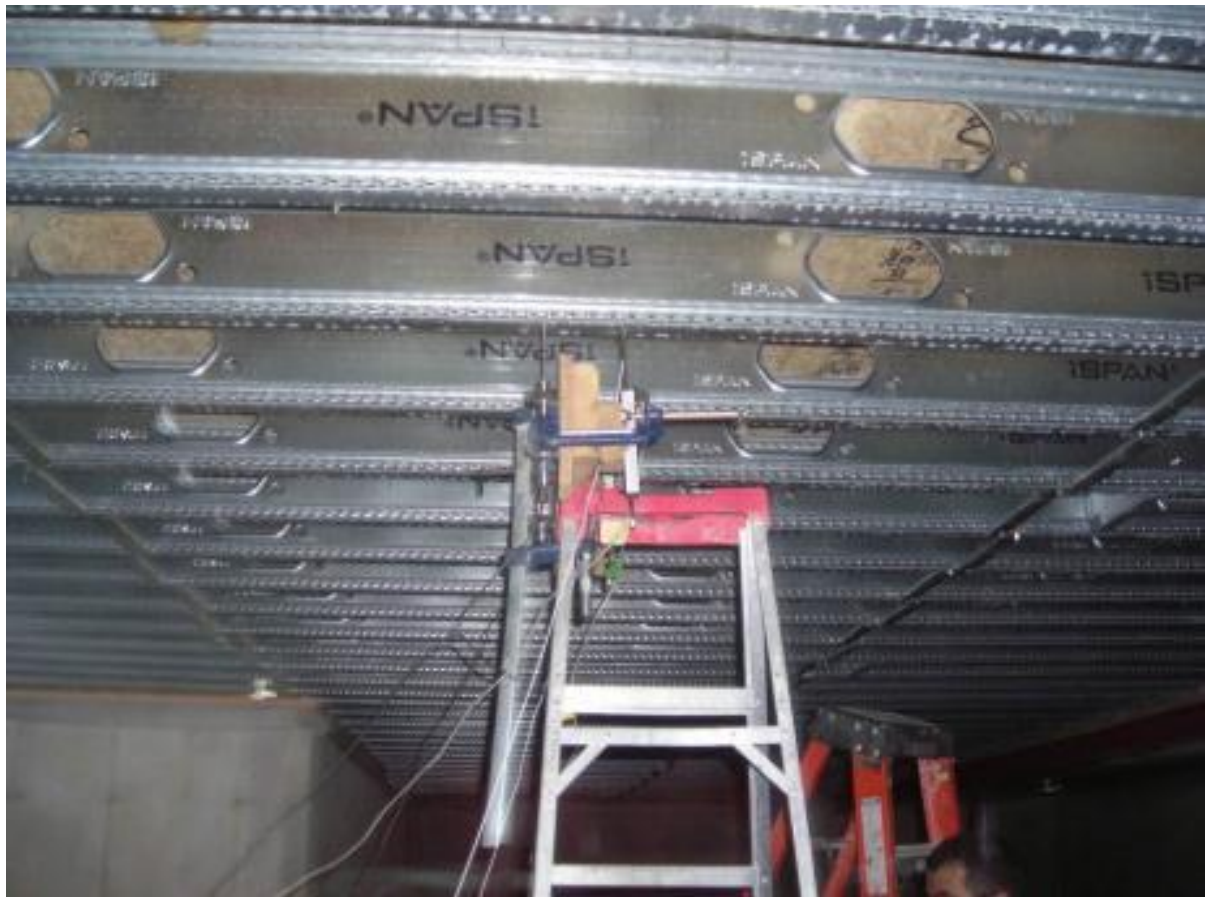

Figure 3.56: View of the LVDTs and accelerometers attached to the bottom flange of iSPAN joist in test site 4 


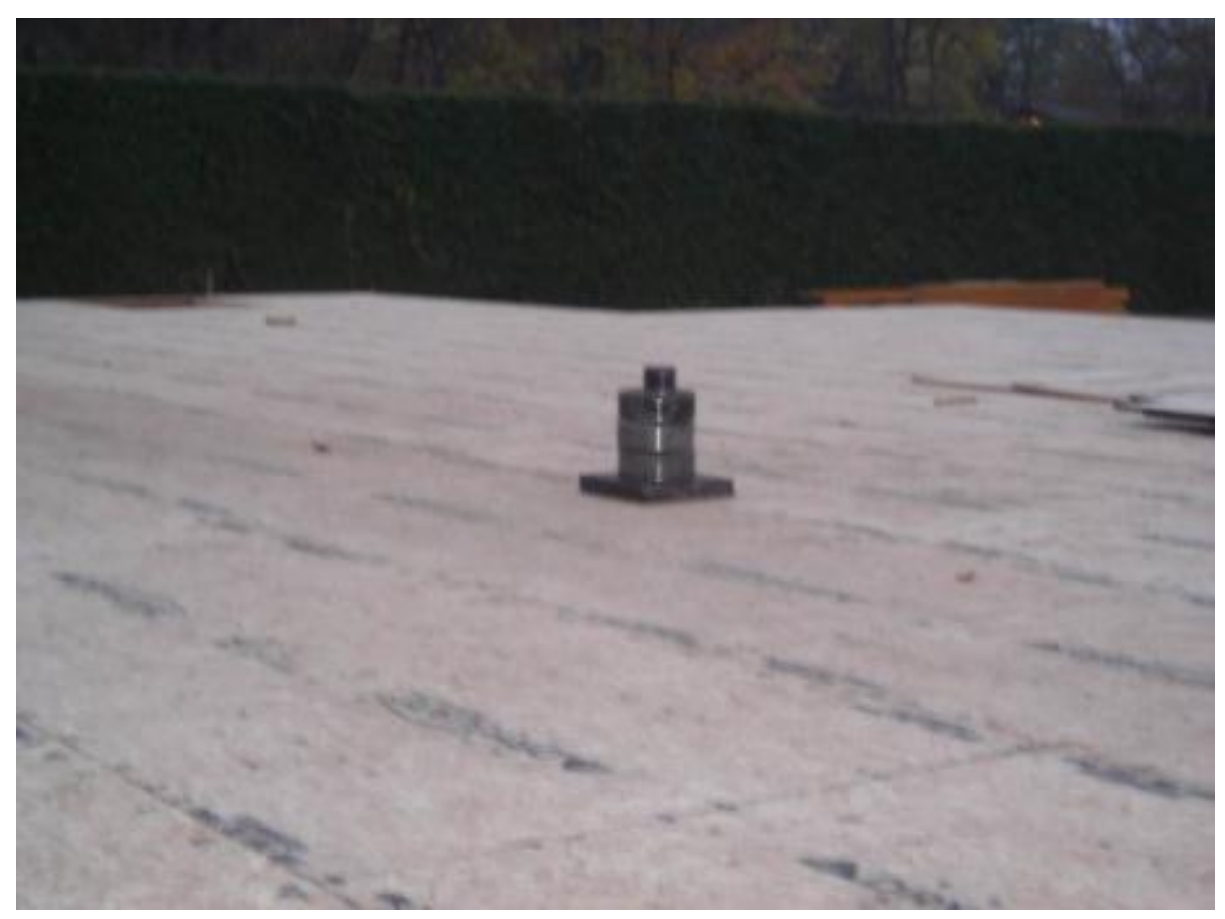

Figure 3.57: View of the 1-kN load placed at mid-span of the joist to measure static deflection in test site 4

\subsection{MECHANICAL PROPERTIES OF COLD FORMED STEEL MATERIAL}

The material properties of the test specimens were determined by tensile coupon tests. For each section tested, three coupons were cut from the center of the plate in the longitudinal direction of the undisturbed specimens. The tensile coupons were prepared and tested according to American Society of Testing and Materials Test Method "ASTM A370" (A370-12). To measure the actual thickness of each coupon, the galvanized coating was removed by hydrochloric acid solution. Figure 3.58 shows dimensions of the coupon sample, while Figure 3.59 shows view of the typical setup for tensile coupon testing. Figure 3.60 shows view of the specimens after failure in the tensile testing machine, while Figure 3.61 shows view of the failure shape in one of the tested coupons. Figure 3.62 shows a typical stress-strain relationship of the tested coupon sample Table 3.5 shows the material mechanical properties of tested specimens in the form of yield strength, ultimate tensile strength and percentage elongation at failure. It should be noted that the average values of the web thickness and the yield strength obtained from coupon tests were considered further to verify the finite-element modelling of the tested floor assemblies. 


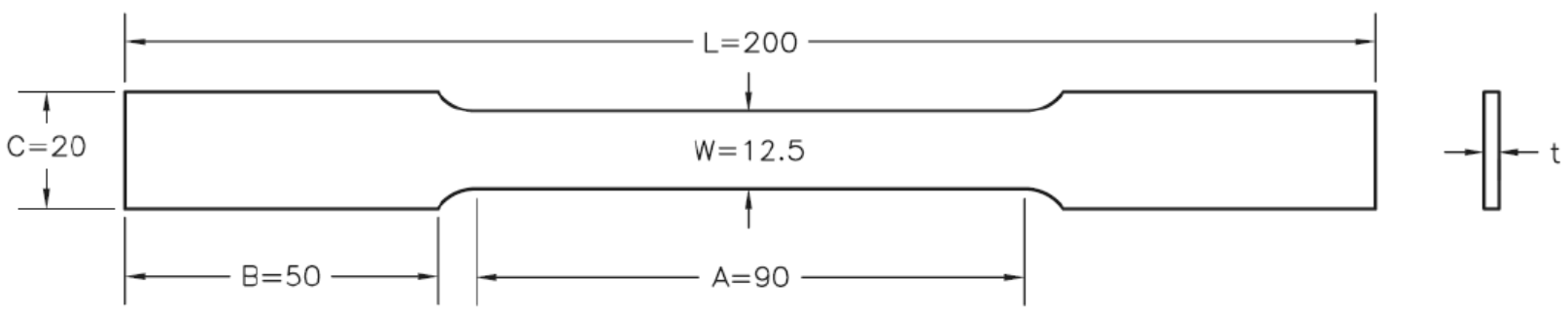

Figure 3.58: Schematic diagram of a CFS coupon sample per ASTM A370

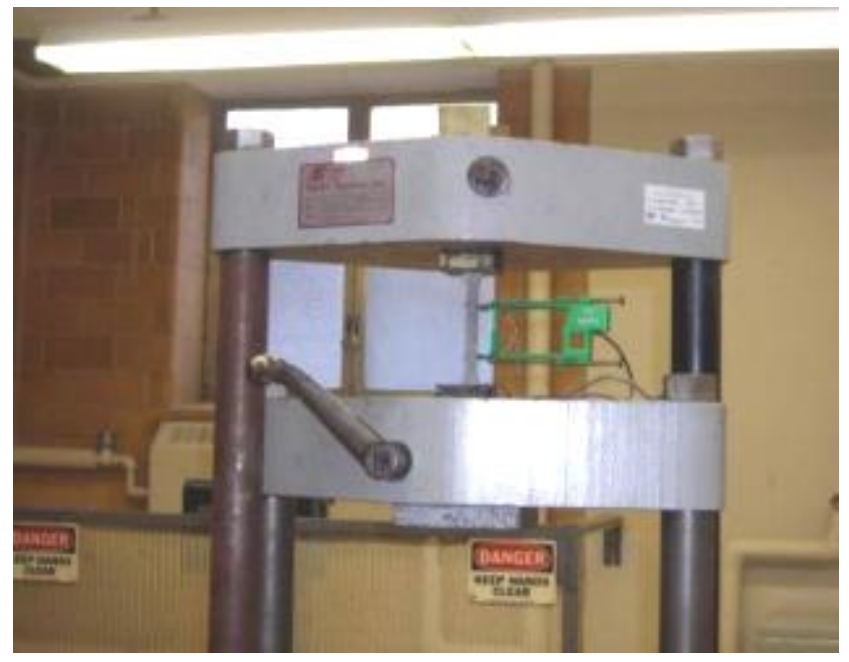

Figure 3.59: View of a typical setup for tensile coupon testing

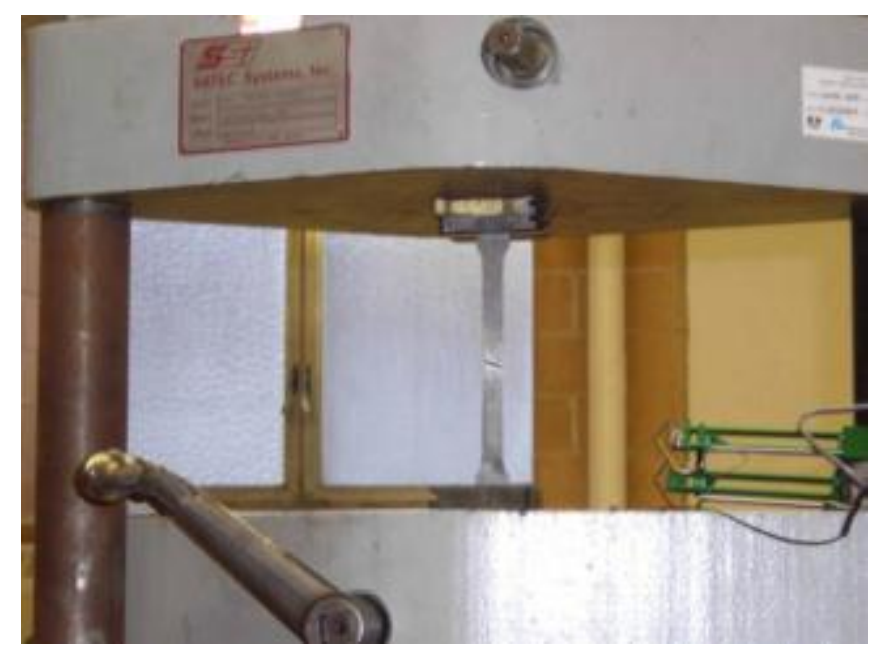

Figure 3.60: View of the coupon sample after failure in the tensile testing machine 


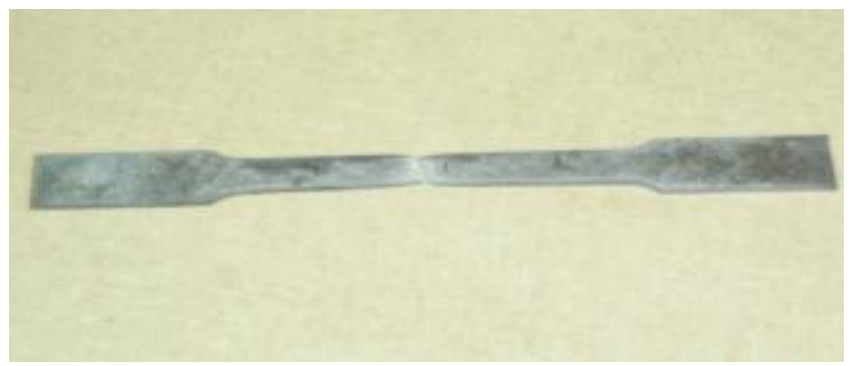

Figure 3.61: View of the failure shape in one of the tested coupons

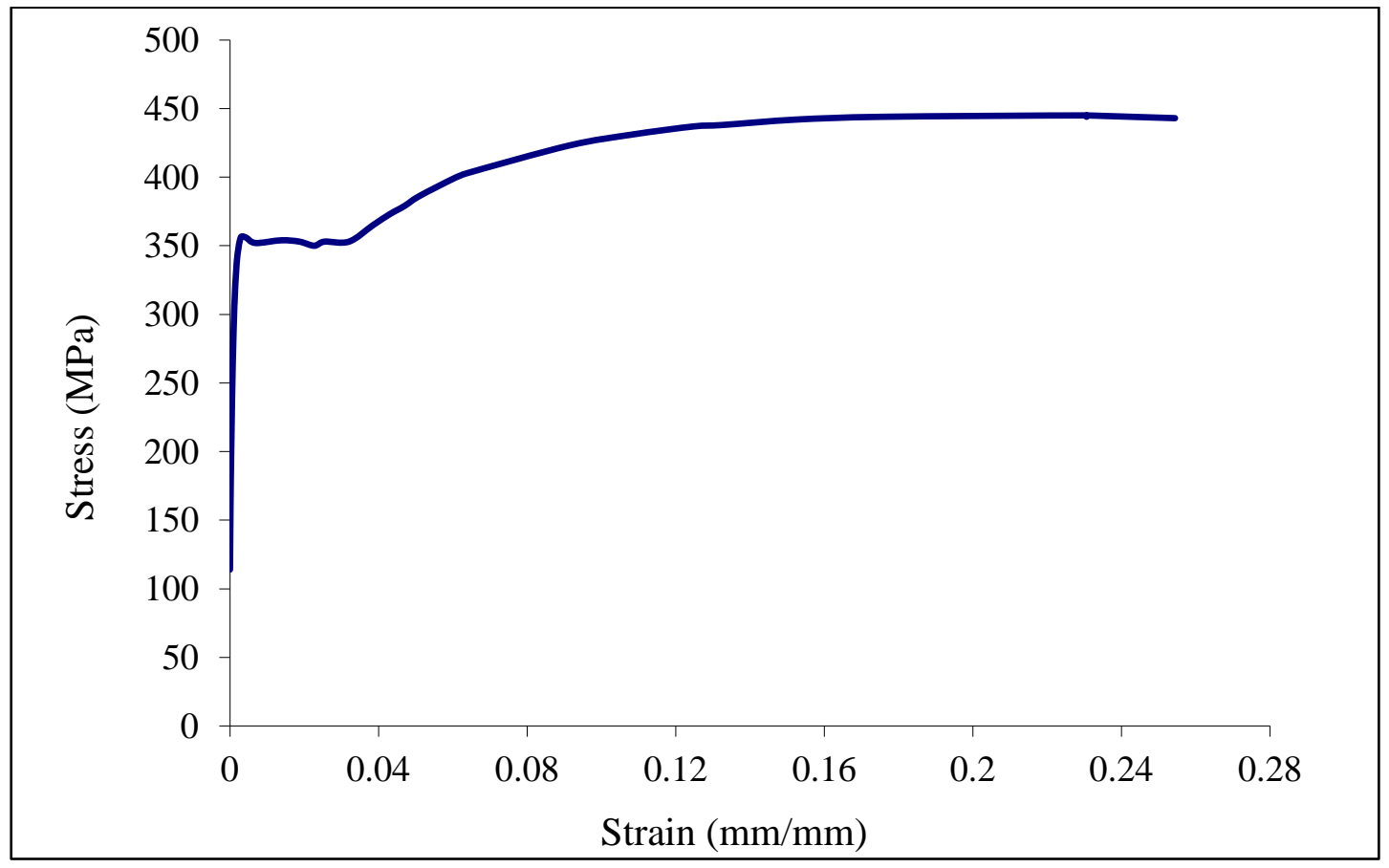

Figure 3.62: View of typical stress-strain relationship of a tested coupon sample 
Table 3.5: Mechanical Properties of CFS coupons

\begin{tabular}{|c|c|c|c|c|c|}
\hline Specimen & Test \# & $\begin{array}{c}\mathrm{t} \\
(\mathrm{mm})\end{array}$ & $\begin{array}{c}\text { Fy } \\
(\mathrm{MPa})\end{array}$ & $\begin{array}{c}\mathrm{Fu} \\
(\mathrm{MPa})\end{array}$ & $\begin{array}{c}\% \\
\text { Elongation* }\end{array}$ \\
\hline \multirow{4}{*}{ A } & 1 & 1.295 & 481.8 & 541.4 & 15.70 \\
\hline & 2 & 1.346 & 471.8 & 527.2 & 15.85 \\
\hline & 3 & 1.346 & 453.2 & 523.6 & 15.20 \\
\hline & Average & 1.329 & 468.9 & 530.7 & 15.58 \\
\hline \multirow{4}{*}{ B } & 1 & 1.448 & 359.5 & 426.1 & 18.35 \\
\hline & 2 & 1.321 & 377.8 & 447.0 & 18.15 \\
\hline & 3 & 1.397 & 374.9 & 445.2 & 17.00 \\
\hline & Average & 1.389 & 370.7 & 439.4 & 17.83 \\
\hline \multirow{4}{*}{$\mathrm{C}$} & 1 & 1.499 & 376.0 & 436.7 & 16.15 \\
\hline & 2 & 1.499 & 390.2 & 454.7 & 18.45 \\
\hline & 3 & 1.499 & 373.6 & 436.5 & 14.65 \\
\hline & Average & 1.499 & 380.0 & 442.6 & 16.42 \\
\hline \multirow{4}{*}{$\mathrm{D}$} & 1 & 1.524 & 295.0 & 365.4 & 28.60 \\
\hline & 2 & 1.549 & 280.6 & 360.5 & 27.50 \\
\hline & 3 & 1.524 & 240.0 & 308.1 & 28.80 \\
\hline & Average & 1.532 & 271.9 & 344.6 & 28.30 \\
\hline
\end{tabular}

* Based on 50 mm gauge length 


\section{CHAPTER 4}

\section{EXPERIMENTAL RESULTS AND COMPARISON WITH CODE EQUATIONS}

\subsection{INTRODUCTION}

The experimental program involved static load tests, dynamic tests and ultimate load tests tocollapse on selected engineered I-joist and iSPAN CFS joists to obtain joist deflections, accelerations and ultimate load carrying capacities under flexural loading. Experimental findings are then compared with the available design methods listed in Chapter 2. As some of the existing design methods are mainly based on consideration of wood floors, it is expected that testing wood floor would serve as a control and baseline for the structural performance of iSPAN coldformed steel joists. The results obtained from the laboratory and field testing are summarized in Table 4.1 to 4.23 and discussed in the following sections. Experimental findings are presented in Chapter 4 in the form of joist natural frequencies, maximum deflection, damping ratios and ultimate flexural capacities. The bandwidth method referred to in Chapter 2 was used in this study to estimate joist damping ratio.

\subsection{IMPACT OF CONSTRUCTION DETAILS ON A FLOOR'S NATURAL FREQUENCIES, MAXIMUM DEFLECTION, DAMPING RATIO AND ULTIMATE FLEXURAL CAPACITY}

The following subsections discuss the impact of the construction details and joist geometry on the vibration characteristics of the light-weight floor system supported by the iSPAN coldformed steel joists. The construction details considered in this study include joist span length, bracing, web holes, and support conditions. The vibration performance of the floor system is judged based on fundamental frequency, damping ratio, and central deflection.

Floor span length has great effect on frequencies, deflection, and damping ratio. The results shows that the frequencies decrease as the floor span increases, as expected. On the other hand, the maximum deflection due to a $1-\mathrm{kN}$ concentrated load increases as the span length increases, as expected. In addition, floor frequency decreases as the length increase because longer spans 
produce more flexible joists with respect to the change in the mass as well as flexural stiffness. The fundamental equation for frequency is shown in equation (4.1)

$\omega=\sqrt{\frac{k}{m}}$

Where

$\omega=$ natural frequency

$k=$ stiffness of the floor system

$m=$ mass of the floor system

From the above formula, one may observe that joist frequency is inversely proportional to the mass of the system and directly proportional to the stiffness. As joist length increases, the central deflection increases. This is attributed to the fact that increasing the length the floor system makes the floor more flexible, this can be shown by the equation (4.2)

$k=\frac{3 E I}{L}$

Where $k=$ stiffness of the floor system, $E=$ modulus of elasticity, $I=$ moment of inertia, $L=$ span length.

From the above formula, one may observe that joist stiffness is inversely proportional to the span length, therefore as the span length increases the stiffness of the floor system decreases.

\subsubsection{EXPERIMENTAL FINDINGS FOR THE ENGINEERED WOODEN I-JOIST ASSEMBLIES}

The free-vibration tests were conducted to provide research data to obtain the natural frequencies and damping rations of the tested wood floor assembly. For example, Figure 4.1 shows the acceleration-time history of the $241 \times 3500 \mathrm{~mm}$ wood joist assembly, while Figure 4.2 shows the resulting frequency spectrum. Acceleration-time history and frequency spectrum for other wood assemblies listed in Table 3.1 are shown in Appendices A1 and A2, respectively. Tables 4.1 and 4.2 present the experimental flexural frequencies of the unbraced and braced joist assemblies, respectively. Results from three identical tests were averaged to obtained joist frequencies under free-vibration response. It can be observed that the joist frequency decreased from $34.2 \mathrm{~Hz}$ to 14.16 Hz with increase in span length from 3.5 to $7.95 \mathrm{~m}$. In addition, it can be observed that the presence of joist bracing has insignificant effect on floor frequency. As an example, floor frequencies were 34.2 and $34.77 \mathrm{~Hz}$ for joists without and with bracings, respectively. 


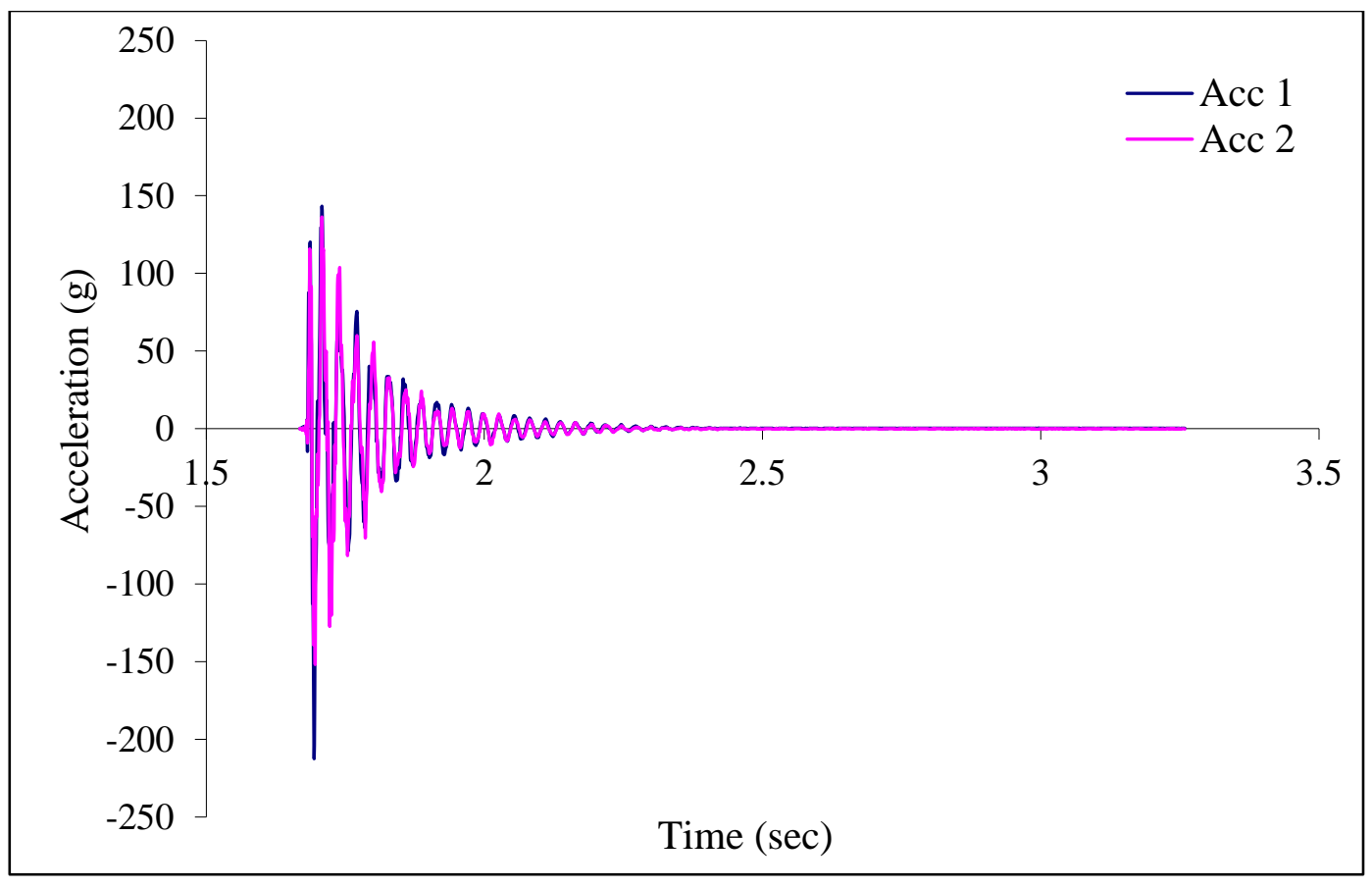

Figure 4.1: Typical acceleration trace for the $241 \times 3500 \mathrm{~mm}$ wooden floor joist assembly (Acc. 1 $=$ results from accelerometer 1 , Acc. 2 = results from accelerometer 2)

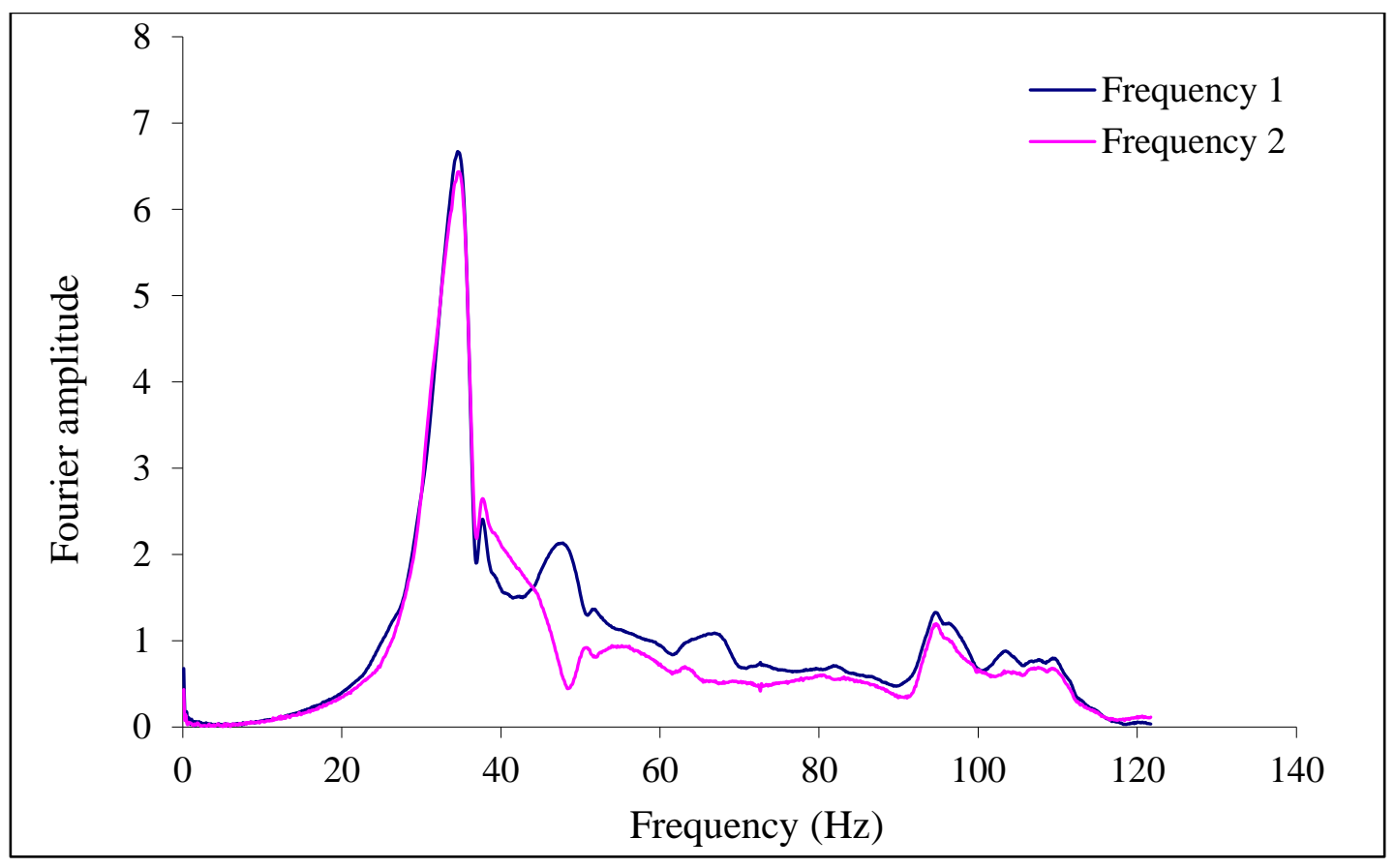

Figure 4.2: Typical frequency spectrum for the $241 \times 3500 \mathrm{~mm}$ wooden floor Joist (Freq $1=$ results from accelerometer 1 , Freq 2 = results from accelerometer 2) 
Table 4.3 presents the results of the joist deflection due to $1-\mathrm{kN}$ concentrated load located at the mid-span of the joist. It can be observed that deflection increased from $0.63 \mathrm{~mm}$ to $1.89 \mathrm{~mm}$ when joist span increased from 3.5 to $7.95 \mathrm{~m}$, as expected. Tables 4.4 and 4.5 summarize damping ratios of the tested engineered wood joist assemblies. It can be observed that wood floor damping ratio ranged from 3.45 to $5.18 \%$ for unbraced joists and between 3.53 to $6.69 \%$ for braced joists. It can be observed that the presence of bracing in timber joists does not affect the floor frequency and damping ratio which seems reasonable conclusion.

Table 4.1: Experimental results of the flexural frequency of the unbraced wooden joists

\begin{tabular}{|c|c|c|c|c|}
\hline $\begin{array}{c}\text { Joist } \\
\text { depth, } \\
\text { d (mm) }\end{array}$ & $\begin{array}{c}\text { Joist } \\
\text { length }(\mathrm{m})\end{array}$ & Tests & $\begin{array}{c}\text { Frequency } \\
f(\mathrm{~Hz})\end{array}$ & $\begin{array}{c}\text { Total avg. } \\
f(\mathrm{~Hz})\end{array}$ \\
\hline \multirow{3}{*}{241} & \multirow{3}{*}{3.50} & Test 1 & 34.37 & \multirow{3}{*}{34.20} \\
\hline & & Test 2 & 34.24 & \\
\hline & & Test 3 & 34.02 & \\
\hline \multirow{3}{*}{241} & \multirow{3}{*}{4.50} & Test 1 & 22.34 & \multirow{3}{*}{22.26} \\
\hline & & Test 2 & 22.22 & \\
\hline & & Test 3 & 22.22 & \\
\hline \multirow{3}{*}{302} & \multirow{3}{*}{5.00} & Test 1 & 21.73 & \multirow{3}{*}{21.65} \\
\hline & & Test 2 & 21.61 & \\
\hline & & Test 3 & 21.61 & \\
\hline \multirow{3}{*}{302} & \multirow{3}{*}{5.25} & Test 1 & 20.39 & \multirow{3}{*}{20.31} \\
\hline & & Test 2 & 20.26 & \\
\hline & & Test 3 & 20.26 & \\
\hline \multirow{3}{*}{356} & \multirow{3}{*}{6.10} & Test 1 & 17.82 & \multirow{3}{*}{17.80} \\
\hline & & Test 2 & 17.82 & \\
\hline & & Test 3 & 17.76 & \\
\hline \multirow{3}{*}{406} & \multirow{3}{*}{7.95} & Test 1 & 14.12 & \multirow{3}{*}{14.16} \\
\hline & & Test 2 & 14.12 & \\
\hline & & Test 3 & 14.25 & \\
\hline
\end{tabular}


Table 4.2: Experimental results of the flexural frequency of the braced wooden joists

\begin{tabular}{|c|c|c|c|c|}
\hline $\begin{array}{c}\text { Joist depth } \\
\text { d (mm) }\end{array}$ & $\begin{array}{c}\text { Joist } \\
\text { length }(\mathrm{m})\end{array}$ & Tests & $\begin{array}{c}\text { Frequency } \\
f(\mathrm{~Hz})\end{array}$ & $\begin{array}{c}\text { Total avg } \\
f(\mathrm{~Hz})\end{array}$ \\
\hline \multirow{3}{*}{241} & \multirow{3}{*}{3.50} & Test 1 & 34.73 & \multirow{3}{*}{34.77} \\
\hline & & Test 2 & 34.80 & \\
\hline & & Test 3 & 34.80 & \\
\hline \multirow{3}{*}{241} & \multirow{3}{*}{4.50} & Test 1 & 22.10 & \multirow{3}{*}{22.18} \\
\hline & & Test 2 & 22.22 & \\
\hline & & Test 3 & 22.22 & \\
\hline \multirow{3}{*}{302} & \multirow{3}{*}{5.00} & Test 1 & 21.61 & \multirow{3}{*}{21.61} \\
\hline & & Test 2 & 21.61 & \\
\hline & & Test 3 & 21.61 & \\
\hline \multirow{3}{*}{302} & \multirow{3}{*}{5.25} & Test 1 & 19.77 & \multirow{3}{*}{19.73} \\
\hline & & Test 2 & 19.77 & \\
\hline & & Test 3 & 19.65 & \\
\hline \multirow{3}{*}{356} & \multirow{3}{*}{6.10} & Test 1 & 17.70 & \multirow{3}{*}{17.72} \\
\hline & & Test 2 & 17.76 & \\
\hline & & Test 3 & 17.70 & \\
\hline \multirow{3}{*}{406} & \multirow{3}{*}{7.95} & Test 1 & 14.16 & \multirow{3}{*}{14.12} \\
\hline & & Test 2 & 14.16 & \\
\hline & & Test 3 & 14.10 & \\
\hline
\end{tabular}


Table 4.3: Experimental results of the 1-kN static load deflection of braced wooden joists

\begin{tabular}{|c|c|c|c|c|}
\hline $\begin{array}{c}\text { Joist } \\
\text { depth, } \\
\mathrm{d}(\mathrm{mm})\end{array}$ & $\begin{array}{c}\text { Joist } \\
\text { length (m) }\end{array}$ & Tests & $\begin{array}{l}\text { Deflection } \\
\text { under } 1 \mathrm{kN} \\
\quad \Delta \mathrm{mm}\end{array}$ & $\begin{array}{l}\text { Total avg } \\
\Delta_{\text {Tot }} \mathrm{mm}\end{array}$ \\
\hline \multirow{3}{*}{241} & \multirow{3}{*}{3.50} & Test 1 & 0.635 & \multirow{3}{*}{0.63} \\
\hline & & Test 2 & 0.620 & \\
\hline & & Test 3 & 0.625 & \\
\hline \multirow{3}{*}{241} & \multirow{3}{*}{4.50} & Test 1 & 1.56 & \multirow{3}{*}{1.51} \\
\hline & & Test 2 & 1.53 & \\
\hline & & Test 3 & 1.44 & \\
\hline \multirow{3}{*}{302} & \multirow{3}{*}{5.00} & Test 1 & 1.50 & \multirow{3}{*}{1.47} \\
\hline & & Test 2 & 1.45 & \\
\hline & & Test 3 & 1.45 & \\
\hline \multirow{3}{*}{302} & \multirow{3}{*}{5.25} & Test 1 & 1.68 & \multirow{3}{*}{1.64} \\
\hline & & Test 2 & 1.62 & \\
\hline & & Test 3 & 1.61 & \\
\hline \multirow{3}{*}{356} & \multirow{3}{*}{6.10} & Test 1 & 1.57 & \multirow{3}{*}{1.58} \\
\hline & & Test 2 & 1.60 & \\
\hline & & Test 3 & 1.58 & \\
\hline \multirow{3}{*}{406} & \multirow{3}{*}{7.95} & Test 1 & 1.89 & \multirow{3}{*}{1.89} \\
\hline & & Test 2 & 1.88 & \\
\hline & & Test 3 & 1.89 & \\
\hline
\end{tabular}


Table 4.4: Experimental results of damping ratio of unbraced wooden joist

\begin{tabular}{|c|c|c|c|c|}
\hline $\begin{array}{c}\text { Joist } \\
\text { depth, } \\
\text { d (mm) }\end{array}$ & $\begin{array}{c}\text { Joist } \\
\text { length }(\mathrm{m})\end{array}$ & Tests & $\begin{array}{c}\text { Damping } \\
\text { ratio, } \beta_{\mathrm{d}}\end{array}$ & $\begin{array}{c}\text { Total avg. } \\
\beta_{\mathrm{d}}\end{array}$ \\
\hline \multirow{3}{*}{241} & \multirow{3}{*}{3.50} & Test 1 & $4.94 \%$ & \multirow{3}{*}{$5.18 \%$} \\
\hline & & Test 2 & $4.96 \%$ & \\
\hline & & Test 3 & $5.64 \%$ & \\
\hline \multirow{3}{*}{241} & \multirow{3}{*}{4.50} & Test 1 & $3.98 \%$ & \multirow{3}{*}{$3.80 \%$} \\
\hline & & Test 2 & $3.57 \%$ & \\
\hline & & Test 3 & $3.85 \%$ & \\
\hline \multirow{3}{*}{302} & \multirow{3}{*}{5.00} & Test 1 & $3.66 \%$ & \multirow{3}{*}{$3.59 \%$} \\
\hline & & Test 2 & $3.45 \%$ & \\
\hline & & Test 3 & $3.66 \%$ & \\
\hline \multirow{3}{*}{302} & \multirow{3}{*}{5.25} & Test 1 & $3.45 \%$ & \multirow{3}{*}{$3.45 \%$} \\
\hline & & Test 2 & $3.45 \%$ & \\
\hline & & Test 3 & $3.45 \%$ & \\
\hline \multirow{3}{*}{356} & \multirow{3}{*}{6.10} & Test 1 & $3.77 \%$ & \multirow{3}{*}{$3.77 \%$} \\
\hline & & Test 2 & $3.77 \%$ & \\
\hline & & Test 3 & $3.77 \%$ & \\
\hline \multirow{3}{*}{406} & \multirow{3}{*}{7.95} & Test 1 & $3.46 \%$ & \multirow{3}{*}{$3.46 \%$} \\
\hline & & Test 2 & $3.46 \%$ & \\
\hline & & Test 3 & $3.46 \%$ & \\
\hline
\end{tabular}


Table 4.5: Experimental results of damping ratio of braced wooden joist

\begin{tabular}{|c|c|c|c|c|}
\hline $\begin{array}{c}\text { Joist } \\
\text { depth, } \\
\text { d (mm) }\end{array}$ & $\begin{array}{c}\text { Joist } \\
\text { length }(\mathrm{m})\end{array}$ & Tests & $\begin{array}{c}\text { Damping } \\
\text { ratio, } \beta_{\mathrm{d}}\end{array}$ & $\begin{array}{c}\text { Total avg. } \\
\beta_{\mathrm{d}}\end{array}$ \\
\hline \multirow{3}{*}{241} & \multirow{3}{*}{3.50} & Test 1 & $7.72 \%$ & \multirow{3}{*}{$6.69 \%$} \\
\hline & & Test 2 & $6.75 \%$ & \\
\hline & & Test 3 & $5.59 \%$ & \\
\hline \multirow{3}{*}{241} & \multirow{3}{*}{4.50} & Test 1 & $3.87 \%$ & \multirow{3}{*}{$3.87 \%$} \\
\hline & & Test 2 & $3.87 \%$ & \\
\hline & & Test 3 & $3.87 \%$ & \\
\hline \multirow{3}{*}{302} & \multirow{3}{*}{5.00} & Test 1 & $3.53 \%$ & \multirow{3}{*}{$3.53 \%$} \\
\hline & & Test 2 & $3.53 \%$ & \\
\hline & & Test 3 & $3.53 \%$ & \\
\hline \multirow{3}{*}{302} & \multirow{3}{*}{5.25} & Test 1 & $3.70 \%$ & \multirow{3}{*}{$3.70 \%$} \\
\hline & & Test 2 & $3.70 \%$ & \\
\hline & & Test 3 & $3.70 \%$ & \\
\hline \multirow{3}{*}{356} & \multirow{3}{*}{6.10} & Test 1 & $4.83 \%$ & \multirow{3}{*}{$4.83 \%$} \\
\hline & & Test 2 & $4.83 \%$ & \\
\hline & & Test 3 & $4.83 \%$ & \\
\hline \multirow{3}{*}{406} & \multirow{3}{*}{7.95} & Test 1 & $3.45 \%$ & \multirow{3}{*}{$3.57 \%$} \\
\hline & & Test 2 & $3.80 \%$ & \\
\hline & & Test 3 & $3.48 \%$ & \\
\hline
\end{tabular}


Table 4.6: Ultimate jacking load and corresponding deflection of wooden joists subjected to flexural loading

\begin{tabular}{|c|c|c|c|}
\hline $\begin{array}{c}\text { Joist } \\
\text { depth, } \\
\mathrm{d}(\mathrm{mm})\end{array}$ & $\begin{array}{c}\text { Joist } \\
\text { length }(\mathrm{m})\end{array}$ & $\begin{array}{c}\text { Applied } \\
\text { load, } \\
\mathrm{P}(\mathrm{kN})\end{array}$ & $\begin{array}{c}\text { Average } \\
\Delta(\mathrm{mm})\end{array}$ \\
\hline 241 & 3.50 & 81.76 & 35.29 \\
\hline 241 & 4.50 & 57.80 & 54.37 \\
\hline 302 & 5.00 & 50.25 & 49.04 \\
\hline 302 & 5.25 & 37.75 & 43.11 \\
\hline 356 & 6.10 & 45.15 & 50.22 \\
\hline 406 & 7.95 & 70.78 & 73.79 \\
\hline
\end{tabular}

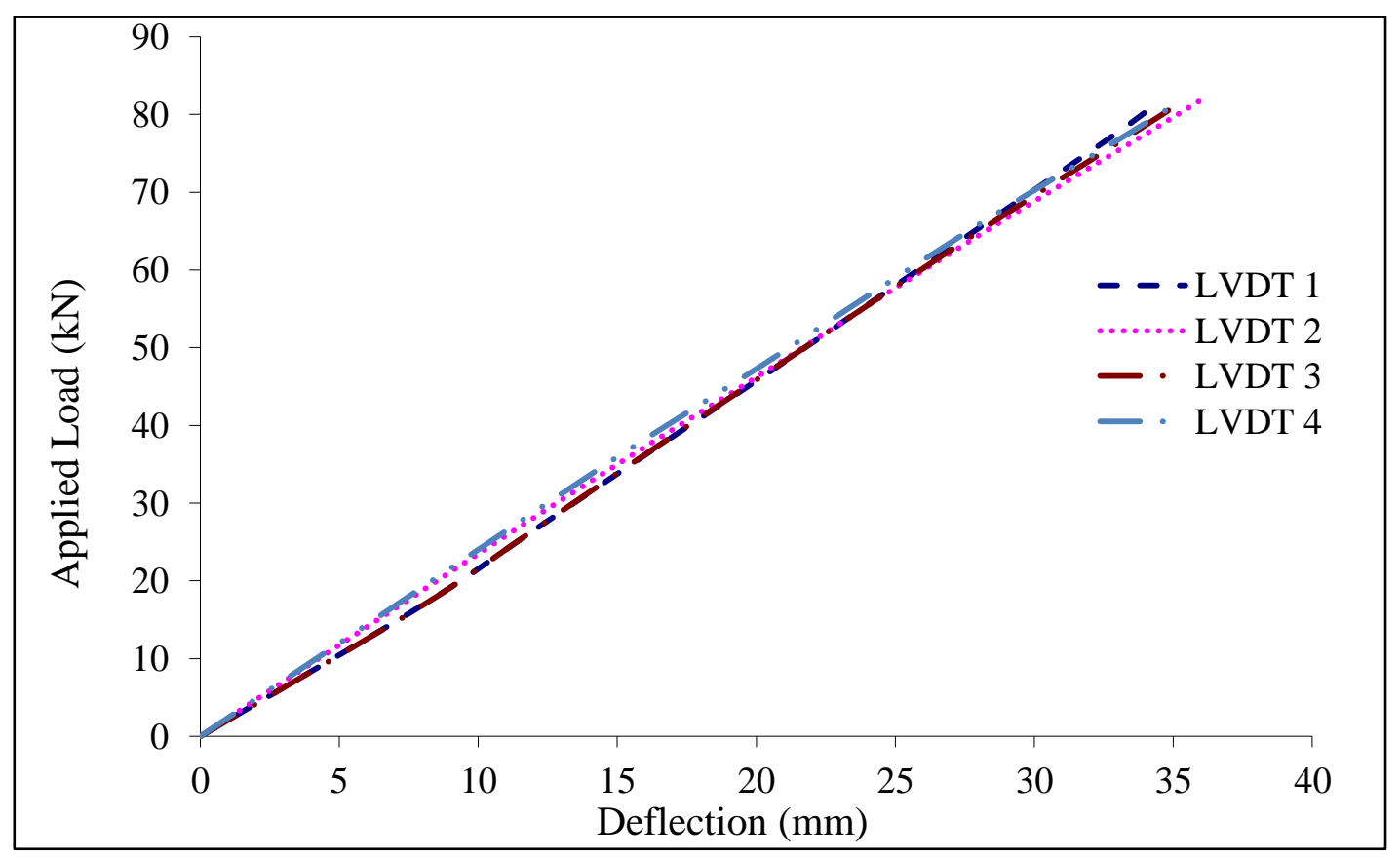

Figure 4.3: Typical jacking load-deflection relationship for the $241 \times 3500 \mathrm{~mm}$ wooden floor joist assembly

Table 4.6 summarizes the ultimate jacking load and the corresponding maximum deflection of wooden floor assembly when subjected to uniform gravity loading. Figure 4.3 represents an example of the jacking load-deflection relationship obtained for the $241 \times 3500 \mathrm{~mm}$ wood joist assembly subjected to flexural uniform loading. Load-deflection relationships of other tested 
wood assemblies listed in Table 3.1 can be found in Appendix A3. Such load-deflection relationships showed linear relationship till failure which gives an indication that the failure of the wood joists tested in this study is not ductile. Figure 4.4 shows view of the deflected shape of the tested timber joist assembly at failure, while Figure 4.5 show close-up view of the failure more at the mid-span region. The failure mode of such wood assembly was observed to be primarily due to bending fracture of the bottom flange and connected OSB sheet. Separation of the OSB web from the top flange of the I-joist was also observed at the mid-span. Views of the failure modes of all the tested wood joist assemblies listed in Table 3.1 are shown in Appendix E. The ultimate load capacities of the tested assemblies will be correlated later with code design methods for ultimate limit state design.

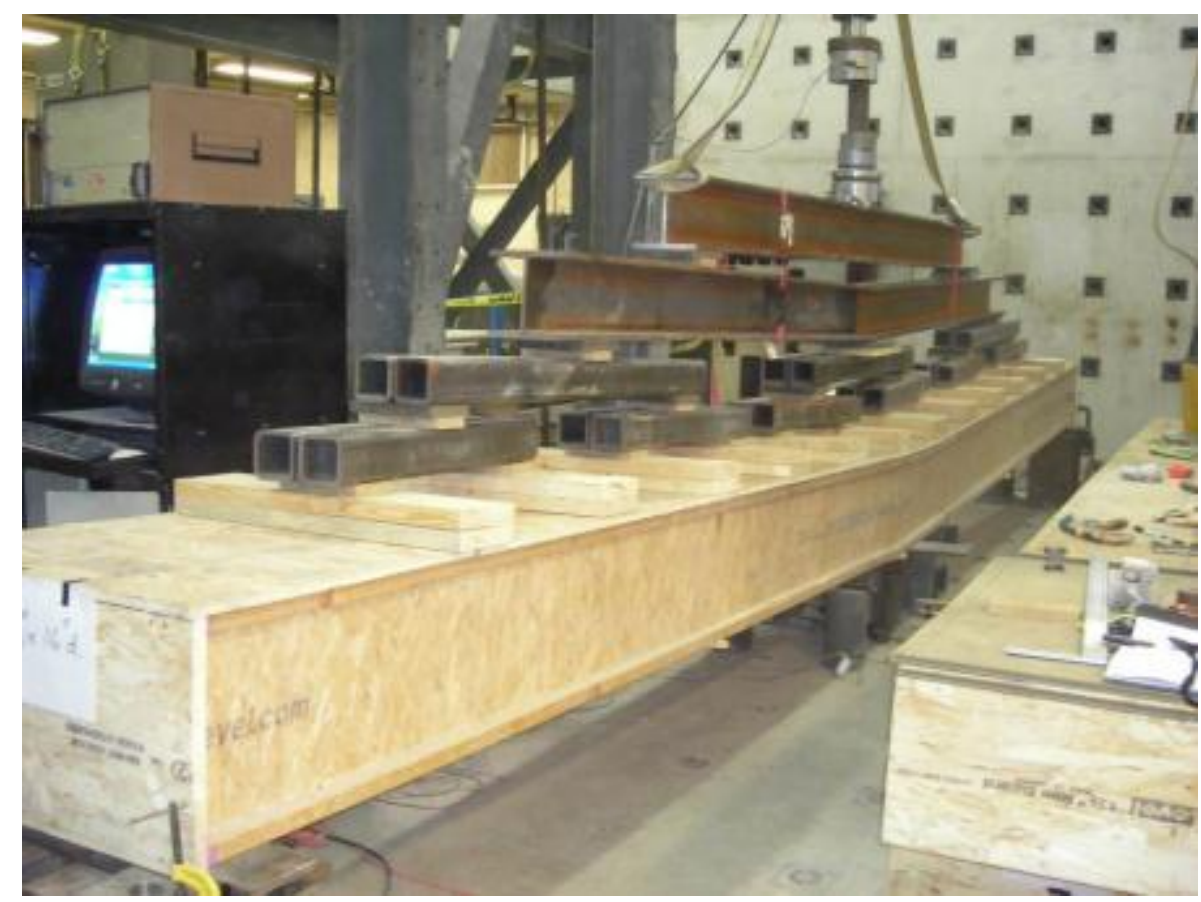

Figure 4.4: View of a wooden twin-joist assembly after pure flexural failure 


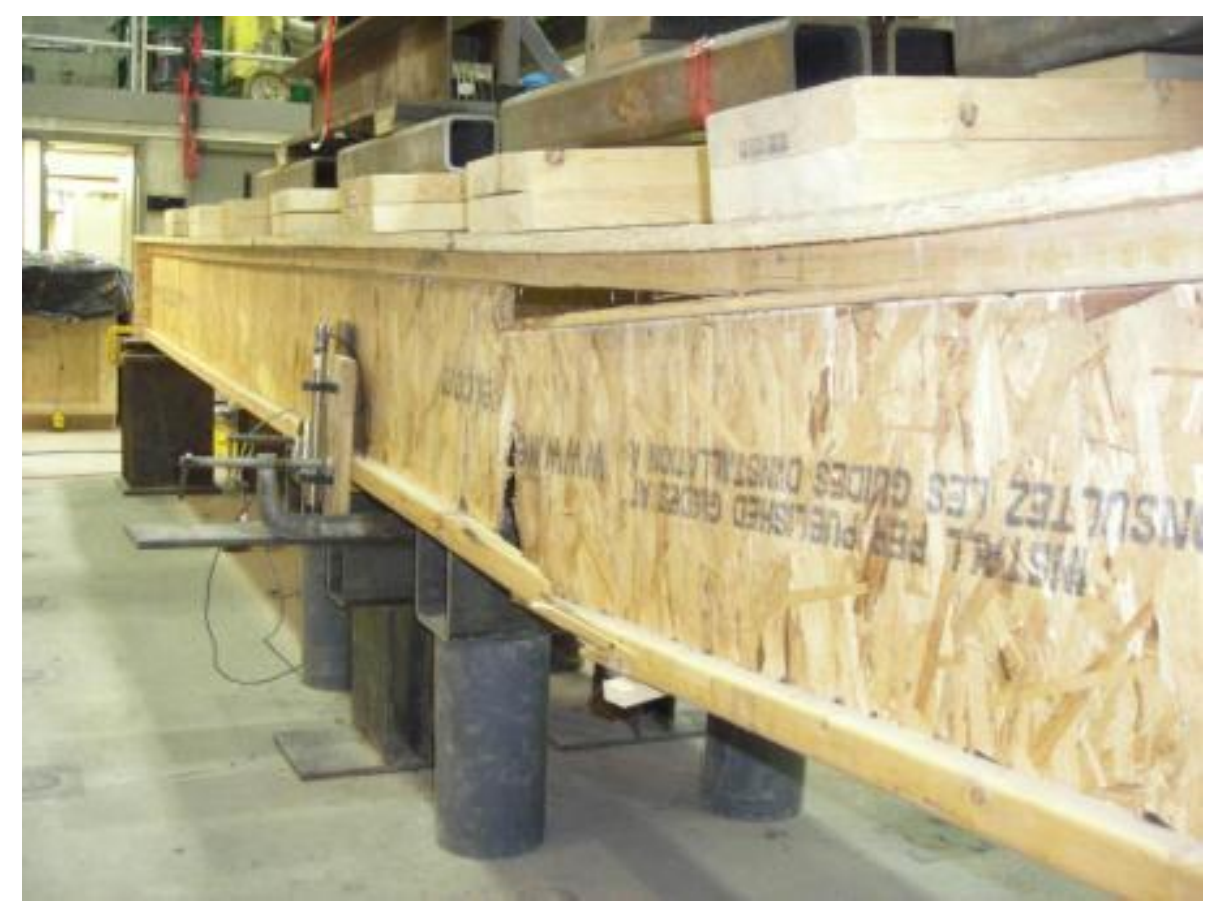

Figure 4.5: Close-up view of a wooden twin-joist assembly showing joist flexural failure and OSB-joist top flange separation

\subsubsection{EXPERIMENTAL FINDINGS FOR ISPAN JOIST ASSEMBLIES}

The free-vibration tests were conducted to provide research date to obtain the natural frequencies and damping rations of the tested iSPAN CFS joist assembly. For example, Figure 4.6 shows the acceleration-time history of the $241 \times 3500 \mathrm{~mm}$ iSPAN joist assembly, while Figure 4.7 shows the resulting frequency spectrum. Acceleration-time history and frequency spectrum for other iSPAN CFS floor assemblies without web holes and with web holes listed in Tables 3.2 and 3.3 are shown in Appendices B1 and B2, respectively. Table 4.7 presents the experimental flexural frequencies of the iSPAN joist assemblies with no web holes and with balloon framing supports. Results from three identical tests were averaged to obtained joist frequencies under free-vibration response. It can be observed that the joist frequency decreased from $36.6 \mathrm{~Hz}$ to $14.22 \mathrm{~Hz}$ with increase in span length from 3.5 to $7.95 \mathrm{~m}$. Table 4.8 presents the results of the joist deflection due to 1-kN concentrated load located at the mid-span of the iSPAN joist with balloon framing and no web holes. It can be observed that deflection increased from $0.49 \mathrm{~mm}$ to $1.33 \mathrm{~mm}$ when joist span increased from 3.5 to $7.95 \mathrm{~m}$, as expected. Table 4.9 summarizes damping ratios of the tested iSPAN joist assemblies with balloon framing supports and no web holes. It can be 
observed that floor damping ratio ranged from 1.87 to $7.73 \%$, with no trend of change with increase in span length.

Similar tested were conducted for the same floor joist assemblies but with simply-supported framing supports. Table 4.10 presents the experimental flexural frequencies of the iSPAN joist assemblies with simply-supported framing supports and no web holes. It can be observed that the joist frequency decreased from $40.73 \mathrm{~Hz}$ to $14.52 \mathrm{~Hz}$ with increase in span length from 3.5 to $7.95 \mathrm{~m}$. Table 4.11 presents the results of the joist deflection due to $1-\mathrm{kN}$ concentrated load located at the mid-span of the iSPAN joist with simply-supported framing and no web holes. It can be observed that deflection increased from $0.55 \mathrm{~mm}$ to $1.54 \mathrm{~mm}$ when joist span increased from 3.5 to $7.95 \mathrm{~m}$, as expected. Table 4.12 summarizes damping ratios of the tested iSPAN joist assemblies with simply-supported framing supports and no web holes. It can be observed that floor damping ratio ranged from 1.75 to $8.90 \%$, with no trend of change with increase in span length. Comparison between experimental findings of floors with balloon framing and simplysupported framing will be discussed later in this Chapter.

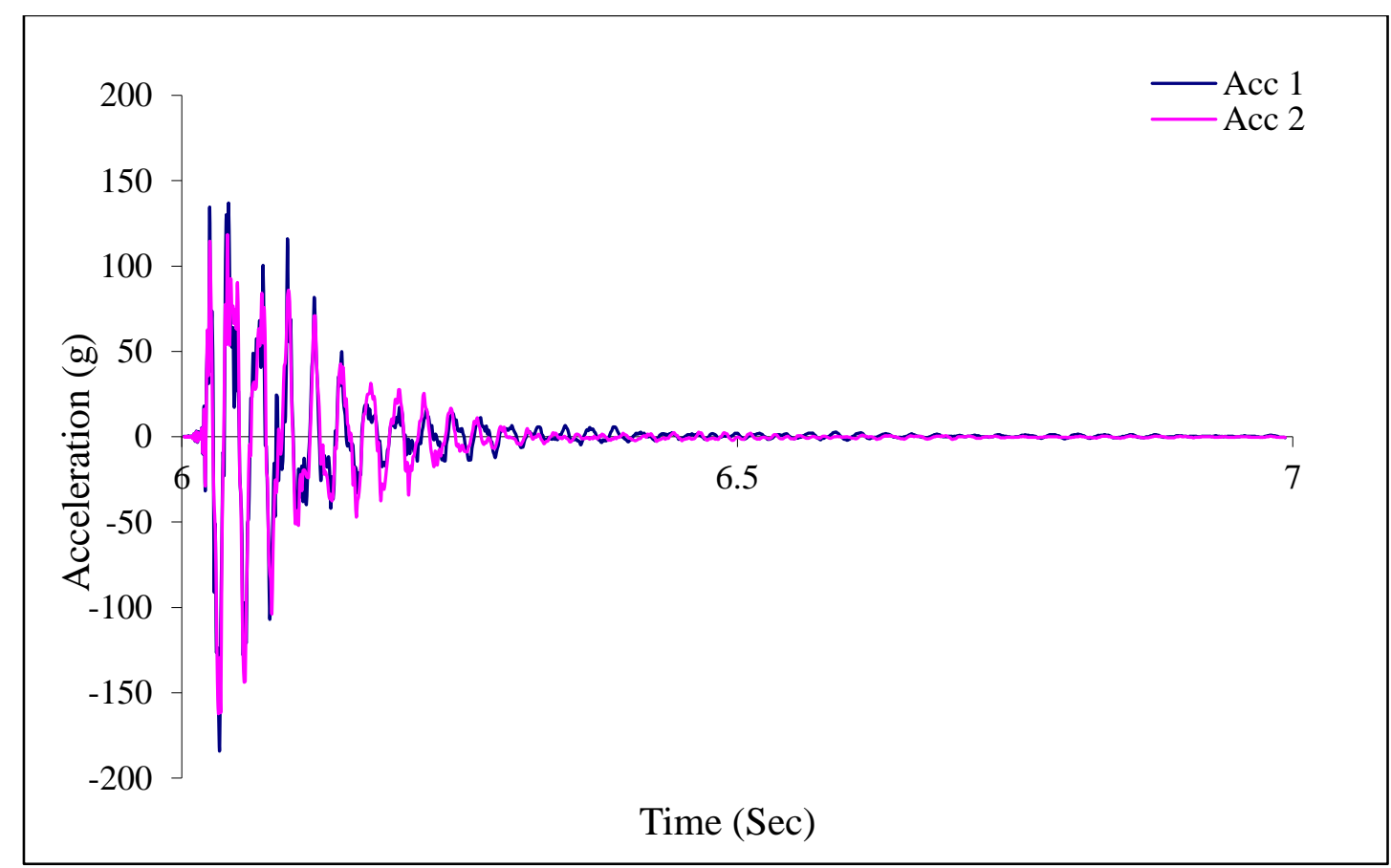

Figure 4.6: Typical acceleration-time trace for the 241x3500 mm iSPAN floor joist assembly (Acc. $1=$ results from accelerometer 1 , Acc. 2 = results from accelerometer 2 ) 


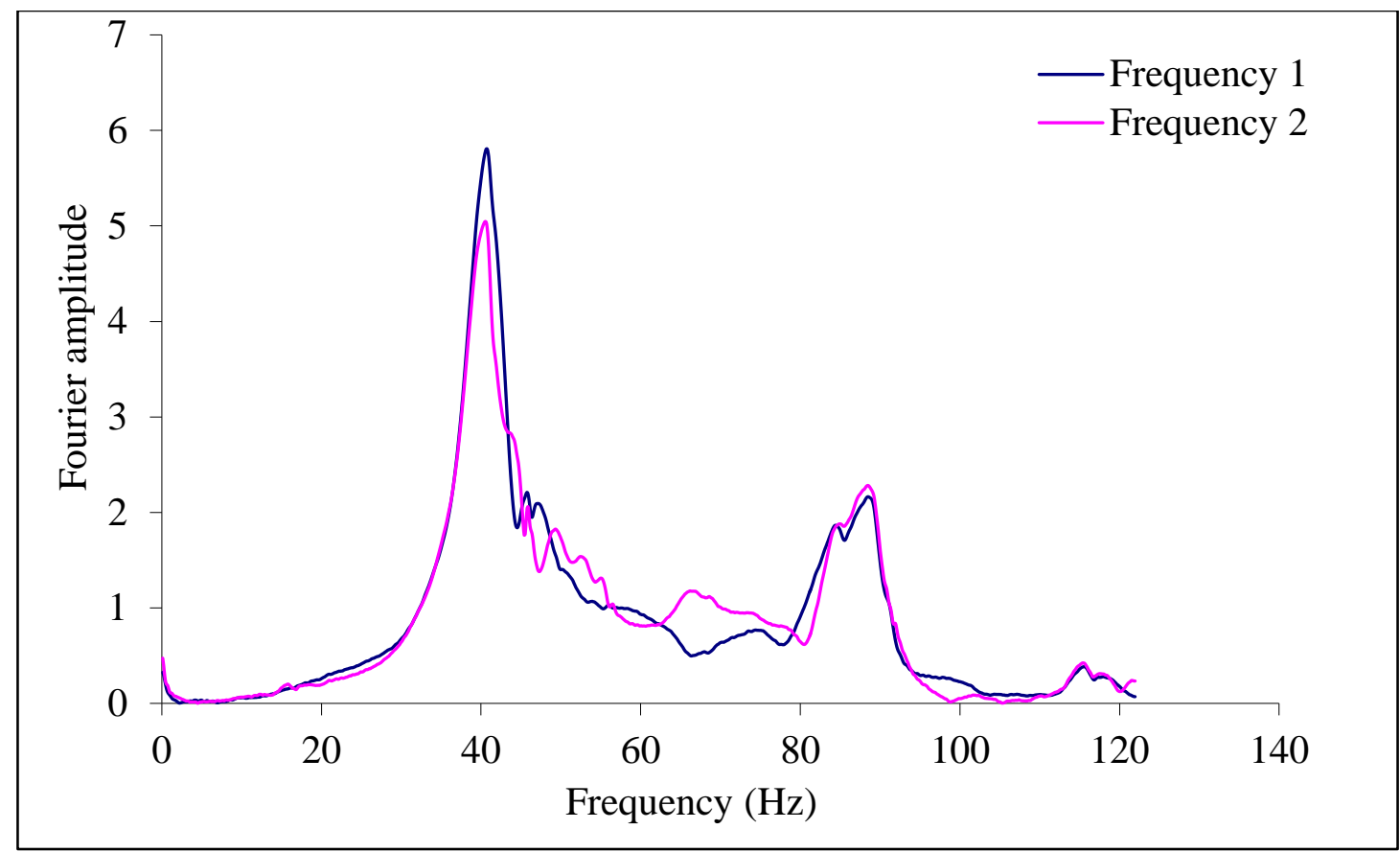

Figure 4.7: Typical frequency spectrum for the 241x3500 mm iSPAN floor joist assembly (Freq $1=$ results from accelerometer 1 , Freq $2=$ results from accelerometer 2 ) 
Table 4.7: Experimental results of flexural frequencies of iSPAN joist with balloon framing support and no web holes

\begin{tabular}{|c|c|c|c|c|}
\hline $\begin{array}{c}\text { Joist } \\
\text { depth, } \\
\text { d (mm) }\end{array}$ & $\begin{array}{c}\text { Joist } \\
\text { length }(\mathrm{m})\end{array}$ & Tests & $\begin{array}{c}\text { Frequency } \\
f(\mathrm{~Hz})\end{array}$ & $\begin{array}{c}\text { Total avg. } \\
f(\mathrm{~Hz})\end{array}$ \\
\hline \multirow{3}{*}{241} & \multirow{3}{*}{3.50} & Test 1 & 36.62 & \multirow{3}{*}{36.36} \\
\hline & & Test 2 & 36.56 & \\
\hline & & Test 3 & 35.89 & \\
\hline \multirow{3}{*}{241} & \multirow{3}{*}{4.50} & Test 1 & 23.80 & \multirow{3}{*}{23.97} \\
\hline & & Test 2 & 23.99 & \\
\hline & & Test 3 & 24.11 & \\
\hline \multirow{3}{*}{302} & \multirow{3}{*}{5.00} & Test 1 & 24.78 & \multirow{3}{*}{24.84} \\
\hline & & Test 2 & 24.84 & \\
\hline & & Test 3 & 24.90 & \\
\hline \multirow{3}{*}{302} & \multirow{3}{*}{5.25} & Test 1 & 22.52 & \multirow{3}{*}{22.52} \\
\hline & & Test 2 & 22.52 & \\
\hline & & Test 3 & 22.52 & \\
\hline \multirow{3}{*}{356} & \multirow{3}{*}{6.10} & Test 1 & 20.14 & \multirow{3}{*}{20.20} \\
\hline & & Test 2 & 20.08 & \\
\hline & & Test 3 & 20.39 & \\
\hline \multirow{3}{*}{406} & \multirow{3}{*}{7.95} & Test 1 & 14.28 & \multirow{3}{*}{14.22} \\
\hline & & Test 2 & 14.16 & \\
\hline & & Test 3 & 14.22 & \\
\hline
\end{tabular}


Table 4.8: Experimental results of 1-kN-load deflection of iSPAN joist with balloon framing support and no web holes

\begin{tabular}{|c|c|c|c|c|}
\hline $\begin{array}{c}\text { Joist } \\
\text { depth, } \\
\text { d (mm) }\end{array}$ & $\begin{array}{c}\text { Joist } \\
\text { length }(\mathrm{m})\end{array}$ & Tests & $\begin{array}{c}\text { Deflection } \\
\text { under } 1 \mathrm{kN} \text {, } \\
\Delta(\mathrm{mm})\end{array}$ & $\begin{array}{l}\text { Total avg. } \\
\Delta_{\text {Tot }}(\mathrm{mm})\end{array}$ \\
\hline \multirow{3}{*}{241} & \multirow{3}{*}{3.50} & Test 1 & 0.49 & \multirow{3}{*}{0.49} \\
\hline & & Test 2 & 0.49 & \\
\hline & & Test 3 & 0.49 & \\
\hline \multirow{3}{*}{241} & \multirow{3}{*}{4.50} & Test 1 & 0.96 & \multirow{3}{*}{0.94} \\
\hline & & Test 2 & 0.94 & \\
\hline & & Test 3 & 0.93 & \\
\hline \multirow{3}{*}{302} & \multirow{3}{*}{5.00} & Test 1 & 0.81 & \multirow{3}{*}{0.81} \\
\hline & & Test 2 & 0.81 & \\
\hline & & Test 3 & 0.81 & \\
\hline \multirow{3}{*}{302} & \multirow{3}{*}{5.25} & Test 1 & 0.88 & \multirow{3}{*}{0.87} \\
\hline & & Test 2 & 0.87 & \\
\hline & & Test 3 & 0.87 & \\
\hline \multirow{3}{*}{356} & \multirow{3}{*}{6.10} & Test 1 & 0.77 & \multirow{3}{*}{0.73} \\
\hline & & Test 2 & 0.71 & \\
\hline & & Test 3 & 0.71 & \\
\hline \multirow{3}{*}{406} & \multirow{3}{*}{7.95} & Test 1 & 1.35 & \multirow{3}{*}{1.33} \\
\hline & & Test 2 & 1.30 & \\
\hline & & Test 3 & 1.36 & \\
\hline
\end{tabular}


Table 4.9: Experimental results of damping ratio, $\beta_{\mathrm{d}}$, of iSPAN joist with balloon framing support and no web holes

\begin{tabular}{|c|c|c|c|c|}
\hline $\begin{array}{c}\text { Joist } \\
\text { depth, } \\
\text { d (mm) }\end{array}$ & $\begin{array}{c}\text { Joist } \\
\text { length (m) }\end{array}$ & Tests & $\begin{array}{c}\text { Damping ratio, } \\
\beta_{\mathrm{d}}\end{array}$ & $\begin{array}{c}\text { Total avg } \\
\beta_{\mathrm{d}}\end{array}$ \\
\hline \multirow{3}{*}{241} & \multirow{3}{*}{3.50} & Test 1 & $7.17 \%$ & \multirow{3}{*}{$7.73 \%$} \\
\hline & & Test 2 & $7.18 \%$ & \\
\hline & & Test 3 & $8.85 \%$ & \\
\hline \multirow{3}{*}{241} & \multirow{3}{*}{4.50} & Test 1 & $6.81 \%$ & \multirow{3}{*}{$6.20 \%$} \\
\hline & & Test 2 & $4.71 \%$ & \\
\hline & & Test 3 & $7.09 \%$ & \\
\hline \multirow{3}{*}{302} & \multirow{3}{*}{5.00} & Test 1 & $8.17 \%$ & \multirow{3}{*}{$7.70 \%$} \\
\hline & & Test 2 & $7.15 \%$ & \\
\hline & & Test 3 & $7.79 \%$ & \\
\hline \multirow{3}{*}{302} & \multirow{3}{*}{5.25} & Test 1 & $3.39 \%$ & \multirow{3}{*}{$3.48 \%$} \\
\hline & & Test 2 & $3.66 \%$ & \\
\hline & & Test 3 & $3.39 \%$ & \\
\hline \multirow{3}{*}{356} & \multirow{3}{*}{6.10} & Test 1 & $5.14 \%$ & \multirow{3}{*}{$5.64 \%$} \\
\hline & & Test 2 & $6.52 \%$ & \\
\hline & & Test 3 & $5.25 \%$ & \\
\hline \multirow{3}{*}{406} & \multirow{3}{*}{7.95} & Test 1 & $1.50 \%$ & \multirow{3}{*}{$1.87 \%$} \\
\hline & & Test 2 & $2.17 \%$ & \\
\hline & & Test 3 & $1.94 \%$ & \\
\hline
\end{tabular}


Table 4.10: Experimental results of flexural frequencies of iSPAN joist with simplysupported framing ends and no web holes

\begin{tabular}{|c|c|c|c|c|}
\hline $\begin{array}{c}\text { Joist } \\
\text { depth, } \\
\text { d (mm) }\end{array}$ & $\begin{array}{c}\text { Joist } \\
\text { length }(\mathrm{m})\end{array}$ & Tests & $\begin{array}{l}\text { Frequency, } f \\
(\mathrm{~Hz})\end{array}$ & $\begin{array}{l}\text { Total avg. } \\
f(\mathrm{~Hz})\end{array}$ \\
\hline \multirow{3}{*}{241} & \multirow{3}{*}{3.50} & Test 1 & 39.86 & \multirow{3}{*}{40.10} \\
\hline & & Test 2 & 39.92 & \\
\hline & & Test 3 & 40.53 & \\
\hline \multirow{3}{*}{241} & \multirow{3}{*}{4.50} & Test 1 & 25.70 & \multirow{3}{*}{25.45} \\
\hline & & Test 2 & 25.33 & \\
\hline & & Test 3 & 25.33 & \\
\hline \multirow{3}{*}{302} & \multirow{3}{*}{5.00} & Test 1 & 27.10 & \multirow{3}{*}{26.98} \\
\hline & & Test 2 & 26.92 & \\
\hline & & Test 3 & 26.92 & \\
\hline \multirow{3}{*}{302} & \multirow{3}{*}{5.25} & Test 1 & 24.11 & \multirow{3}{*}{24.05} \\
\hline & & Test 2 & 24.11 & \\
\hline & & Test 3 & 23.93 & \\
\hline \multirow{3}{*}{356} & \multirow{3}{*}{6.10} & Test 1 & 23.13 & \multirow{3}{*}{23.01} \\
\hline & & Test 2 & 23.19 & \\
\hline & & Test 3 & 22.71 & \\
\hline \multirow{3}{*}{406} & \multirow{3}{*}{7.95} & Test 1 & 14.40 & \multirow{3}{*}{14.32} \\
\hline & & Test 2 & 14.28 & \\
\hline & & Test 3 & 14.28 & \\
\hline
\end{tabular}


Table 4.11: Experimental results of 1-kN-load deflection of iSPAN joist with simplysupported framing ends and no web holes

\begin{tabular}{|c|c|c|c|c|}
\hline $\begin{array}{c}\text { Joist } \\
\text { depth, } \\
\text { d (mm) }\end{array}$ & $\begin{array}{c}\text { Joist } \\
\text { length }(\mathrm{m})\end{array}$ & Tests & $\begin{array}{c}\text { Deflection } \\
\text { under } 1 \mathrm{kN} \text {, } \\
\Delta(\mathrm{mm})\end{array}$ & $\begin{array}{c}\text { Total avg. } \\
\Delta_{\text {Tot }} \mathrm{mm}\end{array}$ \\
\hline \multirow{3}{*}{241} & \multirow{3}{*}{3.50} & Test 1 & 0.55 & \multirow{3}{*}{0.55} \\
\hline & & Test 2 & 0.56 & \\
\hline & & Test 3 & 0.55 & \\
\hline \multirow{3}{*}{241} & \multirow{3}{*}{4.50} & Test 1 & 0.93 & \multirow{3}{*}{0.97} \\
\hline & & Test 2 & 0.98 & \\
\hline & & Test 3 & 0.99 & \\
\hline \multirow{3}{*}{302} & \multirow{3}{*}{5.00} & Test 1 & 0.77 & \multirow{3}{*}{0.75} \\
\hline & & Test 2 & 0.75 & \\
\hline & & Test 3 & 0.74 & \\
\hline \multirow{3}{*}{302} & \multirow{3}{*}{5.25} & Test 1 & 0.92 & \multirow{3}{*}{0.92} \\
\hline & & Test 2 & 0.91 & \\
\hline & & Test 3 & 0.92 & \\
\hline \multirow{3}{*}{356} & \multirow{3}{*}{6.10} & Test 1 & 0.69 & \multirow{3}{*}{0.71} \\
\hline & & Test 2 & 0.69 & \\
\hline & & Test 3 & 0.74 & \\
\hline \multirow{3}{*}{406} & \multirow{3}{*}{7.95} & Test 1 & 1.74 & \multirow{3}{*}{1.54} \\
\hline & & Test 2 & 1.67 & \\
\hline & & Test 3 & 1.22 & \\
\hline
\end{tabular}


Table 4.12: Experimental results of damping ratio, $\beta_{d}$, of iSPAN joist with simplysupported framing ends and no web holes

\begin{tabular}{|c|c|c|c|c|}
\hline $\begin{array}{c}\text { Joist } \\
\text { depth, } \\
\text { d (mm) }\end{array}$ & $\begin{array}{c}\text { Joist } \\
\text { length (m) }\end{array}$ & Tests & $\begin{array}{c}\text { Damping ratio, } \\
\beta_{\mathrm{d}}\end{array}$ & $\begin{array}{c}\text { Total avg. } \\
\beta_{\mathrm{d}}\end{array}$ \\
\hline \multirow{3}{*}{241} & \multirow{3}{*}{3.50} & Test 1 & $5.44 \%$ & \multirow{3}{*}{$5.25 \%$} \\
\hline & & Test 2 & $5.35 \%$ & \\
\hline & & Test 3 & $4.97 \%$ & \\
\hline \multirow{3}{*}{241} & \multirow{3}{*}{4.50} & Test 1 & $9.04 \%$ & \multirow{3}{*}{$8.90 \%$} \\
\hline & & Test 2 & $8.34 \%$ & \\
\hline & & Test 3 & $9.31 \%$ & \\
\hline \multirow{3}{*}{302} & \multirow{3}{*}{5.00} & Test 1 & $3.38 \%$ & \multirow{3}{*}{$2.64 \%$} \\
\hline & & Test 2 & $2.27 \%$ & \\
\hline & & Test 3 & $2.27 \%$ & \\
\hline \multirow{3}{*}{302} & \multirow{3}{*}{5.25} & Test 1 & $4.18 \%$ & \multirow{3}{*}{$4.44 \%$} \\
\hline & & Test 2 & $4.56 \%$ & \\
\hline & & Test 3 & $4.59 \%$ & \\
\hline \multirow{3}{*}{356} & \multirow{3}{*}{6.10} & Test 1 & $5.02 \%$ & \multirow{3}{*}{$4.69 \%$} \\
\hline & & Test 2 & $4.48 \%$ & \\
\hline & & Test 3 & $4.57 \%$ & \\
\hline \multirow{3}{*}{406} & \multirow{3}{*}{7.95} & Test 1 & $2.12 \%$ & \multirow{3}{*}{$1.75 \%$} \\
\hline & & Test 2 & $1.63 \%$ & \\
\hline & & Test 3 & $1.49 \%$ & \\
\hline
\end{tabular}


Table 4.13: Ultimate jacking load and corresponding deflection of iSPAN joists with no web holes subjected to flexural loading

\begin{tabular}{|c|c|c|c|}
\hline $\begin{array}{c}\text { Joist } \\
\text { depth, } \\
\mathrm{d}(\mathrm{mm})\end{array}$ & $\begin{array}{c}\text { Joist } \\
\text { length (m) }\end{array}$ & $\begin{array}{c}\text { Applied } \\
\text { load, } \mathrm{P} \\
(\mathrm{kN})\end{array}$ & $\begin{array}{c}\text { Average } \\
\Delta(\mathrm{mm})\end{array}$ \\
\hline 241 & 3.50 & 104.62 & 24.93 \\
\hline 241 & 4.50 & 69.19 & 39.96 \\
\hline 302 & 5.00 & 49.58 & 34.53 \\
\hline 302 & 5.25 & 54.84 & 31.46 \\
\hline 356 & 6.10 & 62.53 & 33.82 \\
\hline 406 & 7.95 & 60.94 & 51.03 \\
\hline
\end{tabular}

Table 4.13 summarizes the ultimate jacking load and the corresponding maximum deflection of iSPAN CFS floor assembly when subjected to uniform gravity loading. It should be noted that floor assemblies were tested to-collapse with simply-supported framing condition at joist ends. Figure 4.8 represents an example of the jacking load-deflection relationship obtained for the $241 \times 3500 \mathrm{~mm}$ iSPAN joist assembly subjected to flexural uniform loading. Load-deflection relationships of other tested CFS joist assemblies with no web holes listed in Table 3.2 can be found in Appendix B3. Such load-deflection relationships showed linear relationship during a considerable part of the load history. However, non-linear behavior was exhibited in the deflections readings of two LVDTs connected to the failed joist out of the twin-joist assembly, leading to move ductile failure mode in compared to the reported failure in the wooden joist assembly.

As for flexural strain readings, Figure 4.9 shows locations of strain gauges along section depth at mid-span location. While Figure 4.10 depicts the jacking load-strain relationship for the $241 \times 3500 \mathrm{~mm}$ iSPAN floor joist under loading to-collapse. In addition, Figure 4.11 depicts the flexural strain distribution along the joist cross-section depth at different jacking load levels. Results confirm the well-known linear distribution of strains across the joist cross-section. Appendix B4 reports strain readings at mid-span loadings during loading the iSPAN joist assemblies with no web holes to-collapse. 
Views of the failure modes of all the tested iSPAN joist assemblies listed in Tables 3.2 and 3.3 are shown in Appendix E. Figure 4.12 shows view of the deflected shape of the tested iSPAN joist assembly with no web holes at failure which was failure due to lateral torsional buckling. Similar failure more was observed in case of iSPAN joist assembly with web holes as depicted in Figures 4.13 and 4.14. The failure mode of such CFS joist assembly was observed to be primarily due to lateral torsional buckling of the joists. However, local failure occurred at the support due to web and rim board crippling, as depicted in Figure 4.15, which led to joist collapse. This local failure occurred in the $254 \times 3500$ iSPAN joist assembly with web holes as shown in Figure E.27. Other failure occurred in the 406x7950 mm iSPAN joist assembly in the form of local bucking of the lip at the top flange of the joist and local buckling in the web at the same location at the mid-span region as depicted in Figures E.24 and E.25. The ultimate load capacities of the tested assemblies will be correlated later with code design methods for ultimate limit state design.

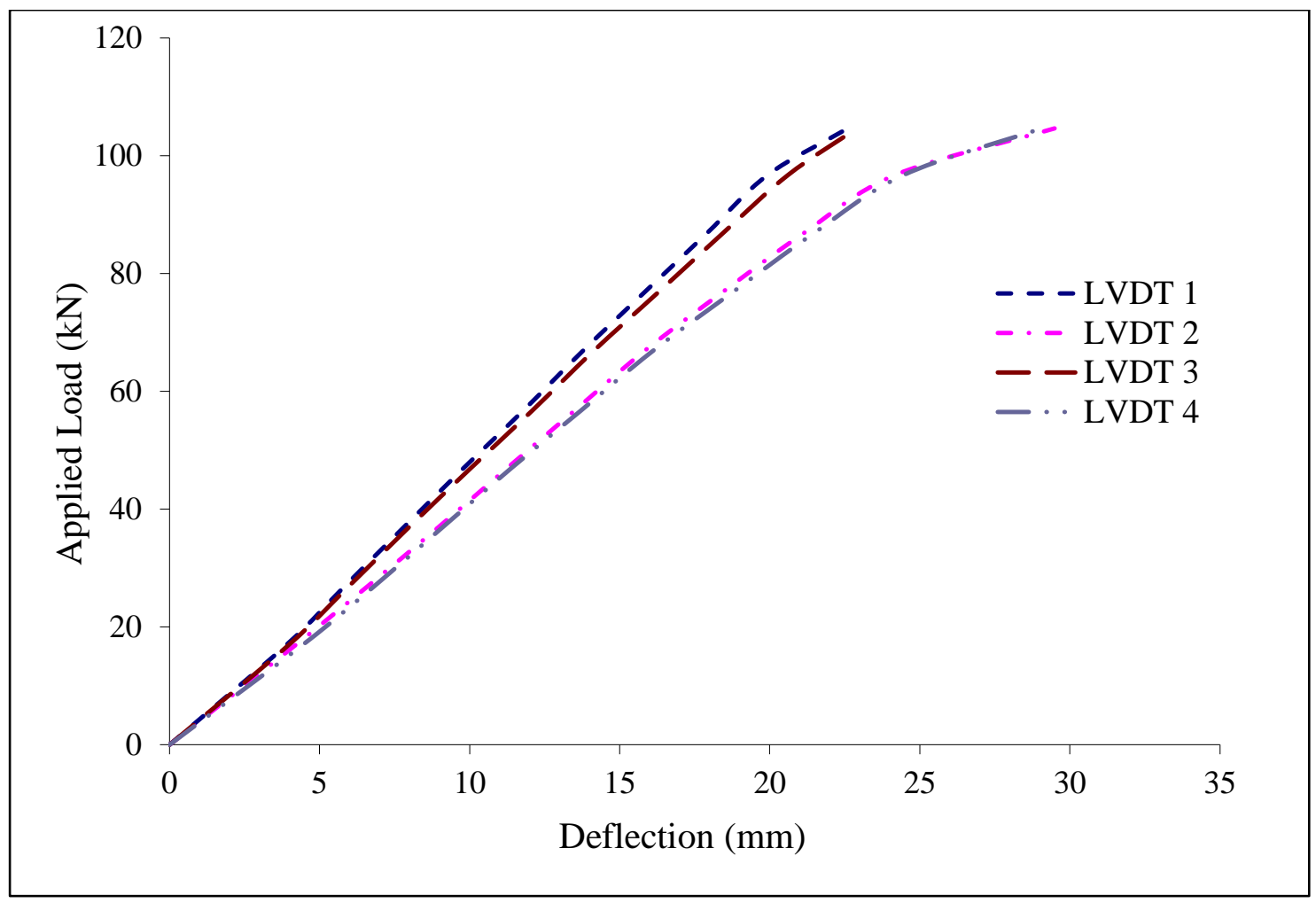

Figure 4.8: Typical jacking load-deflection relationship for the 241x3500 mm iSPAN floor joist assembly 


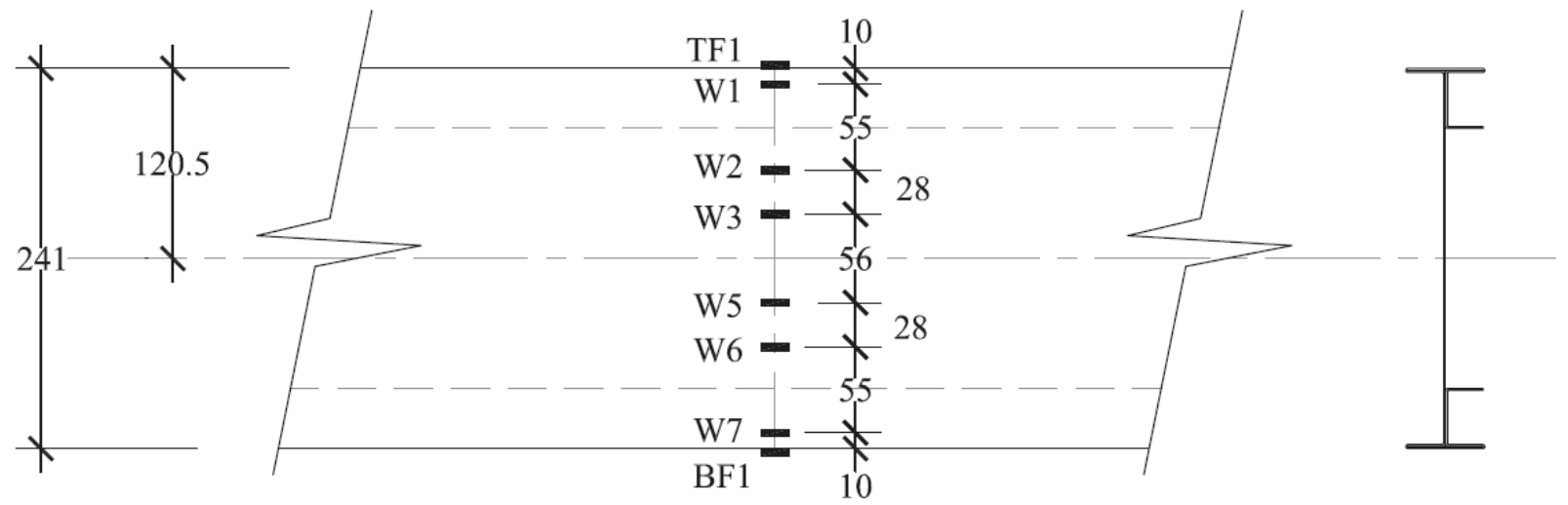

Figure 4.9: Typical strain gauge locations for the 241x3500 mm iSPAN floor joist

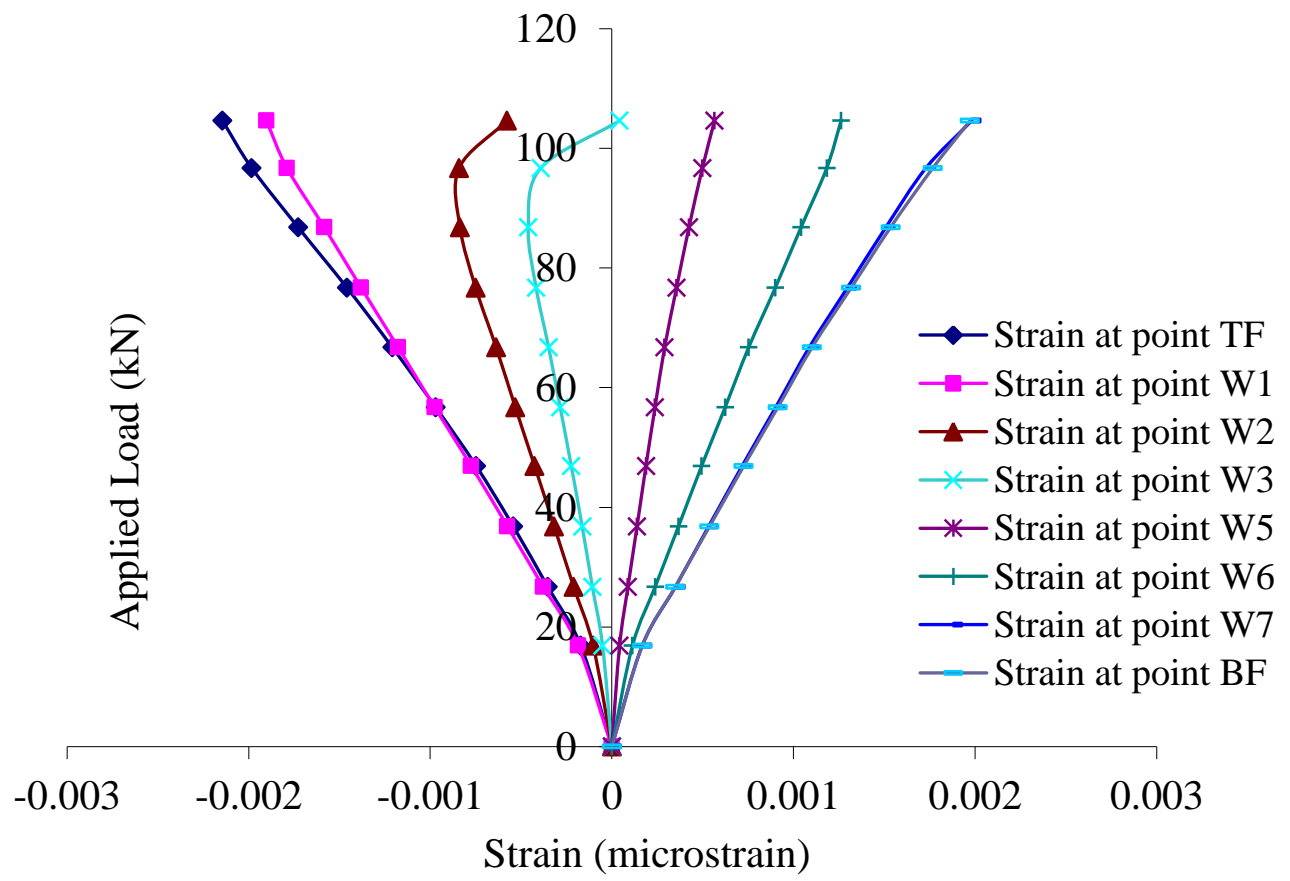

Figure 4.10: View of jacking load-strain relationship for the $241 \times 3500 \mathrm{~mm}$ iSPAN floor joist under flexural loading to-collapse 


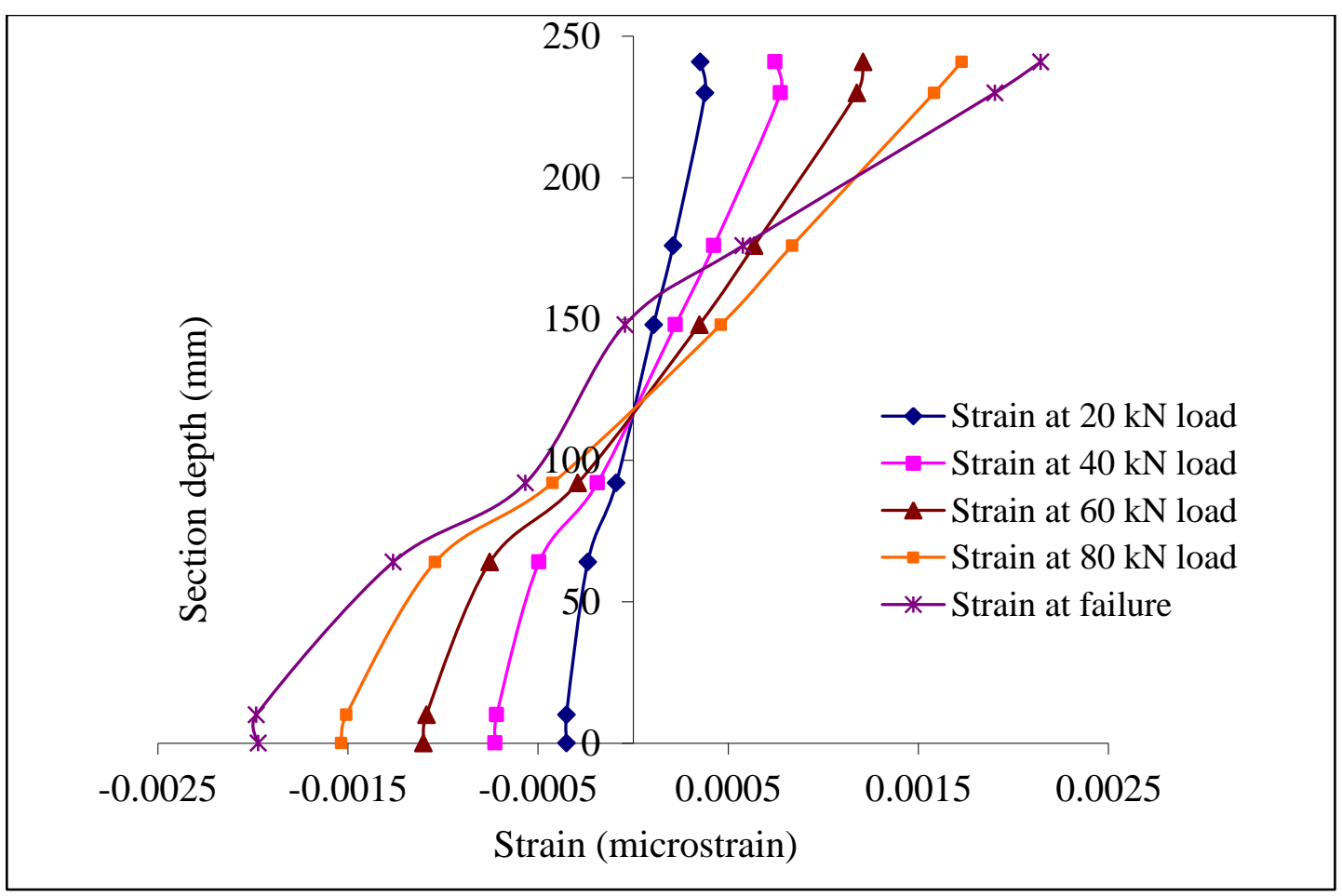

Figure 4.11: Flexural strain distribution along the depth of the 241x3500 mm iSPAN joist crosssection at the mid-span location

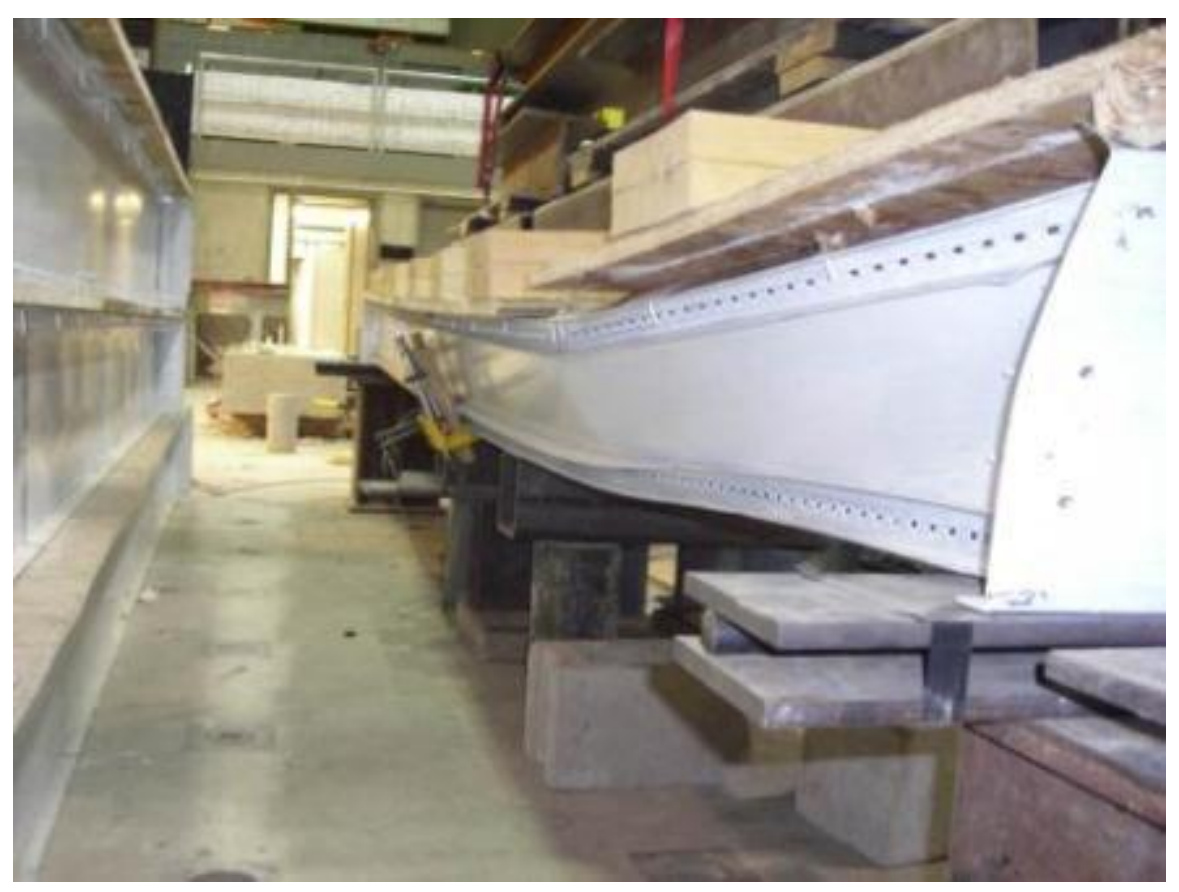

Figure 4.12: View of an iSPAN twin-joist assembly without web holes after failure due to global lateral torsional buckling 


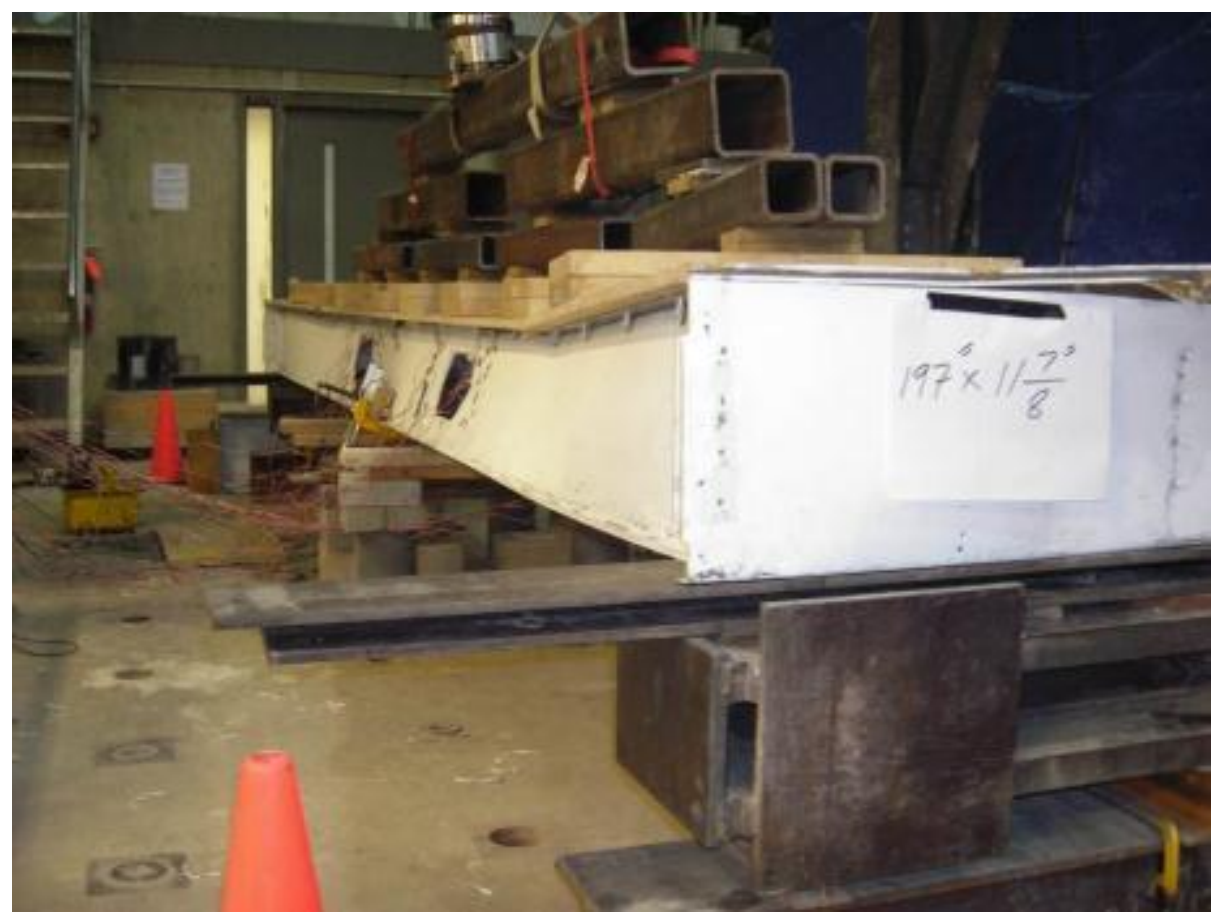

Figure 4.13: View of an iSPAN twin-joist assembly with web hole after failure due to lateral torsional buckling failure 


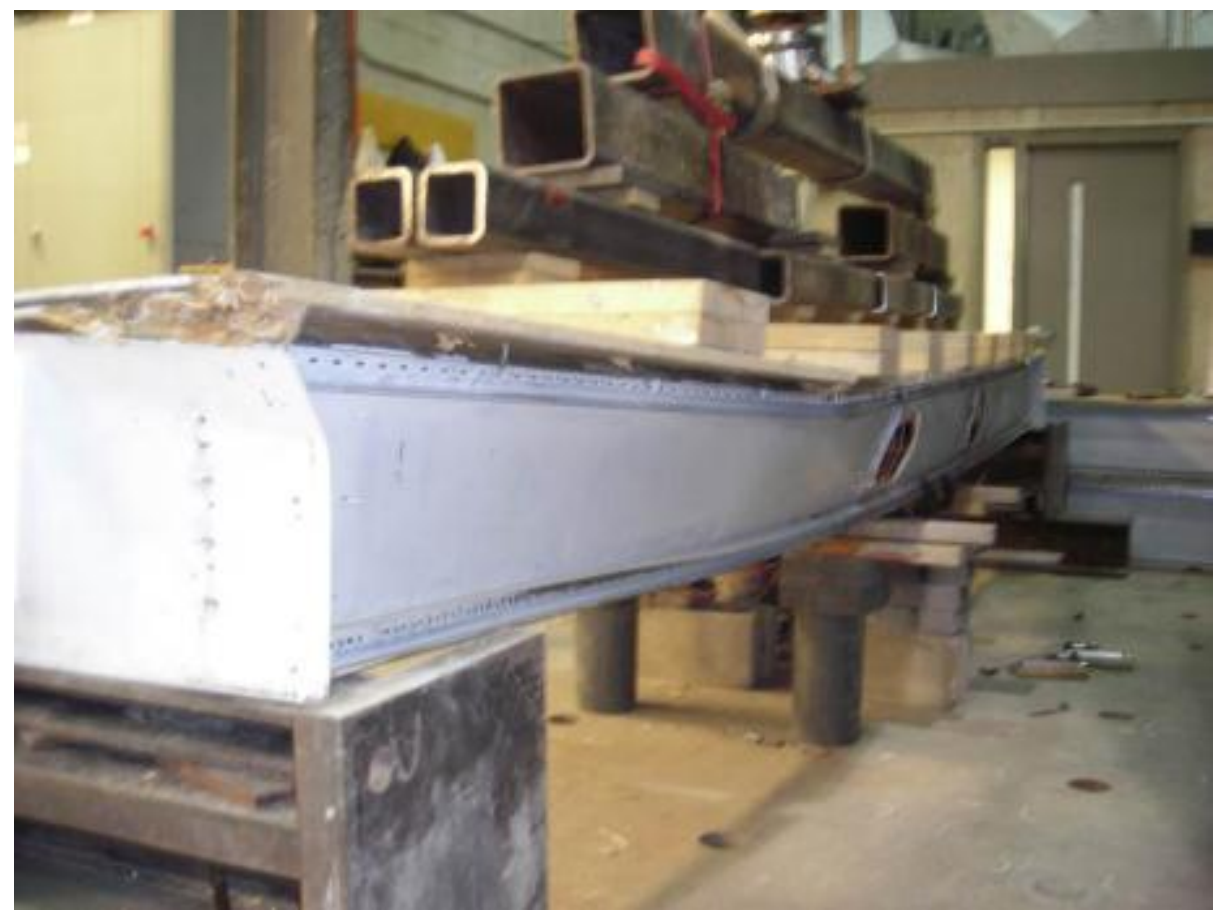

Figure 4.14: View of an iSPAN twin-joist assembly with web hole after failure due to lateral torsional buckling failure

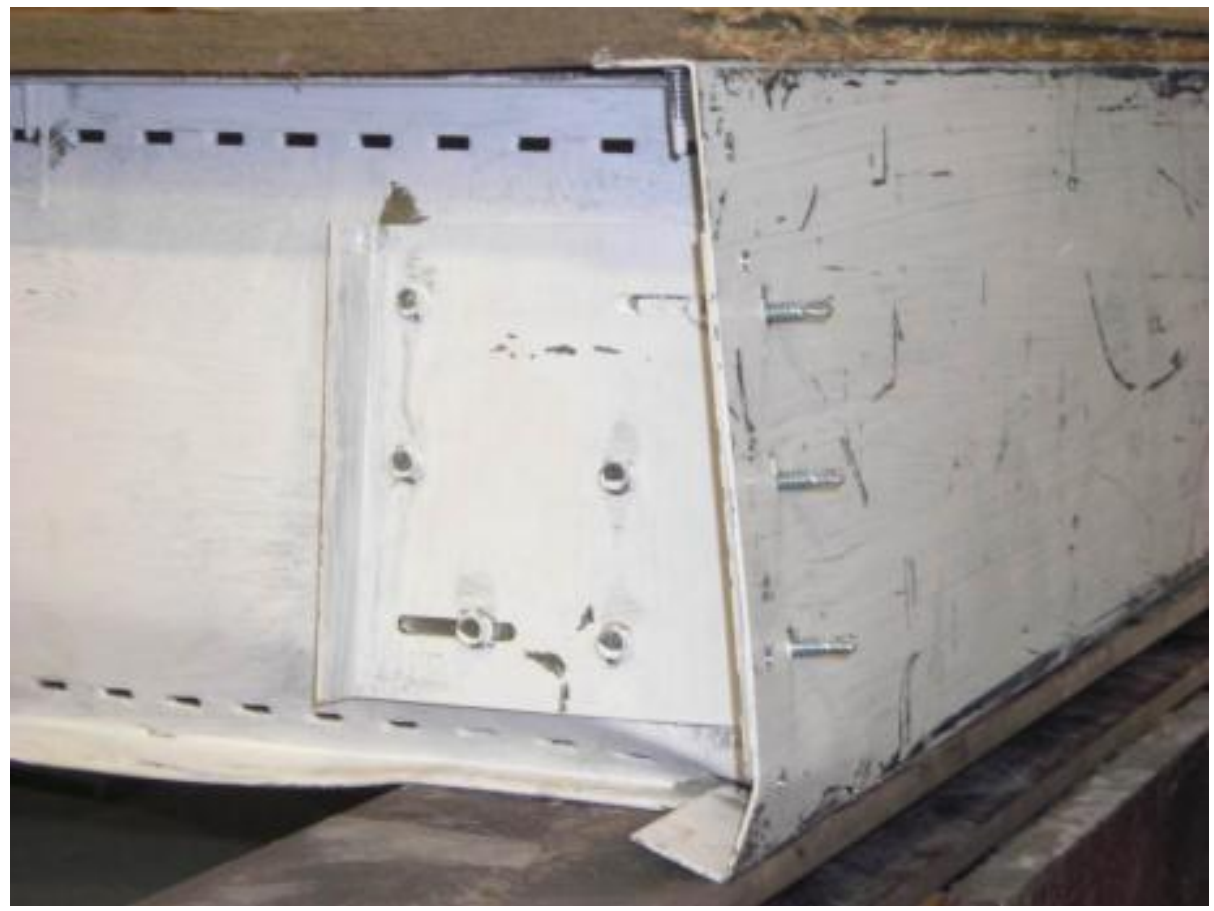

Figure 4.15: View of an iSPAN joist failed due to web crippling at support location 


\subsubsection{EFFECT OF WEB HOLES}

The effect of holes on floor vibration was studied experimentally through testing four iSPAN twin joist assembly shown in Table 3.3 which are identical to those in Table 3.2 except that they have two web holes as discussed in Chapter 3. It should be noted that the two web holes were located close to the mid-span region and reinforced with lip as shown in Figures 3.18 and 3.23. As it will be proven by the finite-element modeling in Chapter 6, the joist with lipped web holes increases the capacity of the web against local buckling when subjected flexural stress gradient. Results from the experimental testing showed that the presence of lip-reinforced holes in the tested iSPAN twin-joist assembly has generally insignificant effect of the dynamic performance of the floor system. For example, comparing frequency values reported in Tables 4.7 and 4.14 for iSPAN joist assemblies without and with web holes, respectively, it can be observed that the floor frequencies changed from $36.60,24.23,25.13$, and $22.64 \mathrm{~Hz}$ to $40.85,27.34,25.96$, and $25.14 \mathrm{~Hz}$ when using web holes per details presented in Chapter 3, for joist spans of 3.5, 4.5, 5.0 and $5.25 \mathrm{~m}$, respectively. Similarly, the 1-kN-load deflection of joists without web holes and those with web holes are listed in Tables 4.8 and 4.15, respectively. It can be observed that the static floor deflection changed from to $0.49,0.94,0.81$ and $0.87 \mathrm{~mm}$ to $0.41,0.83,0.69$ and 0.78 $\mathrm{mm}$ when using web holes per details presented in Chapter 3, for joist spans of 3.5, 4.5, 5.0 and $5.25 \mathrm{~m}$, respectively.

Tables 4.19 and 4.16 reported the experimental damping ratios of iSPAN joists without and with web holes. It can be observed that floor damping ratio changed from 7.73, 6.2, 7.70 and $3.48 \%$ to 7.85, 6.04, 5.97 and 3.44\% when using lip-reinforced web holes for joist spans of 3.5, 4.5, 5.0 and $5.25 \mathrm{~m}$, respectively. This proves that the presence of web opening per details shown in Chapter 3 generally has insignificant effect on floor damping ratio. While Tables 4.14 to 4.16 reported results of joists with balloon framing and reinforced web holes, Tables 4.17 to 4.19 present similar results for joists with simply-supported framing and reinforced web holes, leading to similar general conclusions regarding the effect of web holes on the dynamic characteristics of the joists. Comparing Tables 4.13 and 4.20 with respect to the ultimate load carrying capacities due to flexural loading for iSPAN joists without and with reinforced web holes, it can be observed that jacking load changed from 104.62, 69.19, 49.58 and $54.84 \mathrm{kN}$ to $97.00,89.00,71.70$ and $62.68 \mathrm{kN}$. Although the change in load carrying capacity is not 
consistent, one may conclude that the presence of the web hole generally increase the load capacity of the larger span joists. On the other hand, the presence of web holes showed to have insignificant effect on the maximum deflection at failure. For example, maximum deflection at failure was reported to be $24.93,39.96,34.53$ and $31.46 \mathrm{~mm}$ for iSPAN joists without web holes as opposed to $21.48,42.70,32.12$ and $30.88 \mathrm{~mm}$ for joists with web holes for joist spans of 3.5 , $4.5,5.0$ and $5.25 \mathrm{~m}$, respectively.

Table 4.14: Experimental results of flexural frequency of iSPAN joist with balloon framing and web holes

\begin{tabular}{|c|c|c|c|c|}
\hline $\begin{array}{c}\text { Joist } \\
\text { depth, } \\
\text { d (mm) }\end{array}$ & $\begin{array}{c}\text { Joist } \\
\text { length (m) }\end{array}$ & Tests & $\begin{array}{c}\text { Frequency, } \\
f(\mathrm{~Hz})\end{array}$ & $\begin{array}{c}\text { Total avg. } \\
f(\mathrm{~Hz})\end{array}$ \\
\hline \multirow{3}{*}{254} & \multirow{3}{*}{3.50} & Test 1 & 41.02 & \multirow{3}{*}{40.85} \\
\hline & & Test 2 & 40.77 & \\
\hline & & Test 3 & 40.77 & \\
\hline \multirow{3}{*}{254} & \multirow{3}{*}{4.50} & Test 1 & 27.35 & \multirow{3}{*}{27.34} \\
\hline & & Test 2 & 27.35 & \\
\hline & & Test 3 & 27.35 & \\
\hline \multirow{3}{*}{302} & \multirow{3}{*}{5.00} & Test 1 & 25.63 & \multirow{3}{*}{25.96} \\
\hline & & Test 2 & 25.88 & \\
\hline & & Test 3 & 26.37 & \\
\hline \multirow{3}{*}{302} & \multirow{3}{*}{5.25} & Test 1 & 25.14 & \multirow{3}{*}{25.14} \\
\hline & & Test 2 & 25.14 & \\
\hline & & Test 3 & 25.14 & \\
\hline
\end{tabular}


Table 4.15: Experimental results of 1-kN-load deflection of iSPAN joist with balloon framing and web holes

\begin{tabular}{|c|c|c|c|c|}
\hline $\begin{array}{c}\text { Joist } \\
\text { depth, } \\
\text { d (mm) }\end{array}$ & $\begin{array}{c}\text { Joist } \\
\text { length }(\mathrm{m})\end{array}$ & Tests & $\begin{array}{c}\text { Deflection } \\
\text { under } 1 \mathrm{kN}, \\
\Delta(\mathrm{mm})\end{array}$ & $\begin{array}{c}\text { Total avg. } \\
\Delta_{\text {Tot }} \mathrm{mm}\end{array}$ \\
\hline \multirow{3}{*}{254} & \multirow{3}{*}{3.50} & Test 1 & 0.42 & \multirow{3}{*}{0.41} \\
\hline & & Test 2 & 0.42 & \\
\hline & & Test 3 & 0.40 & \\
\hline \multirow{3}{*}{254} & \multirow{3}{*}{4.50} & Test 1 & 0.84 & \multirow{3}{*}{0.83} \\
\hline & & Test 2 & 0.83 & \\
\hline & & Test 3 & 0.82 & \\
\hline \multirow{3}{*}{302} & \multirow{3}{*}{5.00} & Test 1 & 0.70 & \multirow{3}{*}{0.69} \\
\hline & & Test 2 & 0.69 & \\
\hline & & Test 3 & 0.70 & \\
\hline \multirow{3}{*}{302} & \multirow{3}{*}{5.25} & Test 1 & 0.67 & \multirow{3}{*}{0.78} \\
\hline & & Test 2 & 0.80 & \\
\hline & & Test 3 & 0.87 & \\
\hline
\end{tabular}


Table 4.16: Experimental results of damping ratio, $\beta_{d}$, of iSPAN joist with balloon framing and web holes

\begin{tabular}{|c|c|c|c|c|}
\hline $\begin{array}{c}\text { Joist } \\
\text { depth, } \\
\text { d (mm) }\end{array}$ & $\begin{array}{c}\text { Joist } \\
\text { length }(\mathrm{m})\end{array}$ & Tests & $\begin{array}{l}\text { Damping } \\
\text { Ratio } \beta_{\mathrm{d}}\end{array}$ & $\begin{array}{c}\text { Total avg. } \\
\beta_{\mathrm{d}}\end{array}$ \\
\hline \multirow{3}{*}{254} & \multirow{3}{*}{3.50} & Test 1 & $8.45 \%$ & \multirow{3}{*}{$7.85 \%$} \\
\hline & & Test 2 & $6.50 \%$ & \\
\hline & & Test 3 & $8.61 \%$ & \\
\hline \multirow{3}{*}{254} & \multirow{3}{*}{4.50} & Test 1 & $5.91 \%$ & \multirow{3}{*}{$6.04 \%$} \\
\hline & & Test 2 & $6.07 \%$ & \\
\hline & & Test 3 & $6.13 \%$ & \\
\hline \multirow{3}{*}{302} & \multirow{3}{*}{5.00} & Test 1 & $5.82 \%$ & \multirow{3}{*}{$5.97 \%$} \\
\hline & & Test 2 & $6.29 \%$ & \\
\hline & & Test 3 & $5.80 \%$ & \\
\hline \multirow{3}{*}{302} & \multirow{3}{*}{5.25} & Test 1 & $2.75 \%$ & \multirow{3}{*}{$3.44 \%$} \\
\hline & & Test 2 & $2.04 \%$ & \\
\hline & & Test 3 & $5.55 \%$ & \\
\hline
\end{tabular}


Table 4.17: Experimental results of flexural frequency of iSPAN joist with simplysupported framing and web holes

\begin{tabular}{|c|c|c|c|c|}
\hline $\begin{array}{c}\text { Joist } \\
\text { depth, } \\
\text { d (mm) }\end{array}$ & $\begin{array}{c}\text { Joist } \\
\text { length }(\mathrm{m})\end{array}$ & Tests & $\begin{array}{c}\text { Frequency, } f \\
(\mathrm{~Hz})\end{array}$ & $\begin{array}{c}\text { Total avg. } \\
f(\mathrm{~Hz})\end{array}$ \\
\hline \multirow{3}{*}{254} & \multirow{3}{*}{3.50} & Test 1 & 46.26 & \multirow{3}{*}{46.41} \\
\hline & & Test 2 & 46.45 & \\
\hline & & Test 3 & 46.51 & \\
\hline \multirow{3}{*}{254} & \multirow{3}{*}{4.50} & Test 1 & 26.37 & \multirow{3}{*}{26.69} \\
\hline & & Test 2 & 26.37 & \\
\hline & & Test 3 & 27.34 & \\
\hline \multirow{3}{*}{302} & \multirow{3}{*}{5.00} & Test 1 & 25.88 & \multirow{3}{*}{26.04} \\
\hline & & Test 2 & 26.37 & \\
\hline & & Test 3 & 25.88 & \\
\hline \multirow{3}{*}{302} & \multirow{3}{*}{5.25} & Test 1 & 24.41 & \multirow{3}{*}{24.25} \\
\hline & & Test 2 & 24.41 & \\
\hline & & Test 3 & 23.93 & \\
\hline
\end{tabular}


Table 4.18: Experimental results of 1-kN-load deflection of iSPAN joist with simplysupported framing and web holes

\begin{tabular}{|c|c|c|c|c|}
\hline $\begin{array}{c}\text { Joist } \\
\text { depth, } \\
\text { d (mm) }\end{array}$ & $\begin{array}{c}\text { Joist } \\
\text { length (m) }\end{array}$ & Tests & $\begin{array}{c}\text { Deflection } \\
\text { under } 1 \mathrm{kN}, \\
\Delta(\mathrm{mm})\end{array}$ & $\begin{array}{c}\text { Total avg. } \\
\Delta_{\text {Tot }} \mathrm{mm}\end{array}$ \\
\hline \multirow{3}{*}{254} & \multirow{3}{*}{3.50} & Test 1 & 0.53 & \multirow{3}{*}{0.54} \\
\hline & & Test 2 & 0.53 & \\
\hline & & Test 3 & 0.56 & \\
\hline \multirow{3}{*}{254} & \multirow{3}{*}{4.50} & Test 1 & 0.85 & \multirow{3}{*}{0.90} \\
\hline & & Test 2 & 0.87 & \\
\hline & & Test 3 & 1.00 & \\
\hline \multirow{3}{*}{302} & \multirow{3}{*}{5.00} & Test 1 & 0.78 & \multirow{3}{*}{0.75} \\
\hline & & Test 2 & 0.68 & \\
\hline & & Test 3 & 0.79 & \\
\hline \multirow{3}{*}{302} & \multirow{3}{*}{5.25} & Test 1 & 0.89 & \multirow{3}{*}{0.85} \\
\hline & & Test 2 & 0.88 & \\
\hline & & Test 3 & 0.79 & \\
\hline
\end{tabular}

Appendices $\mathrm{C} 1, \mathrm{C} 2, \mathrm{C} 3$ and $\mathrm{C} 4$ report the results of acceleration-time histories, natural frequency spectrum, load-deflection relationships and flexural strain diagram at mid-span location of iSPAN joists with web holes, respectively. 
Table 4.19: Experimental results of damping ratio, $\beta_{d}$, of iSPAN joist with simplysupported framing and web holes

\begin{tabular}{|c|c|c|c|c|}
\hline $\begin{array}{c}\text { Joist } \\
\text { depth, } \\
\text { d (mm) }\end{array}$ & $\begin{array}{c}\text { Joist } \\
\text { length }(\mathrm{m})\end{array}$ & Tests & $\begin{array}{c}\text { Damping } \\
\text { ratio, } \beta_{\mathrm{d}}\end{array}$ & $\begin{array}{c}\text { Total avg. } \\
\beta_{\mathrm{d}}(\%)\end{array}$ \\
\hline \multirow{3}{*}{254} & \multirow{3}{*}{3.50} & Test 1 & $3.93 \%$ & \multirow{3}{*}{$4.31 \%$} \\
\hline & & Test 2 & $3.88 \%$ & \\
\hline & & Test 3 & $5.11 \%$ & \\
\hline \multirow{3}{*}{254} & \multirow{3}{*}{4.50} & Test 1 & $3.72 \%$ & \multirow{3}{*}{$4.48 \%$} \\
\hline & & Test 2 & $4.64 \%$ & \\
\hline & & Test 3 & $5.09 \%$ & \\
\hline \multirow{3}{*}{302} & \multirow{3}{*}{5.00} & Test 1 & $6.12 \%$ & \multirow{3}{*}{$6.03 \%$} \\
\hline & & Test 2 & $6.16 \%$ & \\
\hline & & Test 3 & $5.81 \%$ & \\
\hline \multirow{3}{*}{302} & \multirow{3}{*}{5.25} & Test 1 & $4.16 \%$ & \multirow{3}{*}{$4.94 \%$} \\
\hline & & Test 2 & $5.08 \%$ & \\
\hline & & Test 3 & $5.57 \%$ & \\
\hline
\end{tabular}

Table 4.20 Experimental ultimate jacking load and corresponding deflection for iSPAN joists with holes due to flexural loading

\begin{tabular}{|c|c|c|c|}
\hline $\begin{array}{c}\text { Joist } \\
\text { depth, } \\
\mathrm{d}(\mathrm{mm})\end{array}$ & $\begin{array}{c}\text { Joist } \\
\text { length }(\mathrm{m})\end{array}$ & $\begin{array}{c}\text { Applied } \\
\text { load, } \mathrm{P} \\
(\mathrm{kN})\end{array}$ & $\begin{array}{c}\text { Deflection avg. } \\
\Delta(\mathrm{mm})\end{array}$ \\
\hline 254 & 3.50 & 97.00 & 21.48 \\
\hline 254 & 4.50 & 89.09 & 42.70 \\
\hline 302 & 5.00 & 71.70 & 32.12 \\
\hline 302 & 5.25 & 62.68 & 30.88 \\
\hline
\end{tabular}




\subsubsection{TEST SITE EXPERIMENTAL RESULTS}

Appendices D1 and D2 report the results of acceleration-time histories and natural frequency spectrum of iSPAN CFS floors with reinforced web holes at test sites, respectively. Table 4.21 reported floor flexural frequency in site 1 as 28.10 and $28.69 \mathrm{~Hz}$ before and after installing joist bracing, respectively. Thus, attaching the bracing to the joist does not influence floor flexural frequency. On the other hand, presence of joist bracing reduces floor static deflection under 1-kN concentrated load as depicted in Table 4.22. In site 1, the 1-kN static deflection changed from 0.75 to $0.69 \mathrm{~mm}$ after adding joist bracing, a decrease of $8 \%$. This may be attributed to the distribution of the concentrated load to adjacent joists with the presence of bracing. Table 4.23 presents floor damping ratios in the test sites. It can be observed that floor damping ratios in site 1 changed from 5.86 to $8.07 \%$ with the addition of joist bracing. It should be noted that increase in damping ratio improves the vibration performance of the floor. This would make the vibration amplitude decay more quickly and floor vibration will be less noticeable to the occupant. 
Table 4.21: Experimental results for flexural frequencies of iSPAN joists in test sites

\begin{tabular}{|c|c|c|c|c|c|}
\hline Sites & $\begin{array}{l}\text { Joist } \\
\text { depth, d } \\
\text { (mm) }\end{array}$ & $\begin{array}{c}\text { Joist } \\
\text { length }(\mathrm{m})\end{array}$ & Tests & $\begin{array}{c}\text { Frequency, } \\
f(\mathrm{~Hz})\end{array}$ & $\begin{array}{c}\text { Total avg } \\
f(\mathrm{~Hz})\end{array}$ \\
\hline \multirow{3}{*}{$\begin{array}{c}\text { Site } 1 \\
\text { (Unbraced) }\end{array}$} & \multirow{3}{*}{241} & \multirow{3}{*}{5.20} & Test 1 & 28.10 & \multirow{3}{*}{28.10} \\
\hline & & & Test 2 & 28.10 & \\
\hline & & & Test 3 & 28.10 & \\
\hline \multirow{3}{*}{$\begin{array}{c}\text { Site } 1 \\
\text { (Braced) }\end{array}$} & \multirow{3}{*}{241} & \multirow{3}{*}{5.20} & Test 1 & 28.69 & \multirow{3}{*}{28.69} \\
\hline & & & Test 2 & 28.69 & \\
\hline & & & Test 3 & 28.69 & \\
\hline \multirow{3}{*}{$\begin{array}{c}\text { Site } 2 \\
\text { (Unbraced) }\end{array}$} & \multirow{3}{*}{302} & \multirow{3}{*}{7.26} & Test 1 & 15.87 & \multirow{3}{*}{15.46} \\
\hline & & & Test 2 & 14.65 & \\
\hline & & & Test 3 & 15.87 & \\
\hline \multirow{3}{*}{$\begin{array}{c}\text { Site } 3 \\
\text { (Braced) }\end{array}$} & \multirow{3}{*}{241} & \multirow{3}{*}{5.33} & Test 1 & 27.58 & \multirow{3}{*}{27.23} \\
\hline & & & Test 2 & 27.58 & \\
\hline & & & Test 3 & 26.52 & \\
\hline \multirow{3}{*}{$\begin{array}{c}\text { Site } 4 \\
\text { (Braced) }\end{array}$} & \multirow{3}{*}{241} & \multirow{3}{*}{6.50} & Test 1 & 14.89 & \multirow{3}{*}{14.89} \\
\hline & & & Test 2 & 14.89 & \\
\hline & & & Test 3 & 14.89 & \\
\hline
\end{tabular}


Table 4.22: Experimental results of 1-kN-load deflection of iSPAN joists in test sites

\begin{tabular}{|c|c|c|c|c|c|}
\hline Sites & $\begin{array}{c}\text { Joist } \\
\text { depth, d } \\
(\mathrm{mm})\end{array}$ & $\begin{array}{c}\text { Joist } \\
\text { length }(\mathrm{m})\end{array}$ & Tests & $\begin{array}{c}\text { Deflection } \\
\text { under } 1 \\
\mathrm{kN}, \Delta \\
(\mathrm{mm})\end{array}$ & $\begin{array}{l}\text { Total avg } \\
\Delta_{\text {Tot }} \mathrm{mm}\end{array}$ \\
\hline \multirow{3}{*}{$\begin{array}{c}\text { Site } 1 \\
\text { (Unbraced) }\end{array}$} & \multirow{3}{*}{241} & \multirow{3}{*}{5.20} & Test 1 & 0.78 & \multirow{3}{*}{0.75} \\
\hline & & & Test 2 & 0.76 & \\
\hline & & & Test 3 & 0.72 & \\
\hline \multirow{3}{*}{$\begin{array}{c}\text { Site } 1 \\
\text { (Braced) }\end{array}$} & \multirow{3}{*}{241} & \multirow{3}{*}{5.20} & Test 1 & 0.70 & \multirow{3}{*}{0.69} \\
\hline & & & Test 2 & 0.69 & \\
\hline & & & Test 3 & 0.69 & \\
\hline \multirow{3}{*}{$\begin{array}{c}\text { Site } 2 \\
\text { (Unbraced) }\end{array}$} & \multirow{3}{*}{302} & \multirow{3}{*}{7.26} & Test 1 & 0.91 & \multirow{3}{*}{0.93} \\
\hline & & & Test 2 & 1.11 & \\
\hline & & & Test 3 & 0.76 & \\
\hline \multirow{3}{*}{$\begin{array}{c}\text { Site } 3 \\
\text { (Braced) }\end{array}$} & \multirow{3}{*}{241} & \multirow{3}{*}{5.33} & Test 1 & 0.65 & \multirow{3}{*}{0.65} \\
\hline & & & Test 2 & 0.65 & \\
\hline & & & Test 3 & 0.65 & \\
\hline \multirow{3}{*}{$\begin{array}{c}\text { Site } 4 \\
\text { (Braced) }\end{array}$} & \multirow{3}{*}{241} & \multirow{3}{*}{6.50} & Test 1 & 1.09 & \multirow{3}{*}{1.09} \\
\hline & & & Test 2 & 1.09 & \\
\hline & & & Test 3 & 1.09 & \\
\hline
\end{tabular}


Table 4.23: Experimental results of damping ratio of iSPAN joists in test sites

\begin{tabular}{|c|c|c|c|c|c|}
\hline Sites & $\begin{array}{c}\text { Joist } \\
\text { depth, d } \\
(\mathrm{mm})\end{array}$ & $\begin{array}{c}\text { Joist } \\
\text { length }(\mathrm{m})\end{array}$ & Tests & $\begin{array}{c}\text { Damping } \\
\text { ratio, } \beta_{\mathrm{d}}\end{array}$ & $\begin{array}{c}\text { Total avg } \\
\beta_{\mathrm{d}}\end{array}$ \\
\hline \multirow{3}{*}{$\begin{array}{c}\text { Site 1 } \\
\text { (Unbraced) }\end{array}$} & \multirow{3}{*}{241} & \multirow{3}{*}{5.20} & Test 1 & $7.68 \%$ & \multirow{3}{*}{$5.86 \%$} \\
\hline & & & Test 2 & $3.90 \%$ & \\
\hline & & & Test 3 & $6.00 \%$ & \\
\hline \multirow{3}{*}{$\begin{array}{c}\text { Site } 1 \\
\text { (Braced) }\end{array}$} & \multirow{3}{*}{241} & \multirow{3}{*}{5.20} & Test 1 & $10.67 \%$ & \multirow{3}{*}{$8.07 \%$} \\
\hline & & & Test 2 & $5.42 \%$ & \\
\hline & & & Test 3 & $8.10 \%$ & \\
\hline \multirow{3}{*}{$\begin{array}{c}\text { Site } 2 \\
\text { (Unbraced) }\end{array}$} & \multirow{3}{*}{302} & \multirow{3}{*}{7.26} & Test 1 & $4.82 \%$ & \multirow{3}{*}{$5.74 \%$} \\
\hline & & & Test 2 & $7.60 \%$ & \\
\hline & & & Test 3 & $4.82 \%$ & \\
\hline \multirow{3}{*}{$\begin{array}{c}\text { Site } 3 \\
\text { (Braced) }\end{array}$} & \multirow{3}{*}{241} & \multirow{3}{*}{5.33} & Test 1 & $2.45 \%$ & \multirow{3}{*}{$2.43 \%$} \\
\hline & & & Test 2 & $2.47 \%$ & \\
\hline & & & Test 3 & $2.39 \%$ & \\
\hline \multirow{3}{*}{$\begin{array}{c}\text { Site } 4 \\
\text { (Braced) }\end{array}$} & \multirow{3}{*}{241} & \multirow{3}{*}{6.50} & Test 1 & $4.18 \%$ & \multirow{3}{*}{$3.74 \%$} \\
\hline & & & Test 2 & $3.89 \%$ & \\
\hline & & & Test 3 & $3.14 \%$ & \\
\hline
\end{tabular}




\subsection{RESULTS COMPARISONS}

\subsubsection{COMPARISON BETWEEN WOODEN TWIN JOIST AND ISPAN TWIN JOIST}

Tables 4.24 to 4.26 show the comparisons between the experimental results of iSPAN twin-joist assembly listed in Table 3.2 and the wooden twin-joist assembly listed in Tables 3.1. Table 4.24 shows the ratio of flexural frequency of iSPAN joist to the wooden joist for each joist span.

It can be observed that iSPAN twin-joist assembly has in average $20 \%$ higher frequency than that for wooden twin-joist assembly designed for the same live load and deflection limit as reported in Chapter 3. Table 4.25 shows the ratio of the experimental static deflection under 1$\mathrm{kN}$ load for iSPAN joist and wooden joist assemblies. It can be observed that the iSPAN twin joist has in average 36\% less deflection than the wooden twin-joist. Similarly, Table 4.26 shows the ratio of the experimental damping ratio of iSPAN joist to the wooden joist. Results show that iSPAN joist has in average $8 \%$ higher damping ratio than wooden joist. In conclusion, iSPAN joist gives better performance than wooden joist with respect to frequency, deflection and damping ratio.

Table 4.24: Experimental frequency comparison between wooden and iSPAN twin-joist assembly

\begin{tabular}{|c|c|c|c|c|}
\hline \multirow{2}{*}{$\begin{array}{c}\text { Joist } \\
\text { depth } \\
(\mathrm{mm})\end{array}$} & \multirow{2}{*}{$\begin{array}{c}\text { Joist } \\
\text { length }\end{array}$} & \multicolumn{2}{|c|}{ Frequency $(\mathrm{mz})$} & \multirow{2}{*}{$f_{\text {iSPAN }} / f_{\text {wood }}$} \\
\cline { 4 - 5 } & & $f_{\text {wood }}$ & $f_{\text {iSPAN }}$ & \\
\hline 241 & 3.50 & 34.77 & 40.73 & 1.17 \\
\hline 241 & 4.50 & 22.18 & 26.59 & 1.20 \\
\hline 302 & 5.00 & 21.61 & 27.04 & 1.25 \\
\hline 302 & 5.25 & 19.73 & 24.15 & 1.22 \\
\hline 356 & 6.10 & 17.72 & 23.19 & 1.31 \\
\hline 406 & 7.95 & 14.12 & 14.51 & 1.03 \\
\hline
\end{tabular}


Table 4.25: Experimental 1-kN-load deflection comparison between wooden and iSPAN twin-joist assembly

\begin{tabular}{|c|c|c|c|c|}
\hline \multirow{2}{*}{$\begin{array}{l}\text { Joist } \\
\text { depth } \\
(\mathrm{mm})\end{array}$} & \multirow{2}{*}{$\begin{array}{l}\text { Joist } \\
\text { length } \\
\text { (m) }\end{array}$} & \multicolumn{2}{|c|}{$\begin{array}{c}\text { Deflection under } 1 \mathrm{kN} \\
\text { load }(\mathrm{mm})\end{array}$} & \multirow{2}{*}{$\begin{array}{c}\Delta_{\text {iSPAN }} / \\
\Delta_{\text {wood }}\end{array}$} \\
\hline & & $\Delta_{\text {wood }}$ & $\Delta_{\mathrm{iSPAN}}$ & \\
\hline 241 & 3.50 & 0.63 & 0.55 & 0.87 \\
\hline 241 & 4.50 & 1.51 & 0.97 & 0.64 \\
\hline 302 & 5.00 & 1.47 & 0.75 & 0.51 \\
\hline 302 & 5.25 & 1.64 & 0.92 & 0.56 \\
\hline 356 & 6.10 & 1.58 & 0.71 & 0.45 \\
\hline 406 & 7.95 & 1.89 & 1.54 & 0.81 \\
\hline & & & Average & 0.64 \\
\hline
\end{tabular}

Table 4.26: Experimental damping ratio comparison between wooden and iSPAN twinjoist assembly

\begin{tabular}{|c|c|c|c|c|}
\hline \multirow{2}{*}{$\begin{array}{c}\text { Joist } \\
\text { depth } \\
(\mathrm{mm})\end{array}$} & \multirow{2}{*}{$\begin{array}{c}\text { Joist } \\
\text { length }\end{array}$} & \multicolumn{2}{|c|}{ Damping ratio, $\beta_{\mathrm{d}}$} & \multirow{2}{*}{$\beta_{\text {iSPAN }} / \beta_{\text {wood }}$} \\
\cline { 3 - 4 } & $(\mathrm{m})$ & $\beta_{\text {wood }}$ & $\beta_{\text {iSPAN }}$ & \\
\hline 241 & 3.50 & 6.69 & 5.25 & 0.78 \\
\hline 241 & 4.50 & 3.87 & 8.9 & 2.30 \\
\hline 302 & 5.00 & 3.53 & 2.64 & 0.75 \\
\hline 302 & 5.25 & 3.7 & 4.44 & 1.20 \\
\hline 356 & 6.10 & 4.83 & 4.69 & 0.97 \\
\hline 406 & 7.95 & 3.57 & 1.75 & 0.49 \\
\hline
\end{tabular}




\subsubsection{COMPARISON BETWEEN BALLOON FRAMING AND SIMPLY-SUPPORTED FRAMING RESULTS.}

Tables 4.27 to 4.29 show the comparisons between the experimental results of iSPAN joists with balloon framing and simply-supported framing conditions. Table 4.27 shows the ratio of the experimental flexural frequency of iSPAN joists with simply-supported framing and balloon frame conditions. It can be observed that the simply-supported framing condition increases floor frequency by $8 \%$ in average. This may be attributed to the fact that balloon framing provides more flexural structural system as compared to the pure simply-supported condition. Table 4.28 shows the ratio of the experimental static deflection under 1-kN concentrated load for simplysupported and balloon framing conditions. Results show that balloon framing condition slightly changed the joist deflection (about 4\% that is considered insignificant). Table 4.29 reports the ratio of the experimental damping ratio for joists with simply-supported framing to that with balloon framing. It can be observed that balloon framing increased floor damping ratio by an average of $8 \%$. In summary, joist simply-supported framing condition leads to higher frequency values while balloon framing conditions has better performance with respect to damping ratio.

Table 4.27: Experimental frequency comparison between iSPAN joists with balloon framing and those with simply-supported framing

\begin{tabular}{|c|c|c|c|c|}
\hline \multirow{2}{*}{$\begin{array}{c}\text { Joist } \\
\text { depth } \\
(\mathrm{mm})\end{array}$} & \multirow{2}{*}{$\begin{array}{c}\text { Joist } \\
\text { length } \\
(\mathrm{m})\end{array}$} & \multicolumn{2}{|c|}{ Frequency $(\mathrm{Hz})$} & \multirow{2}{*}{$f_{\mathrm{SS}} / f_{\mathrm{BF}}$} \\
\cline { 3 - 4 } & $f_{\mathrm{BF}}{ }^{*}$ & $f_{\mathrm{SS}}{ }^{*}$ & \\
\hline 241 & 3.50 & 36.60 & 40.73 & 1.11 \\
\hline 241 & 4.50 & 24.23 & 26.59 & 1.10 \\
\hline 302 & 5.00 & 25.13 & 27.04 & 1.08 \\
\hline 302 & 5.25 & 22.64 & 24.15 & 1.07 \\
\hline 356 & 6.10 & 20.65 & 23.19 & 1.12 \\
\hline 406 & 7.95 & 14.22 & 14.51 & 1.02 \\
\hline
\end{tabular}

${ }^{*} \mathrm{BF}=$ balloon framing, $\mathrm{SS}=$ simply-supported condition 
Table 4.28: Experimental 1-kN-load deflection comparison between iSPAN joists with balloon framing and those with simply-supported framing

\begin{tabular}{|c|c|c|c|c|}
\hline \multirow{2}{*}{$\begin{array}{c}\text { Joist } \\
\text { depth } \\
(\mathrm{mm})\end{array}$} & \multirow{2}{*}{$\begin{array}{c}\text { Joist } \\
\text { length } \\
(\mathrm{m})\end{array}$} & \multicolumn{2}{|c|}{$\Delta(\mathrm{mm})$} & \multirow{2}{*}{$\Delta_{\mathrm{SS}} / \Delta_{\mathrm{BF}}$} \\
\cline { 3 - 4 } & $\Delta_{\mathrm{BF}}{ }^{*}$ & $\Delta_{\mathrm{SS}}{ }^{*}$ & \\
\hline 241 & 3.50 & 0.49 & 0.55 & 1.12 \\
\hline 241 & 4.50 & 0.94 & 0.97 & 1.03 \\
\hline 302 & 5.00 & 0.81 & 0.75 & 0.93 \\
\hline 302 & 5.25 & 0.87 & 0.92 & 1.06 \\
\hline 356 & 6.10 & 0.73 & 0.71 & 0.97 \\
\hline 406 & 7.95 & 1.33 & 1.54 & 1.16 \\
\hline
\end{tabular}

${ }^{*} \mathrm{BF}=$ balloon framing, $\mathrm{SS}=$ simply-supported condition

Table 4.29: Experimental damping ratio comparison between iSPAN joists with balloon framing and those with simply-supported framing

\begin{tabular}{|c|c|c|c|c|}
\hline \multirow{2}{*}{$\begin{array}{c}\text { Joist } \\
\text { depth } \\
(\mathrm{mm})\end{array}$} & \multirow{2}{*}{$\begin{array}{c}\text { Joist } \\
\text { length } \\
(\mathrm{m})\end{array}$} & \multicolumn{2}{|c|}{ Damping ratio, $\beta_{\mathrm{d}}$} & \multirow{2}{*}{$\beta_{\mathrm{SS}} / \beta f_{\mathrm{BF}}$} \\
\cline { 3 - 4 } & $\beta_{\mathrm{BF}}{ }^{*}$ & $\beta f_{\mathrm{SS}}{ }^{*}$ & \\
\hline 241 & 3.50 & 7.73 & 5.25 & 0.68 \\
\hline 241 & 4.50 & 6.2 & 8.9 & 1.44 \\
\hline 302 & 5.00 & 7.7 & 2.64 & 0.34 \\
\hline 302 & 5.25 & 3.48 & 4.44 & 1.28 \\
\hline 356 & 6.10 & 5.64 & 4.69 & 0.83 \\
\hline 406 & 7.95 & 1.87 & 1.75 & 0.94 \\
\hline
\end{tabular}

${ }^{*} \mathrm{BF}=$ balloon framing, $\mathrm{SS}=$ simply-supported condition 


\subsubsection{COMPARISON BETWEEN EXPERIMENTAL RESULTS WITH CANADIAN WOOD COUNCIL DESIGN METHOD (CWC)}

The Canadian wood council (CWC) design method is used to determine the maximum deflection of the laboratory and site tested joists. The CWC design method only provides the procedure for the calculation of deflection, and it does not calculate the frequency of the floor. For the calculation of floor frequency, the ATC design method is used. The results are shown in Table $4.30,4.31,4.32$ and 4.33 in the form of ratio of experimental deflection to CWC deflection $\left(\Delta_{\text {Test }}\right.$ / $\Delta_{\mathrm{CWC}}$ ) and ratio of experimental frequency to ATC frequency ( $\mathrm{f}_{\text {Test }} / \mathrm{f}_{\mathrm{ATC}}$ ) for wood floor assembly, iSPAN joist assemblies without web holes, ISPAN joists with web holes and iSPAN floors in the test sites, respectively. It can be observed that the average $\Delta_{\text {Test }} / \Delta_{\text {CWC }}$ ratios were $1.23,1.20,1.13$ and 1.18 for wood floor assembly, iSPAN joist assemblies without web holes, ISPAN joists with web holes and iSPAN floors in the test sites, respectively. However, the average $\mathrm{f}_{\text {Test }} / \mathrm{f}_{\text {ATC }}$ were $1.00,1.01,1.00$ and 1.02 for wood floor assembly, iSPAN joist assemblies without web holes, ISPAN joists with web holes and iSPAN floors in the test sites, respectively. This supports the conclusion that Canadian wood council (CWC) design method underestimates the 1-kN load deflection while the ATC design method accurately estimates floor flexural frequency.

Table 4.30: Comparison between experimental results of engineered wood twin-joist assembly and CWC design method

\begin{tabular}{|c|c|c|c|c|c|c|c|}
\hline $\begin{array}{c}\text { Joist } \\
\text { depth, d } \\
(\mathrm{mm})\end{array}$ & $\begin{array}{c}\text { Joist } \\
\text { length } \\
(\mathrm{m})\end{array}$ & $\begin{array}{c}\Delta_{\text {Test }} \\
\text { under } \\
1 \mathrm{kN} \\
(\mathrm{mm})\end{array}$ & $\begin{array}{c}\Delta_{\mathrm{CWC}} \\
(\mathrm{mm})\end{array}$ & $\Delta_{\text {Test }} / \Delta_{\mathrm{CWC}}$ & $\begin{array}{c}f_{\text {Test }} \\
(\mathrm{Hz})\end{array}$ & $\begin{array}{c}f_{\mathrm{ATC}} \\
(\mathrm{Hz})\end{array}$ & $f_{\text {Test }} / f_{\text {ATC }}$ \\
\hline 241 & 3.50 & 0.63 & 0.85 & 0.74 & 34.77 & 33.77 & 1.03 \\
\hline 241 & 4.50 & 1.51 & 1.28 & 1.18 & 22.19 & 22.30 & 1.00 \\
\hline 302 & 5.00 & 1.47 & 1.20 & 1.23 & 21.60 & 21.05 & 1.03 \\
\hline 302 & 5.25 & 1.64 & 1.17 & 1.40 & 19.73 & 20.71 & 0.95 \\
\hline 356 & 6.10 & 1.58 & 1.19 & 1.33 & 17.72 & 18.35 & 0.97 \\
\hline 406 & 7.95 & 1.89 & 1.26 & 1.50 & 14.12 & 13.88 & 1.02 \\
\hline & & & & & & &
\end{tabular}


Table 4.31: Comparison between experimental results of iSPAN twin-joist assembly with no web holes and $\mathrm{CWC}$ design method

\begin{tabular}{|c|c|c|c|c|c|c|c|}
\hline $\begin{array}{c}\text { Joist } \\
\text { depth, d } \\
(\mathrm{mm})\end{array}$ & $\begin{array}{c}\text { Joist } \\
\text { length } \\
(\mathrm{m})\end{array}$ & $\begin{array}{c}\Delta_{\text {Test }} \\
\text { under } \\
1 \mathrm{kN} \\
(\mathrm{mm})\end{array}$ & $\begin{array}{c}\Delta_{\mathrm{CWC}} \\
(\mathrm{mm})\end{array}$ & $\Delta_{\text {Test }} / \Delta_{\mathrm{CWC}}$ & $\begin{array}{c}f_{\text {Test }} \\
(\mathrm{Hz})\end{array}$ & $\begin{array}{c}f_{\text {ATC }} \\
(\mathrm{Hz})\end{array}$ & $f_{\text {Test }} / f_{\text {ATC }}$ \\
\hline 241 & 3.50 & 0.55 & 0.48 & 1.15 & 40.73 & 42.96 & 0.95 \\
\hline 241 & 4.50 & 0.97 & 0.85 & 1.14 & 26.59 & 26.11 & 1.02 \\
\hline 302 & 5.00 & 0.75 & 0.71 & 1.06 & 27.04 & 26.41 & 1.02 \\
\hline 302 & 5.25 & 0.92 & 0.79 & 1.16 & 24.15 & 23.92 & 1.01 \\
\hline 356 & 6.10 & 0.71 & 0.68 & 1.04 & 23.19 & 21.85 & 1.06 \\
\hline 406 & 7.95 & 1.54 & 0.94 & 1.64 & 14.51 & 14.60 & 0.99 \\
\hline
\end{tabular}

Table 4.32: Comparison between experimental results of iSPAN twin-joist assembly with web holes and CWC design method

\begin{tabular}{|c|c|c|c|c|c|c|c|}
\hline $\begin{array}{c}\text { Joist } \\
\text { depth } \\
\mathrm{d}(\mathrm{mm})\end{array}$ & $\begin{array}{c}\text { Joist } \\
\text { ength } \\
(\mathrm{m})\end{array}$ & $\begin{array}{c}\Delta_{\text {Test }}^{\text {under }} \\
1 \mathrm{kN} \\
(\mathrm{mm})\end{array}$ & $\begin{array}{c}\Delta_{\mathrm{CWC}} \\
(\mathrm{mm})\end{array}$ & $\Delta_{\text {Test }} / \Delta_{\mathrm{CWC}}$ & $\begin{array}{c}f_{\text {Test }} \\
(\mathrm{Hz})\end{array}$ & $\begin{array}{c}f_{\text {ATC }} \\
(\mathrm{Hz})\end{array}$ & $f_{\text {Test }} / f_{\text {ATC }}$ \\
\hline 254 & 3.5 & 0.54 & 0.44 & 1.23 & 46.22 & 45.19 & 1.02 \\
\hline 254 & 4.5 & 0.9 & 0.78 & 1.15 & 26.37 & 27.47 & 0.96 \\
\hline 302 & 5 & 0.75 & 0.71 & 1.06 & 26.34 & 26.41 & 1 \\
\hline 302 & 5.25 & 0.85 & 0.79 & 1.08 & 24.41 & 23.92 & 1.02 \\
\hline
\end{tabular}


Table 4.33: Comparison between experimental results of iSPAN joists in test sites and CWC design method

\begin{tabular}{|c|c|c|c|c|c|c|c|c|}
\hline Sites & $\begin{array}{c}\text { Joist } \\
\text { depth, d } \\
(\mathrm{mm})\end{array}$ & $\begin{array}{c}\text { Joist } \\
\text { length } \\
(\mathrm{m})\end{array}$ & $\begin{array}{c}\Delta_{\text {Test }} \\
\text { under 1 } \\
\mathrm{kN}\end{array}$ & $\begin{array}{c}\Delta_{\text {cwc }} \\
(\mathrm{mm})\end{array}$ & $\Delta_{\text {Test }} / \Delta_{\text {CWC }}$ & $\begin{array}{c}f_{\text {Test }} \\
(\mathrm{Hz})\end{array}$ & $\begin{array}{c}f_{\text {ATC }} \\
(\mathrm{Hz})\end{array}$ & $f_{\text {Test }} / f_{\text {ATC }}$ \\
\hline $\begin{array}{c}\text { Site 1 } \\
\text { (Unbraced) }\end{array}$ & 241 & 5.48 & 0.75 & 0.70 & 1.07 & 28.08 & 29.71 & 0.95 \\
\hline $\begin{array}{c}\text { Site 1 } \\
\text { (Braced) }\end{array}$ & 241 & 5.48 & 0.69 & 0.55 & 1.25 & 28.73 & 29.71 & 0.97 \\
\hline $\begin{array}{c}\text { Site 2 } \\
\text { (Unbraced) }\end{array}$ & 302 & 7.32 & 0.93 & 0.77 & 1.21 & 15.46 & 14.24 & 1.09 \\
\hline $\begin{array}{c}\text { Site 3 } \\
\text { (Braced) }\end{array}$ & 241 & 6.35 & 0.65 & 0.60 & 1.08 & 27.57 & 27.98 & 0.99 \\
\hline $\begin{array}{c}\text { Site 4 } \\
\text { (Braced) }\end{array}$ & 241 & 6.58 & 1.09 & 0.86 & 1.27 & 14.89 & 13.44 & 1.11 \\
\hline \multicolumn{2}{c}{} & & & Mean & 1.18 & & & 1.02 \\
\hline
\end{tabular}

It should be noted that the floor joist stiffness is calculated using CWC formula to calculate floor deflection, while the ATC formula for effective floor stiffness was used to calculate floor flexural frequency. Figure 4.16 shows a graphical representation of the CWC deflection limit under 1-kN load along with experimental findings for all tested joists. The Figure shows that for joist span lengths less than $3.08 \mathrm{~m}$, the deflection under $1-\mathrm{kN}$ point load should be less $2 \mathrm{~mm}$. However, with increase in span length, the deflection limit deceases. Results reported in Figure 4.16 show that most of the wooden joists considered in this study generally satisfy the CWC design criteria. Only the $241 \times 3500 \mathrm{~mm}$ wooden joist is shown below the CWC deflection limiting line, while all other wooden joist panels are shown above the CWC limiting line. Results show that iSPAN joists perform very well with respect to meeting the CWC deflection limit criteria. It can be observed that all iSPAN joists fall below the CWC limiting line except the 406x7950mm floor joist which is shown falling above the CWC limiting line. As for test site results, static deflections for sites 1 and 3 are shown to fall under the CWC limiting line, while those for sites 2 and 4 fall above the limiting line of CWC design criteria. It should be noted that joists in site 2 were unbraced. The site 2 was unbraced at the time of testing. As such, it may be assumed that if bracing exists, floor deflection could meet the design criteria. As for site 4 , while the floor was fully braced, it was observed that it does not have any partition walls above the 
floor as depicted in Figure 3.55. It is known that partitions across the joists directly influence the transverse stiffness of the floor. The attachment of the bottom plate of wood partition directly to the joist through the subflooring can result in significant improvement. Partitions located parallel to the joist stiffen the floor, which also improves vibration performance (ATC, 1999).

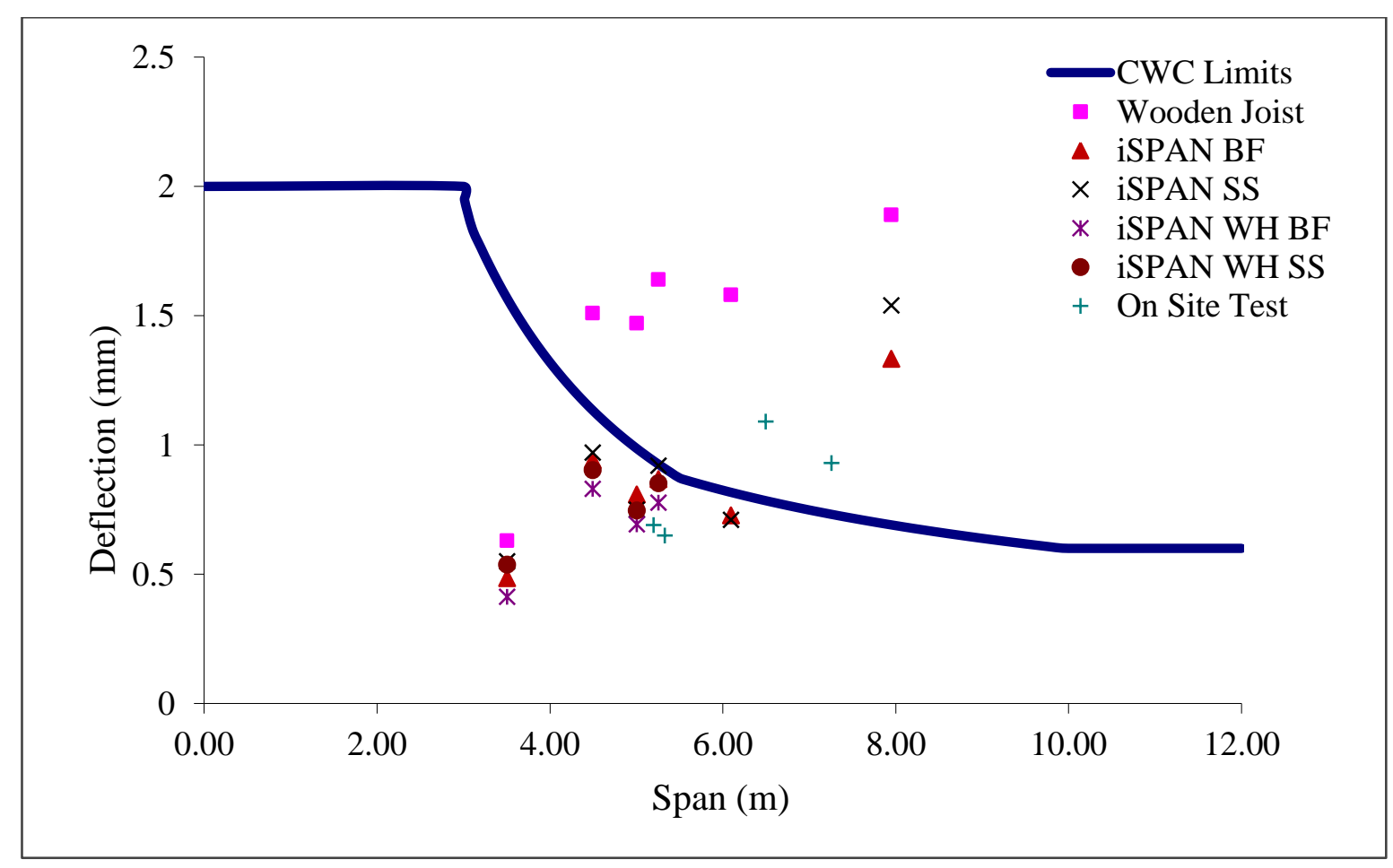

Figure 4.16: Correlation between experimental results and $\mathrm{CWC}$ design criteria $(\mathrm{BF}=$ balloon framing, $\mathrm{SS}=$ simply-supported framing, $\mathrm{WH}=$ joist with web holes) Note: for twin joist multi joist effect was not applied to experimental value

\subsubsection{COMPARISON BETWEEN EXPERIMENTAL RESULTS WITH ATC DESIGN METHOD}

The Applied Technology Council Design method (ATC) is used to determine the max deflection of the laboratory and site tested joists. The results are shown in Table 4.34, 4.35, 4.36 and 4.37 in the form of ratio of experimental deflection to ATC deflection $\left(\Delta_{\text {Test }} / \Delta_{\mathrm{ATC}}\right)$ and ratio of experimental frequency to ATC frequency ( $\mathrm{f}_{\text {Test }} / \mathrm{f}_{\mathrm{ATC}}$ ) for wood floor assembly, iSPAN joist assemblies without web holes, ISPAN joists with web holes and iSPAN floors in the test sites, respectively. It can be observed that the average $\Delta_{\text {Test }} / \Delta_{\mathrm{ATC}}$ ratios were $1.11,1.24,1.25$ and 0.81 
for wood floor assembly, iSPAN joist assemblies without web holes, ISPAN joists with web holes and iSPAN floors in the test sites, respectively. However, the average $f_{\text {Test }} / f_{\text {ATC }}$ were 1.00 , 1.01, 1.00 and 1.39 for wood floor assembly, iSPAN joist assemblies without web holes, ISPAN joists with web holes and iSPAN floors in the test sites, respectively. This supports the conclusion that ATC design method does not show general trend in estimating the 1-kN load deflection s well as floor frequency. As such, it is considered unacceptable. Figure 4.17 shows a graphical representation of the ATC deflection limit under 1-kN load. The figure shows similar trends as those presented in Figure 4.16.

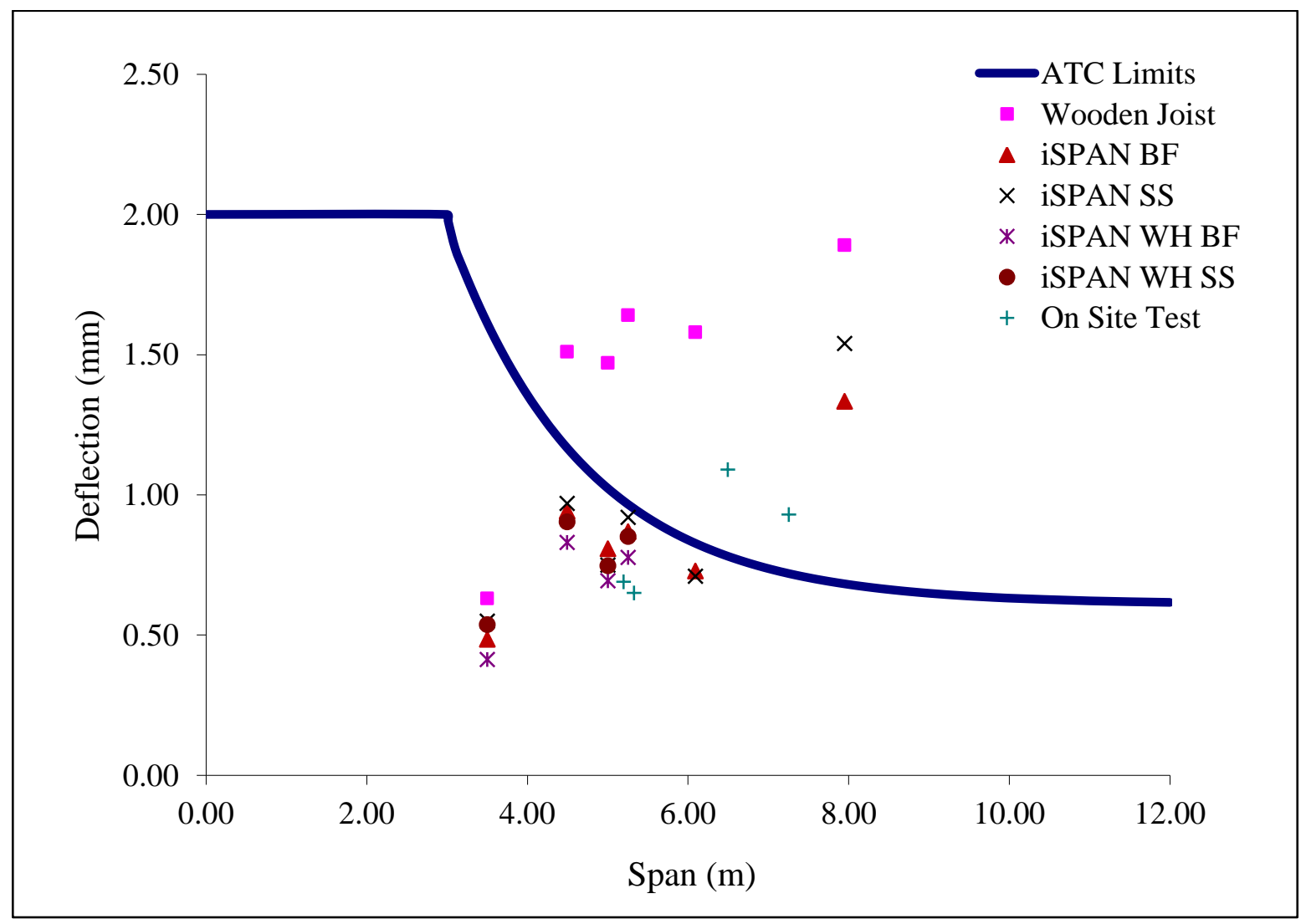

Figure 4.17: Correlation between experimental results and ATC design criteria $(\mathrm{BF}=$ balloon framing, $\mathrm{SS}=$ simply-supported framing, $\mathrm{WH}=$ joist with holes)

Note: for twin joist multi joist effect was not applied to experimental value 
Table 4.34: Comparison between experimental results of engineered wood twin-joist assembly and ATC design method

\begin{tabular}{|c|c|c|c|c|c|c|c|}
\hline $\begin{array}{c}\text { Joist } \\
\text { depth, d } \\
(\mathrm{mm})\end{array}$ & $\begin{array}{c}\text { Joist } \\
\text { length } \\
(\mathrm{m})\end{array}$ & $\begin{array}{c}\Delta_{\text {Test }} \\
\text { under } \\
1 \mathrm{kN} \\
(\mathrm{mm})\end{array}$ & $\begin{array}{c}\Delta_{\text {ATC }} \\
(\mathrm{mm})\end{array}$ & $\Delta_{\text {Test }} / \Delta_{\text {ATC }}$ & $\begin{array}{c}f_{\text {Test }} \\
(\mathrm{Hz})\end{array}$ & $\begin{array}{c}f_{\text {ATC }} \\
(\mathrm{Hz})\end{array}$ & $f_{\text {Test }} / f_{\text {ATC }}$ \\
\hline 241 & 3.50 & 0.63 & 0.76 & 0.83 & 34.77 & 33.77 & 1.03 \\
\hline 241 & 4.50 & 1.51 & 1.36 & 1.11 & 22.19 & 22.30 & 1.00 \\
\hline 302 & 5.00 & 1.47 & 1.31 & 1.12 & 21.60 & 21.05 & 1.03 \\
\hline 302 & 5.25 & 1.64 & 1.28 & 1.28 & 19.73 & 20.71 & 0.95 \\
\hline 356 & 6.10 & 1.58 & 1.36 & 1.16 & 17.72 & 18.35 & 0.97 \\
\hline 406 & 7.95 & 1.89 & 1.60 & 1.18 & 14.12 & 13.88 & 1.02 \\
\hline & & & Mean & 1.11 & & & 1.00 \\
\cline { 6 - 10 }
\end{tabular}

Table 4.35: Comparison between experimental results of iSPAN twin-joist assembly with no web holes and ATC design method

\begin{tabular}{|c|c|c|c|c|c|c|c|}
\hline $\begin{array}{c}\text { Joist } \\
\text { depth, } \\
\mathrm{d}(\mathrm{mm})\end{array}$ & $\begin{array}{c}\text { Joist } \\
\text { length } \\
(\mathrm{m})\end{array}$ & $\begin{array}{c}\Delta_{\text {Test }} \\
\text { under } \\
1 \mathrm{kN} \\
(\mathrm{mm})\end{array}$ & $\begin{array}{c}\Delta_{\text {ATC }} \\
(\mathrm{mm})\end{array}$ & $\Delta_{\text {Test }} / \Delta_{\text {ATC }}$ & $\begin{array}{c}f_{\text {Test }} \\
(\mathrm{Hz})\end{array}$ & $\begin{array}{c}f_{\text {ATC }} \\
(\mathrm{Hz})\end{array}$ & $f_{\text {Test }} / f_{\text {ATC }}$ \\
\hline 241 & 3.50 & 0.55 & 0.38 & 1.45 & 40.73 & 42.96 & 0.95 \\
\hline 241 & 4.50 & 0.97 & 0.81 & 1.20 & 26.59 & 26.11 & 1.02 \\
\hline 302 & 5.00 & 0.75 & 0.67 & 1.12 & 27.04 & 26.41 & 1.02 \\
\hline 302 & 5.25 & 0.92 & 0.78 & 1.18 & 24.15 & 23.92 & 1.01 \\
\hline 356 & 6.10 & 0.71 & 0.67 & 1.06 & 23.19 & 21.85 & 1.06 \\
\hline 406 & 7.95 & 1.54 & 1.09 & 1.41 & 14.51 & 14.60 & 0.99 \\
\hline
\end{tabular}


Table 4.36: Comparison between experimental results of iSPAN twin-joist assembly with web holes and ATC design method

\begin{tabular}{|c|c|c|c|c|c|c|c|}
\hline $\begin{array}{c}\text { Joist } \\
\text { depth } \\
\mathrm{d}(\mathrm{mm})\end{array}$ & $\begin{array}{c}\text { Joist } \\
\text { length }(\mathrm{m})\end{array}$ & $\begin{array}{c}\Delta_{\text {Test }} \text { under } \\
1 \mathrm{kN}(\mathrm{mm})\end{array}$ & $\begin{array}{c}\Delta_{\text {ATC }} \\
(\mathrm{mm})\end{array}$ & $\Delta_{\text {Test }} / \Delta_{\text {ATC }}$ & $\begin{array}{c}f_{\text {Test }} \\
(\mathrm{Hz})\end{array}$ & $\begin{array}{c}f_{\text {ATC }} \\
(\mathrm{Hz})\end{array}$ & $f_{\text {Test }} / f_{\text {ATC }}$ \\
\hline 254 & 3.5 & 0.54 & 0.35 & 1.54 & 46.22 & 45.19 & 1.02 \\
\hline 254 & 4.5 & 0.9 & 0.73 & 1.23 & 26.37 & 27.47 & 0.96 \\
\hline 302 & 5 & 0.75 & 0.67 & 1.12 & 26.34 & 26.41 & 1 \\
\hline 302 & 5.25 & 0.85 & 0.77 & 1.1 & 24.41 & 23.92 & 1.02 \\
\hline
\end{tabular}

Table 4.37: Comparison between experimental results of iSPAN joists in test sites and ATC design method

\begin{tabular}{|c|c|c|c|c|c|c|c|c|}
\hline Sites & $\begin{array}{c}\text { Joist } \\
\text { depth } \\
\mathrm{d}(\mathrm{mm})\end{array}$ & $\begin{array}{c}\text { Joist } \\
\text { length } \\
\text { (m) }\end{array}$ & $\begin{array}{c}\Delta_{\text {Test }} \\
\text { under 1 } \\
\text { kN }\end{array}$ & $\begin{array}{c}\Delta_{\mathrm{ATC}} \\
(\mathrm{mm})\end{array}$ & $\Delta_{\text {Test }} / \Delta_{\mathrm{ATC}}$ & $\begin{array}{l}f_{\text {Test }} \\
(\mathrm{Hz})\end{array}$ & $\begin{array}{l}f_{\text {ATC }} \\
(\mathrm{Hz})\end{array}$ & $f_{\text {Test }} / f_{A T C}$ \\
\hline $\begin{array}{c}\text { Site } 1 \\
\text { (Unbraced) }\end{array}$ & 241 & 5.48 & 0.75 & 0.998 & 0.75 & 28.08 & 18.77 & 1.50 \\
\hline $\begin{array}{c}\text { Site } 1 \\
\text { (Braced) }\end{array}$ & 241 & 5.48 & 0.69 & 0.94 & 0.73 & 28.73 & 18.77 & 1.53 \\
\hline $\begin{array}{c}\text { Site } 2 \\
\text { (Unbraced) }\end{array}$ & 302 & 7.32 & 0.93 & 1.09 & 0.85 & 15.46 & 12.48 & 1.24 \\
\hline $\begin{array}{c}\text { Site } 3 \\
\text { (Braced) }\end{array}$ & 241 & 6.35 & 0.65 & 0.77 & 0.84 & 27.57 & 17.83 & 1.55 \\
\hline $\begin{array}{c}\text { Site } 4 \\
\text { (Braced) }\end{array}$ & 241 & 6.58 & 1.09 & 1.26 & 0.87 & 14.89 & 12.97 & 1.15 \\
\hline & & & & Mean & 0.81 & & & 1.39 \\
\hline
\end{tabular}




\subsubsection{COMPARISON BETWEEN EXPERIMENTAL RESULTS WITH EUROPEAN DESIGN METHOD (EC5)}

The European design method (Eurocode EC5) was used to determine the maximum deflection of the laboratory and site tested joists. The results are shown in Table 4.38, 4.39, 4.40 and 4.41 in the form of ratio of experimental deflection to EC5 deflection $\left(\Delta_{\text {Test }} / \Delta_{\mathrm{EC} 5}\right)$ and ratio of experimental frequency to EC5 frequency $\left(\mathrm{f}_{\text {Test }} / \mathrm{f}_{\mathrm{EC} 5}\right)$ for wood floor assembly, iSPAN joist assemblies without web holes, ISPAN joists with web holes and iSPAN floors in the test sites, respectively. It can be observed that the average $\Delta_{\text {Test }} / \Delta_{\mathrm{EC} 5}$ ratios were $0.96,1.08,1.09$ and 0.83 for wood floor assembly, iSPAN joist assemblies without web holes, ISPAN joists with web holes and iSPAN floors in the test sites, respectively. However, the average $\mathrm{f}_{\text {Test }} / \mathrm{f}_{\mathrm{EC} 5}$ were 1.10 , 1.07, 1.08 and 1.13 for wood floor assembly, iSPAN joist assemblies without web holes, ISPAN joists with web holes and iSPAN floors in the test sites, respectively. In summary, the European design method (Eurocode EC5) showed better correlation with experimental findings than the ATC design method but it is still unacceptable in estimating joist deflection and natural frequencies.

Table 4.38: Comparison between experimental results of engineered wood twin-joist assembly and EC5 deign method

\begin{tabular}{|c|c|c|c|c|c|c|c|}
\hline $\begin{array}{c}\text { Joist } \\
\text { depth, d } \\
(\mathrm{mm})\end{array}$ & $\begin{array}{c}\text { Joist } \\
\text { length } \\
(\mathrm{m})\end{array}$ & $\begin{array}{c}\Delta_{\text {Test }} \\
\text { under } \\
1 \mathrm{kN} \\
(\mathrm{mm})\end{array}$ & $\begin{array}{c}\Delta_{\mathrm{EC} 5} \\
(\mathrm{~mm})\end{array}$ & $\Delta_{\text {Test }} / \Delta_{\mathrm{EC} 5}$ & $\begin{array}{c}f \text { Test } \\
(\mathrm{Hz})\end{array}$ & $\begin{array}{c}f_{\mathrm{EC} 5} \\
(\mathrm{~Hz})\end{array}$ & $f_{\text {Test }} / f_{E C 5}$ \\
\hline 241 & 3.50 & 0.63 & 0.88 & 0.72 & 34.77 & 30.22 & 1.15 \\
\hline 241 & 4.50 & 1.51 & 1.57 & 0.96 & 22.19 & 19.96 & 1.11 \\
\hline 302 & 5.00 & 1.47 & 1.51 & 0.97 & 21.60 & 19.03 & 1.14 \\
\hline 302 & 5.25 & 1.64 & 1.48 & 1.11 & 19.73 & 18.72 & 1.05 \\
\hline 356 & 6.10 & 1.58 & 1.58 & 1.00 & 17.72 & 16.67 & 1.06 \\
\hline 406 & 7.95 & 1.89 & 1.85 & 1.02 & 14.12 & 12.89 & 1.10 \\
\hline & & & Mean & 0.96 & & & 1.10 \\
\hline
\end{tabular}


Table 4.39: Comparison between experimental results of iSPAN twin-joist assembly with no web holes and EC5 design method

\begin{tabular}{|c|c|c|c|c|c|c|c|}
\hline $\begin{array}{c}\text { Joist } \\
\text { depth, d } \\
(\mathrm{mm})\end{array}$ & $\begin{array}{c}\text { Joist } \\
\text { length } \\
(\mathrm{m})\end{array}$ & $\begin{array}{c}\Delta_{\text {Test }} \\
\text { under } \\
1 \mathrm{kN} \\
(\mathrm{mm})\end{array}$ & $\begin{array}{c}\Delta_{\mathrm{EC} 5} \\
(\mathrm{~mm})\end{array}$ & $\Delta_{\text {Test }} / \Delta_{\mathrm{EC} 5}$ & $\begin{array}{c}f_{\text {Test }} \\
(\mathrm{Hz})\end{array}$ & $\begin{array}{c}f_{\mathrm{EC} 5} \\
(\mathrm{~Hz})\end{array}$ & $f_{\text {Test }} / f_{E C 5}$ \\
\hline 241 & 3.50 & 0.55 & 0.44 & 1.25 & 40.73 & 39.77 & 1.02 \\
\hline 241 & 4.50 & 0.97 & 0.93 & 1.04 & 26.59 & 24.18 & 1.10 \\
\hline 302 & 5.00 & 0.75 & 0.77 & 0.97 & 27.04 & 24.66 & 1.10 \\
\hline 302 & 5.25 & 0.92 & 0.89 & 1.03 & 24.15 & 22.33 & 1.08 \\
\hline 356 & 6.10 & 0.71 & 0.77 & 0.92 & 23.19 & 20.93 & 1.11 \\
\hline 406 & 7.95 & 1.54 & 1.25 & 1.23 & 14.51 & 14.07 & 1.03 \\
\hline & & & & & & &
\end{tabular}

Table 4.40: Comparison between experimental results of iSPAN twin-joist assembly with web holes and EC5 design method

\begin{tabular}{|c|c|c|c|c|c|c|c|}
\hline $\begin{array}{c}\text { Joist } \\
\text { depth } \\
\mathrm{d}(\mathrm{mm})\end{array}$ & $\begin{array}{c}\text { Joist } \\
\text { length } \\
(\mathrm{m})\end{array}$ & $\begin{array}{c}\Delta_{\text {Test }} \\
\text { under } \\
1 \mathrm{kN} \\
(\mathrm{mm})\end{array}$ & $\begin{array}{c}\Delta_{\mathrm{EC} 5} \\
(\mathrm{~mm})\end{array}$ & $\Delta_{\text {Test }} / \Delta_{\mathrm{EC} 5}$ & $\begin{array}{c}f_{\text {Test }} \\
(\mathrm{Hz})\end{array}$ & $\begin{array}{c}f_{\mathrm{EC} 5} \\
(\mathrm{~Hz})\end{array}$ & $f_{\text {Test }} / f_{E C 5}$ \\
\hline 254 & 3.50 & 0.54 & 0.40 & 1.35 & 46.22 & 41.83 & 1.10 \\
\hline 254 & 4.50 & 0.90 & 0.84 & 1.07 & 26.37 & 25.43 & 1.04 \\
\hline 302 & 5.00 & 0.75 & 0.77 & 0.97 & 26.34 & 24.66 & 1.07 \\
\hline 302 & 5.25 & 0.85 & 0.89 & 0.96 & 24.41 & 22.33 & 1.09 \\
\hline
\end{tabular}


Table 4.41: Comparison between experimental results of iSPAN joists in test sites and EC5 design method

\begin{tabular}{|c|c|c|c|c|c|c|c|c|}
\hline Sites & $\begin{array}{c}\text { Joist } \\
\text { depth, d } \\
(\mathrm{mm})\end{array}$ & $\begin{array}{c}\text { Joist } \\
\text { length } \\
(\mathrm{m})\end{array}$ & $\begin{array}{c}\Delta_{\text {Test }} \\
\text { under } \\
1 \mathrm{kN}\end{array}$ & $\begin{array}{c}\Delta_{\mathrm{EC} 5} \\
(\mathrm{~mm})\end{array}$ & $\Delta_{\text {Test }} / \Delta_{\mathrm{EC} 5}$ & $\begin{array}{c}f_{\text {Test }} \\
(\mathrm{Hz})\end{array}$ & $\begin{array}{c}f_{\mathrm{EC5}} \\
(\mathrm{Hz})\end{array}$ & $f_{\text {Test }} / f_{E C 5}$ \\
\hline $\begin{array}{c}\text { Site 1 } \\
\text { (Unbraced) }\end{array}$ & 241 & 5.48 & 0.75 & 0.84 & 0.89 & 28.08 & 22.86 & 1.23 \\
\hline $\begin{array}{c}\text { Site 1 } \\
\text { (Braced) }\end{array}$ & 241 & 5.48 & 0.69 & 0.81 & 0.85 & 28.73 & 22.86 & 1.26 \\
\hline $\begin{array}{c}\text { Site 2 } \\
\text { (Unbraced) }\end{array}$ & 302 & 7.32 & 0.93 & 1.18 & 0.79 & 15.46 & 15.82 & 0.98 \\
\hline $\begin{array}{c}\text { Site 3 } \\
\text { (Braced) }\end{array}$ & 241 & 6.35 & 0.65 & 0.88 & 0.74 & 27.57 & 21.57 & 1.28 \\
\hline $\begin{array}{c}\text { Site 4 } \\
\text { (Braced) }\end{array}$ & 241 & 6.58 & 1.09 & 1.27 & 0.86 & 14.89 & 16.67 & 0.89 \\
\hline \multicolumn{2}{c}{} & & & Mean & 0.83 & & & 1.13 \\
\hline
\end{tabular}

Figure 4.18 shows a graphical representation of the EC5 deflection limit under 1-kN load. The Figure shows that for joist span less than $4.0 \mathrm{~m}$, the deflection under $1-\mathrm{kN}$ point load should be less $1.8 \mathrm{~mm}$ in contract to $2 \mathrm{~mm}$ in case of CWC and ATC design methods. Results in Figure 4.18 shows that most of the wooden joists do not satisfy the EC5 design criteria. Only the $241 \times 3500 \mathrm{~mm}$ and $241 \times 4500 \mathrm{~mm}$ wooden joists are below the EC5 deflection limiting line, while all other wooden joists are above the EC5 limiting line. On the other hand, iSPAN joists showed better performance. All iSPAN joists fall below the EC5 deflection limit except the 406x7950 mm floor joist which falls above the EC5 deflection limit. As for joists in test sites, all joists generally satisfy EC5 deflection limiting criteria. 


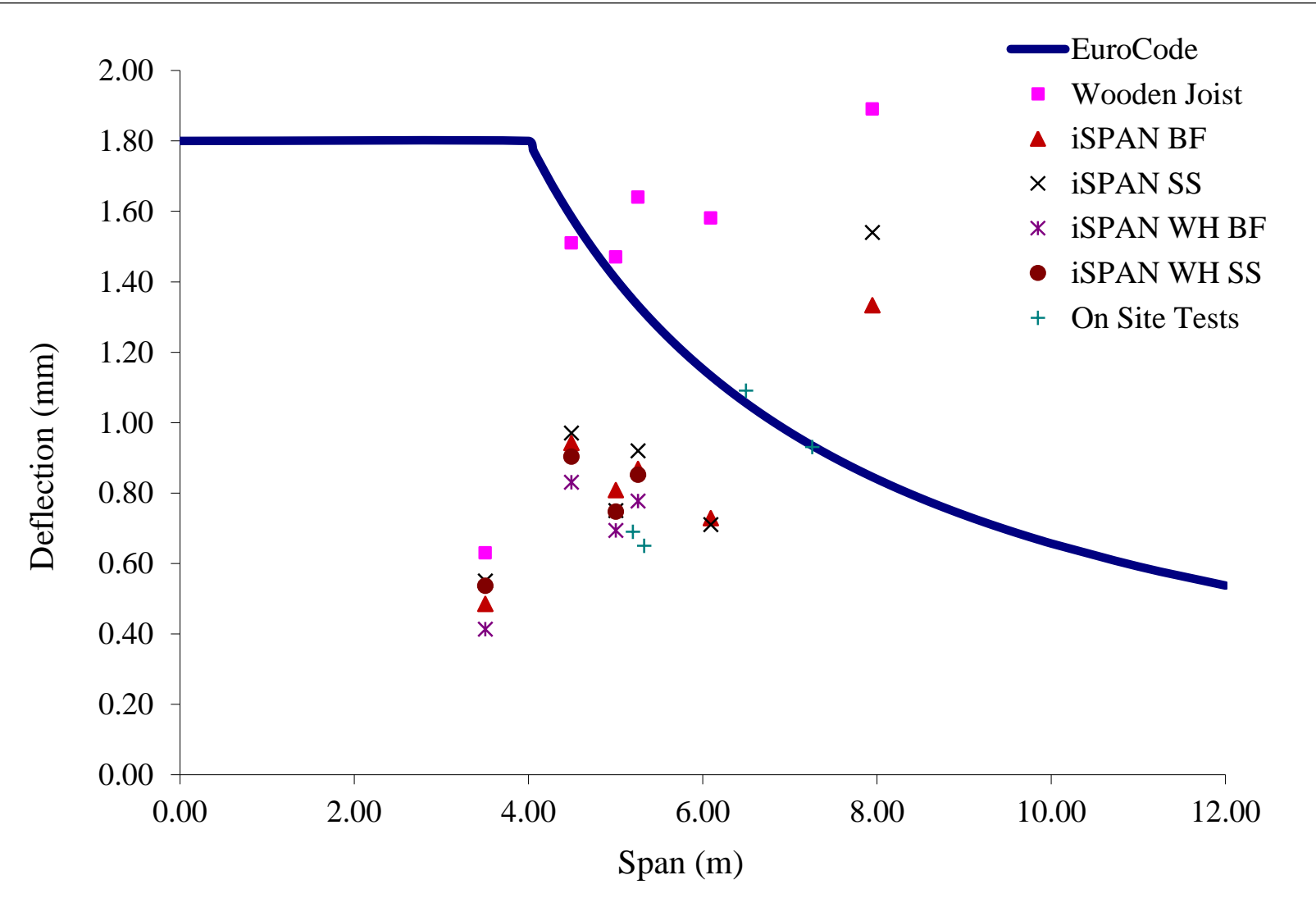

Figure 4.18: Correlation between experimental results and EC5 design criteria $(\mathrm{BF}=$ balloon framing, SS = simply-supported framing, WH = joist with holes)

Note: for twin joist multi joist effect was not applied to experimental value

\subsection{RESONANCE MODEL ACCEPTABILITY CRITERIA}

Only AISC and ATC design guides provide a method to calculate the acceleration response of the floor system under walking excitation. The design criteria based on the resonance model applies to steel and concrete floor construction whose natural frequency is in the range of 3 to 15 Hz. According to this criterion, the floor system is satisfactory if the peak acceleration $a_{p}$ due to walking does not exceed the acceleration limit $a_{0}$. The peak acceleration due to walking is determined from equation (4.3).

$\frac{a_{p}}{g}=\frac{P_{o} \exp \left(-0.35 f_{n}\right)}{\beta W}$

Where

$\mathrm{a}_{\mathrm{p}} / \mathrm{g}=$ estimated peak acceleration

$\mathrm{P}_{0}=$ constant force equal to $0.29 \mathrm{kN}(65 \mathrm{lb})$ for residential and office floor system 
$f_{n}=$ fundamental frequency of the floor system

$\beta W=$ is the product of the modal damping ratio and effective weight of the floor

The maximum RMS acceleration response (as a fraction of gravity) for each floor system is plotted on ISO acceleration criterion and is shown in Figure 4.19. Then, experimental findings are plotted. Figure 4.19 show that all tested iSPAN joist assemblies, except the one with the largest span of $7.95 \mathrm{~m}$ with simply-supported conditions and no web holes, meet acceptance criteria for floor vibration. Also, Figure 4.19 show that all tested wood joist assemblies, except the one with the largest span of $7.95 \mathrm{~m}$, meet acceptance criteria for floor vibration

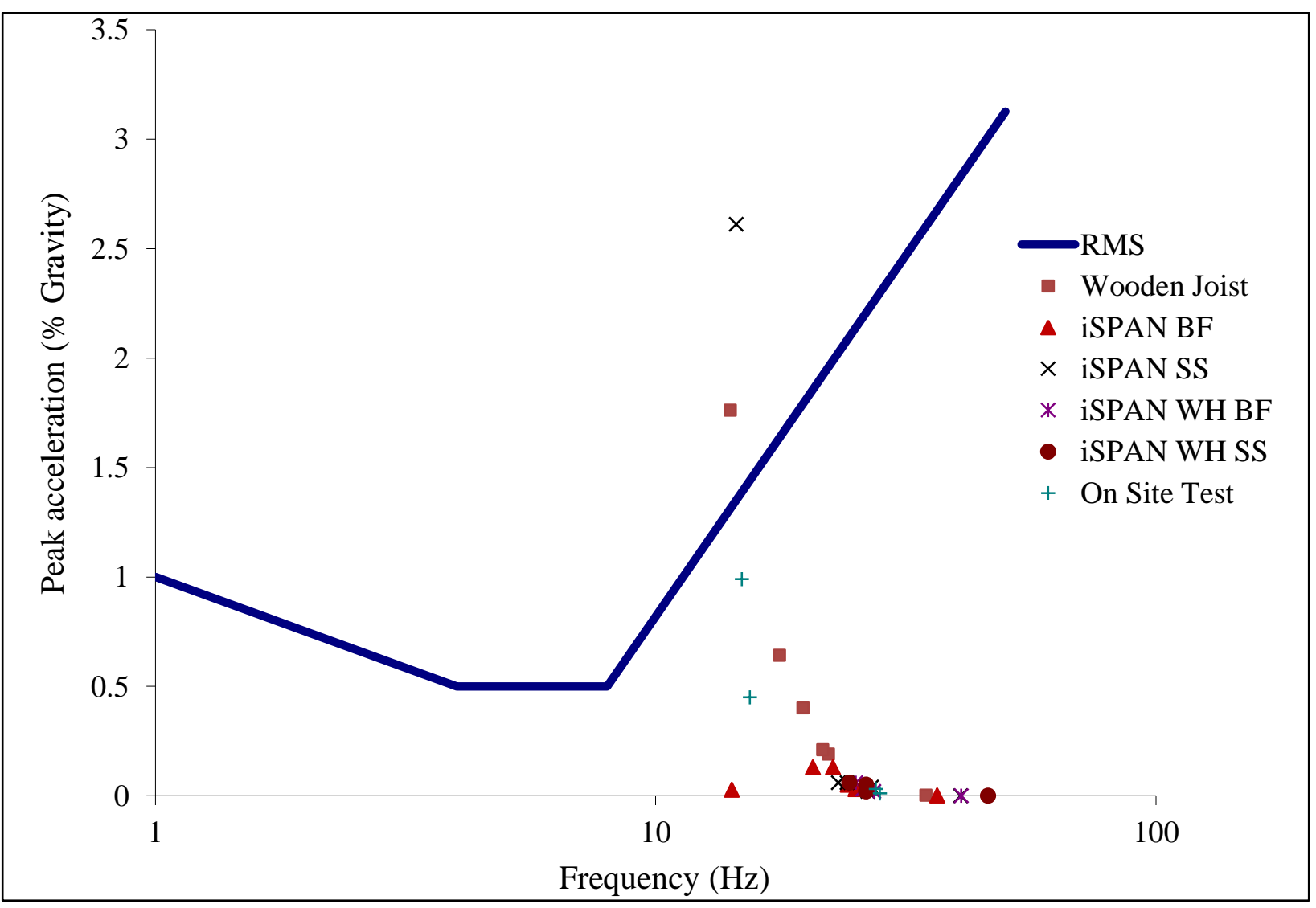

Figure 4.19: Correlation between experimental results and ISO acceleration design criteria $(\mathrm{BF}=$ balloon framing, $\mathrm{SS}=$ simply-supported framing, $\mathrm{WH}=$ joist with holes) 


\subsection{ULTIMATE STRENGTH DESIGN}

The ultimate capacity of engineered wood I-joist assemblies was determined using the Canadian Wood Council (CSA-O86) design method, while for the iSPAN cold-formed steel joist, the ultimate capacity was determined using North American Specification for the Design of Coldformed Steel Design (CSA-S136-07). The results are shown in Table 4.42, 4.43, and 4.44 for the wooden twin-joist assemblies, iSPAN twin-joist assemblies with no holes and iSPAN twin-joist assemblies with holes, respectively. In addition, results are presented in a graphical format in Figure 4.20. Results show that most of the iSPAN cold-formed steel joists failed in lateral torsional buckling, except few two joists failed in local buckling and web crippling as discussed earlier in this chapter. The reason for lateral torsional failure was that in the case of twin-joist ultimate test, the joists were not fully laterally braced. Although the bracing was provided between the two joists, it did not help restraint the lateral or distortional effect of the joist. In practice, bridging and blocking are used and first blocking is attached to the foundation wall or to the stud wall to prevent the lateral torsional buckling or distortional buckling of the floor joist, and the compression flange of the floor joist is restrained by the floor deck. Therefore, lateral torsional buckling or distortional buckling failures are generally prevented in the actual application, and the local buckling is a primary failure mode in the floor joists.(Yu, 2011). In any case, Figure 4.20 show that S136-07 predicts an average ultimate load carrying capacity of $1 \%$ and $17 \%$ less that the experimental ultimate load for the tested iSPAN joist assemblies without and with web holes, respectively. However, the Canadian Wood Council (CSA-O86) design method underestimated the load carrying capacities of the tested wood joists by about 35 to $60 \%$. 


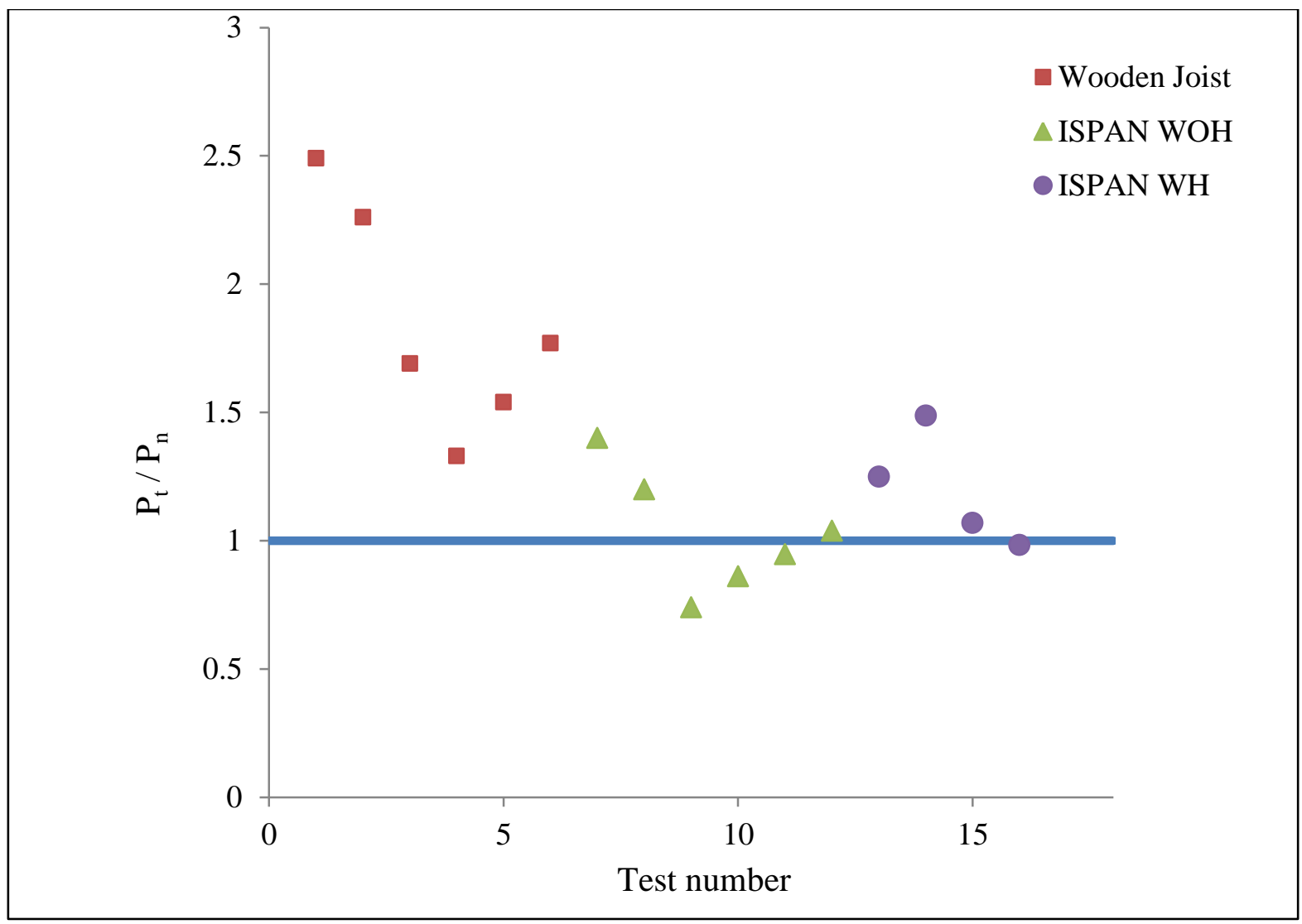

Figure 4.20: Experimental ultimate load-to-nominal ultimate load ration, $\mathrm{P}_{\mathrm{t}} / \mathrm{P}_{\mathrm{n}}(\mathrm{WOH}=$ joist without web holes, $\mathrm{WH}=$ joist with web holes)

Table 4.42: Comparison between experimental flexural results of engineered wood twinjoist assembly and CWC Design flexural strength

\begin{tabular}{|c|c|c|c|c|}
\hline $\begin{array}{c}\text { Joist depth, } \\
\mathrm{d}(\mathrm{mm})\end{array}$ & $\begin{array}{c}\text { Joist } \\
\text { length }(\mathrm{m})\end{array}$ & $\begin{array}{c}\text { Experimental } \\
\text { load, } \mathrm{P}_{\mathrm{t}}(\mathrm{kN})\end{array}$ & $\begin{array}{c}\text { CWC resisting } \\
\text { load, } \mathrm{P}_{\mathrm{n}(\mathrm{CWC})}(\mathrm{kN})\end{array}$ & $\mathrm{P}_{\mathrm{t}} / \mathrm{P}_{\mathrm{n}}$ \\
\hline 241 & 3.50 & 40.88 & 16.40 & 2.49 \\
\hline 241 & 4.50 & 28.90 & 12.80 & 2.26 \\
\hline 302 & 5.00 & 25.20 & 14.87 & 1.69 \\
\hline 302 & 5.25 & 18.90 & 14.15 & 1.33 \\
\hline 356 & 6.10 & 22.60 & 14.67 & 1.54 \\
\hline 406 & 7.95 & 35.40 & 20 & 1.77 \\
\hline
\end{tabular}




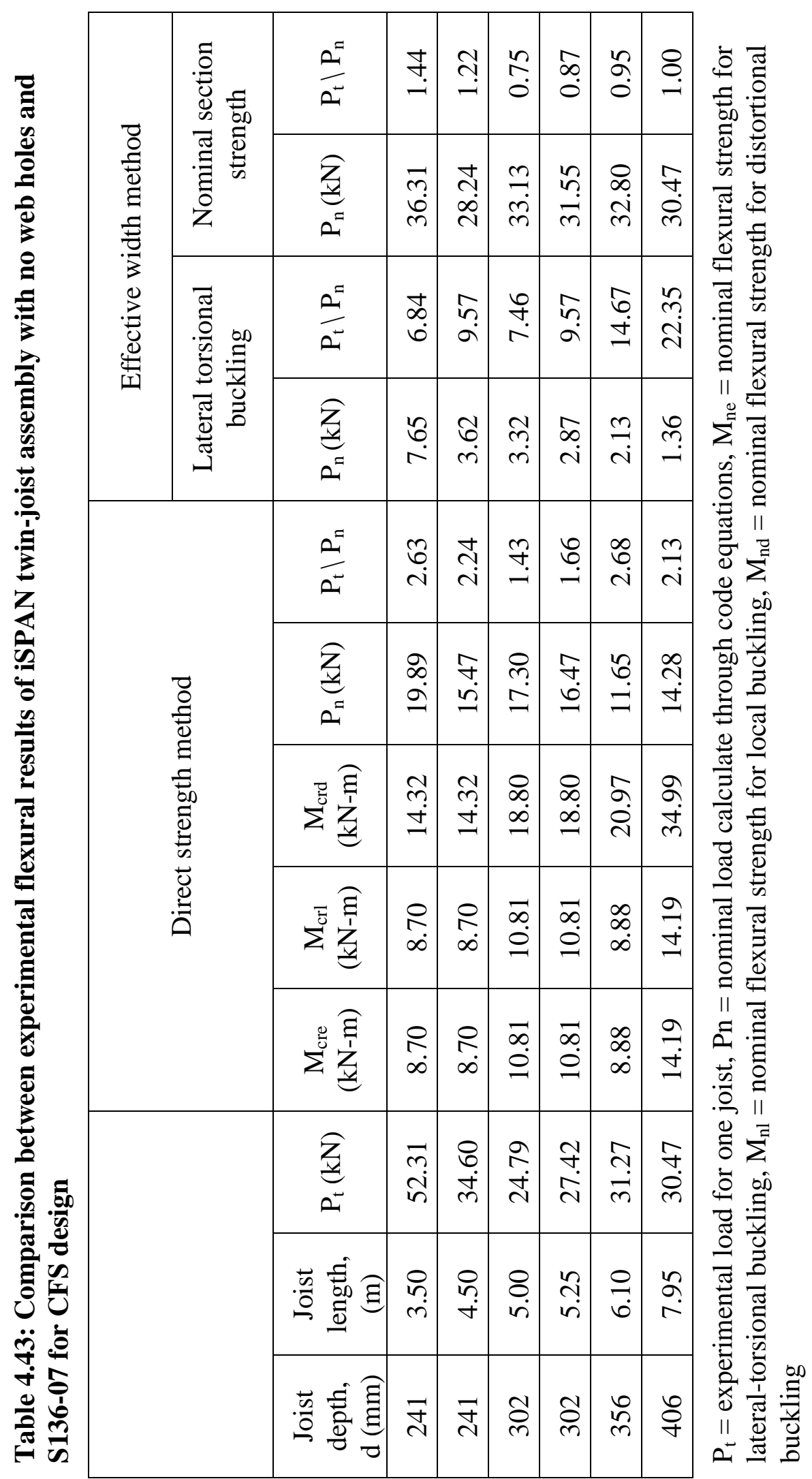




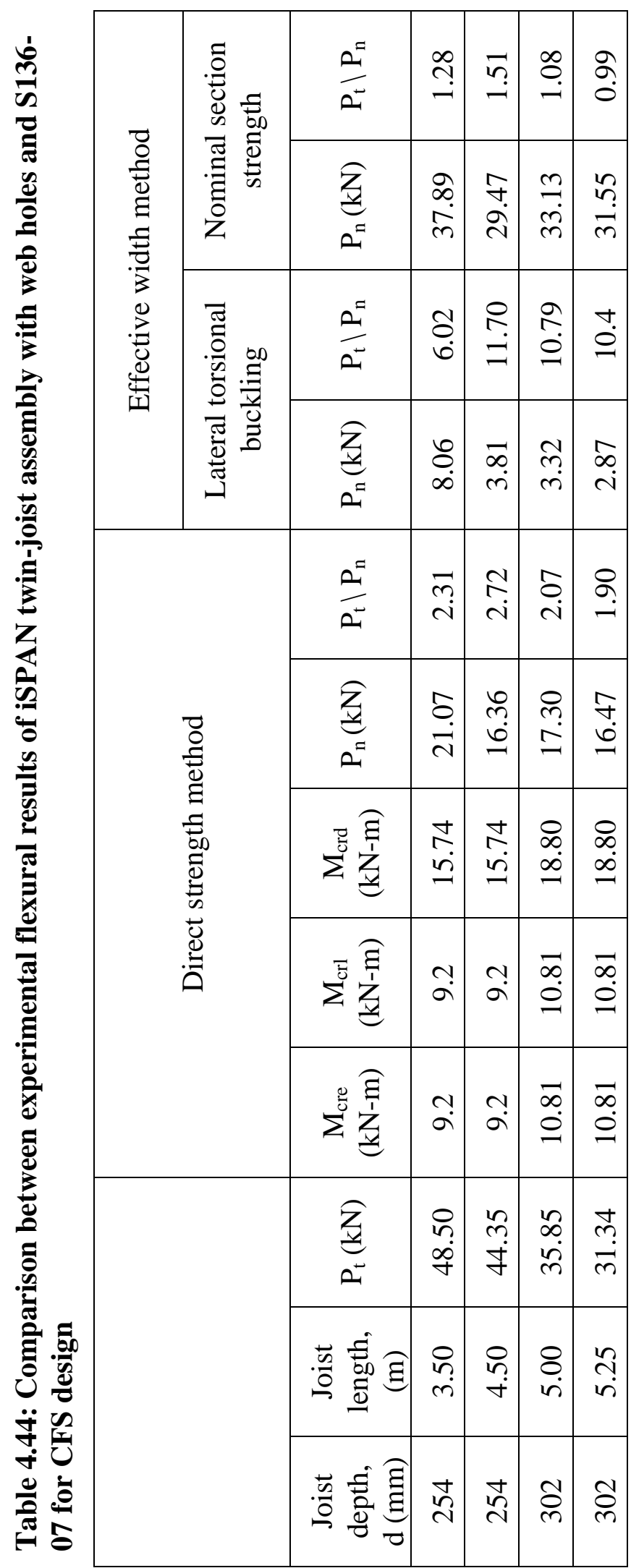




\subsection{PROPOSED MODIFICATION TO CURRENT METHODS SPECIFICALLY FOR FLOOR SUPPORTED BY COLD-FORMED STEEL JOISTS.}

From the above-mentioned discussions, it is clear that none of the available design codes accurately predict the central deflection, and fundamental frequency of floors supported with iSPAN cold-formed steel joists due to inherent assumptions and empirical coefficients included in the design equations that were primarily obtained for wood construction. In case of engineered wood twin-joist assembly, the percentage difference between the experimental deflections and those obtained from CWC, ATC, and EC5 code equations were 23, 11, and 4\%, respectively. This comparison shows that EC5 predicts well the joist deflection better than other methods. In case of iSPAN twin-joist assembly without web holes, the percentage difference in deflection calculations obtained experimentally and from CWC, ATC, and EC5 code equations were 20, 24 , and $8 \%$, respectively. Also, in case of iSPAN twin-joist assemblies with web hole, the percentage difference between experimental deflection and those obtained using CWC, ATC, and EC5 code equations were 13, 25, and 9\%, respectively. As for test site results, the percentage difference in site deflection and those obtained from CWC, ATC, and EC5 code equations were 18,19 , and $17 \%$, respectively. In summary, the results show that EC5 provides better results than those obtained from the CWC and ATC design methods.

In the case of frequency calculation, it should be noted that $\mathrm{CWC}$ does not have the formula to calculate the frequency. However, the ATC formula was used but with the CWC flexural stiffness equation. Results showed that in the case of engineered wood twin-joist assemblies, the percentage difference for frequencies obtained experimentally and from ATC and EC5 design methods were 0 and $10 \%$, respectively. In case of the iSPAN twin-joist assemblies without web holes, the percentage difference between the experimental frequencies and those obtained from ATC and EC5 were 1 and 7\%, respectively. While those values were 1 and 8\% for iSPAN twinjoist assemblies with web holes. On the other hand, the percentage difference between the experimental frequencies obtained from the sites and from ATC and EC5 design methods were 39 and $13 \%$, respectively. As a result, modification to floor equivalent flexural stiffness is required. 
Floor stiffness is the most important vibration property of the floor because it affects both point load response and natural frequency of the light-frame floor system. The floor system is assumed to consist of frame construction with the floor joist running in one direction and supported by girder or walls in the other directions. The stiffness of the floor system includes the contribution of floor components to the stiffness of the floor joist. Floor stiffness is primarily due to flexural action of the combined floor joist and floor deck. However, the presence of joist shear deformation decreases floor stiffness. As such, it should be considered in the flexural stiffness equation. Therefore, care must be taken in the calculation of effective flexural stiffness $\left(E I_{\text {eff }}\right)$ of the floor system. Equation (4.4) is used to account for shear contribution in the floor system (Allen et al., 1999). This equation is used to calculate (i) the static deflection under 1-kN load and (ii) the natural frequency of the floor system.

$$
\begin{aligned}
& \Delta \mathrm{p}=\frac{C_{p d}}{N_{e f f}} \frac{P L^{3}}{48 E I_{e f f}} \\
& f_{n}=0.18 \sqrt{\frac{g}{\Delta_{j}}} \\
& \Delta_{j}=C_{f l r} \frac{5 w L^{4}}{384 E I_{e f f}} \\
& E I_{e f f}=\frac{E I}{1+\frac{\gamma E I}{C_{p d^{E I m}}}}
\end{aligned}
$$

The above formulas show that $E I_{\text {eff }}$ affects both the floor stiffness and natural frequency. EI in the above-mentioned equations is the flexural stiffness of the floor panel, including the composite action, while $E I_{m}$ is the flexural stiffness of the member, and $\gamma$ is a coefficient representing the ratio of shear deflection to flexural deflection for the member. Table 4.45 shows the values of $\gamma$ used for wood and steel construction. Since iSPAN cold-formed steel joist are similar to wood I-joist in term of the ratio of web area to moment of inertia, therefore the wood Ijoist equation for the computation of $\gamma$ can be modified for the design of iSPAN cold-formed steel joists. Table 4.45 shows the proposed value of $\gamma$ for the iSPAN cold-formed steel joist. While Table 4.46 shows new values of static deflection and natural frequency calculated with the 
proposed value of $\gamma$ for the onsite tested floor system. The new mean static deflection calculated with the proposed $\gamma$ is $5.0 \%$ compare to $24.11 \%$ calculated with old $\gamma$ value. Similarly, the new mean frequency calculated with the new proposed $\gamma$ is $24 \%$ compared to $39 \%$ calculated with the old $\gamma$ value. 
Table 4.45: Recommended Values of the shear deflection coefficient, $\gamma$, obtained from Allen et al. (1999) as well as the proposed $\gamma$ values for iSPAN CFS joists

\begin{tabular}{|c|c|c|}
\hline Construction & Limits & Shear Deflection Coefficient " $\gamma$ " \\
\hline Wood members & & $\gamma=96 \mathrm{EI}_{\mathrm{m}} /\left(\mathrm{K}_{\mathrm{s}} \mathrm{L}^{2}\right)$, where \\
\hline Wood "I" joist & & $\mathrm{K}_{\mathrm{s}}=0.4 \mathrm{~d} \times 10^{6} \mathrm{lb}$ \\
\hline Tubular metal web truss & & $\mathrm{K}_{\mathrm{s}}=\mathrm{d} \times 10^{6} \mathrm{lb}$ \\
\hline Metal plate connected trusses & & $\mathrm{K}_{\mathrm{s}}=2 \times 10^{6} \mathrm{lb}$ \\
\hline Steel Members : Hot-rolled & $\mathrm{L} / \mathrm{d}>12$ & 0.0 \\
\hline Steel Members : Hot-rolled & $\mathrm{L} / \mathrm{d}<12$ & $\gamma=\left(9.6 \mathrm{EA}_{\mathrm{m}}\right) /\left((\mathrm{L} / \mathrm{r})^{2} \mathrm{GA}_{\mathrm{web}}\right)$ \\
\hline $\begin{array}{l}\text { Steel trusses: OWJ - web } \\
\text { angles }\end{array}$ & $6<\mathrm{L} / \mathrm{d}<24$ & $\gamma=1 / \mathrm{C}_{\mathrm{r}}-1$, where $\mathrm{C}_{\mathrm{r}}=0.9\left(1-\mathrm{e}^{-0.28 \mathrm{~L} / \mathrm{d}}\right)^{2.8}$ \\
\hline Steel trusses: OWJ - web bars & $10<\mathrm{L} / \mathrm{d}<24$ & $\begin{array}{l}\gamma=1 / C_{r}-1 \\
\text { where } C_{r}=0.721+0.00725(L / d)\end{array}$ \\
\hline Cold formed C-joists & & 0.0 \\
\hline \multicolumn{3}{|c|}{ Proposed " $\gamma$ " values for iSPAN cold formed steel joist } \\
\hline iSPAN cold-formed steel joist & & $\begin{array}{l}\gamma=35 \mathrm{EI}_{\mathrm{m}} /\left(\mathrm{K}_{\mathrm{s}} \mathrm{L}^{3.96}\right) \\
\text { Where } \\
\mathrm{K}_{\mathrm{s}}=0.2822 \mathrm{~d} \times 10^{3}(\mathrm{~N}) \\
\mathrm{K}_{\mathrm{s}}=0.6345 \mathrm{~d} \times 10^{2}(\mathrm{lb})\end{array}$ \\
\hline
\end{tabular}

Notes:

$\mathrm{L} / \mathrm{d}=$ span divided by member depth (both in inches)

$\mathrm{I}_{\mathrm{m}}=$ moment of inertia of member

$\mathrm{K}_{\mathrm{s}}=$ shear stiffness for wood members

$\mathrm{A}_{\mathrm{m}}=$ cross-sectional area of member

$\mathrm{A}_{\mathrm{web}}=$ cross-sectional area of web

$\mathrm{r}=$ radius of gyration

$\mathrm{E}=$ modulus of elasticity

$\mathrm{G}=$ effective shear modulus 
Table 4.46: Results of 1-kN-load deflection and frequency of iSPAN joists based on the proposed modification to the ATC design method using the proposed parameter $\gamma$

\begin{tabular}{|c|c|c|c|c|c|c|c|c|}
\hline Sites & $\begin{array}{c}\text { Joist } \\
\text { depth, } \\
\text { d (mm) }\end{array}$ & $\begin{array}{l}\text { Joist } \\
\text { length } \\
\text { (m) }\end{array}$ & $\begin{array}{c}\Delta_{\text {Test }} \\
\text { under } \\
1-\mathrm{kN} \\
\text { load }\end{array}$ & $\begin{array}{l}\text { New } \\
\Delta_{\text {ATC }}\end{array}$ & $\begin{array}{c}\Delta \% \\
\text { Difference }\end{array}$ & $\begin{array}{l}f_{\text {Test }} \\
(\mathrm{Hz})\end{array}$ & $\begin{array}{l}f_{\text {ATC }} \\
(\mathrm{Hz})\end{array}$ & $\begin{array}{c}f \% \\
\text { Difference }\end{array}$ \\
\hline $\begin{array}{c}\text { Site } 1 \\
\text { (Unbraced) }\end{array}$ & 241 & 5.48 & 0.75 & 0.82 & 0.91 & 28.08 & 21.30 & 1.32 \\
\hline $\begin{array}{c}\text { Site 1 } \\
(\text { Braced })\end{array}$ & 241 & 5.48 & 0.69 & 0.78 & 0.88 & 28.73 & 21.30 & 1.35 \\
\hline $\begin{array}{c}\text { Site } 2 \\
\text { (Unbraced) }\end{array}$ & 302 & 7.32 & 0.93 & 0.95 & 0.98 & 15.46 & 13.66 & 1.13 \\
\hline $\begin{array}{c}\text { Site } 3 \\
\text { (Braced) }\end{array}$ & 241 & 6.35 & 0.65 & 0.66 & 0.98 & 27.57 & 20.13 & 1.37 \\
\hline $\begin{array}{c}\text { Site } 4 \\
(\text { Braced }) \\
\end{array}$ & 241 & 6.58 & 1.09 & 1.11 & 0.98 & 14.89 & 14.13 & 1.05 \\
\hline & & & & Mean & 0.95 & & & 1.24 \\
\hline
\end{tabular}




\subsection{CONCLUSIONS}

Experimental findings and comparison with available code equations led to the following conclusions:

- The presence of bracing in wood I-joist floors does not affect the floor frequency and damping ratio which seems reasonable conclusion. Studied wood floor I-joist assembly has damping ratio ranging from 3.45 to $5.18 \%$ for unbraced joists and between 3.53 to $6.69 \%$ for braced joists. The scattered values of the damping ratio may be associated with the noise interfered with the specimen during testing. This created multiple peaks of acceleration at the same, or close to, frequency of the joist that make it the band-width method applicability to calculate damping ratio in this case as inaccurate.

- The non-linear behavior exhibited in the deflection and flexural strain readings of the iSPAN CFS twin-joist assembly showed ductile failure mode in contrast to the failure of wooden joist assembly that exhibited linear load-deflection relationship till failure.

- Results from the experimental testing showed that the presence of Lip-reinforced holes in the tested iSPAN twin-joist assembly has generally insignificant effect of the dynamic performance of the floor system; the joist with lipped web holes increases the capacity of the web against local buckling when subjected flexural stress gradient.

- Test site results showed that attachment of bracing to the CFS joists does not influence floor flexural frequency while it reduces floor static deflection under $1-\mathrm{kN}$ concentrated load. This may be attributed to the fact that bracing distributed the concentrated load to adjacent joists. Also, floor damping ratios in site 1 changed from 5.86 to $8.07 \%$ with the addition of joist bracing. It should be noted that increase in damping ratio improves the vibration performance of the floor. This would make the vibration amplitude decay more quickly and floor vibration will be less noticeable to the occupants.

- Experimental findings show that joist simply-supported framing condition increases floor frequency by $8 \%$ in average. This may be attributed to the fact that balloon framing provides more flexural structural system as compared to the pure simply-supported condition. However, the change in support condition slightly affects joist deflection. On the other hand, floor damping ratio increases with the use of balloon framing condition.

- Experimental findings show that the Canadian wood council (CWC) design method underestimates the $1-\mathrm{kN}$ load deflection while it provides accurate results for the floor 
flexural frequency. On the other hand, the ATC design method does not show general trend in estimating the 1-kN load deflection as well as floor frequency. As such, it is considered unacceptable. The European design method (Eurocode EC5) showed better correlation with experimental findings than the ATC design method but it is still unacceptable in estimating joist deflection and natural frequencies.

- Experimental findings reveal that North American Specifications for the Design of Coldformed Steel Members (S136-07) predicts an average ultimate load carrying capacity of 1 and $17 \%$ less that the experimental ultimate load for the tested iSPAN joist assemblies without and with web holes, respectively. However, the Canadian Wood Council (CSAO86) design method underestimated the load carrying capacities of the tested wood joists by about 35 to $60 \%$.

- To better estimate the joist deflection due to $1-\mathrm{kN}$ load and the joist frequency, a coefficient $\gamma$, representing the ratio of shear deflection to flexural deflection for the member, was developed for the design of iSPAN cold-formed steel joists. 


\section{CHAPTER 5}

\section{FINITE ELEMENT MODELING AND RESULTS}

\subsection{INTRODUCTION}

The finite element method (FEM) is a numerical technique for finding approximate solutions to partial differential equations and their systems. In simple terms, FEM is a method for dividing up a very complicated problem into small elements that can be solved in relation to each other. FEM cuts a structure into several elements (pieces of the structure) then reconnects elements at "nodes" as if nodes were pins or drops of glue that hold elements together. This process results in a set of simultaneous algebraic equations. Finite-element is a convenient way to find displacement and stress of structures at definite coordinates called nodes. The finite-element method originated in structural engineering and has been used in different fields like, fluid flow, heat transfer, aero dynamic, electric and magnetic fields and many others. The finite-element method is a powerful tool to calculate the dynamic properties, elastic buckling mode and ultimate strength of cold-formed steel structural member. In addition, the finite-element method is considered more economical than experimental results if the modelling was done properly. The finite-element software ABAQUS 6.10 (Hibbitt et al., 2010) was used to find the dynamic properties, elastic buckling and post buckling analysis of iSPAN cold formed steel joists in this research.

\subsection{OBJECTIVES OF FINITE ELEMENT ANALYSIS}

The main objectives of the finite-element study was to develop an experimentally calibrated, computer based, analytical models capable of predicting accurately CFS joist response when subjected to service, and ultimate loading conditions. The established finite-element model was verified and substituted in this Chapter by correlating the experimental findings with the FE results. A parametric study was then carried out to investigate the influence of metal deck, OSB sheet, and stiffened web holes on the free-vibration response and ultimate load of the iSPAN joists. 


\subsection{GENERAL STEPS OF THE FINITE-ELEMENT METHOD}

The finite-element analysis consists of four steps as follows:

i) Selecting the element type and creating the geometry;

ii) Generating the mesh for the model;

iii) Applying the loading and boundary conditions; and

iv) Analysis result (solution)

The generalized equation of the finite-element analysis is shown below.

$\{F\}=[K]\{d\}$

Where $\{F\}$ is the vector of global nodal forces, $[K]$ is the structures global or total stiffness matrix and $\{d\}$ is the vector of known and unknown nodal degrees of freedom or generalized displacements.

\subsection{ELEMENTS USED IN FINITE ELEMENT MODELING}

A three-dimensional finite-element model of the full scale floor joist assembly was developed to simulate the experimental findings. The accuracy of the finite-element results is highly dependent on selecting the proper element type to predict the actual behaviour of the structures. In this study, shell elements, solid elements, and multiple-point constraint elements (MPC) were used to model the twin-joist assembly. The following subsections provide explanations for each element used in the FE model.

\subsubsection{SHELL ELEMENTS}

Shell elements are used to model structures in which one dimension, i.e. the thickness, is significantly smaller than the other dimensions. In this case, the thickness is defined through the section property definition. Shell elements have displacement and rotational degrees of freedom. Since the material thickness of cold-formed steel is thin compared to the element width, shell element is the best choice. In cold-formed steel flexural members, the in-plane stress and deformation are of primary importance, while the beam elements only calculate the bending stresses while ignoring membrane stresses. In addition, beam elements do not allow cross-section distortion and therefore, shell elements were used in this research. ABAQUS software provides a full library of shell elements, as shown in Figure 5.1(a), which can be used for different types of 
analysis. In this research, shell element S4R was used to model CFS flanges and webs and lips of web holes. S4R is a 4-node, quadrilateral, stress/displacement shell element with reduced integration and a large-strain formulation. Element type S4 is a fully integrated, general-purpose, finite-membrane-strain shell element. The element's membrane response is treated with an assumed strain formulation that gives accurate solutions to in-plane bending problems. The element has four integration locations per element compared with one integration location for S4R, which makes the element computationally more expensive. S4 is compatible with both S4R and S3R. S4 can be used for problems prone to membrane- or bending-mode, in areas where greater solution accuracy is required or for problems where in-plane bending is expected. In all of these situations S4 will outperform element type S4R.

\subsubsection{SOLID ELEMENTS}

Solid elements were used to model the end supports of the two-joist assembly. Figure 5.1(b) shows views of solid elements available in ABAQUS software (Hibbitt et al., 2010). The 8 node linear solid element type C3D8R was considered in this study.

\subsubsection{MULTI-POINT CONSTRAINTS (MPC)}

ABAQUS provides multi-point constraints for different connection/contact modeling. For bracing, the multi-point constraint type "Link was considered in this study. LINK provides a pinned rigid link between two nodes to keep the distance between the nodes constant, as shown in Figure 5.2. In ABAQUS version 6.10, new contact functionality is available called fasteners. The mesh independent fastener is a convenient method to define a point-to-point connection between two or more surfaces such as a spot weld, screws or rivet connection (Figure 5.3). It can be located anywhere between two or more surfaces regardless of the mesh refinement or location of nodes on each surface. A fastener can connect selected faces with multi-point constraints. MPC type "TIE" was used to represent the fasteners. TIE is usually used to join two parts so that the global displacements and rotations as well as all other active degrees of freedom are forced to be equal at the two nodes. 


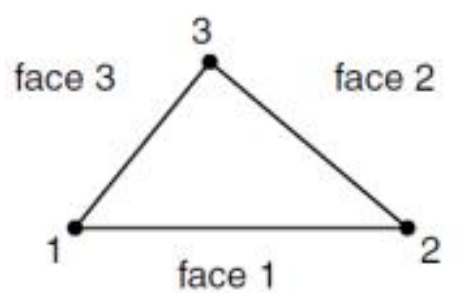

3-node element

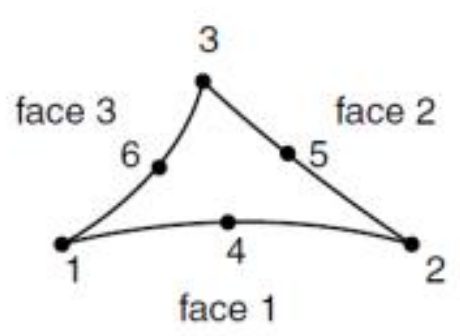

6-node element

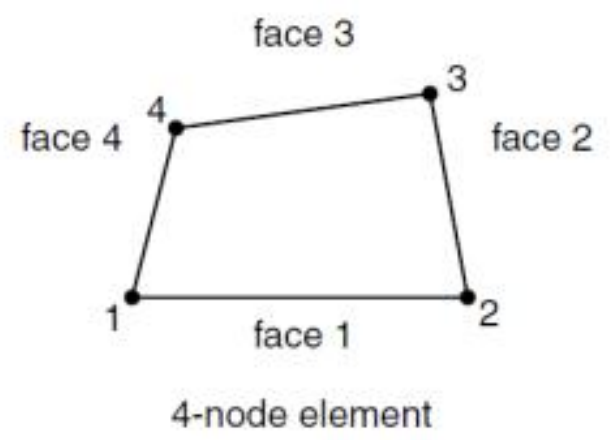

face 3

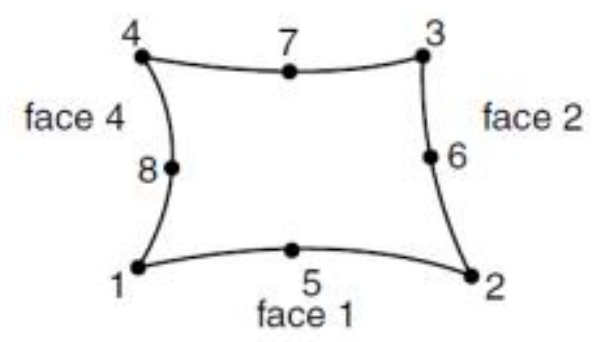

8-node element

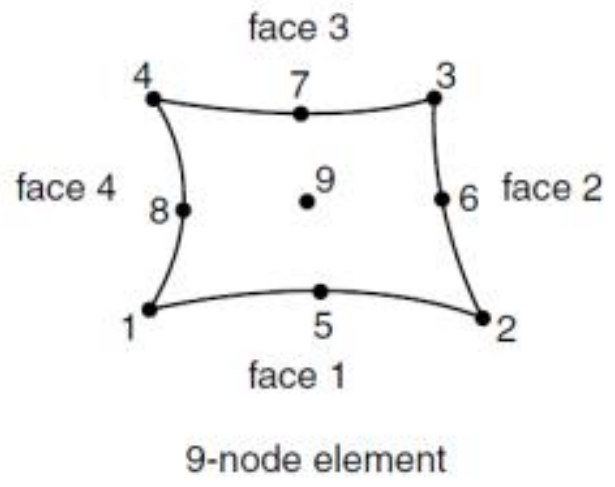

Figure 5.1(a): View of shell elements available in ABAQUS software (adopted from Hibbitt et al., 2010) 


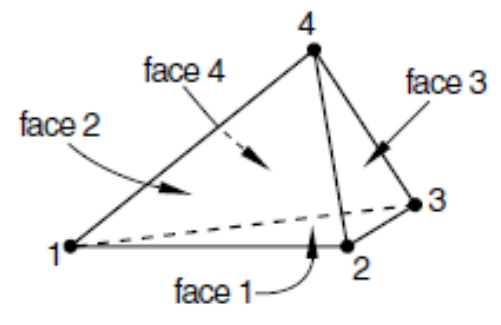

4 - node element

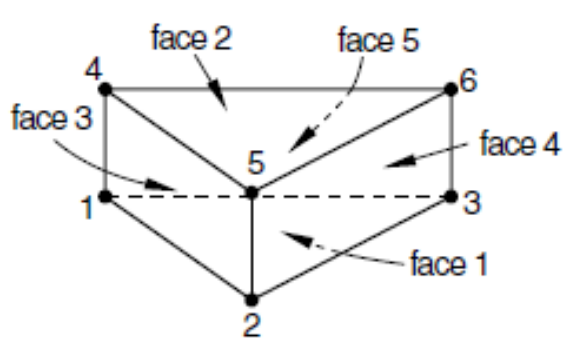

6 - node element
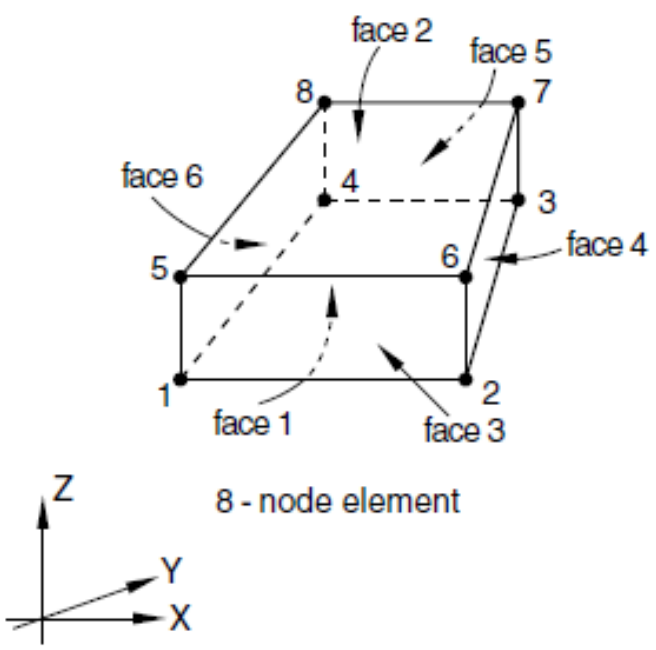

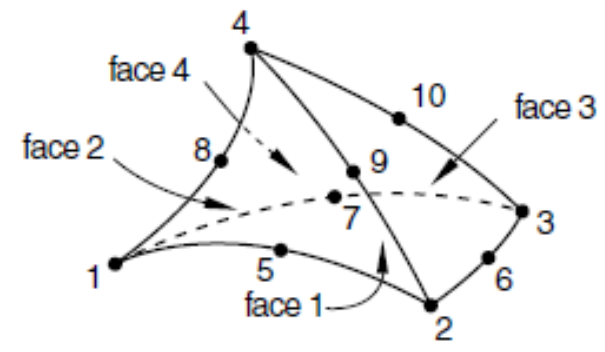

10 - node element

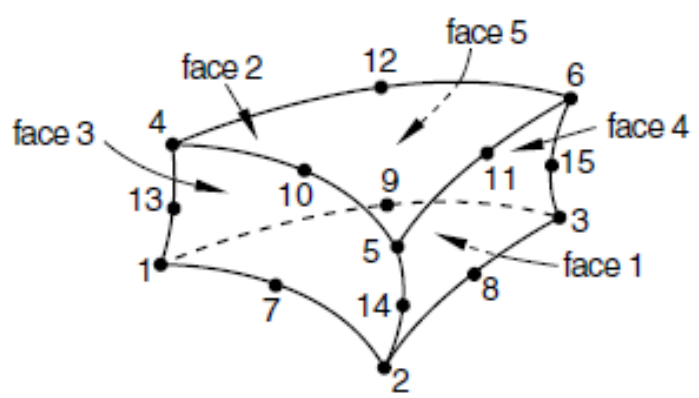

15 - node element

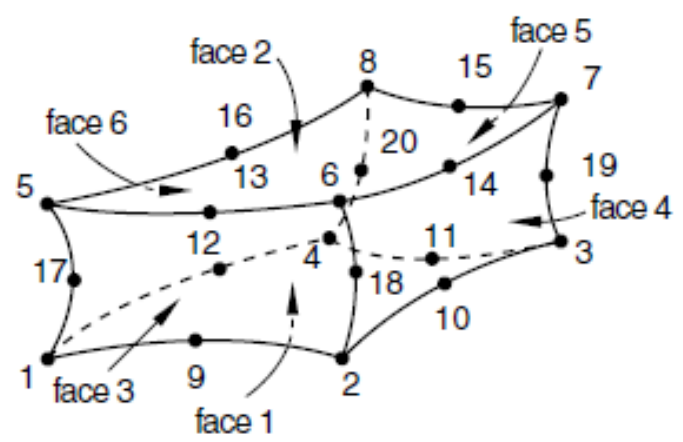

20 - node element

Figure 5.1(b): View of solid elements available in ABAQUS software (adopted from Hibbitt et al., 2010) 


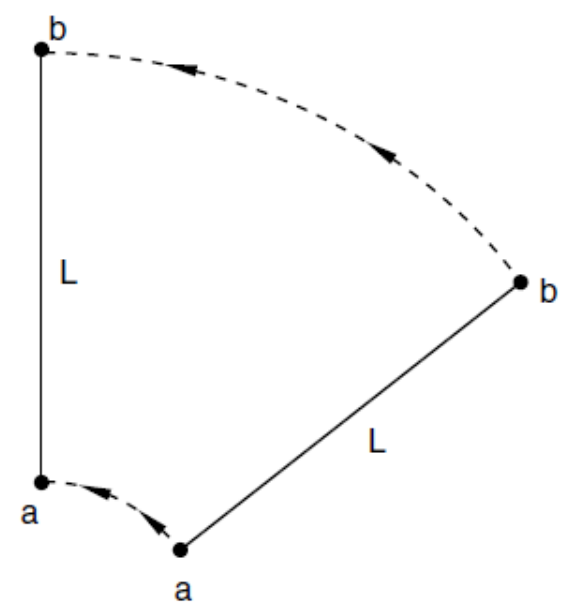

Figure 5.2: View of the LINK element in ABAQUS (adopted from Hibbitt et al., 2010)

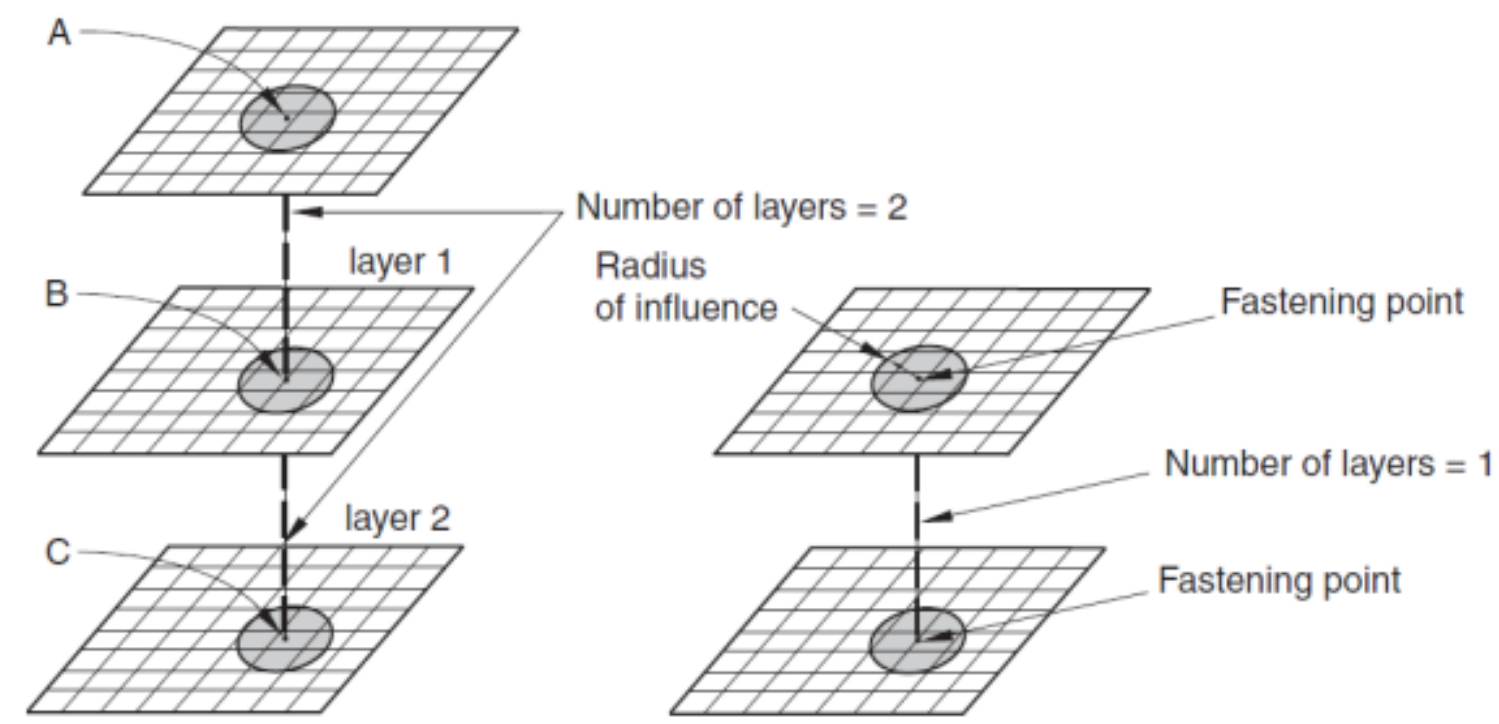

Figure 5.3: Typical one-layer and two-layer fastener configuration (adopted from Hibbitt et al., 2010 )

\subsection{MODELING DETAILS AND LOADING / BOUNDARY CONDITIONS}

Boundary conditions have great influence on the accuracy of the finite-element analysis. The cold-formed steel joist and OSB sheet were modeled using S4R shell elements. The 1-kN point load was applied directly to both joists at their mid-span location. The assembly was modelled as simply-supported over two solid supports incorporating the solid elements mentioned earlier. Multi-point constraints type "TIE" were utilized to (i) connect the OSB sheet with the joist top flange nodes, (ii) connect the joist web with the clip angles at joist ends and (iii) connect the 
track to the joist and clip angles, simulating fastener connections. MPC type "LINK" was utilized to bracing (i.e. straps between connecting joists at their top and bottom flanges).

\subsection{MESHING OF FINITE-ELEMENT MODEL}

After creating the FE model in ABAQUS software, the area was meshed with S4R elements. Different mesh densities were used to find the best mesh density for the joist. FE model may get a sufficient fine mesh to model the essential features of the deformed shape, but not too dense to minimize the number of elements to reduce the computation time. The mesh sizes used in the mesh density analysis were 100x100 mm, 50x50 mm, 25x25 mm and 12x12 mm. The loaddeflection curves for the $302 \times 5000 \mathrm{~mm}$ iSPAN joist are depicted in Figure 5.4 for different mesh sizes. It can be observed that the mesh density of $25 \times 25 \mathrm{~mm}$ shows good correlation with the experimental findings. As such, this mesh size was used to model the tested joists to-collapse. However, 100x100 mm mesh sizes were used to model the OSB sheets since they are secondary members when considering joist load carrying capacity under flexural loading.

\subsection{MATERIAL AND GEOMETRIC NONLINEARITY}

Material nonlinearity can be defined as a nonlinear relationship between stress and strain. In order to predicate the ultimate strength, both geometric and material nonlinearities are required. Material nonlinearity is a consideration for post-buckling analysis of cold-formed steel member. ABAQUS software requires material stress-strain data to be entered as true stress and true plastic strain. To convert the nominal stress (engineering stress) to true stress, equation 5.2 can be used while equation 5.3 can be used to convert the nominal strain to true strain. To convert the true strain to true plastic strain, equation 5.4 can be used. The true and engineering stress-strain curves are depicted in Figure 5.5.

$$
\begin{aligned}
& \sigma_{\text {true }}=\sigma_{\text {nom }}\left(1+\varepsilon_{\text {nom }}\right) \\
& \varepsilon_{\text {true }}=\ln \left(1+\varepsilon_{\text {nom }}\right) \\
& \varepsilon_{\text {pl }}=\varepsilon_{\text {true }}-\frac{\sigma_{\text {true }}}{\mathrm{E}}
\end{aligned}
$$




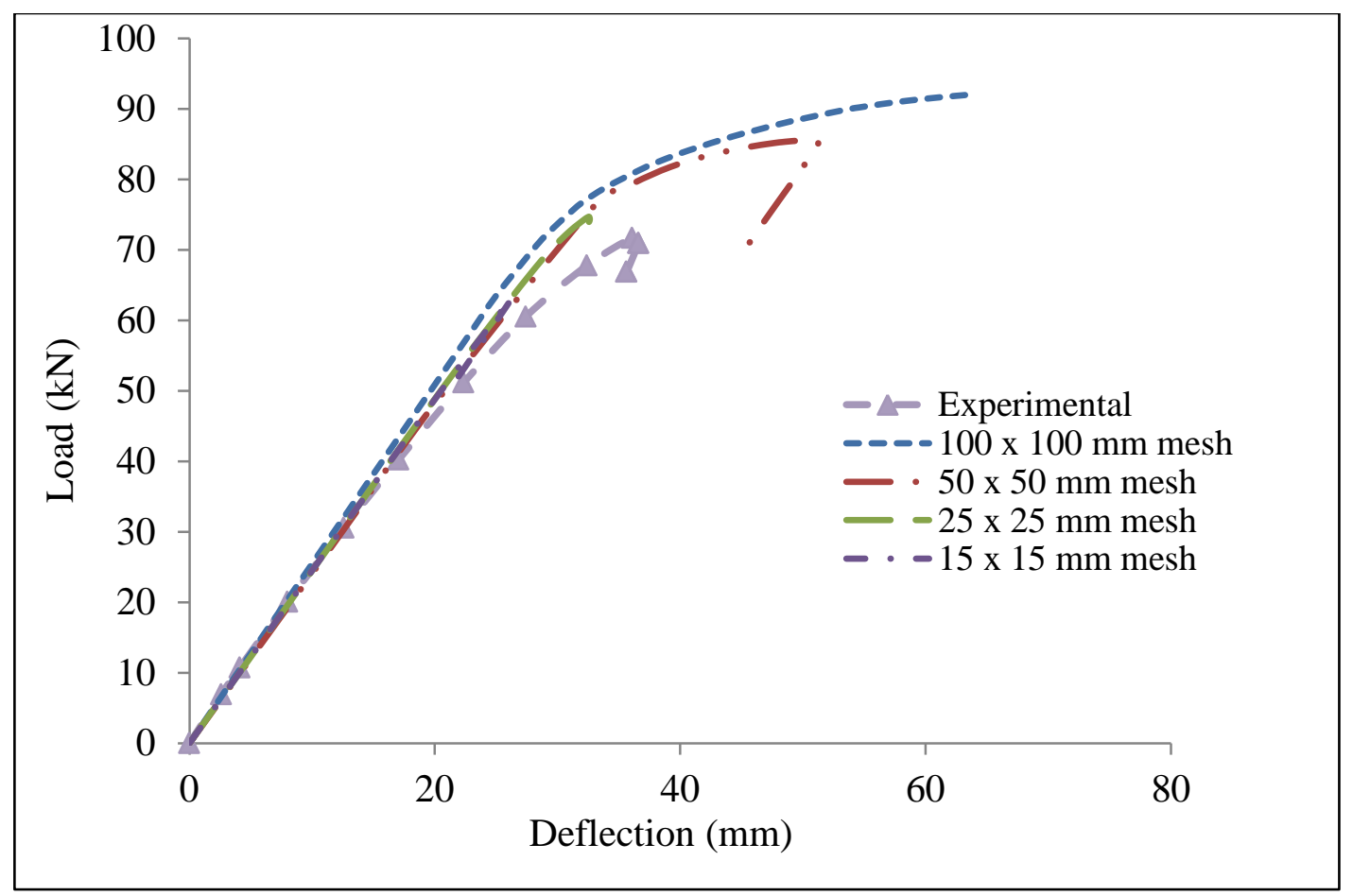

Figure 5.4: Effect of FE mesh sensitivity on the load-deflection history of the $302 \times 5000 \mathrm{~mm}$ iSPAN joist assembly

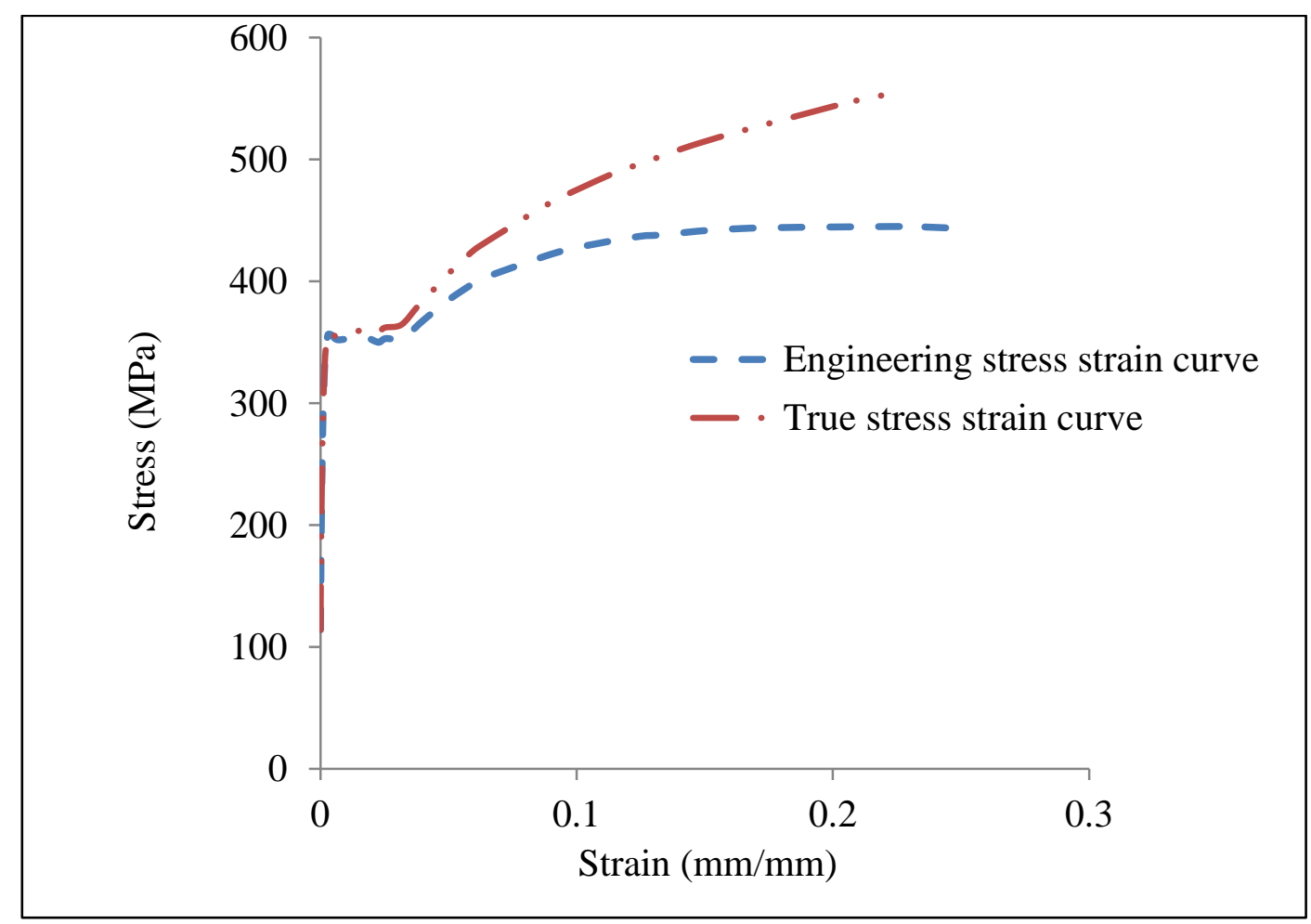

Figure 5.5: True and engineering stress-strain curves for CFS members 
For cold-formed steel material modelling, Poisson's ratio, v, was set to 0.3 , and the modulus of elasticity, E, was set to $200,000 \mathrm{MPa}$. In this study, a large-displacement static analysis considering geometric nonlinearities was carried out to determine the ultimate load carrying capacity of the cold-formed steel joist under flexural loading. It should be noted that in calculating the ultimate resisting moment of the tested joisted in Chapter 4, the commercial steel yield strength of $350 \mathrm{MPa}$ was used in code equations. However, in the finite-element modelling,

yield strength of $350 \mathrm{MPa}$ was used for joist groups A, B and C listed in Tables 3.2 and 3.3. However, a yield stress of $270 \mathrm{MPa}$ was used for joist group D based on the results from steel coupon testing reported earlier. Also the CFS member thickness of 1.22 and $1.36 \mathrm{~mm}$ specified in table 3.2 through 3.4 were used in the FEA modeling.

\subsection{GEOMETRIC IMPERFECTION}

Geometric imperfection can be defined as the deviation of a member from its perfect geometry. Imperfection of a member may include bowing, warping and twisting as well as local deviation. The geometric imperfection is generally introduced in a model for a postbuckling load displacement analysis. The exact postbuckling problem often cannot be analysed directly due to the discontinuous response (bifurcation) at the point on buckling. To analysis a post-buckling problem, one must turn into a problem with continuous response instead of bifurcation, which can be accomplished by introducing a geometric imperfection pattern in the perfect geometry so that there is some response in the buckling mode before the critical load is reached. The usual approach involves two analysis runs with the same model definition to establish the probable collapse modes and then to perform the postbuckling analysis. First analysis run performs an eigenvalue buckling analysis on the "perfect" structure to establish probable collapse modes and to verify that the mesh discretizes those modes accurately and store these modes in the results file with the extension ".fill". However, the second analysis introduces an imperfection in the geometry by adding these buckling modes to the "perfect" geometry. The "IMPERFECTION" option in ABAQUS can be used to read the buckling modes corresponding to the lowest eigenvalues, scale them, and use them to perturb the nodal coordinates of the samples. The magnitudes of the perturbations used are typically a few percent of a relative a plate thickness (Hibbitt et al., 2010). As a simple rule of thumb, the use of a maximum deviation that is approximately equal to the plate thickness can be used. In this study, the maximum imperfections 
from the perfect geometry are taken 1.5 times the plate thickness (Pekoz and Schafer, 1998). From the results, typical plots of the geometric imperfection are shown later in this Chapter in Figures 5.35 to 5.44. The geometric imperfection has a significant effect on the strength.

The second method of introducing the imperfection in the model is by introducing the loading imperfection in the model. In this case, fictitious "trigger" loads can be used to initiate the instability. The trigger loads should perturb the structure in the expected buckling modes. Typically, these loads are applied as dead loads prior to the Riks step so that they have fixed magnitudes. The magnitudes of trigger loads must be sufficiently small so that they do not affect the overall postbuckling solution. It is the programmer responsibility to choose appropriate magnitudes and locations for such fictitious loads since ABAQUS / Standard does not examine whether these values are reasonable (Hibbitt et al., 2010).

\subsection{RESIDUAL STRESSES}

Like hot-rolled steel sections, the residual stresses do not play the dominating role in coldformed steel section. During the cooling process, the residual stress in hot-rolled steel section can be as high as $1 / 3$ of the yield stress, or even greater than that. The residual stress can occur in the important regions of I- and C-sections such as flange tips. The effects of residual stresses are introduced to cold-formed sections during the manufacturing process of roll-forming and pressbreaking. The effect of residual stresses causes an early yielding of the steel resulting in a reduction of the member strength (Krisda, 2011). It has been concluded in Gardner and Nethercot (2004) and Ellobody and Young (2005) that this effect can be neglected in the finiteelement modeling, if the material property is directly derived from the coupons obtained from an actual member, since residual stresses are already inherently embedded. Ignoring residual stresses in a member is common for both hot-rolled and cold-formed structural steel design.

\subsection{MODIFIED RIKS METHOD}

The Riks method is generally used to predict unstable and geometrically nonlinear collapse of a structure. It can include nonlinear materials and boundary conditions. It often follows an eigenvalue buckling analysis to provide complete information about a structure's collapse and can be used to speed convergence of ill-conditioned or snap-through problems that do not exhibit 
instability. It is often necessary to obtain nonlinear static equilibrium solutions for unstable problems, where the load displacement response can exhibit the type of behavior sketched in Figure 5.6 that is, during periods of the response, the load and/or the displacement may decrease as the solution progresses. The modified Riks method is an algorithm that allows effective solution of such cases (Hibbitt et al., 2010).

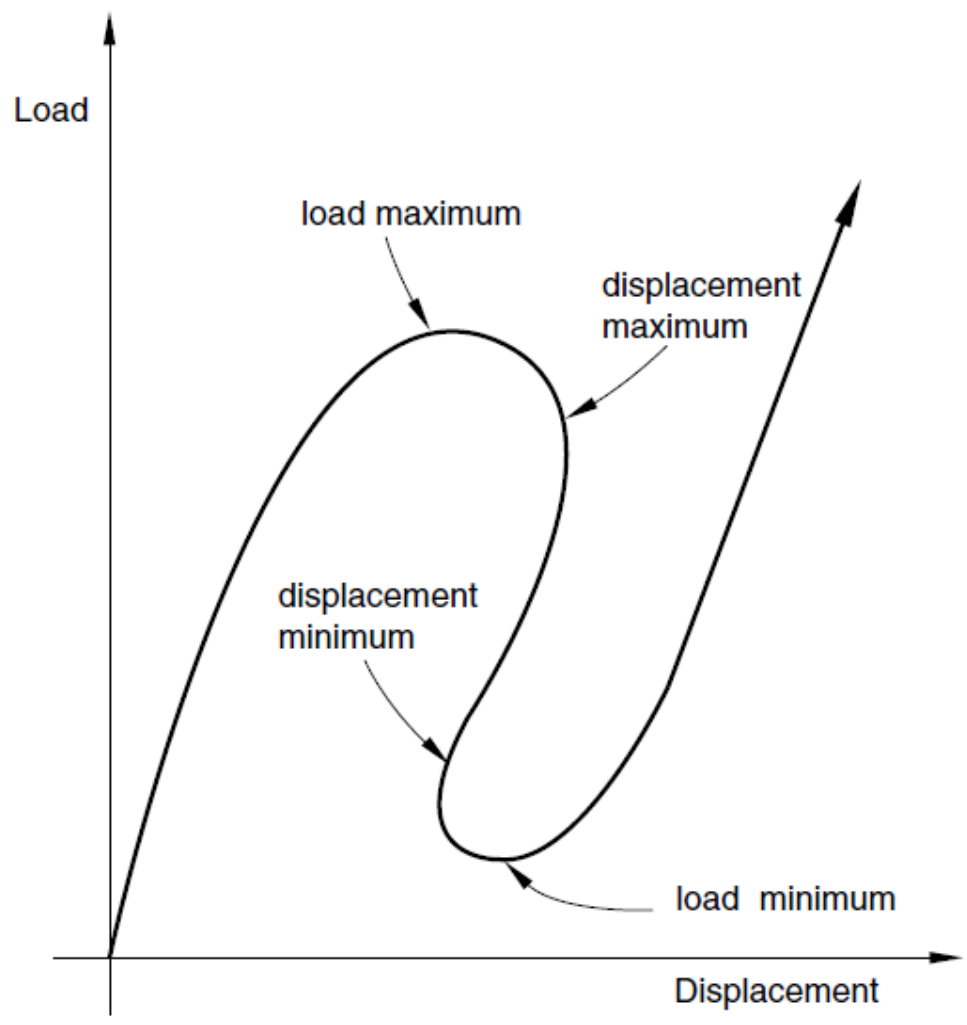

Figure 5.6: Typical unstable static response (Hibbitt et al., 2010)

Several methods have been proposed and applied to such problems, including the NewtonRaphson method, Modified New-Raphson Method, Incremental Methods, Quasi-Newton Method, etc. Of these methods, the most successful efficient and accurate method is the modified Riks method (Crisfield, 1981; Ramm, 1981; Powell and Simons, 1981), and a version of this method has been implemented in ABAQUS software. The essence of this method is that the solution is viewed as the discovery of a single equilibrium path in a space defined by the nodal variables and the loading parameter. 


\subsection{VALIDATION OF FINITE-ELEMENT MODEL}

The three-dimensional finite-element model of the full scale joists was developed to simulate the test setup shown in Figure 5.9. The classical Eigen value buckling analysis and inelastic postbuckling analysis was performed for this type of problem. In a classical Eigen value buckling problem, the analysis estimates the critical buckling loads as well as useful estimates of collapse mode shapes. The collapse mode shapes are then be used to introduce an initial geometric imperfection in the post buckling analysis. In the post-buckling analysis, ABAQUS software employs the modified Riks method to perform a load-displacement analysis where other important nonlinear effects, such as material inelasticity or degree of imperfection, can be included. The modified Riks algorithm is the method suitable for obtaining nonlinear static equilibrium solutions for unstable problems (Hibbitt et al., 2010). The essence of the method is that the solution is viewed as the discovery of a single equilibrium path. The basic algorithm assumes that there is a path-dependent response. For these reasons, it is essential to limit the increment size.

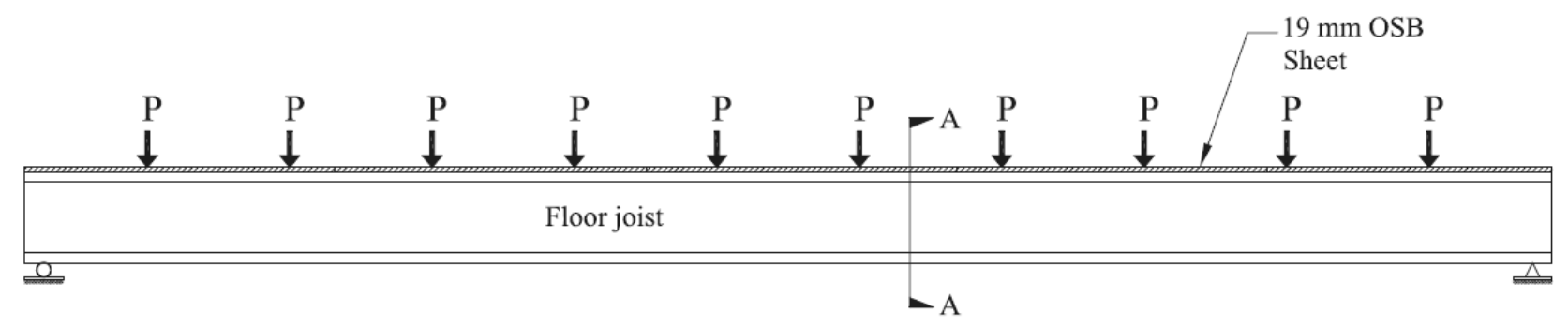

(a) Elevation of the tested iSPAN joist

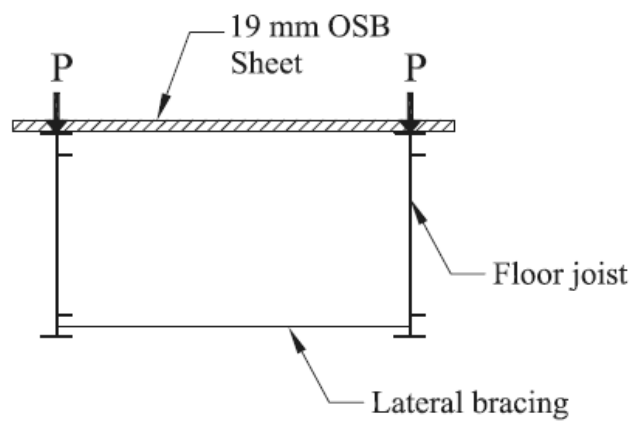

(b) Section A-A

Figure 5.7: Schematic diagram of the tested iSPAN joist assembly considered in the FE modelling 


\subsection{FINITE-ELEMENT ANALYSIS RESULTS}

\section{a) ELASTIC BUCKLING RESULTS}

First, the eigenvalue elastic buckling analysis was performed to get the expected buckling mode, and then these buckling modes were introduced in the nonlinear analysis to produce the imperfection in model.

\section{b) ULTIMATE STRENGTH / POSTBUCKLING RESULTS}

It is important to be sure that the finite-element model gives reasonable results and can predict the actual behaviour of the structures. The best way to verify the accuracy of the model is to compare the FE results with experimental results. The result from the finite-element simulation in the form of joist flexural frequency, static deflection under 1-kN load, deformed shape and load-deflection curves can be correlated with the experimental findings. For each joist type, the frequency analysis, static analysis, buckling analysis and two nonlinear finite-element analyses were performed. The frequency analysis was used to calculate the frequency of the tested joist assembly, while static analysis was used to obtain the joist static deflection under the $1-\mathrm{kN}$ load over the floor assembly. Buckling analysis was used to get the expected mode shapes, and then these buckling mode shapes were introduced in the nonlinear analysis. The two nonlinear analyses were performed, namely: one nonlinear analysis model with no imperfection ( $0 \%$ of thickness) and one with $1.5 \mathrm{t}$ imperfections of plate thickness where $\mathrm{t}$ is the thickness of plate. To determine the ultimate load carrying capacity of the cold-formed steel joist, the modified Riks method was used and the load was applied in very small increments. The analysis by this method typically stopped when the ultimate load capacity is reached as a result of convergence problem, even for the very small increments of loading, as shown later in Figures 5.38 to 5.44. The load versus mid-span deflection curves obtained finite-element analysis was then compared with experimental results. The Von Mises stress criterion was used as theories of failure for static loading.

As a sample FE results, Figure 5.10 shows view of the FE model for the 254x3500 mm iSPAN two-joist assembly with web hole. While Figure 5.11 shows the deformed shape of the assembly with contour lines pointing on stress concentration at the web-track-end support region. When 
magnifying this region, web and track crippling observed in the tested joist shown in Figure 5.12 was observed in the close-up view of the FE contour lines and deformed shape shown in Figure 5.13. Other example of the FE results is shown in Figures 5.14 to 5.17. Figures 5.14 and 5.15 show views of the deformed shape of the 406x7950 mm iSPAN two-joist assembly without web hole as obtained experimentally and from the FE modelling, respectively. The failure of this assembly was due to local buckling in the top flange at the mid-span region as depicted experimentally in Figure 5.16 and using the FE modelling in Figure 5.17. 


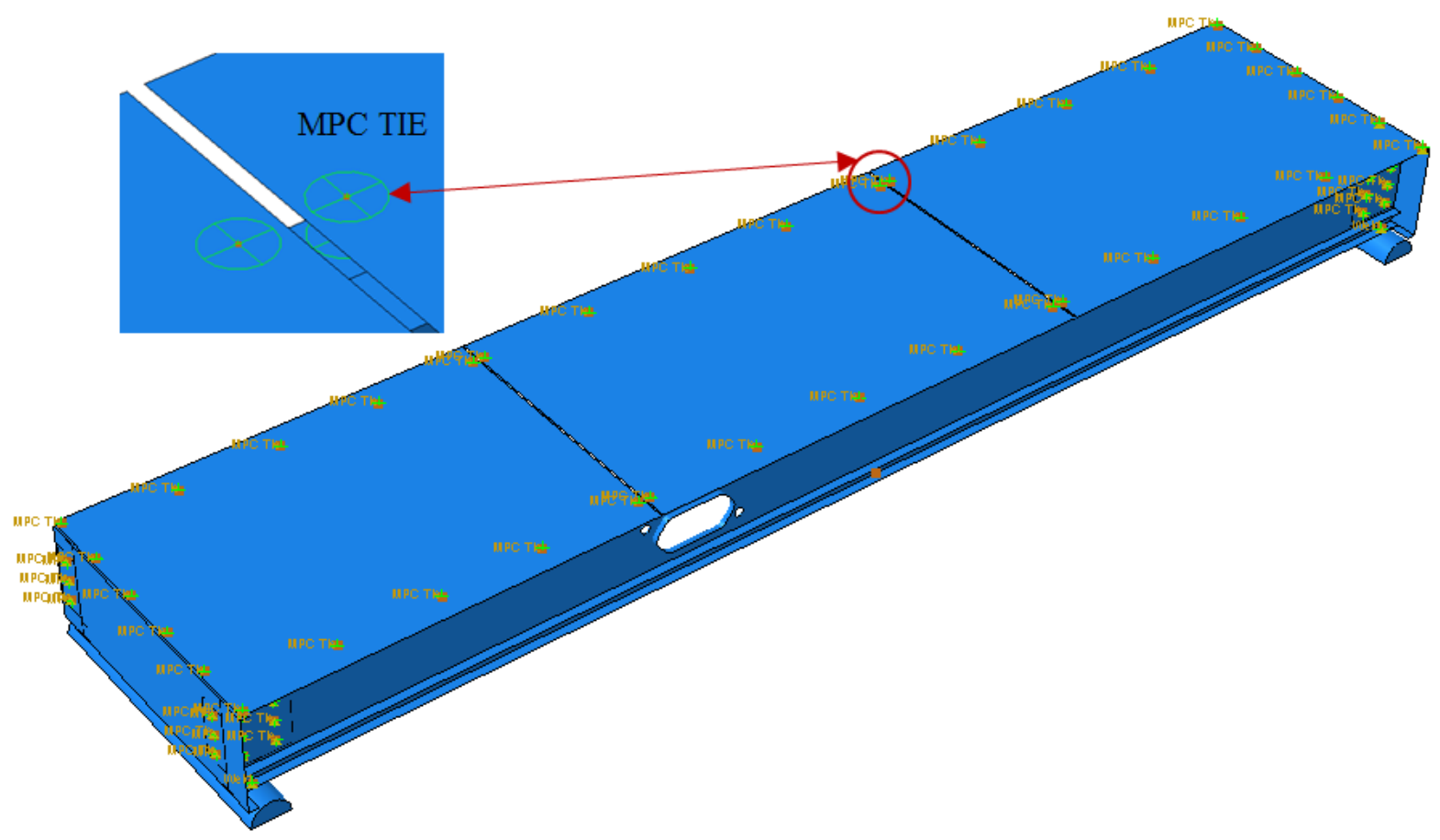

Figure 5.8: View of the FE model of the 254x3500 mm ISPAN two-joist Assembly with web hole

\section{S, Mises}

SNEG, (fraction $=-1.0$ )

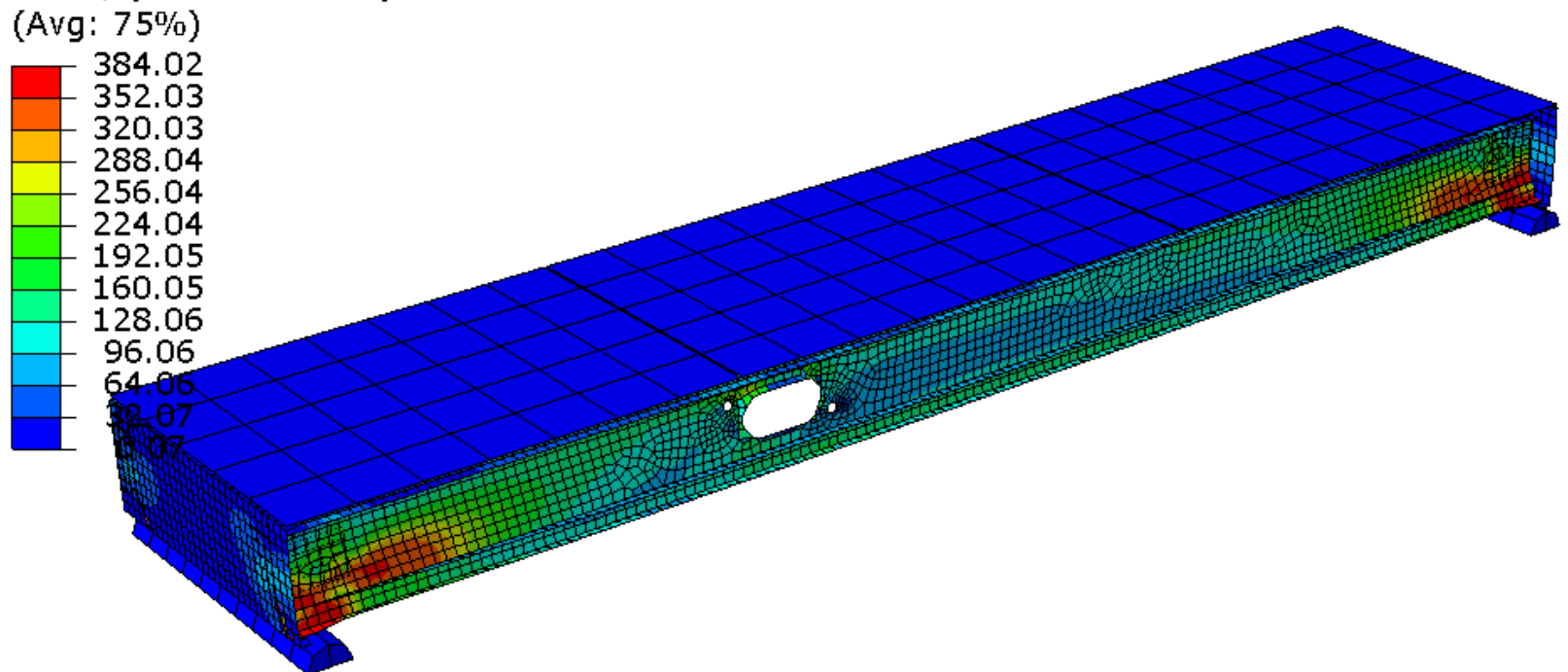

Figure 5.9: View of the FE deformed shape of the 254x3500 mm ISPAN two-joist Assembly with web hole 


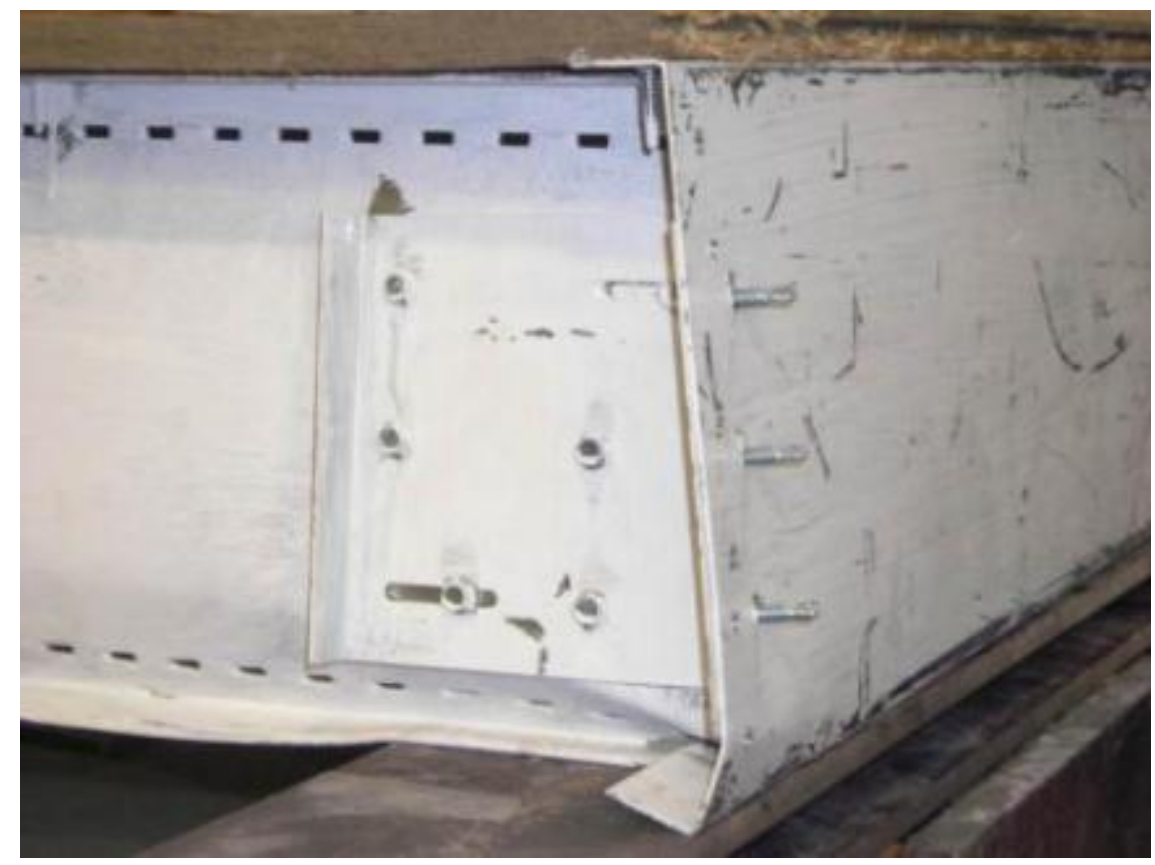

Figure 5.10: View of the experimental deformed shape of the 254x3500 mm iSPAN joist assembly showing web and track crippling at failure
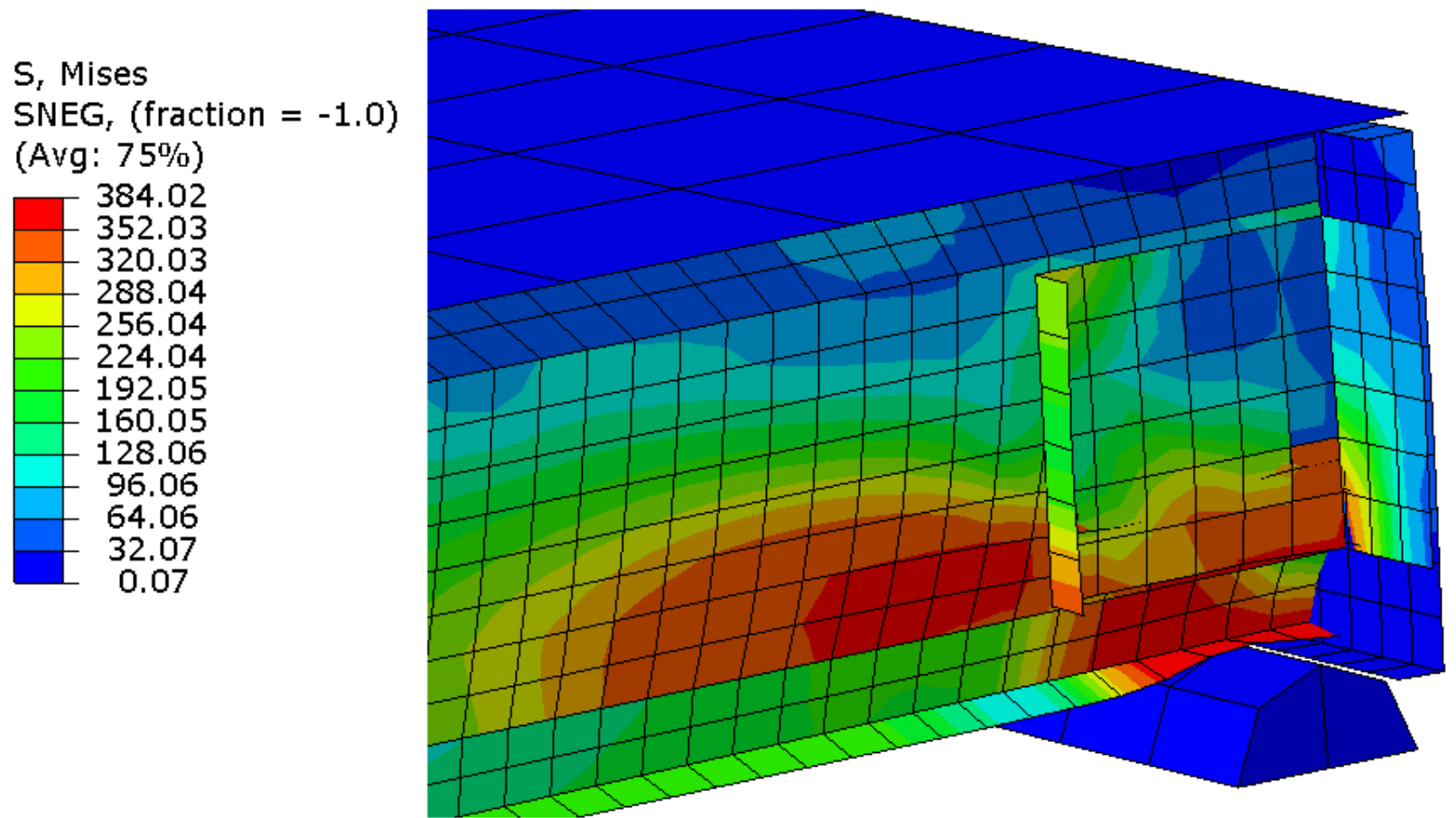

Figure 5.11: View of the FE deformed shape of the 254x3500 mm iSPAN joist assembly showing web and track crippling in the form of in-plane stress reaching and exceeding the yield stress 


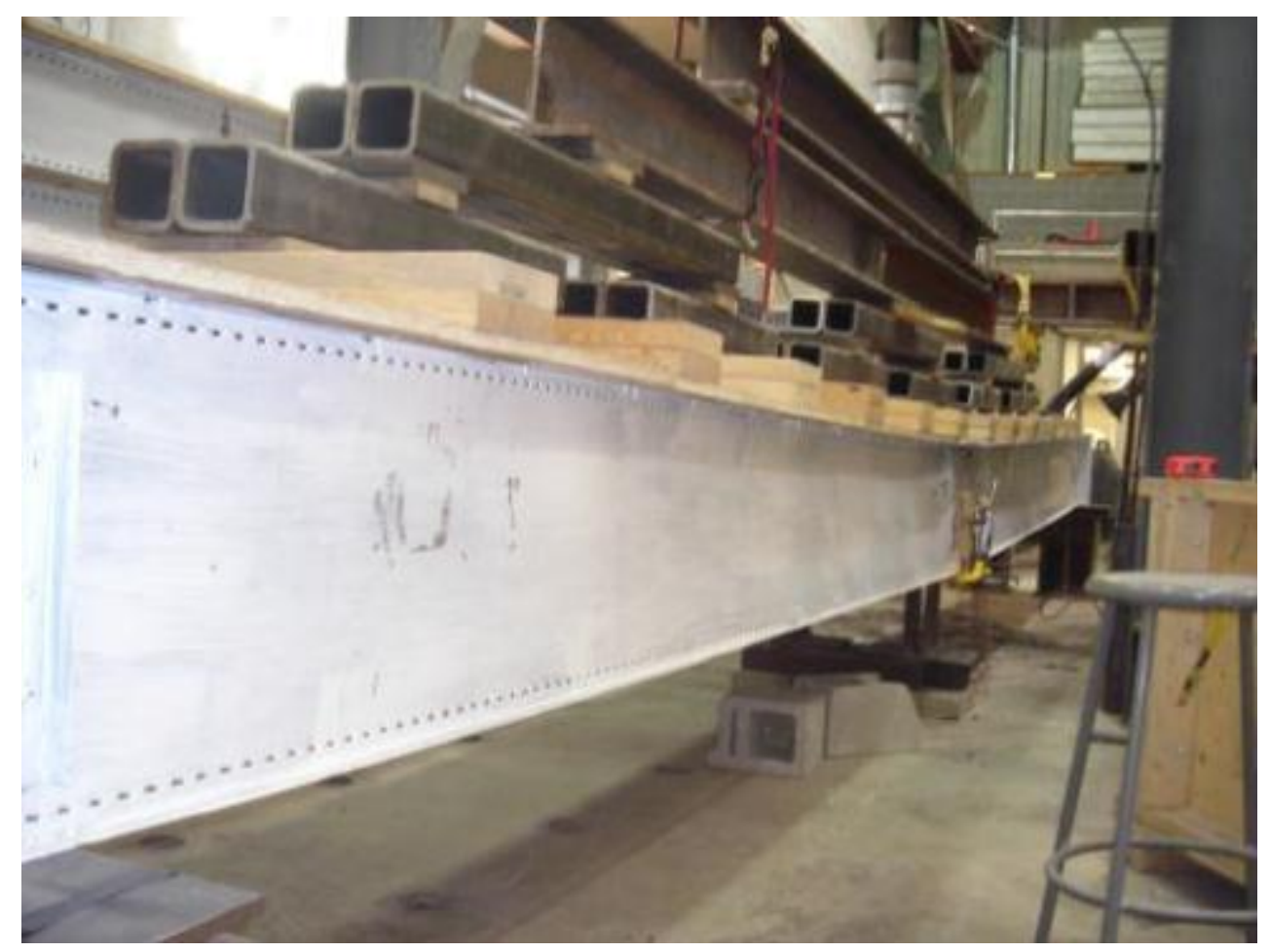

Figure 5.12: View of the experimental deformed shape at failure of the 406x7950 mm iSPAN joist assembly

S, Mises

SNEG, (fraction $=-1.0$ )

(Avg: $75 \%$ )

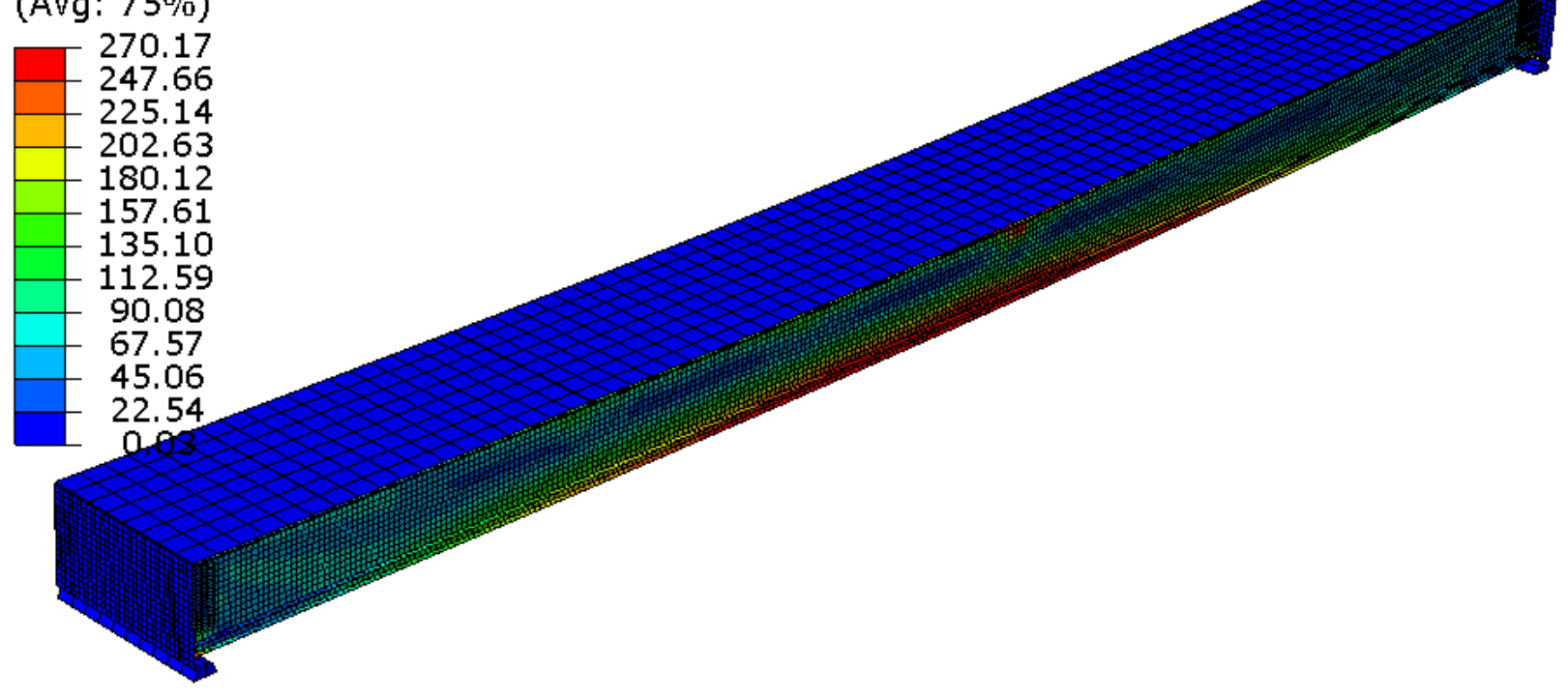

Figure 5.13: View of the FE deformed shape of the 406x7950 mm iSPAN joist assembly 


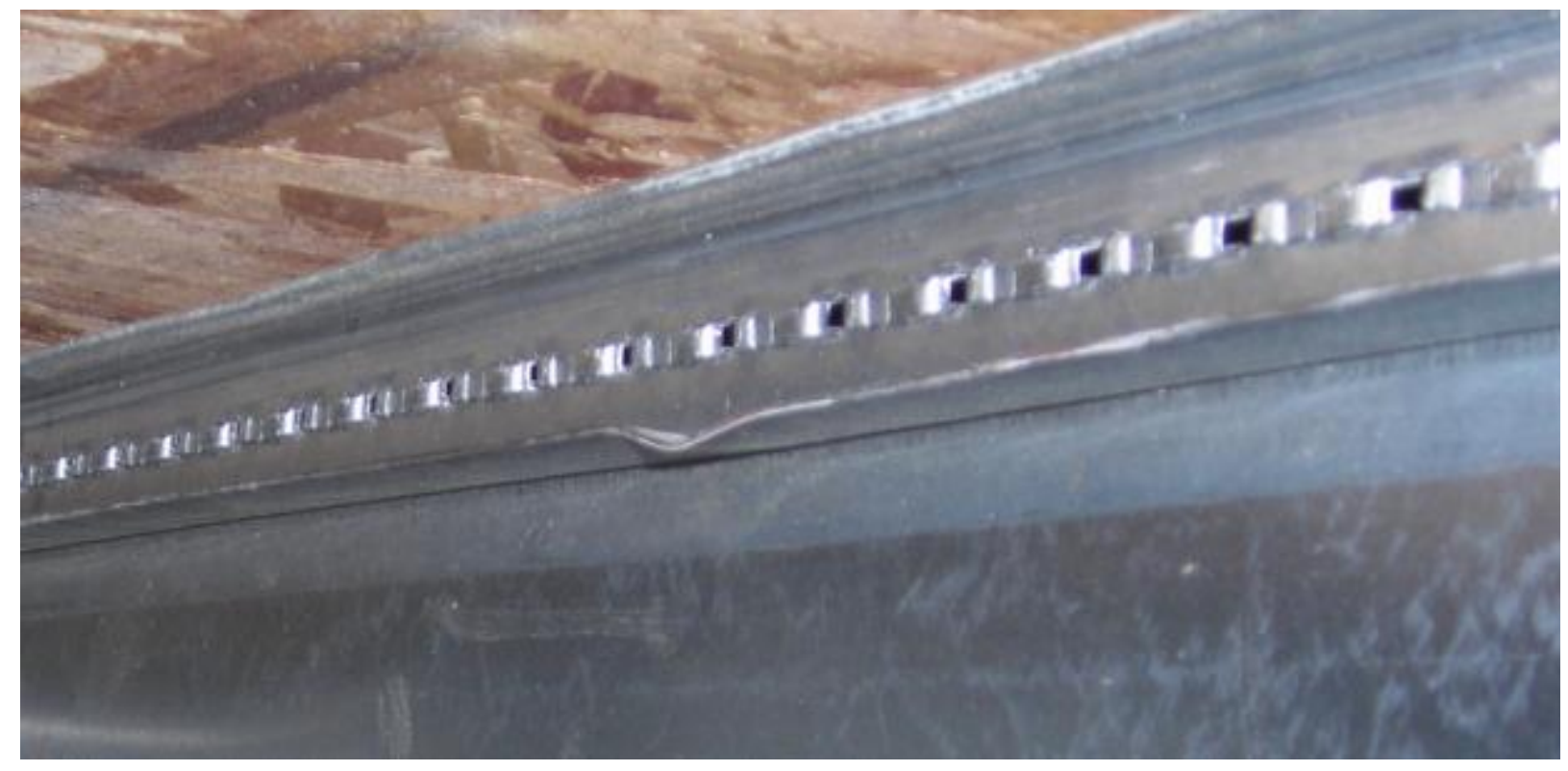

Figure 5.14: View of the experimental local buckling shape in the top flange lip of the 406x7950 iSPAN joist assembly
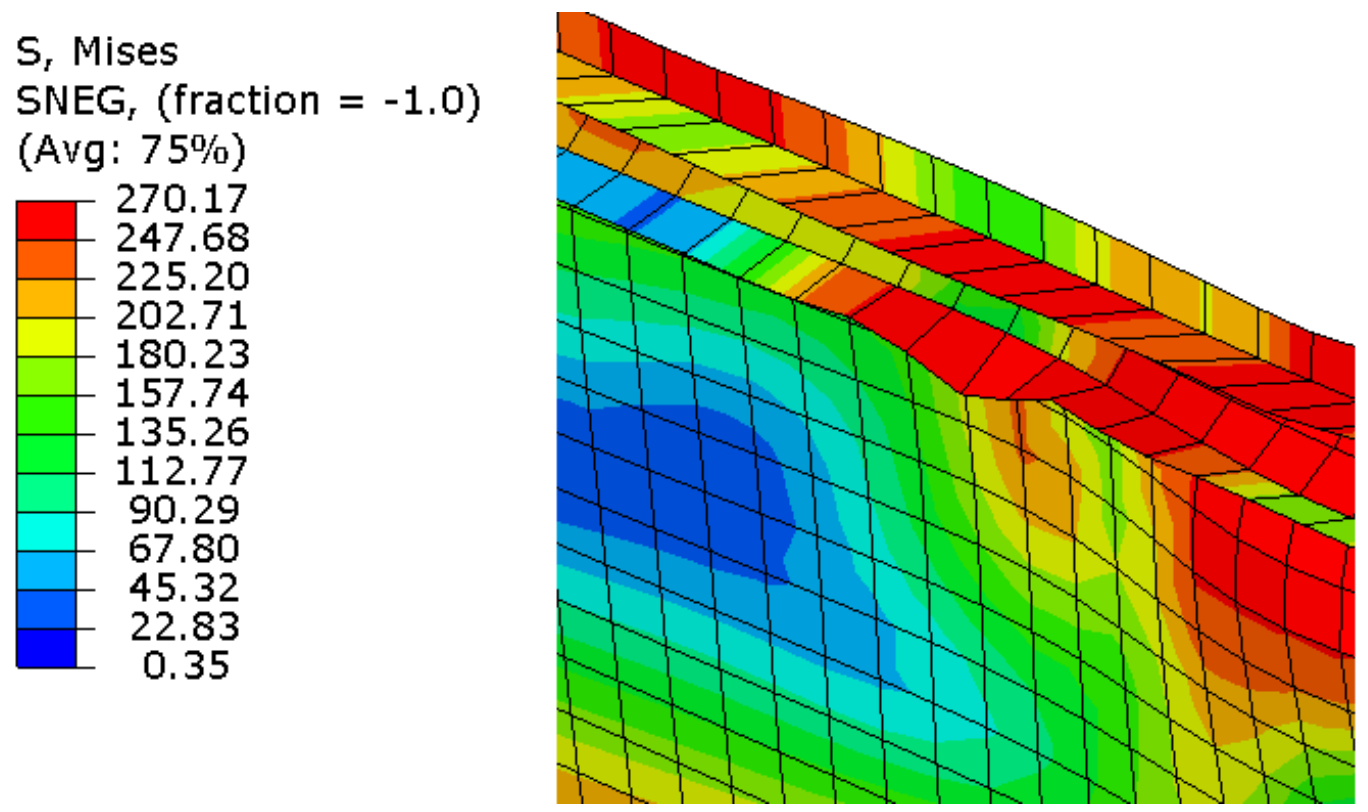

Figure 5.15: View of the FE local buckling shape in the top flange lip of the 406x7950 mm iSPAN joist assembly 


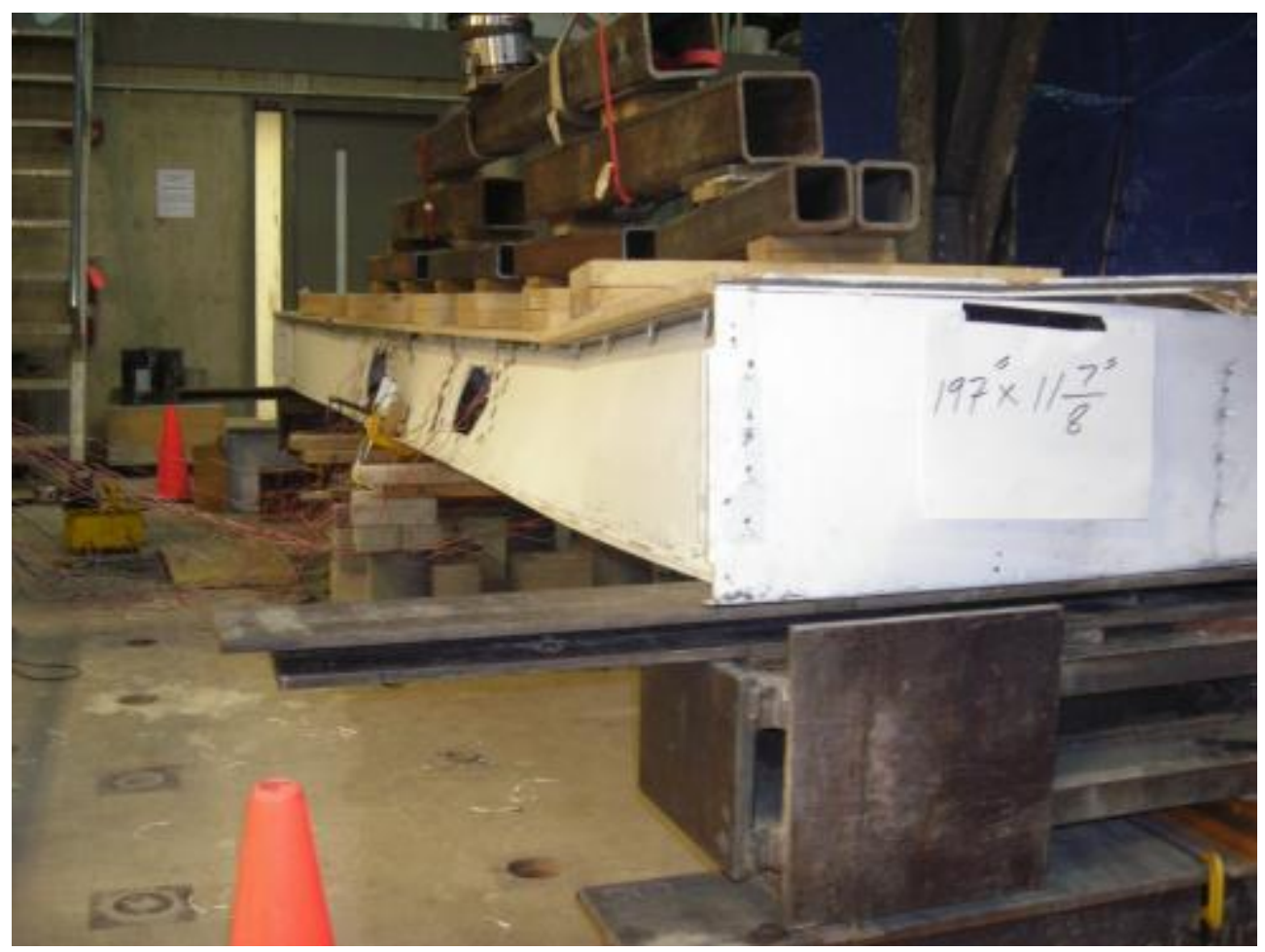

Figure 5.16: View of the experimental lateral torsional buckling shape of the 300x5000 mm iSPAN joist assembly

S, Mises

SNEG, $($ fraction $=-1.0$ )

(Avg: $75 \%$ )

377.57

346.20

314.83

283.47

252.10

220.73

189.37

158.00

126.63

95.27

63.90

$-32.53$

1.17

Figure 5.17: View of the FE lateral torsional buckling shape of the 300x5000 mm iSPAN joist assembly 
Nonlinear finite-element models were constructed for the tested ISPAN joist assemblies to determine their ultimate load capacities under flexural loading. Two types of imperfections were considered in this study, namely: zero imperfection and imperfection equal to $1.5 \mathrm{t}$ where $\mathrm{t}$ equal the thickness of the joist web. Tables 5.1 and 5.2 summarize the correlation between the experimental jacking loads and the corresponding FE values for iSPAN joist assemblies without and with web holes, respectively. Results show that the presence of plate initial imperfection in the order of $1.5 \mathrm{t}$ generally decreases the ultimate load carrying capacity of the joist assembly. For example, the average ratios between the FE ultimate load and the experimental ultimate load of joist assemblies without web holes decreases from 1.14 to 1.02 , respectively, when initial imperfection is considered. Also, the average ratios between the FE ultimate load and the experimental ultimate load of joist assemblies with web holes decreases from 1.06 to 1.02 , respectively, when initial imperfection is considered.

Table 5.1: Comparison between ultimate jacking loads obtained experimentally and from the FE modelling of iSPAN joist assembly without web holes

\begin{tabular}{|c|c|c|c|c|c|c|c|}
\hline $\begin{array}{c}\text { Joist } \\
\text { depth } \\
(\mathrm{mm})\end{array}$ & $\begin{array}{c}\text { Joist } \\
\text { length } \\
(\mathrm{m})\end{array}$ & $\mathrm{P}_{\text {test }}(\mathrm{kN})$ & $\begin{array}{c}\mathrm{P}_{\text {FEM 0\%t }} \\
(\mathrm{kN})\end{array}$ & $\begin{array}{c}\mathrm{P}_{\text {FEM 0\%t }} \\
/ \mathrm{P}_{\text {test }}\end{array}$ & $\begin{array}{c}\mathrm{P}_{\text {FEM 1.5t }} \\
(\mathrm{kN})\end{array}$ & $\begin{array}{c}\mathrm{P}_{\text {FEM 1.5t }} \\
/ \mathrm{P}_{\text {test }}\end{array}$ & $\begin{array}{c}\mathrm{P}_{\text {mean }} \\
/ \mathrm{P}_{\text {test }}\end{array}$ \\
\hline 241 & 3.50 & 104.62 & 109.74 & 1.05 & 101.72 & 0.97 & 1.01 \\
\hline 241 & 4.50 & 69.19 & 72.96 & 1.05 & 71.42 & 1.03 & 1.04 \\
\hline 302 & 5.00 & 49.58 & 72.30 & 1.46 & 62.40 & 1.26 & 1.36 \\
\hline 302 & 5.25 & 54.84 & 64.14 & 1.17 & 51.14 & 0.93 & 1.05 \\
\hline 356 & 6.10 & 62.53 & 64.75 & 1.04 & 60.20 & 0.96 & 1.00 \\
\hline 313 & 7.95 & 60.94 & 64.37 & 1.06 & 58.80 & 0.96 & 1.01 \\
\hline Mean & & & & 1.14 & & 1.02 & 1.08 \\
\hline $\begin{array}{c}\text { Standard } \\
\text { deviation }\end{array}$ & & & & $16 \%$ & & 12 & 14 \\
\hline
\end{tabular}

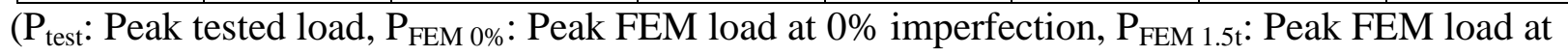
$1.5 t$ imperfection, $\mathrm{P}_{\text {mean }}$ : Average value of $\mathrm{P}_{\mathrm{FEM} 0 \%}$ and $\mathrm{P}_{\mathrm{FEM}} 1.5 \mathrm{t}$ ) 
Table 5.2: Comparison between ultimate jacking loads obtained experimentally and from the FE modelling of iSPAN joist assembly with web holes

\begin{tabular}{|c|c|c|c|c|c|c|c|}
\hline $\begin{array}{c}\text { Joist } \\
\text { depth } \\
(\mathrm{mm})\end{array}$ & $\begin{array}{c}\text { Joist } \\
\text { length } \\
(\mathrm{m})\end{array}$ & $\mathrm{P}_{\text {test }}(\mathrm{kN})$ & $\begin{array}{c}\mathrm{P}_{\text {FEM } 0 \% t} \\
(\mathrm{kN})\end{array}$ & $\mathrm{P}_{\text {FEM 0\%t }} / \mathrm{P}_{\text {test }}$ & $\begin{array}{c}\mathrm{P}_{\text {FEM } 1.5 t} \\
(\mathrm{kN})\end{array}$ & $\begin{array}{c}\mathrm{P}_{\text {FEM } 1.5 t} \\
/ \mathrm{P}_{\text {test }}\end{array}$ & $\mathrm{P}_{\text {mean }} / \mathrm{P}_{\text {test }}$ \\
\hline 254 & 3.50 & 98.30 & 102.54 & 1.04 & 101.80 & 1.04 & 1.04 \\
\hline 254 & 4.50 & 89.09 & 98.00 & 1.10 & 94.00 & 1.06 & 1.08 \\
\hline 302 & 5.00 & 71.82 & 72.57 & 1.01 & 69.78 & 0.97 & 0.99 \\
\hline 302 & 5.25 & 62.80 & 69.20 & 1.10 & 63.20 & 1.01 & 1.05 \\
\hline Mean & & & & 1.06 & & 1.02 & 1.04 \\
\hline $\begin{array}{c}\text { Standard } \\
\text { deviation }\end{array}$ & & & & $4 \%$ & & $4 \%$ & $4 \%$ \\
\hline
\end{tabular}

$\left(\mathrm{P}_{\text {test }}\right.$ : Peak tested load, $\mathrm{P}_{\text {FEM 0\%: }}$ Peak FEM load at 0\% imperfection, $\mathrm{P}_{\text {FEM 1.5t }}:$ Peak FEM load at $1.5 t$ imperfection, $\mathrm{P}_{\text {mean }}$ : Average value of $\mathrm{P}_{\mathrm{FEM} 0 \%}$ and $\mathrm{P}_{\mathrm{FEM} 1.5 \mathrm{t}}$ )

Table 5.3: Comparison between 1-kN-load deflection and flexural frequencies obtained experimentally and using the FE modeling of iSPAN joist without web holes

\begin{tabular}{|c|c|c|c|c|c|c|c|}
\hline $\begin{array}{c}\text { Joist } \\
\text { depth } \\
(\mathrm{mm})\end{array}$ & $\begin{array}{c}\text { Joist } \\
\text { length } \\
(\mathrm{m})\end{array}$ & $\begin{array}{c}\Delta_{\text {Test }} \text { under } \\
1-\mathrm{kN} \text { load } \\
(\mathrm{mm})\end{array}$ & $\begin{array}{c}\Delta_{\mathrm{FEM}} \\
(\mathrm{mm})\end{array}$ & $\Delta_{\text {FEM }} / \Delta_{\text {Test }}$ & $\begin{array}{c}f_{\text {Test }} \\
(\mathrm{Hz})\end{array}$ & $\begin{array}{c}f_{\text {FEM }} \\
(\mathrm{Hz})\end{array}$ & $f_{\text {FEM }} / f_{\text {Test }}$ \\
\hline 241 & 3.50 & 0.55 & 0.51 & 0.93 & 40.73 & 39.80 & 0.97 \\
\hline 241 & 4.50 & 0.97 & 0.91 & 0.94 & 26.59 & 26.66 & 1.00 \\
\hline 302 & 5.00 & 0.75 & 0.76 & 1.01 & 27.04 & 27.95 & 1.03 \\
\hline 302 & 5.25 & 0.92 & 0.85 & 0.92 & 24.15 & 25.71 & 1.06 \\
\hline 356 & 6.10 & 0.71 & 0.74 & 1.04 & 23.19 & 21.00 & 0.91 \\
\hline 406 & 7.95 & 1.54 & 1.40 & 0.91 & 14.51 & 15.50 & 1.06 \\
\hline Mean & & & & 0.96 & & & 1.01 \\
\hline $\begin{array}{c}\text { Standard } \\
\text { Deviation }\end{array}$ & & & & $5.49 \%$ & & & $6.16 \%$ \\
\hline
\end{tabular}

Tables 5.3 and 5.4 show correlation between the experimental 1-kN-load deflection and flexural frequencies and those obtained using the FE modeling of iSPAN joist without and with web holes, respectively. Good agreement is observed between the experimental findings and those obtained from FE modelling. For example, the average ratios between the FE static deflection and the experimental static deflection were 0.96 and 0.87 for joist assemblies without and with 
web holes, respectively. Also, the average ratios between the FE frequency and the experimental frequency were 1.01 and 1.04 for joist assemblies without and with web holes, respectively.

Table 5.4: Comparison between the experimental 1-kN-load deflection and flexural frequencies and those obtained using the FE modeling of iSPAN joist with web holes

\begin{tabular}{|c|c|c|c|c|c|c|c|}
\hline $\begin{array}{c}\text { Joist } \\
\text { depth } \\
(\mathrm{mm})\end{array}$ & $\begin{array}{c}\text { Joist } \\
\text { ength } \\
(\mathrm{m})\end{array}$ & $\begin{array}{c}\Delta_{\text {Test }} \text { under } \\
1-\mathrm{kN} \text { load } \\
(\mathrm{mm})\end{array}$ & $\begin{array}{c}\Delta_{\text {FEM }} \\
(\mathrm{mm})\end{array}$ & $\Delta_{\text {FEM }} / \Delta_{\text {Test }}$ & $\begin{array}{c}f_{\text {Test }} \\
(\mathrm{Hz})\end{array}$ & $\begin{array}{c}f_{\text {FEM }} \\
(\mathrm{Hz})\end{array}$ & $f_{\text {FEM }} / f_{\text {Test }}$ \\
\hline 254 & 3.50 & 0.54 & 0.42 & 0.78 & 46.22 & 43.60 & 0.94 \\
\hline 254 & 4.50 & 0.90 & 0.85 & 0.94 & 26.37 & 27.40 & 1.03 \\
\hline 302 & 5.00 & 0.75 & 0.70 & 0.94 & 26.34 & 28.10 & 1.07 \\
\hline 302 & 5.25 & 0.85 & 0.82 & 0.96 & 24.41 & 26.76 & 1.10 \\
\hline Mean & & & & 0.91 & & & 1.04 \\
\hline $\begin{array}{c}\text { Standard } \\
\text { Deviation }\end{array}$ & & & & $8.3 \%$ & & & $6.63 \%$ \\
\hline
\end{tabular}

Table 5.5: Comparison between experimental 1-kN-load deflection and flexural frequencies and those obtained using the FE modeling of iSPAN joists in test sites

\begin{tabular}{|c|c|c|c|c|c|c|c|c|}
\hline Sites & $\begin{array}{c}\text { Joist } \\
\text { depth } \\
(\mathrm{mm})\end{array}$ & $\begin{array}{c}\text { Joist } \\
\text { length } \\
(\mathrm{m})\end{array}$ & $\begin{array}{c}\Delta_{\text {Test }} \\
\text { Under } \\
\mathrm{kN}\end{array}$ & $\begin{array}{c}\Delta_{\mathrm{FEM}} \\
(\mathrm{mm})\end{array}$ & $\begin{array}{c}\Delta_{\mathrm{FEM}} / \\
\Delta_{\text {Test }}\end{array}$ & $\begin{array}{c}f_{\text {Test }} \\
(\mathrm{Hz})\end{array}$ & $\begin{array}{c}f_{\text {FEM }} \\
(\mathrm{Hz})\end{array}$ & $\begin{array}{c}f_{\text {FEM }} / f \\
\text { Test }\end{array}$ \\
\hline $\begin{array}{c}\text { Site 1 } \\
\text { (Unbraced) }\end{array}$ & 241 & 5.48 & 0.75 & 0.78 & 1.04 & 28.10 & 25.70 & 0.91 \\
\hline $\begin{array}{c}\text { Site 1 } \\
\text { (Braced) }\end{array}$ & 241 & 5.48 & 0.69 & 0.75 & 1.09 & 28.73 & 25.90 & 0.90 \\
\hline $\begin{array}{c}\text { Site 2 } \\
\text { (Unbraced) }\end{array}$ & 302 & 7.32 & 0.93 & 0.91 & 0.98 & 15.46 & 14.50 & 0.94 \\
\hline $\begin{array}{c}\text { Site 3 } \\
\text { (Unbraced) }\end{array}$ & 241 & 6.35 & 0.65 & 0.60 & 0.92 & 27.60 & 25.10 & 0.91 \\
\hline $\begin{array}{c}\text { Site 4 } \\
\text { (Braced) }\end{array}$ & 241 & 6.58 & 1.09 & 1.01 & 0.93 & 14.89 & 13.53 & 0.91 \\
\hline \begin{tabular}{c} 
Mean \\
\hline $\begin{array}{c}\text { Standard } \\
\text { Deviation }\end{array}$
\end{tabular} & & & & $7.16 \%$ & & & 0.91 \\
\hline
\end{tabular}

Table 5.5 summarizes the correlation between the experimental 1-kN-load deflection and flexural frequencies and those obtained using the FE modeling of iSPAN joists in the test sites. 
Good agreement is observed between the experimental findings and those obtained from FE modeling. For example, the average ratio between the FE static deflection and the experimental static deflection was 0.99 for joist assemblies with web holes. Also, the average ratio between the FE frequency and the experimental frequency was 0.91 for joist assemblies with web holes in the tested sites. Figures 5.18 through 5.21 depict the correlation between the jacking loaddeflection histories obtained experimentally and using the FE modeling considering zero and 1.5t initial imperfections for iSPAN joist assemblies with web holes listed in Table 3.3. while Figures 5.22 through 5.25 depict the correlation between the jacking load-deflection histories obtained experimentally and using the FE modeling considering zero and 1.5t initial imperfections for iSPAN joist assemblies without web holes listed in Table 3.2. Good agreement is observed between the experimental findings and FE results. Also, results show that the presence of initial imperfection has insignificant effect in the load-deflection history irrespective of the presence of web holes.

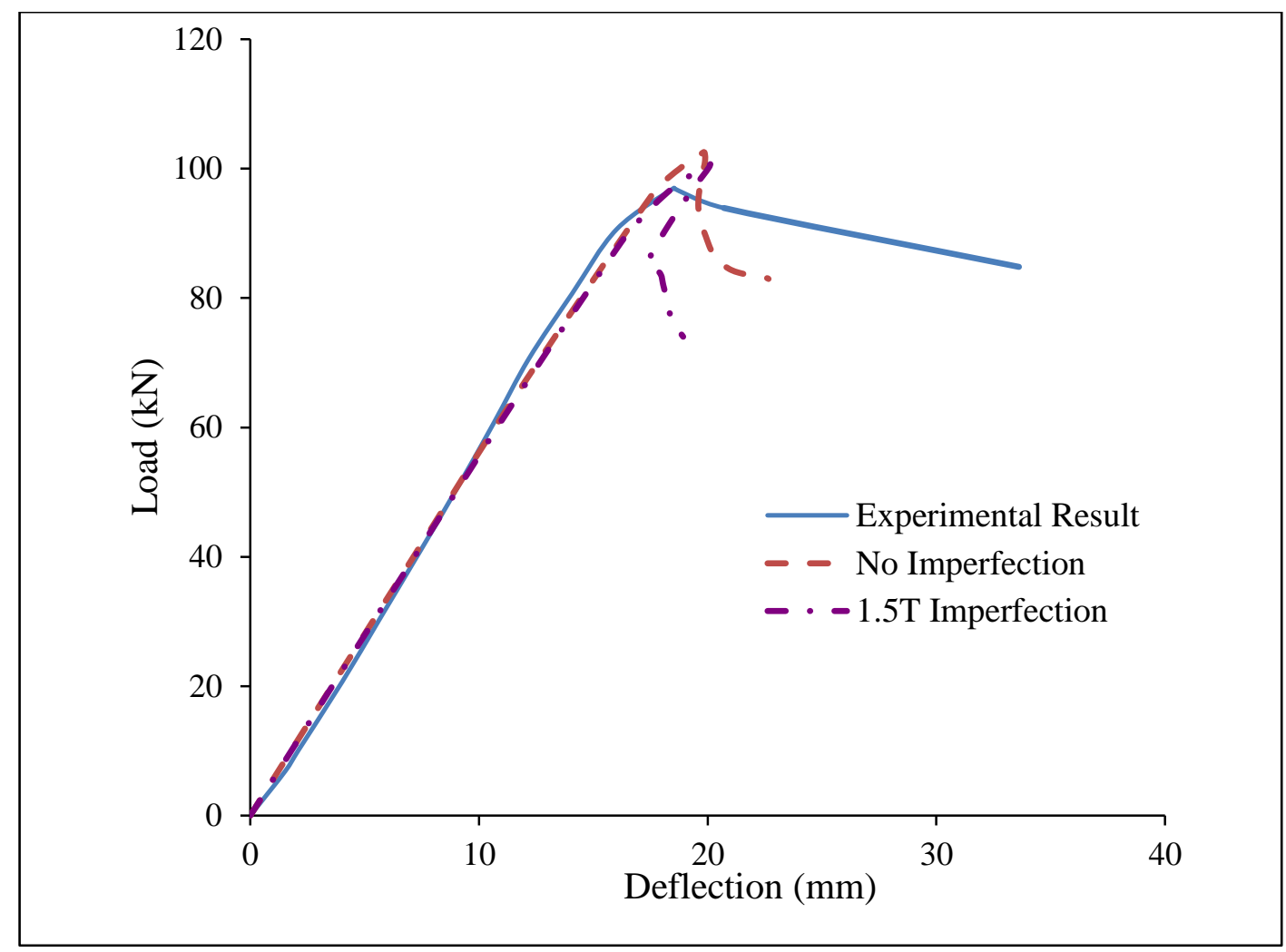

Figure 5.18: Load-deflection relationship of the 254x3500 mm iSPAN joist assembly with web holes 


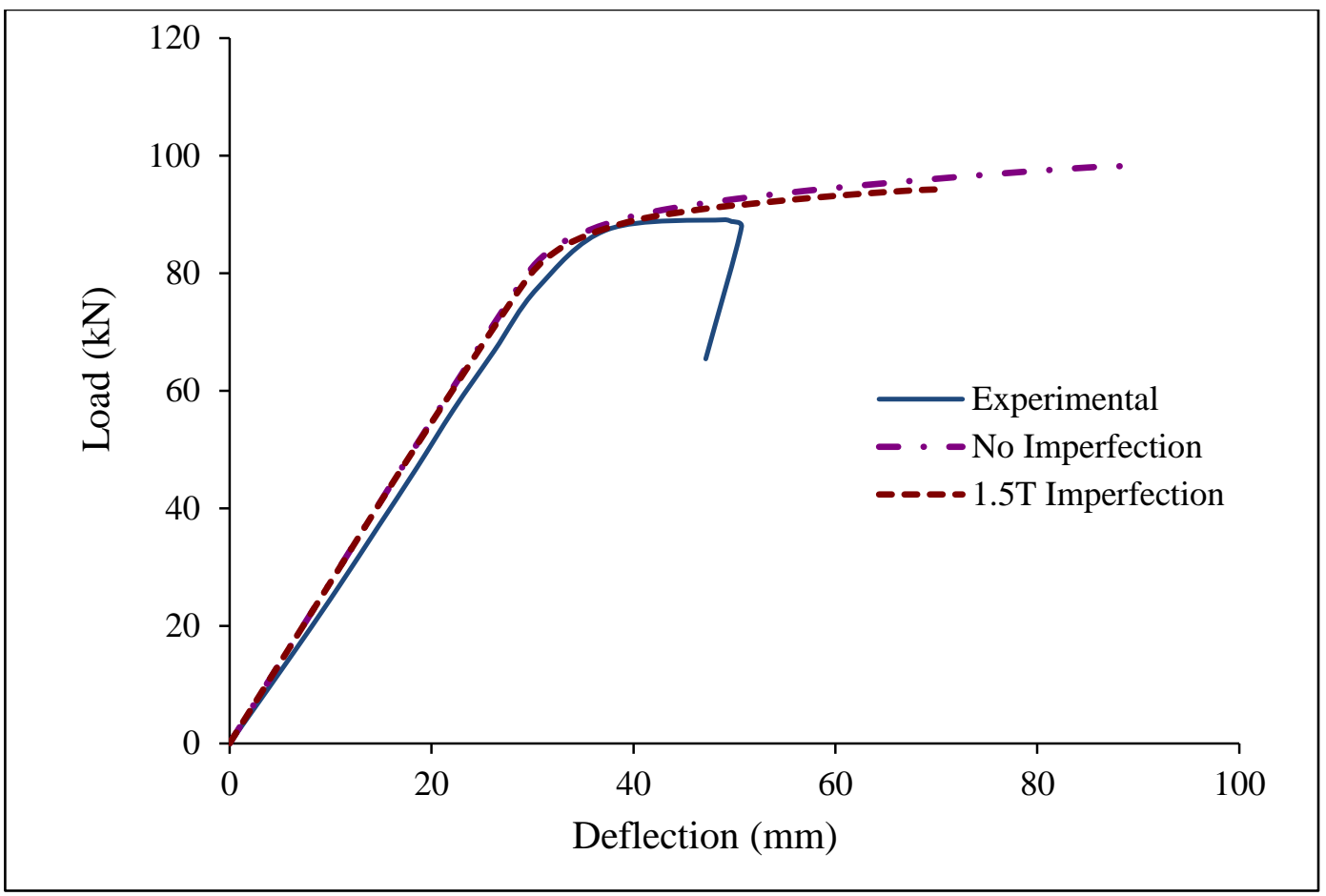

Figure 5.19: Load-deflection relationship of the $254 \times 4500 \mathrm{~mm}$ iSPAN joist assembly with web holes

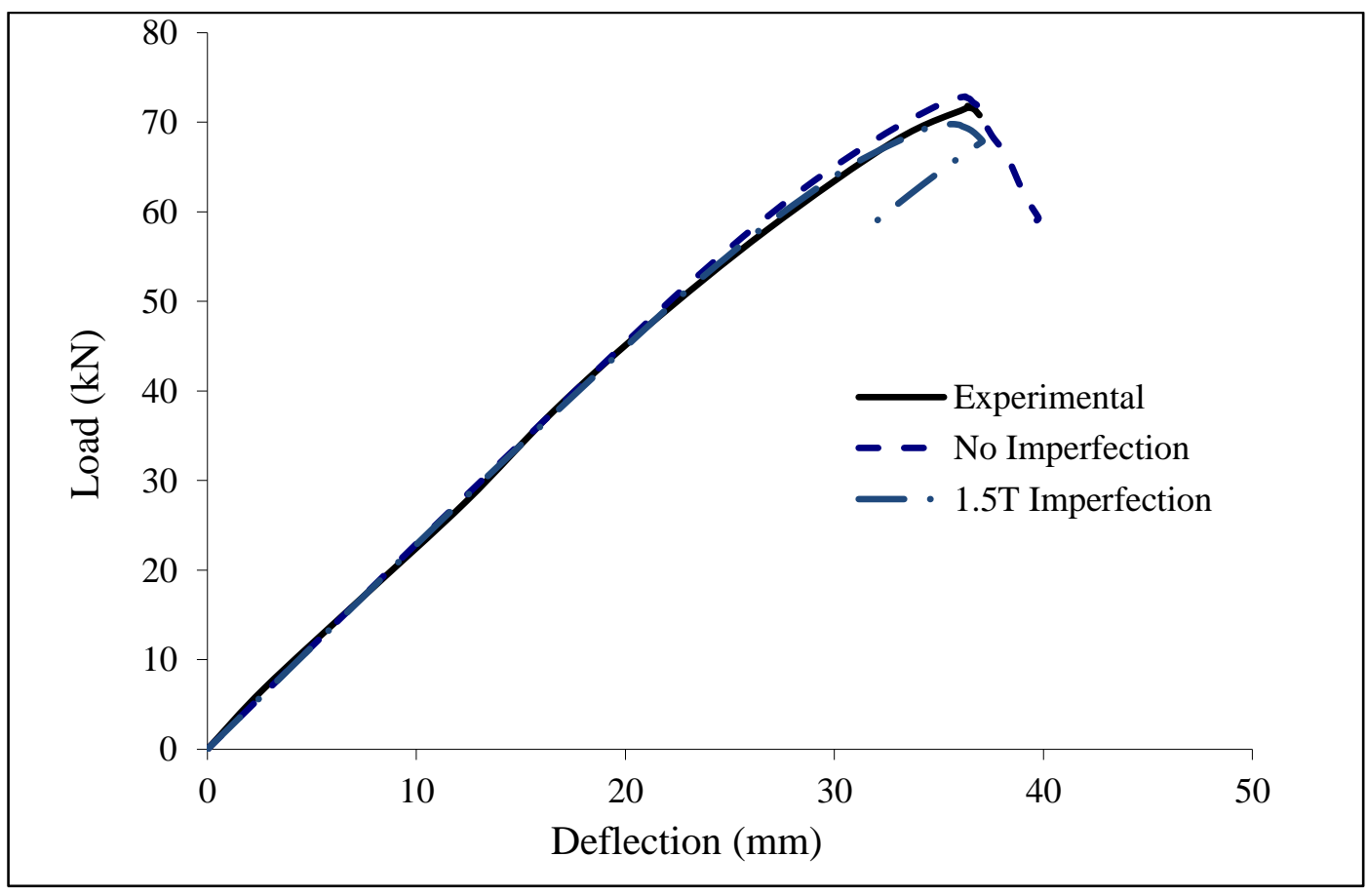

Figure 5.20: Load-deflection relationship of the 300x5000 mm iSPAN joist assembly with web holes 


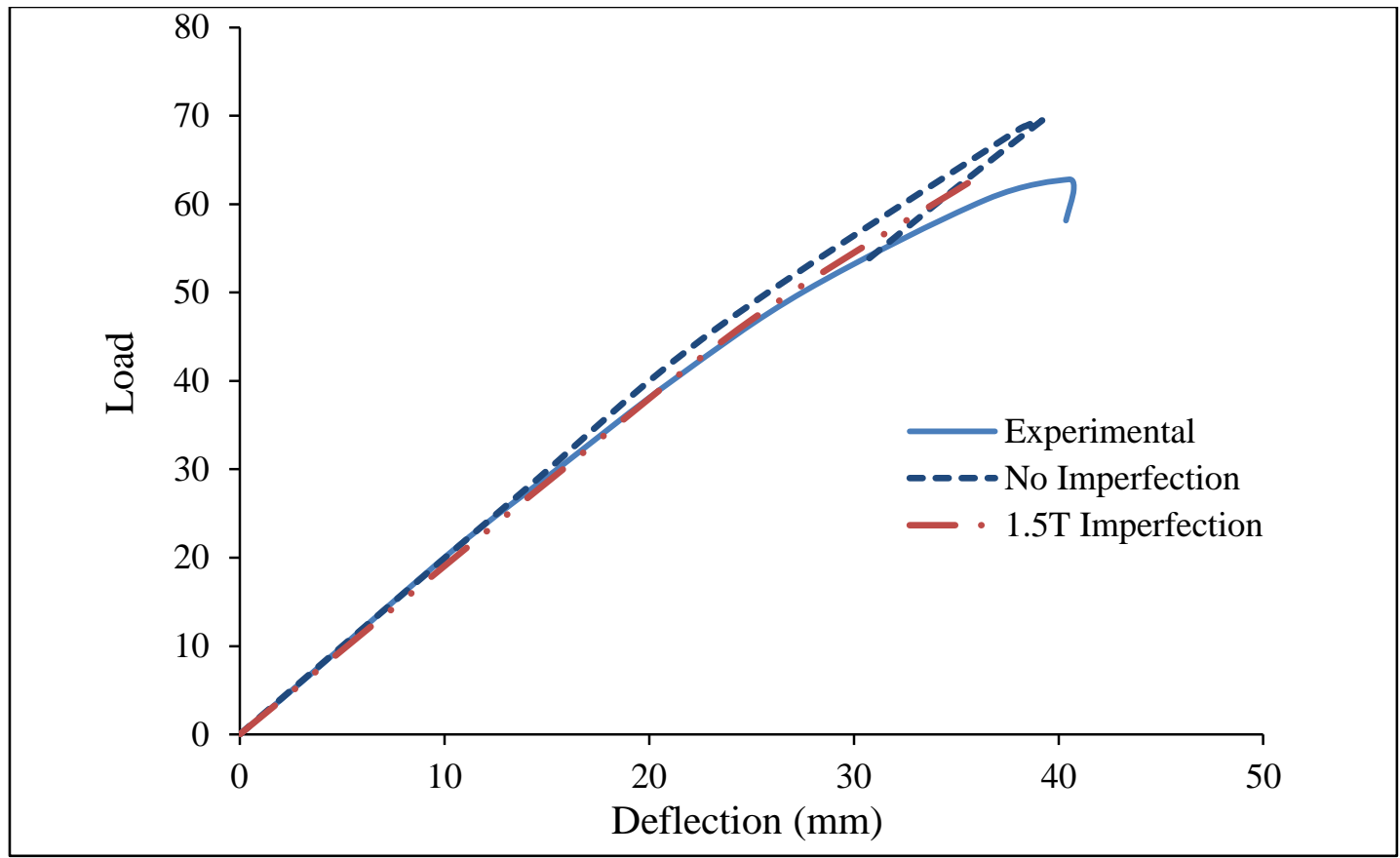

Figure 5.21: Load-deflection relationship of the 300x5250 mm iSPAN joist assembly with web holes

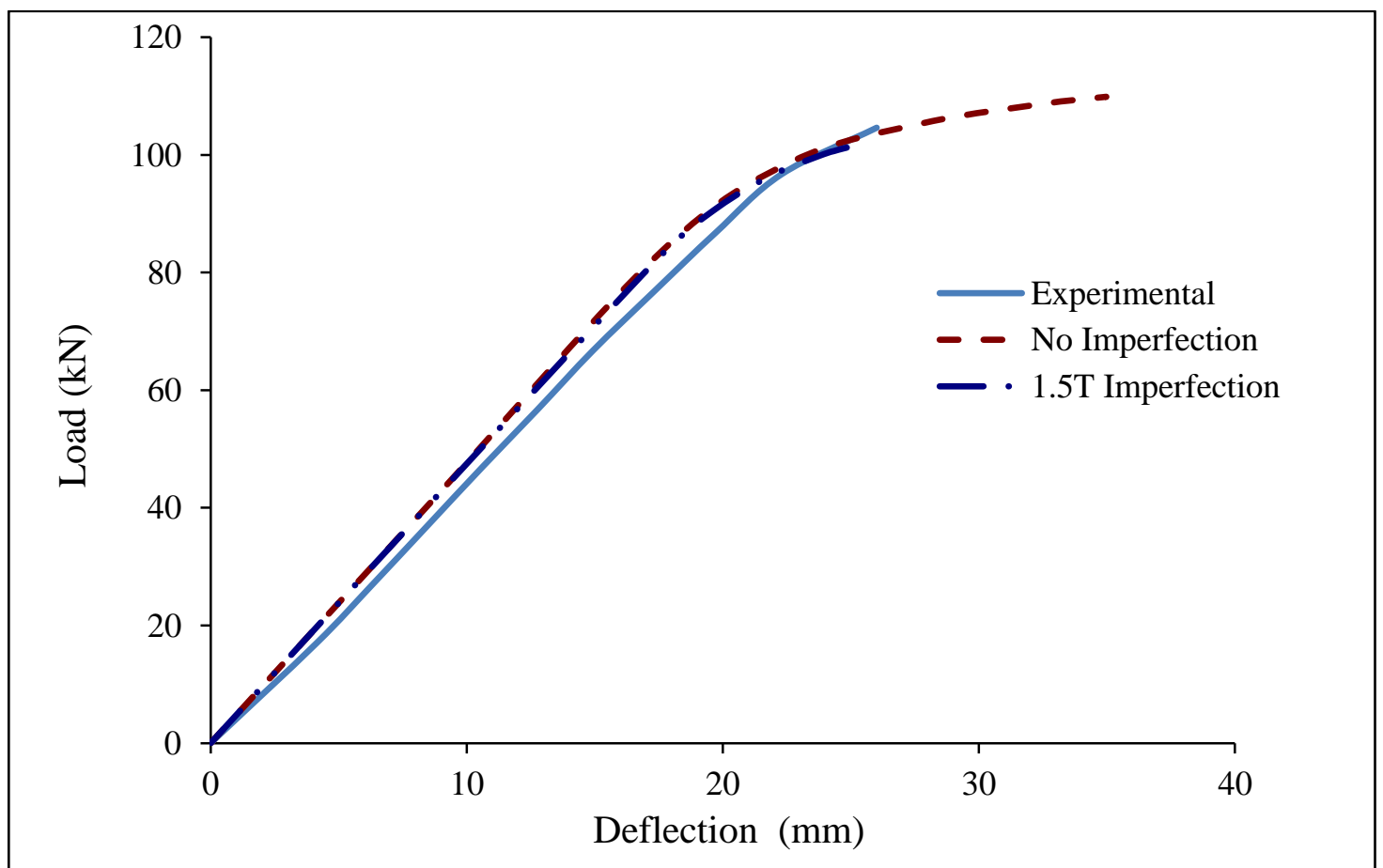

Figure 5.22: Load-deflection relationship of the 241x3500 mm iSPAN joist assembly without web holes 


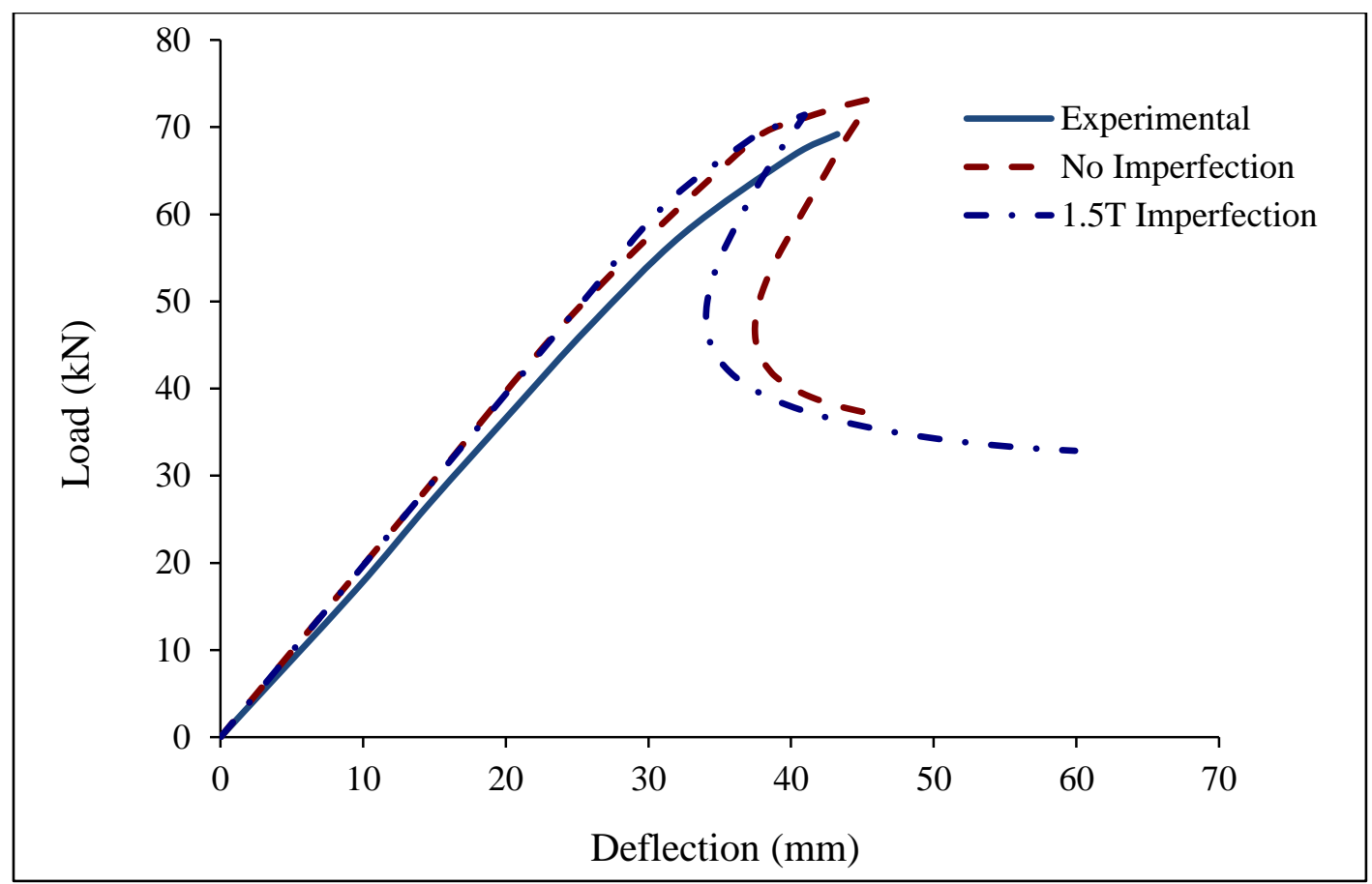

Figure 5.23: Load-deflection relationship of the 241x4500 mm iSPAN joist assembly without web holes

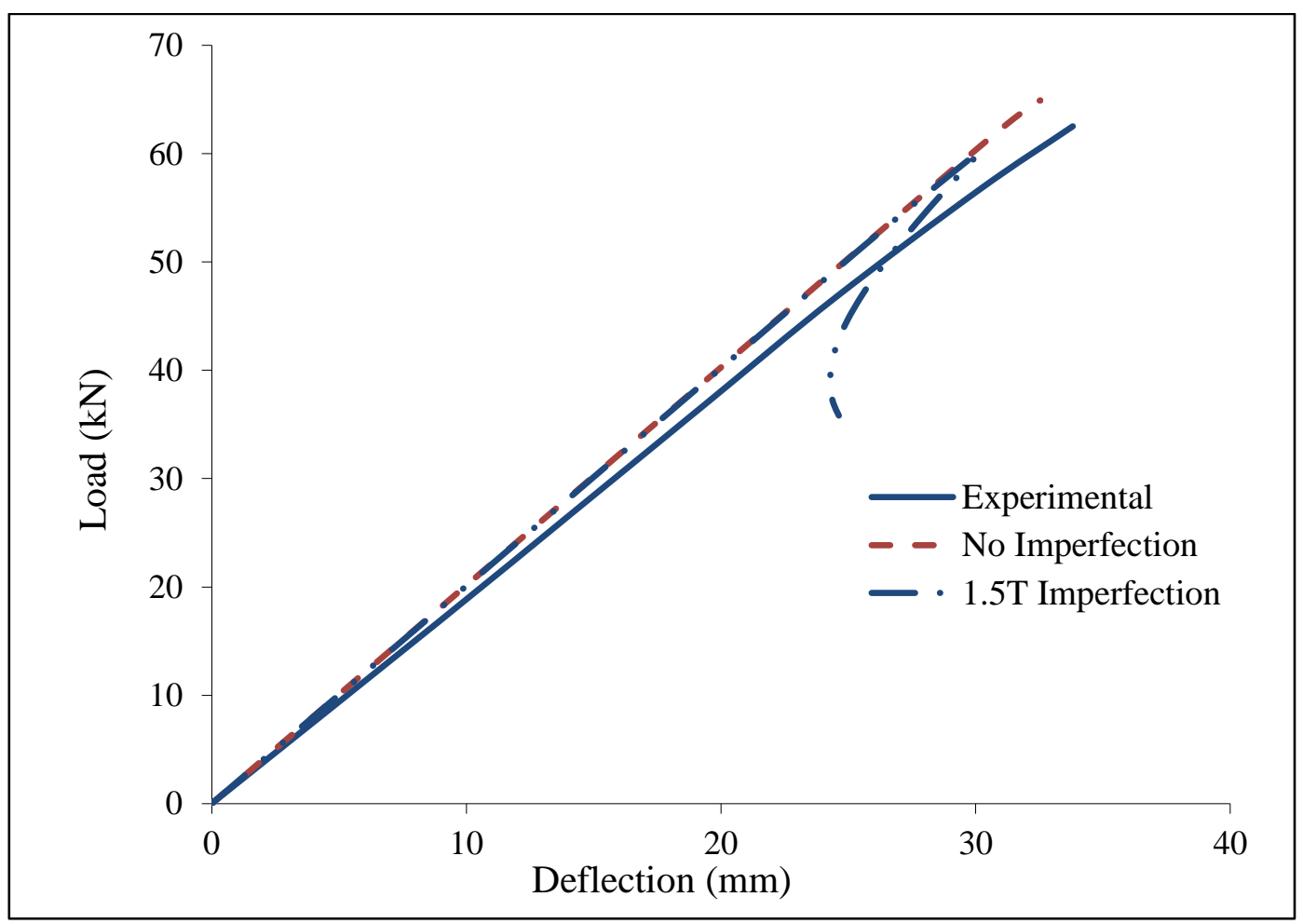

Figure 5.24: Load-deflection relationship of the 356x6100 mm iSPAN joist assembly without web holes 


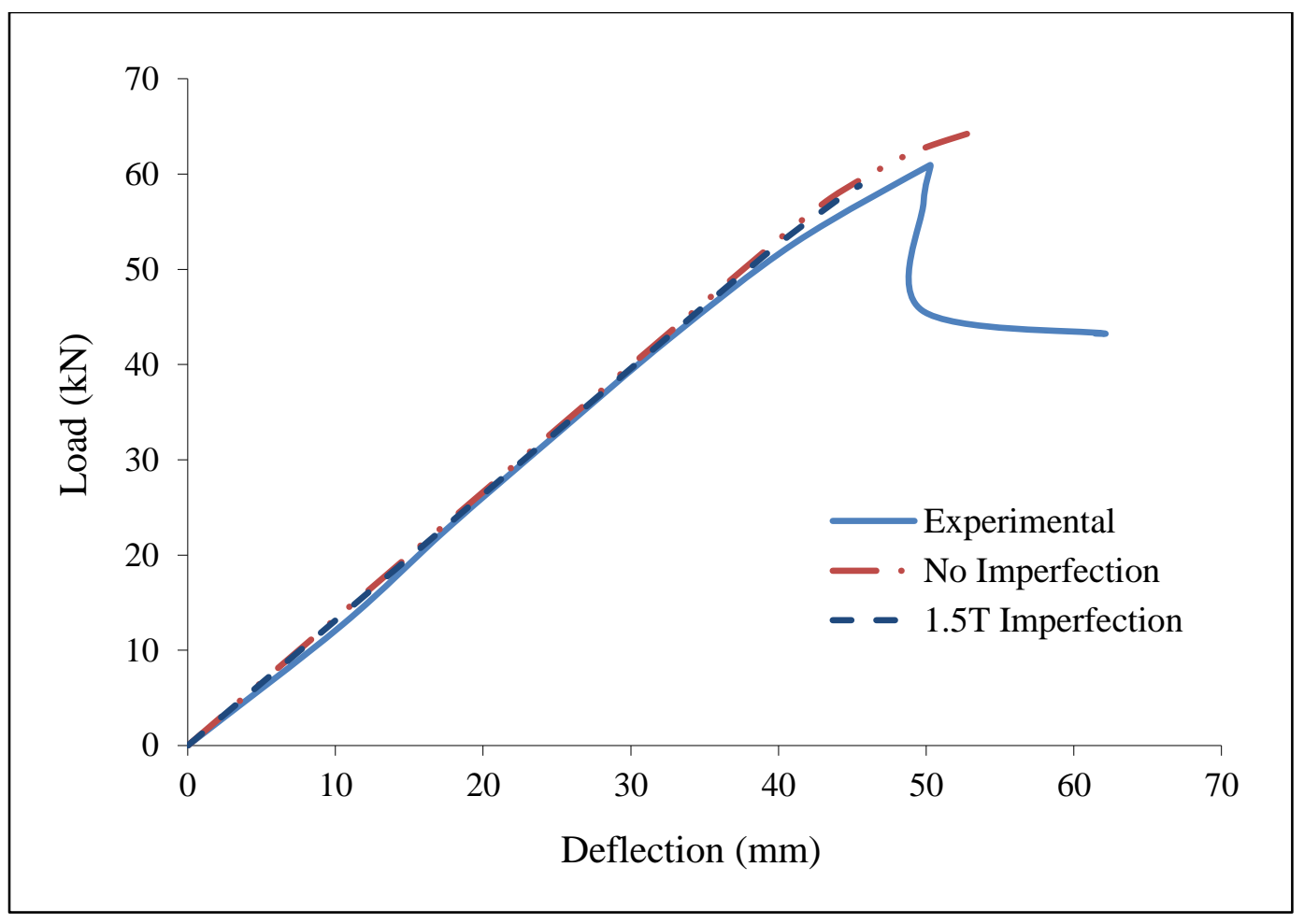

Figure 5.25: Load-deflection relationship of the 406x7950 mm iSPAN joist assembly without web holes

\subsection{PARAMETRIC STUDY}

After successful verification of the finite-element modelling using experimental data, Few parameters were studied to examine their effect on the ultimate load carrying capacity of iSPAN joists. There parameters included (i) use of either metal deck or OSB sheet to form the floor over the joists; (ii) presence of multi joists in full-scale floors; and (iii) effect of lip-stiffened web holes on floor vibration.

\subsubsection{USE OF METAL DECK OR OSB SHEET}

The effect of the presence of OSB sheet or metal cladding as floor material supported over the joists was investigated herein. A 38-mm metal deck deep with $1.22 \mathrm{~mm}$ thickness and corrugated profile as shown in Figure 5.26 was considered in this study. Nonlinear analysis was conducted on a $241 \times 4500 \mathrm{~mm}$ iSPAN twin-joist assembly, one time with metal decking and other time with 19-mm OSB flooring. Both metal decking and OSB sheets were fastened to the top flange of the joist with identical fastening configuration used in the experimental study. The jacking loaddeflection relationships showed in Figure 5.27 show that the use of different decking material 
does not have an effect on the structural response of the joist. As for the failure mode under flexural loading, FE results showed that the primary failure modes in iSPAN two-joist assemblies with OSB sheet fastened to the joist top flanges were yielding of the joist at the midspan region that may be accompanied by local buckling in the free-standing lip in the joist top flange. However, the majority of the tested joist assemblies failed in lateral torsional buckling mode that could not be reached using the FE modelling. To excite such global lateral torsional buckling mode, it was decided to eliminate portion of the OSB decking at the mid-span region so that the joist would be laterally flexible to promote such failure. As such, the $241 \times 4500 \mathrm{~mm}$ iSPAN twin-joist assembly was modelled with the OSB sheet connected to the joist top flange using "TIE" elements over 66\%,75\%,80\% and 90\% of the floor assembly area as depicted in Figures 29, 30, 31 and 32, respectively. Results showed that with increase in joist lateral flexibility with the omission of portion of the OSB sheets at the mid-span region, lateral torsional buckling mode appeared at failure. Figure 5.28 depicts the load-deflection relationship of the modelled joist assembly with difference OSB floor coverage. It can be observed that loaddeflection history within the linear stage of loading is identical for all models irrespective of restraint level of flange connection with the OSB sheet before failure. However, the ultimate load carrying capacity appears to decrease with decrease in restraint level of the top flange with the OSB sheet. In addition, the linear relationship of load and deflection up to or very close to failure indicates the sudden failure mode as compared to ductile failure resulting from the nonlinear material behavior which usually occurs after the linear elastic range of applied loading. Further nonlinear FE modelling may be required to have better understanding of the behavior of such joist assembly and change in failure modes among flange and web local buckling and global lateral torsional buckling. This would be achieved with the use of nonlinear link elements between the OSB sheet and joist flanges, simulating the behavior of the fasteners' shear forceslip relationship. 


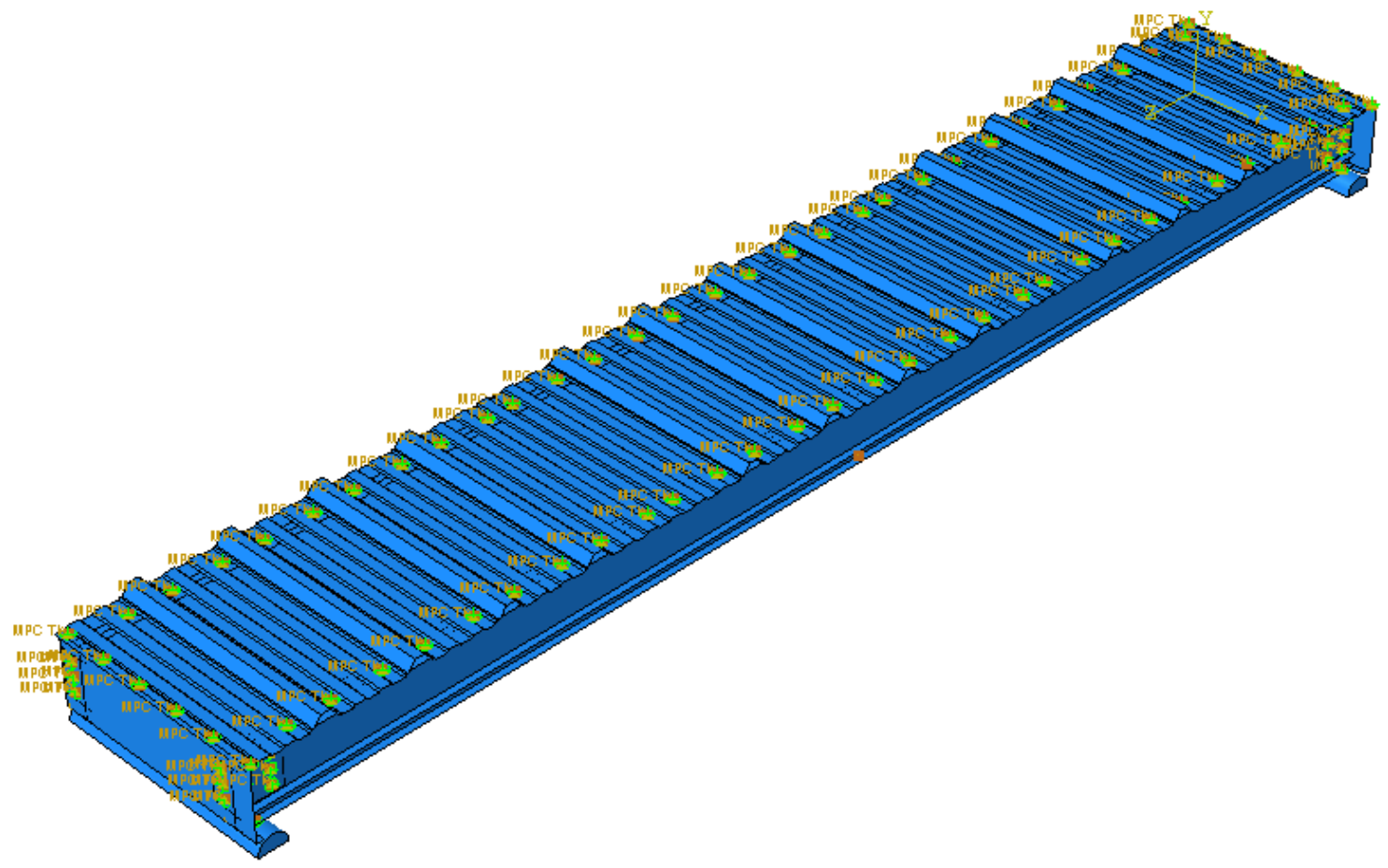

Figure 5.26: View of the FE model of the $241 \times 4500 \mathrm{~mm}$ joist with metal decking attached to the joist

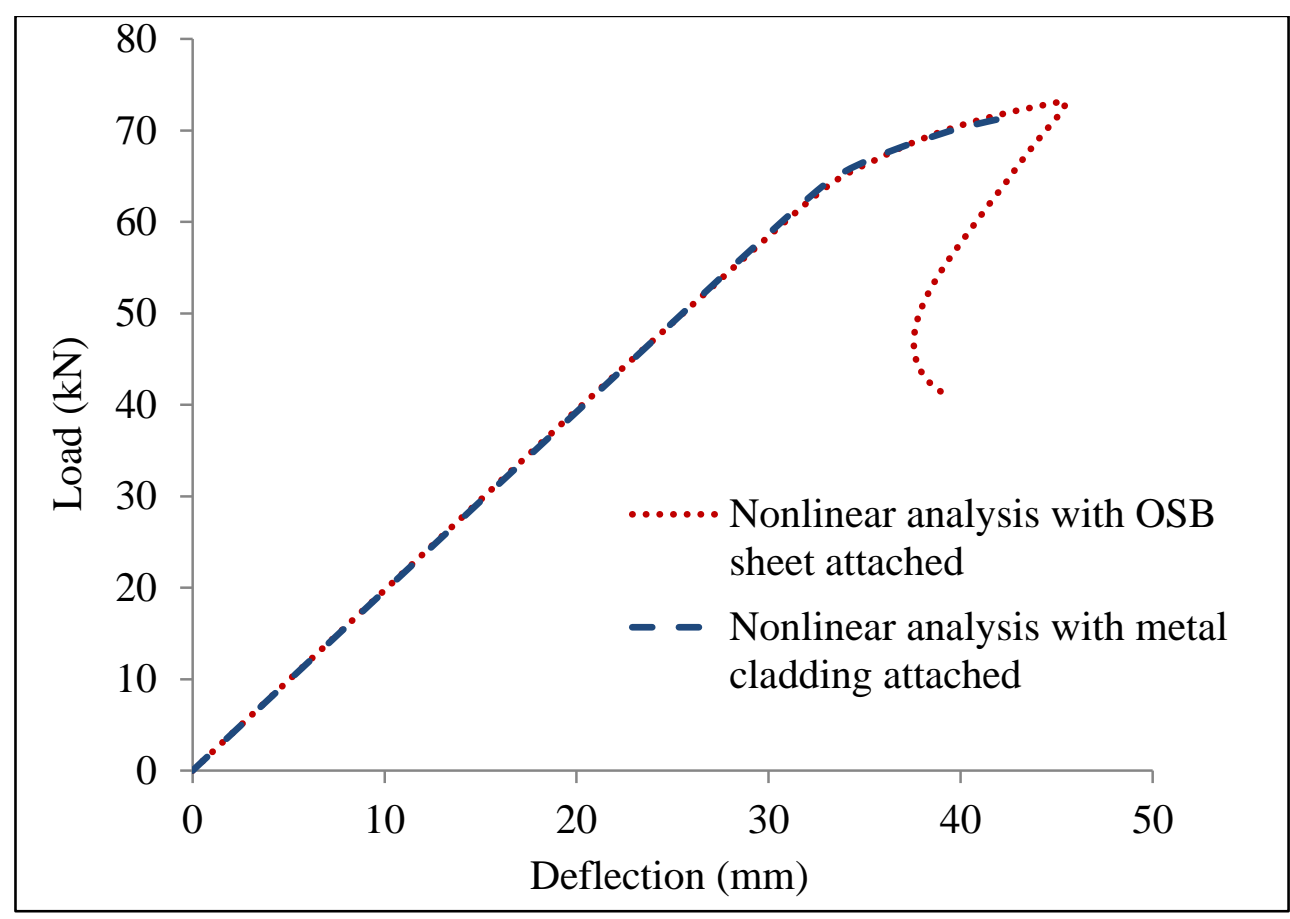

Figure 5.27: Load-deflection relationship of 241x4500 mm iSPAN joist assembly with the presence of OSB Sheet and metal cladding 


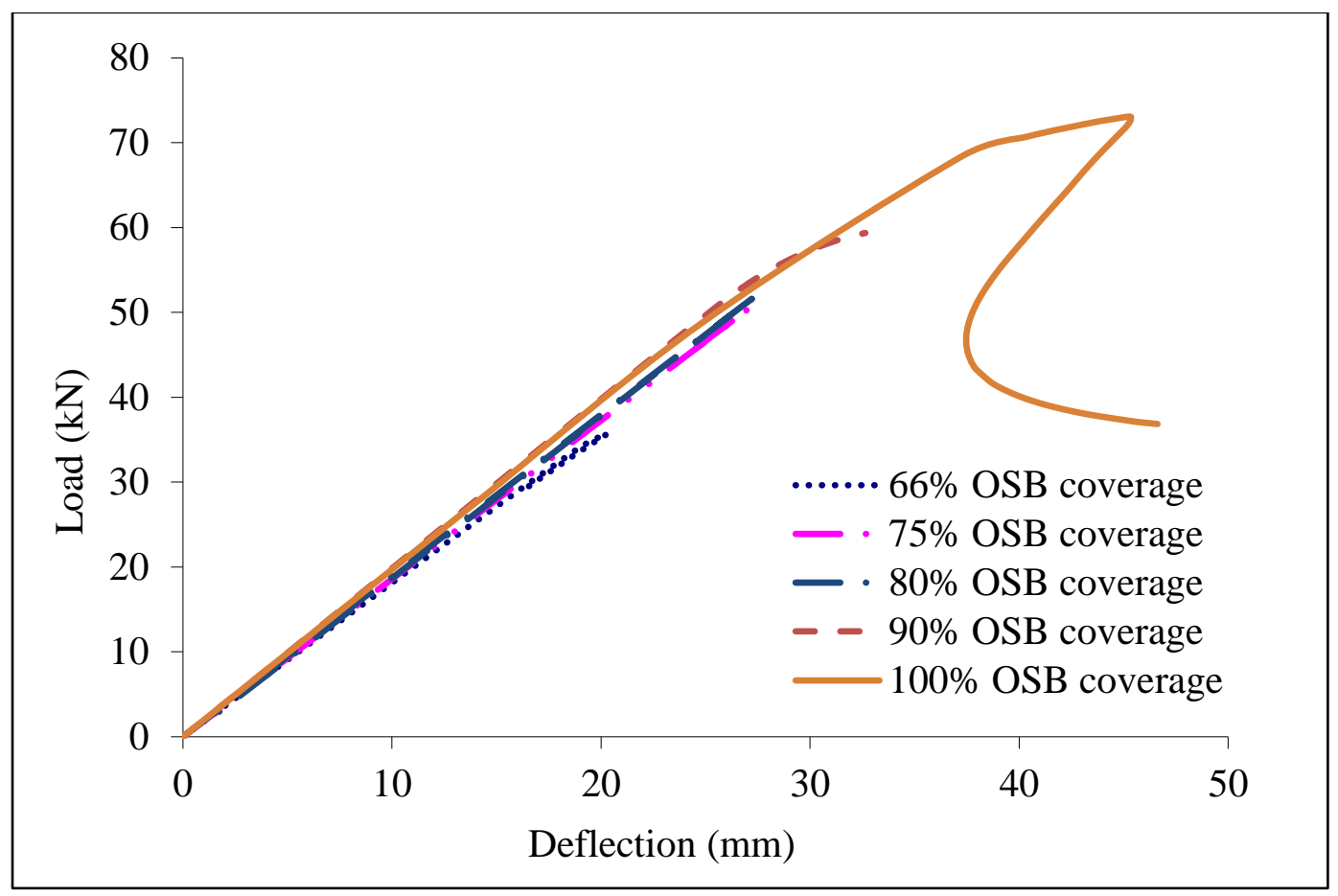

Figure 5.28: Effect of OSB sheet coverage on the 241x4500 mm iSPAN joist assembly

\section{$\mathrm{S}$, Mises}

SNEG, $($ fraction $=-1.0$ )

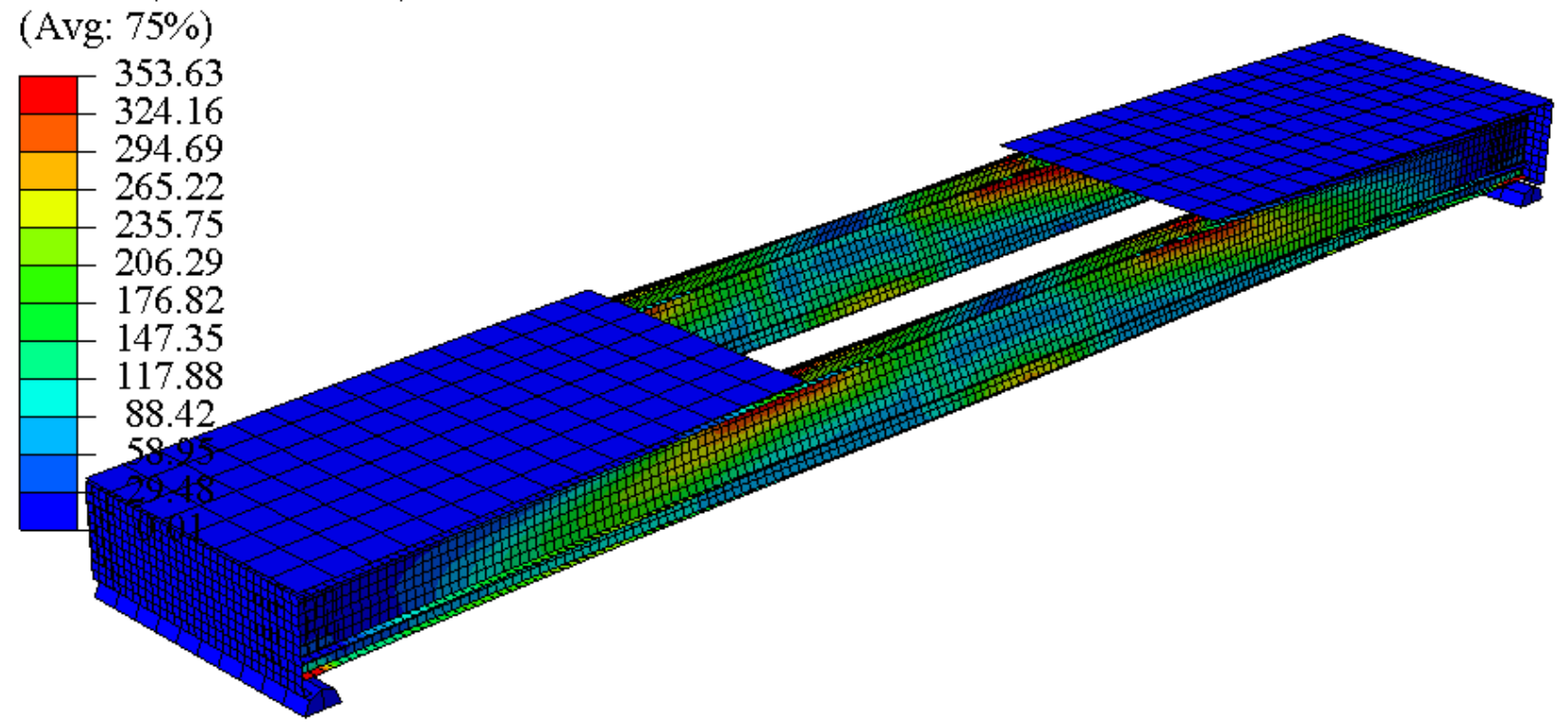

Figure 5.29: View of the FE modelling and stress contour lines of the 241x4500 mm iSPAN joist assembly with $66 \%$ coverage of OSB sheet 
S, Mises

SNEG, $($ fraction $=-1.0$ )

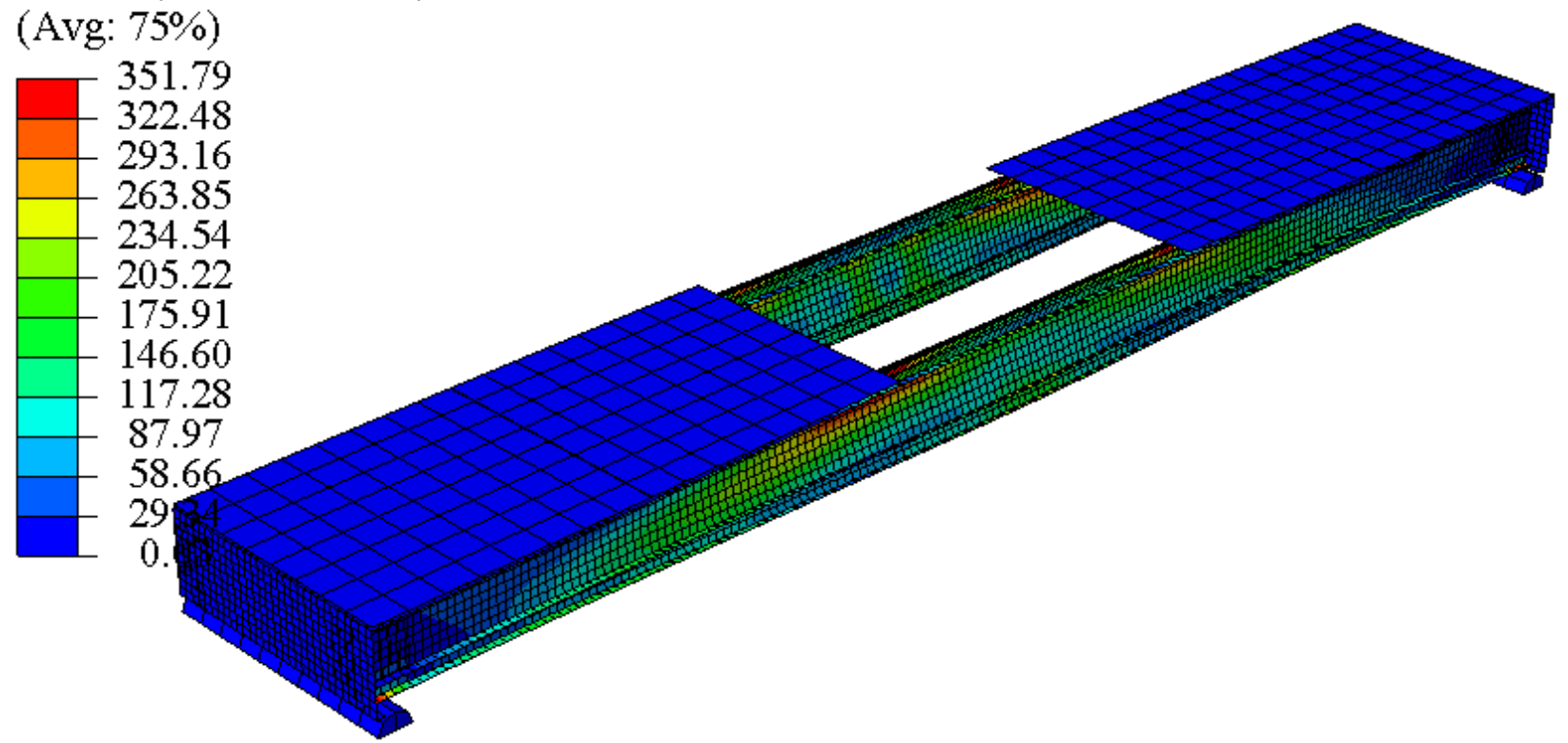

Figure 5.30: View of the FE modelling and stress contour lines of the 241x4500 mm iSPAN joist assembly with $75 \%$ coverage of OSB sheet

S, Mises

SNEG, $($ fraction $=-1.0$ )

(Avg: $75 \%$ )

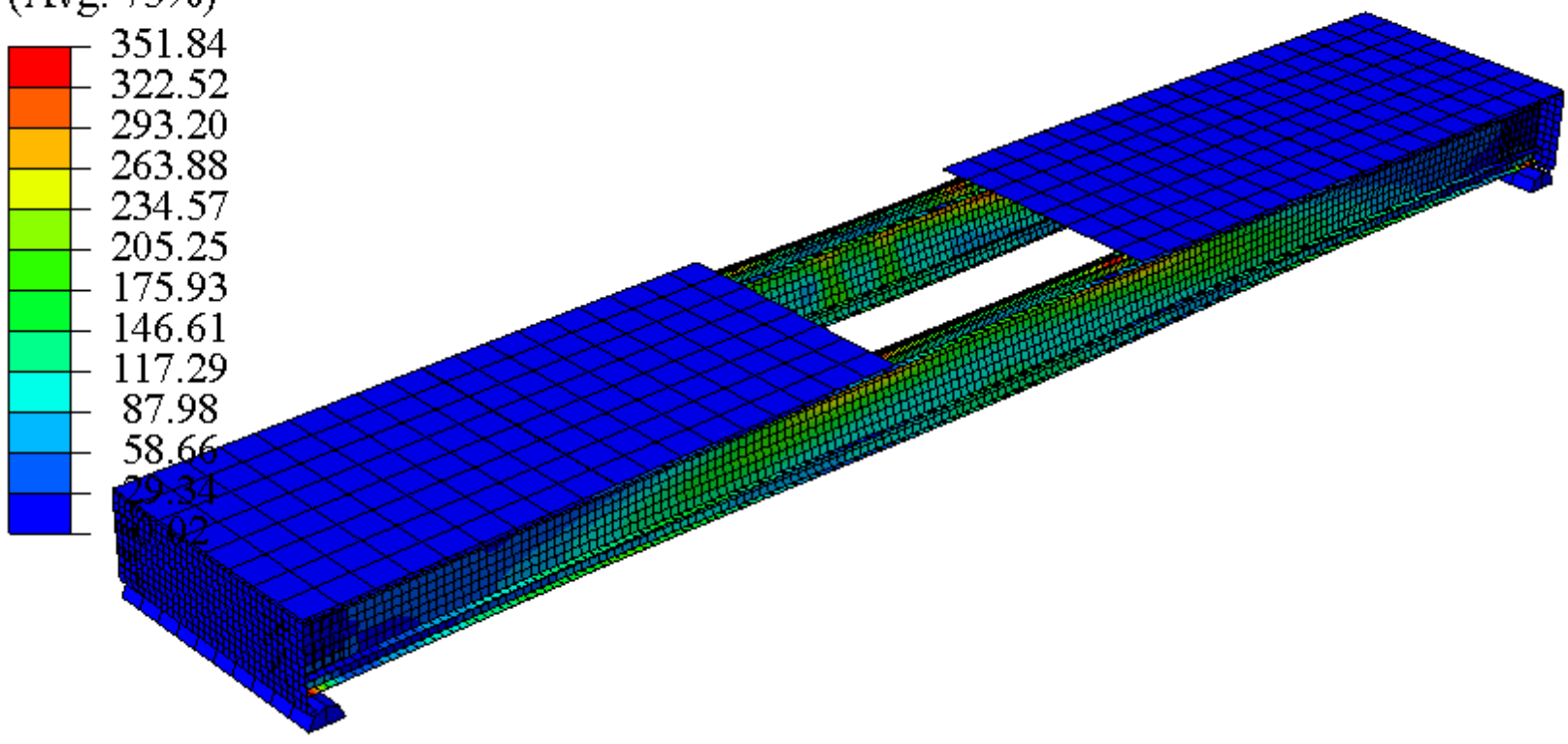

Figure 5.31: View of the FE modelling and stress contour lines of the $241 \times 4500 \mathrm{~mm}$ iSPAN joist assembly with $80 \%$ coverage of OSB sheet 


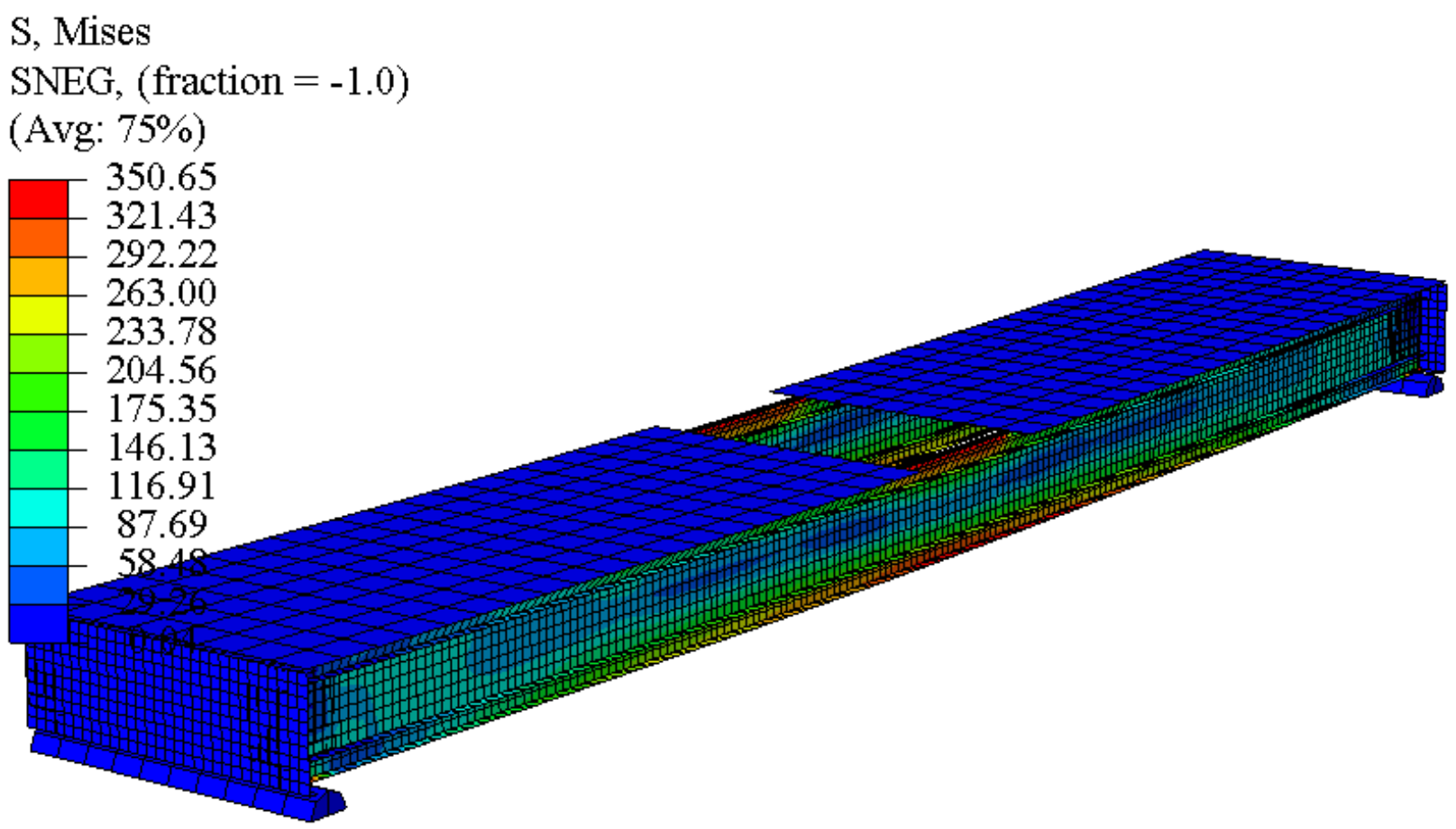

Figure 5.32: View of the FE modeling and stress contour lines of the 241x4500 mm iSPAN joist assembly with $90 \%$ coverage of OSB sheet

\subsubsection{COMPARISON BETWEEN TWIN-JOIST RESULTS AND FULL-SCALE FLOOR RESULTS}

While conducting this research, a question was raised as of whether the two-joist assembly is an actual representation of the full-scale floor system. In this research, it was believed that the twinjoist assembly would behave as the actual floor system, given the one-way pattern of load transfer. However, a FE modelling was conducted to prove this hypothesis. Two joist sizes were modelled using ABAQUS software, namely: (i) a 254x3000 mm joist; and (ii) a 406x9000 mm long joist. For the first joist size, a twin-joist assembly was modelled as shown in Figure 5.33, while $3 \times 3 \mathrm{~m}, 6 \times 3 \mathrm{~m}$, and 9x3 m floor system were modelled as shown in Figure 5.34, 5.35, and 5.36, respectively. All joists were connected to the OSB sheathing using Tie elements. For the second joist size, a twin-joist assembly was modelled as shown in Figure 5.37, while 3x9 m, 6x9 $\mathrm{m}$, and 9x9 m floor system were modelled as shown in Figure 5.38, 5.39, and 5.40, respectively. All joists were connected to the OSB sheathing using "TIE" elements. FE results are reported in Table 5.6 in the form of ultimate load carrying capacity and the flexural frequency of the system. It can be observed that the ultimate load carrying capacity slightly changed in the order of 
maximum $11 \%$. For example, the twin-joist assembly exhibited FE ultimate capacity of $96.76 \mathrm{kN}$ compared to $107.25 \mathrm{kN}$ for a floor with the same joist span and $9 \mathrm{~m}$ width in lieu of $0.6 \mathrm{~m}$. It can also be observed that the joist frequency slightly changed in the order of maximum $2.7 \%$ for a floor of the same joist span and $9 \mathrm{~m}$ width. Figure 5.41 depicts the load-deflection history of the modelled floors. One can observe that all models exhibited identical linear elastic performance in the straight line portion of the load history, while their nonlinear performance beyond the elastic range were very close, indicating that there is insignificant difference between the twin-joist modelling and the modelling of the actual floor system. Similar conclusions can be drawn for the 406x9000 mm two-joist assembly and associated floor systems of widths 3,6 and $9 \mathrm{~m}$ as depicted in Figure 5.42 and Table 5.7.

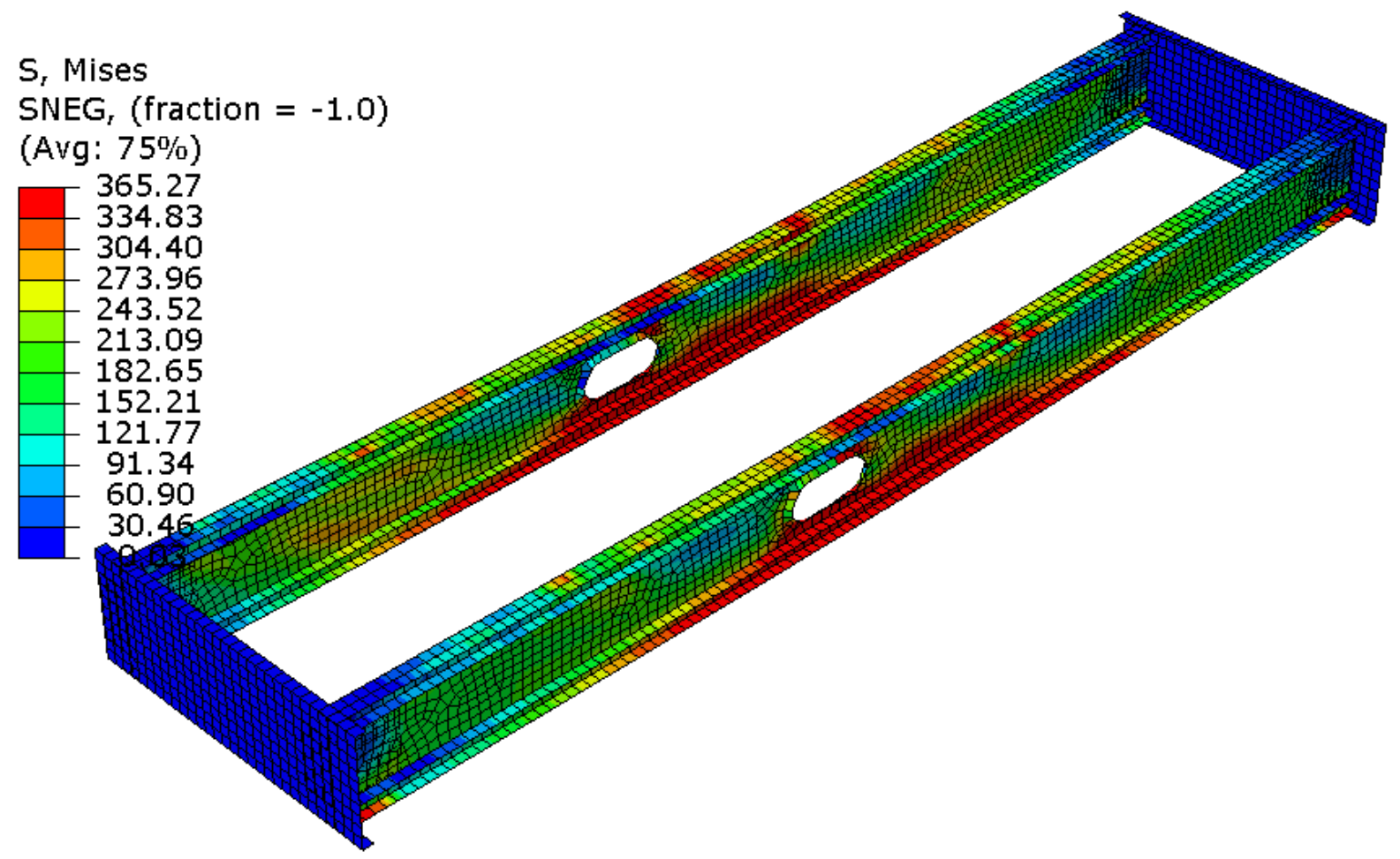

Figure 5.33: View of the FE modelling and stress contour lines resulting from the nonlinear analysis of the $254 \times 3000 \mathrm{~mm}$ iSPAN joist assembly (OSB sheet is not shown for clarity) 


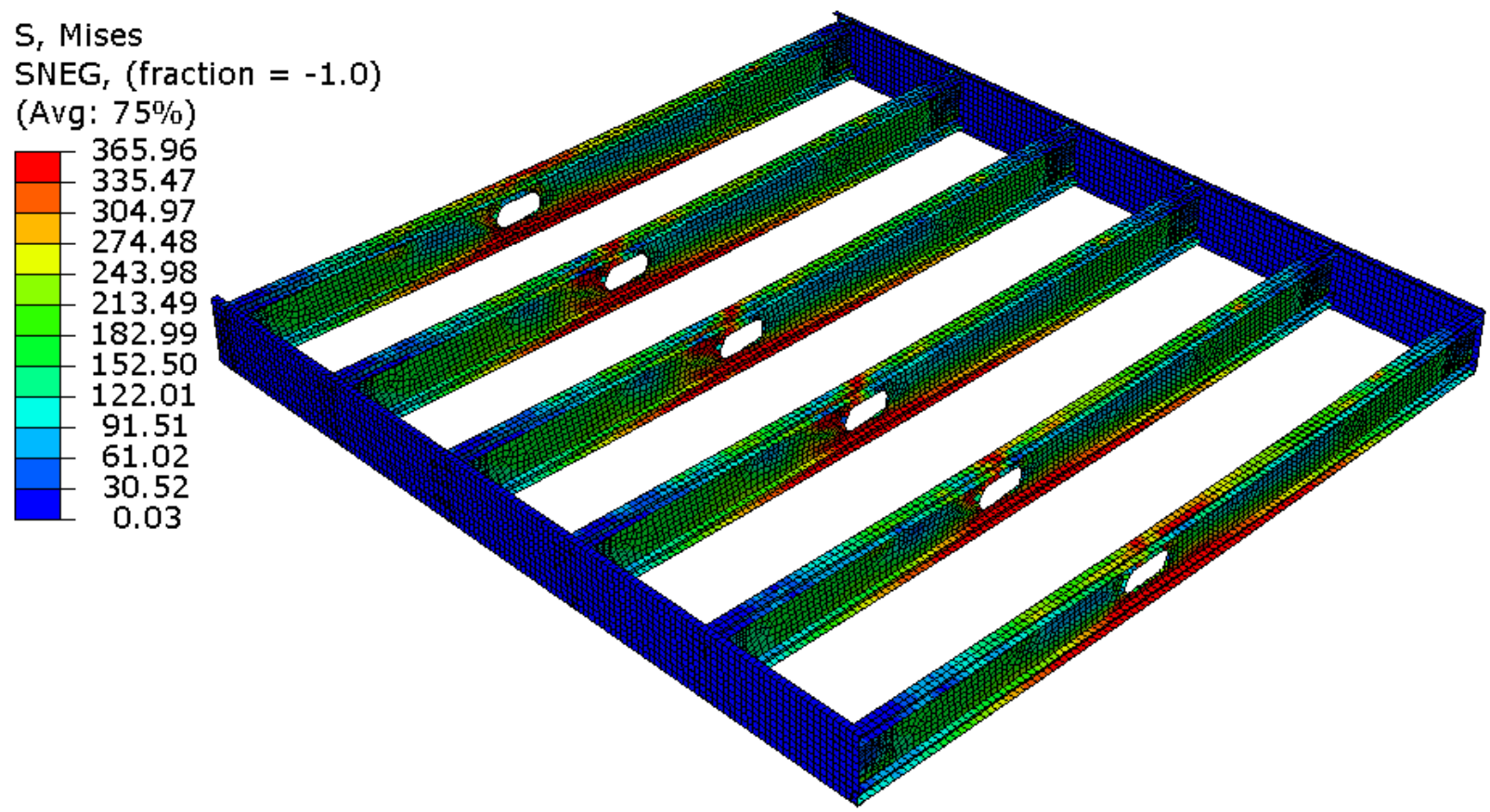

Figure 5.34: View of the FE modelling and stress contour lines resulting from the nonlinear analysis of a $3 \times 3 \mathrm{~m}$ iSPAN joist floor system (OSB sheet is not shown for clarity)

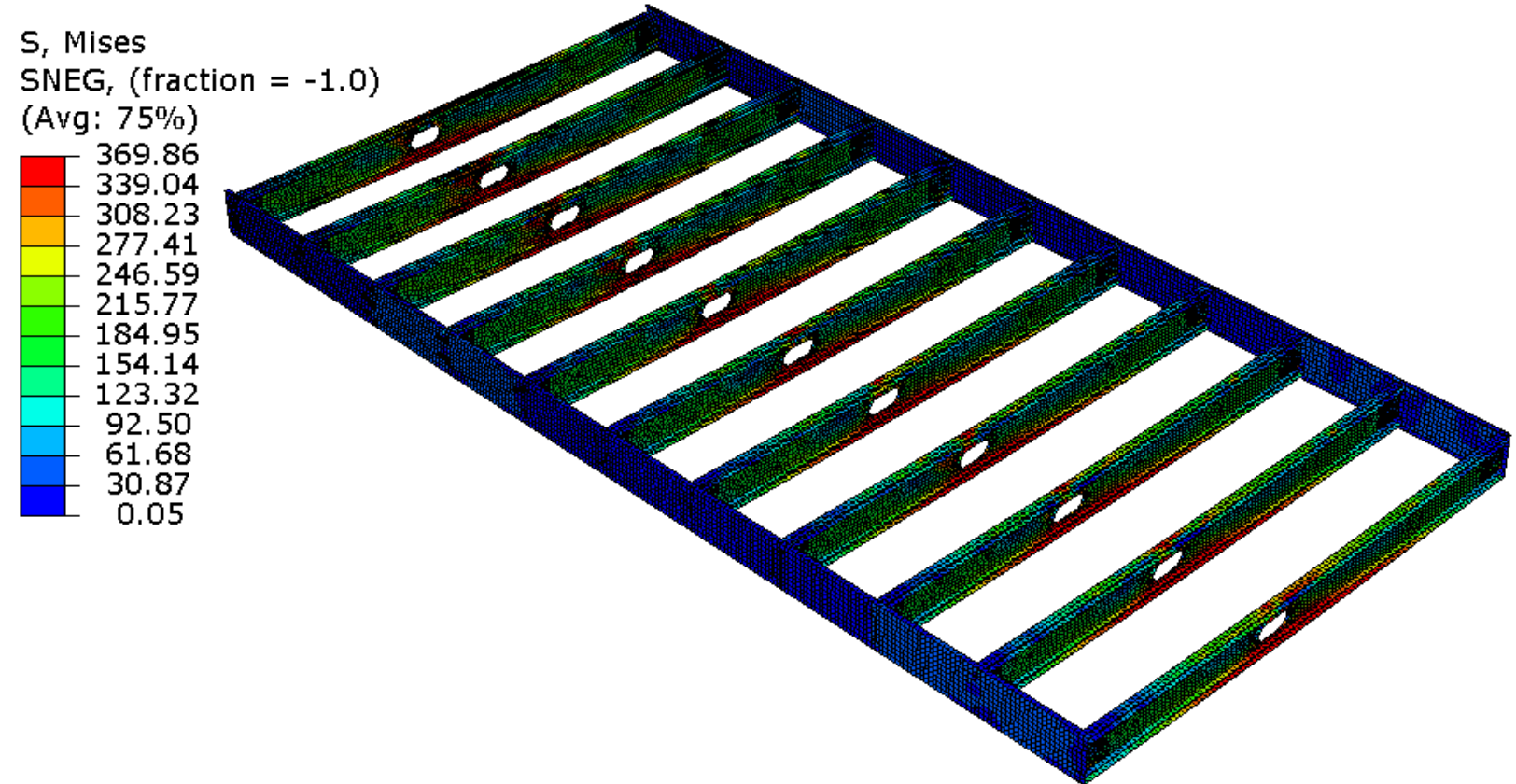

Figure 5.35: View of the FE modelling and stress contour lines resulting from the nonlinear analysis of a 6x3 m iSPAN joist floor system (OSB sheet is not shown for clarity) 


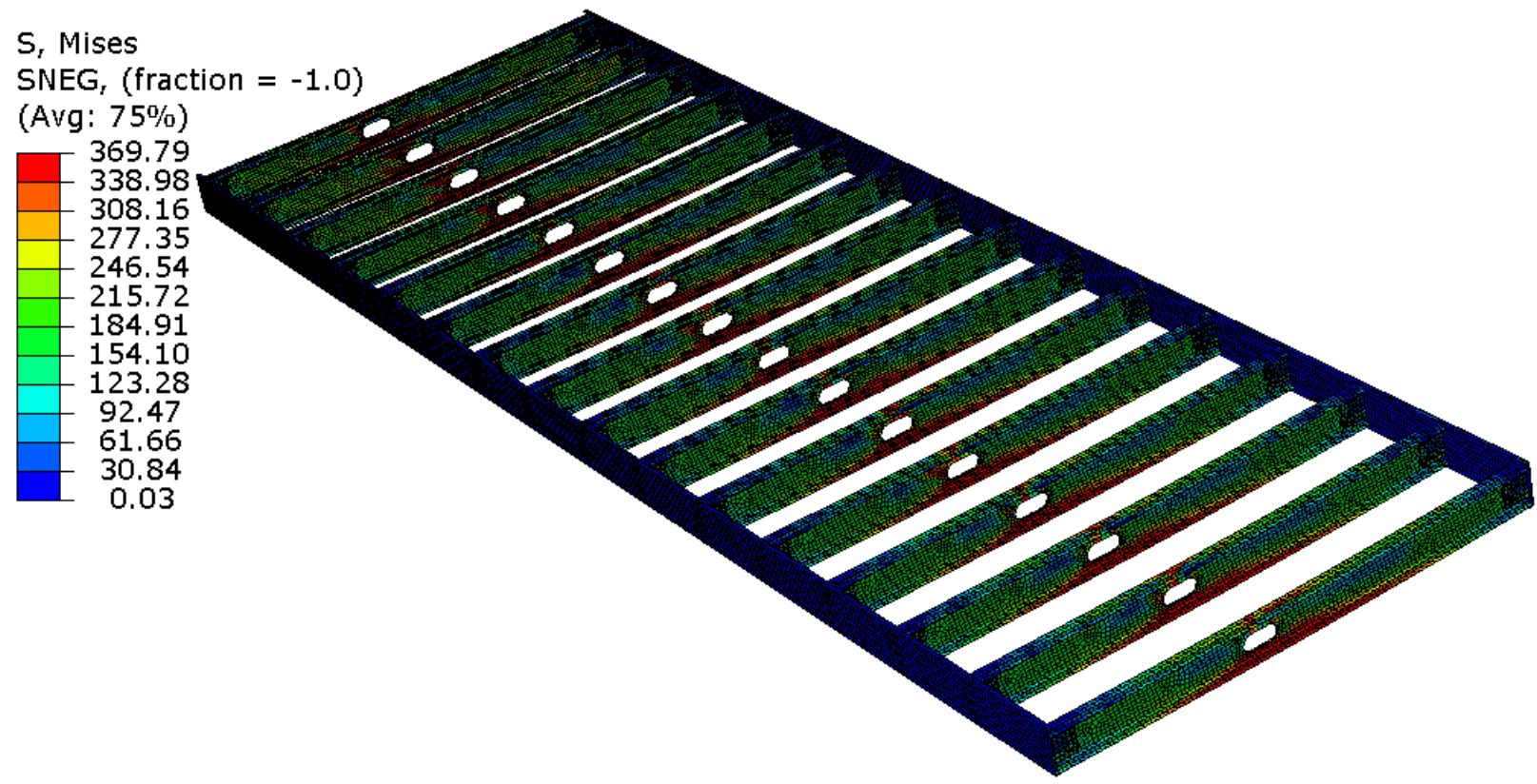

Figure 5.36: View of the FE modelling and stress contour lines resulting from the nonlinear analysis of a 9x3 m iSPAN joist floor system (OSB sheet is not shown for clarity)

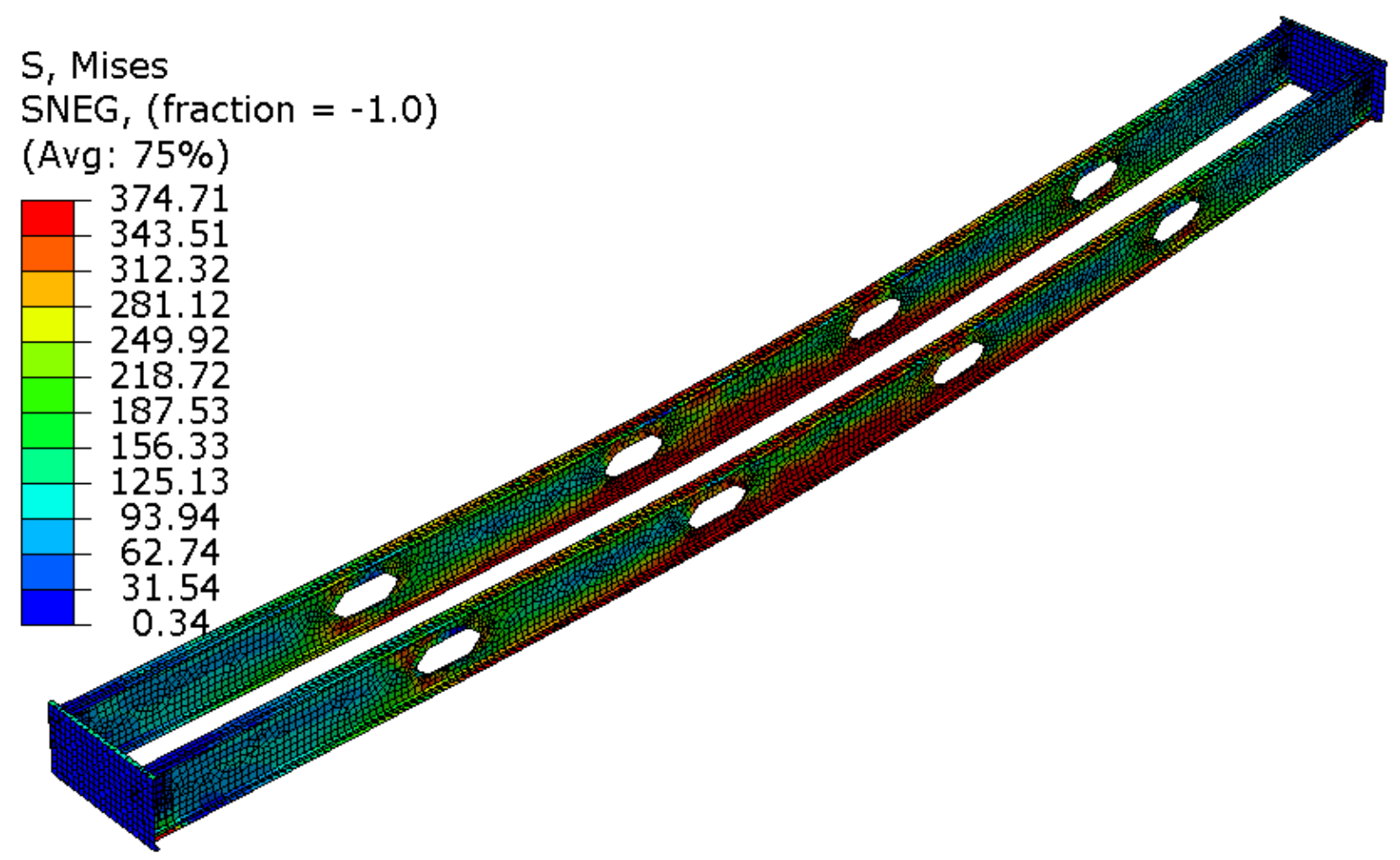

Figure 5.37: View of the FE modelling and stress contour lines resulting from the nonlinear analysis of twin joist 400x9000 mm iSPAN joist assembly (OSB sheet is not shown for clarity) 


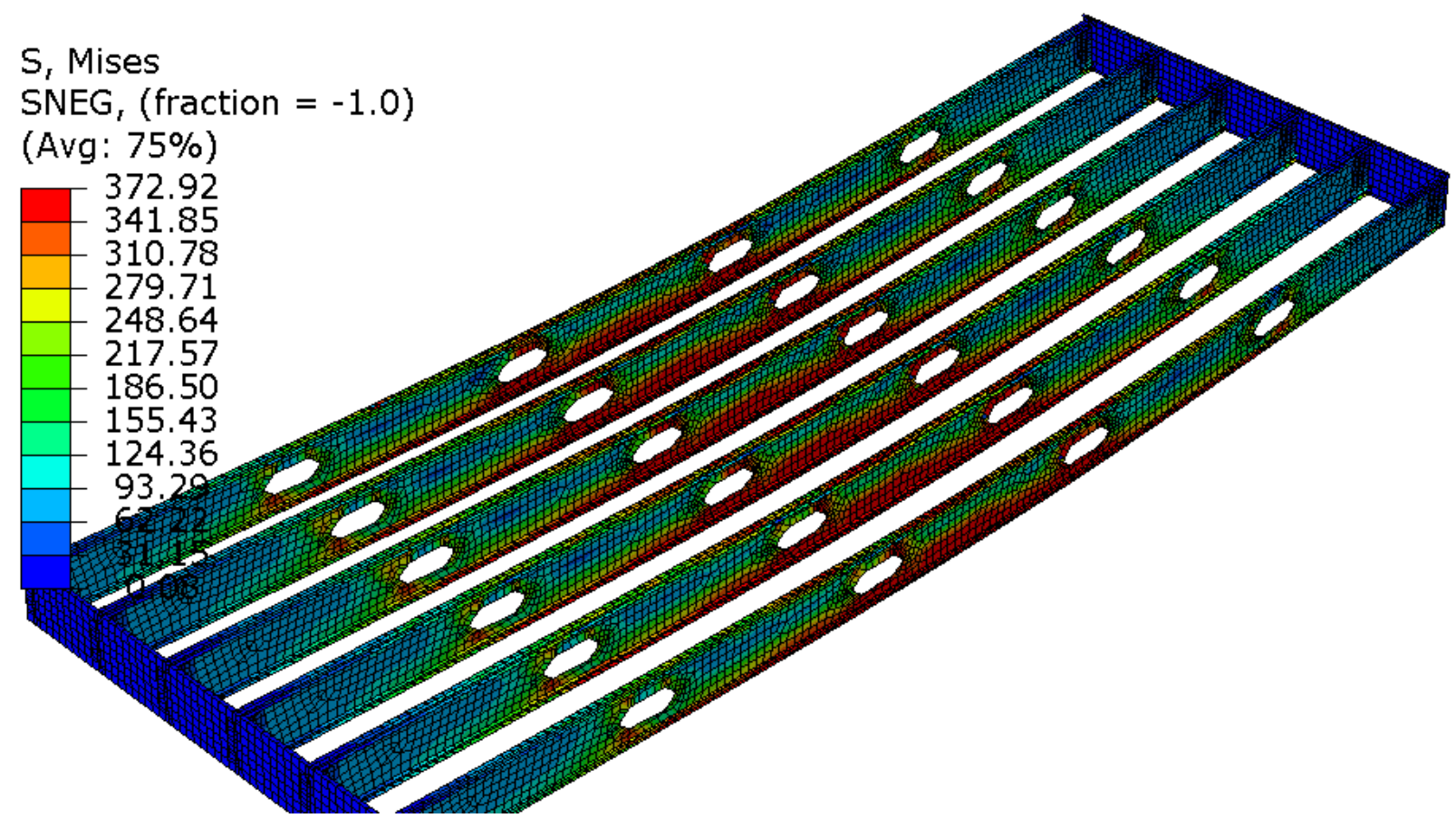

Figure 5.38: View of the FE modelling and stress contour lines resulting from the nonlinear analysis of a 3x9 m iSPAN joist floor system (OSB sheet is not shown for clarity)

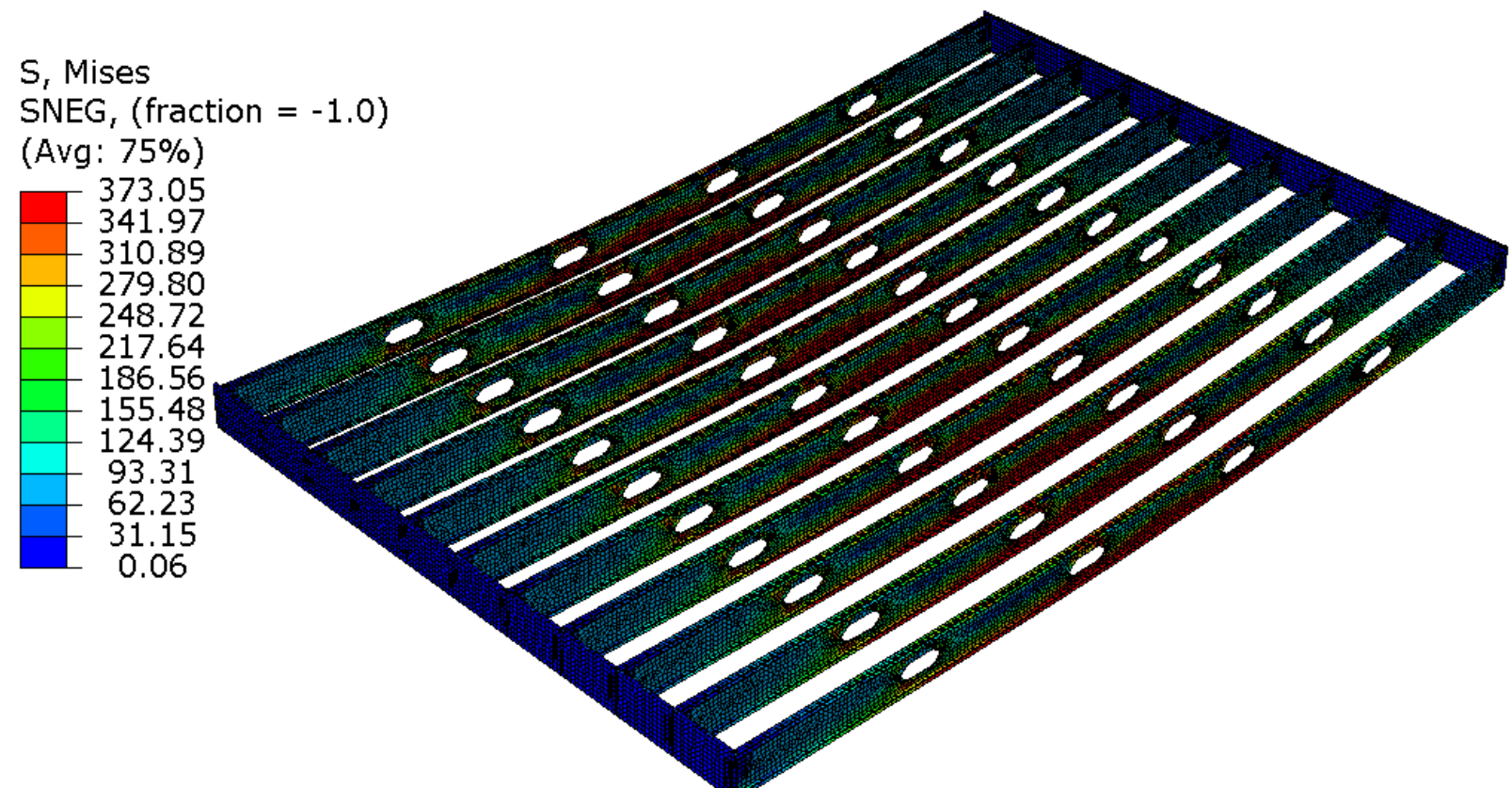

Figure 5.39: View of the FE modelling and stress contour lines resulting from the nonlinear analysis of a 6x9 m iSPAN joist floor system (OSB sheet is not shown for clarity) 


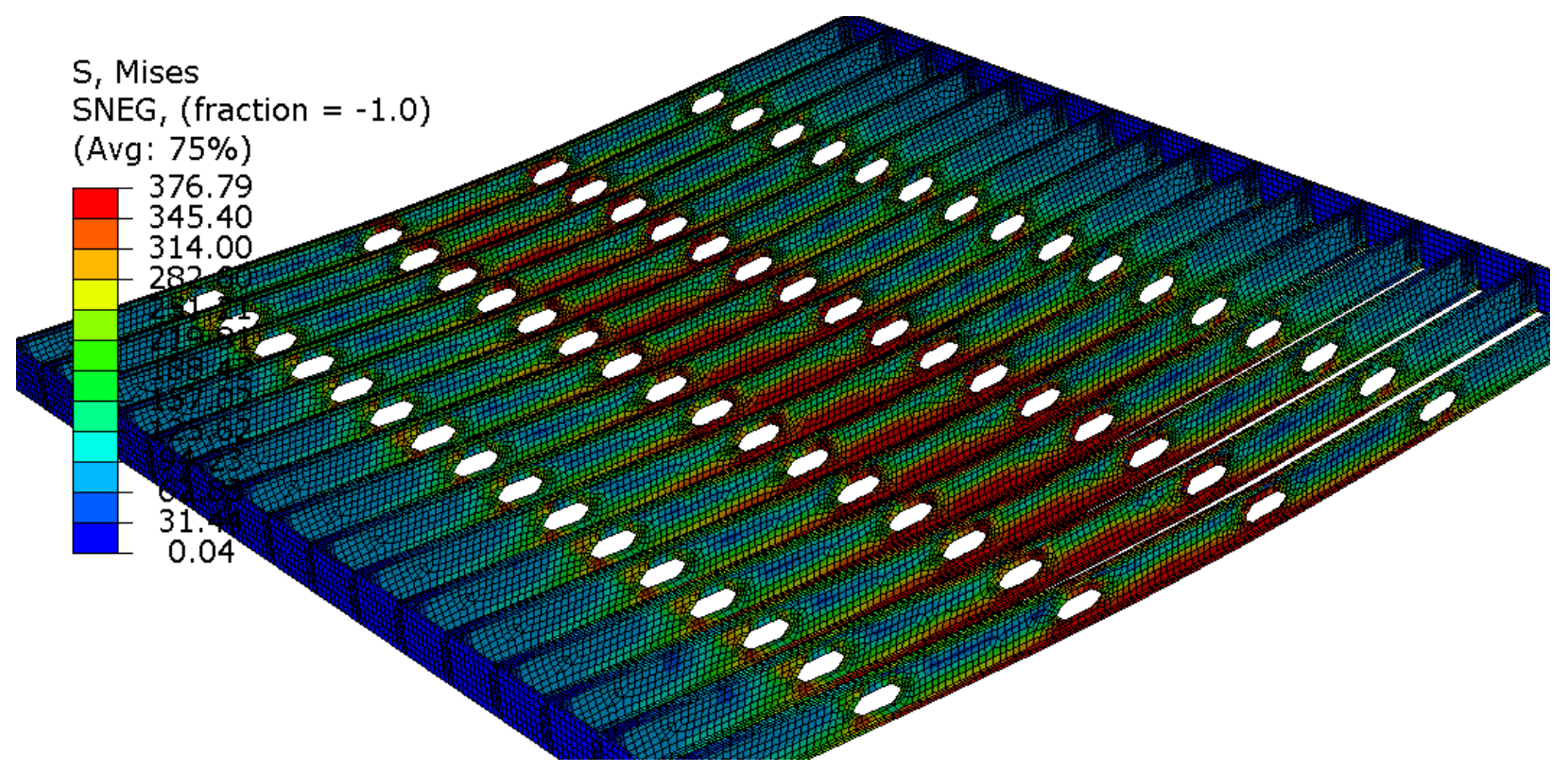

Figure 5.40: View of the FE modelling and stress contour lines resulting from the nonlinear analysis of a 9x9 m iSPAN joist floor system (OSB sheet is not shown for clarity) 


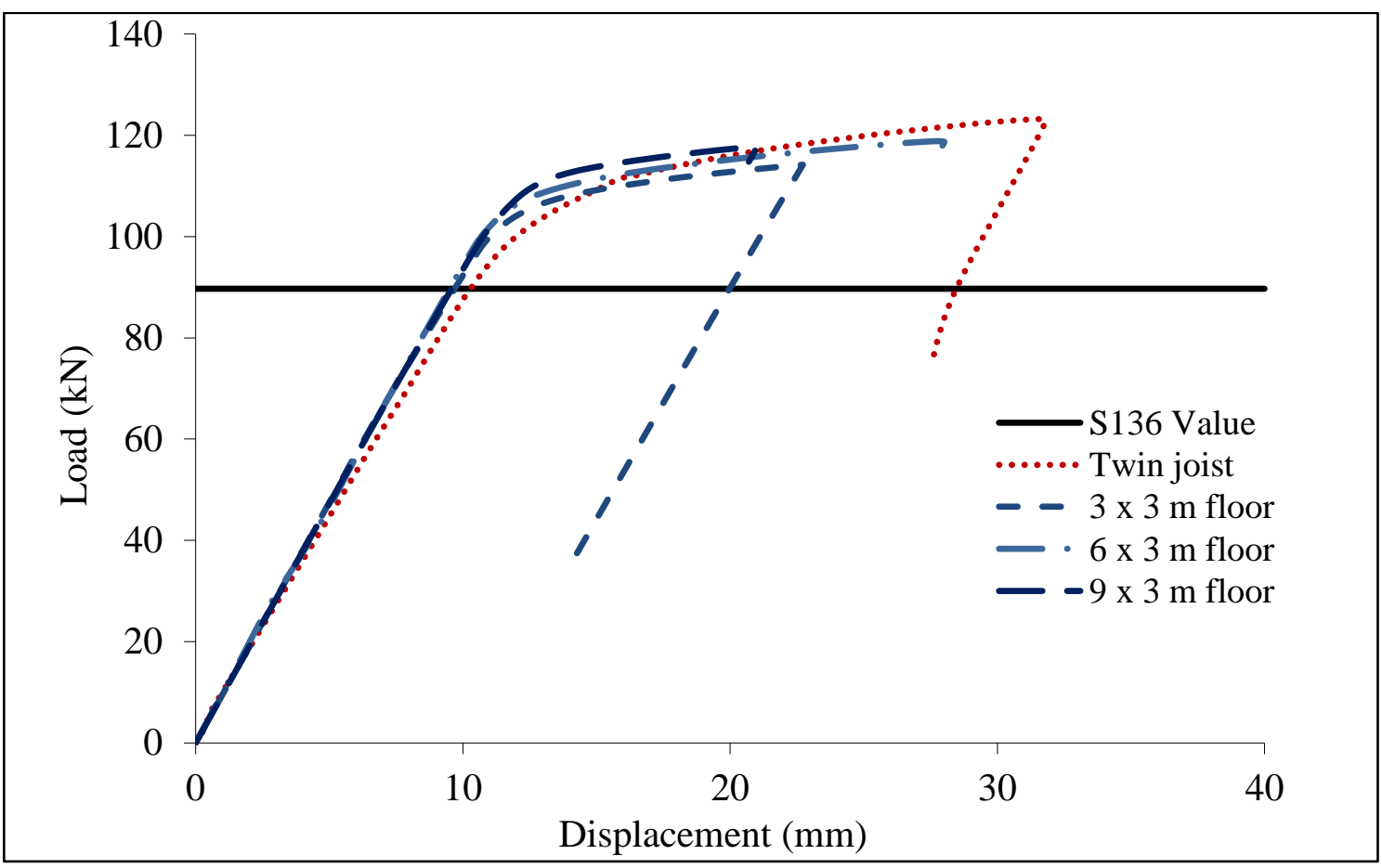

Figure 5.41: Comparison of load-deflection relationship of 254x3000 mm floor joist used in different floor plan sizes

Table 5.6: FEM results for various floor plan sizes made of $254 \times 3000 \mathrm{~mm}$ iSPAN joists

\begin{tabular}{|c|c|c|c|c|c|}
\hline \multirow{3}{*}{ Ultimate load } & \multicolumn{5}{|c|}{ Maximum load (kN) } \\
\cline { 2 - 7 } & $\mathrm{S} 136$ & Twin joist & $3 \mathrm{~m} \times 3 \mathrm{~m}$ & $6 \mathrm{~m} \times 3 \mathrm{~m}$ & $9 \mathrm{~m} \times 3 \mathrm{~m}$ \\
\cline { 2 - 7 } & 89.70 & 96.76 & 103.54 & 103.34 & 107.25 \\
\hline \multirow{3}{*}{ Vibration } & ATC & Twin joist & $3 \mathrm{~m} \times 3 \mathrm{~m}$ & $6 \mathrm{~m} \times 3 \mathrm{~m}$ & $9 \mathrm{~m} \times 3 \mathrm{~m}$ \\
\cline { 2 - 7 } & 61.80 & 64.50 & 64.10 & 63.35 & 62.75 \\
\cline { 2 - 7 } & &
\end{tabular}




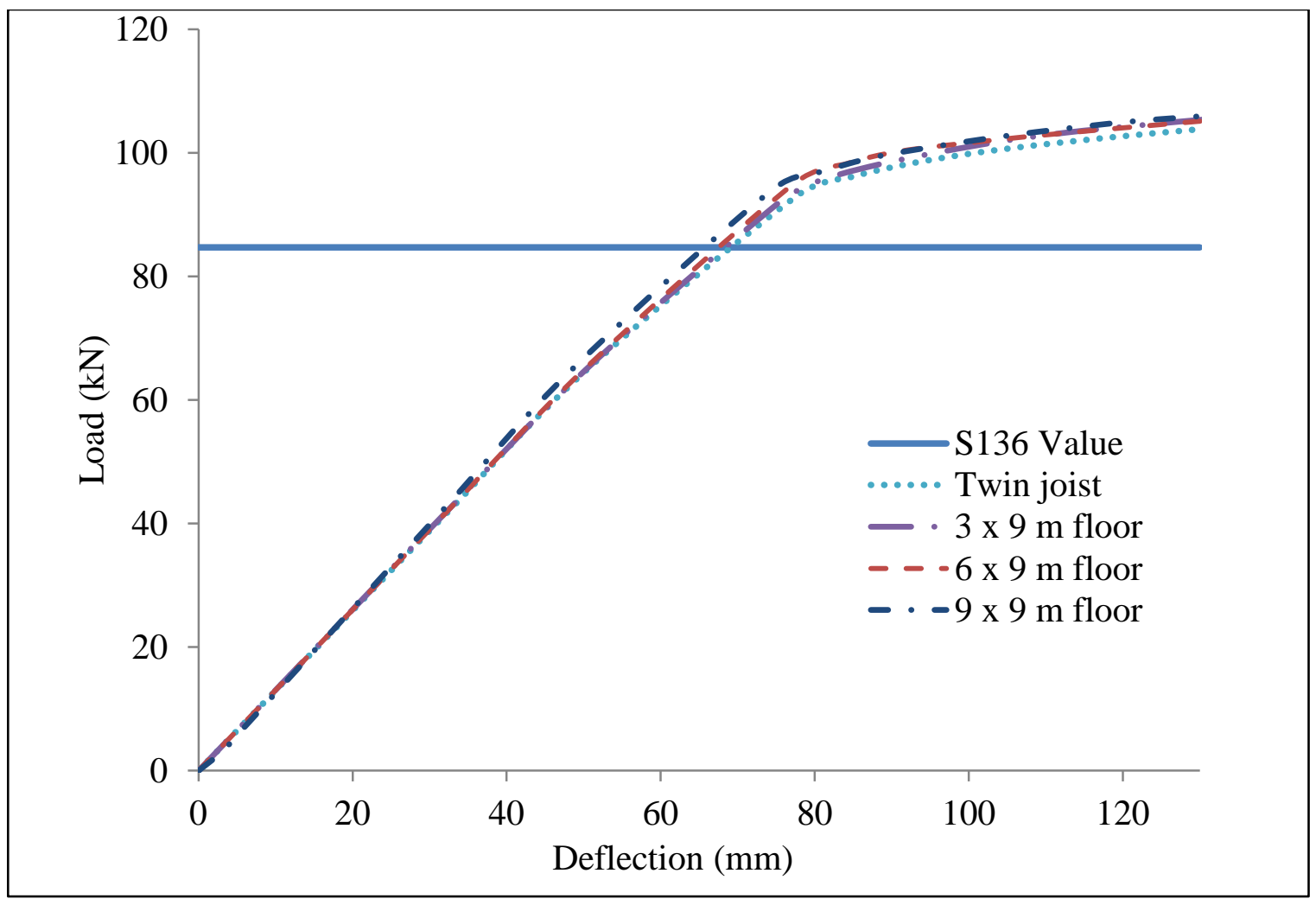

Figure 5.42: Comparison of load-deflection relationship of 406x9000 mm floor joist used in different floor plan sizes

Table 5.7: FEM results for various floor plan sizes made of $406 \times 9000 \mathrm{~mm}$ iSPAN joists

\begin{tabular}{|c|c|c|c|c|c|}
\hline \multirow{2}{*}{ Ultimate load } & \multicolumn{5}{|c|}{ Maximum load (kN) } \\
\cline { 2 - 7 } & $\mathrm{S} 136$ & Twin joist & $3 \mathrm{~m} \times 9 \mathrm{~m}$ & $6 \mathrm{~m} \times 9 \mathrm{~m}$ & $9 \mathrm{~m} \times 9 \mathrm{~m}$ \\
\cline { 2 - 7 } & 84.72 & 94.97 & 94.79 & 95.00 & 97.05 \\
\hline \multirow{3}{*}{ Vibration } & ATC & Twin joist & $3 \mathrm{~m} \times 9 \mathrm{~m}$ & $6 \mathrm{~m} \times 9 \mathrm{~m}$ & $9 \mathrm{~m} \times 9 \mathrm{~m}$ \\
\cline { 2 - 7 } & 12.09 & 13.34 & 12.6 & 12.32 & 12.26 \\
\cline { 2 - 7 } & &
\end{tabular}

\subsubsection{EFFECT OF WEB HOLES ON FLOOR VIBRATION}

In this study, the effect of lip-stiffened web holes on the frequency was studied by analysing a 406x9000 mm long iSPAN joist with different arrangements of web holes as shown in Figure 5.43. The number of holes and location are shown in Fig 6.43. Results are reported in Table 5.8 

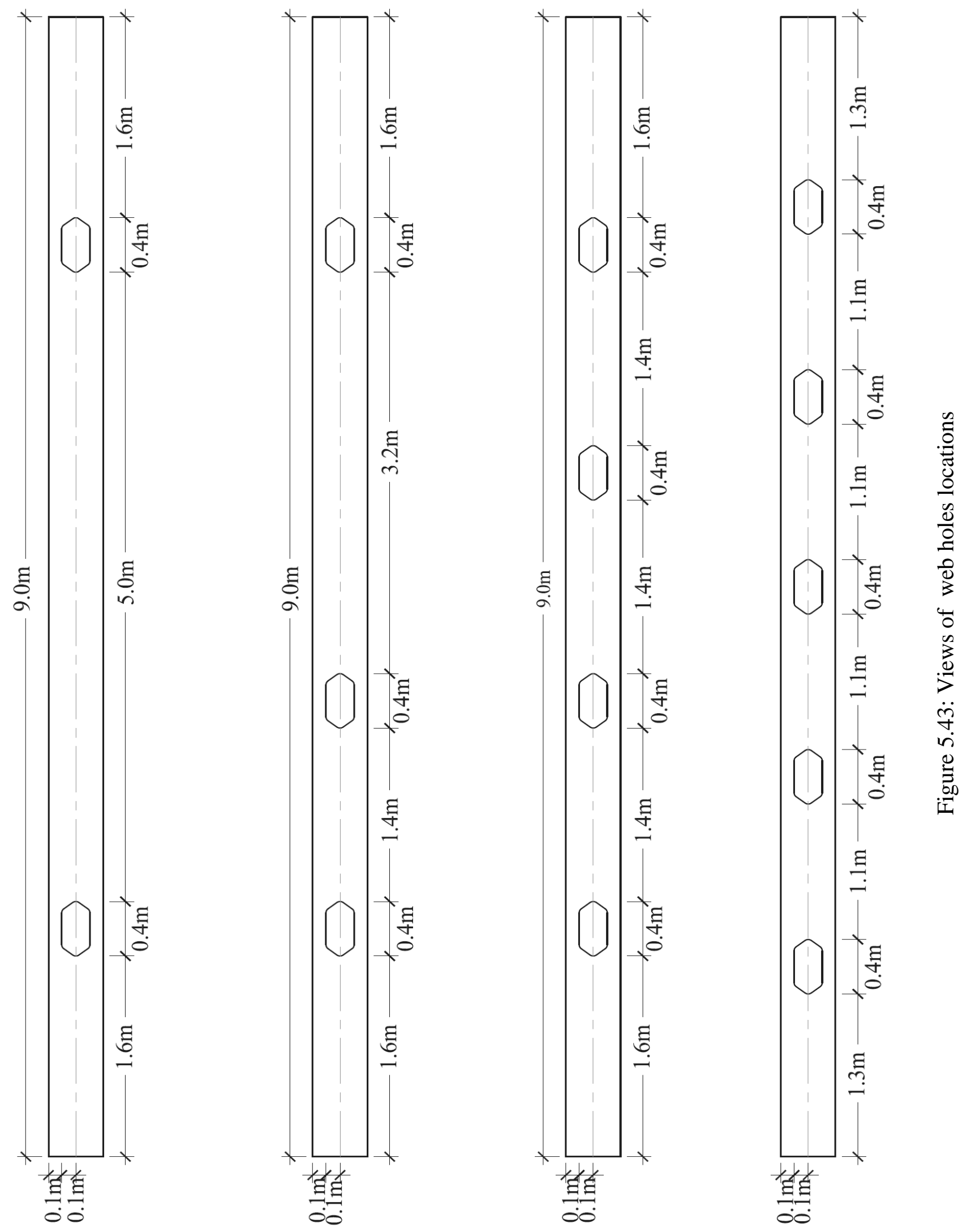
in the form of the fundamental flexural frequency of the joist. Results show that the presence of the stiffened web holes and change in the number of holes from 1 to 5 holes distributed along the length of the joist has insignificant effect on floor flexural frequency. The effect of number of web holes on the ultimate load carrying capacity of the joists is presented in Chapter 6 .

\section{Table 5.8: Results of FE modelling for the effect of web holes on the vibration performance of the $406 \times 9000 \mathrm{~mm}$ floor joist assembly}

\begin{tabular}{|c|c|c|c|c|c|}
\hline \multicolumn{7}{|c|}{ Frequency (Hz) } \\
\hline $\begin{array}{c}\text { No web } \\
\text { hole }\end{array}$ & $\begin{array}{c}1 \text { web } \\
\text { hole }\end{array}$ & $\begin{array}{c}2 \text { web } \\
\text { holes }\end{array}$ & $\begin{array}{c}3 \text { web } \\
\text { holes }\end{array}$ & $\begin{array}{c}4 \text { web } \\
\text { holes }\end{array}$ & $\begin{array}{c}5 \text { web } \\
\text { holes }\end{array}$ \\
\hline 13.26 & 13.23 & 13.13 & 13.20 & 13.34 & 13.26 \\
\hline
\end{tabular}

\subsection{CONCLUSIONS}

In this Chapter, geometric and material nonlinear finite-element modelling was conducted and FE results were correlated with the experimental findings. Elastic buckling analysis was used to extract the mode shapes which were further considered for a nonlinear analysis including geometric imperfection and post buckling. Good agreement between the FE results and the experimental findings was generally observed. FE results showed that the change of metal decking to OSB sheathing to form the joist floor has no effect on the structural response of ISPAN CFS joists. Also, FE results showed that the presence of the stiffened web holes and change in the number of holes, which are distributed along the length of the joist, has insignificant effect on floor flexural frequency. 


\section{CHAPTER 6}

\section{DESIGN OF COLD-FORMED STEEL EDGE-STIFFENED HOLES}

\subsection{INTRODUCTION}

Circular or slot holes are commonly found on the web of the cold formed steel members for different purpose, for examples for plumbing, electrical works, or for installing lateral bracing. Normally the holes in the cold-formed members are flat punched. These punch out holes are typical range in size from $38.10 \mathrm{~mm}$ by $101.6 \mathrm{~mm}$ to $19.10 \mathrm{~mm}$ by $50.80 \mathrm{~mm}$ are located a middepth of the web, and are spaced longitudinally $610 \mathrm{~mm}$ on center. (Shan et al., 1996). Due to these punched holes the flexural strength weakened. To overcome this reduction in the flexural strength the stiffened holes in cold-formed steel member are developed by the industries. Figure 6.1 shows a typical cold-formed iSPAN floor joist with stiffened utility holes. With the stiffened hole the opening could be larger in the web and has satisfactory flexural strength. Three different shapes of holes are studied in this research, namely: circular hole, slot hole and tri-slot hole. The hole shapes are shown in figure 6.2.

The boundary condition of holes is changed with the stiffener around the holes; also the stress distribution around the holes is also changed because of the stiffened holes. In the cold-formed steel the unstiffened holes is the usually the weakest area, because the unstiffened holes split the joist web into two unstiffened parts as shown in figure 6.3(a). From table 2.1 we can see that, the value of " $\mathrm{k}$ " for plate simply supported on four edges under compression is 4.0, while the plate simply supported on three edges and one free edge has " $k$ " values of 0.425 . This shows that the stiffened element has 9 times more elastic buckling stress than unstiffened element under compression. The lip of the stiffened hole is act as edge support to the two flat portion of the web. The hole split the web element to two stiffened parts as shown in figure 6.3(b) and 6.3(c). The cold-formed steel having stiffened holes gives the better performance in flexural and compression compare to the joist having the unstiffened holes. This chapter discussed the flexural strength of the cold-formed C, and iSPAN joist section, with circular, slot, and tri-slot holes. 
There is no design criteria is available for the design of stiffen holes in the NAS 2007 (CSAS136), and also in the newly design method called "Direct Strength Method." NAS 2007 has a design specification for C-section webs with punched holes under stress gradient, and these specifications cannot be used for cold formed steel members with stiffened edge hole. Therefore the main objective of this research is to (i) study the effect of stiffened hole on cold formed steel joist and plate, (ii) to find the optimized profile for joist having the stiffened hole, and (iii) to modified the currently design equations for the flexural strength of the cold formed joist with stiffened three types of holes. to study the above three parameters the finite element program ABAQUS V.6.10 is used to study the stability of cold-formed steel "C" section and iSPAN joist with edge stiffened circular, slot and tri-slot holes.

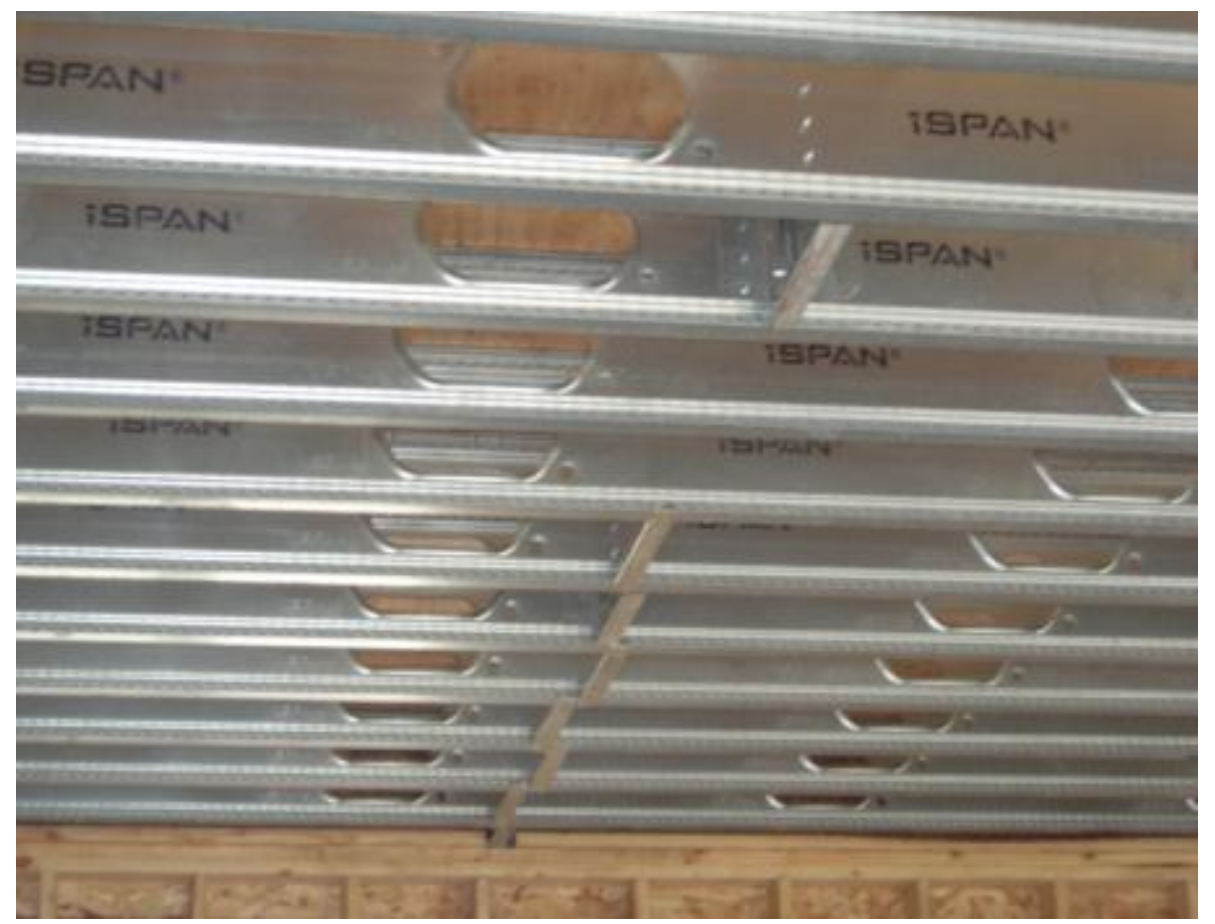

Figure 6.1: View of a typical floor built with iSPAN joists with edge-stiffened web holes 


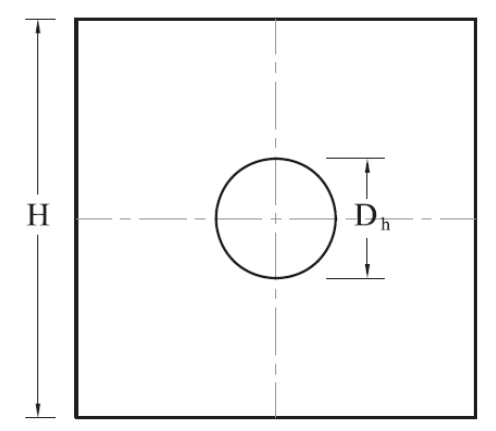

a) Plate with circular hole

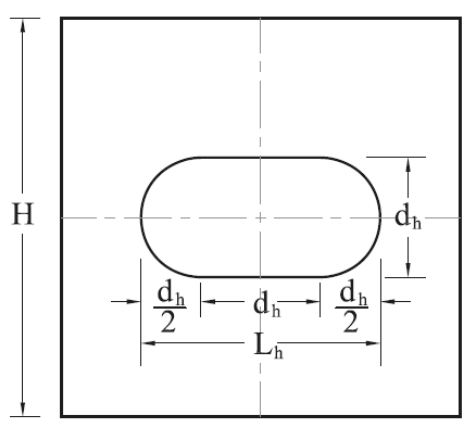

b) Plate with slot hole

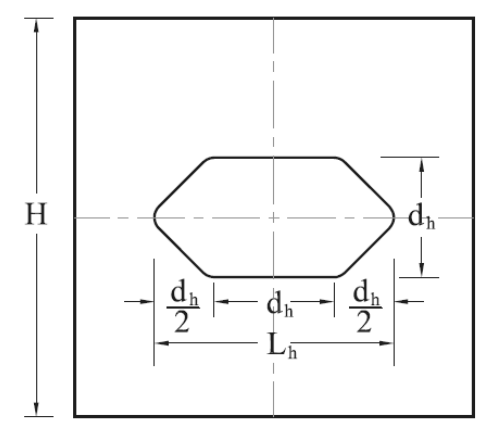

c) Plate with Tri-slot hole

Figure 6.2: Views of hole patterns

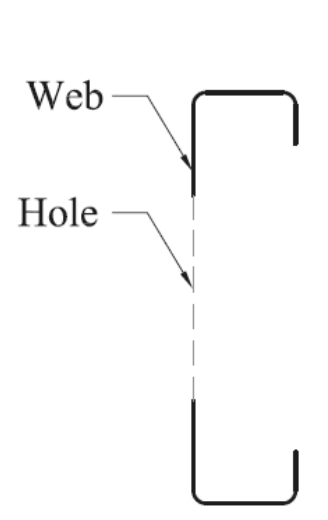

a) C-section unstiffened hole

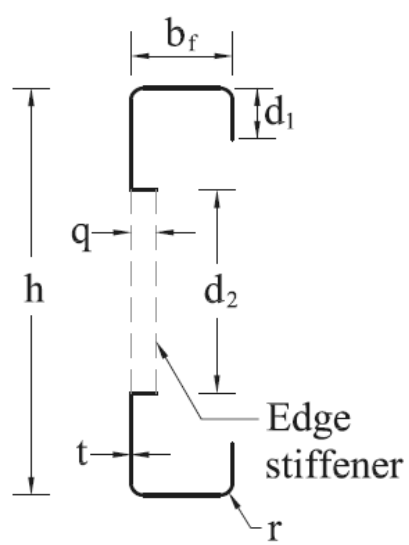

b) C-section stiffened hole

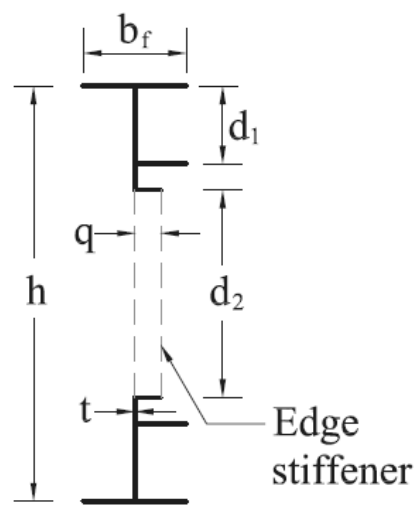

c) iSPAN joist section

Figure 6.3: View of cold formed steel joist sections (see Tables 6.19 and 6.20) 


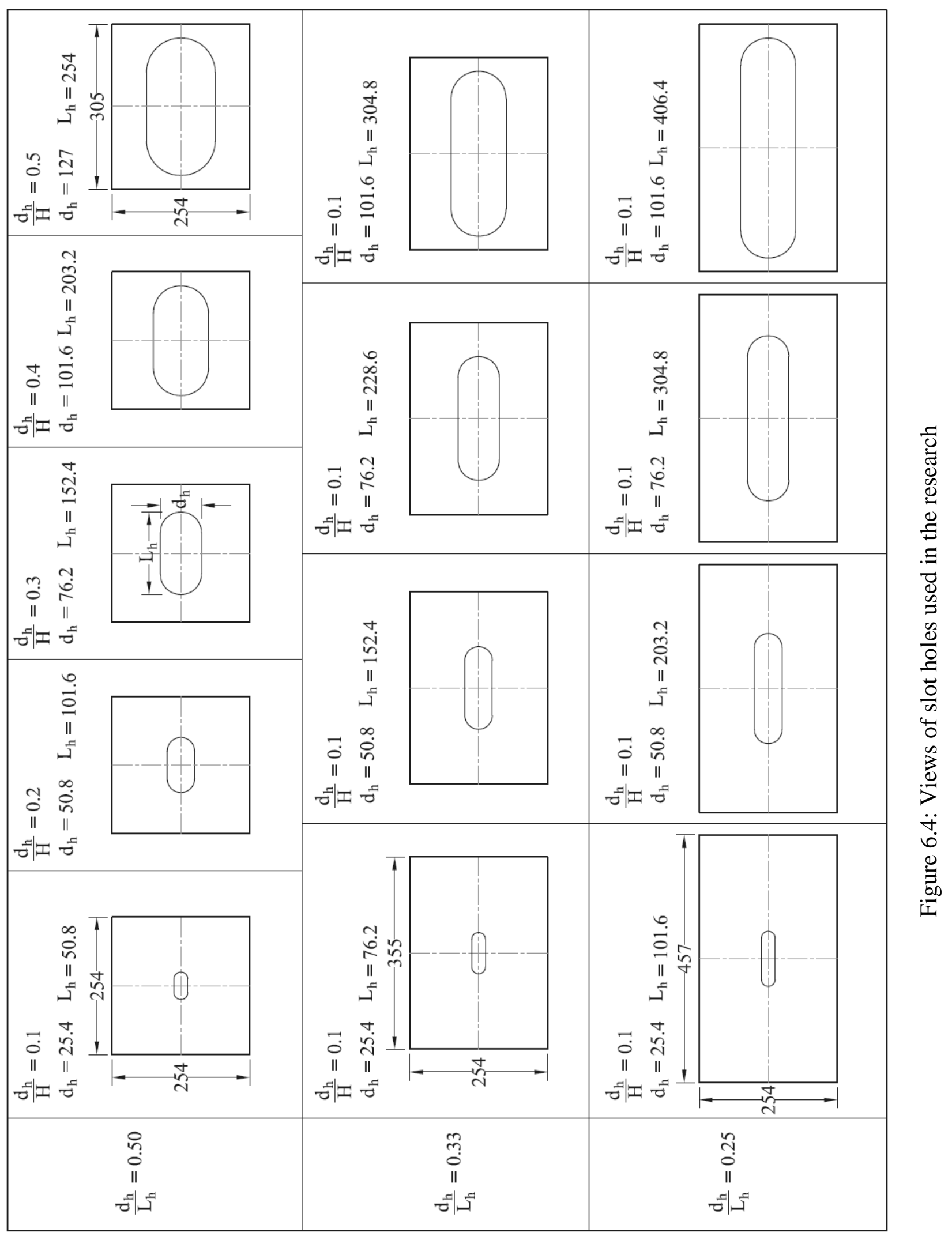




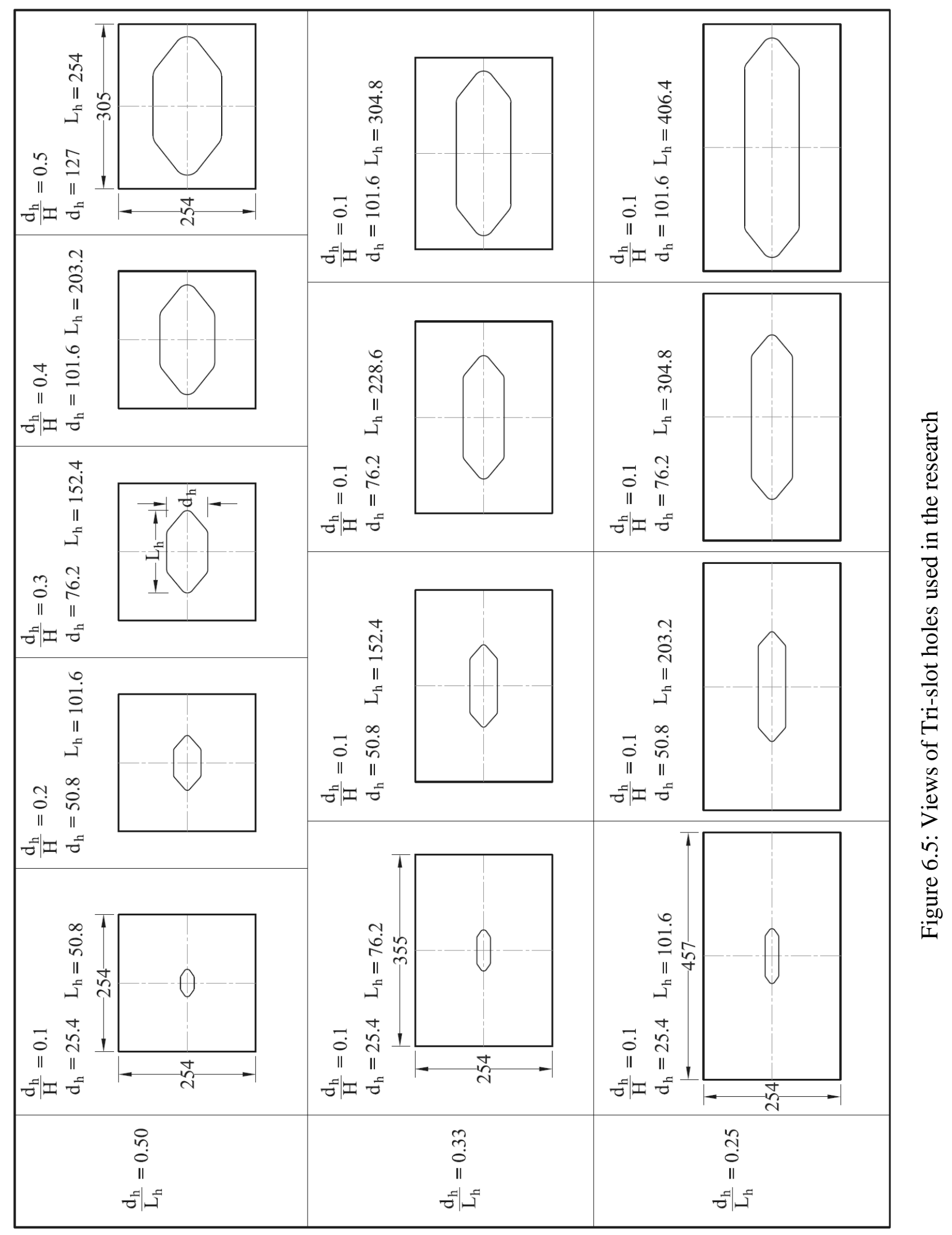




\subsection{ELASTIC BUCKLING OF COLD-FORMED STEEL THIN PLATES WITH STIFFENED HOLES}

The plate stability normally determines the strength of build-up members such as CFS C-section and iSPAN joists when those members fail by local buckling. In the actual applications, the floor joists are usually laterally supported by bridging and the compression flange of floor joists is commonly restrained by the decking. Therefore, lateral-torsional buckling and distortional buckling failure are generally restricted in practice, and the local buckling becomes the primary failure mode for floor joists. Thus, the first step of this research was to examine the stability of thin plates with stiffened or unstiffened holes as explained in the following sub-sections. (Yu, 2011).

\subsubsection{THIN PLATES SUBJECT TO UNIFORM COMPRESSION}

The FE program ABAQUS V6.10 was used to determine the elastic buckling load of CFS thin plates under uniform compression. The shell element was used to model the cold formed steel joists. Shell element is used when one dimension i.e thickness is significantly smaller than the other dimension. ABAQUS software provides a full library of shell elements. In this study the S4R element was selected to model the cold formed steel joists. The 12.7x12.7 mm mesh size was selected for plate buckling analysis. The plate thickness considers in this study is $2.54 \mathrm{~mm}$ and $0.508 \mathrm{~mm}$ which covers the thickness of the standard floor joists. The materials properties consider in this study were; Young's modulus $\mathrm{E}=203,400 \mathrm{MPa}$ and Poisson's ratio $\mu=0.3$. Wide range of slot hole and tri-slot hole dimensions was considered in this study as shown in Figures 6.4 and 6.5, respectively. Figure 6.6 shows a view of the FE mesh and the boundary conditions of a thin plate with a flat circular hole subjected to uniform compression. To simplify the model the sharp corner holes are modeled for all the holes. All the plates are square and holes are in the centre of the plates. The uniform compressive stress is applied at the both ends of the plate. The nodes around the edge of the plate are restricted in direction 3 , expect the centre nodes. The centre nodes on the two loaded sides are fixed in direction 2, while the other two

unload side, the centre nodes are fixed in direction 3, so the model can be solvable in finite element modeling. 
The results of finite element model is verified by results of thin plate without hole using the classical elastic buckling load equation. The critical buckling load calculate through finite element is $47.42 \mathrm{kN}$ for a $254 \times 254 \times 2.54 \mathrm{~mm}$ plate, and $0.381 \mathrm{kN}$ for $0.508 \mathrm{~mm}$ thick plate respectively. The theoretical loads calculated are 47.40 and $0.379 \mathrm{kN}$ respectively. Then the FE model applied to a total of 176 (slot and tri-slot holes) different thin plate with stiffened and unstiffened holes under uniform compression. Figures 6.7, 6.8, and 6.9 show the typical buckling shapes of thin plates as obtained from elastic buckling analysis using the FE modeling. The results are summarized in Tables 6.1 through 6.6 on which the ratios of FE vs. theoretical results of elastic buckling load are listed for different plate thicknesses, edge stiffener height and hole diameter in case of circular holes and depth and length of the hole in case of slotted holes. The result shows that when the hole is unstiffened and the holes are getting bigger the elastic buckling load is decreasing. When we look to the stiffened holes results we can see that as the edge stiffing length is increasing and the holes size is getting bigger the elastic buckling load is increasing, because the stiffened hole changed the boundary conditions of the unstiffened hole from free end to supported edge, the larger edge stiffener can resist more against buckling load. From table 2.1 (Timoshenko and Gere, 1961) the buckling coefficient k for one edge free and one edge simply supported are 0.425 , and the buckling coefficient $\mathrm{k}$ for one edge simply supported and one edge fixed is 5.42. The hole size also has great effect on the plate stability. The elastic buckling stress $\left(F_{c r}\right)$ of the plate can be calculated as $F_{c r}=k \frac{\pi^{2} E t^{3}}{12\left(1-\mu^{2}\right) h}$, where $\mathrm{t}$ is the plate thickness, $\mathrm{h}$ is the plate width of the loaded side and $\mathrm{k}$ is the bucking coefficient, while the other parameters are constants not related to the geometric profile. When a stiffened hole is formed in the plate, the width $\mathrm{h}$ is reduced at the hole cross-section, which helps increase the buckling load. At the same time, buckling coefficient, $\mathrm{k}$, will not change significantly for the resultant two flat portions since the edge stiffener produces stiffened edges. When combining the effect of the edge stiffener and the reduced flat width, the elastic buckling of a thin plate can be greatly improved. The FE results show that the increase can be as high as 6 times by comparing plates with stiffened holes and the plates without holes. (Yu, 2011)

From table 6.1 to 6.6 we can observe that as we increase the edge stiffener height the buckling load increase, but it won't increase much buckling load when we increase the edge stiffener after $15.2 \mathrm{~mm}$ for $2.54 \mathrm{~mm}$ thick plate and $10.2 \mathrm{~mm}$ for $0.508 \mathrm{~mm}$ thick plate. From the results of 
table 6.1 to 6.6 we can conclude that the by making the stiffened holes in the plate the elastic buckling load is increased, and the ratio of hole size to plate width and edge stiffener length to plate width $(\mathrm{q} / \mathrm{h})$. The edge stiffener width $\mathrm{q} / \mathrm{h}=0.06$ is recommended for the plate thickness ranges from $2.54 \mathrm{~mm}$ to $0.508 \mathrm{~mm}$. ( $\mathrm{Yu}, 2011$ ).

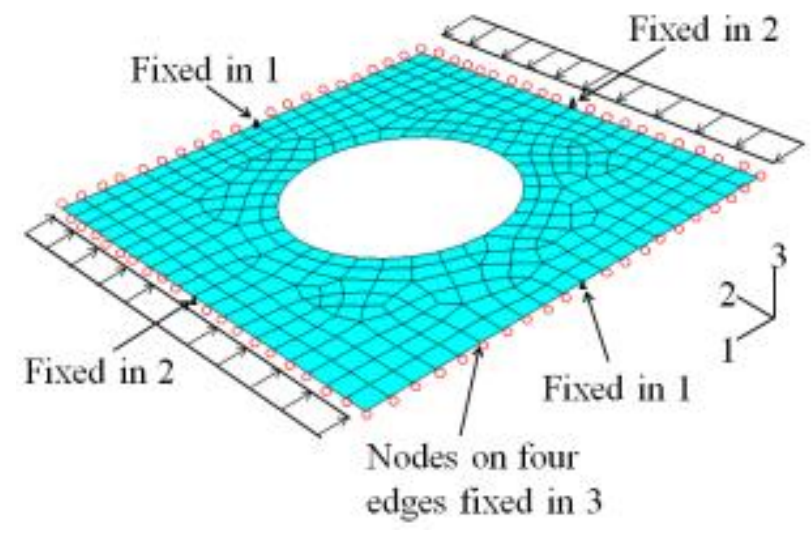

Figure 6.6: View of the FE mesh and boundary conditions for plates under uniform compression

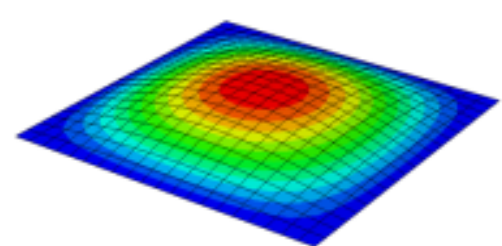

a) Plate with no hole

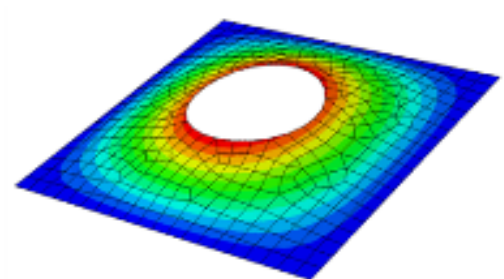

b) Unstiffened circular hole

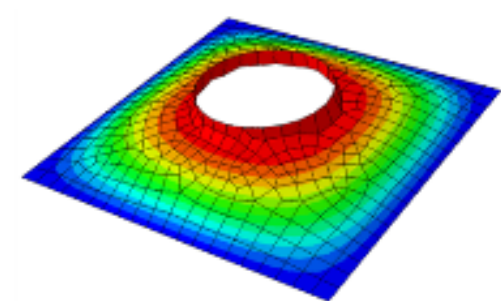

c) Stiffened circular hole

Figure 6.7: Views of the buckling shapes for circular hole under compression

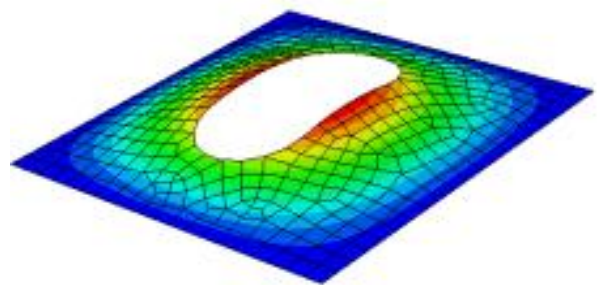

a) Unstiffened slot hole

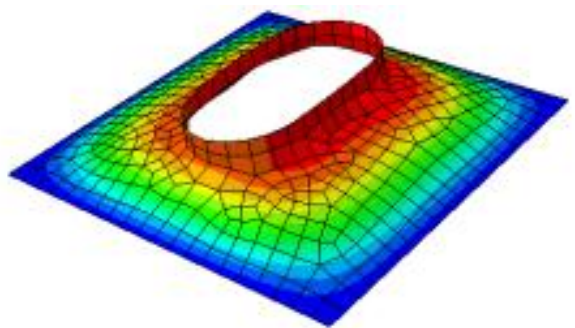

b) Stiffened slot hole

Figure 6.8: Views of the buckling shape for slotted hole under compression 


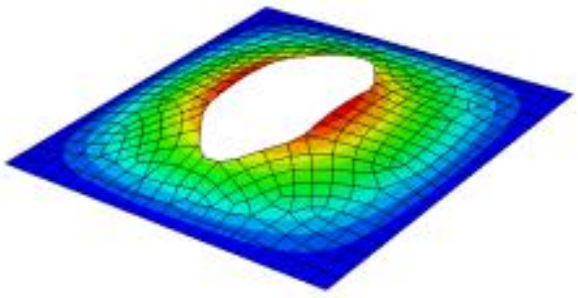

a) Unstiffened Tri-slot hole

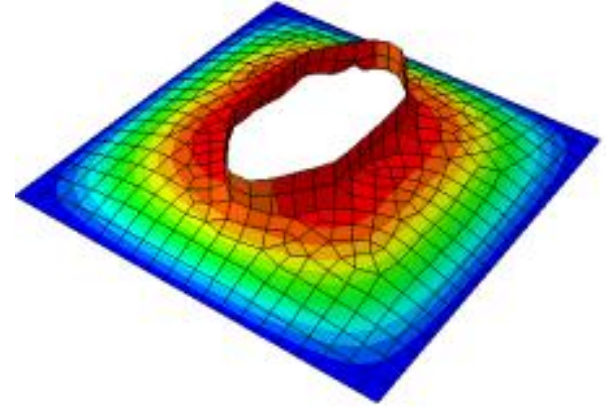

b) Stiffened Tri-slot hole

Figure 6.9: Views of the buckling shape for Tri-slotted hole under compression

Table 6.1: Ratio of FE vs. theoretical results of elastic buckling load for 254x254x2.54 mm plate under compression for circular hole (adopted from Yu, 2011)

\begin{tabular}{|c|c|c|c|c|c|c|c|c|c|c|c|}
\hline \multirow{2}{*}{$\begin{array}{c}\text { Hole } \\
\text { diameter } \\
(\mathrm{mm})\end{array}$} & \multicolumn{10}{|c|}{ Edge stiffener height (mm) } \\
\cline { 2 - 14 } & 0 & 2.54 & 5.08 & 10.2 & 15.2 & 20.3 & 25.4 & 30.5 & 38.1 & 45.7 & 50.8 \\
\hline 12.7 & 0.99 & 1.00 & 1.00 & 1.00 & 1.00 & 1.00 & 1.00 & 1.00 & 1.00 & 1.00 & 1.00 \\
\hline 25.4 & 0.96 & 0.99 & 1.02 & 1.03 & 1.03 & 1.03 & 1.03 & 1.03 & 1.03 & 1.03 & 1.03 \\
\hline 50.8 & 0.88 & 0.93 & 1.08 & 1.13 & 1.13 & 1.13 & 1.13 & 1.13 & 1.13 & 1.13 & 1.13 \\
\hline 76.2 & 0.80 & 0.87 & 1.13 & 1.29 & 1.30 & 1.30 & 1.30 & 1.30 & 1.30 & 1.30 & 1.30 \\
\hline 102 & 0.75 & 0.82 & 1.17 & 1.52 & 1.56 & 1.56 & 1.56 & 1.56 & 1.56 & 1.56 & 1.57 \\
\hline 127 & 0.72 & 0.78 & 1.20 & 1.83 & 1.96 & 1.97 & 1.97 & 1.97 & 1.97 & 1.97 & 1.98 \\
\hline 152 & 0.70 & 0.76 & 1.22 & 2.25 & 2.54 & 2.60 & 2.61 & 2.61 & 2.62 & 2.63 & 2.63 \\
\hline 178 & 0.69 & 0.74 & 1.21 & 2.77 & 3.40 & 3.55 & 3.61 & 3.66 & 3.72 & 3.74 & 3.76 \\
\hline 203 & 0.74 & 0.76 & 1.20 & 3.27 & 4.90 & 5.42 & 5.61 & 5.72 & 5.87 & 5.97 & 6.01 \\
\hline
\end{tabular}


Table 6.2: Ratio of FE vs. theoretical results of elastic buckling load for $254 \times 254 \times 0.508 \mathrm{~mm}$ plate under compression for circular hole (adopted from Yu, 2011)

\begin{tabular}{|c|c|c|c|c|c|c|c|c|c|c|c|}
\hline \multirow{2}{*}{$\begin{array}{c}\text { Hole } \\
\text { diameter } \\
(\mathrm{mm})\end{array}$} & \multicolumn{10}{|c|}{ Edge stiffener height (mm) } \\
\cline { 2 - 13 } & 0 & 2.54 & 5.08 & 10.2 & 15.2 & 20.3 & 25.4 & 30.5 & 38.1 & 45.7 & 50.8 \\
\hline 12.7 & 0.99 & 1.01 & 1.01 & 1.01 & 1.01 & 1.01 & 1.01 & 1.01 & 1.01 & 1.01 & 1.01 \\
\hline 25.4 & 0.96 & 1.04 & 1.04 & 1.04 & 1.04 & 1.04 & 1.04 & 1.04 & 1.04 & 1.04 & 1.04 \\
\hline 50.8 & 0.88 & 1.13 & 1.15 & 1.15 & 1.15 & 1.15 & 1.15 & 1.15 & 1.15 & 1.15 & 1.15 \\
\hline 76.2 & 0.81 & 1.26 & 1.35 & 1.35 & 1.35 & 1.35 & 1.35 & 1.35 & 1.35 & 1.35 & 1.35 \\
\hline 102 & 0.76 & 1.42 & 1.64 & 1.65 & 1.65 & 1.65 & 1.65 & 1.65 & 1.65 & 1.65 & 1.65 \\
\hline 127 & 0.73 & 1.59 & 2.06 & 2.10 & 2.11 & 2.11 & 2.11 & 2.12 & 2.12 & 2.12 & 2.12 \\
\hline 152 & 0.71 & 1.76 & 2.69 & 2.82 & 2.83 & 2.85 & 2.86 & 2.87 & 2.88 & 2.89 & 2.89 \\
\hline 178 & 0.70 & 1.91 & 3.52 & 3.76 & 3.82 & 3.87 & 3.92 & 3.97 & 4.05 & 4.12 & 4.17 \\
\hline 203 & 0.75 & 2.08 & 5.43 & 6.26 & 6.38 & 6.49 & 6.61 & 6.72 & 6.88 & 7.04 & 7.15 \\
\hline
\end{tabular}

Table 6.3: Ratio of FE vs. theoretical results of elastic buckling load for $254 \times 254 \times 2.54 \mathrm{~mm}$ plate under compression for slot hole

\begin{tabular}{|c|c|c|c|c|c|c|c|c|c|c|c|c|c|}
\hline \multirow{2}{*}{$\begin{array}{c}\text { Slot } \\
\text { size } \\
(\mathrm{mm})\end{array}$} & \multirow{2}{*}{$\begin{array}{c}\text { Length } \\
\mathrm{L}_{\mathrm{h}} \\
(\mathrm{mm})\end{array}$} & \multirow{2}{*}{$\begin{array}{c}\text { depth } \\
\mathrm{d}_{\mathrm{h}} \\
(\mathrm{mm})\end{array}$} & \multicolumn{11}{|c|}{ Edge stiffener height (mm) } \\
\hline & & & 0 & 2.54 & 5.08 & 10.2 & 15.2 & 20.3 & 25.4 & 30.5 & 38.1 & 45.7 & 50.8 \\
\hline \multirow{4}{*}{$\begin{array}{c}\mathrm{d}_{\mathrm{h}} / \\
\mathrm{L}_{\mathrm{h}}= \\
0.5\end{array}$} & 50.8 & 25.4 & 0.90 & 1.04 & 1.13 & 1.12 & 1.12 & 1.14 & 1.12 & 1.13 & 1.13 & 1.13 & 1.12 \\
\hline & 101.6 & 50.8 & 0.74 & 0.95 & 1.23 & 1.37 & 1.39 & 1.43 & 1.43 & 1.44 & 1.44 & 1.44 & 1.39 \\
\hline & 152.4 & 76.2 & 0.60 & 0.77 & 1.11 & 1.61 & 1.81 & 1.88 & 1.91 & 1.92 & 1.97 & 1.99 & 2.02 \\
\hline & 203.2 & 101.6 & 0.47 & 0.56 & 0.79 & 1.49 & 2.19 & 2.69 & 2.93 & 3.06 & 3.24 & 3.43 & 3.43 \\
\hline
\end{tabular}

Table 6.4: Ratio of FE vs. theoretical results of elastic buckling load for $254 \times 254 \times 0.508 \mathrm{~mm}$ plate under compression for slot hole

\begin{tabular}{|c|c|c|c|c|c|c|c|c|c|c|c|c|c|}
\hline \multirow{2}{*}{$\begin{array}{l}\text { Slot } \\
\text { size } \\
(\mathrm{mm})\end{array}$} & \multirow{2}{*}{$\begin{array}{c}\text { Length } \\
\mathrm{L}_{\mathrm{h}} \\
(\mathrm{mm})\end{array}$} & \multirow{2}{*}{$\begin{array}{c}\text { depth } \\
\mathrm{d}_{\mathrm{h}} \\
(\mathrm{mm})\end{array}$} & \multicolumn{11}{|c|}{ Edge stiffener height $(\mathrm{mm})$} \\
\hline & & & 0 & 2.54 & 5.08 & 10.2 & 15.2 & 20.3 & 25.4 & 30.5 & 38.1 & 45.7 & 50.8 \\
\hline \multirow{4}{*}{$\begin{array}{c}\mathrm{d}_{\mathrm{h}} / \mathrm{L}_{\mathrm{h}} \\
=0.5\end{array}$} & 50.8 & 25.4 & 0.90 & 1.22 & 1.23 & 1.14 & 116 & 1.19 & 1.17 & 1.18 & 1.18 & 1.18 & 1.18 \\
\hline & 101.6 & 50.8 & 0.74 & 1.54 & 1.65 & 1.50 & 1.4 & 1.56 & 1.5 & 1.57 & 1.55 & 1.56 & 1.57 \\
\hline & 152.4 & 76.2 & 0.60 & 1.85 & 2.15 & 2.03 & 2.10 & 2.10 & 2.10 & 2.12 & 2.18 & 2.19 & 2.27 \\
\hline & 203.2 & 101.6 & 0.47 & 1.63 & 2.53 & 2.90 & 3.31 & 3.68 & 3.83 & 3.91 & 3.98 & 4.08 & 4.04 \\
\hline
\end{tabular}


Table 6.5: Ratio of FE vs. theoretical results of elastic buckling load for $254 \times 254 \times 2.54 \mathrm{~mm}$ plate under compression for Tri-slot hole

\begin{tabular}{|c|c|c|c|c|c|c|c|c|c|c|c|c|c|}
\hline \multirow{2}{*}{$\begin{array}{l}\text { Slot } \\
\text { size } \\
(\mathrm{mm})\end{array}$} & \multirow{2}{*}{$\begin{array}{c}\text { Length } \\
\mathrm{L}_{\mathrm{h}} \\
(\mathrm{mm})\end{array}$} & \multirow{2}{*}{$\begin{array}{c}\text { depth } \\
\mathrm{d}_{\mathrm{h}} \\
(\mathrm{mm})\end{array}$} & \multicolumn{11}{|c|}{ Edge stiffener height (mm) } \\
\hline & & & 0 & 2.54 & 5.08 & 10.2 & 15.2 & 20.3 & 25.4 & 30.5 & 38.1 & 45.7 & 50.8 \\
\hline \multirow{4}{*}{$\begin{array}{c}\mathrm{d}_{\mathrm{h}} / \\
\mathrm{L}_{\mathrm{h}}= \\
0.5\end{array}$} & 50.8 & 25.4 & 0.91 & 1.01 & 1.05 & 1.08 & 1.08 & 1.09 & 1.08 & 1.09 & 1.08 & 1.09 & 1.09 \\
\hline & 101.6 & 50.8 & 0.75 & 0.96 & 1.20 & 1.36 & 1.38 & 1.38 & 1.39 & 1.39 & 1.40 & 1.40 & 1.41 \\
\hline & 152.4 & 76.2 & 0.61 & 0.79 & 1.12 & 1.62 & 1.80 & 1.92 & 1.91 & 1.92 & 1.90 & 1.93 & 1.97 \\
\hline & 203.2 & 101.6 & 0.48 & 0.58 & 0.85 & 1.59 & 2.10 & 2.61 & 2.83 & 3.03 & 3.03 & 3.17 & 3.24 \\
\hline
\end{tabular}

Table 6.6: Ratio of FE vs. theoretical results of elastic buckling load for 254x254x0.508 mm plate under compression for Tri-slot hole

\begin{tabular}{|c|c|c|c|c|c|c|c|c|c|c|c|c|c|}
\hline \multirow{2}{*}{$\begin{array}{c}\text { Slot } \\
\text { size } \\
(\mathrm{mm}) \\
\end{array}$} & \multirow{2}{*}{$\begin{array}{c}\text { Length } \\
\mathrm{L}_{\mathrm{h}} \\
(\mathrm{mm})\end{array}$} & \multirow{2}{*}{$\begin{array}{c}\text { depth } \\
\mathrm{d}_{\mathrm{h}} \\
(\mathrm{mm})\end{array}$} & \multicolumn{11}{|c|}{ Edge stiffener height (mm) } \\
\hline & & & 0 & 2.54 & 5.08 & 10.2 & 15.2 & 20.3 & 25.4 & 30.5 & 38.1 & 45.7 & 50.8 \\
\hline \multirow{4}{*}{$\begin{array}{c}\mathrm{d}_{\mathrm{h}} / \\
\mathrm{L}_{\mathrm{h}}= \\
0.5\end{array}$} & 50.8 & 25.4 & 0.91 & 1.13 & 1.11 & 1.12 & 1.11 & 1.12 & 1.11 & 1.12 & 1.11 & 1.11 & 1.13 \\
\hline & 101.6 & 50.8 & 0.76 & 1.50 & 1.53 & 1.49 & 1.47 & 1.47 & 1.49 & 1.49 & 1.49 & 1.50 & 1.54 \\
\hline & 152.4 & 76.2 & 0.61 & 1.85 & 2.13 & 2.04 & 2.05 & 2.18 & 2.15 & 2.12 & 2.10 & 2.16 & 2.21 \\
\hline & 203.2 & 101.6 & 0.48 & 1.71 & 2.48 & 2.77 & 2.86 & 3.53 & 3.36 & 3.81 & 3.62 & 3.75 & 4.01 \\
\hline
\end{tabular}

\subsubsection{THIN PLATES SUBJECT TO TRANSVERSE STRESS GRADIENT}

The web of a C- and iSPAN section members performing flexure is subjected to a flexural stress gradient in the transverse direction. The same thin plates analyzed in the previous section, as indicated in Figures 6.2 through 6.5 were investigated herein but when subjected to flexural stress gradient on both ends as shown in Figure 6.10. A typical FE model of the thin plate with circular hole is shown in Figure 6.10, while Figures 6.11, 6.12, and 6.13 show typical buckling modes obtained from the elastic buckling analyses of plates with circular, slotted and Tri-slotted holes, respectively. Figure 6.10(a) shows the first buckling mode of a solid thin plate. In figure 6.7(a) the first buckling mode for plate without hole under uniform stress gradient is single half wave, but when same plate is loaded under stress gradient the first buckling mode change from single half wave to full wave. In figure 6.11 (b), 6.12 (a), and figure 6.13 (a) when the hole is unstiffened the first buckling shape is one half. When the hole becomes stiffened the first 
buckling mode is full wave as in the case of solid plate. Table 6.7 to 6.12 summarize the results for the plate under stress gradient. From the results we can conclude that as we increase the edge stiffener length or the holes size get bigger the elastic buckling load is also increasing. Similarly like plate under uniform compression, the $\mathrm{q} / \mathrm{h}=0.06$ for the plate under stress gradient, and its apply for the plate thickness range from $2.54 \mathrm{~mm}$ to $0.508 \mathrm{~mm}$.

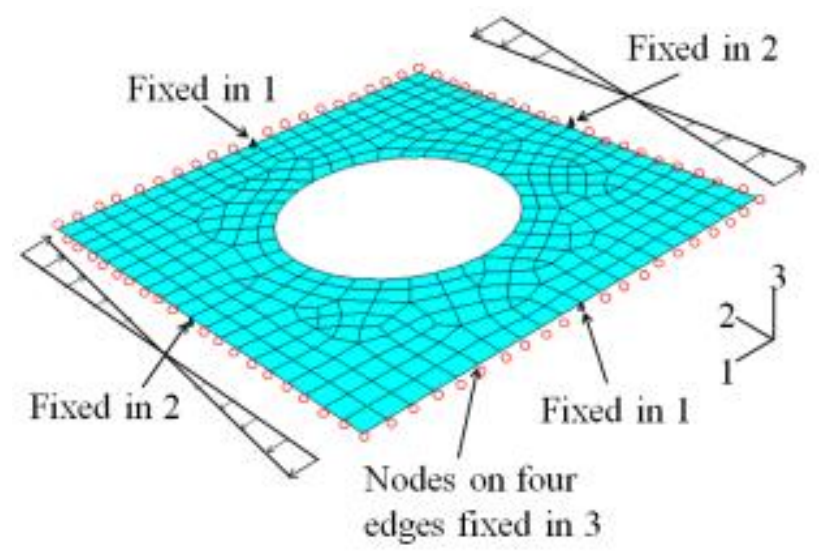

Figure 6.10: View of the FE mesh and boundary conditions for plates under stress gradient

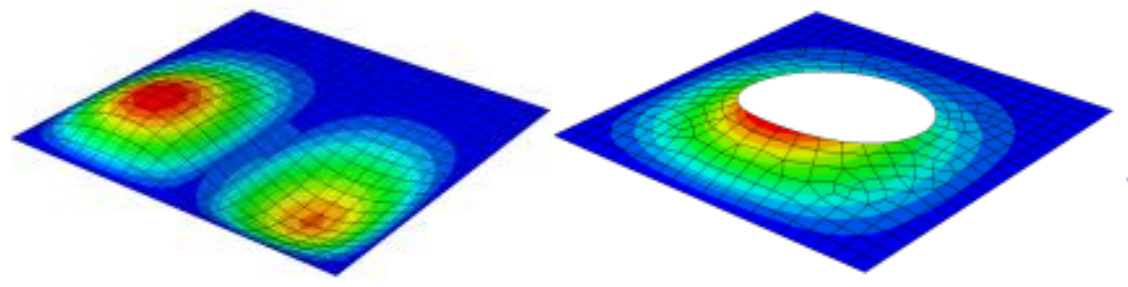

a) Plate with no hole

b) Unstiffened circular hole

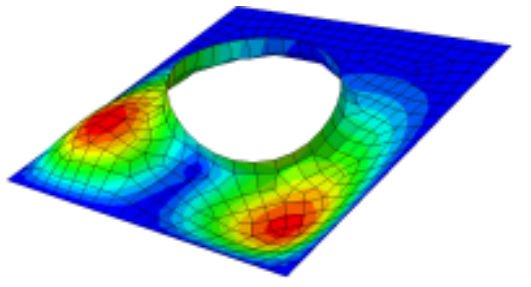

c) Stiffened circular hole

Figure 6.11: Views of the buckling shape for circular hole under stress gradient 


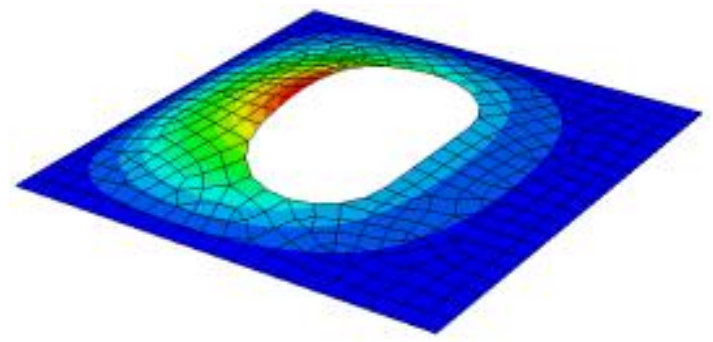

a) Unstiffened slot hole

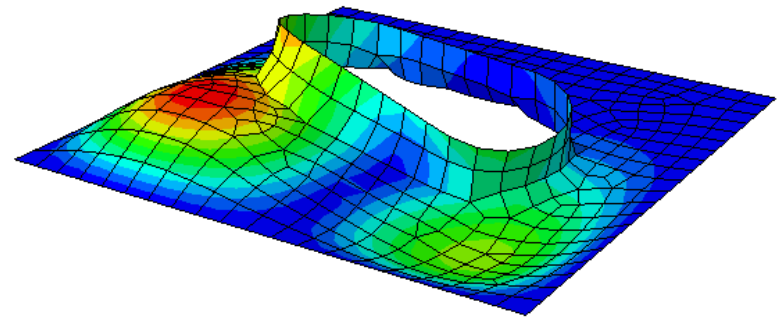

b) Stiffened slot hole

Figure 6.12: Views of the buckling shape for slotted hole under stress gradient

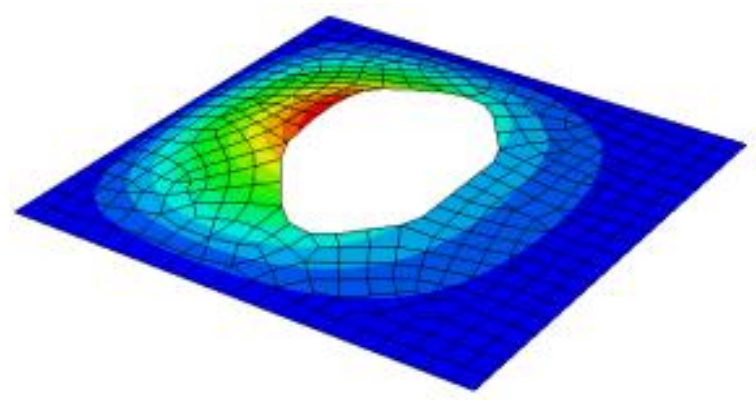

a) Unstiffened Tri-slot hole

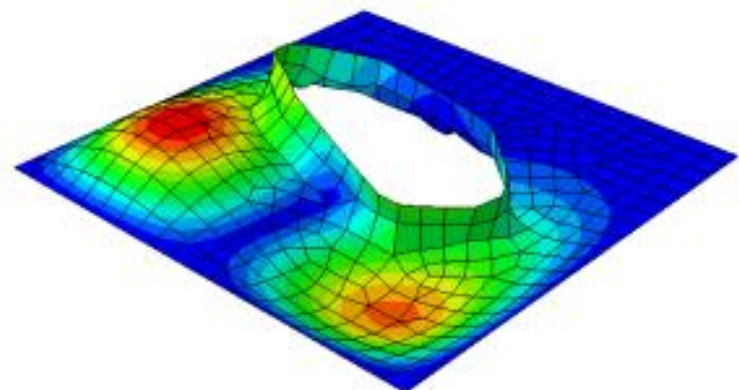

b) Stiffened Tri-slot hole

Figure 6.13: Views of the buckling shape for Tri-slotted hole under stress gradient

Table 6.7: Ratio of FE vs. theoretical results of elastic buckling load for $254 \times 254 \times 2.54 \mathrm{~mm}$ plate under stress gradient for circular hole (adopted from Yu, 2011)

\begin{tabular}{|c|c|c|c|c|c|c|c|c|c|c|c|}
\hline \multirow{2}{*}{$\begin{array}{c}\text { Hole } \\
\text { diameter } \\
(\mathrm{mm})\end{array}$} & \multicolumn{10}{|c|}{ Edge stiffener height (mm) } \\
\cline { 2 - 13 } & 0 & 2.54 & 5.08 & 10.2 & 15.2 & 20.3 & 25.4 & 30.5 & 38.1 & 45.7 & 50.8 \\
\hline 12.7 & 1.00 & 1.00 & 1.01 & 1.01 & 1.01 & 1.01 & 1.01 & 1.01 & 1.01 & 1.01 & 1.01 \\
\hline 25.4 & 1.00 & 1.00 & 1.01 & 1.02 & 1.02 & 1.02 & 1.03 & 1.03 & 1.03 & 1.03 & 1.03 \\
\hline 50.8 & 0.97 & 0.99 & 1.01 & 1.03 & 1.04 & 1.06 & 1.07 & 1.08 & 1.09 & 1.09 & 1.09 \\
\hline 76.2 & 0.85 & 0.90 & 1.02 & 1.06 & 1.08 & 1.10 & 1.12 & 1.14 & 1.16 & 1.17 & 1.17 \\
\hline 102 & 0.73 & 0.79 & 1.06 & 1.14 & 1.17 & 1.19 & 1.21 & 1.23 & 1.26 & 1.29 & 1.30 \\
\hline 127 & 0.66 & 0.71 & 1.07 & 1.29 & 1.33 & 1.35 & 1.37 & 1.39 & 1.42 & 1.45 & 1.47 \\
\hline 152 & 0.65 & 0.69 & 1.09 & 1.54 & 1.61 & 1.64 & 1.66 & 1.68 & 1.71 & 1.74 & 1.76 \\
\hline 178 & 0.68 & 0.72 & 1.17 & 2.01 & 2.16 & 2.20 & 2.23 & 2.25 & 2.28 & 2.32 & 2.34 \\
\hline 203 & 0.77 & 0.83 & 1.33 & 2.87 & 3.21 & 3.26 & 3.29 & 3.32 & 3.36 & 3.41 & 3.44 \\
\hline
\end{tabular}


Table 6.8: Ratio of FE vs. theoretical results of elastic buckling load for 254x254x0.508 mm plate under stress gradient for circular hole (adopted from Yu, 2011)

\begin{tabular}{|c|c|c|c|c|c|c|c|c|c|c|c|}
\hline $\begin{array}{c}\text { Hole } \\
\text { diameter }\end{array}$ & \multicolumn{10}{|c|}{ Edge stiffener height $(\mathrm{mm})$} \\
\cline { 2 - 12 }$(\mathrm{mm})$ & 0 & 2.54 & 5.08 & 10.2 & 15.2 & 20.3 & 25.4 & 30.5 & 38.1 & 45.7 & 50.8 \\
\hline 12.7 & 1.00 & 1.01 & 1.01 & 1.01 & 1.01 & 1.01 & 1.01 & 1.01 & 1.01 & 1.01 & 1.01 \\
\hline 25.4 & 1.00 & 1.01 & 1.01 & 1.02 & 1.03 & 1.03 & 1.03 & 1.03 & 1.03 & 1.03 & 1.03 \\
\hline 50.8 & 0.97 & 1.37 & 1.02 & 1.04 & 1.05 & 1.08 & 1.08 & 1.09 & 1.10 & 1.10 & 1.10 \\
\hline 76.2 & 0.85 & 1.04 & 1.06 & 1.08 & 1.09 & 1.11 & 1.13 & 1.15 & 1.17 & 1.19 & 1.19 \\
\hline 102 & 0.74 & 1.11 & 1.15 & 1.17 & 1.19 & 1.21 & 1.23 & 1.23 & 1.28 & 1.31 & 1.33 \\
\hline 127 & 0.67 & 1.23 & 1.33 & 1.36 & 1.37 & 1.39 & 1.41 & 1.43 & 1.46 & 1.49 & 1.51 \\
\hline 152 & 0.65 & 1.44 & 1.65 & 1.67 & 1.69 & 1.71 & 1.73 & 1.75 & 1.78 & 1.81 & 1.83 \\
\hline 178 & 0.69 & 1.79 & 2.26 & 2.30 & 2.32 & 2.35 & 2.38 & 2.41 & 2.44 & 2.48 & 2.51 \\
\hline 203 & 0.77 & 2.21 & 3.45 & 3.47 & 3.52 & 3.59 & 3.67 & 3.73 & 3.81 & 3.88 & 3.93 \\
\hline
\end{tabular}




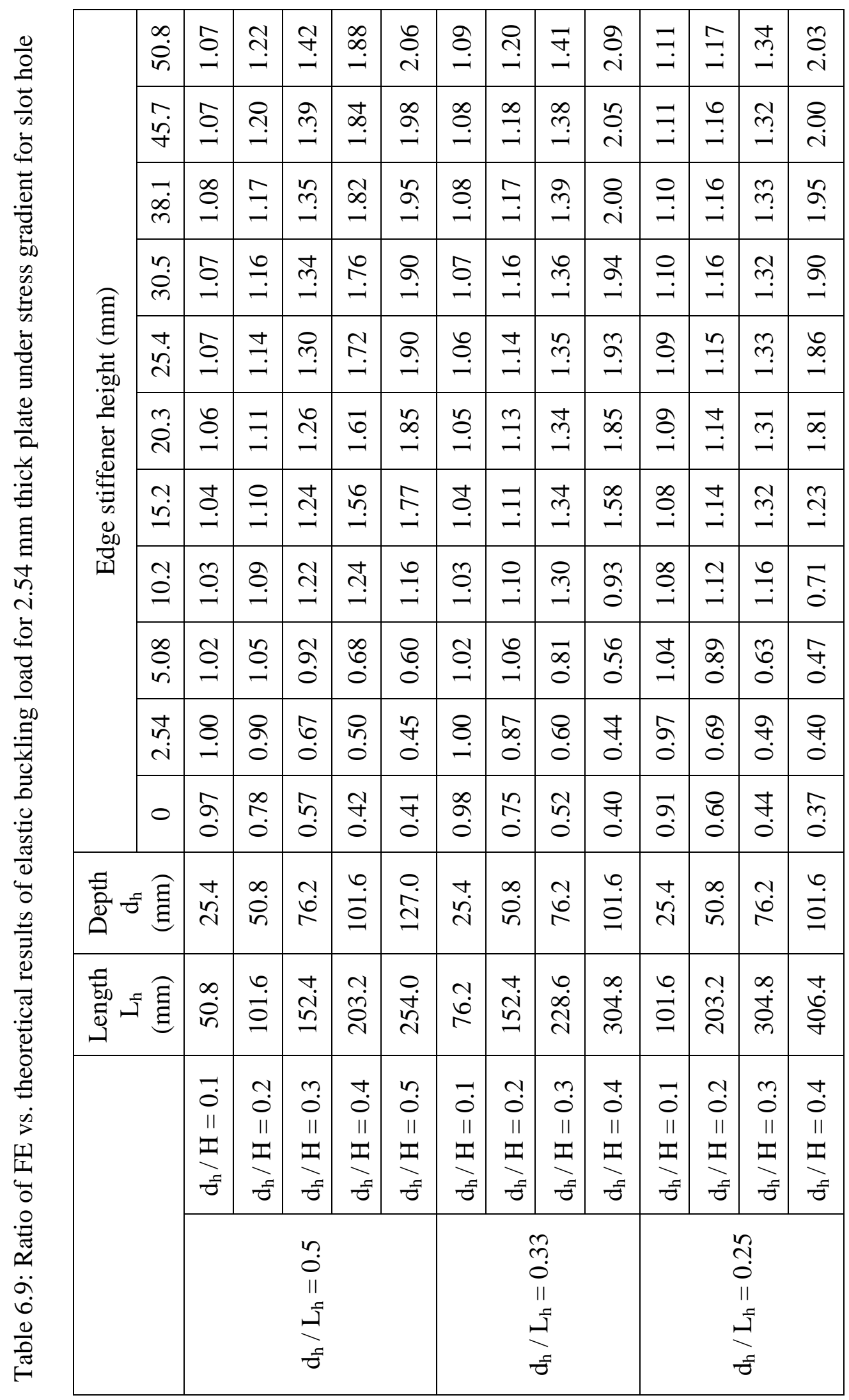




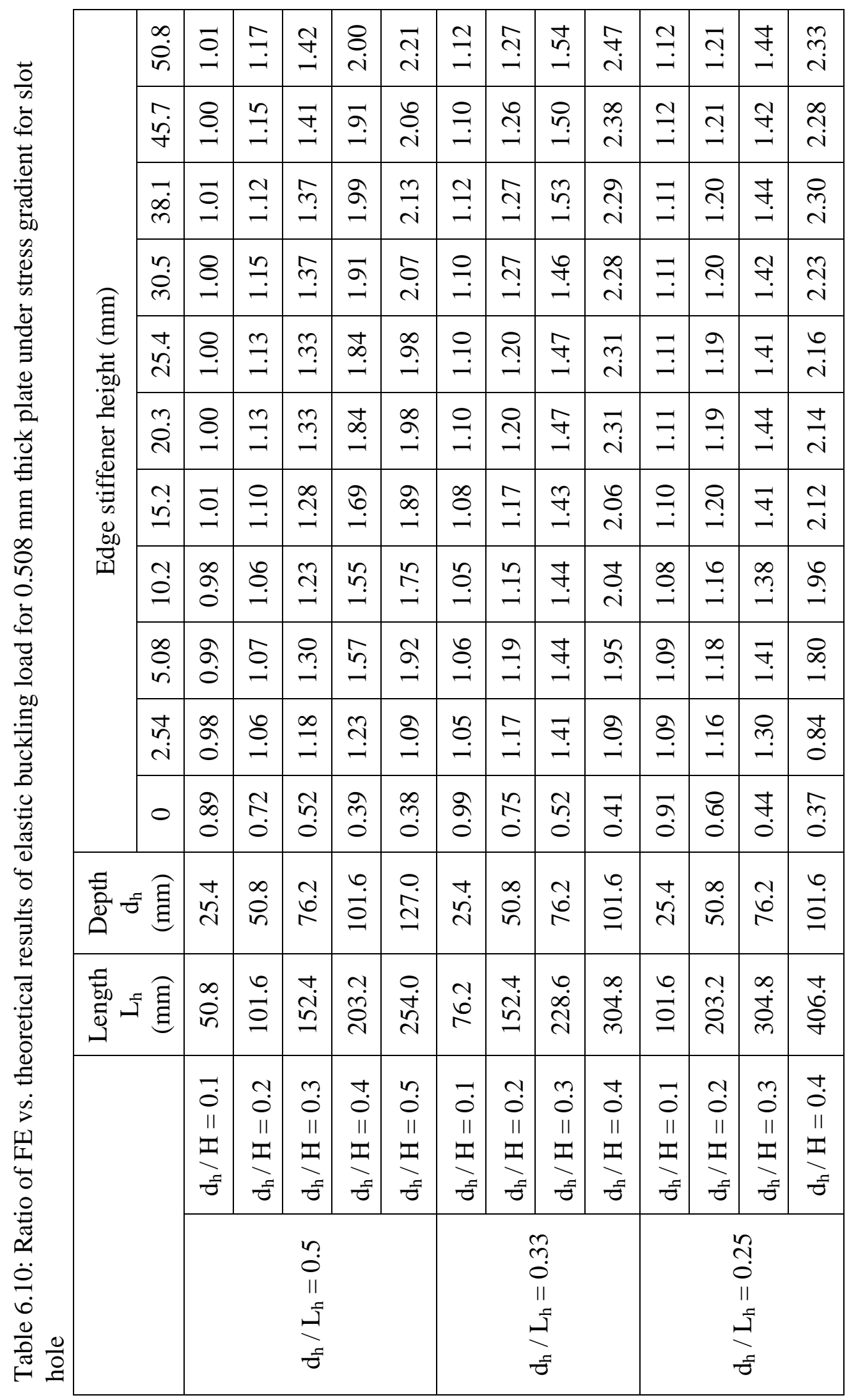




\begin{tabular}{|c|c|c|c|c|c|c|c|c|c|c|c|c|c|c|}
\hline \multirow{11}{*}{ 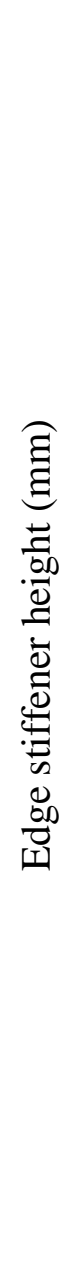 } & $\ddot{\circ}$ & 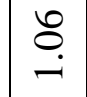 & $\stackrel{\vartheta}{\leftrightarrows}$ & $\stackrel{\mathscr{P}}{\rightarrow}$ & $\stackrel{\substack{\infty \\
-}}{-}$ & 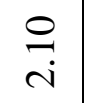 & $\stackrel{\infty}{\stackrel{\infty}{\rightarrow}}$ & $\stackrel{\vec{N}}{\unlhd}$ & $\stackrel{\mathcal{P}}{-}$ & $\underset{i}{\Delta}$ & $\stackrel{?}{\stackrel{1}{\rightarrow}}$ & $\exists$ & $\stackrel{\widehat{m}}{\rightarrow}$ & 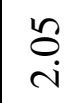 \\
\hline & $\ddot{q}$ & $\stackrel{\leftrightarrow}{\longrightarrow}$ & $\stackrel{9}{\leftrightarrows}$ & $\underset{\exists}{\exists}$ & $\underset{\sim}{\stackrel{\infty}{-}}$ & $\underset{i}{i}$ & $\stackrel{\infty}{\stackrel{\infty}{-}}$ & 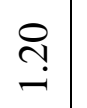 & $\stackrel{\mathcal{P}}{-}$ & 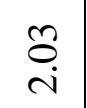 & $\stackrel{9}{\rightarrow}$ & 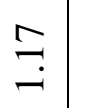 & $\stackrel{\hat{m}}{\rightarrow}$ & \\
\hline & $\vec{\infty}$ & 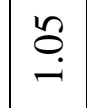 & $\stackrel{\infty}{\stackrel{\infty}{二}}$ & $\stackrel{\text { mे }}{.}$ & $\stackrel{0}{?}$ & $\overrightarrow{\vec{i}}$ & $\underset{-}{8}$ & $\stackrel{\infty}{\exists}$ & $\underset{I}{f}$ & $\stackrel{s}{s}$ & 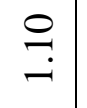 & $\exists$ & $\stackrel{m}{\rightarrow}$ & s. \\
\hline & ڤे & 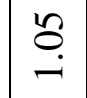 & 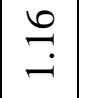 & $\stackrel{m}{g}$ & $\stackrel{?}{i}$ & $\stackrel{\infty}{\rightarrow}$ & $\underset{-}{0}$ & $\stackrel{\varrho}{ت}$ & $\underset{\stackrel{q}{i}}{-}$ & $\stackrel{\leftrightarrow}{\stackrel{s}{s}}$ & $\stackrel{\leftrightarrow}{\circ}$ & $\stackrel{0}{=}$ & 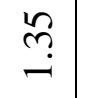 & $\stackrel{2}{\circ}$ \\
\hline & 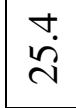 & $\stackrel{r}{0}$ & $\stackrel{2}{=}$ & $\stackrel{\oplus}{\rightarrow}$ & $\stackrel{\substack{\circ \\
-}}{.}$ & $\stackrel{5}{-}$ & 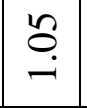 & $\stackrel{\varrho}{ت}$ & $\stackrel{q}{\stackrel{q}{i}}$ & $\stackrel{8}{-}$ & $\stackrel{\ominus}{\rightarrow}$ & $\stackrel{0}{=}$ & $\stackrel{\widehat{m}}{\rightarrow}$ & $\bar{\sigma}$ \\
\hline & 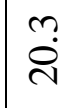 & 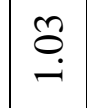 & $\stackrel{\oplus}{=}$ & $\stackrel{\oplus}{\rightarrow}$ & $\stackrel{\beta}{\stackrel{\beta}{0}}$ & $\stackrel{\widetilde{S}}{-}$ & $\underset{\rightarrow}{\stackrel{t}{t}}$ & $\stackrel{ \pm}{ \pm}$ & $\stackrel{\infty}{\stackrel{\infty}{\rightarrow}}$ & $\stackrel{+}{\infty}$ & $\stackrel{\infty}{\rightarrow}$ & $\stackrel{\curvearrowleft}{\longrightarrow}$ & $\stackrel{\stackrel{t}{m}}{\rightarrow}$ & $\stackrel{\infty}{\infty}$ \\
\hline & ֶี & $\stackrel{\overbrace{}}{\stackrel{O}{*}}$ & $\stackrel{9}{\leftrightarrows}$ & $\stackrel{\overbrace{}}{\unlhd}$ & $\stackrel{n}{n}$ & $\stackrel{ }{I}$ & 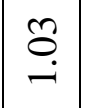 & $\stackrel{M}{ت}$ & $\stackrel{m}{m}$ & $\stackrel{\infty}{n}$ & $\stackrel{\infty}{\rightarrow}$ & $\stackrel{?}{=}$ & $\stackrel{m}{\rightarrow}$ & 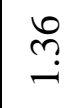 \\
\hline & $\stackrel{\sim}{\varrho}$ & 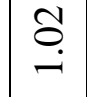 & 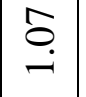 & $\stackrel{\widetilde{I}}{-}$ & 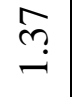 & $\stackrel{q}{g}$ & $\stackrel{\leftrightarrow}{\mathscr{O}}$ & $\exists$ & 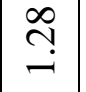 & $\stackrel{\infty}{\stackrel{-}{\rightarrow}}$ & 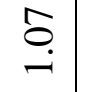 & $\stackrel{?}{\rightarrow}$ & $\stackrel{Э}{\varsubsetneqq}$ & $\begin{array}{l}\infty \\
\infty \\
\infty\end{array}$ \\
\hline & $\begin{array}{l}\infty \\
i \\
i\end{array}$ & $\underset{-}{\stackrel{8}{2}}$ & 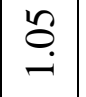 & $\begin{array}{l}\tilde{a} \\
o \\
o\end{array}$ & $\stackrel{\hat{\sigma}}{0}$ & 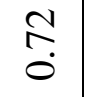 & $\underset{\sim}{\vec{\sigma}}$ & 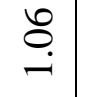 & $\begin{array}{l}\infty \\
\infty \\
0 \\
0\end{array}$ & $\begin{array}{l}\vec{b} \\
\dot{0}\end{array}$ & $\stackrel{\overbrace{}}{\leftrightarrow}$ & $\hat{o}$ & : & $\stackrel{g}{G}$ \\
\hline & 点 & oे & $\bar{\sigma}$ & $\stackrel{\hat{N}}{\hat{0}}$ & in & $\hat{n}$ & $\underset{-}{8}$ & $\stackrel{8}{8}$ & $\begin{array}{l}0 \\
0 \\
0\end{array}$ & f & 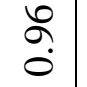 & $\overrightarrow{0}$ & $\vec{n}$ & $\begin{array}{l}7 \\
0\end{array}$ \\
\hline & 0 & $\hat{a}$ & \begin{tabular}{c}
$\mathscr{D}$ \\
\hdashline \\
0
\end{tabular} & हैं & fof & 䊝 & $\mid \begin{array}{l}\infty \\
\stackrel{0}{0}\end{array}$ & $\stackrel{R}{\circ}$ & \begin{tabular}{l}
\multirow{2}{n}{} \\
0
\end{tabular} & $\stackrel{\mathfrak{f}}{0}$ & $\vec{\sigma}$ & $\begin{array}{l}\overrightarrow{0} \\
0\end{array}$ & 售 & $\stackrel{\infty}{\stackrel{\infty}{0}}$ \\
\hline & & 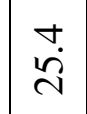 & $\begin{array}{l}\infty \\
\dot{0} \\
\dot{n}\end{array} \mid$ & $\begin{array}{l}\text { ָூ } \\
\curvearrowright\end{array}$ & $\begin{array}{l}\stackrel{0}{\dot{\Xi}} \\
\stackrel{0}{0}\end{array}$ & 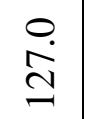 & 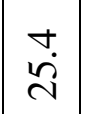 & $\begin{array}{l}\infty \\
\stackrel{i}{i}\end{array}$ & ְ̊ & $\begin{array}{l}0 \\
\dot{0} \\
0\end{array}$ & $\begin{array}{l}\dot{\vec{u}} \\
\ddot{i}\end{array}$ & $\begin{array}{l}\infty \\
\stackrel{0}{0} \\
\dot{n}\end{array}$ & ત్ֶ & $\begin{array}{l}0 \\
\dot{0}\end{array}$ \\
\hline & & 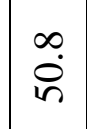 & $\mid \begin{array}{l}0 \\
\dot{0} \\
\stackrel{0}{2}\end{array}$ & 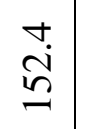 & 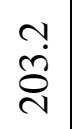 & $\begin{array}{l}0 \\
\dot{d} \\
\text { in }\end{array}$ & ڤ̊ & 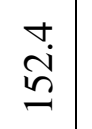 & $\begin{array}{l}0 \\
0 \\
0 \\
\vec{d}\end{array}$ & $\begin{array}{l}\infty \\
\stackrel{d}{\dot{d}} \\
\text { d }\end{array}$ & $\begin{array}{l}\dot{0} \\
\dot{\vec{D}}\end{array}$ & 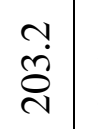 & $\left|\begin{array}{l}\infty \\
\dot{0} \\
\dot{d}\end{array}\right|$ & $\begin{array}{l}\vec{t} \\
\dot{\sigma}\end{array}$ \\
\hline & & $\begin{array}{l}\overrightarrow{0} \\
\text { II } \\
\underline{I} \\
\vec{t}\end{array}$ & 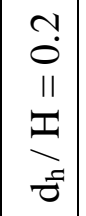 & 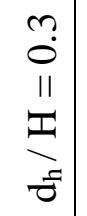 & 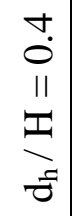 & 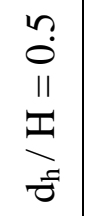 & 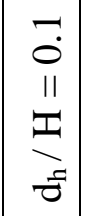 & 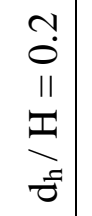 & 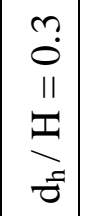 & 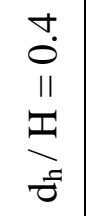 & 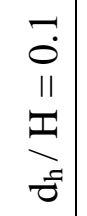 & 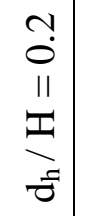 & 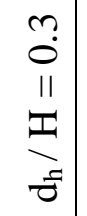 & 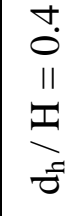 \\
\hline & & & & 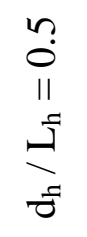 & & & & $t$ & & & & تf & $\begin{array}{l}11 \\
\text { If } \\
\text { Ef } \\
\text { fon }\end{array}$ & \\
\hline
\end{tabular}




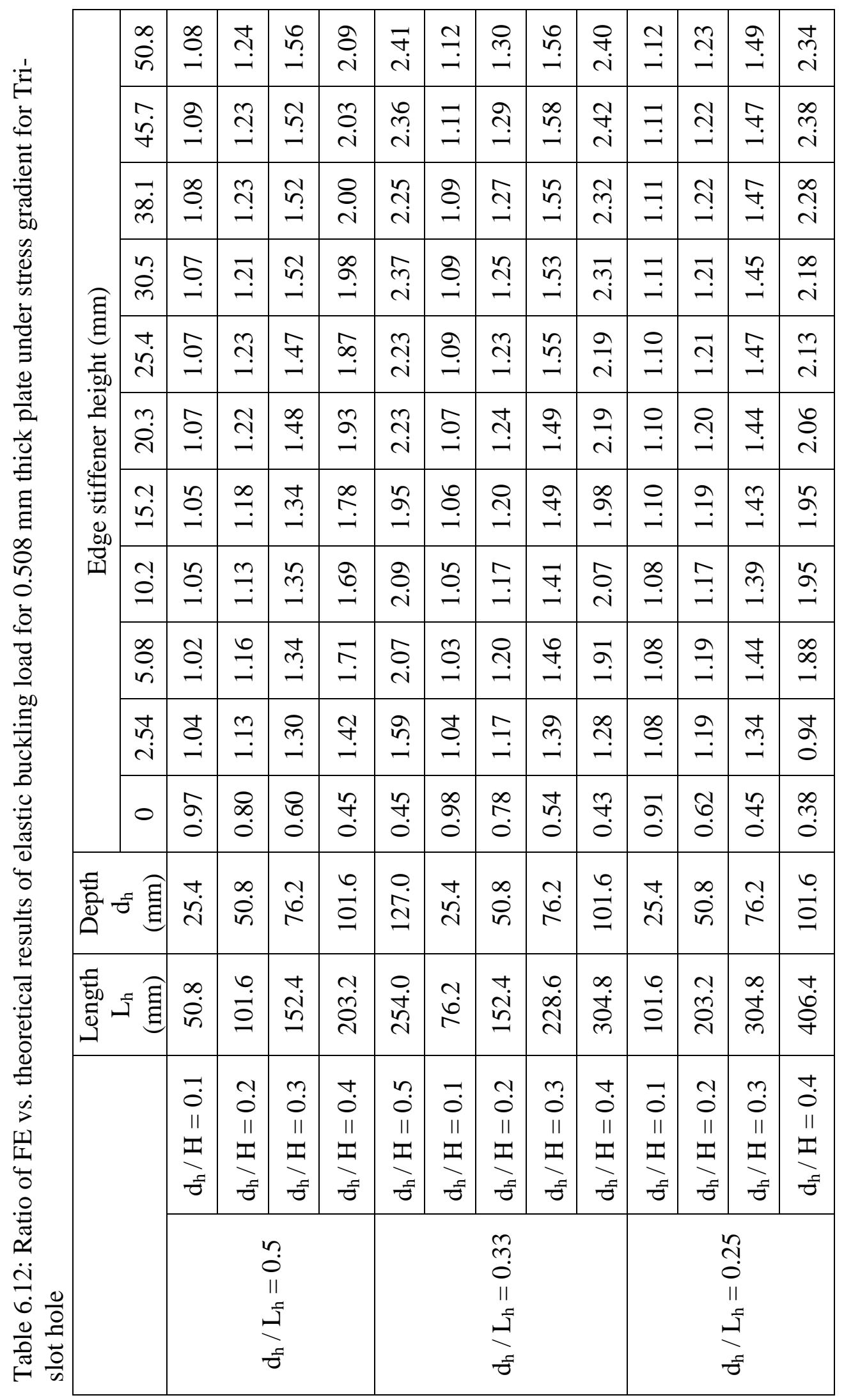




\subsection{ELASTIC BUCKLING OF COLD-FORMED STEEL FLEXURAL MEMBERS WITH STIFFENED HOLES}

From the previous section it was concluded that the stiffened hole increase the elastic buckling load as we increase the hole size and edge stiffener. In this section the elastic buckling analysis is presented on the cold formed steel joist with stiffened hole, and finds the optimized size of hole and spacing between the holes.

Figure 6.14, 6.15, and 6.16 shows the finite element model for the elastic buckling analysis for circular, slot, and tri-slot holes. Like the plate buckling analysis the sharp corner are adopted in the finite element model. The S4R shell element is selected for the model and element size is set to $12.7 \times 12.7 \mathrm{~mm}$ for $\mathrm{C}$-section and $25 \times 25 \mathrm{~mm}$ mesh size for iSPAN joist. The material properties are the same as used for the plate buckling analysis. The joist is simply supported at both ends. To generate uniform moment along the joist length the stress gradient is applied to both ends of the joist. For C-section the optimised size of hole and spacing between holes is already done by Yu. (Yu, 2011). For iSPAN joist two sections were selected namely: 254-i-2 and 254-i-3 joists (from Table 6.20). The parameters considered in this study are the (i) ratio of the hole size to the web depth $\left(\mathrm{d}_{\mathrm{h}} / \mathrm{h}\right)$ which varies from 0.2 to 0.6 , (ii) the ratio of the edge stiffener length vs. the web height $(\mathrm{q} / \mathrm{h})$ which was taken as 0.06 , as concluded in the previous section, and (iii) the hole clear spacing which varies from $0.5 \mathrm{~h}$ to $3 \mathrm{~h}$. The joist length was taken $6.10 \mathrm{~m}$ for all models.

A total of 192 joist arrangements were analyzed and comparison was made between the joist with no holes and joist with stiffened circular, slot, and tri-slot holes in term of the elastic buckling moments of the lateral torsional mode and first localized mode. The results are tabulated in table 6.13 through 6.18 . The results show that the stiffened hole does not have the significant effect on the lateral torsional buckling moment of the joist. From table 6.13 we can see that there is a $5 \%$ increase in the case of circular holes when $d_{h} / H$ ratio is equal to 0.5 . Similarly the hole spacing also has the little effect on the lateral torsional moment. The table 6.13 shows that as we increase the hole spacing there is a reduction in the lateral torsional buckling. Similarly for the local buckling moment, the results from table 6.13 to table 6.16 shows that the 
stiffened holes has a significant effect on the local buckling moment, and its increase as the holes size getting bigger, and the increase in moment is up to $11 \%$ as shown in table 6.13 . The tables also show that holes spacing has the effect on the local buckling moment as in the case of lateral buckling moment. The joist has the maximum local buckling moment when the clear hole spacing is 0.5 , and the moment getting decrease as the clear holes spacing is up to $3 \mathrm{~h}$. The failure mode in the iSPAN joist without hole, the joist failed in local buckling of web and local buckling of flange as shown in Figure 6.17(b). When the stiffed holes are introduced in the web, the web becomes stiff, and the lower top flange becomes the weak area to buckle first as shown in Figure 6.18(b). It is of importance to enforce the local buckling to be the failure mode so that the joists with edge stiffened holes will exercise its maximum advantages.

In summary the stiffened holes has effect on both lateral and local buckling moment. It is proposed that the maximum hole depth be the half of the web height, and the clear spacing between holes should not be more than half of the web height.

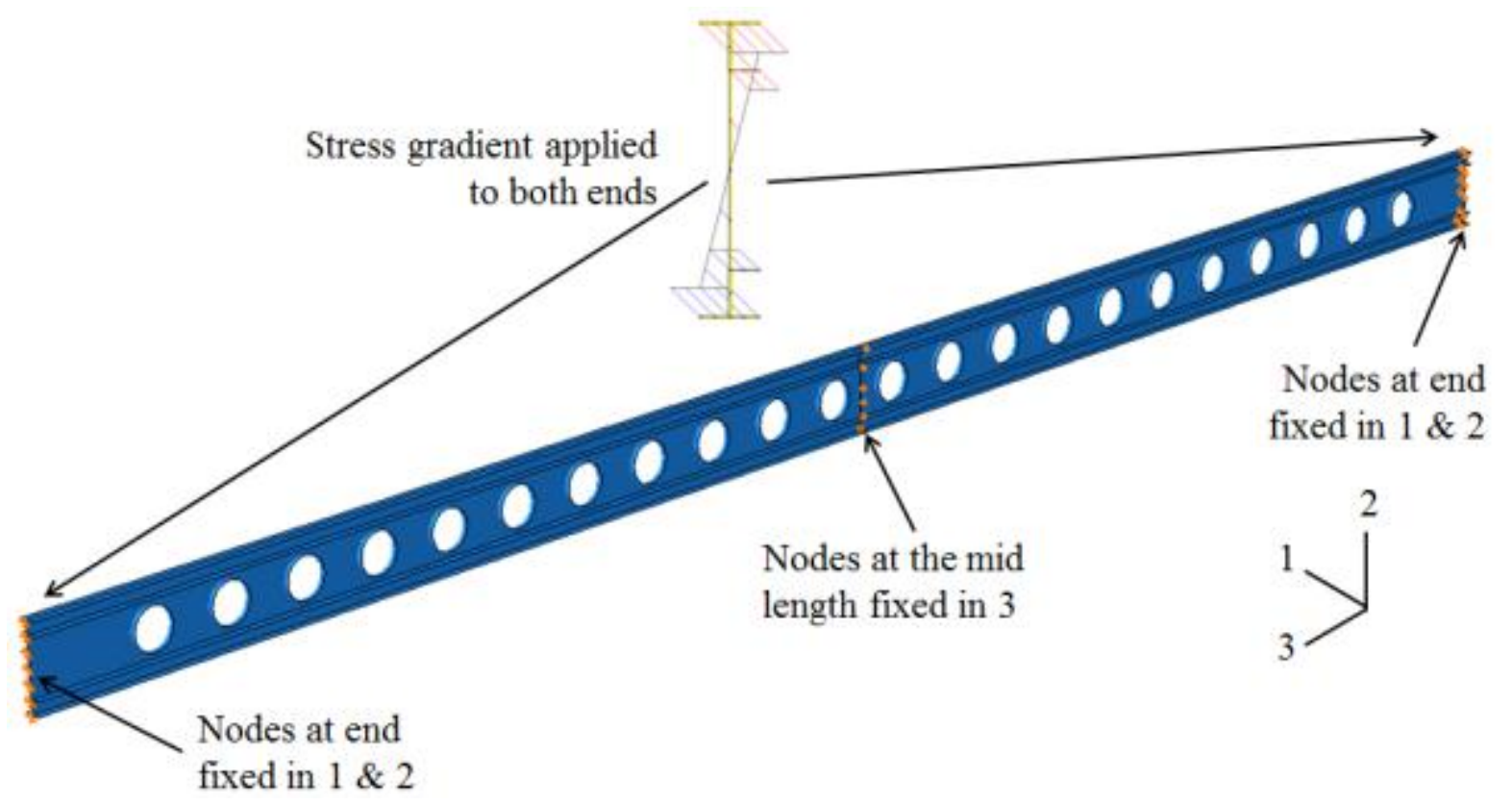

Figure 6.14: FE model for elastic buckling analysis on joist with circular holes 


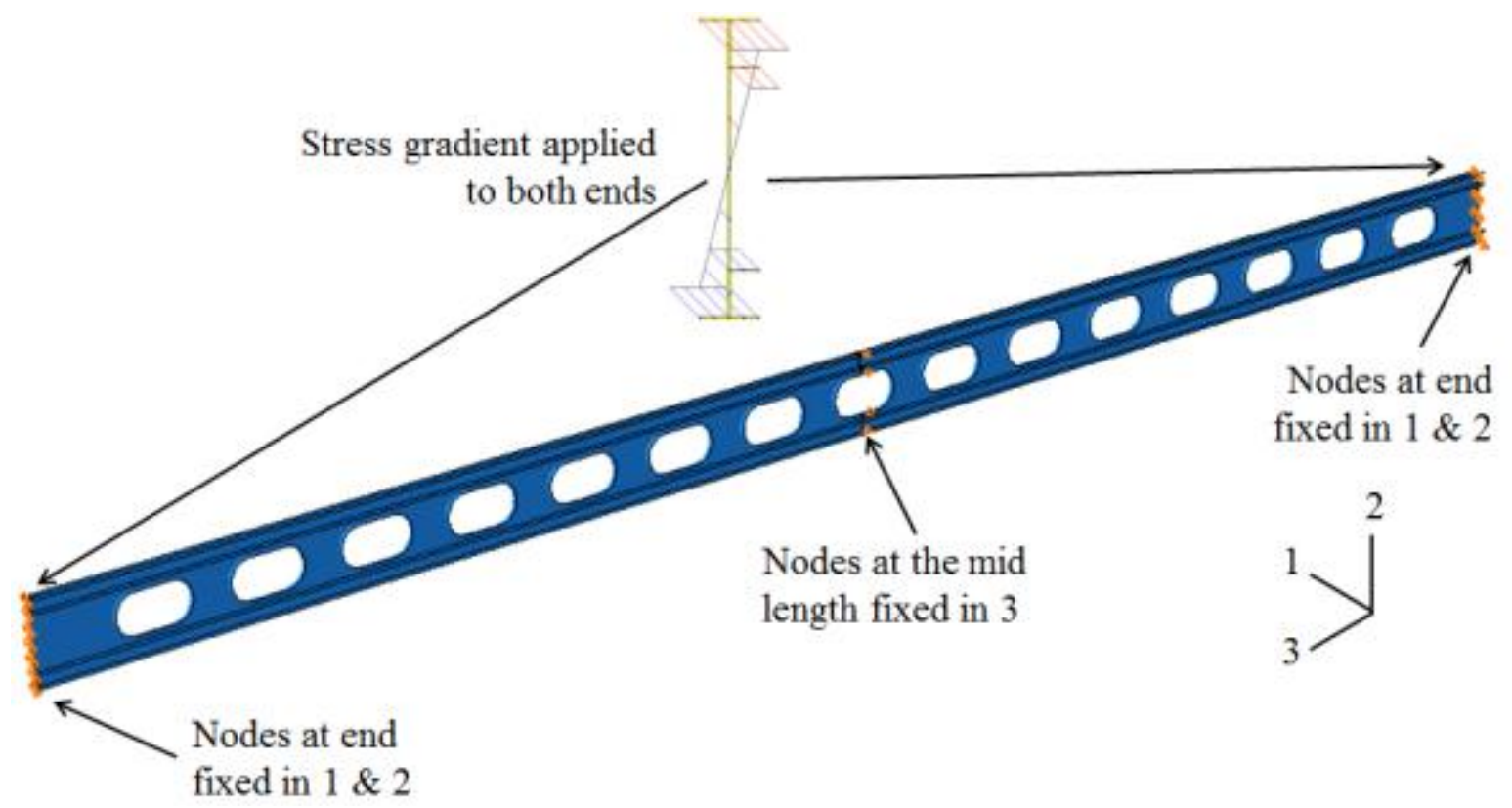

Figure 6.15: FE model for elastic buckling analysis on joist with slot holes

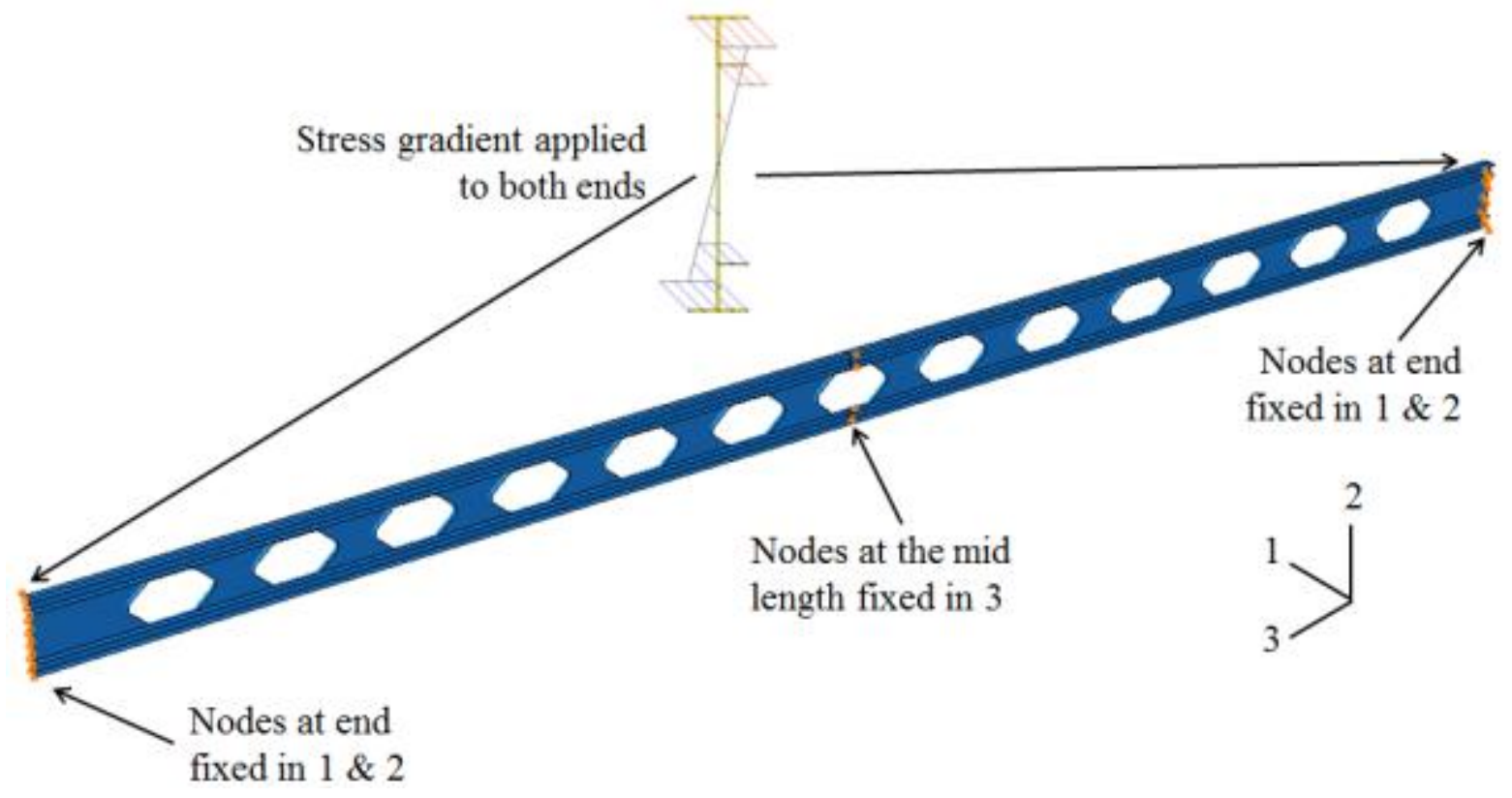

Figure 6.16: FE model for elastic buckling analysis on joist with Tri-slot holes 


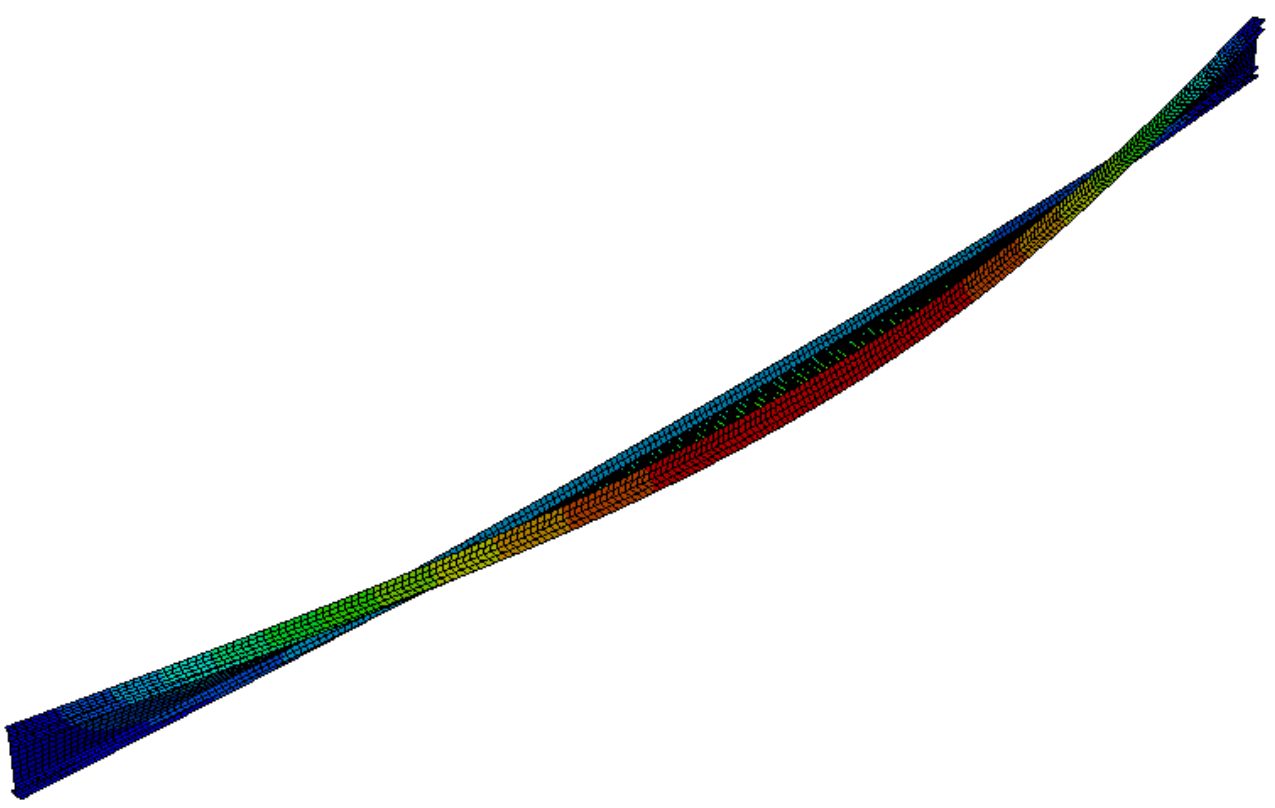

(a) View of lateral torsional mode for joist without holes

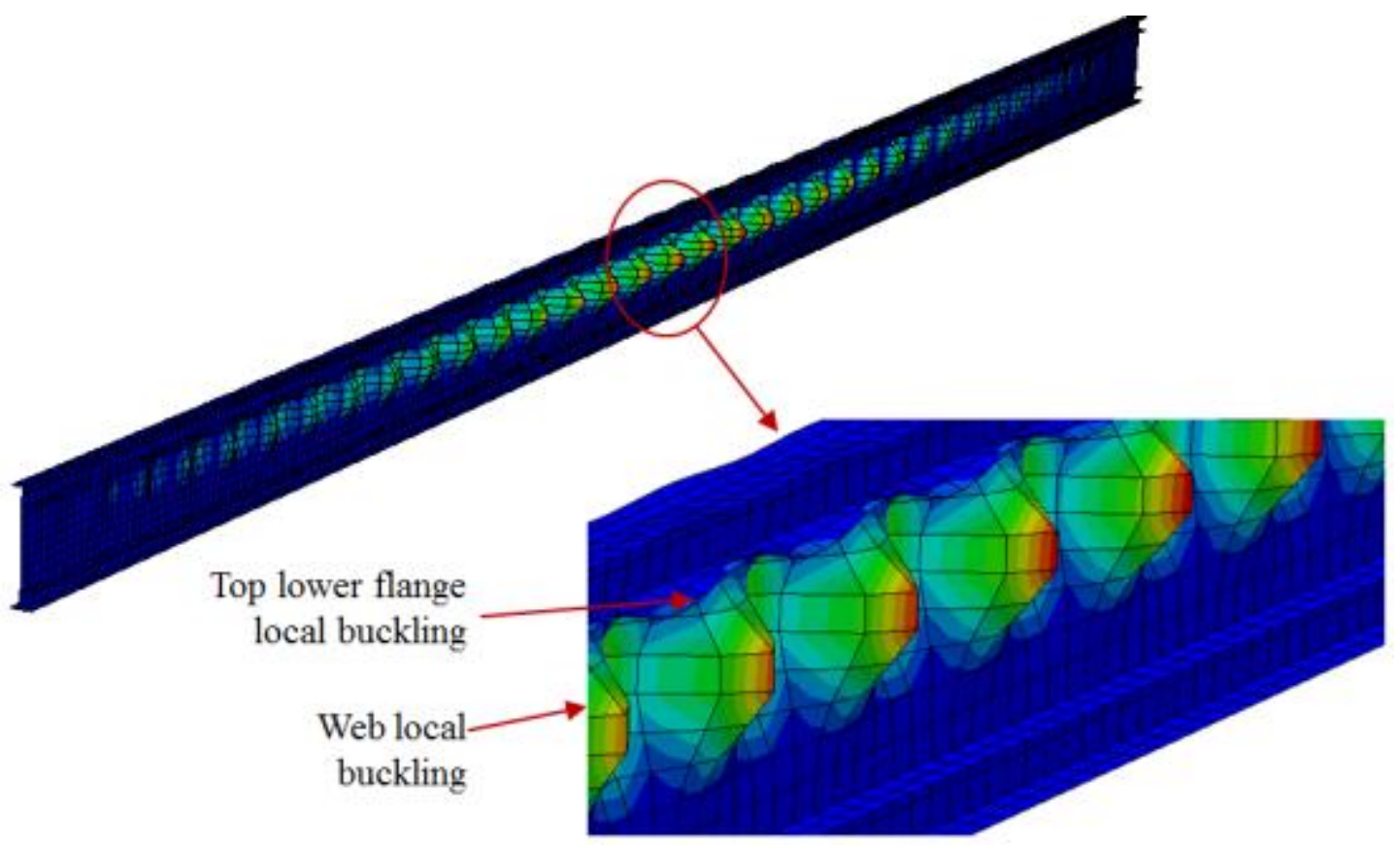

(b) First localized buckling mode without holes

Figure 6.17: Views of elastic bulking shapes for 254-i-2 joists without holes 


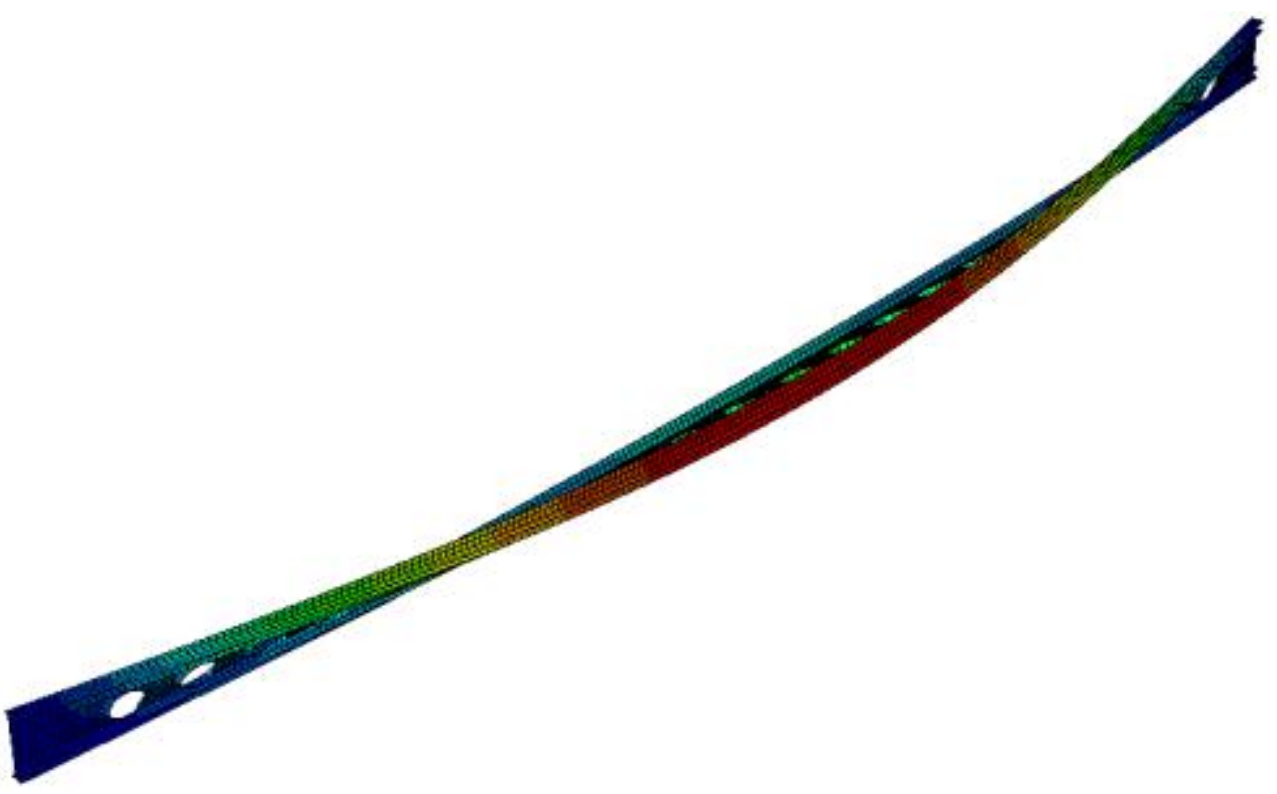

(a) View of lateral torsional mode for joist with holes

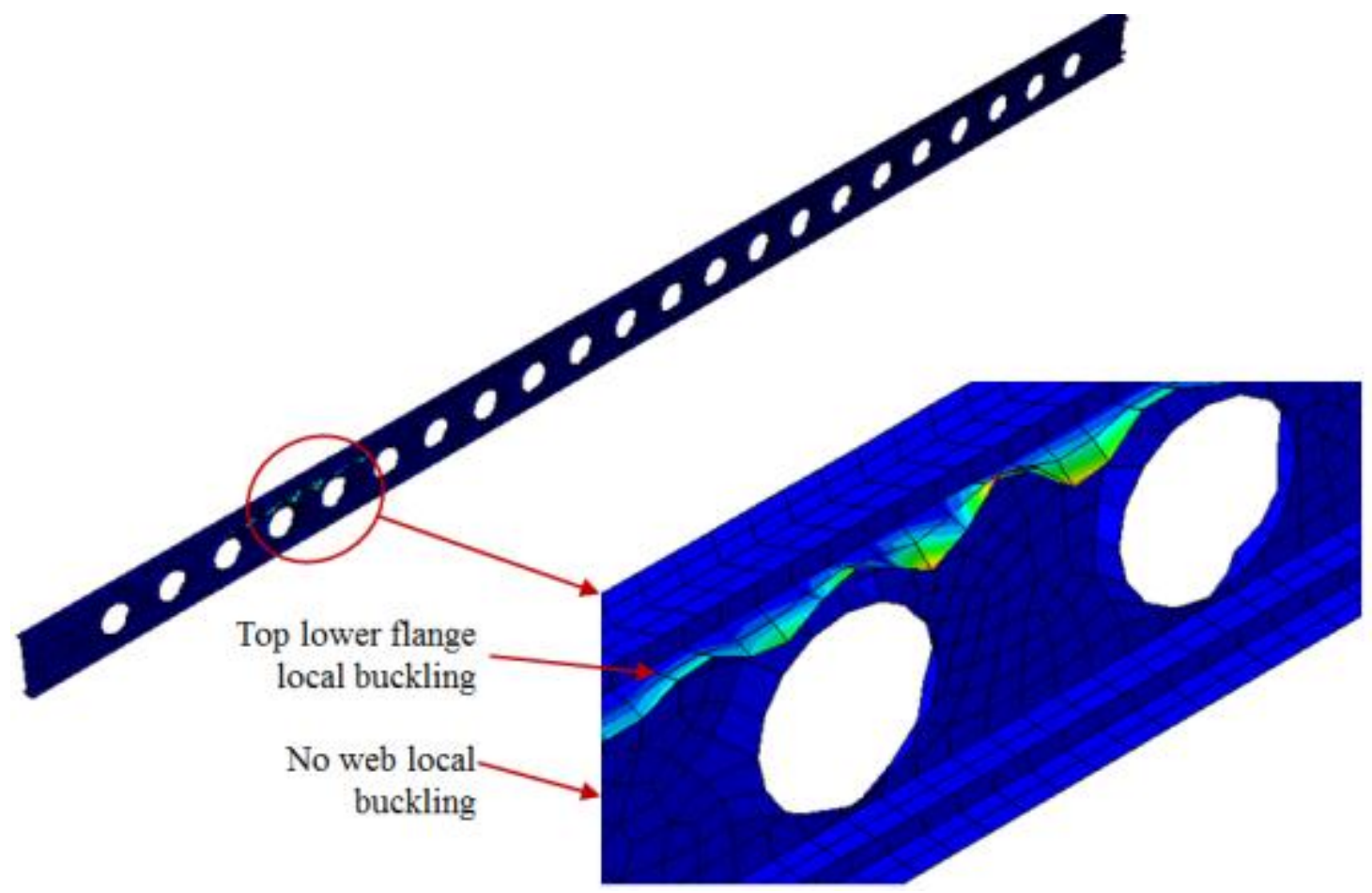

(b) $1^{\text {st }}$ localized buckling mode without holes

Figure 6.18: Views of elastic bulking shapes for 254-i-2 joists with holes 
Table 6.13: Ratio of elastic buckling moment of iSPAN 254-i-2 joist with circular holes vs. no holes

\begin{tabular}{|c|c|c|c|c|c|c|c|c|c|}
\hline \multirow[t]{3}{*}{$\mathrm{q} / \mathrm{h}$} & \multirow{3}{*}{$\begin{array}{l}\text { Holes clear } \\
\text { spacing } \\
(\mathrm{mm})\end{array}$} & \multicolumn{4}{|c|}{ Lateral torsional buckling } & \multicolumn{4}{|c|}{ Local buckling } \\
\hline & & \multicolumn{4}{|c|}{$\mathrm{d}_{\mathrm{h}} / \mathrm{H}$} & \multicolumn{4}{|c|}{$\mathrm{d}_{\mathrm{h}} / \mathrm{H}$} \\
\hline & & 0.20 & 0.40 & 0.50 & 0.60 & 0.20 & 0.40 & 0.50 & 0.60 \\
\hline \multirow{4}{*}{0.06} & $0.5 \mathrm{~h}=127$ & 1.01 & 1.05 & 1.05 & 1.05 & 1.01 & 1.06 & 1.10 & 1.11 \\
\hline & $1.0 \mathrm{~h}=254$ & 1.01 & 1.02 & 1.05 & 1.04 & 1.00 & 1.04 & 1.07 & 1.09 \\
\hline & $2.0 \mathrm{~h}=508$ & 1.00 & 1.03 & 1.03 & 1.03 & 1.00 & 1.03 & 1.05 & 1.08 \\
\hline & $3.0 \mathrm{~h}=762$ & 1.00 & 1.01 & 1.01 & 1.01 & 1.00 & 1.01 & 1.03 & 1.04 \\
\hline
\end{tabular}

Table 6.14: Ratio of elastic buckling moment of iSPAN 254-i-3 joist with circular holes vs. no holes

\begin{tabular}{|c|c|c|c|c|c|c|c|c|c|}
\hline \multirow{2}{*}{$\mathrm{q} / \mathrm{h}$} & $\begin{array}{c}\text { Holes clear } \\
\text { spacing } \\
(\mathrm{mm})\end{array}$ & \multicolumn{3}{|c|}{ Lateral torsional buckling } & \multicolumn{5}{c|}{ Local buckling } \\
\hline \multirow{6}{*}{} & & \multicolumn{3}{|c|}{$\mathrm{d}_{\mathrm{h}} / \mathrm{H}$} & \multicolumn{4}{c|}{$\mathrm{d}_{\mathrm{h}} / \mathrm{H}$} \\
\cline { 3 - 11 } & 0.20 & 0.40 & 0.50 & 0.60 & 0.20 & 0.40 & 0.50 & 0.60 \\
\hline \multirow{5}{*}{0.06} & $0.5 \mathrm{~h}=127$ & 1.01 & 1.04 & 1.04 & 1.04 & 1.01 & 1.06 & 1.09 & 1.11 \\
\cline { 2 - 11 } & $1.0 \mathrm{~h}=254$ & 1.01 & 1.02 & 1.04 & 1.04 & 1.00 & 1.04 & 1.07 & 1.08 \\
\cline { 2 - 10 } & $2.0 \mathrm{~h}=508$ & 1.00 & 1.02 & 1.03 & 1.02 & 1.00 & 1.02 & 1.04 & 1.05 \\
\cline { 2 - 10 } & $3.0 \mathrm{~h}=762$ & 1.00 & 1.01 & 1.02 & 1.01 & 1.00 & 1.02 & 1.03 & 1.04 \\
\hline
\end{tabular}


Table 6.15: Ratio of elastic buckling moment of iSPAN 254-i-2 joist with slot holes vs. no holes

\begin{tabular}{|c|c|c|c|c|c|c|c|c|c|}
\hline \multirow{2}{*}{$\mathrm{q} / \mathrm{h}$} & $\begin{array}{c}\text { Holes clear } \\
\text { spacing } \\
(\mathrm{mm})\end{array}$ & \multicolumn{3}{|c|}{ Lateral torsional buckling } & \multicolumn{5}{c|}{ Local buckling } \\
\hline \multirow{4}{*}{} & & \multicolumn{4}{|c|}{$\mathrm{d}_{\mathrm{h}} / \mathrm{H}$} & \multicolumn{5}{c|}{$\mathrm{d}_{\mathrm{h}} / \mathrm{H}$} \\
\cline { 3 - 11 } & & 0.20 & 0.40 & 0.50 & 0.60 & 0.20 & 0.40 & 0.50 & 0.60 \\
\hline \multirow{4}{*}{0.06} & $0.5 \mathrm{~h}=127$ & 1.01 & 1.06 & 1.04 & 1.03 & 1.01 & 1.07 & 1.09 & 1.10 \\
\cline { 2 - 10 } & $1.0 \mathrm{~h}=254$ & 1.00 & 1.03 & 1.03 & 1.02 & 1.01 & 1.04 & 1.06 & 1.08 \\
\cline { 2 - 10 } & $2.0 \mathrm{~h}=508$ & 1.00 & 1.02 & 1.02 & 1.01 & 1.01 & 1.02 & 1.04 & 1.05 \\
\cline { 2 - 10 } & $3.0 \mathrm{~h}=762$ & 1.00 & 1.02 & 1.02 & 1.01 & 1.00 & 1.02 & 1.03 & 1.04 \\
\hline
\end{tabular}

Table 6.16: Ratio of elastic buckling moment of iSPAN 254-i-3 joist with slot holes vs. no holes

\begin{tabular}{|c|c|c|c|c|c|c|c|c|c|}
\hline \multirow{2}{*}{$\mathrm{q} / \mathrm{h}$} & $\begin{array}{c}\text { Holes clear } \\
\text { spacing } \\
(\mathrm{mm})\end{array}$ & \multicolumn{3}{|c|}{ Lateral torsional buckling } & \multicolumn{5}{c|}{ Local buckling } \\
\hline \multirow{6}{*}{} & & \multicolumn{4}{|c|}{$\mathrm{d}_{\mathrm{h}} / \mathrm{H}$} & \multicolumn{5}{c|}{$\mathrm{d}_{\mathrm{h}} / \mathrm{H}$} \\
\cline { 3 - 11 } & & 0.20 & 0.40 & 0.50 & 0.60 & 0.20 & 0.40 & 0.50 & 0.60 \\
\hline \multirow{4}{*}{0.06} & $0.5 \mathrm{~h}=127$ & 1.01 & 1.05 & 1.04 & 1.02 & 1.02 & 1.07 & 1.08 & 1.08 \\
\cline { 2 - 11 } & $1.0 \mathrm{~h}=254$ & 1.01 & 1.02 & 1.02 & 1.01 & 1.01 & 1.04 & 1.06 & 1.07 \\
\cline { 2 - 10 } & $2.0 \mathrm{~h}=508$ & 1.00 & 1.01 & 1.02 & 1.01 & 1.01 & 1.03 & 1.04 & 1.05 \\
\cline { 2 - 10 } & $3.0 \mathrm{~h}=762$ & 1.00 & 1.01 & 1.01 & 1.01 & 1.00 & 1.02 & 1.03 & 1.03 \\
\hline
\end{tabular}


Table 6.17: Ratio of elastic buckling moment of iSPAN 254-i-2 joist with Tri-slot holes vs. no holes

\begin{tabular}{|c|c|c|c|c|c|c|c|c|c|}
\hline \multirow[t]{3}{*}{$\mathrm{q} / \mathrm{h}$} & $\begin{array}{l}\text { Holes clear } \\
\text { spacing }\end{array}$ & \multicolumn{4}{|c|}{ Lateral torsional buckling } & \multicolumn{4}{|c|}{ Local buckling } \\
\hline & & \multicolumn{4}{|c|}{$\mathrm{d}_{\mathrm{h}} / \mathrm{H}$} & \multicolumn{4}{|c|}{$\mathrm{d}_{\mathrm{h}} / \mathrm{H}$} \\
\hline & & 0.20 & 0.40 & 0.50 & 0.60 & 0.20 & 0.40 & 0.50 & 0.60 \\
\hline \multirow{4}{*}{0.06} & $0.5 \mathrm{~h}=127$ & 1.01 & 1.04 & 1.05 & 1.05 & 1.01 & 1.06 & 1.09 & 1.09 \\
\hline & $1.0 \mathrm{~h}=254$ & 1.01 & 1.01 & 1.04 & 1.03 & 1.01 & 1.04 & 1.07 & 1.07 \\
\hline & $2.0 \mathrm{~h}=508$ & 1.00 & 1.01 & 1.03 & 1.03 & 1.01 & 1.02 & 1.05 & 1.05 \\
\hline & $3.0 \mathrm{~h}=762$ & 1.00 & 1.00 & 1.03 & 1.01 & 1.00 & 1.02 & 1.03 & 1.03 \\
\hline
\end{tabular}

Table 6.18: Ratio of elastic buckling moment of iSPAN 254-i-3 joist with Tri-slot holes vs. no holes

\begin{tabular}{|c|c|c|c|c|c|c|c|c|c|}
\hline \multirow[t]{3}{*}{$\mathrm{q} / \mathrm{h}$} & $\begin{array}{l}\text { Holes clear } \\
\text { spacing }\end{array}$ & \multicolumn{4}{|c|}{ Lateral torsional buckling } & \multicolumn{4}{|c|}{ Local buckling } \\
\hline & & \multicolumn{4}{|c|}{$\mathrm{d}_{\mathrm{h}} / \mathrm{H}$} & \multicolumn{4}{|c|}{$\mathrm{d}_{\mathrm{h}} / \mathrm{H}$} \\
\hline & & 0.20 & 0.40 & 0.50 & 0.60 & 0.20 & 0.40 & 0.50 & 0.60 \\
\hline \multirow{4}{*}{0.06} & $0.5 \mathrm{~h}=127$ & 1.01 & 1.04 & 1.04 & 1.04 & 1.02 & 1.06 & 1.08 & 1.08 \\
\hline & $1.0 \mathrm{~h}=254$ & 1.01 & 1.01 & 1.03 & 1.02 & 1.01 & 1.04 & 1.06 & 1.06 \\
\hline & $2.0 \mathrm{~h}=508$ & 1.01 & 1.01 & 1.02 & 1.02 & 1.01 & 1.03 & 1.04 & 1.05 \\
\hline & $3.0 \mathrm{~h}=762$ & 1.01 & 1.01 & 1.02 & 1.01 & 1.00 & 1.02 & 1.04 & 1.03 \\
\hline
\end{tabular}




\subsection{FLEXURAL STRENGTH OF COLD-FORMED STEEL JOISTS WITH STIFFENED HOLES}

Using the FE modelling, the optimized dimensions for the stiffened holes were developed in the previous section by elastic buckling analyses. This section was to determine the flexural strength of the CFS C-section and iSPAN joists with the optimized stiffened holes. The finite element non-linear post-buckling analysis was used to simulate the behaviour of the cold-formed steel subjected to typical loading and boundary conditions. Figures 6.19, 6.20, 6.21 shows the postbuckling FE model for iSPAN joists with different types of holes, which simulates a typical four point bending test. The $6.10 \mathrm{~m}$ long joist was selected for this study. The joist was simply supported at both ends, and the load was applied at 1/3 of the joist length. As in actual practice the top flange of the joist is attached to sub-floor and fasteners are at every $305 \mathrm{~mm}$ apart. To simulate this top flange of joist was laterally retrain at every $305 \mathrm{~mm}$ apart as shown in figure 6.19 to 6.21 . to simulate the simply supported condition one bottom end of the joist was restrained in direction 1,2, and 3, while the bottom end of the joist was fixed the in the direction 1 and 2. To restrain the web crippling in the joist the both ends of web was fixed in direction 2. Similarly in actual practice there are bracing attached to the joist at every $2.03 \mathrm{~m}$, to simulate this the bottom flange of the joist was fixed in direction 1 at $1 / 3$ of the joist length. Same element type and meshing was used as in the case of elastic buckling analysis. The exact postbuckling problem often cannot be analysed directly due to the discontinuous response at the point of buckling. To analysis a post-buckling problem, one must turn into a problem with continuous response instead of bifurcation, which can be accomplished by introducing a geometric pattern in the perfect geometry so that there is some response in the buckling mode before the critical load is reached. So the geometric imperfection is introduced in the joist. As mentioned above the lateral torsional buckling mode was restricted, so the first local buckling mode was introduced in the post-buckling analysis that was obtained from the elastic buckling analysis. The magnitude of the initial geometric imperfection was set to be 0.5 times of the material thickness.

The post-buckling analysis was done for both the C-section and iSPAN joist, with and without the stiffened holes. Table 6.19 and 6.20 list the geometric and yield stresses of the studied joist. The notations used to define the dimension are shown in figure 6.3. The results of post-buckling analysis for C-section and iSPAN joist are tabulated in table 6.21 through 6.26. Finite element 
results showed that four normal joists (without web holes) failed in local buckling, and the rest four joists failed in distortional buckling. The flexural strengths of the C-section normal joists obtained by the FE model agreed with the predictions by the Direct Strength Method (DSM, Appendix 1 of CSA-S136-07). The average FE vs. predicted ratio was 1.034 with a standard deviation of 0.051 for $\mathrm{C}$-section with circular stiffened hole as depicted in Table 6.21 (Yu, 2011). In the current study, finite element results showed that the average FE vs. predicted ratio is 1.031 with a standard deviation of 0.044 for $\mathrm{C}$-section with slot, and tri-slot stiffened holes as shown in Tables 6.22 and 6.23, respectively. Also, FE results showed that the average FE vs. predicted ratio was 1.056 with a standard deviation of 0.057 for the iSPAN joist with circular, slot, and tri-slot stiffened hole as shown in Tables 6.24, 6.25 and 6.26, respectively. When the optimized circular stiffened holes were formed on the web of the identical normal $\mathrm{C}$-joists, the flexural strength increased by an average of $12.9 \%$ (i.e. $\mathrm{M}_{\mathrm{feH}} / \mathrm{M}_{\mathrm{feN}}$ in Table 6.21) (Yu, 2011). Similarly, for the C-section with slot and tri-slot hole, the flexural strength increased by an average of $9 \%$, and $6 \%$, as depicted in Tables 6.22 and 6.23, respectively. The results showed that circular stiffened hole gives better performance than the slot and tri-slot hole. For the iSPAN joists, FE results showed that holes have no effects on the increase of the strength because of the shape of the joist. With stiffening the holes, the web of the joist is stiffened but the top lower flange of the joist appeared to be the weak area, so local buckling failure was observed to occur first in the top lower flange of the joist as shown in the Figure 6.22. Failure modes observed using the FEA modeling of other joists are reported in Appendix G.

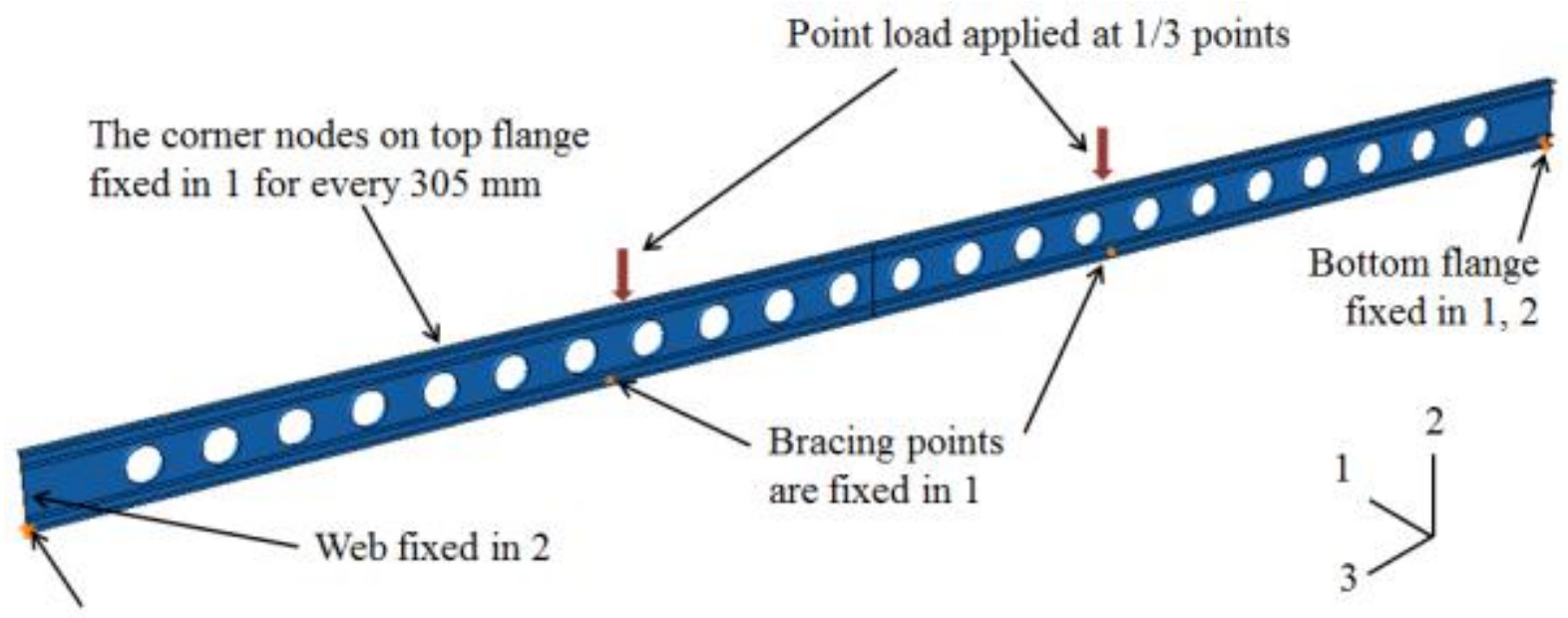

Bottom flange

fixed in $1,2,3$

Figure 6.19: FE model for post buckling analysis on joist with stiffened hole 


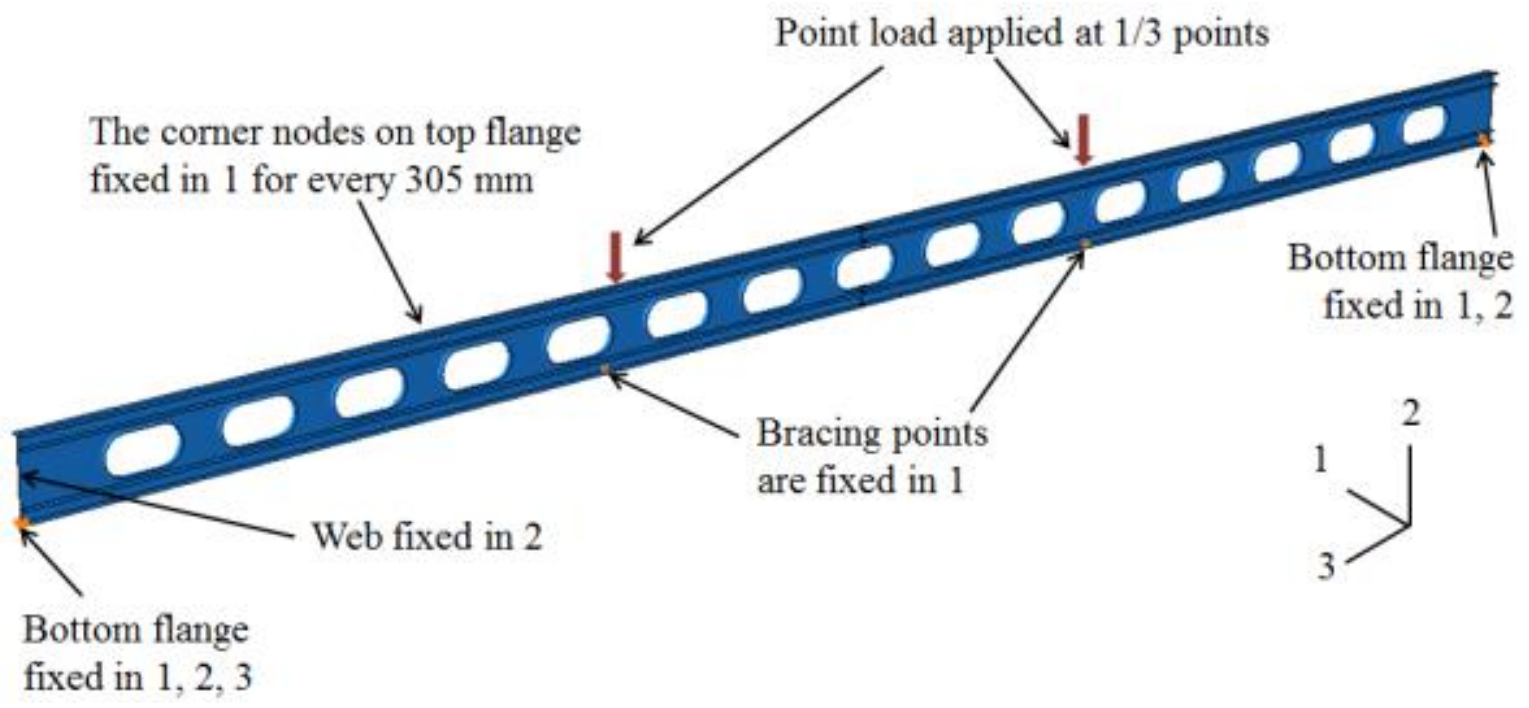

Figure 6.20: FE model for post buckling analysis on joist with stiffened hole

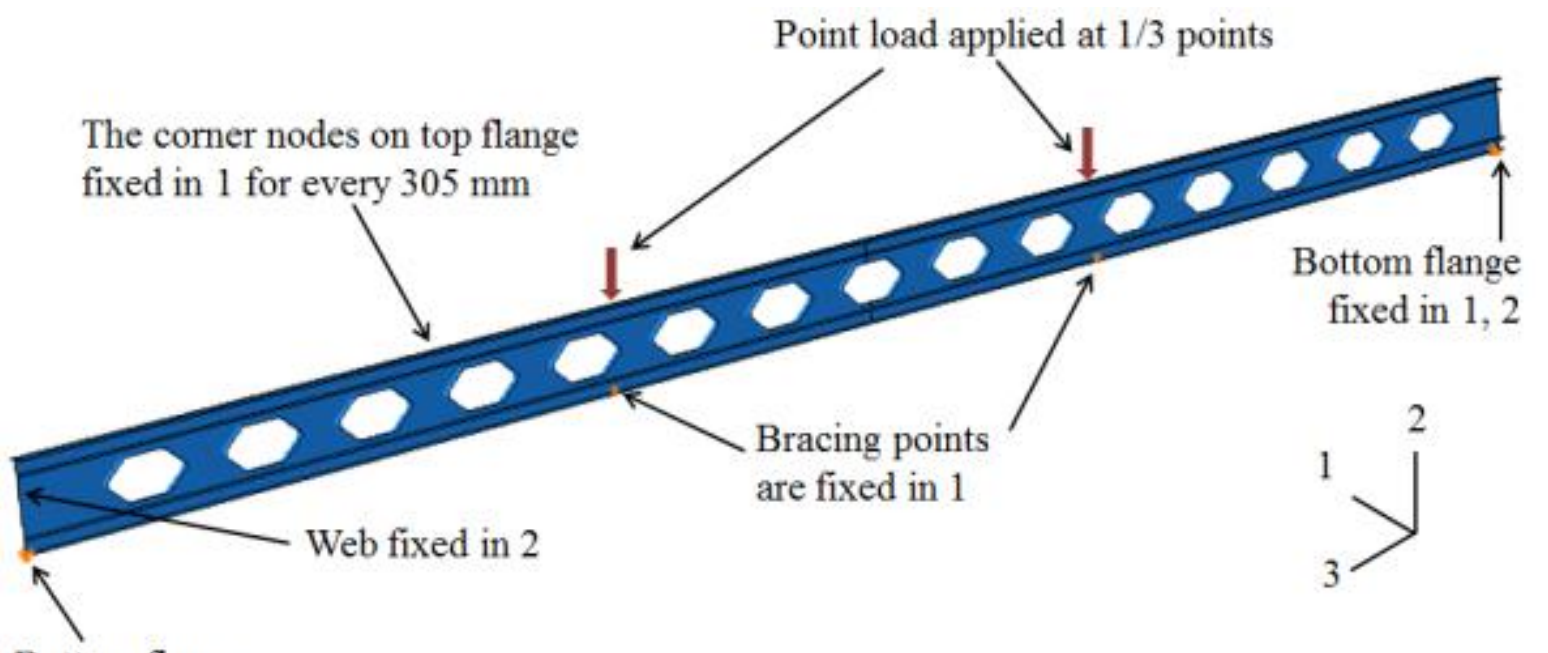

Bottom flange

fixed in $1,2,3$

Figure 6.21: FE model for post buckling analysis on joist with stiffened hole 
Table 6.19: Geometric and yield stress of the C-section (adopted from $\mathrm{Yu}, 2011$ )*

\begin{tabular}{|c|c|c|c|c|c|c|c|c|}
\hline Member & $\begin{array}{c}\mathrm{h} \\
(\mathrm{mm})\end{array}$ & $\begin{array}{c}\mathrm{b}_{\mathrm{f}} \\
(\mathrm{mm})\end{array}$ & $\begin{array}{c}\mathrm{d}_{1} \\
(\mathrm{~mm})\end{array}$ & $\begin{array}{c}\mathrm{t} \\
(\mathrm{mm})\end{array}$ & $\begin{array}{c}\mathrm{r} \\
(\mathrm{mm})\end{array}$ & $\begin{array}{c}\mathrm{d}_{2} \\
(\mathrm{~mm})\end{array}$ & $\begin{array}{c}\mathrm{q} \\
(\mathrm{mm})\end{array}$ & $\begin{array}{c}\mathrm{F}_{\mathrm{y}} \\
(\mathrm{Mpa})\end{array}$ \\
\hline $600 \mathrm{~S} 162-33$ & 152.4 & 41.3 & 12.7 & 0.8788 & 2.82 & 76.2 & 9.1 & 228 \\
\hline $600 \mathrm{~S} 250-97$ & 152.4 & 63.5 & 15.9 & 2.5832 & 6.45 & 76.2 & 9.1 & 345 \\
\hline $800 \mathrm{~S} 162-33$ & 203.2 & 41.3 & 12.7 & 0.8788 & 2.82 & 101.6 & 12.2 & 228 \\
\hline $800 \mathrm{~S} 250-97$ & 203.2 & 63.5 & 15.9 & 2.5832 & 6.45 & 101.6 & 12.2 & 345 \\
\hline $1000 \mathrm{~S} 162-43$ & 254.0 & 41.3 & 12.7 & 1.1455 & 2.95 & 127.0 & 15.2 & 228 \\
\hline $1000 \mathrm{~S} 250-97$ & 254.0 & 63.5 & 15.9 & 2.5832 & 6.45 & 127.0 & 15.2 & 345 \\
\hline $1200 \mathrm{~S} 162-54$ & 304.8 & 41.5 & 12.7 & 1.4376 & 3.61 & 152.4 & 18.3 & 228 \\
\hline $1200 \mathrm{~S} 250-97$ & 304.8 & 63.5 & 15.9 & 2.5832 & 6.45 & 152.4 & 18.3 & 345 \\
\hline
\end{tabular}

* See Figure 6.3. for symbols

Table 6.20: Geometric and yield stress of the "iSPAN joist" section*

\begin{tabular}{|c|c|c|c|c|c|c|c|}
\hline Member & $\begin{array}{c}\mathrm{h} \\
(\mathrm{mm})\end{array}$ & $\begin{array}{c}\mathrm{b}_{\mathrm{f}} \\
(\mathrm{mm})\end{array}$ & $\begin{array}{c}\mathrm{d}_{1} \\
(\mathrm{~mm})\end{array}$ & $\begin{array}{c}\mathrm{t} \\
(\mathrm{mm})\end{array}$ & $\begin{array}{c}\mathrm{d}_{2} \\
(\mathrm{~mm})\end{array}$ & $\begin{array}{c}\mathrm{q} \\
(\mathrm{mm})\end{array}$ & $\begin{array}{c}\mathrm{F}_{\mathrm{y}} \\
(\mathrm{Mpa})\end{array}$ \\
\hline $254-\mathrm{i}-2$ & 254 & 50 & 40 & 1.2 & 127 & 20 & 350 \\
\hline $254-\mathrm{i}-3$ & 254 & 50 & 40 & 1.65 & 127 & 20 & 350 \\
\hline $305-\mathrm{i}-2$ & 305 & 50 & 40 & 1.2 & 152 & 20 & 350 \\
\hline $305-\mathrm{i}-3$ & 305 & 50 & 40 & 1.65 & 152 & 20 & 350 \\
\hline $355-\mathrm{i}-3$ & 355 & 50 & 40 & 1.65 & 177 & 20 & 350 \\
\hline $355-\mathrm{i}-4$ & 355 & 50 & 40 & 2.1 & 177 & 20 & 350 \\
\hline $406-\mathrm{i}-3$ & 406 & 50 & 40 & 2.1 & 203 & 20 & 350 \\
\hline $406-\mathrm{i}-4$ & 406 & 50 & 40 & 2.4 & 203 & 20 & 350 \\
\hline
\end{tabular}

* See Figure 6.3. for symbols 
$\mathrm{S}$, Mises

SNEG, $($ fraction $=-1.0$ )

(Avg: 75\%)

$-351.61$

322.45

293.29

264.12

234.96

205.80

176.64

147.47

118.31

89.15

59.99

30.82

1.66

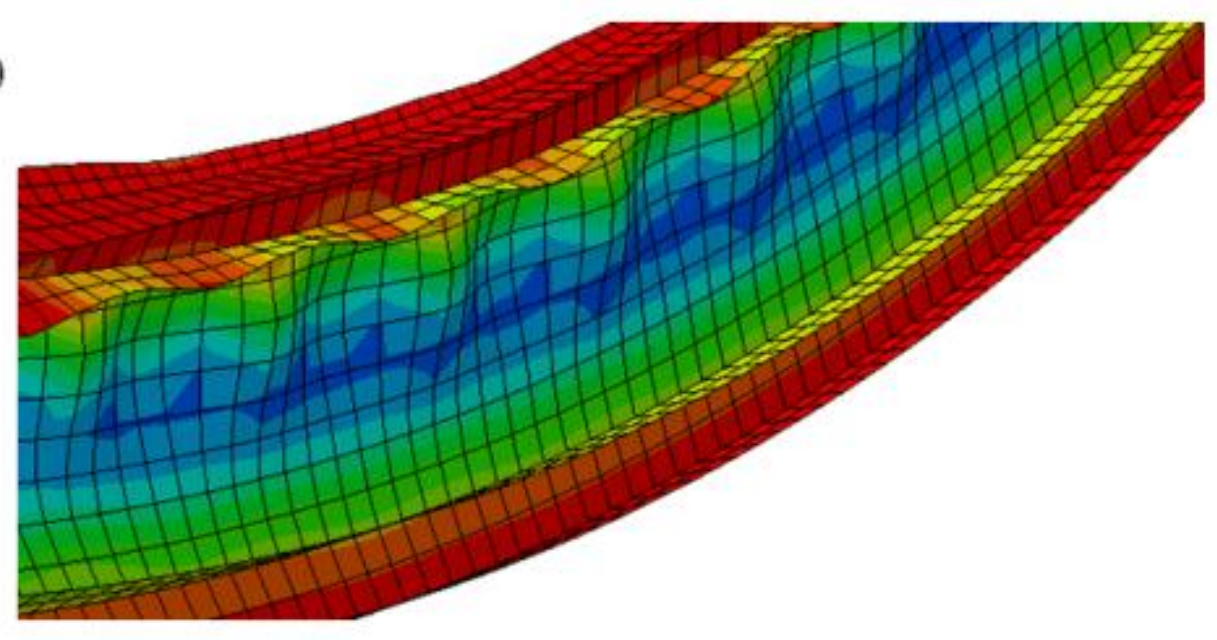

(a) View of a joist failed in local buckling of web and top lower flange

$\mathrm{S}$, Mises

SNEG, $($ fraction $=-1.0$ )

(Avg: 75\%)
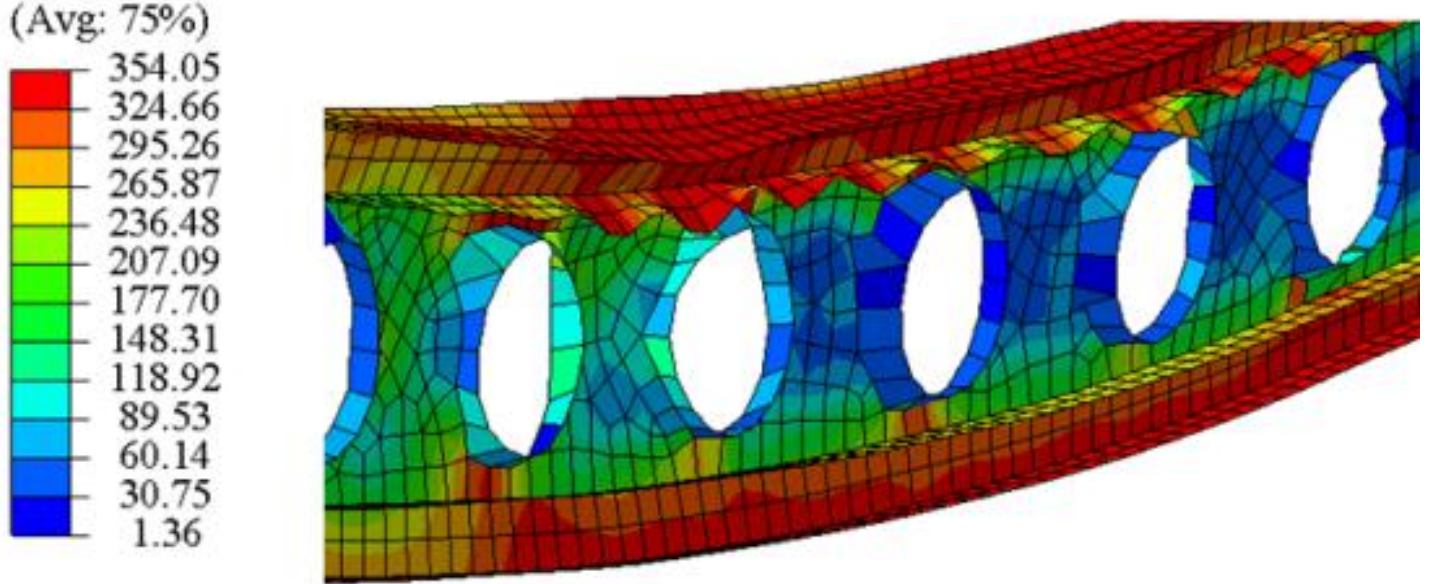

(b) View of a joist with stiffened hole failed in the local buckling of top lower flange

Figure 6.22: Failure modes of 254-i-2 joist without hole and with holes 
Table 6.21: C-section with circular hole (adopted from Yu, 2011)

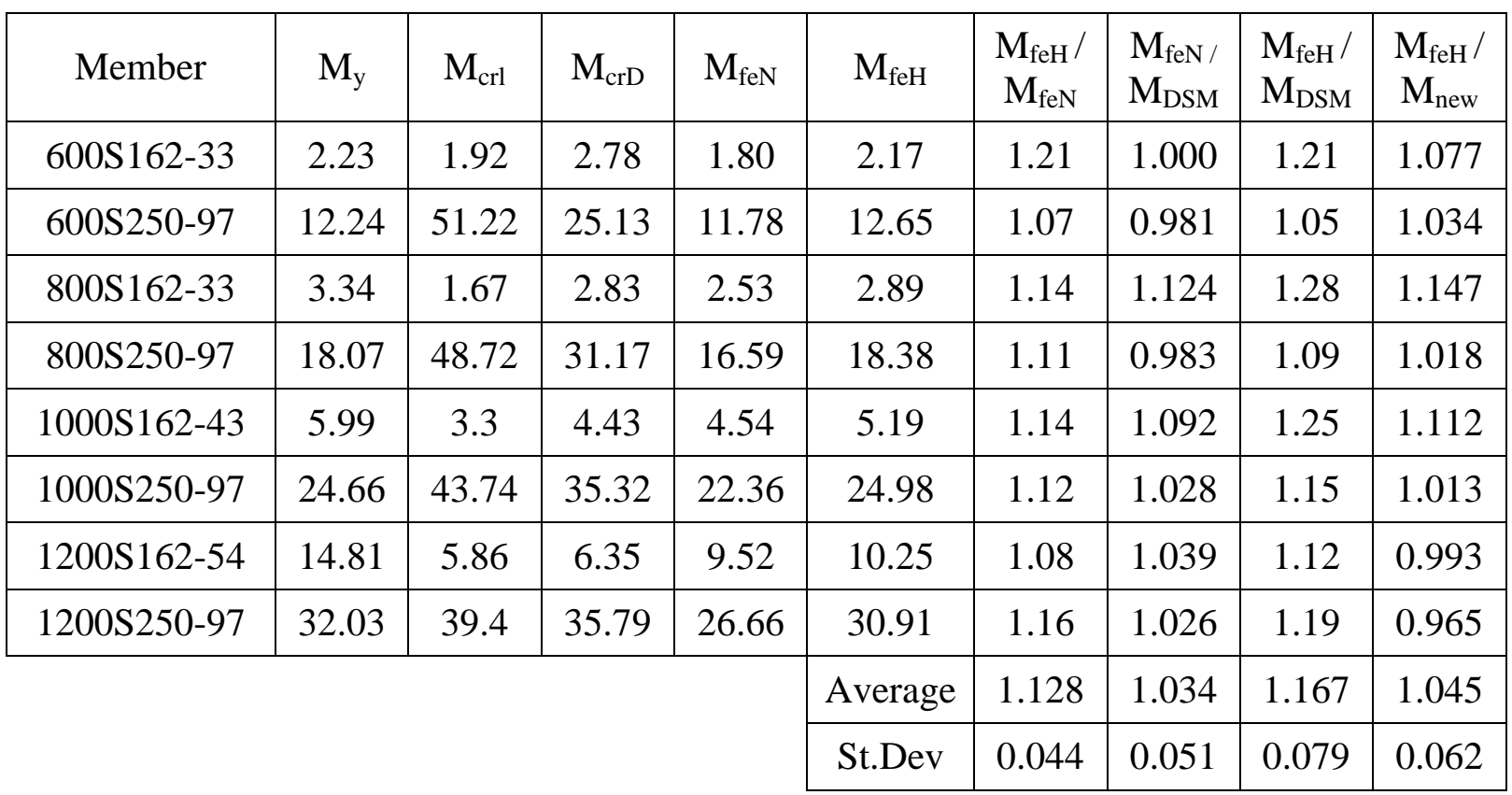

Notes: $\mathrm{M}_{\mathrm{y}}=$ resisting yield moment, $\mathrm{M}_{\mathrm{crl}}=$ elastic local buckling moment using elastic buckling analysis software, $\mathrm{M}_{\mathrm{crD}}=$ elastic distortional buckling moment using elastic buckling analysis software; $\mathrm{M}_{\mathrm{feN}}=$ flexural strength of normal joists resisting moment obtained from FEA modeling for joist without hole, $\mathrm{M}_{\mathrm{feH}}=$ flexural strength of joists resisting moment obtained from FEA modeling for joist with stiffened holes, $\mathrm{M}_{\mathrm{DSM}}=$ resisting moment based on Direct Strength Method, $\mathrm{M}_{\text {new }}=$ flexural strength by the proposed design method for joists with stiffened holes . 
Table 6.22: C-section with Slotted hole

\begin{tabular}{|c|c|c|c|c|c|c|c|c|c|}
\hline Member & $\mathrm{M}_{\mathrm{y}}$ & $\mathrm{M}_{\mathrm{crl}}$ & $\mathrm{M}_{\mathrm{crD}}$ & $\mathrm{M}_{\mathrm{feN}}$ & $\mathrm{M}_{\mathrm{feH}}$ & $\begin{array}{c}\mathrm{M}_{\mathrm{feH}} / \\
\mathrm{M}_{\mathrm{feN}}\end{array}$ & $\begin{array}{c}\mathrm{M}_{\mathrm{feN}} / \\
\mathrm{M}_{\mathrm{DSM}}\end{array}$ & $\begin{array}{c}\mathrm{M}_{\mathrm{feH}} / \\
\mathrm{M}_{\mathrm{DSM}}\end{array}$ & $\begin{array}{c}\mathrm{M}_{\mathrm{feH}} / \\
\mathrm{M}_{\text {new }}\end{array}$ \\
\hline $600 \mathrm{~S} 162-33$ & 2.26 & 1.88 & 2.71 & 1.83 & 2.10 & 1.15 & 1.01 & 1.16 & 1.06 \\
\hline $600 \mathrm{~S} 250-97$ & 13.56 & 48.81 & 25.76 & 12.93 & 13.66 & 1.06 & 0.99 & 1.05 & 1.01 \\
\hline $800 \mathrm{~S} 162-33$ & 3.34 & 1.67 & 2.67 & 2.70 & 2.65 & 0.98 & 1.21 & 1.18 & 1.08 \\
\hline $800 \mathrm{~S} 250-97$ & 18.50 & 49.43 & 32.43 & 18.11 & 18.76 & 1.04 & 0.99 & 1.03 & 1.01 \\
\hline $1000 \mathrm{~S} 162-43$ & 6.10 & 3.48 & 4.58 & 4.51 & 5.28 & 1.17 & 1.06 & 1.24 & 1.13 \\
\hline $1000 \mathrm{~S} 250-97$ & 24.20 & 43.22 & 35.84 & 22.59 & 24.36 & 1.08 & 1.01 & 1.09 & 1.01 \\
\hline $1200 \mathrm{~S} 162-54$ & 14.69 & 5.88 & 6.46 & 9.14 & 10.11 & 1.11 & 1.10 & 1.22 & 1.02 \\
\hline $1200 \mathrm{~S} 250-97$ & 31.4 & 38.3 & 33.9 & 27.00 & 30.86 & 1.14 & 1.02 & 1.17 & 0.99 \\
\hline
\end{tabular}

Table 6.23: C-section with Tri-slot hole

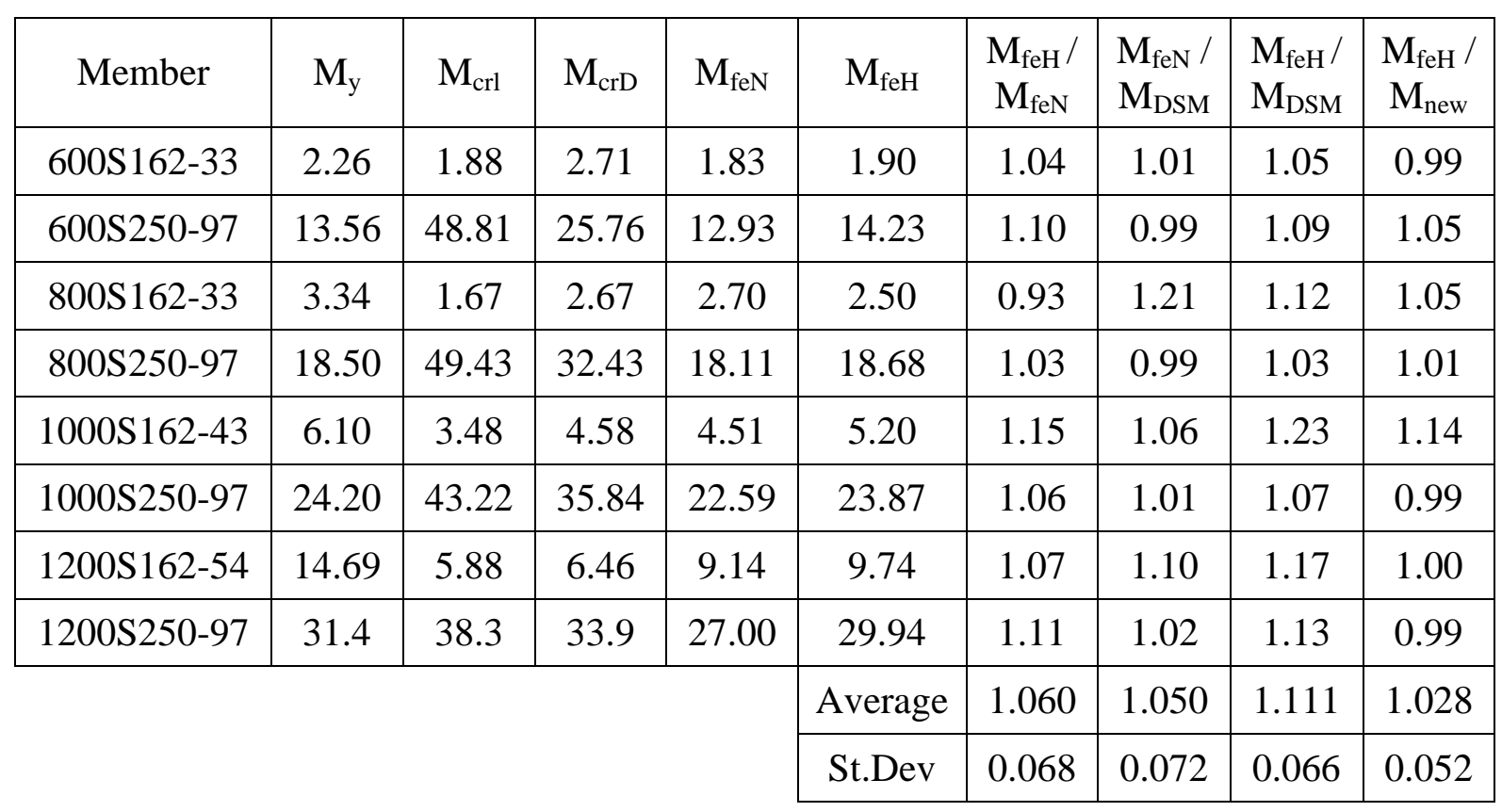


Table 6.24: iSPAN section with circular hole

\begin{tabular}{|c|c|c|c|c|c|c|c|c|c|}
\hline Member & $\mathrm{M}_{\mathrm{y}}$ & $\mathrm{M}_{\mathrm{crl}}$ & $\mathrm{M}_{\mathrm{crD}}$ & $\mathrm{M}_{\mathrm{feN}}$ & $\mathrm{M}_{\mathrm{feH}}$ & $\begin{array}{c}\mathrm{M}_{\mathrm{feH}} / \\
\mathrm{M}_{\mathrm{feN}}\end{array}$ & $\begin{array}{c}\mathrm{M}_{\mathrm{feN}} / \\
\mathrm{M}_{\mathrm{DSM}}\end{array}$ & $\begin{array}{c}\mathrm{M}_{\mathrm{feH}} / \\
\mathrm{M}_{\mathrm{DSM}}\end{array}$ & $\begin{array}{c}\mathrm{M}_{\mathrm{feH}} / \\
\mathrm{M}_{\mathrm{new}}\end{array}$ \\
\hline $254-\mathrm{i}-2$ & 18.78 & 28.17 & 23.10 & 19.29 & 19.52 & 1.01 & 1.23 & 1.24 & 1.04 \\
\hline $254-\mathrm{i}-3$ & 25.84 & 38.76 & 31.80 & 27.49 & 27.20 & 0.99 & 1.27 & 1.26 & 1.05 \\
\hline $305-\mathrm{i}-2$ & 24.00 & 19.69 & 24.25 & 21.96 & 22.53 & 1.03 & 1.17 & 1.20 & 1.12 \\
\hline $305-\mathrm{i}-3$ & 33.05 & 27.10 & 33.38 & 32.07 & 33.84 & 1.06 & 1.24 & 1.31 & 1.02 \\
\hline $355-\mathrm{i}-3$ & 40.78 & 39.55 & 39.96 & 38.51 & 38.27 & 0.99 & 1.22 & 1.21 & 1.06 \\
\hline $355-\mathrm{i}-4$ & 51.80 & 80.24 & 55.91 & 50.34 & 52.98 & 1.05 & 1.21 & 1.28 & 1.02 \\
\hline $406-\mathrm{i}-3$ & 62.14 & 65.25 & 58.41 & 54.20 & 54.30 & 1.00 & 1.14 & 1.15 & 0.97 \\
\hline $406-\mathrm{i}-4$ & 70.77 & 94.83 & 70.06 & 70.04 & 72.40 & 1.03 & 1.27 & 1.32 & 1.05 \\
\hline & & & & & & & & &
\end{tabular}

Table 6.25: iSPAN section with slotted hole

\begin{tabular}{|c|c|c|c|c|c|c|c|c|c|}
\hline Member & $\mathrm{M}_{\mathrm{y}}$ & $\mathrm{M}_{\mathrm{crl}}$ & $\mathrm{M}_{\mathrm{crD}}$ & $\mathrm{M}_{\mathrm{feN}}$ & $\mathrm{M}_{\mathrm{feH}}$ & $\begin{array}{c}\mathrm{M}_{\mathrm{feH}} / \\
\mathrm{M}_{\mathrm{feN}}\end{array}$ & $\begin{array}{c}\mathrm{M}_{\mathrm{feN}} / \\
\mathrm{M}_{\mathrm{DSM}}\end{array}$ & $\begin{array}{c}\mathrm{M}_{\mathrm{feH}} / \\
\mathrm{M}_{\mathrm{DSM}}\end{array}$ & $\begin{array}{c}\mathrm{M}_{\mathrm{feH}} / \\
\mathrm{M}_{\mathrm{new}}\end{array}$ \\
\hline $254-\mathrm{i}-2$ & 18.78 & 28.17 & 23.10 & 19.29 & 18.49 & 0.96 & 1.23 & 1.17 & 0.98 \\
\hline $254-\mathrm{i}-3$ & 25.84 & 38.76 & 31.80 & 27.49 & 25.98 & 0.95 & 1.27 & 1.20 & 1.01 \\
\hline $305-\mathrm{i}-2$ & 24.00 & 19.69 & 24.25 & 21.96 & 20.10 & 0.91 & 1.17 & 1.07 & 1.00 \\
\hline $305-\mathrm{i}-3$ & 33.05 & 27.10 & 33.38 & 32.07 & 31.47 & 0.98 & 1.24 & 1.22 & 0.95 \\
\hline $355-\mathrm{i}-3$ & 40.78 & 39.55 & 39.96 & 38.51 & 36.54 & 0.95 & 1.22 & 1.16 & 1.02 \\
\hline $355-\mathrm{i}-4$ & 51.80 & 80.24 & 55.91 & 50.34 & 50.34 & 1.00 & 1.21 & 1.21 & 0.97 \\
\hline $406-\mathrm{i}-3$ & 62.14 & 65.25 & 58.41 & 54.20 & 53.19 & 0.98 & 1.14 & 1.12 & 0.95 \\
\hline $406-\mathrm{i}-4$ & 70.77 & 94.83 & 70.06 & 70.04 & 71.25 & 1.02 & 1.27 & 1.30 & 1.03 \\
\hline & & & & & & & & &
\end{tabular}


Table 6.26: iSPAN section with Tri-slot hole

\begin{tabular}{|c|c|c|c|c|c|c|c|c|c|}
\hline Member & $\mathrm{M}_{\mathrm{y}}$ & $\mathrm{M}_{\mathrm{crl}}$ & $\mathrm{M}_{\mathrm{crD}}$ & $\mathrm{M}_{\mathrm{feN}}$ & $\mathrm{M}_{\mathrm{feH}}$ & $\begin{array}{c}\mathrm{M}_{\mathrm{feH}} / \\
\mathrm{M}_{\mathrm{feN}}\end{array}$ & $\begin{array}{c}\mathrm{M}_{\mathrm{feN}} / \\
\mathrm{M}_{\mathrm{DSM}}\end{array}$ & $\begin{array}{c}\mathrm{M}_{\mathrm{feH}} / \\
\mathrm{M}_{\mathrm{DSM}}\end{array}$ & $\begin{array}{c}\mathrm{M}_{\mathrm{feH}} / \\
\mathrm{M}_{\mathrm{new}}\end{array}$ \\
\hline $254-\mathrm{i}-2$ & 18.78 & 28.17 & 23.10 & 19.29 & 18.29 & 0.95 & 1.23 & 1.16 & 0.97 \\
\hline $254-\mathrm{i}-3$ & 25.84 & 38.76 & 31.80 & 27.49 & 26.39 & 0.96 & 1.27 & 1.22 & 1.02 \\
\hline $305-\mathrm{i}-2$ & 24.00 & 19.69 & 24.25 & 21.96 & 20.30 & 0.92 & 1.17 & 1.08 & 1.01 \\
\hline $305-\mathrm{i}-3$ & 33.05 & 27.10 & 33.38 & 32.07 & 32.48 & 1.01 & 1.24 & 1.26 & 0.98 \\
\hline $355-\mathrm{i}-3$ & 40.78 & 39.55 & 39.96 & 38.51 & 38.00 & 0.99 & 1.22 & 1.20 & 1.06 \\
\hline $355-\mathrm{i}-4$ & 51.80 & 80.24 & 55.91 & 50.34 & 51.16 & 1.02 & 1.21 & 1.23 & 0.99 \\
\hline $406-\mathrm{i}-3$ & 62.14 & 65.25 & 58.41 & 54.20 & 54.20 & 1.00 & 1.14 & 1.14 & 0.97 \\
\hline $406-\mathrm{i}-4$ & 70.77 & 94.83 & 70.06 & 70.04 & 73.28 & 1.05 & 1.27 & 1.33 & 1.06 \\
\hline & & & & & & & & &
\end{tabular}




\subsection{PROPOSED DESIGN EQUATIONS}

\section{i) For C-section}

Since the stiffened holes proved to improve the flexural strength of the C-joist by an average of $12.9 \%, 9 \%$, and $6 \%$ for the circular, slot and tri-slot hole, respectively, the DSM design method which is adopted by North American Specification, S136-07, is no longer accurate. As such, a new design procedure based on the DSM concept was developed to predict the flexural strength of the C-section joists with optimized edge stiffened holes on the web. The new provisions were proposed as follows.

\section{a) For joist with circular hole: (Yu, 2011)}

for $\lambda_{1} \leq 0.925, \quad \mathrm{M}_{\mathrm{nl}}=\mathrm{M}_{\mathrm{y}}$

$\lambda_{1}>0.925$

$\mathrm{M}_{\mathrm{nl}}=\left(1-0.05\left(\frac{\mathrm{M}_{\mathrm{crl}}}{\mathrm{M}_{\mathrm{y}}}\right)^{0.35}\right)\left(\frac{\mathrm{M}_{\mathrm{crl}}}{\mathrm{M}_{\mathrm{y}}}\right)^{0.35} \mathrm{M}_{\mathrm{y}}$

\section{b) For joist with slot hole:}

for $\lambda_{1} \leq 0.90, \quad \mathrm{M}_{\mathrm{nl}}=\mathrm{M}_{\mathrm{y}}$

$\lambda_{1}>0.90$

$\mathrm{M}_{\mathrm{nl}}=\left(1-0.069\left(\frac{\mathrm{M}_{\mathrm{crl}}}{\mathrm{M}_{\mathrm{y}}}\right)^{0.37}\right)\left(\frac{\mathrm{M}_{\mathrm{crl}}}{\mathrm{M}_{\mathrm{y}}}\right)^{0.37} \mathrm{M}_{\mathrm{y}}$

\section{c) For joist with tri-slot hole:}

for $\lambda_{1} \leq 0.85, \quad \mathrm{M}_{\mathrm{nl}}=\mathrm{M}_{\mathrm{y}}$

$\lambda_{1}>0.85$

$\mathrm{M}_{\mathrm{nl}}=\left(1-0.10\left(\frac{\mathrm{M}_{\mathrm{rrl}}}{\mathrm{M}_{\mathrm{y}}}\right)^{0.37}\right)\left(\frac{\mathrm{M}_{\mathrm{rrl}}}{\mathrm{M}_{\mathrm{y}}}\right)^{0.37} \mathrm{M}_{\mathrm{y}}$

Where

$\mathrm{M}_{\mathrm{nl}}=$ Nominal flexural strength resistance for local buckling

$\mathrm{M}_{\mathrm{y}}=$ Yield moment

$\mathrm{M}_{\mathrm{crl}}=$ Elastic local buckling moment of the joist without considering the holes obtained using elastic analysis software. 
$\lambda_{\mathrm{l}}=\sqrt{\mathrm{M}_{\mathrm{y}} / \mathrm{M}_{\mathrm{crl}}}$

\section{ii) For "iSPAN" joist}

For the iSPAN joists, the stiffened holes did not improve the flexural strength of the joist due to local buckling of the top lower flange, so a design equation was proposed as follows.

for $\lambda_{1} \leq 0.83, \quad \mathrm{M}_{\mathrm{nl}}=\mathrm{M}_{\mathrm{y}}$

$\lambda_{1}>0.83$

$M_{n l}=\left(1-0.11\left(\frac{M_{c r l}}{M_{y}}\right)^{0.36}\right)\left(\frac{M_{c r l}}{M_{y}}\right)^{0.36} M_{y}$

\subsection{LIMITATIONS OF PROPOSED DESIGN EQUATIONS}

The proposed design procedure is applicable for the laterally braced C- and iSPAN joist with the optimized edge stiffened holes. The hole spacing shall not be larger than $0.5 \mathrm{~h}$ and the edge stiffener length vs. web height ratio shall not be less than 0.06 . The hole size is taken half the web height, and the joist should be laterally supported to prevent lateral-torsional buckling. Figure 6.23 shows a comparison of the FE results of C-joists, while FE results for iSPAN joists are shown in Figure 6.24, with the design curves. It can be observed that the new design curve based on the developed equations in this research provides reasonable and conservative predictions for the studied C-section and iSPAN joists. FE results showed that the average FE vs. predicted ratios for the new design curve were 1.045, 1.038, and 1.028 with a standard deviation of 0.062, 0.049, and 0.052 for the C-joist with circular, slot, and tri-slot holes, respectively, as depicted in Tables 6.21 through 6.23. Similarly, for the iSPAN joist, the average FE vs. predicted ratios for the new design curve were observed to be $1.043,0.989$, and 1.008 with a standard deviation of $0.044,0.031$, and 0.037 for the circular, slot, and tri-slot holes, respectively as depicted in Tables 6.24 through 6.26. Figures 6.23 and 6.24 shows a graphical representation of code design curves, finite-element results and the proposed design curves. The vertical axis represents the ratio between the resisting moment $\left(\mathrm{M}_{\mathrm{fe}}\right)$ and the yield moment $\left(\mathrm{M}_{\mathrm{y}}\right)$ of the joist, while the horizontal axis represents the ratio between the square root of the yielding moment of the joist and the elastic local buckling moment of the joist without considering the web hole for the C-joist or iSPAN joist. Figures 6.23 and 6.24 show that the direct strength method provides very conservative results compared to the FE results. Also, Figures 6.23 and 6.24 shows that the 
proposed design curves yields reasonable, yet more economical results for the C-joists and iSPAN joists, respectively, when compared to the Direct Design Method.

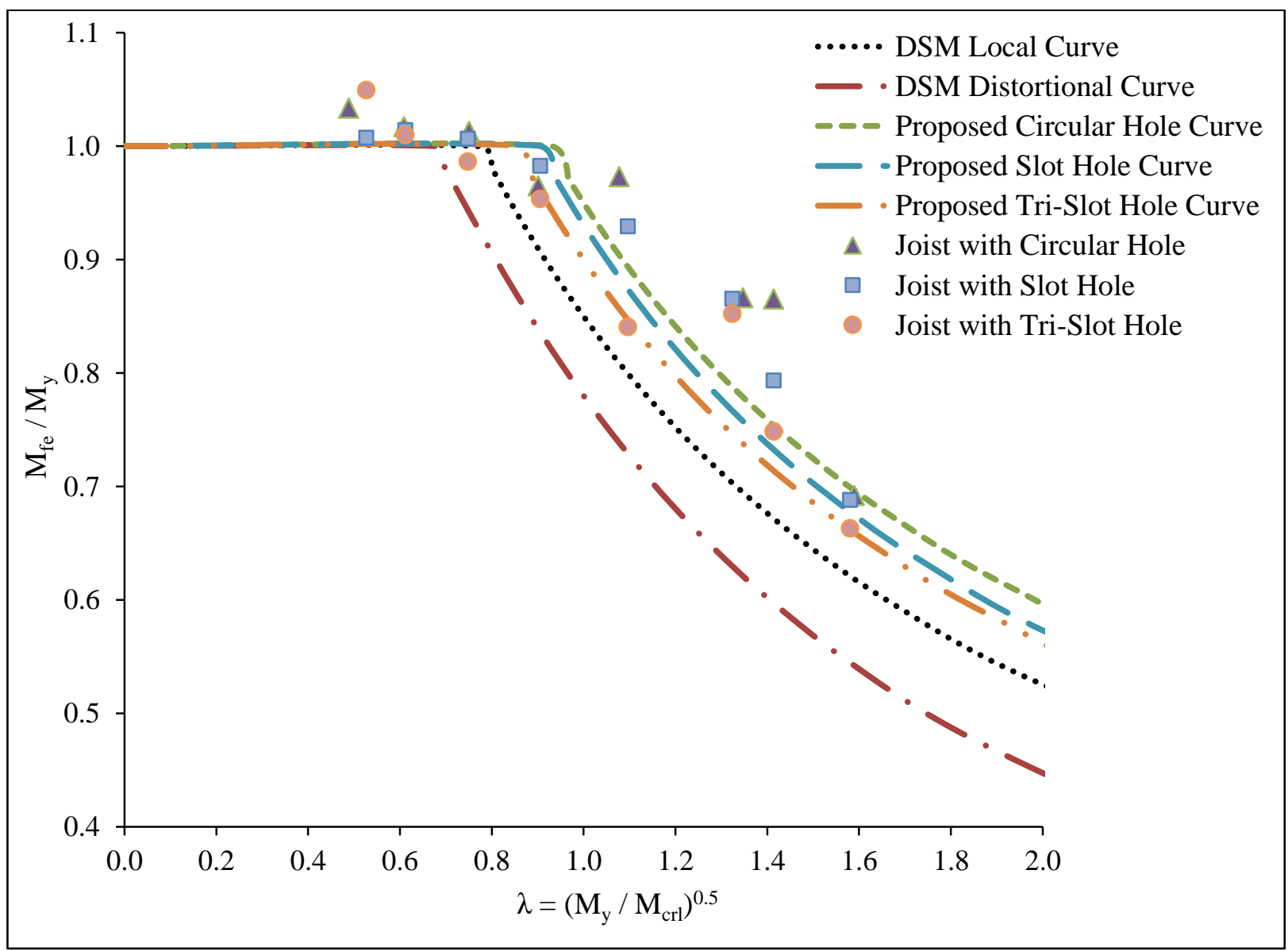

Figure 6.23: Design curves for C-sections 


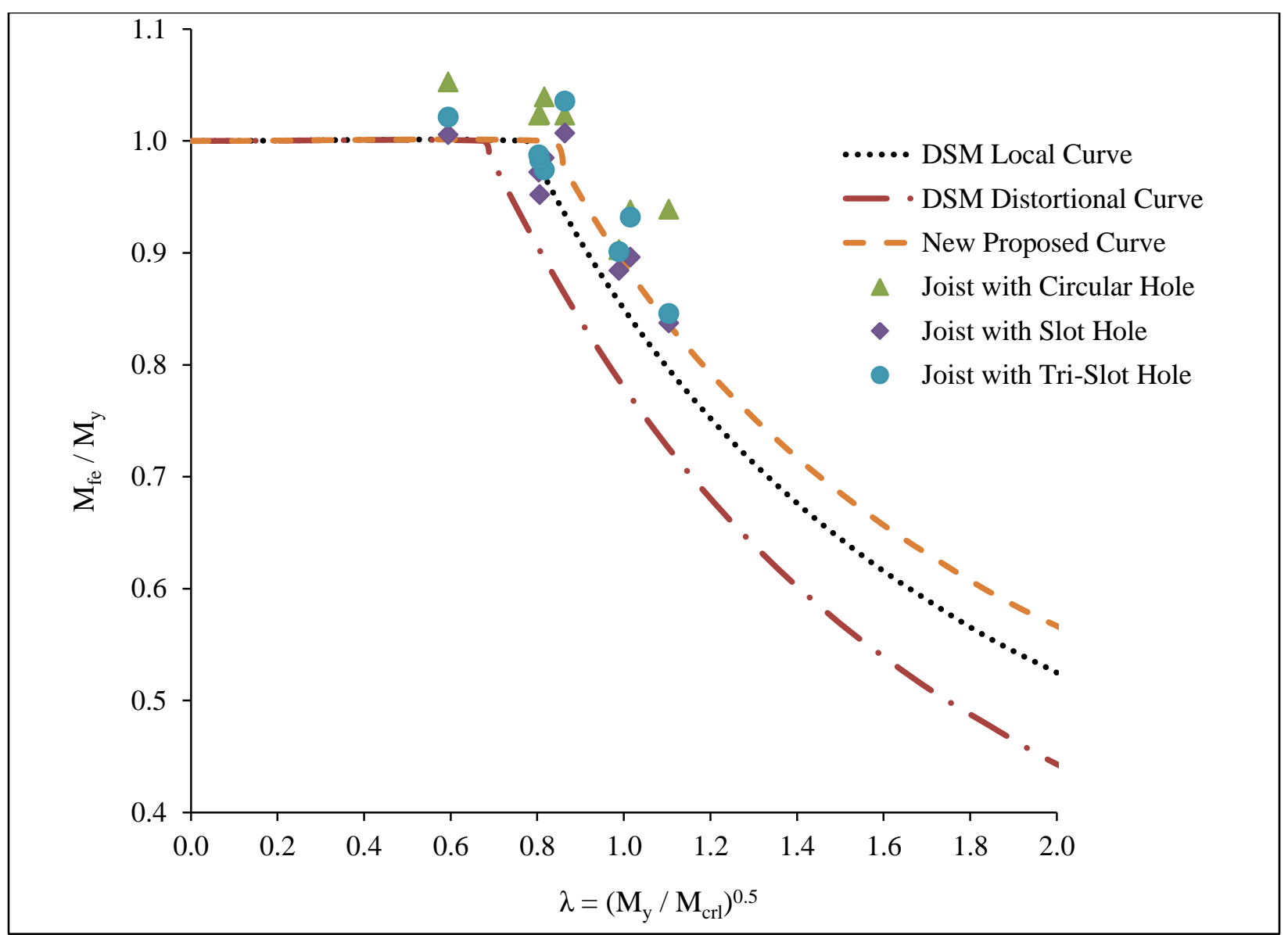

Figure 6.24: Design curves for iSPAN Joists 


\subsection{CALIBRATION OF THE NEW SAFETY CO-EFFICIENTS}

The objective of structural design is to produce safe, serviceable, economic, durable and aesthetic structures. Structures must be able to withstand the loads acting on them during a reasonable lifetime. North American Specification for CFS Member Design specifies two different design methods, namely: Limit State Design (LSD) and Allowable Stress Design (ASD). Based on a probabilistic concept, the structural safety can be measured in terms of a reliability index, $\beta$. The theory of probability can be applied to both design methods to achieve the same degree of structural safety. The following subsections elaborate on both methods of design as stated in S-136-07.

\subsubsection{LIMIT STATE DESIGN (LSD)}

The use of LSD is mandatory in Canada but it is specified also in United States in addition to the ASD. LSD is a method in which the performance of a structure is checked against various limiting conditions at appropriate load levels. These limits are the ultimate strength limit state, and serviceability limit state. Ultimate limit state design (LRFD as known in the United States) is concerned with those states concerning safety, such as exceeding the load carrying capacity. Load factors and resisting factors are used in the proportioning of the members to minimize the risk arising from overloads and under strength elements. The following equations are expressed in $\mathrm{S} 136-07$ as follows for the relationship between the design forces and member resistance.

$\sum \gamma_{\mathrm{i}} \mathrm{Q}_{\mathrm{i}} \leq \phi \mathrm{R}_{\mathrm{n}} \quad$ (for LRFD)

$\phi \mathrm{R}_{\mathrm{n}} \geq \sum \gamma_{\mathrm{i}} \mathrm{Q}_{\mathrm{i}} \quad$ (for LSD)

Where

$\sum \gamma_{\mathrm{i}} \mathrm{Q}_{\mathrm{i}}=$ Required strength [effect of factored loads];

$\mathrm{R}_{\mathrm{n}}=$ Average value of all test results

$\phi=$ Resistance factor;

$\Upsilon_{\mathrm{i}}=$ load factors;

$\mathrm{Q}_{\mathrm{i}}=$ load effects; and

$\phi \mathrm{Rn}=$ design strength.

The resistance factor $\phi$ is specified to cover the variability of material properties, dimensions, and uncertainty in the predication of the resistance and is usually less than 1 . While the load factors compensate for uncertainties and variability of the loads and is usually greater than 1 . The 
advantage of strength limit state design is that the uncertainties and variability of varies types of loads are different (e.g. dead load is less variable than wind load), and so these differences can be accounted for by the use of multiple factors, which leads to a more consistent reliability in design.

\subsubsection{ALLOWABLE STRESS DESIGN (ASD)}

In this method, the expected resistance of the structural member is divided by a factor of safety to obtain an allowable or working stress, and the member size is then chosen so that the stress induced by the expected service load, or service load combination is equal to or less than the allowable value. The allowable design strength specified in S136-07 is calculated as:

$\mathrm{R}=\mathrm{R}_{\mathrm{n}} / \Omega$

Where

$\mathrm{R}_{\mathrm{n}}=$ Average value of all test results;

$\Omega=$ Factor of safety to be computed as: $\Omega=1.6 / \phi$

The fundamental nature of the factor of safety is to compensate for uncertainties inherent in the design, fabrication, or erection of building components, as well as uncertainties in the estimation of the applied loads. The ASD method considers only one factor of safety for a certain mode of failure, regardless of the combination of applied loads.

\subsection{CALIBRATION OF NEW VALUES FOR RESISTANCE FACTORS}

Procedure for calculating both the resisting factor, $\phi$ for load resistance factored design (LRFD), and the factor of safety, $\Omega$, for allowable stress design (ASD), is well described in North American Specifications, S136-07. The resistance factor $\phi$ can be calculated as follows.

$\phi=C_{\phi}\left(M_{m} F_{m} P_{m}\right) e^{-\beta_{0} \sqrt{V_{M}^{2}+V_{F}^{2}+C_{p} V_{p}^{2}+V_{Q}^{2}}}$

Where:

$\mathrm{C}_{\phi}=$ Calibration coefficient and is equal to 1.52 for the United States and Mexico and 1.42 For Canada

$\mathrm{M}_{\mathrm{m}}=$ Mean value of material factor, (1.10 for Bending Strength)

$\mathrm{F}_{\mathrm{m}}=$ Mean value of fabrication factor, (1.00 for Bending Strength)

$\mathrm{P}_{\mathrm{m}}=$ Mean value of professional factor, $\mathrm{P}$, for tested component $=1.0$; 
$\beta_{\mathrm{o}}=$ Target reliability index, equal to 2.5 for structural members and 3.5 for connections for the United States and Mexico, and 3.0 for structural members and 4.0 for connections for Canada;

$\mathrm{V}_{\mathrm{M}}=$ Coefficient of variation of material factor ( 0.10 for Bending Strength)

$\mathrm{V}_{\mathrm{F}}=$ Coefficient of variation of fabrication factor ( 0.05 for Bending Strength)

$C_{P}=$ Correction factor and is equal to $(1+1 / n) m /(m-2)$ for $n \geq 4$, and 5.7 for $n=3$;

$\mathrm{n}=$ Number of tests;

$m=$ Degrees of freedom and is equal to (n-1);

$V_{P}=$ Coefficient of variation of test results, but not less than $6.5 \%$;

$\mathrm{V}_{\mathrm{Q}}=$ Coefficient of variation of load effect $=0.21$; for LSD and LRFD

$e=$ Natural logarithmic base (2.718);

Based on the data generated from the FE modelling, the resistance factors for LSD and LRFD designs were developed based on equations 6.7 and 6.8 as listed in Table 6.27.

Table 6.27: New proposed safety factor for the developed design equations

\begin{tabular}{|c|c|c|c|}
\hline \multicolumn{4}{|c|}{ New safety factors } \\
\hline & S136 (LSD) & \multicolumn{2}{|c|}{ AISI (LRFD) } \\
\cline { 2 - 4 } & $\phi$ & $\phi$ & $\Omega$ \\
\hline C-joist & 0.73 & 0.89 & 1.80 \\
\hline iSPAN joist & 0.73 & 0.89 & 1.80 \\
\hline
\end{tabular}

\subsection{CONCLUSIONS}

The elastic buckling analyses on CFS thin plates, C-joists and iSPAN joists with edge-stiffened holes were analyzed by FE models using ABAQUS software. The results showed that the stiffened holes can greatly increase the critical loads of those CFS members. A parametric study was performed to obtain optimized dimensions of hole profiles for C- and iSPAN joists. Then, these joists with optimized holes were analyzed using post-buckling FE modelling to determine their ultimate flexural strength. FE results indicated that an average $12.9 \%, 9 \%$, and $6 \%$ increase in flexural strength can be achieved by forming the optimized stiffened holes on the web of Cjoist for circular, slot, and tri-slot holes, respectively. For the iSPAN joist, the stiffened hole has 
no effect in increasing the flexural strength of the joist since local buckling failure occurred first in the top lower flange which is the weak area of the joist. A DSM-based new design method for the $\mathrm{C}$ - and iSPAN joist flexural members with optimized edge stiffened holes was developed. The new method showed good agreement with the results of the FE analyses and demonstrated the same level of reliability as the DSM. The provisions of the above sections shall apply within the following limits:
a) The depth of hole " $\mathrm{d}_{\mathrm{h}}$ " should be equal to $0.5 \mathrm{~h}$,
b) Clear distance between holes should be equal to $0.5 \mathrm{~h}$,
c) The edge stiffener length, q, should not be less than $0.06 \mathrm{~h}$,
d) Joist should be laterally supported,
e) Holes centred at mid depth of web,
f) For tri-slot holes the corner radii $\geq 2 t$, and
g) For slot and tri-slot hole the $\mathrm{L}_{\mathrm{h}}=2 \mathrm{~d}_{\mathrm{h}}$
$d_{h}=$ depth of the web hole,
$\mathrm{L}_{\mathrm{h}}=$ length of web hole,
$\mathrm{h}=$ joist web height,
$\mathrm{q}=$ edge stiffener length, and
$\mathrm{t}=\quad$ web thickness.

Where 


\section{CHAPTER 7}

\section{CONCLUSIONS}

\subsection{GENERAL}

Floor vibrations are usually caused by human activities such as walking or rhythmic activity, machinery or other external forces, such as vehicular traffic. The acceptability of floor vibration is a function of the occupant's sensitivity to floor vibrations, which can be quite subjective and variable. The structural and cost benefits associated with cold-formed steel floor systems can result in vibration serviceability issues if proper design considerations are not made. The vibration problems that may be present in cold-formed steel floor systems, like any other floor system, can be addressed if proper consideration is given by designers. The available design methods to calculate the dynamic properties of floor systems are used for the design of lightframe timber-based systems, CFS C-shape joists, and structural steel and concrete floor systems. The applicability of such methods to I-shape CFS joists is as yet unavailable. In addition, the North American Code for Cold-formed Steel structural Members (CSA-S136-07) provides specifications of ultimate and serviceability limit state design of C-shape joists rather than Ishape joists. As such, experimental study on CFS I-shape joists is needed to obtain experimental data to evaluate the available ultimate strength equations and serviceability design procedure when applied to such joist type with or without utility holes. Since CSA-S136-07 does not provide design provisions for the edge-stiffened (i.e. lipped) holes, a practical-design-oriented parametric study is required to evaluate CFS I- and C-shape members with circular, slotted and tri-slotted, edge-stiffened, holes under flexural loading.

The research conducted in the current study investigated, experimentally and using the finiteelement modelling, the dynamic characteristics of cold-formed steel iSPAN floor systems, and recommended an adequate model for predicting the dynamic response and modal properties of the floor system in order to aid the design process. Also, it evaluated the accuracy and applicability of commonly used design methods for predicting fundamental frequency, static deflection, and acceleration response to walking excitation. Moreover, this research investigated, experimentally and using the finite-element modelling, the ultimate flexural strength of the 
iSPAN joists with or without web holes. Finally, a practical-design-oriented parametric study, using the finite-element modelling, on CFS I- and C-shape members with circular, slotted and tri-slotted, edge-stiffened, holes under flexural loading was conducted. The data generated from the parametric study led to the development of new design provisions to predict the flexural strength of such joists with the presence of edge-stiffened holes. The following sections summarize the conclusions of this research as well as recommendations for future research.

\subsection{CONCLUSIONS}

The conclusions drawn from the experimental and theoretical investigations conducted in this research can be summarized as follows.

- The presence of bracing in wood I-joist floors does not affect the floor frequency and damping ratio which seems reasonable conclusion. Studied wood floor I-joist assembly has damping ratio ranging from 3.45 to $5.18 \%$ for unbraced joists and between 3.53 to $6.69 \%$ for braced joists.

- The deflection and flexural strain readings of the iSPAN CFS twin-joist assembly generally showed nonlinear behaviour and plastic deformation before failure when compared to the failure of wooden joist assembly that generally exhibited linear load-deflection relationship till failure.

- Results from the experimental testing showed that the presence of Lip-reinforced holes in the tested iSPAN twin-joist assembly has generally insignificant effect of the dynamic performance of the floor system; the joist with lipped web holes increases the capacity of the web against local buckling when subjected flexural stress gradient.

- Site test results under $1-\mathrm{kN}$ concentrated load showed that attachment of bracing to the CFS joists does not influence floor flexural frequency while it reduces floor static deflection. This may be attributed to the fact that bracing distributed the concentrated load to adjacent joists. Also, floor damping ratios in site 1 changed from 5.86 to $8.07 \%$ with the addition of joist bracing. It should be noted that increase in damping ratio improves the vibration performance of the floor. This would make the vibration amplitude decay more quickly and floor vibration will be less noticeable to the occupants. 
- Experimental findings show that joist simply-supported framing condition increases floor frequency by $8 \%$ in average. This may be attributed to the fact that balloon framing provides more flexural structural system as compared to the pure simply-supported condition. However, the change in support condition slightly affects joist deflection. On the other hand, floor damping ratio increases with the use of balloon framing condition.

- Experimental findings show that the Canadian wood council (CWC) design method underestimates the 1-kN load deflection while it provides accurate results for the floor flexural frequency. On the other hand, the ATC design method does not show general trend in estimating the 1-kN load deflection as well as floor frequency. As such, it is considered unacceptable. The European design method (Eurocode EC5) showed better correlation with experimental findings than the ATC design method.

- To better estimate the joist deflection due to $1-\mathrm{kN}$ load and the joist frequency, a coefficient $\gamma$, representing the ratio of shear deflection to flexural deflection for the member, was developed for the design of iSPAN cold-formed steel joists.

- FE results show that change in number of holes in joist web has insignificant effect on floor. However, it is recommended that the spacing between holes in joist webs be limited to a minimum of half of the web height $(0.5 \mathrm{~h})$.

- Experimental findings reveal that North American Specifications for the Design of Coldformed Steel Members (CSA-S136-07) predicts an average ultimate load carrying capacity of 1 and 17\% less that the experimental ultimate load for the tested iSPAN joist assemblies without and with web holes, respectively. However, the Canadian Wood Council (CSA-O86) design method underestimated the load carrying capacities of the tested wood joists by about 35 to $60 \%$.

- The experimental flexural results of iSPAN joist are compared with North American Coldformed Steel Specification S136-07 design equation, and it is concluded that the design equation given in the code can be used to calculate the flexural strength of the iSPAN joist.

- Edge-stiffened holes can greatly increase the critical loads of the C-and ISPAN joists. FE results indicated that an average $12.9 \%, 9 \%$, and $6 \%$ increase in flexural strength can be achieved by forming the optimized stiffened holes on the web of C-joist for circular, slot, and tri-slot holes, respectively. For the iSPAN joist, the stiffened hole has no effect in 
increasing the flexural strength of the joist since local buckling failure occurred first in the top lower flange which is the weak area of the joist.

- A DSM-based new design method for the C- and iSPAN joist flexural members with optimized edge stiffened holes was developed. The new method showed good agreement with the results of the FE analyses and demonstrated the same level of reliability as the DSM. The new design methods for the studied joists shall apply within the following limits: (i) the depth of hole "dh" should be equal to $0.5 \mathrm{~h}$; (ii) clear distance between holes should be equal to $0.5 \mathrm{~h}$; (iii) the edge stiffener length, q, should not be less than $0.06 \mathrm{~h}$; (iv) joist should be laterally supported; (v) holes centered at mid depth of web; (vi) for tri-slot holes the corner radii $\geq$ to $2 \mathrm{t}$; and (vii) for slot and tri-slot hole the $\mathrm{L}_{\mathrm{h}}=2 \mathrm{~d}_{\mathrm{h}}$.

- For the new design method of the C-joists and iSPAN joists subjected to flexural loading, the resisting factor, $\phi$, for load resistance factored design (LRFD), and the factor of safety, $\Omega$, for allowable stress design (ASD) were developed per the procedure prescribed in the North American Specifications for the Design of Cold-formed Steel Members, CSA-S13607.

\subsection{RECOMMENDATIONS FOR FUTURE RESEARCH}

The following are few recommendations for further research in this topic.

- Further research can be conducted to take into account construction details on joist flexural strength and vibrations characteristic. Such details may include the effect of subfloor material (i.e. OSB or metal subfloor materials). The effect of ceiling material including dry wall sheets attached to the floor joist and the effect of drop ceiling on the floor joist system can be studied.

- The effect of bracing and blocking on joist ultimate strength and vibration characteristics can be studied in detail. The effect of live load on floor vibration may also be studied.

- The effect of partial and full partition on vibration performance of the floor system may be studied. These partition walls can be constructed below or above the floor system.

- Effect of the presence of concentrated loads at or close to web opening may be studied.

- The effect of fatigue loading on the joist flexural strength may be studied.

- Stress distribution around the circular, slotted or tri-slot holes under compressive and flexural loading may be investigated in detail. 


\section{APPENDIX A1. ACCELERATION SPECTRUM FOR WOODEN JOISTS}




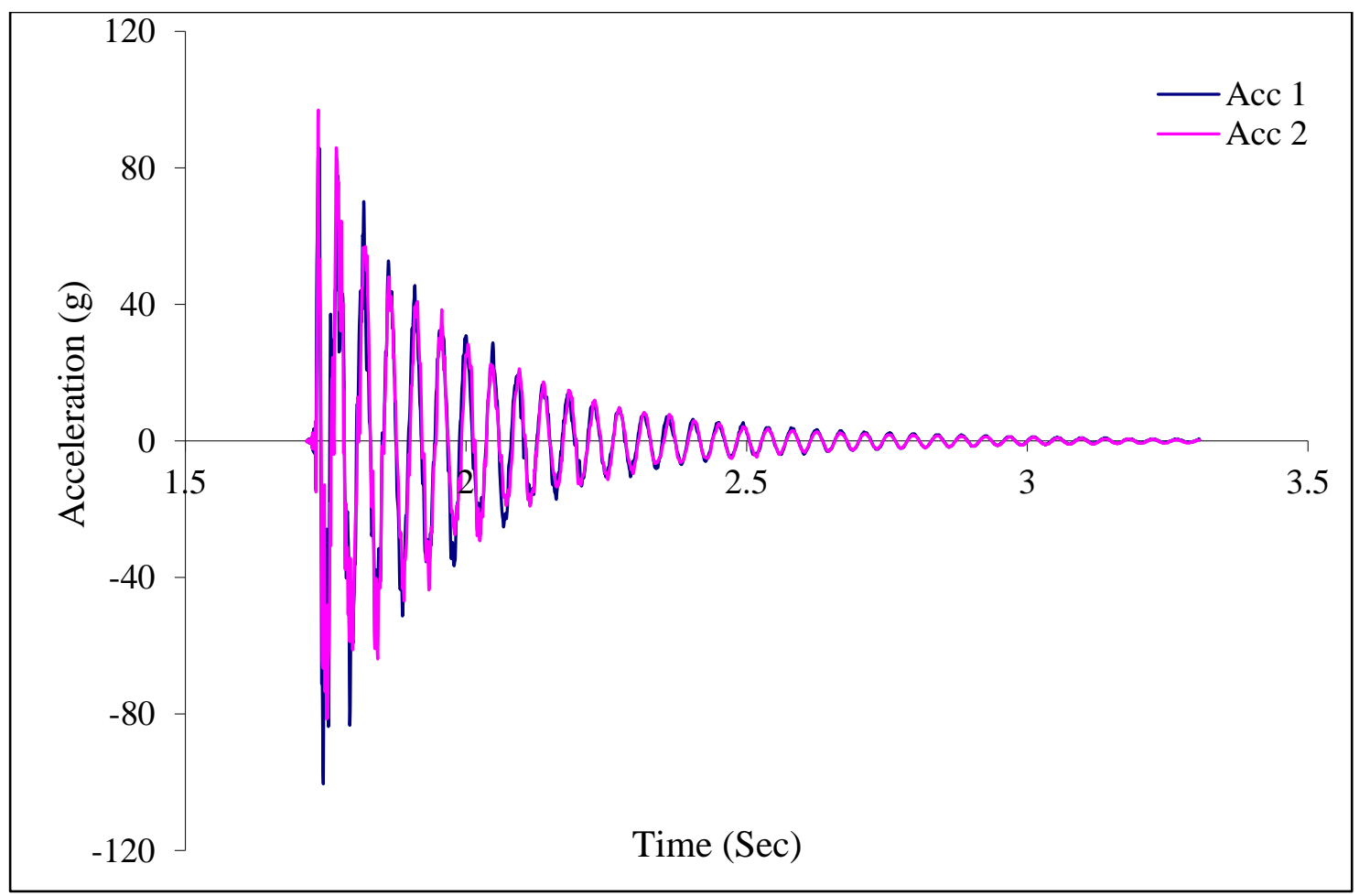

Figure A1.1: Typical acceleration trace for 241x4500 mm wooden floor joist

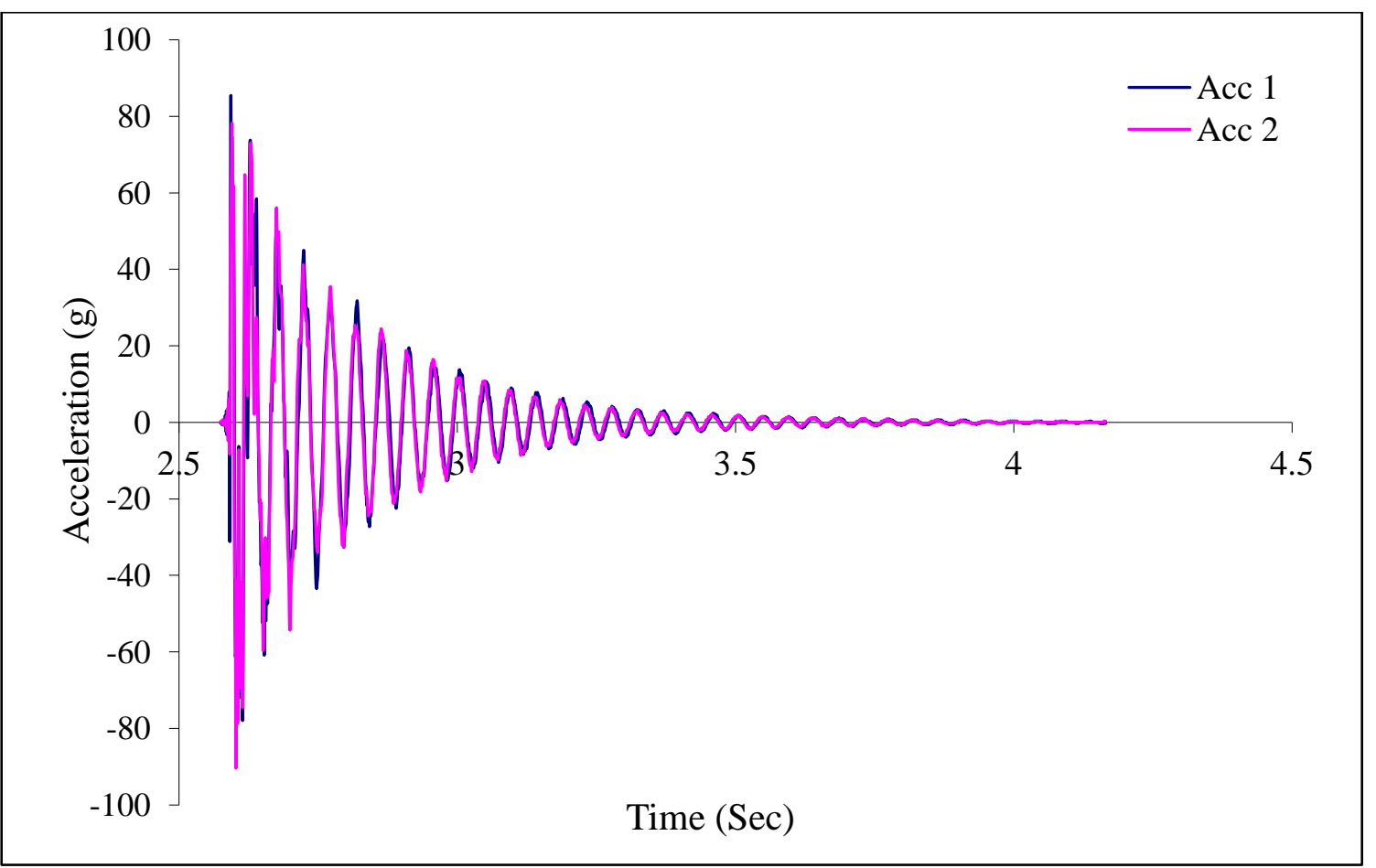

Figure A1.2: Typical acceleration trace for $302 \times 5000 \mathrm{~mm}$ wooden floor joist 


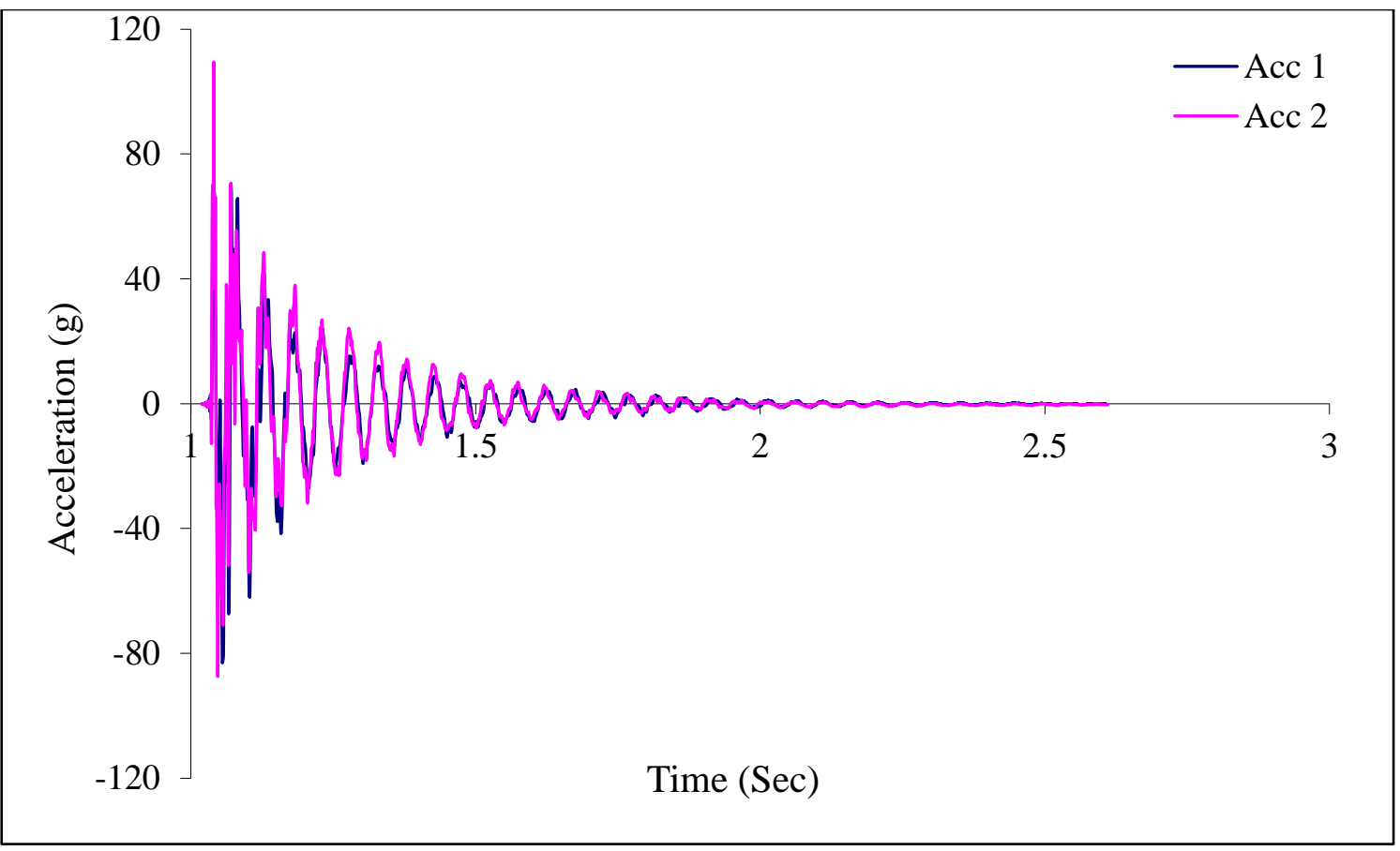

Figure A1.3: Typical acceleration trace for 302x5250 mm wooden floor joist

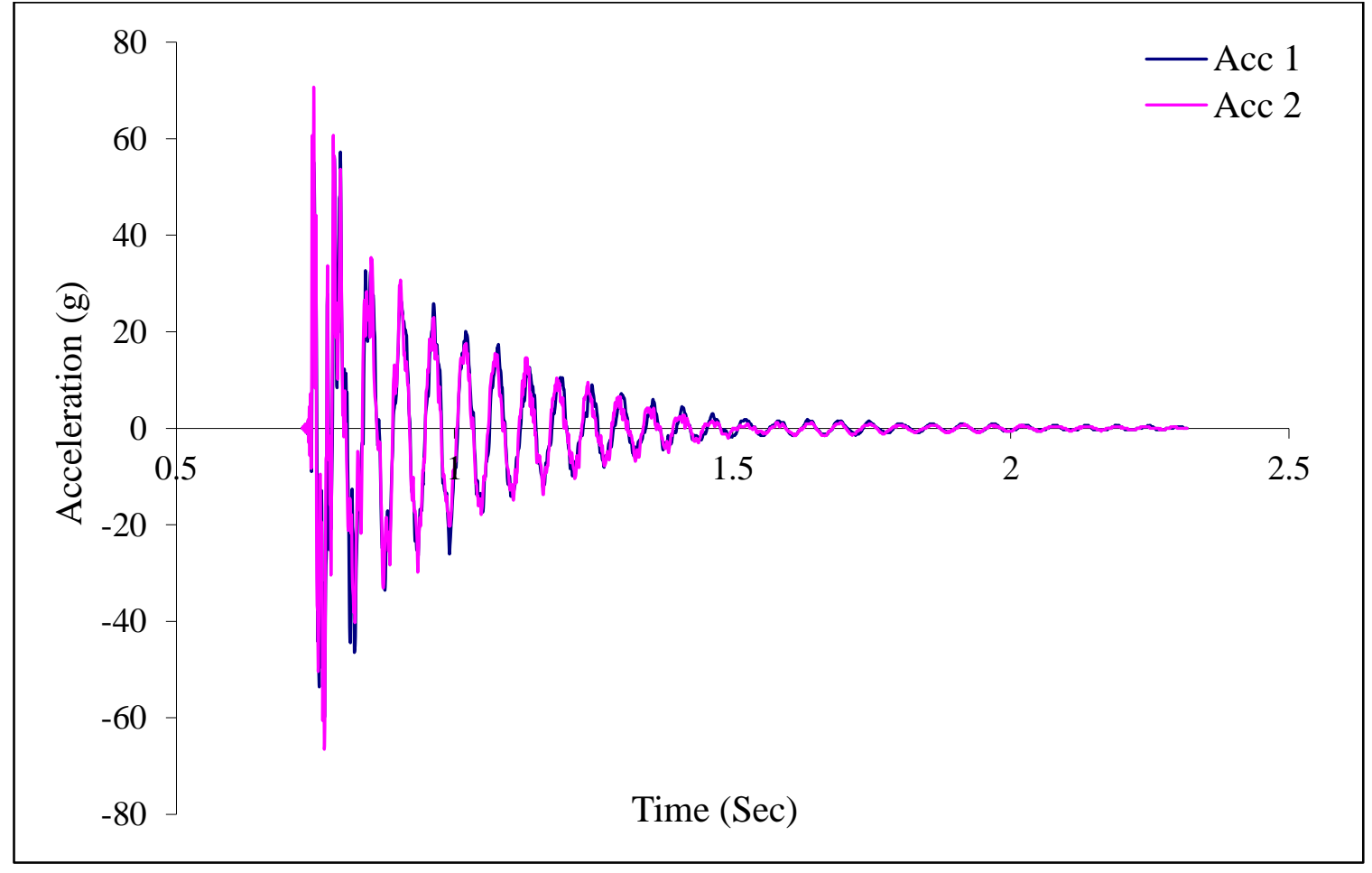

Figure A1.4: Typical acceleration trace for 356x6100 mm wooden floor joist 


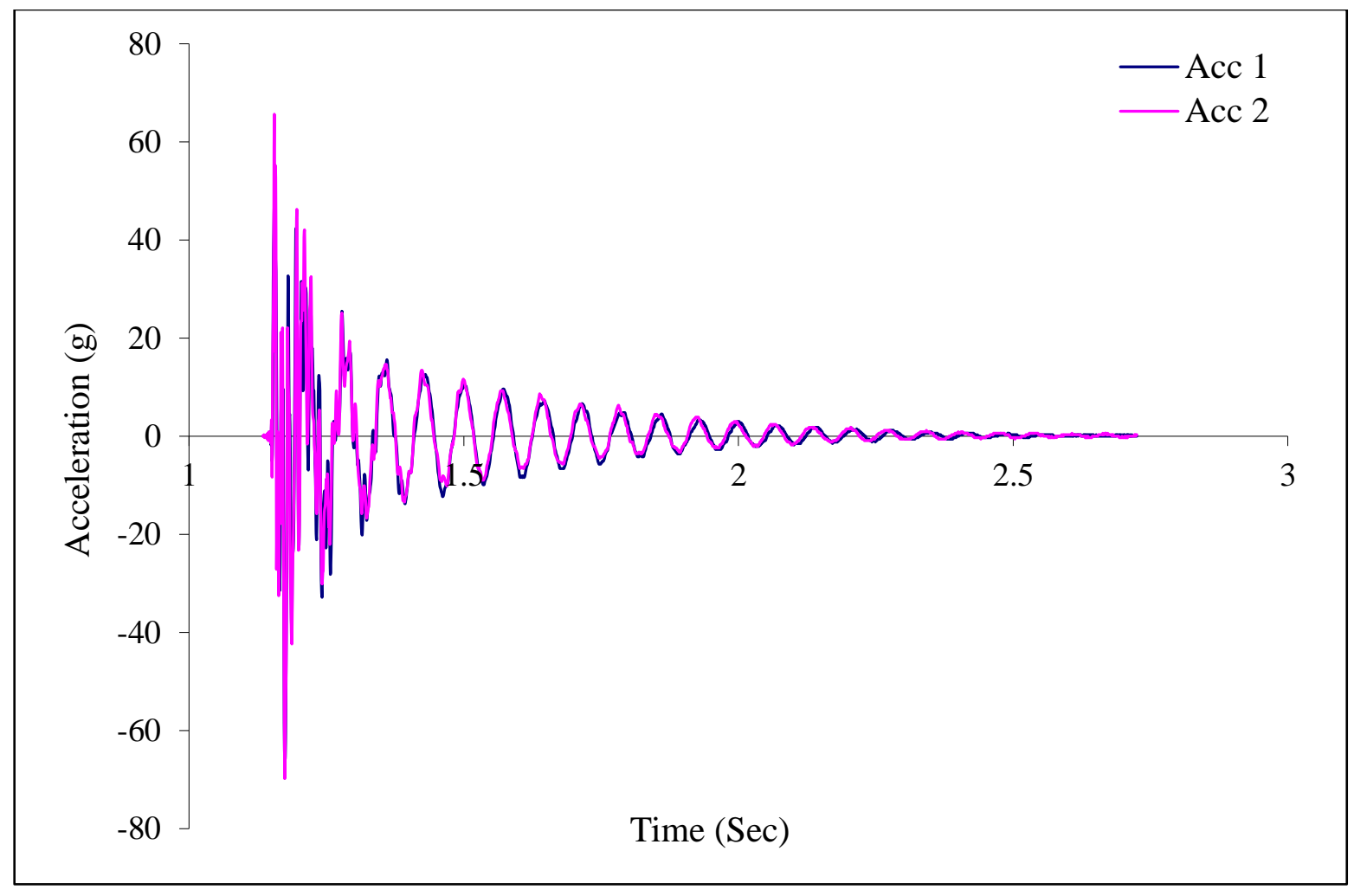

Figure A1.5: Typical acceleration trace for 406x7950 mm wooden floor joist 


\section{APPENDIX A2. NATURAL FREQUENCY SPECTRUM FOR WOODEN JOIST}




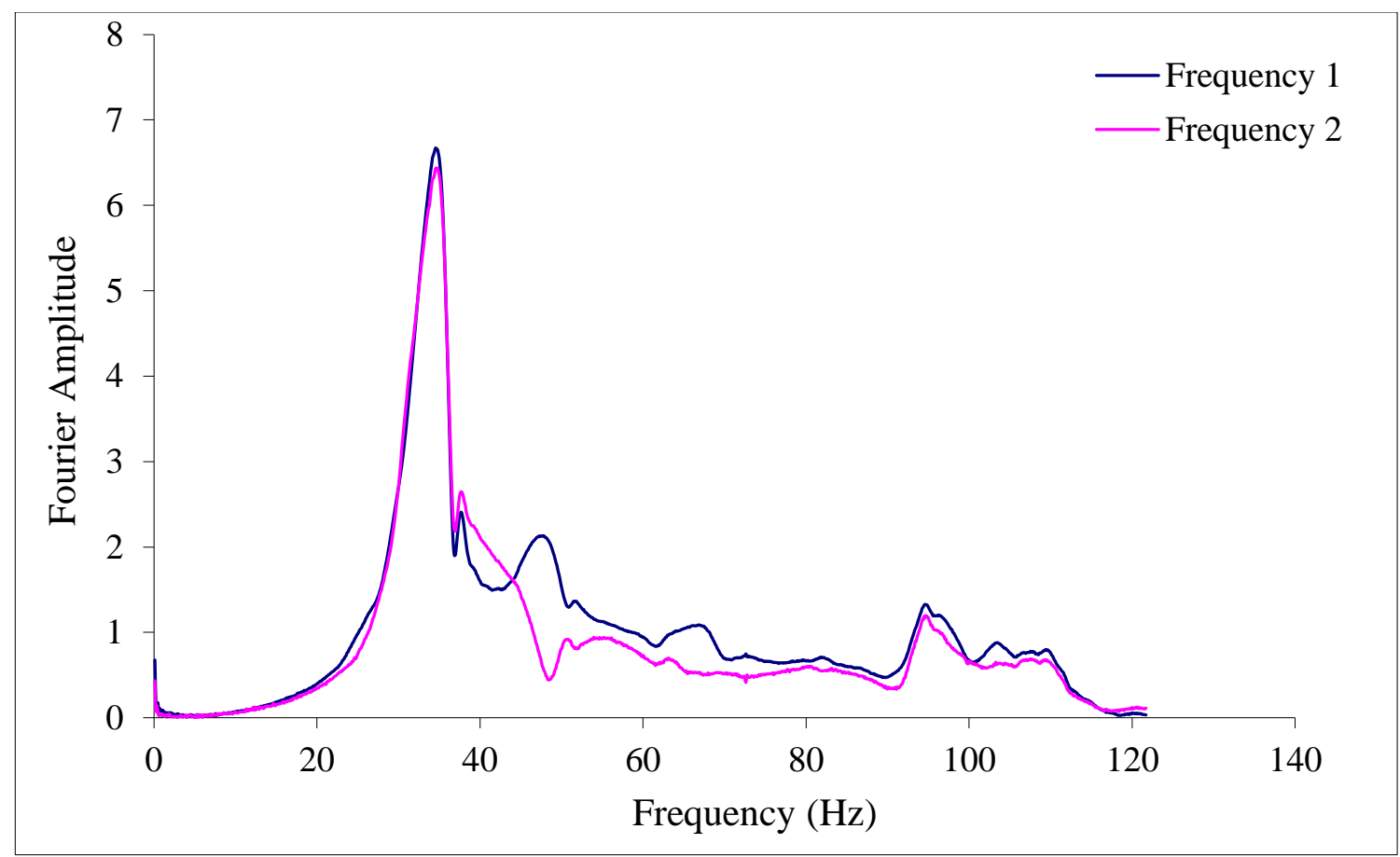

Figure A2.1: Typical frequency spectrum for 241x4500 mm wooden floor Joist

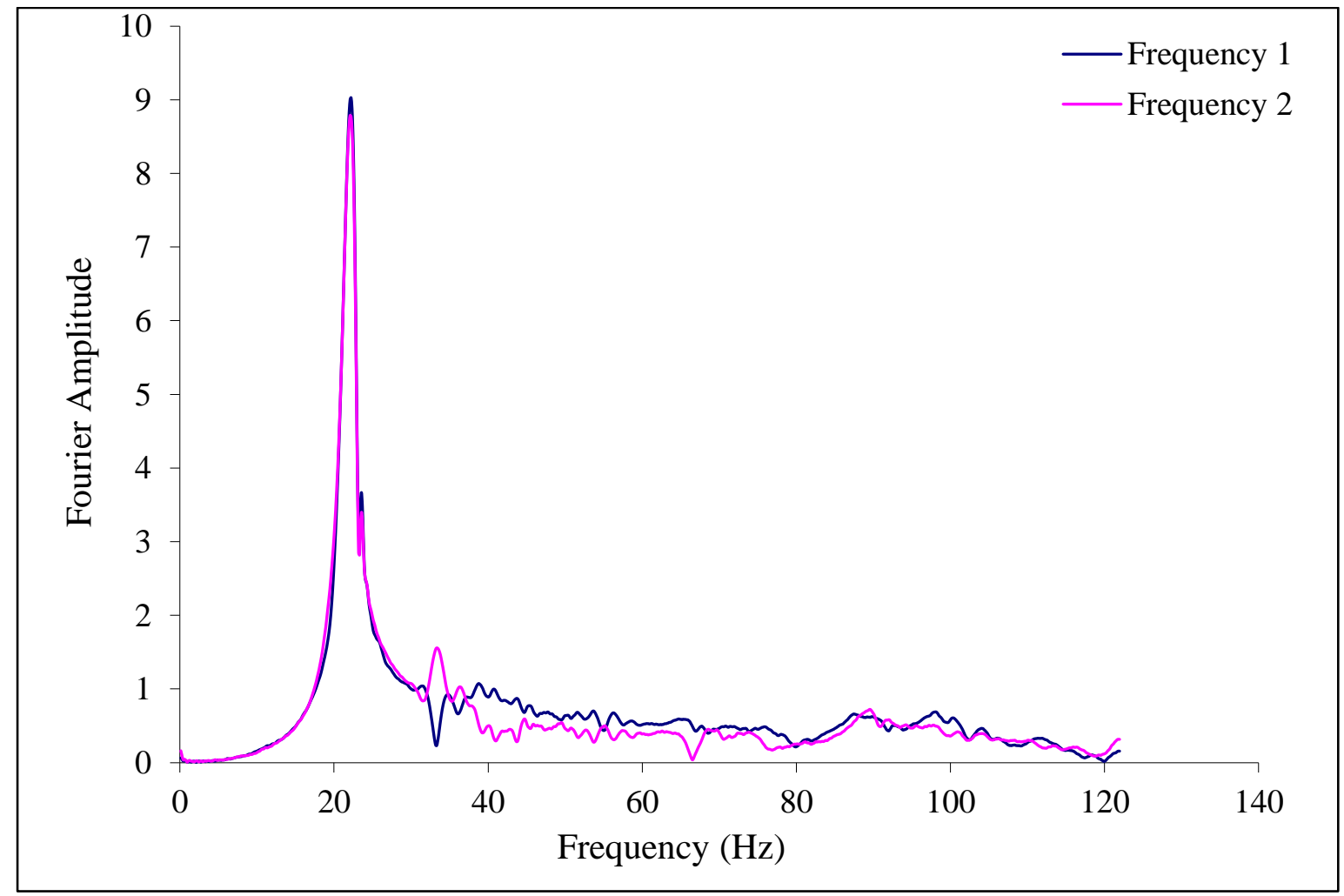

Figure A2.2: Typical frequency spectrum for 302x5000 wooden mm floor Joist 


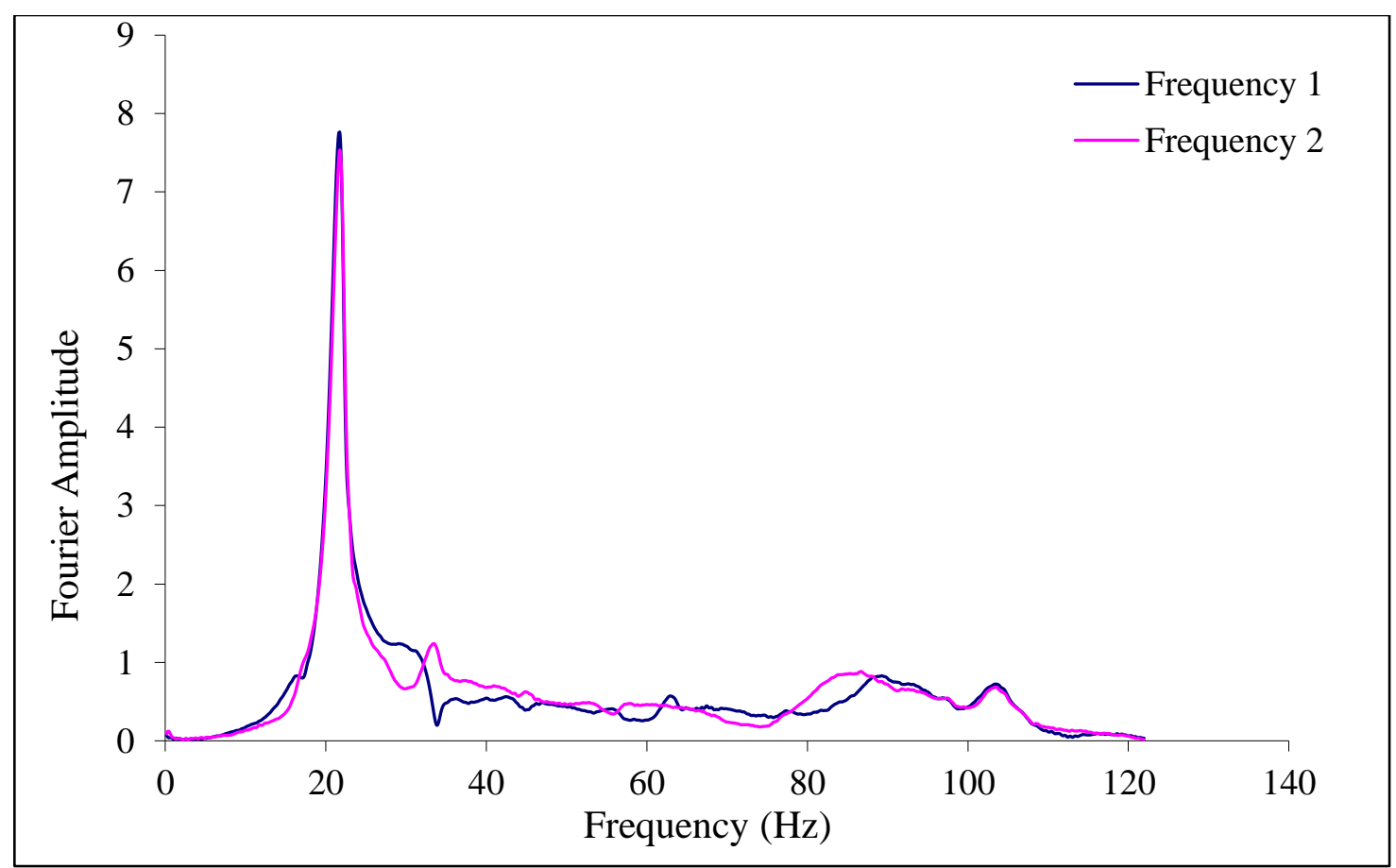

Figure A2.3: Typical frequency spectrum for 302x5250 mm wooden floor Joist

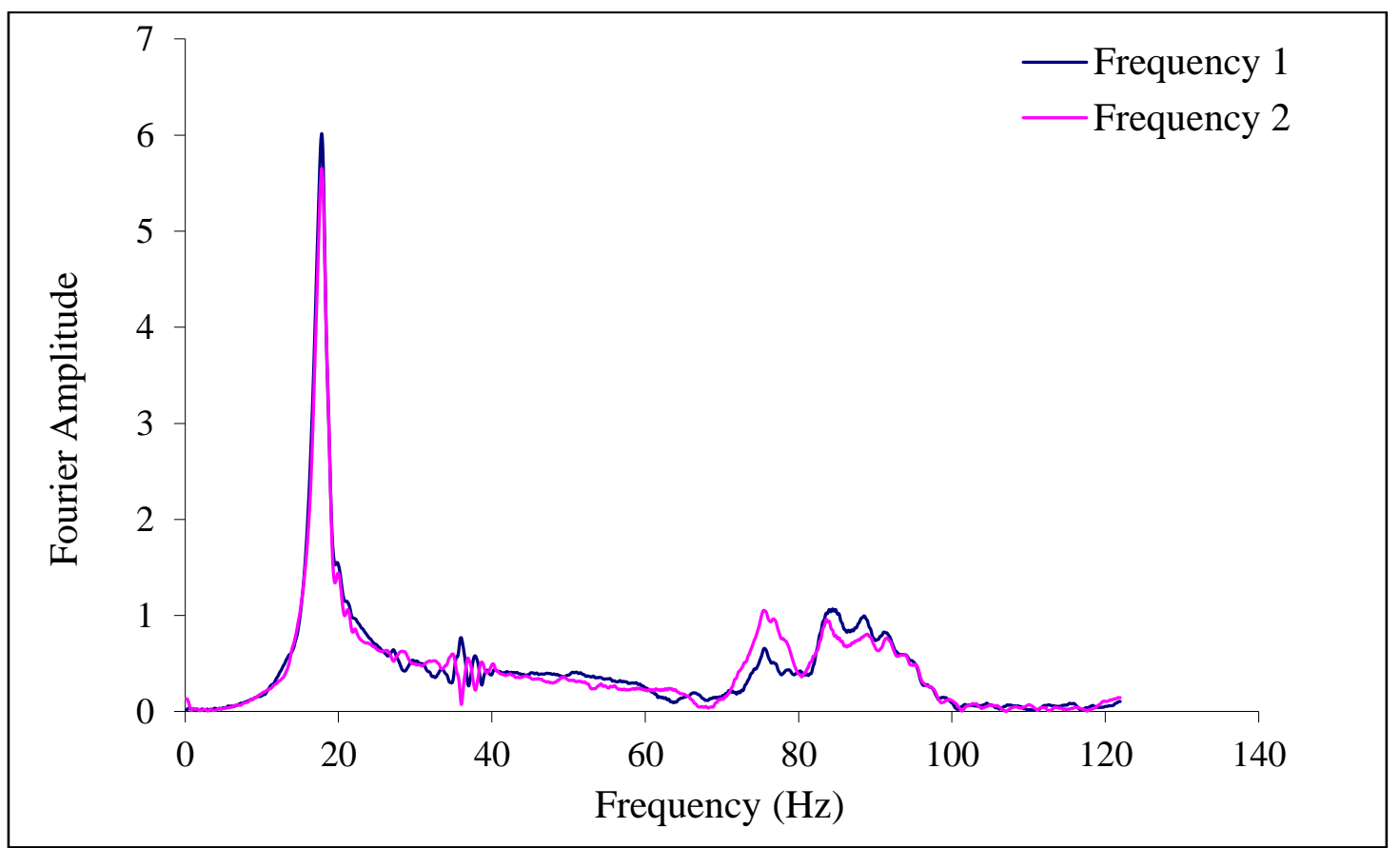

Figure A2.4: Typical frequency spectrum for 356x6100 mm wooden floor Joist 


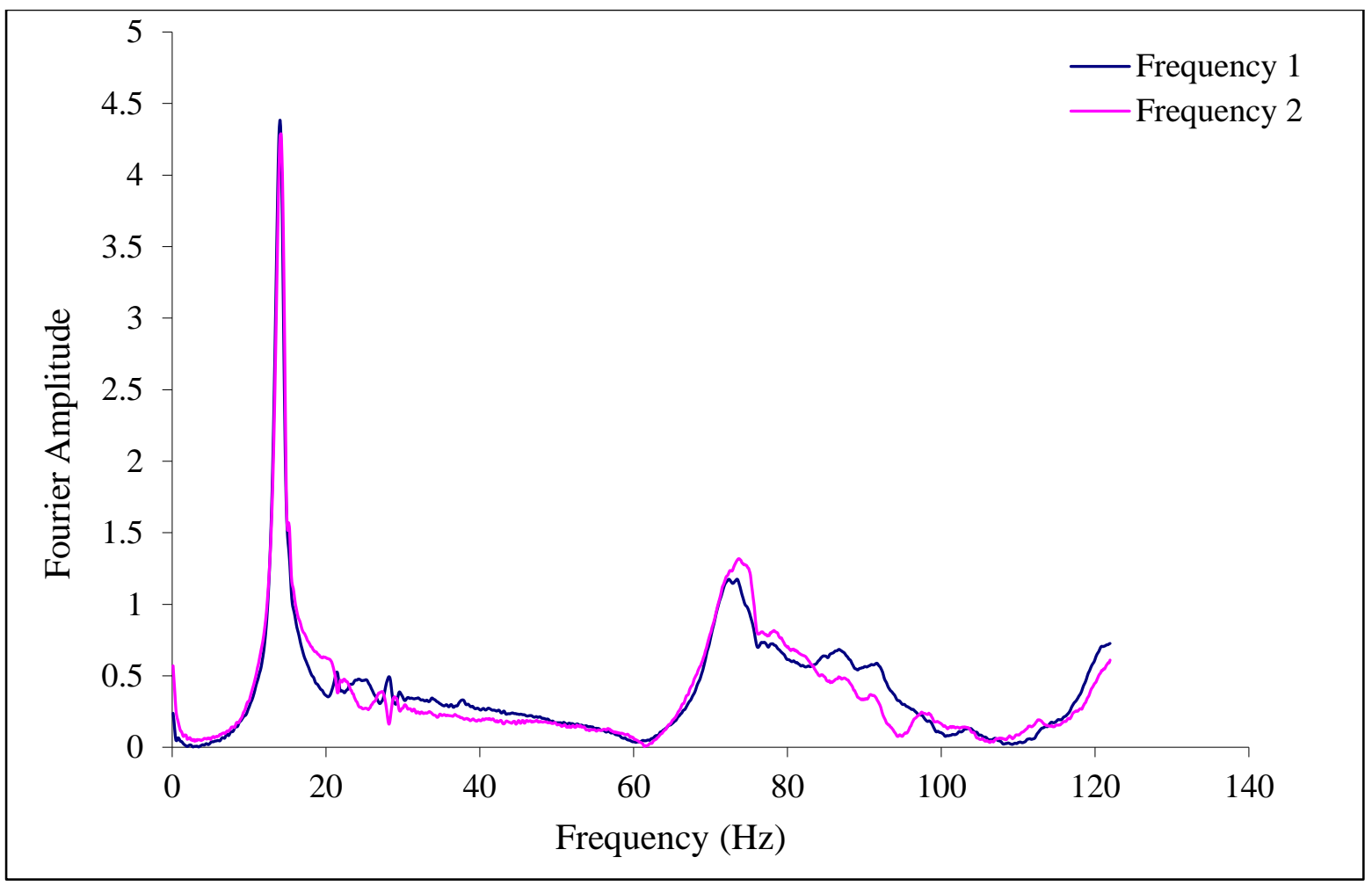

Figure A2.5: Typical frequency spectrum for 406x7950 mm wooden floor Joist 


\section{APPENDIX A3. LOAD DEFLECTION CURVES FOR WOODEN JOISTS}




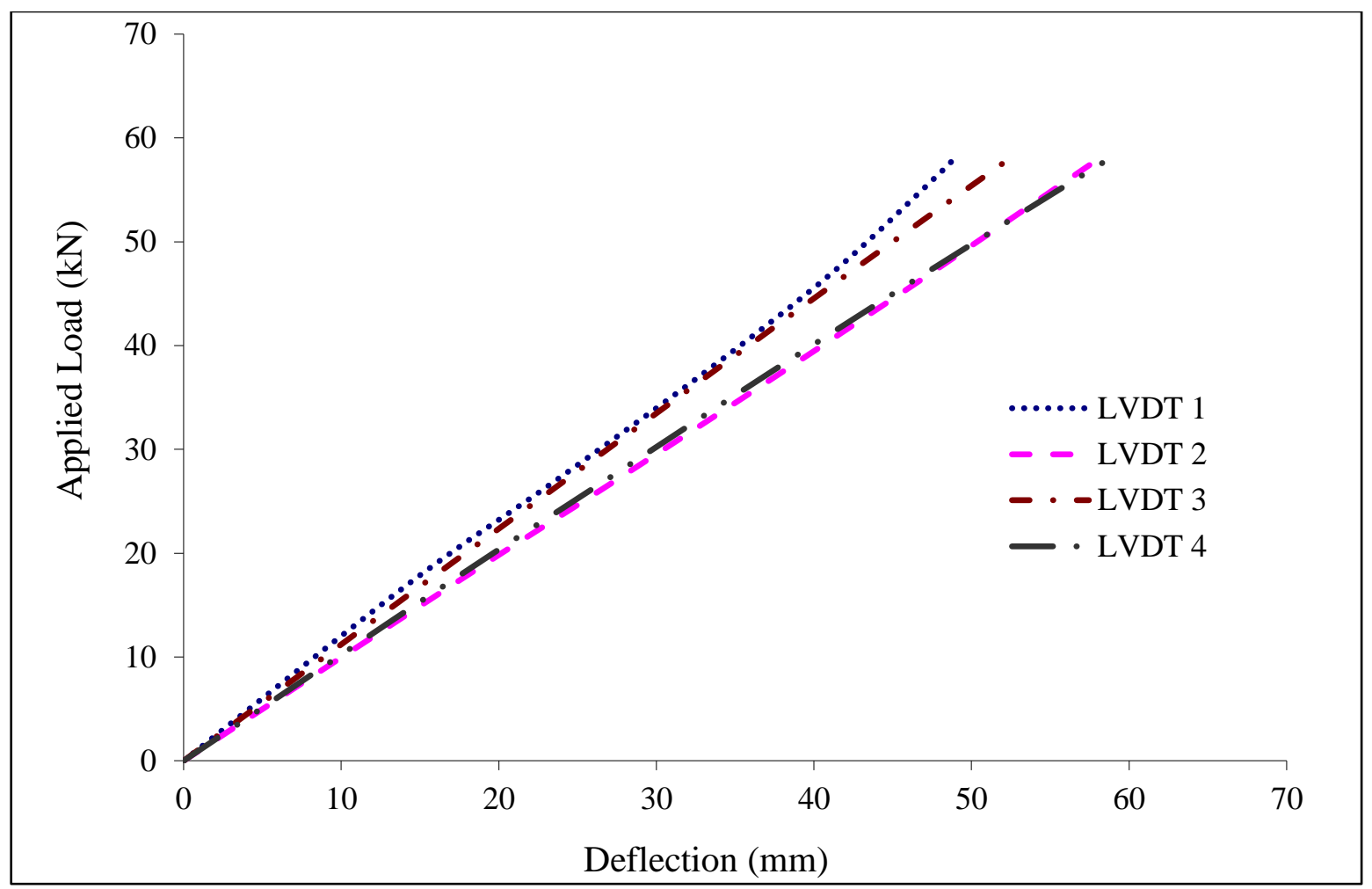

Figure A3.1: Typical load deflection curve for $241 \times 4500 \mathrm{~mm}$ wooden floor joist

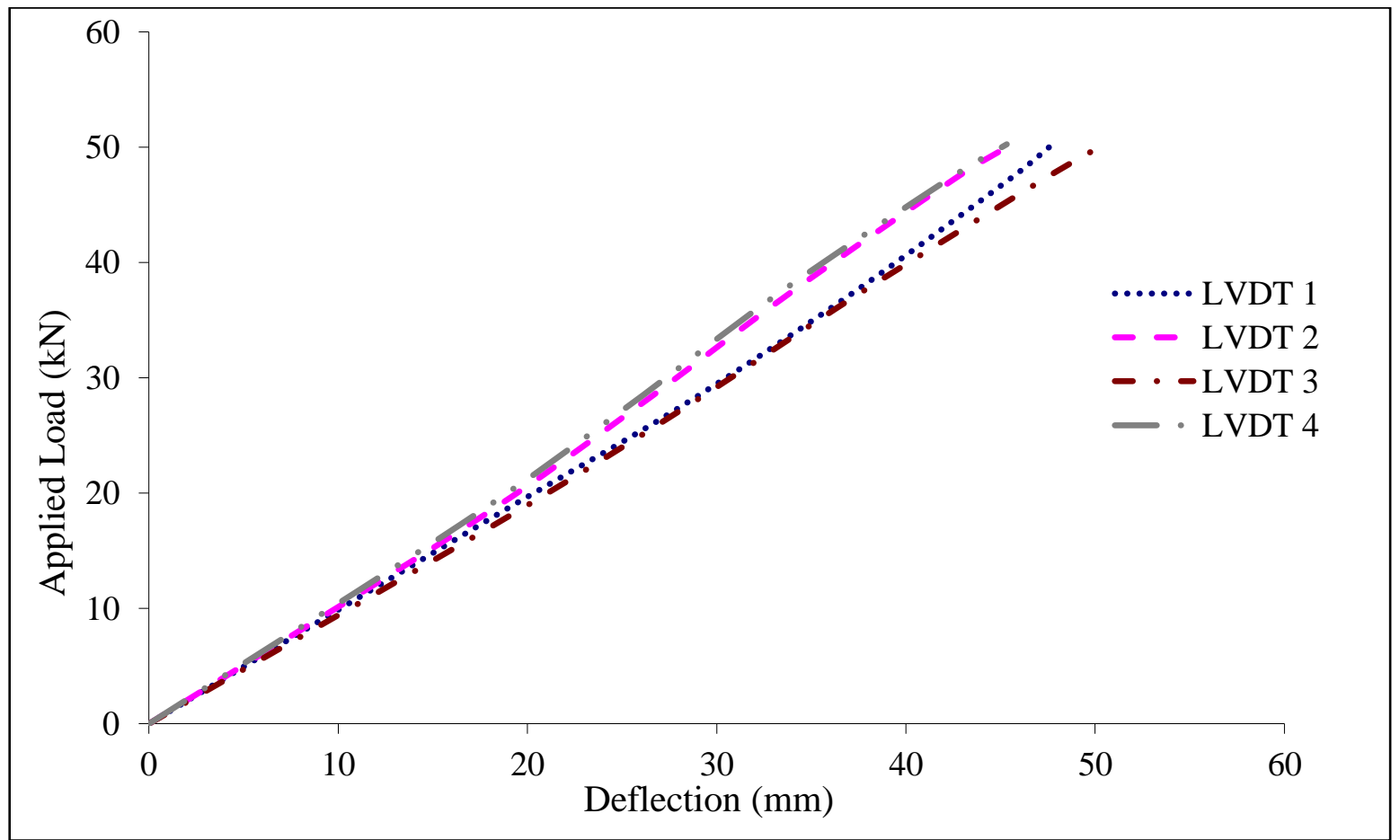

Figure A3.2: Typical load deflection curve for 302x5000 mm wooden floor joist 


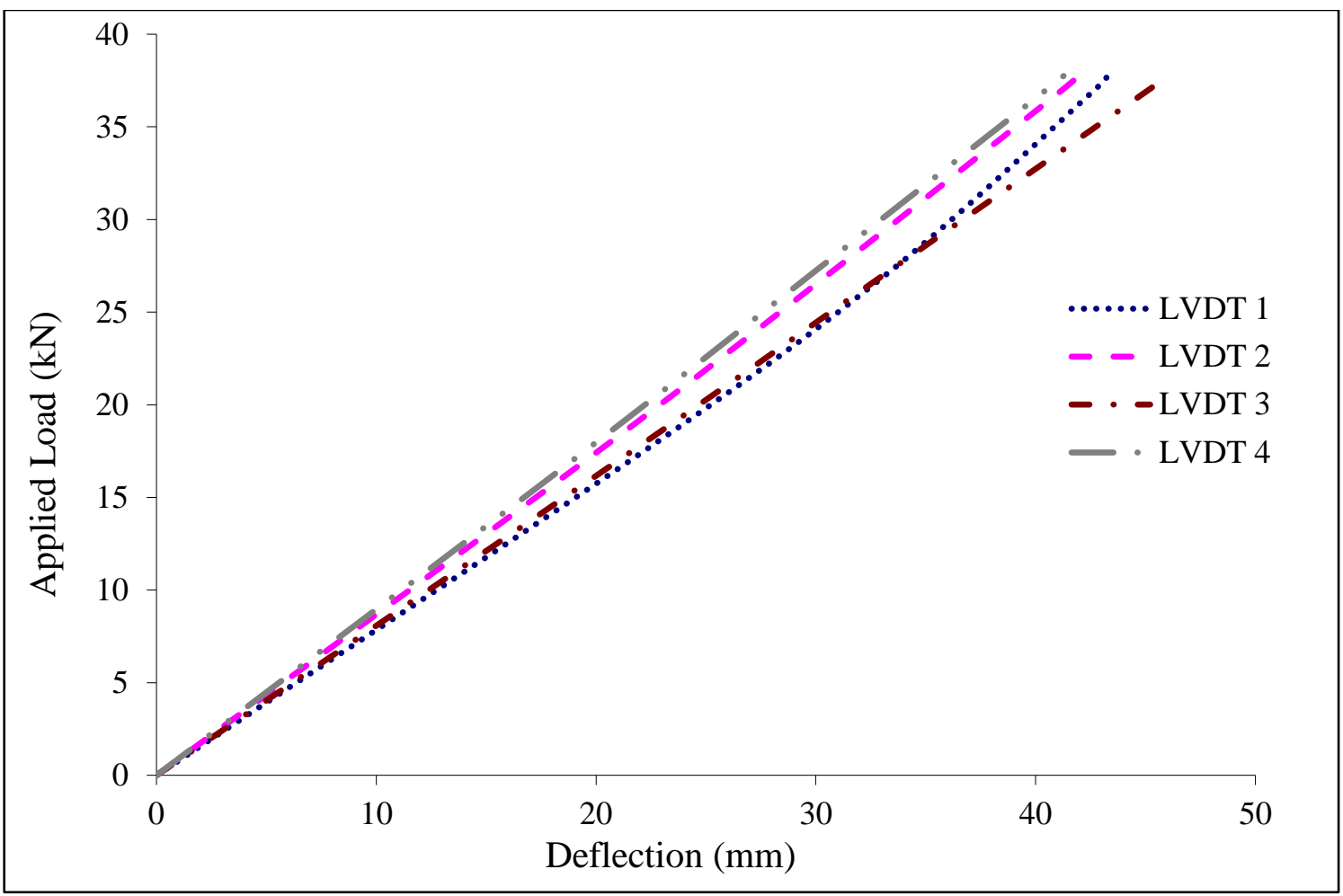

Figure A3.3: Typical load deflection curve for 302x5250 mm wooden floor joist

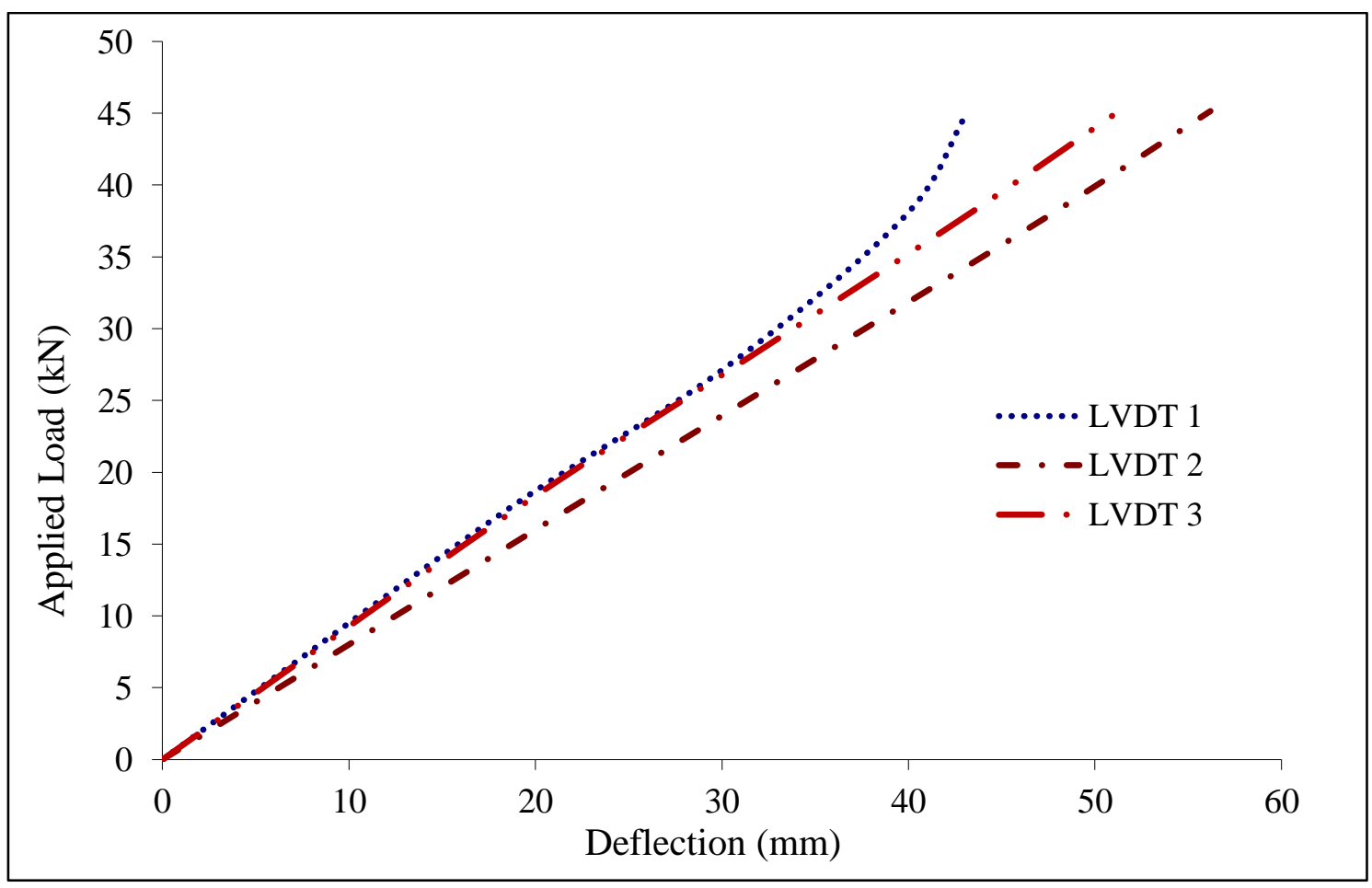

Figure A3.4: Typical load deflection curve for 356x6100 mm wooden floor joist 


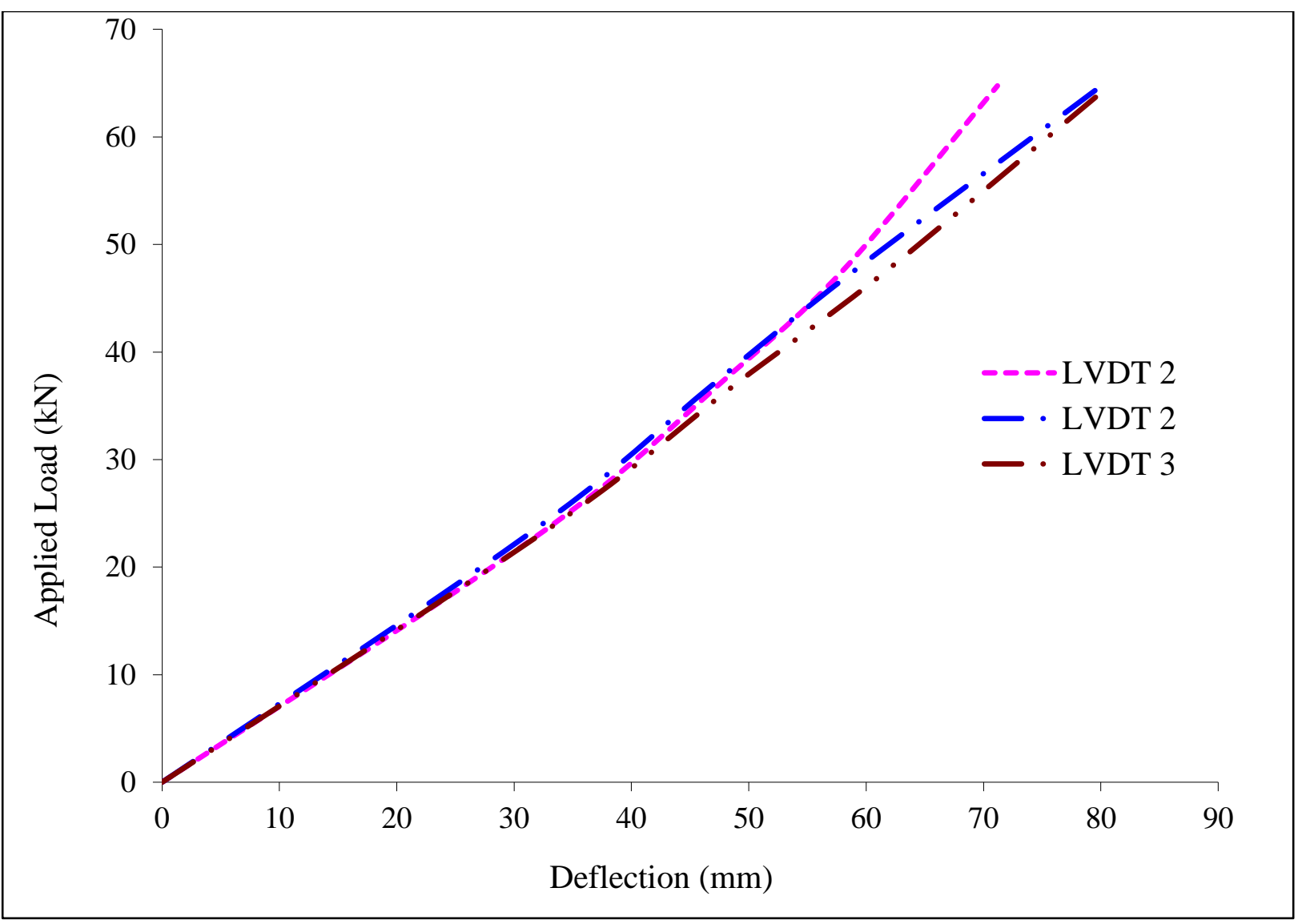

Figure A3.5: Typical load deflection curve for 406 x $7950 \mathrm{~mm}$ wooden floor joist 


\section{APENDEX B1. ACCELERATION SPECTRUM OF ISPAN JOISTS WITH NO HOLES}




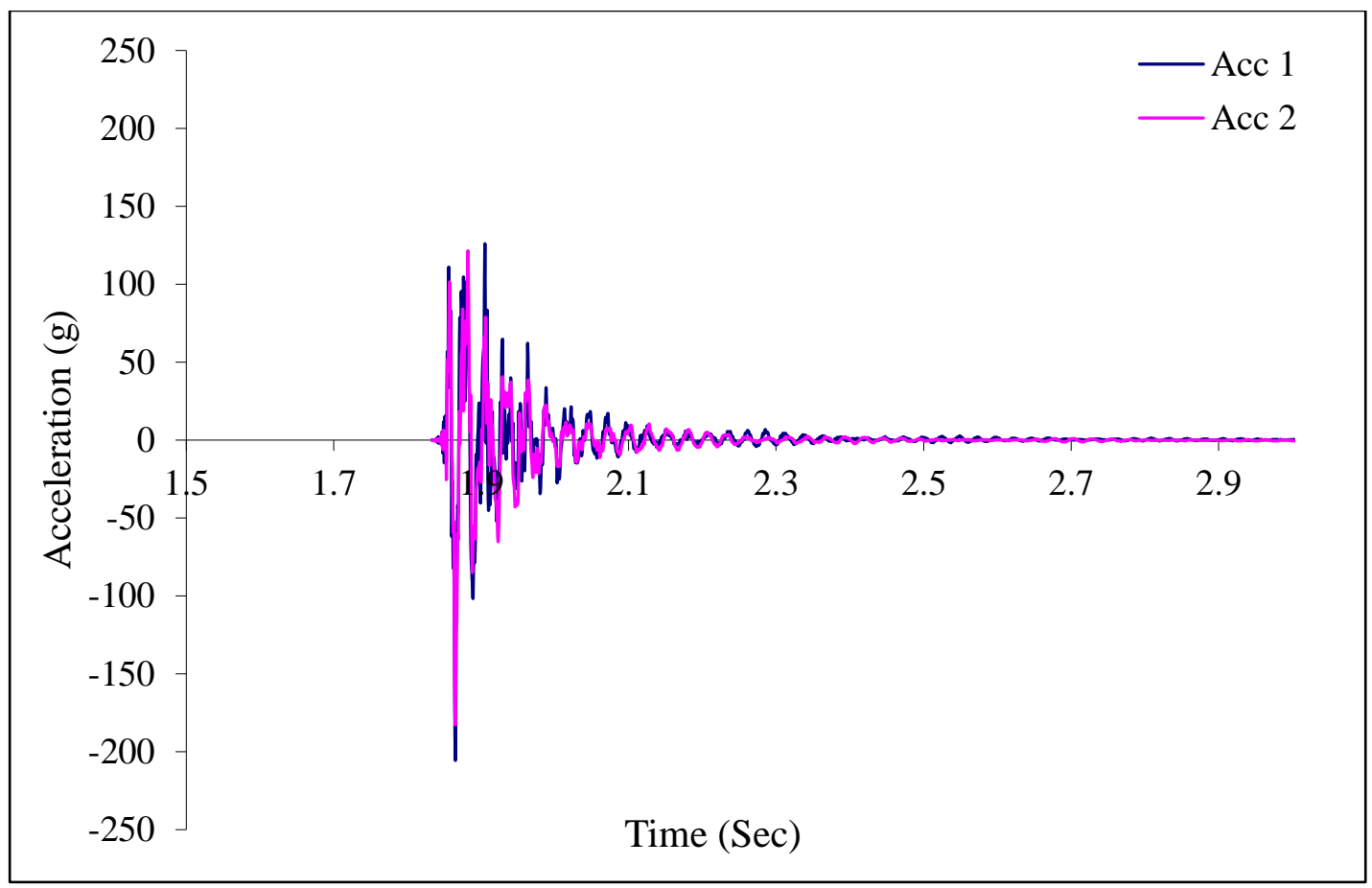

Figure B1.1: Typical acceleration trace for 241x3500 mm iSPAN floor joist (balloon framing)

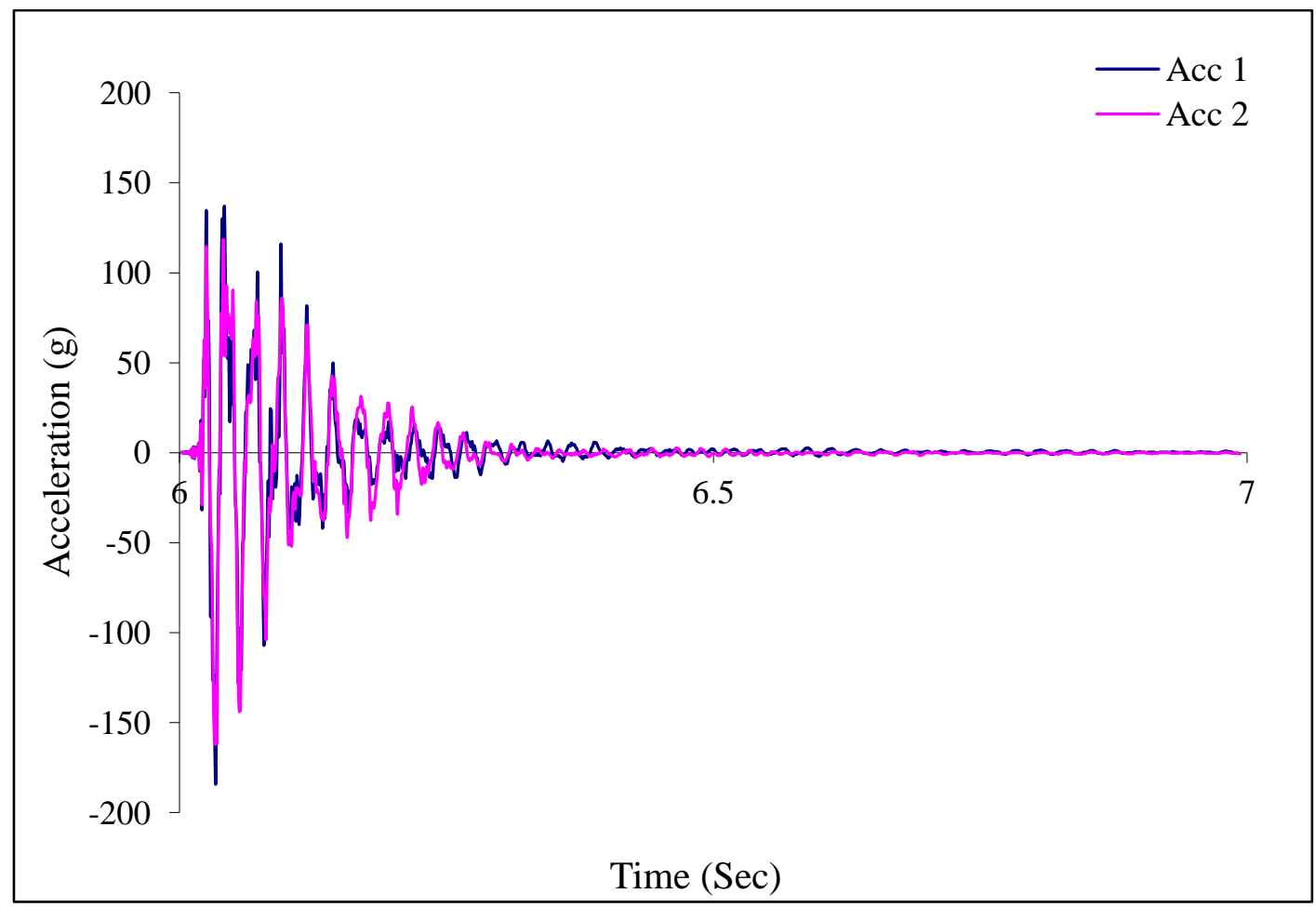

Figure B1.2: Typical acceleration trace for $241 \times 3500 \mathrm{~mm}$ iSPAN floor joist (simply supported) 


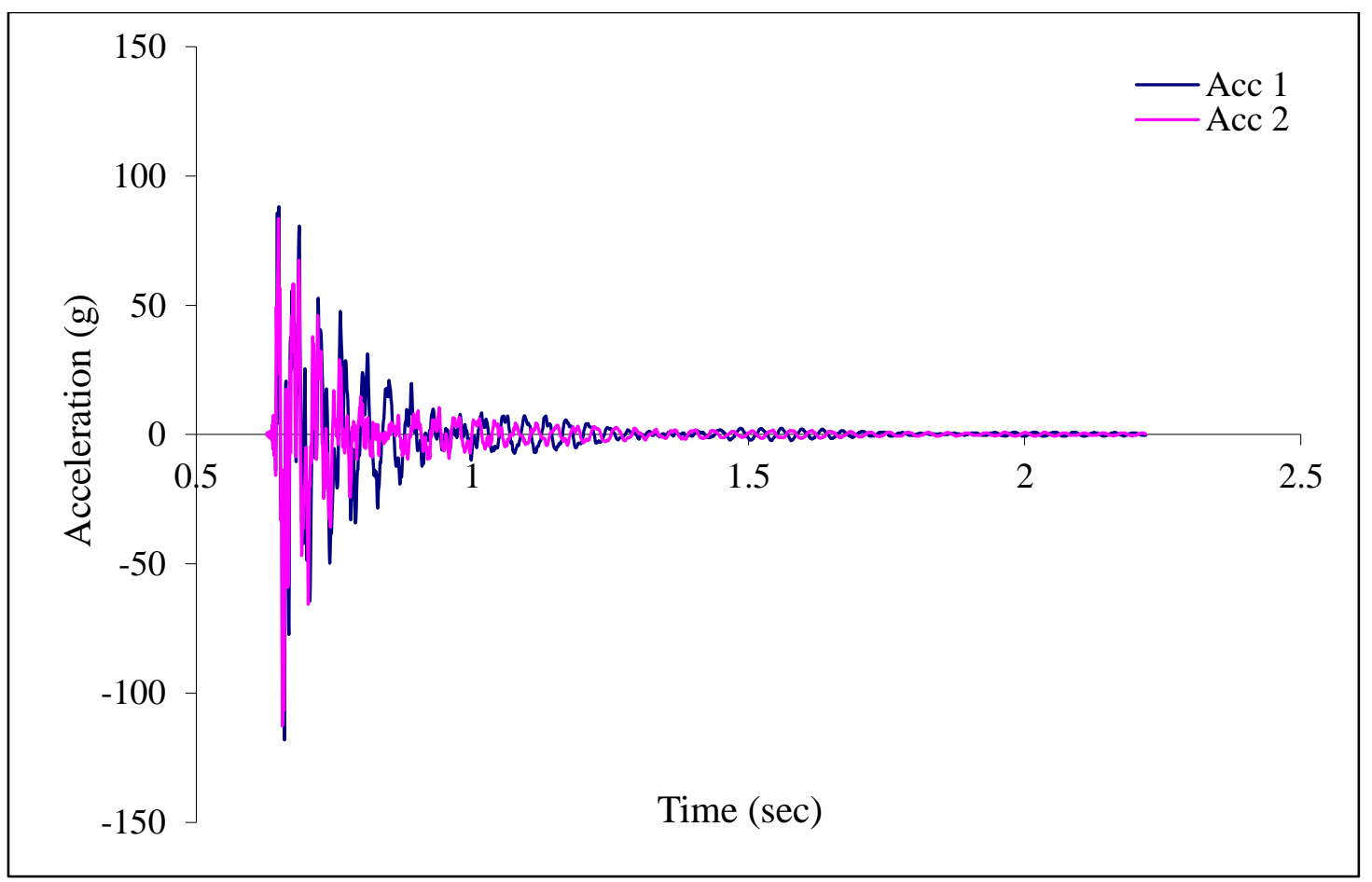

Figure B1.3: Typical acceleration trace for 241x4500 mm iSPAN floor joist (balloon framing)

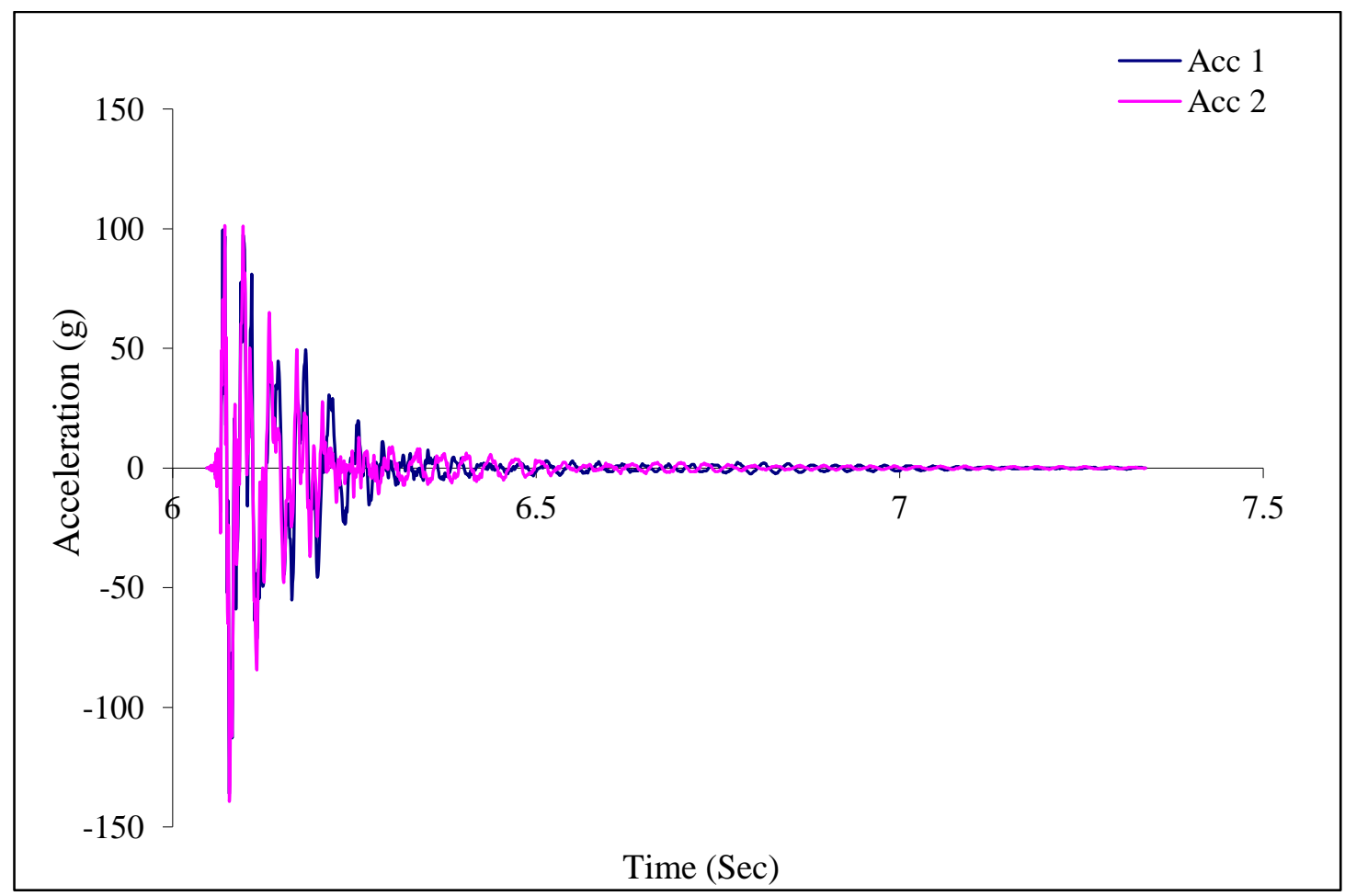

Figure B1.4: Typical acceleration trace for $241 \times 4500 \mathrm{~mm}$ iSPAN floor joist (simply supported) 


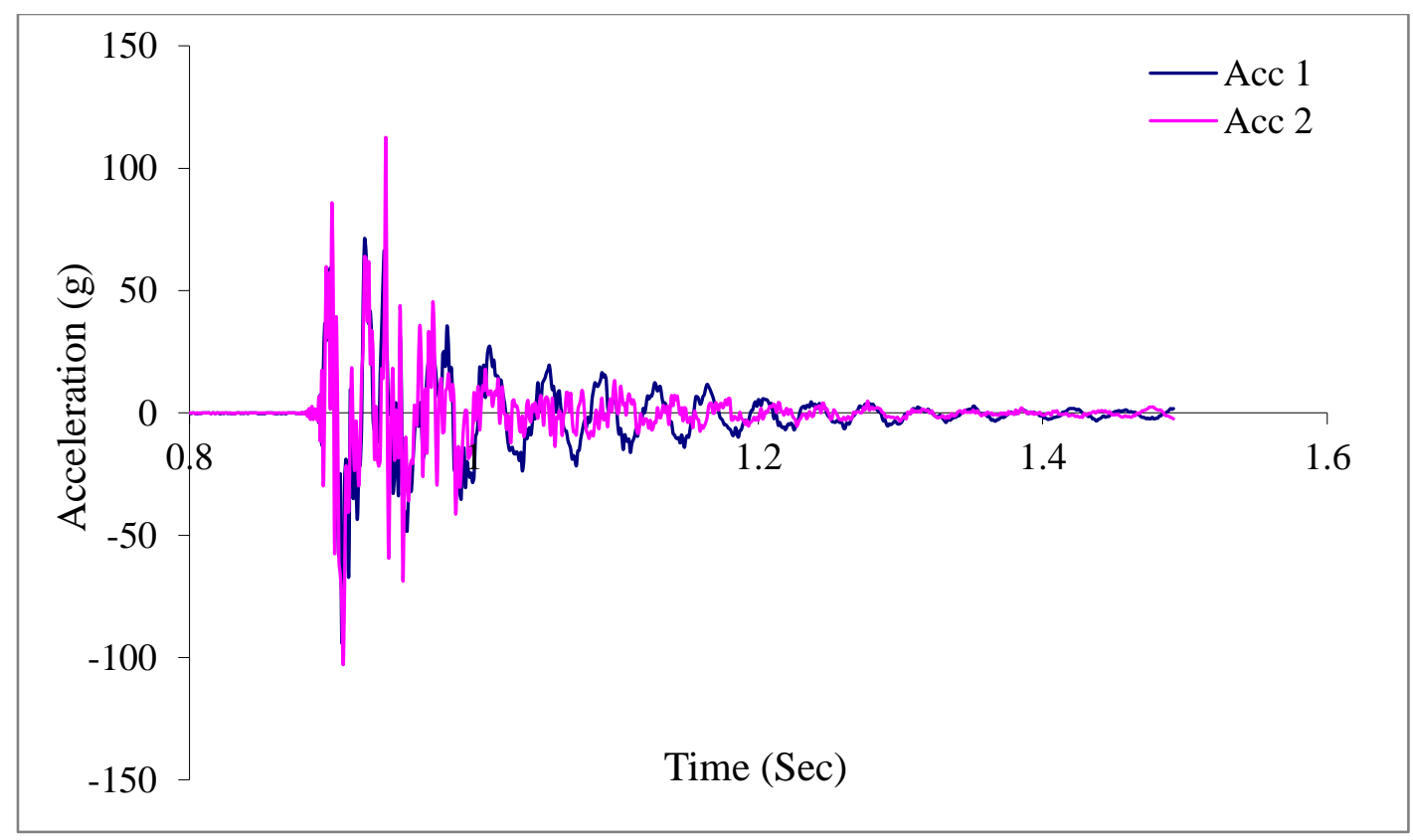

Figure B1.5: Typical acceleration trace for $302 \times 5000 \mathrm{~mm}$ iSPAN floor joist (balloon framing)

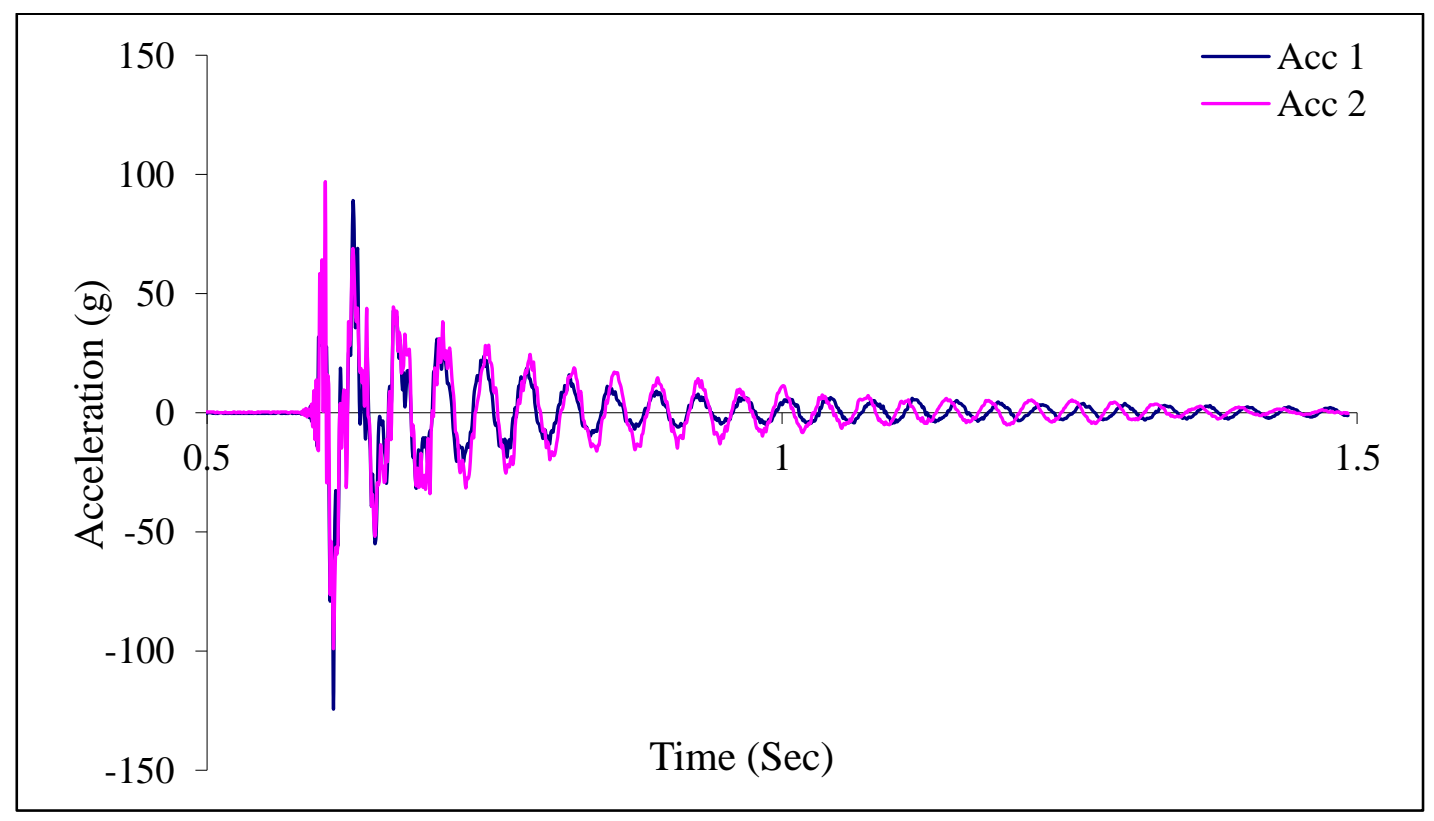

Figure B1.6: Typical acceleration trace for 302x5000 mm iSPAN floor joist (simply supported) 


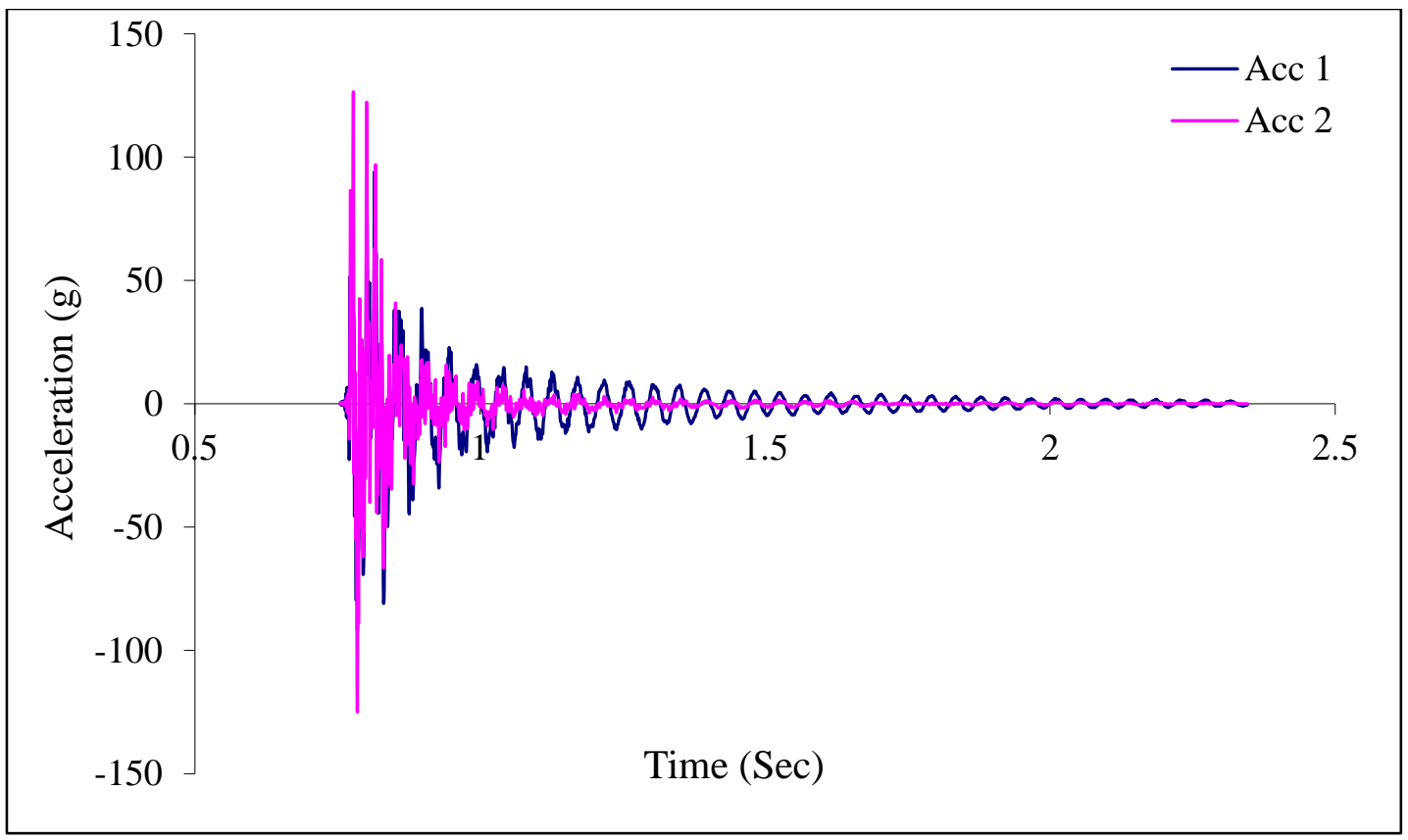

Figure B1.7: Typical acceleration trace for 302x5250 mm iSPAN floor joist (balloon framing)

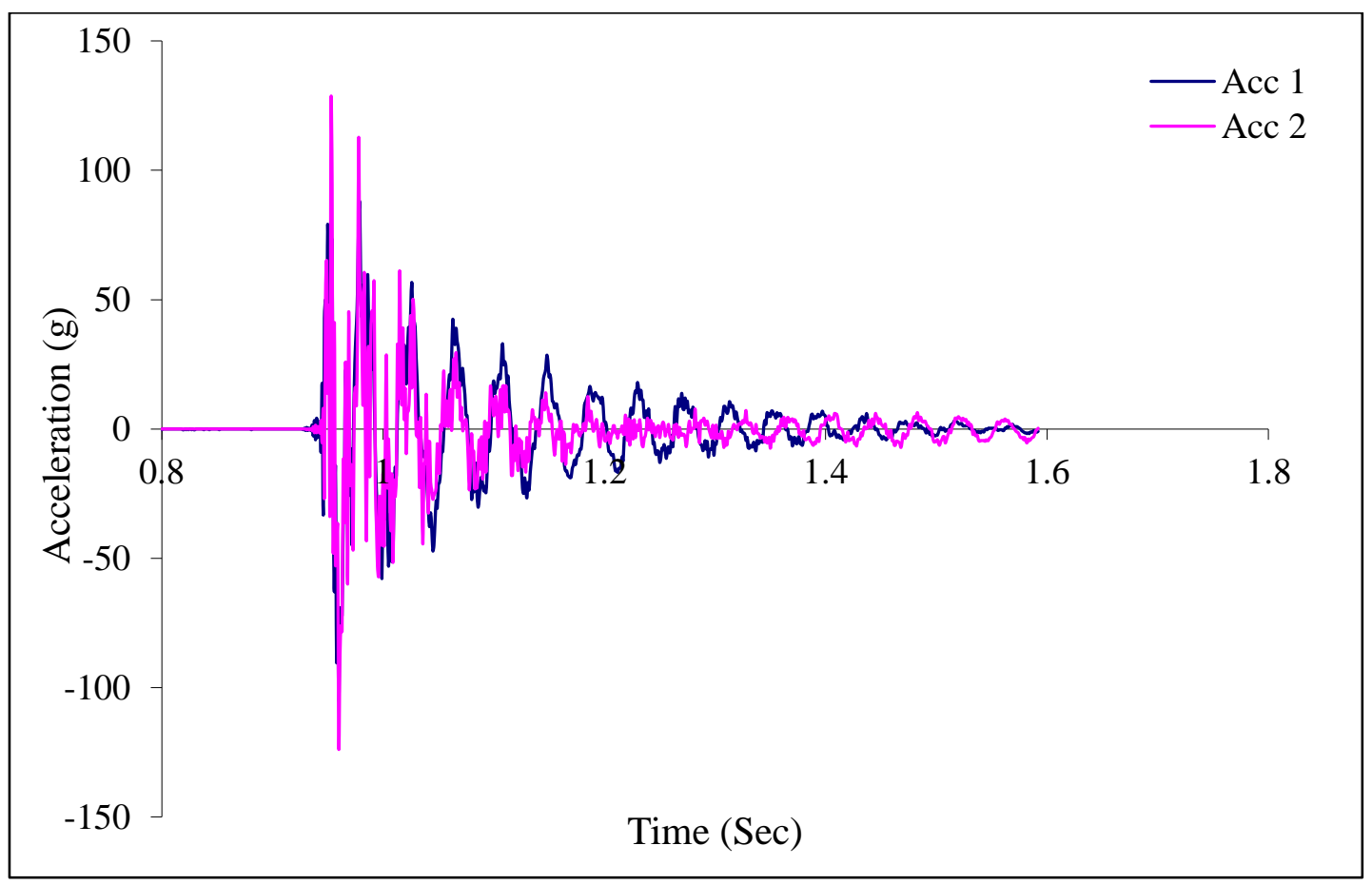

Figure B1.8: Typical acceleration trace for 302x5250 mm iSPAN floor joist (simply supported) 


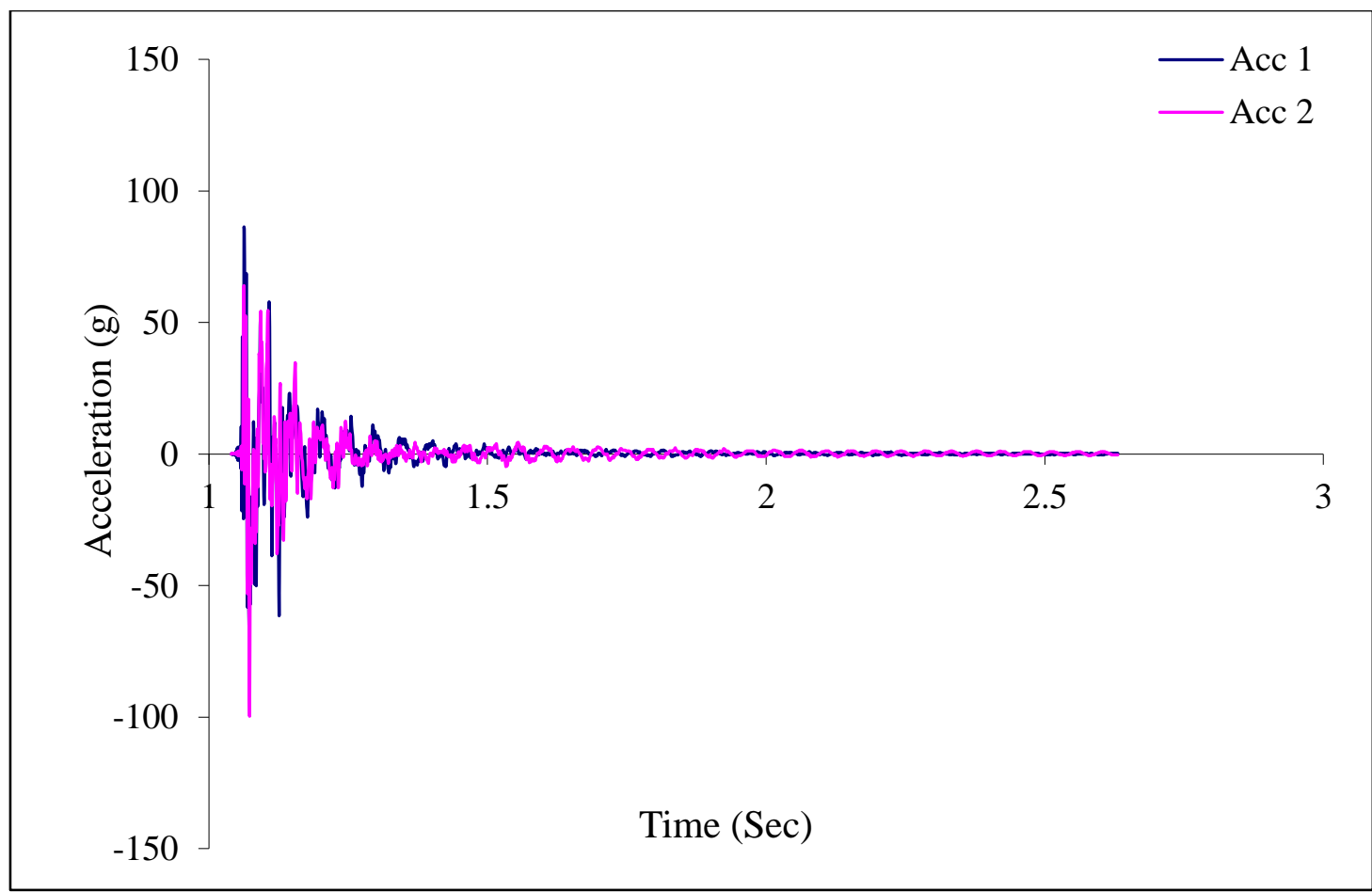

Figure B1.9: Typical acceleration trace for 356x6100 mm iSPAN floor joist (balloon framing)

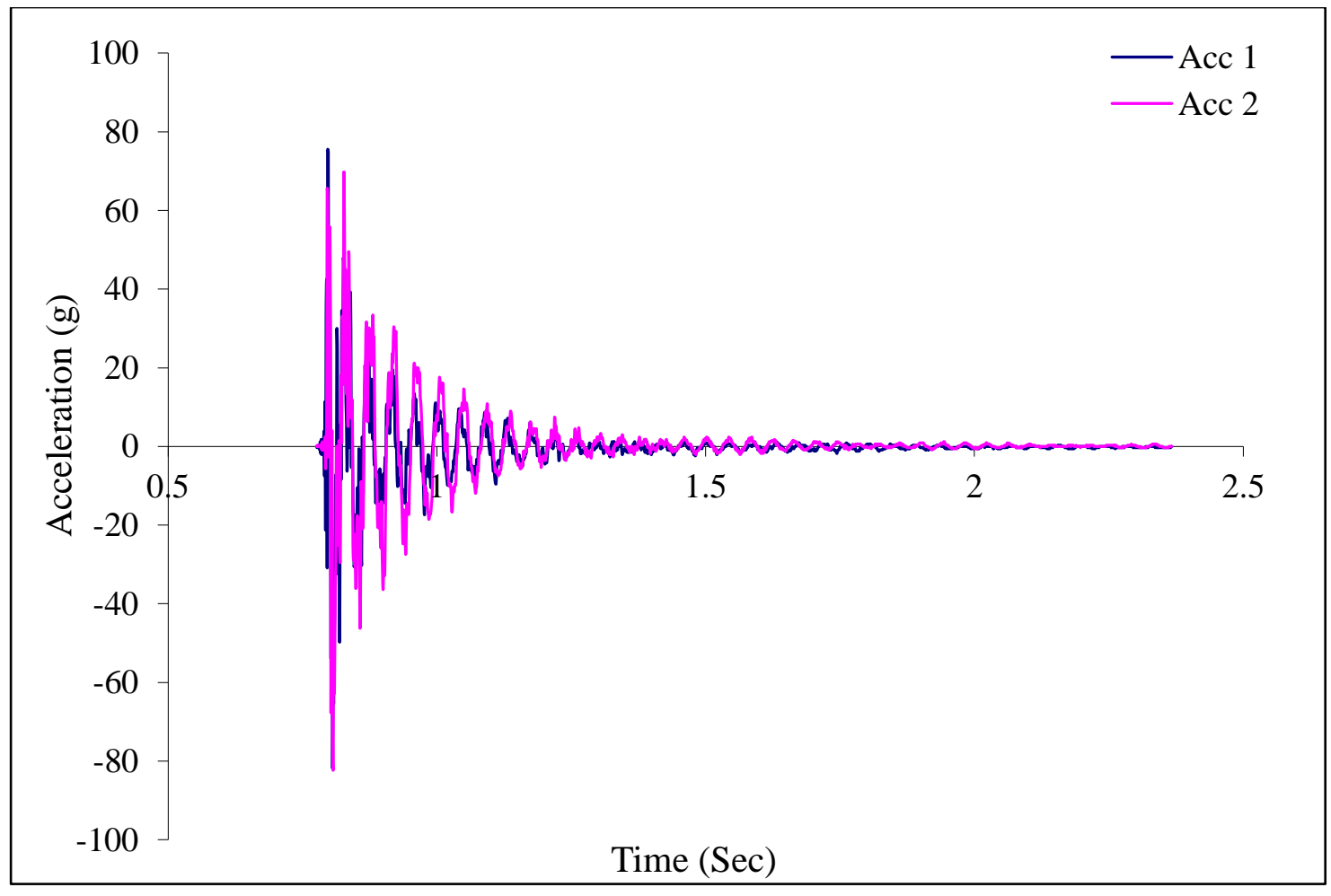

Figure B1.10: Typical acceleration trace for 356x6100 mm iSPAN floor joist (simply supported) 


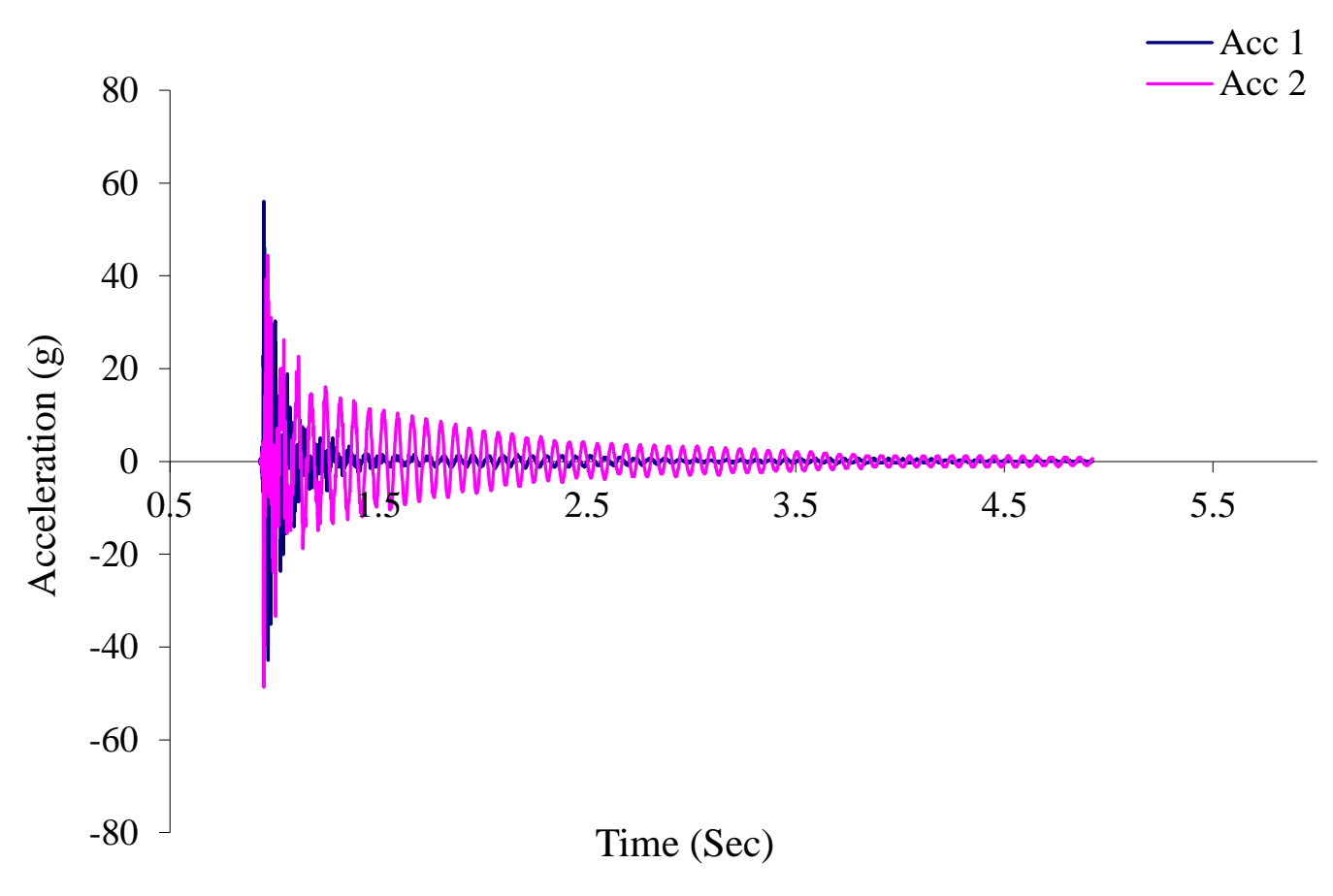

Figure B1.11: Typical acceleration trace for 406x7950 mm iSPAN floor joist (balloon framing)

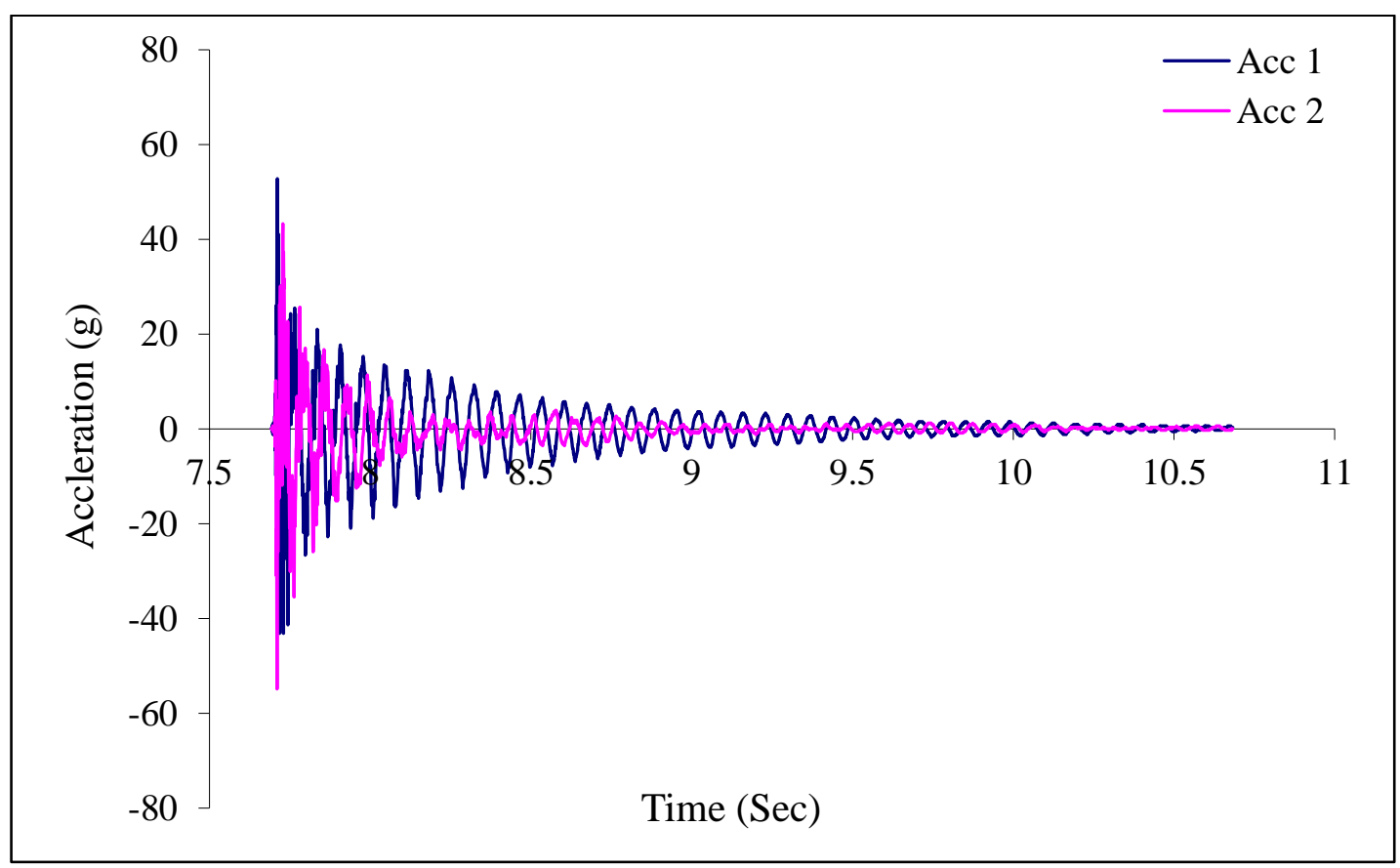

Figure B1.12: Typical acceleration trace for 406x7950 mm iSPAN floor joist (simply supported) 


\section{APPENDIX B2. NATURAL FREQUENCY SPECTRUM OF iSPAN JOISTS WITH NO HOLES}




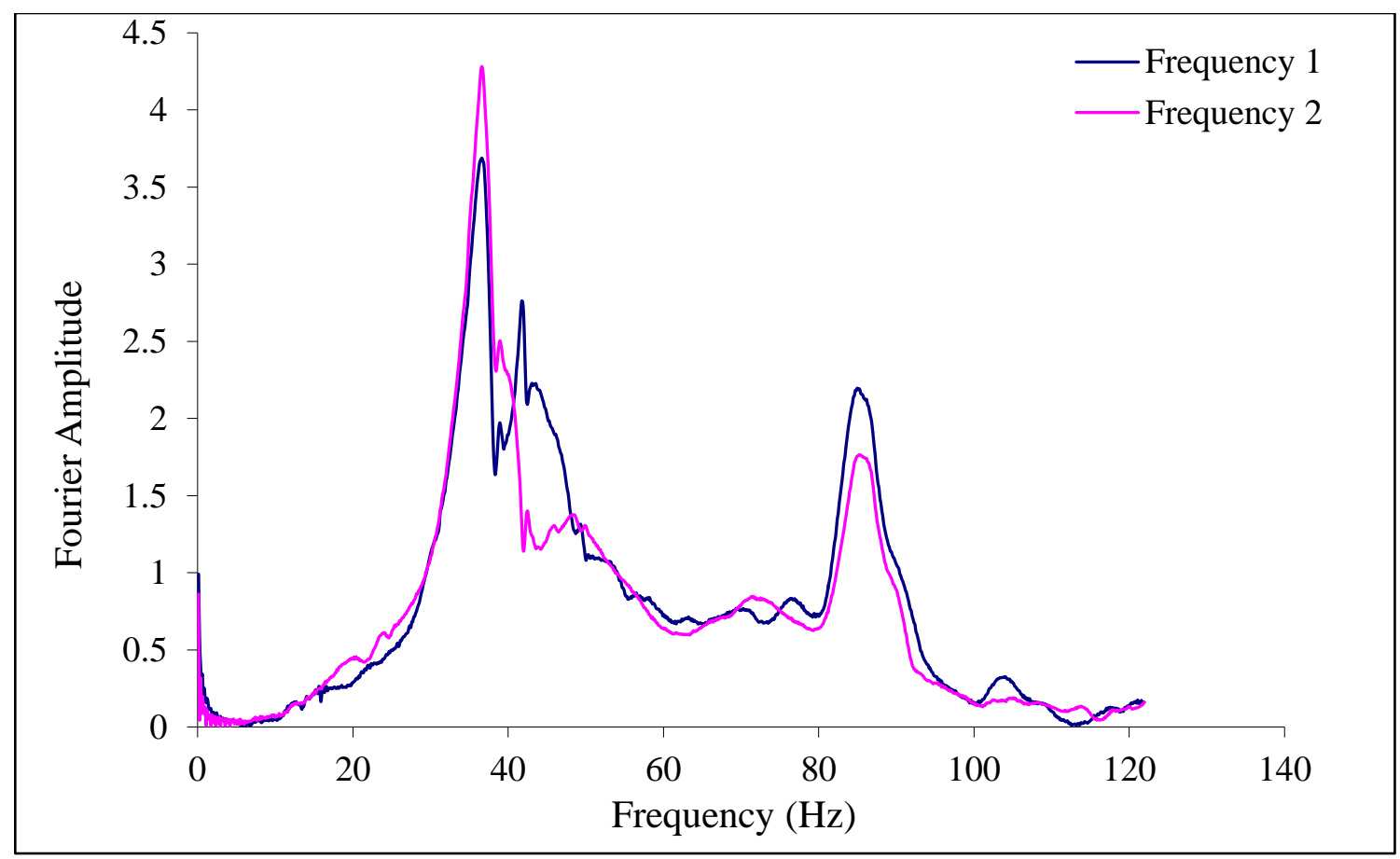

Figure B2.1: Typical frequency spectrum for 241x3500 mm iSPAN floor joist (balloon framing)

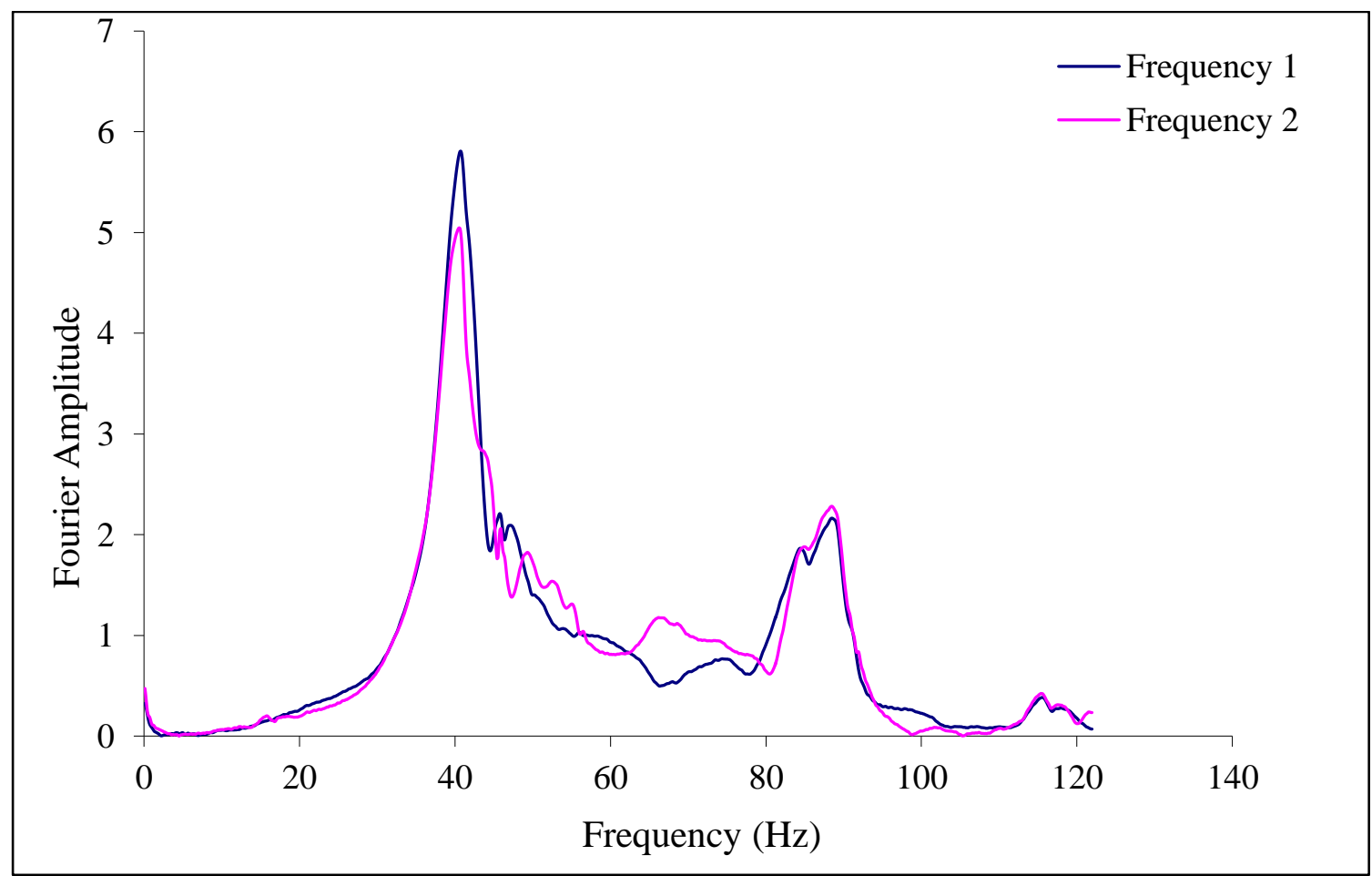

Figure B2.2: Typical frequency spectrum for 241x3500 mm iSPAN floor joist (simply supported) 


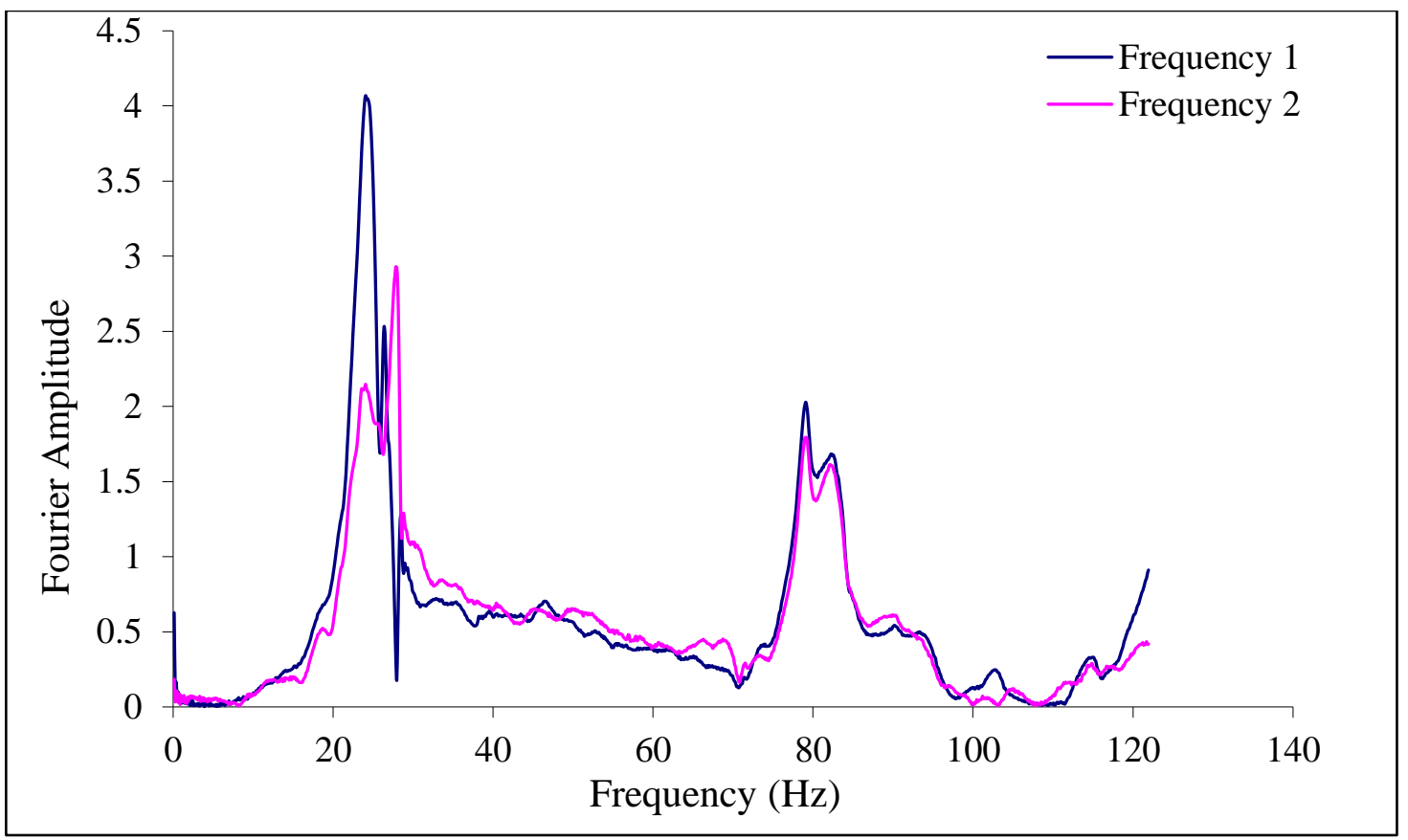

Figure B2.3: Typical frequency spectrum for 241x4500 mm iSPAN floor joist (balloon framing)

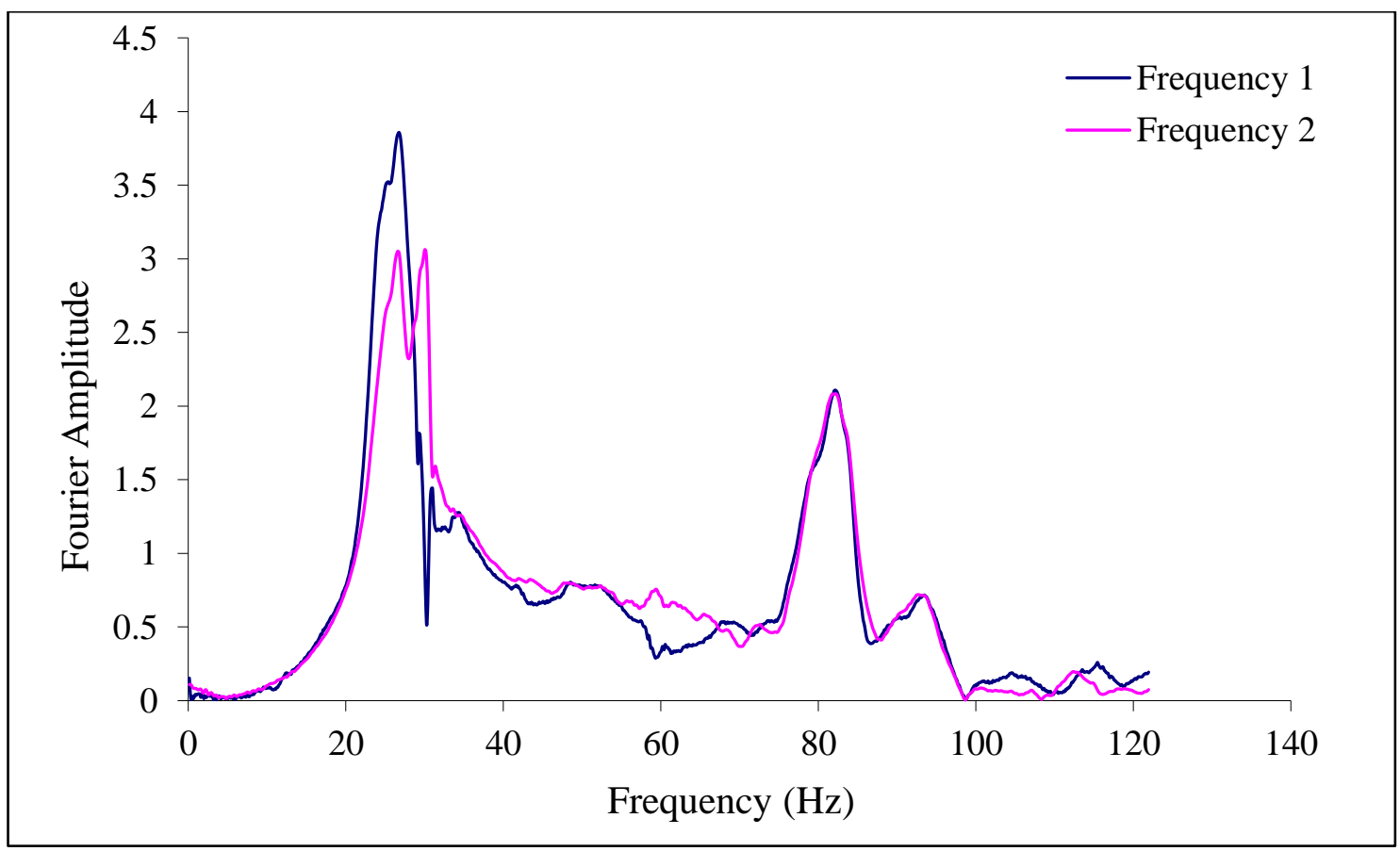

Figure B2.4: Typical frequency spectrum for $241 \times 4500 \mathrm{~mm}$ iSPAN floor joist (simply supported) 


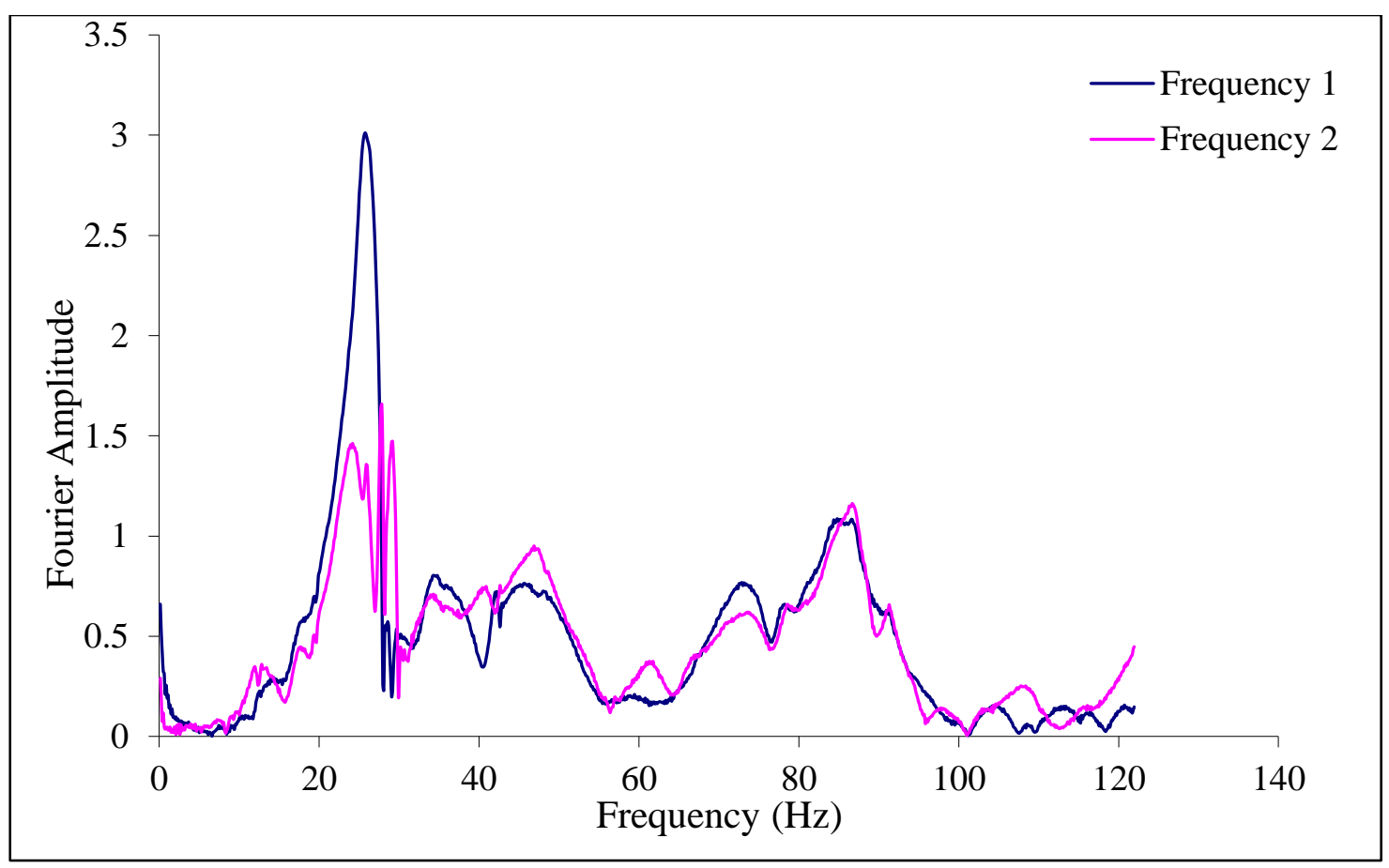

Figure B2.5: Typical frequency spectrum for 302x5000 mm iSPAN floor joist (balloon framing)

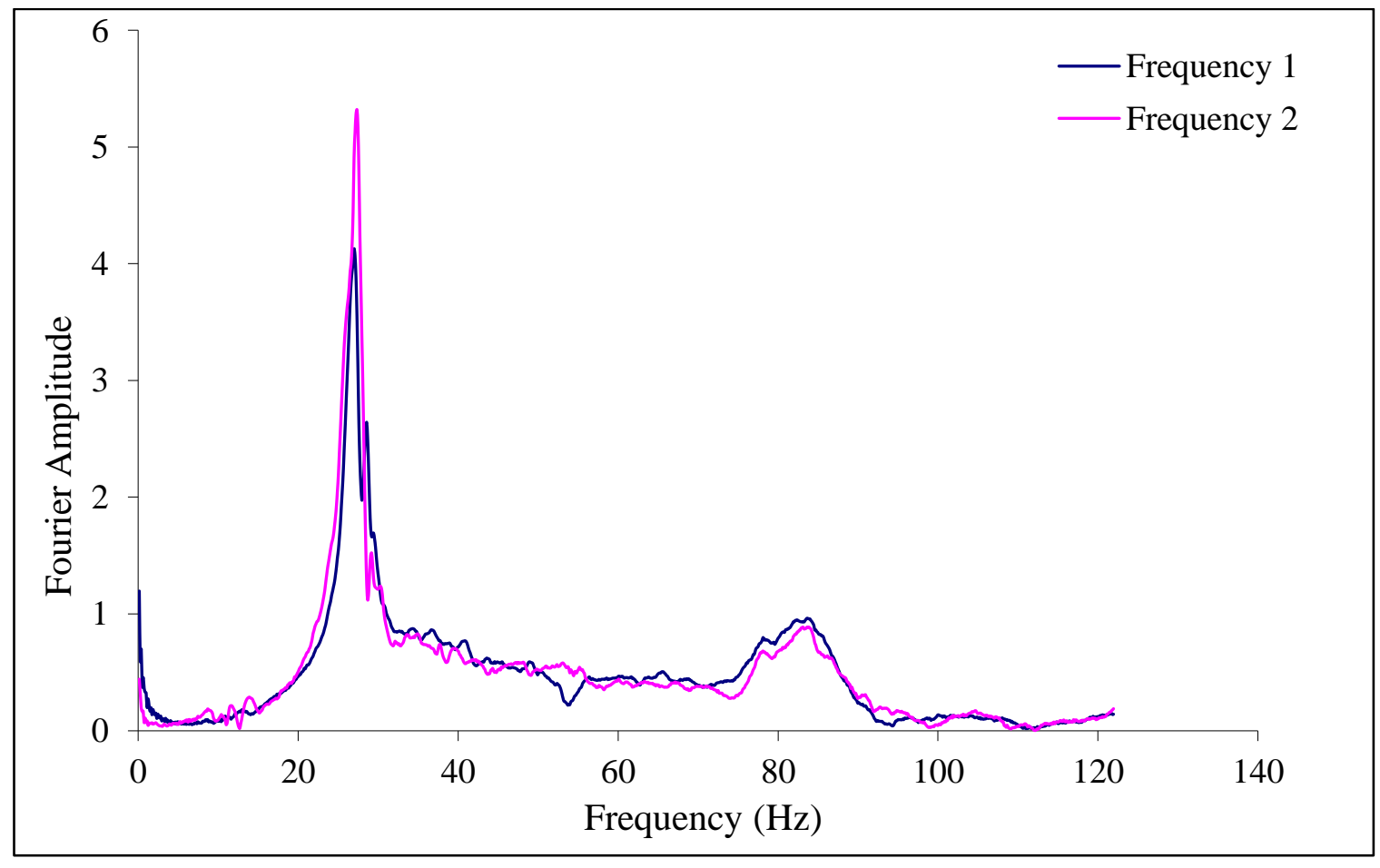

Figure B2.6: Typical frequency spectrum for 302x5000 mm iSPAN floor joist (simply supported) 


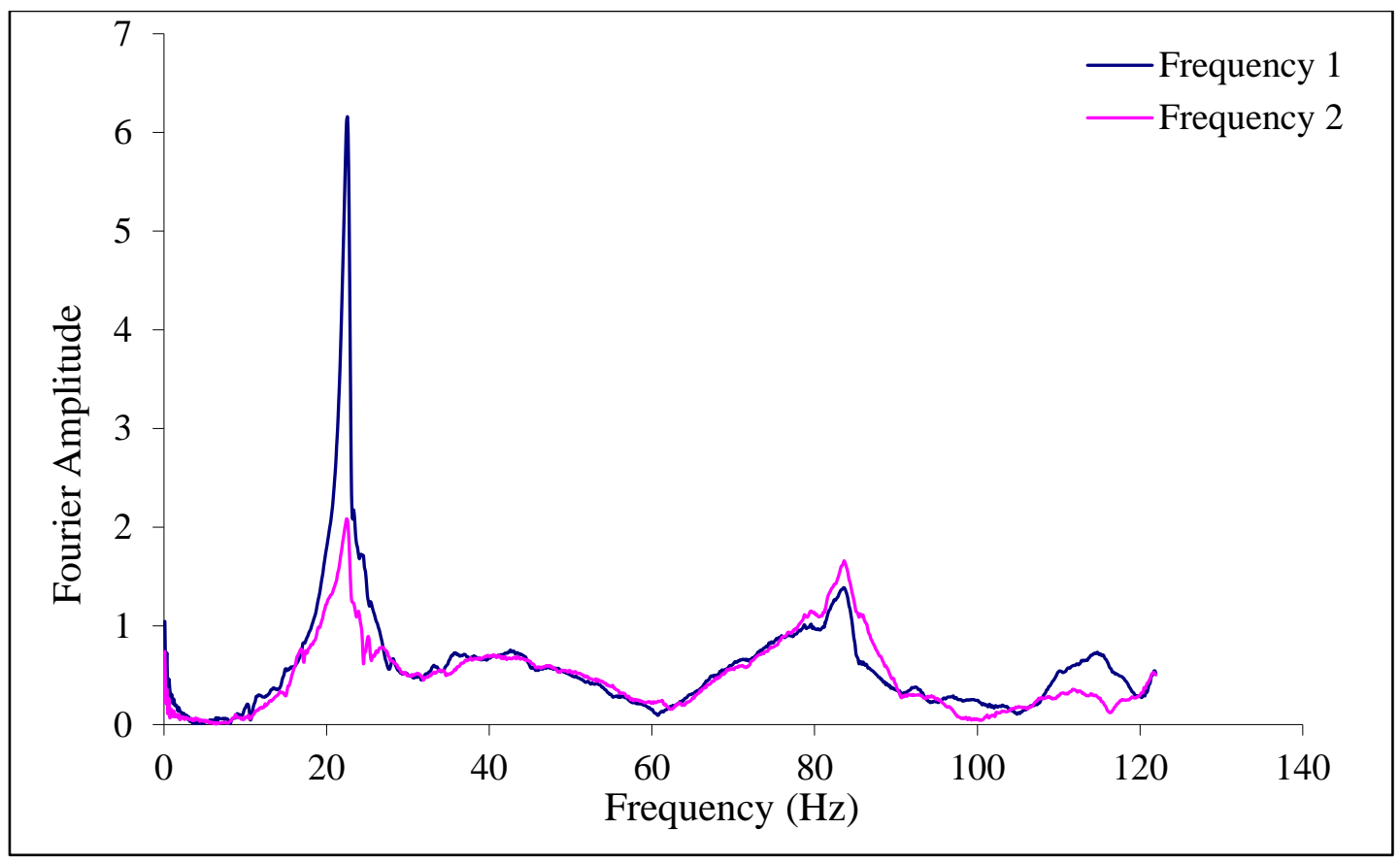

Figure B2.7: Typical frequency spectrum for 302x5250 mm iSPAN floor joist (balloon framing)

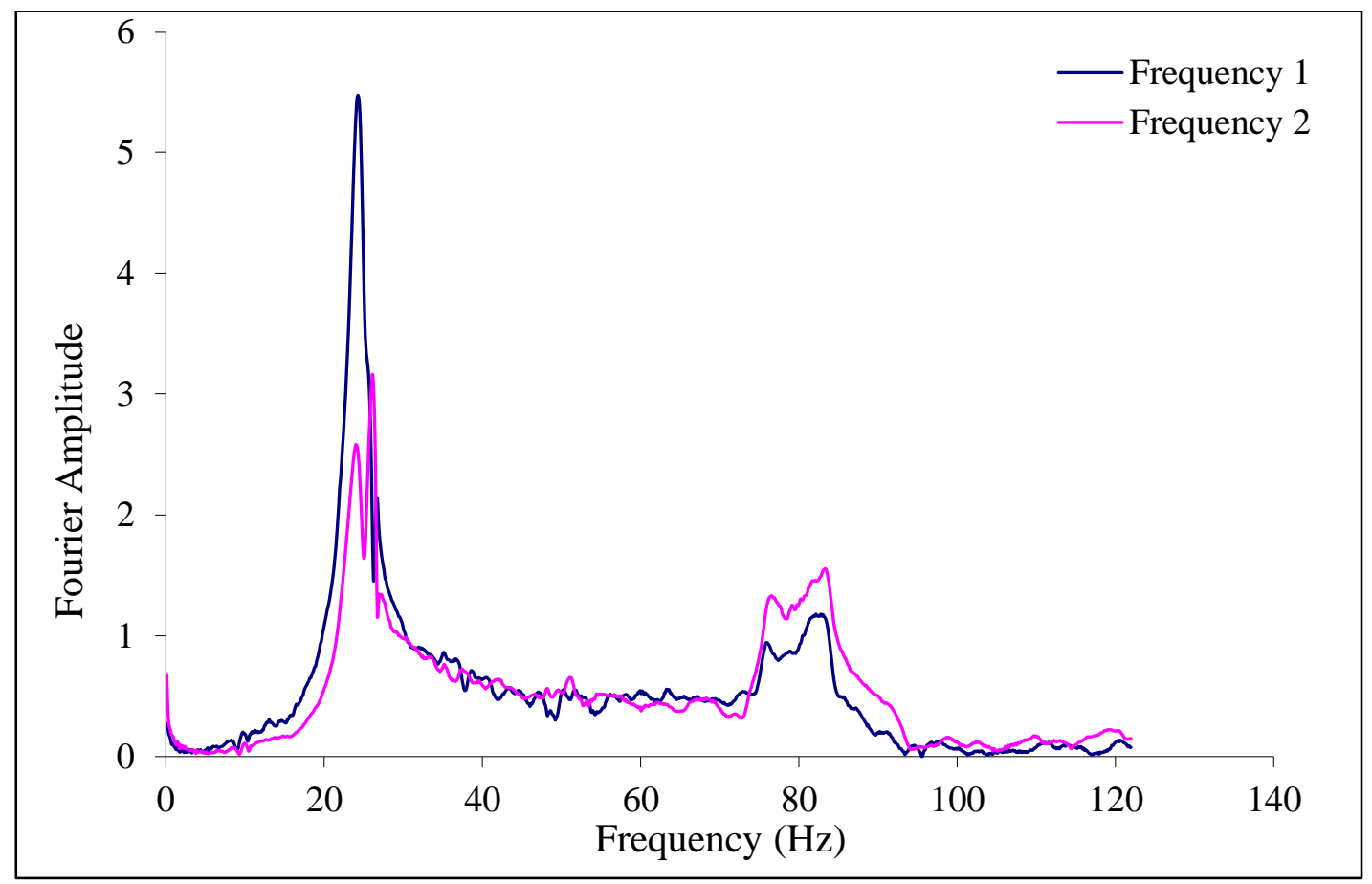

Figure B2.8: Typical frequency spectrum for 302x5250 mm iSPAN floor joist (simply supported) 


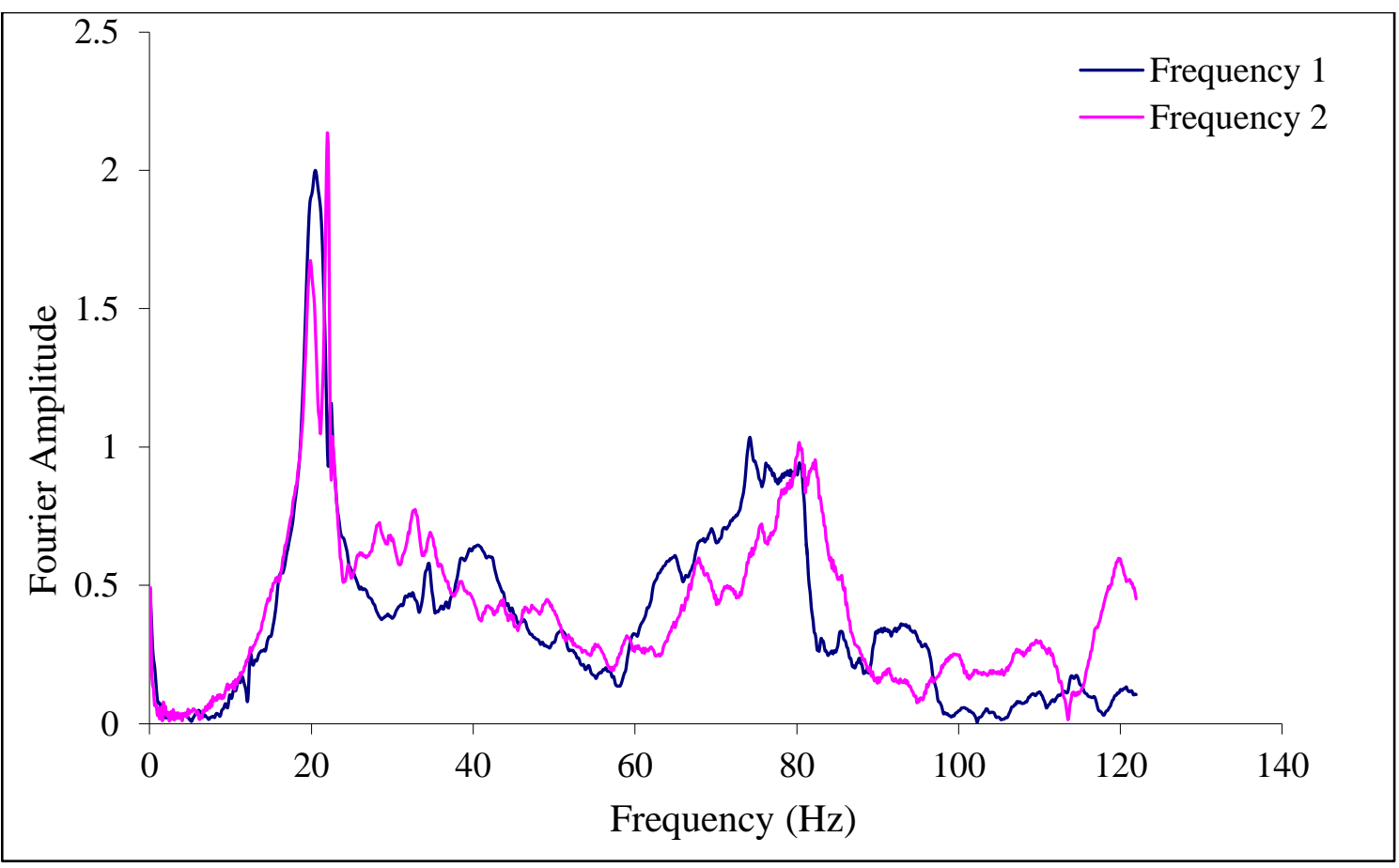

Figure B2.9: Typical frequency spectrum for 356x6100 mm iSPAN floor joist (balloon framing)

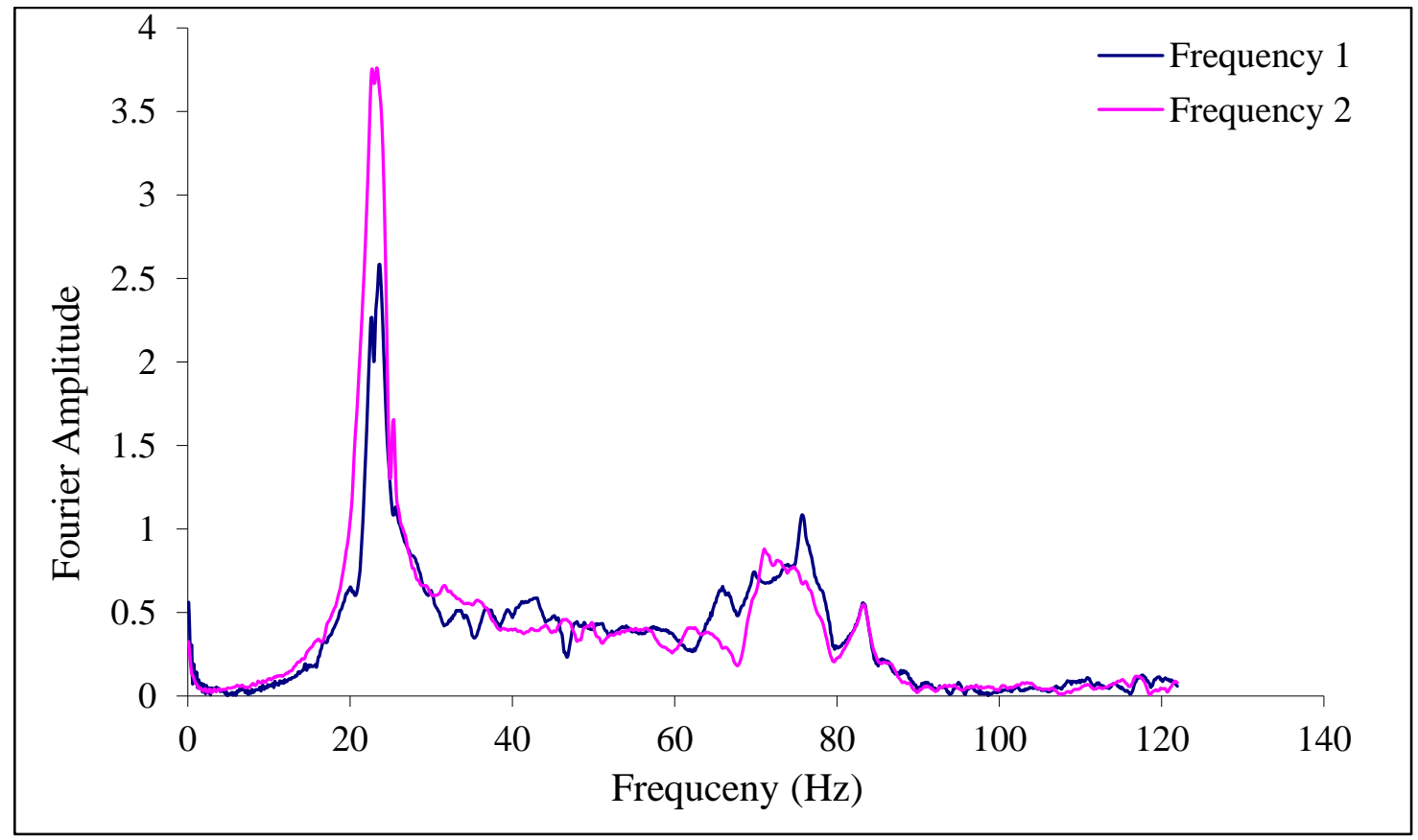

Figure B2.10: Typical frequency spectrum for 356x6100 mm iSPAN floor joist (simply supported) 


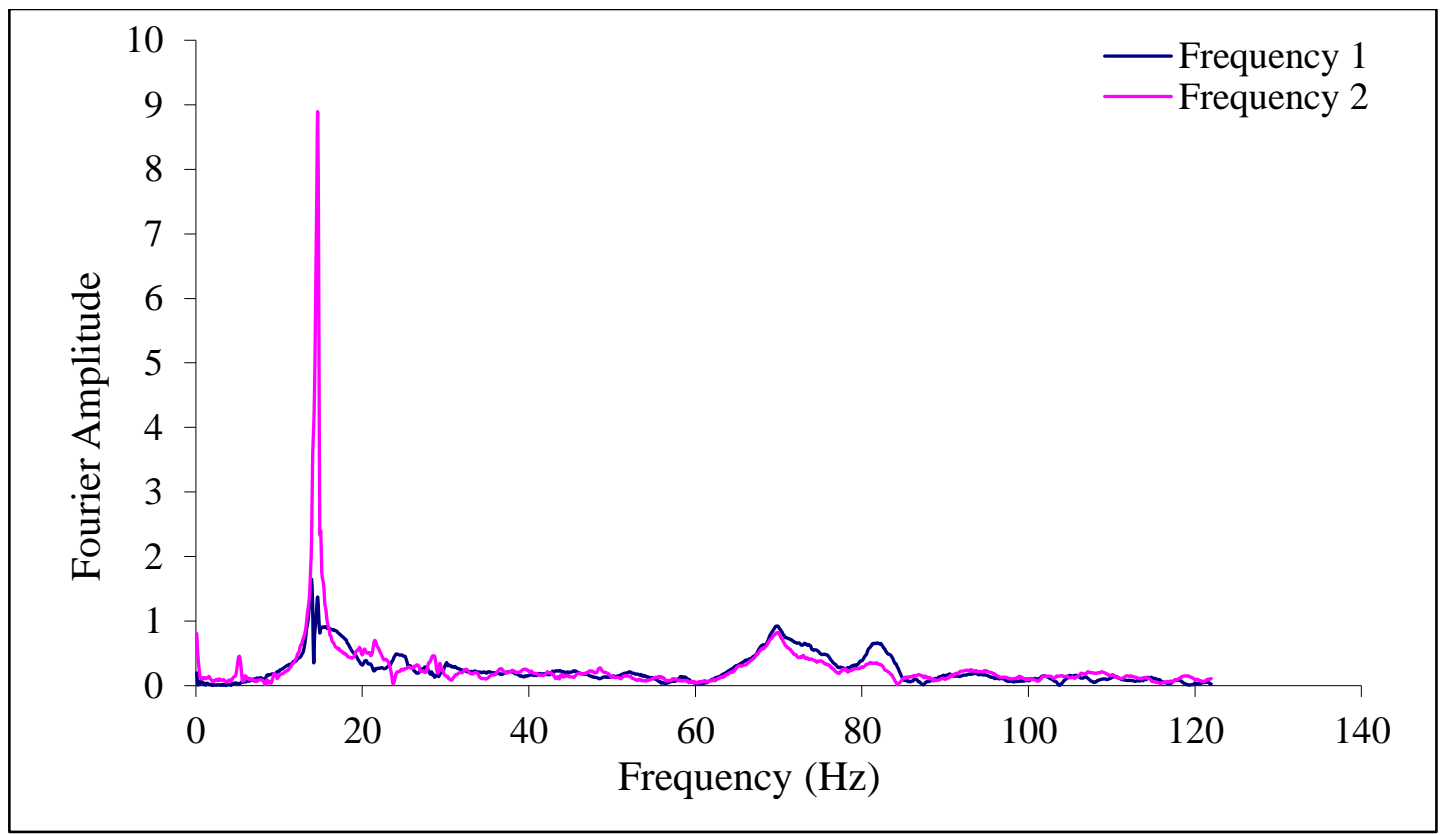

Figure B2.11: Typical frequency spectrum for 406x7950 mm iSPAN floor joist (balloon framing)

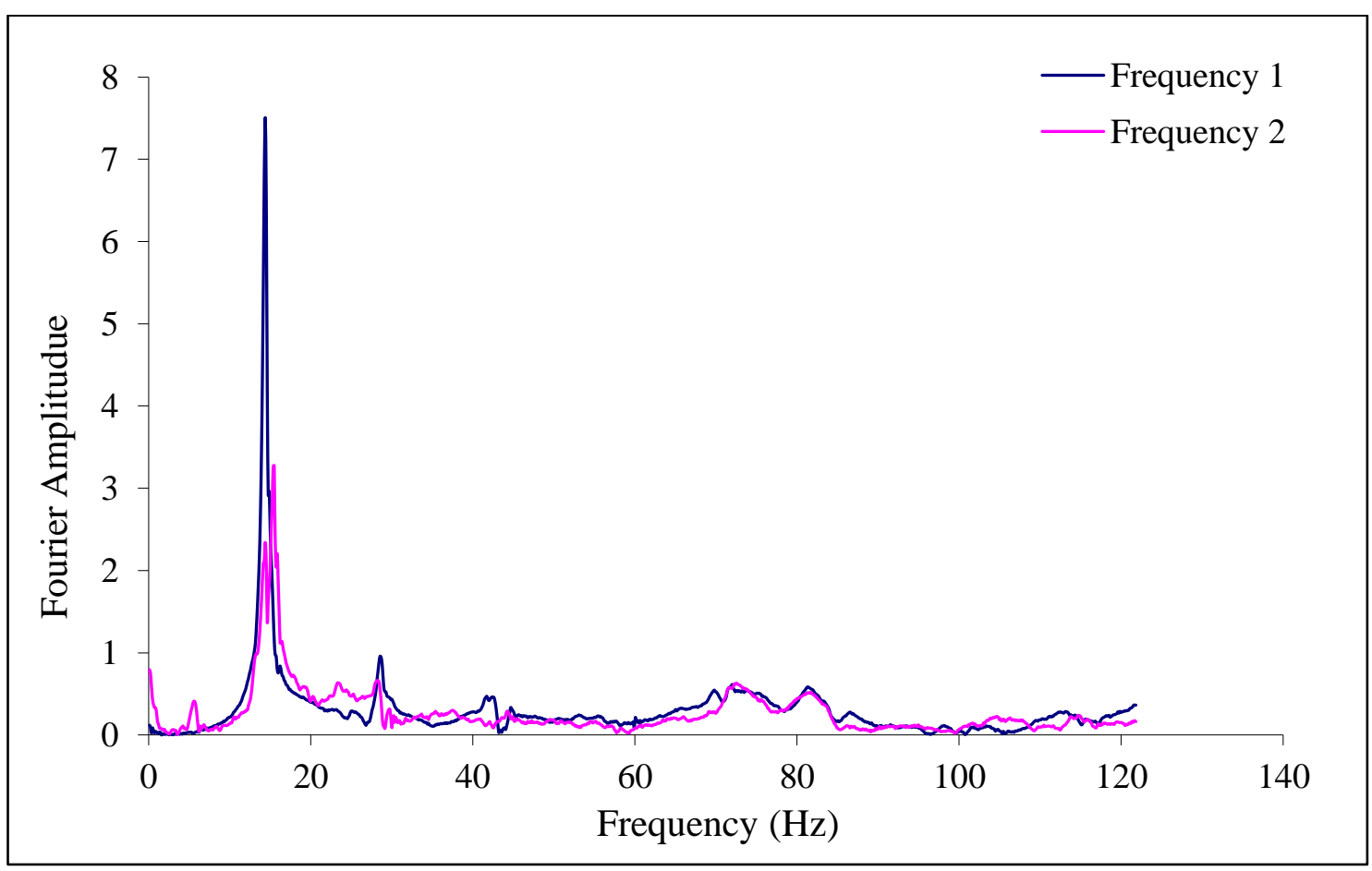

Figure B2.12: Typical frequency spectrum for 406x7950 mm iSPAN floor joist (simply supported) 


\section{APPENDIX B3. LOAD DEFLECTION CURVES OF iSPAN JOISTS WITH NO HOLES}




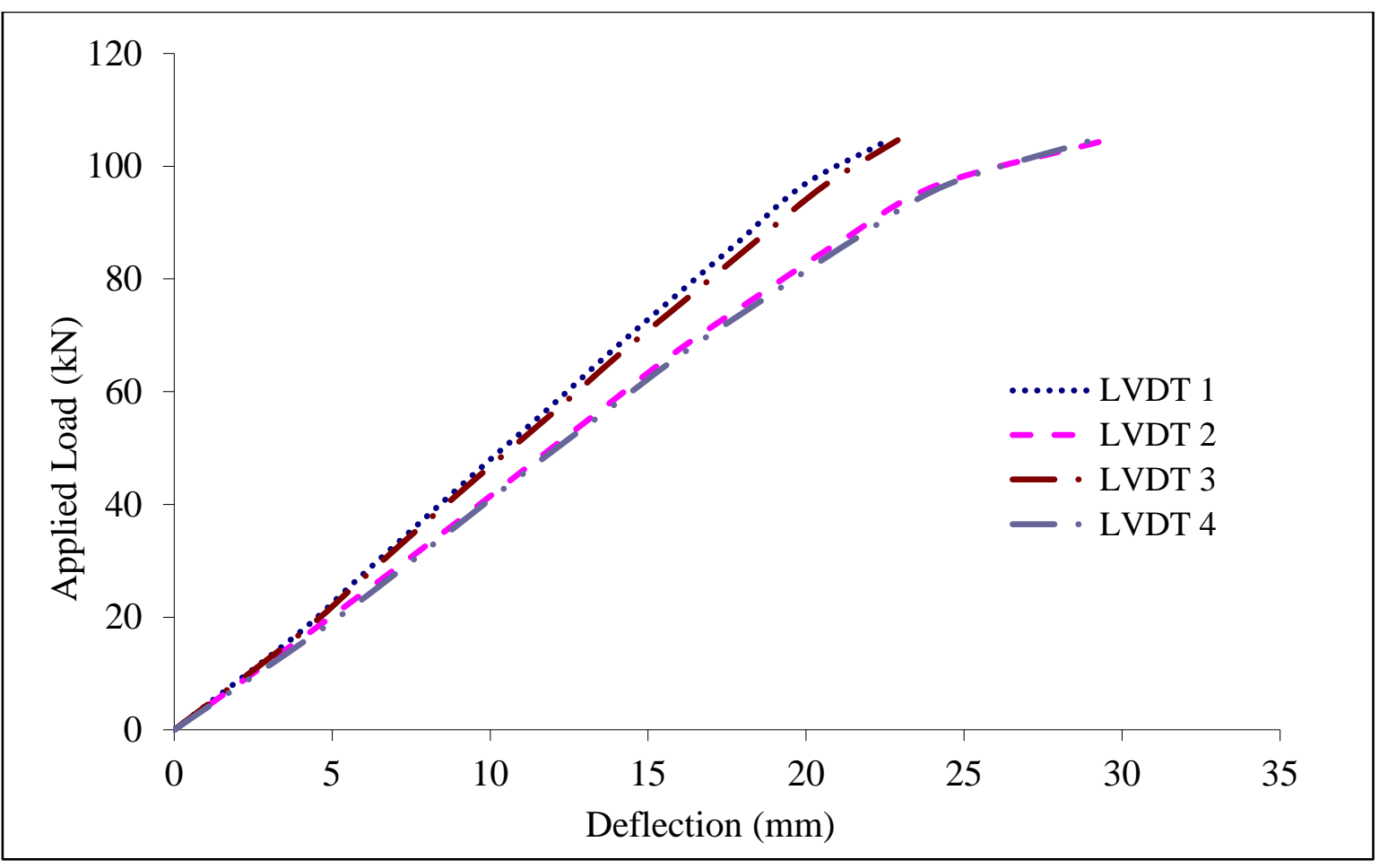

Figure B3.1: Typical load deflection curve for 241x3500 mm iSPAN floor joist

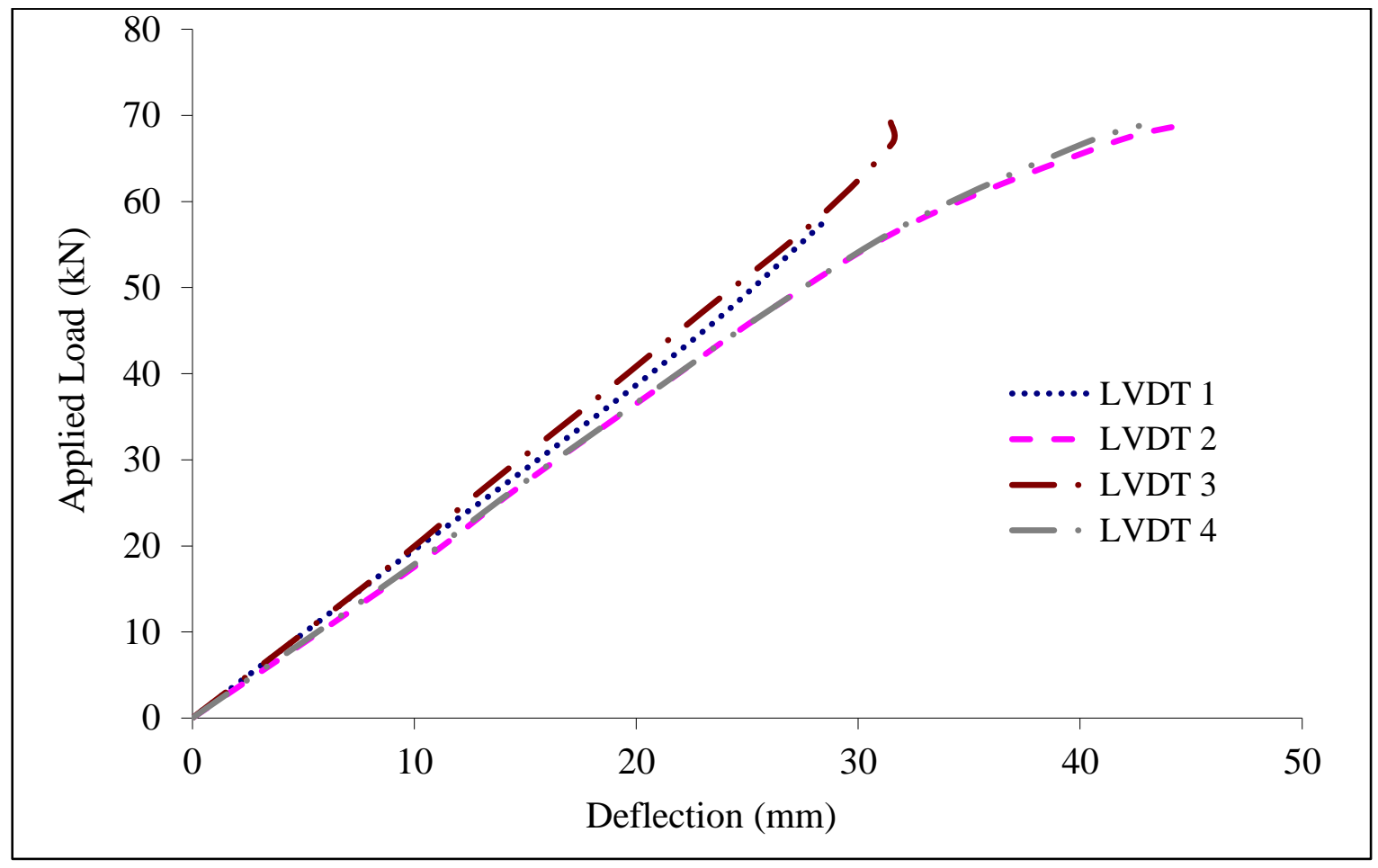

Figure B3.2: Typical load deflection curve for $241 \times 4500 \mathrm{~mm}$ iSPAN floor joist 


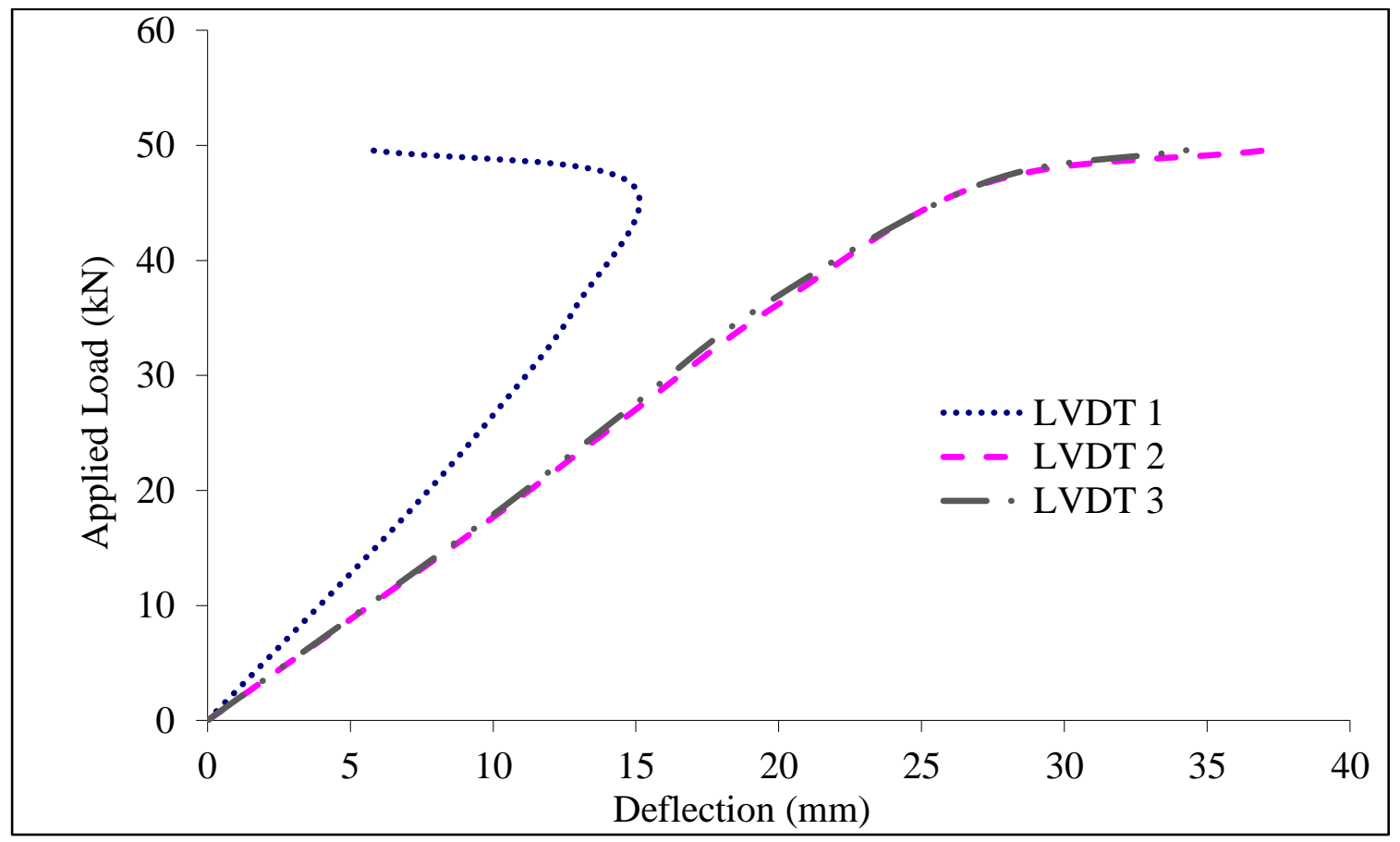

Figure B3.3: Typical load deflection curve for 302x5000 mm iSPAN floor joist

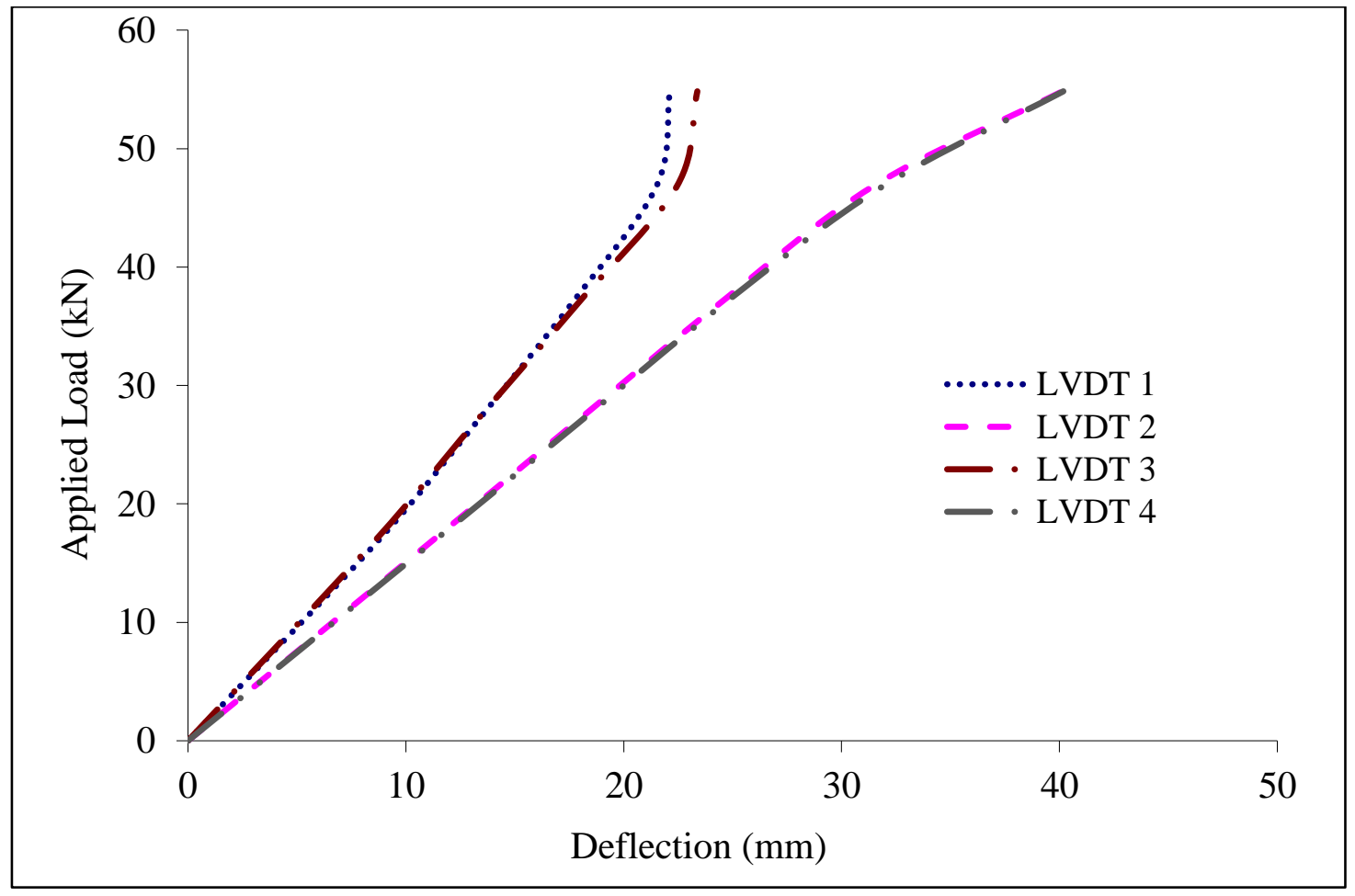

Figure B3.4: Typical load deflection curve for 302x5250 mm iSPAN floor joist 


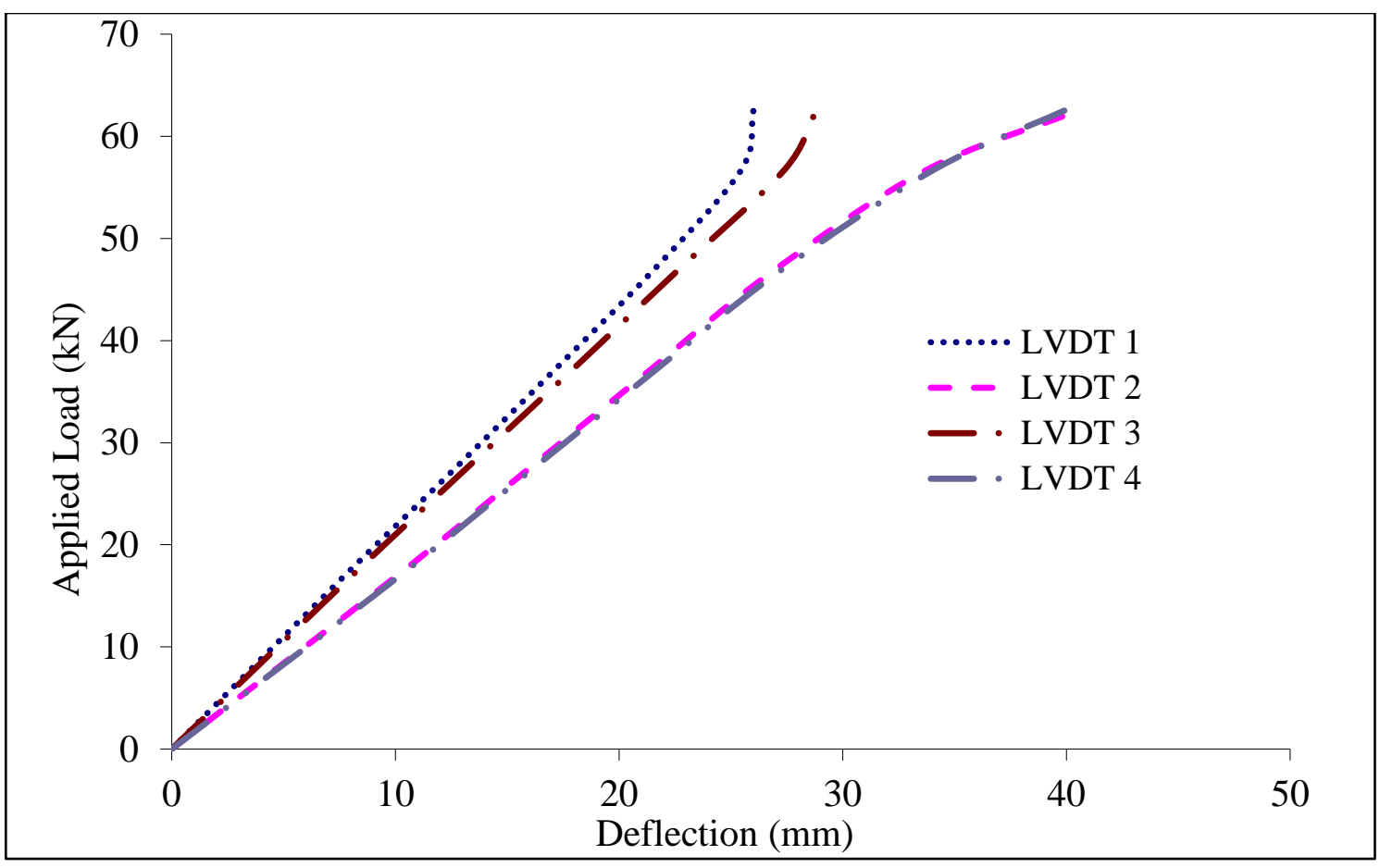

Figure B3.5: Typical load deflection curve for 356x6100 mm iSPAN floor joist

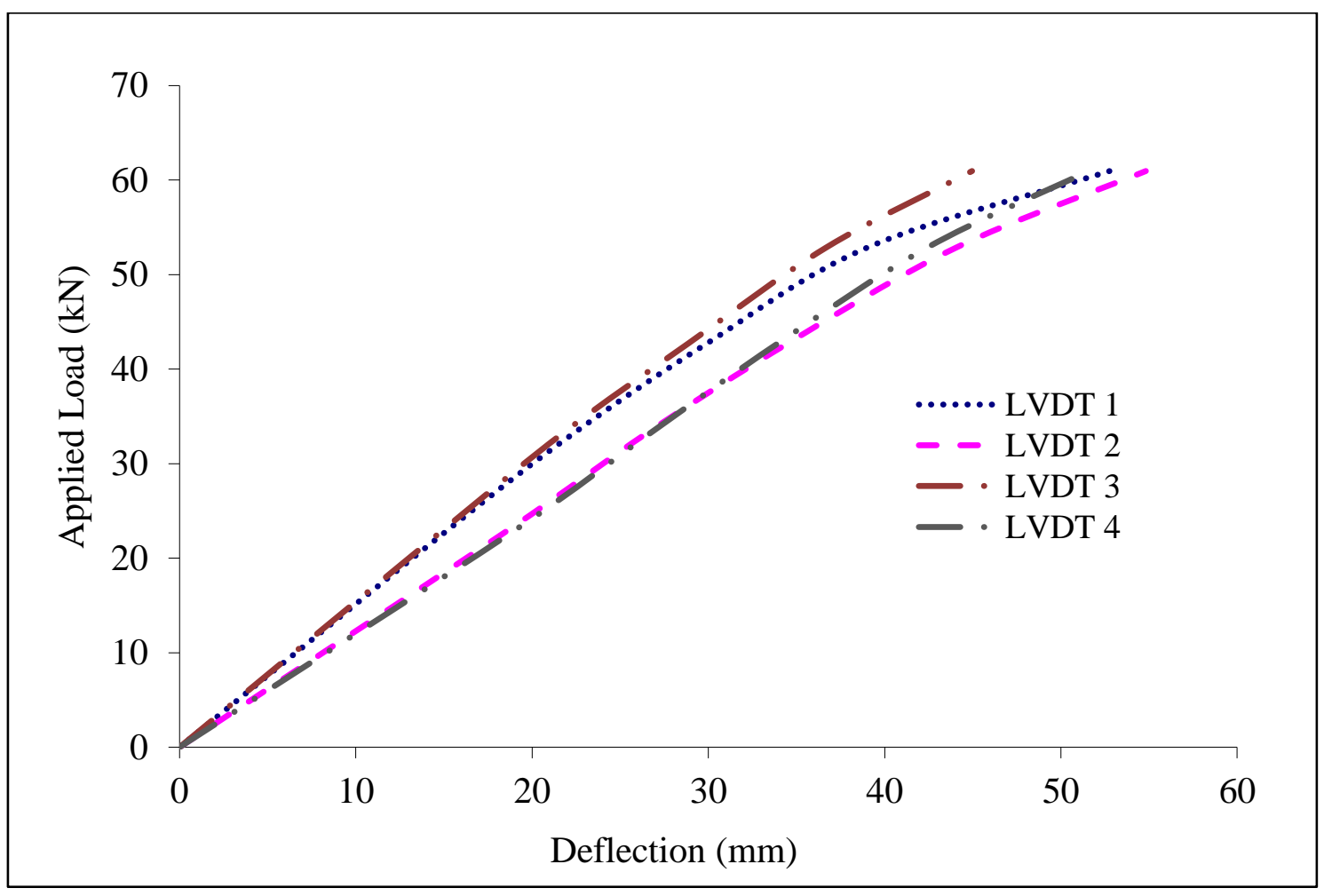

Figure B3.6: Typical load deflection curve for 406x7950 mm iSPAN floor joist 


\section{APPENDIX B4. FLEXURAL STRAIN DISTRIBUTION OF iSPAN JOISTS WITH NO HOLES}




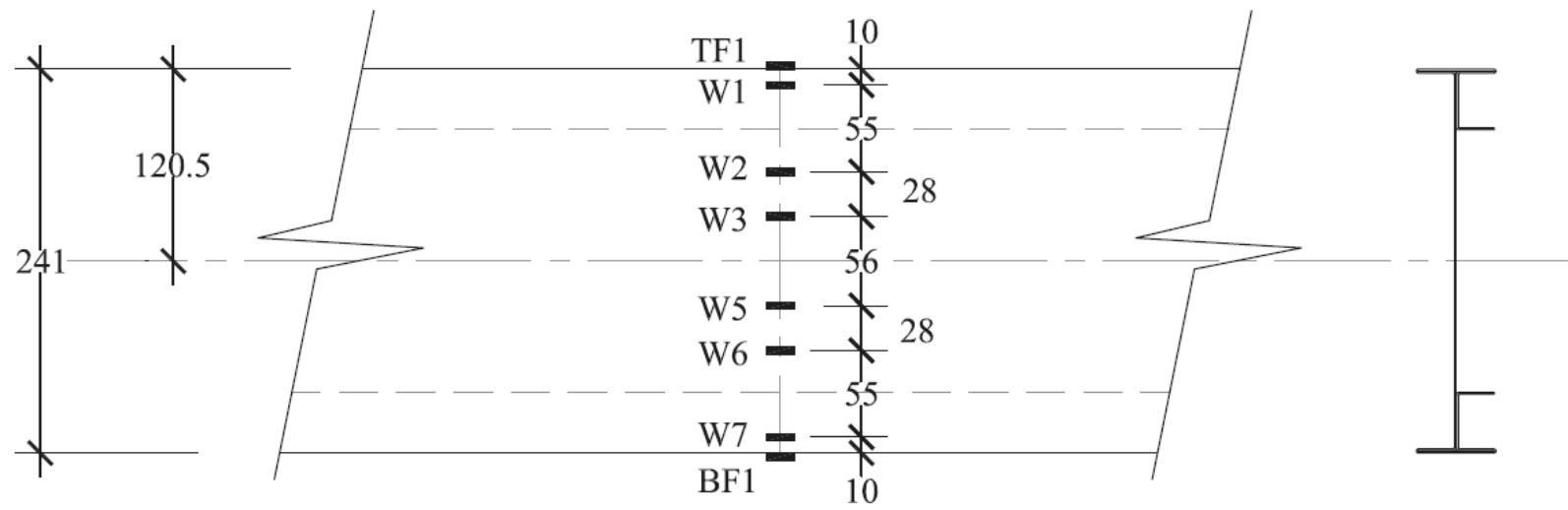

Legend:

TF1

W1

W2

W3

W5

W6

W7

BF1
Strain gauge at top flange

Strian gauge at web point 1

Strian gauge at web point 2

Strian gauge at web point 3

Strian gauge at web point 5

Strian gauge at web point 6

Strain gauge at web point 7

Strain gauge at bottom flange

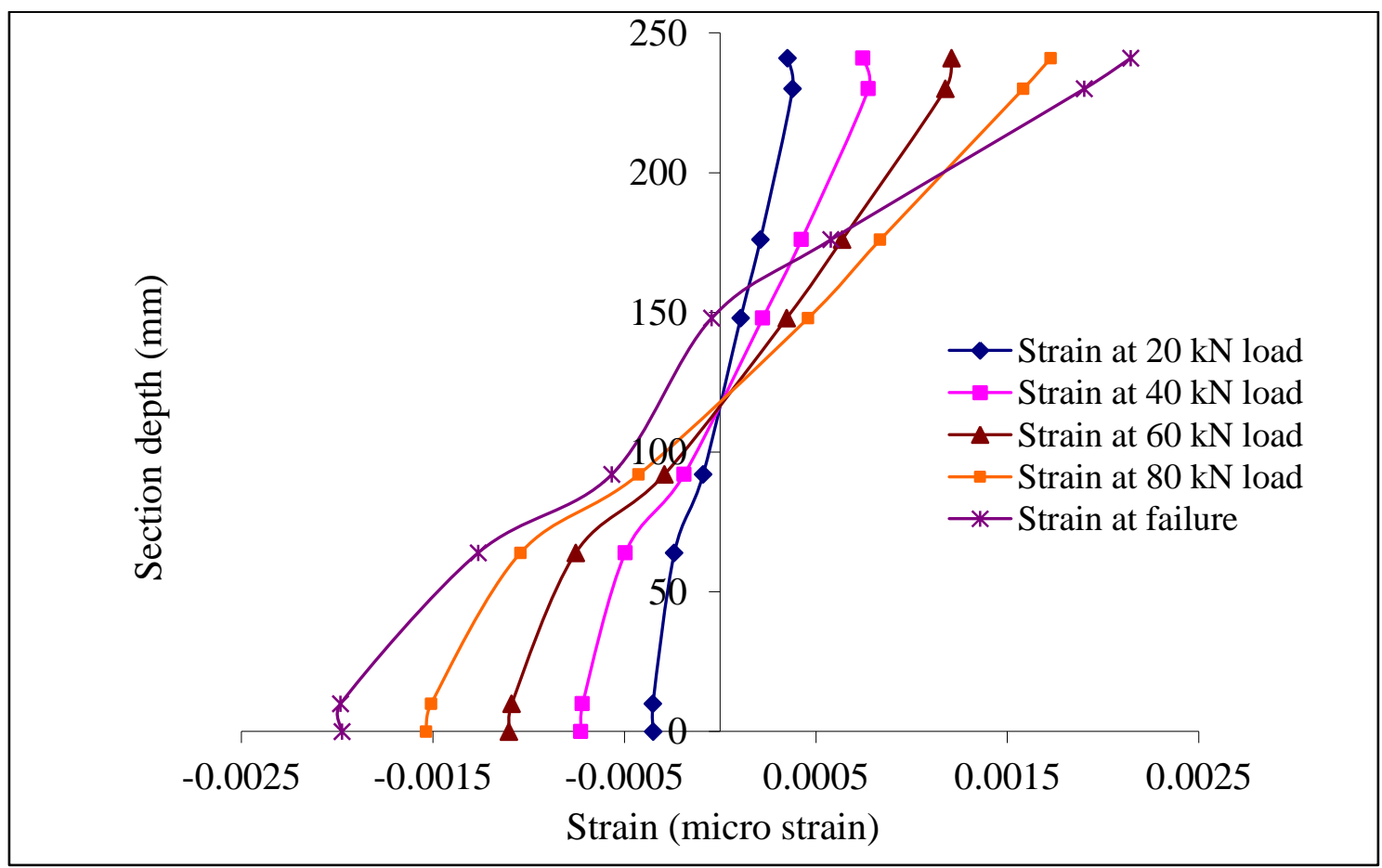

Figure B4.1: Flexural strain distribution at the middle of the $241 \times 3500 \mathrm{~mm}$ joist 1 


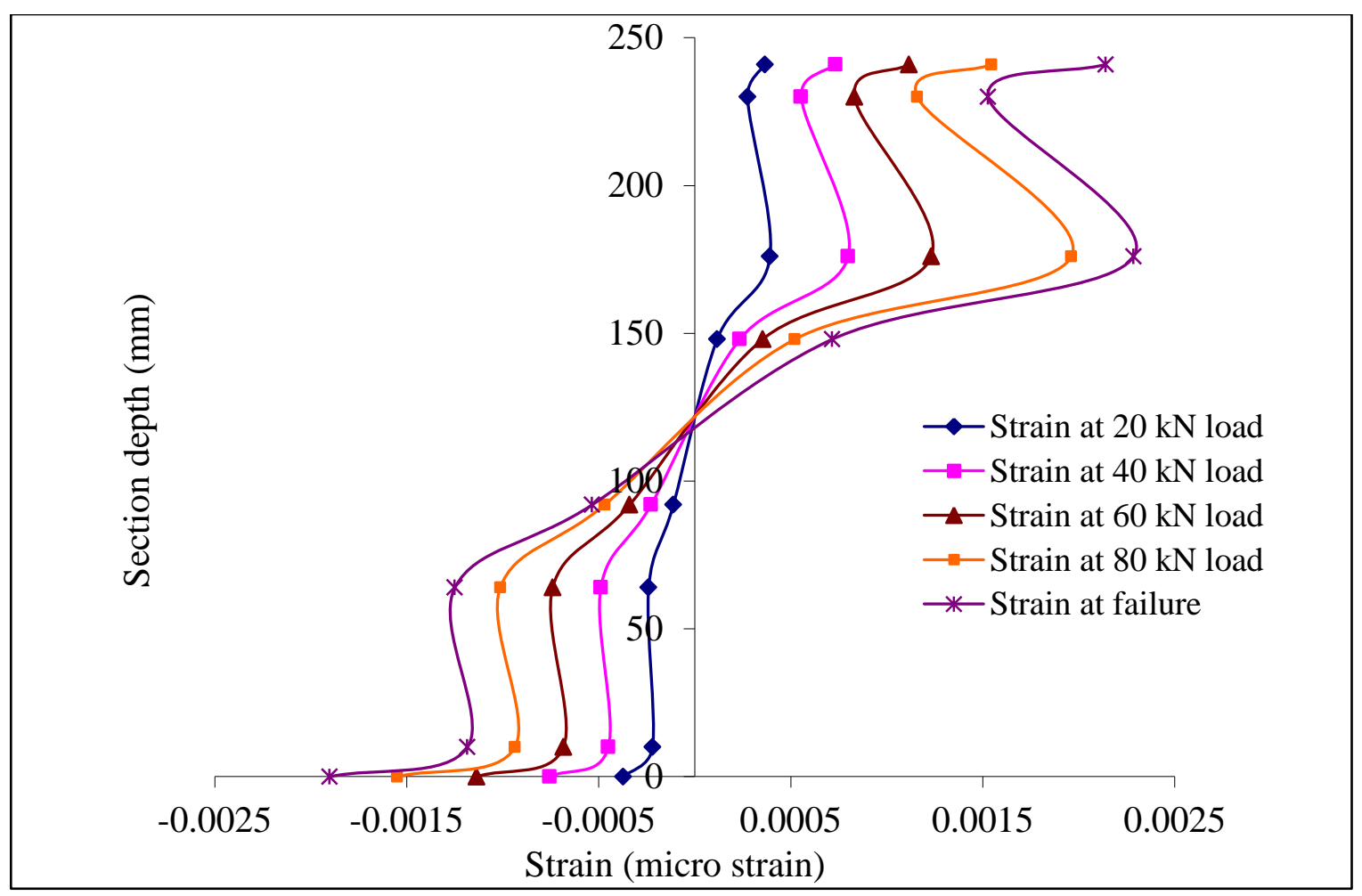

Figure B4.2: Flexural strain distribution at the middle of the $241 \times 3500 \mathrm{~mm}$ joist 2

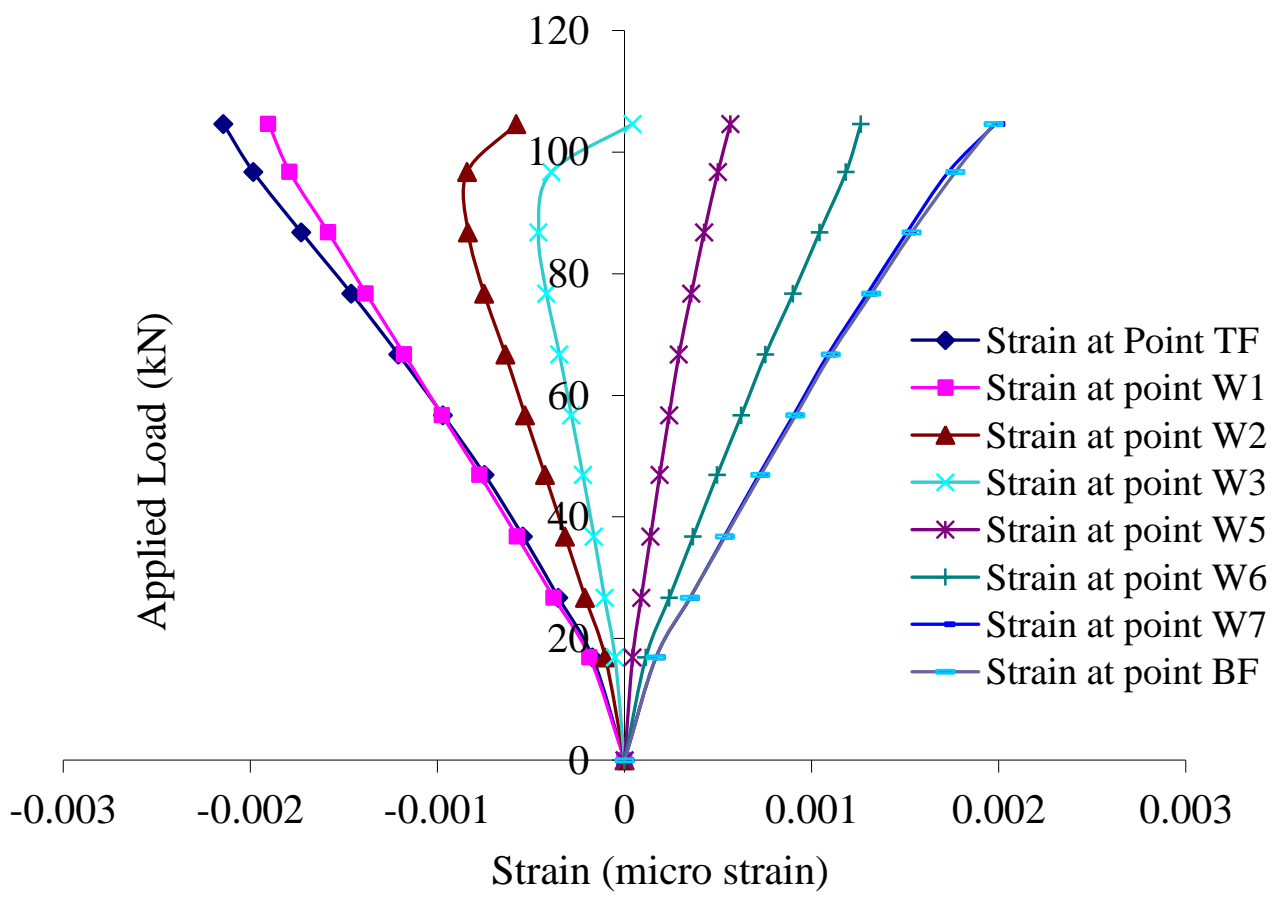

Figure B4.3: Load-strain distribution at the middle of the $241 \times 3500 \mathrm{~mm}$ joist 1 


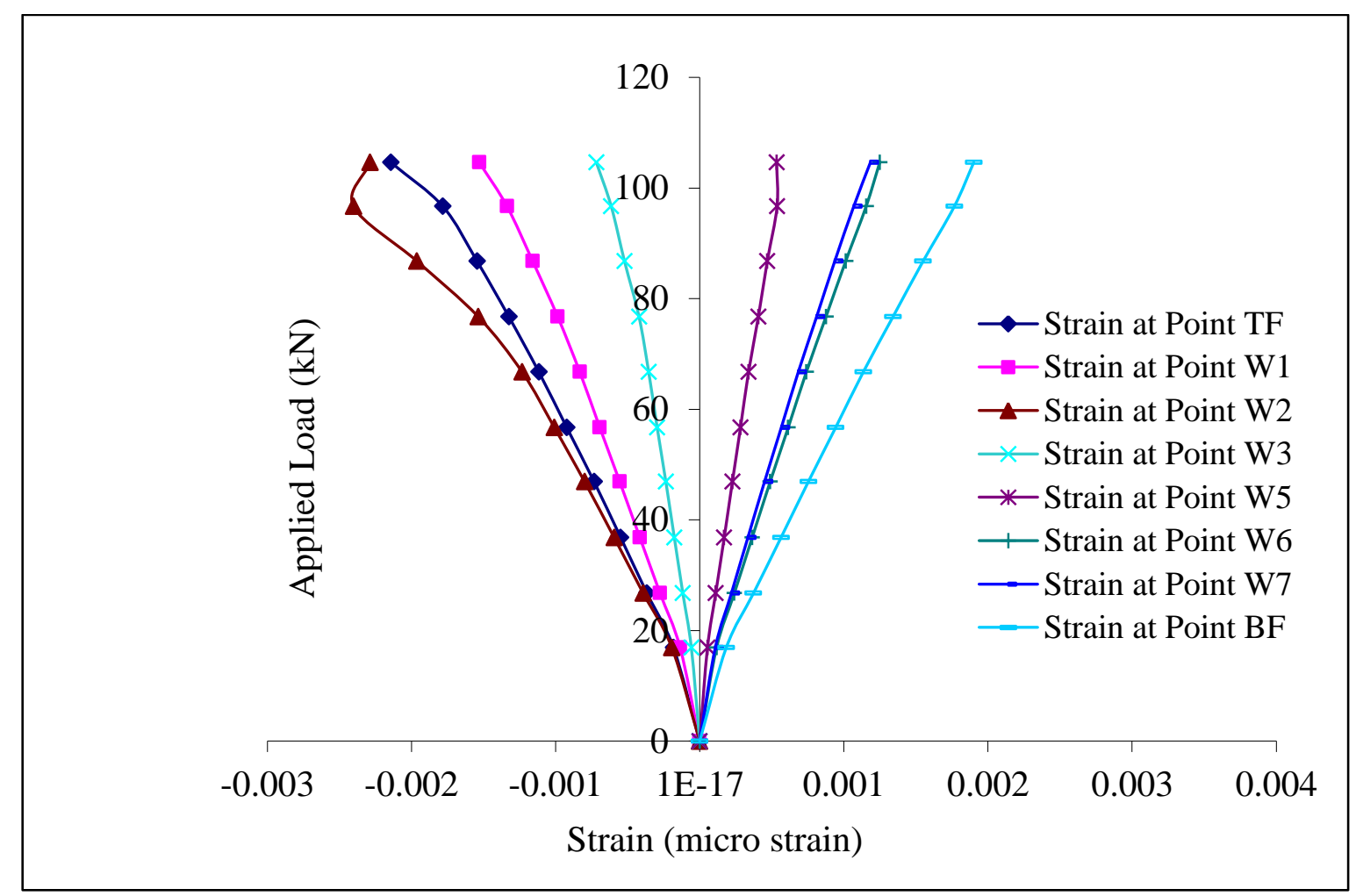

Figure B4.4: Load-strain distribution at the middle of the 241 x3500 mm joist 2 


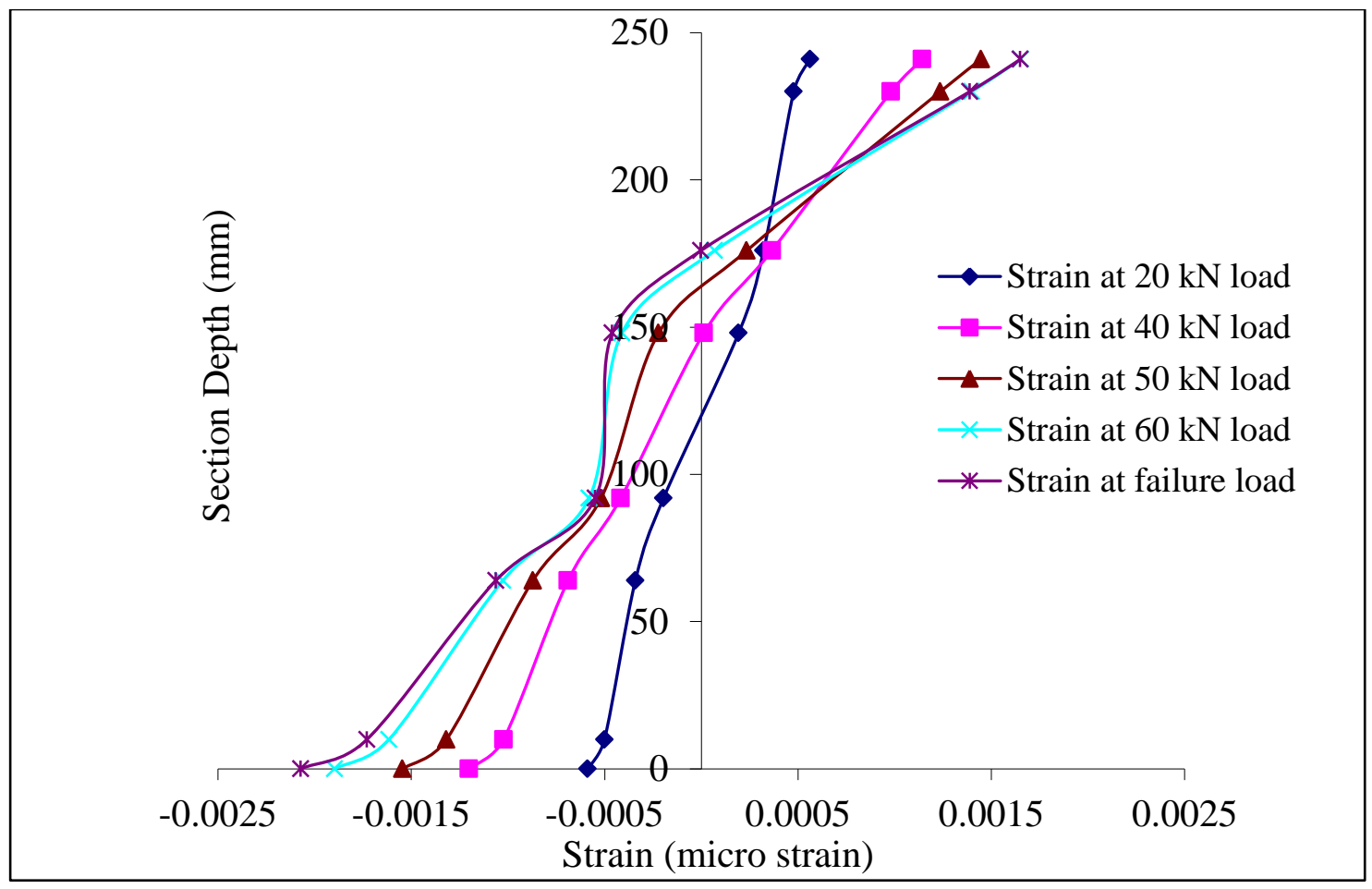

Figure B4.5: Flexural-strain distribution at the middle of the 241x4500 mm joist 1

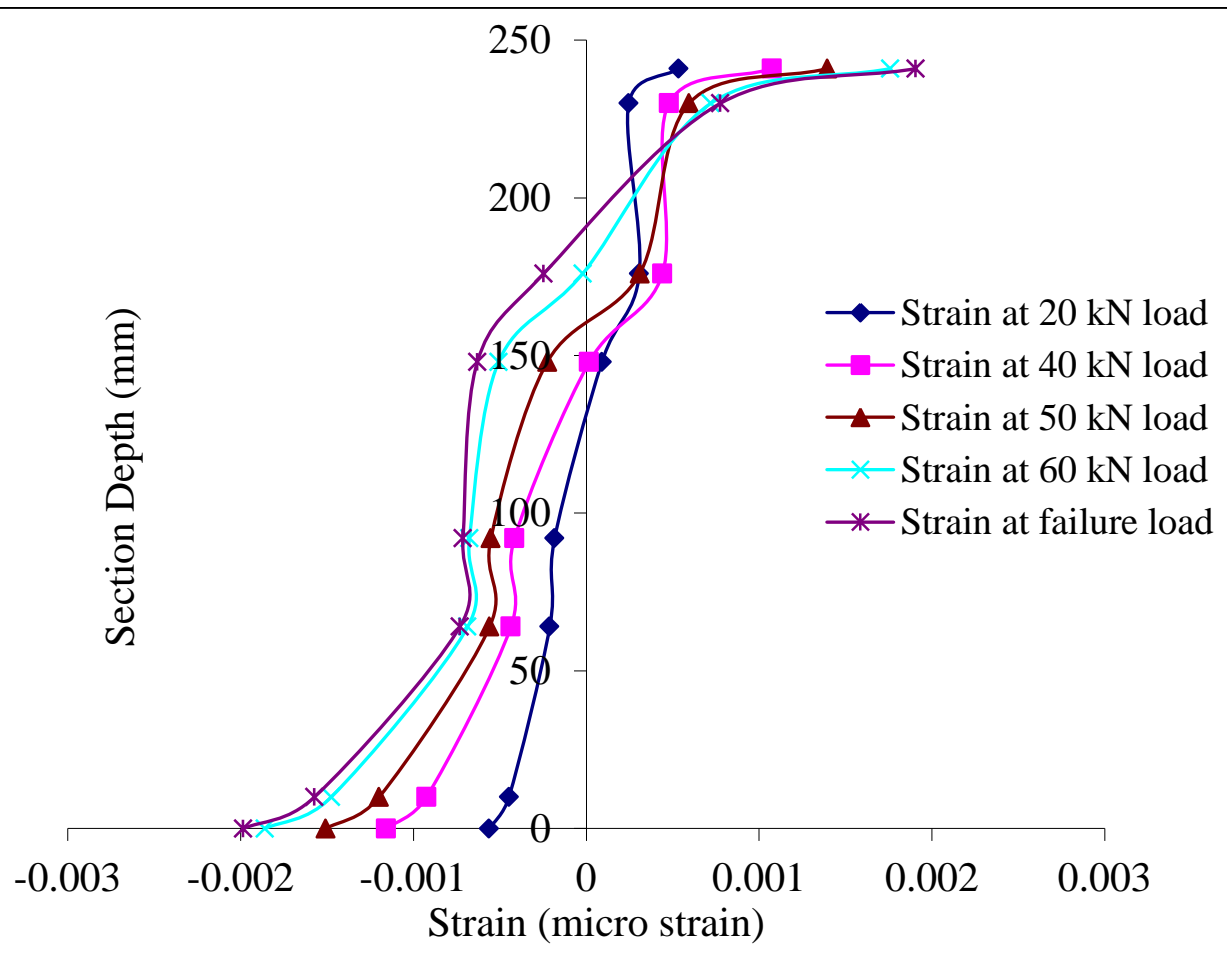

Figure B4.6: Flexural-strain distribution at the middle of the $241 \times 4500 \mathrm{~mm}$ joist 2 


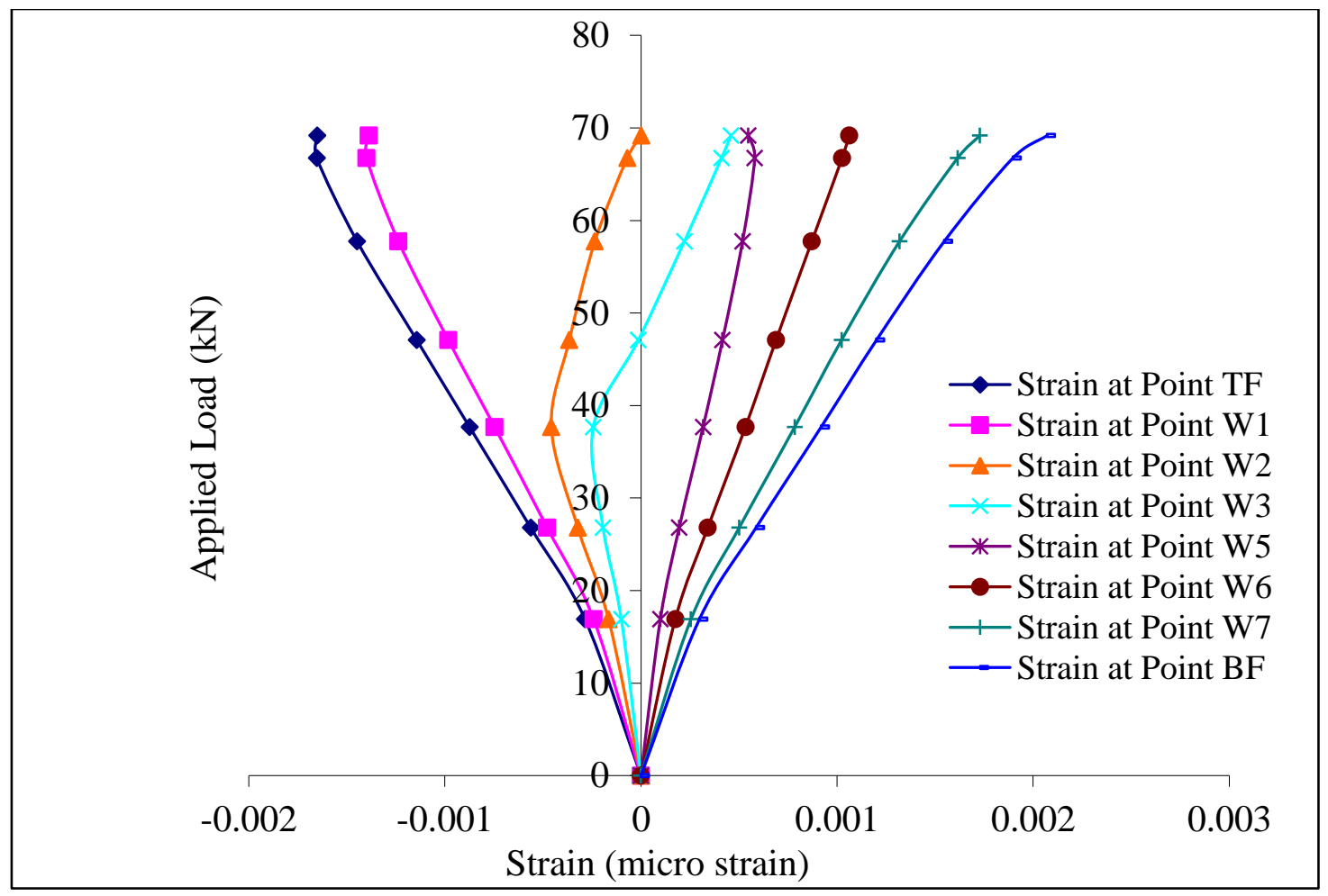

Figure B4.7: Load-strain distribution at the middle of $241 \times 4500 \mathrm{~mm}$ joist 1

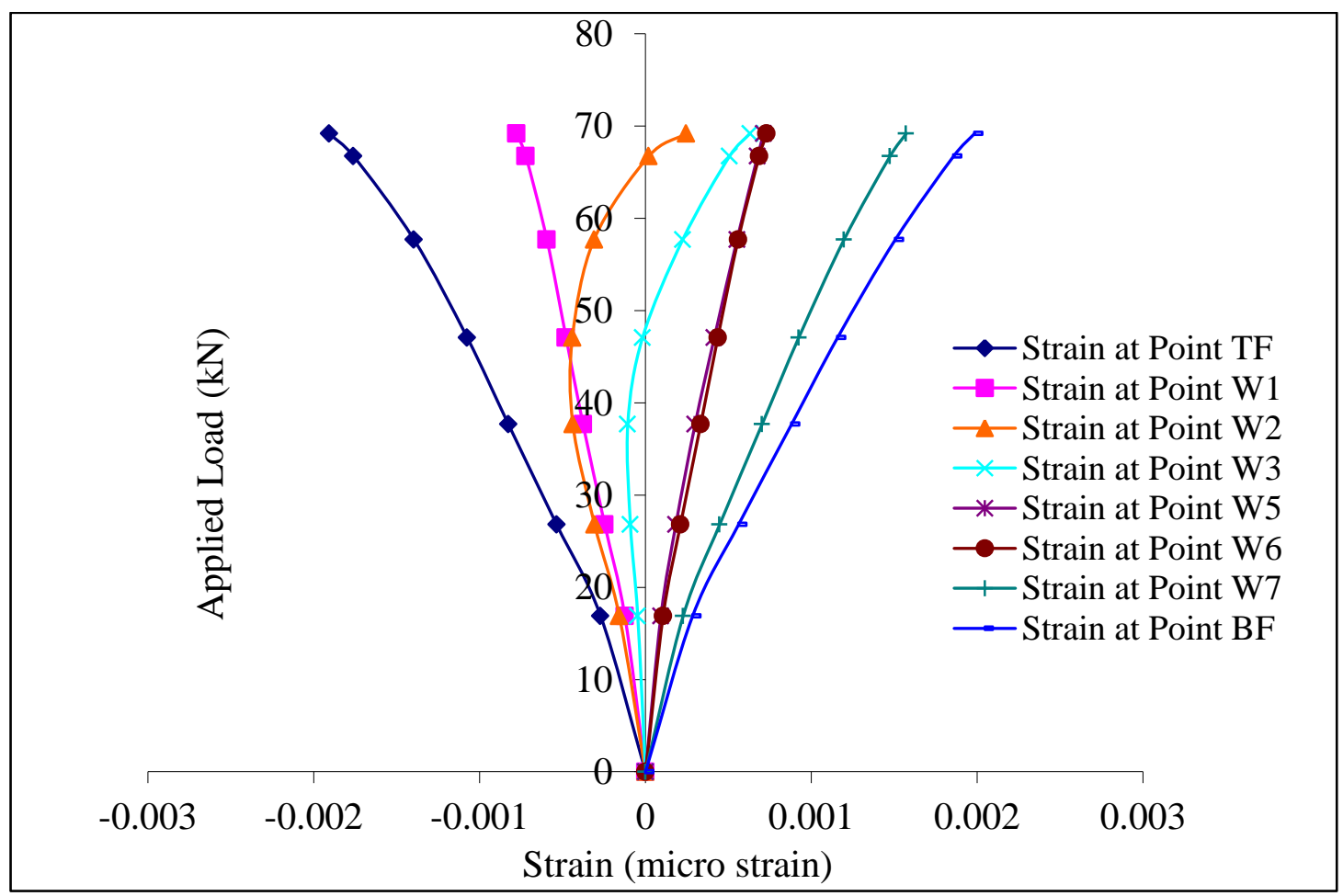

Figure B4.8: Load-strain distribution at the middle of $241 \times 4500 \mathrm{~mm}$ joist 2 


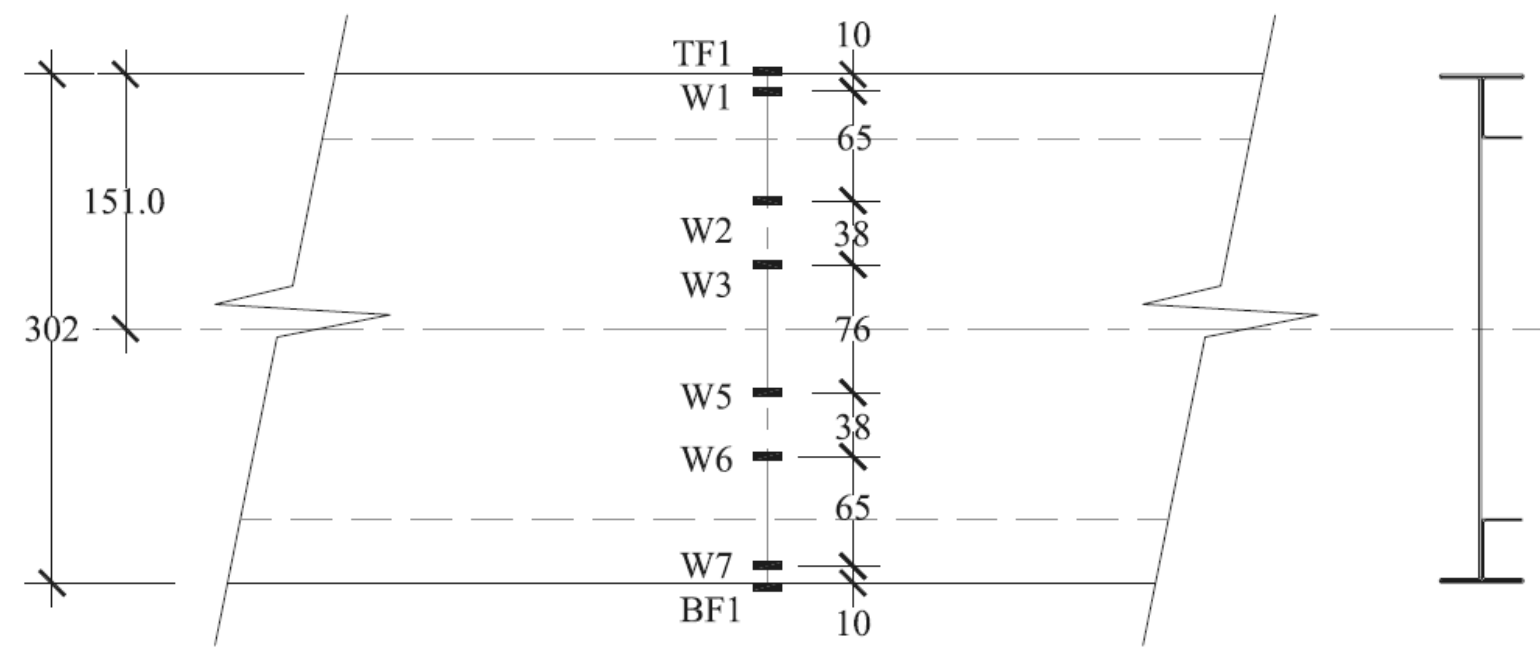

Legend:

TF1

W1

W2

W3

W5

W6

W7

BF1
Strain gauge at top flange

Strian gauge at web point 1

Strian gauge at web point 2

Strian gauge at web point 3

Strian gauge at web point 5

Strian gauge at web point 6

Strain gauge at web point 7

Strain gauge at bottom flange

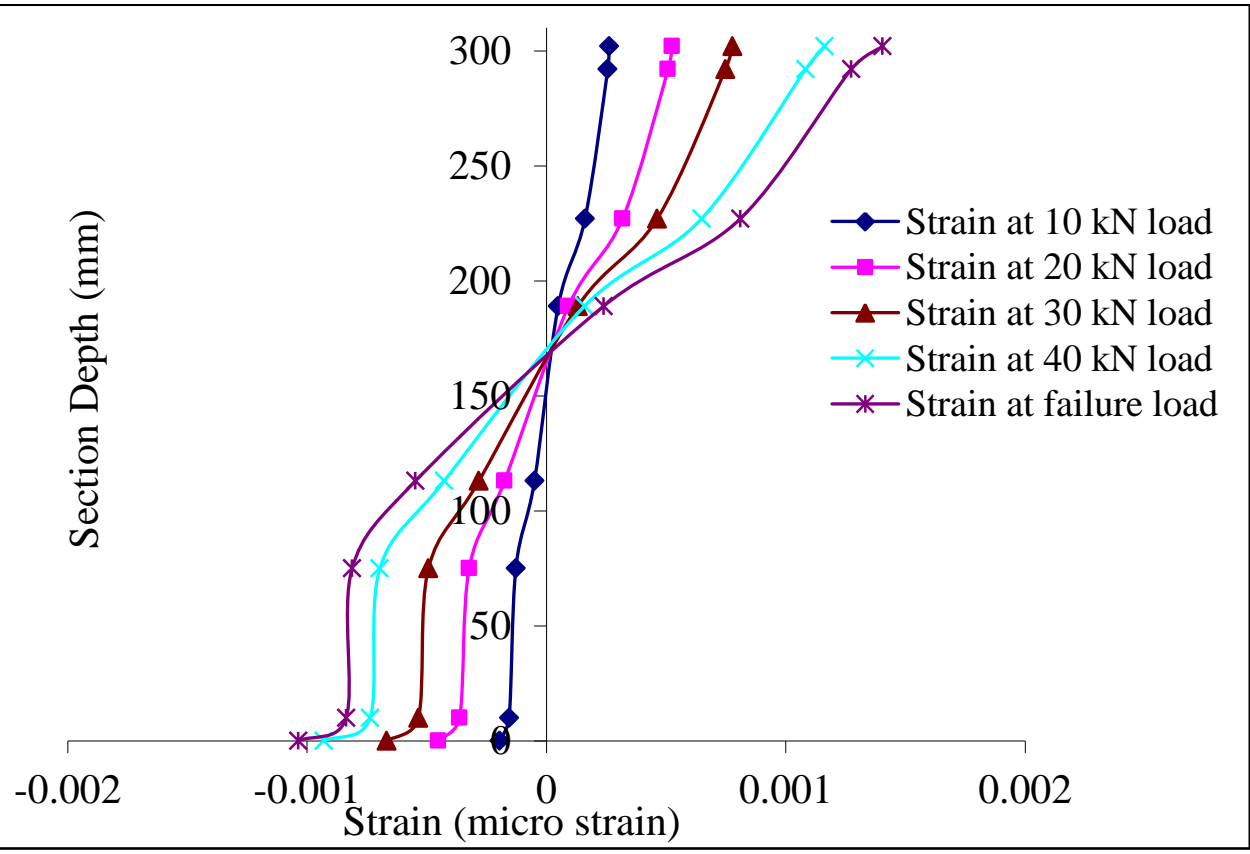

Figure B4.9: Flexural-strain distribution at the middle of the $302 \times 5000 \mathrm{~mm}$ joist 1 


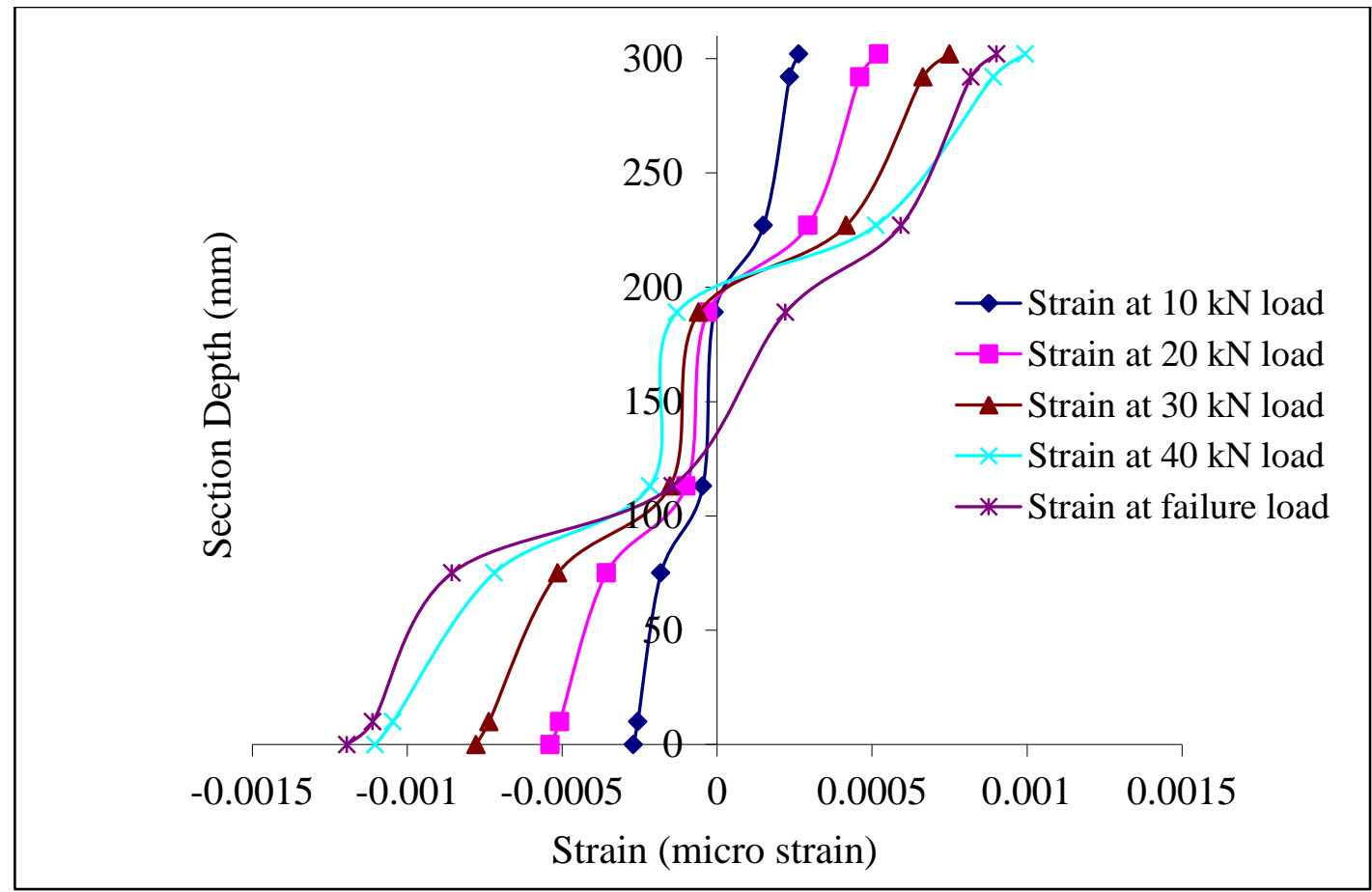

Figure B4.10: Flexural-strain distribution at the middle of the $302 \times 5000 \mathrm{~mm}$ joist 2

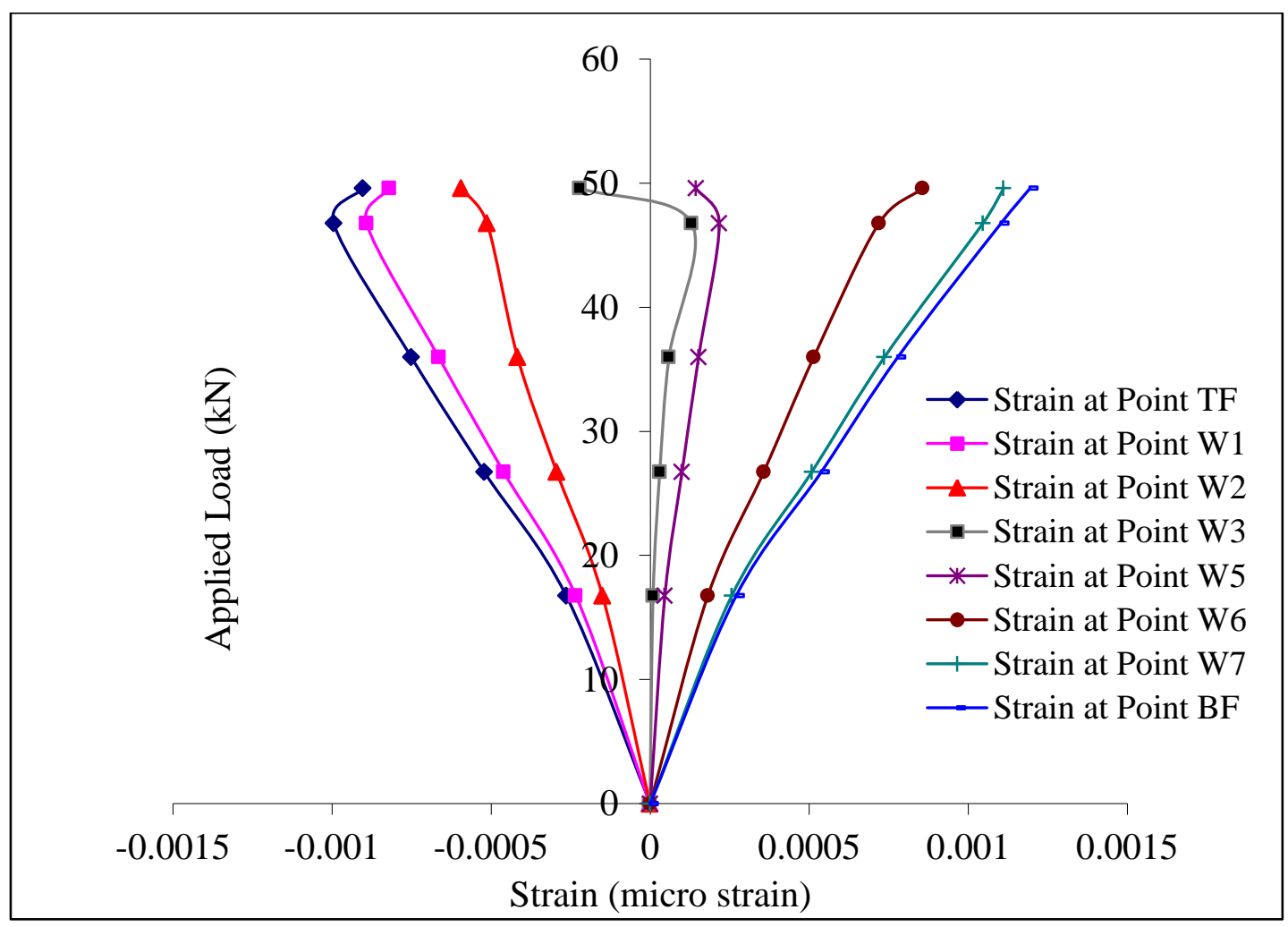

Figure B4.11: Load-strain distribution at the middle of 300x5000 mm joist 1 


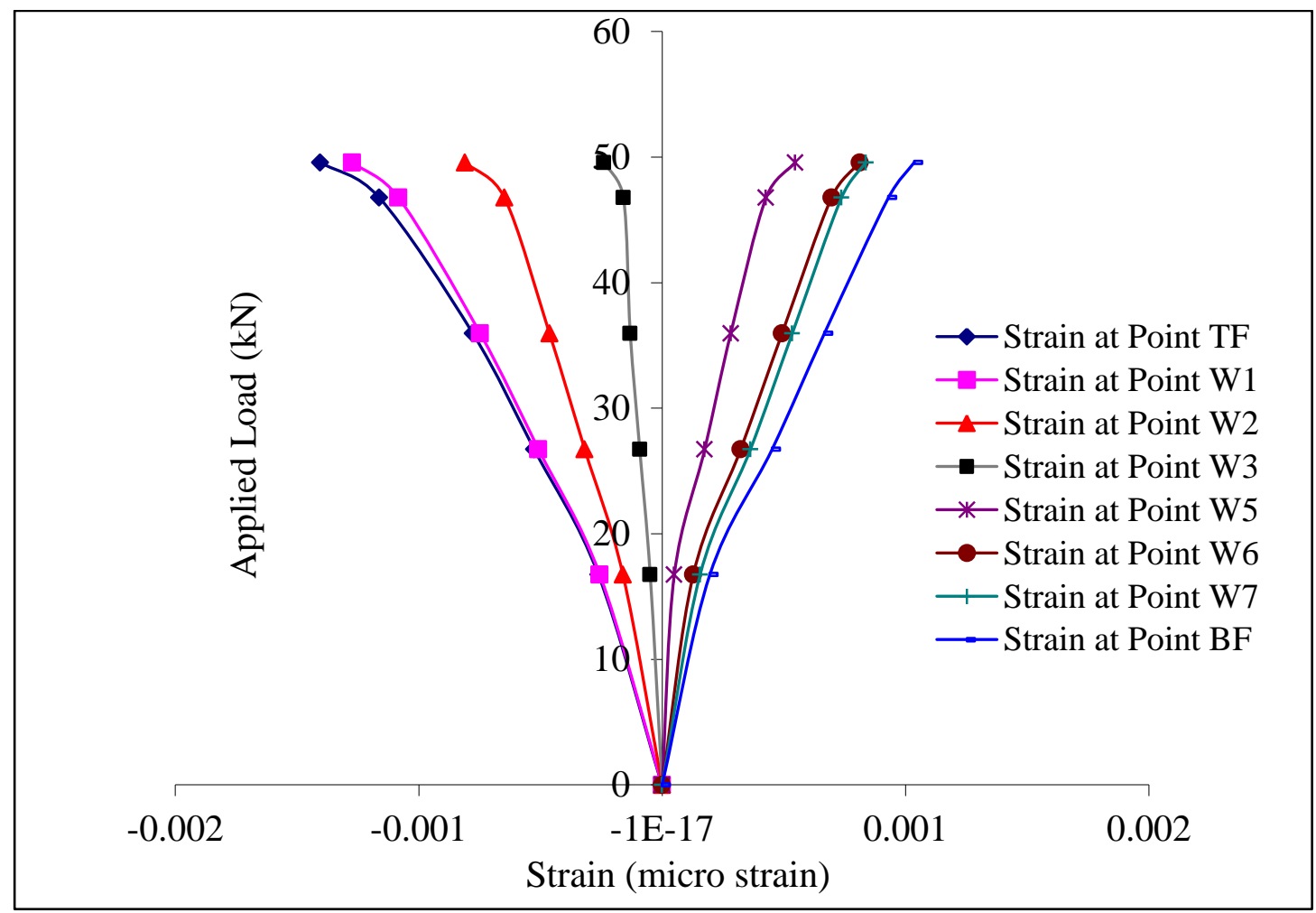

Figure B4.12: Load-strain distribution at the middle of 300x5000 mm joist 2 


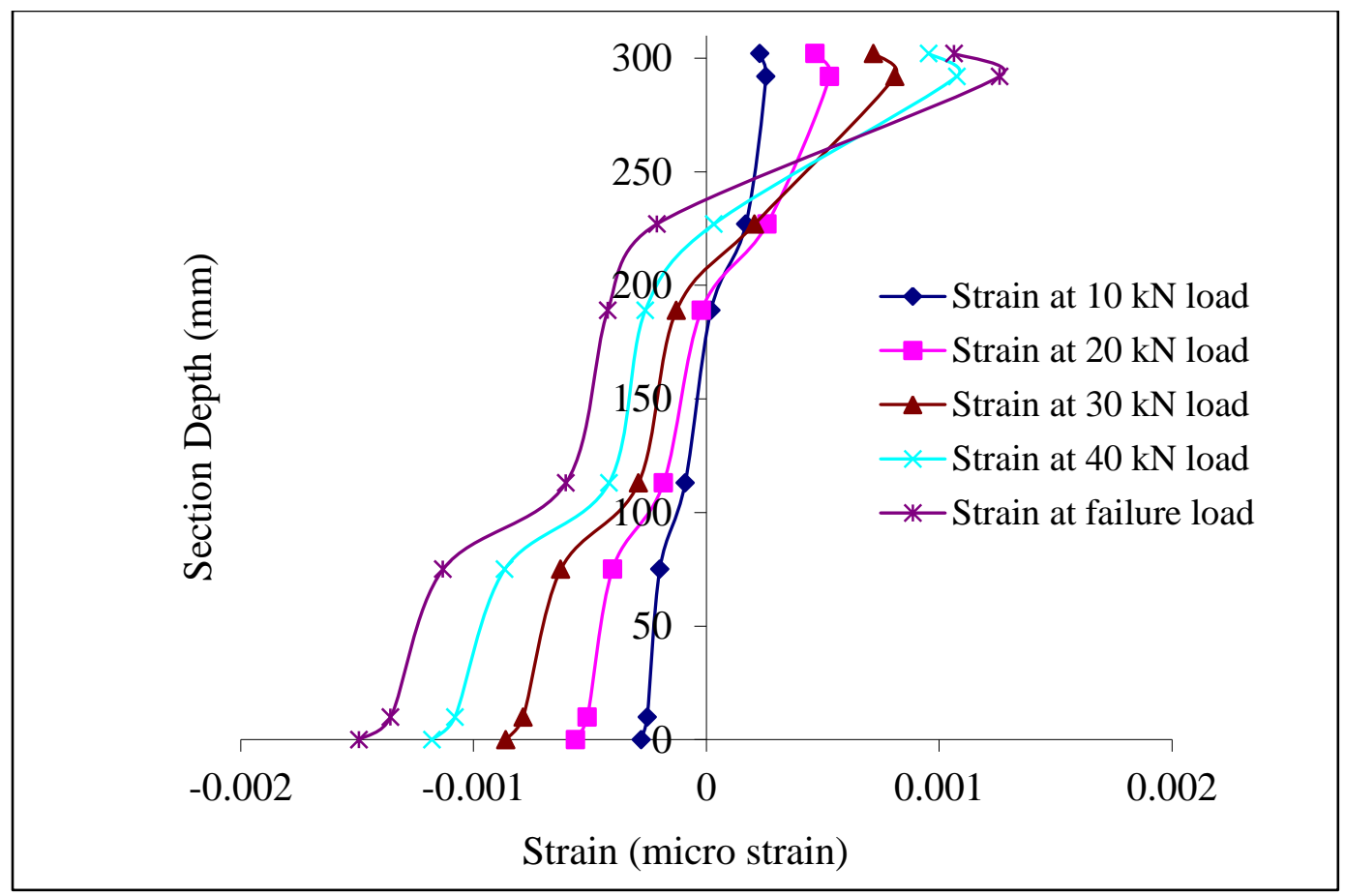

Figure B4.13: Flexural-strain distribution at the middle of the 300x5250 mm joist 1

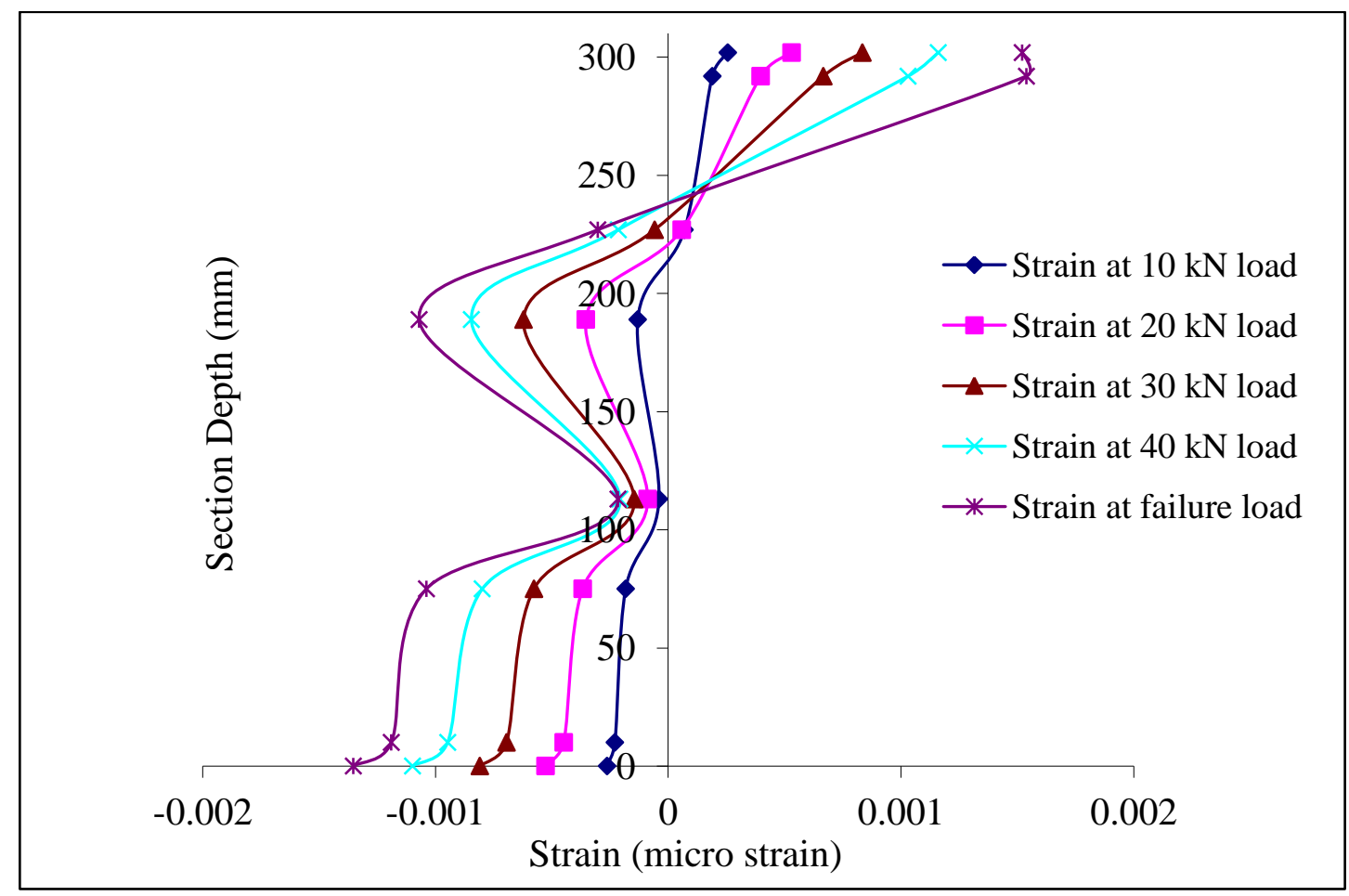

Figure B4.14: Flexural-strain distribution at the middle of the $300 \times 5250 \mathrm{~mm}$ joist 2 


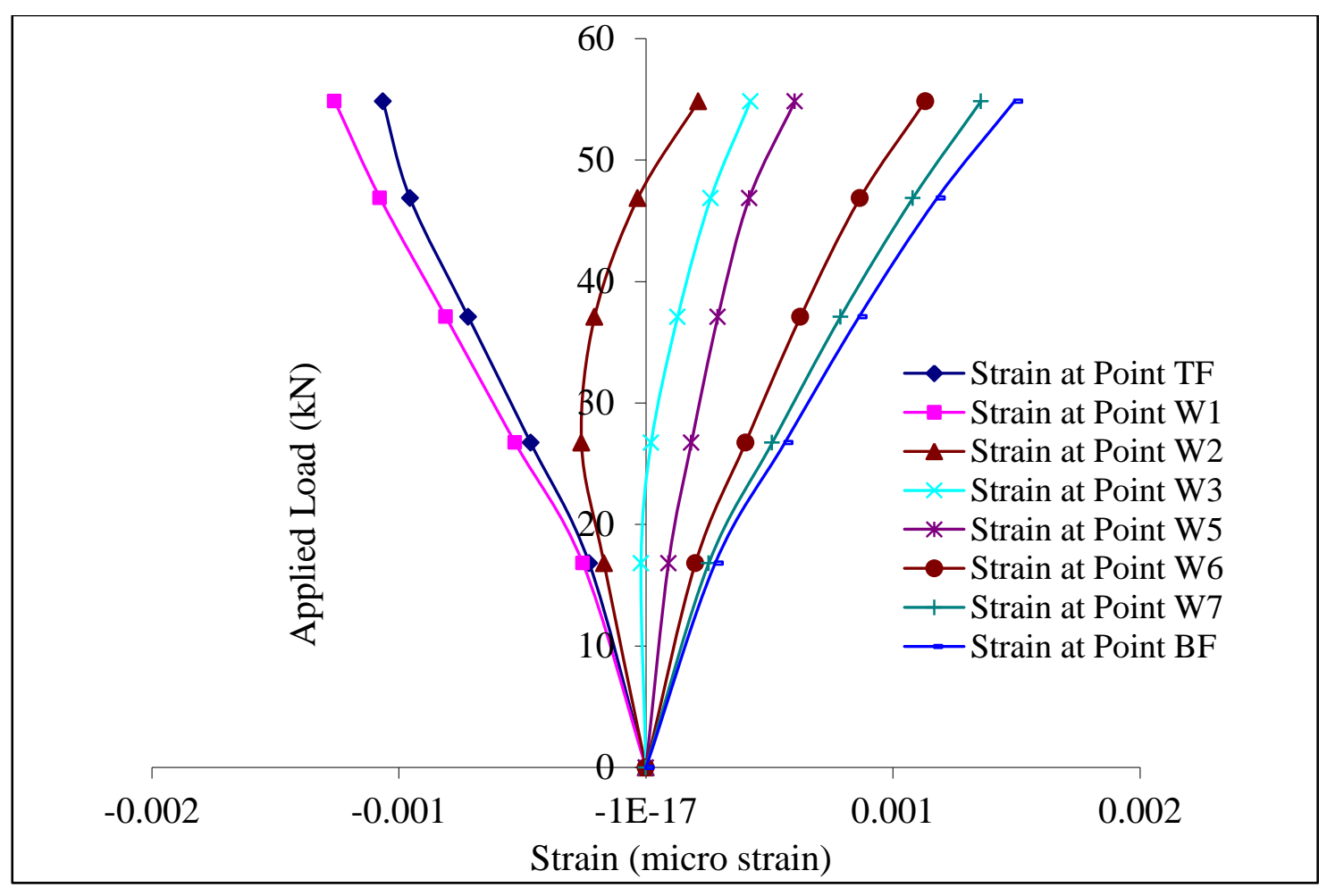

Figure B4.15: Load-strain distribution at the middle of 300x5250 mm joist 1

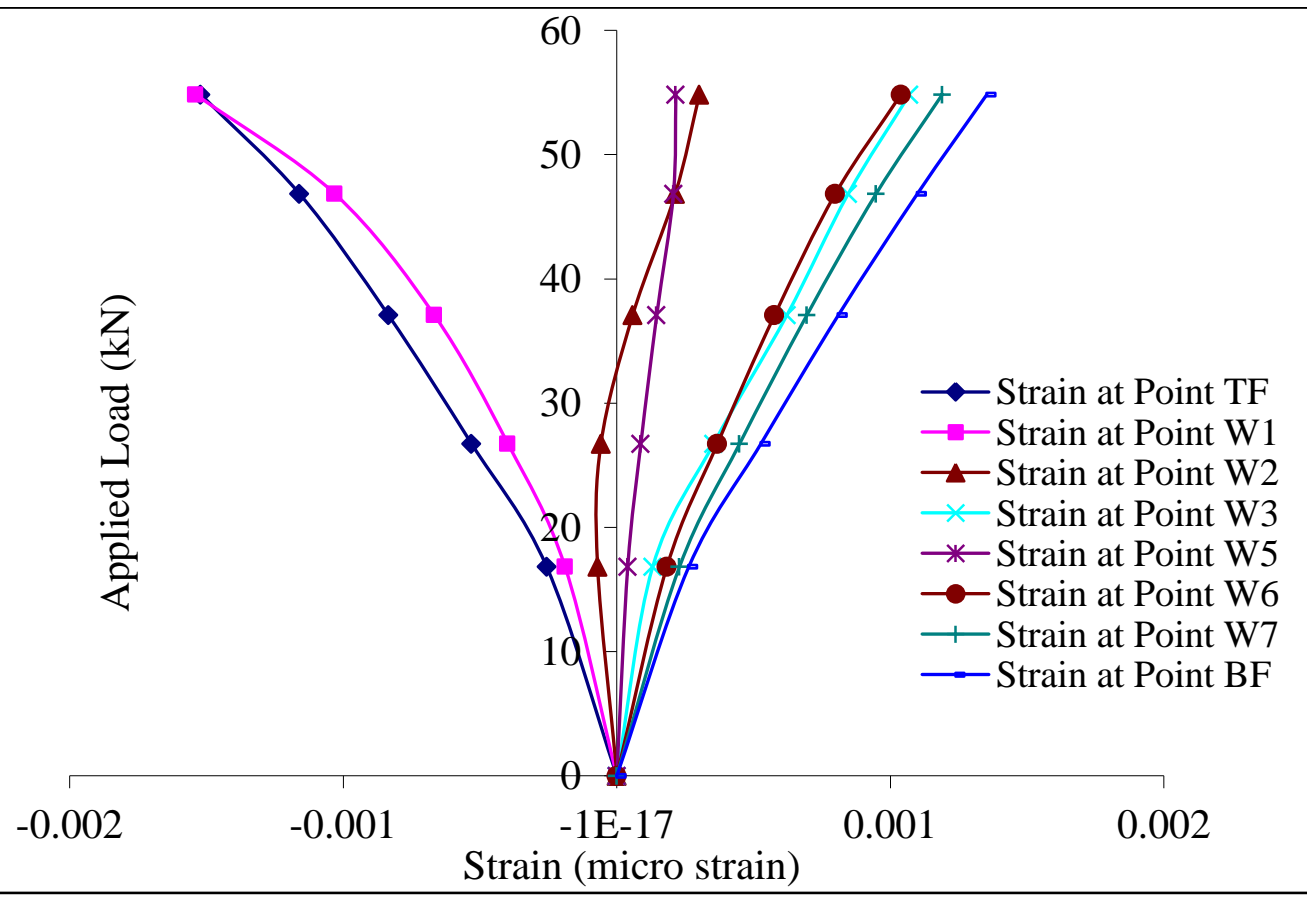

Figure B4.16: Load-strain distribution at the middle of 300x5250 mm joist 2 


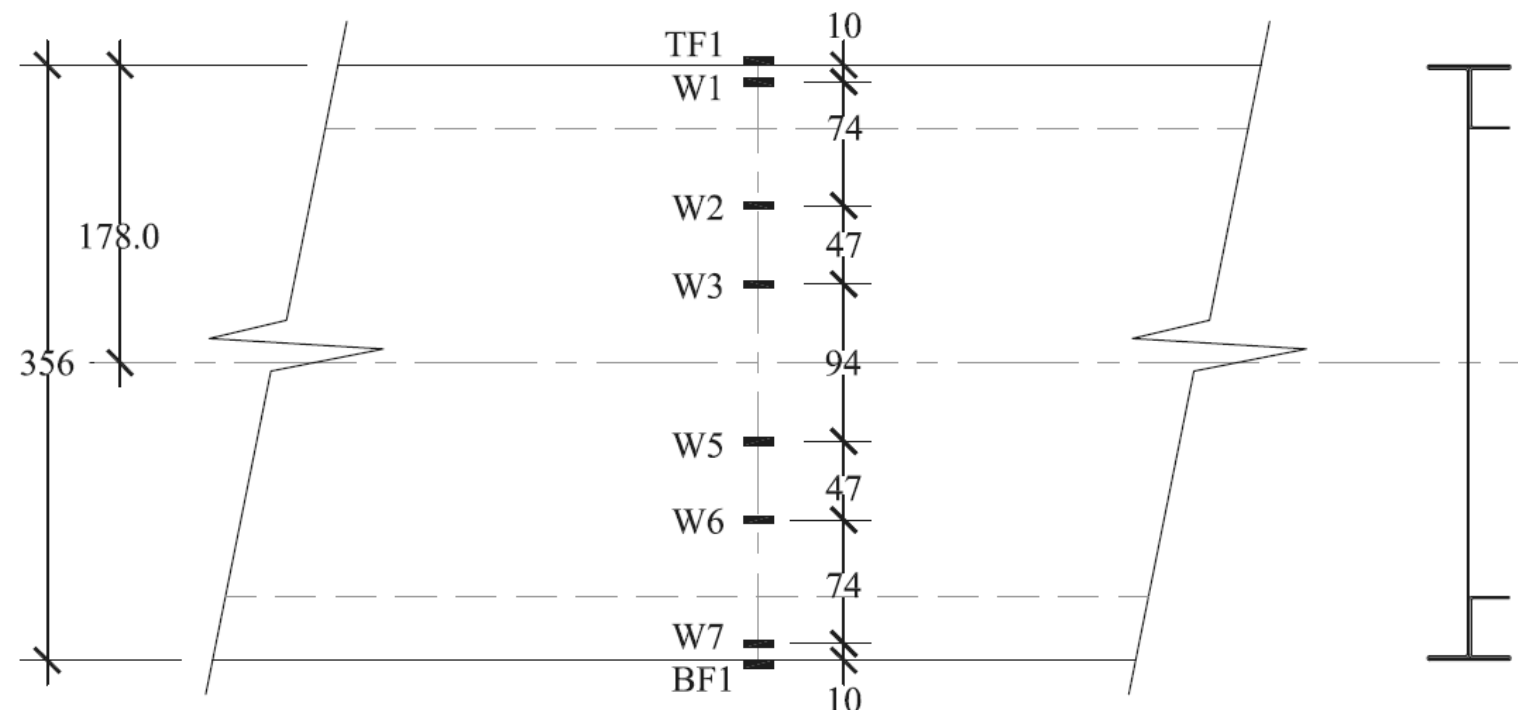

Legend:

$\begin{array}{ll}\text { TF1 } & \text { Strain gauge at top flange } \\ \text { W1 } & \text { Strian gauge at web point 1 } \\ \text { W2 } & \text { Strian gauge at web point } 2 \\ \text { W3 } & \text { Strian gauge at web point 3 } \\ \text { W5 } & \text { Strian gauge at web point } 5 \\ \text { W6 } & \text { Strian gauge at web point 6 } \\ \text { W7 } & \text { Strain gauge at web point } 7 \\ \text { BF1 } & \text { Strain gauge at bottom flange }\end{array}$

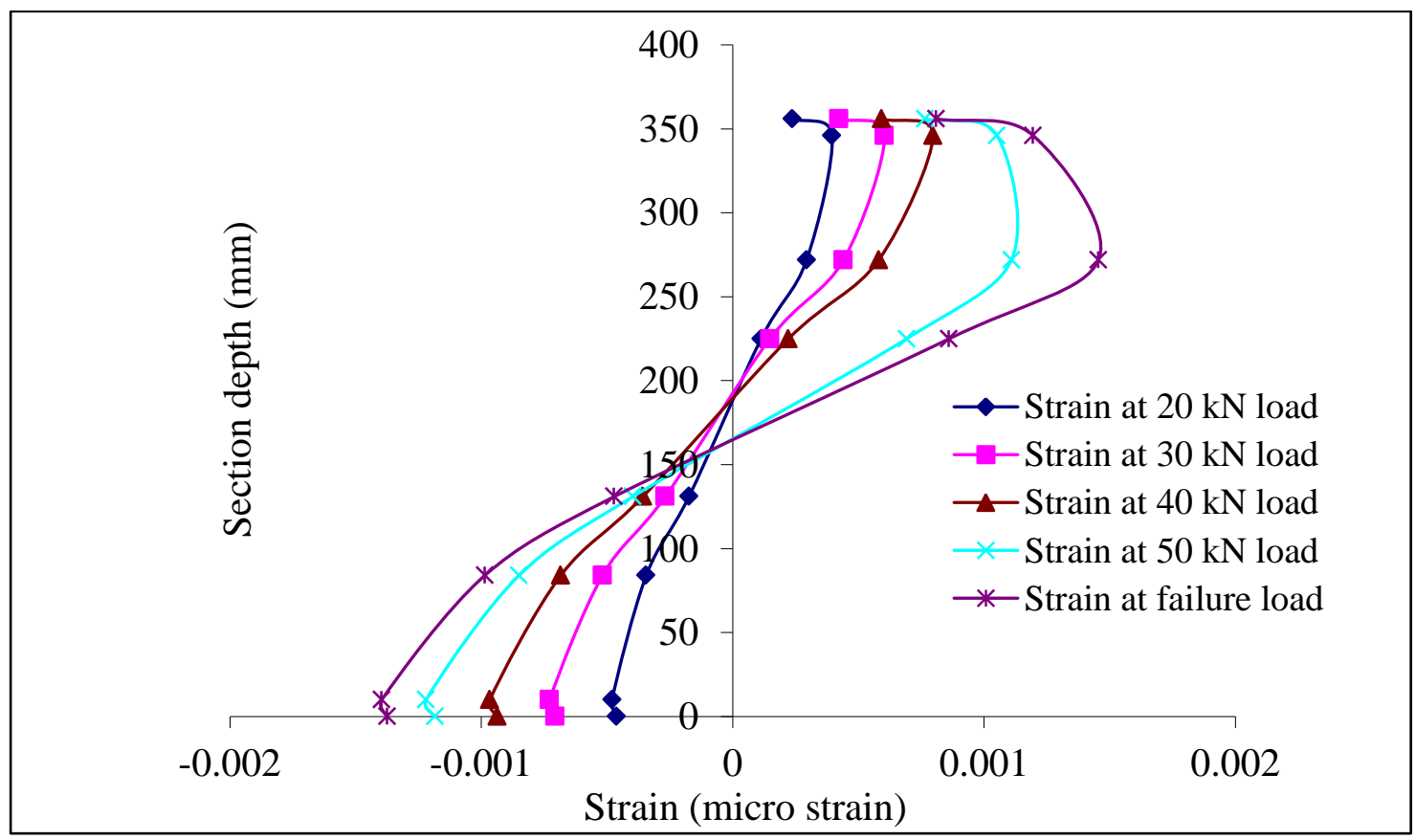

Figure B4.17: Flexural-strain distribution at the middle of the 356x6100 mm joist 1 


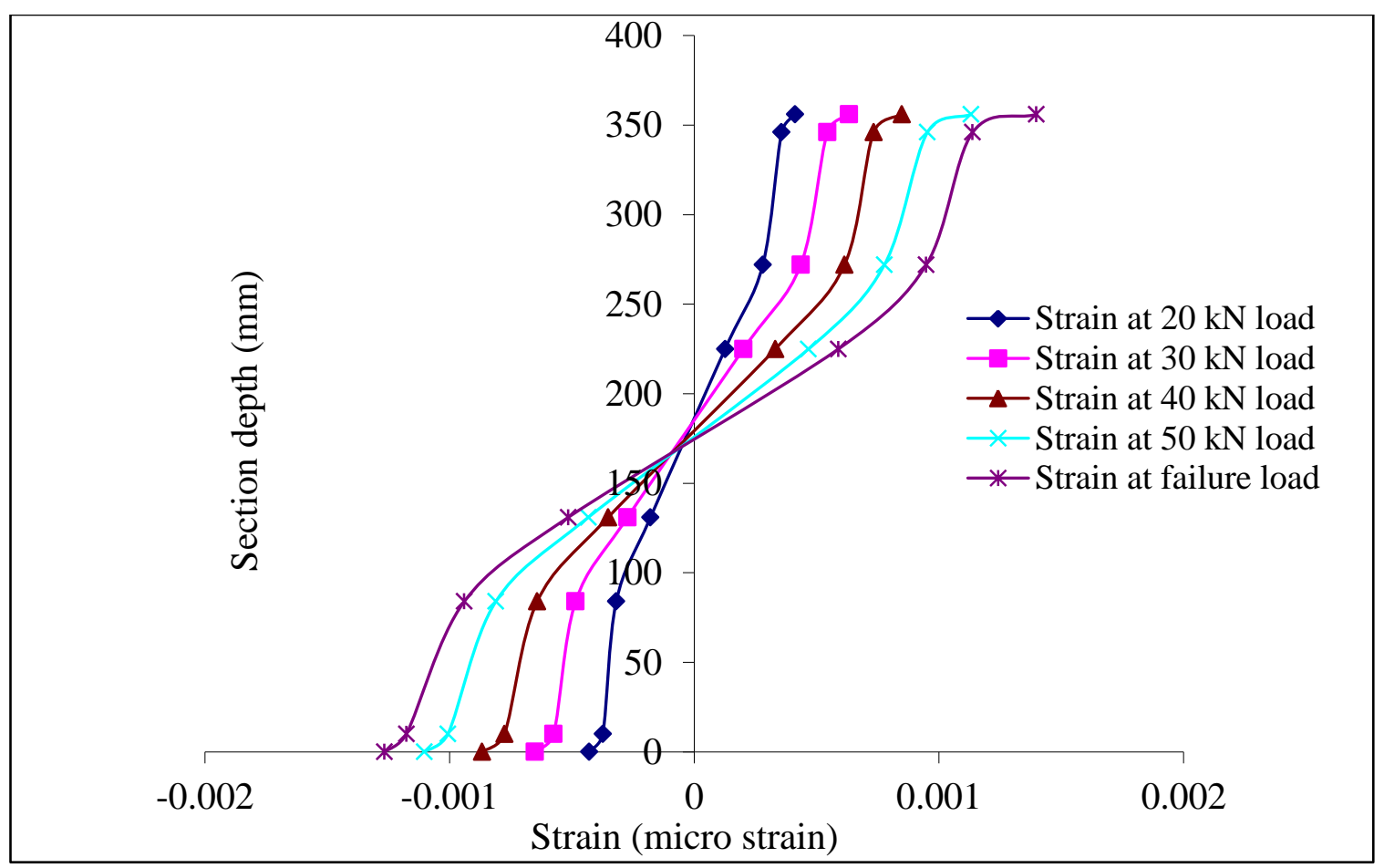

Figure B4.18: Flexural-strain distribution at the middle of the 356x6100 mm joist 2

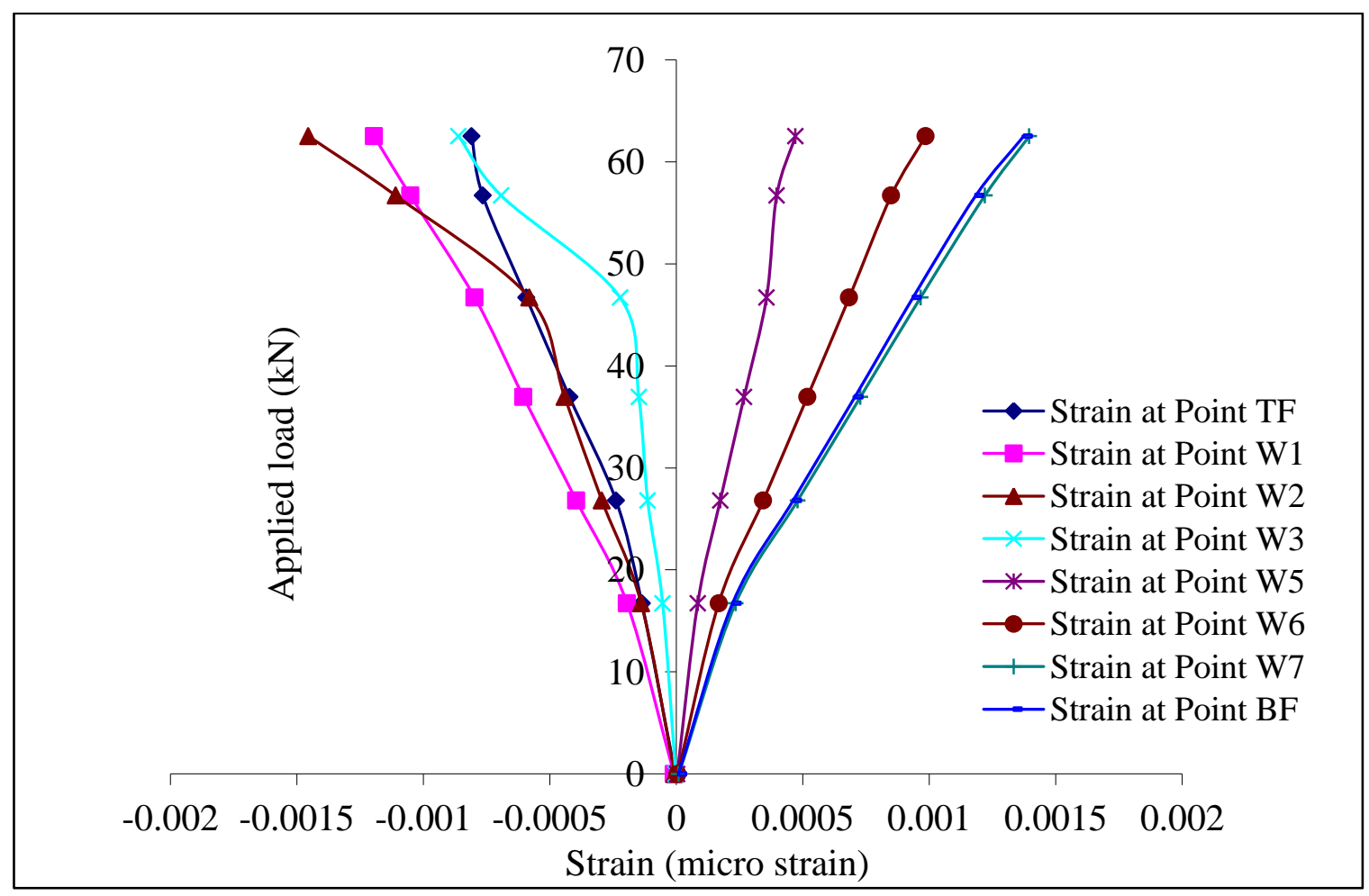

Figure B4.19: Load-strain distribution at the middle of 356x6100 mm joist 1 


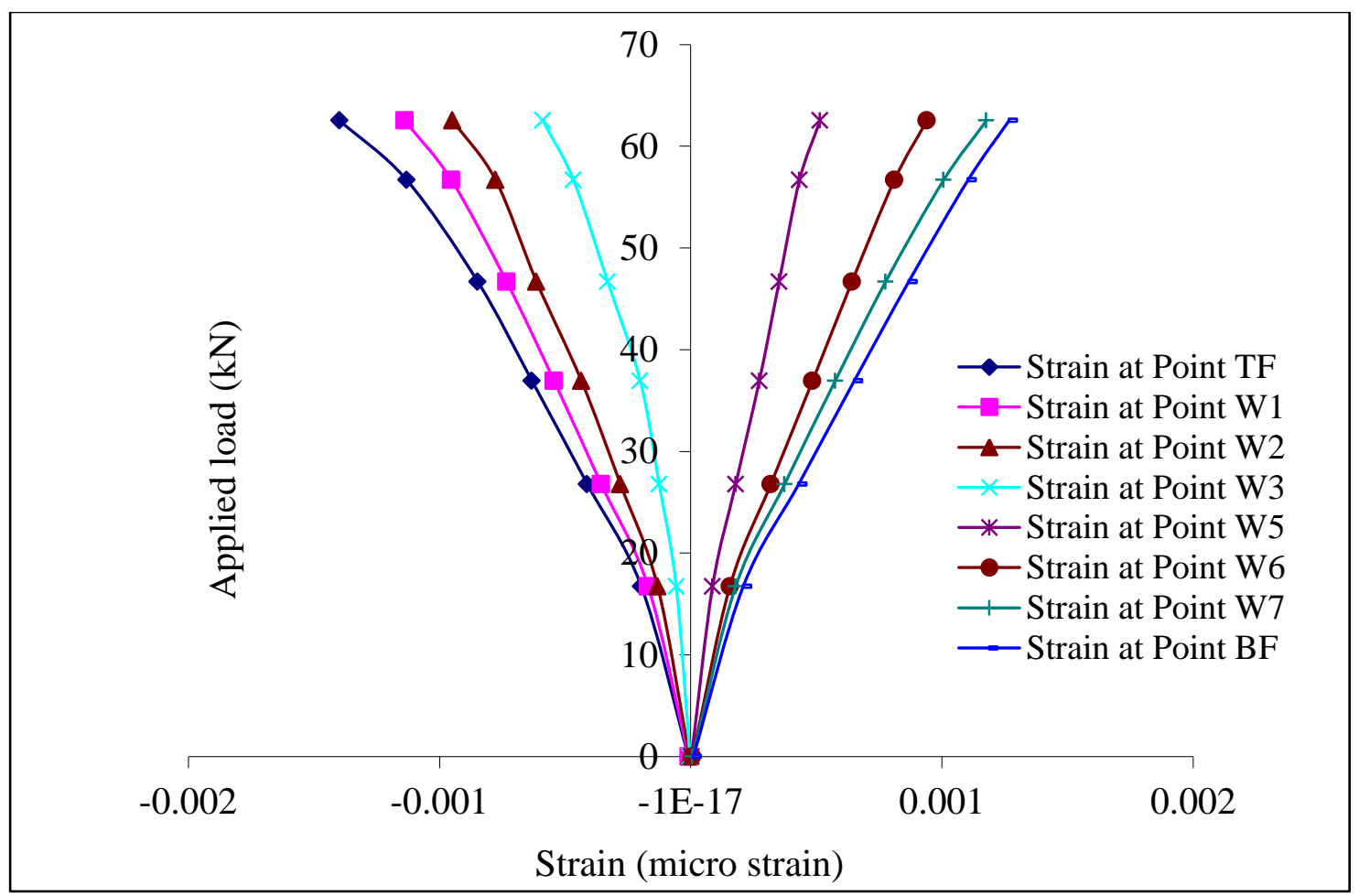

Figure B4.20: Load-strain distribution at the middle of 356x6100 mm joist 2 


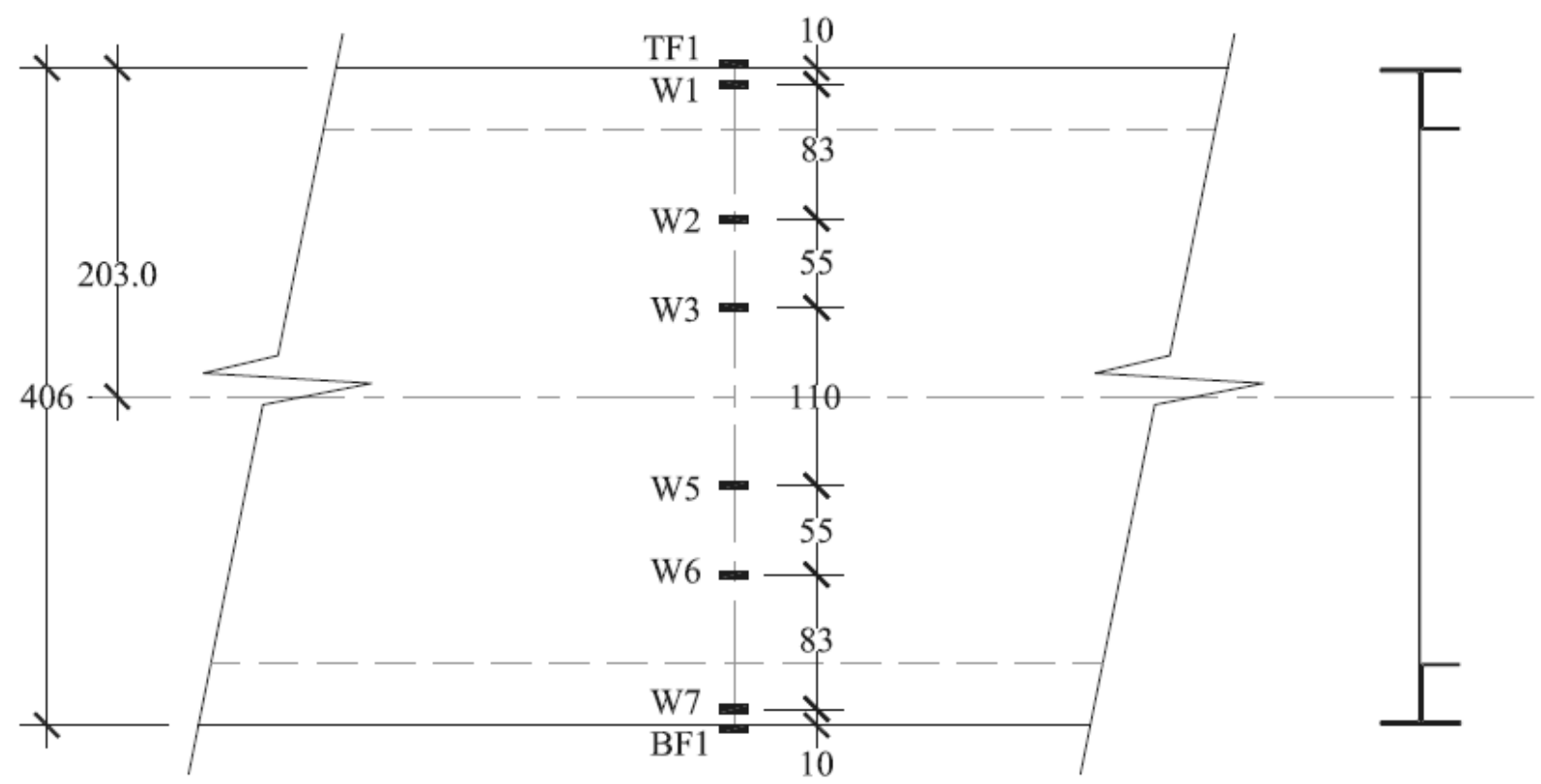

Legend:

TF1

W1

Strain gauge at top flange

W2

Strian gauge at web point 1

W3

Strian gauge at web point 2

W5

Strian gauge at web point 3

W6

Strian gauge at web point 5

W7

Strian gauge at web point 6

BF1

Strain gauge at web point 7

Strain gauge at bottom flange 


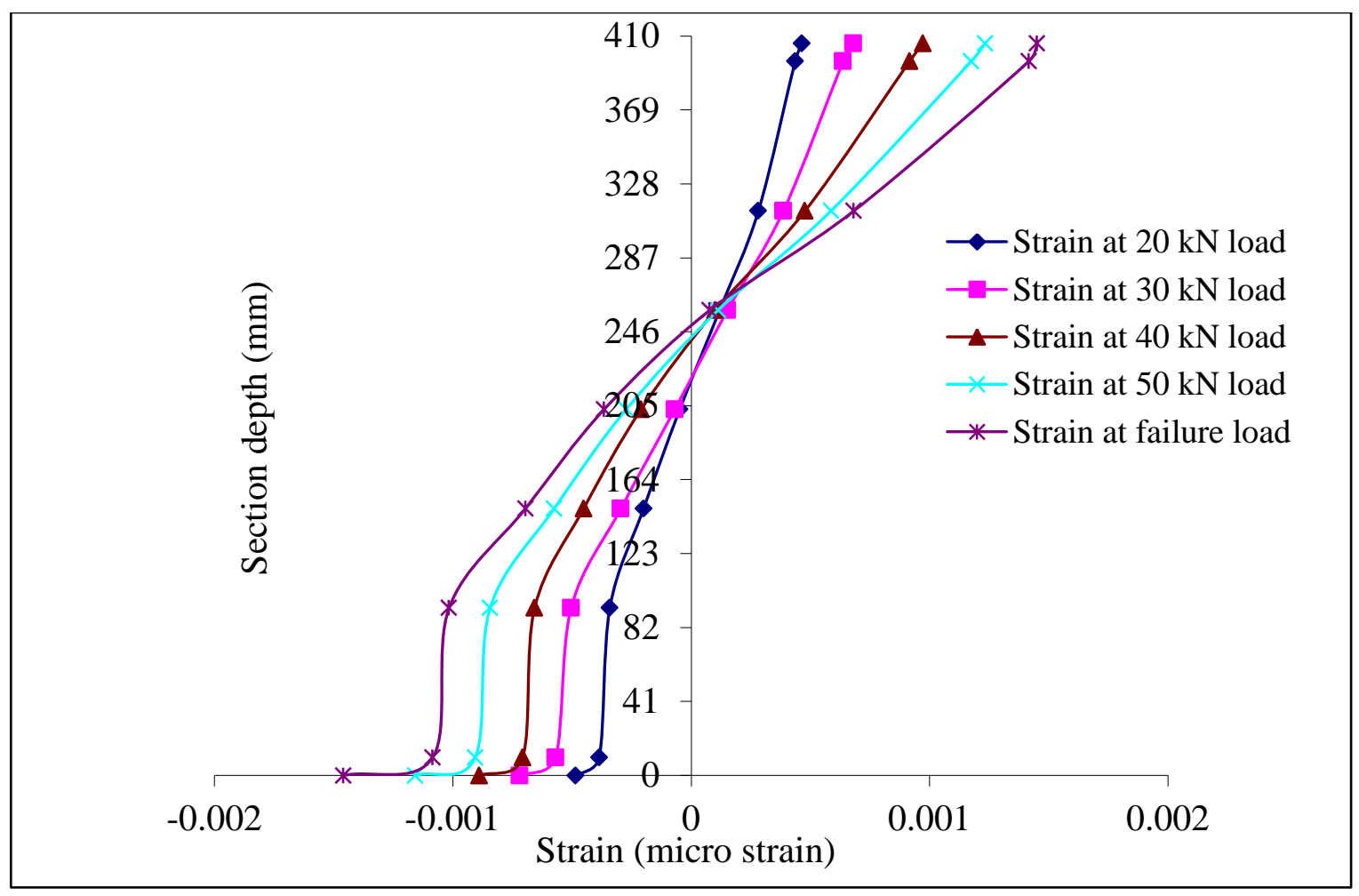

Figure B4.21: Flexural-strain distribution at the middle of the 400x7950 mm joist 1

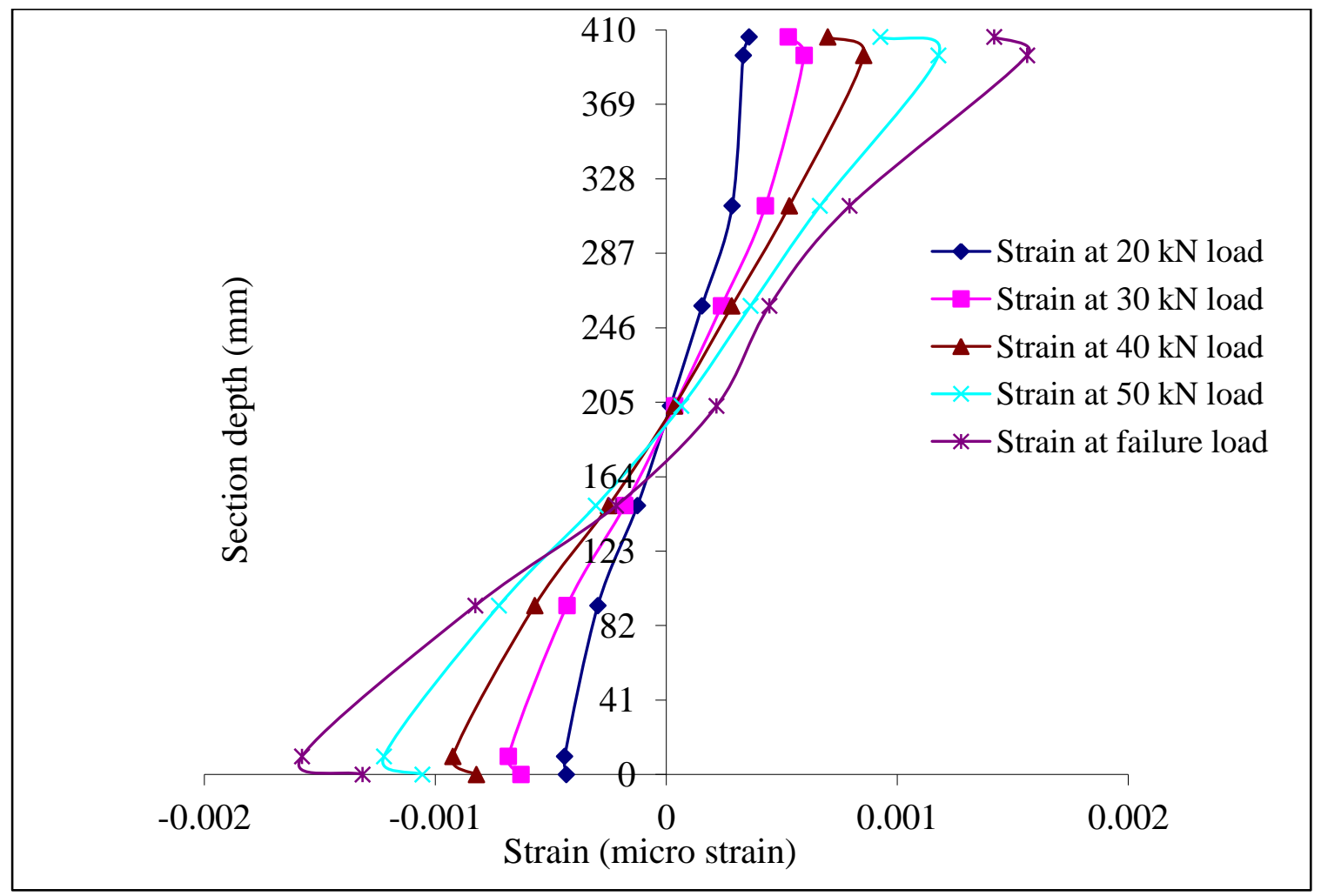

Figure B4.22: Flexural-strain distribution at the middle of the $400 \times 7950 \mathrm{~mm}$ joist 2 


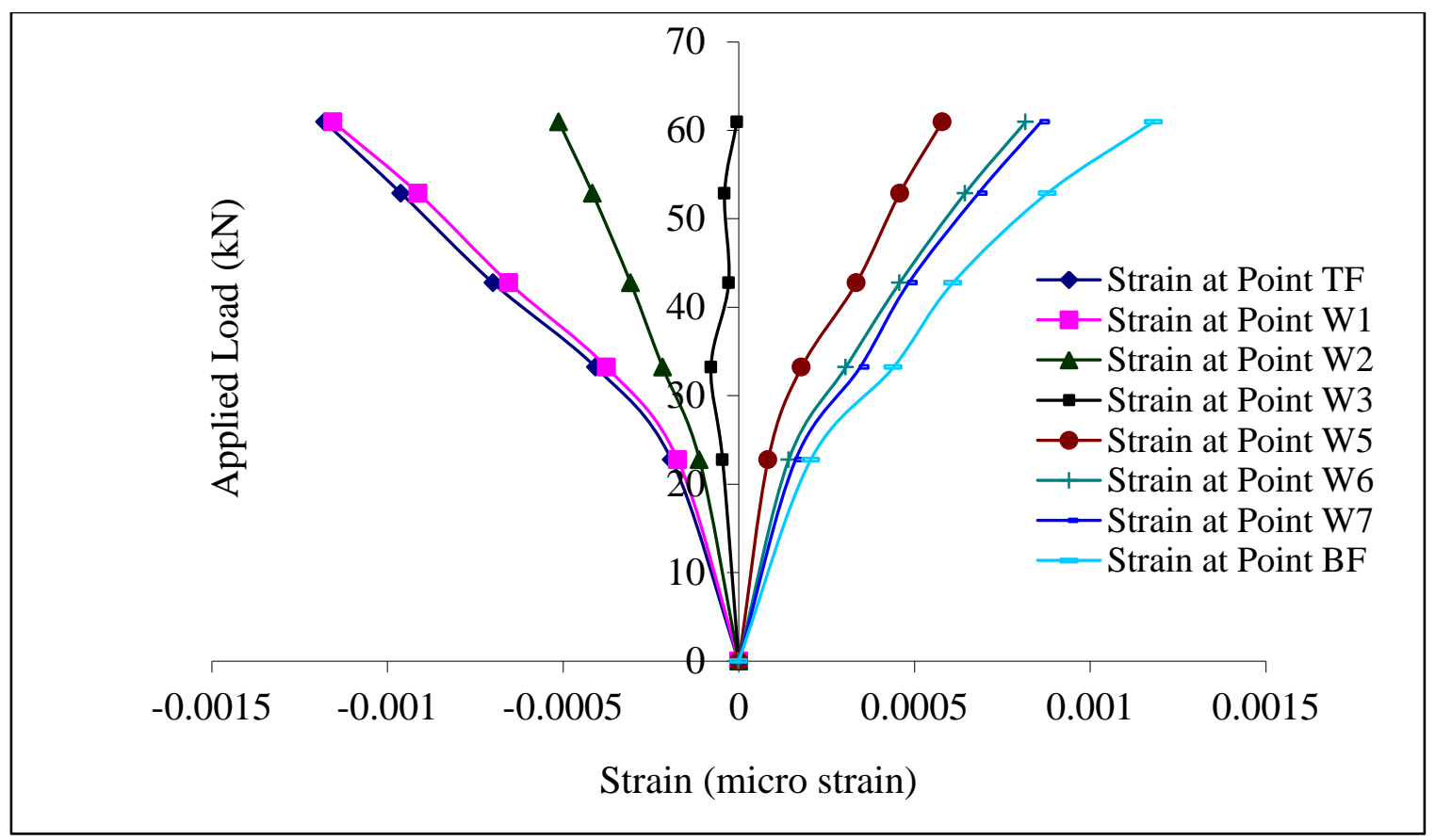

Figure B4.23: Load-strain distribution at the middle of 400x7950 mm joist 1

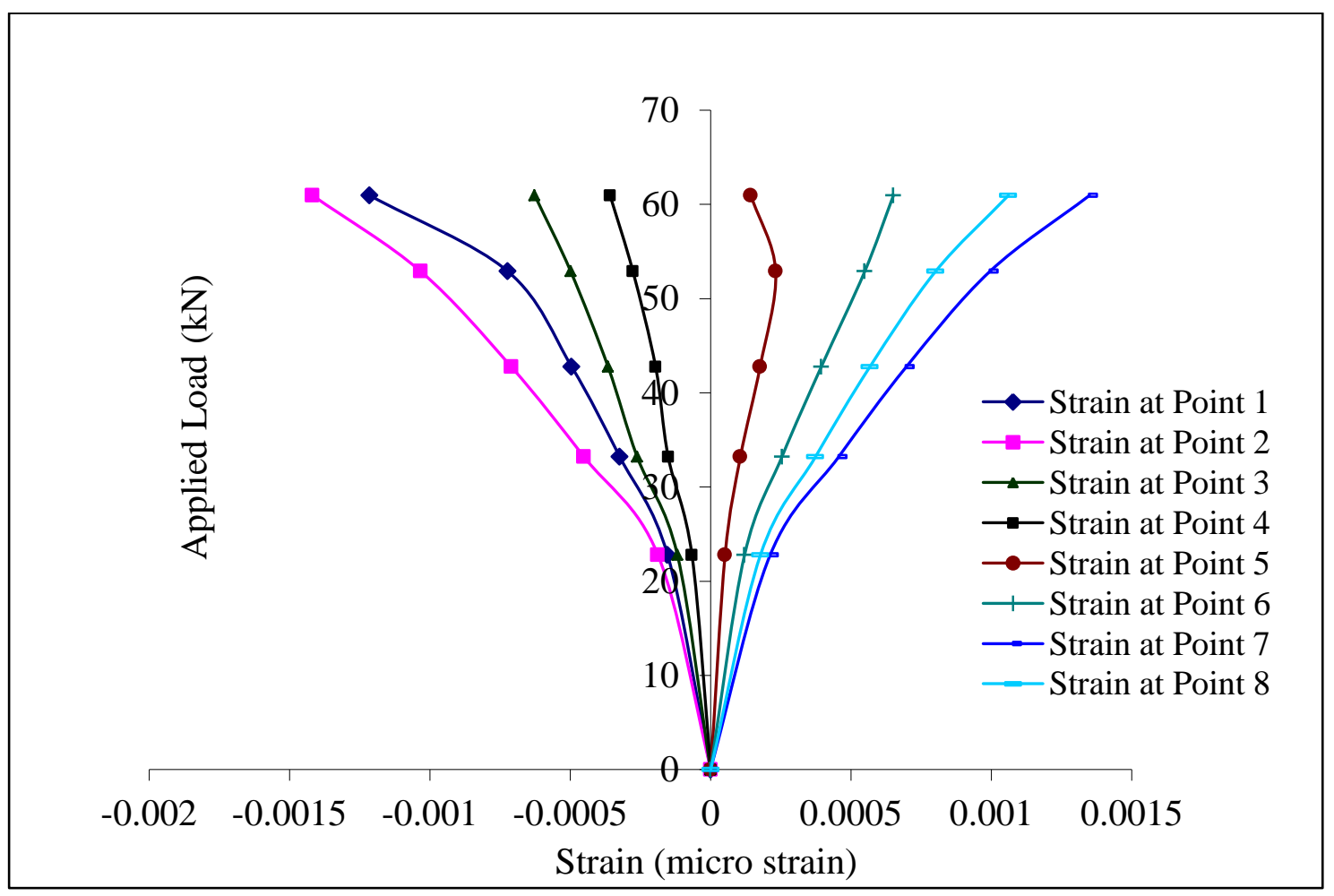

Figure B4.24: Load-strain distribution at the middle of 400x7950 mm joist 2 


\section{APPENDIX C1. ACCELERATION SPECTRUM OF ISPAN JOIST WITH HOLES}




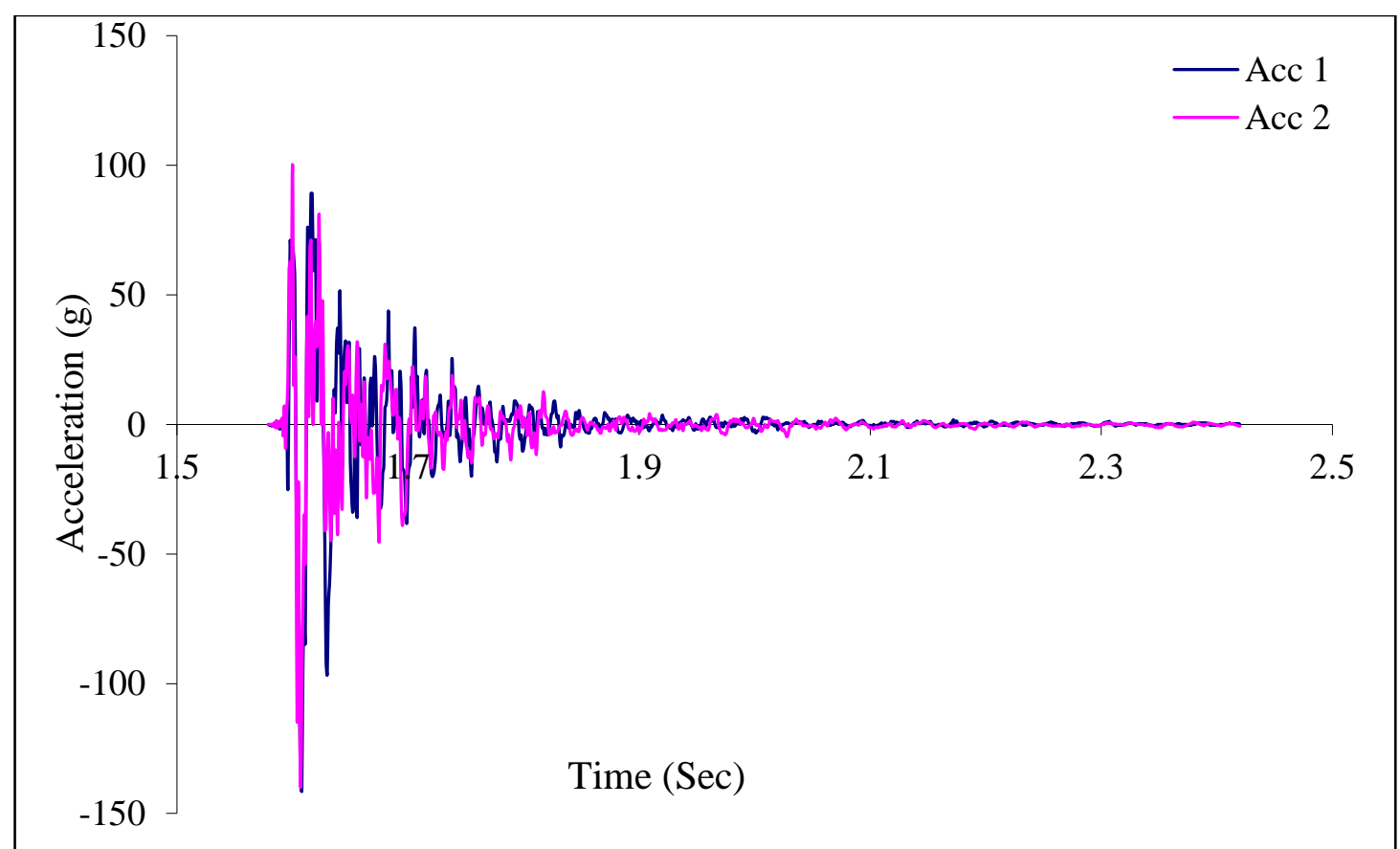

Figure C1.1: Typical acceleration trace for 254x3500 mm iSPAN floor joist (balloon framing)

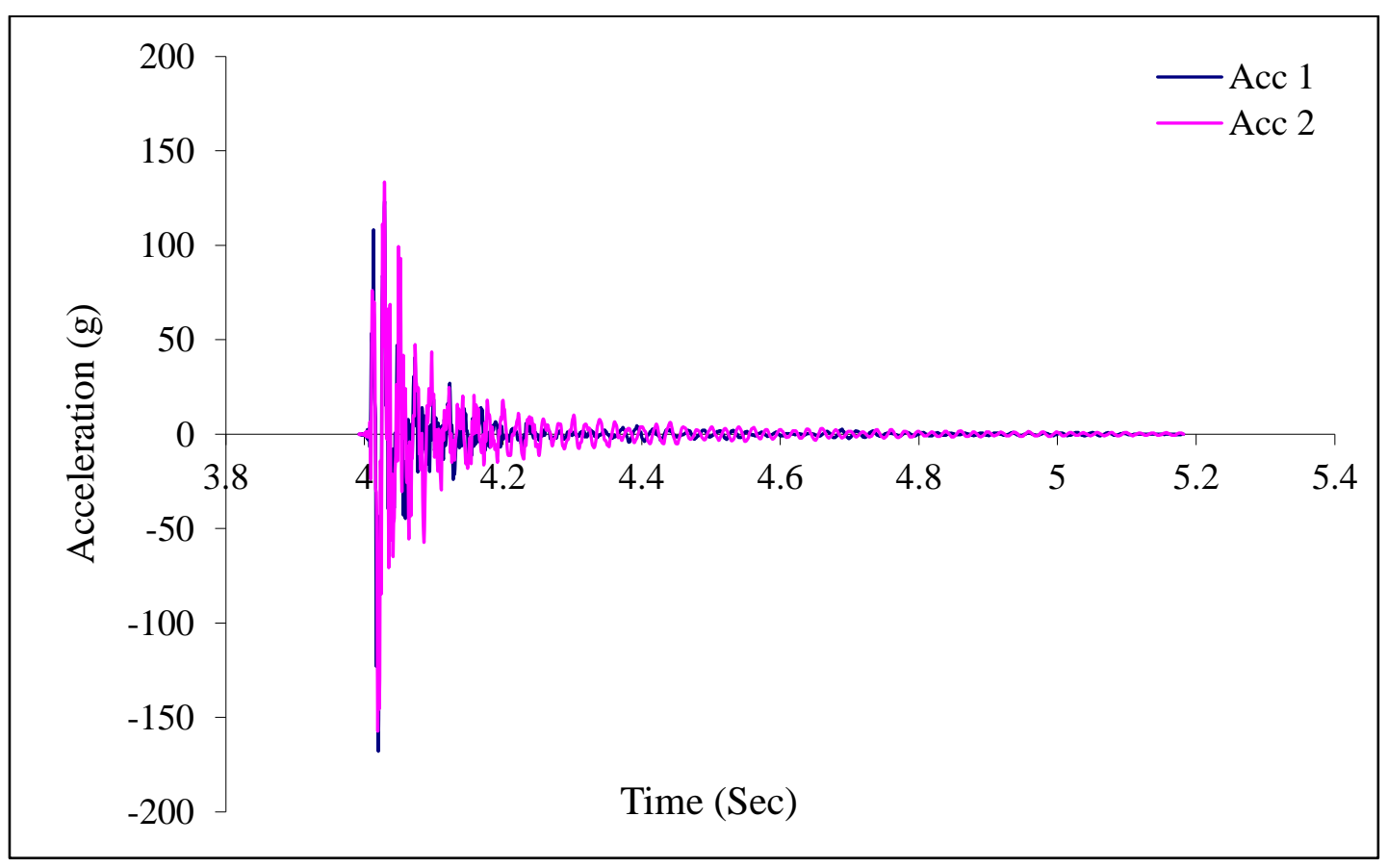

Figure C1.2: Typical acceleration trace for 254x3500 mm iSPAN floor joist (simply supported) 


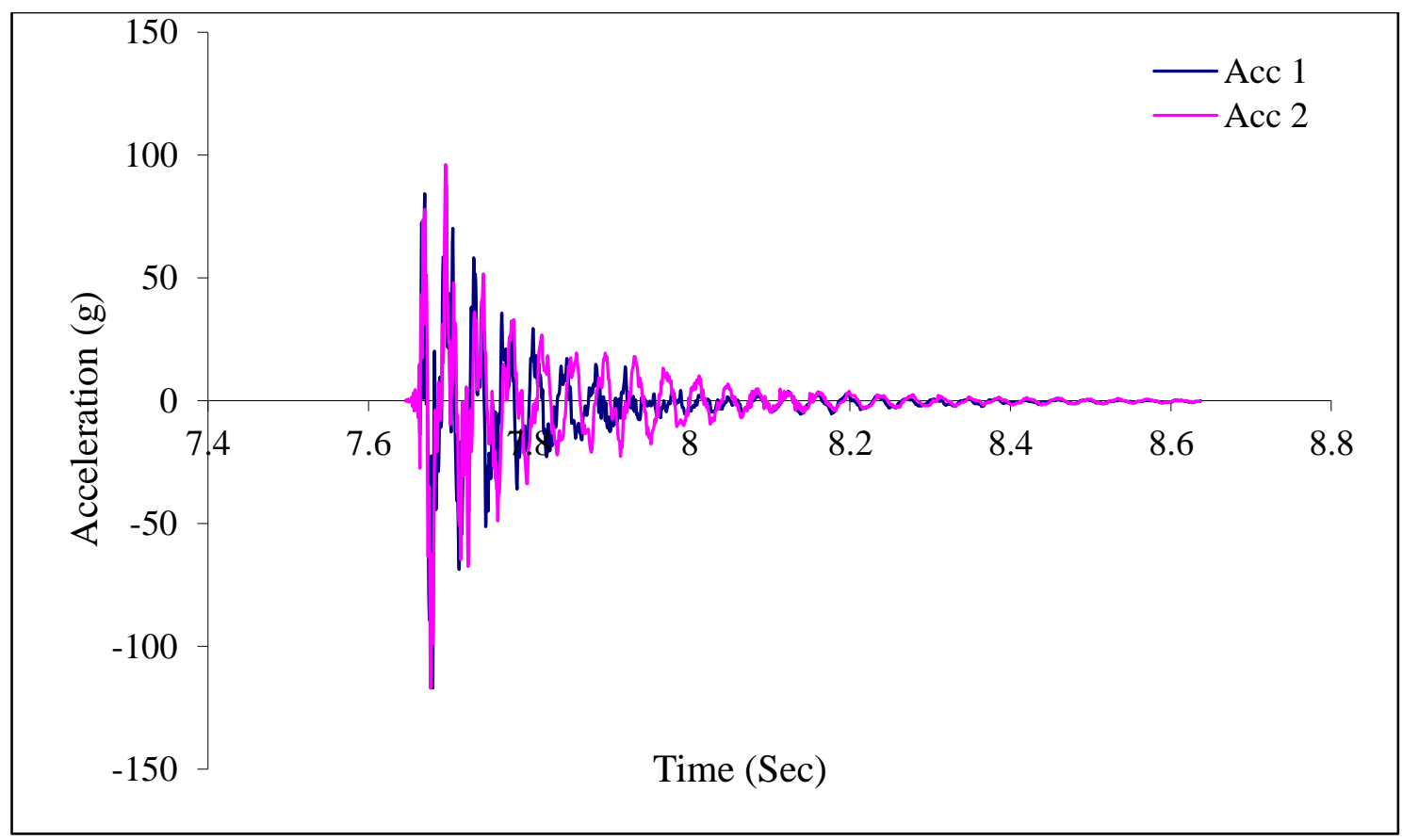

Figure C1.3: Typical acceleration trace for $254 \times 4500 \mathrm{~mm}$ iSPAN floor joist (balloon framing)

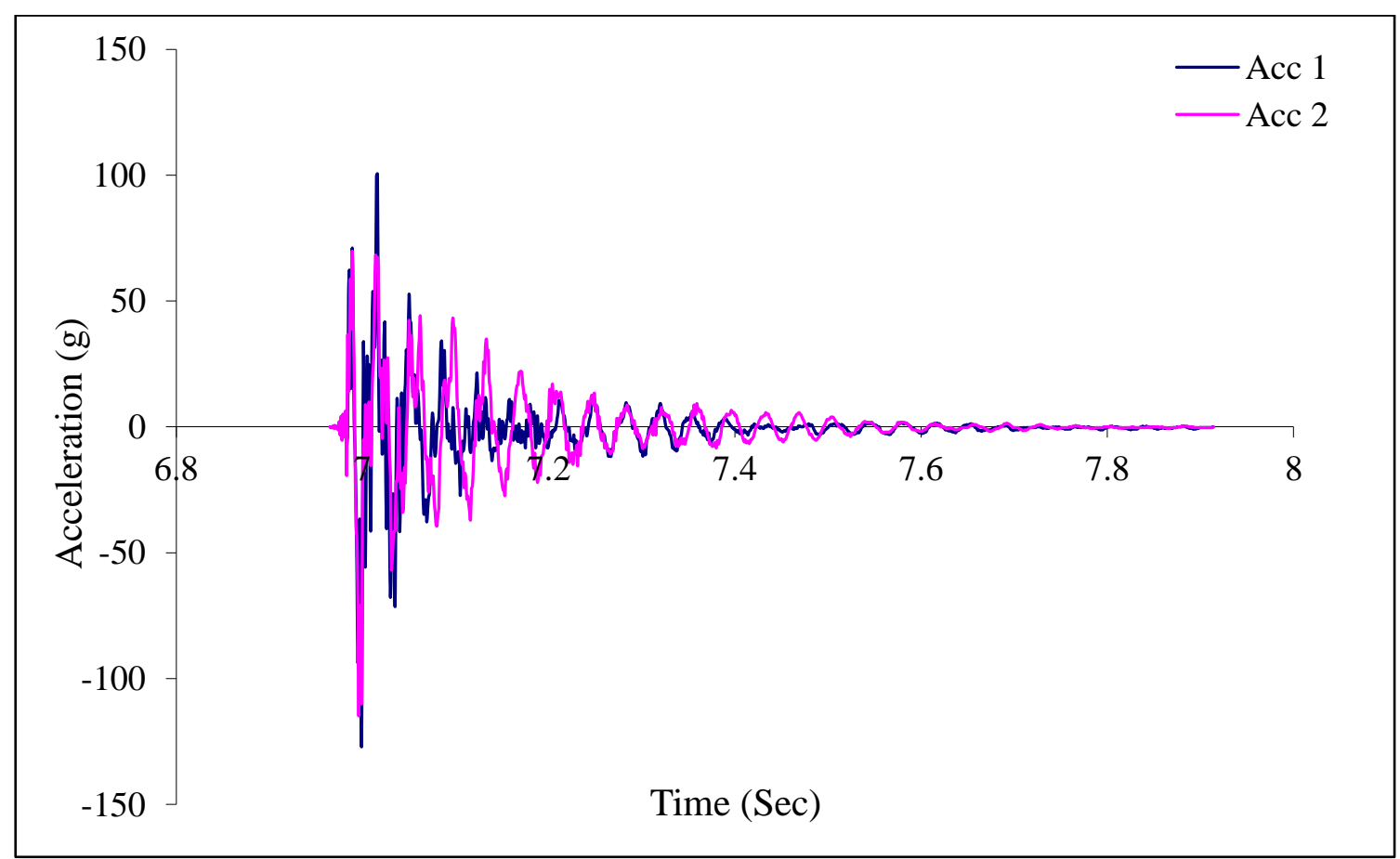

Figure C1.4: Typical acceleration trace for 254x4500 mm iSPAN floor joist (simply supported) 


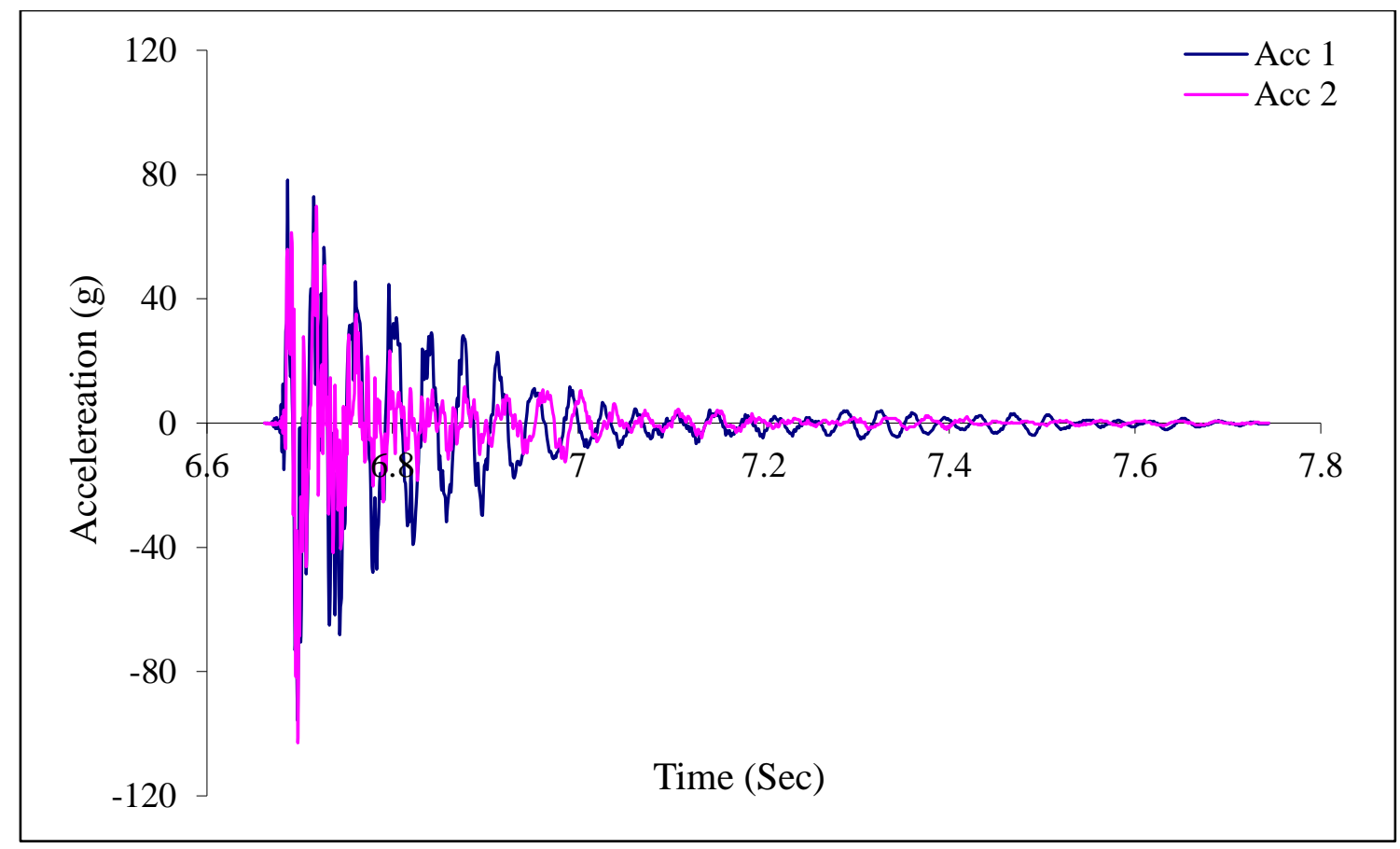

Figure C1.5: Typical acceleration trace for 302x5000 mm iSPAN floor joist (balloon framing)

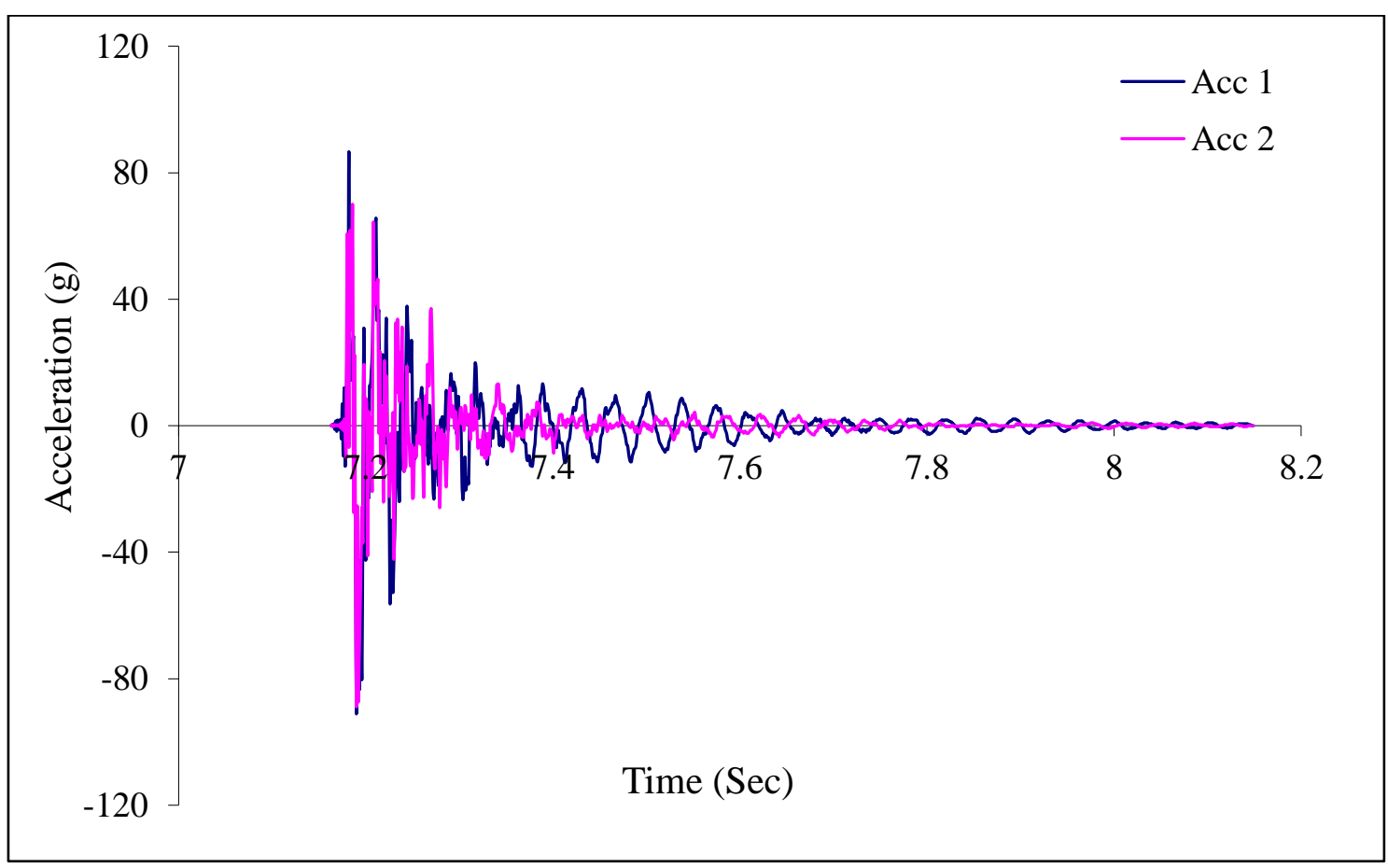

Figure C1.6: Typical acceleration trace for 302 x $5000 \mathrm{~mm}$ iSPAN floor joist (simply supported) 


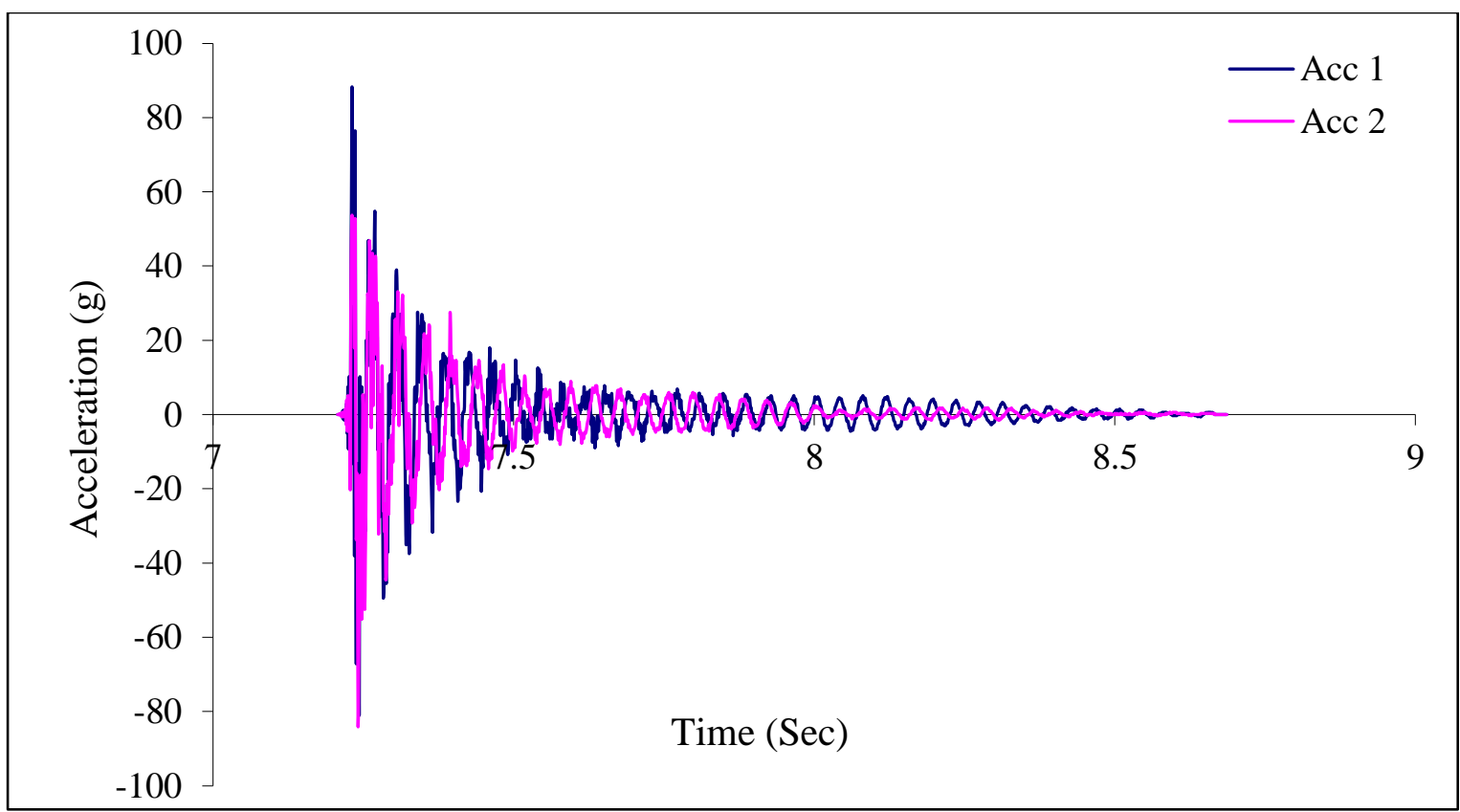

Figure C1.7: Typical acceleration trace for 302x5250 mm iSPAN floor joist (balloon framing)

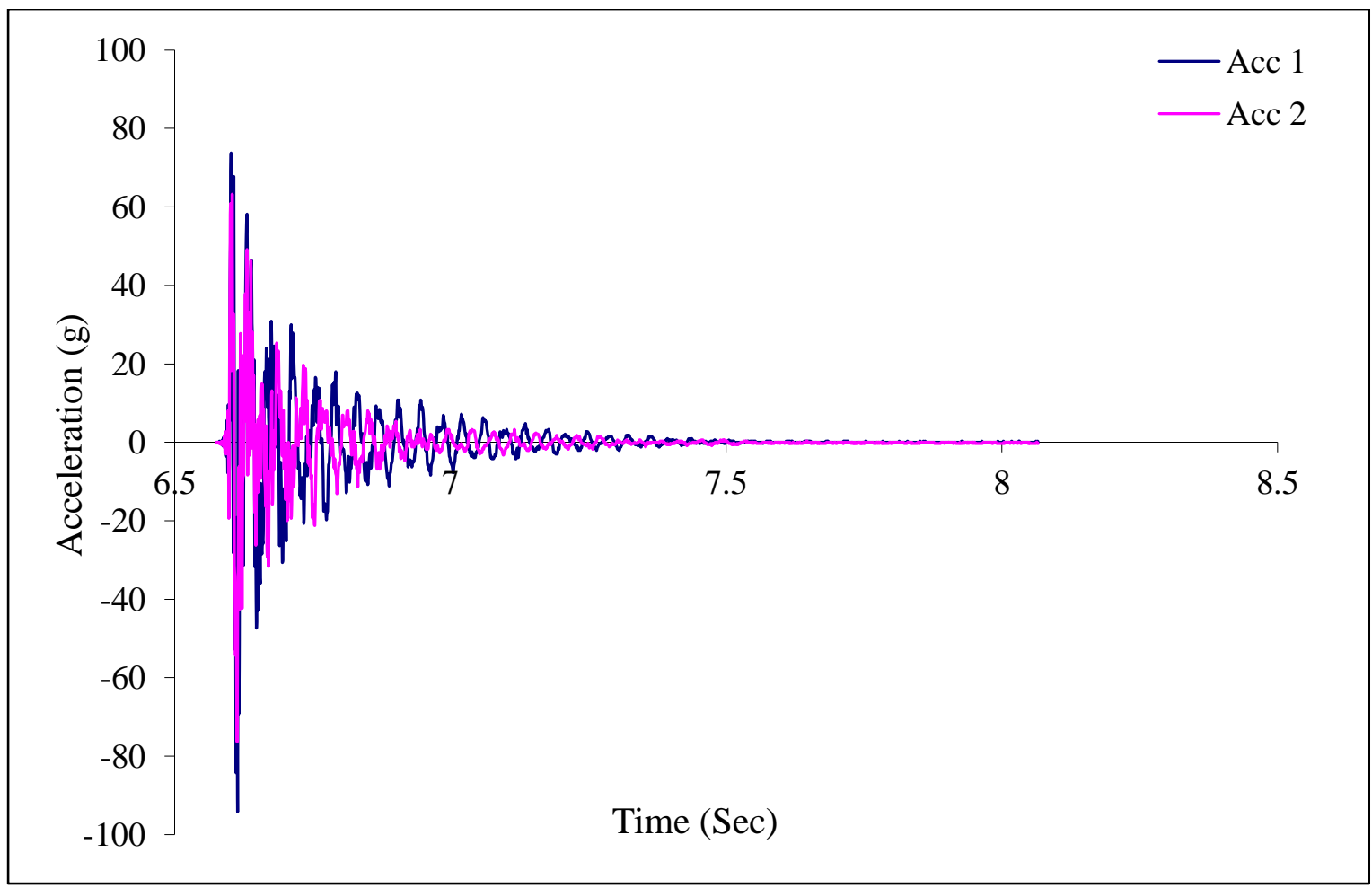

Figure C1.8: Typical acceleration trace for 302x5250 mm iSPAN floor joist (simply supported) 


\section{APPENDIX C2. NATURAL FREQUENCY SPECTRUM OF ISPAN JOISTS WITH HOLES}




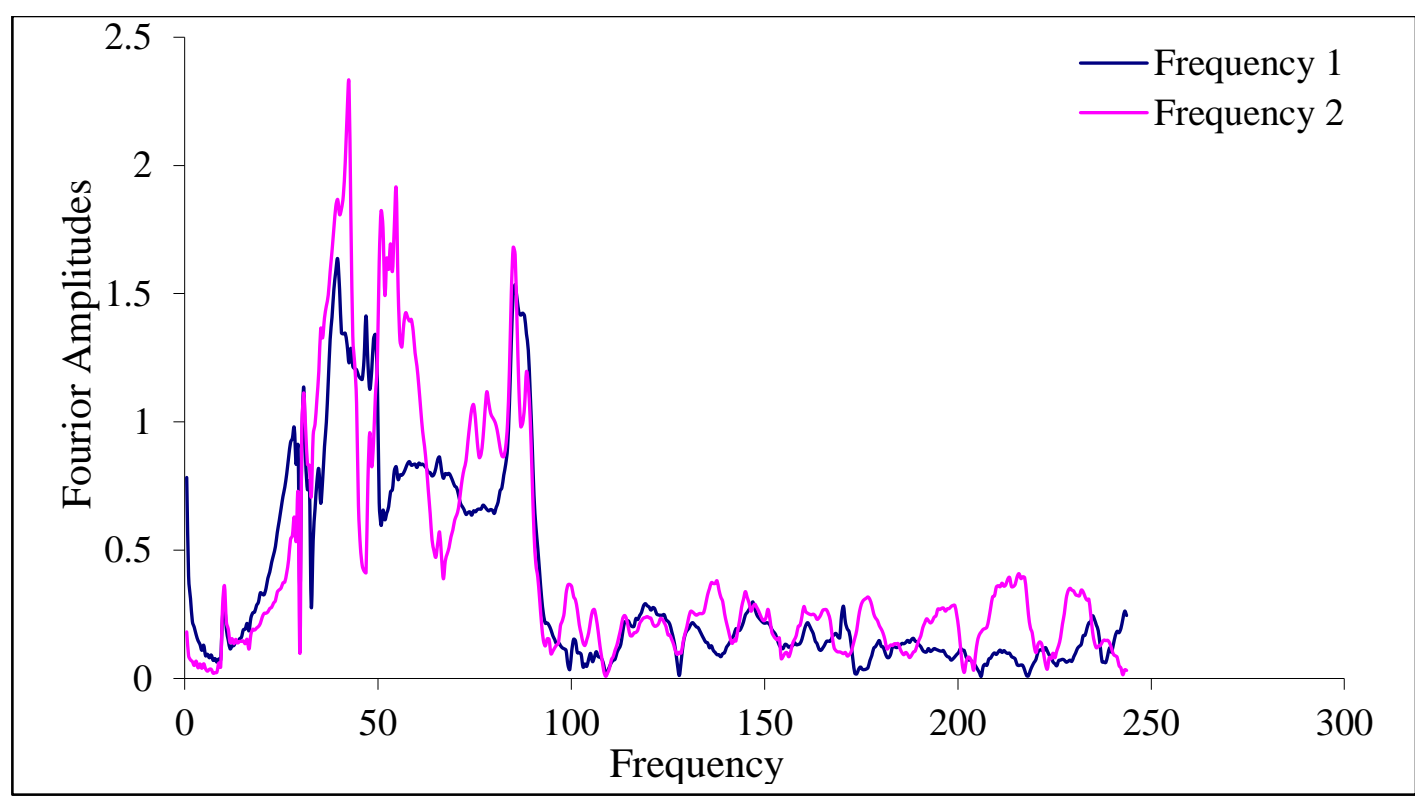

Figure C2.1: Typical frequency spectrum for 254x3500 mm iSPAN floor joist (balloon framing)

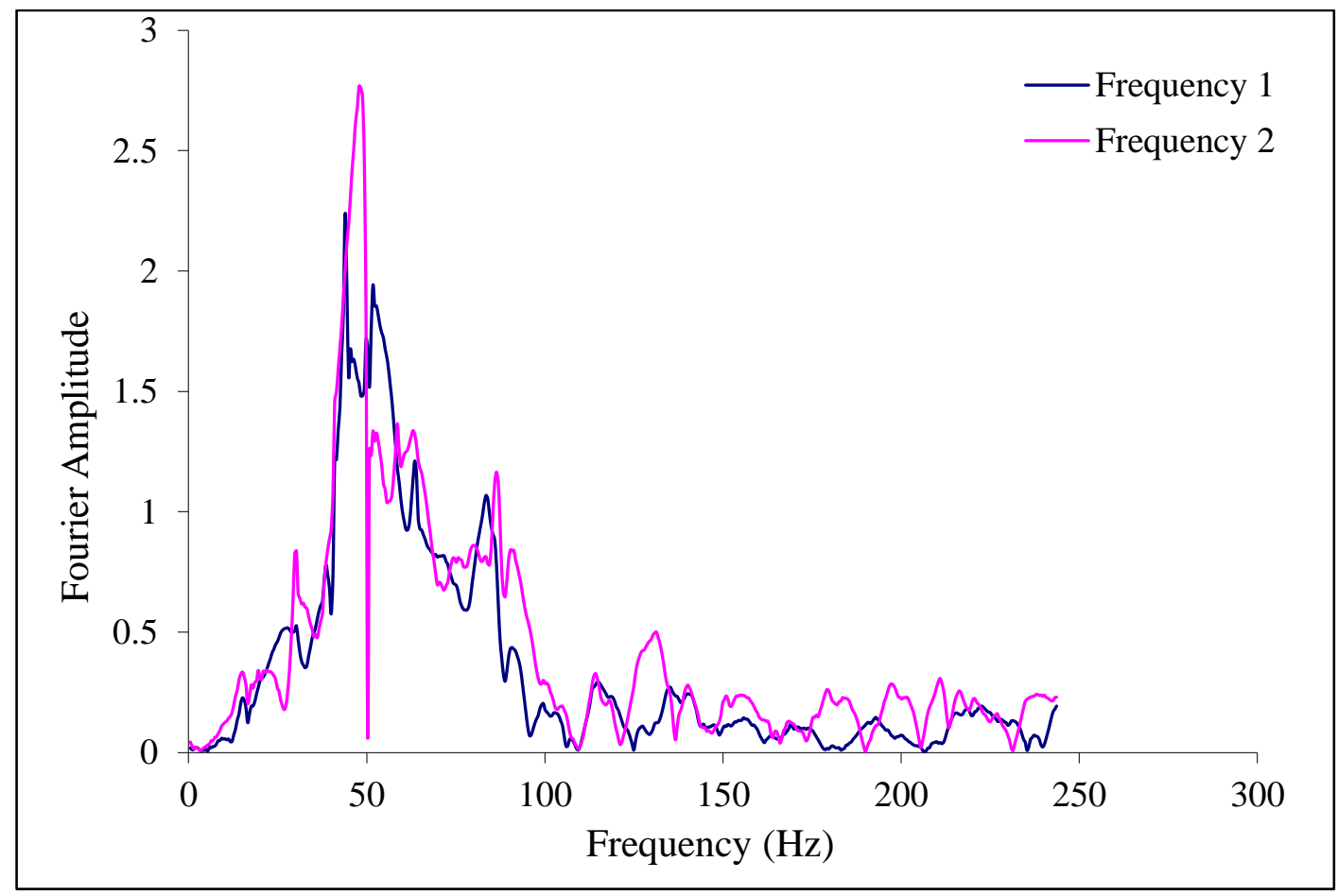

Figure C2.2: Typical frequency spectrum for 254x3500 mm iSPAN floor joist (simply supported) 


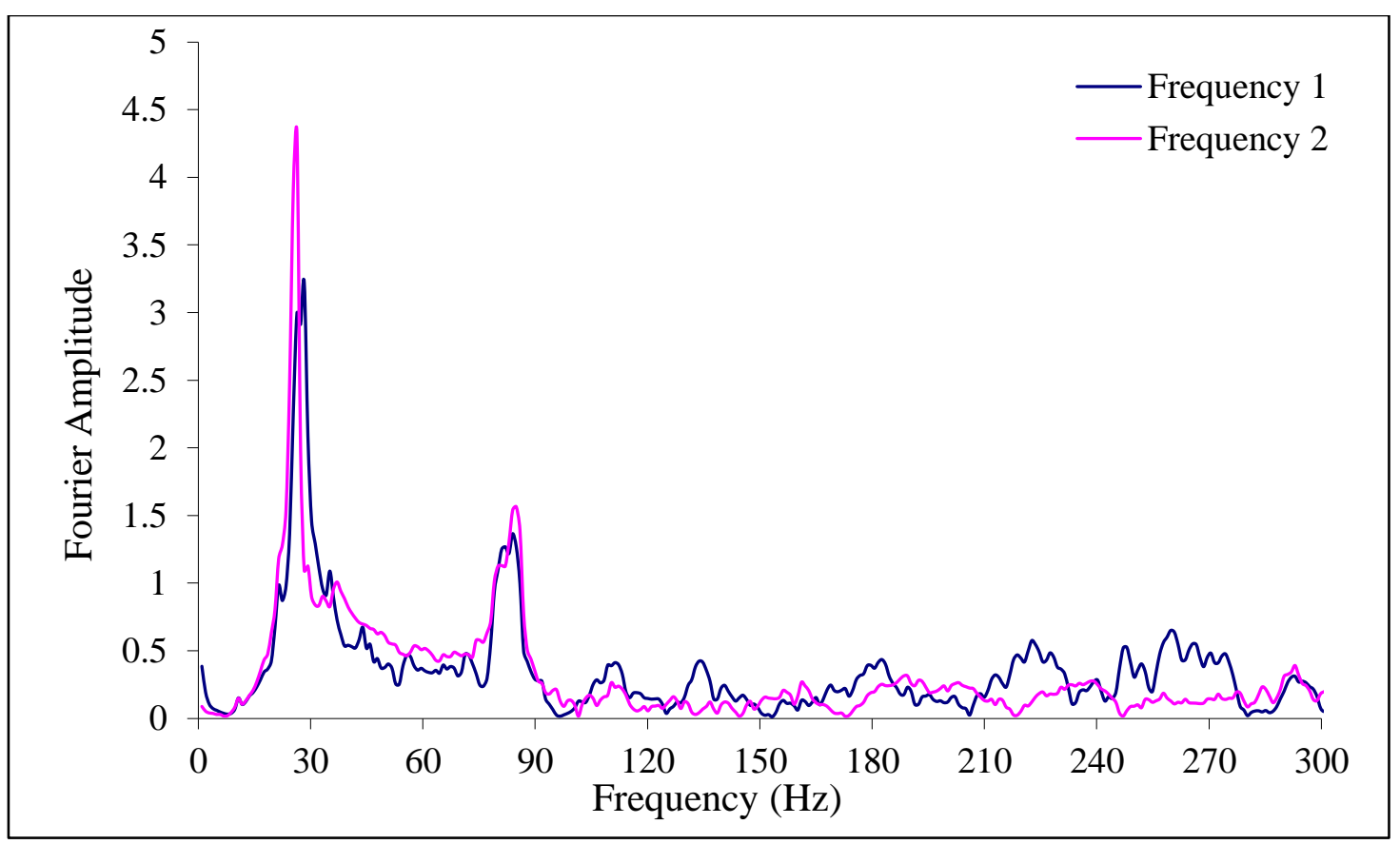

Figure C2.3: Typical frequency spectrum for 254x4500 mm iSPAN floor joist (balloon framing)

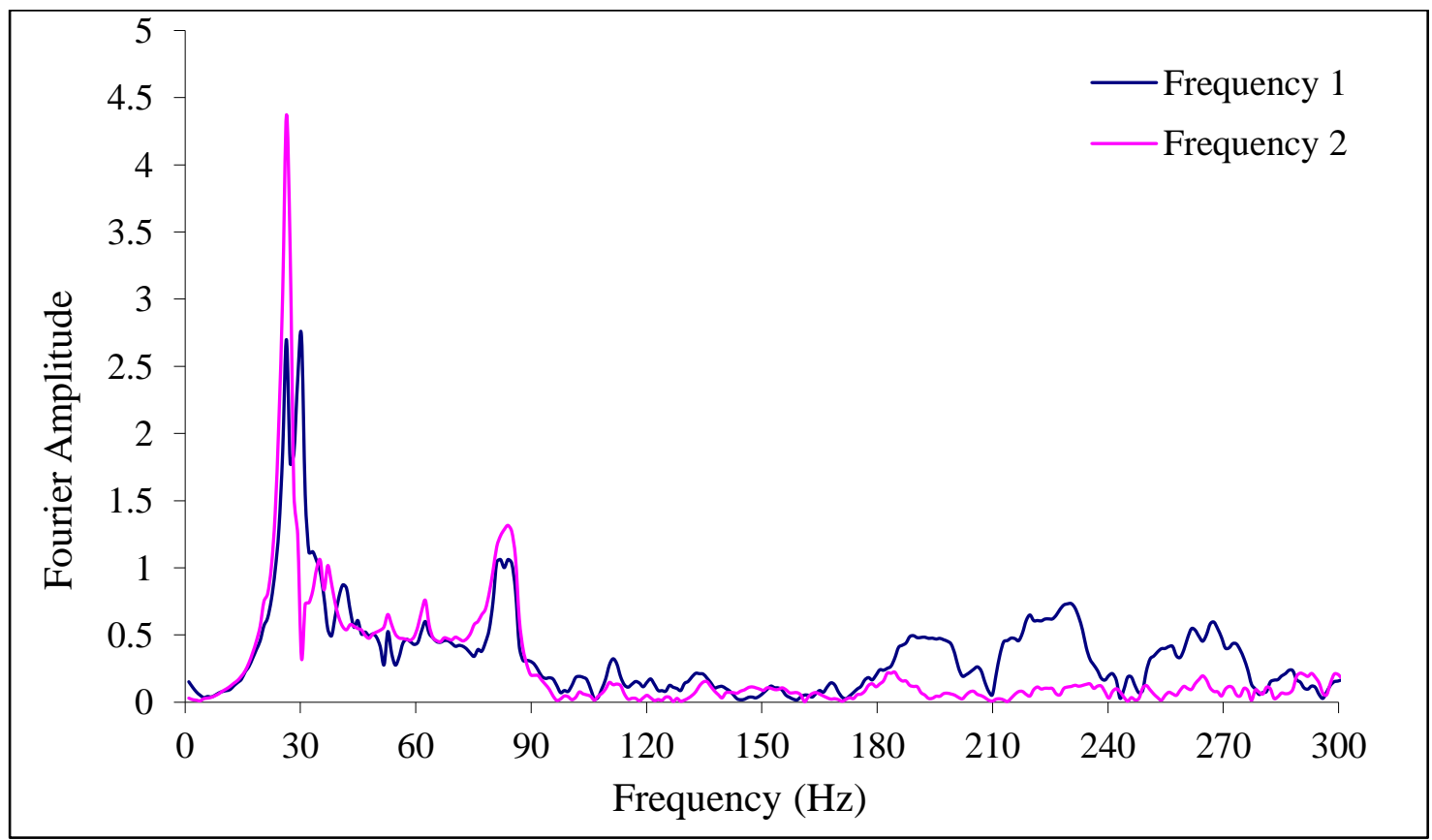

Figure C2.4: Typical frequency spectrum for $254 \times 4500 \mathrm{~mm}$ iSPAN floor joist (simply supported) 


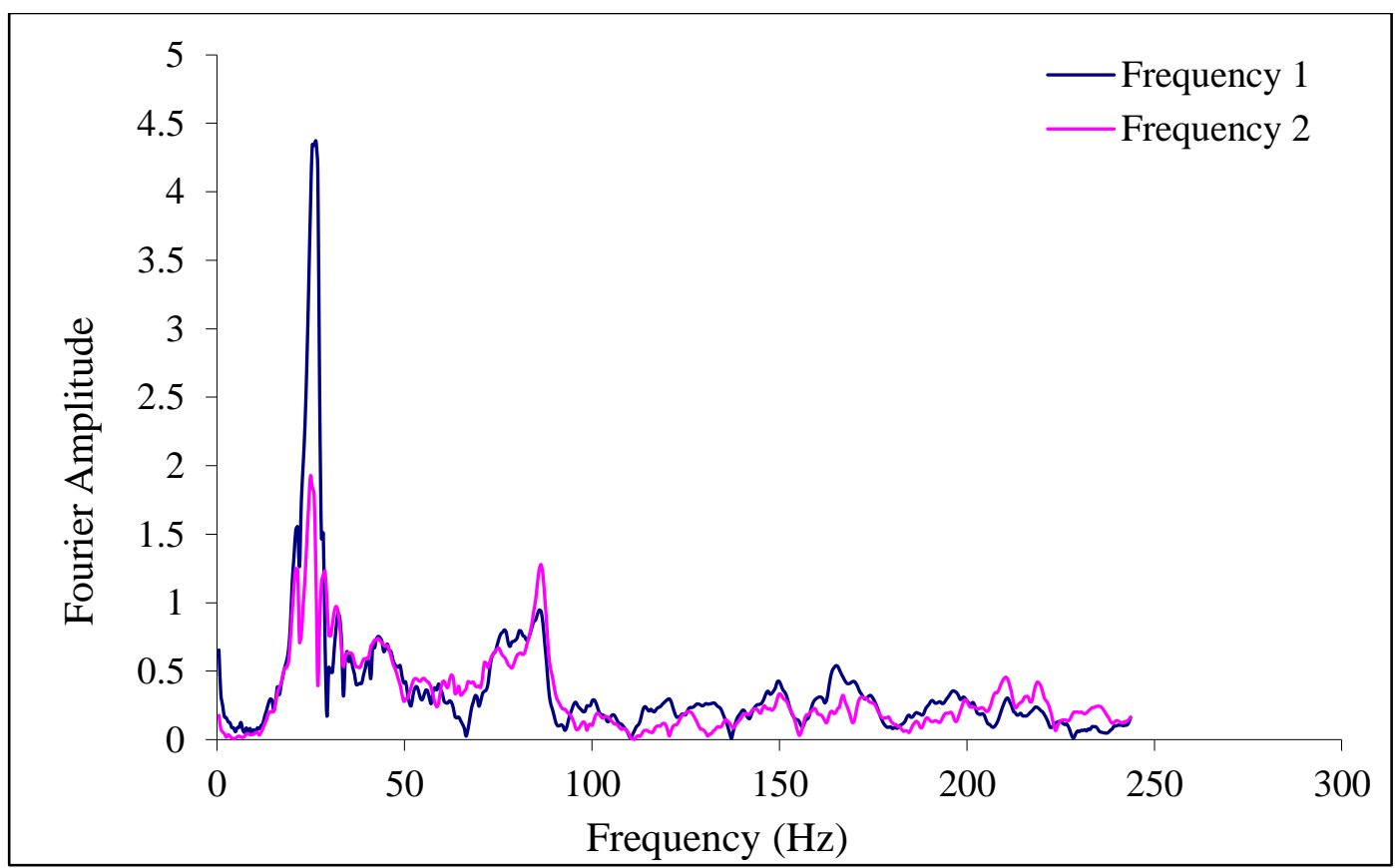

Figure C2.5: Typical frequency spectrum for 302x5000 mm iSPAN floor joist (balloon framing)

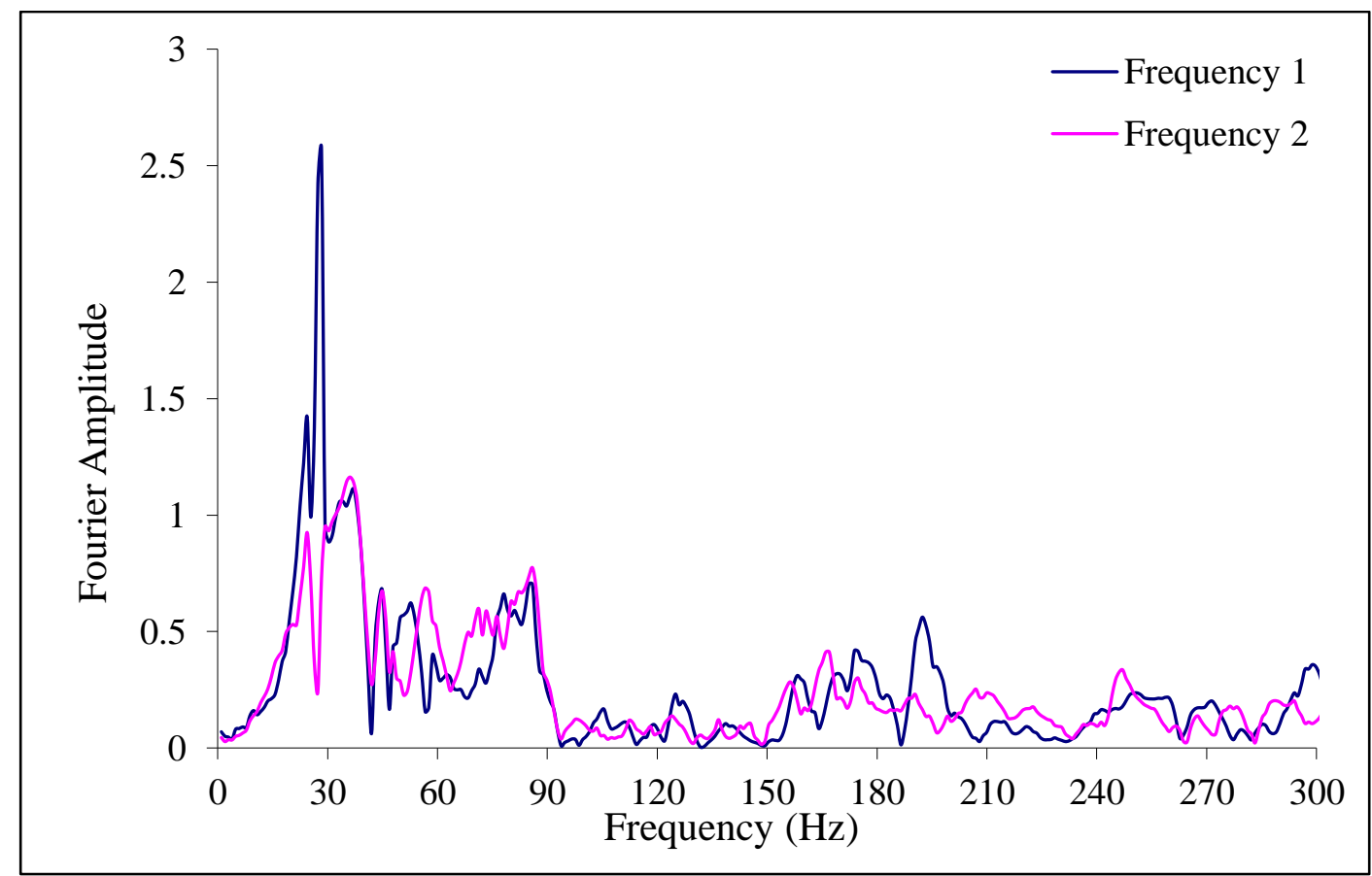

Figure C2.6: Typical frequency spectrum for 302x5000 mm iSPAN floor joist (simply supported) 


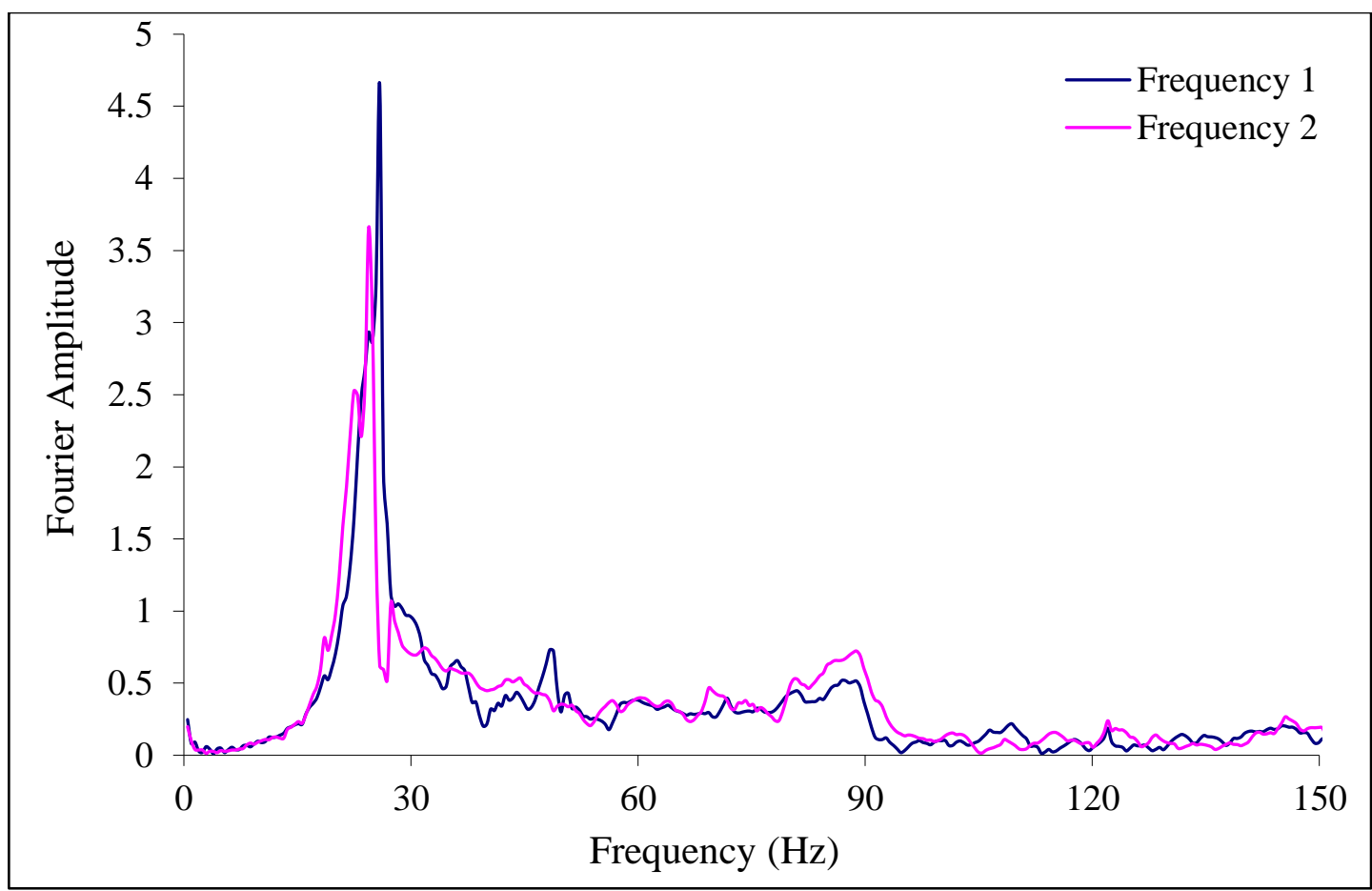

Figure C2.7: Typical frequency spectrum for 302x5250 mm iSPAN floor joist (balloon framing)

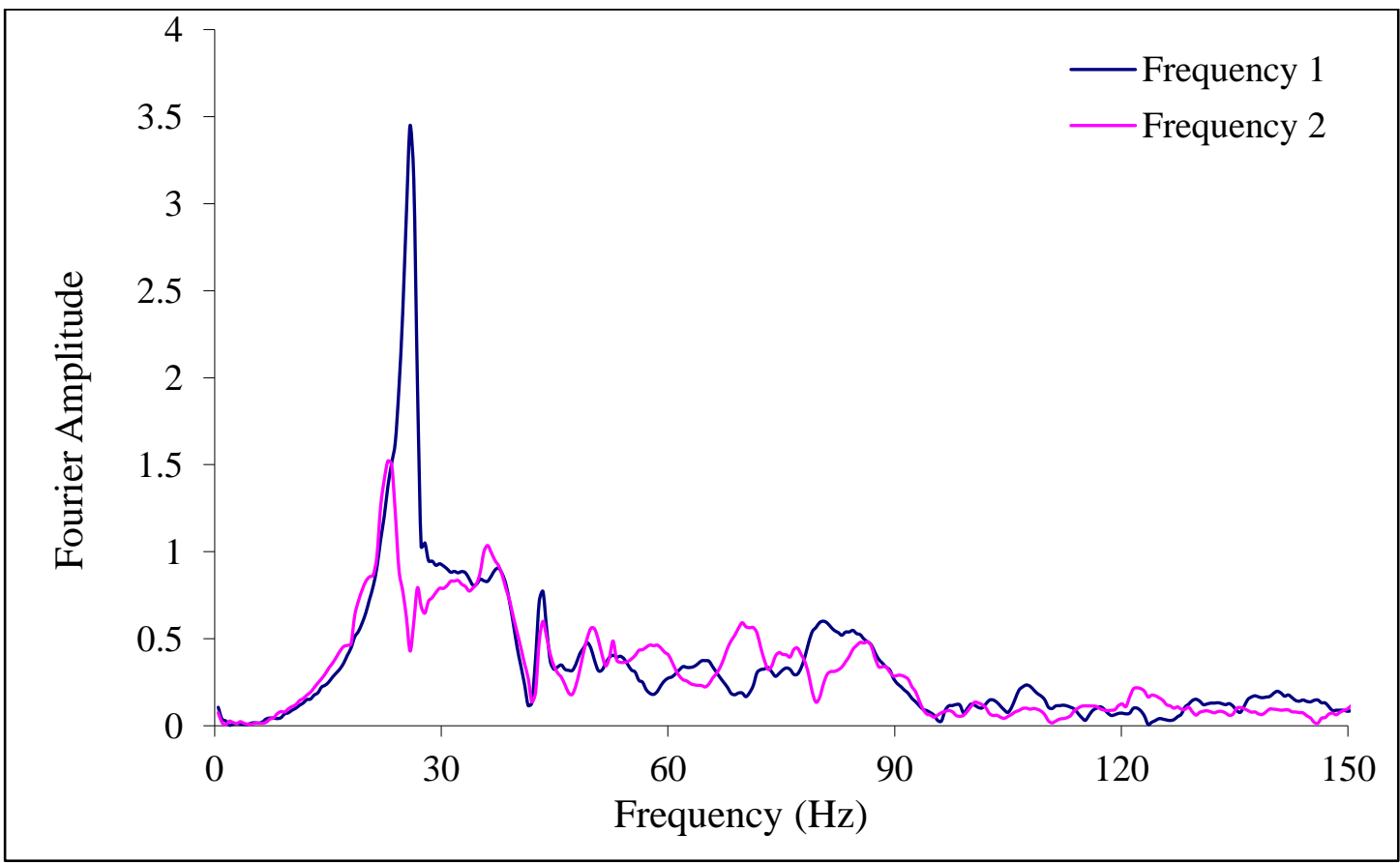

Figure C2.8: Typical frequency spectrum for 302 x $5250 \mathrm{~mm}$ iSPAN floor joist (simply supported) 


\section{APPENDIX C3. LOAD-DEFLECTION CURVES OF iSPAN JOISTS WITH HOLES}




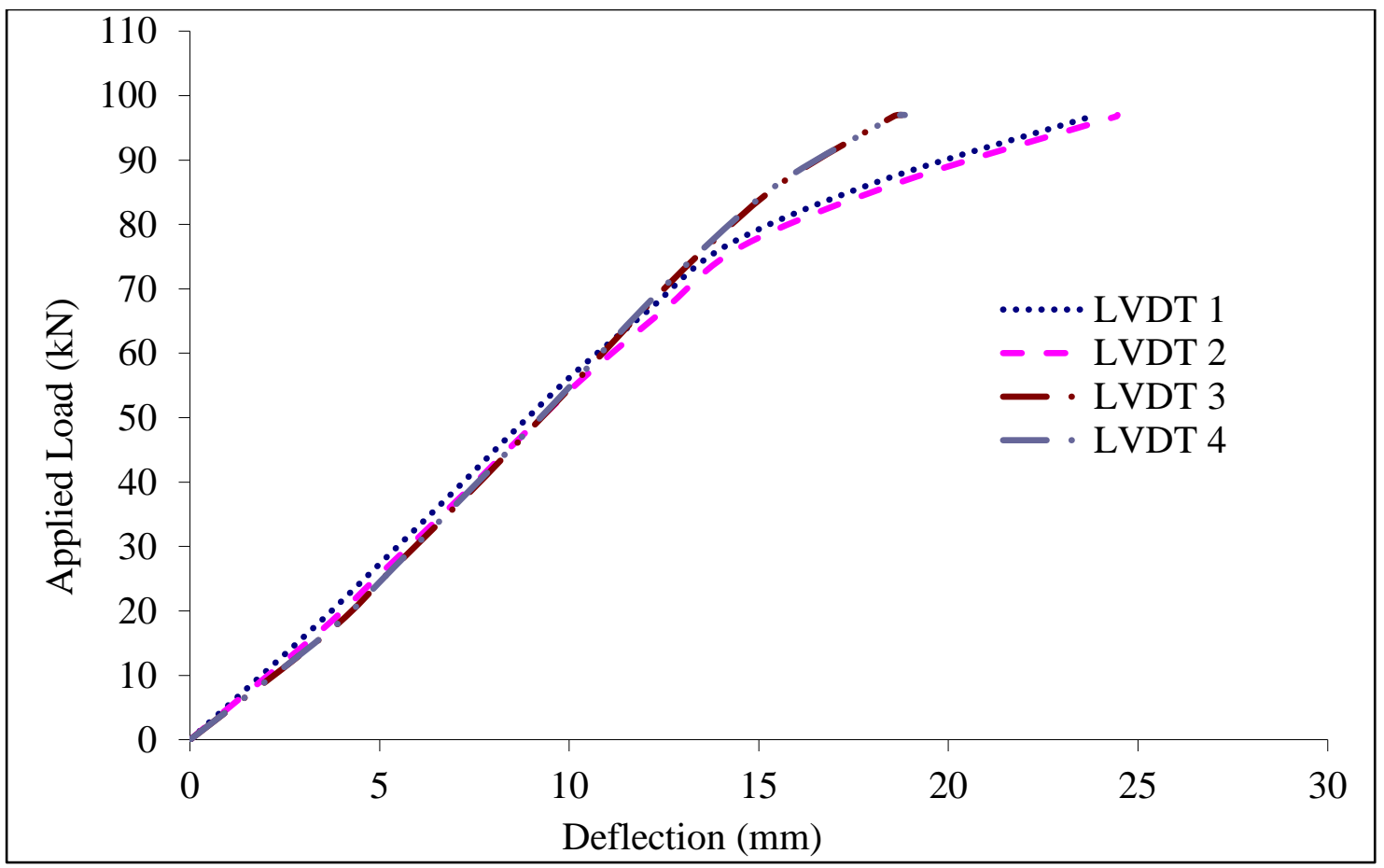

Figure C3.1: Typical load deflection curve for 254x3500 mm iSPAN floor joist

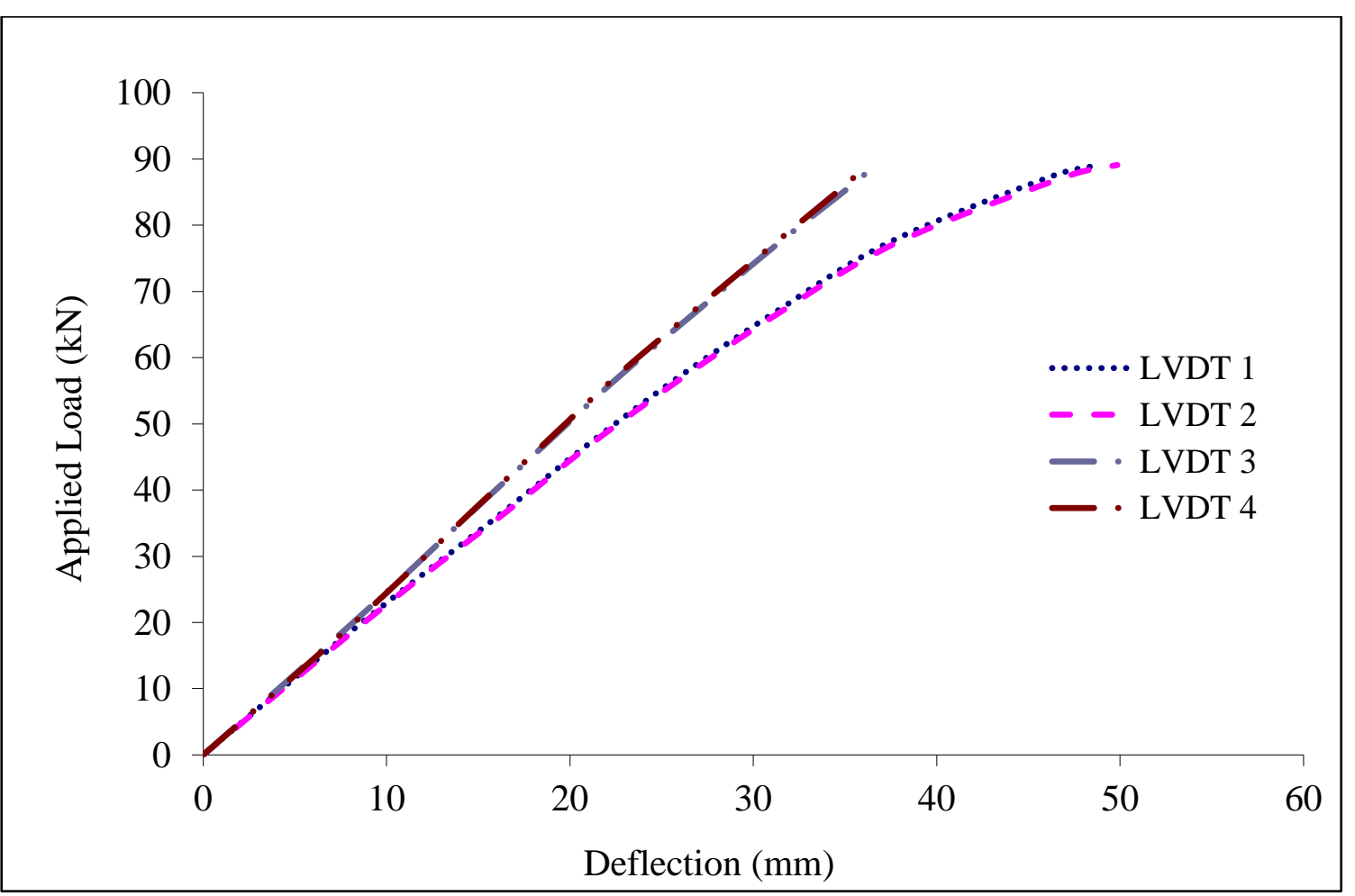

Figure C3.2: Typical load deflection curve for 254x4500 mm iSPAN floor joist 


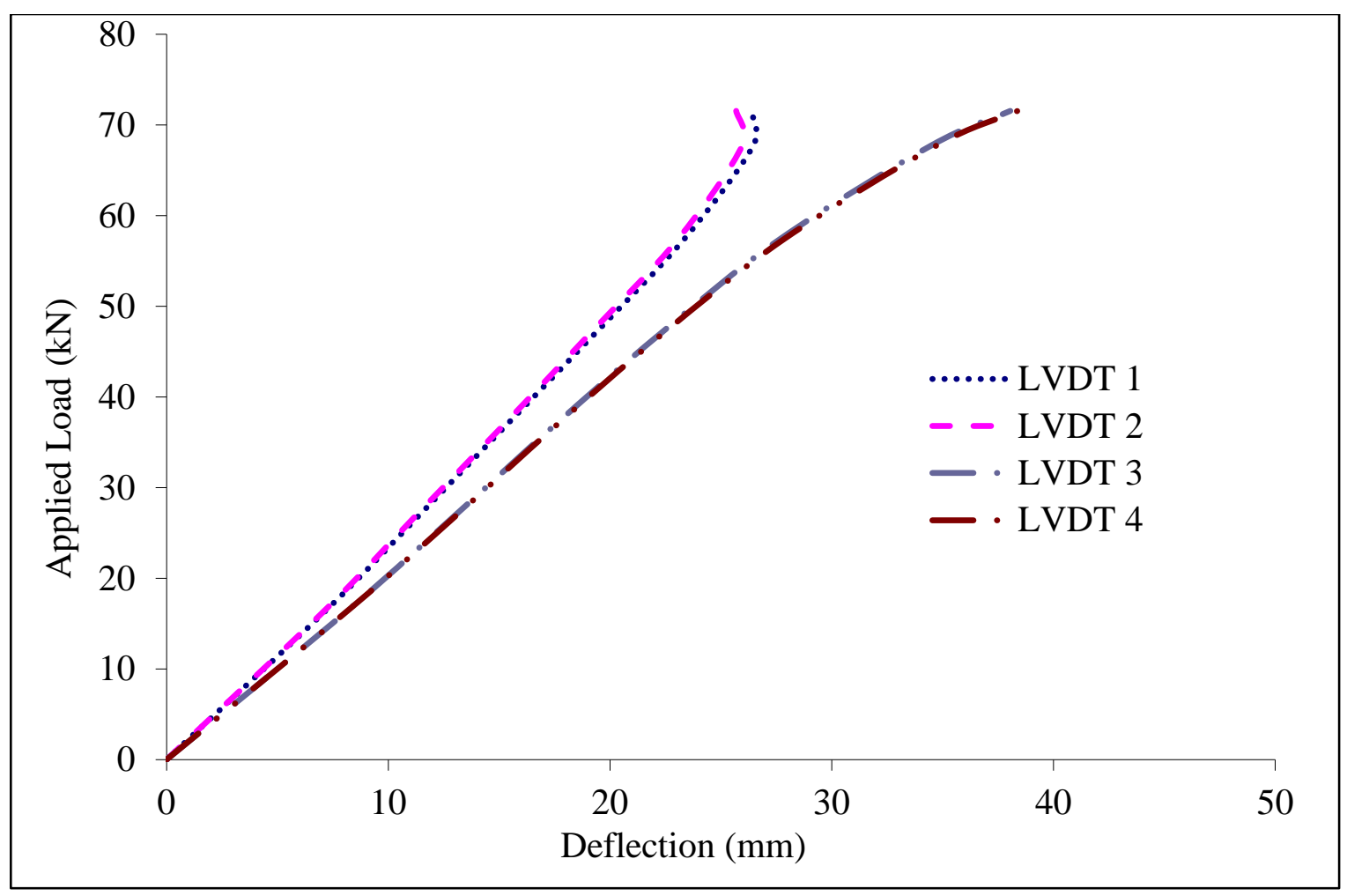

Figure C3.3: Typical load deflection curve for 302x5000 mm iSPAN floor joist

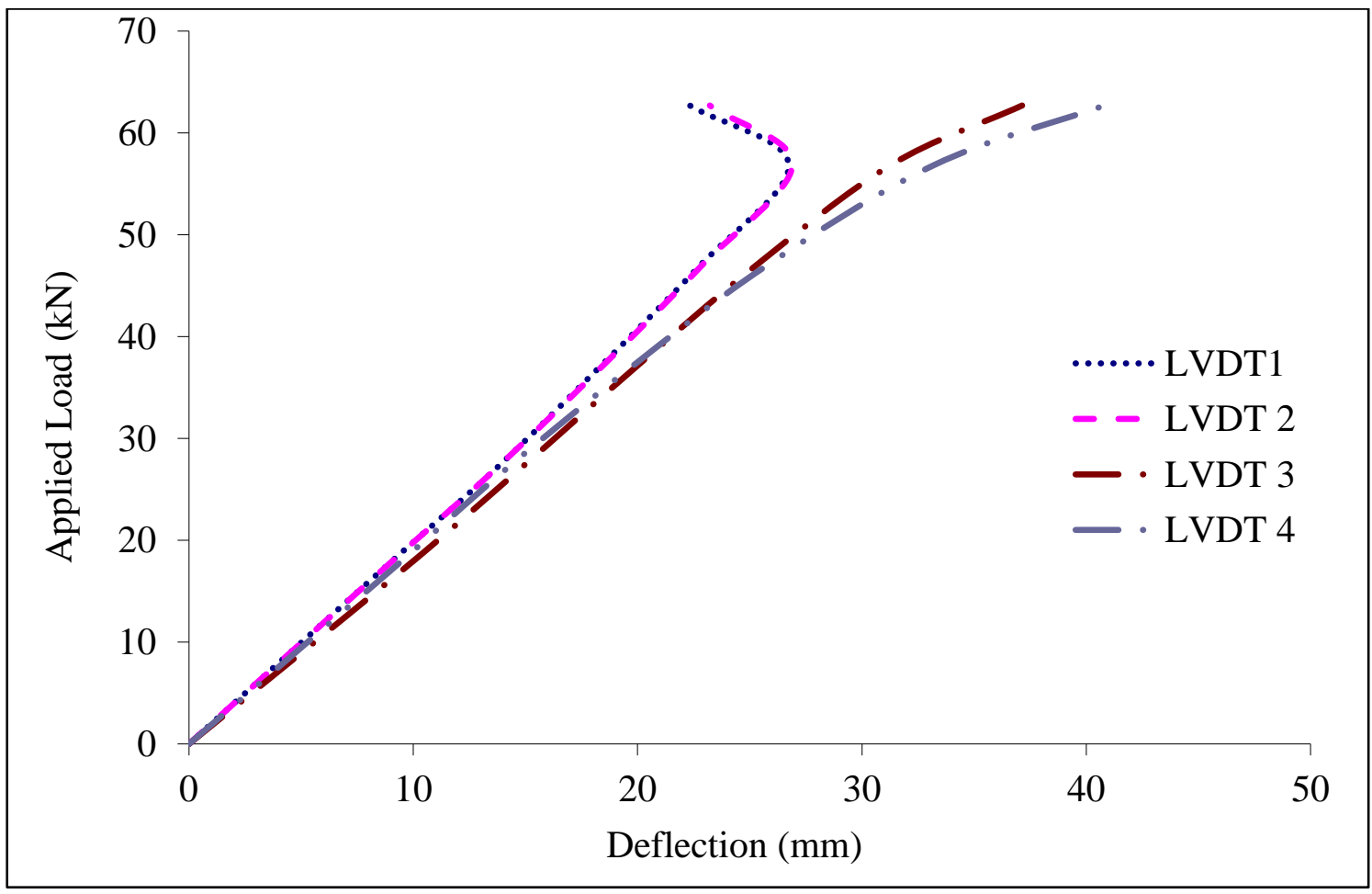

Figure C3.4: Typical load deflection curve for 302x5250 mm iSPAN floor joist 


\section{APPENDIX C4. NORMAL STRAIN VALUES FOR ISPAN JOIST WITH HOLES}



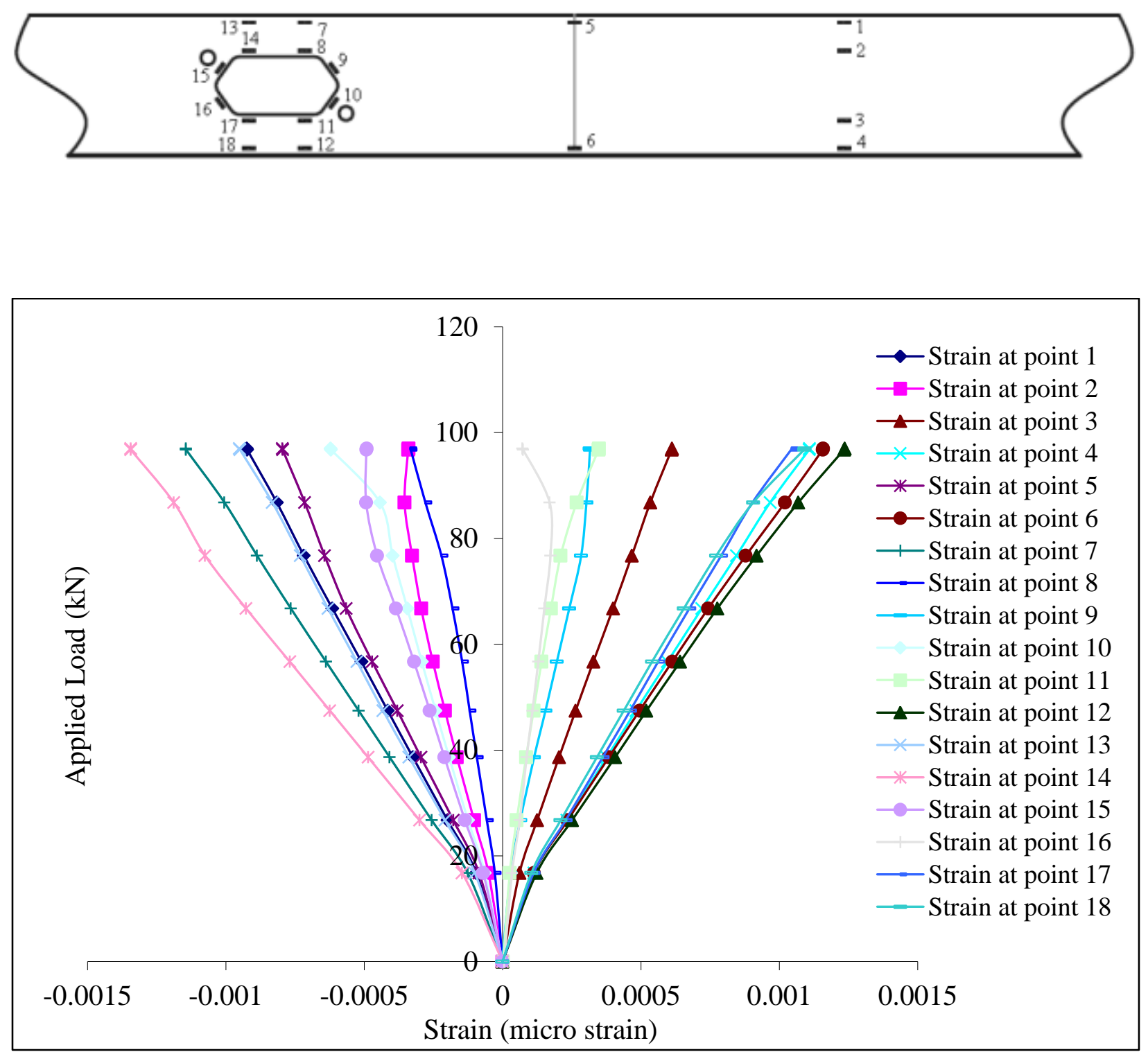

Figure C4.1: Load-strain distribution at the middle of 254x3500 mm joist 1 

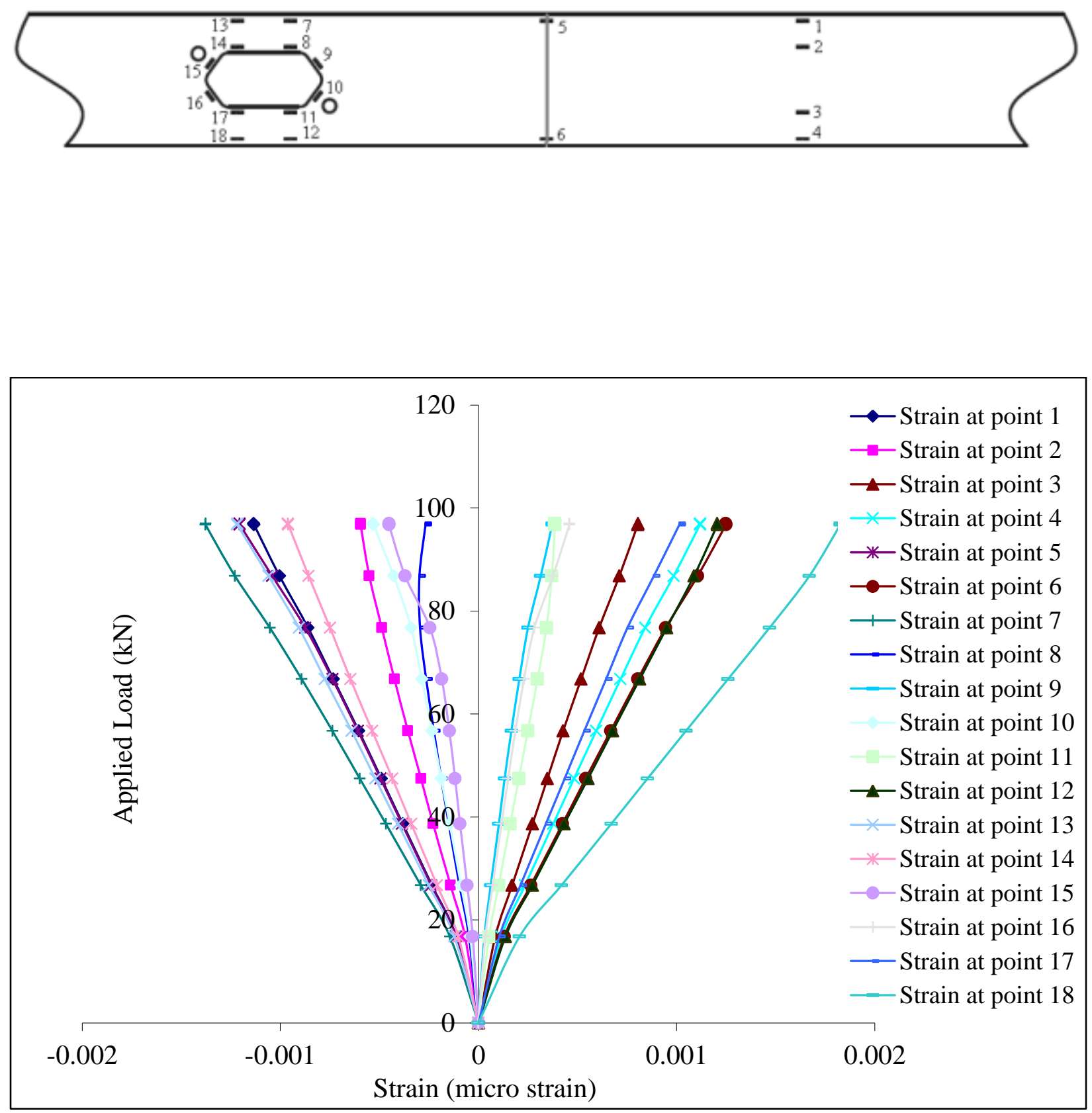

Figure C4.2: Load-strain distribution at the middle of 254x3500 mm joist 2 

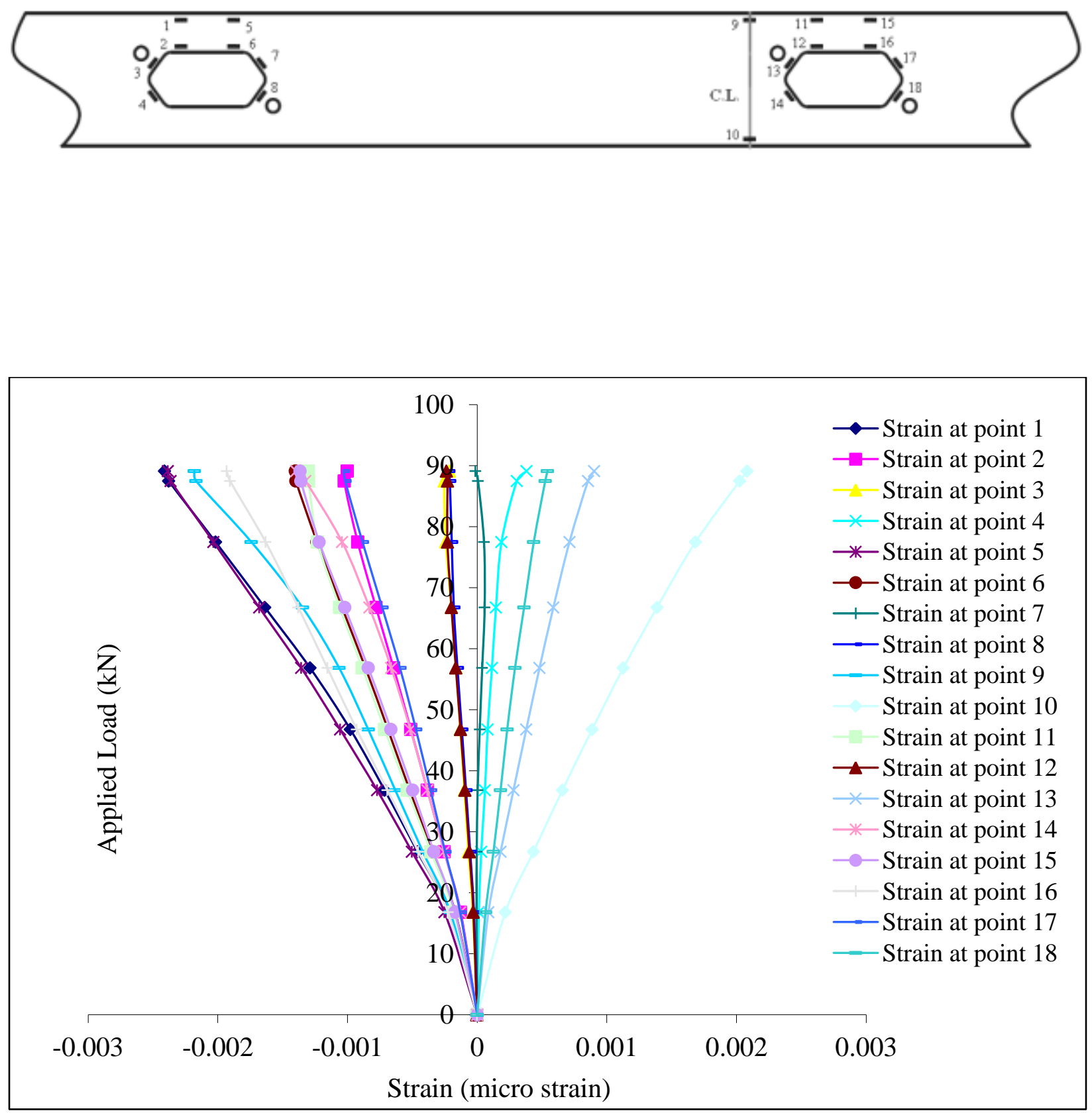

Figure C4.3: Load-strain distribution at the middle of $254 \times 4500 \mathrm{~mm}$ joist 1 

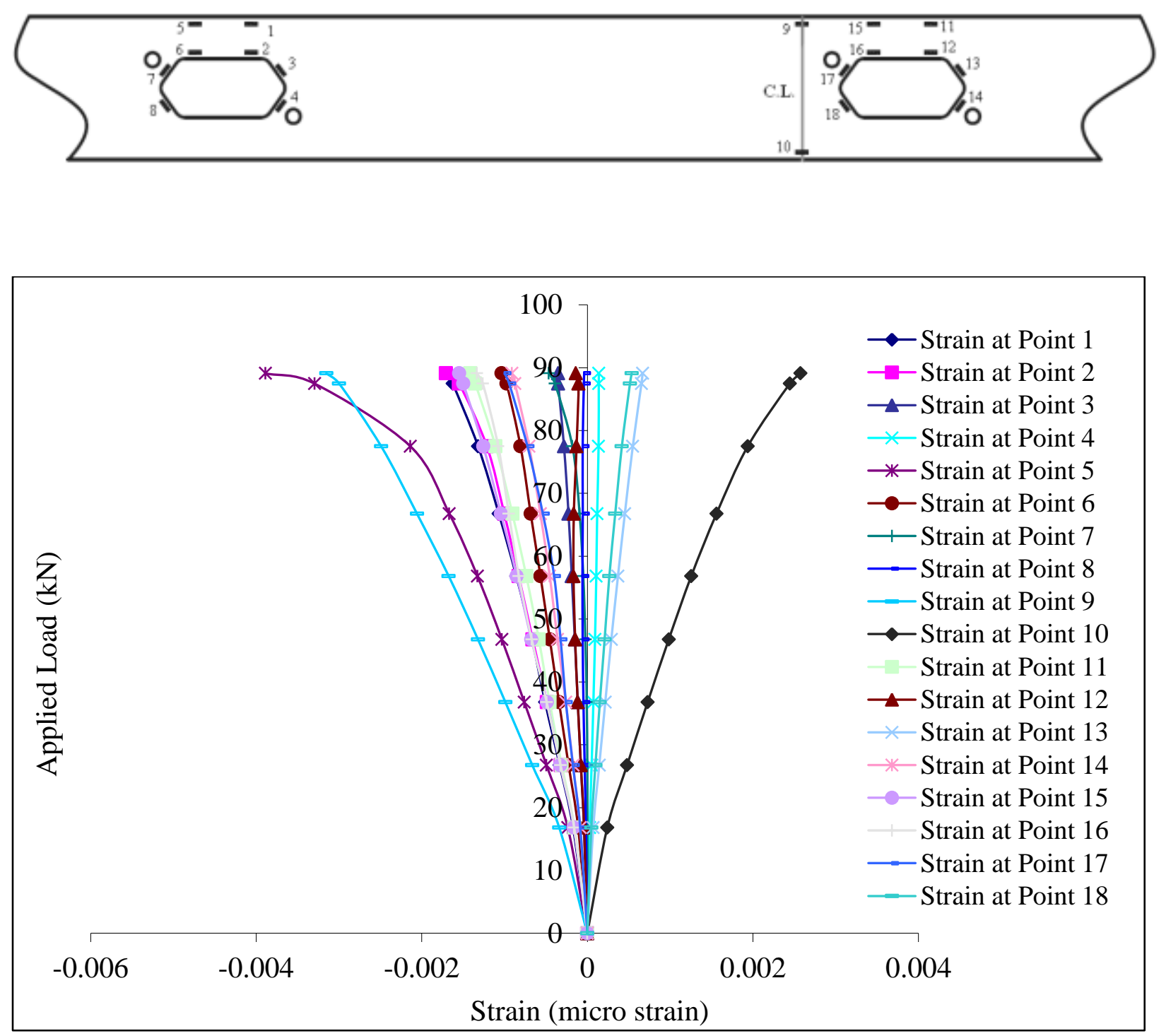

Figure C4.4: Load-strain distribution at the middle of 254x $4500 \mathrm{~mm}$ joist 2 

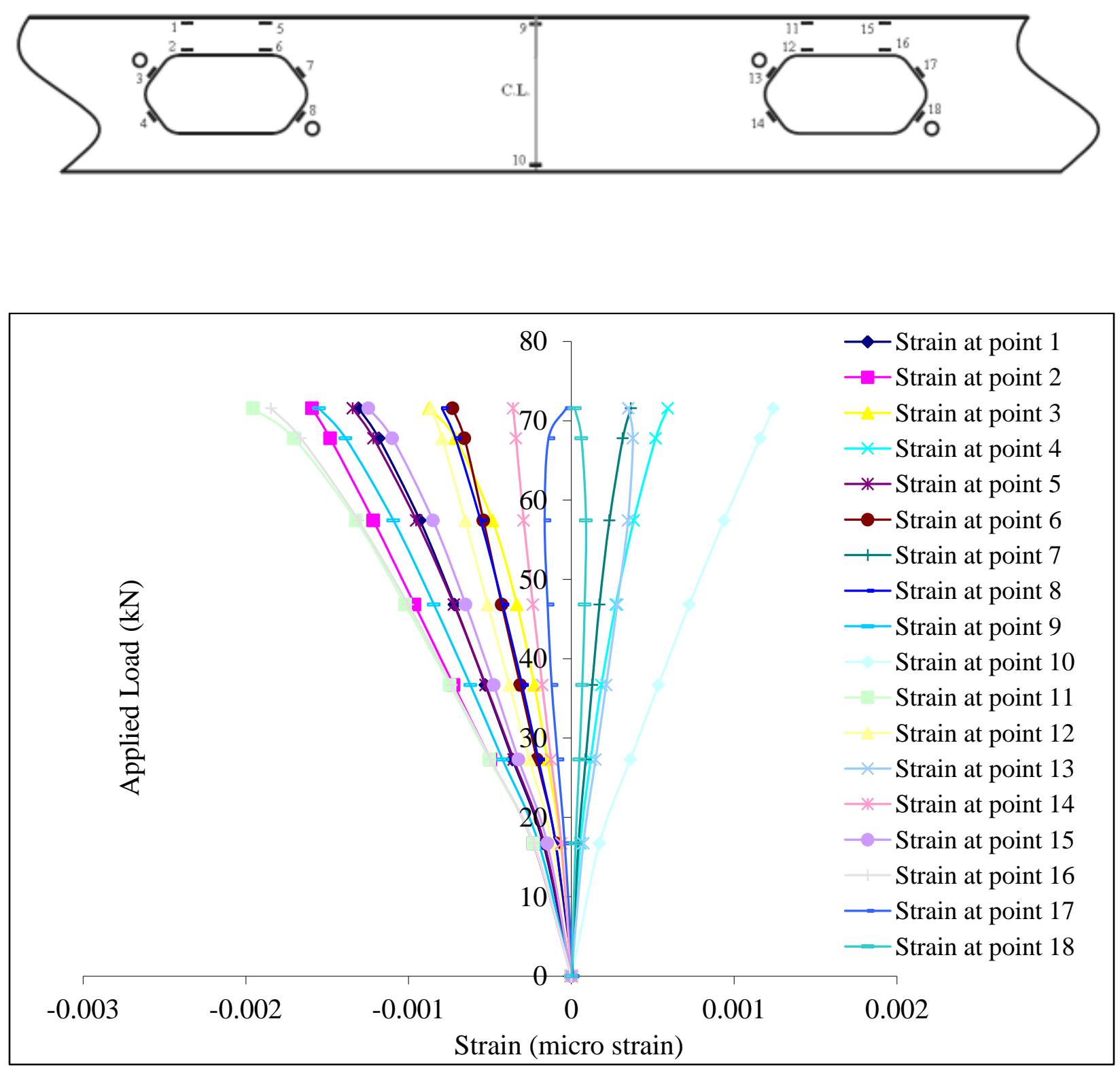

Figure C4.5: Load-strain distribution at the middle of 300x5000 $\mathrm{mm}$ joist 1 

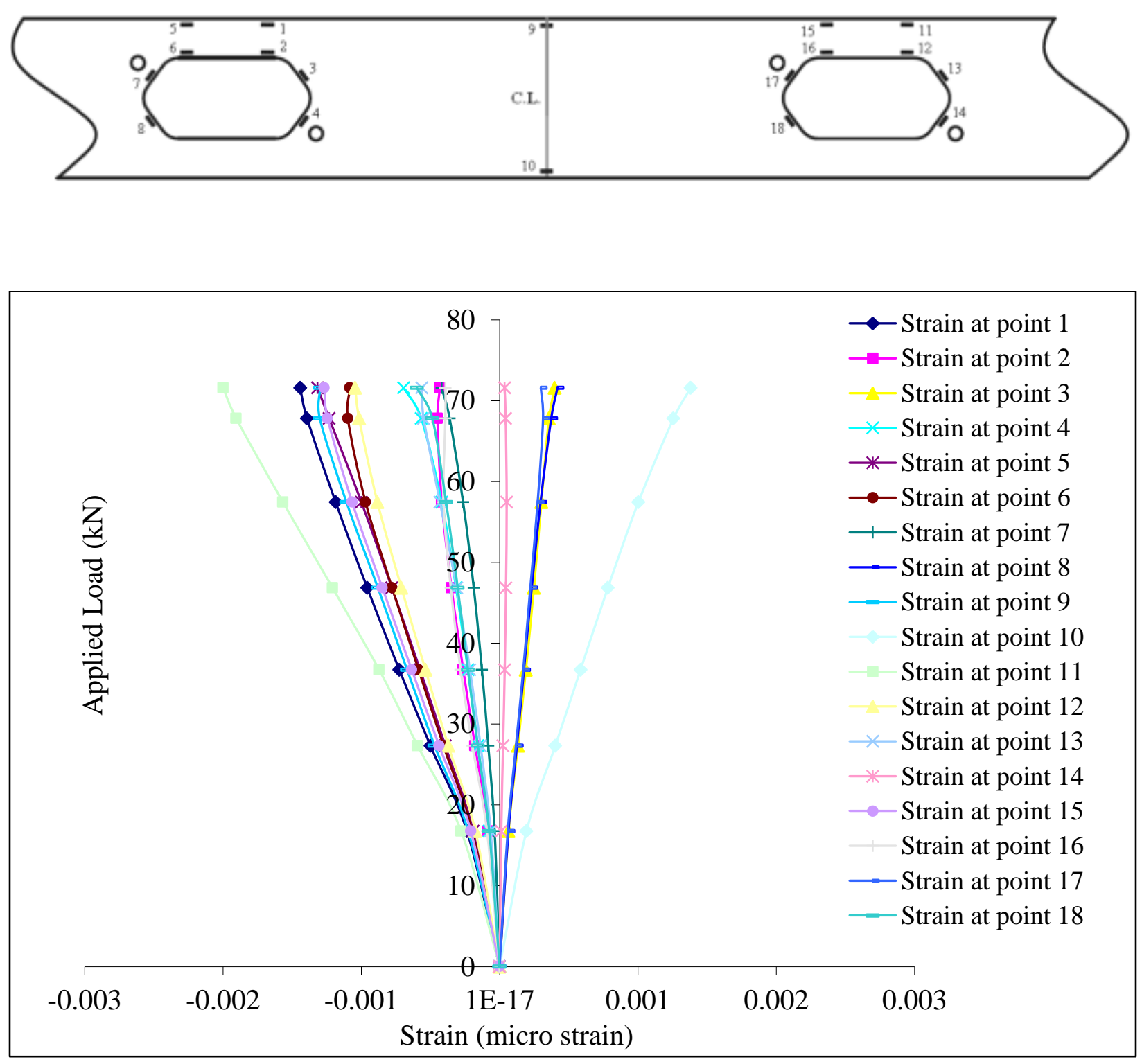

Figure C4.6: Load-strain distribution at the middle of 300x5000 mm joist 2 

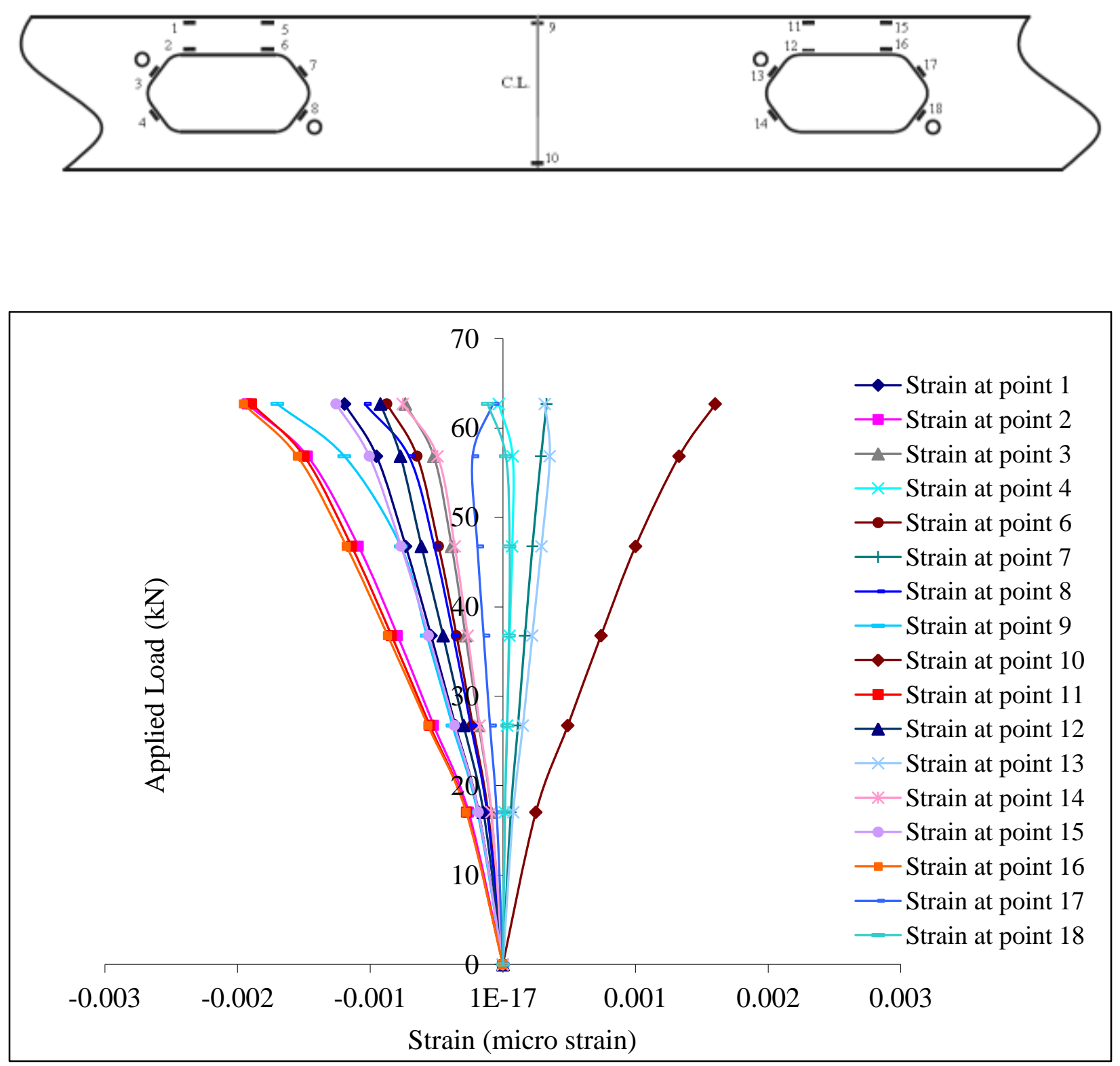

Figure C4.7: Load-strain distribution at the middle of 300x5250 mm joist 1 

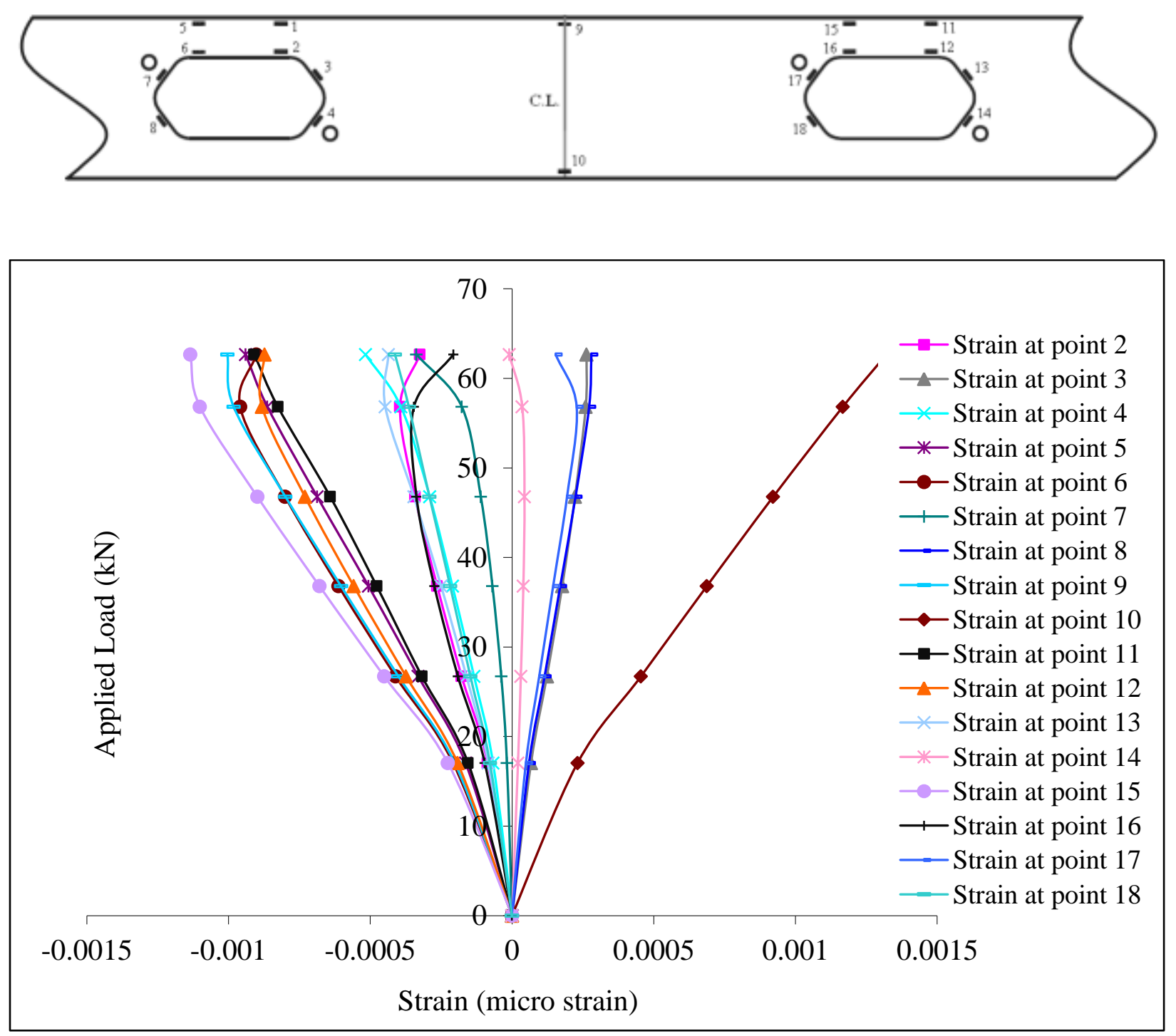

Figure C4.8: Load-strain distribution at the middle of 300x5250 mm joist 2 


\section{APPENDIX D1. ACCLERATION SPECTRUM OF ISPAN JOIST FOR THE ON-SITE FULL SCALE TEST}




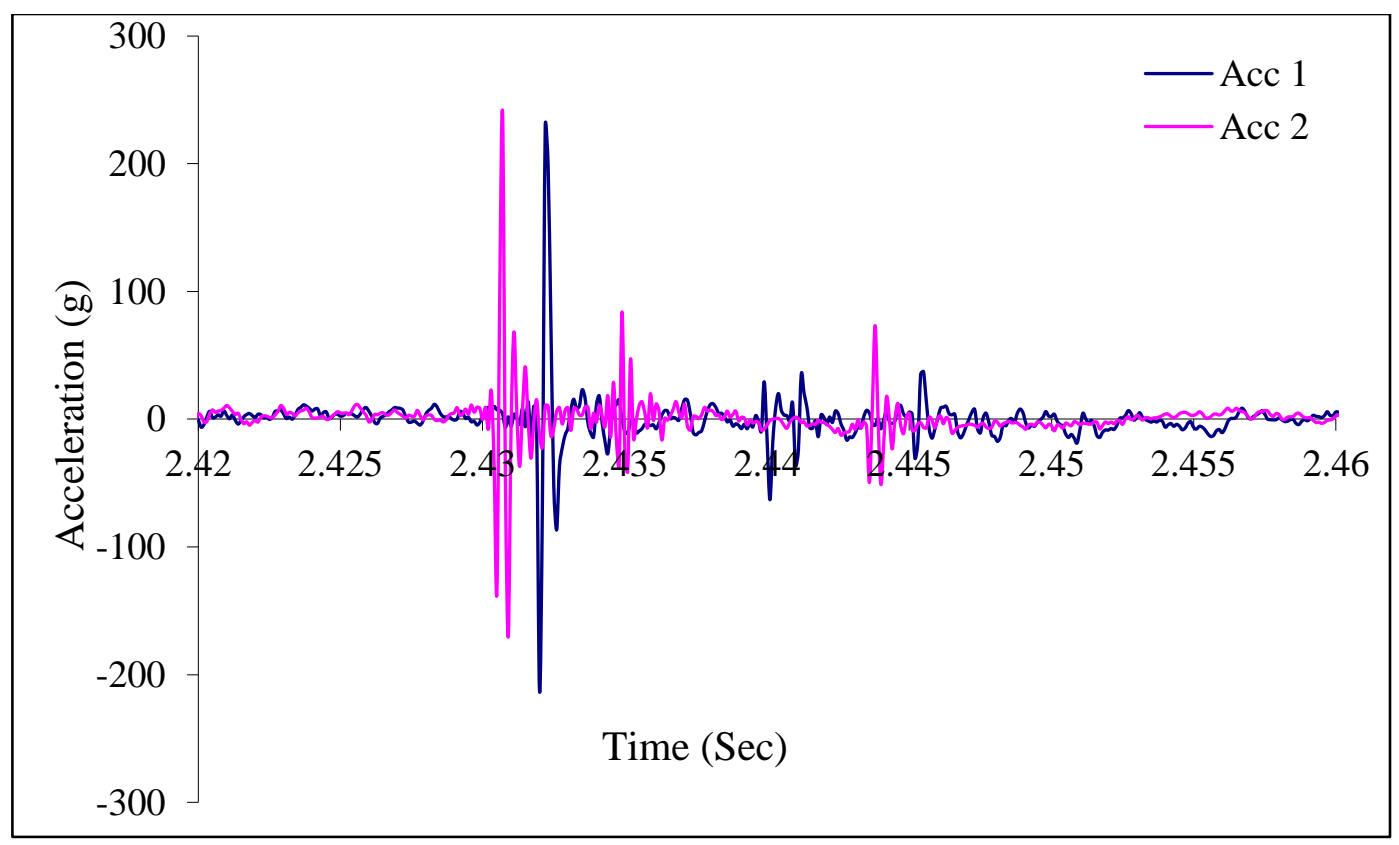

Figure D1.1: Typical acceleration trace unbraced floor joists in site 1

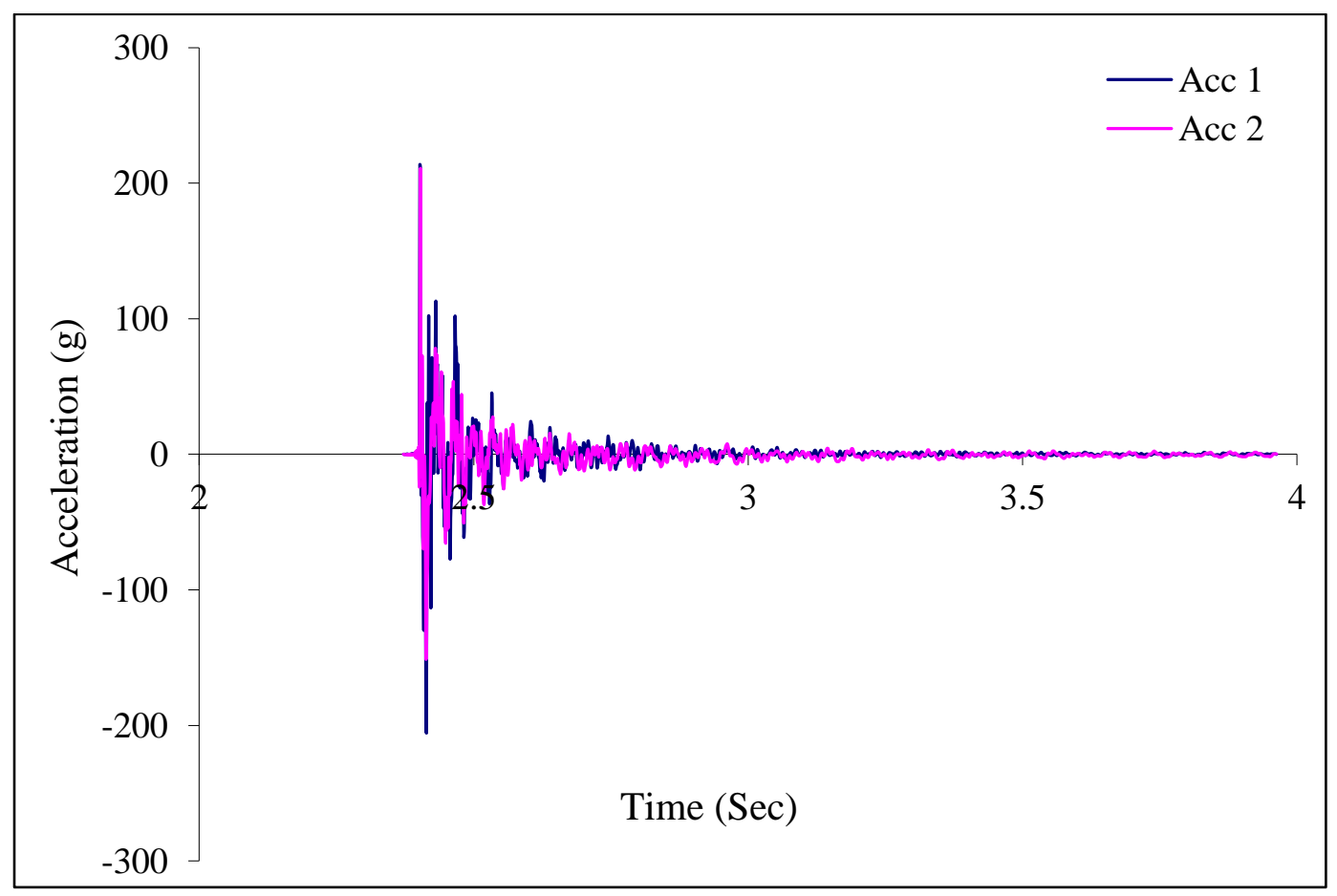

Figure D1.2: Typical acceleration trace braced floor joists in site 1 


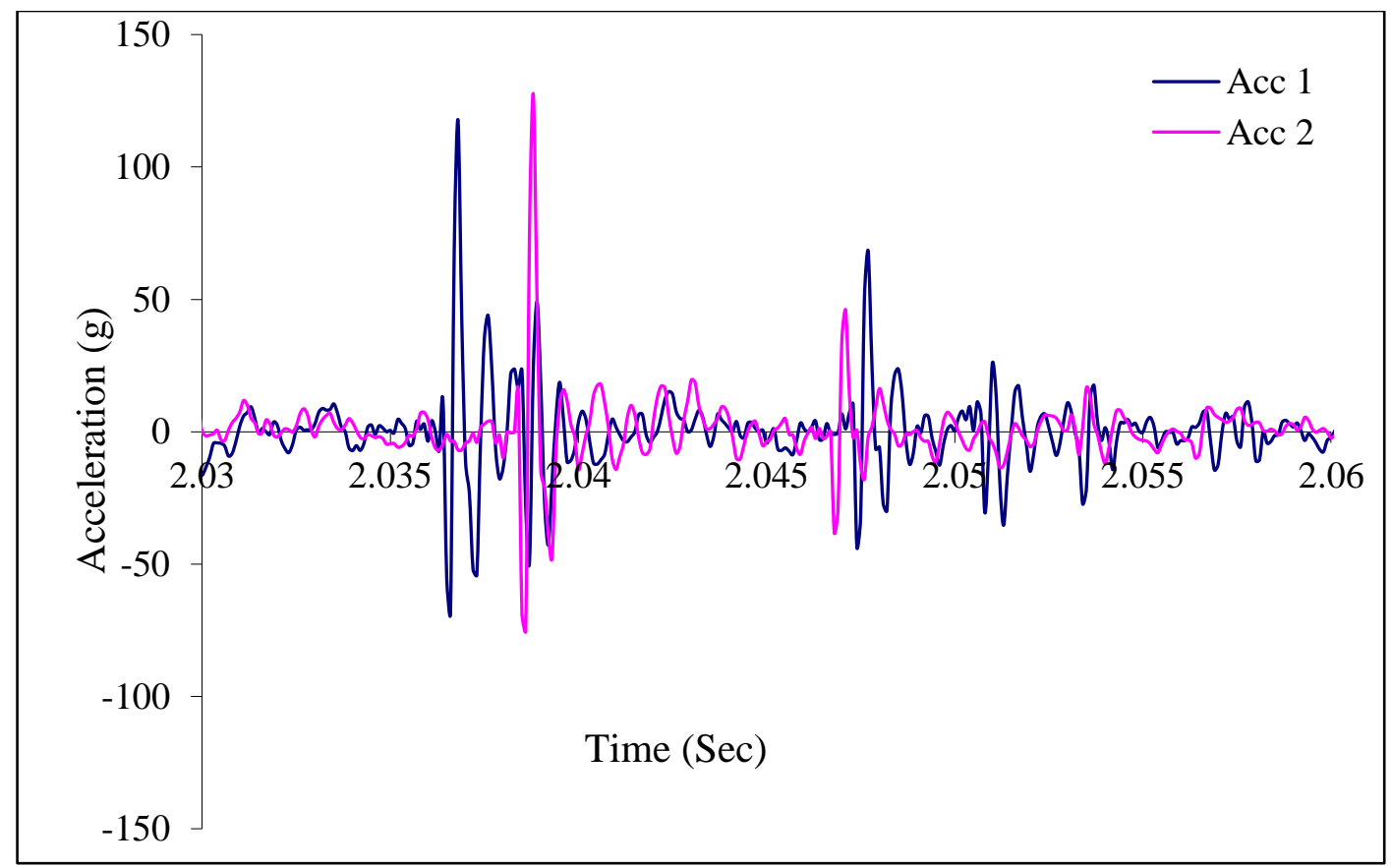

Figure D1.3: Typical acceleration trace braced floor joists in site 2

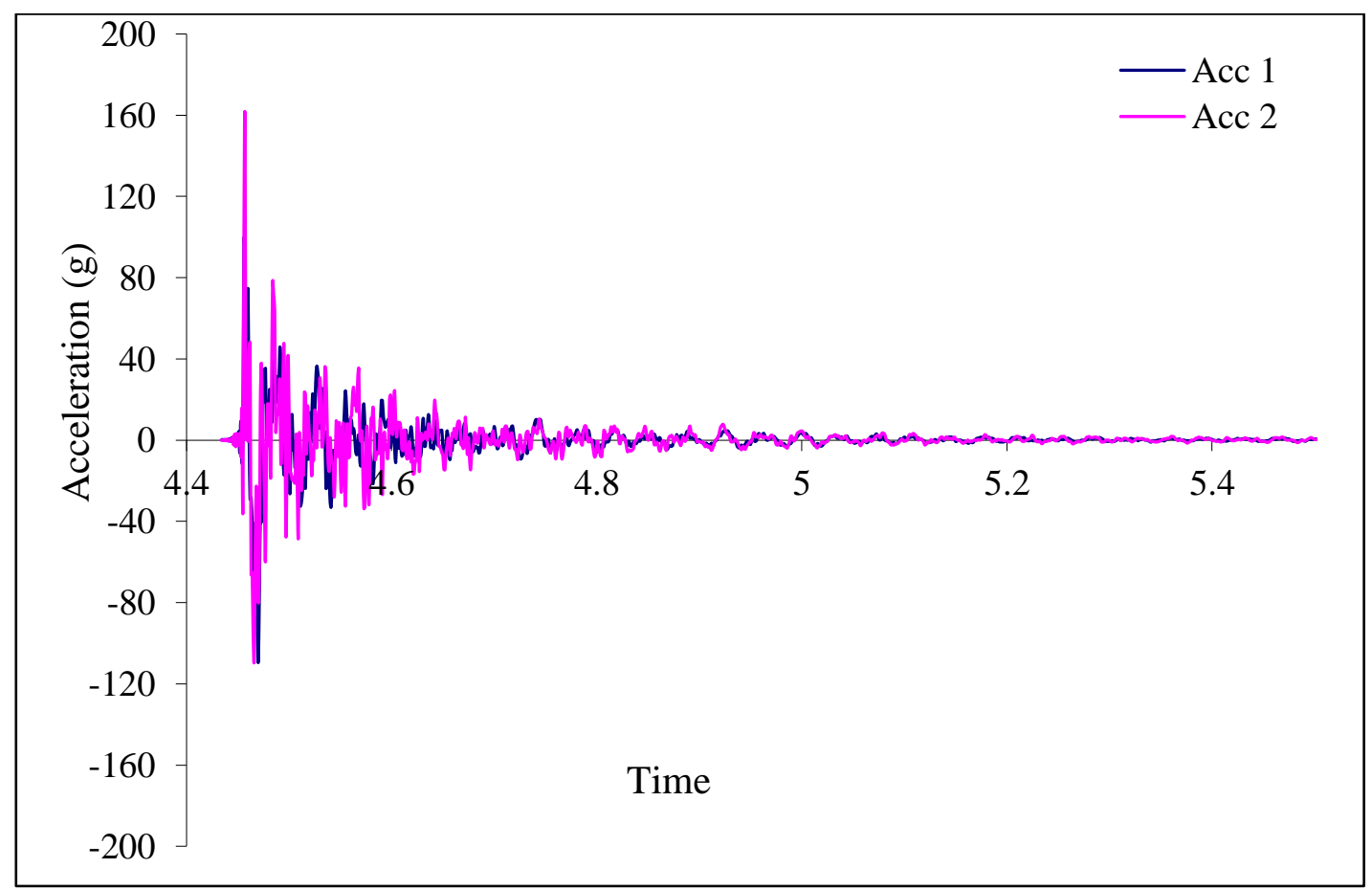

Figure D1.4: Typical acceleration trace braced floor joists in site 3 


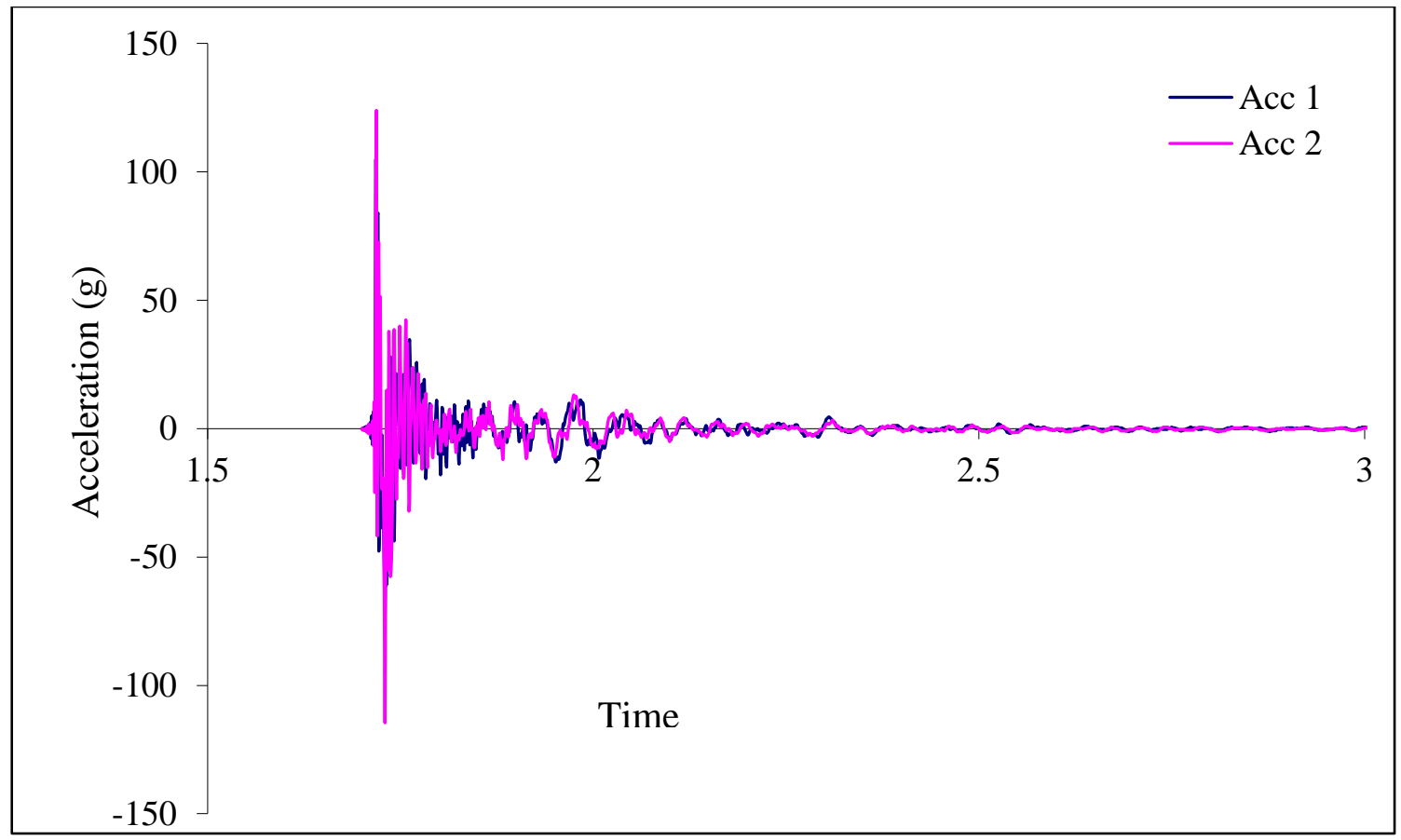

Figure D1.5: Typical acceleration trace braced floor joists in site 4 


\section{APPENDIX D2. NATURAL FREQUENCY SPECTRUM OF ISPAN JOIST FOR THE ONSITE FULL SCALE TEST}




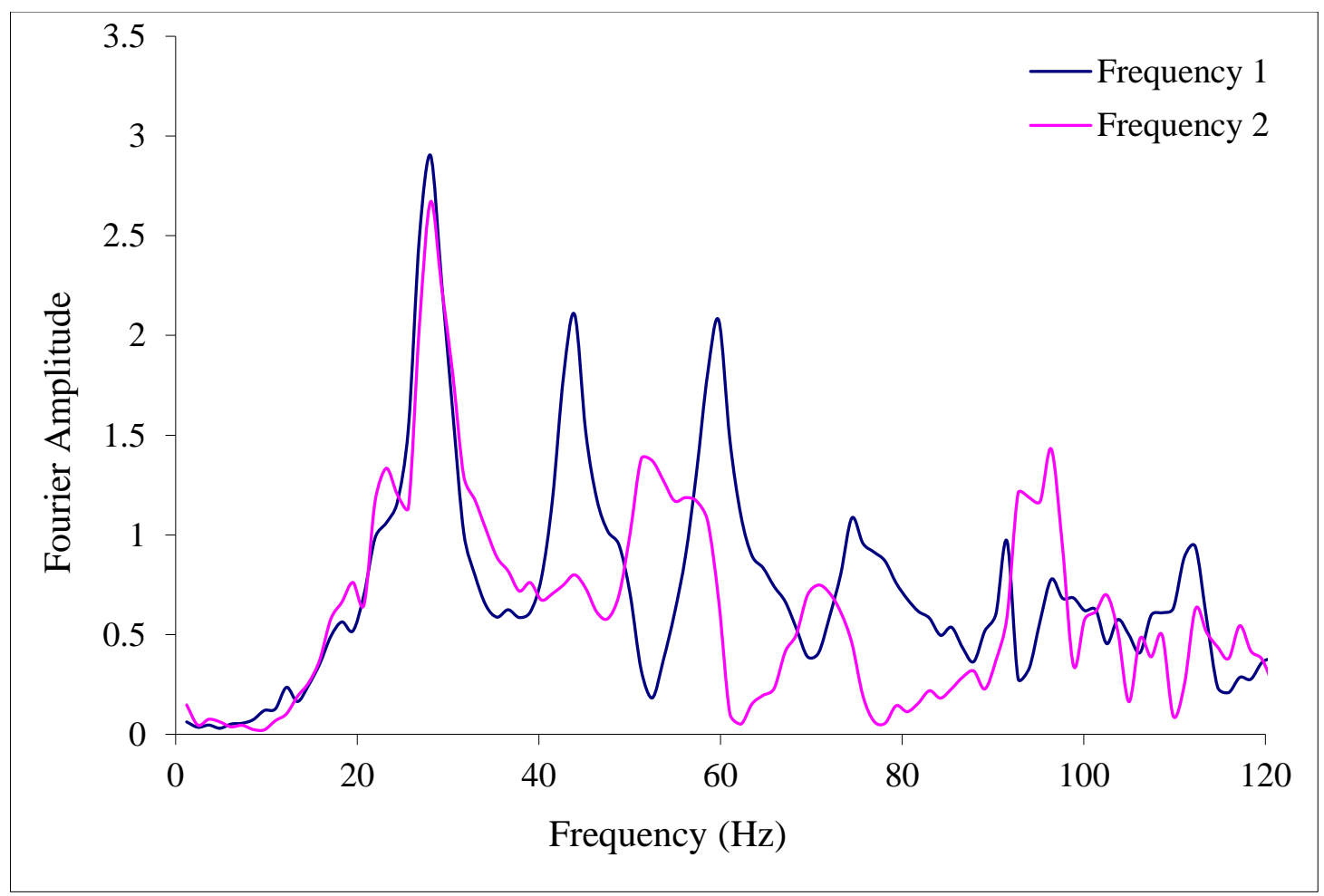

Figure D2.1: Typical frequency spectrum unbraced floor joists for site 1

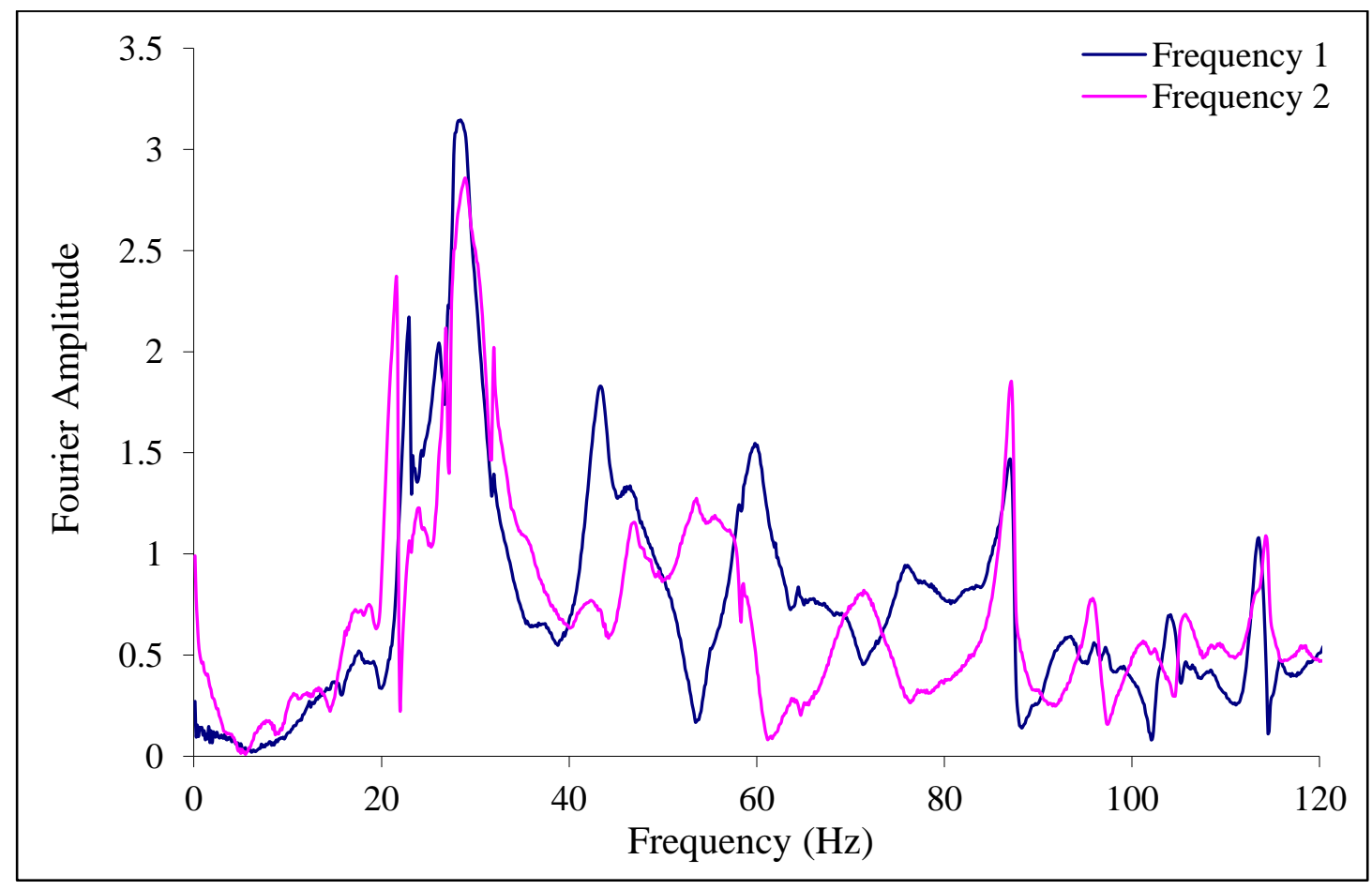

Figure D2.2: Typical frequency spectrum braced floor joists for site 1 


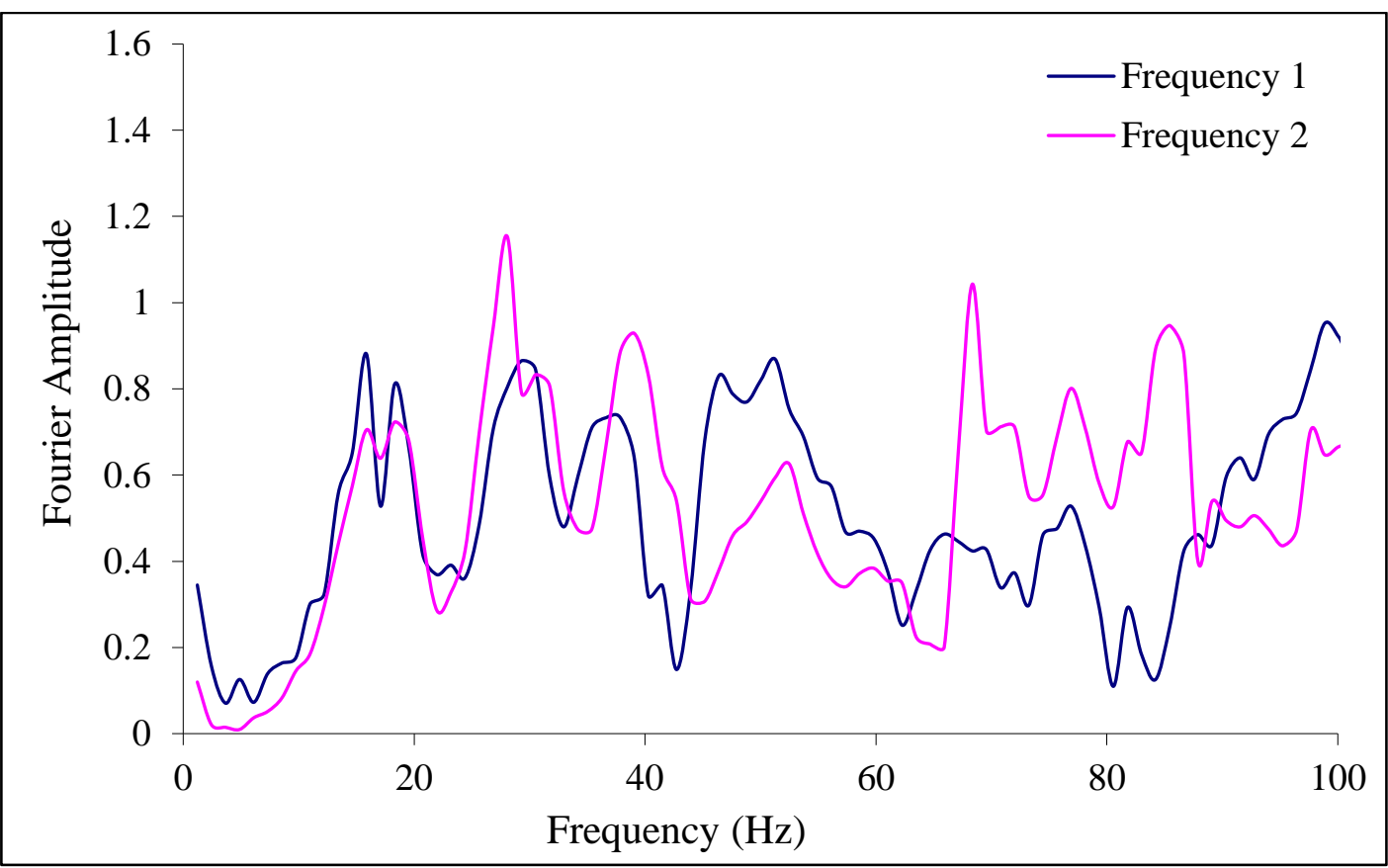

Figure D2.3: Typical frequency spectrum braced floor joists for site 2

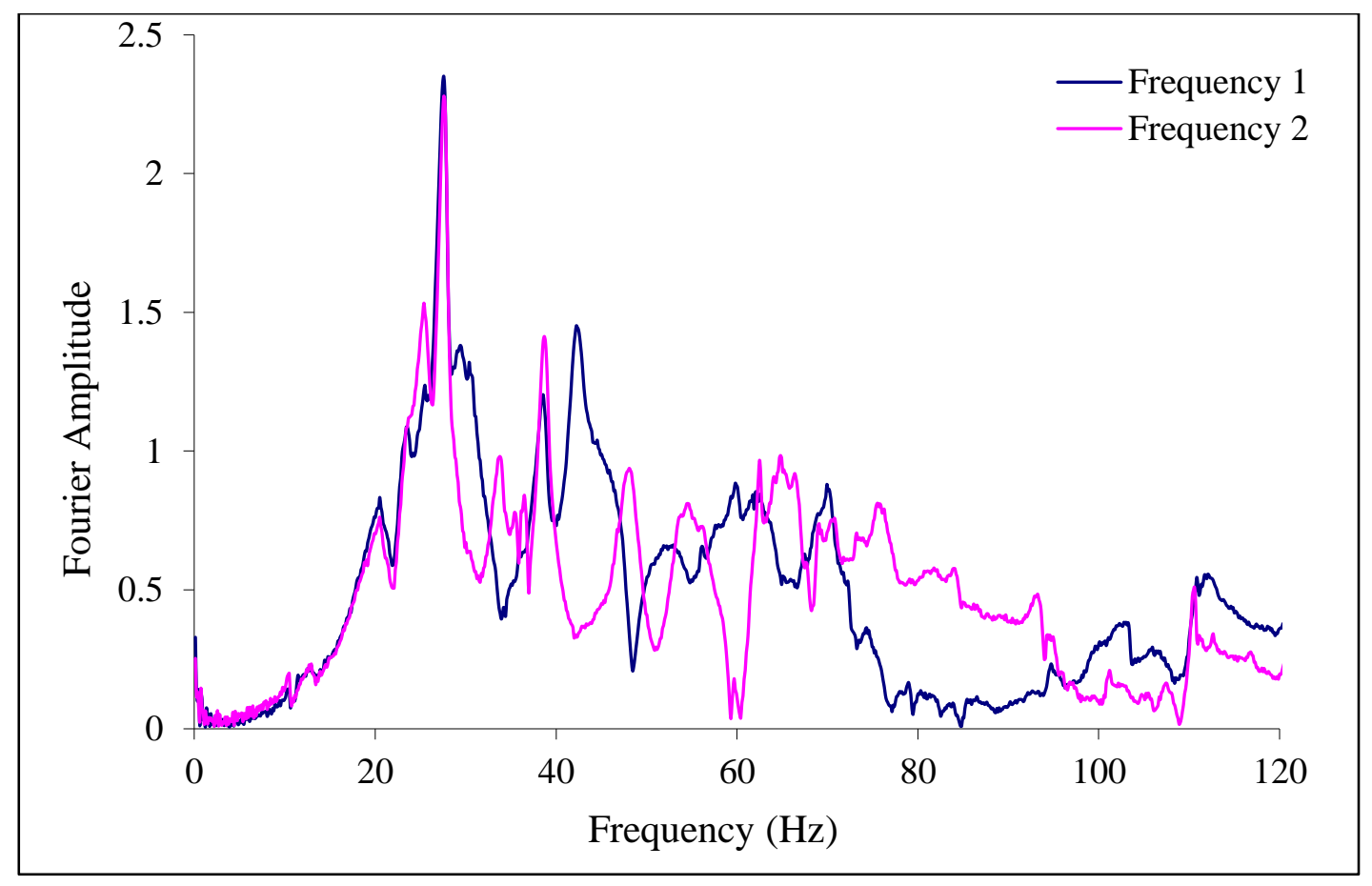

Figure D2.4: Typical frequency spectrum braced floor joists for site 3 


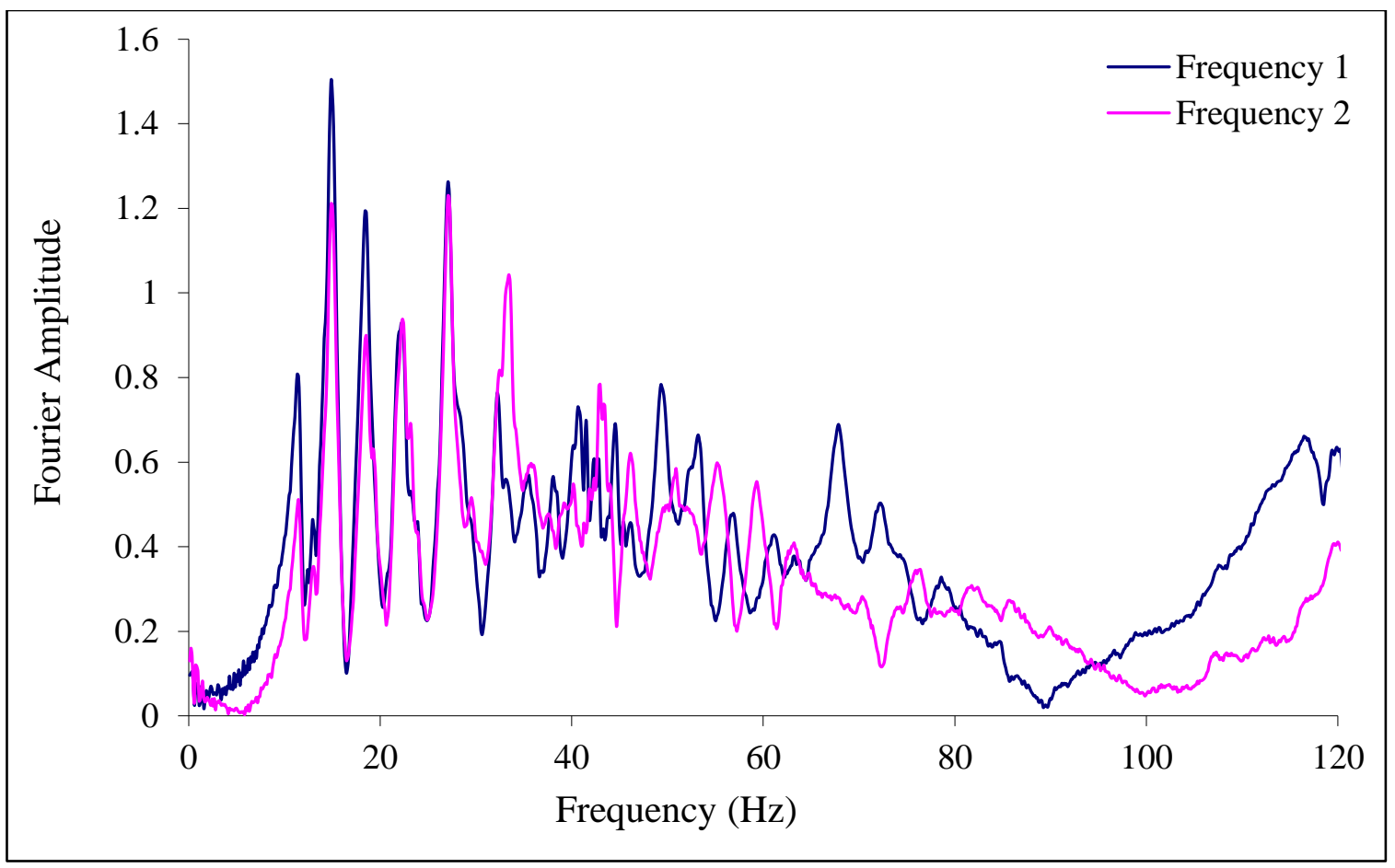

Figure D2.5: Typical frequency spectrum braced floor joists for site 4 


\section{APPENDIX E: FAILURE MODES OF TESTED FLOOR JOIST ASSEMBLIES}




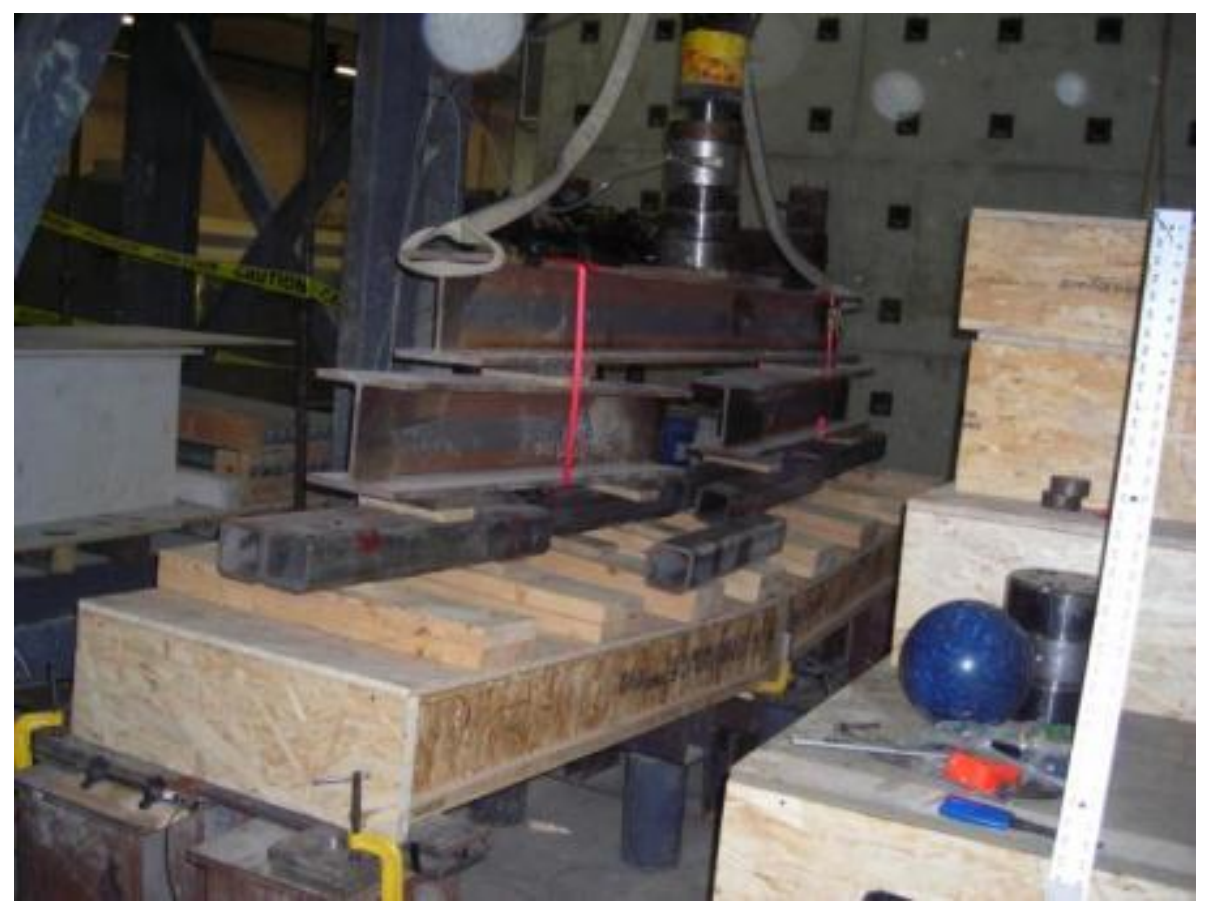

Figure E.1: View of deformed shape at failure of the 241x3500 mm wooden joist assembly

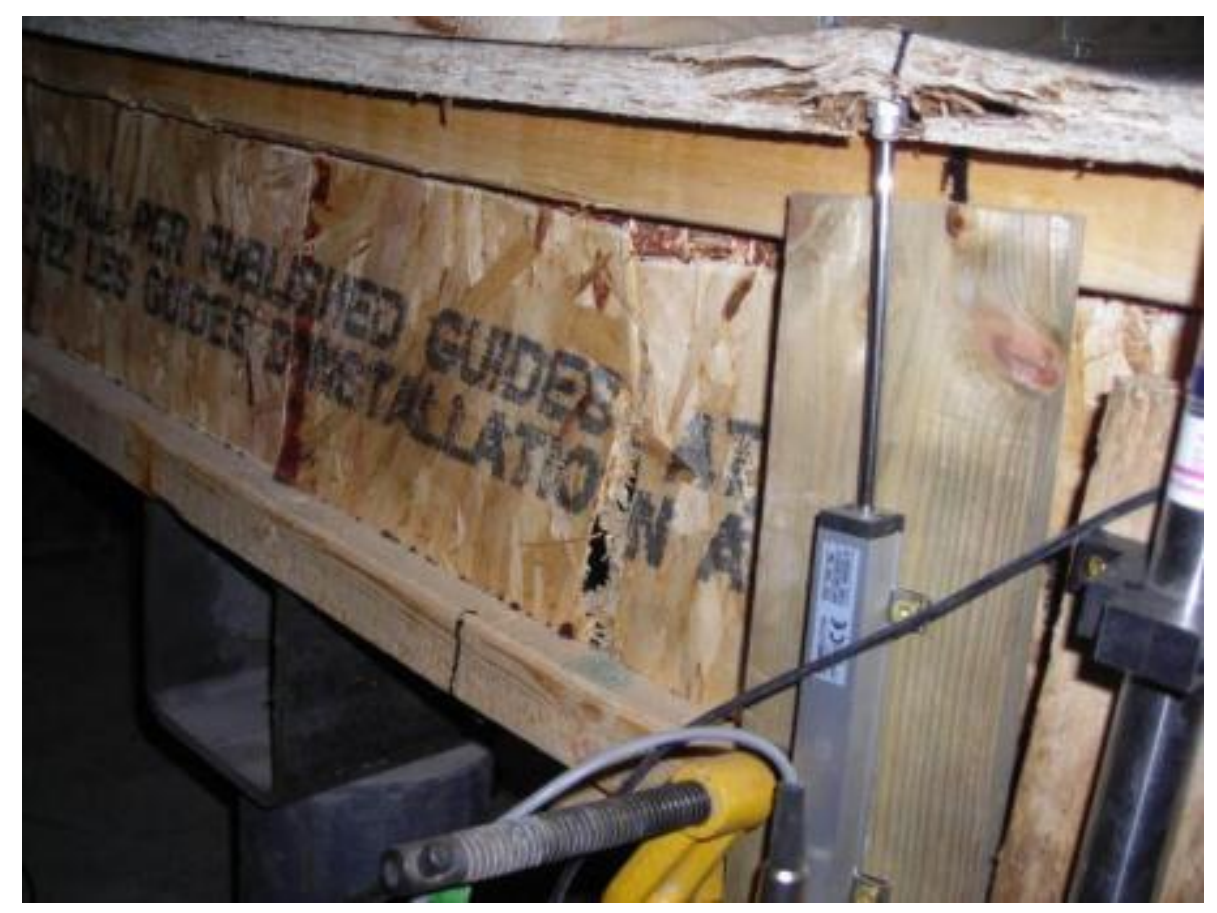

Figure E.2: Close-up view of the bending fracture of the OSB web and top flange-OSB web separation at failure of the $241 \times 3500 \mathrm{~mm}$ wooden joist assembly 


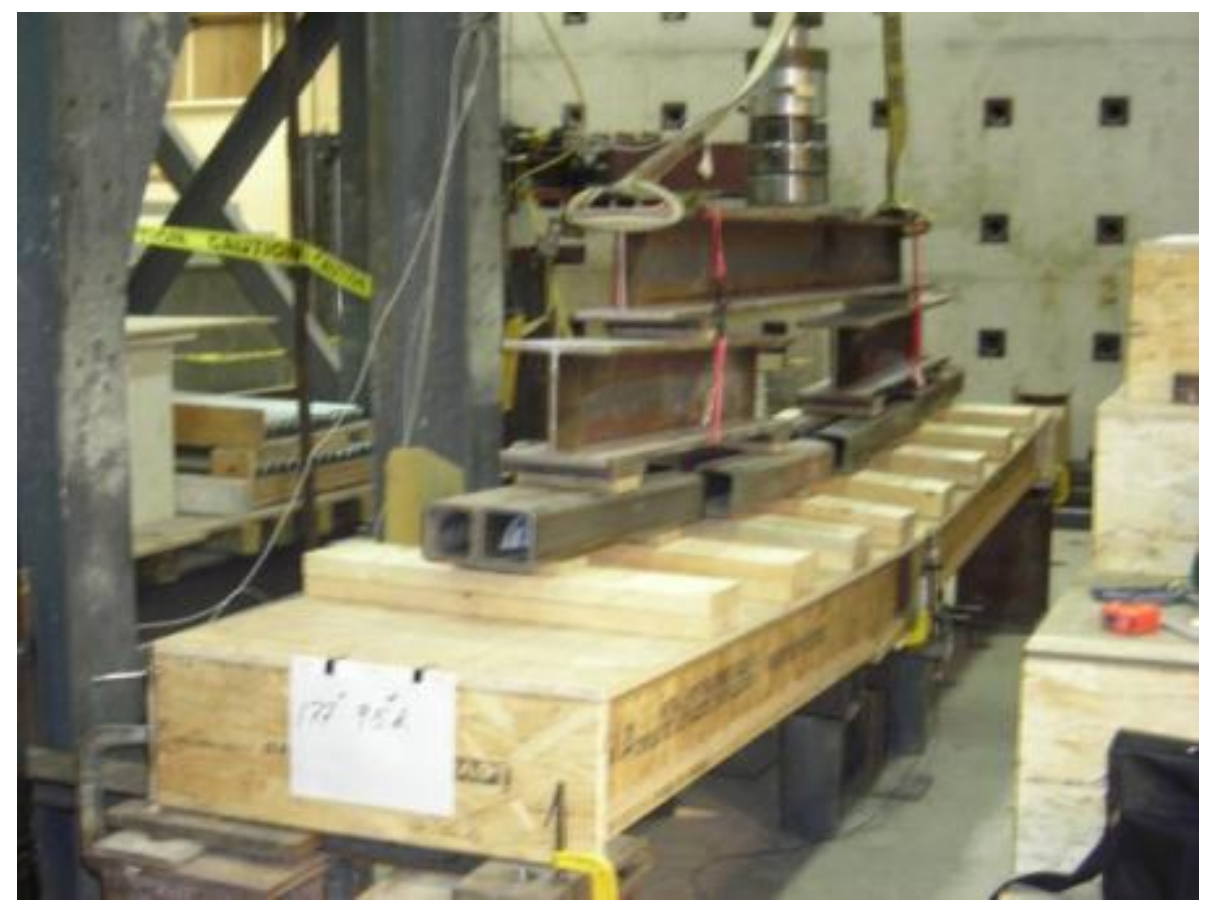

Figure E.3: View of deformed shape at failure of the 241x4500 mm wooden joist assembly

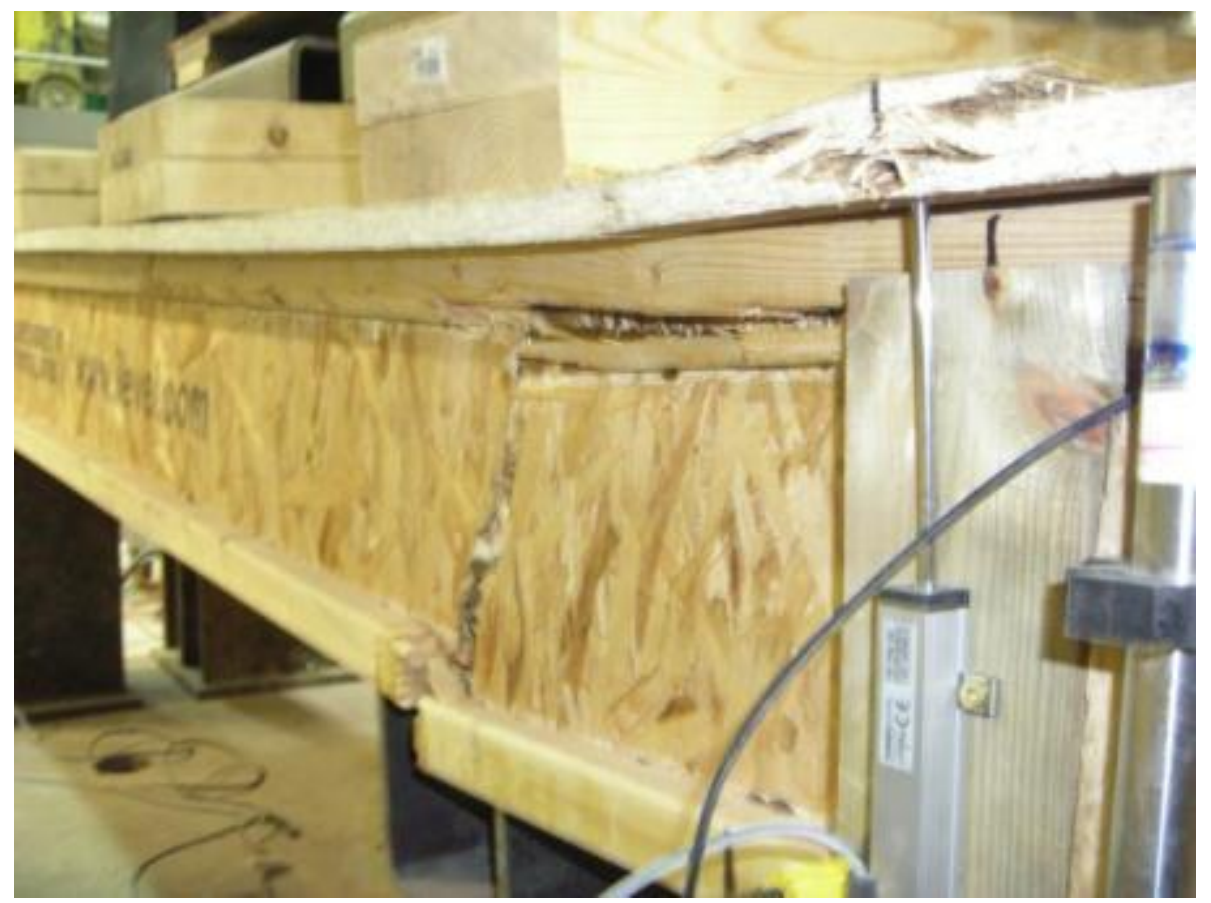

Figure E.4: Close-up view of bending fracture of the joist and top flange-OSB web separation of 241x4500 mm wooden joist assembly 


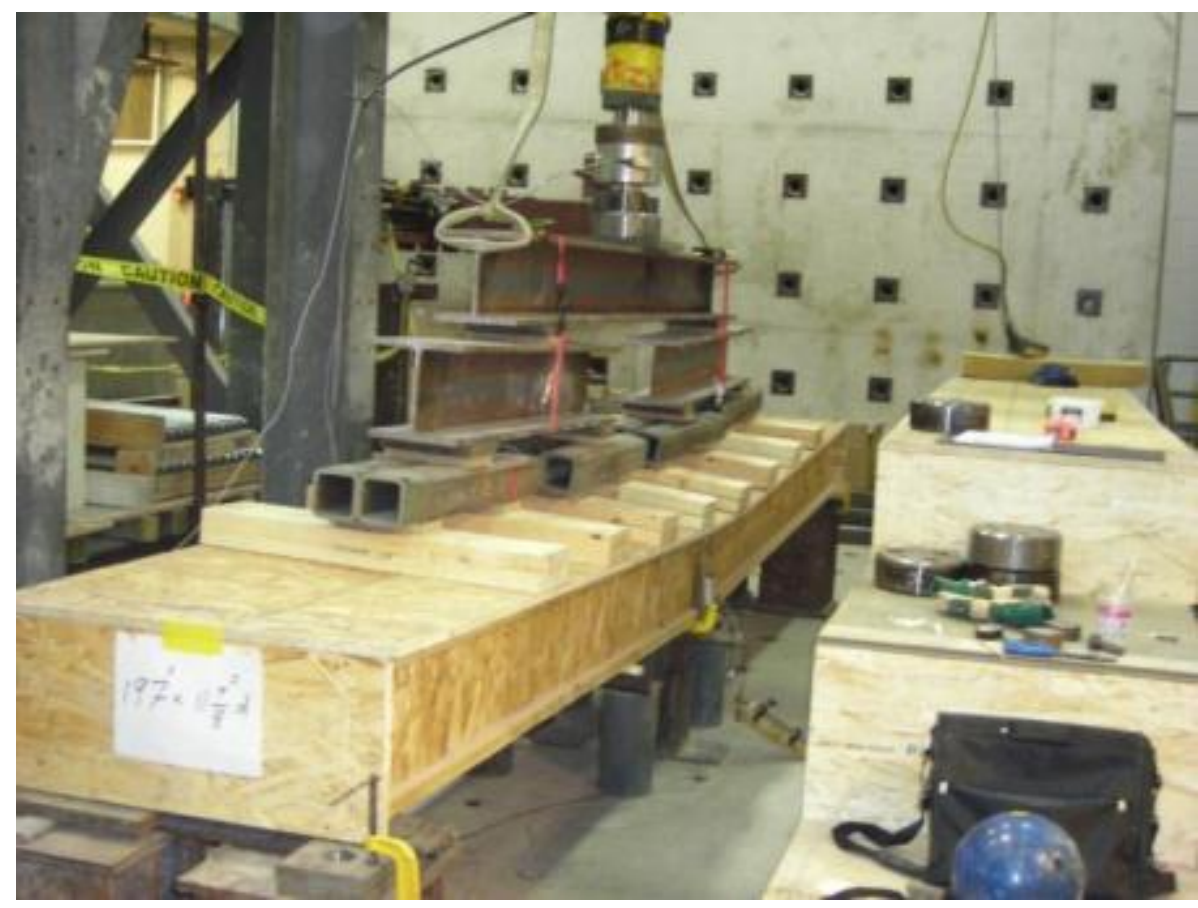

Figure E.5: View of the deformed shape at failure of the $302 \times 5000 \mathrm{~mm}$ wooden joist assembly

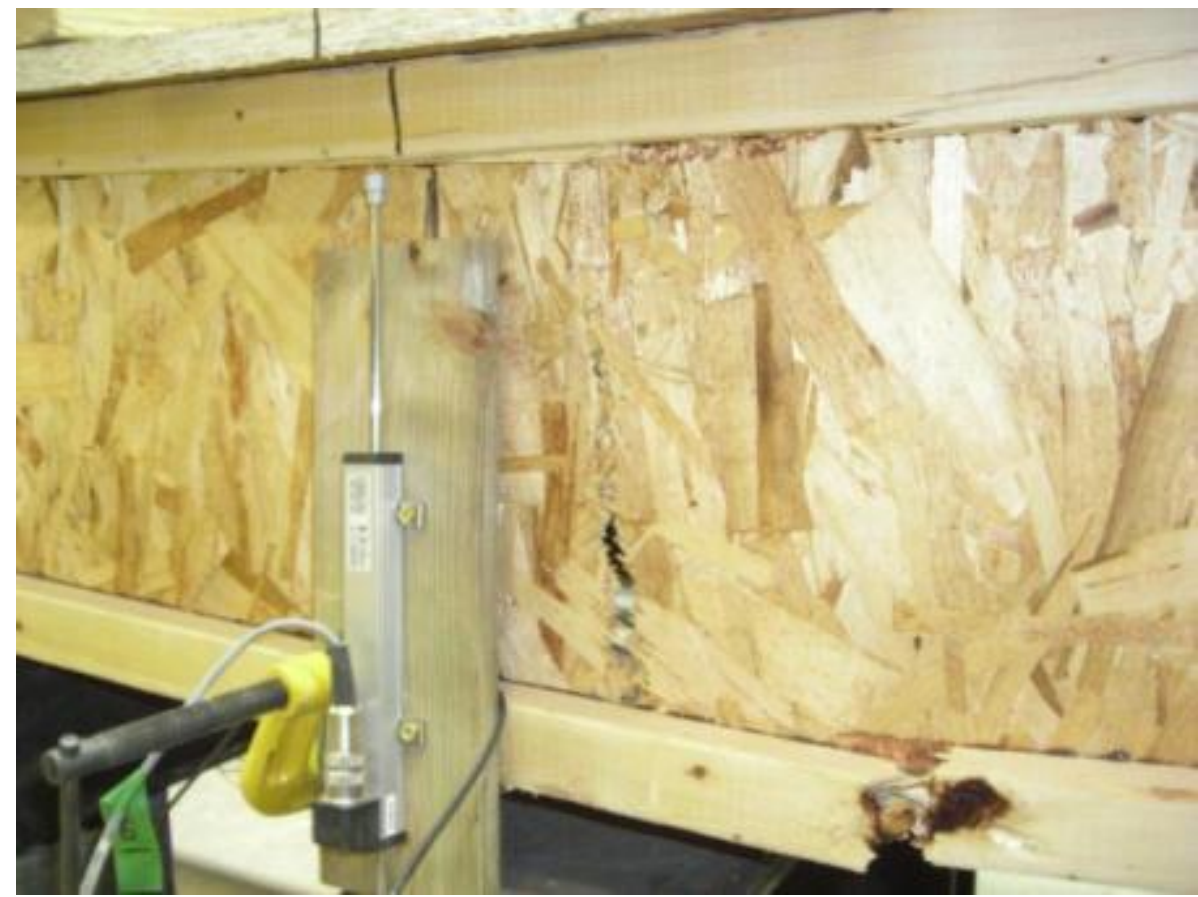

Figure E.6: Close-up view of the bending fracture of bottom flange and web of the $302 \times 5000$ mm wooden joist assembly at failure 


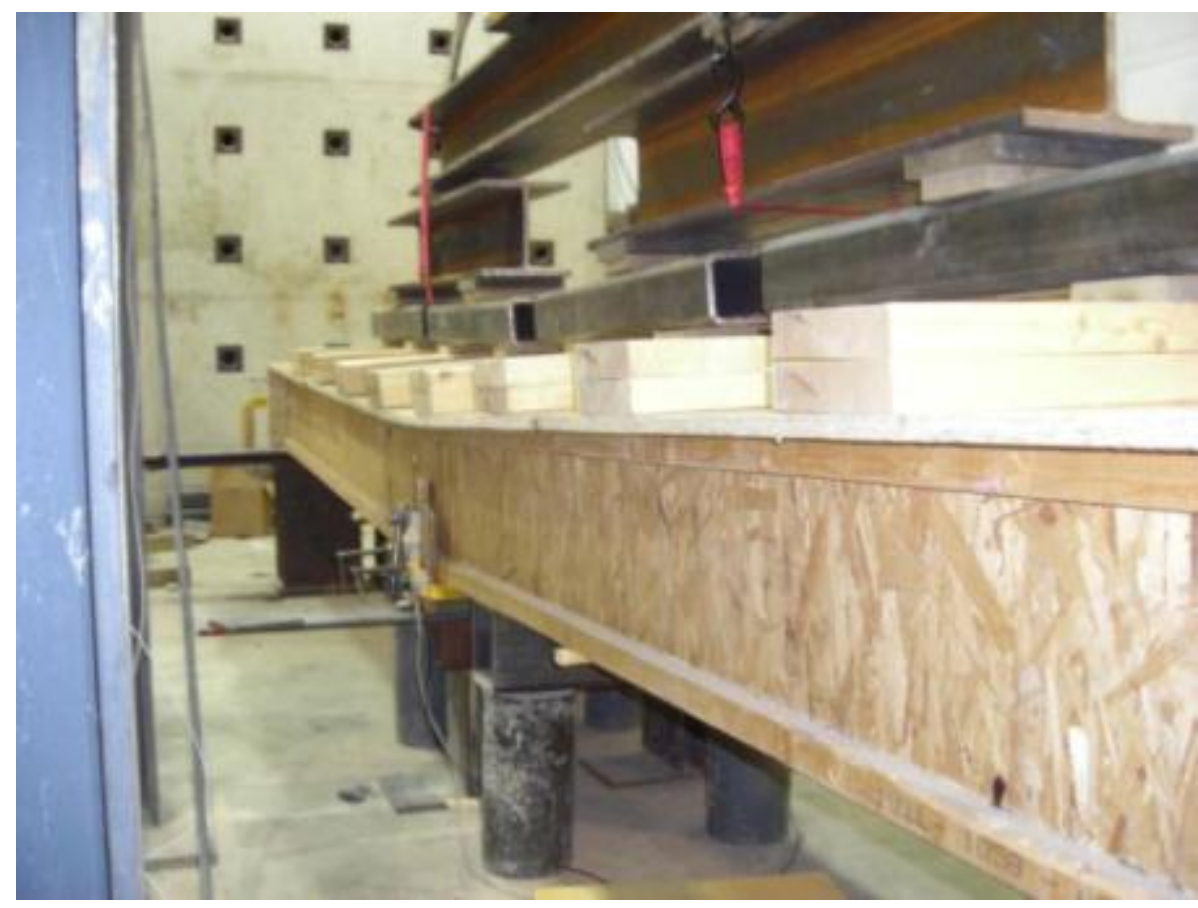

Figure E.7: View of the deformed shape at failure of the $302 \times 5250 \mathrm{~mm}$ wooden joist assembly

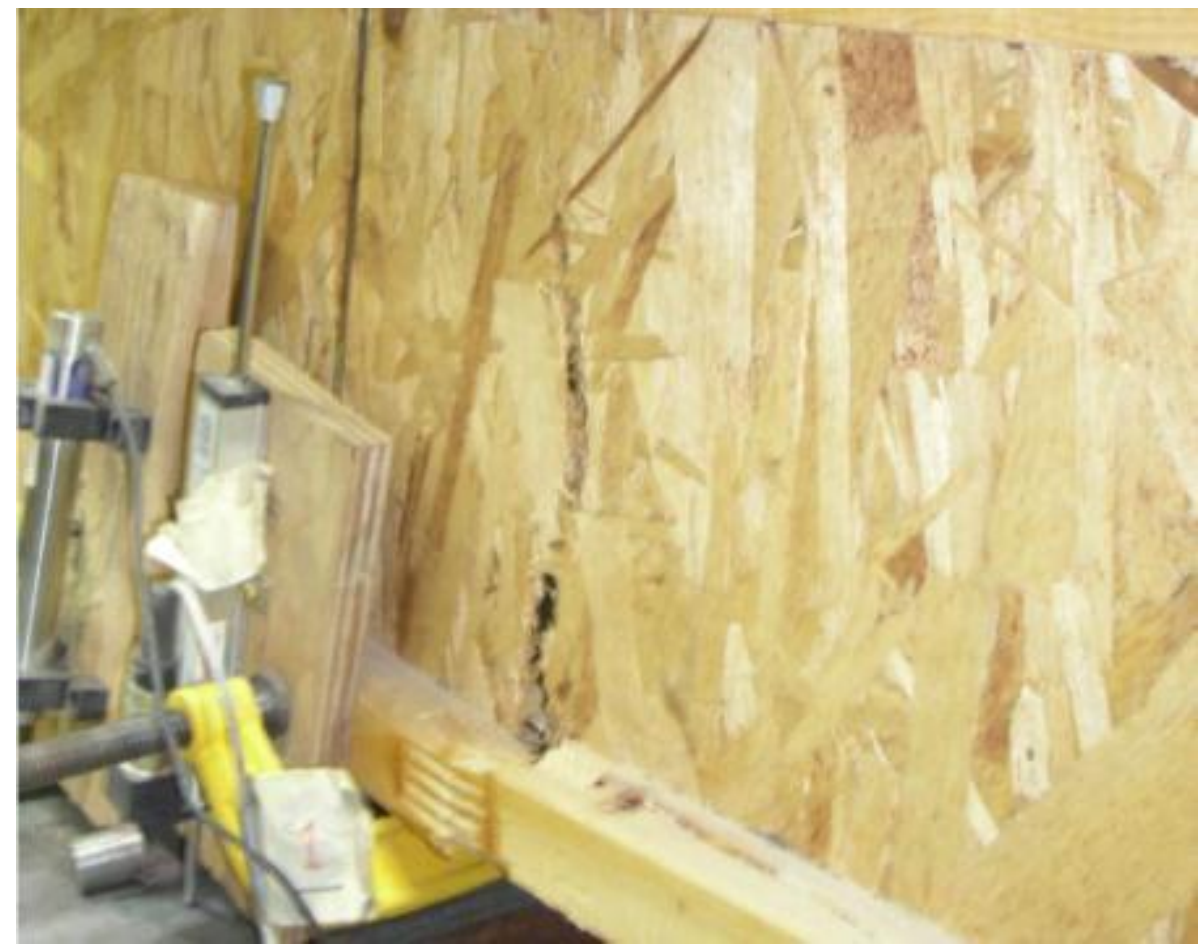

Figure E.8: Close-up view of the bending fracture of the bottom flange of web of the $302 \times 5250$ mm wooden joist assembly 


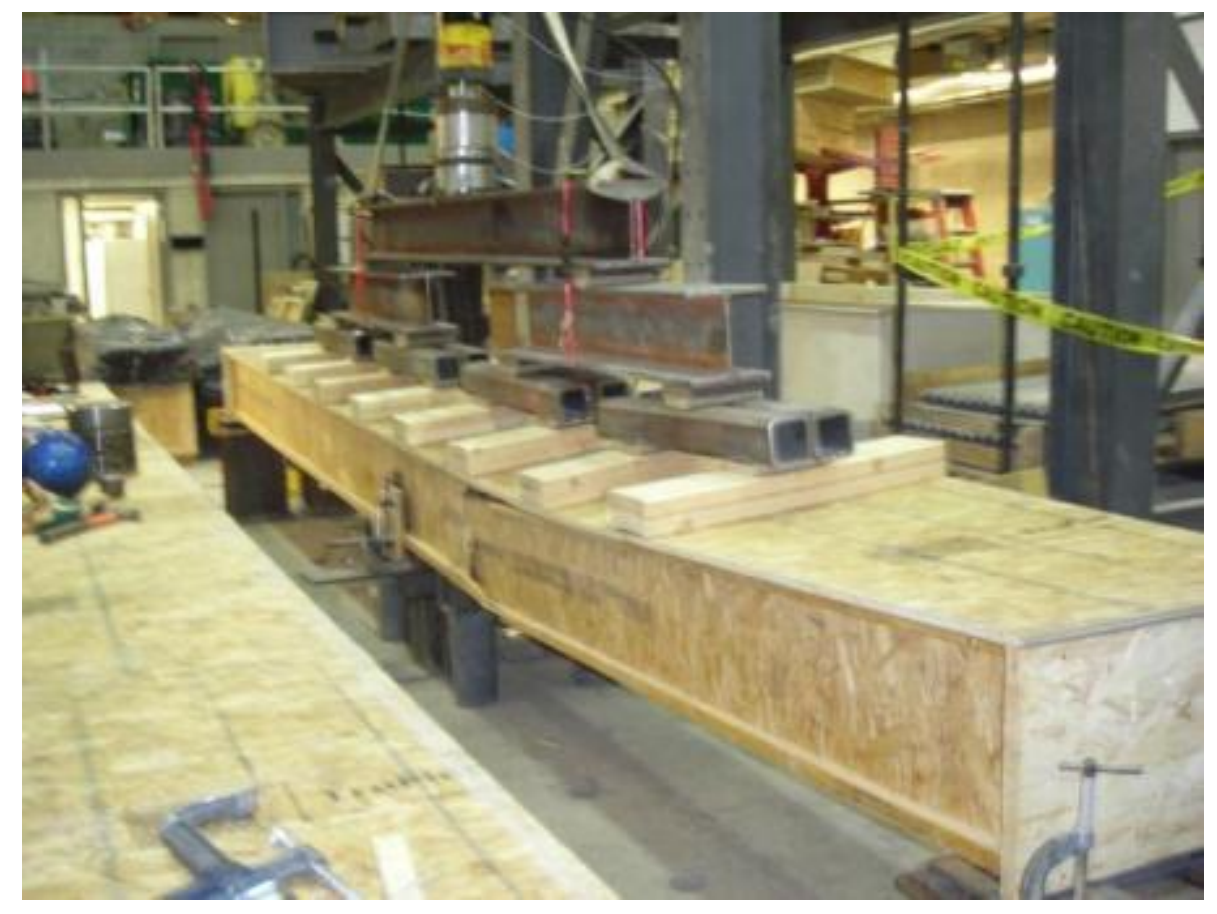

Figure E.9: View of the deformed shape at failure of the 356x6100 mm wooden joist assembly

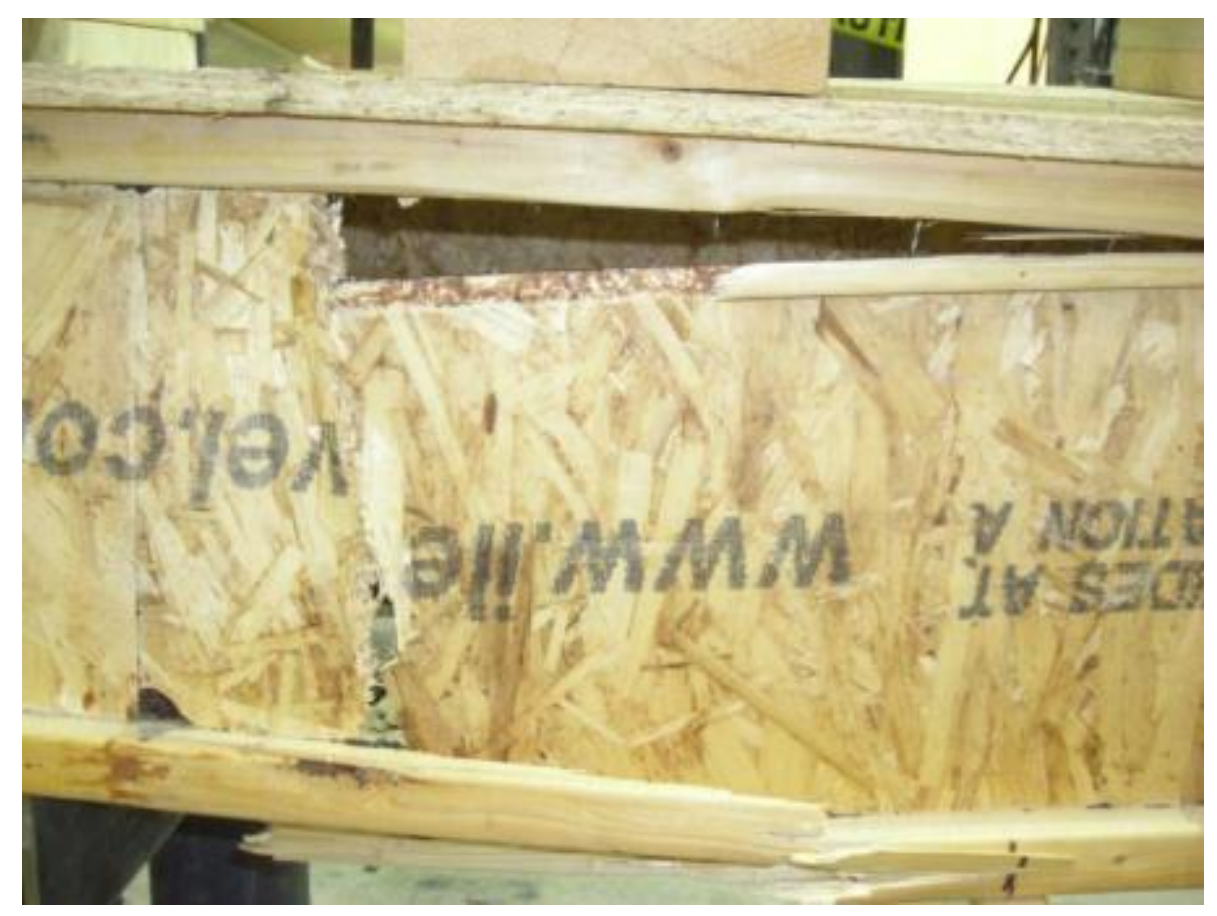

Figure E.10: Close-up view of the bottom flange and web fracture and top flange-web separation at failure of the $356 \times 6100 \mathrm{~mm}$ wooden joist assembly 


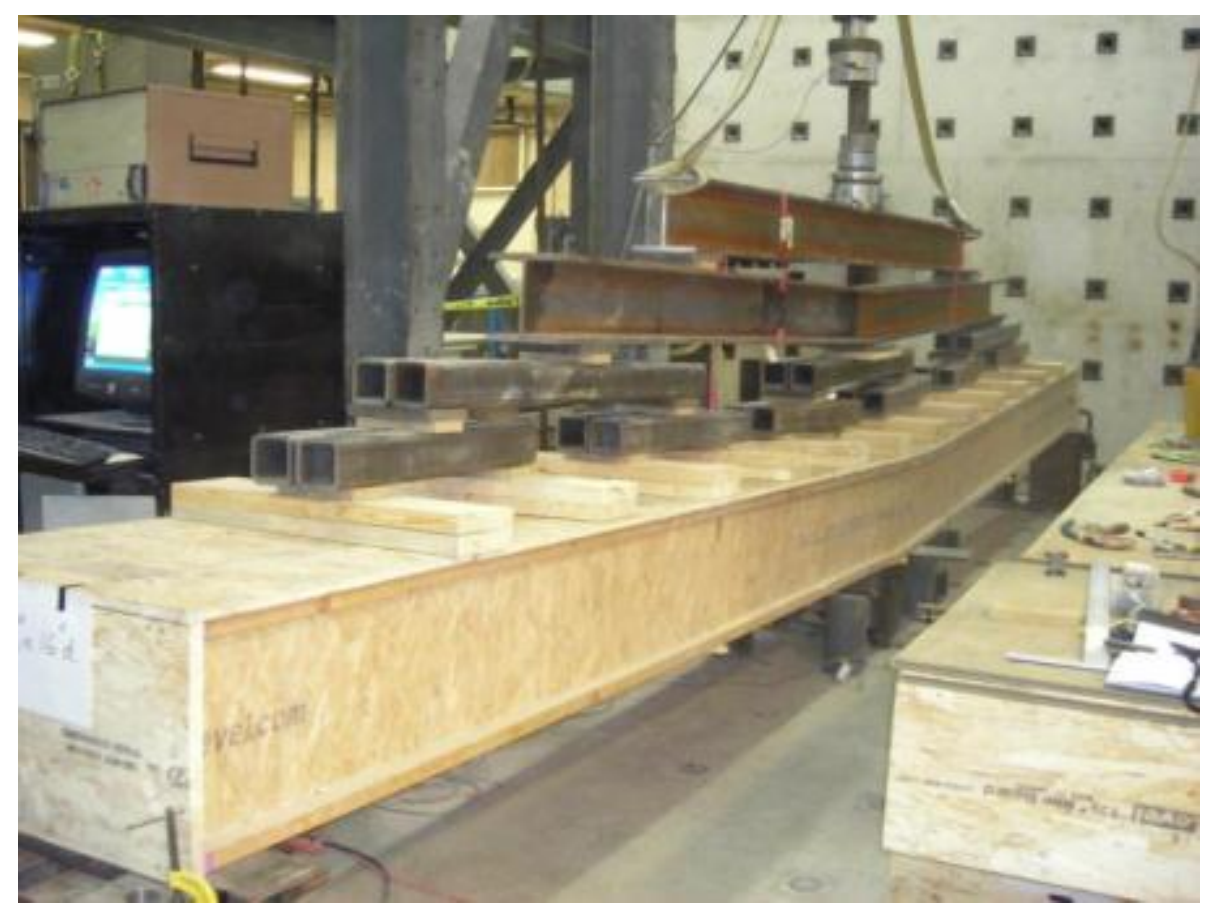

Figure E.11: View of the deformed shape at failure of the 406x7950 mm wooden joist assembly

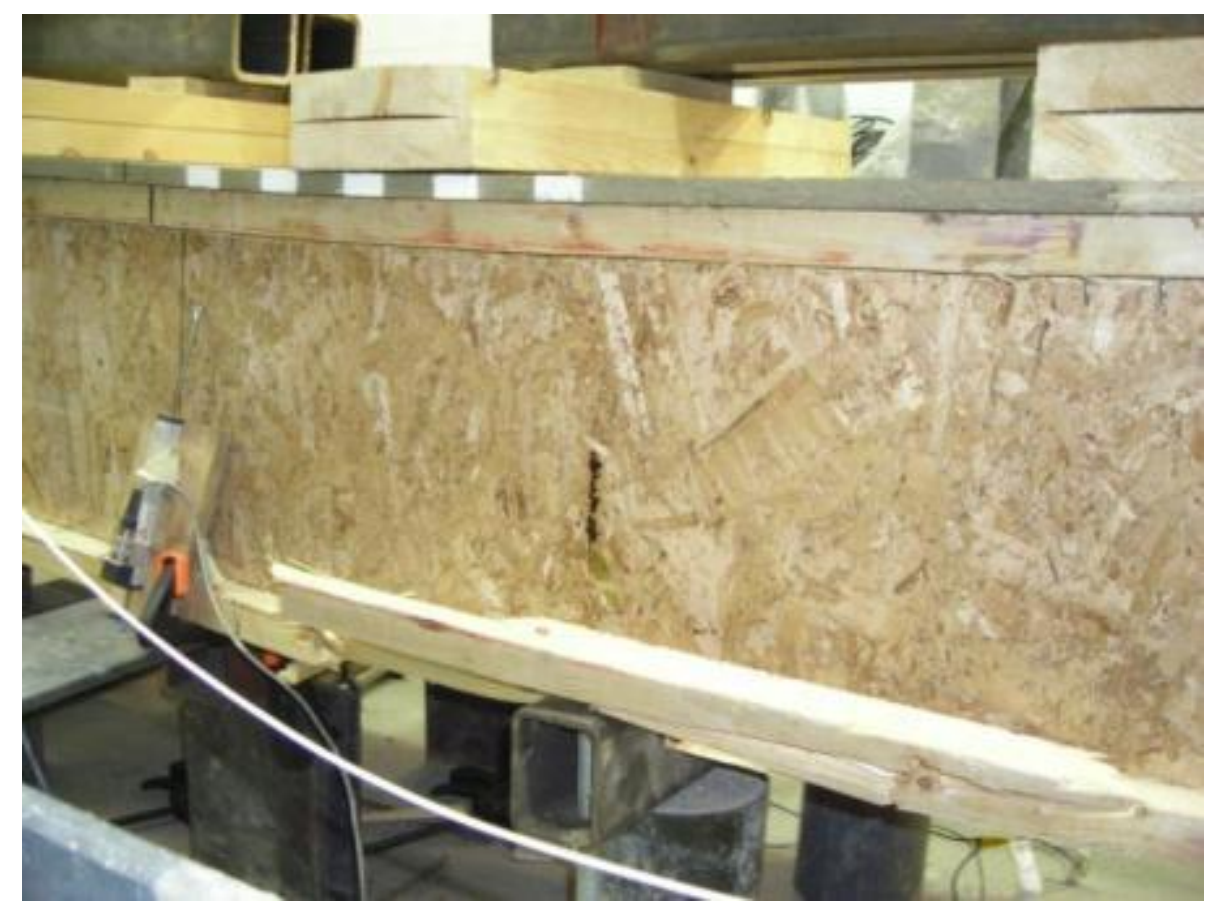

Figure E.12: Close-up view of the bending fracture of the bottom flange and web of the 406x7950 mm wooden joist assembly 


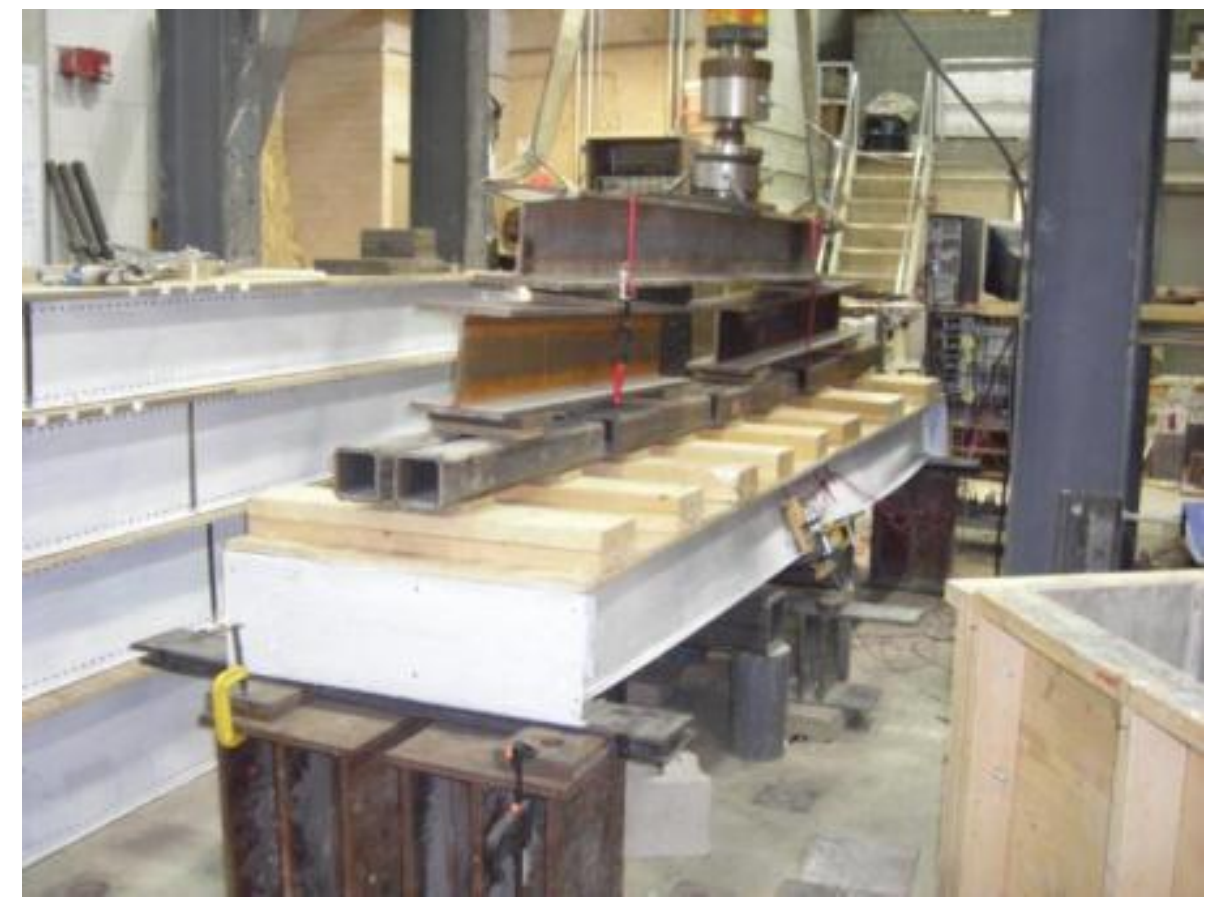

Figure E.13: View of the deformed shape at failure of the $241 \times 3500 \mathrm{~mm}$ iSPAN joist assembly

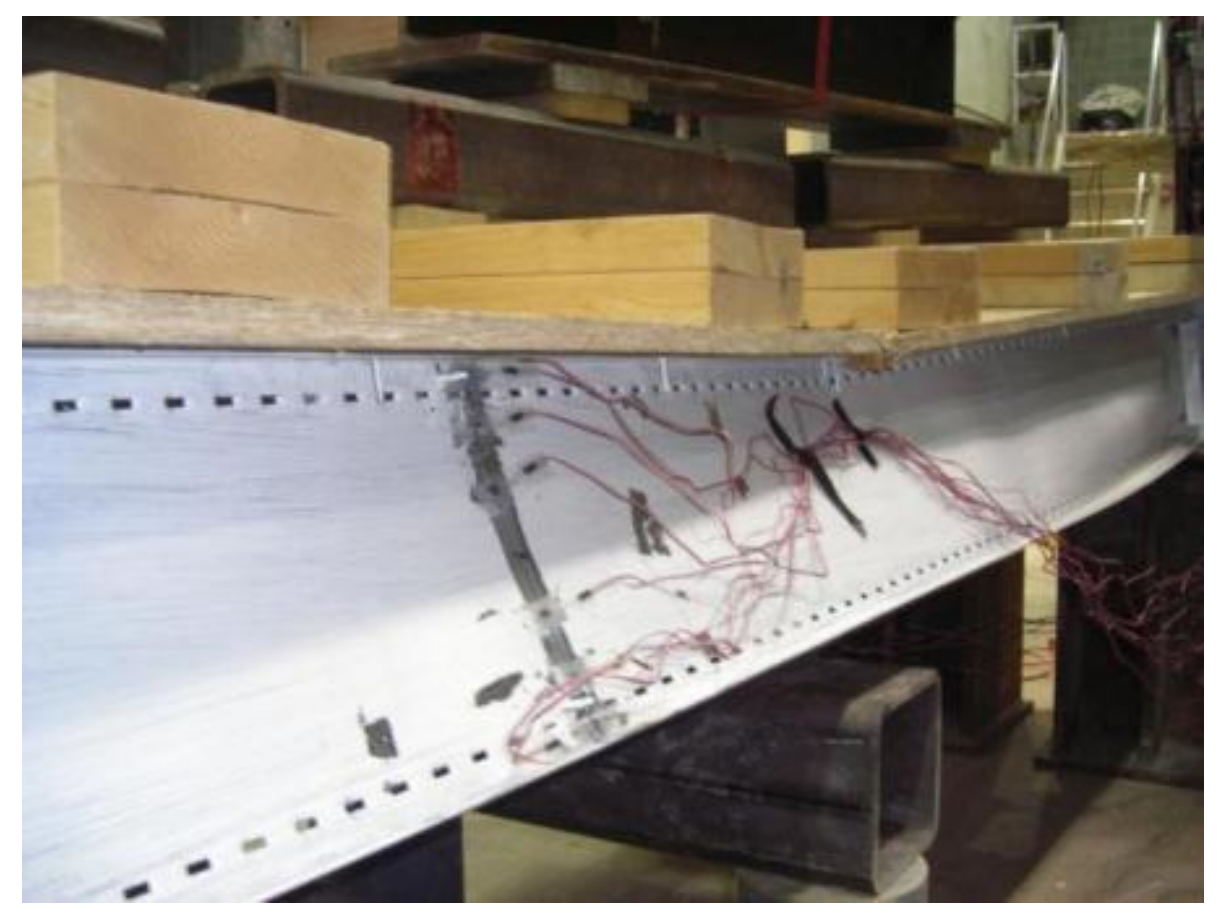

Figure E.14: Close-up view of the lateral torsional buckling failure of the 241x3500 mm iSPAN joist assembly 


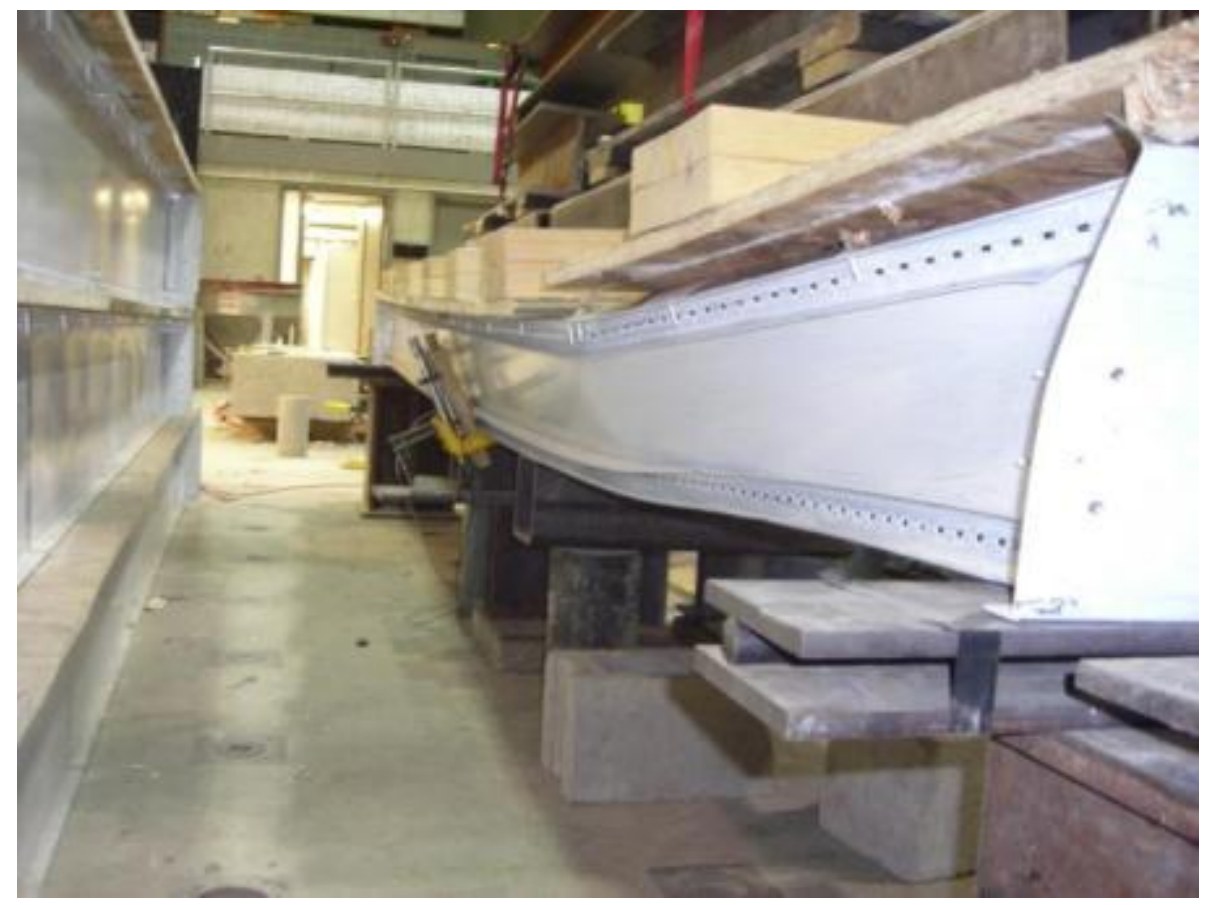

Figure E.15: View of lateral torsional buckling failure of the $241 \times 4500 \mathrm{~mm}$ iSPAN joist assembly

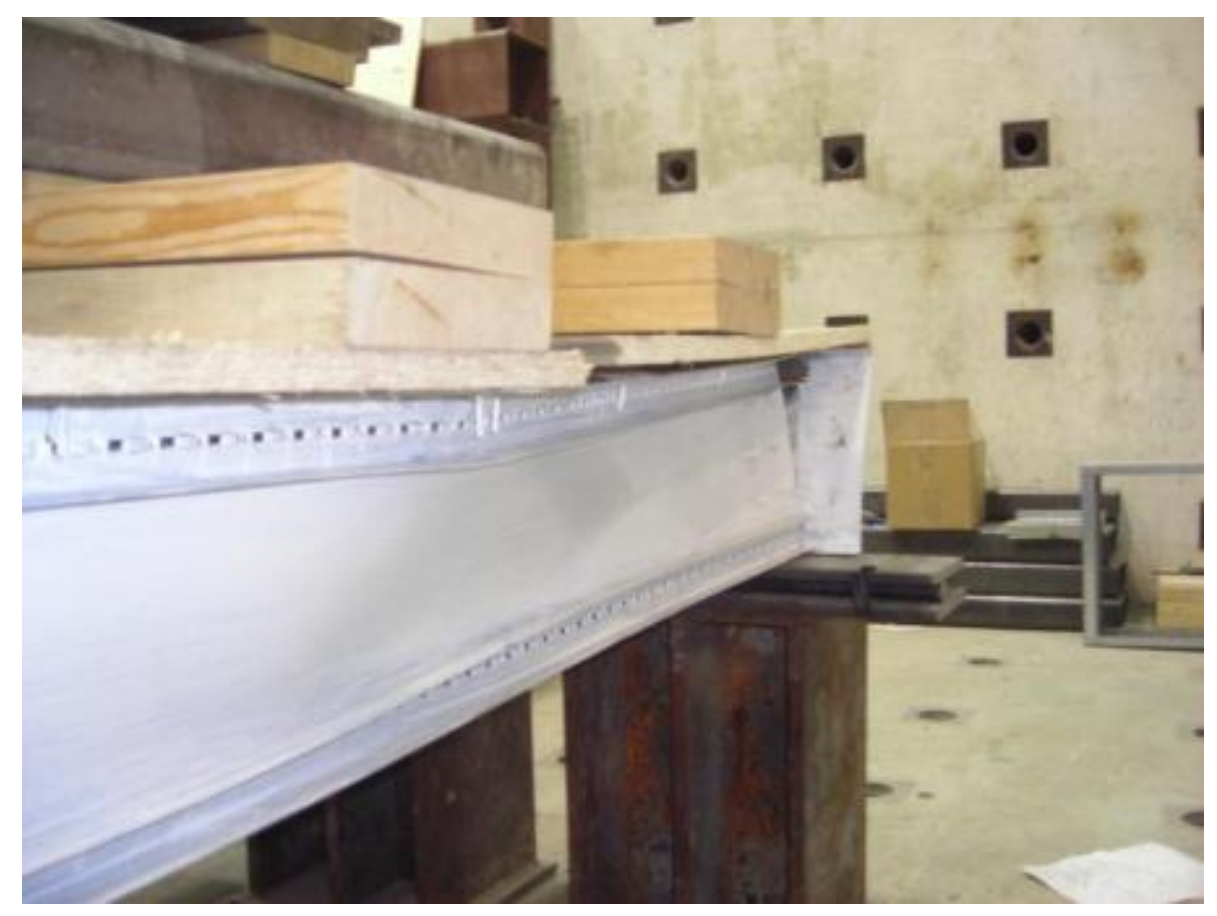

Figure E.16: Close-up View of lateral torsional buckling failure of the $241 \times 4500 \mathrm{~mm}$ iSPAN joist assembly along with rim board separation from the joist at the support 


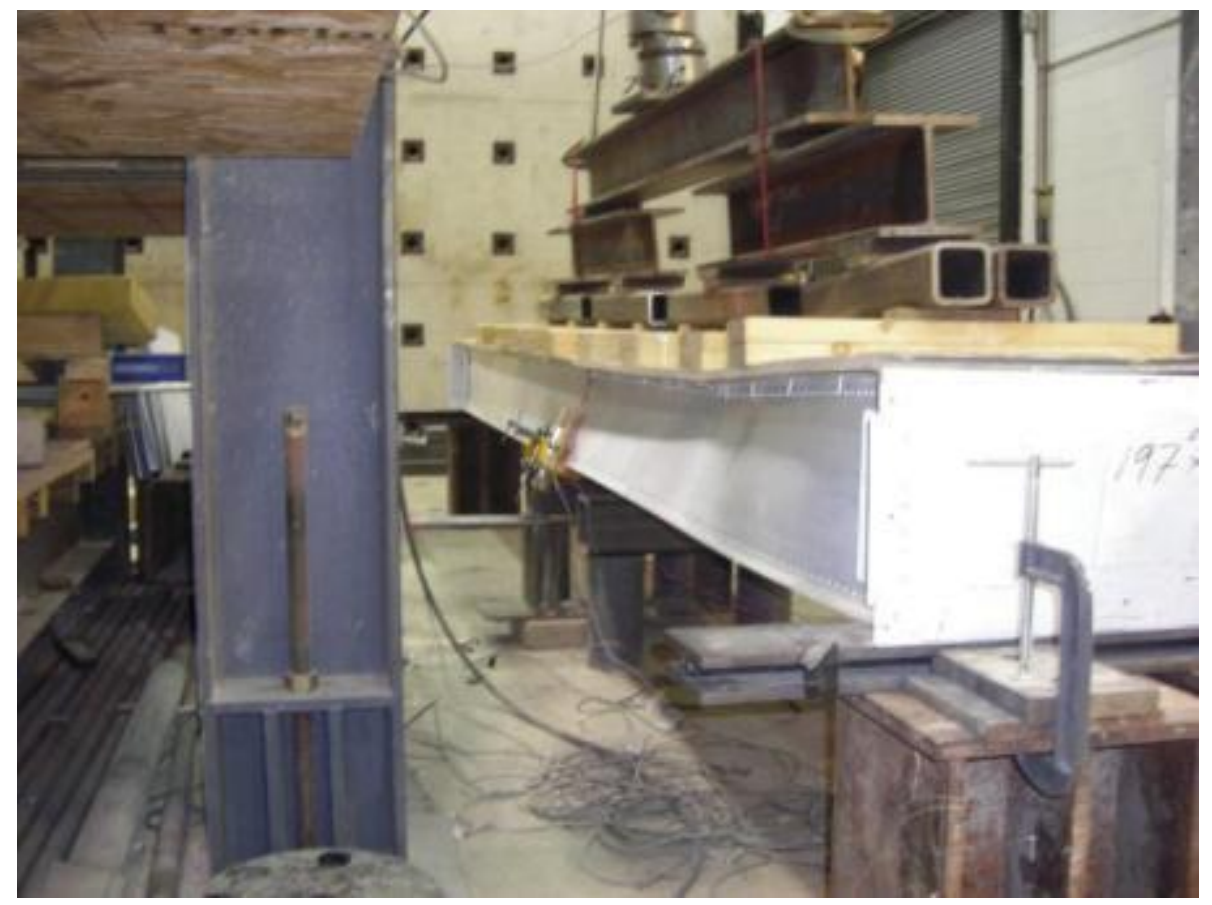

Figure E.17: View of lateral torsional buckling failure of the $302 \times 5000 \mathrm{~mm}$ iSPAN joist assembly

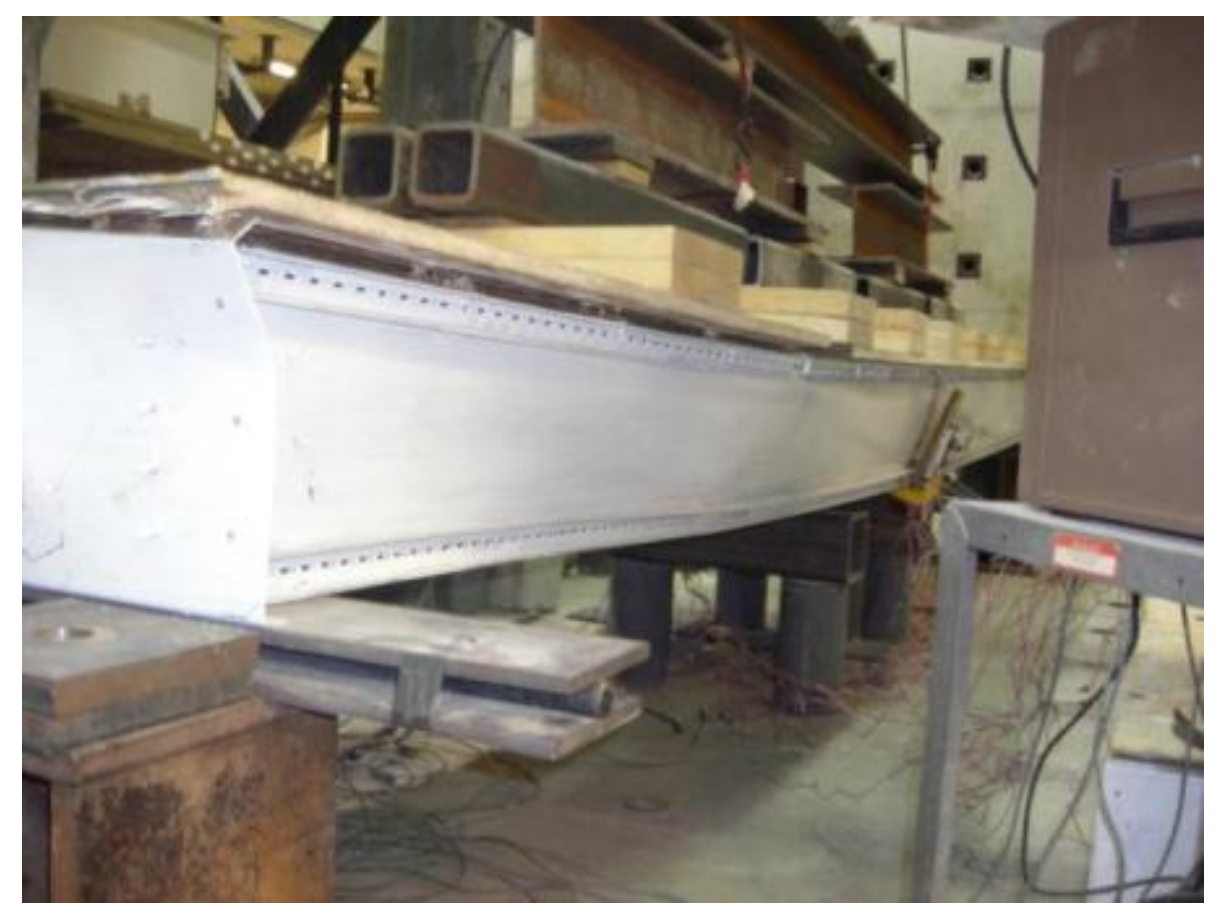

Figure E.18: Close-up view of lateral torsional buckling failure of 302x5000 mm iSPAN joist assembly along with crippling of the rim board over the support 


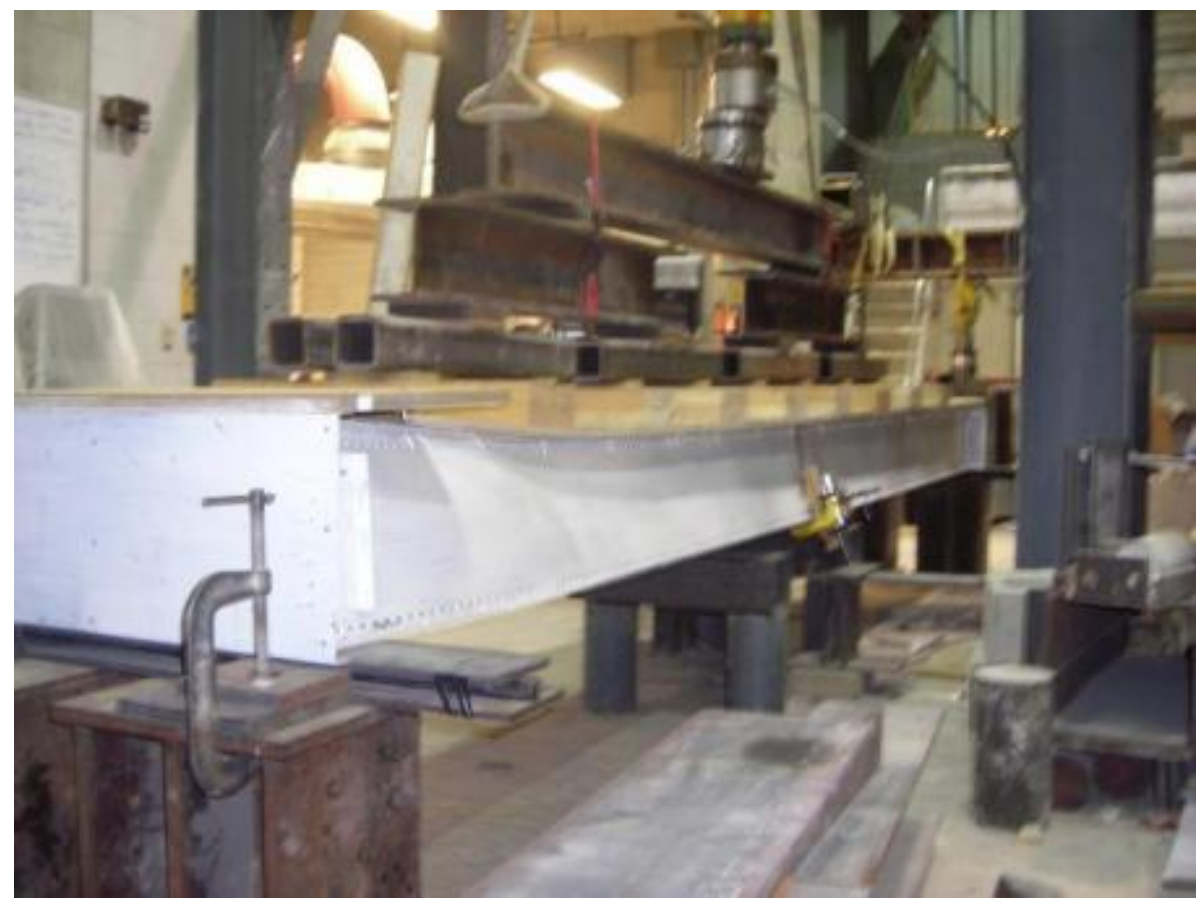

Figure E.19: View of lateral torsional buckling failure of the $302 \times 5250 \mathrm{~mm}$ iSPAN joist assembly

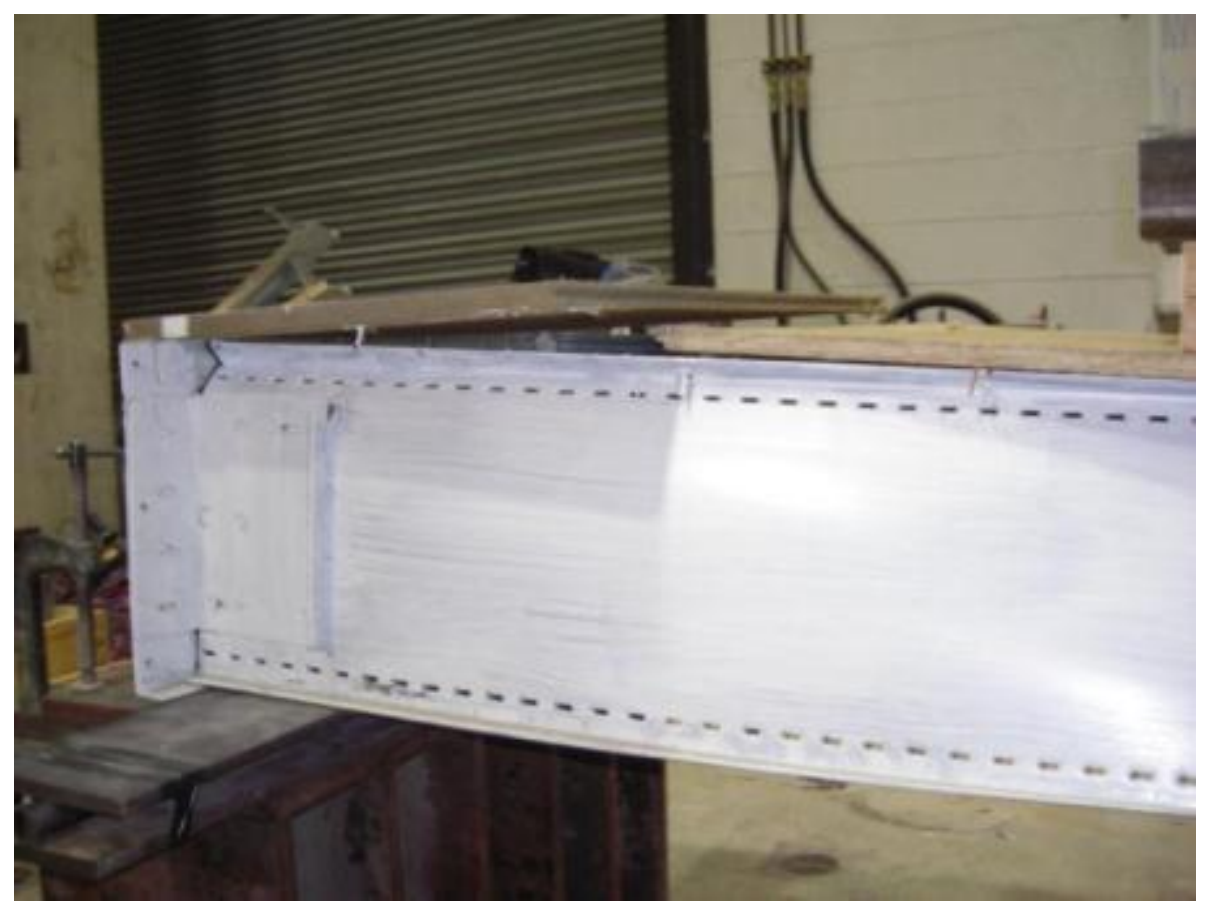

Figure E.20: View of splitting of the OSB sheets and separation of OSB sheet and the top flange at the support region of the $302 \times 5250 \mathrm{~mm}$ iSPAN joist assembly 


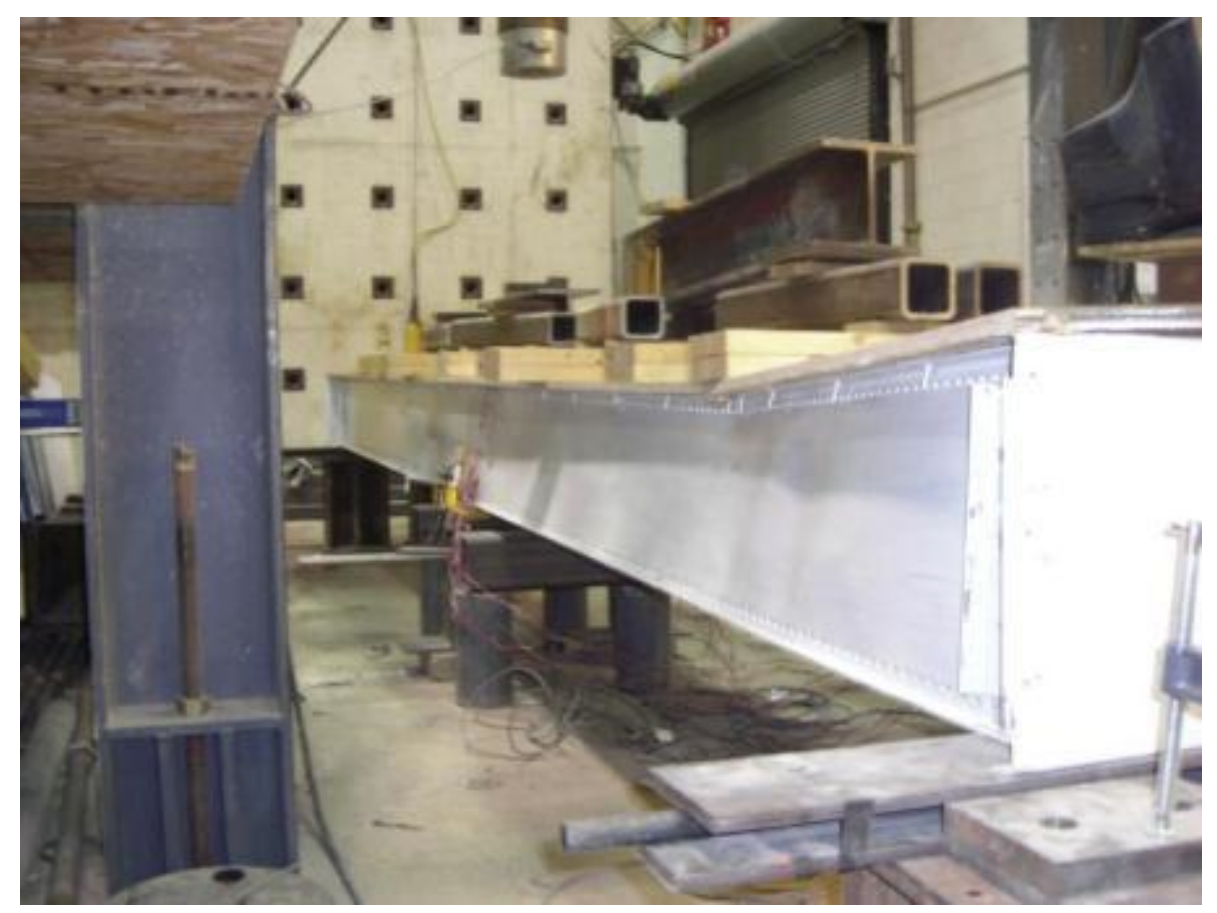

Figure E.21: View of lateral torsional buckling failure of the 356x6100 mm iSPAN joist assembly

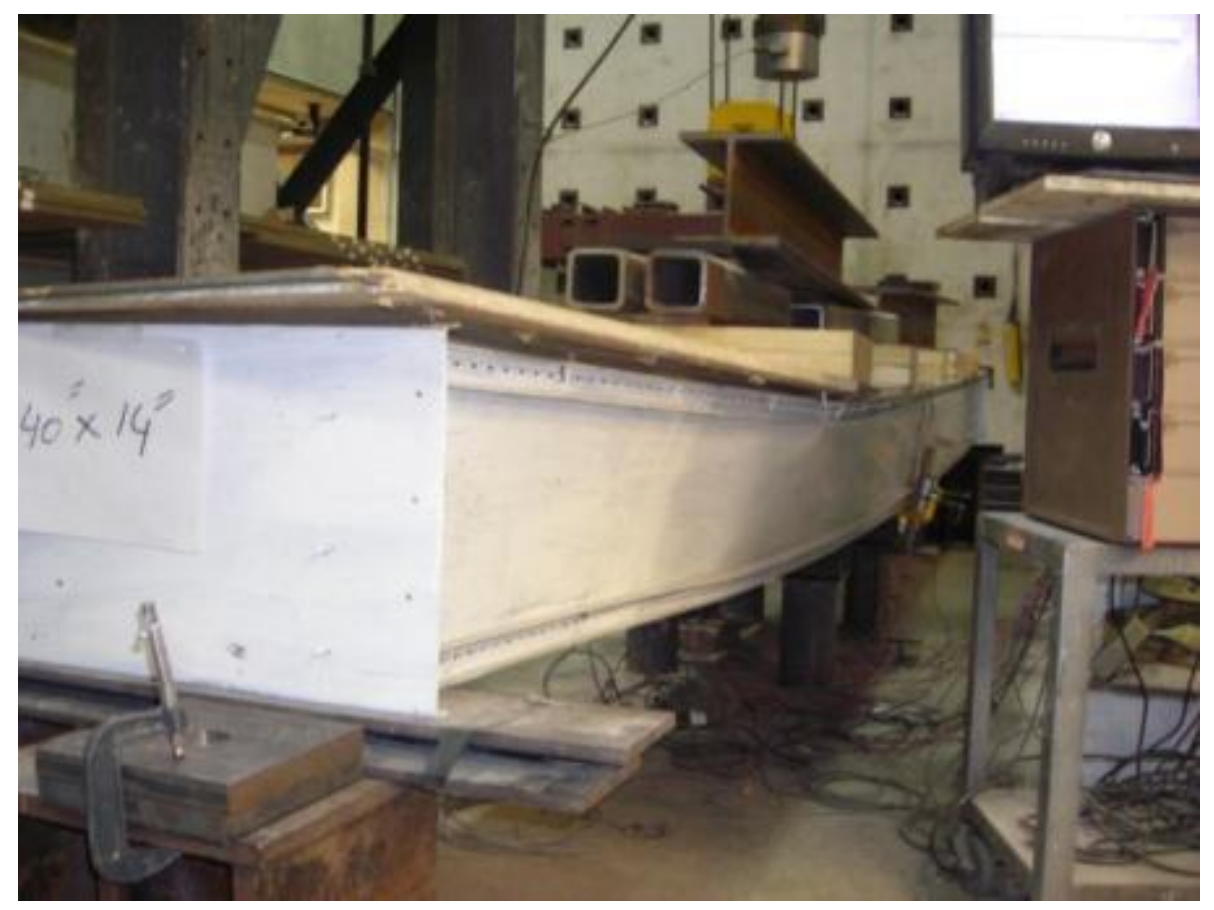

Figure E.22: View of lateral torsional buckling failure at the other side of the 356x6100 mm iSPAN joist assembly 


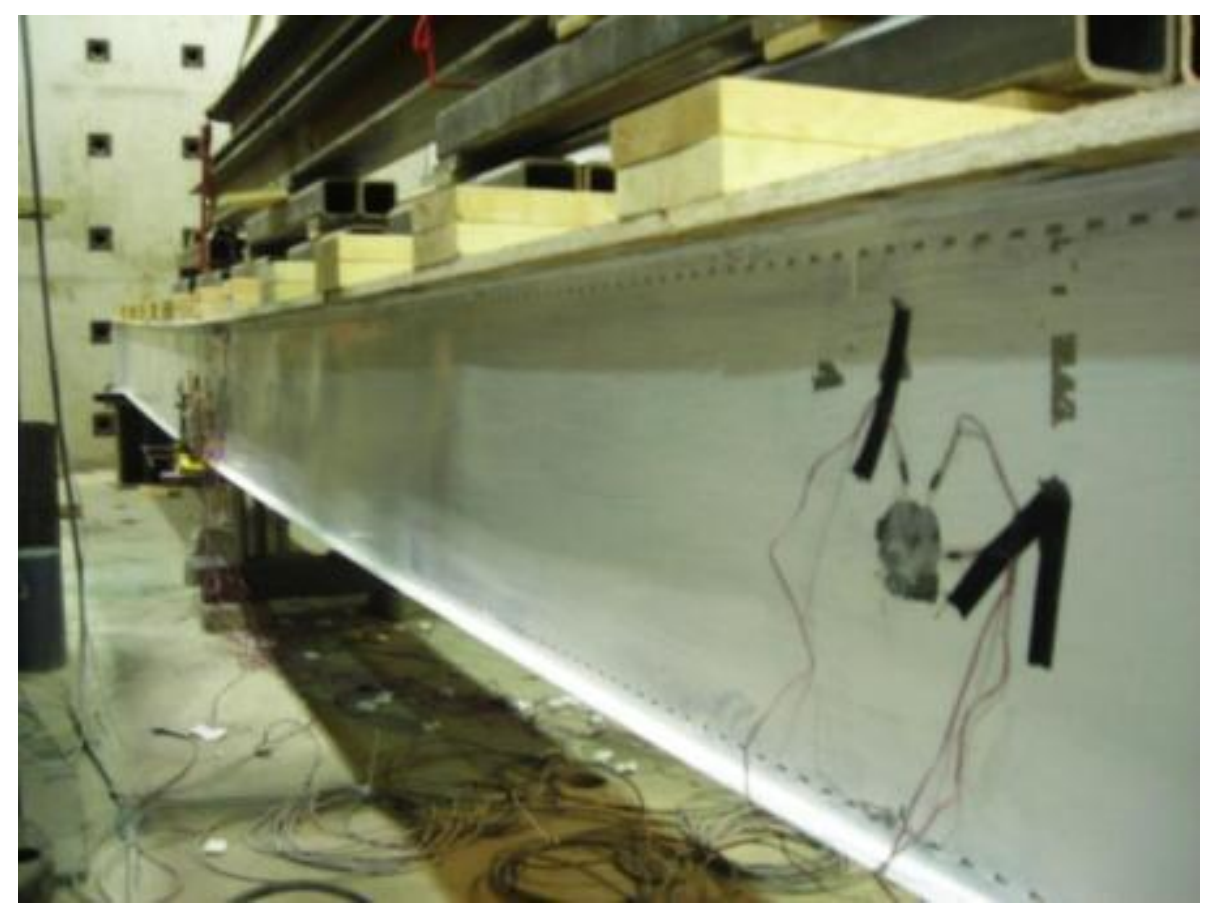

Figure E.23: View of the deformed shape of the 406x7950 mm iSPAN joist assembly

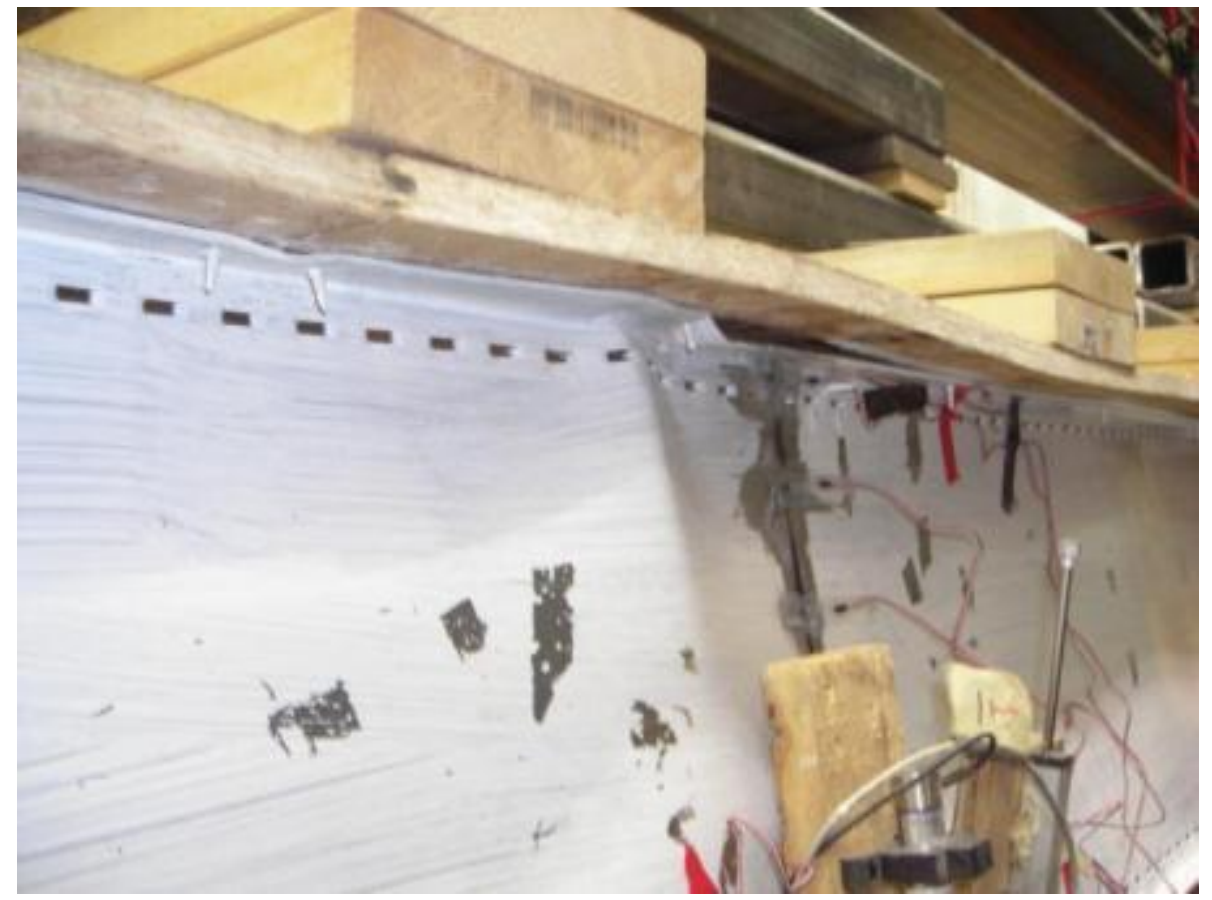

Figure E.24: Close-up view of the local buckling of the top flange along with web local buckling at the mid-span region of the $406 \times 7950 \mathrm{~mm}$ iSPAN joist assembly 


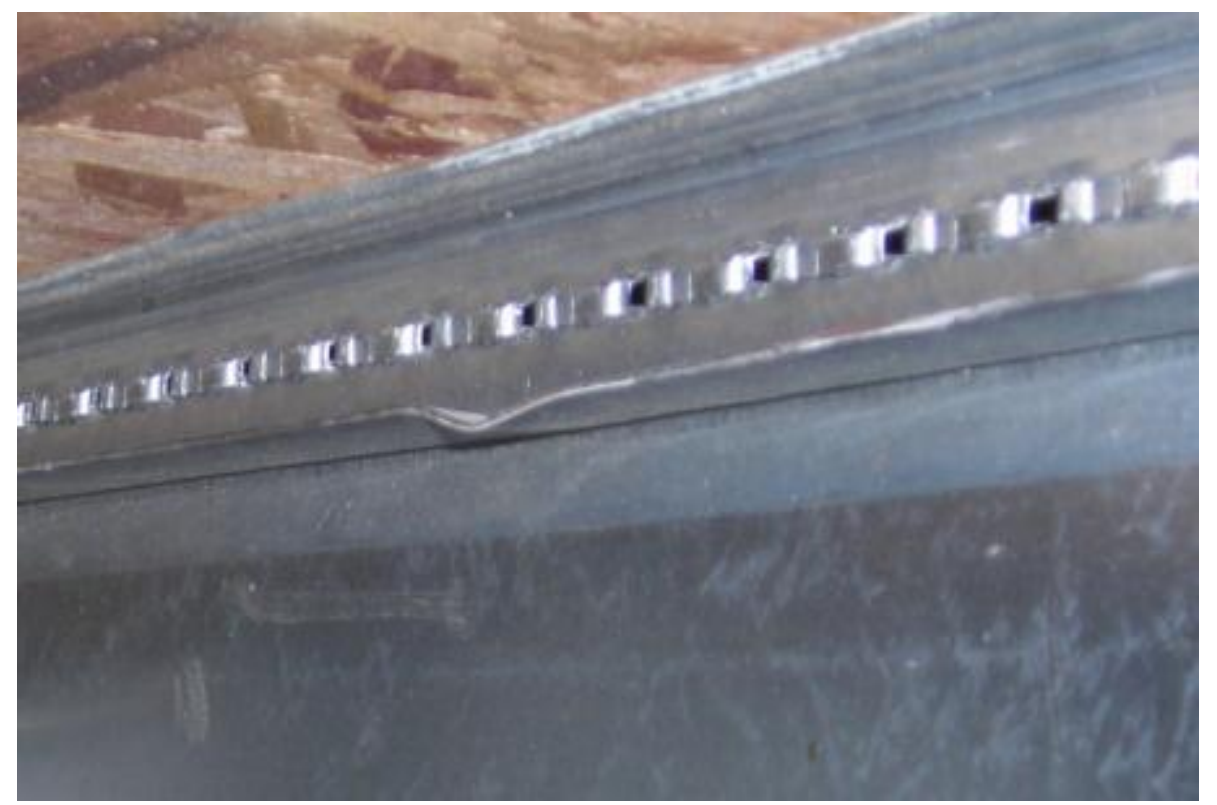

Figure E.25: Close-up view of the local buckling of the free lip at the top flange of the 406x7950 mm iSPAN joist assembly 


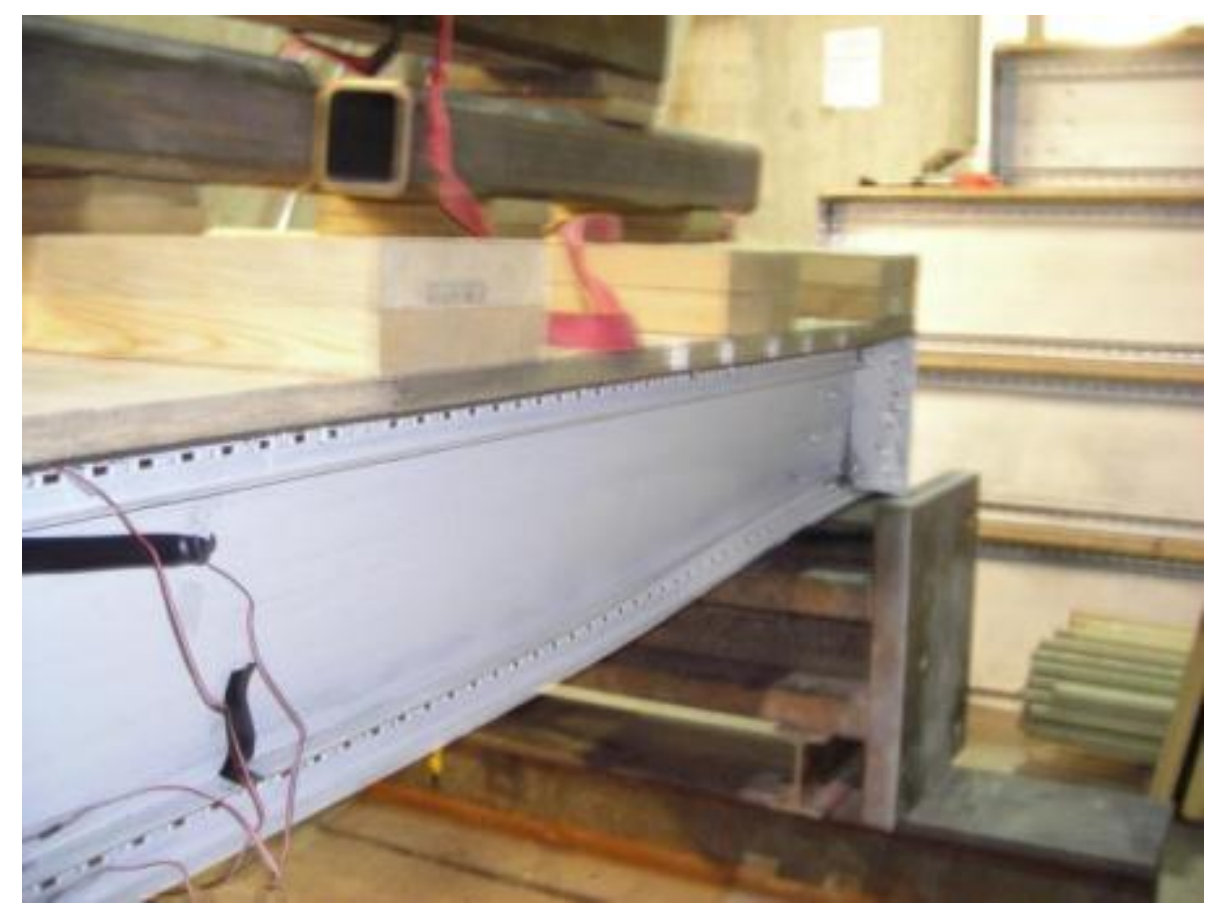

Figure E.26: View of the deformed shape at failure of the $254 \times 3500 \mathrm{~mm}$ iSPAN joist assembly at support

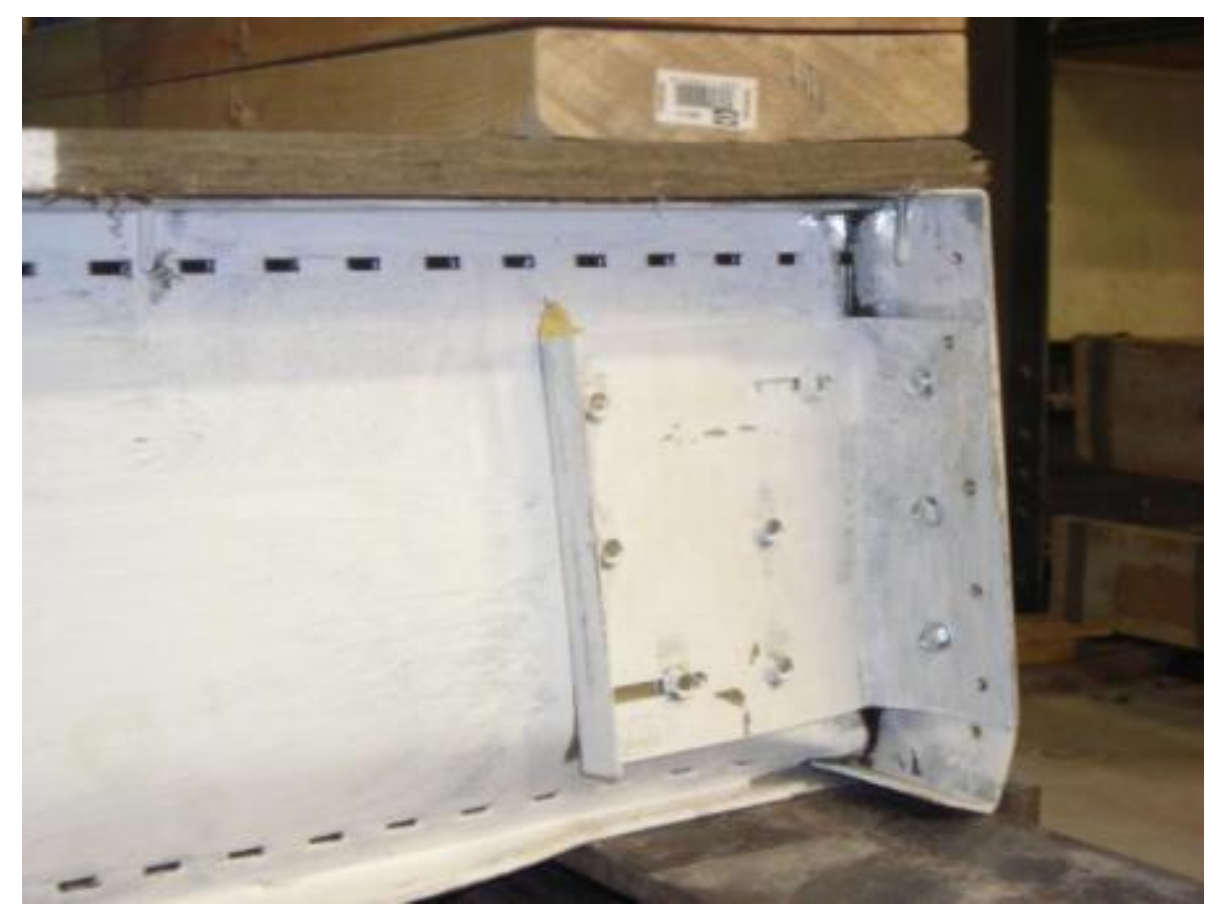

Figure E.27: View of web and rim board crippling at failure at support of the $254 \times 3500 \mathrm{~mm}$ iSPAN joist assembly with web holes 


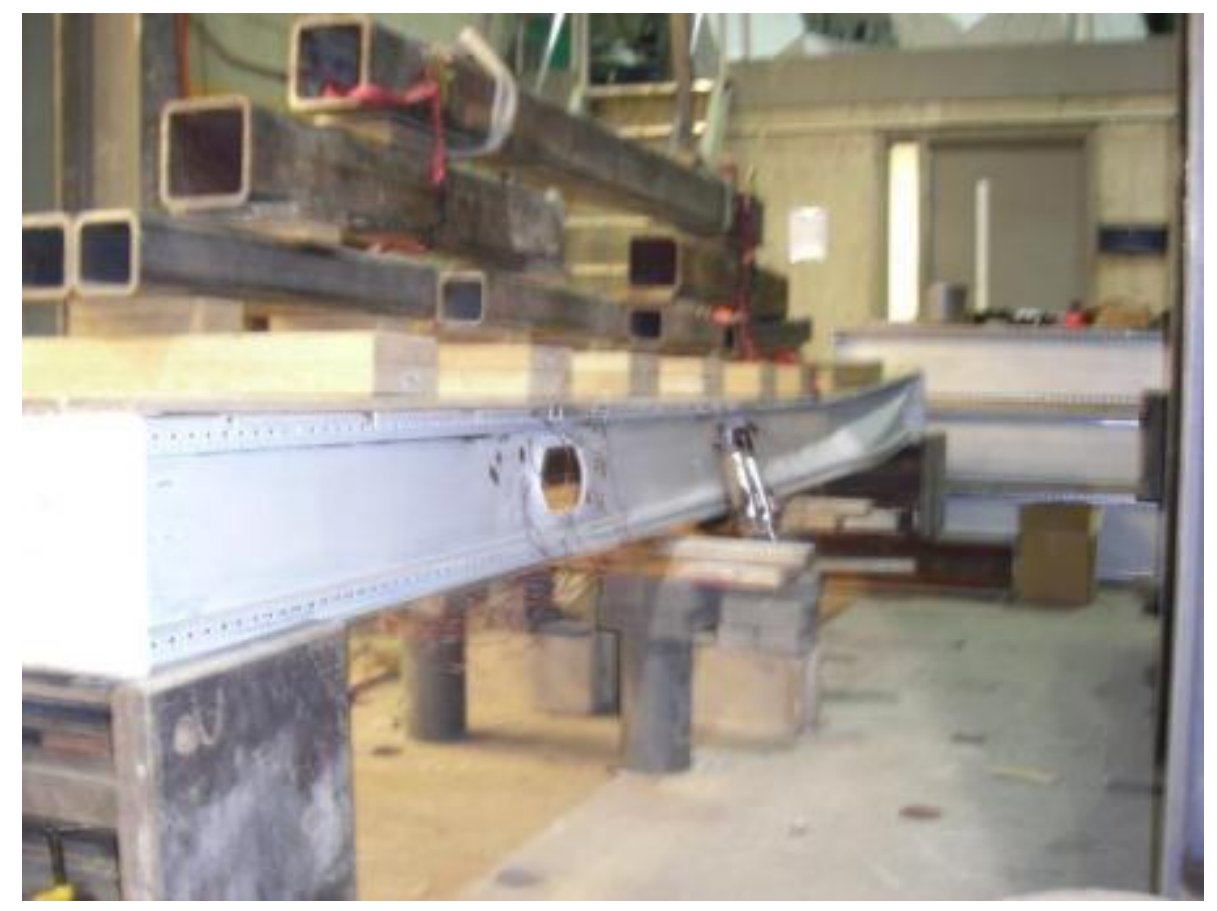

Figure E.28: View of lateral torsional buckling failure of the $254 \times 4500 \mathrm{~mm}$ iSPAN joist assembly with web holes

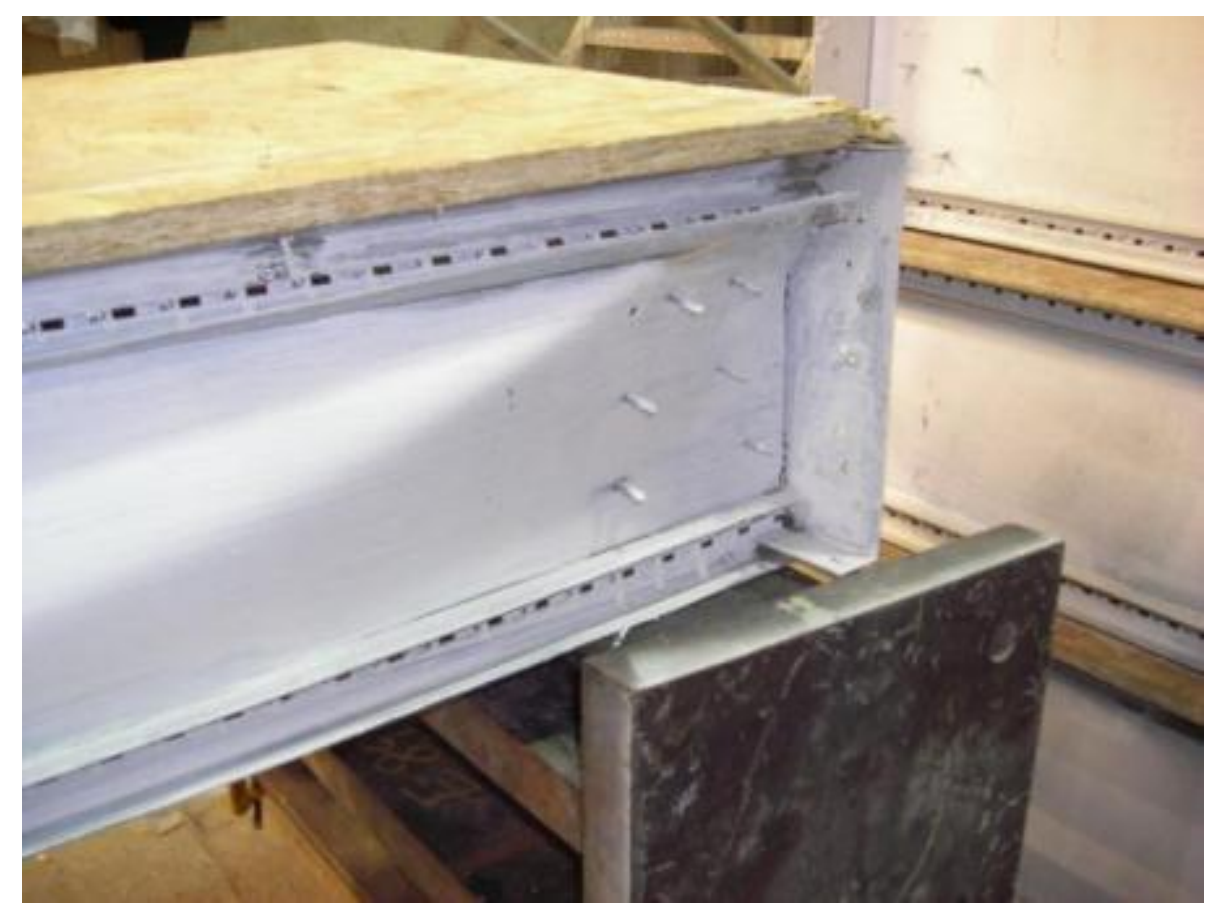

Figure E.29: Close-up view of lateral torsional buckling failure of the 254x4500 mm iSPAN joist assembly with web holes 


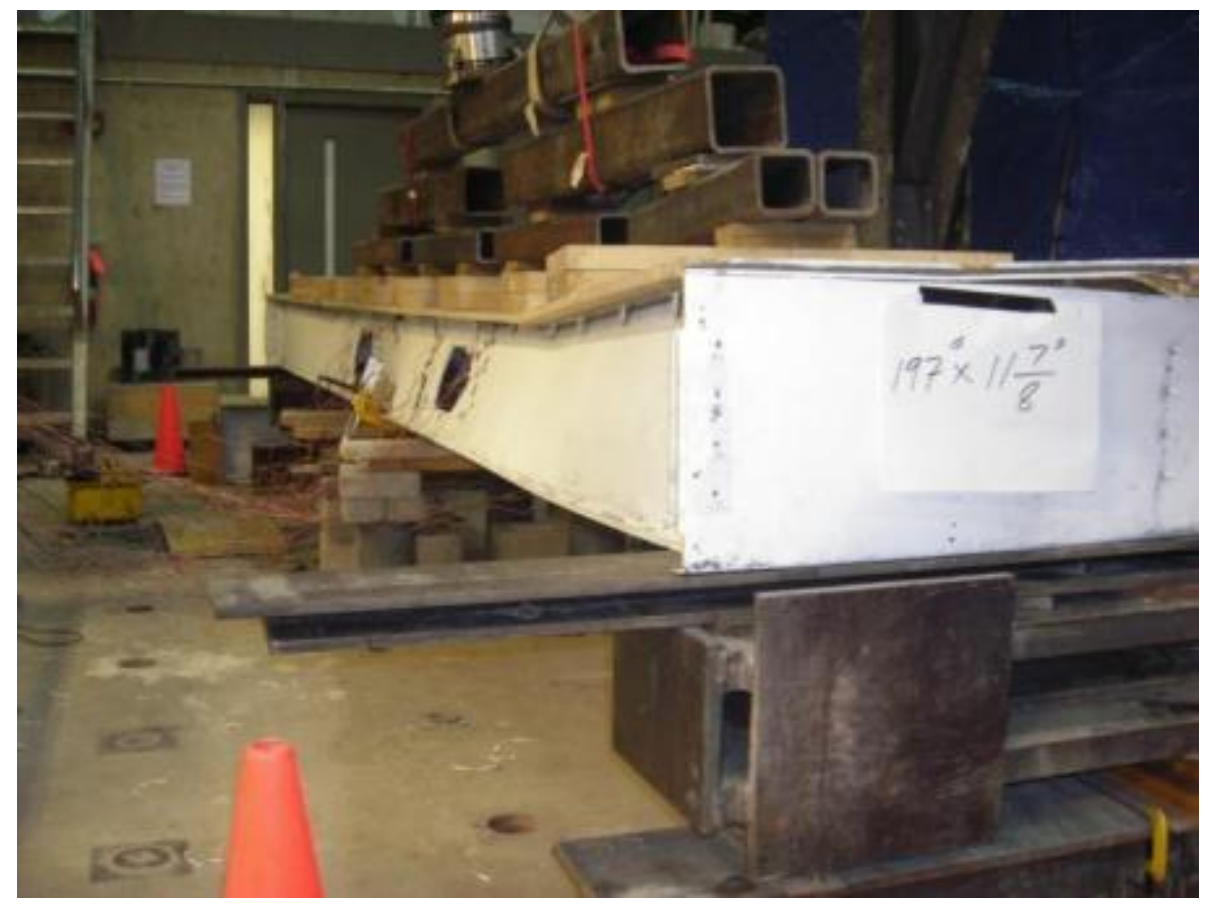

Figure E.30: View of the lateral torsional buckling failure of the $302 \times 5000 \mathrm{~mm}$ iSPAN joist assembly with web holes

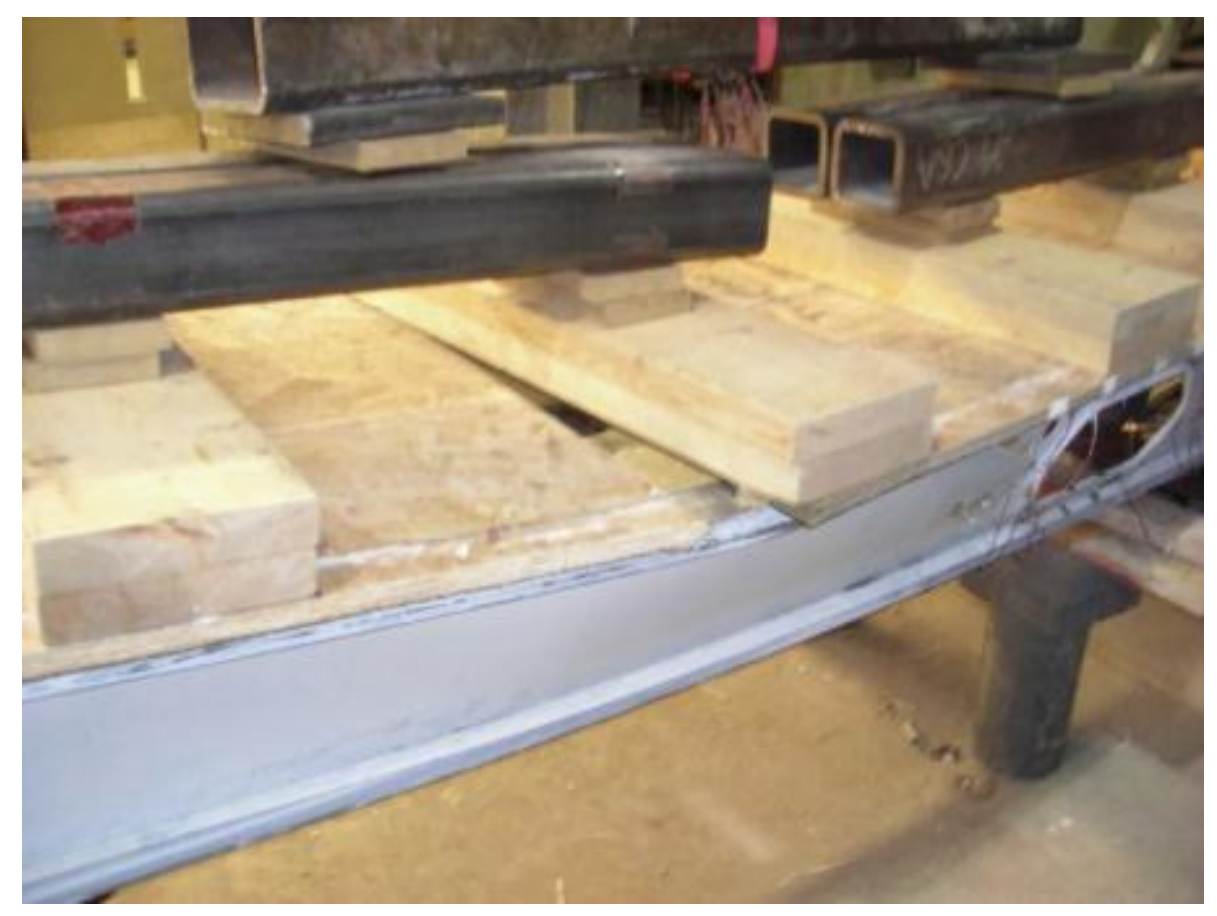

Figure E.31: Close-up view of lateral torsional buckling failure along with OSB separation normal to the joist of $302 \times 5000 \mathrm{~mm}$ iSPAN joist assembly 


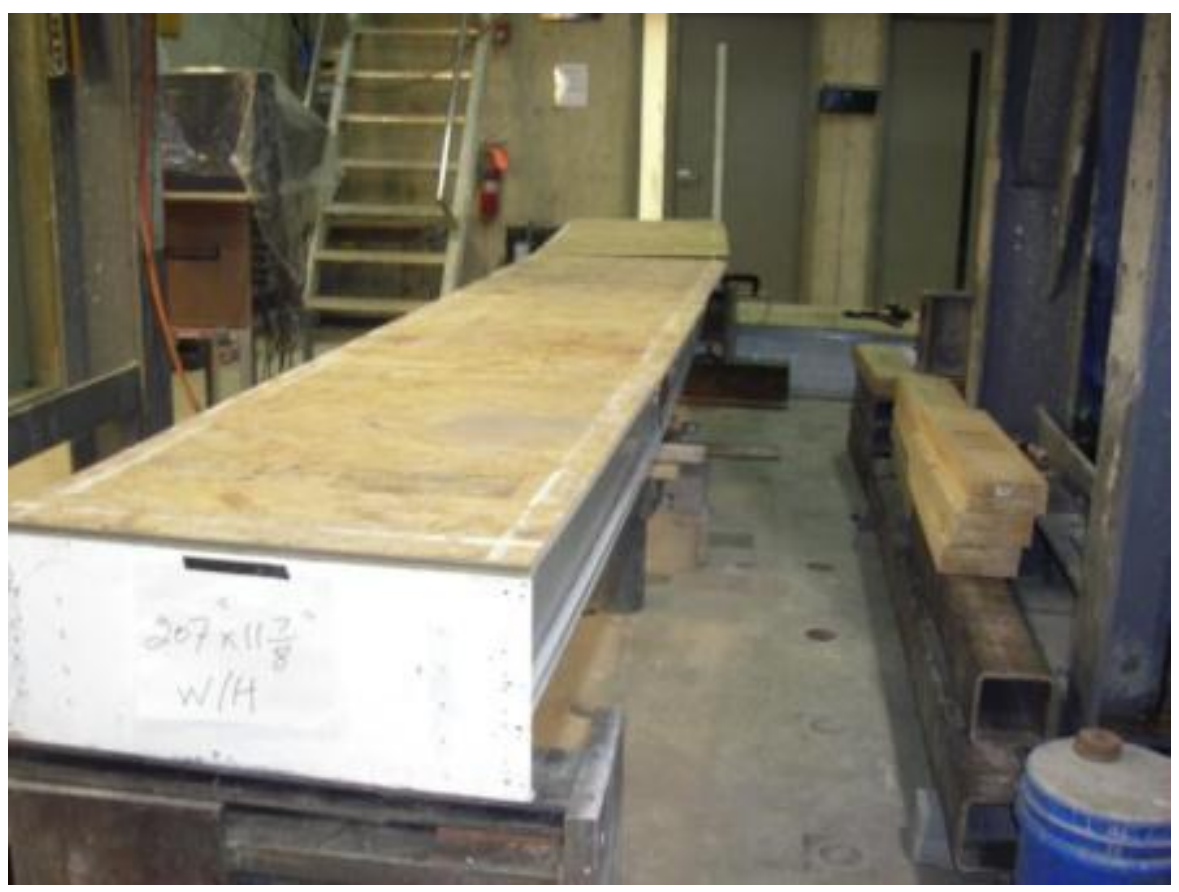

Figure E.32: View of lateral torsional buckling failure of the $302 \times 5250 \mathrm{~mm}$ iSPAN joist assembly with web holes

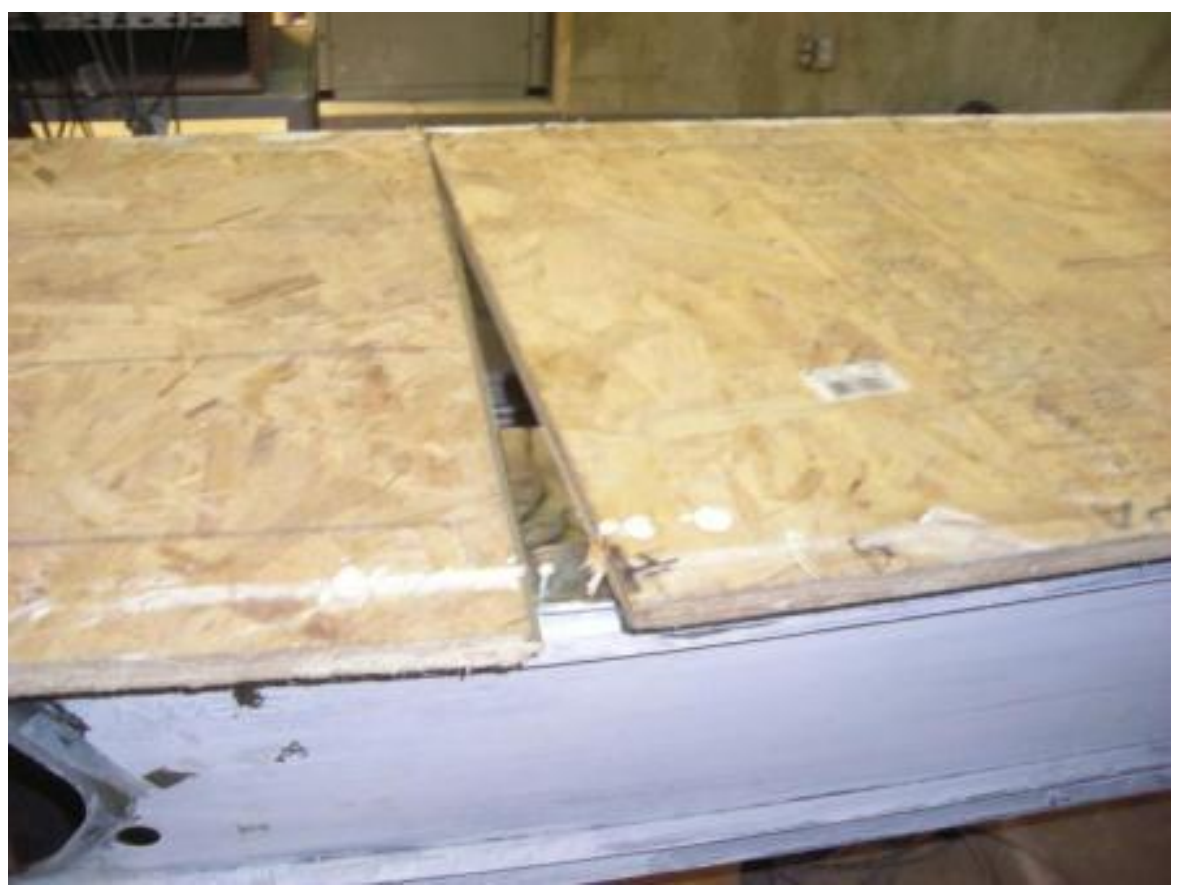

Figure E.33: Close-up view of the lateral torsional buckling failure of the joist and lateral separation of OSB sheets at mid-span region of the $302 \times 5250 \mathrm{~mm}$ iSPAN joist assembly with holes 


\section{APPENDIX F. VIEWS OF ELASTIC BUCKLING MODES CONSIDERED IN FEA MODELLING OF CFS JOISTS}




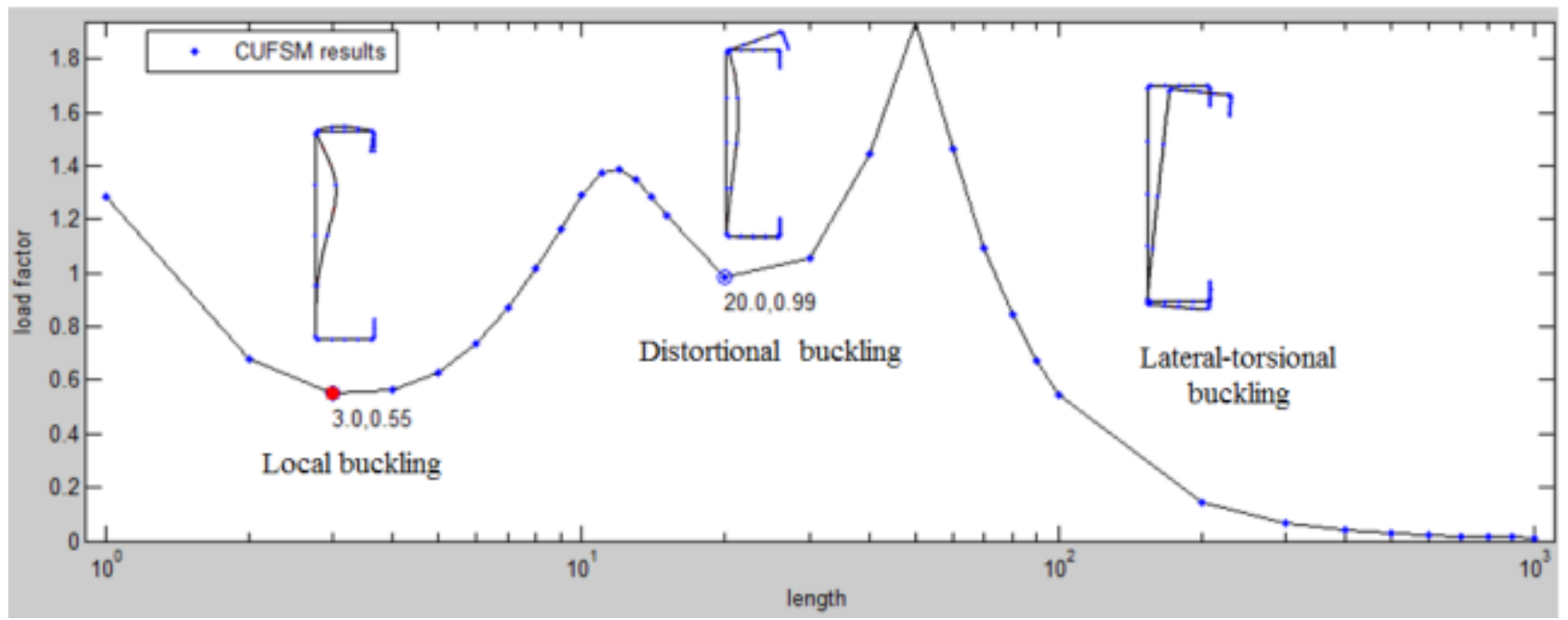

Figure F.1: View of buckling curve obtained from CUFSM for 600S162-33 section

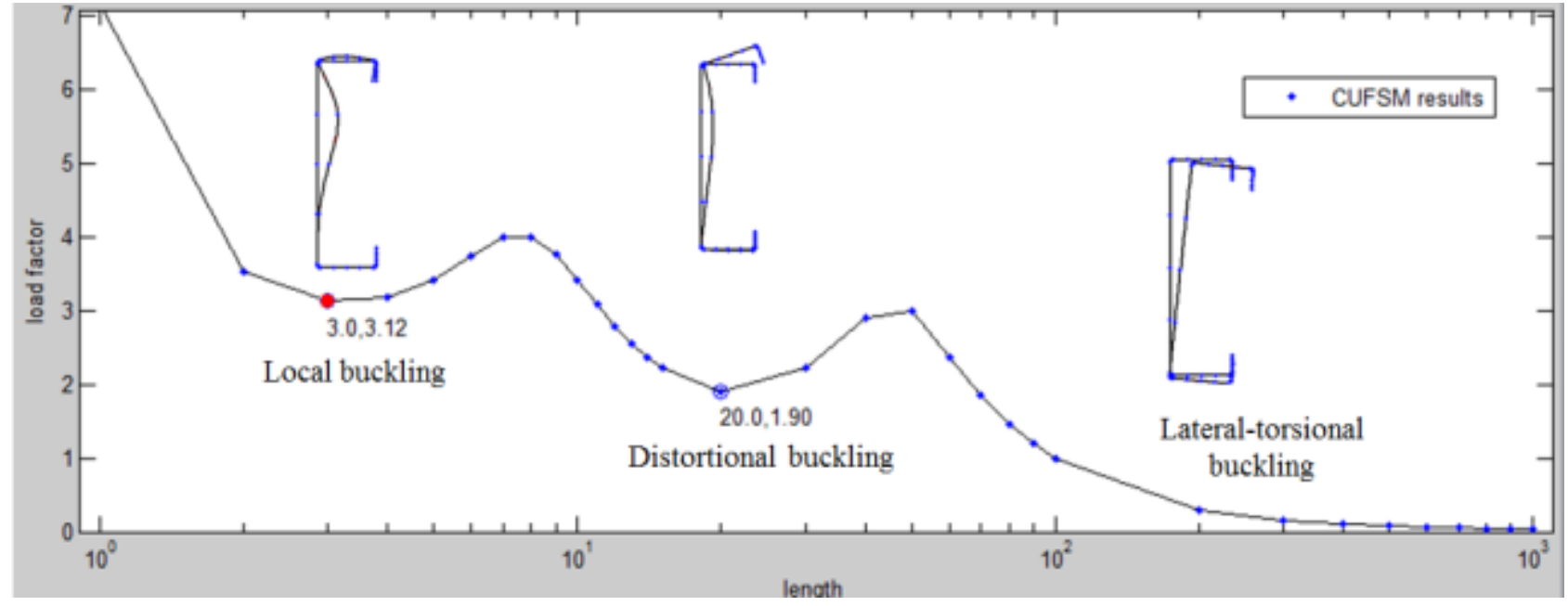

Figure F.2: View of buckling curve obtained from CUFSM for 600S250-97 section 


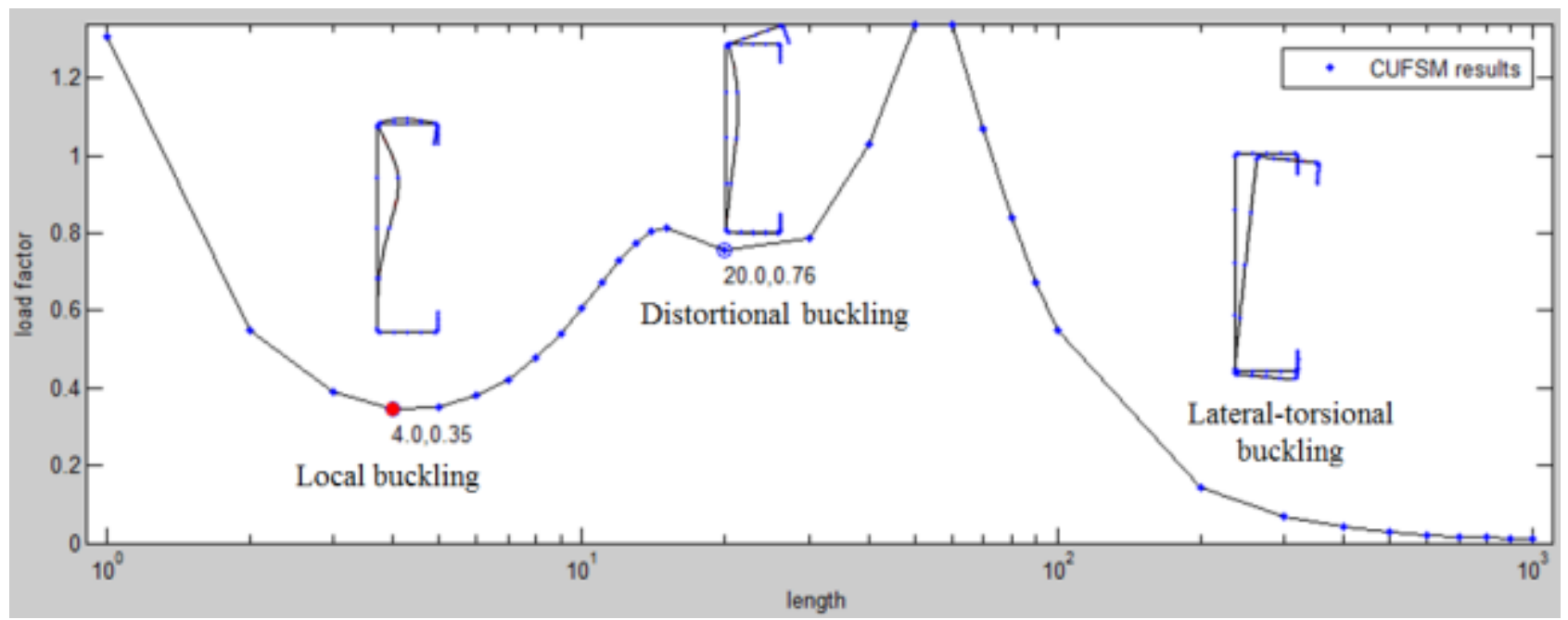

Figure F.3: View of buckling curve obtained from CUFSM for 800S162-33 section

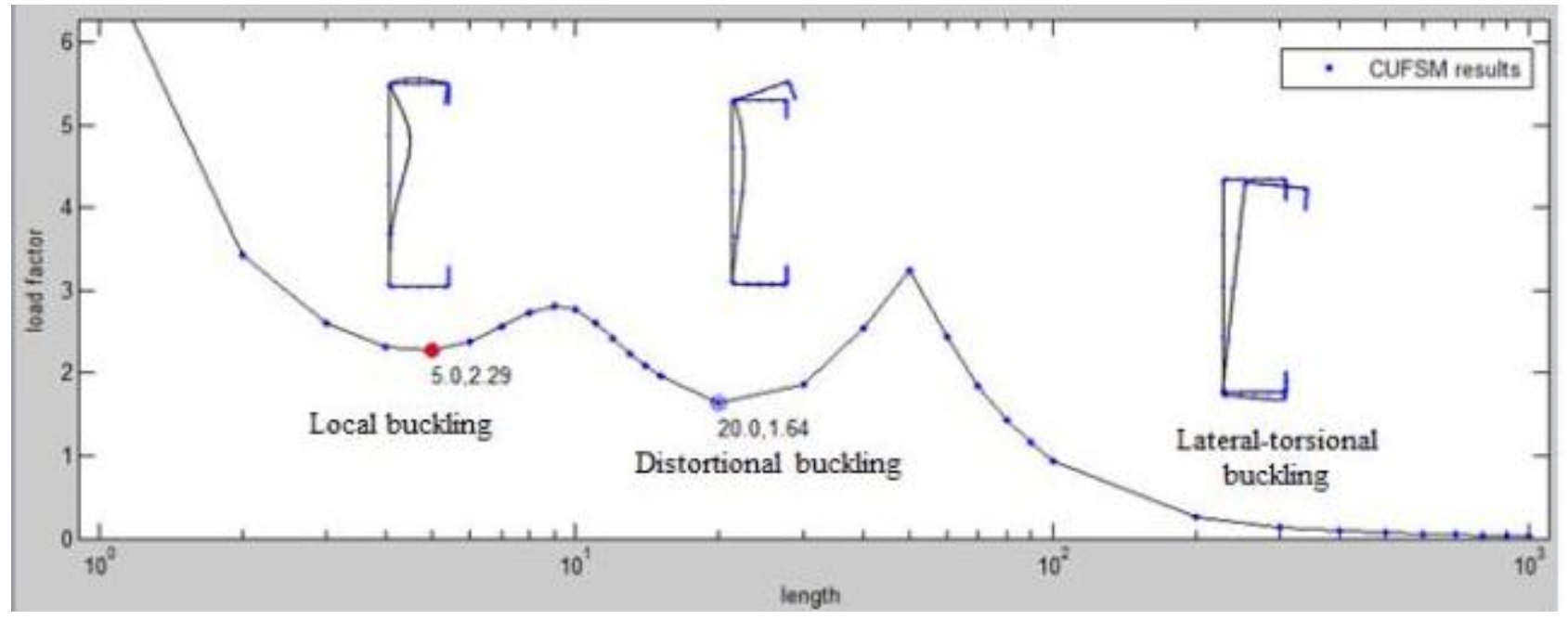

Figure F.4: View of buckling curve obtained from CUFSM for 800S250-97 section 


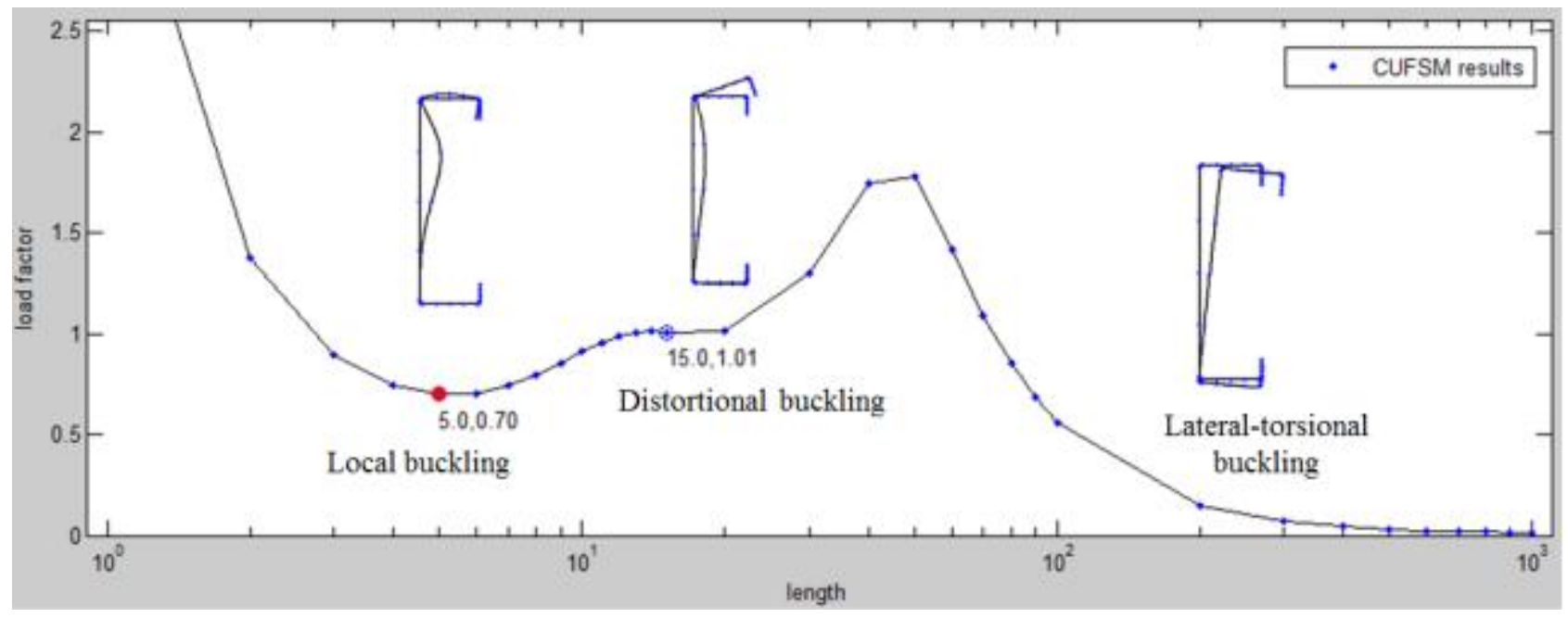

Figure F.5: View of buckling curve obtained from CUFSM for 1000S162-43 section

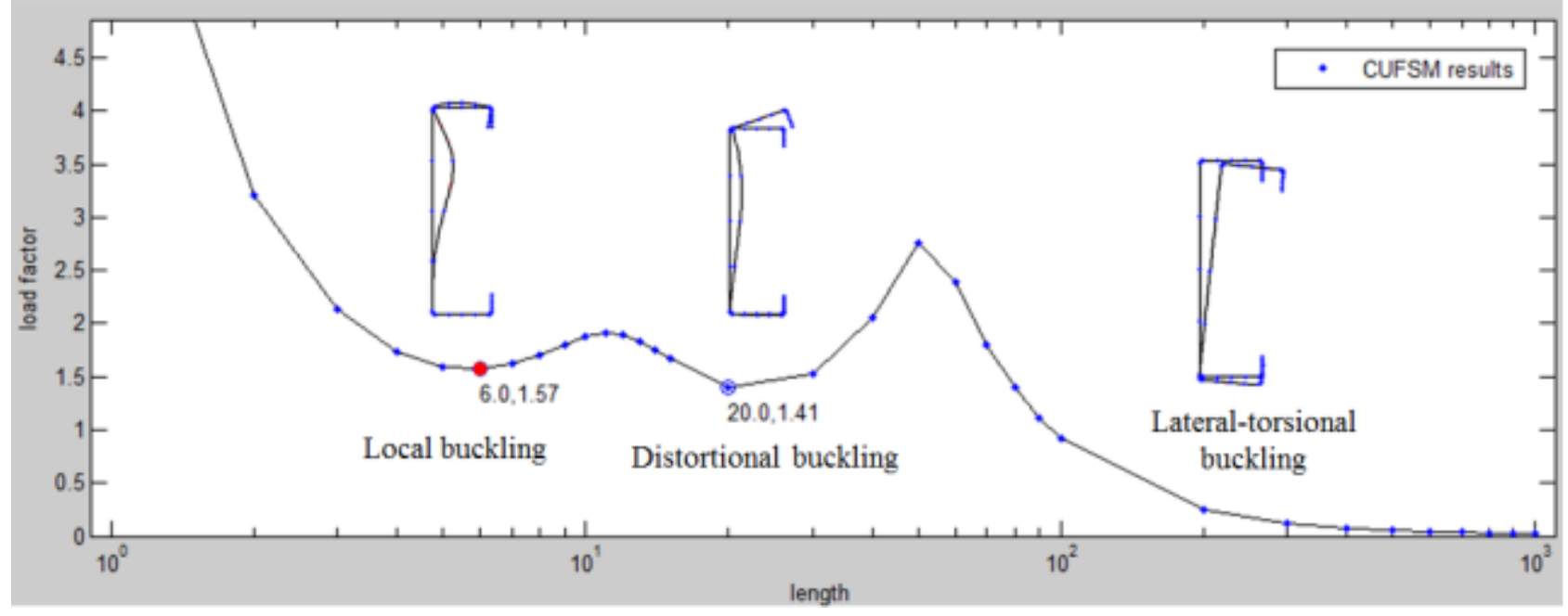

Figure F.6: View of buckling curve obtained from CUFSM for 1000S250-97 section 


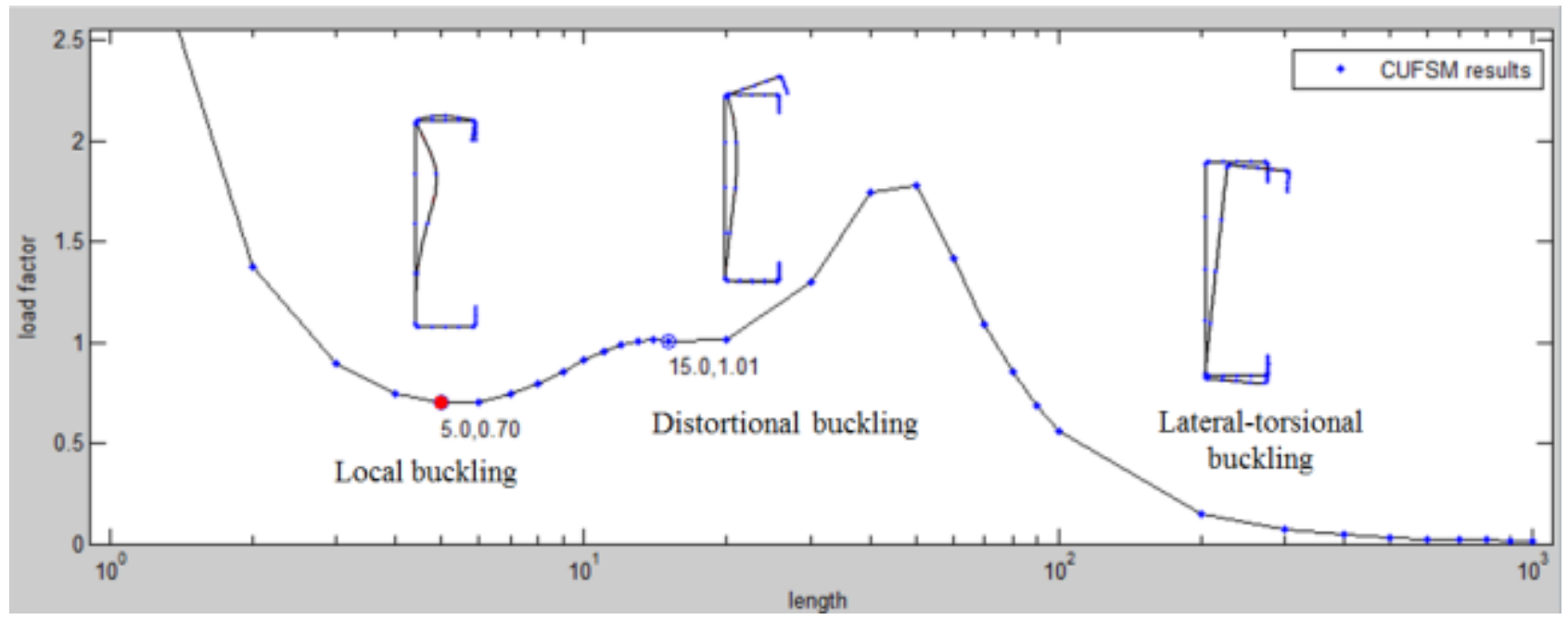

Figure F.7: View of buckling curve obtained from CUFSM for 1200S162-54 section

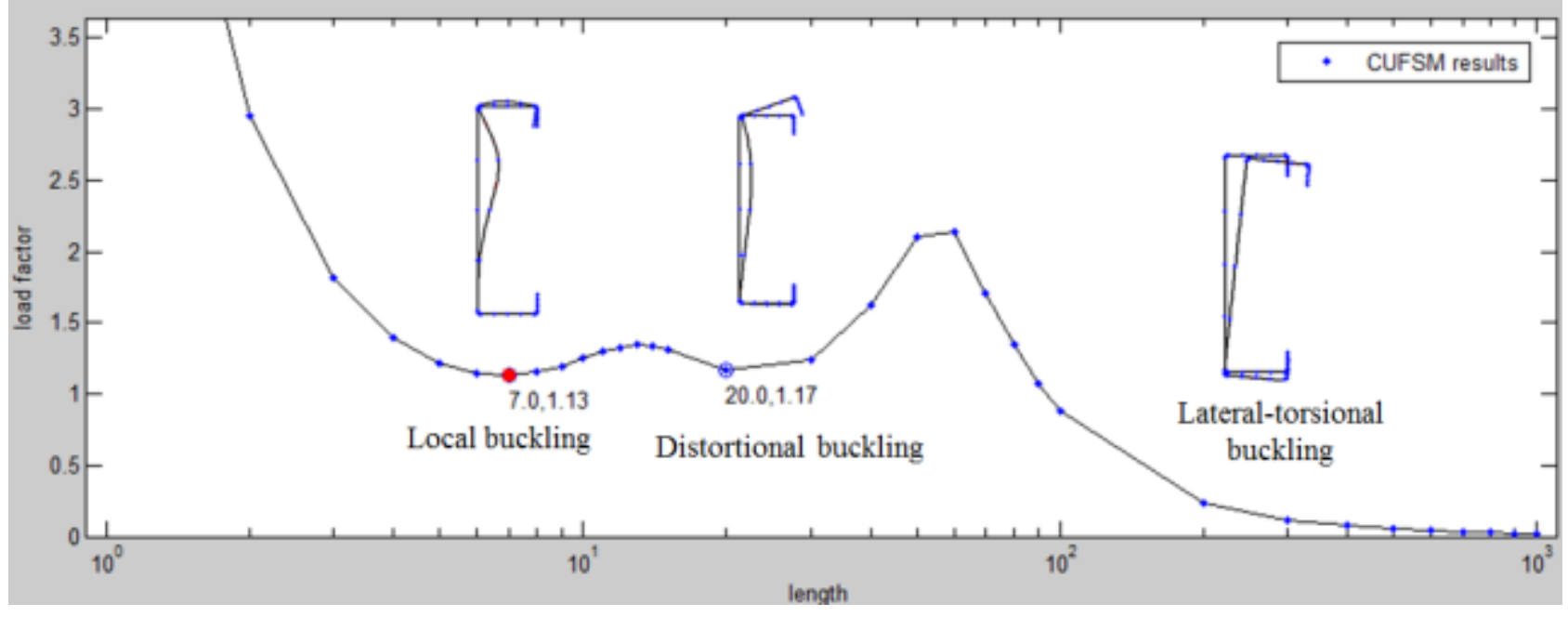

Figure F.8: View of buckling curve obtained from CUFSM for 1200S250-97 section 


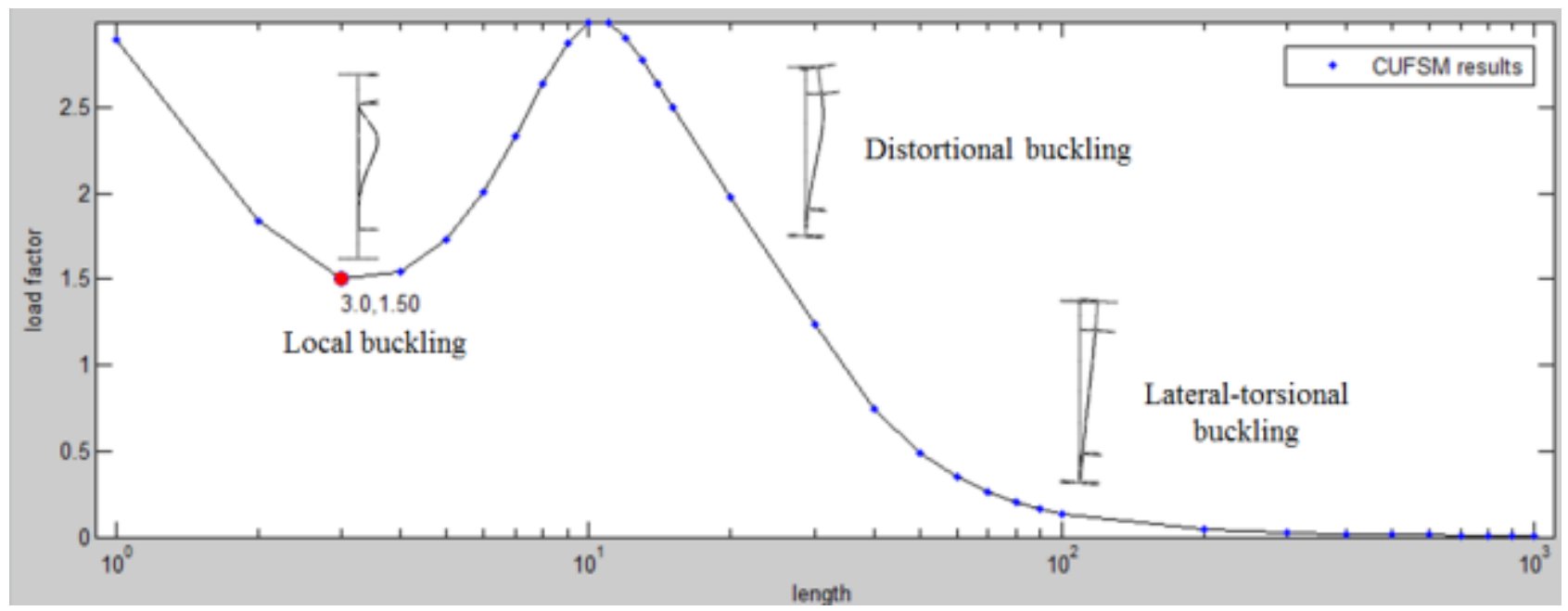

Figure F.9: View of buckling curve obtained from CUFSM for 254-i-2 section

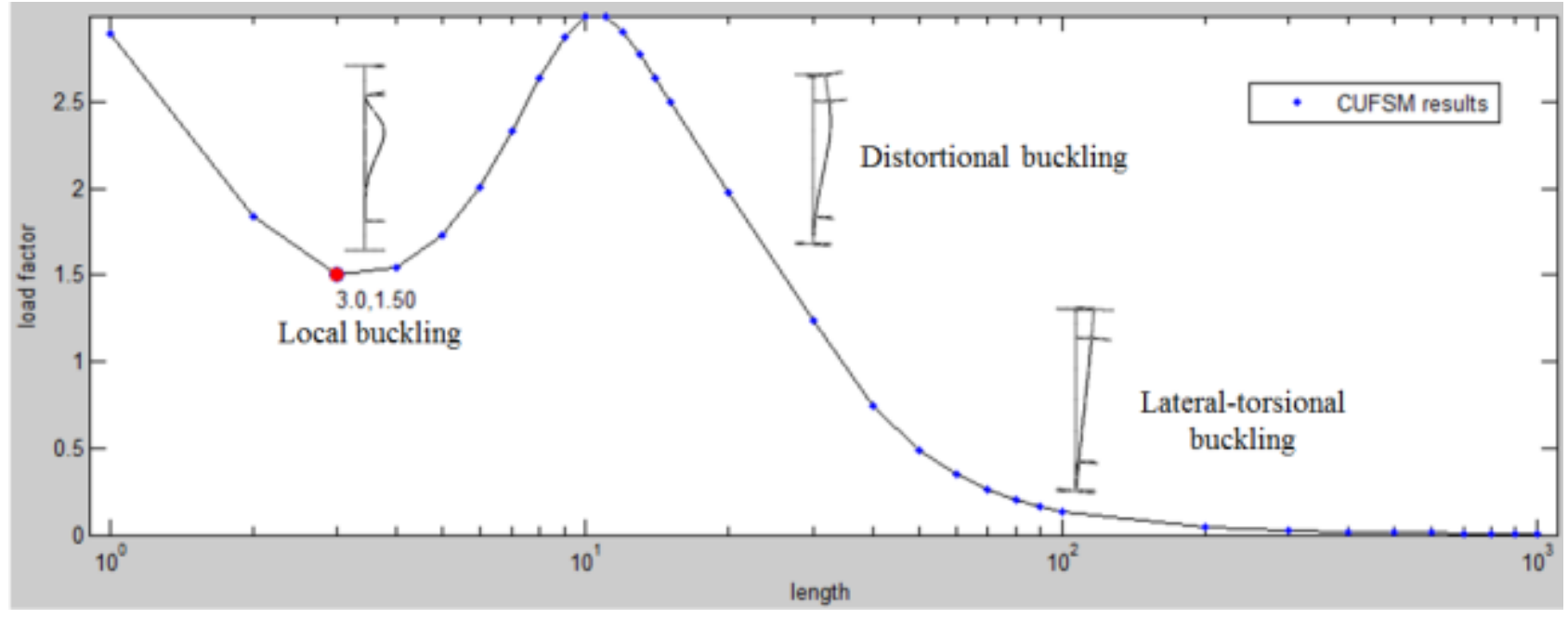

Figure F.10: View of buckling curve obtained from CUFSM for 254-i-3 section 


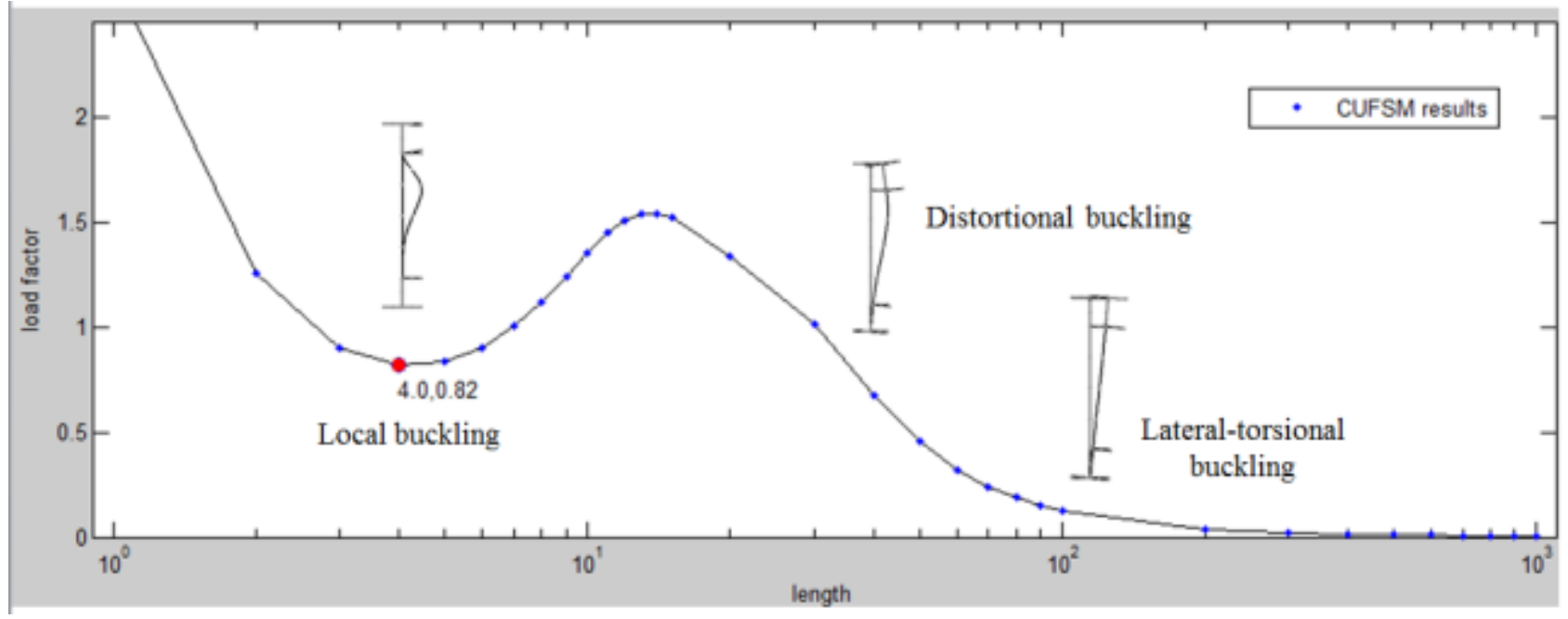

Figure F.11: View of buckling curve obtained from CUFSM for 305-i-2 section

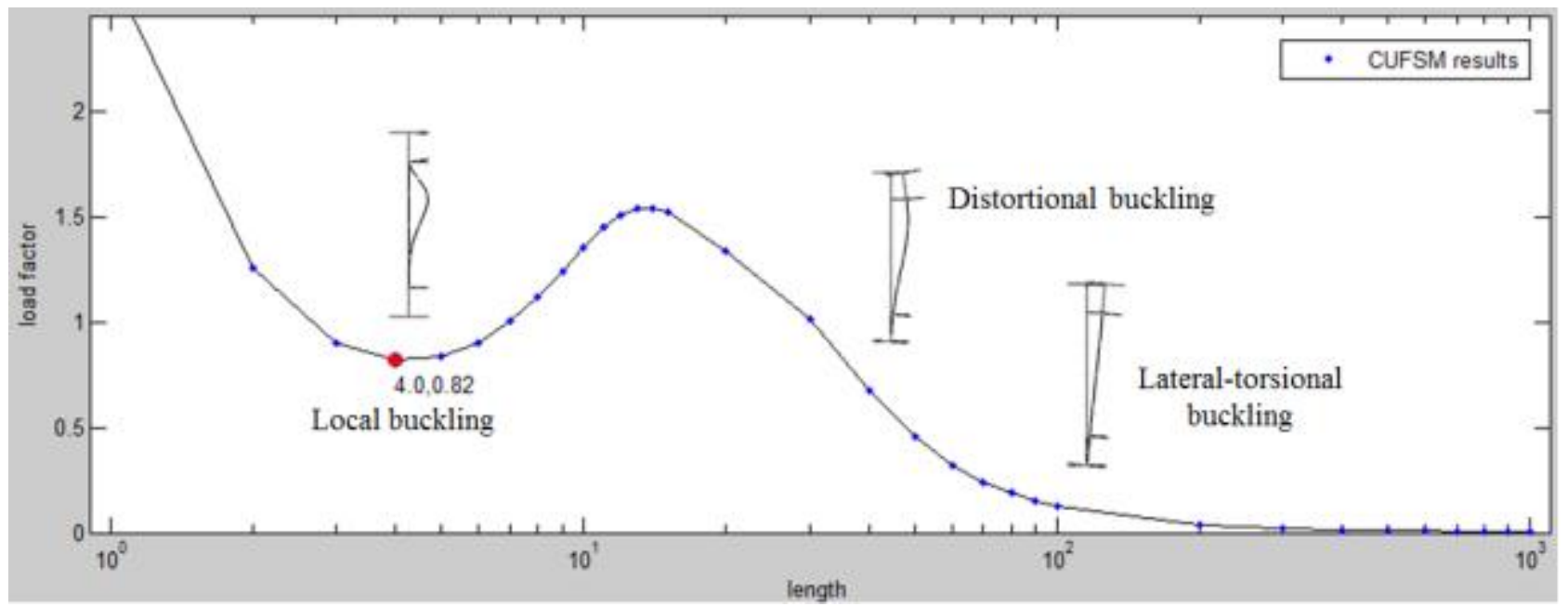

Figure F.12: View of buckling curve obtained from CUFSM for 305-i-3 section 


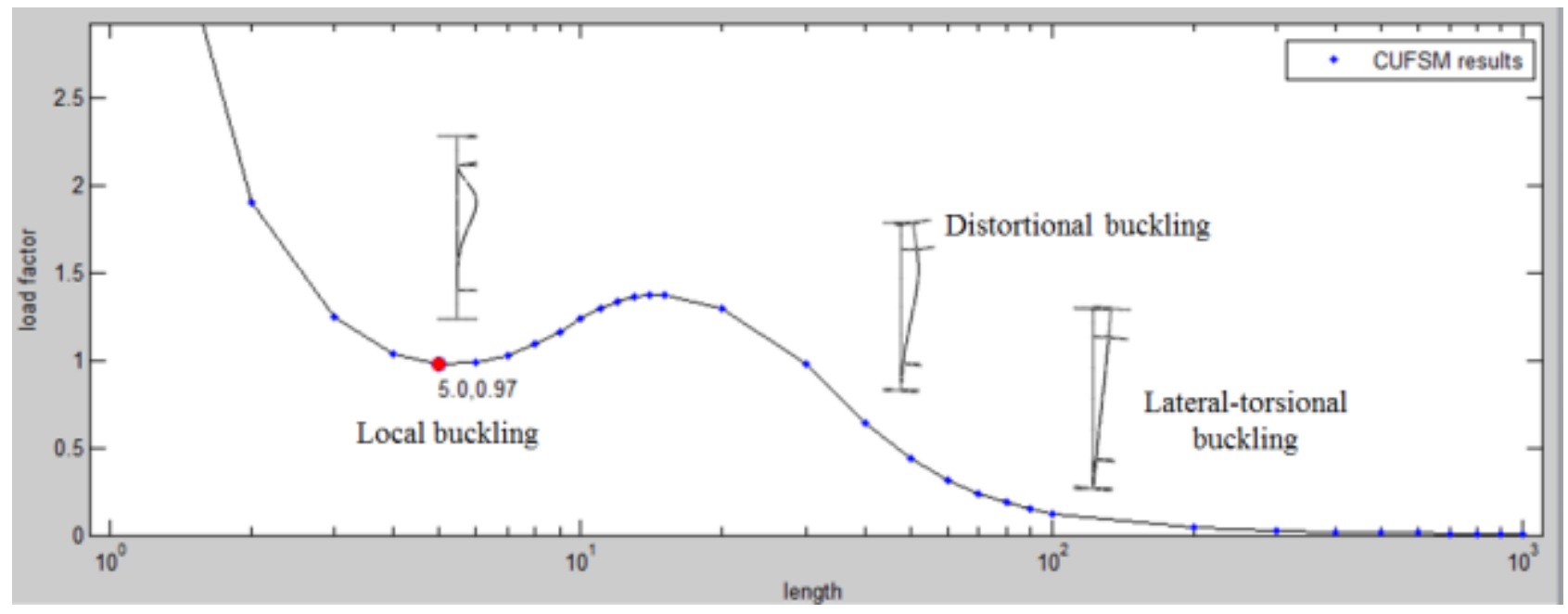

Figure F.13: View of buckling curve obtained from CUFSM for 355-i-3 section

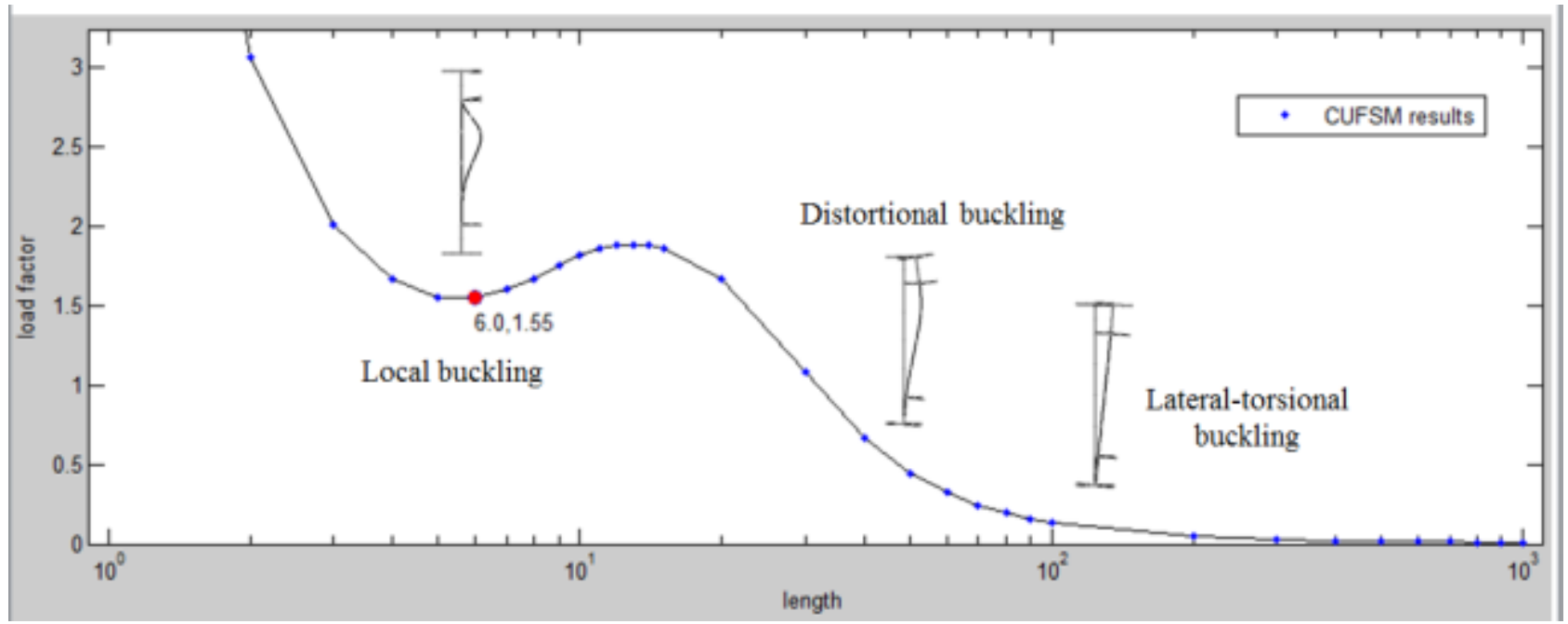

Figure F.14: View of buckling curve obtained from CUFSM for 355-i-4 section 


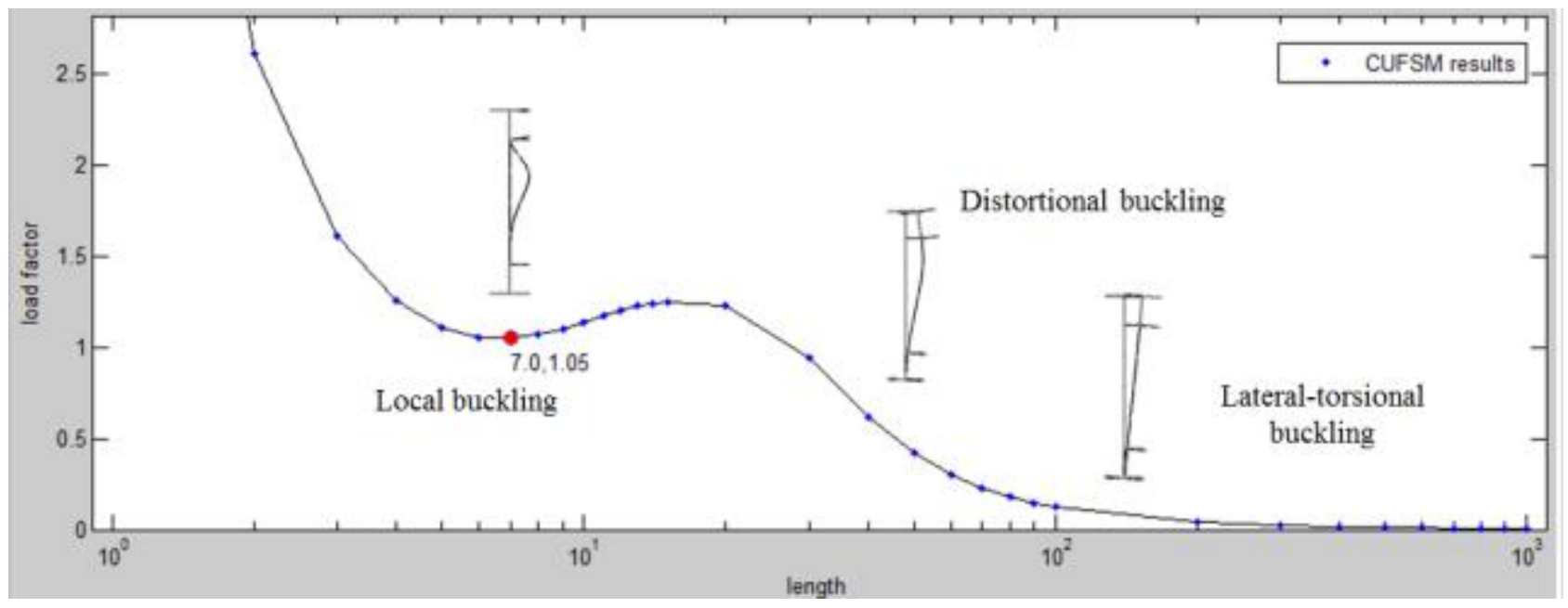

Figure F.15: View of buckling curve obtained from CUFSM for 406-i-3 section

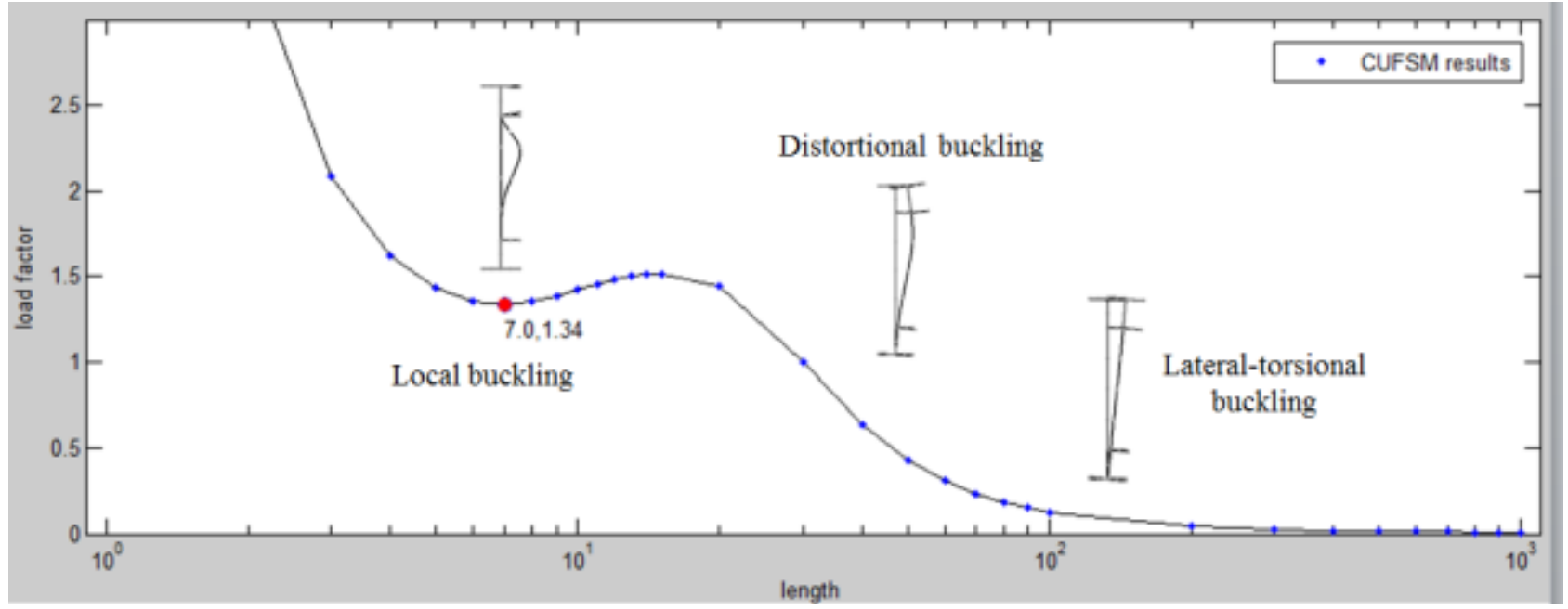

Figure F.16: View of buckling curve obtained from CUFSM for 406-i-4 section 


\section{APPENDIX G. VIEWS OF FAILURE MODES USING FEA MODELS FOR THE JOISTS}




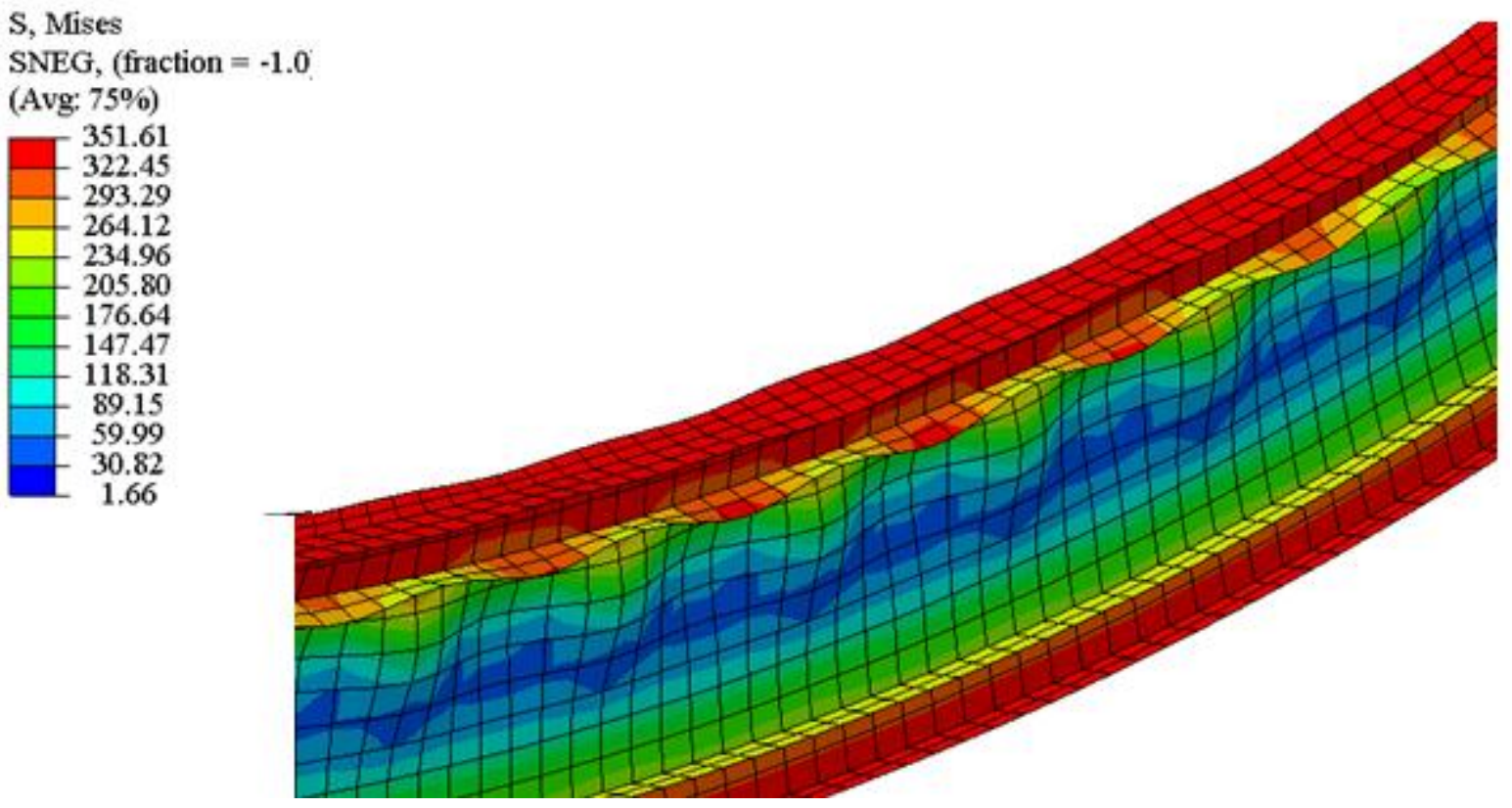

Figure G.1: View of a joist failed in local buckling of web and top lower flange of iSPAN joist 254-i-2 with no holes

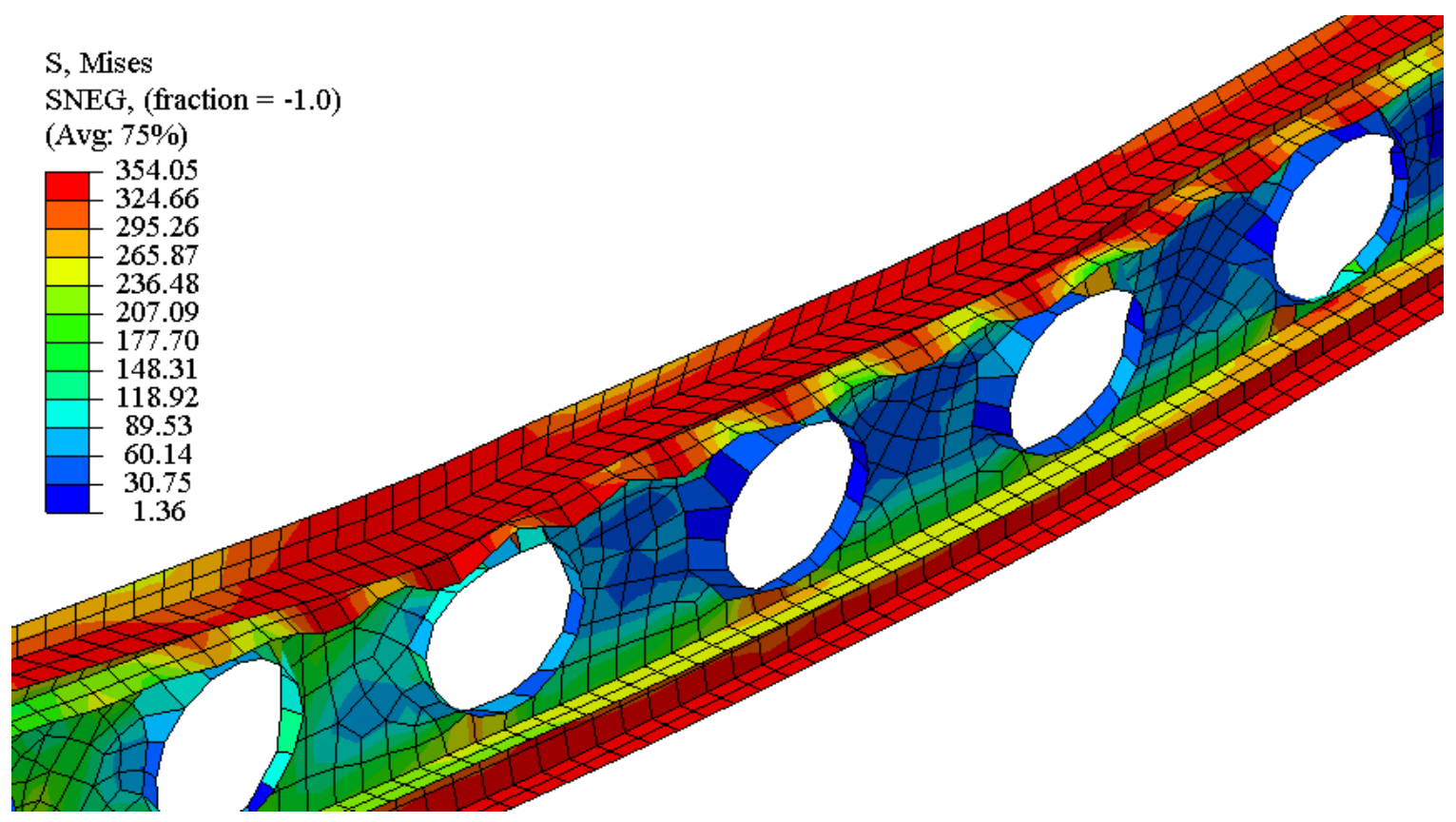

Figure G.2: View of a joist with stiffened hole failed in local buckling of top lower flange of iSPAN joist 254-i-2 with circular holes 


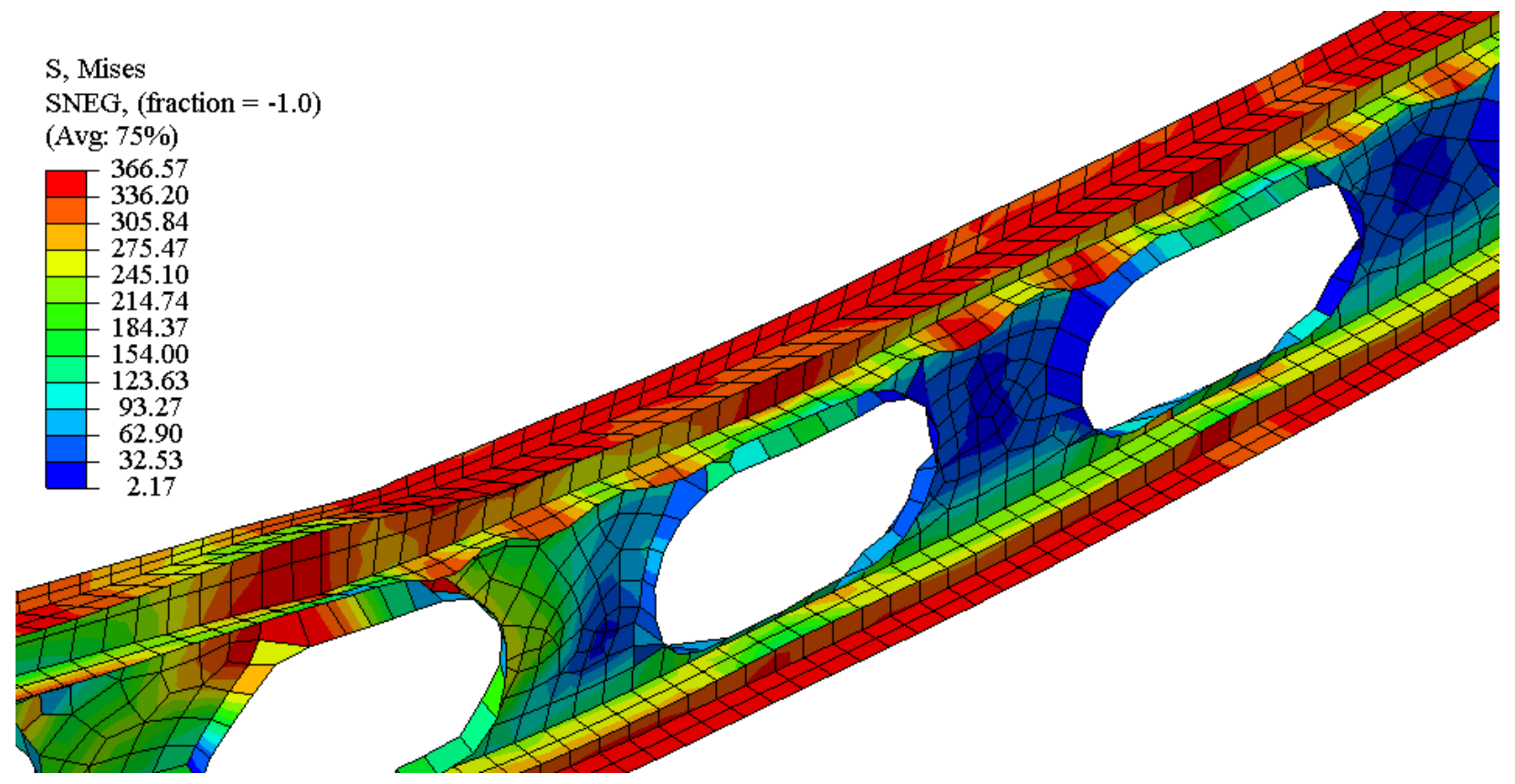

Figure G.3: View of a joist with stiffened hole failed in local buckling of top lower flange of iSPAN joist 254-i-2 with slotted holes

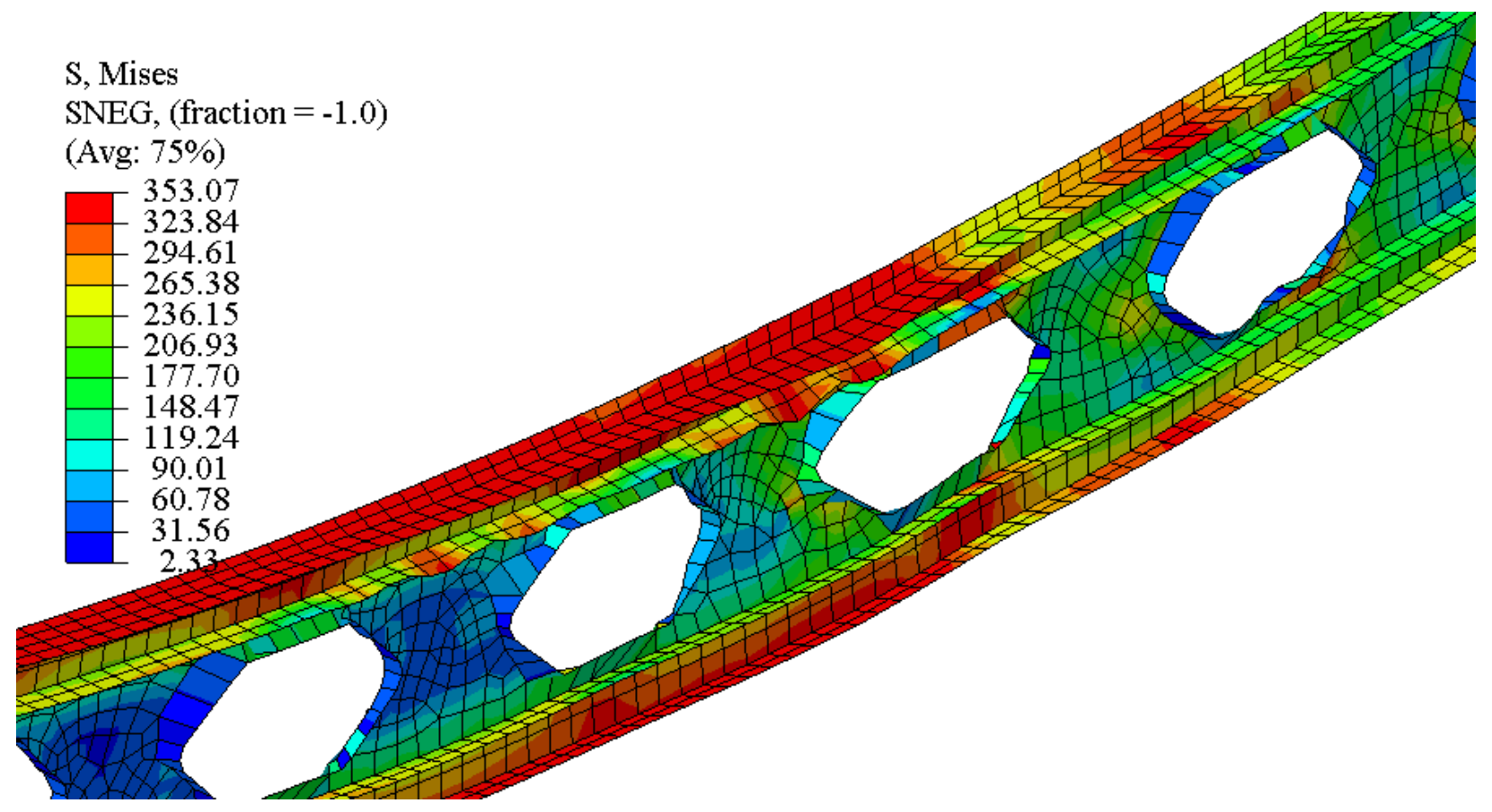

Figure G.4: View of a joist with stiffened hole failed in local buckling of top lower flange of iSPAN joist 254-i-2 with tri-slot holes 


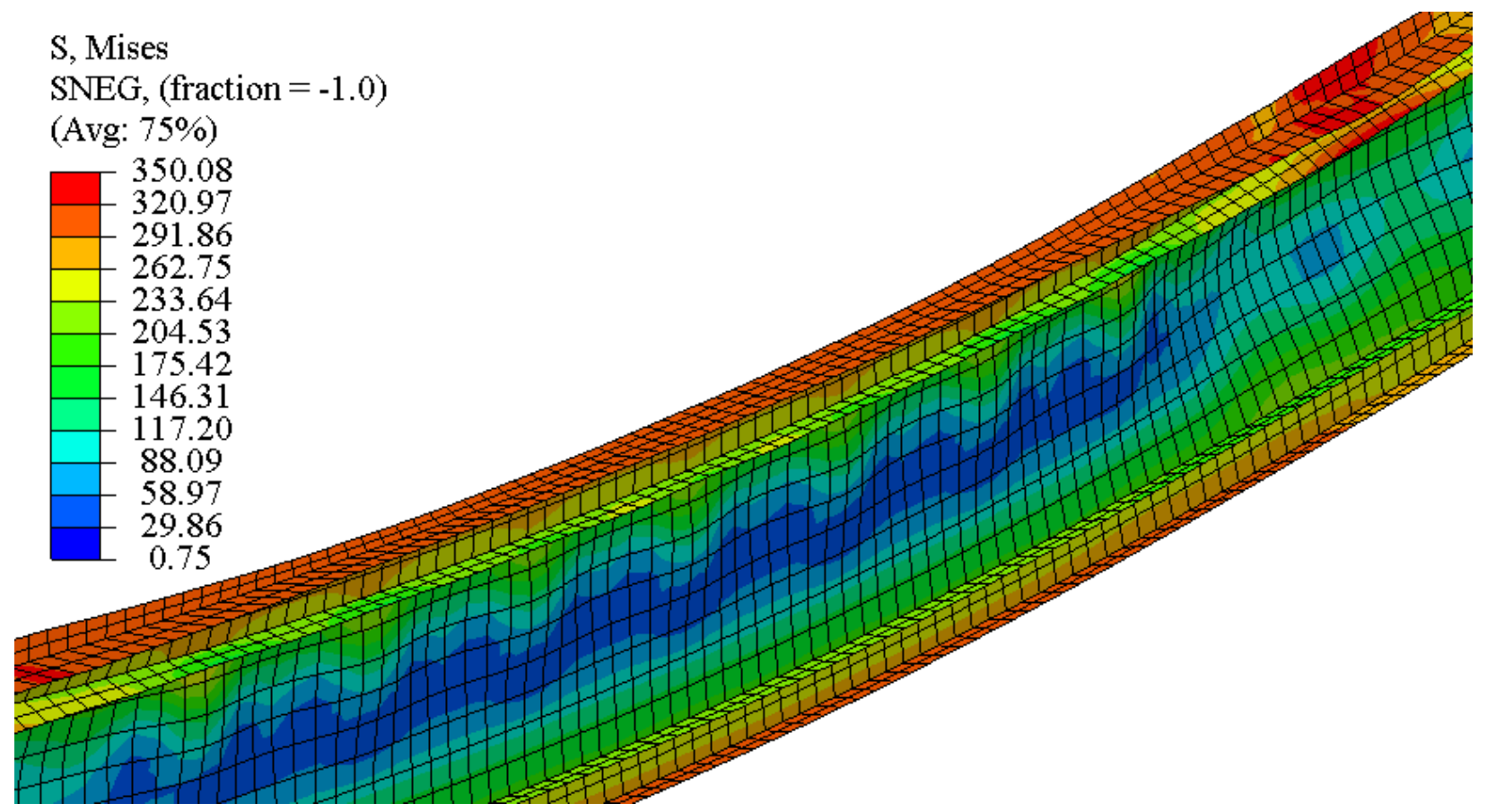

Figure G.5: View of a joist failed in local buckling of web of iSPAN joist 305-i-2 with no holes

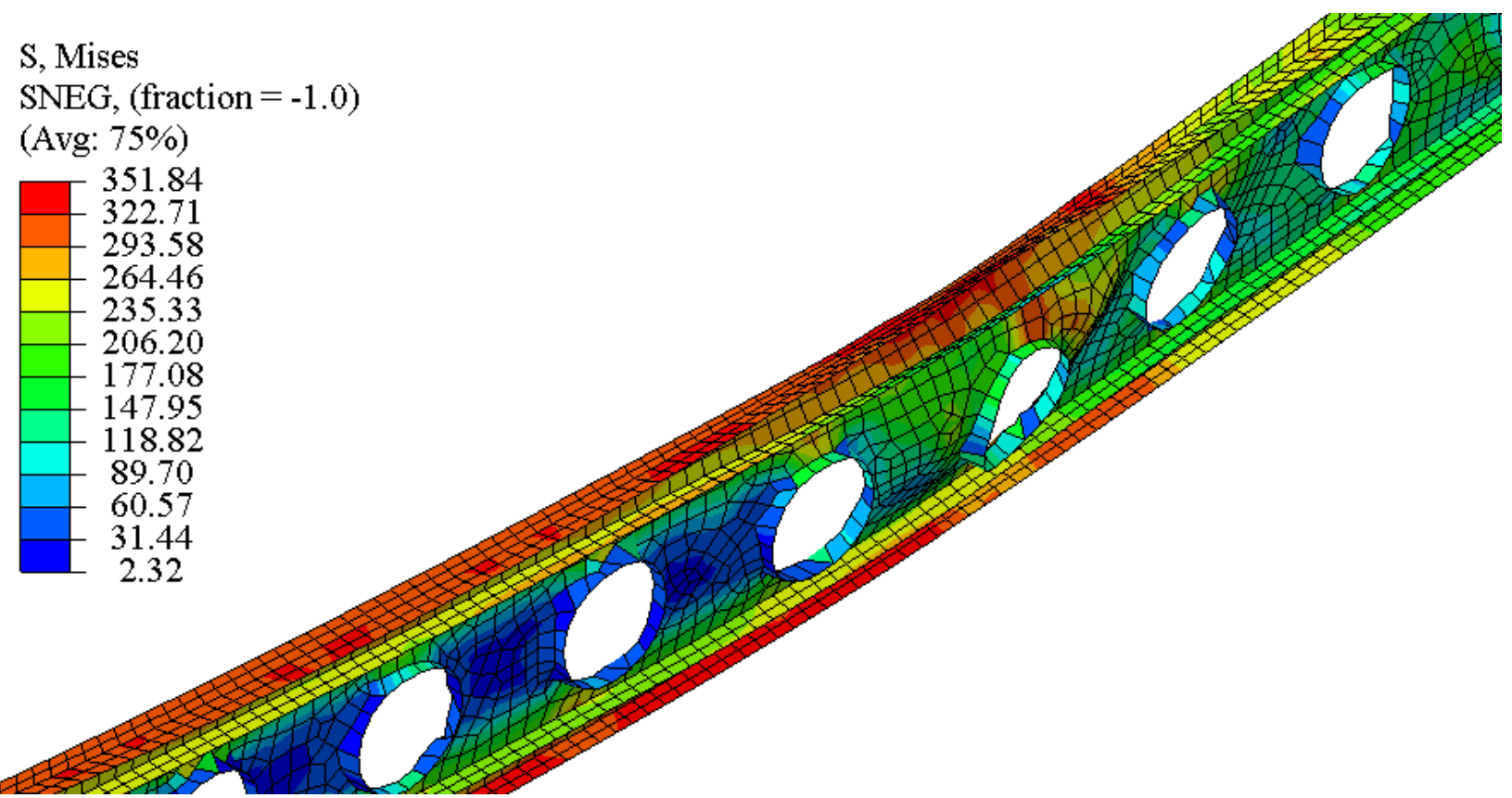

Figure G.6: View of a joist failed in distortion buckling of iSPAN joist 305-i-2 with circular holes 


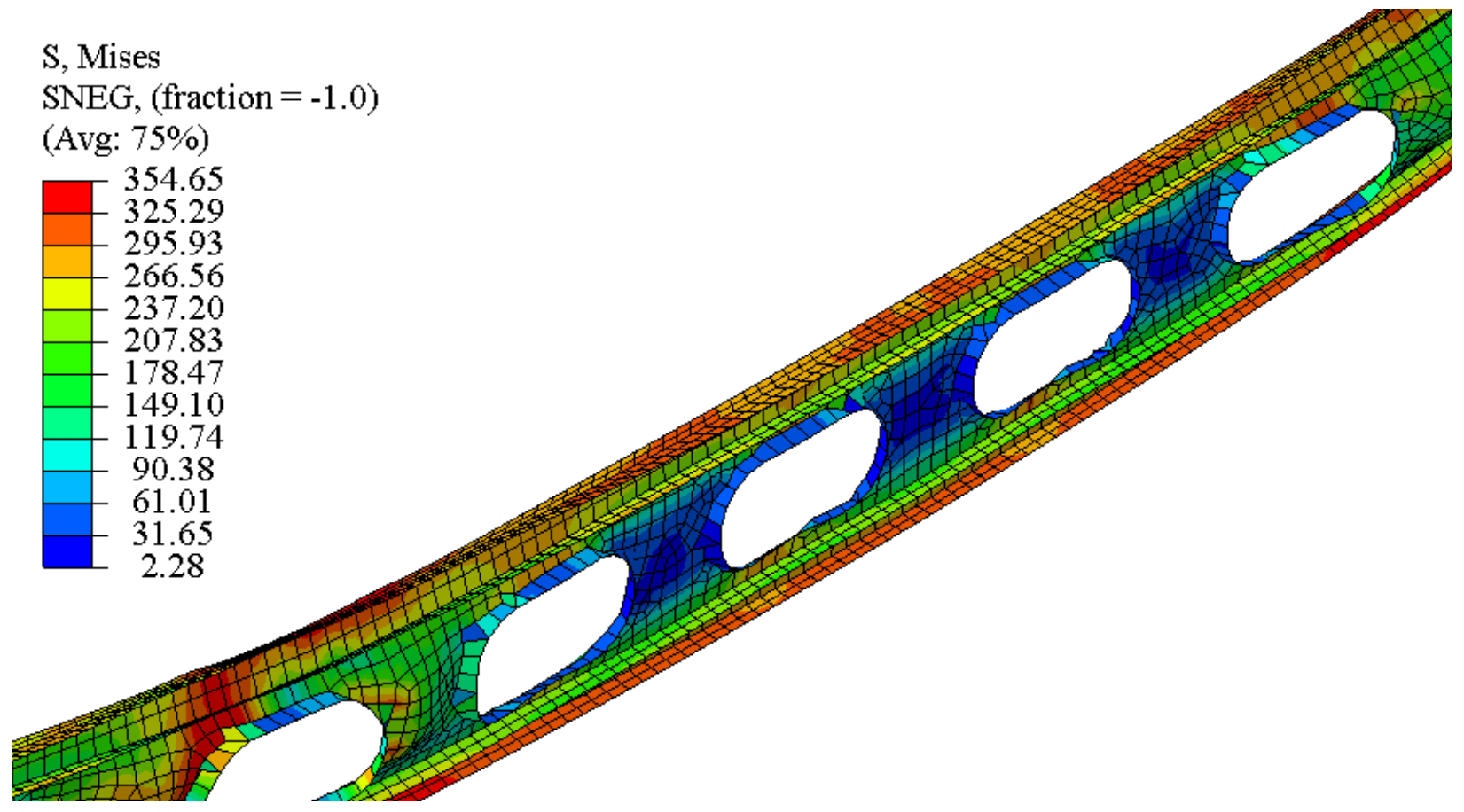

Figure G.7: View of a joist failed in distortion buckling of iSPAN joist 305-i-2 with slotted holes

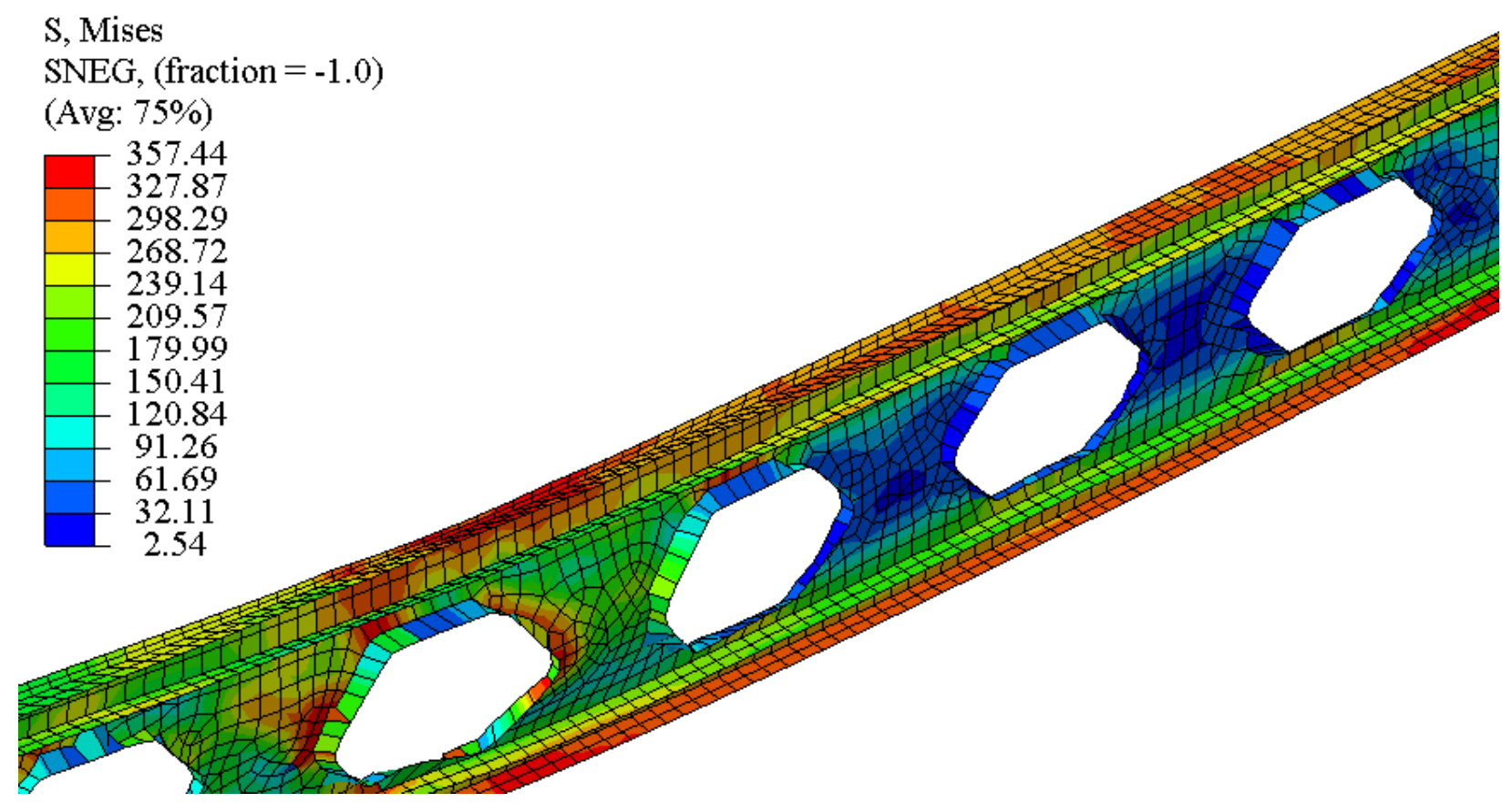

Figure G.8: View of a joist failed in distortion buckling of iSPAN joist 305-i-2 with tri-slot holes 


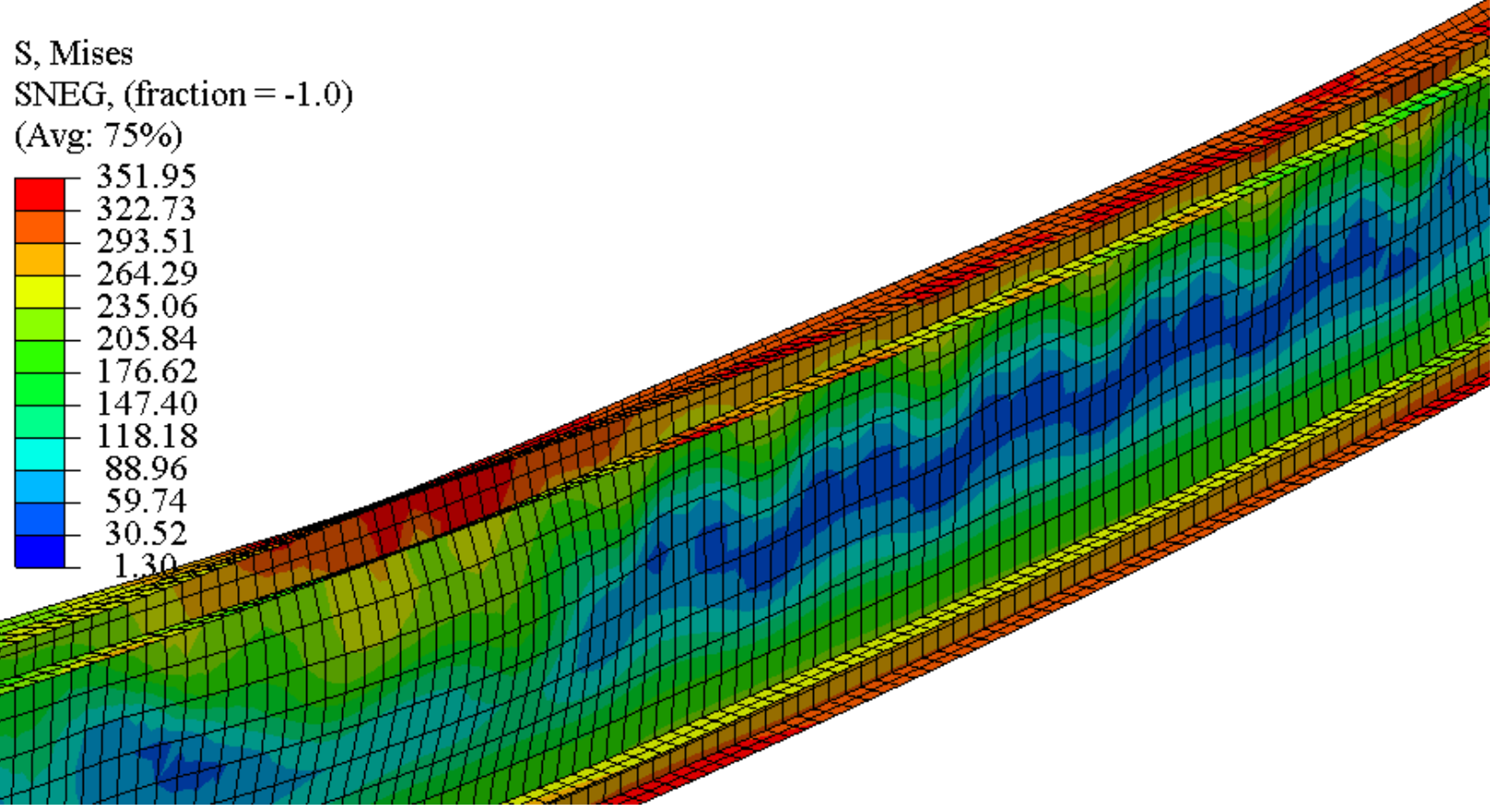

Figure G.9: View of a joist failed in distortion buckling of iSPAN joist 355-i-3 with no holes

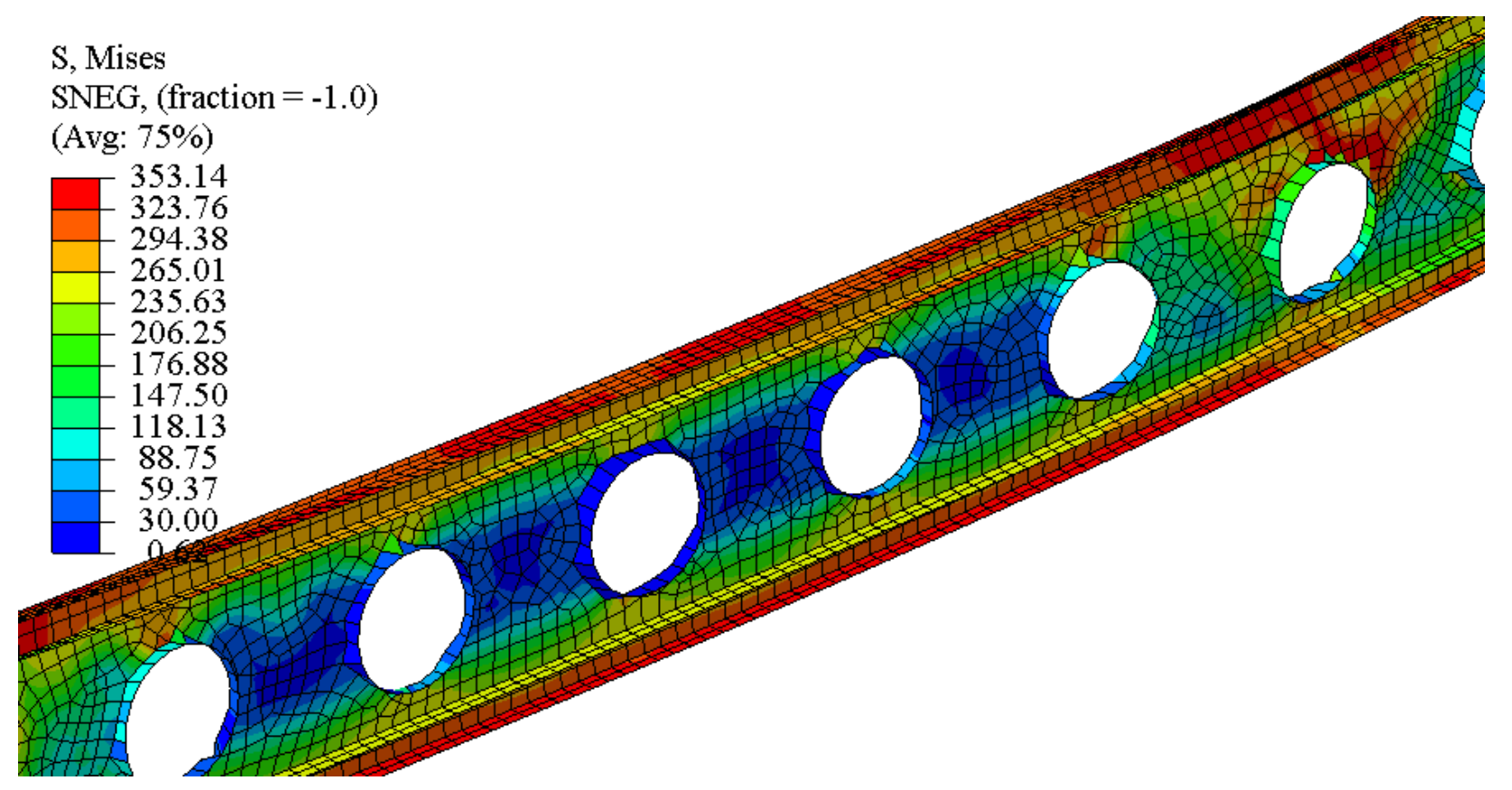

Figure G.10: View of a joist failed in distortion buckling of iSPAN joist 355-i-3 with circular holes 


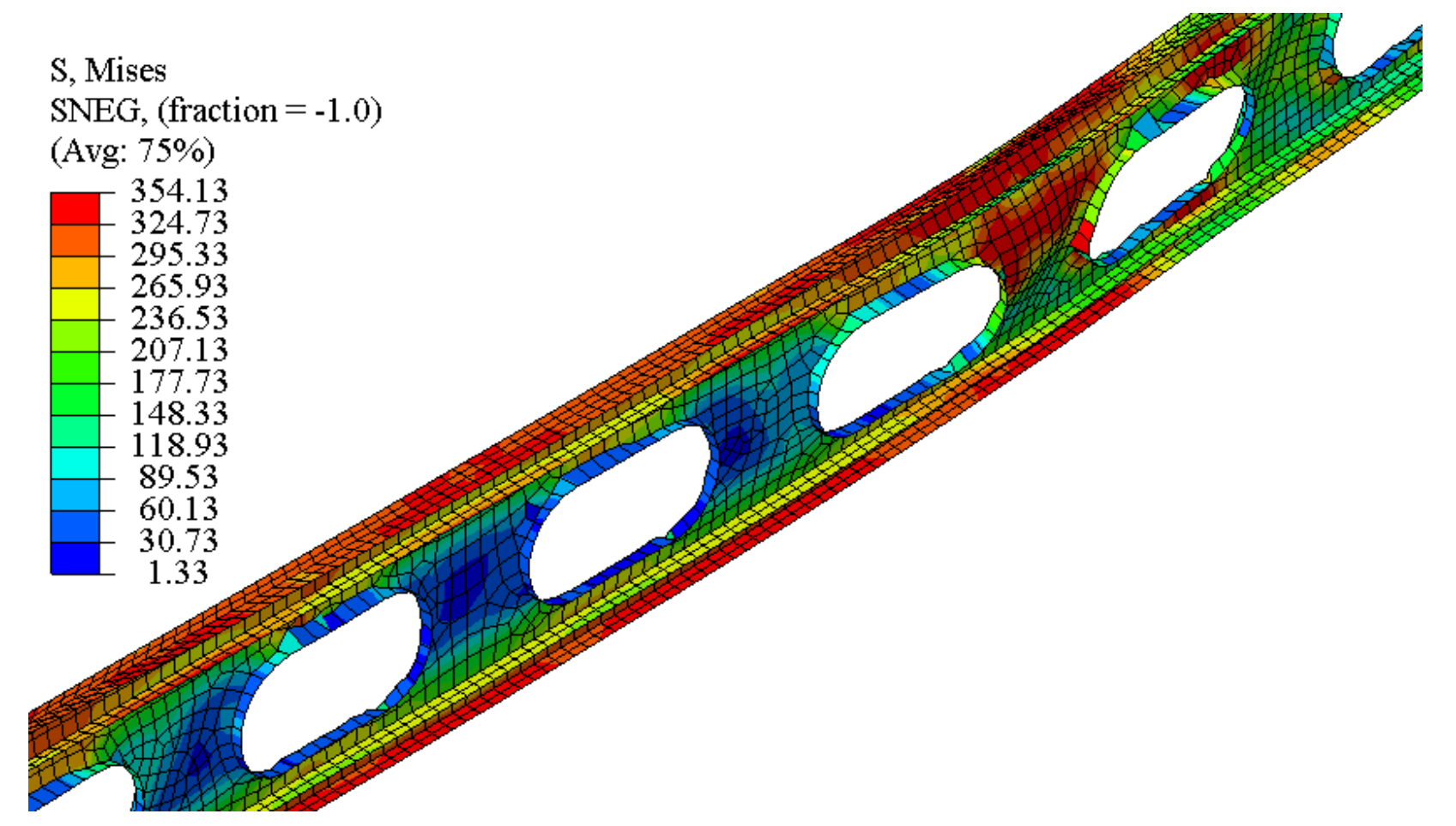

Figure G.11: View of a joist failed in distortion buckling of iSPAN joist 355-i-3 with slotted holes

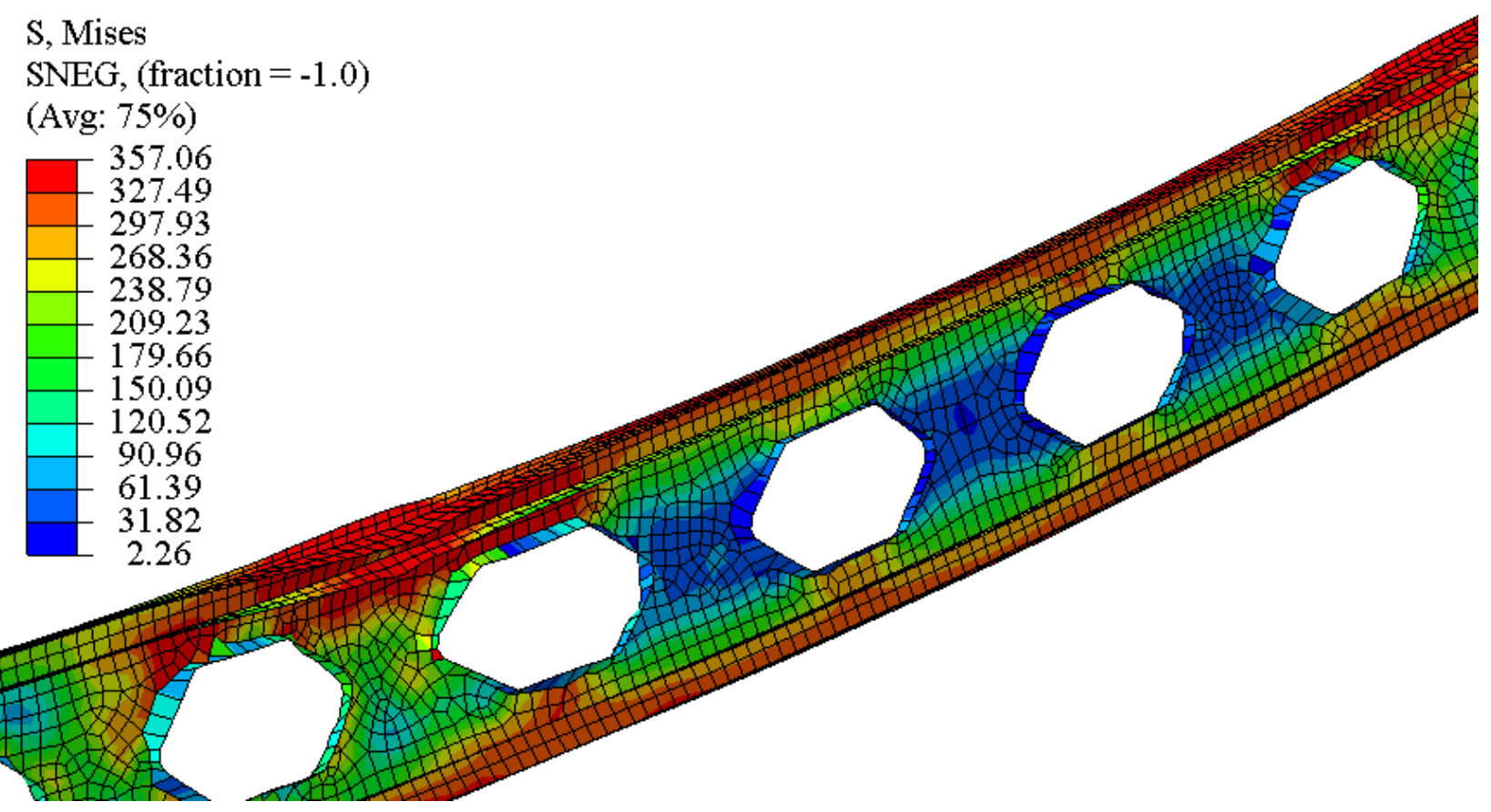

Figure G.12: View of a joist failed in distortion buckling of iSPAN joist 355-i-3 with tri-slot holes 


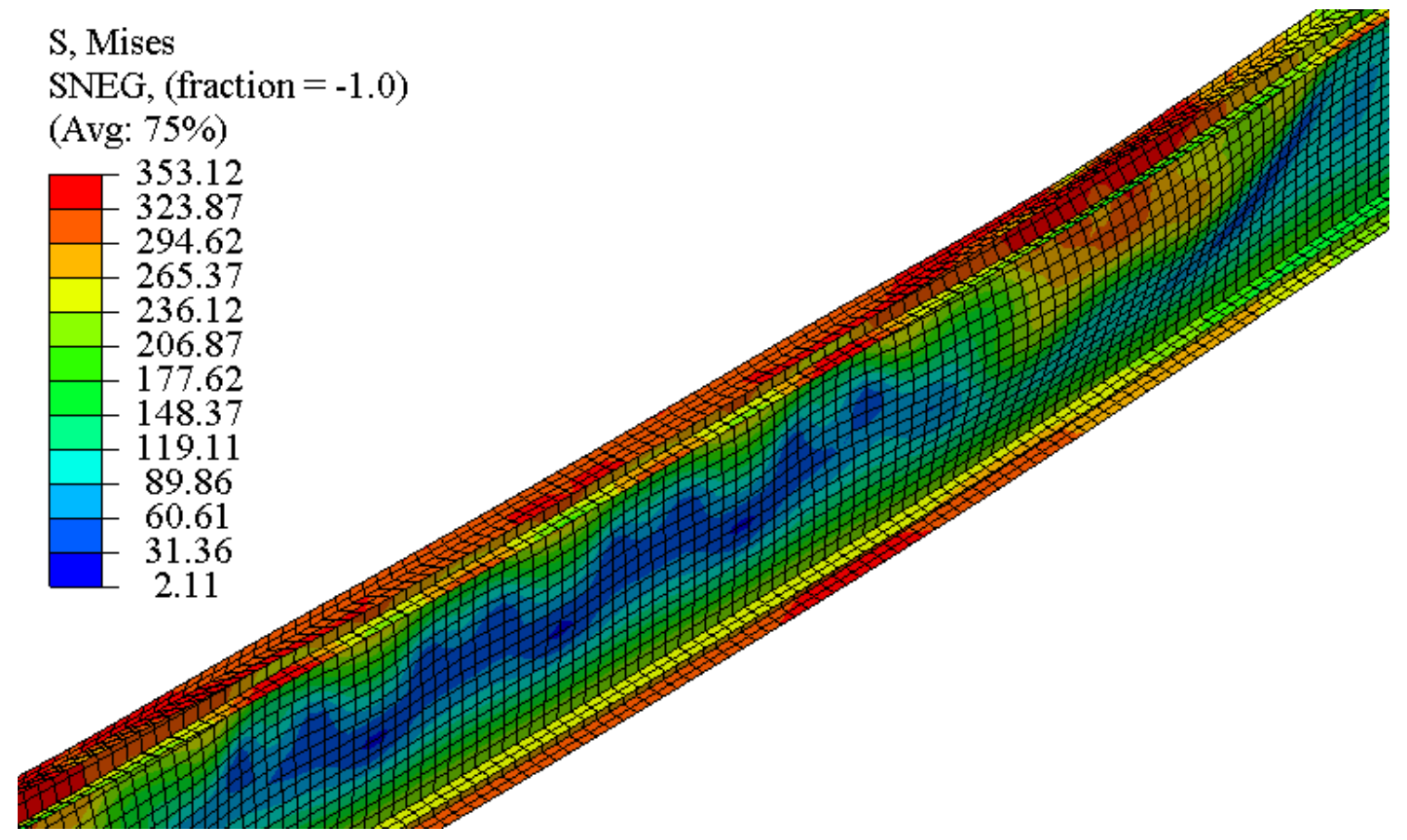

Figure G.13: View of a joist failed in distortion buckling of iSPAN joist 406-i-3 with no holes

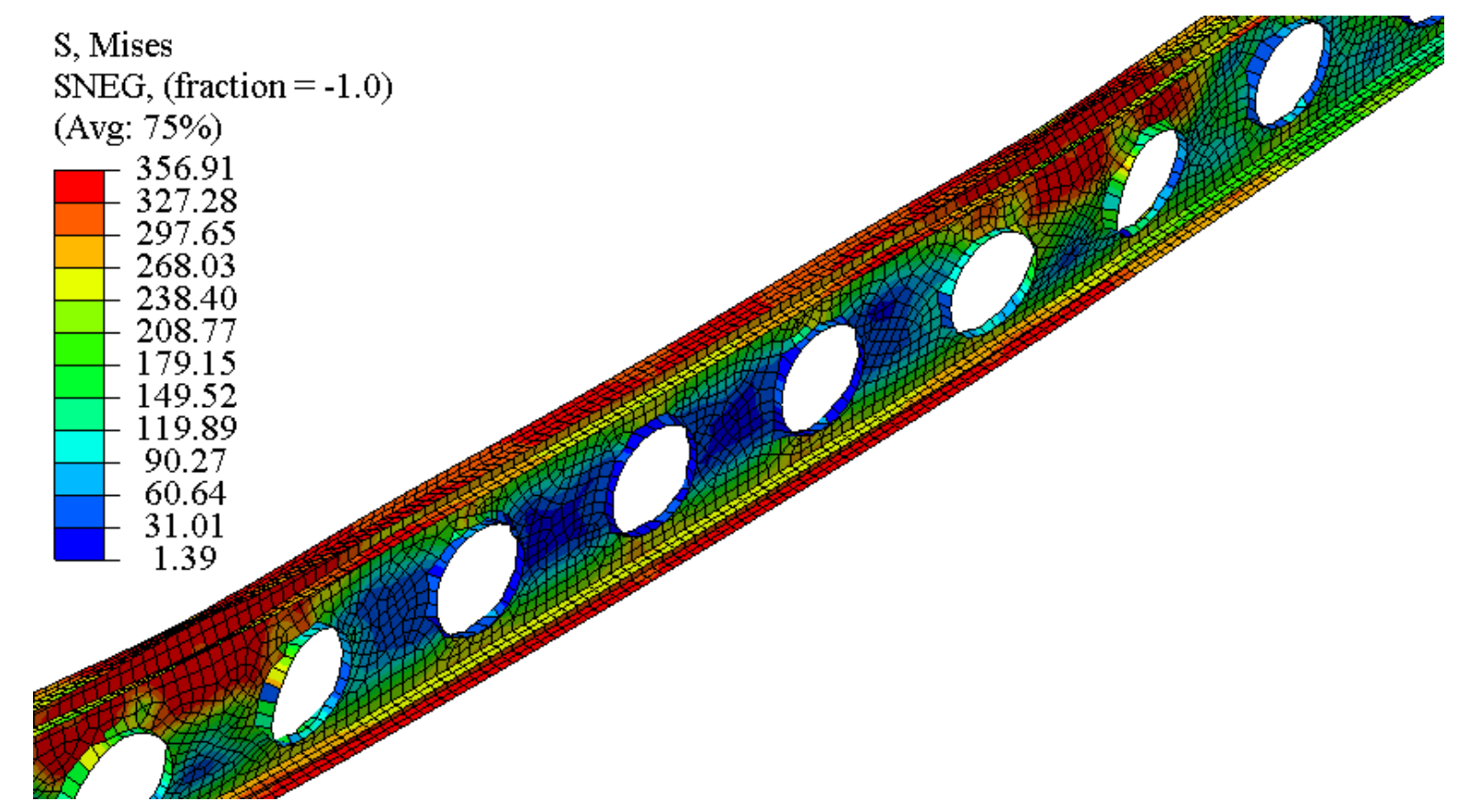

Figure G.14: View of a joist failed in distortion buckling of iSPAN joist 406-i-3 with circular holes 
$\mathrm{S}$, Mises

SNEG, $($ fraction $=-1.0$ )

(Avg: 75\%)

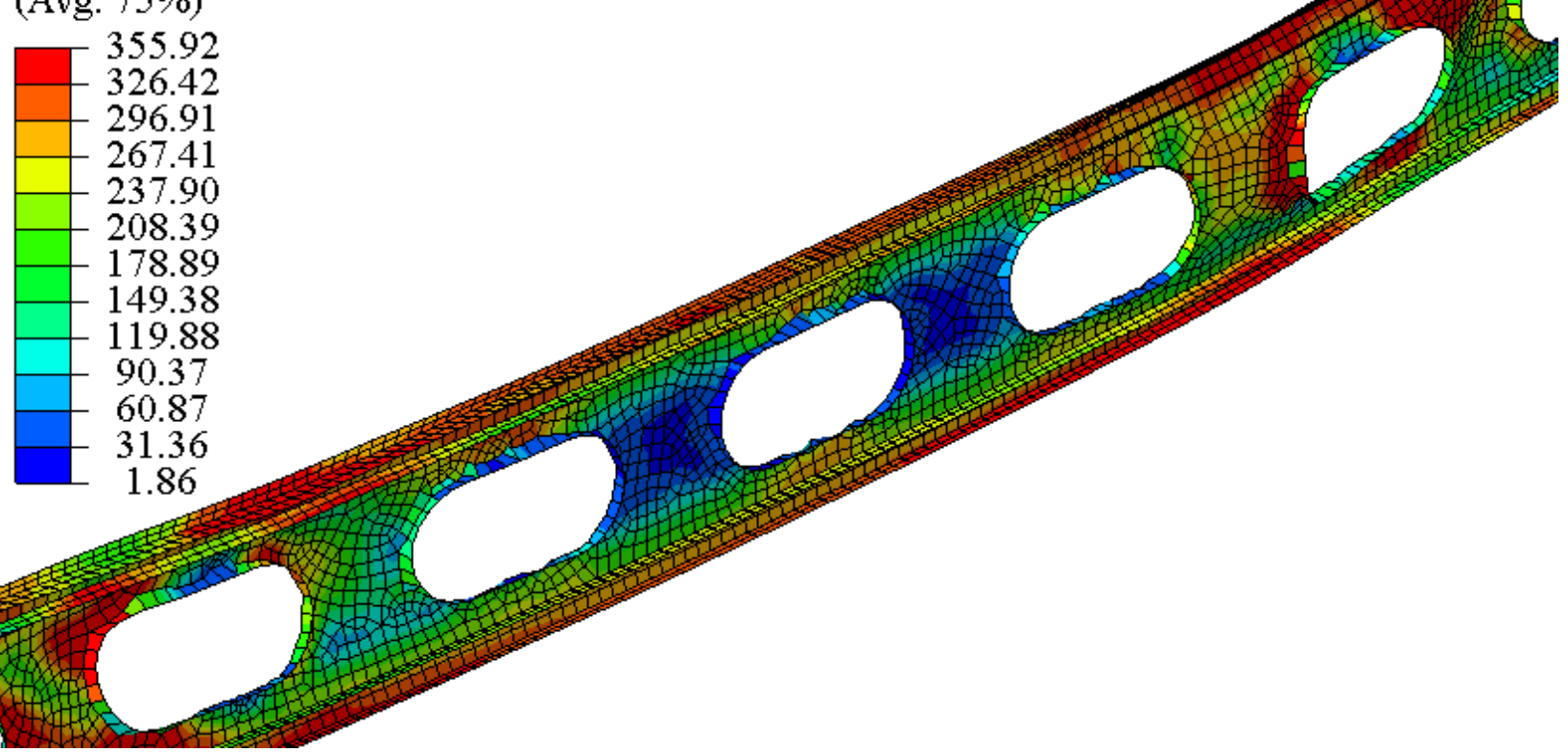

Figure G.15: View of a joist failed in distortion buckling of iSPAN joist 406-i-3 with slotted holes

$\mathrm{S}$, Mises

SNEG, (fraction $=-1.0$ )

(Avg: $75 \%$ )
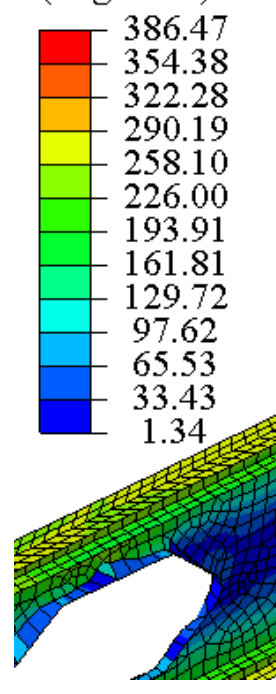

Figure G.16: View of a joist failed in distortion buckling of iSPAN joist 406-i-3 with tri-slotted holes 


\section{APPENDIX H: CALCULATIONS OF FLEXURAL RESISTANCE, STATIC POINT DEFLECTION UNDER 1-KN LOAD, AND FREQUENCY OF CFS iSPAN JOISTS AND WOODEN JOISTS}




\section{BEAM DESIGN BY DIRECT STRENGTH METHOD}

The nominal flexural strength resistance $M_{n}$, shall be the minimum of $M_{n e}, M_{n l}$, and $M_{n d}$ as given below.

a) For lateral torsional buckling

$\mathrm{M}_{\mathrm{ne}}=\frac{10}{9} M_{y}\left(1-\frac{10 M_{y}}{36 M_{\text {cre }}}\right)$

b) For local buckling

$\mathrm{M}_{\mathrm{nl}}=\left(1-0.15\left(\frac{\mathrm{M}_{\mathrm{crl}}}{\mathrm{M}_{\mathrm{ne}}}\right)^{0.4}\right)\left(\frac{\mathrm{M}_{\mathrm{crl}}}{\mathrm{M}_{\mathrm{ne}}}\right)^{0.4} \mathrm{M}_{\mathrm{ne}}$

c) For distortional buckling

$M_{n d}=\left(1-0.22\left(\frac{M_{c r d}}{M_{y}}\right)^{0.5}\right)\left(\frac{M_{c r d}}{M_{y}}\right)^{05} M_{y}$

Table H.1: Flexural strength of CFS iSPAN joists without hole by direct strength method

\begin{tabular}{|c|c|c|c|c|c|c|c|c|c|}
\hline $\begin{array}{c}\text { Joist } \\
\text { depth } \\
(\mathrm{mm})\end{array}$ & $\begin{array}{c}\text { Joist } \\
\text { length } \\
(\mathrm{m})\end{array}$ & $\begin{array}{c}\mathrm{M}_{\mathrm{y}} \\
(\mathrm{Mpa})\end{array}$ & $\begin{array}{c}\mathrm{M}_{\mathrm{cre}} \\
(\mathrm{kN}- \\
\mathrm{m})\end{array}$ & $\begin{array}{c}\mathrm{M}_{\mathrm{crl}} \\
(\mathrm{kN}- \\
\mathrm{m})\end{array}$ & $\begin{array}{c}\mathrm{M}_{\mathrm{crd}} \\
(\mathrm{kN}- \\
\mathrm{m})\end{array}$ & $\begin{array}{c}\mathrm{M}_{\mathrm{ne}} \\
(\mathrm{kN}- \\
\mathrm{m})\end{array}$ & $\begin{array}{c}\mathrm{M}_{\mathrm{nl}} \\
(\mathrm{kN}- \\
\mathrm{m})\end{array}$ & $\begin{array}{c}\mathrm{M}_{\mathrm{nd}} \\
(\mathrm{kN}- \\
\mathrm{m})\end{array}$ & $\begin{array}{c}\mathrm{M}_{\mathrm{n}} \\
(\mathrm{kN}- \\
\mathrm{m})\end{array}$ \\
\hline 241 & 3.50 & 16.73 & 8.70 & 22.25 & 21.91 & 8.70 & 8.70 & 14.32 & 8.70 \\
\hline 241 & 4.50 & 16.73 & 8.70 & 22.25 & 21.91 & 8.70 & 8.70 & 14.32 & 8.70 \\
\hline 302 & 5.00 & 24.01 & 10.81 & 19.69 & 24.25 & 10.81 & 10.81 & 18.80 & 8.70 \\
\hline 302 & 5.25 & 24.01 & 10.81 & 19.69 & 24.25 & 10.81 & 10.81 & 18.80 & 8.70 \\
\hline 406 & 6.10 & 29.61 & 8.88 & 15.40 & 22.80 & 8.88 & 8.88 & 20.97 & 8.88 \\
\hline 406 & 7.95 & 48.93 & 14.19 & 32.30 & 38.66 & 14.19 & 14.19 & 35.00 & 14.19 \\
\hline
\end{tabular}

Table H.2: Flexural strength of CFS iSPAN joists with holes by direct strength method

\begin{tabular}{|c|c|c|c|c|c|c|c|c|c|}
\hline $\begin{array}{c}\text { Joist } \\
\text { depth } \\
(\mathrm{mm})\end{array}$ & $\begin{array}{c}\text { Joist } \\
\text { length } \\
(\mathrm{m})\end{array}$ & $\begin{array}{c}\mathrm{M}_{\mathrm{y}} \\
(\mathrm{Mpa})\end{array}$ & $\begin{array}{c}\mathrm{M}_{\text {cre }} \\
(\mathrm{kN}- \\
\mathrm{m})\end{array}$ & $\begin{array}{c}\mathrm{M}_{\mathrm{crl}} \\
(\mathrm{kN}- \\
\mathrm{m})\end{array}$ & $\begin{array}{c}\mathrm{M}_{\mathrm{crd}} \\
(\mathrm{kN}- \\
\mathrm{m})\end{array}$ & $\begin{array}{c}\mathrm{M}_{\mathrm{ne}} \\
(\mathrm{kN}- \\
\mathrm{m})\end{array}$ & $\begin{array}{c}\mathrm{M}_{\mathrm{nl}} \\
(\mathrm{kN}- \\
\mathrm{m})\end{array}$ & $\begin{array}{c}\mathrm{M}_{\mathrm{nd}} \\
(\mathrm{kN}- \\
\mathrm{m})\end{array}$ & $\begin{array}{c}\mathrm{M}_{\mathrm{n}} \\
(\mathrm{kN}- \\
\mathrm{m})\end{array}$ \\
\hline 254 & 3.50 & 18.78 & 9.20 & 28.17 & 23.10 & 9.20 & 9.20 & 15.74 & 9.20 \\
\hline 254 & 4.50 & 18.78 & 9.20 & 28.17 & 23.10 & 9.20 & 9.20 & 15.74 & 9.20 \\
\hline 302 & 5.00 & 24.01 & 10.81 & 19.69 & 24.25 & 10.81 & 10.81 & 18.80 & 8.70 \\
\hline 302 & 5.25 & 24.01 & 10.81 & 19.69 & 24.25 & 10.81 & 10.81 & 18.80 & 8.70 \\
\hline
\end{tabular}


Table H.3: Flexural strength of CFS iSPAN joists without hole by effective width method

\begin{tabular}{|c|c|c|c|c|c|}
\hline $\begin{array}{c}\text { Joist } \\
\text { depth } \\
(\mathrm{mm})\end{array}$ & $\begin{array}{c}\text { Joist length } \\
(\mathrm{m})\end{array}$ & $\mathrm{S}_{\mathrm{xe}}\left(\mathrm{mm}^{\wedge} 3\right)$ & $\begin{array}{c}\mathrm{F}_{\mathrm{y}} \\
(\mathrm{Mpa})\end{array}$ & $\begin{array}{c}\mathrm{M}=\mathrm{F}_{\mathrm{y}} \mathrm{x} \\
\mathrm{S}_{\mathrm{xe}}(\mathrm{kN}-\mathrm{m})\end{array}$ & $\mathrm{P}_{\mathrm{n}}(\mathrm{kN})$ \\
\hline 241 & 3.50 & 45392.17 & 350.00 & 15.89 & 19.89 \\
\hline 241 & 4.50 & 45392.17 & 350.00 & 15.89 & 15.47 \\
\hline 302 & 5.00 & 59157.30 & 350.00 & 20.71 & 17.30 \\
\hline 302 & 5.25 & 59157.30 & 350.00 & 20.71 & 16.47 \\
\hline 356 & 6.10 & 71447.60 & 350.00 & 25.01 & 11.65 \\
\hline 406 & 7.95 & 108154.62 & 280.00 & 30.28 & 14.28 \\
\hline
\end{tabular}

Table H.4: Flexural strength of CFS iSPAN joists with hole by effective width method

\begin{tabular}{|c|c|c|c|c|c|}
\hline $\begin{array}{c}\text { Joist } \\
\text { depth } \\
(\mathrm{mm})\end{array}$ & $\begin{array}{c}\text { Joist length } \\
(\mathrm{m})\end{array}$ & $\mathrm{S}_{\mathrm{xe}}\left(\mathrm{mm}^{\wedge} 3\right)$ & $\begin{array}{c}\mathrm{F}_{\mathrm{y}} \\
(\mathrm{Mpa})\end{array}$ & $\begin{array}{c}\mathrm{M}=\mathrm{F}_{\mathrm{y}} \mathrm{x} \\
\mathrm{S}_{\mathrm{xe}}(\mathrm{kN}-\mathrm{m})\end{array}$ & $\mathrm{P}_{\mathrm{n}}(\mathrm{kN})$ \\
\hline 254 & 3.50 & 47358.61 & 350.00 & 16.58 & 19.89 \\
\hline 254 & 4.50 & 47358.61 & 350.00 & 16.58 & 15.47 \\
\hline 302 & 5.00 & 59157.30 & 350.00 & 20.71 & 17.30 \\
\hline 302 & 5.25 & 59157.30 & 350.00 & 20.71 & 16.47 \\
\hline
\end{tabular}

Table H.5: Flexural strength of CFS iSPAN joists without hole by effective width method (LTB)

\begin{tabular}{|c|c|c|c|c|c|}
\hline $\begin{array}{c}\text { Joist } \\
\text { depth } \\
(\mathrm{mm})\end{array}$ & $\begin{array}{c}\text { Joist } \\
\text { length } \\
(\mathrm{m})\end{array}$ & $\mathrm{S}_{\mathrm{x}}\left(\mathrm{mm}^{\wedge} 3\right)$ & $\begin{array}{c}\mathrm{F}_{\mathrm{e}} \\
(\mathrm{Mpa})\end{array}$ & $\begin{array}{c}\mathrm{M}=\mathrm{F}_{\mathrm{e}} \mathrm{x} \\
\mathrm{S}_{\mathrm{x}}(\mathrm{kN}-\mathrm{m})\end{array}$ & $\mathrm{P}_{\mathrm{n}}(\mathrm{kN})$ \\
\hline 241 & 3.50 & 49161.19 & 68.05 & 3.35 & 7.65 \\
\hline 241 & 4.50 & 49161.19 & 41.37 & 2.03 & 3.62 \\
\hline 302 & 5.00 & 66695.35 & 31.13 & 2.08 & 3.32 \\
\hline 302 & 5.25 & 66695.35 & 28.19 & 1.88 & 2.87 \\
\hline 356 & 6.10 & 83737.90 & 19.41 & 1.63 & 2.13 \\
\hline 406 & 7.95 & 124377.82 & 10.89 & 1.35 & 1.36 \\
\hline
\end{tabular}


Table H.6: Flexural strength of CFS iSPAN joists with hole by effective width method (LTB)

\begin{tabular}{|c|c|c|c|c|c|}
\hline $\begin{array}{c}\text { Joist } \\
\text { depth } \\
(\mathrm{mm})\end{array}$ & $\begin{array}{c}\text { Joist } \\
\text { length } \\
(\mathrm{m})\end{array}$ & $\mathrm{S}_{\mathrm{x}}\left(\mathrm{mm}^{\wedge} 3\right)$ & $\begin{array}{c}\mathrm{F}_{\mathrm{e}} \\
(\mathrm{Mpa})\end{array}$ & $\begin{array}{c}\mathrm{M}=\mathrm{F}_{\mathrm{e}} \mathrm{X} \\
\mathrm{S}_{\mathrm{x}}(\mathrm{kN}-\mathrm{m})\end{array}$ & $\mathrm{P}_{\mathrm{n}}(\mathrm{kN})$ \\
\hline 254 & 3.50 & 51783.12 & 68.05 & 3.52 & 8.06 \\
\hline 254 & 4.50 & 51783.12 & 41.37 & 2.14 & 3.81 \\
\hline 302 & 5.00 & 66695.35 & 31.13 & 2.08 & 3.32 \\
\hline 302 & 5.25 & 66695.35 & 28.19 & 1.88 & 2.87 \\
\hline
\end{tabular}

\section{WOODEN JOIST BENDING RESISTANCE}

The factored bending moment resistance of a panel web beam shall be the lesser of the factored resistance of the tension or compression flanges determined as follows:

\section{For Compression Flange}

$M_{r}=\phi F_{c} K_{z c} \frac{(E I)_{e}}{E K_{S E} C_{c}}$

\section{For Tension Flange}

$M_{r}=\phi F_{t} K_{z t} \frac{(E I)_{e}}{E K_{S E} C_{t}}$

Table H.7: Flexural strength of wooden joists

\begin{tabular}{|c|c|c|c|}
\hline $\begin{array}{c}\text { Joist depth } \\
(\mathrm{mm})\end{array}$ & Joist length $(\mathrm{m})$ & $\mathrm{M}(\mathrm{kN}-\mathrm{m})$ & $\mathrm{P}_{\mathrm{n}}(\mathrm{kN})$ \\
\hline 241 & 3.50 & 7.19 & 16.43 \\
\hline 241 & 4.50 & 7.19 & 12.78 \\
\hline 302 & 5.00 & 9.30 & 14.88 \\
\hline 302 & 5.25 & 9.30 & 14.17 \\
\hline 356 & 6.10 & 11.18 & 14.66 \\
\hline 406 & 7.95 & 19.84 & 19.97 \\
\hline
\end{tabular}


Formula to calculate the static point deflection under $1 \mathrm{kN}$ load

$\Delta \mathrm{p}=\frac{C_{p d}}{N_{e f f}} \frac{P L^{3}}{48 E I_{e f f}}$

Table H.8: Static point load deflection calculations under $1 \mathrm{kN}$ load for iSPAN twin joists without holes

\begin{tabular}{|c|c|c|c|c|c|}
\hline $\begin{array}{c}\text { Joist depth } \\
(\mathrm{mm})\end{array}$ & $\begin{array}{c}\text { Joist length } \\
(\mathrm{mm})\end{array}$ & $\begin{array}{c}\mathrm{N}_{\text {eff }}(\mathrm{N}- \\
\mathrm{mm}^{2 \mathrm{x}}\end{array}$ & $\mathrm{P}(\mathrm{kN})$ & $\begin{array}{c}\mathrm{EI}_{\text {eff }}(\mathrm{N}- \\
\left.\mathrm{mm}^{2} \times 10^{9}\right)\end{array}$ & $\Delta_{\mathrm{p}}(\mathrm{mm})$ \\
\hline 241 & 3500 & 2 & 1.00 & 1153 & 0.39 \\
\hline 241 & 4500 & 2 & 1.00 & 1153 & 0.82 \\
\hline 302 & 5000 & 2 & 1.00 & 1922 & 0.68 \\
\hline 302 & 5250 & 2 & 1.00 & 1922 & 0.78 \\
\hline 356 & 6100 & 2 & 1.00 & 3492 & 0.68 \\
\hline 406 & 7950 & 2 & 1.00 & 4735 & 1.11 \\
\hline
\end{tabular}

Table H.9: Static point load deflection calculations under $1 \mathrm{kN}$ load for iSPAN twin joists with holes

\begin{tabular}{|c|c|c|c|c|c|}
\hline $\begin{array}{c}\text { Joist depth } \\
(\mathrm{mm})\end{array}$ & $\begin{array}{c}\text { Joist length } \\
(\mathrm{mm})\end{array}$ & $\begin{array}{c}\mathrm{N}_{\text {eff }}(\mathrm{N}- \\
\mathrm{mm}^{2 \times}\end{array}$ & $\mathrm{P}(\mathrm{kN})$ & $\begin{array}{c}\mathrm{EI}_{\text {eff }}(\mathrm{N}- \\
\left.\mathrm{mm}^{2} \times 10^{9}\right)\end{array}$ & $\Delta_{\mathrm{p}}(\mathrm{mm})$ \\
\hline 254 & 3500 & 2 & 1.00 & 1276 & 0.35 \\
\hline 254 & 4500 & 2 & 1.00 & 1276 & 0.74 \\
\hline 302 & 5000 & 2 & 1.00 & 1922 & 0.68 \\
\hline 302 & 5250 & 2 & 1.00 & 1922 & 0.78 \\
\hline
\end{tabular}


Table H.10: Static point load deflection calculations under $1 \mathrm{kN}$ load for iSPAN joists in test sites

\begin{tabular}{|c|c|c|c|c|c|c|}
\hline Sites & $\begin{array}{c}\text { Joist } \\
\text { depth } \\
(\mathrm{mm})\end{array}$ & $\begin{array}{c}\text { Joist } \\
\text { length } \\
(\mathrm{mm})\end{array}$ & $\mathrm{N}_{\text {eff }}$ & $\mathrm{P}(\mathrm{kN})$ & $\begin{array}{c}\mathrm{EI}_{\mathrm{eff}}\left(\mathrm{N}-\mathrm{mm}^{2} \mathrm{x}\right. \\
\left.10^{9}\right)\end{array}$ & $\Delta_{\mathrm{p}}(\mathrm{mm})$ \\
\hline $\begin{array}{c}\text { Site 1 } \\
\text { (Unbraced) }\end{array}$ & 241 & 5200 & 2.39 & 1.00 & 1495.47 & 0.82 \\
\hline $\begin{array}{c}\text { Site 1 } \\
\text { (Braced) }\end{array}$ & 241 & 5200 & 2.54 & 1.00 & 1495.47 & 0.77 \\
\hline $\begin{array}{c}\text { Site 2 } \\
\text { (Unbraced) }\end{array}$ & 302 & 7260 & 3.41 & 1.00 & 2406.66 & 0.97 \\
\hline $\begin{array}{c}\text { Site 3 } \\
\text { (Braced) }\end{array}$ & 241 & 5330 & 3.26 & 1.00 & 1495.47 & 0.65 \\
\hline $\begin{array}{c}\text { Site 4 } \\
\text { (Braced) }\end{array}$ & 241 & 6500 & 3.55 & 1.00 & 1466.95 & 1.10 \\
\hline
\end{tabular}

Table H.11: Static point load deflection calculations under $1 \mathrm{kN}$ load for wooden twin joists

\begin{tabular}{|c|c|c|c|c|c|}
\hline $\begin{array}{c}\text { Joist } \\
\text { depth } \\
(\mathrm{mm})\end{array}$ & $\begin{array}{c}\text { Joist } \\
\text { length } \\
(\mathrm{mm})\end{array}$ & $\mathrm{N}_{\text {eff }}$ & $\mathrm{P}(\mathrm{kN})$ & $\begin{array}{c}\mathrm{EI}_{\text {eff }}(\mathrm{N}- \\
\left.\mathrm{mm}^{2} \times 10^{9}\right)\end{array}$ & $\Delta_{\mathrm{p}}(\mathrm{mm})$ \\
\hline 241 & 3500 & 2 & 1.00 & 588 & 0.76 \\
\hline 241 & 4500 & 2 & 1.00 & 694 & 1.37 \\
\hline 302 & 5000 & 2 & 1.00 & 999 & 1.30 \\
\hline 302 & 5250 & 2 & 1.00 & 1179 & 1.28 \\
\hline 356 & 6100 & 2 & 1.00 & 1728 & 1.37 \\
\hline 406 & 7950 & 2 & 1.00 & 3272 & 1.60 \\
\hline
\end{tabular}


Formula to calculate the flexural frequency

$$
f_{n}=0.18 \sqrt{\frac{g}{\Delta_{j}}} \quad \Delta_{j}=C_{f l r} \frac{5 w L^{4}}{384 E I_{e f f}}
$$

Table H.12: Flexural frequency calculation for iSPAN twin joists without holes

\begin{tabular}{|c|c|c|c|c|c|}
\hline $\begin{array}{c}\text { Joist } \\
\text { depth } \\
(\mathrm{mm})\end{array}$ & $\begin{array}{c}\text { Joist } \\
\text { length } \\
(\mathrm{mm})\end{array}$ & $\begin{array}{c}\mathrm{W} \\
(\mathrm{N} / \mathrm{mm})\end{array}$ & $\begin{array}{c}\mathrm{EI}_{\text {eff }}(\mathrm{N}- \\
\mathrm{mm}^{2} \mathrm{x} \\
\left.10^{9}\right)\end{array}$ & $\Delta_{\mathrm{j}}(\mathrm{mm})$ & $f(\mathrm{~Hz})$ \\
\hline 241 & 3500 & 0.205 & 1153 & 0.174 & 42.85 \\
\hline 241 & 4500 & 0.205 & 1153 & 0.475 & 25.92 \\
\hline 302 & 5000 & 0.218 & 1922 & 0.462 & 26.30 \\
\hline 302 & 5250 & 0.218 & 1922 & 0.561 & 23.85 \\
\hline 356 & 6100 & 0.263 & 3492 & 0.678 & 21.70 \\
\hline 406 & 7950 & 0.276 & 4735 & 1.516 & 14.51 \\
\hline
\end{tabular}

Table H.13: Flexural frequency calculation for iSPAN twin joists with holes

\begin{tabular}{|c|c|c|c|c|c|}
\hline $\begin{array}{c}\text { Joist } \\
\text { depth } \\
(\mathrm{mm})\end{array}$ & $\begin{array}{c}\text { Joist } \\
\text { length } \\
(\mathrm{mm})\end{array}$ & $\begin{array}{c}\mathrm{W} \\
(\mathrm{N} / \mathrm{mm})\end{array}$ & $\begin{array}{c}\mathrm{EI}_{\text {eff }}(\mathrm{N}- \\
\mathrm{mm}^{2} \mathrm{x} \\
\left.10^{9}\right)\end{array}$ & $\Delta_{\mathrm{j}}(\mathrm{mm})$ & $f(\mathrm{~Hz})$ \\
\hline 254 & 3500 & 0.205 & 1276 & 0.157 & 45.07 \\
\hline 254 & 4500 & 0.205 & 1276 & 0.430 & 27.27 \\
\hline 302 & 5000 & 0.218 & 1922 & 0.462 & 26.30 \\
\hline 302 & 5250 & 0.218 & 1922 & 0.561 & 23.85 \\
\hline
\end{tabular}


Table H.14: Flexural frequency calculation for iSPAN joists in test sites

\begin{tabular}{|c|c|c|c|c|c|c|}
\hline Sites & $\begin{array}{c}\text { Joist } \\
\text { depth } \\
(\mathrm{mm})\end{array}$ & $\begin{array}{c}\text { Joist } \\
\text { length } \\
(\mathrm{mm})\end{array}$ & Neff & $\begin{array}{c}\mathrm{EI}_{\text {eff }}(\mathrm{N}- \\
\left.\mathrm{mm}^{2} \times 10^{9}\right)\end{array}$ & $\Delta_{\mathrm{j}}(\mathrm{mm})$ & $f(\mathrm{~Hz})$ \\
\hline $\begin{array}{c}\text { Site 1 } \\
\text { (Unbraced) }\end{array}$ & 241 & 5200 & 2.39 & 1495.47 & 0.686 & 21.58 \\
\hline $\begin{array}{c}\text { Site 1 } \\
\text { (Braced) }\end{array}$ & 241 & 5200 & 2.54 & 1495.47 & 0.686 & 21.58 \\
\hline $\begin{array}{c}\text { Site 2 } \\
\text { (Unbraced) }\end{array}$ & 302 & 7260 & 3.41 & 2406.66 & 1.694 & 13.73 \\
\hline $\begin{array}{c}\text { Site 3 } \\
\text { (Braced) }\end{array}$ & 241 & 5330 & 3.26 & 1495.47 & 0.772 & 20.34 \\
\hline $\begin{array}{c}\text { Site 4 } \\
\text { (Braced) }\end{array}$ & 241 & 6500 & 3.55 & 1466.95 & 1.582 & 14.21 \\
\hline
\end{tabular}

Table H.15: Flexural frequency calculation for wooden twin joists

\begin{tabular}{|c|c|c|c|c|c|}
\hline $\begin{array}{c}\text { Joist } \\
\text { depth } \\
(\mathrm{mm})\end{array}$ & $\begin{array}{c}\text { Joist } \\
\text { length } \\
(\mathrm{mm})\end{array}$ & $\begin{array}{c}\mathrm{W} \\
(\mathrm{N} / \mathrm{mm})\end{array}$ & $\begin{array}{c}\mathrm{EI}_{\text {eff }}(\mathrm{N}- \\
\mathrm{mm}^{2} \mathrm{x} \\
\left.10^{9}\right)\end{array}$ & $\Delta_{\mathrm{j}}(\mathrm{mm})$ & $f(\mathrm{~Hz})$ \\
\hline 241 & 3500 & 0.167 & 588 & 0.277 & 33.97 \\
\hline 241 & 4500 & 0.167 & 694 & 0.641 & 22.32 \\
\hline 302 & 5000 & 0.175 & 999 & 0.714 & 21.15 \\
\hline 302 & 5250 & 0.175 & 1179 & 0.735 & 20.84 \\
\hline 356 & 6100 & 0.181 & 1728 & 0.945 & 18.38 \\
\hline 406 & 7950 & 0.207 & 3272 & 1.648 & 13.92 \\
\hline
\end{tabular}




\section{APPENDIX I: ABAQUS INPUT EXAMPLE}




\section{Postbuckling analysis example for $254 \times 3500 \mathrm{~mm}$ iSPAN floor joist}

** MATERIALS

$* *$

*Material, name="OSB Sheet"

*Density

7.85e-10,

*Elastic

5000., 0.28

*Material, name $=$ Steel

*Density

7.85e-09,

*Elastic

200000., 0.3

*Plastic

$350 ., \quad 0$.

360., 0.012

390., 0.039

$460 ., 0.084$

$500 ., 0.122$

$550 ., 0.224$

$* *$

$* *$

** STEP: Load

$* *$

*Step, name=Load, perturbation

*Buckle

$30,, 38,300$

**

** BOUNDARY CONDITIONS

$* *$

** Name: Hinged Type: Displacement/Rotation

*Boundary, op=NEW, load case $=1$

_PickedSet132, 1, 1

_PickedSet132, 2, 2

_PickedSet132, 3, 3

*Boundary, op $=$ NEW, load case $=2$

_PickedSet132, 1, 1

_PickedSet132, 2, 2

_PickedSet132, 3, 3

** Name: Roller Type: Displacement/Rotation

$*$ Boundary, op $=$ NEW, load case $=1$

_PickedSet131, 1, 1

_PickedSet131, 2, 2

*Boundary, op=NEW, load case $=2$
(Define Material Properties)

(Define Material Nonlinearity)

(Start Elastic Buckling Analysis)

(Command "Buckle" used for Elastic Buckling)

(Define Boundary Conditions) 


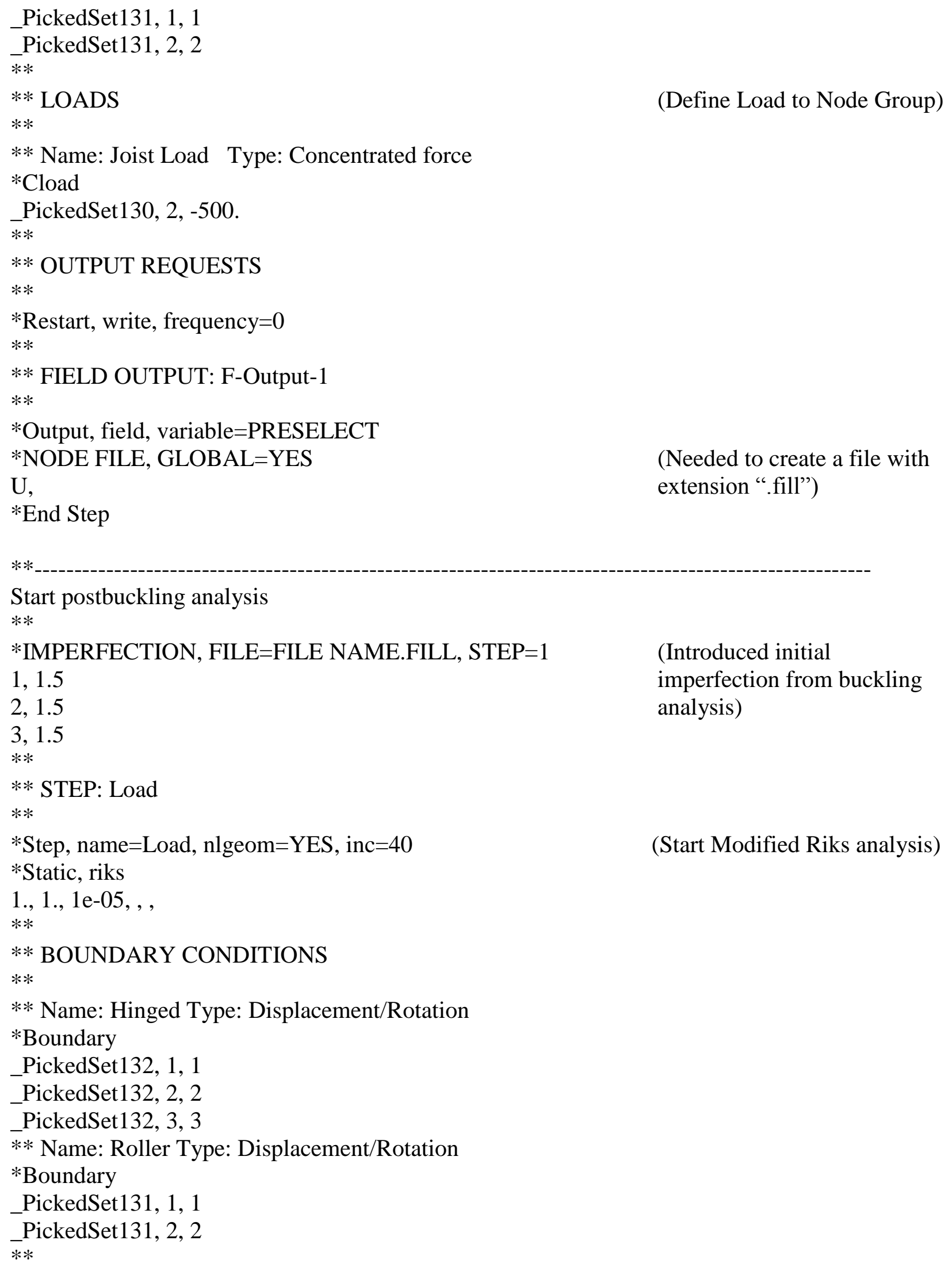

(Introduced initial imperfection from buckling analysis)

(Start Modified Riks analysis) 
** LOADS

**

** Name: Joist Load Type: Concentrated force

*Cload

_PickedSet130, 2, -500.

**

** OUTPUT REQUESTS

**

$*$ Restart, write, frequency $=0$

$* *$

** FIELD OUTPUT: F-Output-1

$* *$

*Output, field, variable=PRESELECT

**

** HISTORY OUTPUT: Displcement

$* *$

*Output, history

*Node Output, nset="Total Load"

$\mathrm{U} 2$,

**

** HISTORY OUTPUT: H-Output-1

$* *$

*Output, history, variable=PRESELECT

*End Step 


\section{REFERENCES}

Acharya, S. R. and Sivakumaran, K. S. 2008. Bending Strength of Cold Formed Steel Member With Reinforced Web Opening. $2^{\text {nd }}$ Canadian Conference on Effective Design of Structures, McMaster University Hamilton, ON, Canada.

Aghayere, A., and Vigil, J. 2007. Structural Wood Design, A Practice Oriented Approach Using the ASD Method.

AISI Standard. 2001. Commentary on North American Specification for the Design of Cold Formed Steel Structure Members.

Allen, D. E., Murray, T. M., and Unger, E. E. 1997. Design Guide Series 11: Floor Vibrations Due to Human Activity. Chicago: American Institute of Steel Construction and Canadian Institute of Steel Construction

Allen, D. E., Onysko, D. M., and Murray, T. M. 1999. Minimizing Floor Vibration. Redwood City, CA: ATC Design Guide 1.

American Iron and Steel Institute (AISI). 1946. Specification for the Design of Light Gauge Cold-Formed Steel Structural Members. New York, NY.

American Iron and Steel Institute (AISI). 1968. Specification for the Design of Cold-Formed Steel Structural Members. New York, NY,.

American Iron and Steel Institute (AISI). 2001. Commentary on North American Specification for the Design of Cold-Formed steel structural Members. New York, NY. .

American Iron and Steel Institute (AISI). 2002. Direct Strength Method Design Guide.

American Iron and Steel Institute (AISI). 2006. Direct Strength Method Design Guide.

American Iron and Steel Institute. 1986. Cold -Formed Steel Design Manual. Washington, D.C.

American Society of Testing and Materials. 2012. Standard Method and Definitions for Mechanical Testing of Steel Products, ASTM A370-12.

AS3623 1993. Australian Standard: Domestic Metal Faming Code. Standards Association of Australian, Homebush, NSW.

Beshara, B., and Lawson, T.J. 2002. Built-Up Girder Screw Connection Variation Flexural Tests. Dietrich Design Group Internal Report, April 2002.

Canadian Standard Association. 1963. Cold-Formed Steel Structural Members, S136-1963 
Canadian Standard Association. 2001. Engineering Design of Wood, CAN/CSA-O86.09. Etobicoke, Ontario, Canada.

Canadian Standard Association. 2007. North American Specification for the Design of Coldformed Steel Structures Members, S136-07.

CCMC. 1997. Development of Design Procedures for Vibration Controlled Spans Using Engineering Wood Members, Concluding Report. Canadian Construction Materials Centre, Institute for Research in Construction, National Research Council of Canada, Ottawa.

Chui, Y. H. 1988. Evaluation of Vibrational Performance of Lightweight Wooden Floors.

Cohen, J.M., and Pekoz, T.B., 1987. Local Buckling Behaviour of Plate Elements. Research Report, Department of Structural Engineering, Cornell University.

David, D. 1990. Steel and Composite Beams with Web Openings. Steel Design Guide Series 2 AISC.

Davis, B. 2008. Influence of Construction Details on Vibration Characteristics of Cold Formed Steel Floor Systems. University of Waterloo, Waterloo, ON, Canada.

Dinis, P. Borges., Dinar, Camotim. 2010. Local / Distortional Mode Interaction in Cold-Formed Steel Lipped Channel Beams. Thin-Walled Structures 48: 771-785.

Dung, M. Lue., Chung, Ping-Tsung., Liu, Jui-Ling., and Pan, Chi-Ling. 2009. The Compressive Strength of Slender C- Shaped Cold Formed Steel Members with Web Opening. International Journal of Steel Structures. Vol 9, No3: 231-240.

Ellobody, E. and Young, B. 2005. Structural Performance of Cold-Formed High Strength Stainless Steel Columns. Journal of Constructional Steel Research, 61(12): 1631-1649.

EN 1995 Eurocode 5: Practical Design of Timber Structures to Eurocode 5.

Gardner, L., and Nethercot, D. 2004. Numerical Modeling of Stainless Steel Structural Components a Consistent Approach. Journal of Structural Engineering, ASCE, 130(10): $1586-1601$.

Haidarali, Mohammad R., and David, A. Nethercot. 2011. Finite Element Modelling of Cold Formed Steel Beams Under Local Buckling or Combined Local / Distortional Buckling. ThinWalled Structures, 49: 1554-1562.

Hanagan, L. 2005. Walking-Induced Floor Vibration Case Studies. Journal of Architectural Engineering, Vol. 11 (No. 1): 14-18.

Hibbitt, D., Karlsson, I., and Sorenson, J. 2010. ABAQUS User's Manual Version 6.10. 
International Standards Organization. ISO 2631-2. 1989. Mechanical Vibration and Shock Evaluation of Human Exposure to Whole Body Vibration-Part 2.

Johnson, J. 1994. Vibration Acceptability of Floor under Impact Vibration. Blacksburg, Virginia: Virginia Polytechnic Institute and State University.

Karman, Von T., E. E. Sechler, and L. H. Donnell. 1932. The Strength of Thin Plates in Compression. Transactions ASME, Vol.54, APM 54-5

Kraus, C. A., \& Murray, T. M. 1997. Floor Vibration Criterion for Cold-Formed C-Shaped Supported Residential Floor Systems. Blacksburg: Virginia Polytechnic Institute.

Lenzen, K. H. 1966. Vibration of Steel Joist-Concrete Slab Floors. Engineering Journal, 3rd Qtr. 133-136.

Liu, Wei. 2001. Vibration Of Floors Supported By Cold Formed Steel Joist. M.Sc Thesis University of Waterloo, ON, Canada.

Meon, D. Cristopher., and Schafer, B.W. 2008. Experiments on Cold Formed Steel Columns with Holes. Thin-Walled Structures, 46: 1164-1182.

Meon, D. Cristopher., Anna, Schudlich., and Aaron, Von der Heyden. 2012. Journal of Structural Engineering (ASCE).

Miller, E.A. 1943. A Study of the Strength of Short Thin Walled Steel Studs. Master Thesis, Cornell University.

Moen, D. Cristopher., Igusa, T., Schafer, B. W. 2008. Prediction of Residual Stresses and Strains in Cold Formed Steel Members. Thin-Walled Structure, 46: 1274-89.

Murray, T. 1979. Acceptability Criterion for Occupant Induced Floor Vibrations.

National Association of Home Builder. 1999. Innovative Residential Floor Construction: Structural Evaluation of Steel Joists with Pre-Formed Web Openings. Research Report.

NBCC. 1995. User Guide - Structural Commentaries to Part 4 of the National Building Code of Canada 1995. Commentary A - Serviceability Criteria for Deflections and Vibration Institute for Research in Construction, National Research Council of Canada, Ottawa.

NBCC. 2010. User Guide - Structural Commentaries to Part 4 of the National Building Code of Canada 1995. Commentary A - Serviceability Criteria for Deflections and Vibration Institute for Research in Construction, National Research Council of Canada, Ottawa.

Nuthaporn, 2005. Experimental and Analytical Studies of The Behaviour of Cold Formed Steel Roof Truss Element. Ph.D Dissertation, Virginia Polytechnic Institute and state University. 
Ohlsson, S. V. 1988 a. Ten Years of Floor Vibration Research - A review of Aspects and Some Results. National Research Council Canada.

Ohlsson, S. V. 1988 b. Springiness and Human-Induced Floor Vibrations: A Design Guide (Vol. D12). Stockholm: Swedish Council for Building Research.

Onysko, D. M. 1970. Performance of Wood-Joist Floor System: A Literature Review. Ottawa: Canadian Forestry Service.

Onysko, D. M. 1985. Serviceability Criteria for Residential Floors Based on a Field Study of Consumer Response. Ottawa, Ontario: Forintek Canada Corp.

Onysko, D. M. 1995. Some Background on Factors Affecting Performance of Floors and Setting of Performance Criteria. Forintek Canada Corp.

Onysko, D.M., 1988. Performance Criteria for Residential Floors Based on Consumer Response. Proceeding 1988 International Conference on Timber Engineering, Seattle. Forest Products Research Society, Madison, WI. Vol 1: 736 - 745

Paik, J. K., and Thayamballi, A. K. 2006. Some Recent Developments on Ultimate Limit State Design Technology for Ships and Offshore Structures.

Parnell, A. Russel. 2008. Vibration Serviceability and Dynamic Modeling Of Cold Formed Steel Floor System. M.Sc Thesis University of Waterloo, ON, Canada.

Pekoz, T. B. 1986. Development of a Unified Approach to the Design of Cold Formed Steel Members. Report SG-86-4, American Iron and Steel Institute.

Pekoz, T. B. and Schafer, B. W. 1998. Computational Modeling of Cold-Formed Steel Characterizing Geometric Imperfections and Residual Stresses. Journal of Construction steel research, 47: 193-210.

Piyawat, Krisda. 2011. A Suggested Design Approach For Built-Up Cold Formed Steel Columns Based On Research Using Nonlinear Finite Element Method. Ph.D Dissertation, University Of Oklahoma.

Reiher, H., and Meister, F. J. 1931. The Effect of Vibration on People. Wright Field, Ohio: AMC, 1946.

Rizwan, U. 2000. Evaluation of Different Floor Vibration Criteria for Cold-Formed Steel Residential Construction. University of Waterloo, ON, Canada.

Schafer, B. W. 2006. Designing Cold Formed Steel using the Direct Strength Method. $18^{\text {th }}$ International Specialty Conference on Cold Formed Steel Structures, Orlando, Florida. 
Schafer, B. W., Li, Z., and Moen, C. D. 2010. Computational Modeling of Cold-Formed Steel. Thin-Walled Structure, 48: 752-62.

Schafer, B.W., Li, Z. (2010). Buckling analysis of cold-formed steel members with general boundary conditions using CUFSM: conventional and constrained finite strip methods. Proceedings of the 20th Int;1. Spec. Conf. on Cold-Formed Steel Structures, St. Louis, MO. November, 2010.

Schafer, B. W., Pekoz, T. 1998. Direct Strength Prediction of Cold-Formed Steel Members using Numerical Elastic Buckling Solutions. Proceeding of the $14^{\text {th }}$ International Specialty Conference on Cold Formed Steel Structures, St. Louis, MO, USA.

Seismosoft Earth Quick Software. www.seismosoft.com

Shan, M. Y., LaBoube, R. A., and Yu, W. W. 1994. Behavior Of Web Elements With Openings Subjected To Bending, Shear and The Combination Of Bending and Shear. Final Report, Department of Civil Engineering, University of Missouri-Rolla.

Shanmugam, N.E., Dhanalakshmi, M. 2001. Design for Opening in Cold Formed Steel Channel Stub Columns. Thin Walled Structures, 39: 961-981.

Sivakumaran, K.S., Ming, Yin Ng, and Steven, R. Fox. 2005. Flexural Strength of Cold Formed Steel Joists with Reinforced Web Openings. Canadian Journal of Civil Engineering, Vol. 33,: $1195-1208$.

Smith, I., and Chui, Y. H. 1988. Design of Lightweight Wooden Floors to Avoid Human Discomfort.

Sultana, Papia. 2007. Predictions of Flexural Behaviour of Built-up Cold Formed Steel Section. M.Sc thesis, University of Waterloo, Waterloo, ON, Canada.

Sultana, Papia., Lei, Xu., and Zhou, Xuhong 2009. Flexural Strength of Cold Formed Steel Builtup Box Sections. Thin Walled Structures 47: 807-815.

Tangorra, F. M. 2005. A Design Procedure for Floors Supported by Cold-Formed Steel Joists. University of Waterloo, ON, Canada.

Timoshenko, S. P., Gere, J. M. 1961. Theory of Elastic Stability. New York, U.S.A: McGrawHill Book Company.

Uzzaman, B. P. Lim., David, Nash., Rhodes, Jim. and Ben, Young. 2012a. Cold Formed Steel Section With Web Openings Subjected to Web Crippling Under Two Flange Loading Conditions, Part 1: Test and Finite Element Analysis. Thin Walled Structures, 56: 34-48. 
Uzzaman, B. P. Lim., David, Nash., Rhodes, Jim., and Ben, Young 2012b. Cold Formed Steel Section With Web Openings Subjected to Web Crippling under Two Flange Loading Conditions, Part 2: Parametric Study and Proposed Design Equation. Thin Walled Structures, 56: 79-87.

Whalen, E. 2013. Unethical Wood. "From the President" Article, Advantage Steel Magazine, Canadian Institute for Steel Construction, No. 46, Summer 2013, page10.

Winter, G. 1946. Strength of Thin Steel Compression Flanges. ASCE Transactions, Vol.112: 527-554.

Winter, G. 1970. Commentary on the 1968 Edition of the Specification for the Design of ColdFormed Steel Structural Members," American Iron and Steel institute.

Xu, L. 2000. Dynamic Behaviour of Residential Floor Systems Using Cold-Formed Steel Joists. University of Waterloo, Waterloo, ON, Canada.

Xu, L., Ling, Z., Xie, W. C., Liu, Y., \& Schuster, R. M. 2002. Dynamic Behaviour of Floors with Cold-Formed Steel Joists. Research Developments in Cold-Formed Steel Design and Construction, Fifteenth International Specialty Conference on Cold Formed Steel Structures, St. Louis, Missouri, U.S.A, 377-392

Yu, Cheng. 2005. Distortional Buckling of Cold Formed Steel Member in Bending. Ph.D. Dissertation, Johns Hopkins University Baltimore, Maryland, USA.

Yu, Cheng. 2011. Cold Formed Steel Flexural Member With Stiffed Edge Holes: Behavior, Optimization, and Design. Journal of Constructional Steel Research,71: 210-218.

Yu, Wei-Wen., LaBoube, Roger. A. 2010. Cold Formed Steel Design. New York: John Wiley \& Sons. 